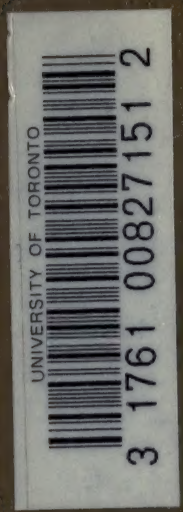



Digitized by the Internet Archive in 2008 with funding from Microsoft Corporation 



\section{FLORA HONGKONGENSIS.}




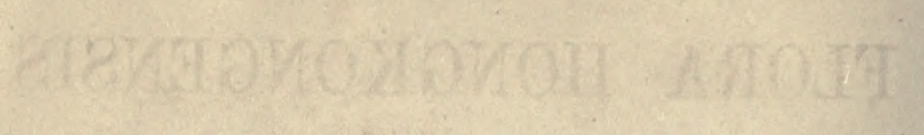

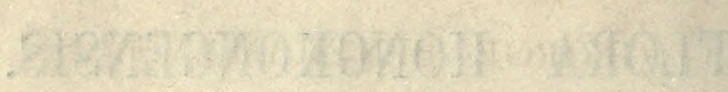




\title{
FLORA HONGKONGENSIS:
}

\author{
A DESCRIPTION
}

OF

\section{THE FLOWERING PLANTS AND FERNS}

$$
\text { OF THE }
$$

औู

BY

\section{GEORGE BENTHAM, V.P.I.S.}

\author{
WITH A MAP OF THE ISLAND.
}

PUBLISHED UNDER THE AUTHORITY OF HER MAJESTY'S SECRETARY OF STATE FOR THE COLONIES.

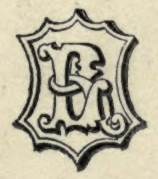

LONDON :

LOVELL REEVE, HENRIETTA STREET, COVENT GARDEN. 1861. 


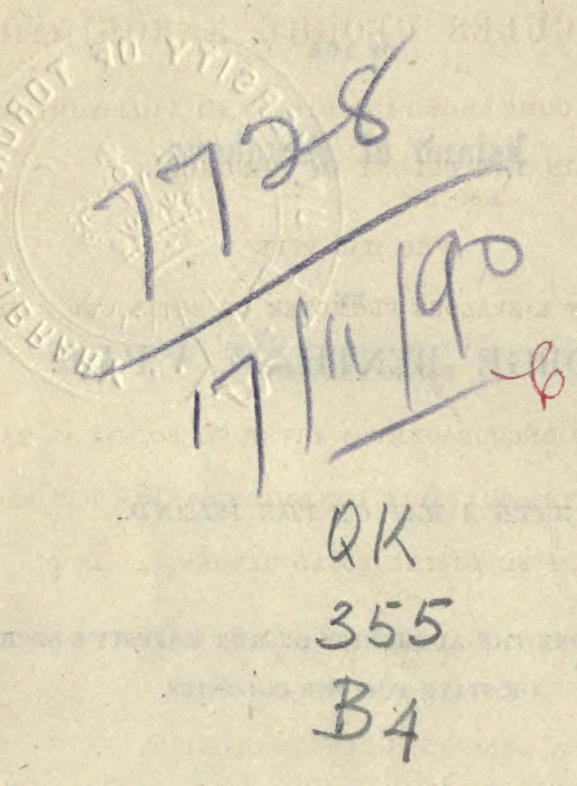




\section{SIR HERCULES GEORGE R. ROBINSON,}

\section{GOVERNOR, COMMANDER-IN-CHIEF, AND VICE-ADMIRAL}

IN THE COLONY OF HONGKONG,

WHO HAS EVER

PROVED HIMSELF A ZEALOUS PROMOTER OF BOTANICAL RESKARCH, ESPECTALLY BY

THE ASSISTANCE AND ENCOURAGEMENT GIVEN TO BOTANICAL TRAVELLER,,

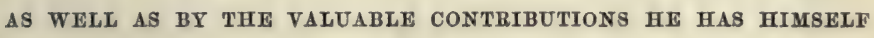
TRANSMITTED TO THE ROYAL GARDENS AT KEW,

THIS WORK

IS RESPECTFULLY DEDICATED. 



\section{PREFACE.}

Tine little island of Hongkong is situated off the southern coast of China, at the mouth of the Canton river, between lat. $22^{\circ} 9^{\prime}$ and $22^{\circ} 21^{\prime}$ $\mathrm{N}$. It consists of a rugged mountain ridge, running from east to west, broken into three or four peaks attaining an elevation of between 1700 and 1800 feet above the level of the sea, and intersected by deep narrow ravines. It is of very irregular outline, cut into deep inlets, especially on the south coast, where the hills occasionally slope down to a broad sandy beach, whilst several of the headlands terminate in perpendicular cliffs. Its greatest length is about eight miles, by a breadth of little more than four, and has an area of rather more than twenty-nine square miles. It is separated from the opposite hilly, and in some places more elevated, mainland by a strait, variously called Cap-Syng-Moon, or Cum-Sing-Moon,* which in its narrowest part (the Lye-Moon pass) is only half a mile in breadth, and, opposite to our newly acquired district of Kowloon, expands into a capacious harbour.

What we know of its physical condition and climate as affecting its Flora, is chiefly derived from the "Remarks on the physical aspect and vegetation of Hongkong," published by the late Mr. R. B. Hinds, in Hooker's 'London Journal of Botany,' vol. i. p. 476 (1842), and from Dr. B. Seemann's 'Introduction to the Flora of Hongkong,' in his Botany of the Voyage of H.M.S. Herald (1857). Both these writers represent its general aspect, especially when viewed from the south-east during the dry or winter season, as barren and bleak in the extreme, and apparently denuded of anything like arborescent vegetation. The more sheltered valleys and ravines, on the contrary, on the northern and

* So it is explained by Seemann. Other anthorities restrict the name of Cap-Syug-Moon to the pass lying between the Isle of Lautao and the mainland. 
western sides, saturated with moisture during the long-continued heavy rains of spring and early summer, and never exposed to real drought, afford to the botanist who examines them in detail an extraordinarily varied Flora. And a large proportion of this Flora is characterized by the collectors as arborescent or shrubby, although on the other hand the woods are stated to be of very limited extent, generally of stunted growth, and to consist mainly of very few species, Pinus sinensis on the more exposed parts, Ternstromia japonica and a few others in the more sheltered valleys; the numerous species of Oak, Fig, and other trees being usually limited to few individuals.

The rock of the island is chiefly granite (syenite), with occasional masses of basaltic trap. Limestone is entirely wanting. The temperature is as variable as the degree of humidity, the burning heats of a tropical sun alternating with the cold devastating fury of a Chinese typhoon. The annual range of the thermometer is from about $47^{\circ}$ to $93^{\circ}$ Fahr., according to a table of six years' observation given by Dr. Seemann from a Hongkong Almanack, but it is probably still wider, as $\mathrm{Mr}$. Hinds states that at Canton it is from $29^{\circ}$ to $94^{\circ}$, and the daily range is also considerable.

Previous to the year 1841, the collections of South Chinese plants received in Europe were chiefly from the neighbourhood of Macao or Canton, or from the islands of the Canton river lying between those two towns. Some collectors or botanical amateurs had indeed, from Macao, made excursions to the opposite coast, and may probably have landed in -Hongkong, and the plants recorded in the 'Plantæ Meyenianæ,' as from the Cap-Syng-Moon, although mostly from the island of Lantao, a few miles higher up the river, may also in some instances be of Hongkong origin, but we have no authentic record of any plants gathered in that island until the survey made by the officers of H.M.S. Sulphur, under Captain Sir Edward Belcher, in the year 1841. It was on the occasion of this survey that the late Mr. Richard Brinster Hinds, surgeon of the vessel, made the first collection of Hongkong plants which has reached us. Notwithstanding the unfavourable period of the year,his stay round the island was only for a few weeks during the winter or dry season,- - he was enabled on his return home to place in my hands specimens of nearly 140 species, the Enumeration of which I published in Hooker's 'London Journal of Botany,' vol. i. p. 482.

Early in 1847, the late Colonel (then Captain) J. G. Champion, of the 95th Regiment, who had already, during his residence in Ceylon, 
made several interesting additions to the known plants of that colony, removed with his regiment to Hongkong. He remained there three years, and during his leisure moments devoted himself with ardour to the investigation of the Flora of the island. He very early transmitted to his friend the late Dr. Gardner, then Superintendent*o of the Botanic Gardens at Peradenia, in Ceylon, several entirely new species, descriptions of which that botanist remitted for publication to Sir W. Hooker, who inserted them in the first volume of his ' Kew Journal of Botany.' On his return to England in 1850, Col. Champion brought with him a fine collection of between five and six hundred species of phænogamous plants and ferns, the result of his labours. These included the great majority of the dicotyledonous plants, orchids and ferns, which have hitherto been found in the vicinity of Victoria, in the rich watery or wooded valleys of the north-west from West Point to the Happy Valley, and thence up to the principal central peaks, Mounts Victoria, Gough, and Parker. He had also extended his herborizations to Chuck-chew (Stanley) on the south coast, and to Saywan on the east, and perhaps to a few other distant points, but he had seldom been able to visit the back of the island, and we miss in his collection a few interesting species previously gathered by Mr. Hinds about Tytam-took, as well as the Flora of the maritime sands generally. He paid also but little attention to glumaceous plants, or indeed to almost any monocotyledons except orchids. Early in 1851 he placed in my hands a complete set of his specimens, accompanied frequently by analytical sketches and descriptions made on the spot, and almost always by most valuable memoranda relating to precise station, to stature, colour, etc., which it were to be wished were less neglected by the majority of collectors; and on leaving England for the fatal Crimean campaign, he deposited the remaining specimens which he had reserved for himself, in the herbarium of Sir W. J. Hooker. In the meantime, with Col. Champion's assistance, I had proceeded to the enumeration of the species gathered by him, including descriptions of numerous entirely new ones, which appeared successively in detached portions in Hooker's 'Kew Journal of Botany,' vols. iii. to vii. and ix.

Dr. H. F. HaNce, now at Canton, has been almost continuously resident in Southern China since 1844, and the greater portion of the time in Hongkong, where he zealously applied himself to the study of the Flora of the island. He remitted a few descriptions of species which he believed to be new, to Sir W. J. Hooker, who published them in the first volume of his 'Kew Journal of Botany,' and placed the diagnoses 
of many others in the hands of the late Dr. Walpers, who inserted them in the second and third volumes of his 'Annales Botanices Systematicæ.' Shortly afterwards (in 1851), being on a visit to this country, Dr. Hance entrusted the whole of his Hongkong herbarium to Dr. Berthold Seemann, who, as naturalist on board H.M. surveying-ship the Herald, had visited Hongkong in December, 1850, and himself made some collections there, and was then, on his return to England, about to publish the botanical results of that Expedition. Accordingly, at the close of Dr. Seemann's 'Botany of the Voyage of H.M.S. Herald,' we find a "Flora of the Island of Hongkong," published in 1857, and containing an enumeration of 773 phænogamous plants and ferns, based chiefly upon Dr. Hance's collections, and, in some Orders, confined to those and to Dr. Seemann's own, but in the generality of cases comprising also Mr. Hinds's and Col. Champion's plants. Since that period, I have received several valuable communications from Dr. Hance, either notes on species already enumerated, or specimens of others since found in the island, as well as many interesting species from Canton, Amoy, and other points of the Chinese coast, illustrative of the general botanical regions of which Hongkong forms a part. On Dr. Seemann's recent departure for the South Sea, he left Dr. Hance's and his own original specimens which he had examined for his Flora (with the exception of orchids and ferns) at Kew, where he has liberally allowed me access to them for the purpose of identification and comparison.

The late Dr. W.A. Harland, Government Surgeon at Hongkong, brought to this country in 1857 a very valuable set of Hongkong plants, including many that had escaped the notice of previous collectors. He allowed me to select specimens of all that appeared new or interesting, and I took notes of a few others which I then thought were very familiarly known species, but of which I have subsequently regretted I had not retained specimens for more exact comparison.

Mr. Chardes Wright, of the United States, so well known for the beauty and excellence of the specimens distributed from his various botanical expeditions, was naturalist on board the U.S. ship the Vincennes, and other vessels forming the United States North Pacific Exploring Expedition, under the command first of Captain Ringgold and afterwards of Captain John Rodgers. During this eruise Mr. Wright staid at Hongkong from March to September, 1854, and from January to April, 1855, and has proved himself as zealous and active on this as on other occasions, for he brought away specimens of above 500 species, several of them of great interest, and not received from any other 
source. An almost complete set has been remitted to me for publication by Dr. Asa Gray.

Mr. Chardes Wimford, collector for the Royal Gardens at Kew, remained in Hongkong from November 1857 to June 1858, and remitted to this country above 400 species now deposited in the Hookerian herbarium. This collection has been of considerable use to me, the specimens being good, usually in several duplicates, and often accompanied by memoranda of their stations, with occasionally a few other notes.

Col. Champion's herbarium contained also a few specimens gathered by General (then Lieut.-Col.) J. Erre, R.A., who also in 1854 showed me a beautiful set of botanical drawings made in the island, from which I took several notes. And lastly, in Sir W. J. Hooker's herbarium is a very fine set of Hongkong ferns transmitted to him by CoLONEL URQUHART, and some others from Dr. Dili, J. C. Bowman, Esq., and T. Alexander, Esq.

Such are the materials from the examination of which the present Flora has been compiled. They have been throughout compared with such allied forms from other countries as are contained in the rich Hookerian and other herbaria deposited at Kew, with occasional reference to Linnæan types, where it has been necessary, in clearing up dubious synonyms. I have also to acknowledge most valuable assistance received from botanical friends in particular Orders, upon which they have severally been monographically engaged. I would specially express my thanks to DR. T. ANDERson, for the generic arrangement and characters, and specific determination of Acanthacec; to Dr. BоoтT for the determination of the species of Carex; to SIR W. J. Hooker, for the determination of the Ferns ; to Dr. LindLex for the determination of Col. Champion's and Mr. Hinds's Orchidec, and for assistance in comparing Hongkong specimens of that and other Orders with his own herbarium; to CoL. Munko, for the determination of all the Graminece of the island, with numerous important communications on their generic arrangement and characters; to Prof. DAN. OLIver, for the communication of his MS. notes on and characters and arrangement of Aurantiacece and of Utricularia; and, above all, to DR. J. D. Hooker, for his advice and assistance through the whole work, as well as for the communication of the invaluable notes and observations made by him on the living Flora of Sikkim and Khasia, so closely connected with that of Hongkong. I must add, however, that in the case of all the above-named Orders, as well as in the rest of the Flora, I have myself verified, on the specimens themselves, the characters which I have given; and whilst I fully acknowledge the sources from whence I may have de- 
rived any systematic modifications which may be considered as improvements, I alone am responsible for any errors they may contain.

It is hoped, indeed, that these generic characters will in no instance be found to have been copied from other works without collating them in the case of each Hougkong species, as far as our specimens would admit, and modifying them or indicating exceptional points where necessary. In a few instances it will be seen that I have proposed considerable innovations, chiefly in the way of consolidating small genera which appeared to have been established on insufficient grounds. 1 have been obliged, however, to leave others still in a very unsatisfactory state, where the fixing their limits and characters would have required a general revision of whole Orders, which we can only hope to accomplish for the 'Genera Plantarum' I am preparing in conjunction with Dr. Hooker.

In many instances also our specimens are as yet very imperfect, and much remains to be done before the Flora of this diminutive island can be said to be well known. And this deficiency is not to be ascribed to any want of zeal on the part of the collectors. When we read upon their labels, accompanying specimens of some of the most striking plants, such memoranda as "Only three trees known in the island," "Once seen in a ravine near the top of Mount Victoria," "Picked out of a faggot which a Chinaman was carrying home," etc., we can scarcely hope that the history of such species as are yet only known in the state of bud, or in that of fruit, or in one sex, etc., will be very soon completed from specimens gathered in the island itself. But most probably they may all be found in greater abundance and perfection in the billy ranges bordering the opposite mainland, a portion of which has now been added to our territory. To these hills, therefore, we would especially call the attention of botanical explorers, to procure materials for the further illustration of the Hongkong Flora.

The specific descriptions, like the generic characters, have been always drawn up from the actual examination of specimens gathered in the island, where they were sufficient for the purpose; or, where these were imperfect, specimens from the nearest station from whence we have the same species, whether continental China, the Philippine Islands, or eastern India, have been made use of to complete the character. In each such case the origin of the specimens described has been stated; and on all occasions where the limits of the species are known to extend beyond the island, the Hongkong specimens have been compared with others taken from different parts of its geographical range. This has 
enabled me, with the assistance of Dr. Hooker's lists and notes, to give that range for every species, as far as can be derived from the Kew herbaria or other reliable sources. This distribution is, however, only stated in a few general terms specially directed to showing the immediate relation of the Hongkong Flora to that of other countries. The precise limitation of the area of each species would require far too much labour and detail to come within the scope of the present work.

For the purpose of obtaining even a general notion of the nature of this geographical relation of our Flora, it was necessary to tabulate the species according to the areas they occupy as far as our present knowledge of them extends, although our information on the subject is as yet far too scanty to give any very satisfactory results. The Flora of the hilly ranges of continental South China, of which Hongkong is as it were an outlying spur, is almost unknown to us ; that of the country connecting these hills and the Cochin-Chinese coasts with Burmah, Silhet, and Assam, is a complete blank. On the other side, looking to the Philippine Islands, the nearest land connecting Hongkong with the eastern islands of the Indian Archipelago, although a large number of their species have been described, yet this has been done so imperfectly, and piecemeal, as it were, at Manilla, or in different European capitals, with so little critical comparison between the different collections or with the general tropical Asiatic Flora, that it is very difficult to obtain any definite notions of their vegetation. We have no serviceable general Flora of the Philippines (for Blanco's species require re-identification), and no one of our herbaria contains probably more than one-half of the plants indigenous to them.

Such lists, however, as I have been able to prepare of the Hongkong species arranged according to their geographical areas, and of which I give below some numerical results, offer some interesting features. At a first glance one is struck with the very large total amount of species crowded upon so small an island, which all navigators depict as apparently so bleak and bare; - with the tropical character of the great majority of species, when botanists agree in representing the general aspect (derived from the majority of individuals) to present the features of a much more northern latitude; - with the large proportion of arborescent and shrubby species, on a rocky mass where the woods are limited to a few ravines or short narrow valleys half-monopolized by cultivation;-and with the very great diversity in the species themselves, the proportion of orders and genera to species, the comparative number of monotypic genera, being far greater in the Hongkong Flora than in that of any other Flora 
of similar extent known to me. The very large number of apparently endemic species, - of species only known to us from the island,-is probably occasioned by our ignorance, already alluded to, of the vegetation of continental S. China.

Another noteworthy fact apparent on the comparison of these lists, is the great preponderance of woody and long-lived plants among the species of limited areas, and of herbaceous or comparatively short-lived ones among those of a more extended range. This is, however, a general rule applicable to all Floras; for although trees and shrubs, when once in possession of the soil, tend to expel a great proportion of the herbaceous vegetation, yet the slight advantages they have in the greater power of resisting individual injury or destruction, are nore than compensated by the small number of individuals, and by the slow operation of their limited means of propagation and dispersion, as compared with the countless myriads of herbs, each producing annually and widely scattering their seeds by thousands, tens or even hundreds of thousands, always ready to take possession of any land rendered vacant by the destruction of a forest into or near to which one or two individuals might have previously straggled. And when once in possession of the land, herbaceous plants, so much more capable of resisting destruction from climate or from animals than seedling trees, will often effectually prevent the re-invasion of arborescent vegetation.

In its general character, the Hongkong Flora is, as already observed, that of tropical Asia, of which it offers in numerous instances the northern limit. Taking rather more in detail the more restricted portions of the Flora, that of the damp wooded ravines of the north and west will be found to be closely allied to that of north-east India (Khasia, Assam, and Sikkim), and will probably hereafter prove to be connected with it by a gradual transition across south China ; the Hongkong specimens, when specifically identical, generally showing a less luxuriant vegetation, larger flowers, and other peculiarities attributable, no doubt, to a more open situation. Other species in considerable numbers have a much more tropical character, extending with little variation over the Indian Archipelago, the Malayan Peninsula, and even to Ceylon and tropical Africa, without penetrating into the continent of India. Northwards of Hongkong the vegetation appears to change much more rapidly. Very few of the species known to range across from the Himalaya to Japan are believed to come much further south than Amoy, where, with a difference of latitude of only two degrees, the tropical features of the Hongkong Flora have (as far as we know) almost entirely 
disappeared. And notwithstanding the prevailing idea of the close connection of the Floras of Japan and Hongkong, suggested perhaps by the presence in both of a few striking species or genera (Kadsura, Stauntonia, Actinidia, Camellia, Eriobotrya, Distylium, Liquidambar, Benthania, Farfugium, Houttuynia, etc.), I cannot enumerate 80 species known to be common to the two countries.

With Australia our Flora exhibits a few curious points of connection, either as species or types (such as Pycnospora, Lagenophora, Stylidium, Mitrasacme, Thysanotus, Philydrum, Lipocarpha microcephala, Arthrostyles, Zoysia, etc.). They are indeed all herbaceous, and are probably found in the intermediate Philippine and South Pacific islands; some of them also are maritime plants, which have always a wide range in latitude as well as longitude; yet it must be observed that many of them belong to genera which have many other herbaceous or maritime species, not one of which spreads beyond Australia itself. A few of the above-mentioned maritime species, like Carex pumila, extend from Australia to Japan. Other maritime plants belonging to the northern or Japanese Floras, as Ixeris debilis and repens, appear to have their southern limits in Hongkong.

With America the Hongkong Flora has no direct connection, the singular band of vegetation which appears to cross from N. America to Japan, and die off through Mantchuria in central Asia, some species extending as far as the Himalaya, passes to the north of Hongkong, although we may even there be reminded of it by a few such types as Lespedeza, Solidago, Eupatorium, Olea marginata, Gelsemium, ete. Those species which the island has in common with tropical America are almost all generally spread over tropical Asia and Africa, and offer nothing exceptional in their distribution, except perhaps the West Indian Teucrium inflatum, which appears to be abundant in several of the South Pacific islands, but unknown in tropical Asia generally.

The total number of species enumerated in the present work is $\mathbf{1 0 5 6}$, distributed into 591 Genera and 125 Orders. From this however must be deducted 25 genera and 32 species which there is reason to believe are escapes from cultivation, or may only occur where they have actually been planted. Nearly 100 more species may be classed as weeds of cultivation,- " plantes cultivées malgré la volonté de l'homme," of A. DC.,-occurring, perhaps exclusively, in paddy-fields and other cultivated spots. Of these about 6 appear to be of American origin, about 12 more may have been introduced with European seeds; the remainder however are so widely spread, as weeds also, over tropical Asia, that 
whatever may have been their origin, they have now acquired the right to be included in the native Flora, which will thus consist of about 1000 species and 550 genera of phrnogamic plants and ferns.

In the following table I have distributed these into the seven following geographical classes or Floras, viz.:-

1. The Tropical Asiatic Frora. Plants generally distributed over India and the Archipelago, excepting the dry parched regions of western India. Many of them extend over the South Pacific islands to North Australia in the south-east. Most of them have the coast of south China for their northern limits. A few extend to the isles of Loochoo or Bonin, or even to Japan. A considerable number cross the moister regions of tropical Africa to the west, and not a few, especially amongst the roadside herbs and weeds of cultivation, are common also in many parts of tropical America.

2. The North-east Indian Flora. Plants of the hot, wet, hilly regions of Khasia and Assam, many of them extending westward along the Himalaya and even to some mountains of the Indian Peninsula, but not found in Lower India, nor for the most part in the Malayan Peninsula. Their northern limits will be found somewhere in the unknown regions of east-central Asia and China, a very few extending to Mantchuria and Japan, and perhaps a still smaller number to the Philippines.

3. The South-east Indian Flora. Plants of the Malayan Peninsula and the Archipelago, many of them extending westward to Chittagong and eastern Bengal, several to Ceylon, and a few to tropical Africa, but not known in Central India or the Peninsula. To the eastward many range over the South Pacific islands to North Australia, and reach Hongkong to the northward, probably over the little-known regions of Cochin China and South China.

4. The Archipelago and Pacific Flora. Nearly the same as the last, but with a more eastern range, and not hitherto found within our Indian limits, and probably more nearly connected with Hongkong through the Philippine Islands.

5. The Chinese Flora. Plants hitherto not known to the westward or southward of China, and most of them only from South China. A few however extend northward to Shanghai, Chusan, and Japan, and a very few to Pekin.

6. The Endemic Frora. Plants hitherto only known from the island of Hongkong. Although most if not all of them may be found also in the hilly ranges of the opposite mainland, it is probable that even there they extend only over a limited area. 
7. The Temperate Asiatio Flora. South Siberian, Dahurian, Mantchurian, and Japanese plants, which attain their southern limit in Hongkong.

The number of Hongkong species which I would attribute to each of these Floras is given in the following Table. It must be remembered, however, that these are approximative only, the limits of the areas of species are so vague, their extent so diversified, scarcely two species being ever precisely similar in this respect, that it would be impossible to class them with precision, even were their area always perfectly well known to us.

\section{Table of the Hongkong Species, classed according to their Geographical Areas.}

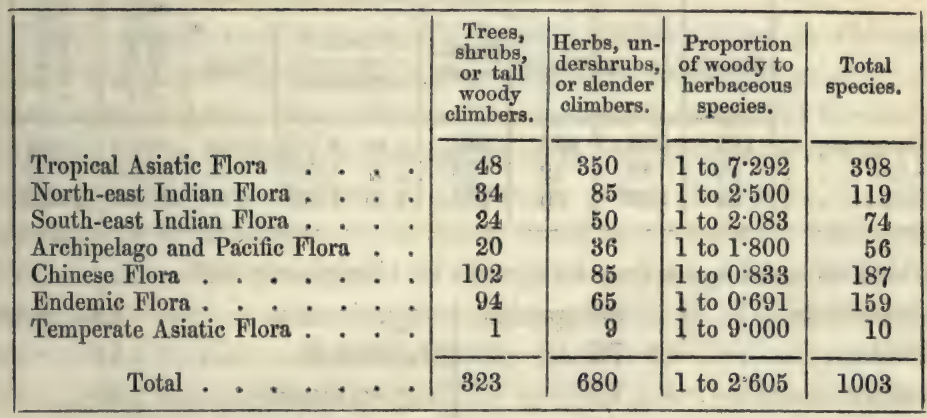

Let these be compared with the Floras of two districts similarly circumstanced as to maritime position and proximity to the mainland, nearly the same in size and elevation above the sea, but widely different as to soil and climate, viz. :-

1. Aden Peninsula, off the coast of Arabia, in lat. $12^{\circ} 47^{\prime}$. A dry, parched, volcanic, rocky peninsula or almost an island, about 5 miles long by 3 in breadth, the highest peak attaining $1775 \mathrm{ft}$., and connected with the mainland by a narrow sandy isthmus. It is exposed throughout the year to a scorching sun, occasionally deprived of rain for a year and a half, and never receives an annual fall of above 6 or 7 inches. Winds are not frequent and seldom violent.

2. Ischia Island, off the Neapolitan coast, in lat. $40^{\circ} 41^{\prime}$. A voleanic rocky mountain mass, nearly 6 miles long by $3 \frac{1}{2}$ in breadth, the highest peak attaining $2,407 \mathrm{ft}$., and about 9 miles distant from the mainland. Hot and dry during the summer months, it is however well refreshed by rains during the remainder of the year. The thermometer very rarely. 
descends below the freezing point, but the island is exposed to frequent and violent winds.

The numbers in the following Table are taken, for Aden, from Dr. T. Anderson's 'Florula Adenensis' (Journ. Linn. Soc. Lond. vol.v. Suppl.), a work drawn up on the same standard as to the limits of genera and species as the Hongkong Flora; and for Ischia, from Prof. Gussone's 'Enumeratio Plantarum Vascularium in Insula Inarime provenientium' (Neapoli, 1854). From the latter however I have found it necessary, in order to establish a fair comparison, to deduct the cultivated species, and to reduce the remainder to the specific and generic standard of our Hongkong Flora.

\begin{tabular}{|c|c|c|c|c|c|c|c|c|}
\hline & & & & & pecies. & & हैँ & \% \\
\hline & Orders. & Genera. & Woody. & $\begin{array}{l}\text { Herba- } \\
\text { ceous. }\end{array}$ & $\begin{array}{l}\text { Proportion } \\
\text { of woody to } \\
\text { herbaceous. }\end{array}$ & Total. & 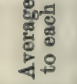 & 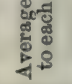 \\
\hline Hongkong & 125 & 550 & 323 & 680 & 1 to $2 \cdot 105$ & 1003 & 8.024 & 1.805 \\
\hline Aden . . & 42 & 80 & 19 & 76 & 1 to 4.000 & 95 & $2 \cdot 024$ & 1.019 \\
\hline Ischia. . & 82 & 389 & 66 & 726 & 1 to 11.000 & 792 & $9 \cdot 645$ & $2 \cdot 034$ \\
\hline
\end{tabular}

The Orders most numerous in species in Hongkong are*-

Gramineæ . . 86 species.

Filices . . . . 75

Leguminosæ . . . 72

Compositæ . . 67

Cyperaceæ ... 62

Euphorbiaceæ . . 52

Rubiaceæ . . . 42

Orchideæ . . . . 36

Urticer . . . 27

Scrophularines . , 21

Acanthacer : 18

Verbenaceæ . . 17

Labiatæ . . . 16
Myrsinaceæ . . 15 species.

Laurineæ . . . . 14

Apocynace» : . . 13

Convolvulaceæ . . 13

Liliaceæ . . . . 13

Ternstrœmiaceæ . 12

Malvaceæ . . . 12

Rosaceæ . . . . 11

Asclepiadeæ . : . 11

Solanaceæ . . . 10

Polygonaceæ. . . 10

Amentaceæ . . . 10

6 Orders have 8 species each.

$\begin{array}{rlll}5 & & 7 & \\ 11 & \# & 6 & " \\ 6 & & 5 & "\end{array}$

8 Orders have 4 species each.

15
13
36

$\begin{array}{lll}" & 3 & " \\ " & 2 & "\end{array}$

* The discrepancies between the total number of Orders and genera in this and the preceding Tables is owing to the half-naturalized species being here reckoned, but necessarily excluded when considering geographical areas, 
The genera most numerous in species are-

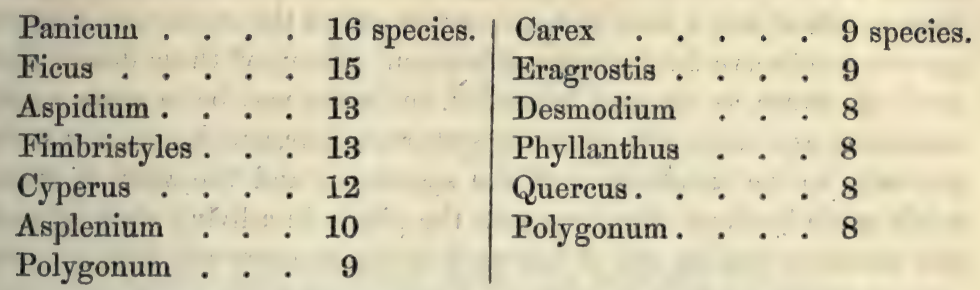

5 genera have 7 species each.

$\begin{array}{rlll}10 & n & 6 & " \\ 7 & n & 5 & " \\ 14 & n & 4 & "\end{array}$

43 genera have 3 species each.

$\begin{array}{rrrr}91 & \prime & 2 & \\ 408 & \prime & 1 & n\end{array}$

With regard to the Economic Botany of the island, to the uses to which the Chinese apply any of the indigenous vegetable productions, or to the plants which they cultivate, we have no information beyond what is contained in Seemann's 'Introduction to the Hongkong Flora' above quoted, derived chiefly from Dr. Hance's notes, and which it would be needless here to repeat. It is much to be regretted that botanical collectors pay so little attention to the cultivated vegetation of the countries they visit; or if they do gather specimens, they are so frequently worse than useless, not being distinguished from the indigenous ones. Even when marked "cultivated," the specimens are seldom accompanied by memoranda distinguishing those grown by a few individuals in gardens for ornament or shade, from those which may form the standard agricultural crops. And very rarely indeed have we any indication for what special purpose the cultivated species or varieties are grown or the indigenous ones collected. It is to be hoped that naturalists resident for a time in the country will turn their attention to the subject, and remit to us specimens and notes specially directed to the illustration of the Economic Botany of Southern China.

It only remains for me to state that in the form and language adopted in the present work it has been my endeavour to follow out the principles laid down in the Introduction, so as to facilitate as much as possible the finding out the name of any plant gathered in the island by the comparison of specimens with the descriptions here given. For this purpose the Orders of the whole Flora, the genera of each Order, and the species of each genus, are universally preceded by analytical tables in which their more prominent characters are contrasted. In the descriptions them- 
selves, which I have been obliged to shorten as much as consistent with their practical use, I have endeavoured to select the characters most important to observe for their identification. Many of these descriptions are, I am aware, as yet very imperfect, and some may be in some respect erroneous, especially with regard to stature, colour, and dimensions, owing generally to the insufficiency of the specimens and the want of memoranda made by those who have seen the plants in a living state. Travellers therefore making use of this work in the country will have to guard against attaching much importance to discrepancies in characters which dried specimens cannot show, when the descriptions apply well to the plant they are examining as to form and structure.

With regard to the synonymy, I have thought it generally unnecessary to repeat that which is already detailed in the general works referred to in the case of each well-known species. I have however entered into more detail as to the names under which Hongkong species may be entered in works specially relating to South Chinese botany. I have quoted such figures as it may be useful to consult and are contained in works to which the Asiatic, and especially the Indian botanist, is likely to have access ; and I have added, for the general botanist, numerous new synonyms which my researches for the identification of Hongkong species have enabled me to verify.

The contractions used in the references to works, are those which general custom has sanctioned, following in most cases the rule laid down by De Candolle for abridging authors' names; that is, to give the first syllable with the first consonant of the second syllable. Initials only are used in the case of DC. for De Candolle, and H. B. and K. for Humboldt, Bonpland, and Kunth. Dimensions are given in English feet, inches, and lines of twelve to an inch. 


\section{CONTENTS.}

INTRODUCTION.

Odthines of Botany, with Spectal Reference to Looat Floras . . iii

Chap. I. Definitions and Desoriptive Botany . . . . . . . . . iii

$\S 1$. The Plant in General . . . . . . . . . . . . . . . . , iv

§ 2. The Root . . . . . . . . . . . . . . . . . . . . iv

§. The Stock . . . . . . . . . . . . . . . . . . . . vi vi

§4. The Stem . . . . . . . . . . . . . . . . . . . vii

$\S 5$. The Leaves . . . . . . . . . . . . . . . . . . . . vii

§ 6. Scales, Bracts, and Stipules . . . . . . . . . . . . . . . xi

§ 7. Inflorescence and its Bracts . . . . . . . . . . . . . . . xii

§. The Flower in General. . . . . . . . . . . . . . . . . xiv

§ 9. The Calyx and Corolla or Perianth . . . . . . . . . . . xv

\$10. The Stamens . . . . . . . . . . . . . . . . xvii

$\S$ 11. The Pistil . . . . . . . . . . . . . . . . . . . . xviii

§ 12. The Receptacle and Relative Attachment of the Floral Whorls . . . $\quad \mathbf{x}$

§ 13. The Fruit . . . . . . . . . . . . . . . . . . . . xxii

§ 14. The Seed . . . . . . . . . . . . . . . . . . . . xxiii

$\S 15$. Accessory Organs . . . . . . . . . . . . . . . . . . xxiv

Chap. II. Classification, on Systematic Botany . . . . . . . . xxvi

Chap. III. Vegetable Anatomy and Physiology . . . . . . . . xxvii

§ 1. Structure of the Elementary Tissues . . . . . . . . . . . . xxrii

§ 2. Arrangement of the Elementary Tissues, or Structure of the Organs of

Plants . . . . . . . . . . . . . . xxix

§ 3. Growth of the Organs. . . . . . . . . . . . . . . . xxxi

§ 4. Functions of the Organs . . . . . . . . . . . . . . . . xxxii

Chap. IV. Collection, Pregervation, and Determination of Plants - xxxiv

Index of Terms, on Glossary . . . . . . . . . . . . . . xxxix

Anatyticat Kex to the Hongrong Orders and Anomalous Genera . xliv

Flora Hongkongensis.

Class I. Dicotyledons . . . . . . . . . . . . . . . . . . 1

Class II. Monocotyledons . . . . . . . . . . . . . . . . . 338

Class III. Cryptogams . . . . . . . . . . . . . . . . . . 435

IndeX of Genera $\mathrm{NND}$ Speles . . . . . . . . . . . . 465 



\section{INTRODUC'IION.}

\section{OUTLINES OF BOTANY, WITH SPECIAL REFERENCE TO}

\section{LOCAL FLORAS.}

\section{Chap. I. Definitions and Descriptive Botany.}

1. The principal object of a Flora of a country, is to afford the means of determining (i.e. ascertaining the name of) any plant growing in it, whether for the purpose of ulterior study or of intellectual exercise.

2. With this view, a Flora consists of descriptions of all the wild or native plants contained in the country in question, so drawn up and arranged that the student may identify with the corresponding description any individual specimen which he may gather.

3. These descriptions should be clear, concise, accurate, and characteristic, so as that each one should be readily adapted to the plant it relates to, and to no other one; they should be as nearly as possible arranged under natural (184) divisions, so as to facilitate the comparison of each plant with those nearest allied to it ; and they should be accompanied by an artificial key or index, by means of which the student may be guided step by step in the observation of such peculiarities or characters in his plant, as may lead him, with the least delay, to the individual description belonging to it.

4. For descriptions to be clear and readily intelligible, they should be expressed as much as possible in ordinary well-established language. But, for the purpose of accuracy, it is necessary not only to give a more precise technical meaning to many terms used more or less vaguely in common conversation, but also to introduce purely technical names for such parts of plants or forms as are of little importance except to the botanist. In the present chapter it is proposed to define such technical or technically limited terms as are made use of in these Floras.

5. At the same time mathematical accuracy must not be expected. The forms and appearances assumed by plants and their parts are infinite. Names cannot be invented for all; those even that have been proposed are too numerous for ordinary memories. Many are derived from supposed resemblances to well-known forms or objects. These resemblances are differently appreciated by different persons, and the same term is not only differently applied by two different botanists, but it frequently happens that the same writer is led on different occasions to give somewhat different meanings to the same word. The botanist's endeavours should always be, on the one hand, to make as near an approach to precision as circumstances will allow, and on the other hand to avoid that prolixity of detail and overloading with teehnical terms which tends rather to confusion than clearness. In this he will be more or less successful. The aptness of a botanical description, like the beauty of a work of imagination, will always vary with the style and genius of the author. 


\section{§ 1. The Plant in General.}

6. The Plant, in its botanical sense, includes every being which has vegetable life, from the loftiest tree which adorns our landscapes, to the humblest moss which grows on its stem, to the mould or fungus which attacks our provisions, or the green scum that floats on our ponds.

7. Every portion of a plant which has a distinct part or function to perform in the operations or phenomena of vegetable life is called an Organ.

8. What constitutes vegetable life, and what are the functions of each organ, belong to Vegetable Physiology; the microscopical structure of the tissues composing the organs, to Vegetable Anatomy; the composition of the substances of which they are formed, to Vegetable Chemistry; under Descriptive and Systematic Botany we have chiefly to consider the forms of organs, that is, their Morphology, in the proper sense of the term, and their general structure so far as it affects classification and specific resemblances and differences. The terms we shall now define belong chiefly to the latter branch of Botany, as being that which is essential for the investigation of the Flora of a country. We shall add, however, a short chapter on Vegetable Anatomy and Physiology, as a general knowledge of both imparts an additional interest to and facilitates the comparison of the characters and affinities of the plants examined.

9. In the more perfect plants, their organs are comprised in the general terms Root, Stem, Ieaves, Flowers, and $\boldsymbol{F}^{2}$ uit. Of these the three first, whose function is to assist in the growth of the plant, are Organs of Vegetation; the flower and fruit, whose office is the formation of the seed, are the Organs of Reproduction.

10. All these organs exist, in one shape or another, at some period of the life of most, if not all, flowering plants, technically called phanogamous or phanerogamous plants; which all bear some kind of flower and fruit in the botanical sense of the term. In the lower classes, the ferns, mosses, fungi, moulds or mildews, seaweeds, etc., called by botanists cryptogamous plants, the flowers, the fruit, and not unfrequently one or more of the organs of vegetation, are either wanting, or replaced by organs so different as to be hardly capable of bearing the same name.

11. The observations comprised in the following pages refer exclusively to the flowering or phænogamous plants. The study of the cryptogamous classes has now become so complicated as to form almost a separate science. They are therefore not included in these introductory observations, nor, with the exception of ferns, in the present Flora.

\section{Plants are}

Monocarpic, if they die after one flowering-season. These include Annuals, which flower in the same year in which they are raised from seed; and Biennials, which only llower in the year following that in which they are sown.

Caulocarpic, if, after flowering, the whole or part of the plant lives through the winter and produces fresh flowers another season. These include Herbaceous perennials, in which the greater part of the plant dies after flowering, leaving only a small perennial portion called the Stock or Caudex, close to or within the earth; Undershrubs, suffruticose or suffrutescent plants, in which the flowering branches, forming a considerable portion of the plant, die down after flowering, but leave a more or less prominent perennial and woody base; Shrubs (frutescent or fruticose plants), in which the perennial woody part forms the greater part of the plant, but branches near the base, and does not much exceed a man's height; and Trees (arboreous or arborescent plants) when the height is greater and forms a woody trunk, scarcely branching from the base. Bushes are low, much branched shrubs.

13. The terms Monocarpic and Caulocarpic are but little used, but the other distinctions enumerated above are universally attended to, although more useful to the gardener than to the botanist, who cannot always assign to them any precise character. Monocarpic plants, which require more than two or three years to produce their flowers, will often, under certain circumstances, become herbaceous perennials, and are generally confounded with them. Truly perennial herbs will often commence flowering the first year, and have then all the appearance of annuals. Many tall shrubs and trees lose annually their flowering branches like undershrubs. And the same 
botanical species may be an annual or a perennial, a herbaceous perennial or an undershrub, an undershrub or a shrub, a shrub or a tree, according to climate, treatment, or variety.

14. Plants are usually terrestrial, that is, growing on earth, or aquatic, i.e. growing in water; but sometimes they may be found attached by their roots to other plants, in which case they are epiphytes when simply growing upon other plants without penetrating into their tissue, parasites when their roots penetrate into and derive more or less nutriment from the plant to which they are attached.

15. The simplest form of the perfect plant, the annual, consists of-

(1) The $\mathbf{R}$ oot, or descending axis, which grows downwards fiom the stem, divides and spreads in the earth or water, and absorbs food for the plant through the extremities of its branches.

(2) The Stem, or ascending axis, which grows upwards from the root, branches and bears first one or more leaves in succession, then one or more flowers, and fiully one or more fruits. It contains the tissues or other channels (217) by which the nutriment absorbed by the roots is conveyed in the form of sap (192) to the leaves or other points of the surface of the plant, to be elaborated or digested (218), and afterwards redistributed over different parts of the plant for its support and growth.

(3) The Ireaves, usually flat, green, and horizontal, are variously arranged on the stem and its branches. They elaborate or digest (218) the nutriment brought to them through the stem, absorb carbonic acid gas from the air, exhaling the superfluous oxygen, and returning the assimilated sap to the stem.

(4) The Flowers, usually placed at or towards the extremities of the branches. They are destined to form the future seed. When perfect and complete they consist: 1st, of a pistil in the centre, consisting of one or more carpels, each containing the germ of one or more seeds; $2 \mathrm{nd}$, of one or more stamens outside the pistil, whose action is necessary to fertilize the pistil or enuble it to ripen its seed; 3rd, of a perianth or flosal envelope, which usually encloses the stamens and pistil when young, and expands and exposes them to view when fully formed. This complete perianth is double; the outer one, called Calyx, is usually more green and leaf-like; the inner one, called the Corolla, more conspicuous, and variously coloured. It is the perianth, and especially the corolla, as the most showy part, that is generally called the flower in popular language.

(5) The Fruit, consisting of the pistil or its lower portion, which persists or remains. attached to the plant after the remainder of the flower has withered and fallen off. It enlarges and alters more or less in shape or consistence, becomes a seed-vessel, enelosing the seed until it is ripe, when it either opens to discharge the seed or falls to the ground with the seed. In popular language the term fruit is often limited to such seed-vessels as are or look juicy and eatable. Botanists give that name to all seedvessels.

16. The herbaceous perennial resembles the annual during the first year of its growth; but it also forms (usually towards the close of the season), on its stock (the portion of the stem and root which does not die), one or more buds, either exposed, and then popularly called eyes, or concealed among leaves. These buds, called leafbuds, to distinguish them from flower-buds or unopened flowers, are future branches as yet undeveloped; they remain dormant through the winter, and the following spring grow out into new stems bearing leaves and flowers like those of the preceding year, whilst the lower part of the stock emits fresh roots to replace those which had perished at the same time as the stems.

17. Shrubs and trees form similar leaf-buds either at the extremity of their branches, or along the branches of the year. In the latter case these buds are usually axillary, that is, they appear in the axil of each leaf, $i . e$. in the ai:gle formed by the leaf and the branch. When they appear at any other part of the plant they are called adventitious. If these buds by producing roots (19) become distinct plants before separating from the parent, or if adventitious leaf-buds are produced in the place of flowers or seeds, the plant is said to be viviparous or proliferous. 


\section{§ 2. The Root.}

18. Roots ordinarily produce neither buds, leaves, nor flowers. Their branches, called fibres when slender and long, proceed irregularly from any part of their surface.

19. Although roots proceed usually from the base of the stem or stock, they may also be produced from the base of any bud, especially if the bud lie along the ground, or is otherwise placed by nature or art in circumstances favourable for their development, or indeed occasionally from almost any part of the plant. They are then often distinguished as adventitious, but this term is by some applied to all roots which are not in prolongation of the original radicle.

\section{Roots are}

fibrors, when they consist chiefly of slender fibres.

tuberous, when either the main root or its branches are thickened into one or more short fleshy or woody masses called tubers (25).

taproots, when the main root descends perpendicularly into the earth, emitting only very small fibrous branches.

21. The stock of a herbaceous perennial, or the lower part of the stem of an annual or perennial, or the lowest branches of a plant, are sometimes underground and assume the appearance of a root. They then take the name of rhizome. The rhizome may always be distinguished from the true root by the presence or production of une or more buds, or leaves, or scales.

\section{§ 3. The Stock.}

22. The Stock of a herbaceous perennial, in its most complete state, includes a small portion of the summits of the previous year's roots, as well as of the base of the previous year's stems. Such stocks will increase yearly, so as at length to form denso tufts. They will often preserve through the winter a few leaves, amongst which are placed the buds which grow out into stems the following vear, whilst the under side of the stock emits new roots from or amongst the remains of the old ones. These perennial stocks only differ from the permanent base of an undershrub in the shortness of the perennial part of the stems and in their texture usually less woody.

23. In some perennials, however, the stock consists merely of a branch, which proceeds in autumn from the base of the stem either aboveground or underground, and produces one or more buds. This branch, or a portion of it, alone survives the winter. In the following year its buds produce the new stem and roots, whilst the rest of the plant, even the branch on which these buds were formed, has died away. These annual stocks, called sometimes hybernacula, offsets, or stolons, keep up the communication between the annual stem and root of one year and those of the following year, thus forming altogether a perennial plant.

24. The stock, whether annual or perennial, is often entirely underground or rootlike. This is the rootstock, to which some botanists limit the meaning of the term rhizome. When the stock is entirely root-like, it is popularly called the crown of the root.

25. The term tuber is applied to a short, thick, more or less succulent rootstock or rhizome, as well as to a root of that shape (20), although some botanists propose to restrict its meaning to the one or to the other. An Orchis tuber, ealled by some a knob, is an annual tuberous rootstock with one bud at the top. A potato is an annual tuberous rootstock with several buds.

26. A bulb is a stock of a shape approaching to globular, usually rather conical above and flattened underneath, in which the bud or buds are concealed, or nearly so, under scales. These scales are the more or less thickened bases of the decayed leaves of the preceding year, or of the undeveloped leaves of the future year, or of both. Bulbs are annual or perennial, usually underground or close to the ground, but occasionally buds in the axils of the upper leaves become transformed into bulbs. Bulbs are said to be scaly when their scales are thick and loosely imbricated, tunicated when the scales are thinner, broader, and closely rolled round each other in concentric layers.

27. A corm is a tuberous rootstock, usually annual, shaped like a bulb, but in which the bud or buds are not covered by scales, or of which the scales are very thin and membranous. 


\section{Stems are}

\section{§4. The Stem.}

erect, when they ascend perpendicularly from the root or stock; twiggy or virgate, when at the same time they are slender, stiff, and scarcely branched.

decumbent or ascending, when they spread horizontally, or nearly so, at the base, and then turn upwards and become erect.

procumbent, when they spread along the ground the whole or the greater portion of their length; diffuse, when at the same time very much and rather loosely branched. prostrate, when they lie still closer to the ground.

creeping, when they emit roots at their nodes. This term is also frequently applied to any rhizomes or roots which spread horizontally. stock.

tufted or caspitose, when very short, close, and many together from the same

29. Weak climbing stems are said to twine, when they support themselves by wind: ing spirally round any object; such stems are also called voluble. When they simply climb without twining, they support themselves by their leaves, or by special clasping organs called tendrils (169), or sometimes, like the Iry, by small root-like excrescences.

30. Suckers are young plants formed at the end of creeping, underground rootstocks. Scions, runners, and stolons, or stoles, are names given to young plants formed at the end or at the nodes (31) of branches or stocks creeping wholly or partially aboveground, or sometimes to the creeping stocks themselves.

31. A node is a point of the stem or its branches at which one or more leaves, branches, or leaf-buds (16) are given off. An internode is the portion of the stem comprised between two nodes.

\section{Branches or leaves are}

opposite, when two proceed from the same node on opposite sides of the stem.

whorled or verticillate (in a whorl or verticil), when several proceed from the same node, arranged regularly round the stem; geminate, ternate, fascicled, or fasciculate when two, three, or more proceed from the same node on the same side of the stem. A tuft of fasciculate leaves is usually in fact an axillary leafy branch, so short that the leaves appear to proceed all from the same point.

alternate, when one only proceeds from each node, one on one side and the next above or below on the opposite side of the stem.

decussate, when opposite, but each pair placed at right-angles to the next pair above or below it ; distichous, when regularly arranged one above another in two opposite rows, one on each side of the stem; tristichous, when in three rows, etc. (92).

scattered, when irregularly arranged round the stem; frequently, however, botanists apply the term alternate to all branches or leaves that are neither opposite nor whorled.

secund, when all start from or are turned to one side of the stem.

33. Branches are dichotomous, when several times forked, the two branches of each fork being nearly equal; trichotomous, when there are three nearly equal branches at each division instead of two; but when the middle branch is evidently the principal one, the stem is usually said to have two opposite branches; umbellate, when divided in the same manner into several nearly equal branches proceeding from the same point. If however the central branch is larger than the two or more lateral ones, the stem is said to have opposite or whorled branches, as the case may be.

34. A culm is a name sometimes given to the stem of Grasses, Sedges, and some other Monocotyledonous plants.

\section{§ 5. The Leaves.}

35. The ordinary or perfect Leaf consists of a flat blade or lamina, usually green, and more or less horizontal, attached to the stem by a stalk called a footstalk or petiole. When the form or dimensions of a leaf are spoken of, it is generally the blade that is meant, without the petiole or stalk.

36 . The end by which a leaf, a part of the flower, a seed, or any other organ, is attached to the stem or other organ, is called its base, the opposite end is its apex or summit, excepting sometimes in the case of anther-cells (115). 


\section{Leaves are}

sessile, when the blade rests on the stem without the intervention of a petiole. amplexicaul or stem-clasping, when the sessile base of the blade clasps the stem horizontally. perfoliate, when the base of the blade not only clasps the stem, but closes round it on the opposite side, so that the stem appears to pierce through the blade. decurrent, when the edges of the leaf are continued down the stem so as to form raised lines or narrow appendages, called wings. sheathing, when the base of the blade, or of the more or less expanded petiole, forms a vertical sheath round the stem for some distance above the node.

38. Leaves and flowers are called radical, when inserted on a rhizome or stock, or so close to the base of the stem as to appear to proceed from the root, rhizome, or stock; cauline, when inserted on a distinct stem. Radical leaves are rosulate when they spread in a circle on the ground.

39. Leaves are

simple and entire, when the blade consists of a single piece, with the margin nowhere indented, simple being used in opposition to compound, entire in opposition to dentate, lobed, or divided.

ciliate, when bordered with thick hairs or fine hair-like teeth.

dentate or toothed, when the margin is only cut a little way in, into what have been compared to teeth. Such leaves are serrate, when the teeth are regular and pointed like the teeth of a saw; crenate, when regular and blunt or rounded (compared to the battlements of a tower); serrulate, and crenulate, when the serratures or crenatures are small; sinuate, when the teeth are broad, not deep, and irregular (compared to bays of the coast); wavy or undulate, when the edges are not flat, but bent up and down (compared to the waves of the sea).

lobed or cleft, when more deeply indented or divided, but so that the incisions do not reach the midrib or petiole. The portions thus divided take the name of lobes. When the lobes are narrow and very irregular, the leaves are said to belaciniate. The spaces between the teeth or lobes are called sinuses.

divided or dissected, when the incisions reach the midrib or petiole, but the parts so divided off, called segments, do not separate from the petiole, even when the leaf falls, without tearing.

compound, when divided to the midrib or petiole, and the parts so divided off, called leaflets, separate, at least at the fall of the leaf, from the petiole, as the whole leaf does from the stem, without tearing. The common stalk upon which the leaflets are inserted is called the common petiole or the rhachis; the separate stalk of each leaflet is a petiolule.

40. Leaves are more or less marked by veins, which, starting from the stalk, diverge or branch as the blade widens, and spread all over it more or less visibly. The principal ones, when prominent, are often called ribs or nerves, the smaller branches only then retaining the name of veins, or the latter are termed veinlets. The smaller veins are often connected together like the meshes of a net, they are then said to anastomose, and the leaf is said to be reticulate or net-veined. When one principal vein runs direct from the stalk towards the summit of the leaf, it is called the midrib. When several start from the stalk, diverge slightly without branching, and converge again towards the summit, they are said to be parallel, although not mathematically so. When 3 or 5 or more ribs or nerves diverge from the base, the leaf is said to be 3-nerved, 5-nerved, etc., but if the lateral ones diverge from the midrib a little above the base, the leaf is triplinerved, quintuplinerved, etc. The arrangement of the veins of a leaf is called their venation.

\section{The Leaflets, Segments, Lobes, or Veins of leares are}

pinnate (feathered), when there are several succeeding each other on each side of the midrib or petiole, compared to the branches of a feather. A pinnately lobed or divided leaf is called lyrate when the terminal lobe or segment is much larger and broader than the lateral ones, compared, by a stretch of imagination, to a lyre; runcinate, when the lateral lobes are curved backwards towards the base of the leaf; pectinate, when the lateral lobes are numerous, narrow, and regular, like the teeth of a comb. 
palmate or digitate, when several diverge from the same point, compared to the fingers of the hand.

ternate, when three only start from the same point, in which case the distinction between the palmate and pinnate arrangement often ceases, or can only be determined by analogy with allied plants. A leaf with ternate lobes is called trifid. A leaf with three leaflets is sometimes improperly called a ternate leaf: it is the leaflets that are ternate; the whole leaf is trifoliolate. Ternate leaves are leaves growing three together.

pedate, when the division is at first ternate, but the two outer branches are forked, the outer ones of each fork again forked, and so on, and all the branches are near together at the base, compared vaguely to the foot of a bird.

42. Leaves with pinnate, palmate, pedate, etc., leaflets, are usually for shortness called pinnate, palmate, pedate, etc., leaves. If they are so cut into segments only, they are usually said to be pinnatisect, palmatisect, pedatisect, etc., although the distinction between segments and leaflets is often unheeded in descriptions, and cannot indeed always be ascertained. If the leaves are so cut only into lobes, they are said to be pinnatifid, palmatifid, pedatifid, etc.

43. The teeth, lobes, segments, or leaflets, may be again toothed, lobed, divided, or compounded. Some leaves are even three or more times divided or compounded. In the latter case they are termed decompound. When twice or thrice pinnate (bipinnate or tripinnate), each primary or secondary division, with the leaflets it comprises, is called a pinna. When the pinna of a leaf or the leaflets of a pinna are in pairs, without an odd terminal pinna or leaflet, the leaf or pinna so divided is said to be abruptly pinnate; if there is an odd terminal pinna or leaflet, the leaf or pinna is unequally pinnate (imparipinnatum).

44. The number of leaves or their parts is expressed adjectively by the following numerals, derived from the Latin :-

uni-, bi-, tri-, quadri-, quinque-, sex-, septem-, octo-, novem-, decem-, multi-

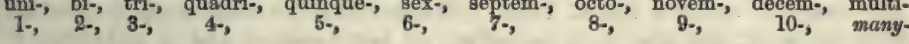

prefixed to a termination, indicating the particular kind of part referred to. Thus-

unidentate, bidentate, multidentate, mean one-toothed, two-toothed, many-toothed, etc.

bifid, trifid, multifid, mean two-lobed, three-lobed, many-lobed, etc.

unifoliolate, bifoliolate, multifoliolate, mean having one leaflet, two leaflets, many leaflets, etc. etc.

unifoliate, bifoliate, multifoliate, mean having one leaf, two leaves, many leaves,

biternate and triternate, mean twice or thrice ternately divided.

unijugate, bijugate, multijugate, etc., pinnæ or leaflets, mean that they are in one, two, many, etc., pairs (juga).

45. Ieaves or their parts, when flat, or any other flat organs in plants, are

linear, when long and narrow, at least four or five times as long as broad, falsely compared to a mathematical line, for a linear leaf has always a perceptible breadth.

lanceolate, when about three or more times as long as broad, broadest below the middle, and tapering towards the summit, compared to the head of a lance.

cuneate, when broadest above the middle, and tapering towards the base, compared to a wedge with the point downwards; when very broadly cuneate and rounded at the top, it is often called flabelliform or fan-shaped.

spathulate, when the broad part near the top is short, and the narrow tapering part long, compared to a spatula or flat ladle.

ovate, when scarcely twice as long as broad, and rather broader below the middle, compared to the longitudinal section of an egg; obovate is the same form, with the broadest part above the middle.

orbicular, oval, oblong, elliptical, rhomboidal, etc., when compared to the corresponding mathematical figures.

transversely oblong, or oblate, when conspicuously broader than long.

falcate, when curved like the blade of a scythe.

46. Internecdiate forms between any two of the above are expressed by combining 
two terms. Thus, a linear-lanceolate leaf is long and narrow, yet broader below the middle, and tapering to a point; a linear-oblong one is scarcely narrow enough to be called linear, yet too narrow to be strictly oblong, and does not conspicuously taper either towards the summit or towards the base.

47. The apex or summit of a leaf is

acute or pointed, when it forms an acute angle or tapers to a point.

obtuse or blunt, when it forms a very obtuse angle, or more generally when it is more or less rounded at the top.

acuminate or cuspidate, when suddenly narrowed at the top, and then more or less prolonged into an acumen or point, which may be acute or obtuse, linear or tapering. Some botanists make a slight difference between the acuminate and cuspidate apex, the acumen being more distinct from the rest of the leaf in the latter case than in the former; but in general the two terms are used in the same sense, some preferring the one and some the other.

truncate, when the end is cut off square.

retuse, when very obtuse or truncate, and slightly indented.

emarginate or notched, when more decidedly indented at the end of the midrib; obcordate, if at the same time approaching the shape of a heart with its point downwards. point.

mucronate, when the midrib is produced beyond the apex in the form of a small

aristate, when the point is fine like a hair.

48. The base of the leaf is liable to the same variations of form as the apex, but the terms more commonly used are tapering or narrowed for acute and acuminate, rounded for obtuse, and cordate for emarginate. In all cases the petiole or point of attachment prevent any such absolute termination at the base as at the apex.

49. A leaf may be cordate at the base whatever be its length or breadth, or whatever the shape of the two lateral lobes, called auricles (or little ears), formed by the indenture or notch, but the term cordiform or heart-shaped leaf is restricted to an ovate and acute leaf, cordate at the base, with rounded auricles. The word auricles is more particularly used as applied to sessile and stem-clasping leaves.

50. If the auricles are pointed, the leaf is more particularly called auriculate; it is moreover said to be sagittate, when the points are directed downwards, compared to an arrow-head; hastate, when the points diverge horizontally, compared to a halbert.

51. A reniform leaf is broader than long, slightly but broadly cordate at the base, with rounded auricles, compared to a kidney.

52. In a peltate leaf, the stalk, instead of proceeding from the lower edge of the blade, is attached to the under surface, usually near the lower edge, but sometimes in the very centre of the blade. The peltate leaf has usually several principal nerves radiating from the point of attachment, being, in fact, a cordate leaf, with the auricles united.

53. All these modifications of division and form in the leaf pass so gradually one into the other that it is often difficult to say which term is the most applicablewhether the leaf be toothed or lobed, divided or compound, oblong or lanceolate, obtuse or acute, etc. The choice of the most apt expression will depend on the skill of the describer.

54. Ieaves, when solid, Stems, Fruits, Tubers, and other parts of plants, when not flattened like ordinary leaves, are setaceous or capillary, when very slender like bristles or hairs. acicular, when very slender, but stiff and pointed like needles. subulate, when rather thicker and firmer like awls.

linear, when at least four times as long as thick; oblong, when from about two to about four times as long as thick, the terms having the same sense as when applied to flat surfaces.

ovoid, when egg-shaped, with the broad end downwards, obovoid if the broad end is upwards ; these terms corresponding to ovate and obovate shapes in flat surfaces.

globular or spherical, when corresponding to orbicular in a flat surface. Round applies to both. 
turbinate, when shaped like a top.

conical, when tapering upwards ; obconical, when tapering downwards, if in both cases a transverse section shows a circle.

pyramidal, when tapering upwards; obpyramidal, when tapering downwards, if in both cases a transverse section shows a triangle or polygon.

fusiform, or spindle-shaped, when tapering at both ends; cylindrical, when not tapering at either end, if in both cases the transverse section shows a circle, or sometimes irrespective of the transverse shape.

terete, when the transverse section is not angular; trigonous, triquetrous, if the transverse section shows a triangle, irrespective in both cases of longitudinal form. compressed, when more or less flattened laterally; depressed, when more or less flattened vertically, or at any rate at the top; obcompressed (in the achenes of Compo. sitce), when flattened from front to back.

articulate or jointed, if at any period of their growth (usually when fully formed and approaching their decay, or in the case of fruits when quite ripe) they separate, without tearing, into two or more pieces placed end to end. The joints where they separate are called articulations, each separate piece an article. The name of joint is, in common language, given both to the articulation and the article, but more especially to the former. Some modern botanists, however, propose to restrict it to the article, giving the name of joining to the articulation.

didymous, when slightly two-lobed, with rounded obtuse lobes.

moniliform, or beaded, when much contracted at regular intervals, but not separating spontaneously into articles.

55. In their consistence Leaves or other organs are

fleshy, when thick and soft; succulent is generally used in the same sense, but implies the presence of more juice.

coriaceous, when firm and dry, or very tough, of the consistence of leather. membranous, when thin and not stiff.

scarious or scariose, when very thin, more or less transparent and not green, yet rather stiff.

56. The terms applied botanically to the consistence of solids are those in general use in common language.

57. The mode in which unexpanded leaves are disposed in the leaf-bud is called their vernation or profoliation; it varies considerably, and technical terms have been proposed to express some of its varieties, but it has been hitherto rarely noticed in descriptive botany.

\section{§ 6. Scales, Bracts, and Stipules.}

58. Scales (Squam $)$ are leaves very much reduced in size, usually sessile, seldom green or capable of performing the respiratory functions of leaves. In other words, they are organs resembling leaves in their position on the plant, but differing in size, colour, texture, and functions. They are most frequent on the stock of perennial plants, or at the base of annual branches, especially on the buds of future shoots, when they serve apparently to protect the dormant living germ from the rigour of winter. In the latter case they are usually short, broad, close together, and more or less imbricated, that is, overlapping each other like the tiles of a roof. It is this arrangement as well as their usual shape that hassuggested the name of scales, borrowed from the scales of a fish. Imbricated scales, bracts, or leaves, are said to be squarrose, when their tips are pointed and very spreading or recurved.

59. Sometimes, however, most or all the leaves of the plant are reduced to small scales, in which case they do not appear to perform any particular function. The name of scales is also given to any small broad scale-like appendages or reduced organs, whether in the flower or any other part of the plant.

60. Bracts (Bractece) are the upper leaves of a plant in flower (either all those of the flowering branches, or only one or two immediately under the flower), when different from the stem-leaves in size, shape, colour, or arrangement. They are generally much smaller and more sessile. They often partake of the colour of the flower, 
although they very frequently also retain the green colour of the leaves. When amall they are often called scales.

61. Floral leaves or leafy bracts are generally the lower bracts on the upper leaves at the base of the flowering branches, intermediate in size, shape, or arrangement, between the stem-leaves and the upper bracts.

62. Bracteoles are the one or two last bracts under each flower, when they differ materially in size, shape, or arrangement from the other bracts.

63. Stipules are leaf-like or scale-like appendages at the base of the leaf-stalk, or on the node of the stem. When present there are generally two, one on each side of the leaf, and they sometimes appear to protect the young leaf before it is developed. They are however exceedingly variable in size and appearance, sometimes exactly like the true leaves except that they have no buds in their axils, or looking like the leaflets of a compound leaf, sometimes apparently the only leaves of the plant; generally small and narrow, sometimes reduced to minute scales, spots, or scars, sometimes united into one opposite the leaf, or more or less united with, or adnate to the petiole, or quite detached from the leaf, and forming a ring or sheath round the stem in the axil of the leaf. In a great number of plants they are entirely wanting.

64. Stipella, or secondary stipules, are similar organs, sometimes found on compound leaves at the points where the leaflets are inserted.

65. When scales, bracts, or stipules, or almost any part of the plant besides leaves and flowers are stalked, they are said to be stipitate, from stipes, a stall.

\section{$\S 7$. Inflorescence and its Bracts.}

66. The Inflorescence of a plant is the arrangement of the flowering branches, and of the flowers upon them. An Inflorescence is a flowering branch, or the flowering summit of a plant above the last stem-leaves, with its branches, bracts, and flowers.

67. A single flower, or an inflorescence, is terminal when at the summit of a stem or leafy branch, axillary when in the axil of a stem-leaf, leaf-opposed when opposite to a stem-leaf. The inflorescence of a plant is said to be terminal or determinate when the main stem and principal branches end in a flower or inflorescence (not in a leafbud), axillary or indeterminate when all the flowers or inflorescences are axillary, the stem or branches ending in leaf-buds.

68. A Peduncle is the stalk of a solitary flower, or of an inflorescence; that is to say, the portion of the flowering branch from the last stem-leaf to the flower, or to the first ramification of the inflorescence, or even up to its last ramifications; but the portion extending from the first to the last ramifications or the axis of inflorescence is often distinguished under the name of rhachis.

69. A Scape or radical Peduncle is a leafless peduncle proceeding from the stock, or from near the base of the stem, or apparently from the root itself.

70. A Pedicel is the last branch of an inflorescence, supporting a single flower.

71. The branches of inflorescences may be, like those of stems, opposite, alternate, etc. (32, 33), but very often their arrangement is different from that of the leafy branches of the same plant.

72. Inflorescence is

centrifugal, when the terminal flower opens first, and those on the lateral branches are successively developed.

centripetal, when the lowest flowers open first, and the main stem continues to elongate, developing fresh flowers.

73. Determinate inflorescence is usually centrifugal. Indeterminate inflorescence is always centripetal. Both inflorescences may be combined on one plant, for it often happens that the main branches of an inflorescence are centripetal, whilst the flowers on the lateral branches are centrifugal ; or vice versa.

74. An Inflorescence is

a Spike, or spicate, when the flowers are sessile along a simple undivided axis or

a Raceme, or racemose, when the flowers are borne on pedicels along a single undivided axis or rhachis. 
a Panicle, or paniculate, when the axis is divided into branches bearing two or more flowers.

a Head, or capitate, when several sessile or nearly sessile flowers are collected into a compact head-like cluster. The short, flat, convex or conical axis on which the flowers are seated, is called the receptacle, a term also used for the torus of a single flower (135). The very compact flower-heads of Composites are often termed compound flowers.

an Umbel, or umbellate, when several branches or pedicels appear to start from the same point and are nearly of the same length. It differs from the head, like the raceme from the spike, in that the flowers are not sessile. An umbel is said to be simple, when each of its branches or rays bears a single flower; compound, when each ray bears a partialsumbel or umbellule.

a Corymb, or corymbose, when the branches and pedicels, although starting from different points, all attain the same level, the lower ones being much longer than the upper. It is a flat-topped or fastigiate panicle.

a Cyme, or cymose, when branched and centrifugal. It is a centrifugal panicle, and is often corymbose. The central flower opens first. The lateral branches successively developed are usually forked or opposite (dichotomous or trichotomous), but sometimes after the first forking the branches are no longer divided, but produce a succession of pedicels on their upper side forming apparently unilateral centripetal racemes ; whereas if attentively examined, it will be found that each pedicel is at first terminal, but becomes lateral by the development of one outer branch only, immediately under the pedicel. Such branches, when in bud, are generally rolled back at the top, like the tail of a scorpion, and are thence called scorpioid.

a Thyrsus, or thyrsoid, when crmes, usually opposite, are arranged in a narrow pyramidal panicle.

75. There are numerous cases where inflorescences are intermediate between some two of the above, and are called by different botanists by one or the other name, according as they are guided by apparent or by theoretical similarity. A spike-like panicle, where the axis is divided into very short branches forming a cylindrical compact inflorescence, is called sometimes a spike, sometimes a panicle. If the flowers are in distinct clusters along a simple axis, the inflorescence is described as an interrupted spike or raceme, according as the flowers are nearly sessile or distinctly pedicellate; although when elosely examined the flowers will be found to be inserted not on the main axis, but on a very short branch, thus, strictly speaking, constituting a panicle.

76. The catkins (amenta) of Amentacea, the spadices of several Monocotyledons, the ears and spikelets of Grasses are forms of the spike.

77. Bracts are generally placed singly under each branch of the inflorescence, and under each pedicel; bracteoles are usually two, one on each side, on the pedicel or close under the flower, or even upon the calyx itself; but bracts are also frequently scattered along the branches without axillary pedicels; and when the differences between the bracts and bracteoles are trifling or immaterial, they are usually all called bracts.

78. When these bracts appear to proceed from the same point, they will, on examination, be found to be really either one bract and two stipules, or one bract with two bracteoles in its axil. When two bracts appear to proceed from the same point, they will usually be found to be the stipules of an undeveloped bract, unless the branches of the inflorescence are opposite, when the bracts will of course be opposite also.

79. When several bracts are collected in a whorl, or are so close together as to appear whorled, or are closely imbricated round the base of a head or umbel, they are collectively called an Involucre. The bracts composing an involucre are described under the names of leaves, leaflets, bracts, or scales, according to their appearance. Phyllaries is a useless term, lately introduced for the bracts or seales of the involucre of Composita. An Involucel is the involucre of a partial umbel.

80. When several very small bracts are placed round the base of a calyx or of an involucre, they have been termed a calycule, and the calyx or involucre said to becalyculate, but these terms are now falling into disuse, as conveying a false impression.

81. A Spatha is a bract or floral leaf enclosing the inflorescence of some Monocoty. ledons. 
82. Palea, Pales, or Chaff, are the inner bracts or scales in Composita, Araminea, and some other plants, when of a thin yet stiff consistence, usually narrow and of a pale colour.

83. Glumes are the bracts enclosing the flowers of Cyperacea and Graminea.

\section{\$ 8. The Flower in General.}

84. A complete Flower (15) is one in which the calyx, corolla, stamens, and pistils are all present; a perfect flower, one in which all these organs, or such of them as are present, are capable of performing their several functions. Therefore, properly speaking, an incomplete flower is one in which any one or more of these organs is wanting; and an imperfect flower, one in which any one or more of these organs is so altered us to be incapable of properly performing its functions. These imperfect organs are said to be abortive if much reduced in size or efficiency, rudimentary if so much so as to be scarcely perceptible. But, in many works, the term incomplete is specially applied to those flowers in which the perianth is simple or wanting, and imperfect to those in which either the stamens or pistil are imperfect or wanting.

85. A Flower is

dichlamydeous, when the perianth is double, both calyx and corolla being present and distinct.

monochlamydeous, when the perianth is single, whether by the union of the calyx and corolla, or the deficiency of either.

asepalous, when there is no calyx.

apetalous, when there is no corolla.

naked, when there is no perianth at all.

hermaphrodite or bisexual, when both stamens and pistil are present and perfect. male or staminate, when there are one or more stamens, but either no pistil at all or an imperfect one.

female or pistillate, when there is a pistil, but either no stamens at all, or only imperfect ones.

neuter, when both stamens and pistil are imperfect or wanting.

barren or sterile, when from any cause it produces no seed.

fertile, when it does produce seed. In some works the terms barren, fertile, and perfect are also used respectively as synonyms of male, female, and hermaphrodite.

86. The flowers of a plant or species are said collectely to be unisexual or diclinous when the flowers are all either male or female.

monoecious, when the male and female flowers are distinct, but on the same plant. dioecious, when the male and female flowers are on distinct plants.

polygamous, when there are male, female, and hermaphrodite flowers on the same or on distinet plants.

87. A head of flowers is heterogamous when male, female, hermaphrodite, and neuter flowers, or any two or three of them, are included in one head; homogamous, when all the flowers included in one head are alike in this respect. A spike or head of flowers is androgynous when male and female flowers are mixed in it. These terms are only used in the case of very few Natural Orders.

88. As the scales of buds are leaves undeveloped or reduced in size and altered in shape and consistence, and bracts are leaves likewise reduced in size, and occasionaliy altered in colour; so the parts of the flower are considered as leaves still further altered in shape, colour, and arrangement round the axis, and often more or less combined with each other. The details of this theory constitute the comparatively modern branch of botany called Vegetable Metamorphosis, or Homology, sometimes improperly termed Morphology (8).

89. To understand the arrangement of the floral parts, let us take a complete flower, in which moreover all the parts are free from each other, definite in number, i.e. always the same in the same species, and symmetrical or isomerous, $i . e$. when each whorl consists of the same number of parts.

90. Such a complete symmetrical flower consists usually of either four or five whorls of altered leaves (88), placed immediately one within the other.

The Calys forms the outer whorl. Its parts are called sepals. 
The Corolla forms the next whorl. Its parts, called petals, usually alternate with the sepals ; that is to say, the centre of each petal is immediately over or within the interval between two sepals.

The Stamens form one or two whorls within the petals. If two, those of the outer whorl (the outer stamens) alternate with the petals, and are consequently opposite to, or over the centre of the sepals; those of the inner whorl (the inner stamens) alternate with the outer ones, and are therefore opposite to the petals. If there is only one whorl of stamens, they most frequently alternate with the petals; but sometimes they are opposite the petals and alternate with the sepals.

The Pistil forms the inner whorl; its carpels usually alternate with the inner row of stamens.

91. In an axillary or lateral flower the upper parts of each whorl (sepals, petals, stamens, or carpels) are those which are next to the main axis of the stems or branch, the lower parts those which are furthest from it; the intermediate ones are said to be lateral. The words anterior (front) and posterior (back) are often used for lower and upper respectively, but their meaning is sometimes reversed if the writer supposes himself in the centre of the flower instead of outside of it.

92. The number of parts in each whorl of a flower is expressed adjectively by the following numerals derived from the Greek :-

mono-, di-, tri-, tetra-, penta-, hexa-, hepta-, octo., ennea-, deca-, etc., poly-

prefixed to a termination indicating the whorl referred to.

93. Thus, a Flower is

disepalous, trisepalous, tetrasepalous, polysepalous, etc., according as there are $\mathbf{2}$, 3, 4, or many (or an indefinite number of) sepals. petals.

dipetalous, tripetalous, polypetalous, etc., according as there are 2, 3, or many

diandrous, triandrous, polyandrous, etc., according as there are 2, 3, or many stamens.

digynous, trigynous, polygynous, etc., according as there 2, 3, or many carpels.

And generally (if symmetrical), dimerous, trimerous, polymerous, etc., according as they are 2,3 , or many (or an indefinite number of) parts to each whorl.

94. Flowers are unsymmetrical or anisomerous, strictly speaking, when any one of the whorls has a different number of parts from any other; but when the pistils alone are reduced in number, the flower is still frequently called symmetrical or isomerous, if the calyx, corolla, and staminal whorls have all the same number of parts.

95. Flowers are irregular when the parts of any one of the whorls are unequal in size, dissimilar in shape, or do not spread regularly round the axis at equal distances. It is however more especially irregularity of the corolla that is referred to in descriptions. A slight inequality in size or direction in the other whorls does not prevent the flower being classed as regular, if the corolla or perianth is conspicuous and regular.

\section{§ 9. The Calyx and Corolla, or Perianth.}

96. The Calyx (90) is usually green, and smaller than the corolla; sometimes very minute, rudimentary, or wanting, sometimes very indistinctly whorled, or not whorled at all, or in two whorls, or composed of a large number of sepals, of which the outer ones pass gradually into bracts, and the inner ones into petals.

97. The Corolla (90) is usually coloured, and of a more delicate texture than the calyx, and, in popular language, is often more specially meant by the flower. Its petals are more rarely in two whorls, or indefinite in number, and the whorl more rarely broken than in the case of the calyx, at least when the plant is in a natural state. Double flowers are in most cases an accidental deformity or monster in which the ordinary number of petals is multiplied by the conversion of stamens, sepals, or even carpels into petals, by the division of ordinary petals, or simply by the addition of supernumerary ones. Petals are also sometimes very small, rudimentary, or entirely deficient.

98. In very many cases, a so-called simple perianth (15) (of which the parts are 
usually called leaves or segments) is one in which the sepals and petals are similar in form and texture, and present apparently a single whorl. But if examined in the young bud, one half of the parts will generally be found to be placed outside the other half, and here will frequently be some slight difference in texture, size, and colour, indicating to the close observer the presence of both calyx and corolla. Hence much discrepancy in descriptive works. Where one botanist describes a simple perianth of six segments, another will speak of a double perianth of three sepals and three petals.

99. The following terms and prefixes, expressive of the modifications of form and arrangement of the corolla and its petals, are equally applicable to the calyx and its sepals, and to the simple perianth and its segments.

100. The Corolla is said to be monopetalous when the petals are united, either entirely or at the base only, into a cup, tube, or ring; polypetalous when they are all free from the base. These expressions, established by a long usage, are not strictly correct, for monopetalous (consisting of a single petal) should apply rather to a corolla really reduced to a single petal, which would then be on one side of the axis; and polypetalous is sometimes used more appropriately for a corolla with an indefinite number of petals. Some modern botanists have therefore proposed the term gamopetalous for the corolla with united petals, and dialypetalous for that with free petals ; but the old established expressions are still the most generally used.

101. When the petals are partially united, the lower entire portion of the corolla is called the tube, whatever be its shape, and the free portions of the petals are called the teeth, lobes, or segments (39), according as they are short or long in proportion to the whole length of the corolla. When the tube is excessively short, the petals appear at first sight free, but their slight union at the base must be carefully attended to, being of importance in classification.

102. The Fistivation of a corolla, is the arrangement of the petals, or of such portion of them as is free, in the unexpanded bud. It is

valvate, when they are strictly whorled in their whole length, their edges being placed against each other without overlapping. If the edges are much inflexed, the rstivation is at the same time induplicate; involute, if the margins are rolled inward; reduplicate, if the margins project outwards into salient angles; revolute, if the margins are rolled outwards; plicate, if the petals are folded in longitudinal plaits.

imbricate, when the whorl is more or less broken by some of the petals being outside the others, or by their overlapping each other at least at the top. Five-petaled imbricate corollas are quincuncially imbricate when one petal is outside, and an adjoining one wholly inside, the three others intermediate and overlapping on one side; bilabiate, when two adjoining ones are inside or outside the three others. Imbricate petals are described as crumpled (corrugate) when puckered irregularly in the bud.

twisted, contorted, or convolute, when each petal overlaps an adjoining one on one side, and is overlapped by the other adjoining one on the other side. Some botanists include the twisted æstivation in the general term imbricate; others carefully distinguish the one from the other.

103. In a few cases the overlapping is so slight that the three rstivations cannot easily be distinguished one from the other; in a few others the rstivation is variable, even in the same species, but, in general, it supplies a constant character in species, in genera, or even in Natural Orders.

104. In general shape the Corolla is cylinder.

tubular, when the whole or the greater part of it is in the form of a tube or campanulate, when approaching in some measure the shape of a cup or bell. urceolate, when the tube is swollen or nearly globular, contracted at the top, and slightly expanded again in a narrow rim. rotate or stellate, when the petals or lobes are spread out horizontally from the base, or nearly so, like a wheel or star.

hypocrateriform or salver-shaped, when the lower part is cylindrical and the upper portion expanded horizontally. In this case the name of tube is restricted to the cylindrical part, and the horizontal portion is called the limb, whether it be divided to the base or not. The orifice of the tube is called its mouth or throat. 
infundibuliform or funnel-shaped, when the tube is cylindrical at the base, but enlarged at the top into a more or less campanulate limb, of which the lobes often spread horizontally. In this case the campanulate part, up to the commencement of the lobes, is sometimes considered as a portion of the tube, sometimes as a portion of the limb, and by some botanists again described as independent of either, under the name of throat (fauces). Generally speaking, however, in campanulate, infundibuliform, or other corollas, where the lower entire part passes gradually into the upper divided and more spreading part, the distinction between the tube and the limb is drawn either at the point where the lobes separate, or at the part where the corolla first expands, according to which is the most marked.

105. Irregular corollas have received various names according to the more familiar forms they have been compared to. Some of the most important are the

bilabiate, or two-lipped corolla, when, in a four- or five-lobed corolla, the two or three upper lobes stand obviously apart, like an upper lip, from the two or three lower ones or under lip. In Orchidece and some other families the name of lip, or labellum, is given to one of the divisions or lobes of the perianth.

personate, when two-lipped, and the orifice of the tube closed by a projection from the base of the upper or lower lip, called a palate.

ringent, when very strongly two-lipped, and the orifice of the tube very open.

spurred, when the tube or the lower part of a petal has a conical hollow projection, compared to the spur of a cock; saccate, when the spur is short and round like a little bag; gibbous, when projecting at any part into a slight swelling.

resupinate or reversed, when a lip, spur, etc., which in allied species is usually lowest, lies uppermost, and vice versa.

106. The above terms are mustly applied to the forms of monopetalous corollas, but several are also applicable to those of polypetalous ones. Terms descriptive of the special forms of corolla in certain Natural Orders, will be explained under those Orders respectively.

107. Most of the terms used for describing the forms of leaves $(39,45)$ are also applicable to those of individual petals; but the flat expanded portion of a petal, corresponding to the blade of the leaf, is called its lamina, and the stalk, corresponding to the petiole, its claw (unguis). The stalked petal is said to be unguiculate.

\section{§ 10. The Stamens.}

108. Although in a few cases the outer stamens may gradually pass into petals, yet, in general, Stamens are very different in shape and aspect from leaves, sepals, or petals. It is only in a theoretical point of view (not the less important in the study of the physiological economy of the plant) that they can be called altered leaves.

109. This usual form is a stalk, called the filament, bearing at the top an anther divided into two pouches or cells. These anther-cells are filled with pollen, consisting of minute grains, usually forming a yellow dust, which, when the flower expands, is scattered from an opening in each cell. When the two cells are not closely contiguous, the portion of the anther that unites them is called the connectivum.

110. The filament is often wanting, and the anther sessile, yet still the stamen is perfect; but if the anther, which is the essential part of the stamen, is wanting, or does not contain pollen, the stamen is imperfect, and is then said to be barren or sterile (without pollen), abortive, or rudimentary (84), according to the degree to which the imperfection is carried. Imperfect stamens are often called staminodia.

111. In unsymmetrical flowers, the stamens of each whorl are sometimes reduced in number below that of the petals, even to a single one, and in several Natural Orders they are multiplied indefinitely.

112. The terms monandrous and polyandrous are restricted to flowers which have really but one stamen, or an indefinite number respectively. Where several stamens are united into one, the flower is said to be synandrous.

113. Stamens are

monadelphous, whon united by their filaments into one cluster. This cluster either orms a tube round the pistil, or, if the pistil is wanting, occupies the centre of the ower. 
diadelphous, when so united into two clusters. The term is more especially applied to certain Leguminose, in which nine stamens are united in a tube slit open on the upper side, and a tenth, placed in the slit, is free. In some other plants the stamens are equally distributed in the two clusters.

triadelphous, pentadelphous, polyadelphous, when so united into three, five, or many clusters.

syngenesious, when united by their anthers in a ring round the pistil, the filaments usually remaining free.

didynamous, when (usually in a bilabiate flower) there are four stamens in two pairs, those of one pair longer than those of the other.

tetradynamous, when (in Crucifere) there are six, four of them longer than the two others.

exserted, when longer than the corolla, or even when longer than its tube, if the limb be very spreading.

\section{An Anther (109) is}

adnate, when continuous with the filament, the anther-cells appearing to lie their whole length along the upper part of the filament.

innate, when firmly attached by their base to the filament. This is an adnate anther when rather more distinet from the filament.

versatile, when attached by their back to the very point of the filament, so as to swing loosely.

115. Anther-cells may be parallel or diverging at a less or greater angle; or divaricate, when placed end to end so as to form one straight line. The end of each an. ther-cell placed nearest to the other cell is generally called its apex or summit, and the other end its base (36) ; but some botanists reverse the sense of these terms.

116. Anthers have often, on their connectivum or cells, appendages termed bristles (setr), spurs, crests, points, glands, etc., according to their appearance.

117. Anthers have occasionally only one cell : this may take place eitler by the disappearance of the partition between two closely contiguous cells, when these cells are said to be confluent; or by the abortion or total deficiency of one of the cells, when the anther is said to be dimidiate.

118. Anthers will open or dehisce to let out the pollen, like capsules, in valves, pores, or slits. Their dehiscence is introrse, when the opening faces the pistil; extrorse, when towards the circumference of the flower.

119. Pollen (109) is not always in the form of dust. It is sometimes collected in each cell into one or two little wax-like masses. Special terms used in describing these masses or other modifications of the pollen will be explained under the Orders where they occur.

\section{$\S$ 11. The Pistil.}

120. The carpels (91) of the Pistil, although they may occasionally assume, rather more than stamens, the appearance and colour of leaves, are still more different in shape and structure. They are usually sessile; if stalked, their stalk is called a podocarp. This stalk, upon which each separate carpel is supported above the receptacle, must not be confounded with the gynobasis (143), upon which the whole pistil is sometimes raised.

121. Each carpel consists of three parts :

1. the Ovary; or enlarged base, which includes one or more cavities or cells, containing one or more small bodies called ovules. These are the earliest condition of the future seeds.

2. the Style, proceeding from the summit of the ovary, and supporting-

3. the Stigma, which is sometimes a point (or punctiform stigma) or small head (a capitate stigma) at the top of the style or ovary, sometimes a portion of its surface more or less lateral and variously shaped, distinguished by a looser texture, and covered with minute protuberances called papilla.

122. The style is often wanting, and the stigma is then sessile on the ovary, but in the perfect pistil there is always at least one ovule in the ovary, and some portion of stigmatic surface. Without these the pistil is imperfect, and said to be barren (not setting seed), abortive, or rudimentary (84), according to the degree of imperfection. 
123. The ovary being the essential part of the pistil, most of the terms relating to the number, arrangement, etc., of the carpels, apply specially to their ovaries. In some works each separate carpel is called a pistil, all those of a flower constituting together the gynocium; but this term is in little use, and the word pistil is more generally applied in a collective sense. When the ovaries are at all united, they are commonly termed collectively a compound ovary.

124. The number of carpels or ovaries in a flower is frequently reduced below that of the parts of the other floral whorls, even in flowers otherwise symmetrical. In a very few genera, however, the ovaries are more numerous than the petals, or indefinite. They are in that case either arranged in a single whorl, or form a head or spike in the centre of the flower.

125. The terms monogynous, digynous, polygynous, etc. (with a pistil of one, two, or more parts), are vaguely used, applying sometimes to the whole pistil, sometimes to the ovaries alone, or to the styles or stigmas only. Where a more precise nomenclature is adopted, the flower is

monocarpellary, when the pistil consists of a single simple carpel.

bi-, tri-, etc., to poly-carpellary, when the pistil consists of two, three, or an indefinite number of carpels, whether separate or united.

syncarpous, when the carpels or their ovaries are more or less united into one compound ovary.

apocarpous, when the carpels or ovaries are all free and distinct.

126. A compound ovary is

unilocular or one-celled, when there are no partitions between the ovules, or when these partitions do not meet in the centre so as to divide the cavity into several cells.

plurilocular or several-celled, when completely divided into two or more cells by partitions called dissepiments (septa), usually vertical and radiating from the centre or axis of the ovary to its circumference.

$b i$-, tri-, etc., to multi-locular, according to the number of these cells, two, three, etc., or many.

127. In general the number of cells or of dissepiments, complete or partial, or of rows of ovules, corresponds with that of the carpels, of which the pistil is composed. But sometimes each carpel is divided completely or partially into two cells, or has two rows of ovules, so that the number of carpels appears double what it really is. Sometimes again the carpels are so completely combined and reduced as to form a single cell, with a single ovule, although it really consist of several carpels. But in these cases the ovary is usually described as it appears, as well as such as it is theoretically supposed to be.

128. In apocarpous pistils the styles are usually free, each bearing its own stigma. Very rarely the greater part of the styles, or the stigmas alone, are united, whilst the ovaries remain distinct.

\section{Syncarpous flowers are said to have}

several styles, when the styles are free from the base.

one style, with several branches, when the styles are connected at the base, but separate below the point where the stigmas or stigmatic surfaces commence.

one simple style, with several stigmas, when united up to the point where the stigmas or stigmatic surfaces commence, and then separating.

one simple style, with a branshed, lobed, toothed, notched, or entire stigma (as the case may be), when the stigmas also are more or less united. In many works, however, this precise nomenclature is not strictly adhered to, and considerable confusion is often the result.

130. In general the number of styles, or branches of the style or stigma, is the same as that of the carpels, but sometimes that number is doubled, especially in the stigmas, and sometimes the stigmas are dichotomously, or pinnately branched, or penicillate, that is, divided into a tuft of hair-like branches. All these variations sometimes make it a difficult task to determine the number of carpels forming a compound ovary, but the point is of considerable importance in fixing the affinities of plants, and, by careful consideration, the real as well as the apparent number has now in most cases been agreed upon.

131. The Placenta is the part of the inside of the ovary to which the ovules are 
attached, sometimes a mere point or line on the inner surface, often more or less thickened or raised. Placentation is therefore the indication of the part of the ovary to which the ovules are attached.

132. Placentas are

axile, when the ovules are attached to the axis or centre, that is, in plurilocular ovaries, when they are attached to the inner angle of each cell; in unilocular simple ovaries, which have almost always an excentrical style or stigma, when the ovules are attached to the side of the ovary nearest to the style; in unilocular compound ovaries, when the ovules are attached to a central protuberance, column, or axis rising up from the base of the cavity. If this column does not reach the top of the cavity, the placenta is said to be free and central.

parietal, when the ovules are attached to the inner surface of the cavity of a onecelled compound ovary. Parietal placentas are usually slightly thickened or raised lines, sometimes broad surfaces nearly covering the inner surface of the cavity, sometimes projecting far into the cavity, and constituting partial dissepiments, or even meeting in the centre, but without cohering there. In the latter case the distinction between the one-celled and the several celled ovary sometimes almost disappears.

133. Each Ovule (121), when fully formed, usually consists of a central mass or mucleus enclosed in two bag-like coats, the outer one called primine, the inner one secundine. The chalaza is the point of the ovule at which the base of the nucleus is confluent with the coats. The foramen is a minute aperture in the coats over the apex of the nucleus.

134. Ovales are

orthotropous or straight, when the chalaza coincides with the base (36) of the ovule, and the foramen is at the opposite extremity, the axis of the ovule being straight.

campylotropous or incurved, when the chalaza still coinciding with the base of the ovule, the axis of the ovule is curved, bringing the foramen down more or less towards that base.

anatropous or inverted, when the chalaza is at the apex of the ovule, and the foramen next to its base, the axis remaining straight. In this, one of the most frequent forms of the ovule, the chalaza is connected with the base by a cord, called the rhaphe, adhering to one side of the ovule, and becoming more or less incorporated with its coats, as the ovule enlarges into a seed.

amphitropous or half-inverted, when the ovule being as it were attached laterally, the chalaza and foramen at opposite ends of its straight or curved axis are about equally distant from the base or point of attachment.

\section{§ 12. The Receptacle and Relative Attachment of the Floral Whorls.}

135. The Receptacle or torus is the extremity of the peduncle (above the calyx), upon which the corolla, stamens, and ovary are inserted. It is sometimes little more than a mere point or minute hemisphere, but it is often also more or less elongated, thickened, or otherwise enlarged. It must not be confounded with the receptacle of inflorescence (74).

136. A Disk, or disc, is a circular enlargement of the receptacle, usually in the form of a cup (cupular), of a flat disk or quoit, or of a cushion (pulvinate). It is either immediately at the base of the ovary within the stamens, or between the petals and stamens, or bears the petals or stamens or both on its margin, or is quite at the extremity of the receptacle, with the ovaries arranged in a ring round it or under it.

137. The disk may be entire, or toothed or lobed, or divided into a number of parts, usually equal to or twice that of the stamens or carpels. When the parts of the disk are quite separate and short, they are often called glands.

138. Nectaries, are either the disk, or small deformed petals, or abortive stamens, or appendages at the base of petals or stamens, or any small bodies within the flower which do not look like petals, stamens, or ovaries. They were formerly supposed to supply bees with their honey, and the term is frequently to be met with in the older Flores, but is now deservedly going out of use.

139. When the disk bears the petals and stamens, it is frequently adberent to, and 
apparently forms part of, the tube of the calyx, or it is adherent to, and apparently forms part of, the ovary, or of both calyx-tube and ovary. Hence the three following important distinctions in the relative insertion of the floral whorls.

140. Petals, or as it is frequently expressed, flowers, are

hypogynous (i.e. under the ovary), when they or the disk that bears them are entirely free both from the calyx and ovary. The ovary is then described as free or superior, the calyx as free or inferior, the petals as being inserted on the receptacle.

perigynous (i.e. round the ovary), when the disk bearing the petals is quite free from the ovary, but is more or less combined with the base of the calyx-tube. The ovary is then still described as free or superior, even though the combined disk and calyx-tube may form a deep cup with the ovary lying in the bottom; the calyx is said to be free or inferior, and the petals are described as inserted on the calyx.

epigynous (i.e. upon the ovary), when the disk bearing the petals is combined both with the base of the calyx-tube and the base outside of the ovary; either closing over the ovary so as only to leave a passage for the style, or leaving more or less of the top of the ovary free, but always adhering to it above the level of the insertion of the lowest ovule (except in a very few cases where the ovules are absolutely suspended from the top of the cell). - In epigynous flowers the ovary is described as adherent or inferior, the calyx as adherent or superior, the petals as inserted on or above the ovary. In some works, however, most epigynous flowers are included in the perigynous ones, and a very different meaning is given to the term epigynous (144), and there are a few cases where no positive distinction can be drawn between the epigynous and perigynous flowers, or again between the perigynous and hypogynous flowers.

141. When there are no petals, it is the insertion of the stamens that determines the difference between the hypogynous, perigynous, and epigynous flowers.

142. When there are both petals and stamens,

in hypogynous flowers, the petals and stamens are usually free from each other, but sometimes they are combined at the base. In that case, if the petals are distinct from each other, and the stamens are monadelphous, the petals are often said to be inserted on or combined with the staminal tube; if the corolla is gamopetalous and the stamens distinct from each other, the latter are said to be inserted in the tube of the corolla.

in perigynous flowers, the stamens are usually inserted immediately within the petals, or alternating with them on the edge of the disk, but occasionally much lower down within the disk, or even on the unenlarged part of the receptacle.

in epigynous flowers, when the petals are distinct, the stamens are usually inserted as in perigynous flowers; when the corolla is gamopetalous, the stamens are either free and hypogynous, or combined at the base with (inserted in) the tube of the corolla.

143. When the receptacle is distirctly elongated below the ovary, it is often called a gynobasis, gynophore, or stalk of the ovary. If the elongation takes place below the stamens or below the petals, these stamens or petals are then said to be inserted on the stalk of the ovary, and are occasionally, but falsely, described as epigynous. Really epigynous stamens (i.e. when the filaments are combined with the ovary) are very rare, unless the rest of the flower is epigynous.

144. An epigynous disk is a name given either to the thickened summit of the ovary in epigynous flowers, or very rarely to a real disk or enlargement of the receptacle closing over the ovary.

145. In the relative position of any two or more parts of the flower, whether in the same or in different whorls, they are

connivent, when nearer together at the summit than at the base.

divergent, when further apart at the summit than at the base.

coherent, when united together, but so slightly that they can be separated with little or no laceration; and one of the two coherent parts (usually the smallest or least important) is said to be adherent to the other. Grammatically speaking, these two terms convey nearly the same meaning, but require a different form of phrase; practically however it has been found more convenient to restrict cohesion to the union of parts of the same whorl, and adhesion to the union of parts of different whorls.

connate, when so elosely united that they cannot be separated without laceration. 
Each of the two connate parts, and especially that one which is considered the smaller or of the least importance, is said to be adnate to the other.

free, when neither coherent nor connate.

distinct is also used in the same sense, but is also applied to parts distinctly visible or distinctly limited.

\section{§ 13. The Frwit.}

146. The Fruit (15) consists of the ovary and whatever other parts of the flower are persistent (i.e. persist at the time the seed is ripe), usually enlarged, and more or less altered in shape and consistence. It encloses or covers the seed or seeds till the period of maturity, when it either opens for the seed to escape, or falls to the ground with the seed. When stalked, its stalk has been termed a carpophore.

147. Fruits are, in elementary works, said to be simple when the result of a single flower, compound when they proceed from several flowers closely packed or combined in a head. But as a fruit resulting from a single flower, with several distinct carpels, is compound in the sense in which that term is applied to the ovary, the terms single and aggregate, proposed for the fruit resulting from one or several flowers, may be more appropriately adopted. In descriptive botany a fruit is always supposed to result from a single flower unless the contrary be stated. It may, like the pistil, be syncarpous or apocarpous (125); and as in many cases carpels united in the flower may become separate as they ripen, an apocarpous fruit may result from a syncarpous pistil.

148. The involucre or bracts often persist and form part of aggregate fruits, but very seldom so in single ones.

149. The receptacle becomes occasionally enlarged and succulent; if when ripe it falls off with the fruit, it is considered as forming part of it.

150. The adherent part of the calyx of epigynous flowers always persists and forms part of the fruit; the free part of the calyx of epigynous flowers or the calyx of perigy nous flowers, either persists entirely at the top of or round the fruit, or the lobes alone fall off, or the lobes fall off with whatever part of the calyx is above the insertion of the petals, or the whole of what is free from the ovary falls off, including the disk bearing the petals. The calyx of hypogynous flowers usually falls off entirely or persists entirely. In general a calyx is called deciduous if any part falls off. When it persists it is either enlarged round or under the fruit, or it withers and dries up.

151. The corolla usually falls off entirely; when it persists it is usually withered and dry (marcescent), or very seldom enlarges round the fruit.

152. The stamens either fall off, or more or less of their filaments persists, usually withered and dry.

153. The style sometimes falls off or dries up and disappears ; sometimes persists, forming a point to the fruit, or becomes enlarged into a wing or other appendage to the fruit.

154. The Pericarp is the portion of the fruit formed of the ovary, and whatever adheres to it exclusive of and outside of the seed or seeds, exclusive also of the persistent receptacle, or of whatever portion of the calyx persists round the ovary without adhering to it.

155. Fruits have often external appendages called wings (alæ), beaks, crests, awns, etc., according to their appearance. They are either formed by persistent parts of the flower more or less altered, or grow out of the ovary or the persistent part of the calyx. If the appendage be a ring of hairs or scales round the top of the fruit, it is called a pappus.

156. Fruits are generally divided into succulent (including fleshy, pulpy, and juicy fruits) and $d r y$. They are dehiscent when they open at maturity to let out the seeds, indehiscent when they do not open spontaneously but fall off with the seeds. Succulent fruits are usually indehiscent.

157. The principal kinds of succulent fruits are

the Berry, in which the whole substance of the pericarp is fleshy or pulpy, with the exception of the outer skin or rind, called the Epicarp. 'The seeds themselves are usually immersed in the pulp; but in some berries, the seeds are separated from the 
pulp by the walls of the cavity or cells of the ovary, which form as it were a thin inner skin or rind, called the Endocarp.

the Drupe, in which the pericarp, when ripe, consists of two distinct portions, an outer succulent one called the Sarcocarp (covered like the berry by a skin or epicarp), and an inner dry endocarp called the Putamen, which is either cartilaginous (of the consistence of parchment) or hard and woody. In the latter case it is commonly a stone, and the drupe a stone-fruit.

158. The principal kinds of dry fruits are

the Capsule or Pod,* which is dehiscent. When ripe the pericarp usually splits longitudinally into as many or twice as many pieces, called valves, as it contains cells or placentas. If these valves separate at the line of junction of the carpels, that is, along the line of the placentas or dissepiments, either splitting them or leaving them attached to the axis, the dehiscence is termed septicidal; if the valves separate between the placentas or dissepiment, the dehiscence is loculicidal, and the valves either bear the placentas or dissepiments along their middle line, or leave them attached to the axis. Sometimes also the capsule discharges its seeds by slits, chinks, or pores, more or less regularly arranged, or bursts irregularly, or separates into two parts by a horizontal line; in the latter case it is said to be circumsciss.

the Nut or Achene, which is indehiscent and contains but a single seed. When the pericarp is thin in proportion to the seed it encloses, the whole fruit (or each of its lobes) has the appearance of a single seed, and is so called in popular language. If the pericarp is thin and rather loose, it is often called an Utricle. A Samara is a nut with a wing at its upper end.

159. Where the carpels of the ovary are distinct (125) they may severally become as many distinct berries, drupes, capsules, or achenes. Separate carpels are usually more or less compressed laterally, with more or less prominent inner and outer edges, called sutures, and, if dehiscent, the carpel usually opens at these sutures. A Follicle is a carpel opening at the inner suture only. In some cases where the carpels are united in the ovary they will separate when ripe; they are then called Cocci if oneseeded.

160. The peculiar fruits of some of the large Orders have received special names, which will be explained under each Order. Such are the siliqua and silicule of Cruciferæ, the legume of Leguminosæ, the pome of Pyrus and its allies, the pepo of Cucurbitaceæ, the cone of Coniferæ, the grain or caryopsis of Gramineæ, etc.

\section{§ 14. The Seed.}

161. The Seed is enclosed in the pericarp in the great majority of flowering plants, called therefore Angiosperms, or angiospermous plants. In Coniferce and a very few allied genera, called Gymnosperms, or gymnospermous plants, the seed is naked, without any real pericarp. These truly gymnospermous plants must not be confounded with Labiate, Boraginea, etc., which have also been falsely called gymnospermous, their small nuts having the appearance of seeds (158).

162. The seed when ripe contains an embryo or young plant, either filling or nearly filling the cavity, but not attached to the outer skin or the seed, or more or less immersed in a mealy, oily, fleshy, or horn-like substance, called the albumen, or perisperm. The presence or absence of this albumen, that is, the distinction between albuminous and exalbuminous seeds, is one of great importance. The embryo or albumen can often only be found or distinguished when the seed is quite ripe, or sometimes only when it begins to germinate.

163. The shell of the seed consists usually of two separable coats. The outer coat, called the testa, is usually the principal one, and in most eases the only one attended to in descriptions. It may be hard and crustaceous, woody or bony, or thin and membranous (skin-like), dry, or rarely succulent. It is sometimes expanded into wings, or bears a tuft of hair, cotton, or wool, called a coma. The inner coat is called the tegmen.

* In English descriptions, pod is more frequently used when it is long and narrow; capsule, or sometimes pouch, when it is short and thick or broml. 
164. The funicle is the stalk by which the seed is attached to the placenta. It is occasionally enlarged into a membranous, pulpy, or fleshy appendage, sometimes spreading over a considerable part of the seed, or nearly enclosing it, called an aril. A strophiole or caruncle is a similar appendage proceeding from the testa by the side of or near the funicle.

165. The hilum is the scar left on the seed where it separates from the funicle. The micropyle is a mark indicating the position of the foramen of the ovule (133).

166. The Embryo (162) consists of the Radicle or base of the future root, one or two Cotyledons or future seed-leaves, and the Plumule or future bud within the base of the cotyledons. In some seeds, especially where there is no albumen, these several parts are very conspicuous, in others they are very difficult to distinguish until the seed begins to germinate. Their observation, however, is of the greatest importance, for it is chiefly upon the distinction between the embryo with one or with two cotyledons that are founded the two great classes of phænogamous plants, Monocotyledons and Dicotyledons.

167. Although the embryo lies loose (unattached) within the seed, it is generally in some determinate position with respect to the seed or to the whole fruit. This position is described by stating the direction of the radicle next to or more or less remote from the hilum, or it is said to be superior if pointing towards the summit of the fruit, inferior if pointing towards the base of the fruit.

\section{§ 15. Accessory Organs.}

168. Under this name are included, in many elementary works, various external parts of plants which do not appear to act any essential part either in the vegetation or reproduction of the plant. They may be classed under four heads: Tendrils and Hooks, Thorns and Prickles, Hairs, and Glands.

169. Tendrils (cirrhi) are usually abortive petioles, or abortive peduncles, or sometimes abortive ends of branches. They are simple or more or less branched, flexible, and coil more or less firmly round any objects within their reach, in order to support the plant to which they belong. Hooks are similar holdfasts, but of a firmer consistence, not branched, and less coiled.

170. Thorns and Prickles have been fancifully called the weapons of plants. A Thorn or Spine is the strongly pointed extremity of a branch, or abortive petiole, or abortive peduncle. A Prickle is a sharply pointed excrescence from the epidermis, and is usually produced on a branch, on the petiole or veins of a leaf, or on a peduncle, or even on the calyx or corolla. When the teeth of a leaf or the stipules are pungent, they are also called prickles, not thorns. A plant is spinous if it has thorns, aculeate if it has prickles.

171. Hairs, in the general sense, or the indumentum (or clothing) of a plant, include all those productions of the epidermis which have, by a more or less appropriate comparison, been termed bristles, hairs, down, cotton, or wool.

172. Hairs are often branched. They are said to be attached by the centre, if parted from the base, and the forks spread along the surface in opposite directions; plumose, if the branches are arranged along a common axis, as in a feather; stellate, if several branches radiate horizontally. These stellate hairs have sometimes their rays connected together at the base, forming little flat circular disks attached by the centre, and are then called scales, and the surface is said to be scaly or lepidote.

173. The Epidermis, or outer skin, of an organ, as to its surface and indumentum, is smooth, when without any protuberance whatever.

glabrous, when without hairs of any kind.

striate, when marked with parallel longitudinal lines, either slightly raised or merely discoloured.

furrowed (sulcate) or ribbed (costate) when the parallel lines are more distinctly raised.

rugose, when wrinkled or marked with irregular raised or depressed lines.

umbilicate, when marked with a small round depression.

umbonate, when bearing a small boss like that of a shield. 
viscous, viscid, or glutinous, when covered with a sticky or clammy exudation. scabrous, when rough to the touch.

tuberculate or warted, when covered with small, obtuse, wart-like protuberances. hard. muricate, when the protuberances are more raised and pointed but yet short and

echinate, when the protuberances are longer and sharper, almost prickly.

setose or bristly, when bearing very stiff erect straight hairs.

glandular-setose, when the setre or bristles terminate in a minute resinous head or drop. In some works, especially in the case of Roses and Rubus, the meaning of seto has been restricted to such as are glandular.

glochidiate, when the setæ are hooked at the top.

pilose, when the surface is thinly sprinkled with rather long simple hairs.

hispid, when more thickly covered with rather stiff hairs.

hirsute, when the hairs are dense and not so stiff.

downy or pubescent, when the hairs are short and soft; puberulent, when slightly pubescent.

strigose, when the hairs are rather short and stiff, and lie close along the surface all in the same direction; strigillose, when slightly strigose.

tomentose or cuttony, when the hairs are very short and soft, rather dense and more or less intricate, and usually white or whitish.

woolly (lanate), when the hairs are long and loosely intricate, like wool. The wool or tomentum is said to be floccose when closely intricate and readily detached, like fleece.

mealy (farinose), when the hairs are excessively short, intricate and white, and come off readily, having the appearance of meal or dust.

canescent or hoary, when the hairs are so short as not readily to be distinguished by the naked eye, and yet give a general whitish hue to the epidermis.

glaucous, when of a pale bluish-green, often covered with a fine bloom.

174. The meanings here attached to the above terms are such as appear to have been most generally adopted, but there is much vagueness in the use practically made of many of them by different botanists. This is especially the case with the terms pilose, hispid, hirsute, pubescent, and tomentose.

175. The name of Glands is given to several different productions, and principally to the four following :-

1. Small wart-like or shield-like bodies, either sessile or sometimes stalked, of a fungous or somewhat fleshy consistence, occasionally secreting a small quantity of oily or resinous matter, but more frequently dry. They are generally few in number, often definite in their position and form, and occur chiefly on the petiole or principal veins of leaves, on the branches of inflorescences, or on the stalks or principal veins of bracts, sepals, or petals.

2. Minute raised dots, usually black, red, or dark-coloured, of a resinous or oily nature, always superficial, and apparently exudations from the epidermis. They are often numerous on leaves, bracts, sepals, and green branches, and occur even on petals and stamens, more rarely on pistils. When raised upon slender stalks they are called pedicellate (or stipitate) glands, or glandular hairs, according to the thickness of the stalk.

3. Small, globular, oblong or even linear vesicles, filled with oil, imbedded in the substance itself of leaves, bracts, floral organs, or fruits. They are often very numerous, like transparent dots, sometimes few and determinate in form and position. In the pericarp of Umbelliferce they are remarkably regular and conspicuous, and take the name of vitto.

4. Lobes of the disk (137), or other small fleshy excrescences within the flower, whether from the receptacle, calyx, corolla, stamens, or pistil. 


\section{Chap. II. Classmimoation, or Systematio Botany.}

176. It has already been observed (3) that descriptions of plants should, as nearly as possible, be arranged under natural divisions, so as to facilitate the comparison of each plant with those most nearly allied to it. The descriptions of plants here alluded to are descriptions of species; the natural divisions of the Flora refer to natural groups of species.

177. A Species comprises all the individual plants which resemble each other suffciently to make us conclude that they are all, or may have been all, descended from a common parent. These individuals may often differ from each other in many striking particulars, such as the colour of the flower, size of the leaf, etc., but these particulars are such as experience teaches us are liable to vary in the seedlings raised from one individual.

178. When a large number of the individuals of a species differ from the others in any striking particular they constitute a Variety. If the variety generally comes true from seed, it is often called a Race,

179. A Variety can only be propagated with certainty by grafts, cuttings, bulbs, tubers, or any other method which produces a nẹw plant by the development of one or more buds taken from the old one. A Race may with care be propagated by seed, although seedlings will always be liable, under certain circumstances, to lose those particulars which distinguish it from the rest of the species. A real Species will always come true from seed.

180. The known species of plants (now near 100,000) are far too numerous for the human mind to study without classification, or even to give distinct single names to. To facilitate these objects, an admirable system, invented by Linnæus, has been universally adopted, viz. one common substantive name is given to a number of species which resemble each other more than they do any other species; the species so collected under one name are collectively called a Genus, the common name being the generic name. Each species is then distinguished from the others of the same genus by the addition of an adjective epithet or specific name. Every species has thus a botanical name of two words. In Latin, the language usually used for the purpose, the first word is a substantive and designates the genus; the second, an adjective, indicates the species.

181. The genera thus formed being still too numerous (above 6,000 ) for study without further arrangement, they have been classed upon the same principles; viz. genera which resemble each other more than they do any other genera, have been collected together into groups of a higher degree called Families or Natural Orders, to each of which a common name has been given. This name is in Latin an adjective plural, usually taken from the name of some one typical genus, generally the best known, the first discovered, or the most marked (e.g. Ranunculacea from Ranunculus). This is however for the purpose of study and comparison. To speak of a species, to refer to it and identify it, all that is necessary is to give the generic and specific names.

182. Natural Orders themselves (of which we reckon near 200) are often in the same manner collected into Classes; and where Orders contain a large number of genera, or genera a large number of species, they require further classification. The genera of an Order are then collected into minor groups called Tribes, the species of a genus into Sections, and in a few cases this intermediate classification is carried still further. The names of these several groups the most generally adopted are as follows, beginning with the most comprehensive or highest:-

Classes.

Subclasses or Alliances.

Natural Orders or Families.

Suborders.

Tribes.

Subtribes.

Divisions.

Subdivisions.
Genera.

Subgenera.

Sections.

Subsections.

Species.

Varieties. 
183. The characters (3) by which a speeies is distinguished from all other species of the same genus are collectively called the specific character of the plant; those by which its genus is distinguished from other genera of the Order, or its Order from other Orders, are respectively called the generic or ordinal character, as the case may be. The habit of a plant, of a species, a genus, etc., consists of such general characters as strike the eye at first sight, such as size, colour, ramification, arrangement of the leaves, inflorescence, etc., and are chiefly derived from the organs of vegetation.

184. Classes, Orders, Genera, and their several subdivisions, are called natural when, in forming them, all resemblances and differences are taken into account, valuing them according to their evident or presumed importance; artificial, when resemblances and differences in some one or very few particulars only are taken into account independently of all others.

185. The number of species included in a genus, or the number of genera in an Order, is very variable. Sometimes two or three or even a single species may be so different from all others as to constitute the entire genus; in others, several hundred species may resemble each other so much as to be all included in one genus; and there is the same discrepancy in the number of genera to a Family. There is moreover, unfortunately, in a number of instances, great difference of opinion as to whether certain plants differing from each other in certain particulars are varieties of one species or belong to distinct species ; and again, whether two or more groups of species should constitute as many sections of one genus, or distinct genera, or tribes of one Order, or even distinct Natural Orders. In the former case, as a species is supposed to have a real existence in nature, the question is susceptible of argument, and sometimes of absolute proof. But the place a group should occupy in the scale of degree is very arbitrary, being often a mere question of convenience. The more subdivisions upon correct principles are multiplied, the more they facilitate the study of plants, provided always the main resting-points for constant use, the Order and the Genus, are comprehensive and distinct. But if every group into which a genus can be divided be erected into a distinct genus, with a substantive name to be remembered whenever a species is spoken of, all the advantages derived from the beautiful simplicity of the Linnæan nomenclature are gone.

\section{Chap. III. Vegetable anatomy and Phystology.}

\section{§ 1. Structure and Growth of the Elementary Tissues.}

186. If a very thin slice of any part of a plant be placed under a microscope of high magnifying power, it will be found to be made up of variously shaped and arranged ultimate parts, forming a sort of honeycombed structure. These ultimate parts are called cells, and form.by their combination the elementary tissues of which the entire plant is composed.

187. A cell in its simplest state is a closed membranous sac, formed of a substance permeable by fluids, though usually destitute of visible pores. Each cell is a distinct individual, separately formed and separately acting, though cohering with the cells with which it is in contact, and partaking of the common life and action of the tissue of which it forms a part. The membranes separating or enclosing the cells are also called their walls.

188. Botanists usually distinguish the following tissues :-

(1) Cellular tissue, or parenchyma, consists usually of thin-walled cells, more or less round in form, or with their length not much exceeding their breadth, and not tapering at the ends. All the soft parts of the leaves, the pith of stems, the pulp of fruits, and all young growing parts, are formed of it. It is the first tissue produced, and 
continues to be formed while growth continues, and when it ceases to be active the plant dies.

(2) Woody tissue, or prosenchyma, differs in having its cells considerably longer than broad, usually tapering at each end into points and overlapping each other. The cells are commonly thick-walled; the tissue is firm, tenacious, and elastic, and constitutes the principal part of wood, of the inner bark, and of the nerves and veins of leaves, forming, in short, the framework of the plant.

(3) Vascular tissue, or the vessels or ducts of plants, so called from the mistaken notion that their functions are analogous to those of the vessels (veins and arteries) of animals. A vessel in plants consists of a vertical row of cells, which have their transverse partition-walls obliterated, so as to form a continuous tube. All phrnogamous plants, as well as ferns and a few other cryptogamous plants, have vessels, and are therefore called vascular plants; so the majority of cryptogams having only cellular tissue are termed cellular plants. Vessels have their sides very variously marked; some, called spiral vessels, have a spiral fibre coiled up their inside, which unrolls when the ressel is broken; others are marked with longitudinal slits, cross bars, minute dots or pits, or with transverse rings. The size of vessels is also very variable in different plants; in some they are of considerable size and visible to the naked eye in cross sections of the stem, in others they are almost absent or can only be traced under a strong magnifier.

189. Various modifications of the above tissues are distinguished by vegetable anatomists under names which need not be enumerated here as not being in general practical use. Air-vessels, cysts, turpentine-vessels, oil-reservoirs, etc., are either cavities left between the cells, or large cells filled with peculiar secretions.

190. When tissues are once formed, they increase, not by the general enlargement of the whole of the cells already formed, but by cell-division, that is, by the division of young and vitally active cells, and the enlargement of their portions. In the formation of the embryo, the first cell of the new plant is formed, not by division, but around a segregate portion of the contents of a previously existing cell, the embryo-sac. This is termed free cell-formation, in contradistinction to cell-division.

191. A young and vitally active cell consists of the outer wall, formed of a more or less transparent substance called cellulose, permeable by fluids, and of ternary chemical composition (carbon, hydrogen, and oxygen); and of the cell-contents, usually viscid or mucilaginous, consisting of protoplasm, a substance of quaternary chemical composition (carbon, hydrogen, oxygen, and nitrogen), which fills an important part in celldivision and growth. Within the cell (either in the centre or excentrical) is usually a minute, soft, subgelatinous body called the nucleus, whose functions appear to be intimately connected with the first formation of the new cell. As this cell increases in size, and its walls in thickness, the protoplasm and watery cell-sap become absorbed or dried up, the firm cellulose wall alone remaining as a permanent fabric, either empty or filled with various organized substances produced or secreted within it.

192. The principal organized contents of cells are

sap, the first product of the digestion of the food of plants; it contains the elements of vegetable growth in a dissolved condition.

sugar, of which there are two kinds, called cane-sugar and grape-sugar. It usually exists dissolved in the sap. It is found abundantly in growing parts, in fruits, and in germinating seeds.

dextrine, or vegetable mucilage, a gummy substance, between mucilage and starch. starch or fecula, one of the most universal and conspicuous of cell-contents, and often so abundant in farinaceous roots and seeds as to fill the cell-cavity. It consists of minute grains called starch-granules, which vary in size and are marked with more or less conspicuous concentric lines of growth. The chemical constitution of starch is the same as that of cellulose; it is unaffected by cold water, but forms a jelly with boiling water, and turns blue when tested by iodine. When fully dissolred it is no longer starch, but dextrine.

chlorophyll, very minute granules, containing nitrogen, and coloured green under the action of sunlight. These granules are most abundant in the layers of cells immediately below the surface or epidermis of leaves and young bark. The green colouring matter is soluble in alcohol, and may thus be removed from the granules. 
chromule, a name given to a similar colouring matter when not green.

wax, oils, camphor, and resinous matter, are common in cells or in cavities in the tissues between the cells, also various mineral substances, either in an amorphous state or as microscopic crystals, when they are called Raphides.

\section{§ 2. Arrangement of the Elementary Tissues, or Structure of the Organs of Plants.}

193. Leaves, young stems, and branches, and most parts of phænogamous plants, during the first year of their existence consist anatomically of

1 , a cellular system, or continuous mass of cellular tissue, which is developed both vertically as the stem or other parts increase in length, and horizontally or laterally as they increase in thickness or breadth. It surrounds or is intermixed with the fibrovascular system, or it may exist alone in some parts of phænogamous plants, as well as in cryptogamous ones.

2, a fibro-vascular system, or continuous mass of woody and vascular tissue, which is gradually introduced vertically into, and serves to bind together, the cellular system. It is continued from the stem into the petioles and veins of the leaves, and into the pedicels and parts of the flowers, and is never wholly wanting in any phænogamous plant.

3, an epidermis, or outer skin, formed of one or more layers of flattened (horizontal), firmly coherent, and usually emptiy cells, with either thin and transparent or thick and opaque walls. It covers almost all parts of plants exposed to the outward air, protecting their tissues from its immediate action, but is wanting in those parts of aquatic plants which are constantly submerged.

194. The epidermis is frequently pierced by minute spaces between the cells, called Stomates. They are oval or mouth-shaped, bordered by lips, formed of two or more elastic cells so disposed as to cause the stomate to open in a moist, and to close up in a dry state of the atmosphere. They communicate with intercellular cavities, and are obviously designed to regulate evaporation and respiration. They are chiefly found upon leaves, especially on the under surface.

195. When a phænogamous plant has outlived the first season of its growth, the anatomical structure of its stem or other perennial parts becomes more complicated and very different in the two great classes of phænogamous plants called Exogens and Endogens, which correspond with very few exceptions to the two classes Dicotyledons and Monocotyledons (167), founded on the structure of the embryo. In Exogens (Dicotyledons) the woody system is placed in concentric layers between a central pith $(198,1)$, and an external separable bark $(198,5)$. In Endogens (Monocotyledons) the woody system is in separate small bundles or fibres running through the cellular system without apparent order, and there is usually no distinct central pith, nor outer separable bark.

196. The anatomical structure is also somewhat different in the different organs of plants. In the Root, although it is constructed generally on the same plan as the stem, yet the regular organization, and the difference between Exogens and Endogens, is often disguised or obliterated by irregularities of growth, or by the production of large quantities of cellular tissue filled with starch or other substances (192). There is seldom, if ever, any distinet pith, the concentric circles of fibro-vascular tissue in Exogens are often very indistinct or have no relation to seasons of growth, and the epidermis has no stomates.

197. In the Stem or branches, during the first year or season of their growth, the difference between Exogens and Endogens is not always very conspicuous. In both there is a tendency to a circular arrangement of the fibro-vascular system, leaving the centre either vacant or filled with cellular tissue (pith) only, and a more or less distinct outer rind is observable even in several Endogens. More frequently, however, the distinction is already very apparent the first season, especially towards its close. The fibro-vascular bundles in Endogens usually anastomose but little, passing continuously into the branches and leaves. In Exogens the circle of fibro-vascular bundles forms a more continuous cylinder of network emitting lateral offsets into the branches and leaves. 
198. The Exogenous stem, after the first year of its growth, consists of

1 , the pith, a cylinder of cellular tissue, oceupying the centre or longitudinal axis of the stem. It is active only in young stems or brunches, becomes dried up and compressed as the wood hardens, and often finally disappears, or is scarcely distinguishable in old trees.

2 , the medullary sheath, which surrounds and encases the pith. It abounds in spiral vessels $(188,3)$, and is in direct connection, when young, with the leaf-buds and branches, with the petioles and veins of leaves, and other ramifications of the system. Like the pith, it gradually disappears in old wood.

3 , the wood, which lies immediately outside the medullary sheath. It is formed of woody tissue $(188,2)$, through which, in most cases, vessels $(188,3)$ variously disposed are interspersed. It is arranged in annual concentric circles (211), which usually remain active during several years, but in older stems the central and older layers become hard, dense, comparatively inactive, and usually deeper coloured, forming what is called heart-wood or duramen, the outer,younger, and usually paler-coloured living layers constituting the sapwood or alburnum.

4, the medullary rays, which form vertical plates, originating in the pith, and, radiating from thence, traverse the wood and terminate in the bark. They are formed of cellular tissue, keeping up a communication between the living portion of the centre of the stem and its outer surface. As the heart-wood is formed, the inner portion of the medullary rays ceases to be active, but they usually may still be seen in old wood, forming what carpenters call the silver grain.

5, the bark, which lies outside the wood, within the epidermis. It is, like the wood, arranged in annual concentric circles (211), of which the outer older ones become dry and hard, forming the corky layer or outer bark, which, as it is distended by the thickening of the stem, either cracks or is cast off with the epidermis, which is no longer distinguishable. Within the corky layer is the cellular, or green, or middle bark, formed of loose thin-walled pulpy cells containing chlorophyll (192); and which is usually the layer of the preceding season. The innermost and youngest circle, next the young wood, is the liber or inner bark, formed of long tough woody tissue called bast-cells.

199. The Endogenous stem, as it grows old, is not marked by the concentric cireles of Exogens. The wood consists of a matrix of cellular tissue irregularly traversed by vertical cords or bundles of woody and vascular tissue, which are in connection with the leaves. These vascular bundles change in structure and direction as they pass down the stem, losing their vessels, they retain only their bast- or long wood-cells, usually curving outwards towards the rind. The old wood becomes more compact and harder towards the circumference than in the centre. The epidermis or rind either hardens so as to prevent any increase of diameter in the stem, or it distends, without increasing in thickness or splitting or casting off any outer layers.

200. In the Leaf, the structure of the petioles and principal ribs or veins is the same as that of the young branches of which they are ramifications. In the expanded portion of the leaf the fibro-vascular system becomes usually very much ramified, forming the smaller veins. These are surrounded and the interstices filled up by a copious and very active cellular tissue. The majority of leaves are horizontal, having a differently constructed upper and under surface. The cellular stratum forming the upper surface consists of closely set cells, placed vertically, with their smallest ends next the surface, and with few or no stomates in the epidermis. In the stratum forming the under surface, the cells are more or less horizontal, more loosely placed, and have generally empty spaces between them, with stomates in the epidermis communicating with these intercellular spaces. In vertical leaves (as in a large number of Australian plants) the two surfaces are nearly similar in structure.

201. When leaves are reduced to scales, acting only as protectors of young buds, or without taking any apparent part in the economy of vegetable life, their structure, though still on the same plan, is more simple; their fibro-vascular system is less ramified, their cellular system more uniform, and there are few or no stomates.

202. Bracts and floral envelopes, when green and much developed, resemble leaves in their anatomical structure, but in proportion as they are reduced to scales or trans- 
formed into petals, they lose their stomates, and their systems, both fibro-vascular and cellular, become more simple and uniform, or more slender and delicate.

203. In the stamens and pistils the structure is still nearly the same. The fibrovascular system, surrounded by and intermixed with the cellular tissue, is usually simple in the filaments and style, more or less ramified in the flattened or expanded parts, such as the anther-cases, the walls of the ovary, or carpellary leaves, etc. The pollen consists of granular cells variously shaped, marked, or combined, peculiar forms being constant in the same species, or often in large genera, or even Orders. The stigmatic portion of the pistil is a mass of loosely cellular substance, destitute of epidermis, and usually is in communication with the ovary by a channel running down the centre of the style.

204. Tubers, fleshy thickenings of the stem or other parts of the plant, suceulent leaves or branches, the fleshy, woody, or bony parts of fruits, the albumen, and the thick fleshy parts of embryos, consist chiefly of largely developed cellular tissue, replete with starch or other substances (192), deposited apparently in most cases for the eventual future use of the plant or its parts when recalled into activity at the approach of a new season.

205. Hairs (171) are usually expansions or processes of the epidermis, and consist of one or more cells placed end to end. When thick or hardened into prickles, they still consist usually of cellular tissue only. Thorns (170) contain more or less of a fibrovascular system, according to their degree of development.

206. Glands, in the primary sense of the word $(175,1)$, consist usually of a rather loose cellular tissue without epidermis, and often replete with resinous or other sub. stances.

\section{§ 3. Growth of the Organs.}

207. Roots grow in length constantly and regularly at the extremities only of their fibres, in proportion as they find the requisite nutriment. They form no buds containing the germ of future branches, but their fibres proceed irregularly from any part of their surface without previous indication, and when their growth has been stopped for a time, either wholly by the close of the season, or partially by a deficiency of nutriment at any particular spot, it will, on the return of favourable circumstances, be resumed at the same point, if the growing extremities be uninjured. If during the dead season, or at any other time, the growing extremity is cut off, dried up, or otherwise injured, or stopped by a rock or other obstacle opposing its progress, lateral fibres will be formed on the still living portion; thus enabling the root as a whole to diverge in any direction, and travel far and wide when lured on by appropriate nutriment.

208. This growth is not however by the successive formation of terminal cells attaining at once their full size. The cells first formed on a fibre commencing or renewing its growth, will often dry up and form a kind of terminal cap, which is pushed on as cells are formed immediately under it; and the new cells, constituting a greater or lesser portion of the ends of the fibres, remain some time in a growing state before they have attained their full size.

209. The roots of Exogens, when perennial, increase in thickness like stems by the addition of concentric layers, but these are usually much less distinctly marked; and in a large number of perennial Exogens and most Endogens the roots are annual, perish. ing at the close of the season, fresh adventitious roots springing from the stock when vegetation commences the following season.

210. The Stem, including its branches and appendages (leaves, floral organs, etc.), grows in length by additions to its extremity, but a much greater proportion of the extremity and branches remains in a growing and expanding state for a much longer time than in the case of the root. At the close of one season, leaf-buds or seeds are formed, each containing the germ of a branch or young plant to be produced the following season. At a very early stage of the development of these buds or seeds, a commencement may be found of many of the leaves it is to bear; and before a leaf unfolds, every leaflet of which it is to consist, every lobe or tooth which is to mark its margin, may often be traced in miniature, and thenceforth till it attains its full size, the branch grows and expands in every part. In some cases however the lower part of a branch 
and more rarely (e.g. in some Meliacea) the lower part of a compound leaf attains its full size before the young leaves or leaflets of the extremity are yet formed.

211. The perennial stem, if exogenous (198), grows in thickness by the addition every season of a new layer or ring of wood between the outermost preceding layer and the inner surface of the bark, and by the formation of a new layer or ring of bark within the innermost preceding layer and outside the new ring of wood, thus forming a succession of concentric circles. The sap elaborated by the leaves finds its way, in a manner not as yet absolutely ascertained, into the cambium-region, a zone of tender thin-walled cells connecting the wood with the bark, by the division and enlargement of which new cells $(190)$ are formed. These cells separate in layers, the inner ones constituting the new ring of wood, and the outer ones the new bark or liber. In most exogenous trees, in temperate climates, the seasons of growth correspond with the years, and the rings of wood remain sufficiently distinct to indicate the age of the tree; but in many tropical and some evergreen trees, two or more rings of wood are formed in one year.

212. In endogenous perennial stems (199), the new wood or woody fibre is formed towards the centre of the stem, or irregularly mingled with the old. The stem consequently either only becomes more dense without increasing in thickness, or only in. creases by gradual distention, which is never very considerable. It affords therefore no certain criterion for judging of the age of the tree.

213. Flowers have generally all their parts formed, or indicated by protuberances or growing cells at a very early stage of the bud. These parts are then usually more regularly placed than in the fully developed flower. Parts which afterwards unite are then distinct, many are present in this rudimentary state which are never further developed, and parts which are afterwards very unequal or dissimilar are perfectly alike at this early period. On this account flowers in this very early stage are supposed by some modern botanists to be more normal, that is, more in conformity to a supposed type; and the study of the early formation and growth of the floral organs, called Organogenesis, has been considered essential for the correct appreciation of the affinities of plants. In some cases, however, it would appear that modifications of development, not to be detected in the very young bud, are yet of great importance in the distinction of large groups of plants, and that Organogenesis, although it may often assist in clearing up a doubtful point of affinity, cannot nevertheless be exclusively relied on in estimating the real value of peculiarities of structure.

214. The flower is considered as a bud (flower-bud, alabastrum) until the perianth expands, the period of flowering (anthesis) is that which elapses from the first expanding of the perianth, till the pistil is set or begins to enlarge, or, when it does not set, until the stamens and pistil wither or fall. After that, the enlarged ovary takes the name of young fruit.

215. At the close of the season of growth, at the same time as the leaf-buds or seeds are formed containing the germ of future branches or plants, many plants form also, at or near the bud or seed, large deposits, chiefly of starch. In many cases,-such as the tubers of a potato or other root-stock, the scales or thickened base of a bulb, the albumen or the thick cotyledons of a seed,-this deposit appears to be a store of nutriment, which is partially absorbed by the young branch or plant during its first stage of growth, before the roots are sufficiently developed to supply it from without. In some cases, however, such as the fleshy thickening of some stems or peduncles, the periearps of fruits which perish long before germination (the first growth of the seed), neither the use nor the cause of these deposits has as yet been clearly explained.

\section{§ 4. Functions of the Organs.}

216. The functions of the Root are,-1. To fix the plant in or to the soil or other substance on which it grows. 2. To absorb nourishment from the soil, water, or air, into which the fibres have penetrated (or from other plants in the case of parasites), and to transmit it rapidly to the stem. The absorption takes places through the young growing extremities of the fibres, and through a peculiar kind of hairs or absorbing organs which are formed at or near those growing extremities. The transmission to the stem is through the tissues of the root itself. The nutriment absorbed consists 
chiefly of carbonic acid and nitrogen or nitrogenous compounds dissolved in water. 3. In some cases roots secrete or exude small quantities of matter in a manner and with a purpose not satisfactorily ascertained.

217. The Stem and its branches support the leaves, flowers, and fruit, transmit the crude sap, or nutriment absorbed by the roots and mixed with previously organized matter, to the leaves, and re-transmit the assimilated or elaborated sap from the leaves to the growing parts of the plant, to be there used up, or to form deposits for future use (204). The transmission of the ascending crude sap appears to take place chiefly through the elongated cells associated with the vascular tissues, passing from one cell to another by a process but little understood, but known by the name of endosmose.

218. Leaves are functionally the most active of the organs of vegetation. In them is chiefly conducted digestion or Assimilation, a name given to the process which accomplishes the following results:-1. The chemical decomposition of the oxygenated matter of the sap, the absorption of carbonic acid, and the liberation of pure oxygen at the ordinary temperature of the air. 2. A counter-operation by which oxygen is absorbed from the atmosphere and carbonic acid is exhaled. 3. The transformation of the residue of the crude sap into the organized substances which enter into the composition of the plant. The exhalation of oxygen appears to take place under the influence of solar heat and light, chiefly from the under surface of the leaf, and to be in some measure regulated by the stomates; the absorption of oxygen goes on always in the dark, and in the daytime also in certain cases. The transformation of the sap is effected within the tissues of the leaf, and continues probably more or less throughout the active parts of the whole plant.

219. The Floral Organs seldom contribute to the growth of the plant on which they are produced; their functions are wholly concentrated on the formation of the seed with the germ of a future plant.

220. The Perianth (calyx and corolla) acts in the first instance in protecting the stamens and pistils during the early stages of their development. When expanded, the use of the brilliant colours which they often display, of the sweet or strong odours they emit, has not been adequately explained. Perhaps they may have great influence in attracting those insects whose concurrence has been shown in many cases to be necessary for the due transmission of the pollen from the anther to the stigma.

221. The pistil, when stimulated by the action of the pollen, forms and nourishes the young seed. The varied and complicated contrivances by which the pollen is conveyed to the stigma, whether by elastic action of the organs themselves, or with the assistance of wind, of insects, or other extraneous agents, have been the subject of numerous observations and experiments of the most distinguished naturalists, and are yet far from being fully investigated. Their details, however, as far as known, would be far too long for the present outline.

222. The fruit nourishes and protects the seed until its maturity, and then often promotes its dispersion by a great variety of contrivances or apparently collateral circumstances, e.g. by an elastic dehiscence which casts the seed off to a distance; by the development of a pappus, wings, hooked or other appendages, which allows them to be carried off by winds, or by animals, etc., to which they may adhere; by their small specific gravity, which enables them to float down streams; by their attractions to birds, etc., who taking them for food drop them often at great distances, etc. Appendages to the seeds themselves also often promote dispersion.

223. Hairs have various functions. The ordinary indumentum (171) of stems and leaves indeed seems to take little part in the economy of the plant besides perhaps some occasional protection against injurious atmospheric influences, but the root-hairs (216) are active absorbents, the hairs on styles and other parts of flowers appear often materially to assist the transmission of pollen, and the exudations of glandular hairs $(175,2)$ are often too copious not to exercise some influence on the phenomena of vegetation. The whole question, however, of vegetable exudations and their influence on the economy of vegetable life, is as yet but imperfectly understood. 


\section{Chap. IV. Coluection, Pregervation, and Determination of Plants.}

224. Plants can undoubtedly be most easily and satisfactorily examined when freshly gathered. But time will rarely admit of this being done, and it is moreover desirable to compare them with other plants previously observed or collected. Specimens must, therefore, be selected for leisurely observation at home, and preserved for future reference. A collection of such specimens constitutes a Herbarium.

225. A botanical Specimen, to be perfect, should have root, stem, leaves, flowers (both open and in bud) and fruit (both young and mature). It is not, however, always possible to gather such complete specimens, but the collector should aim at completeness. Fragments, such as leaves without flowers, or flowers without leaves, are of little or no use.

226. If the plant is small (not exceeding $15 \mathrm{in}$.) or can be reduced to that length by folding, the specimen should consist of the whole plant, including the principal part of the root. If it be too large to preserve the whole, a good flowering branch should be selected, with the foliage as low down as can be gathered with it; and one or two of the lower stem-leaves or radical leaves, if any, should be added, so as to preserve as much as possible of the peculiar aspect of the plant.

227. The specimens should be taken from healthy uninjured plants of a medium size. Or if a specimen be gathered because it looks a little different from the majority of those around it, apparently belonging to the same species, a specimen of the more prevalent form should be taken from the same locality for comparison.

228. For bringing the specimens home, a light portfolio of pasteboard, covered with calico or leather, furnished with straps and buckles for closing, and another for slinging on the shoulder, and containing a few sheets of stout coarse paper, is better than the old-fashioned tin box (except, perhaps, for stiff prickly plants and a few others). The specimens as gathered are placed between the leaves of paper, and may be crowded together if not left long without sorting.

229. If the specimen brought home be not immediately determined when fresh, but dried for future examination, a note should be taken of the time, place, and situation in which it was gathered; of the stature, habit, and other particulars relating to any tree, shrub, or herb of which the specimen is only a portion; of the kind of root it has; of the colour of the flower; or of any other particulars which the specimen itself cannot supply, or which may be lost in the process of drying. These memoranda, whether taken down in the field, or from the living specimen when brought home, should be written on a label attached to the specimen or preserved with it.

230. To dry specimens, they are laid flat between several sheets of bibulous paper, and subjected to pressure. The paper is subsequently changed at intervals, until they are dry.

231. In laying out the specimen, care should be taken to preserve the natural position of the parts as far as consistent with the laying flat. In general, if the specimen is fresh and not very slender, it may be simply laid on the lower sheet, holding it by the stalk and drawing it slightly downwards ; then, as the upper sheet is laid over, if it be slightly drawn downwards as it is pressed down, it will be found, after a few trials, that the specimen will have retained a natural form with very little trouble. If the specimen has been gathered long enough to have become flaceid, it will require more care in laying the leaves flat and giving the parts their proper direction. Specimens kept in tin boxes, will also often have taken unnatural bends which will require to be corrected.

232. If the specimen is very bushy, some branches must be thinned out, but always so as to show where they have been. If any part, such as the head of a thistle, the stem of an Orobanche, or the bulb of a Lily, be very thick, a portion of what is to be the under side of the specimen may be sliced off. Some thick specimens may be split from top to bottom before drying.

233. If the specimen be succulent or tenacious of life, such as a Sedum or an 
Orchis, it may be dipped in boiling water all but the flowers. This will kill the plant at once, and enable it to be dried rapidly, losing less of its colour or foliage than would otherwise be the case. Dipping in boiling water is also useful in the case of Heaths and other plants which are apt to shed their leaves during the process of drying.

234. Plants with very delicate corollas may be placed between single leaves of very thin unglazed tissue-paper. In shifting these plants into dry paper the tissue-paper is not to be removed, but lifted with its contents on to the dry paper.

235. The number of sheets of paper to be placed between each specimen or sheet of specimens, will depend, on the one hand, on the thickness and humidity of the specimens ; on the other hand, on the quantity and quality of the paper one has at command. The more and the better the paper, the less frequently will it be necessary to change it, and the sooner the plants will dry. The paper ought to be coarse, stout, and unsized. Common blotting-paper is much too tender.

236. Care must be taken that the paper used is well dried. If it be likewise hot, all the better; but it must then be very dry; and wet plants put into hot paper will require changing very soon, to prevent their turning black, for hot damp without ventilation produces fermentation, and spoils the specimens.

237. For pressing plants, various more or less complicated and costly presses are made. None is better than a pair of boards the size of the paper, and a stone or other heavy weight upon them if at home, or a pair of strong leather straps round them if travelling. Each of these boards should be double, that is, made of two layers of thin boards, the opposite way of the grain, and joined together by a row of clenched brads round the edge, without glue. Such boards, in deal, rather less than half an inch thick (each layer about $2 \frac{1}{2}$ lines) will be found light and durable.

238. It is useful also to have extra boards or pasteboards the size of the paper, to separate thick plants from thin ones, wet ones from those nearly dry, etc. Open wooden frames with cross-bars, or frames of strong wire-work lattice, are still better than boards for this purpose, as accelerating the drying by promoting ventilation.

239. The more frequently the plants are shifted into dry paper the better. Excepting for very stiff or woody plants, the first pressure should be light, and the first shifting, if possible, after a few hours. Then, or at the second shifting, when the specimens will have lost their elasticity, will be the time for putting right any part of a specimen which may have taken a wrong fold or a bad direction. After this the pressure may be gradually increased, and the plants left from one to several days without shifting. The exact amount of pressure to be given will depend on the consistence of the specimens, and the amount of paper. It must only be borne in mind that too much pressure crushes the delicate parts, too little allows them to shrivel, in both cases interfering with their future examination.

240. The most convenient specimens will be made, if the drying-paper is the same size as that of the herbarium in which they are to be kept. That of writing demy, rather more than 16 inches by $10 \frac{1}{2}$ inches, is a common and very convenient size. A small size reduces the specimens too much, a large size is both costly and inconvenient for use.

241. When the specimens are quite dry and stiff, they may be packed up in bundles with a single sheet of paper between each layer, and this paper need not be bibulous. The specimens may be placed very closely on the sheets, but not in more than one layer on each sheet, and care must be taken to protect the bundles by sufficient covering from the effects of external moisture or the attacks of insects.

242. In laying the specimens into the herbarium, no more than one species should ever be fastened on one sheet of paper, although several specimens of the same species may be laid side by side. And throughout the process of drying, packing, and laying in, great care must be taken that the labels be not separated from the specimens they belong to.

243. To examine or dissect flowers or fruits in dried specimens it is necessary to soften them. If the parts are very delicate, this is best done by gradually moistening them in cold water; in most cases, steeping them in boiling water or in steam is much quicker. Very hard fruits and seeds will require boiling to be able to dissect them easily. 
244. For dissecting and examining flowers in the field, all that is necessary is a penknife and a pocket-lens of two or three glasses from 1 to 2 inches focus. At home it is more convenient to have a mounted lens or simple microscope, with a stage holding a glass plate, upon which the flowers may be laid; and a pair of dissectors, one of which should be narrow and pointed, or a mere point, like a thick needle, in a handle; the other should have a pointed blade, with a sharp edge, to make clean sections across the ovary. A compound microscope is rarely necessary, except in cryptogamic botany and vegetable anatomy. For the simple microscope, lenses of $\frac{1}{4}, \frac{1}{2}, 1$, and $1 \frac{1}{2}$ inches focus are sufficient.

245. To assist the student in determining or ascertaining the name of a plant belonging to a Flora, analytical tables should be prefixed to the Orders, Genera, and Species. These tables should be so constructed as to contain, under each bracket, or equally indented, two (rarely three or more) alternatives as nearly as possible contradictory or incompatible with each other, each alternative referring to another bracket, or having under it another pair of alternatives further indented. The student having a plant to determine, will first take the general table of Natural Orders, and examining his plant at each step to see which alternative agrees with it, will be led on to the Order to which it belongs, he will then compare it with the detailed character of the Order given in the text. If it agrees, he will follow the same course with the table of the genera of that Order, and again with the table of species of the genus. But in each case, if he finds that his plant does not agree with the detailed description of the genus or species to which he has thus been referred, he must revert to the beginning and carefully go through every step of the investigation before he can be satisfied. $\mathbf{A}$ fresh examination of his specimen, or of others of the same plant, a critical consideration of the meaning of every expression in the characters given, may lead him to detect some minute point overlooked or mistaken, and put him into the right way. Species vary within limits which it is often very difficult to express in words, and it proves often impossible, in framing these analytical tables, so to divide the genera and species, that those which come under one alternative should absolutely exclude the others. In such doubtful cases both alternatives must be tried before the student can come to the conclusion that his plant is not contained in the Flora, or that it is erroneously described.

246. In those Floras where analytical tables are not given, the student is usually guided to the most important or prominent characters of each genus or species, either by a general summary prefixed to the genera of an Order or to the species of the genus, for all such genera or species; or by a special summary immediately preceding the detailed description of each genus or species. In the latter case this summary is called a diagnosis. Or sometimes the important characters are only indicated by italicizing them in the detailed description.

247. It may also happen that the specimen gathered may present some occasional or accidental anomalies peculiar to that single one, or to a very few individuals, which may prevent the species from being at once recognized by its technical characters. It may be useful here to point out a few of these anomalies which the botanist may be most likely to meet with. For this purpose we may divide them into two classes, viz. :

1. Aberrations from the ordinary type or appearance of a species for which some. general cause may be assigned.

A bright, light, and open situation, particularly at considerable elevations above the sea, or at high latitudes, without too much wet or drought, tends to increase the size and heighten the colour of flowers, in proportion to the stature and foliage of the plant.

Shade, on the contrary, especially if accompanied by richness of soil and sufficient moisture, tends to increase the foliage and draw up the stem, but to diminish the number, size, and colour of the flowers.

A hot climate and dry situation tend to increase the hairs, prickles, and other productions of the epidermis, to shorten and stiffen the branches, rendering thorny plants yet more spinous. Moisture in a rich soil has a contrary effect.

The neighbourhood of the sea, or a saline soil or atmosphere, imparts a thicker and more succulent consistence to the foliage and almost every part of the plant, and ap- 
pears not unfrequently to enable plants usually annual to live through the winter. Flowers in a maritime variety are often much fewer, but not smaller.

The luxuriance of plants growing in a rich soil, and the dwarf stunted character of those crowded in poor soils, are too well known to need particularizing. It is also an everyday observation how gradually the specimens of a species become dwarf and stunted as we advance into the cold damp regions of the summits of high mountain ranges, or into high northern latitudes; and yet it is frequently from the want of attention to these circumstances that numbers of false species have been added to our Enumerations and Floras. Luxuriance entails not only increase of size to the whole plant, or of particular parts, but increase of number in branches, in leaves, or leaflets of a compound leaf; or it may diminish the hairiness of the plant, induce thorns to grow out into branches, etc.

Capsules which, while growing, lie close upon the ground, will often become larger, more succulent, and less readily dehiscent, than those which are not so exposed to the moisture of the soil.

Herbs eaten down by sheep or cattle, or crushed underfoot, or otherwise checked in their growth, or trees or shrubs cut down to the ground, if then exposed to favourable circumstances of soil and climate, will send up luxuriant side-shoots, often so different in the form of their leaves, in their ramification and inflorescence, as to be scarcely recognizable for the same species.

Annuals which have germinated in spring, and flowered without check, will often be very different in aspect from individuals of the same species, which, having germinated later, are stopped by summer droughts or the approach of winter, and only flawer the following season upon a second growth. The latter have often been mistaken for perennials.

Hybrids, or crosses between two distinct species, come under the same category of anomalous specimens from a known cause. Frequent as they are in gardens, where they are artificially produced, they are probably rare in nature, although on this subject there is much diversity of opinion, some believing them to be very frequent, others almost denying their existence. Absolute proof of the origin of a plant found wild, is of course impossible; but it is pretty generally agreed that the following particulars must always co-exist in a wild hybrid. It partakes of the characters of its two parents; it is to be found isolated, or almost isolated, in places where the two parents are abundant; if there are two or three, they will generally be dissimilar from each other, one partaking more of one parent, another of the other; it seldom ripens good seed; it will never be found where one of the parents grows alone.

Where two supposed species grow together, intermixed with numerous intermediates bearing good seed, and passing more or less gradually from the one to the other, it may generally be concluded that the whole are mere varieties of one species. The beginner, however, must be very cautious not to set down a specimen as intermediate between two species, because it appears to be so in some, even the most striking characters, such as stature and foliage. Extreme varieties of one species are connected together by transitions in all their characters, but these transitions are not all observable in the same specimens. The observation of a single intermediate is therefore of little value, unless it be one link in a long series of intermediate forms, and, when met with, should lead to the search for the other connecting links.

2. Accidental aberrations from the ordinary type, that is, those of which the cause is unknown.

These require the more attention, as they may sometimes lead the beginner far astray in his search for the genus, whilst the aberrations above-mentioned as reducible more or less to general laws, affect chiefly the distinction of species.

Almost all species with coloured flowers are liable to occur occasionally with them all white.

Many may be found even in a wild state with double flowers, that is, with a multiplication of petals.

Plants which have usually conspicuous petals will oceasionally appear without any at all, either to the flowers produced at particular seasons, or to all the flowers of individual plants, or the petals may be reduced to narrow slips. 
Flowers usually very irregular, may, on certain individuals, lose more or less of their irregularity, or appear in some very different shape. Spurs, for instance, may disappear, or be produced on all instead of one only of the petals.

One part may be occasionally added to, or subtracted from, the usual number of parts in each floral whorl, more especially in regular polypetalous flowers.

Plants usually monœcious or diøecious may become occasionally hermaphrodite, or hermaphrodite plants may produce oceasionally unisexual flowers by the abortion of the stamens or of the pistils.

Leaves cut or divided where they are usually entire, variegated or spotted where they are usually of one colour, or the reverse, must also be classed amongst those accidental aberrations which the botanist must always be on his guard against mistaking for specific distinctions. 


\section{INDEX OF TERMS, OR GLOSSARY.}

\section{The figures refer to the Paragraphs of the Outlines.}

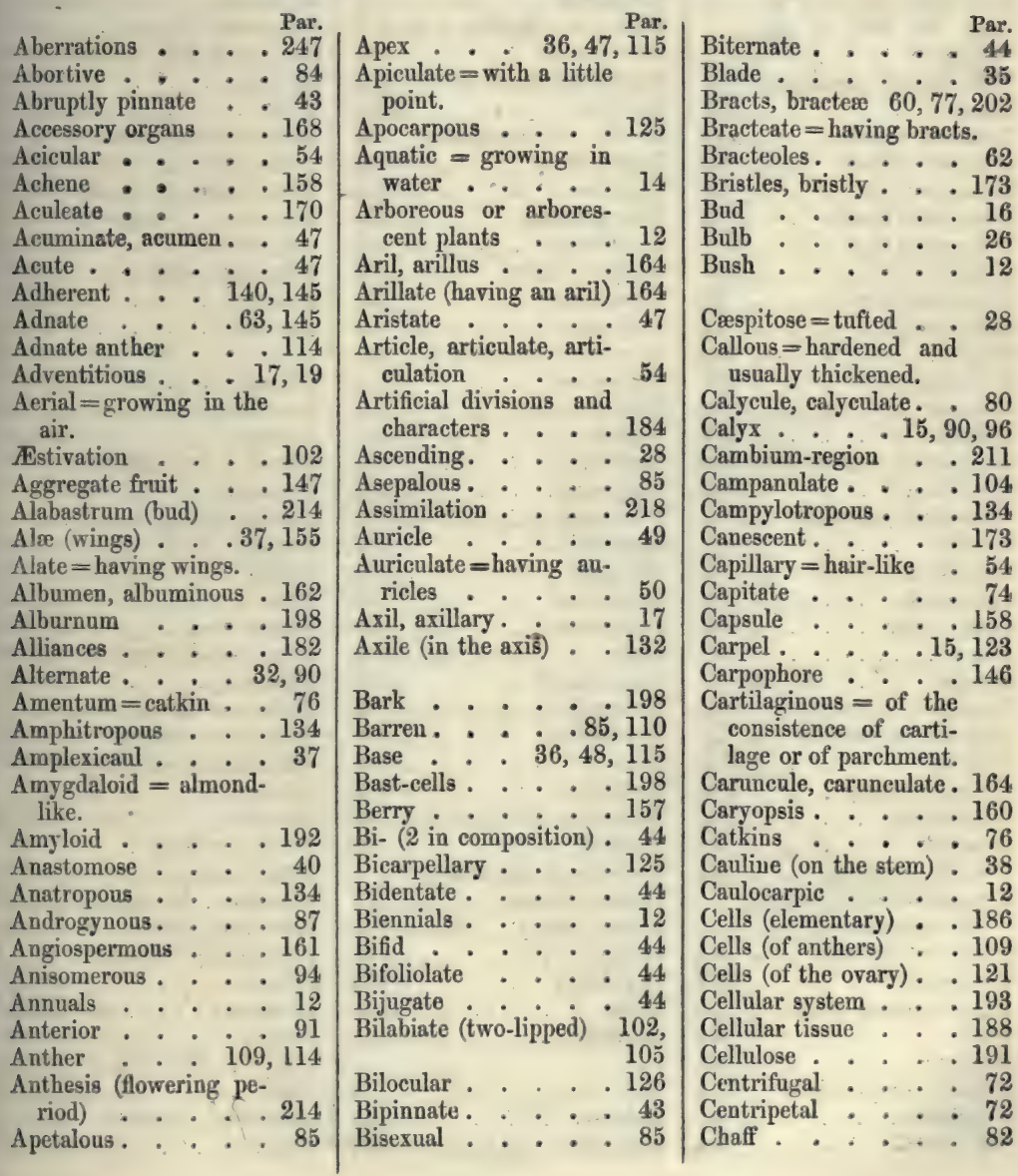




\begin{tabular}{|c|c|c|c|}
\hline & & & \\
\hline$\cdot \cdot \cdot$ & . 133 & Cyme, сутове & Glementary cells and tis. \\
\hline acter . . & & & sues . \\
\hline rophyll . & . 192 & $\mathrm{n}-(10 \mathrm{in}$ & Elliptical . \\
\hline mule. & & . 44,92 & Emarginate \\
\hline & & . 152 & Embryo . \\
\hline ircumsciss . . & 158 & Decompound . & Endocarp . . . . 157 \\
\hline irrhus = tendril & & Decumbent . & Endogens, endogenous \\
\hline & & Decurrent. & plants. . \\
\hline a petal) & & Décussate . & Endogenous stem \\
\hline stem. & - 29 & Definite . & Endosmose . . . 217 \\
\hline the ovule & .133 & .. (p. iii.) & Ennea- (9 iu composi- \\
\hline the seed & & dehiscent & tion) \\
\hline & & 118,156 & Ent \\
\hline t. . . & & . $\quad 39$ & Epi \\
\hline $1=$ inserted 0 & & & . 173,1 \\
\hline & & Botany . (p. iii.) & is . . . . \\
\hline & & $\therefore 67$ & as disk . . \\
\hline$n$ of specin & ns 224 & on of plants 245 & $\therefore 0$ \\
\hline & & . . . 192 & \\
\hline petiole. & & omposition) 92 & ninous (withont \\
\hline flower & - 89 & $\cdot . .113$ & \\
\hline f. & 39 & 246 & ants. \\
\hline wer & . 74 & us. . . 100 & exogenous \\
\hline nit . & .147 & $\therefore . . .93$ &.$\quad .18$ \\
\hline ry & & cous . & us stem. \\
\hline umbel & & . . & $d \cdot \cdots$ \\
\hline essed . . & &. .86 & rse . . \\
\hline . . . & .160 & ous plants 167 & \\
\hline ent . . & & 1 & a \\
\hline . . & & s... . 113 & s \\
\hline e... & & .. & e : : . \\
\hline ve, connectiv & & $\cdot 0.41$ & d, fasciculate \\
\hline$\cdots$ & & $.93,125$ & ate... . \\
\hline , convolute & & . . 93 & $\therefore \quad . \quad$ \\
\hline$\therefore$. & & . & $\therefore$ \\
\hline & & $\varepsilon$ & 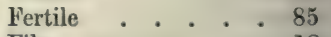 \\
\hline us. & & . & . . . \\
\hline yer. & 198 & is. ... & us root . . . \\
\hline & & 136 & ascular system \\
\hline & & 126 & $t \ldots$. \\
\hline te (crumpled) & & . . . . & $=$ thread-like. \\
\hline & & s. : . . & \\
\hline & & 145 & orm $=$ fan-shaped \\
\hline cottony . & & ate. . . & . . . . \\
\hline & & , divergent 1 & 173 \\
\hline & . 28 & & nvelope . \\
\hline crenulate & . & $=$ on the back. & leaves . \\
\hline$=$ having a cre & & wers . . & s. $15,84,213,219$ \\
\hline the root & 2 & owny & $\begin{array}{l}\text { ng plants } \\
\text { us = leaf-li }\end{array}$ \\
\hline & 10 & & . \\
\hline moue nlants & 10 & 1 & en \\
\hline & 34 & Duramen . & \\
\hline & & & $89,132,140,145$ \\
\hline (cup-shaped) & & $\therefore$ & . . $15,146,222$ \\
\hline$\cdots$ & & . & ent, fruticose \\
\hline & & rated sap & \\
\hline
\end{tabular}




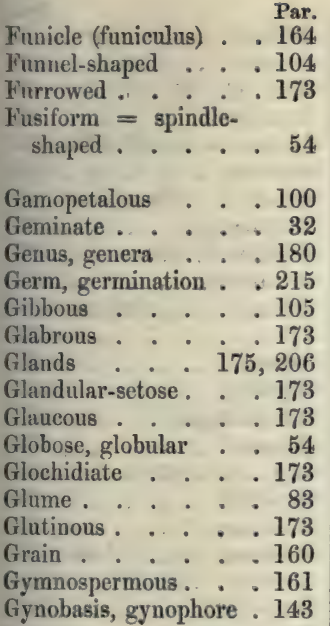

Habit . . . . . 183

Hairs . . 171, 205, 223

Hastate .. . . . 50

Head . .... . . 74

Heart-wood . . . 198

Hepta- ( 7 in composition) 92

Herbaceous perennials . 12

Herbarium ... . . 224

Hermaphrodite .. . . 85

Heterogamous ․ . 87

Hexa- (6 in composition) 92

Hilum . . . . . 165

Hirsute . . . . . 173

Hispid . . . . . 173

Hoary . . . . . 173

Homogamous . . . 87

Hooks . . . . . . 169

Hybernaculum ‘ . . 23

Hybrids . . . . 247

Hypocrateriform (salvershaped) . . 104

Hypogynous . . . . 140

Imbricate, imbricated 58, 102

Impari-pinnate . . : 43

Imperfect . . . . . 84

Incomplete . . . . 84

Indefinite . . . . . 92

Indehiscent . . . 156

Indeterminate . . . 67

Indumentum . . . . 171

Induplicate . . . . 102

Inferior . . . . 140

Inferior radicle . . 167

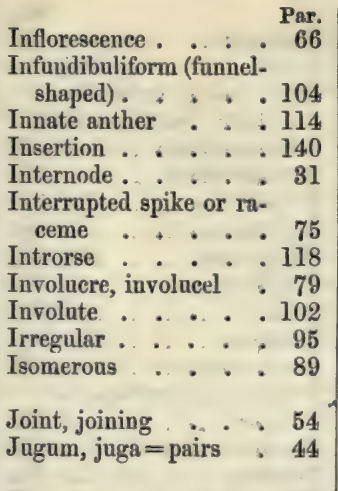

Kernel . . . . . 157

Knob . . . . . 25

Labellum . . . . . 105

Laciniate . . . . . 39

Lamina : . 85, 107

Lanate $=$ woolly $\quad .173$

Lanceolate . . . . 45

Lateral . . . . 91

Leaf, leaves 15, 35, 200, 218

Leaf-bud . . . . . 16

Leaflet . . . . . . 39

Leaf-opposed . . . . 67

Legume . . . . 160

Lepidote . . . . 172

Liber . . . . . 198, 211

Ligulate $=$ strap-shaped.

Limb . . . . . . 104

Linear . . . . . 45, 54

Lip, lipped . . . . 105

Lobe, lobed . . . . . 39

Loculicidal . . . 158

Lower . . . . . . . 91

Lunate $=$ crescent-shaped.

Lyrate . . . . . . 41

Male ... . . . . 85

Marcescent. . . . 151

Mealy ..... . . 173

Medullary rays and sheath . .. . . 198

Membranous . . . 55

Micropyle. . . . 165

Midrib. . . . . 40

Monadelphous . . . 113

Monandrous . . . . 112

Moniliform ... . . 54

Mono- (1 in composition) . . . . 92

Monocarpellary . . 125
Par.

Monocarpic : . . 12

Monochlamydeous . . 85

Monocotyledonous plants 167

Monœeious . . . . 86

Monogynous . . . 125

Monopetalous ... . 100

Morphology . . . 8,88

Mucronate . . . 47

Multi- (many, or an indefinite number, in composition) ․ . 44

Muricate . . . . 173

Naked . . . . . 85, 161

Natural divisions and characters . . . 184

Natural Order . . . 181

Navicular = boat-shaped

Nectary . . . . . 138

Nerve . . . . . . 40

Net-veined . . . . 40

Neuter. . . . . 85

Node . . . . . . 31

Novem- (9 in composi-

tion) ... 44

Nuclens of a cell. . 191

Nucleus of the ovule . 133

Nut. . . . . . 158

Obcompressed . . . 54

Obconical . . . . 54

Obcordate. . . . 47

Oblate. . . . . 45

Oblong . . .45, 54

Obovate. . . . . . 45

Obovoid .... 54

Obpyramidal . . . 54

Obtuse. . . . . 47

Oet- or octo- (8 in composition) . . 44, 92

Offset . . . . . 23

Opposite . . . . . 32

Orbicular . . . . . 45

Order ... . . . . 181

Organ . . . . . 7

Organogenesis . . . 213

Organs of vegetation and

reproduction ... 9

Orthotropous. . . 134

Oval . . . . . . 45

Ovary ..... . . 121

Ovate . . . . : 45

Ovoid ... . . . 54

Ovule . . 121, 133

Palate . . . . . 105

Palea, paler .... . 82 
Paleaceous $=$ of a chaffy Par. consistence.

Palmate . . . 41,42

Palmatifid, palmatisect. 42

Panicle, paniculate . . 74

Papillæ .. . . . 122

Pappus . . . . . . 155

Parallel veins.. . . . 40

Parasite . . . . 14

Parenchyma . . . 188

Parietal ... . . 132

Pectinate .. . . . . 41

Pedate. . . 41, 42

Pedatifid, pedatisect. : 42

Pedicel. . . . . 70

Pedicellate $=$ on a pedicel.

Peduncle

Pedunculate $=$ on a peduncle.

Peltate.

Penicillate .. . 130

Penta- (5 in composition) 92

Pepo . . . . 160

Perennial . . . . 12

Perfect flower . . . 84

Perfoliate . . . . 37

Perennials. . . 12

Perianth . 15, 98, 202, 220

Pericarp . . . 154

Perigynous . . . . 140

Perisperm.. . . . . 162

Persistent. . . . 146

Personate . . . . 105

Petal .. . . . . 90

Petiole. . . . . . 35

Petiolule . . . . . 39

Phænogamous, phanerogamous. .. .... 10

Phyllaries. . . . . 79

Phyllodium = a flat petiole with no blade.

Pilose .... . . . 173

Pinna . . ... . 43

Pinnate . . . 41, 42

Pinnatifid, pinnatisect . 42

Pistil . 15, 90, 120, 203, 221

Pistillate. . . . 85

Pith . . . . . . 198

Placenta, placentation . 131

Plant . . . . . . 6

Plicate. . . . . . 102

Plumose ....... 172

Plumule ....... 166

Pluri- = several, in composition.

Plurilocular ..... 126

Pod
Podocarp . . . . 120

Pollen. . . 109, 119

Poly- (many, or an indefinite number, in composition) ... . 92

Polyadelphous . . 113

Polyandrons $\quad .92,112$

Polygamous . . . . 86

Polygynous . . .92, 125

Polypetalous . . . . 100

Pome . . . . 160

Posterior . . . . . 91

Præfoliation . . . 57

Preservation of speci-

mens . . . . 224

Prickles . . . . . 170

Primine . . . . 133

Procumbent . . . . 28

Proliferous . . . . 17

Prosenchyma . . 188

Prostrate . . . . 28

Protoplasm . . . 191

Pubescent, puberulent . 173

Pulvinate (cushionshaped). . . . 136

Punctiform $=$ like a point or dot.

Putamen .... . . 157

Pyramidal. . . . 54

Quadri- (4 in composition) .... . 44

Quincuncial . . . 102

Quinque- (5 in composition) . . . . 44

Quintuplinerved ... 40

Race . . . . 178

Raceme, racemose . . 74

Rachis . . . . 39, 68

Radical . . . . 38

Radicle . . . 166

Raphe . . . . . 134

Raphides ... . . 192

Receptacle . . 74, 135

Reduplicate ..... 102

Regular . . . . . 95

Reniform . .... . 51

Resupinate . . . 105

Reticulate .... 40

Retuse ....... . 47

Revolute ..... . 102

Rhachis ... . 39,68

Rhaphe ..... . 134

Rhizome . . . 21, 24

Rhomboidal . . . 45

Ribs : : : 40
Ribbed . . ${ }_{173}^{\text {Par. }}$

Ringent . . . 105

Root 15, 18, 196, 207, 216

Root-stock . . . 24

Rostrate $=$ beaked.

Rosulate . . . . 38

Rotate . . . . . . 104

Rudimentary . . . . 84

Rugose ‘. . . 173

Runcinate . . . . 41

Runner . . . 30

Saccate .... 105

Sagittate . . . . 50

Salver-shaped . . 104

Samara . . . 158

Sap . . . . 192

Sapwood . . . . 198

Sarcocarp . . . . 157

Scabrous . . . 173

Scales . . 58, 59, 172, 201

Scaly bulb . . . 26

Scaly surface. . . . 172

Scape . . . . . . 69

Scariose, scarious . : 55

Scattered . . . . . 32

Scion . : 30

Scorpioid cyme . . . 74

Section . . . . 182

Secund . . . . 32

Secundine... : 133

Seed . . . . 161

Segment * . . . 39

Sepals . . . . . 90

Septem- (7 in composition) . . . . 44

Septicidal . . . 158

Septum = partition.$\quad .126$

Serrate, serrulate : . 39

Sessile . . . . . 37

Seta, setæ (bristles) . 173

Setaceous (bristle-like) . 54

Setose (bearing bristles) 173

Sex- (6 in composition) 44

Sheathing. . . . 37

Shrubs. : : 12

Silicule, siliqua . . 160

Silver grain . . . . 198

Simple. . . . . 39

Sinuate . . . . . 39

Sinus . . . 39

Smooth . . . . 173

Spadix . . . . . 76

Spatha. . . . 81

Spatulate . . . . 45

Species .. . . . 177

Specimen . . . 225 


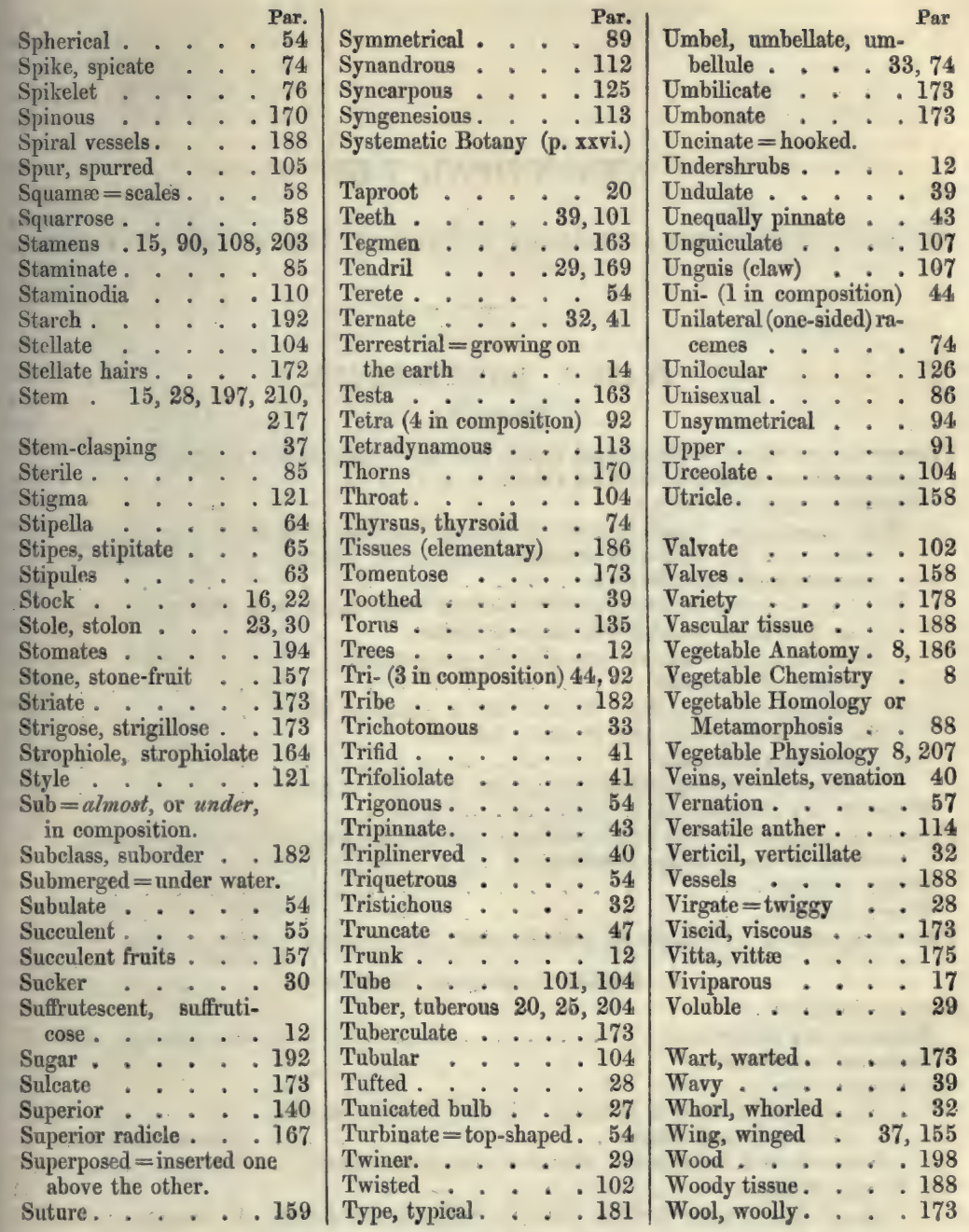




\section{ANALYTICAL KEY}

\section{TO THE ORDERS AND ANOMALOUS GENERA OF THE HONGKONG FLORA.}

\section{CLASS I. DICOTYLEDONS.}

\section{(See p. 1.)}

Flowers polypetalous (with several petals free from each other, although sometimes adherent to the staminal tube).

Flowers regular or nearly so.

Pistil apocarpous (consisting of several carpels, either quite distinct or slightly cohering at the base with distinct styles), or of 1 carpel with 1 unilateral

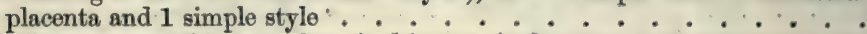
Pistil syncarpous (the carpels united into a single ovary, with 2 or more cells or 2 or more parietal placentas or styles).

Stamens hypogynous or very slightly perigynous.

Stamens indefinite . . . . . . . . . . . B.

Stamens definite, twice the number of petals or fewer . . . . . . C.

Stamens very perigynous or ovary inferior.

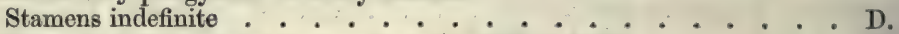

Stamens definite, twice the number of petals or fewer . . . . . . E.

Flowers very irregular . . . . . . . . . . . . . . . F.

Flowers monopetalous (the petals united at least at the base into a single lobed, toothed, or rarely entire corolla).

Ovary inferior . . . . . . . . . . . . . . . . . G.

Ovary superior .

Flowers apetalous. Perianth of a single whorl of segments or lobes, or none . I.

\section{A. Regular apocarpous Polypetals.}

Stamens indefinite.

Stamens very perigynous . . . . . . . . . RosaCEฐ, p. 103.

Stamens hypogynous.

Carpel solitary.

Sepals and petals 4 or 5, small, valvate. Trees or shrubs, with compound leaves . . . . . . . . Mrmosez, p. 73.

Sepals 3 to 5, imbricate. Climber with simple leaves . Dencma, p. 7. Carpels many.

Sepals 5, valvate, no petals. Climber with opposite leaves

Sepals 3. Petals 6 to 12, all much imbricate in series of 3 each . . . . . . . . . . . .

Sepals 3. Petals in 1 or 2 series of 3 each, all valvate,

or the petals slightly imbricate . . . . . . . ANonaces, p. 9.

Stamens definite. (See also Sagittaria in Monocotyledons.)

Clematis, p. 6.

Magnomiacea, p. 7.

Stamens equal in number and opposite to the petals (alternate with the sepals when the petals are wanting). Climbers.

Carpels 3, with 1 ovule in each. Leaves simple . . Menispermaces, p. 11. Carpels 3, with several ovules in each. Leaves digitate. Stauntonia, p. 14. 
Stamens twice the petals, or if equal to, alternate with them.

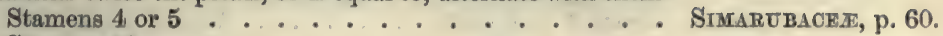

Stamens 10.

Carpels (in the flower) several . . . . . . RouREA, p. 71.

Carpels solitary . . . . . . . . . Lequminoss, p. 71.

\section{B. Regular syncarpous Polypetals with indefinite hypogynous stamens.}

Leaves opposite.

Sepals and petals 5 each. Fruit a capsule . . . . HYPERICINEx, p. 23.

Sepals 4. Petals 4 or more. Fruit a drupe . . . . Guttifer e, p. 24.

Leaves alternate.

Placentas parietal. Ovary 1-celled.

Sepals 2. Petals 4, large. Prickly herb . . . . . Argemone, p. 15.

Sepals 4 or more.

Placentas 2. Fruit stalked or oblong . . . . . CAPPARIDEx, p. 17.

Placentas 3. Berry sessile. Flowers small . . . . Scoropis, p. 19.

Ovary 2- or more celled. Ovules in the axis.

Stamens united in a colvimn or tube round the style.

Anthers 1-celled, on distinct filaments . . . . Malvaces, p. 31.

Anthers crowded in a terminal head . . . . . Stencultaces, p. 35.

Anthers 2-celled, on distinct filaments . . . . Pterospermum, p. 39.

Stamens free or united in a ring at the base.

Sepals 2 . . . . . . . . Portulaca, p. 127.

Sepals 3 to 5 , valvate.

Flowers unisexual

Flowers hermaphrodite.

Style single . . . . . . . : Trumacess, p. 40.

Styles several $\quad . \quad . \quad . \quad$ Actinidia, p. 26.

Sepals 3 to 5 , imbricate.

Leaves dotted. Prickly shrub . . . ... . Ataidantia, p. 51.

Leaves not dotted. Trees or shrubs, not prickly.

Petals free or shortly united at the base. Flowers hermaplırodite or polygamous . . . . Tennstromiace正, p. 25.

Petals united in a tube at the base. Flowers always unisexual. .

Ebenaces, p. 209.

C. Regular syncarpous Polypetals with definite hypogynous stamens.

Leaves opposite, simple or campound.

Herbs. Leaves quite entire . . . . . . . . Caryophyllez, p. 21.

Woody climber. Calyx with a gland outside. Leaves simple 'HrPTAGE, p. 49.

Trees or shrubs. Leaves simple or compound.

Ovary 2- or 3-celled. Leaves not dotted . . . . SAPINDACE 2 , p. 45.

Ovary 4- or 5-celled. Leaves dotted . . . . . . Rutace E, p. 57.

Leaves alternate, simple.

Stamens monadelphous. Calyx valvate.

Staminal tube long, connate with the stalk of the ovary. Heurcteres, p. 37.

Stamens shortly united at the base . . . . . BuetTNERIACEe, p.38.

Stamens free, double the number of petals.

Flowers unisexual

Flowers hermaphrodite.

Sepals 4, valvate . . . . . . . ELmOCARPUs, p. 42.

Calyx small, 4- or 5-cleft. Leaves dotted . . . Atalantia, p. 51.

Calyx truncate, scarcely toothed. Pubescence mealy. STrrax, p. 213.

Stamens free, the same number as the petals.

Stamens opposite the petals.

Petals very small, concave or hood-shaped

RHAMNACEA, p. 66. 
Petals longer than the sepals and alternate with them. Petals valvate. Ovary 2- to 6-celled . . . . . . . .

Petals longer than the sepals and opposite to them - SABIA, p. 70.

Stamens alternate with the petals.

Stamens distinctly hypogynous.

Petals erect, clawed. Ovary incompletely 2-celled. Shrub .

Petals spreading. Ovary 1 -celled, with parietal placentas. Herb : -

Stamens slightly perigynous or adhering to the petals. Stamens inserted on a broad fleshy disk . . . Stamens adhering to the base of the petals. Ovary 5-celled, with 2 ovules in each cell . . . Ovary 4-celled, with 1 ovule in each cell . ${ }^{\circ}$.

Stamens free, not corresponding in number with the petals.

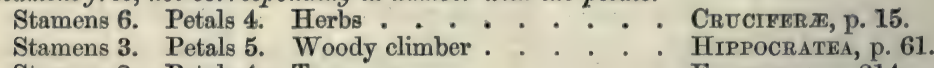

Stamens 2. Petals 4. Tree . . . . . . . . Fraxinus, p. 214.

Leaves alternate, compound.

Herbs.

Sepals 4. Petals 4. Stamens 8 (rarely more).

Pod linear, 2-valved . . . . . . . . Polanrsta, p. 17.

Pod inflated, 3-cornered, 3-valved . . . . . . Cardospermum, p. 46.

Sepals 5. Petals 5. Stamens 10 . . . . . . Oxatrs, p. 56.

Trees, shrubs, or tall climbers.

Stamens as many as petals.

Stamens opposite the petals. Climbers . . . . Vrris, p. 53.

Stamens alternate with the petals. Trees or shrubs.

Ovary 1-celled, with 1 ovule . . . . . . RHus, p. 69.

Ovary-cells or carpels 4 or 5.

Leaves dotted . . . . . . . . . . RutackA, p. 57.

Leaves not dotted. - . . . . - Smarubacra, p. 60.

Stamens double the number of petals.

Stamens inserted within an annular disk. Leaves not dotted . . . . . . . . . . . . .

Disk within the stamens or none.

Leaves dotted. Ovules 1 or 2 in each cell of the ovary not dotted. Ovules several in each cell of the ovary .

\section{Nephentum, p. 46.}

Adrantracese, p. 49.

AVERrhoA, p. 56.

D. Regular synoarpous Polypetals, with indefinite perigynous or superior stamens.

Leaves alternate.

Flowers hermaphrodite. Calyx-lobes and petals $\mathbf{5}$ or rarely 4 .

Stamens attached to the base of the petals . . . . . Srmplocos, p. 211.

Stamens free from the petals, inserted with them on the

Flowers unisexual. Sepals 2 or 3 . Petals 2 to 5 . Fruit 3-winged

Rosaceze, p. 103.

BegONIA, p. 126.

Leaves opposite.

Ovary inferior.

Calyx-segments linear, valvate. Petals cut . . . . KandeLIA, p. 110.

Calyx-lobes imbricate or very small. Petals entire . : Mrrtaceas, p. 117.

Ovary free, but enclosed in the calyx-tube . . . . . Lagerstremia, p. 112. 
E. Regular syncarpous Polypetals, with definite perigynous or superior stamens.

Leaves alternate.

Climbers, with tendrils.

Flowers hermaphrodite. Ovary stalked. . . . . PAssiflora, p. 123.

Flowers unisexual. Ovary inferior . . . . . . Cucurbitacex, p. 123.

Trees, shrubs, or herbs, without tendrils.

Ovary 1-celled, at least at the base, with parietal placentas, and more or less free at the top.

Flowers separate. Petals calyx-like or none . . SAMYdACEx, p. 121.

Flowers in compact heads resembling a single flower, the coloured petals all outside.

Ovary 2- or more celled, wholly inferior.

Calyx-lobes conspicuous, valvate, 4 or rarely 5. Ovules numerous .

RHodolara, p. 131.

Ovules 1 in each cell

Onagracex, p. 108.

Calyx-teeth minute or none. Ovules 1 in each cell

Petals 5, small. Ovary 2-celled. Fruit dry. .

Petals 4 or 5, small. Ovary 2- or more celled. Fruit a berry ... . . . . . . . .

Petals 6 to 10, linear. Ovary 2-celled. Fruit a 1seeded drupe . . . . . . . . . . . .

Leaves opposite.

Haloragis, p. 139.

UMBELLIFER

Araliacea, p. 135.

Marlea, p. 138.

Petals imbricate or contorted in the bud.

Ovules several.

Anthers small, opening longitudinally.

Herb of 4 or 5 inches. Flowers 4 -merous . . A Armannis, p. 111.

Shrub with heath-like dotted leaves. Flowers 5merous . . . . . . . . . . BECKEA, p. 118.

Anthers opening by 1 or 2 pores at the top . - Melastomacee, p. 112.

Ovules 2 in each cell. Berry 1-seeded. Shrub or tree. Caratria, p. 110.

Ovules 1 in each cell. Herb . . . . . . . Haloragis, p. 139.

Petals valvate in the bud.

Stamens alternate with the petals . . . . . . . . ConNaCE开, p. 137.

Stamens opposite or on the petals . . . . . . . LoRANTHACEA, p. 140.

\section{F. Irregular Polypetals.}

Flowers spurred. Anthers 5, united round the pistil.

Sepals 5, herbaceous. Petals 5, spreading, one of them spurred.

Sepals 2 outer ones, 1 larger inner one hooded and spurred.

Petals 1 outer entire, 2 inner ones lobed.

Flowers not spurred. Stamens 10 or few ; anthers free, the filaments often united.

Petals 3, small, erect. Stamens 8, in 2 clusters. Ovary 1- or 2-celled, with 1 ovule in each cell . . . . . .

Petals papilionaceous or spreading. Stamens usually 10 .

Ovary 1-celled, with 2 or more ovules ...... Leguminose, p. 71.

VIota, p. 20.

Impatiens, p. 55.

Polygatacem, p. 43.

\section{G. Monopetals with an inferior ovary.}

Anthers united in a ring round the style.

Flowers compound, $i$. e. florets in compact heads, with a common involucre, without separate calyxes . ... . Coмposiт $\approx$, p. 165.

Flowers distinct, irregular.

Stamens 2, comnate with the style . . . . . . . . STrumium, p. 195.

Stamens 5, the filaments free. . . . . . . CAMpanduaces, p. 195. 
Anthers free.

Stamens twice the number of corolla-lobes or teeth.

Corolla shortly toothed. Anthers opening in terminal pores. . . . . . . . . . . . . Corolla deeply toothed. Anthers opening longitudinally

Stamens the same number as the corolla-lobes, and opposite them.

Parasitical shrub. Corolla 4-lobed . . . . . Loranthus, p. 140.

Terrestrial trees or shrubs. Corolla small, 5-lobed . . M Mas p. p. 203.

Stamens the same number as the corolla-lobes, and alternate with them.

Leaves opposite or whorled.

No stipules. Corolla regular or irregular . . . Caprroutacezs, p. 142.

Stipules between the leaves (or rarely like them, and forming a whorl with them) ....... RUBLACEa, p. 144.

Leaves alternate.

Corolla irregular . . . . . . . . . . . . Scxvora, p. 198.

Corolla regular.

Shrub. Berry 1-seeded . . . . . . . . SoHapris, p. 52.

Herbs. Capsule many-seeded . . . . . Wahlenbergis, p. 1 с7

\section{H. Monopetals with a siperior ovary.}

(Stamens more than twice the corolla-lobes : see Polypetals, B.)

Stamens twice the number of corolla-lobes.

Shrubs or trees. Leaves alternate. Anthers oponing in terminal pores . . . . . . . . . . .

Herbs. Leaves opposite, succulent. Anthers opening longitudinally . . . . . . . . . BRYорнуLLU, p. 127.

Stamens equal in number to the corolla-lobes.

Stamens hypogynous.

Herbs with radical leaves. . . . . . . . . Statror, p. 281.

Shrubs. Leaves alternate .. . . . . . Azarka, p. 201.

Stamens opposite the corolla-lobes, and inserted in the tube.

Ovary 1-celled, with a free central placenta.

Herbs. Fruit capsular or dry . . . . . . . .

Shrubs or trees, Fruit succulent, indehiscent - Primdiacese, p. 202.

Ovary 2- to 5-celled. Shrubs or trees . . : : SIDEROXYLON, p. 209.

Stamens alternate with the corolla-lobes, and inserted in the tube.

Leaves opposite or whorled.

Ovary 4-lobed, with 1 ovule in each lobe . . . . .

Ovary 1-celled or partially 2-celled, the placentas not meeting in the axis.

Tall climber. Leaves whorled. Flowers 5-merous

Bitter herb. Leaves opposite. Flowers 4-merous .

Ovary 2-celled, or of 2 carpels with 1 or more ovules in each.

Stamens united in a mass round the pistil .

Stamens, or at least their filaments, distinct.

Carpels 2, distinct

Ovary 2-celled.

Stigma thickened, conical

Stigma capitate or lobed.

Leaves alternate or radical.

Labiati, p. 274.

Altamanda, p. 217.

ExacuM, p. 233.

A.TIEPLADEж, p. 223.

A pocrnacexi, p. 216.

Melodinds, p. 218.

LOGANIACE. p. 229.

Several ovules in each cell of the ovary.

Corolla searious and transparent. . . . . . Plantigo, p. 280.

Corolla not scarious . . . . . . . . Sola Sacera, p. 241. 
One or two ovules in each cell or carpel of the ovary.

Ovary of two distinct carpels, with a common style.

Shrub. Two ovules in each carpel . . . . .

Herb. One ovule in each carpel . ... . . . .

Ovary 5-celled, with 2 pendulous ovules in each . Pentaphylax, p. 28.

Ovary 4-celled, with 1 pendulous ovule in each . . ILEx, p. 64.

Ovary 2- or 3-celled, with 2 erect ovules in each, or 4-celled, with 1 erect ovule in each.

Tree. Fruit a berry ........... EHRETIs, p. 234.

Herbs. Fruit of 41 -seeded, or 22 -seeded nuts . BoraGINEA, p. 234.

Herbs or climbers. Fruit a capsule or berry . Convolvulacese, p. 235.

Stamens 1, 2, or 3 less in number than the corolla-lobes.

Stamens 2. Corolla regular, 4- or more lobed. . . . . JASMINACEA, p. 214.

Stamens 2 or 4 . Corolla more or less irregular.

Ovary 1-celled, with 1 central placenta. Corolla spurred UTrIcularia, p. 255.

Ovary 1-celled, with 2 parietal placentas.

Leafless root-parasite . . . . . . . . . . . EGINeTIA, p. 257.

Leaves opposite or radical . . . . . . . . GesneriaCer, p. 257.

Ovary 4-lobed, with 1 ovule in each lobe. . . . . Labiate, p. 274.

Ovary 2-celled, with 2 collateral ovules in each cell, or 4celled, with 1 ovule in each . . . . . . . .

Ovary 2-celled, with several ovules (or rarely only 2 superposed) in each cell.

Seeds attached to hooked or cup-shaped retinacula . AOANTHACEA, p. 259.

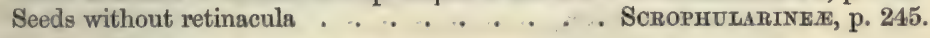

\section{Apetalous Dicotyledons.}

(If the pistil is apocarpous or the stamens more than twice the perianth-segments, see Polypetals.)

Anthers opening in valves turned upwards. Trees, shrubs, or

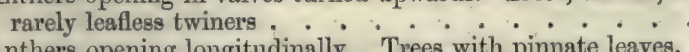

Anthers opening longitudinally. Trees with pinnate leaves.

Flowers hermaphrodite. Fruit succulent
Flowers unisexual. Fruit small, on a large thin $\dot{3}$-lobed

bract

Anthers opening longitudinally. Leaves not pinnate.

Flowers wholly or partially hermaphrodite.

Perianth none.

Anthers 1 or 3, on the top of the ovary. Shrubs. Leaves opposite. Spikes without bracts . . .

Stainens 3, at the base of the ovary. Herb. Leaves alternate. Spikes with 4 coloured bracts . . . HodtTU YNIA, p. 333.

Perianth superior, 5-cleft . . . . . . . . . HaMaMELIDEe, p. 130.

Perianth superior, irregular, with a long bent tube . . ARIsTolochia, p. 333.

Perianth contracted and breaking off above the ovary so as to appear superior, tubular, 4-lobed . . . . . EleAGNUs, p. 298.

Perianth, inferior. Ovary free.

Herbs.

Stipules sheathing or annular . . . . . Polygondices, p. 286.

Stipulez none or scarious.

Ovary 3-celled . . . . . . . . Motudgo, p. 23.

Ovary 1-celled, with 1 or rarely few ovules.

Perianth herbaceous, usually obtuse . . Chenopodiacese, p. 281.

Perianth usually scarious or acute. . . . A MARANTACEA, p. 283.

Trees or shrubs.

Perianth of 4 linear segnients, bearing the stamens . HeLICIA, p. 295. 
Perianth 4- or 5-lobed. Stamens alternate with the lobes or twice as many. Ovules 1 or 2 . . . .

Perianth 5-lobed. Stamens 8 , alternating with as many scales. Placentas 3, parietal .. . . CAsearia, p. 121.

Sepals 3 to 5 , free.

Ovary 2-lobed at the top . . . . . . . . Distruivm, p. 133.

Ovary entire. Fruit 1-seeded . . . . . . URTICE

Flowers wholly unisexual.

Leaflets succulent, root parasite. . . . . . . BAtANopHora, p. 140.

Climbers, with tendrils. . . . . . . . . Cu curbitacres,p.123.

Trees, shrubs, or herbs. Perianth herbaceous or none.

No ovary. Ovule bare or in an open perianth.

Ovule in the females or stamens in the males enclosed in an ovoid perianth. Leaves opposite .

Ovules and seeds in pairs under the scales of a

cone. Leaves alternate, or clustered and subu-

late. . . . . . . . . . . . .

Ovary 1-celled, or if 2 -celled, with 1 ovule in each cell.

No perianth, at least in the female.

Female flowers forming a prickly 2-celled burr, with 2 conical points and styles . . . . .

Flowers minute, crowded inside or outside of succulent receptacles . . . . . . . . .

Flowers crowded in cylindrical leaf-opposed pedunculate spikes .. . . . . . . . . . .

Flowers in catkins. ......

Perianth herbaceous.

Stigma 3- to 5-lobed. Shrubs.

Leaves alternate. Flowers in spikes or catkins . ANTIDEsMA, p. 317.

Leaves opposite. Flowers in axillary clusters . Hensiowia, p. 299.

Style entire or 2-lobed.

Fruit 1-seeded . . . . . . . . . URTICEe, p. 323.

Fruit of 2 cells or cocci . . . . . EUPHORBLACE, p. 299.

Ovary 2-celled, with several ovules in each cell.

Flowers in globular or ovoid heads. Tree. . .

Ovary 3- or more celled, or if 2-celled, with 2 ovules in each.

Ovary 5-lobed. Fruit follicular. Trees with paniculate flowers . . . . . . . . . . . .

Ovary usually 3-celled, rarely 2- or several-celled. Fruit dividing into cocci or baccate. Herbs, shrubs, or trees. Seeds albuminous . . . . EUPHORBIACE

Ovary 2-celled. Fruit a 1-seeded nut, on a cup or in a capsule-like involucre. Trees. No albumen . Amentacex, p. 319.

\section{CLASS II. MONOCOTYLEDONS.}

Stem woody. (See p. 338.)

Leaves pinnate or digitate. Perianth double . . . . . PALMz, p. 339.

Leaves simple. No perianth.

Leaves prickly on the edges, in spiral rows . . . . PANDANEE, p. 340.

Leaves not prickly and not spiral . . . . . . Gramines, p. 403.

Stem herbaceous or none.

Perianth none or of 1 to 6 small scales not longer than the ovary.

Flowers singly sessile within imbricated scales or glumes.

Leaf-sheaths entire. Each flower usually in the axil of one glume without a palea . ... . . . CYPeraces, p. 383. 
Leaf-sheaths split open opposite the blade. A palea to each flower within the glume . . . . . . .

Flowers solitary or crowded, without bracts, or the scalelike bracts not longer than the ovary.

Aquatio plant. Anthers or ovaries singly sessile in the axils of the leaves . . . . . . . . . .

Terrestrial plants. Stamens, ovaries, or sessile flowers crowded on a spadix with a spatha at the base . . ArorDEx, p. 341.

Perianth inferior, longer than the ovary.

Pistil apocarpous (ovaries distinct). Perianth regular, of 3 sepals and 3 petals. . . . . . . . . .

Pistil syncarpous (ovary 3-celled or rarely 1-celled).

Flowers closely packed in terminal compact heads, with imbricated scales.

Flowers hermaphrodite, yellow . . . . . .

Flowers unisexual, very small. Perianth scarious and tronsparent ... . . . . .

Flowers solitary, or in spikes, racemes, or panicles.

Perianth petal-like, of 6 lobes or segments.

Aquatic plants. Flowers appearing to proceed from the side of the petiole. . . . . .

Terrestrial plants. Flowers axillary or terminal . Perianth double, the outer herbaceous, the inner very delicate and petal-like.

Leaves radical, linear. Inner perianth-segments rolled in at the edges . . . . . . . .

MoNochonta, p. 374.

LILIACEe, p. 368.

Thysanotus, p. 372.

Leaves with sheathing petioles. Petals not rolled in CommeLYNaCEe, p. 375

Perianth of 2 petal-like segments . . . . . . . PhiLYdrum, p. 379.

Perianth of 6 small dry stiff segments . . . . . JUNCUs, p. 380.

Perianth superior.

Perianth very irregular.

Anthers $\mathbf{1}$ or $\mathbf{5}$, on subulate or petal-like filaments.

Leaf-veins pinnate

Anthers 1 or rarely 2, sessile, on a central column or

style. Leaf-reins simple

Perianth regular or nearly so.

Flowers unisexual.

Aquatic plant. Stamens 8 or 9. Female perianth with a long tube ..........

Terrestrial twiners. Stamens 6. No tube to the perianth . . . . . . . . . . . ,

Flowers hermaphrodite.

Stamens 6

Stamens 3.

Perianth tubular. Small, slender, leafless plant .

Períanth of 6 spreading segments. Leaves equitant.

ScItaminea, p. 347.

OrOHIDEA, p. 349.

BIYXa, p. 347.

Dioscorea, p. 367.

Amaryluidex, p. 365.

Gonyanthes, p. 364.

Pardanthus, p. 365.

CLASS III. CRYPTOGAMS.

(See p. 435.) 



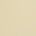




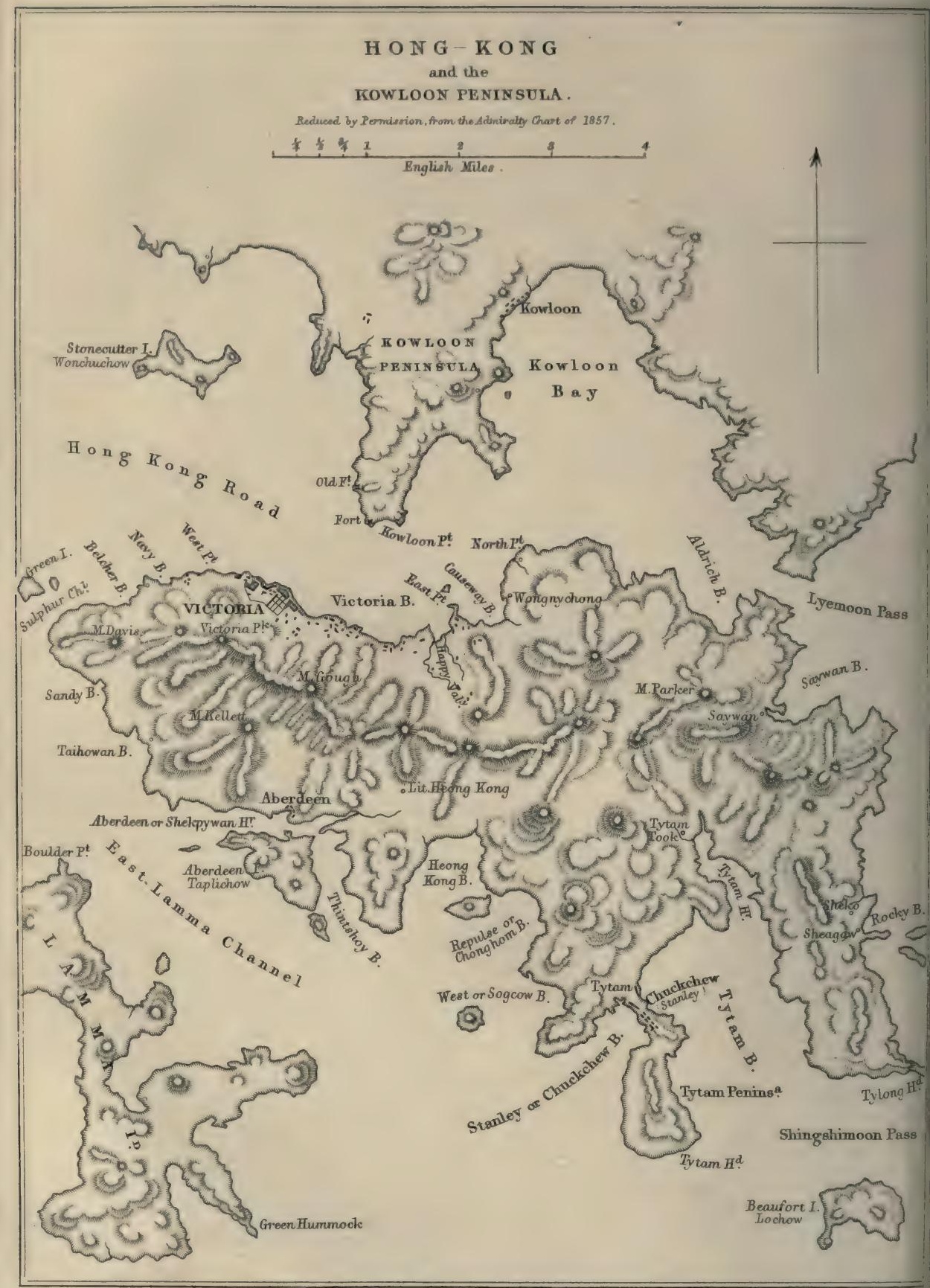




\section{FLORA HONGKONGENSIS.}

\section{Ci.ASS I. DICOTYLEDONS.}

Stem, when perennial, consisting of a pith in the centre, of one or more concentric circles containing fibrous tissue, and of the bark on the outside. Seeds with two cotyledons, the young stem in germination proceeding from between the two lobes of the embryo or from a notch at its summit.

The above characters are all that can be said to be constant to separate Dicotyledons from Monocotyledons; these two great classes have, however, each a peculiar habit which in most cases is readily recognized. All Hongkong trees or shrubs, except Palms and Bamboos, are Dicotyledons, so also are all plants with opposite or whorled or netted-veined leaves (except Smila. and some Aroidece), and almost all those which have the parts of the flowers in fours, fives, or eights.

(The following list of Orders is intended to show the arrangement adopted in this work. The characters given are not absolute, nor without exception, and are inserted only for the purpose of calling the attention to one or two of the most striking or most important features of each Order. In some cases where an Order is only represented in the island by some anomalous genus, its exceptional character is placed in a parenthesis.)

Strbclass I. Thalamifloræe.-Petals distinct from the calyx and from each other, sel. dom wanting. Stamens hypogynous.

\section{$\S 1$. Ovary apocarpous.}

I. Ranunculaces. Sepals petal-like, 5 or fewer. Stamens indefinite. No arillus. Herbs with alternate leaves; or climbers with opposite leaves.

II. Diliteniacex. Sepals herbaceous, 5 or fewer. Stamens indefinite. Seeds with arillus. Woody. Leaves alternate.

III. Magnoliace.s. Sepals and petals forming 3 or more series, and imbricate in each series. Carpels indefinite. Trees or climbers.

IV. \& NONACE E. Sepals 3 , valvate. Petals 6 , in 2 series, valvate or slightly imbricate in each series. Carpels indefinite. Stem woody.

V. Mentspermaces. Flowers small, unisexual. Sepals in 1 or 2 series. Petals in 2 series. Stamens definite, opposite the petals. Carpels 3 or 1, uniovulate. Climbers.

VI. BERBERIDEe. Characters nearly of Menispermacece, but several ovules in each carpel. (Climber, with digitate leaves.)

\section{§ 2. Ovary syncarpors. Placentas parietal.}

VII. Papaveracex. Sepals 2. Petals 4. Stamens indefinite. Albumen copious. Herbaceous.

VIII. Crucifrere. Sepals 4. Petals 4. Stamens 6, of which 4 longer. Herbaceous. 
IX. Capparinew. Sepals 4. Petals 4. Stamens indefinite. Placentas 2. Albumen 0. Herbaceous or woody.

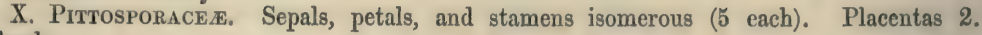
Shrub.

XI. BrXaok Ae. Petals as many as sepals or none. Stamens indefinite. (Placentas 3 or more.) Shrub.

XII. Violacese. Authers 5, connected in a ring round the ovary. (Herb.)

\section{§ 3. Ovary syncarpous. Placentas axile.}

* Disle none. Flower regular. Sepals imbricate.

XIII. Caryophyllew. Stamens definite. Placenta free, central. Embryo curved. Herb. Leaves opposite, entire.

XIV. Hypericine. Stamens indefinite. Flowers usually 5-merous. Leaves opposite.

XV. Guttiferes. Stamens indefinite. Sepals 2, 4, or 6. Trees or shrubs, Leaves opposite.

XVI. Ternstramiaces. Stamens indefinite (except Pentaphylax). Petals often cohering at the base. Leaves alternate. Trees or shrubs.

\section{** Disk none. Flowers regular. Sepals valvate.}

XVII. Malvacex. Stamens indefinite, monadelphous. Anthers 1-celled.

XVIII. Sterculiaceæ. Stamens indefinite or definite, monadelphous. Anthers 2-celled, adnate to the outside of the staminal column.

XIX. Buettneriacex. Stamens definite or rarely indefinite, monadelphous. Anthers 2-celled, terminal.

XX. Trliaceze. Stamens indefinite, free or polyadelphous. Anthers 2-celled, terminal.

\section{*** Disk none. Flowers very irregular.}

XXI. Polygalace 私. Stamens 8 or 4 , monadelphous.

**** Disk or gynobasis prominent (except Olacaceæ).

XXII. SaPInDacem. Petals imbricate. Stamens definite, inside or on the disk (except Turpinia), often anisomerous. Pistil 3-merous.

XXIII. Malpighiaces. Sepals with a conspicuous gland outside one or more of them, otherwise as in Sapindacece. Leaves opposite.

XXIV. Aurantiaces. Leaves dotted. Petals imbricate. Stamens twice as many or more. Berry indehiscent. No albumen.

XXV. Oracacex. Petals valvate. Ovary 1-celled at the top, with 3 pendulous ovules.

XXVI. Ampelide. Petals valvate. Ovary 2- to 6-celled, with erect ovules. Climbers with tendrils.

XXVII. Balsamines. Flowers very irregular, spurred. Anthers 5, cohering round the ovary. Herbs.

XXVIII. Oxalideas. Petals contorted. Stamens 10. Ovary 5-angled or 5-lobed. Seeds albuminous. Leaves compound.

XXIX. Rutaces. Leaves dotted. Petals usually imbricate. Stamens as many or twice as many. Ovary gynobasic or lobed. Seeds often albuminous.

XXX. Simarubacew. Flowers unisexual. Petals valvate or imbricate. Ovary gynobasic or lobed. No albumen. Woody and bitter. Leaves compound, not dotted.

Subcrass II. Calyciflorze.-Petals free. Stamens perigynous or epigynous, except in a few abnormal genera.

* Disk conspicuous (except Aquifoliaceæ), perigynous or hypogynous. Flowers small, regular.

XXXI. Celastracee. Stamens alternate with the petals. Seeds albuminous. Leaves undivided.

XXXII. Aquifoliace ж. Petals often united, stamens alternate with them. Disk none. Seeds albuminous. 
XXXIII. Rhamnacex. Stamens opposite the small petals. Seeds usually albuminous. Leaves undivided.

XXXIV. Terebinthacex. Stamens alternate with the petals or twice as many (opposite them in Sabia). Styles usually distinct. No albumen.

\section{** Ovary apocarpous. No albumen.}

XXXV. Connarace.s. Flowers regular. Stamens 10. Carpels usually 5.

XXXVI. Leguminose. Flowers irregular or (in Mimosece) regular and valvate. Stamens definite or almost hypogynous. Carpel 1 .

XXXVII. ROSACEA. Flowers regular. Petals imbricate. Stamens indefinite, very perigynous.

\section{*** Ovary syncarpous. Placentas axile. No albumen.}

XXXVIII. Onagracew. Sepals valvate. Stamens definite. Ovary inferior. Ovules indefinite. Flowers usually 2 - or 4 -merous.

XXXIX. RHIzophores. Sepals valvate. Stamens various. Ovary inferior or partly so. Ovules few, pendulous:

XL. Lythrarie ж. Ovary within the calyx-tube, but free. Petals crumpled, inserted at the border of the calyx-tube.

XLI. Melastomaces. Ovary within the calyx-tube, free or adnate. Petals contorted. Stamens definite, curved down in the bud.

XlII. Mrrtaces. Ovary inferior. Petals imbricate. Stamens indefinite. Leaves dotted.

\section{**** Placentas parietal.}

XLIII. Samydaces. Petals persistent with the sepals or none. Stamens indefinite or anisomerous or opposite the petals.

XLIV. Passiflorew. Petals persistent with the sepals. Stamens definite, connate with the ovary-stalk. Climber with tendrils.

XlV. Cucurbitacee. Flowers unisexual. Stamens 5 or $\mathbf{3}$. Ovary inferior. Climbers with tendrils.

\section{Anomalous Order,}

XLVI. Begoniacex. Flowers unisexual. Stamens indefinite. Ovary inferior. Fruit usually 3-winged. No albumen. Leaves oblique.

\section{****** Seeds albuminous. Placentas usually axile.}

XLVII. Portulacese. Sepals 2. Petals 5: (Stamens indefinite.)

XLVIII. Crassulaces. Sepals, petals, stameus in 1 or 2 series, and carpels all isomerous. Leaves usually succulent.

XLIX. SAXifragace . Sepals, petals, and stamens in 1 or 2 series, isomerous. Carpels or ovary-cells fewer, usually 2. Ovules several.

L. Hamamelidex. Nearly as in Saxifragacea, but the parts of the flower often reduced, flowers usually capitate, and ovules often 1 or 2 in each cell, and pendulous.

****** Ovary inferior, usually with an epigynous disk. Ovules solitary in each cell and pendulous.

LI. Umbellifrere. Fruit dry, separating from the axis into 2 seed-like carpels. Leaves alternate, often dissected.

LiI. Araliacede. Fruit succulent, not separating. Cells usually more than 2. Leaves alternate, often compound.

LIII. ConNack F. Fruit succulent, 2-celled. Leaves opposite or alternate and undivided. Stamens alternate with the petals.

LIV. Halorageæ. Aquatic or small herbs. Flowers much reduced, 2- or 4-merous.

LV. Balanophorede. Sueculent leafless root-parasites. Flowers much reduced, usually 3-merous.

LVI. Loranthace.e. Parasitical shrubs. Leaves opposite. Stamens on or opposite the petals. 
Subclass III. Monopetalæe.-Petals united, at least at the base, into a single corolla.

\section{\$1. Corolla epigynous, bearing the stamens.}

LVII. Caprifoliaces. Leaves opposite, without stipules. Ovary 2- or more celled.

LVIII. Rubiace E. Leaves opposite, with stipules (stipules sometimes leaf-like, in a whorl with the leaves). Ovary 2- or more celled.

LIX. Composite. Florets in compact heads. Anthers united in a ring round the style Ovary 1-celled, 1-ovulate.

\section{§ 2. Stamens free from the corolla.}

LX. Stylidiex. Stamens 2, connate with the style: otherwise as in Campanulacea.

LXI. Campanulace e. Stamens as many as corolla-lobes, free from the style. Anthers opening longitudinally. Ovary inferior, multi-ovulate. Herbaceous.

LXII. GoodenIACEe. An indusium under the stigma: otherwise as in Campanulacea.

LXIII. Ericaces. Stamens usually twice the corolla-lobes. Anthers opening by terminal pores. Woody.

\section{§ 3. Corolla hypogynous or rarely perigynous, bearing the stamens.}

* Stamens either opposite the corolla-lobes, or more than their number.

LXIV. Primulaces. Stamens opposite the corolla-lobes. Placenta free and central. Fruit capsular. Herbs.

LXV. Mrrsinaces. As in Primulacea, but woody, and fruit a berry.

LXVI. Sapotacee. Stamens opposite the corolla-lobes or twice as many. Ovary 2- or more celled; ovnles 1 or 2 in each.

LXVII. EBenaces. Flowers usually diœeious. Stamens indefinite. Ovary 3- or more celled: ovules 1 or 2 in each.

LXVIII. Styracaceas. Stamens twice the corolla-lobes or more. Ovary more or less inferior, 2- or more celled; ovules 2 or more in each.

** Corolla regular. Stamens alternating with its lobes, and equal to them in number (except Jasminaceæ).

LXIX. JasminaCeE. Stamens 2.

IXX. Apocynace s. Carpels 2, usually distinct. Stigmas united. Filaments distinet.

LXXI. Asclepiade e. Carpels 2, distinct. Filaments forming a short tube round the style. Pollen-masses attached in pairs or in fours to processes of the stigma.

LXXII. Loganiace ж. Stamens free. Ovary 2- or more celled. Placentas axile. Leaves opposite, sometimes stipulate.

LXXIII. Gentianace.e. Bitter plants. Corolla contorted. Placentas parietal, rarely meeting in the axis. Leaves opposite, entire.

LXXIV. Boragines. Fruit 2- or 4-seeded, either 2- or 4-lobed or of 2 or 4 nuts. Leaves alternate, usually rough.

LXXV. Convolvutacee. Corolla plaited. Ovary 2- to 4-celled, with 1 or 2 ovules in each cell. Stem twining or prostrate or low.

I.XXVI. Solanaces. Corolla plaited or valvate. Ovary 2-celled, with several ovules in each. Leaves alternate.

*** Flowers irregular. Stamens 1 less or 3 less than the corolla-lobes.

LXXVII. Scrophularinex. Ovary 2-celled, with several ovules in each. Seeds albuminous. No retinacula.

LXXVIII. LENTIBUT.ACEE. Ovary 1-celled, with a free central placenta and several ovules.

LXXIX. Orobanchacex. Leafless parasites. Ovary l-celled, with 2 single or double parietal placenta and many ovules.

LXXX. Gesneriaces. Stem leafy. Ovary 1-celled, with 2 parietal placentas and many ovules.

I.XXXI, Acanthacede. Ovary 2-celled, with two or more ovules in each cell. Seeds without albumen, attached to hooked retinacula or to placentary papillæ. 
LXXXII. Verbenaces. Ovary 2- or 4-celled, not lobed, with 1 ovule in each cell. Style terminal.

LXXXIII. Labiatw. Ovary 4-lobed, with 1 ovule in each lobe. Style between the lobes.

**** Anomalous Orders.

LXXXIV. Plantaginea. Corolla scarious, regular. Stamens isomerous.

IXXXV. Plumbaginex. Ovary with one cell and 1 ovule, but several styles.

Subchass IV. Monochlamyder.-Perianth really or apparently simple or none (except' in some Euphorbiacea).

LXXXVI. Chenopodiacese. Perianth small, herbaceous. Stamens 5 or fewer. Ovary with 1 ovule, but 2 or more styles or stigmas. Seed albuminous. No stipules.

LXXXVII. Amarantaces. As in Chenopodiacece, but perianth more scarious, and in one tribe several ovules on a free central placenta.

LXXXVIII. Polygonaces. Perianth small. Stamens 9 or fewer. Ovary with 1 ovule but 2 or more styles or stigmas. Seeds albuminous. Stipules sheathing.

LXXXIX. Lavinineas. Anther-cells opening in valves turned upwards. Perianth-segments usually 6. Berry or drupe 1-seeded. No albumen.

XC. Proteace e. Perianth inferior; segments 4, valvate, with a stamen on each. No albumen.

XCI. Thymele e. Perianth-lobes imbricate. Stamens as many or twice as many, inserted in the tube. Ovary 1- or 2-celled, with 1 pendulous ovule in each. Style 1.

XCII. Elatagnaces. Perianth 2- or 4-lobed, contracted over the otherwise free ovary. Orule 1, erect. Style 1.

XCIII. Santalaces. Perianth wholly or partially superior; lobes valvate. Stamens opposite the lobes. Ovary 1-celled, with 3 to 5 suspended ovules.

XCIV. Euphorbiace. F. Flowers unisexual. Ovary of 3, rarely 2 or more than 3, united carpels, with 1 or 2 pendulous ovules, and usually separating into cocci. Seeds albuminous.

XCV. Juglander. As in Amentacere, but leaves pinnate.

XCVI. Amentace.e. Flowers unisexual; males in catkins. Female perianth none or adherent. Fruit a 1-seeded nut. No albumen.

XCVII. URTICE A. Flowers unisexual; nales small, green, not in catkins. Stamens opposite the perianth-segments. Ovary free. Ovule 1 (or if 2, one always abortive). Styles 2, or rarely 1 , unilateral.

XCVIII. Aristolochiacese. Perianth superior, valvate. Ovary 3-celled, with several ovules in each.

XCIX. Saururaces. Perianth 0. Stamens united with the base of the ovary. Ovules several, on 3 axile or parietal placentas.

C. Chloranthace.. Perianth 0 . Starnens 1 or 3 , epigynous. Ovule 1 , pendulous.

CI. Piperacese. Perianth 0. Stamens free from the ovary. Ovule 1, erect.

Subclass V. Gymnospermæ.--Ovules and seeds naked, without ovary or styles.

CII. Gnetacex. Leaves opposite. Stamen in the males, ovule in the females, enclosed in an ovoid or tubular bract.

CIII. Conifere. Anthers in the male, ovules in the females, inserted on scales, often forming false catkins or cones.

\section{ORDER I. RANUNCULACEFE.}

Sepals 3 or more, usually 5, free, usually petaloid and deciduous. Petals of the same number or more, or sometimes none. Stamens indefinite, hypogynous, free. Anthers adnate. Carpels several, usually free, with one or more ovules in each, becoming when ripe indehiscent achenes or berries, or follicular capsules. Seeds without any arillus. Embryo very small, near the base of a copious albumen. 
The majority of genera of this rather large Order consist of herbs from the temperate or cooler regions of the globe, with radical or alternate leaves. Of this group one species, Ranunculus sceleratus, Linn., is said (Bot. Her. 361) to have been found in Hongkong " in waste places near houses." I have seen no specimens, and as the plant in other countries is only to be seen in ditches and wet places, I fear there may have been some mistake, and therefore omit it. 'The following Hongkong species belong to a somewhat anomalous group with opposite leaves.

\section{CLEMATIS, Linn.}

Sepals 4 or 5, valvate in the bud, petaloid and deciduous. Petals none, or sinall and narrow and passing gradually into the stamens. Carpels numerous, with a single pendulous ovule in each. Achenes indehiscent.-Climbers or rarely large herbs with opposite leaves.

A considerable genus, widely distributed over the globe, and almost the only one of the Order which penetrates into the tropics.

Leaves pinnate with 5 segments. Anthers longer than the filaments . 1. C. uncinata. Leaves abont twice ternate. Anthers much shorter than the filaments . 2. C. parviloba.

Leaves once ternate.

Leaf-segments rounded or cordate at the base. Anthers longer than the filaments . . . . . . . . . .

Leaf-segments narrowed at the base. Anthers much shorter than the filaments

3. C. Meyeniana.

4. C. crassifolia.

1. C. uncinata, Champ. in Kew Journ. Bot. iii. 255. A glabrous and somewhat glaucous climber. Leaves pinnate, the segments usually 5 , stalked, ovatelanceolate, acuminate, with a short hooked point $1 \frac{1}{2}-2$ in. long, 3 -nerved at the base. Panicles loose, terminal, with numerous white flowers. Sepals when fully out near $\frac{1}{2}$ in. long, very acute, glabrous with the exception of a narrow tomentose edge, turning black in drying. Anthers linear, much longer than their very short filaments. Achenes terminating when ripe in long feathery awns.

In a ravine behind Mount Parker, near Saywan, Champion. Not in any other collection.

2. C. parviloba, Gardn. and Champ. in Kew Journ. Bot. i. 241. A climber, loosely clothed with short silky hairs. Leaves mostly twice ternate, the segments stalked, ovate-lanceolate, acuminate, quite entire, $1 \frac{1}{2}$ to 2 in. long. Panicles few-flowered and leafy. Sepals white?, about 9 or 10 lines long and 3 lines broad, 7-nerved and hairy outside, glabrous within. Anthers much shorter than their rather slender filaments. Achenes numerous, terminating in long feathery awns.

Rare in the Happy Valley and towards West Point, Champion; also Wright and Wilford. Not as yet found out of the island.

3. C. Meyeniana, $W$ alp. $P l$. Meyen. 297. A somewhat glaucous climber, either quite glabrous or only slightly pubescent. Leaves ternate, the segments stalked, cordate, ovate, or lanceolate, quite entire and rather thick, 2 to 3 in. long. Panicles loose and many-flowered. Flowers white, slightly scented, 5 or 6 lines long, and scarcely pointed. Anthers mostly longer than the filaments. Achenes several, terminating in long feathery awns.-C. hedysarifolia, Bot. Reg. t. 599, not DC.* C. oreophila, Hance in Walp. Ann. ii. 3.

* The true $C$. hedysarifolia, DC., a south Indian plant, has the leaves often pinnately divided, the segments frequently coarsely toothed, and the authers almost as short as in $C$. Gouriana, to which it comes much nearer than to the $C$. Meyeniana. 
Common in ravines, Champion and others; frequent also on the continent of China, extending northward to Amoy and Loochoo.

4. C. crassifolia, Benth. $n$. sp. A perfectly glabrous climber, resembling at first sight the $C$. Meyeniana, but the leaf-segments are much thicker, always narroweil or wedge-shaped at the base, and mostly very obtuse, the flower somewhat larger, the sepals more acuminate, and the anthers very much shorter, more obtuse, with the filaments elongated as in C. parviloba.

In a ravine on Victoria Peak, Wilford. Not received from elsewhere.

The C.ternifolia, DC. (which may be the same as C.chinensis, Retz, and C. biternata, DC.), and the C. apiifolia, DC, appear both to be common about Amoy, but have not been gathered in the vicinity of Hongkong.

\section{ORder II. DILLENIACE无.}

Sepals 4 to 6 , usually 5 , persistent, imbricate in the bud. Petals 5, ol rarely fewer, deciduous, imbricate in the bud. Stamens indefinite, hypogynous, usually free. Anthers adnate. Ovary of several free and distinct carpels, or rarely single and excentrical, one-celled, with one or more ovules in each. Styles diverging. Ripe carpels either indehiscent and succulent, or capsular, opening along the inner edge at the top. Seeds furnished with an arillus. Embryo very small, at the base of a fleshy albumen.-Trees, shrubs, climbers, or herbs. Leaves alternate. Stipules minute or none.

A considerable Order, partly tropical both in the New and the Old World, partly Australian.

\section{DELIMA, Linn.}

Flowers hermaphrodite. Filaments dilated at the upper end. Carpel solitary, nearly globose, attenuated into a subulate style. Ovules few, ascending. Capsule follicular. Seed solitary, surrounded by a cup-shaped toothed arillus.

A genus limited to a single species. The American plants formerly referred to it all belong to Doliocarpus.

1. D. sarmentosa, Linn.; Hook. and Thoms. Fl. Ind. i. 61 ; Bot. Mag. $t$. 2038. A climber with a woody stem. Leaves varying from obovate to broadly"lanceolate, obtuse or acute, 2 to 5 inches long, entire or serrate-crenate, very scabrous, and sprinkled on both sides as well as the branches with appressed hairs. Flowers white, 3 to 4 lines diameter, in broad many-flowered panicles.-Leontoglossum scabrum, Hance in Walp. Ann. ii. 18; iii. 812.

Common in Hongkong, Champion and others. Widely diffused over western and eastern India and the Archipelago, extending northwards to the Philippines, S. China, and Assam, and westward to Ceylon.

\section{ORDER III. MAGNOLIACE虑.}

Sepals and petals usually numerous, hypogynous, imbricate in the bud, in several series of 3 (rarely 5 ) each, and passing gradually one into the other. Stamens indefinite, hypogynous. Anthers adnate. Carpels several, either free or cohering laterally to each other, usually spicate on the torus. Ovules 
2 or more in each carpel. Seeds without any arillus, but the outermost coat usually fleshy. Embryo minute, at the base of a copious oily albumen, which is not ruminate.-Trees, shrubs, or climbers. Leaves alternate, undivided, and usually entire. Stipules lateral, adhering to the petioles, but soon deciduous, or rarely none.

Magnoliacece are not very numerous, and are chiefly natives of the mountainons districts of central, southern, and eastern Asia, and northern and tropical southern America.

Flowers hermaphrodite. Carpels spicate. Trees or shrubs . . . . 1. Magnolia. Flowers unisexual. Carpels capitate. Climbers . . . . . . 2. Kadsura.

\section{MAGNOLIA, Linn.}

Flowers hermaphrodite. Sepals 3. Petals 6 to 12. Carpels biovulate, laterally attached to the axis in a dense spike, coriaceous when ripe, and opening by a longitudinal slit.-Trees or shrubs. Leaves entire.

A genus of but few Asiatic species, with several from N. America.

1. IM. Championi, Benth. An erect shrub, growing out sometimes into a small tree. Leaves oblong, 4 to 6 inches long, coriaceous, glabrous or sprinkled with a few hairs underneath. Peduncles axillary, one-flowered, short, thick, and densely covered with silky hairs. Flowers appearing after the leaves are out, about $1 \frac{1}{4}$ in. long, cream-coloured, and very fragrant at night. Petals 6 . Anthers very numerous. Carpels 2-ovulate, very thickly silky-hairy, when ripe thick and hard, almost woody, shortly apiculate, and opening longitudinally. Seeds usually solitary, oblong, scarlet, hanging by a filiform funiculus long after the carpels have opened.-Talauma pumila, Champ. in Kew Journ. Bot. iii. 255, but not of Blume.

Rather scarce on Victoria Peak, where it is shrubby ; more common and subarboreous in the woods of the Happy Valley, Champion, but not as yet known out of the island. It is also planted in gardens according to Champion, but it is probable that the cultivated plant is the common $\boldsymbol{M}$. pumila, referred by Blume rather doubtfully, and probably without sufficient grounds, to Talauma. The present species, described from Victoria Peak specimens, is certainly a Magnolia, not a Talaumx. It has the stature, foliage, and iufloreseence of $\boldsymbol{M}$. $p u$ mila, but in the latter species the peduncles are much more recurved and glabrous, as well as the ovary, the flowers rather smaller, etc.

\section{KADSURA, Juss.}

Flowers unisexual (diœcious). Sepals 3. Petals 6 or 9 . Stamens indefinite, the short filaments either free or united at the base in a fleshy columu. Carpels indefinite, with 2 or 3 ovules in each, succulent when ripe, and united in a globular head. Seeds usually 2 in each carpel, superposed, enclosed in pulp and separated by a spurious succulent dissepiment.-Climbers. Leaves entire or toothed. Flowers white or reddish.

A small genus, confined to eastern Asia.

1. R. Chinensis, Hance, n. $s p$. A diœcious glabrous climber. Leaves oval-oblong, about 3 to 5 in. long, thickly coriaceous, entire or remotely toothed. Peduncles 1-flowered, axillary, shorter than the flower or the fruit. Male flowers ovoid, 8 or 9 lines long. Staminal column acuminate, rather shorter than the petals, bearing in the lower portion a number of short thick 
filaments, with short adnate anthers, either entire at the top or bearing one or two short branches or antherless filaments. Female flowers globular, about 6 lines diameter. Fruit globular, about $1 \frac{1}{2}$ to 2 in. diameter. $-K$. japonica, Benth. in Kew Journ. Bot. iii. 258, not of Don.

Rare, in a ravine below Victoria Peak, Champion, also Hance. South China, Millett. Not known from elsewhere.

\section{ORDER IV. ANONACE压.}

Sepals 3, valvate in the bud, occasionally united at the base. Petals 6 , in 2 series, or rarely 3 only, those of each series valvate or slightly imbricate in the bud. Stamens hypogynous, indefinite, often closely packed. Filaments very short. Anthers adnate, the connective often produced above the anthercells. Carpels usually indefinite, free or cohering to each other. Ovules solitary or several in each carpel, erect or horizontal, anatropous. Ripe carpels free or united into a many-celled fruit, indehiscent or rarely follicular. Embryo minute, in a copious ruminate albumen.-Trees, shrubs, or climbers, often aromatic. Leaves alternate, entire, without stipules. Flowers terminal, axillary or lateral, solitary or clustered.

A large Order, almost confined to the tropics both in the New and the Old World, a very few species being found in North America; and in Asia, Hongkoug is, as far as yet known, the northern limit of the Order.

Petals of each series imbricate in the bud . . . . . . . . 1. Uvaria.

Petals of each series valvate in the bud.

Petals enclosing the stamens and pistils in their coneave base. Peduncles recurved, forming woody hooks . . . . . . . . .

Petals nearly flat, usually loug and narrow. No hooks . . . . 3. UnoNA.

\section{UVARIA, Linn.}

Petals 6, round, oval or oblong, those of each series slightly imbricate in the bud. Stamens numerous, closely packed, oblong or linear. Carpels indefinite, linear, with several ovules in each. Styles short. Ripe carpels succulent, indehiscent, sessile or stalked, with several seeds in each, rarely reduced to one by abortion.-Shrubs, with weak, usually climbing branches. Peduncles leaf-opposed or rarely axillary.

A considerable genus, confined to the Old World, from Western Africa to the Indian Archipelago.

Petals oval-oblong, about 1 inch. Berries oblong-cylindrical . . . 1. U. purpurea.

Petals nearly orbicular, about $\frac{1}{2}$ inch. Berries nearly globular . . 2. U. microcarpa.

1. U. purpurea, Blume; Hook. and Thoms. Fl. Ind. i. 95. A shrub, with long, weak, climbing branches, the young parts and leaves covered with rusty brown hairs or down. Leaves broadly oblong, 6 to 8 in. or even more in length, narrower below, cordate at the base, when old nearly glabrous on the upper side. Peduncles 1 -flowered, about 1 in., with two large round bracts which enclose the bud, but soon fall off. Petals oval-oblong, at least an inch long. Berries on long stalks, oblong-cylindrical, 2-ribbed on the back.- $U$. platypetala, Champ. in Kew Journ. Bot. iii. 257. U. rhodantha, Hance in Walp. Ann. ii. 19. 
Low jungle, near the Buddhist Temple, East Point, Champion; at the foot of Mount Victoria, Wilford, also Hance. Spreads over the Malayan Peninsula, the Indian Archipelago, and northward to the Philippines.

2. U. microcarpa, Champ. in Kew Journ. Bot. iii. 256. A low shrub, with weak or sometimes half-climbing branches, the young parts rusty-downy. Leaves oval or oblong, 3 to 5 in. long, cordate at the base, rusty-downy underneath. Peduncles $\frac{1}{2}$ to $1 \mathrm{in}$. long, leaf-opposed, 1- or 2 -flowered. 1'etals broadly oval or orbicular, not much above $\frac{1}{2} \mathrm{in}$. long. Berries stipitate, globular or shortly oblong, 3 to 6 lines long, tomentose or at length glabrous, without dorsal ribs.-U. badiiflora, Hance in Walp. Ann. ii. 19.

Very common in Hongkong, Champion and others; and in the islands about Macao, but not exactly matched with any from more distant countries. It appears allied to U. rufa, Bl., an Archipelago species, but has broader leaves, larger flowers, and much smaller berries, not transversely sulcate.

\section{ARTABOTRYS, R. Br.}

Sepals cohering at the base. Petals 6, valvate in the bud in each series, enclosing the stamens and pistils in their hollow base, spreading in the upper part. Stamens numerous, closely packed, oblong or wedge-shaped. Carpels several, oval or oblong, with 2 erect ovules in each. Styles oval or oblong, usually reflexed. Ripe carpels baccate, usually 1-seeded.-Woody climbers. Leaves smooth and shining. Peduncles 1- or 2-flowered, many of them thickened and recurved, becoming hard woody hooks.

A rather small genus, well marked by its habit, chiefly Asiatic, with one African species.

Petals 6-9 lines long, pubescent. Carpels hairy . . . . . . 1. A. Blumei.

Petals above an inch long, glabrous. Carpels glabrous . . . . 2. A. odoratissima.

1. A. Blumei, Hook. and Thoms. Fl. Ind. i. 128 (partly). A woody climber, slightly pube scent on the young shoots, at length glabrous. Leaves ovalelliptical or oblong, obtusely acuminate, 2 to 3 or sometimes $4 \mathrm{in}$. long, coriaceous, smooth and shining; the veins slender but distinct, and the principal ones arched and connected together at some distance from the margin. Hooked peduncles short, bearing one flower on a pedicel of 4 or 5 lines, and often the rudiments of 2 or 3 others. Sepals very short and broad. Petals ovate-lanceolate, 6 to 9 lines long, very thick and pubescent; the inner ones very similar to the outer. Carpels 6 to 8 , hairy.

Abundant near the Buddhist Temple, East Point, and in the woods near the Waterfall in the Happy Valley, Champion. I have seen no specimen from elsewhere.

Notwithstanding the authority above quoted, I think that the Hongkong specimens agree much better with Blume's character and figure of $A$. hamata, than of his A. odoratissima, which is correctly distinguished by Hooker and Thomson from the following, A. odoratissima, Br. Probably our plant is identical with the China one included by Blume in his $A$. hamata, but different, as a variety at least, from the Java one.

2. A. odoratissima, $B r . ; B o t$. Reg.t. 423. A tall climber, like the last, but quite glabrous. Leaves oblong or oblong-lanceolate, 4 to $6 \mathrm{in}$. long, acute at both ends, scarcely coriaceous, although shining; the veins finer than in $A$. Blumei, but the principal ones much more branched and less prominently arcuate. Hooked peduncles 1- or 2-flowered. Sepals small. Petals oblonglanceolate, more than an inch long, and perfectly glabrous, the inner ones similar to the outer. Carpels few and glabrous. 
In similar places to the last, but less common, Champion, also Hance. Received also from other parts of S. China.

\section{UNONA, Linn.}

Petals 6, valvate in the bud in each series, rather thin and long, and nearly flat. Stamens numerous, closely packed, oblong-tetragonous. Carpels indefinite, with 2 or more ovules in each, in a single series. Styles oval or oblong, recurved. Ripe carpels succulent, indehiscent, usually elongated, and separated by constrictions into 1 -seeded joints.-Trees or shrubs, rarely climbers. Flowers rather large, axillary or lateral.

The species are all Asiatic.

1. U. discolor, $V a h l ; H o o k$. and Thoms. Fl. Ind. i. 133. A shrub or small tree. Leaves from oblong to lanceolate, usually 4 or 5 inches long, acute, rounded at the base, very glabrous, and somewhat shining above, glaucous, and often slightly pubescent underneath. Peduncles lateral, 1-flowered, 1 to 2 in. long. Flowers nodding, at first green, then yellowish. Petals broad at the base, lanceolate, rather obtuse, often attaining 2 inches in length, though much shorter when they first open. Carpels several, each divided into 2 to 6 articles about the size of a pea, or sometimes reduced to a single one.

Very common in the lower ravines of Hongkong, Champion and others. Widely spread ovcr the hotter and damper parts of India, from Ceylon to the foot of the Himalaya, the Archipelago, and S. China.

\section{ORDER V. MENISPERMACEZE.}

Flowers unisexual, usually diœcious. Sepals usually 6 , in 2 series, rarely 5 or fewer, or 9 or 12 in 3 or 4 series, the inner ones the largest. Petals usually 6 , nearly equal, and smaller than the calyx, imbricate in 2 series, rarely 5 , or fewer or none. Male flowers: Stamens hypogynous, usually of the same number as the petals, and opposite to them, free or united in a central column. Female flowers: Sterile stamens usually 6, free. Carpels of the ovary distinct and free, usually 3 , sometimes 6 or more, or reduced to 1 , with 1 ovule in each. Styles terminal, usually oblique or recurved. Fruiting carpels drupaceous, the putamen usually concave on the inner face, or very much curved, the endocarp projecting into the cavity. Seed more or less peltately attached to the projection, either albuminous, with a central embryo, or almost without albumen, the embryo then thick and fleshy, with almond-like cotyledons. Radicle superior.-Climbers. Leaves alternate, undivided, usually with palmate veins or peltate. No stipules. Flowers usually small, paniculate, racemose, or cymose, rarely solitary.

A considerable tropical Order both in the New and the Old World, a very few species extending into N. America and northern Asia, and a rather greater number into southern Africa and Australia. It is unknown in Europe.

Sepals and petals 6 each. Carpels 3. Flowers unisexual.

Anthers adnate. Styles short, flat. Flowers in long panicles or racemes, or the females solitary

Anthers terminal, nearly globose. Styles cylindrical. Flowers in long panicles .

1. Limacia.

2. Cocculus. 
Anthers adnate. Styles 2-cleft, subulate, Flowers in dichotomous cymes .

Sepals and petals various. Carpel solitary. Flowers unisexual.

Sepals free. Flowers in umbels or heads.

3. Pericampylus.

Sepals united. Flowers in panicles or racemes

4. Stephania.

5. Cyclea.

\section{LIMACIA, Lour.}

Sepals 6, in 2 series, the outer ones smaller. Petals 6 , much smaller than the inner sepals, embracing the stamens with auricles at their base. Male flowers : Stamens 3,6, or 9, the filaments free. Anthers adnate, opening with longitudinal slits. Female flowers: Sterile stamens 6, club-shaped. Carpels 3. Styles short, flattened. Drupes obovate or reniform, the scar of the style very near the base, the putamen scarcely tuberculate. Seed much curved. Embryo elongated in the centre of the albumen, with semicylindrical cotyledons,

A small genus, limited to tropical Asia.

1. I. cuspidata, Hook. and Thoms. Fl. Ind. i. 189. A tall climber, nearly glabrous, or the young shoots pubescent. Leaves from ovate to oblong or lanceolate, acute at both ends, 2 to 3 inches long, or larger in the barren shoots, 3-nerved. Male panicles scarcely longer than the leaf-stalks. Female flowers few or solitary. Stamens 6 to 9. Drupes nearly globular, slightly flattened, about 6 lines diameter.-Hypserpa nitida, Miers, in Kew Journ. Bot. iii. 258.

In a ravine of Mount Victoria, Champion, also Wright. In eastern and northern India, from Ceylon to the Malayan Peninsula, Silhet, and Khasia.

\section{COCCULUS, DC}

Sepals 6 , in 2 series, the outer ones smaller. Petals 6, smaller than the sepals, wedge-shaped or obovate, often embracing the stamens by auricles at their base. Male flowers: Stamens 6, the filaments free. Anthers terminal, globular, 4-lobed. Female flowers: Sterile stamens 6 or 0. Carpels 3. Styles cylindrical, undivided. Drupes obovate or rounded, laterally compressed, the scar of the style near the base. Putamen fragile, horseshoe-shaped, usually perforated laterally. Seed much curved, with albumen. Cotyledons linear, flat.-Climbers, or rarely half-erect undershrubs. Panicles axillary, elongated, or reduced to few flowers, the females often solitary.

A genus of several species, chiefly Indian, extending also into Africa and Australia, with two North American species.

Leaves rounded. Axillary or lateral panicles very long . . . . 1. C. macrocarpus. Leaves ovate-oblong or 3-lobed. Axillary panicles short . . . . 2. C. ovalifolius.

1. C. macrocarpus, W. and Arn.; Hook. and Thoms. Fl. Ind. i. 191 ; Wight, Illust. t. 7. A glabrous climber. leaves rounded or reniform, 5-nerved, 2 to 3 in. diameter, on slender petioles, 2 to 4 in. long. Panicles proceeding from the old branches or sometimes axillary, several inches, or even a foot long, with numerous small flowers. Petals 3-lobed, the lateral lobes (or auricles) embracing the stamens. Drupes obovate, about an inch long.

In the Happy Valley, Hance, Seemann, Wright. In S. India, in Ceylon, the Peninsula, and Chittagong, and perhaps also in Khasia. 
2. C. ovalifolius, DC. Syst. Veg. i. 426. A climber, usually pubescent, especially the upper branches and inflorescence. Leaves shortly stalked, ovate or oblong, entire or obtusely 3 -lobed, 2 to 3 in. long, glabrous or hairy, especially the under side. Male panicles or racemes axillary and very short, the upper ones forming an elongated leafy terminal panicle. Flowers glabrous. - Nephroica pubinervis, N. ovalifolius, and $N$. cynanchoides, Miers in Kew Journ. Bot. iii. 259.

In ravines of Mount Victoria, Champion, also Wright; appears common in S. China and northwards to Amoy, but not known from elsewhere. It sometimes much resembles the common Indian C. villosus, DC., but is readily distinguished by the glabrous flowers.

\section{PERICAMPYLUS, Miers.}

Flowers of Cocculus, except that the anthers are longer and not 4-lobed, and the styles divided to the base into 2 subulate recurved branches. Fruit less compressed, and the putamen not perforated. Drupes nearly globular.

The genus consists but of a single species.

1. P. incanus, Miers; Hook. and Thoms. Fl. Ind. i. 194. A climber, with the younger branches shortly tomentose, or at length glabrous. Leaves nearly orbicular, sometimes slightly peltate, 2 to 4 in. diameter, glabrous above, usually hoary underneath, on stalks of 1 to 2 in. Flowers very small, in axillary dichotomous cymes, shorter than the leaves. Sepals hairy on the back. Drupes red.

Hongkong, Wright. Common in eastern India, from Sikkim and Chittagong to Java.

\section{STEPHANIA, Lour.}

Male flowers : Sepals 6,8 , or 10, in 2 series. Petals 3,4 , or 5 , shorter than the sepals. Stamens united in a central column, bearing a flat disk with the anthers on the margin. Female flowers : Sepals 3, 4, or 5. Petals as many. Carpel solitary. Drupe flattened, the scar of the style near the base. Putamen horseshoe-shaped. Allbumen thin. Embryo curved, linear, with closed cotyledons. - Leaves mostly peltate. Flowers in axillary umbels.

A small genus, dispersed over tropical and subtropical Africa, Asia, and Australia.

1. S. hernandifolia, Walp.; Hook. and Thoms. Fl. Ind. i. 196. A glabrous or slightly pubescent climber. Leaves broadly ovate, orbicular, or nearly triangular, usually more or less peltate, 3 or $4 \mathrm{in}$. long, on a petiole of 2 or 3 inches. Peduncles axillary, shorter or rather longer than the petioles, becoming an umbel of 5 or 6 rays, each ray terminated by a head, or partial umbel, of 8 to 12 small sessile or shortly pedicellate flowers.

Hongkong, Wright. Common in moist hilly parts of India, extending westward to Abyssinia, eastward over the Archipelago to North Australia, and northward to Nipal, Assam, S. China, Amoy, and the Philippines.

\section{CYCLEA, Arn.}

Male flowers: Sepals 4 to 8 , united into a campanulate or inflated and globose calyx. Petals as many, more or less united. Stamens united in a central column, bearing a flat disk with horizontal anthers, opening transversely. 
Female flowers: Sepals 2, lateral, with a bract below them. Carpel solitary. Stigma divided into 3 to 5 radiating subulate branches. Fruit of Stephania, but less compressed.-Climbers. Leaves mostly peltate. Stamens in axillary panicles.

A small genus confined to southern Asia.

1. C. deltoidea, Miers in Kew Journ. Bot. iii. 258. A glabrous climber, with the peltate broadly ovate or triangular leaves of Stephania hernandifolia, from which it is at once known by the paniculate not umbellate inflorescence. Leaves under $2 \mathrm{in}$. long. Panicles narrow, almost reduced to racemes, and scarcely longer than the leaves. Corolla saucer-shaped, scarcely lobed, half as long as the calyx.

In a ravine of Mount Victoria, Champion; also Wright. Not gathered as yet out of the island.

\section{ORDER VI. BERBERIDEE.}

Sepals 6 or 4 , in two series, or 3 . Petals equal in number to the sepals and opposite them, or double the number, or rarely wanting. Stamens hypogynous, usually definite in number and opposite to the petals. Anthers in the typical genera opening with recurved valves, in others with longitudinal slits. Carpels solitary or 3 , rarely more, free, with several ovules. Styles usually very short or reduced to a sessile stigma. Ripe carpels usually pulpy indehiscent berries, or rarely follicular or capsular. Albumen copious. Embryo axile or minute, with the radicle next the hilum.-Shrubs, climbers, or herbs of various habit. Leaves usually compound.

An Order spread over the temperate or mountain regions of the northern hemisphere and along the great chain of American mountains to their southern extremity. The only Hongkong speeies belongs to the somewhat anomalous tribe or suborder Lardizabalea, which has not the characteristic anther-valves of many of the typical genera, and in which there are always 3 carpels.

\section{STAUNTONIA, DC.}

Flowers monœcious. Sepals 6. Petals none. Male fl. : Stamens 6, united at the base. Anthers opening longitudinally, terminating in a point. Female fl. : Sterile stamens 6. Carpels 3. Ovules several, intermixed with hairs, Berries globular.-Woody climbers. Leaves digitate.

A genus only containing one Japanese species besides the Chinese one.

1. S. chinensis, DC. Prod.i. 96. A glabrous woody climber. Leaves very variable in size, usually consisting of about 5 obovate or oval-oblong leaflets, about $2 \mathrm{in}$. long, on petiolules of $\frac{1}{2} \mathrm{in}$., but the lower ones often with 6 or 7 oblong acuminate leaflets, 3 or 4 in. long, or the upper leaves with only 3 leaflets. Peduncles several together at the base of the young shoots, in the axils of the old leaves, slender, 1 to 3 in. long, bearing a short loose raceme of 3 or 4 flowers of a greenish-purple colour, and emitting a nauseous smell. Sepals broadly lanceolate, acuminate, quite small when first open, varying in the specimens from 4 to 9 lines in length, but probably at different stages of growth. 
In ravines, trailing on rocks, Champion, Wilford. Only known from S. China.

Nelumbium speciosum, Willd., belonging to the Order Nymphaacee, is occasionally cultivated, but has not been found wild in the island.

\section{Order VII. PAPAVERACEE.}

Sepals 2, rarely 3 , deciduous. Petals 4, rarely 6, usually folded in the bud. Stamens indefinite, free, hypogynous. Anthers versatile, opening with longitudinal slits. Ovary free, compound, 1-celled, with 2 or more parietal placentæ, sometimes projecting into the cavity so as nearly to divide it into as many cells. Style simple or none. Stigmas as many as placentæ, usually radiating on the top of the ovary or style. Fruit capsular or rarely a berry. Seeds albuminous, with a small embryo next the hilum.

A small Order, spread over the temperate zone of the northern hemisphere, with a very few southern extratropical species, and a few more now diffused as weeds over many tropical countries.

\section{ARGEMONE, Linn.}

Stigmas 4 to 7, nearly sessile on the top of the ovary. Capsule obovate or oblong, opening at the top in short valves between the parietal placentæ. -Leaves usually prickly.

A small American genus.

1. A. Mexicana, Linn.; Hook and Thoms., Fl. Ind. i. 251 ; Bot. Reg. t. 1343. An erect hard glaucous and glabrous annual, 2 or 3 feet high, with spreading branches. Leaves alternate, half-stem-clasping, sinuately pinnatifid, and bordered with prickly teeth, spotted with white along the primary veins. Flowers terminal, yellow, 1 to 3 inches diameter. Capsule about an inch long.

On the seacoast, on roadsides and waste places. An introduced weed, of American origin, but now extremely abundant in India and other tropical countries.

\section{ORder VIIT. CRUCIFERE.}

Sepals 4. Petals 4. Stamens 6 , of which 2 are usually shorter, hypogynous. Ovary 2-celled, with one or more ovules in each cell. Style single, often very short or almost none, with a capitate or 2-lobed stigma. Fruit a siliqua or silicule, that is, a pod divided into 2 cells by a thin partition from which the valves separate at maturity, or in a few genera the pod is 1-celled or indehiscent, or separates transversely into several joints. Seeds without albumen, attached, in each cell, altemately to the right and left edges of the partitions. Embryo much curved, the radicle either accumbent, $i$. e. folded against the edge of the cotyledons, or incumbent, $i$. e. folded over the back of one of them. Herbs or rarely undershrubs. Leaves alternate, without stipules. Flowers in terminal racemes, usually very short and reduced to a corymb whell the flowering commences, but lengthening out as it advances.

A large and widely diffused Order, most abundant however in the temperate regions of the northern hemisphere. 
Pod a linear siliqua.

Pod-valves very convex. Seeds in 2 rows. Flowers yellow . . . 1. Nasturtium.

Pod-valves flat. Seeds in 1 row. Flowers white. . . : . 2. Cardanine.

Pod a triangular or almost obcordate silicule . . . . . . . . 3. Capselin.

Pod indehiscent, nearly cylindrical, contracted between the seeds . . . 4. RaPHaNus.

\section{NASTURTIUM, R. Br.}

Pod linear or oblong and often curved, the valves very convex, with the midrib scarcely visible. Seeds more or less distinctly arranged in 2 rows in each cell, and not winged. Radicle accumbent.-Flowers yellow, or in one species (not in Hongkong) white.

A small genus, but widely spread over the whole area of the Order.

1. N. montanum, Wall. Catal. n. 4778. A low branching glabrous annual. Leaves from ovate to very nearly lanceolate, coarsely toothed or lobed, the lower ones stalked and often lyrate. Flowers very small, of a pale yellow. Fruiting racemes 2 to $4 \mathrm{in}$. long, divaricate, without the bracts of $N$. benghalense. Pod slender, nearly straight, about 8 or 9 lines long.

Hongkong, Hance, Wright. A common E. Indian weed, extending to Java, the Philippines, and northward to Loochoo. It may be a variety of the still more common Indian $N$. indicum, DC., from which it differs chiefly in the much greater length of the pod, and both come very near to some forms of the $N$. palustre, DC., which has a still shorter pod.

\section{CARDAMINE, Linn.}

Pod narrow-linear, the valves flat, without any conspicuous midrib and usually opening with elasticity. Seeds apparently in a single row in each cell, the radicle accumbent.-Flowers white or pink.

A large and natural genus, widely spread over the temperate and colder regions both of the northern and the southern hemispheres.

1. C. hirsuta, Linn.; DC. Prod. i. 152. An annual, of a deep-green colour, often much branched at the base, with ascending or erect stems usually about 6 in. high, with a few scattered hairs which are not however very conspicuous. Leaves pinnate, the segments small, those of the lower leaves ovate or rounded and angularly toothed; the upper ones narrower and more entire. Flowers very small and white. Pods in a rather loose raceme, 6 lines to 1 in. long.

A naturalized weed, Champion and others. Probably of European or North Asiatic origin, but now frequently met with as a weed throughout the temperate regions of the globe.

\section{CAPSELLA, Vent.}

Pod oblong-obovate or triangular, flattened laterally (at right-angles to the narrow partition), the valves boat-shaped, not winged. Seeds several in each cell, the radicle incumbent on the flat cotyledons.

A genus of 2 or 3 European or Asiatic annuals.

1. C. Bursa-pastoris, DC. Prod.i. 177. An annual, with a deep taproot. Radical leaves spread on the ground, pinnatifid, with a larger ovate or triangular terminal lobe, or sometimes entire. Stem from a few inches to above 
a foot high, rather rough and often hairy, with a few oblong or lanceolate, entire or toothed leaves, clasping the stem with projecting auricles. Pods in a long loose raceme, usually triangular, truncate or sometimes notched at the top. Seeds 10 to 12 in each cell.

A naturalized weed, Hance. Probably of European or North Asiatic origin, now common in waste or cultivated places in most temperate regions of the globe, more rare within the tropics.

\section{RAPHANUS, Linn.}

Pod more or less elongated, thick, pointed, indehiscent, more or less contracted between the seeds, without any longitudinal partition when ripe, but containing several seeds separated by a pithy substance filling the pod. Radicle incumbent on the back of the cotyledons, which are folded over it.

A genus of very few, or perhaps a single species, apparently of Mediterranean origin.

1. R. sativus, Linn.; $D C$. Prod. i. 228. A coarse erect annual 2 or 3 feet high, with a thick succulent root. Leaves pinnately divided, the terminal segment large and ovate or oblong, rough with short hairs, the upper leaves often narrow and entire. Flowers white with coloured veins, or lilac. Pod usually 1 to $1 \frac{1}{2}$ in. long, very thick and nearly cylindrical, terminating in a point.

This, the cultivated Radish, becomes half-spontaneous in Hongkong as in other countries - where it is cultivated. It has been usually stated to be a native of China, but upon no reliable authority, and it is not improbable that it may be a race established by long.cultivation, derived from the S. European and Asiatic R. Raphanistrum.

\section{Order IX. CAPPARIDEF.}

Sepals 4. Petals 4, rarely 8 or 0 . Stamens usually indefinite, or, if definite, 6 or more, or seldom tetradynamous. Ovary 1-celled, with 2 or rarely more parietal placentas, each bearing several or many ovules. Style single, often very short or almost none, the stigma generally round. Fruit either a dehiscent pod or an indehiscent berry. Seeds generally reniform, without albumen, the embryo usually coiled.-Herbs, shrubs, or climbers, rarely trees. Stipules usually none, rarely spinescent or small. Flowers usually in terminal racemes, more rarely solitary or axillary. The ovary in several genera, and sometimes the stamens also, are raised on a stalk or elongated receptacle within the flower.

A considerable Order, found chiefly within the tropics, a few species stretching northwards into more temperate regions, especially in America.

Pod opening in valves. Annual, with digitate leaves . . . . . 1. Polanisia.

Berry indehiscent. Shrubs or climbers, with simple leaves. . . . . 2. Capparis.

\section{POLANISIA, Raf.}

Stamens 8 to 32 . Receptacle not elongated. Ovary sessile or nearly so. Pod linear or oblong, opening in 2 valves, parallel to the persistent dissepiment.-Fetid annuals, with glandular or viscid hairs. Leaves digitate.

A small genus, dispersed over the tropical and subtropical regions both of the New and the Old World. 
1. P. vicosa, $D C$. Prod. i. 242. An erect annual, covered with short glandular hairs. Leaflets 3 or 5, obovate-cuneate or oblong, about 1 in. long. Flowers small, yellow. Stamens 8 to 16 . Pod oblong or linear, striate, glandular-hairy, 2 to 3 in. long.

In waste places, Hance, Seemann. A common weed throughout India, extending westward across northern tropical Africa and eastward to Australia, and occurring also, as an introduced weed, in the West Indies.

\section{CAPPARIS, Linn.}

Stamens usually indefinite. Receptacle not elongated below the stamens. Ovary stalked. Placentas 2. Stigma sessile. Fruit fleshy or pulpy, indehiscent.-Shrubs or climbers, rarely trees. Leaves undivided.

A considerable genus, generally spread over nearly the whole area of the family.

Stems trailing, not prickly. Pedicels 1 to 4 , a little above the axils . 1. C. membranacea. Stems shrubby, prickly. Corymbs terminal, paniculate . . . 2. C. pumila.

1. C. membranacea, Gardn. and Champ. in Kew Journ. Bot. i. 241. A glabrous shrub, with trailing branches and no prickles. Leaves oblong or lanceolate and acuminate, 3 to $5 \mathrm{in}$. long, membranous or slightly coriaceous, reticulate. Pedicels 1 -flowered, 1 to 4 together in a vertical row a little above the axils of the leaves and longer than the petioles. Petals about $\mathbf{5}$ lines long. Berries globular.

Victoria Peak and Happy Valley Woods, Champion, Hance, Wright. Not as yet found out of the island.

2. C. pumila, Champ. in Kew Journ. Bot. iii. 260. A shrub with slender branches but not trailing, glabrous or slightly pubescent in the upper part. Stipules of the lower leaves prickly, the upper ones often wanting. Leaves oval or oblong, acuminate, 2 to $2 \frac{1}{2} \mathrm{in}$. long, with a prominent midrib, the lateral veins inconspicuous. Flowers glabrous, in pedunculate corymbs forming a terminal panicle. Pedicels scarcely longer than the calyx. Ovaries glabrous. Berries globular.

Once seen in a ravine in the Black Mountain, Champion. A single bush behind the Buddhist Temple, Wilford. Not known from elsewhere.

\section{Order X. PITTOSPORACEE.}

Sepals 4 or 5 , free or partially combined, imbricate in the bud. Petals as many, hypogynous, imbricate in the bud. Stamens as many, distinct, hypogynous, alternating with the petals. Ovary single, with 2 or more parietal placentas, or divided into as many cells by the meeting of the placentas in the axis. Ovules several to each cell, anatropal. Style simple, with as many stigmas or stigma-lobes as placentas. Fruit a capsule or a berry. Seeds often covered with pulp. Embryo minute, in a fleshy albumen.-Trees and shrubs or climbers. Leaves ąlternate, mostly entire, without stipules.

A small Order, chiefly Australian, with a few tropical or subtropical African and Asiatic species. 


\section{PITTOSPORUM, Linn.}

Sepals 5. Petals 5, their claws erect and sometimes united. Ovary with 2 or rarely 3 or 5 cells or placentas, with 8 or more ovules to each. Stigma scarcely lobed. Capsule opening in thick valves bearing the placentas in their centre. Seeds covered with a resinous viscid pulp.-Trees or shrubs, mostly evergreen.

The most considerable genus of the Order, spreading over the whole extent of its area.

1. P. glabratum, Lindl. in Journ. Hort. Soc. i. 230. A perfectly glabrous shrub. Leaves evergreen, obovate or oblong, mostly acuminate, 2 to $4 \mathrm{in}$. long, the upper ones crowded together so as to appear whorled. Flowers terminal, solitary or clustered in little terminal almost sessile corymbs, much shorter than the leaves. Sepals 1 to $1 \frac{1}{2}$ lines long. Petals 3 lines long, the claws overlapping each other, forming a cylindrical tube, the laminæ spreading. Capsule ovoid-oblong, attaining 1 in. in length.

Common in the island, Champion and others. Extends on the adjacent continent from Khasia to Amoy.

\section{Order XI. BIXACEE⿰.}

Sepals 2 to 6 , usually 4 or 5 , imbricate or rarely almost valvate in the bud. Petals as many or more, or more frequently none. Stamens usually indefinite, hypogynous, rarely equal in number to the petals, and alternate with them. Ovary l-celled, or incompletely divided into several cells by irregular partitions. Placentas 2 to 12 , parietal, with several or many ovules to each. Styles or sessile stigmas as many as placentas, free or combined into a single one. Fruit an indehiscent berry or a pod, opening in as many valves as placentas. Seeds albuminous, with the embryo in the axis.-Trees or shrubs. Leaves undivided, usually toothed. Stipules minute, or none. Flowers axillary or lateral, rarely terminal, often unisexual.

A considerable family, spread over the tropical or subtropical regions of both the New and the Old World.

\section{SCOLOPIA, Schreb.}

(Phoberos, Lour.)

Flowers hermaphrodite. Sepals 4 to 6 , valvate. Petals as many, imbricate. Stamens indefinite, hypogynous. Anthers oblong, with a glabrous or hairy terminal appendage. Ovary 1-celled. Placentas 3 or 4 . Ovules few. Style filiform. Fruit a berry.

A small genus, confined to southern and eastern Asia and the Arehipelago.

1. S. chinensis, Clos in Ann. Sc. Nat. Par. ser. 4, viii. 249. A glabrous tree or shrub, sometimes armed with stout spines (abortive branches), sometimes quite unarmed. Leaves ovate or oblong, very obtuse or obtusely acuminate, entire or with a few minute teeth, $1 \frac{1}{2}$ to 2 in. long. Flowers small, in axillary racemes, shorter than the leaves.-Phoberos chinensis, Lour.; W. and Arn. Prod. i. 30. Phoberos savus, Hance in Walp. Ann. iii. 825.

Very common in the island, as well as on the adjacent Chinese continent, but not known from elsewhere. 


\section{Order XII. VIOLACEAE.}

Sepals 5, imbricate in the bud. Petals 5, hypogynous, alternate with the sepals, contorted in the bud. Stamens 5, hypogynous, altemate with the petals; filaments very short; anthers introrse, connected in a ring round the ovary. Ovary free, 1-celled, with 3 , rarely 4 or 5 , parietal placentas. Style simple. Fruit a capsule, opening in as many valves as placentas, or rarely an in-, dehiscent berry. Seeds inserted along the centre of the valves. Embryo in the axis of a copious albumen, the radicle next the hilum.-Herbs or shrubs. Leaves alternate or rarely opposite, with stipules. Flowers hermaphrodite, very irregular or nearly regular.

- The Order is generally distributed over the globe, the shrubby genera mostly confined to the tropies, the herbaceous ones more abundant in temperate regions.

\section{VIOLA, Linn.}

Sepals nearly equal, produced at the base below their insertion. Petals unequal, the upper one largest, and produced into a spur or pouch at the base. Fruit a capsule.-Herbs. Stipules persistent. Peduncles axillary, 1-or rarely 2-flowered.

A large genus, widely spread over the temperate regions of the northern hemisphere, more rare within the tropies with a few more southern species.

Stock emitting stolones. Stipules free .. . . . . . . . . 1. V. diffusa.

No stolones. Stipules adnate to the petiole.

Leaves ovate or lanceolate. Stigma dilated . . . . . . . 2. V. Patrinii.

Leaves cordate. Stigma slightly dilated . . . . . . . . 3. V. confusa.

1. V. diffusa, Ging. in DC. Prod.i. 298. A pubescent or hairy perennial. Stock tufted, emitting stolones or runners, but not lengthening into a distinct stem. Leaves radical, ovate or oval-oblong, crenate, about 1 in. long, the petiole flattened, usually longer. Stipules free, linear-lanceolate, toothed. Flowers light-coloured, without scent. Sepals lanceolate. Stigma club-shaped, almost capitate. $-V$. tenuis, Benth. in Lond. Journ. Bot. i. 482, and in Kew Journ. Bot. iii. 260.

Common on the summits of the hills, Champion and others. Extends to Sikkim and Khasia in N.E. India. In this and in the two following species, as in our European Violets, the showy petaliferous flowers appear to be usually sterile althongh hermaphrodite, the capsules proceeding mostly from minute apetalous flowers produced later in the season.

2. V. Patrinii, DC. Prod. i. 293. A glabrous or slightly pubescent perennial, with a tufted stock, as in the last species, but without stolones. Leaves ovate or lanceolate, $1 \frac{1}{2}$ to $2 \frac{1}{2} \mathrm{in}$. long, truncate or very slightly cordate at the base. Stipules linear, adnate to the petiole. Flowers light-blue? Sepals lanceolate. Stigma bordered on each side with a flat margin.

Common with the last on the summits of the hills, Champion and others. Widely spread over Northern India and Southern Siberia.

3. V. confusa, Champ. in Kew Journ. Bot. iii. 260. A slightly pubescent tufted perennial like the last, but much smaller, and resembling some small specimens of the European $V$. hirta; lowest leaves nearly orbicular, the others ovate and all deeply cordate, obtuse and crenate. Stipules small, adnate to the petioles. Flowers like those of $V$. hirta ; but smaller. Sepals lanceolate, 2 lines long. Petals 5 lines long. Stigma slightly dilated. 
On Mount Parker, Champion. Not seen in any other collection. It has much the appearance of the $V$. serpens, Wall., from Northern India, except that it has no stolones. When better known, however, it may prove to be a variety of that species.

\section{Order XIII. CARYOPHYLLEAE.}

Sepals 4 or 5 , free in the Hongkong genera, united in some others. Petals as many, contorted in the bud, sometimes minute or wanting. Stamens free, twice as many as the petals or fewer, hypogynous or very slightly perigynous. Ovary 1-celled, with a free central placenta and several ovules, or very rarely divided into cells. Styles or style-branches 2 to 5, stigmatic along their whole length. Capsule 1-celled, opening at the top into as many or twice as many teeth or valves as there are styles. Seeds with a slender embryo curved or coiled round a mealy albumen.-Herbs, with opposite entire leaves. Stipules none, or small and scarious. Flowers usually small, in dichotomous panicles or leafy cymes.

A considerable Order, widely spread over the globe, most numerous in temperate regions, especially in the northern hemisphere; rare within the tropics, except as weeds of cultivation.

Capsule ]-celled. Petals 5.

Styles 3 or rarely 5. Petals bifid . . . . . . . . . 1. Stellaria.

Style 3-lobed or almost entire. Petals - minute.

Sepals herbaceous. Stipules minute. Leaves broad . . . 2. Drymarta.

Sepals and stipules white and searious. Leaves linear or subulate. 3. PolyCarpea. Capsule 3-celled, no petals, sepals often white at the edge . . . . . 4. Moldugo.

\section{STELLARIA, Linn.}

Sepals 5, free. Petals 5, bifid. Styles 3 or rarely 5, free from the base. Capsule opening to the middle or lower down in as many or twice as many valves.

A considerable genus, having nearly the geographical range of the Order.

Lower leaves ovate-cordate, on long stalks.

Perennial. Petals longer than the calyx. Styles usually 5 . . . 1. S. aquatica.

Annual. Petals shorter than the calyx. Styles 3 . . . . 2. S. media.

All the leaves narrowed at the base, sessile or shortly stalked : . . . 3. S. uliginosa.

1. S. aquatica, Scop. A glabrous perennial, with weak stems a foot or more in length. Leaves ovate-cordate; the lower ones small, on long stalks; the upper ones more. sessile or stem-clasping, often 1 to $2 \mathrm{in}$. long, and very pointed. Flowers in the forks of leafy cymes, the pedicels turned down after flowering. Sepals about 2 lines long when in flower, often enlarged afterwards. Petals narrow, deeply cleft, about one-half longer than the calyx. Styles usually 5, but sometimes 3 only, as in the rest of the genus.-Malachium aquaticum, Fries; Fenzl in Ledeb. Fl. Ross. i. 416. Cerastium petiolare, Hance in Kew Journ. Bot. i. 143. Stellaria fecunda, Hance in Walp. Ann. ii. 95 .

In fields, Wright, Hance. Widely diffused over Europe and central and temperate northern Asia, and accompanying cultivation in other parts of the world.

2. S. media, Vill.; DC. Prod. i. 396. A weak much-branched annual, glabrous with the exception of a line of hairs down one side of the stem, and 
a few long ones on the petioles. Leaves small, ovate and pointed, the lower ones stalked and usually cordate. Flowers small, on rather long slender pedicels, in irregularly forked leafy cymes. Petals shorter than the calyx, with narrow somewhat diverging lobes.

In waste places. An introduced European weed, known in Britain as the common Chickweed.

3. S. uliginosa, Murr.; Fenzl in Ledeb. Fl. Ross. i. 393. A weak slender glabrous annual, usually about 6 in. long. Leaves sessile, oblong or lanceolate. Flowers small, in loose forked panicles, which soon become lateral. Petals shorter than the calyx, with very narrow diverging lobes.S. leptophylla, Hance, in Walp. Ann. ii. 96.

In rice-fields, Champion and others. An introduced European weed.

\section{DRYMARIA, Willd.}

Sepals 5. Petals 5, bifid or 4-lobed. Style single, 3-lobed. Capsule 3valved.-Stipules minute, subulate.

A genus of a few American species, one of which extends over most of the warmer regions of the globe.

1. D. cordata, Willd.; DC. Prod. i. 395. A weak, spreading, glabrous annual, often extending to 2 feet or more. Leaves shortly stalked, ovate-cordate or orbicular, about 4 to 6 lines long and broad. Peduncles slender, dichotomous, axillary or terminal.-Flowers small, green. Petals shorter than the calyx. Ovules from 2 or 3 to about 10 in the ovary.

On roadsides, Little Hongkong, Wilford, also Hance. A common tropical weed, both in the New and the Old World.

\section{POLYCARP开A, Lam.}

Sepals 5, usually scarious. Petals 5, small, usually entire. Stamens 5. Style single, 3-cleft or nearly entire. Capsule 3-valved.-Stipules scarious, white.

A small tropical or subtropical genus, chiefly Asiatic or African, one species extending into tropical America.

1. P. corymbosa, Lam.; Avn. in Tayl. Ann. Nat. Hist. iii. 90 ; Wight, Ic. t. 712. A perennial, but often flowering the first year so as to appear annual. Stems erect, from a few inches to near a foot high, more or less hoary with loose cottony hairs. Leaves linear or subulate, often clustered in the axils, 4 to 8 lines long. Flowers numerous, in dense cymes forming broad terminal dichotomous corymbs. Sepals shining, scarious, white or reddish-brown, lanceolate and pointed, about 2 lines long. Petals not half so long, ovate, obtuse. $-P$. corymbosa and $P$. spadicea, Lam., and P. stellata, DC. Prod. iii. 374. P. brasiliensis, Camb. in St. Hil. Fl. Bras. Mér. ii. 183. P. atherophora, Steud. Flora, 1843, 763.

Hongkong, Wright, Hance. In cultivated and waste places, throughout India and the Archipelago and northward to S. China ; also in tropical Africa and America. 


\section{MOLLUGO, Linn.}

Sepals 5, white on the edges. Petals none. Stamens 5, alternating with the sepals, or fewer. Styles (or stigmas) 3, distinct but short. Capsule 3celled, opening loculicidally in 3 valves.-Stipules minute, subulate.

A small tropical or subtropical genus, dispersed over both the New and the Old World.

1. M. stricta, Linn.; Fenzl in Walp. Rep. ii. 241. A diffuse muchbranched glabrous annual, a few inches or seldom near a foot high. Radical leaves obovate or oblong, stem-leaves in false whorls of 4 or 6 , all or the upper ones much narrower and acute at both ends. Flowers very small, in slender bifid racemes or dichotomous cymes, on slender perluncles. Pedicels short and filiform. Sepals greenish, with white edges, about $\frac{3}{4}$ line long.

Hongkong, Wright. A common weed of cultivation throughout India and the Archipelago, and northward to S. China. The Hongkong specimens are narrow-leaved. When nearly all the leaves are broad and obtuse, it becomes the $\boldsymbol{M}$. triphylla, Linn., or $\boldsymbol{M}$. pentaphylla, Linn., neither of which are specifically distinct.

\section{ORDER XIV. HYPERICINEAE.}

Sepals 5, rarely 4 , free, imbricate in the bud. Petals as many, contorted in the bud. Stamens indefinite, hypogynous, usually united at the base or collected together into 3 or 5 bundles. Ovary single, of 2 to 5 united carpels, either divided into as many cells or with as many projecting parietal placentas, each with several ovules. Styles as many as carpels, free or united at the base. Stigmas terminal. Fruit a capsule, berry, or drupe. Seeds without albumen, the embryo straight or curved.-Herbs, shrubs, or rarely trees. Leaves opposite, entire or with glandular teeth. Stipules none. Leafy parts often glandular-dotted and sometimes the flowers also.

A widely-diffused though not very large family, the shrubby and arboreous species most abundant in the tropics, the herbaceous ones chiefly in the temperate regions of the northern hemisphere.

Capsule opening at the placentas. Seeds not winged. Herbaceous . . 1. Hypericum. Capsule opening between the placentas. Seeds winged. Shrubby . 2. Cratoxylon.

\section{HYPERICUM, Linn.}

Fruit a capsule, opening in 3 to 5 valves at the placentas or dissepiments. Seeds not winged.-Herbs or, in some extra-colonial species, shrubs. Leaves very rarely serrate, and most frequently dotted, either with black or transparent dots. Flowers usually yellow.

The largest genus of the Order, and ranging over the whole of its area, but most numerous without the tropics.

1. F. japonicum, Thunb.; DC. Prod. i. 548; Royle, Illustr. t. 24, $f$. 2. A small glabrous annual or perennial of short duration, diffusely branched or ascending, from a few inches to near a foot high. Leaves small, ovate, stem-clasping, with numerous transparent dots. Flowers small, yellow, in terminal dichotomous cymes. Sepals oblong, entire or with a few glandular teeth. Capsule 3-valved.-H. nervatum, Hance in Walp. Ann. ii. 188.

Common in marshes and fields, Champion and others. Frequent in India and the Archipelago, extending northward to Japan and southward to Australia and New Zealand. 


\section{CRATOXYLON, Blume.}

(Ancistrolobus, Spach.)

Fruit a capsule, opening in 3 valves between the partitions, which remain attached to the centre of the valves. Seeds terminated by a wing.-Shrubs or trees. Leaves entire.

A small genus, confined to Eastern Asia and the Archipelago.

1. C. polyanthum, Korth. Verhand. Nat. Gesch. Bot. 175, t. 36. A glabrous shrub. Leaves from oval-elliptical to oblong-lanceolate, entire, narrowed at both ends or rounded at the base, 2 to $3 \mathrm{in}$. long, on very short petioles. Flowers 1 to 3 together on very short axillary peduncles. Sepals broad, almost orbicular, 2 to $2 \frac{1}{2}$ lines in the flower, lengthening afterwards to 3 or 4 lines. Petals pink, not twice as long. Hypogynous seales small, acute. Capsule oblong, 5 or 6 lines long.-Hypericum carneum, Wall. Catal. n. 4820. Ancistrolobus ligustrinus, Spach in Ann. Sc. Nat. Par. ser. 2, v. 352. Ancistrolobus brevipes, Turczan. Bull. Mosq. 1858, 383. Elodea chinensis, Hance in Lond. Journ. Bot. vii. 472.

Very abundant in the low grounds, Champion and others. Common in S. China and extends to the Philippines, Borneo, Tavoy, and Sumatra. I have not seen Korthals's specimens, but his figure and description agree perfectly with the Chinese plant.

\section{Order XV. GUTTIFER IE.}

Sepals 2, 4, or 6, rarely more, imbricate in pairs. Petals 4 or more, contorted in the bud. Stamens indefinite, hypogynous, free or variously united. Ovary sessile, usually several-celled, with 1 or more ovules in each cell, rarely reduced to a single cell and ovule. Style simple or none. Stigma broad, usually with as many lobes as cells to the ovary. Fruit either a capsule opening in as many valves as cells, or a berry or drupe. Seeds often arillate, without albumen. Embryo thick, with minute cotyledons.-Trees or shrubs. Leaves in the normal genera opposite, entire, coriaceous or thick, without stipules.

A large Order, almost entirely tropical, but common to both the New and the Old World.

Ovary several-celled .............. . . . . Garcinia.

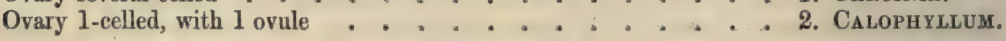

1. GARCINIA, Lam.

Flowers unisexual or rarely hermaphrodite. Sepals 4. Petals 4. Males : Stamens numerous. Ovary rudimentary. Females: Barren stamens 8 or more. Ovary 4- to 10-celled. Ovules solitary in each cell, erect. Style short. Stigma peltate. Fruit a drupe.--Trees or shrubs. Leaves with oblique veins. Flowers usually terminal, solitary or few together, on short, usually simple peduncles, or rarely in a terminal corymb.

A genus limited to the tropical regions of the Old World, since the American species have been referred to Rheedia.

Flowers corymbose. Stamens united into 4 bundles . . . . . 1. G. multiflora.

Flowers solitary or few together. Stamens monadelphous . . 2. G. oblongifolia. 
1. G. multiflora, Champ. in Kew Journ. Bot. iii. 310 ; Seem. Bot. Her. $t$. 79. A shrub. Leaves shortly stalked, ovate or obovate, 3 to $3 \frac{1}{2}$ in. long. Flowers mostly (or all ?) hermaphrodite, in a short terminal trichotomous corymb, each one shortly pedicellate in the axil of a small bract. Sepals orbicular, 3 lines broad. Petals obovate, twice as long. Stamens forming 4 short thick fleshy masses, terminated by very numerous anthers. Ovary square, with a large peltate sessile stigma.

Common towards the Black Mountain, flowering in the heat of summer, Champion, also Wright. Not received from elsewhere.

2. G. oblongifolia, Champ. in Kew Journ. Bot. iii. 311; Seem. Bot. Her. $t$. 93. A tree. Leaves shortly stalked, oblong, narrowed at the base, $2 \frac{1}{2}$ to $3 \mathrm{in}$. long, the upper ones almost sessile. Flowers terminal, unisexual, the males 3 to 7 together, shortly pedunculate. Sepals 2 lines, petals near 5 lines long. Stamens consolidated into a fleshy mass, occupying the centre of the flower. Females solitary, sessile, and rather smaller.

Corminon in the Happy Valley woods, Champion, also Wright. Not known from elsewhere. The foliage is uearly that of the G. Cambogia, from Ceylou, but the male pedicels are much shorter, the anthers more numerous, ete.

\section{CALOPHYLLUM, Linn.}

Flowers hermaphrodite or polygamous. Sepals 2 or 4. Petals 4, rarely 2, or 6 to 8 . Stamens numerous, free or united into several bundles at the base. Ovary 1-celled, with a single erect ovule. Style filiform. Stigma peltate. Fruit a drupe.-Trees. Leaves elegantly striate, with numerous parallel transverse veins. Flowers in terminal or axillary short racemes, sometimes branching into panicles.

A tropical genus common to the New and the Old World.

1. C. membranaceum, Gardn. and Champ. in Kew Journ. Bot. i. 309. A tree, with acutely 4-angled branches. Leaves narrow, oblong or lanceolate, often 3 or 4 in. long, and seldom an inch wide. Flowers very few, in short axillary racemes, scarcely exceeding the petioles, and sometimes solitary. Sepals 4. Petals larger and much more oblique, apparently varying in number from 4 to 3 . Fruit small, ovoid-oblong.-Calophyllum spectabile, Hook. and Arn. Bot. Beech. 174; not of Willd.

In a ravine of Mount Victoria, and in the Happy Valley woods, Champion, also Wright. South China, Beechey, but not known from elsewhere.

\section{ORDER XVI. TERNSTRCEMIACEAE.}

Sepals 5 (rarely 6 or 7 ), imbricate in the bud. Petals 5 (rarely 6 to 9 ), hypogynous, often united in a ring or short tube at the base, contorted or otherwise imbricate in the bud. Stamens indefinite (rarely equal in number to the petals and alternate with them), hypogynous, often shortly united at the base with each other, or with the base of the petals. Ovary superior, completely. or almost completely divided into 3 or more cells, with 2 or more ovules in each. Styles either as many, and free from the base, or more or less united into a single style, sometimes very short, with as many stigmatic lobes as 
ovary-cells. Seeds either without albumen, or with a fleshy or granular albumen, usually not abundant. Embryo straight or folded lengthwise, the radicle next the hilum.- Trees or shrubs. Leaves alternate, or very rarely opposite, undivided, entire, serrate or crenate, without stipules.

A considerable Order, chiefly tropical, ranging over both the New and the Old World, with a very few species extending northward of the tropies in Asia or in America.

Tribe 1. Sauraujeæ. Anthers versatile. Fruit succulent, seldom dehiscent. Seeds albuminous. Embryo straight. Flowers in axillary panicles, or on several-flowered peduncles.

Sepals slightly imbricate. Carpels free at the top, ending in distinct styles 1. Actinidia. Sepals much imbricate. Styles united or close together at the base . 2. Saurauja.

Tribe 2. Ternstromier. Anthers adnate or innate. Fruit succulent or hard and indehiscent or seldom dehiscent. Seeds albuminous. Einbryo folded or much curved. Flowers on short, simple, usually recurved, axillary or lateral pedicels.

Stamens indefinite (more than 10). Fruit indehiscent.

Flowers hermaphrodite, rather large. Ovules 2 to 4 in each cell . 3. Ternstromia.

Flowers diocious, very small. Ovules 8 or more in each cell . . . 4. Eurya.

Stamens 5. Capsule 5-valved ............ 5. Pentaphylax.

Tribe 3. Gordonieß. Anthers versatile. Fruit dehiscent, the valves loculicidal. Albumen little or none. Embryo curved or straight, the cotyledons large. Flowers on short, simple, erect or recurved, axillary or terminal pedicels.

Capsule globular. Seeds flat, reniform . . . . . . . . 6. Schima.

Capsule oblong. Seeds winged at the top . . . . . . 7. Gordonta.

Capsule ovoid or nearly globular. Seeds very thick, without wings . 8. CAMELLIA.

\section{ACTINIDIA, Lindl.}

Flowers diœcious or polygamous. Scpals very slightly imbricated. Petals 5. Stamens very numerous. Anthers versatile, short, opening in longitudinal slits. Ovary of 5 or usually more cells; the carpels scarcely meeting in the centre, diverging at the summit, and tapering into as many distinct diverging styles. Ovules several in each cell. Fruit succulent, indehiscent. Seeds small, with a rather copious albumen. Embryo straight, rather small.-Climbing or trailing shrubs. Flowers in axillary pedunculate cymes.

A genus of several species, natives of India, China, and Japan.

1. A. Championi, Benth. A shrubby climber, the young branches tomentose, at length glabrous. Leaves alternate, on rather long stalks, broadly ovate or almost, cordate, shortly acuminate, 2 to $3 \mathrm{in}$. long, entire or with minute callous teeth, glabrous above, white and tomentose underneath. Peduncles axillary, bearing a dense cyme of white flowers, each about $\frac{1}{2}$ in. diameter. Sepals very tomentose, only slightly overlapping on the edges.-Heptaca? latifolia, Gardn. and Champ. in Kew Journ. Bot. i. 243.

Common in the island, Champion and others. Not received from elsewhere. It is very near the $A$.chinensis, Planch., from the adjoining continent, but differs in the acuminate and more entire leaves, and in the smaller and much more numerous flowers in dense pedunculate cymes. In both species the sepals are united at the base, very obtuse, and but very slightly imbricate in the bud, appearing valvate as the flower opens, but really overlapping each other at an earlier stage.

\section{SAURAUJA, Willd.}

Flowers mostly hermaphrodite. Sepals much imbricated. Petals 5, usually 
united at the base. Stamens very numerous. Anthers versatile, opening by pores or short slits at the extremity. Ovary 3- to 5-celled, with numerous orules in each cell. Styles 3 to 5, free, or more or less united. Fruit succulent, seldom dehiscent. Seeds small, with copious albumen, and a rather small straight embryo.- Shrubs or trees, with more or less of stiff appressed hairs. Leaves usually serrate, with prominent parallel veins diverging from the midrib. Peduncles axillary or lateral, bearing several flowers.

A considerable tropical genus, both in the New and the Old World.

1. S. tristyla, DC. Prod. i. 526, and Mem. Ternstr. t. 7. A tree or shrub, the young branches rather thick. Leaves shortly stalked, obovate or broadly oblong, shortly acuminate, 8 to $10 \mathrm{in}$. long, glabrous, except a few of the stiff scale-like hairs so seldom wanting in the genus. Peduncles short, arising from the axils of the fallen leaves on the last year's wood, bearing usually 3 to 6 flowers, on pedicels 2 or 3 lines long. Sepals about 2 lines long and broad. Petals rather longer. Styles and cells of the ovary 3 only.

Hongkong, Hance, Wright. Ranges over eastern India from the Malayan Peninsula and Chittagong to Khasia and Assam:

\section{TERNSTRGMIA, Linn.}

Flowers usually hermaphrodite. Sepals much imbricate. Petals united in a 5-lobed corolla. Stamens numerous; anthers adnate, glabrous. Ovary 2or 3-celled, with 2 to 4 ovules suspended from near the apex of each cell. Style simple, with a broadly 2- or 3-lobed stigma. Fruit thick and indehiscent, but rather dry. Seeds few, large, horseshoe-shaped inside. Albumen fleshy, often thin or scarcely any. Embryo much curved or folded longitudinally. Trees or shrubs. Leaves coriaceous. Peduncles l-flowered, axillary or lateral, curved downwards, with 2 bracteoles close to the calyx.

A considerable tropical genus both in the New and the Old World.

1. T. japonica, Thunb.; Sieb. and Zucc. Fl. Jap. i. 148, t. 80. A tree, perfectly glabrous in all its parts. Scales of the young leaf-buds ovate. Leaves rather crowded at the ends of the branches, stalked, oblong, more or less narrowed at both ends, 2 to $3 \mathrm{in}$. long, thick and leathery, often whitish or rusty undemeath. Peduncles 6 to 9 lines long. Flowers pale yellow, the corolla spreading, about 8 lines diameter. Fruit globular, $\frac{1}{2}$ to 1 in. diameter.Cleyera fragrans and C. dubia, Champ. in Linn. Trans. xxi. 115.-Ternstroemia japonica, T. Lushia, T. Wightii, T. fragrans, and T. dubia, Chois. Mem. Ternstr. et Camell. pp. 18, 19.

Common in Hongkong, constituting a great part of the woods, Champion and others. Widely spread over India, from Ceylon and the Peninsula to the Archipelago, and northward to China and Japan.

\section{EURYA, Thunb.}

Flowers mostly unisexual. Sepals much imbricate. Petals united at the base. Stamens usually indefinite, but seldom above 15. Anthers adnate. Ovary 3-, rarely 2-, 4-, or 5-celled, with several ovules in each. Styles as many, either almost free, or united to near the top. Fruit a berry. Embryo much curved in a somewhat granular albumen.-Trees or shrubs. Flowers 
axillary, usually fascicled on short pedicels or sessile, and much smaller than in any Ternstrouniaceous genus, except Pentaphylax.

A small genus, restricted to southern and eastern Asia and the Archipelago.

Style entire to near the top. Flowers about 2 lines diameter . . . 1. E. japonica.

Styles cleft to near the base. Flowers about 4 lines diameter . . . 2. E. Macartneyi.

1. E. japonica, Thunb. Fl. Jap. 191, t. 25 ; Thw. Enum. Pl. Ceyl. 41. A shrub, glabrous in all its parts in the Hongkong specimens, but hairy on the young branches in a variety found on the adjacent continent. Leaves obovate or oblong, $1 \frac{1}{2}$ to $2 \mathrm{in}$. long, slightly crenulate, narrowed at the base. Pedicels axillary, usually 2 or 3 together, 1 to $1 \frac{1}{2}$ line long. Flowers about 2 lines diameter, white. Style subulate, very shortly lobed at the top. $-E$. chinensis, Champ. in Linn. Trans. xxi. 113.

In various parts of the island, Champion and others. The species is widely distributed over India, from Ceylon and the Peninsula to the Archipelago, and northward to China and Japan. The variety originally described by Brown under the name of E. chinensis is the one with hairy branches, which has not yet been met with in Hongkong.

2. E. Macartneyi, Champ. in Linn. Trans. xxi. 113 ; Seem. Bot. Her. t. 74. A glabrous shrub, coarser and stouter than the last. Leaves ovalelliptical, 2 to 3 in. long, scarcely toothed, rounded at the base, thicker than in $\boldsymbol{E}$. japonica, with the veins less prominent and less oblique. Flowers almost sessile, about 4 lines diameter. Styles 3 or 4 , free from the base. Anthers scarcely apiculate.

In woods and on rocks, Champion, Wright, and others. Said to be rather more common in the island than the $E$. japonica, but I cannot identify it with any continental specimens.

\section{PENTAPHYLAX, Champ.}

Flowers hermaphrodite. Sepals nearly equal. Petals slightly united at the base. Stamens 5, slightly cohering to the base of the petals and alternate with them. Anthers short, innate, introrse; the cells distinct, nearly globular, opening by terminal pores. Ovary 5-celled, with 2 collateral pendulous ovules in each. Style filiform, mostly 5-cleft at the top. Capsule angular, opening loculicidally; the valves bearing the dissepiments without leaving a central axis. Seeds winged at the top. Albumen thin. Embryo folded longitudinally or horseshoe-shaped.-Habit and small flowers of Eurya.

The genus is hitherto restricted to a single species.

1. P. euryoides, Gardn. and Champ. in Linn. Trans. xxi. 114, t.12. A small tree, of great beauty when in flower, perfectly glabrous in all its parts. Leaves shortly stalked, ovate or oval-oblong, 1 to 2 or rarely $2 \frac{1}{2}$ in. long; quite entire, evergreen, smooth and shining. Peduncles l-flowered, scarcely above a line long, crowded along the short lateral shoots or amongst the leaves. Flowers white, the size of those of Eurya japonica. Capsule almost woody, about 3 lines long.

Common in the woods of Hongkong, Champion, also Wright, but not as yet received from elsewhere.

\section{SCHIMA, Korth.}

Sepals 5, nearly equal. Petals 5, much longer, the outer one enveloping the others, all slightly cohering at the base. Stamens numerous. Anthers 
short, versatile. Ovary usually. 5-celled, with several (2 to 6) pendulous ovules in each. Style simple, with very short stigmatic lobes at the top. Capsule woody, depressed-globular, opening loculicidally; the valves bearing the dissepiment, but leaving a free central axis. Seeds flat, vertical, reniform, expanded round the outer edge into a narrow wing. Albumen thin. Embryo much curved, with broad flat cotyledons and a slender radicle.-Trees. Leaves coriaceous. Peduncles 1-flowered, usually erect. Flowers showy.

A small genus, limited to eastern India and the Archipelago.

1. S. Noronhæ, Reinw.; Miq. Fl. Ned. Ind. i. 492. A tree or shrub of great beauty, glabrous or slightly hairy on the young shoots and amongst the flowers. Leaves stalked, from ovate-elliptical.to oblong, 2 to $4 \mathrm{in}$. long, mostly acuminate, entire or marked with a few obtuse serratures; the veins scarcely conspicuous; flowers white, nearly 2 in. diameter when expanded, on pedicels $\frac{1}{2}$ to $1 \mathrm{in}$. long, in the axils of the upper leaves or forming sometimes a very short terminal raceme.-S. superba, Gardn. and Champ. in Kew Journ. Bot. i. 246 ; Seem. Bot. Her. t. 75 . Gordonia javanica, Hook. Bot. Mag. t. 4539.

Wong-ny-chong Valley, and abundant near the top of the slopes of Little Hongkong, Champion. Common in the Malayan Peninsula, and in Java, extending northward to S. China and Bonin.

\section{GORDONIA, Linn.}

Sepals about 5, much imbricated, very unequal, passing from the bracts to the petals. Petals about as many, the innermost the largest, all usually cohering at the base. Stamens numerous. Anthers short, versatile. Ovary 3to 5-celled (rarely 6-celled), with several (4 to 8) pendulous ovules in each. Capsule woody, oblong, opening loculicidally; the valves bearing the dissepiments, but usually leaving a free central axis. Seeds flattish, oblique, expanded at the top into an oblong wing. Albumen 0. Embryo nearly straight, with flat cotyledons.-Trees. Leaves coriaceous. Peduncles 1-flowered, erect or recurved. Flowers showy.

The genus comprises several tropical or subtropical American as well as Asiatic species.

1. G. anomala, Spreng. Syst. iii. 126. A tree, glabrous in every part except sometimes the very young shoots and the flowers. Leaves thick and evergreen, oblong, obtuse, 3 to $5 \mathrm{in}$. long, quite entire, narrowed into a very short petiole. Flowers almost sessile in the upper axils, or 2 or 3 together at the summits of the branches, white and showy, near 3 in. diameter. Ovary usually 3-celled, but sometimes 4-celled. Capsule about 1 in. long. Seeds with a wing twice as long as themselves. Cotyledons oblong, with a short oblique radicle.-Polyspora axillaris, Don in Hook. Bot. Mag. t. 4019. Camellia axillaris, Bot. Mag. t. 2047.

Common all over the island, Champion and others. Only known from South China.

\section{CAMELLIA, Linn.}

Sepals about 5, very unequal, passing more or less gradually from the bracts to the petals. Petals about as many, the innermost the largest, all usually cohering at the base. Stamens numerous, monadelphous, except the innermost, which are nearly or quite free. Anthers short, versatile. Ovary 3-to 5-celled, 
with several ( 4 or 5) pendulous ovules in each. Capsule hard, usually short, opening loculicidally. Seeds usually solitary in each cell, ovoid, not winged, without albumen. Embryo straight, with thick cotyledons and a short radicle. - Trees. Leaves coriaceous. Flower's almost sessile, solitary, erect or recurved.

A genus limited to southern and eastern Asia.

Flowers 2 to 3 in. diameter. Stamens glabrous. Styles usually $\mathbf{5}$.

Ieaf-veins scarcely prominent. Bracts, sepals, aud petals scarcely pubescent : * : * * * * * * *

Leaf-veins reticulate, prominent. Bracts, sepals, and petals softly

$\begin{aligned} & \text { silky-hairy outside } \therefore \\ & \text { Flowers } 1 \text { to } 1_{2}^{\frac{1}{2}} \text { in. diameter. Stamens hairy. Styles usually } 3 .\end{aligned}$

Bracts and sepals very obtuse .... . . . . . .

Bracts and sepals acute or acuminate . . . . . . 4. C. salicifolia.

1. C. hongkongensis, Seem. in Linn. Trans. xxii. 342, t. 60. A tree of moderate size, glabrous in all its parts. Leaves shortly stalked, evergreen, oblong or lanceolate, acuminate, entire or slightly serrate, 3 to 5 in. long, coriaceous and shining, the veins scarcely conspicuous. Flowers erect or slightly drooping, full $2 \frac{1}{2}$ in. diameter, pink and inodorous; the sepals and petals broadly orbicular, and very slightly silky-pubescent outside. Stamens glabrous. Styles free, hairy, as well as the ovary. Capsule glabrous.

Only 3 trees known in Hongkong, where it was first discovered by Col. Eyre in 1849, and afterwards gathered by Champion and others. Also in Cochin China, Gaudichaud, according to Seemann. This was considered by Col. Champion to be the wild C. japonica, but Seemann has pointed out that besides some slight differences in the shape of the leaves, it has free styles and a hairy ovary, whilst in the Japanese plant the ovary is glabrous, with connate styles.

2. C. reticulata, Lindl.; Seem. in Linn. Trans. xxii. 343. A small tree, the young shoots slightly pubescent. Leaves oblong or lanceolate, acuminate, entire or serrate, 3 to 5 in. long, shining above, but the veins much more prominent than in the last, especially on the under side, and turning yellowish in drying. Flowers near 3 in. diameter. Bracts, sepals, and petals broadly rounded as in the last, but softly silky-hairy outside. Stamens glabrous. Styles free in the upper part, silky as well as the ovary. Capsule softly pubescent. -C. spectabilis, Champ. in Linn. Trans. xxi. 111; Seem. Bot. Her. t. 78.

Hongkong, Champion, Eyre. Not received wild from elsewhere, but the double variety has long been introduced into our gardens from China.

3. C. assimilis, Champ. in Linn. Trans. xxi. 112 ; Seem. Bot. Her. t. 77. A shrub or small tree, the young branches covered with closely appressed hairs. Leaves ovate-lanceolate, or oblong, obtusely acuminate, about 2 in. long, slightly crenate, glabrous. Flowers white, about $1 \frac{1}{2}$ in. diameter and drooping, as in the following species, but with the broadly rounded bracts, sepals, and petals passing into each other of the two last. Stamens hairy, the outer ones connected high up, the 5 innermost free. Styles and ovary hairy. Capsule acute, glabrous. - Thea assimilis, Seem. in Linn. Trans. xxii. 349 .

Hongkong, Champion and others. Not as yet found out of the island, although it is nearly allied to the Khasian $C$. caudata.

4. C. salicifolia, Champ. in Linn. Trans. xxi. 112; Seem. Bot. Her. t. 76. A shrub or small tree, the young branches and under side of the leaves loosely covered with soft sprearling hairs. Leaves lanceolate or oblong, acu- 
minate, about $3 \mathrm{in.}$ long, glabrous above, of a thinner consistence than in the other species. Flowers white, very shortly pedunculate or nearly sessile, drooping. Sepals ovate-lanceolate, long-pointed. Petals, especially the inner ones, broader, larger, with shorter points, all slightly silky-hairy or pubescent outside. Stamens and styles as in the last. Capsule glabrous, beaked.Thea salicifolia, Seem. in Linn. Trans. xxii. 349.

In woods, Champion and others. Not as yet found out of the island.

A single specimen in Wright's collection, with the foliage of $C$. salicifolia, but without flowers, has a single glabrous capsule, obtuse, not rostrate as in that species, and the persistent sepals are much broader and less pointed. The materials are insufficient to determine whether it be a distinct species, or a mere variety of $C$. salicifolia.

\section{Order XVII. MALVACE互.}

Sepals united in a 5-lobed (rarely 4- or 3-lobed) calyx, the lobes valvate in the bud. Petals as many, hypogynous, convolute in the bud, usually adhering at their base to the staminal tube. Stamens indefinite, hypogynous, united in a tube or column round the ovary, free at the top. Anthers 1-celled. Ovary of several carpels variously arranged round the central axis, or united in a several-celled ovary. Style single, with as many or twice as many lobes as carpels, rarely entire. Ovules 1 or more in each cell or carpel, erect or pendulous. Fruit various, usually capsular or separating into 1-seeded cocci. Seeds usually reniform. Albumen little or none. Embryo curved, with twisted cotyledons.-Herbs, or soft-wooded trees and shrubs. Leaves alternate, stipulate, usually palmately veined or lobed. Peduncles 1-flowered, axillary and solitary, or arranged in axillary fascicles or short racemes, or in terminal racemes. Bracteoles often 3 or more, close under or upon the calyx, forming an involucre or outer calyx.

A considerable Order, dispersed over the whole globe except the extreme Aretic regions.

Carpels 1-ovulate, arranged in a ring round the axis.

Style-branches as many as carpels.

Ovule ascending . . . . . . . . . . . . 1. Maldastrum.

Ovule pendulous . . . . . . . . . . . . . 2. Sida.

Style-branches twice as many as carpels . . . . . . . . 4. Urena.

Carpels with 2 or more ovules, more or less united in a several-celled capsule.

Anthers terminating the staminal column. Carpels free at the top. Bracteoles none .. . . . . . . ...

Staminal column ending in 5 teeth, below which the anthers are placed. Carpels united to the top. Bracteoles several

\section{Abutilon.}

(See also Helicteres, in Sterculiacea.)

\section{Hibiscus:}

\section{MALVASTRUM, A. Gray.}

Bracteoles under the calyx, 1 to 3 , small, or sometimes wanting. Calyx 5-lobed. Staminal column divided at the top into several filaments. Carpels 5 or more, in a ring round the axis, 1-ovulate, indehiscent. Style with as many branches as carpels; stigmas terminal. Seed ascending.-Herbs. Flowers rather small, orange, red, or yellow:

An American genus, of which one species is dispersed as a weed over most of the tropical regions of the Old World. 
1. M. tricuspidatum, A. Gr. Pl. Wright. and in Bot. Amer. Expl. Exped. i. 148. An erect branching herb, 2 to $3 \mathrm{ft}$. high, hard and almost woody at the base, although sometimes annual, the branches sprinkled or covered with closely appressed hairs. Leaves on rather long stalks, from broadly ovate to lanceolate, 1 to $2 \mathrm{in}$. long, irregularly toothed, and hairy. Flowers almost sessile in the axils of the leaves, or clustered towards the ends of the branches. Calyx campanulate, broadly 5 -lobed, with 3 small narrow external bracts. Carpels 8 to 12, or even more, closely packed in a depressed ring, each one reniform, with 3 minute unequal points on the upper inner edge.M. ruderale, Hance in Walp. Ann. iii. 830 .

In waste places, Hance. The species is probably of American origin, but is now widely scattered over the warmer regions of the globe.

\section{SIDA, Linn.}

Calyx without outer bracts, 5-lobed. Staminal column divided at the top into several filaments. Carpels 5 or more, in a ring round the axis, 1-ovulate, indehiscent or opening when ripe in 2 short valves at the top. Style with as many branches as carpels; stigmas terminal. Seeds pendulous.-Herbs or (in some extra-colonial species) shrubs, more or less tomentose or softly hairy, rarely glabrous. Flowers usually yellow, on 1-flowered pedicels or heads, single or clustered in the axils of the leaves, or in terminal racemes.

A large genus, widely dispersed over the warmer regions of the globe.

Leaves and branches green, glabrous, slightly pubescent, or with long spreading hairs. Carpels 5.

Stem slender, spreading, and hairy. Leaves cordate . . . . . 1. S. humilis.

Stem erect, glabrous or pubescent. Leaves lanceolate . . . . . 2. S. acuta.

Plant more or less canescent or softly tomentose, at least the under side of the leaves. Carpels about 10.

Leaves oblong or lanceolate, white underneath . . . . . . 3. S. rhombifolia.

Leaves small, nearly orbicular, white underneath . . . . 4. S. fallax.

Leaves broadly cordate, softly tomentose on both sides . . . . . 5. S. cordifolia.

1. S. humilis, Willd.; DC. Prod. i. 463 . A slender diffuse annual, the branches spreading to 1 or $1 \frac{1}{2} \mathrm{ft}$., with long spreading hairs, mixed sometimes with a slight tomentum. Leaves on long stalks, cordiform, 1 to 2 in. long, green, and more or less hairy. Pedicels axillary, slender, hairy, $\frac{1}{2}$ to 1 in. long. Flowers small, yellow. Carpels 5, not curved.

In waste places, Hinds. A common Indian weed.

2. S. acuta, Burm.; DC. Prod. i. 460 ; Wight, Ic.t. 95 . An erect branching perennial, 1 to $2 \mathrm{ft}$. high, glabrous, or slightly pubescent, but without any of the whitish tomentum so general in the genus. Leaves shortly stalked, lanceolate, serrate, $1 \frac{1}{2}$ to $2 \mathrm{in}$. long. Stipules linear and persistent, as long as the petioles. Pedicels axillary, very short, seldom exceeding the petioles. Carpels usually 5 , with 2 short points or beaks.

In waste places, Wilford. Widely spread over India, extending northwards to Amoy.

3. S. rhombifolia, Linn.; DC. Prod. i. 462. A perennial or undershrub, very variable in stature, sometimes tall and erect, with oblong-lanceolate leaves $3 \mathrm{in}$. long, green above, and only slightly hoary underneath, sometimes much branclied, very spreading, with oblong or almost ovate leaves, 
scarcely an inch long, and very white underneath. Peduncles almost always longer than the short petioles, and sometimes almost as long as the leaf. Flowers rather small, yellow. Carpels about 10, with or without terminal awns.

In waste places, Champion and others. A very common weed throughout the tropics, and usually erect, and not much branched.

4. S. fallax, Walp.; A. Gray, Bot. Amer. Expl. Exped. i. 161. A low spreading perennial or undershrub, much like some varieties of $S$. rhombifolia, but the leaves are small, seldom above 1 in. long, broadly ovate or almost cordate, white or hoary on both sides, and the peduncles longer than the leaves. Carpels usually 10, without awns.

Hongkong, Wright. Frequent in many of the islands of the Pacific, and occurs occasionally in South China, and as far as Cochin China. It may possibly, however, prove to be no more than a variety of $S$. rhombifolia.

5. S. cordifolia, Linn.; DC. Prod. i. 464. An erect stout branching perennial, 1 to 2 or $3 \mathrm{ft}$. or even more in height, more or less clothed with a short soft tomentum or soft velvety hairs. Leaves on rather long petioles, broadly cordate or almost orbicular, 1 to $1 \frac{1}{2}$ or rarely 2 in. long, usually soft and thick. Flowers small, yellow, on short axillary peduncles, or clustered into short leafy racemes. Carpels about 10, each terminating in 2 rather long erect awns.

In waste places, Champion and others. Very common throughout the tropics.

\section{AвUTILON, Gærtn.}

Calyx without outer bracts, 5-lobed. Staminal column divided at the top into several filaments. Carpels 5 or more, in a ring round the axis, each with several ovules, and when ripe, united at the base, but diverging at the top, and opening in 2 valves. Style with as many branches as carpels. Stigmas terminal.-Herbs, or in some extra-colonial species, shrubs, with the habit of Sida, from which they only differ in their carpels, and the number of ovules and seeds.

A considerable genus, spread over the tropical and subtropical regions of both Worlds, but more especially in America.

1. A. indicum, Don; W. and Arn. Prod. Fl. Penins. i. 56 ; Wight, Ic. $t$. 12. A rather tall branching perennial, white or hoary all over with a very short close tomentum. Leaves on long petioles, almost orbicular, cordate, acuminate, and unequally toothed, 2 to 3 in. long. Peduncles 1-flowered, axillary, articulate near the flower. Calyx-lobes broad, acute. Flowers yellow. Capsule hairy, 7 to 8 lines diameter, truncate at the top, consisting of 10 to 20 carpels, either acute or shortly awned on their outer upper edge.

On roadsides, Hance. Common in southern Asia and tropical Africa. This was mis. taken by Seemann, in his 'Flora of Hongkong,' for the $A$. graveolens, which has the stem sprinkled with horizontal hairs, and the carpels rounded, not truncate and angled at the top.

\section{URENA, Linn.}

Bracteoles round the calyx united into a 5-lobed involucre. Calyx 5-lobed. Staminal column bearing below the summit a few almost sessile anthers. Car- 
pels 5 , in a ring round the axis, 1 -ovulate, and indehiscent. Style-branches 10. Stigmas terminal. Seed erect.-Herbs or undershrubs, usually tomentose. Flowers yellow or pink, sessile or nearly so, and usually clustered. Carpels more or less echinate, with hooked bristles or prickles.

A small genus, dispersed over the tropical regions of the Old and the New World.

Leaves orbicular, toothed or broadly lobed . . . . . . . 1. U. lobata. Leaves deeply 3 - or 5 -lobed, the middle lobe narrowed at the base . . . 2. U. sinuata.

1. U. lobata, Linn.; DC. Prod. i. 441 ; Bot. Mag.t. 3043. A hard erect herb, 2 to $3 \mathrm{ft}$. high, covered on the stems and under side of the leaves with a whitish close stellate tomentum, green on the upper side of the leaves. Leaves stalked, nearly orbicular, palmately 3 - to 7-veined, toothed, angular or brondly and shortly lobed, the upper ones much narrower, usually oblong or lanceolate. Flowers small, pink, in almost sessile clusters in the upper axils, or the upper ones forming an irregular leafy ráceme.

Hongkong, Champion. Common in India.

2. U. sinuata, Linn.; DC. Prod.i. 442. The habit and most of the characters are the same as in $U$. lobata, of which it is by some considered as a variety. The chief difference consists in the leaves being divided into 3 or 5 lobes by deep sinuses; the lobes all obovoid or rhomboidal, the terminal one much contracted at the base.

Gathered in Hongkong by Champion, with the last species, which it frequently accompanies over nearly the whole of its area.

\section{HIBISCUS, Linn.}

Bracteoles round the calyx several, either free or more or less united into a lobed or toothed involucre. Calyx 5-lobed or 5-toothed. Staminal column bearing several short filaments below the summit. Carpels 5, with several ovules in each, united into a single 5-celled ovary. Style 5-lobed at the top, or nearly entire, with terminal stigmas. Capsule loculicidally opening in 5 valves.-Herbs, shrubs, or trees. Flowers often large and showy.

A considerable genus, widely spread over the warm regions of the globe. Several species of what are considered as the more typical forms of the genus may be met with in Hongkong Gardens, as for example: $H$. Rosa-sinensis, $H$. mutabilis, etc. The two following belong respectively to the sections Abelmoschus and Paritium, which are considered by some botanists as distinct genera.

Hispid annual. Bracteoles free. Calyx split longitudinally . . . 1. H. Abelmoschus. Tree. Bracteoles united into a 10 - to 12-lobed involucre. Calyx not split 2. H. tiliaceus.

1. H. Abelmoschus, Linn.; DC. Prod. i. 452. An erect annual, about 2 feet high, hispid with stiff hairs, which are reflexed on the stem and petioles, nearly appressed on the leaves. Leaves on long petioles, varying from cordate or slightly hastate and 3-lobed, to deeply divided into 5 or 7 spreading lobes, green on both sides, 2 to 3 in. long. Peduncles axillary, 1 to $1 \frac{1}{2}$ in. long. Flowers solitary, large, yellow, with a crimson eye. Involucral bracts about 10 or 12, linear, hispid, shorter than the calyx. Calyx above an inch long, shortly 3 - to 5-toothed, but splitting open on one side to the base and falling off with the petals, which are ab6ve 3 in. long. Capsule oblong, hispid, $1 \frac{1}{2}$ in. long.-Abelmoschus moschatus, Møench; W. and Arn. Prod. Fl. Penins. i. 53 ; Wight, Ic. t. 399. 
Mount Victoria, Champion, also Wright. Common in India, and very variable in the shape of the leaves.

2. H. tiliaceus, Linn.; $D C$. Prod. i. 454. A small tree. Leaves on long stalks, orbicular-cordate, shortly acuminate, entire or crenulate, white or hoary underneath with a short close tomentum, nearly glabrous above, 3 to 5 in. diameter. Peduncles short, in the upper axils or at the ends of the branches. Flowers large, yellow, with a dark crimson eye. Involucre campanulate, divided usually to the middle in 10 to 12 lobes, about half the length of the calyx. Calyx near an inch long, the lobes lanceolate. Capsule near an inch diameter, opening in 5 valves, bearing the placentas on their centre and their thin margins turned inwards so as to make the capsule appear 10-celled. -Paritium tiliaceum, St. Hil.; W. and Arn. Prod. Fl. Penins. i. 52 ; Wight, Ic. t. 7.

Hongkong, Wright. A common seacoast tree in most tropical countries, and very abnn. dant in the islands of the Pacific.

\section{ORdER XVIII. STERCULIACEAE.}

Sepals usually 5 , more or less united in a toothed or lobed calyx, valvate in the bud (except in a very few American species). Petals either 5, hypogynous, free, and convolute in the bud, or none. Stamens hypogynous, united in an entire or lobed tube or column. Anthers definite or indefinite, 2-celled, adnate to the outside of the staminal column or of its lobes. Ovary free, 2- to 5 - or 10-celled, entire or divided into as many distinct carpels, with 2 or more ovules, or very rarely a single ovule in each cell or carpel. Style entire or divided into as many lobes as cells or carpels. Fruit a capsule or drupe, or separating into distinct cocci or follicles. Seeds glabrous, with little or no albumen. Embryo straight or curved.-Trees, soft-wooded shrubs, or rarely herbs. Leaves alternate, either simple and pinnately or digitately nerved, or compound, with digitate leaflets. Stipules rarely wanting. Inflorescence axillary or rarely terminal.

An Order almost entirely tropical, and most abundant in the Old World. It might be considered as a suborder of Malvacea, differing chiefly in the 2-celled anthers.

Petals none. Flowers unisexual.

Anthers about 15. Carpels follicular when ripe . . . . . . 1. Sterculia,

Anthers 5. Carpels hard and indehiscent ... . . . . . 2. Heritiera,

Petals 5. Flowers hermaphrodite.

Calyx campanulate. Flowers in terminal cymes. Ovules 2 in each cell 3. Reevesia.

Calyx tubular. Flowers axillary. Ovules several in each cell . . 4. Helicteres.

\section{STERCULIA, Linn.}

Flowers usually monœcious. Calyx 5-cleft. Petals none. Staminal column in the males cylindrical, with about 15 anthers sessile round its summit. Ovary in the females consisting of 5 carpels, connected together by the style, and often surrounded at the base by imperfect anthers. Ovules 2 or more in each carpel. Ripe carpels distinct, much enlarged, follicular. Seeds with albumen.-Trees. Leaves undivided and pinnately nerved, or palmately lobed or digitate. 
A considerable genus, widely distributed over the tropieal regions both of the New and the Old World, but chiefly in the latter, a very few species extending beyond the tropies in Asia or Australia

I.eaves oblong or lanceolate, entire. Panicles slender, short . . . . 1. S. lanceolata. Leaves broad, palmately lobed. Panicle large, terminal . . . . . 2. S. platanifolia.

1. S. lanceolata, Cav.; Lindl. Bot. Reg. t. 1256. A small tree. Leaves stalked, elliptical-oblong or nearly lanceolate, 3 to $6 \mathrm{in}$. long, quite entire, coriaceous and glabrous. Panicles much branched, slender, sessile in the axils of the leaves and usually shorter than them, more or less tomentose. Calyx 5-cleft nearly to the base, the segments oblong-lanceolate, near 3 lines long, spreading, not bearded as in some other species, green, and slightly reddish at the base. Staminal column shorter than the sepals, and usually rolled inwards. Anthers 10, nearly sessile on the outside of the very short lobes, forming a globular terminal head. Follicles slightly tomentose, sessile, broadly ovate when ripe and open, $1 \frac{1}{2}$ to $2 \mathrm{in}$. long, coriaceous, of a bright scarlet, with 1 or 2 black seeds on each edge near the base.

Common in the Happy Valley woods, Champion and others. Also in the adjacent parts of S. China, but not as yet identified with any specimens from elsewhere.

2. S. platanifolia, Linn.; DC. Prod. i. 483. A handsome tree. Leaves on long stalks, nearly orbicular, palmately lobed, cordate at the base, 6 or 8 in. or even more in breadth, glabrous or minutely tomentose underneath. Flowers small, of a yellowish green, in large terminal panicles. Calyx about 4 lines long, deeply 5 -cleft, but scarcely spreading. Staminal column considerably longer. Anthers about 15 , the cells usually unequal and very irregularly crowded in a terminal head. In the female flowers there are often imperfect, sessile anthers round the base of the ovary. Carpels stipitate, opening into follicles long before they are ripe, attaining full 3 in. in'length, green and glabrous, or pubescent, with 1 or 2 seeds on each edge near the base.-Firmiana platanifolia, Br. in Pl. Jav. Rar. 235.

A native of China, much planted in E. Asia, and said by Champion to have become naturalized in Hongkong.

\section{HERITIERA, Ait.}

Flowers usually monœcious. Calyx campanulate, 5-lobed or 5-toothed. Petals 0 . Staminal column in the males cylindrical, with 5 anthers sessile in a ring round the summit: Ovary in the females consisting of 5 carpels connected by the short style, with one erect ovule in each. Ripe carpels distinct, large, hard and almost woody, indehiscent. Seeds without albumen.-Trees, with the habit and inflorescence of some of the entire-leaved Sterculias.

A genus of 2 species, confined to the seacoasts of Asia, Australia, and the islands of the Pacific.

1. H. littoralis, Ait.; $B r$. in Pl. Jav. Rar.p. 237. A tree attaining a considerable size. Leaves very shortly stalked, oval or oblong, the larger ones $8 \mathrm{in}$. by 4 , but often much smaller, quite entire, coriaceous, glabrous above, silvery underneath, with a close scaly tomentum. Flowers small, numerous, in loose terminal tomentose panicles, much shorter than the leaves. Calyx about 2 lines long. Staminal column, or ovary, much shorter. Ripe carpels sessile, ovoid, full 2 in. long, thick and almost woody, with a slightly 
projecting inner edge, and a strong projecting almost winged keel along the outer edge.

On the seacoast, Hance; a large tree on the road to Chukchew, Champion. Frequent in the Indian Archipelago, the Philippines, and other islands of the Pacific.

\section{REEVESIA, Lindl.}

Calyx turbinate-campanulate, shortly 3- to 5-lobed. Petals 5, unguiculate. Staminal tube elongated, shortly 5 -lobed at the top, each lobe bearing 3 sessile anthers on the outside, and all irregularly crowded in a terminal head. Ovary stalked, enclosed in the staminal tube, 5 -celled, with 2 ovules in each cell, one above the other. Stigma sessile, 5-lobed. Capsule woody, opening loculicidally in 5 valves. Seeds winged on the lower end.-Trees. Leaves entire. Flowers in terminal corymbs.

A genus of 2 or 3 species, all from tropical Asia.

1. R. thyrsoidea, Lindl. Bot. Reg. t. 1236. A small tree, quite glabrous except a minute stellate tomentum on the inflorescence, and sometimes on the younger branches and leaves. Leaves stalked, lanceolate or ovatelanceolate, 2 to $3 \mathrm{in}$. long, or twice that size on luxuriant branches, quite entire, rounded at the base, evergreen and coriaceous. Flowers white, in terminal sessile corymbs, much shorter than the leaves. Calyx 3 lines long. Petals longer, slightly spreading. Staminal tube near twice as long; the ring of anthers very compact, forming a terminal head. Capsule oblong-pearshaped, about $1 \mathrm{in.} \mathrm{long,} \mathrm{5-angled.}$

Common in the Happy Valley woods, Champion and others. The precise Hongkong form has only been gathered in S. China, but the $R$. Wallichii, Br. and Benn., from Khasia, may be a mere variety with rather broader, slightly cordate leaves, and rather larger flowers. I third form, gathered by Griffith in Bootan, appears to be quite a distinct species.

\section{HELICTERES, Linn.}

Calyx tubular, shortly 5-lobed. Petals 5, unguiculate. Staminal tube elongated, connate with the stalk of the ovary, divided at the top into 5 or 10 lobes, with $\mathrm{L}$ anther each, and 5 inner barren lobes or teeth. Anthers 1-celled, or with 2 divaricate cells. Ovary stalked, projecting from the staminal tube, or enclosed within it, 5-lobed, 5-celled, with several ovules in each cell. Styles united. Carpels separating when ripe, opening on the inner edge. Seeds several, with little albumen.-Trees, shrubs, or undershrubs, more or less covered with a stellate tomentum or branched pubescence. Leaves entire or serrate.

A considerable genus, dispersed over the tropical regions of both the Old and the New World.

1. H. angustifolia, Linn.; DC. Prod. i. 476. A shrub, with slender, twiggy, tomentose branches. Leaves shortly stalked, oblong-linear, $1 \frac{1}{2}$ to 2 in. long, obtuse or scarcely pointed, entire, glabrous above or nearly so, covered underneath with a close whitish tomentum. Flowers small, on short axillary 2-or several-flowered peduncles. Calyx $2 \frac{1}{2}$ lines long. Petals narrow, not twice as long. Free part of the staminal tube as long as the ovary, 10-cleft, with 1-celled anthers; the 5 inner barren lobes exceedingly short. Capsule ovoid-oblong, $\frac{3}{4}$ in. long, thickly covered with a loose rusty tomentum, mixed 
with projecting woolly processes, the carpels straight, not spirally twisted, as in some species.-Oudemansia integervima, $\beta$ angustifolia, Miq. Fl. Ned. Ind.i. pars ii. 170 .

Very common on low grounds, Champion and others. Extends from S. China to the Philippines, Java, and the Malayau Peninsula.

\section{ORDER XIX. BUETTNERIACE质.}

Sepals usually 5 , more or less united in a toothed or lobed calyx, valvate in the bud. Petals either 5, free or adhering to the staminal tube, convolute in the bud, or none. Stamens usually united in a short 5- or 10-lobed tube; 5 of the lobes bearing at their summit 1 to 4 2-celled anthers; the other 5 , when present, usually without anthers; sometimes indefinite, united in a column, with the anthers all 2-celled and terminal. Ovary free, 2- to 5- or 10-celled, or divided into as many carpels, rarely reduced to a single carpel, with 2 or more ovules in each cell or carpel. Style entire or divided into as many lobes as cells or carpels. Fruit usually capsular, with a loculicidal dehiscence; the carpels often separating, and rarely indehiscent. Seeds with or without albumen. Embryo straight or curved.-Herbs, shrubs, climbers, or trees. Leaves alternate, simple, entire or lobed. Stipules rarely wanting. Inflorescence axillary, or rarely terminal. Like the last, this Order might be considered as a suborder of Malvacea.

A large family, dispersed throughout the tropics, and extending into Southern Africa and Australia.

Petals oblong, flat. Stamens 5, shortly united. Carpel 1. Herb . Petals on long claws, concave, with a long point. Staminal tube with 5 or 10 sterile lobes, and 5 sessile anthers between them. Capsule 5-celled, prickly. Climber .

Petals long, flat. Staminal tube with 5 long sterile filaments, and

1 to 3 anther-bearing ones between them. Capsule 5-celled. Tree

1. WALtheria.

\section{Buettneria.}

3. Pterospermum.

\section{WALTHERIA, Linn.}

Calyx 5-lobed. Petals oblong-spathulate, flat. Stamens 5, opposite the petals, shortly united at the base. Anthers terminal, with 2 parallel cells. Ovary sessile, of a single carpel, with two erect ovules. Style excentrical; the stigma usually fringed. Capsule usually opening on the back in 2 valves. Seed usually solitary, with albumen.-Herbs, undershrubs, or trees, with a stellate tomentum often mixed with soft hairs or pubescence. Leaves toothed. Stipules narrow. Flowers clustered.

A considerable genus in tropical America, with one species spread over all the warmer regions of the globe.

1. W. americana, Linn.; DC. Prod. i. 492. A perennial or under. shrub, 1 to 2 feet or more high, densely tomentose or softly villous in every part. Leaves shortly stalked, oval-oblong, 1 to $1 \frac{1}{2}$ in. long, obtuse, toothed, soft and plicately veined. Flowers small, yellow, in dense heads, almost sessile in the axils of the leaves, or the upper ones clustered in a short spike. Bracts narrow. Calyx $1 \frac{1}{2}$ line long. Petals, nearly twice as long, narrowoblong.-W. $W$. indica, Linn.; DC. Prod. i. 493.

In open grounds in the island, Champion and others. A common weed within the tropies in both the New and the Old World. In China it extends northward to Amoy. 


\section{BUETTNERIA, Linn.}

Calyx 5-lobed. Petals clawed, concave or hood-shaped, arching over the stamens and ovary, the top of the hood usually 3-lobed, the central lobe long and narrow. Staminal tube short, with 5 (or rarely 10) barren lobes, and 5 nearly sessile 2.celled anthers between them. Ovary sessile, 5-celled, with 2 ovules in each cell. Style shortly 5-cleft at the top. Capsule globular, usually covered with prickles; the carpels separating when ripe, and opening along the inner edge. Seeds solitary, without albumen. Cotyledons spirally convolute.-Undershrubs or tall climbers, often prickly. Flowers small, in umbels, or rarely in corymbs, mostly axillary or lateral.

A considerable tropical genus, chiefly American, with a few African or Asiatic species.

1. B. aspera, Colebr. in Roxb. Fl. Ind. ed. Wall. ii. 383. A very large woody climber, slightly tomentose on the young parts, the inflorescences, and calyx ; the stem not prickly. Leaves broadly ovate, cordate, or nearly orbicular, 4 to 6 or even 8 in. long, very obtuse or with a short narrow point. Flowers small, yellowish and slightly pink inside, in dense umbels or fascicles, several of which are irregularly collected in lateral panicles shorter than the leaves. Calyx broadly campanulate, $1 \frac{1}{2}$ in. long. Petals shortly bifid at the top, with an intermediate linear pointed process much longer than the calyx. Staminal tube with 5 ovate sterile lobes; and 5 intermediate anthers. Capsule globular, near 2 in. diameter, covered with short stout prickles.

Rather local in Hongkong, creeping over the rocks, Champion and others. Common in S. China, Khasia, and Assam.

\section{PTEROSPERMUM, Schreb.}

Calyx tubular, 5-lobed. Petals 5. Stamens united into a column at the base, with 5 long barren filaments and 15 shorter ones, each bearing a linear erect 2-celled anther. Ovary shortly stalked, 5-celled, with several ovules in each cell. Style entire. Capsule woody, with a loculicidal dehiscence. Seeds winged at the upper end. Albumen scarcely any.-Trees or shrubs, with a stellate or scaly pubescence. Leaves coriaceous. Flowers usually large; solitary or few together, on axillary peduncles.

A genus of few species, all from tropical Asia.

1. P. acerifolium, Willd.; W. and Arn. Prod. Fl. Penins. i. 69 ; Wight, Ic. $t .631$. A large tree, with spreading branches. Leaves stalked, broadly and irregularly obovate or ovate-truncate, 6 to 8 in. long, usually sinuately toothed or shortly 5 - to 7 -lobed, and either peltate or deeply cordate at the base, tomentose underneath, nearly glabrous above. Flowers 4 or 5 in. long, white, fragrant, on short pedicels. Sepals tomentose. Petals oblique, long and narrow. Sterile filaments nearly as long. Capsule oblong, with 5 raised angles.

In the woods near the Buddhist Temple, Champion. The species is apparently indigenous in the Indian Archipelago, and perhaps also in Khasia and some other parts of East India. It is, however, frequently planted, and it is therefore uncertain whether it may not have been introduced into Hongkong. 


\section{OrDER XX, TILIACEXE.}

Sepals 5 or rarely 4 , free or rarely united in a lobed calyx, valvate in the bud. Petals as many, imbricate in the bud, or sometimes none. Stamens indefinite or rarely twice the number of petals, hypogynous, free or united in bundles at the base. Anthers terminal, 2-celled. Ovary free, 2- to 10-celled, with several or rarely a single ovule in each cell. Style entire or divided at the top into as many lobes as cells of the ovary, or sometimes the stigma is sessile on the ovary. Fruit dry or succulent, indehiscent or with a loculicidal dehiscence, or rarely separating into cocci. Seeds usually albuminous, with a straight embryo and leafy cotyledons. Radicle next the hilum.-Trees, shrubs, or rarely herbs. Leaves alternate, undivided, with pinnate or palmate nerves. Stipules usually small and deciduous, rarely wanting. Flowers usually hermaphrodite.

A considerable Order, chiefly tropical, with a very few species in the temperate regions of the northern hemisphere.

Herbs or undershrubs. Flowers nearly sessile, solitary or clustered.

Stigma sessile or nearly so. Ovules several in each cell. Capsule dehiscent . . . . . . . . . .

Style distinct. Ovules 2 in each cell. Capsule echinate, indehiscent, or separating into cocei .

\section{Corchorus.}

\section{Triumfetra.}

Trees or shrubs. Flowers umbellate or racemose.

Petals entire. Flowers umbellate . . . . . . . . 3. Grewia.

Petals lobed or fringed. Flowers racemose . . . . . . . 4. EL OCAR PUS.

\section{CORCHORUS, Linn.}

Sepals 5, rarely 4. Stamens indefinite or rarely 10, free. Ovary 2-to 5-celled, with several ovules in each cell. Stigma sessile, or on a very short style. Capsule either long and narrow or nearly globular, opening loculicidally in as many valves as cells. - Herbs or undershrubs. Flowers small, yellow, solitary or few together, on very short axillary peduncles.

A genus of several species, widely dispersed over the tropieal regions of both the New and the Old World.

Pubescent or hairy. Capsule elongated, 3-pointed and usually 3-winged 1. C. acutangulus. Glabrous. Capsule nearly globular, warty, 5-furrowed . . . . . 2. C. capsularis.

1. C. acutangulus, Lam.; W. and Arn. Prod. Fl. Penins. i. 73; Wight, Ic. t. 739. An erect annual about $2 \mathrm{ft}$. high more or less pubescent or hairy. Leaves stalked, ovate or ovate-lanceolate, about $2 \mathrm{in}$. long, serrate, the two lowest teeth usually ending in long points; the lower leaves often small and nearly orbicular. Stipules subulate. Flowers small, yellow, I or 2 together, almost sessile in the axils of the leaves. Capsule nearly cylindrical, $\frac{3}{4}$ to $1 \mathrm{in}$. long, 6-ribbed, 3 of the ribs usually expanded into narrow wings, terminating in 3 entire or bifid points or horns, 3-celled inside.

In waste and cultivated places, Champion and others. A common weed within the tropics, and more especially in India.

2. C. capsularis, Linn.; W. and Arn. Prod. Fl. Penins. i. 73 ; Wight, Ic. $t$. 311 . An erect annual, 1 to 2 feet high like the last, but quite glabrous. Leaves similar but narrower, from ovate-lanceolate to lanceolate, 2 to 3 in. long. Flowers as in C. acutangulus. Capsule nearly globular or melon-shaped, about 4 lines diameter, 5 -celled, marked outside with 10 longitudinal furrows, and covered with warty excrescences. 
Cultivated as Jute in Hongkong and other parts of S. China and tropical Asia, but its precise native country is uncertain.

\section{TRIUMFETTA, Linn.}

Sepals 5. Petals 5 or rarely wanting. Stamens indefinite or sometimes 10 , free, inserted on a short disk bearing 5 glands. Ovary 2 - to 5 -celled, with 2 ovules in each cell. Style filiform. Capsule nearly globular, echinate with hooked slender prickles, indehiscent, but usually separating into as many cocci as cells.-Herbs or undershrubs, or rarely shrubs, with more or less of stellate pubescence. Leaves serrate, undivided or palmately 3- to 7-lobed. Flowers yellow, solitary or fasciculate in the axils of the leaves.

A genus, like the last, widely dispersed over the tropics, especially the annual species, which by their burr-like capsules are readily disseminated as weeds.

Roughly pubescent. Capsules about 2 lines diameter, with prickles not above 1 line

Softly villous. Capsules above 2 lines diameter, with prickles as long or longer

\section{T. angulata.}

2. T. pilosa.

1. T. angulata, Lam.; W. and Arn. Prod. Fl. Penins. i. 75; Wight, Ic. $t$. 320 . An erect branching annual, 2 to $3 \mathrm{ft}$. high, often hard and almost woody (perhaps biennial) at the base, more or less rough with a very short pubescence. Lower leaves long-stalked, usually broad and 3-lobed, 2 or 3 in. diameter; the upper ones ovate-lanceolate, acuminate. Flowers small, yellow, in rather dense axillary clusters. Sepals nearly glabrous, about 2 lines long. Petals scarcely longer. Capsules ovoid or nearly globular, about 2 lines long, tomentose between the prickles, which are seldom 1 line long.

In waste places, Champion and others. A common weed throughout southern Asia.

2. T. pilosa, Roth; W. and Arn. Prod. Fll. Penins. i. 74. An erect branching perennial, 2 to $3 \mathrm{ft}$. high, softly villous or tomentose in all its parts. Leaves ovate-lanceolate or lanceolate, 2 to $4 \mathrm{in}$. long; the lower ones sometimes broad and angular or lobed, but less frequently so than in $T$. angulata. Flowers larger than in that species, similarly clustered in the axils of the leaves. Sepals usually tomentose, full 3 lines long. Petals scarcely longer. Fruits larger than in $T$. angulata, hirsute all over, with the prickles from 2 to 3 lines long.-T. cana, Blume; Benth. in Kew Journ. Bot. iii. 263.

On roadsides and waste places, Champion and others. Common all over India.

\section{GREWIA, Linn.}

Sepals 5. Petals 5, usually marked at the base on the inside with an adnate gland or nectariferous cavity. Stamens indefinite, on a short torus, with or without 5 glands. Ovary. 2- to 4-celled, with 1 or 2, rarely 3 or 4, ovules in each cell. Style distinct. Fruit a drupe, either entire or 2- to 4-lobed, with 1 to 4 kernels, each with 1 to 4 seeds, and spurious partitions between the seeds.-Shrubs or trees, with more or less of stellate pubescence. Leaves entire or serrate, 3- to 7-nerved. Peduncles usually 2 together, axillary, terminal, or leaf-opposed, each bearing an umbel of several flowers, or in a few species the flowers are in terminal panicles. 
A large genus, chiefly dispersed over tropical Asia, but extending also to Africa, Australia, and a few species in eastern Asia, beyond the tropics.

Flowers in terminal panicles, Drupes entire . . . . . . . 1. G. microcos.

Flowers in small lateral or terminal umbels. Drupes lobed . . . . 2. G. glabrescens.

1. G. microcos, Linn.; W. and Arn. Prod. Fl. Penins. i. 81; Wight, Illustr. $t$. 33. A shrub or small tree, glabrous or minutely tomentose. Leaves shortly stalked, ovate-oblong or nearly lanceolate, acuminate, 4 to 6 in. long, slightly toothed towards the upper end. Panicles terminal, oblong, shorter than the leaves; slightly tomentose; the flowers 2 or 3 together, sessile within an involucre of 3 to 6 bracts, not so long as the calyx. Sepals $2 \frac{1}{2}$ lines long. Petals from $\frac{1}{3}$ to $\frac{1}{2}$ as long, the cavity at the base pubescent round the edge. Drupes glabrous, entire; the kernel 3 -celled.

Rather searce in Hongkong, Champion, but widely distributed over India, the Archipelago, and S. China. The fruit is said to attain the size of a gooseberry, and to be generally eaten in India.

2. G. glabrescens, Benth., $n$. 'sp. Apparently a straggling shrub; the young branches pubescent. Leaves shortly stalked, oval-oblong or nearly lanceolate, 1 to 2 in. long, toothed, green on both sides, and glabrous or sparingly sprinkled with a few short hairs on the upper side, and dotted with a minute stellate pubescence underneath; stipules small, subulate. Umbels 1 or 2 at the ends of short leafy branches. Flowers few, tomentose or pubescent; the peduncles and pedicels each about 3 lines long. Sepals about $2 \frac{1}{2}$ lines. Petals $\frac{1}{3}$ as long; the cavity of the base densely ciliate round the edge. Drupes probably 2- to 6-lobed.

Hongkong, Wright. I had at first considered this to be a glabrous narrow-leaved variety of the G. parviflora, Bunge, Enum. Pl. Chin. Bor. 9, of which, besides the original N. Chinese specimens, we have others gathered by Fortune on the Chinese continent (n. 15); but on a closer comparison I feel considerable doubts as to their identity.

\section{EL雨OCARPUS, Linn.}

Sepals 4 or 5. Petals as many, toothed, lobed, or fringed. Stamens several, inserted on a glandular disk. Anthers with adnate cells, opening at the top in transverse valves, often ciliate on the edge. Ovary 3-to 5-celled, with 2 to 4 ovules in each cell. Style subulate. Fruit a drupe; the nut usually 3- to 5-celled. Seeds solitary in each cell, pendulous.-Trees. Leaves usually narrow, entire, or serrate. Flowers in axillary or lateral racemes.

A genus of several species, from tropical Asia, the Mascarene Islands, the Archipelago, Australia and New Zealand.

Petals divided to the middle into a fringe of narrow lobes . . . 1. E. lancecefolius. Petals crenulate or shortly toothed . . . . . . . . . 2. E. chinensis.

1. E. lancerefolius, Roxb. Fl. Ind. ii. $598 ;$ Wight, Ic. t. 65. A tree. Leaves shortly stalked, oblong, obtuse or shortly acuminate, 3 or 4 in. long, serrate, narrowed at the base, coriaceous and glabrous. Racemes axillary or lateral, below the leaves, and shorter than them. Flowers smaller than in the common $E$. serratus, on pedicels about 2 lines long. Sepals 5, rather acute, scarcely $2 \frac{1}{2}$ lines long. Petals glabrous, rather longer, irregularly divided to about the middle into a fringe of narrow-linear lobes. Anthers slightly downy, scarcely ciliate at the top. Stamens numerous. Ovary 3 -celled, with 2 ovules in each cell. Fruit the size of a pigeon's egg, the kernel very thick and hard, 
pitted outside. Seed usually l only. - E. serratus, Benth. in Kew Journ. Bot. iii. 264, but probably not of Linn.

Hongkong, Champion, also in Khasia. The species of Elaocarpus with fringed petals, run very much one into another, but this is certainly nearer to the Indian $E$. lanceafolius than to the true $E$. serratus. The leaves are still more narrowed at the base, and the flowers rather smaller than in the Khasia specimens.

2. E. chinensis, Hook, fil. A small tree. Leaves stalked, oblong or nearly lanceolate, acuminate, 2 to $3 \frac{1}{2} \mathrm{in}$. long, obtuse, slightly toothed, silkyhairy when young, at length glabrous and shining. Flowers rather small, diœcious, in axillary or lateral slightly tomentose racemes, 1 to $1 \frac{1}{2}$ in. long. Sepals 4, acute, scarcely 2 lines long. Petals about as long, slightly tomentose, obtusely toothed or very shortly lobed. Stamens about 8 , without points or beards. Ovary pubescent, 2 -celled, with 2 pairs of collateral suspended ovules in each cell.-Friesia chinensis, Gardn. and Champ. in Kew Journ. Bot. i. 243, and iii. 264.

Woods of the Happy Valley, Champion, Wright. Not as yet gathered out of the island.

\section{Order XXI. POLYGaLACE年.}

Flowers irregular. Sepals 5, imbricate in the bud, the 2 innermost usually larger and petal-like. Petals 3 or 5 , usually adhering at the base to the staminal tube; the lower one or keel concave, enclosing the stamens and pistil; the 2 upper ones connivent, the 2 lateral ones small or wanting. Stamens 8 , rarely 4, hypogynous; the filaments united in a tube open on the upper side. Anthers erect, 1- or 2-celled, each cell opening by a pore at the top. Ovary free, laterally compressed, 2 -celled or rarely 1 -celled; the partition at rightangles to the sides, with 1 or rarely 2 superposed ovules in each cell. Style single, entire or 2-lobed at the top. Fruit either a capsule opening loculicidally, or an indehiscent nut, samara, or drupe. Seed pendulous, having frequently a caruncle at the hilum, with or without albumen. Embryo straight in the axis. Radicle superior.-Herbs or undershrubs, rarely climbers or shrubs. Leaves usually alternate, simple, undivided, and entire, without stipules. Flowers in axillary or terminal spikes or racemes, rarely solitary or paniculate.

A rather numerous Order, ranging over the warmer and temperate regions of the globe.

Ovary 2-celled. Capsule thin and flat. Herbs or shrubs.

Sepals nearly equal. Anthers 4. Flowers very small . . . 1. SAlomonia.

Two sepals large and petal-like. Anthers 8 . . . 2. Polygala.

Ovary 1-celled. Fruit winged, indehiscent. Tree or tall climber . 3. Securidaca.

\section{SALOMONIA, Lour.}

Sepals nearly equal. Upper and lateral petals nearly equal; the keel larger, slightly 3 -lobed. Anthers 4. Ovary 2-celled. Capsule thin and flat, obcordate, usually ciliate, opening at the edge. Seeds without a caruncle.-Small slender herbs. Flowers very small, in terminal racemes or spikes.

A genus of very few species, all from tropical Asia.

Leaves slightly stalked, broadly cordate or orbicular . . . . . 1. S. cantoniensis. Leaves sessile, oblong

2. S. oblongifolia. 
1. S. cantoniensis, Lour.; DC. Prod. i. 334. An erect or spreading glabrous annual, 3 to $6 \mathrm{in}$. high. Leaves on very short stalks, broadly cordate or orbicular, the largest about half an inch diameter, but most of them much smaller. Flowers pink, scarcely a line long, in terminal leafless racemes or loose spikes about an inch long. Capsule about a line broad, but not so long, flattened, didymous, bordered with a fringe of hairs or slender teeth.

In marshy fields, Champion and others. Extends from S. China to the hilly districts of northern and eastern India.

2. S. oblongifolia, DC. Prod. i. 334. A slender glabrous annual like the last, but usually rather smaller and less branched. Leaves sessile, the larger ones oblong, 3 to 4 lines long and scarcely above 1 broad; the lower ones smaller and ovate. Flowers and capsules like those of S. cantoniensis; the spikes usually rather more slender.-S. obovata, Wight, Illustr. t. 22.

In fields, Hance. Common in the warmer districts of India, from Ceylon and the Peninsula to the Archipelago and the Philippine Islands.

\section{POLYGALA, Linn.}

Sepals 3 outer small, 2 inner much larger, erect and petal-like. Petals 2 upper ones narrow and connivent, 2 lateral ones very small or wanting, the lowest or keel larger than the others, concave, hooded, and either 3-lobed or crested at the top. Stamens united above the middle, with 8 anthers. Ovary 2-celled, with 1 ovule in each. Style either dilated at the top with a lateral stigma, or with 2 or 4 short stigmatic lobes. Capsule flat, thin or rarely coriaceous, orbicular, obovate, or elliptical, opening at the edges.-Herbs, undershrubs, or shrubs. Leaves alternate, or in a very few species opposite. Racemes or spikes terminal or lateral, sometimes reduced to clusters, rarely paniculate.

A large genus, ranging over the whole area of the Order, excepting Australia.

Annual. Leaves obtuse. Flowers pink and green, in short sessile clusters 1. P. glomerata. Perennial. Upper leaves acute. Flowers pink and green, in short racemes 2. P. elegans.

Tall half-climbing shrub. Flowers large, yellow, in long racemes . . 3. $P$. arillata.

1. P. glomerata, Lour.; Miq. Fl. Ned. Ind. i. part ii. 125. A decumbent or ascending pubescent annual, branched only near the base, and attaining 1 to $] \frac{1}{2} \mathrm{ft}$. in length. Leaves from broadly ovate to oblong, or the upper ones very narrow, 1 to $1 \frac{1}{2}$ or even $2 \mathrm{in}$. long, all obtuse. Flowers inconspicuous, green or slightly pink, crowded in short axillary or lateral racemes, usually reduced to almost capitate clusters. Wings (or inner sepals) oblong-falcate, about 2 lines long, very acute, or shortly aristate. Keel-petal cristate. Capsules about 3 lines broad, and not so long, didymous, ciliate or hispid round the edge.

Hongkong, Champion, Wright. Common in the moist rich soils of eastern India and the Archipelago, and perhaps only a luxuriant variety of the widely spread $P$. arvensis.

2. P. elegans, Wall.; Royle, Illustr. 76, $t$. 11, f. A. (P. myrsinites on the plate). Stems ascending, branched at the base, and attaining from $6 \mathrm{in}$. to $1 \frac{1}{2} \mathrm{ft}$. in height, much as in the last, but proceeding from a perennial almost woody stock, and the plant is scarcely pubescent. Lower leaves ovate and small; the upper ones lanceolate, acute, 1 to $1 \frac{1}{2}$ in. long. Flowers larger than in the last, greenish, with pink tips, in rather loose but short terminal or 
lateral racemes, often not above $\frac{1}{2}$ in. long. Bracts linear, deciduous; inner sepals full 3 lines long. Capsule shorter, orbicular; surrounded by a broad wing. P. Loureiri, Gardn. and Champ. in Kew Journ. Bot. i. 242.

Mount Victoria, Champion, also Wright. Frequent in the mountain districts of northern India, and very nearly allied on the one hand to the $P$. Heyneana from the Peninsula, and on the other to a species from Loochoo, which may be the $P$.japonica, Houtt.

3. P. arillata, Ham.; W. and Arn. Prod. Fl. Penins. i. 39; Wight, Ic. t. 946. A tall bushy shrub, with weak half-climbing branches, slightly pubescent, as well as the petioles and veins of the leaves. Leaves shortly stalked, oblong, 4 to 6 in. long, mostly acute. Flowers yellow and showy in terminal or leaf-opposed racemes, 3 or 4 in. or more long. Inner sepals broadly oblong, oblique, 7 or 8 lines long. Keel-petal crested at the top. Capsule broadly orbicular, slightly didymous, 6 lines diameter, coriaceous, and prominently veined. Seeds globular, with a large carunculus.

Rare in Hongkong, Champion, on Mount Parker, Wilford, also Wright. Abundant in the hills of northern India, extending to the Peninsula and Ceylon.

\section{SECURIDACA, Linn.}

Sepals 3 outer small, 2 inner much larger, erect and petal-like. Petals 2 upper ones narrow and connivent, 2 lateral sinall or wanting, the lowest and outermost or keel concave, hooded, and usually 3 -lobed at the top. Stamens united above the middle with 8 obscurely bilocular anthers. Ovary 1-celled, with 1 pendulous ovule. Style falcate, with an entire or 2-lobed, or dilated stigma. Fruit an indehiscent samara, with a single seed in the base, winged at the top, and often crested on the edge or sides. Seed without any carunculus.- Woody climbers. Leaves alternate, often large. Flowers in axillary or terminal racemes, often branching into panicles.

A considerable genus in tropical America, with two or perhaps three Asiatic or African species.

1. S. scandens, Ham. in Wall. Catal. n. 4195. A tall woody climber, glabrous or very slightly pubescent on the young shoots. Leaves shortly stalked, ovate-elliptical or oblong, 3 or 4 in. long. Flowers red, numerous, on slender pedicels, in a broad terminal rather loose panicle. Inner sepals about 3 lines long, keel nearly as long, 2 upper petals shorter, the lateral ones wholly wanting. Fruit glabrous, with much-raised veins, and ending in a wing full 2 in. long and $\frac{1}{2} \mathrm{in}$. broad; the inner edge thickened, and notched about $\frac{1}{4}$-way up by the scar of the stigma.

In the woods of Little Hongkong, Wilford. Common in northern and eastern India.

\section{ORDER XXII. SAPINDACE无.}

Sepals 4 or 5, imbricate in the bud, free or rarely united into a cupshaped calyx. Petals as many or one fewer, free, hypogynous, imbricate in the bud, having often a scale on the inside inserted near the base. Stamens 5 to 10 , or rarely up to 20 , often 2 less than twice the number of sepals, inserted within, upon, or rarely outside, an hypogynous disk, which is sometimes reduced to 1 or more glands. Anthers 2-celled, opening longitudinally. Ovary free, 3-celled, or rarely 2- or 4-celled. Ovules 1 or 2 , or rarely more 
in each cell. Styles as many as ovary-cells, usually more or less united. Fruit either a dehiscent capsule, or indehiscent and succulent or separating into winged nuts. Seeds usually arillate. Albumen none (except in Staphylea). Embryo curved or twisted or rarely straight, with thick cotyledons sometimos completely united in a fleshy mass. Radicle next the hilum.Trees, shrubs, or climbers, or very rarely herbs. Leaves alternate or in some genera opposite, with or without stipules, often pinnate or otherwise compound. Flowers usually small, in terminal racemes or panicles.

A large Order, chiefly tropieal, with a few representatives, chiefly among the oppositeleaved genera, in the more temperate regions both of the northern and the southern hemispheres.

SUborder 1. Sapindere. Stamens within or upon the disk. Seeds without albumen.

I.eaves alternate. Carpels or cells usually 3.

Herbaceous or suffrutescent climber. Leaves much dissected. Capsule vesicular . . .......... 1. Cardiospermum.

Tree. Leaves pinnate. Fruit suceulent, indehiscent . . . 2. Nephemium. Leaves opposite. Carpels or cells usually 2. . . . . . 3. ACER.

SUborder 2. Staphyler. Stamens outside the disk. Seeds albuminous. Leaves opposite. Stamens 5. Cells usually 3 . . , . . 4. Turpinia.

\section{CARDIOSPERMUM, Linn.}

Sepals 4, the 2 outer smaller. Petals 4 , in 2 pairs, the 2 larger with a large flat inner scale, the 2 smaller with a hooded or crested inner scale. Disk reduced to 2 glands. Stamens 8, obliquely surrounding the ovary. Ovary excentrical, 3-celled, with 1 ovule in each cell. Stigmas 3, nearly sessile. Capsule vesicular, membranous, more or less 3-cornered, opening loculicidally. Seeds in the centre of each cell, globose, with a thick funiculus or small aril. Herbs or undershrubs, mostly climbing. Leaves dissected. Flowers few, small, on long axillary peduncles, usually bearing a tendril under the panicle.

A small American genus, of which 2 species are widely spread also over the Old world within the tropics.

1. C. Halicacabum, Linn.; DC. Prod. i. 601; Wight, Ic. t. 508. A straggling or somewhat climbing annual, or perhaps perennial, attaining several feet in length, glabrous or slightly pubescent. Leaves usually twice ternate, with ovate or ovate-lanceolate segments, coarsely toothed or lobed; the upper leaves smaller, narrower, and less divided. Peduncles 2 or 3 in. long, bearing a double or treble short recurved tendril under the small panicle, which is often reduced to an umbel of few small white flowers. Capsule flat on the top, usually pubescent.

Hongkong, trailing over shrubs, or scrambling among the herbage, Hance. A common weed in most tropical regions. The Hongkong specimens belong to the variety with fruits scarcely $\frac{3}{4}$ in. diameter, often considered as a distinct species (C. microcarpum, H. B. \& K.). It is fully as frequent and as widely spread as the typical form, with fruits above an inch diameter. A nearly allied species, C. canescens, Wall., is nearly as common in India, and may appear in the island of Hongkong. It is more frequently pubescent, and the shape of the fruit is different, being nearly round, never flat-topped.

\section{NEPHELIUM, Linn.}

Sepals 4 to 6 , sometimes united in a cup-shaped calyx. Petals as many or none. Disk annular. Stamens usually twice as many as sepals, inserted in- 
side the disk. Ovary central, shortly stalked, 2-lobed, 2-celled, with 1 erect ovule in each cell. Style erect, with 2 recurved stigmatic lobes. Fruit globular or ovoid, succulent and indehiscent, usually warted or muricate. Seeds nearly globular, without albumen, enclosed in a fleshy arillus.-Trees, with alternate pinnate leaves, and entire coriaceous leaflets. Flowers small, paniculate.

The species are all from southern Asia, or the Indian Archipelago.

1. N. Initschi, Camb.; Miq. Fl. Ned.Ind. i. part ii. 555 ; Wight, Ic. t. 43. A tree, glabrous in all its parts. Leaves abruptly pinnate; leaflets in 2 to 4 pairs, oblong or oblong-lanceolate, acuminate, 2 to 4 in. long, entire, coriaceous and shining. Flowers small and numerous, in trichotomous cymes, forming an oblong terminal leafless panicle. Calyx small, cup-shaped, slightly 4- or 5-toothed. Petals none. Fruit edible, warted, about an inch diameter.

Frequent in Hongkong, as on the adjoining continent, but in most cases planted for its fruit. It is, however, believed to be a native of $\mathrm{S}$. China, although its precise indigenous stations have not been ascertained. The Longan, another species of Nephelium, is also cultivated in the island.

\section{ACER, Linn.}

Sepals usually 5 , imbricate. Petals 5 , or sometimes 4 , or entirely wanting. Stamens about 8 , inserted on the disk. Ovary 2-lobed, or rarely 3-lobed, each lobe enclosing 1 cell, with 2 suspended ovules. Styles 2 , rarely 3 , often united at the base. Fruit separating into as many indehiscent samaras, winged at the top. Seeds without albumen.-Trees or shrubs. Leaves opposite, palmately veined, entire or lobed. Flowers small, greenish, in axillary or terminal corymbs or racemes.

A genns not numerous in species, but widely spread over the temperate regions of the northern hemisphere, extending also within the tropics to the mountainous districts of India.

Leaves glaucous or whitish underneath. Corymbs pubescent. Wings

of the carpels slightly divergent. .

Leaves green on both sides, much veined. Corymbs glabrous. Wings of the carpels divaricate . . . . . . . . . 2. A. reticulatum,

1. A. oblongum, Wall.; DC. Prod. i. 593 ; Decne. in Jacquem. Voy. i. 34. A tree. Leaves on rather long stalks, ovate or oblong-lanceolate, acuminate, quite entire, penninerved, with the smaller veins scarcely conspicuous, 2 to 4 in. long, glabrous, but glaucous or nearly white underneath. Flowers very small and greenish, in small pubescent trichotomous panicles or corymbs, at the ends of the branches. Fruits glabrous, their wings about an inch long, and but slightly divergent.

Hongkong, Wright. A common tree in the mountains of northern and eastern India, extending also to Loochoo Island.

2. A. reticulatum, Champ. in Kew Journ. Bot. iii. 312 ; Seem. Bot. $H e r . t .80$. A tree, much resembling the last in the shape and size of its leaves and in inflorescence, but the leaves are much firmer, green on both sides, and the reticulate smaller veins much more prominent; the petioles are shorter, the corymbs or panicles quite glabrous, the flowers rather larger, and the wings of the carpels rather longer and narrower and much more spreading. The flowers are white, 3 to 4 lines in diameter, with rose-tinted sepals.

On Mount Gongh and in the Happy Valley woods, Champion, Wilford. Not known out of the island. 


\section{TURPINIA, Vent.}

Sepals 5. Petals 5. Stamens 5. Disk annular, between the stamens and ovary. Ovary sessile, 3 -celled, with several (usually 6 or 8 ) ascending ovules in each cell. Styles 3 , slightly cohering, with a 3-lobed stigma. Fruit succulent and indehiscent, nearly globular or 3-pointed at the top. Seeds few, with a fleshy albumen. Embryo straight or slightly curved.-Trees or shrubs. Leaves opposite, either pinnate or apparently simple (when reduced to a single leaflet). Flowers usually white, in axillary or terminal panicles.

A genus of few species, indigenous to tropical Asia or America. The Staphylea, to which it belongs, are usually considered as forming an independent Order.

Leaves undivided (of a single leaflet). Flowers about 3 lines long . . 1. T. arguta. Leaves pinuate, with 3 or 5 leaflets. Flowers about 1 line long. . . 2. T. nepalensis.

1. T. arguta, Seem. Bot. Her. 371. A shrub of 3 or 4 feet in height. Leaves on short stalks, undivided, that is, reduced to a single leaflet, which, when old, shows an articulation on the petiole, broadly or narrow oblong, slightly crenate, 3 to $6 \mathrm{in}$. long, glabrous. Flowers of a dirty white, or purplish when in bud, about 3 lines long, in a rather dense terminal oblong panicle. Inner sepals and petals oblong-ovate, about equal in length, the two outer sepals rather smaller. Disk searcely crenate. Fruit nearly globular, 5 or 6 lines diameter, containing usually 2 or 3 seeds.-Ochranthe arguta, Lindl. Bot. Reg. t. 1819. Eyrea vernatis, Champ. in Kew Journ. Bot. iii. 331. Staphylea simplicifolia, Gardn. and Champ. in Kew Journ. Bot. i. 309; see also Planch. in Ann. Sc. Nat. ser. 4, ii. 256.

In ravines on Mount Victoria and Mount Gough, Champion and others. Not as yet found out of S. China. Some specimens so closely resemble those of $T$. insignis, Tul. (Lacepedea, H.B.K.), from Mexico, as to make it difficult to draw up a good diagnosis. The panicle is narrower and more dense, and the flowers larger and especially longer.

2. T. nepalensis, Walp.; W: and Arn. Prod. Fl. Penins. i. 156; Wight, Ic. $t .972$. A tree, glabrous in all its parts. Leaves evergreen, pinnate; the common stalk 3 to 6 in. long; leaflets 3 or 5 , shortly petiolulate, oblong or elliptical, acuminate, 2 to 3 in. long, entire or slightly toothed. Flowers small, white and numerous, in trichotomous panicles in the axils of the upper leaves, and shorter than the stems. Sepals and petals broad, scarcely a line long. Fruit globular, often 3-pointed, especially when young.

Common in the island, Champion and others. Extends over the hilly districts of India and eastern tropical Asia.

\section{Order XXIII. MALPIGHIACEAs.}

Sepals 5, usually with a conspicuous gland at the base of one or more of them, imbricate in the bud. Petals 5 , distinctly unguiculate, convolute in the bud. Stamens 10, or rarely fewer, usually shortly monadelphous at the base. Carpels usually 3 , sometimes 2 or 4 , altogether or partially united, the styles distinct or united. Ovules solitary in each, orthotropous, rising up from a long pendulous pedicel, with which they form a sort of hook. Fruit indehiscent, entire or separable into 3 (or 2) nuts, often variously winged or crested. Seed obliquely suspended. Albumen none. Embryo, with a short 
superior radicle.-Trees, shrubs, or climbers, rarely herbs. Leaves opposite or rarely alternate, usually entire. Stipules usually small and deciduous. Inflorescence various.

A considerable Order, almost confined to the tropics, chiefly American, with a few Asiatic or African species.

\section{HIPTAGE, Gærtn.}

Sepals 5, with one large gland between two of them at the base. Stamens 10, unequal, incurved. Style simple. Ovary 3-lobed. Fruit separating into 3 or 2 carpels, each with 3 wings, the central one elongated, with a short crest on the back.-Tall climbers. Leaves opposite.

A small genus, confined to the tropical regions of the Old World.

1. I. Madablota, Gartn.; Walp. Rep. v. 294; Wight, Illustr. t. 50. A tall woody elimber, glabrous, except the young shoots and inflorescences, which are hoary with a closely appressed pubescence. Leaves oval-oblong; acuminate, 3,4 , or rarely 5 in. long, narrowed into a very short petiole, coriaceous and often shining above. Flowers white, yellowish at the base of the upper petal, in axillary racemes, usually forming a terminal leafy paniele. Pedicels about $\frac{3}{4}$ in. Sepals obtuse, 3 or 4 lines long. Petals longer, reflexed, fringed on the margin. Wings of the carpels oblong, the inner one erect, $1 \frac{1}{2}$ in. long, the outer ones shorter, narrow, and spreading.

In the Happy Valley, festooning the trees, more rare on rocks on Mount Gough, Champion. Widely distributed over the greater part of tropical Asia. The H. obtusifolia, Roxb., Fl. Ind. ii. 369 , is a nearly allied but apparently distinct species, introduced into the Calcutta Garden from S. China, but not as yet found in Hongkong.

\section{Order XXIV. AURANTIACE无.}

Sepals 3 to 5, usually united in a short toothed or lobed calyx. Petals 3 to 5 , inserted on the outside of a hypogynous disk, slightly imbricate in the bud. Stamens twice as many, or in a few genera indefinite, inserted outside the disk. Filaments often flattened, and sometimes united at the base. Anthers versatile. Ovary entire, of 1 or more cells, with 1,2 , or more, usually pendulous ovules in each. Style simple, with an entire or slightly lobed thickish stigma. Fruit entire, indehiscent, juicy or pulpy, the cells occasionally separable from the thickened rind. Seeds attached to the axis, the raphe and chalaza usually prominent, without albumen. Cotyledons thick and fleshy. Radicle short.-Trees or shrubs, usually glabrous, and filled everywhere with little glands or receptacles of volatile oil. Leaves alternate, pinnate or simple and otherwise entire. Flowers axillary or terminal, solitary or in cymes or panicles, usually white and fragrant.

An Order not very numerous in species, almost limited to tropical Asia, with a few African or N. Australian speciez.

Leaves pinnate. Inflorescence terminal. Ovules usually 2 in each cell, superposed. Style more or less deciduous.

Flowers corymbose. Petals narrow, erect at the base. (Ovary 2-celled) 1. Murraya.

Flowers paniculate. Petals short, concave. (Ovary 5-celled). . 2. Cuausena. 
Leaves pinnate or unifoliolate. Panicles small, mostly axillary. Ovule solitary. Stigma persistent . . . . . Leaves simple. Flowers in small axillary clusters. Ovules usually 2 ,

3. Glycosmis.

4. Atalantia.

\section{MURRAYA, Linn.}

Calyx 5-lobed or 5-cleft. Petals 5, free. Stamens 10, free. Ovary raised on a short disk, 2-celled (sometimes 3 - to 5 -celled), with 2 ovules in each, either superposed or rarely collateral. Style as long or longer than the ovary, and continuous with it. Berry 1- or 2-seeded.-Unarmed shrubs or small trees. Leaves pinnate. Flowers in terminal corymbs.

A small tropical Asiatic genus.

1. M. exotica, Linn.; W. and Arn. Prod. Fl. Penins. i. 94; Wight, Ic. $t .96$. A glabrous shrub or small tree. Leaflets 5 to 7 , alternate, cuneateobovate, obtuse or obtusely acuminate, $\frac{3}{4}$ to $1 \frac{1}{2} \mathrm{in}$. long, coriaceous and shining. Flowers of a pure white, very fragrant, in compact terminal sessile corymbs. Petals near $\frac{1}{2}$ in. long, erect at the base, spreading in the upper half. Ovary 2-celled. Berry globular, usually 1-seeded.

In Hongkong, perhaps only where planted, Champion. Generally cultivated in tropical Asia, but believed to be a real native of S. China and N. E. India.

\section{CLAUSENA, Burm.}

\section{(Cookia, Sonner.)}

Calyx 4- or 5-cleft. Petals 4 or 5, ovate, coneave. Stamens 8 or 10. Ovary raised on a short disk, 4- or 5-celled, with 2 ovules in each cell, usually superposed, rarely collateral. Style short, deciduous. Berry usually 4- or 5celled, with 1 seed in each cell.-Small trees. Leaves pinnate. Flowers in terminal panicles or loose racemes.

A genus of several species, from tropical Asia or Africa.

1. C. Wampi, Oliv. MS. A tree, with the young branches, petioles, and inflorescence covered with minute asperities, but otherwise glabrous. Leaflets 7 to 9 , usually alternate, very obliquely ovate, obtuse or obtusely acuminate, 3 to 4 in. long. Flowers small, white, crowded on the smaller branches of rather large terminal broad panicles. Petals scarcely 2 lines long. Ovary villous. Berry globular, at most 1 in. long.-Cookia Wampi, Blanco, Fl. Filip. 358. Cookia punctata, Retz; W. and Arn. Prod. Fl. Penins. i. 95.

Cultivated in Hongkong, as in other parts of tropical Asia, for its fruit, known under the name of Whampee (Whung-Pi, Roxb.). It is believed, however, to be really native in S. China.

\section{GLYCOSMIS, Corr.}

Sepals usually 5. Petals as many, free. Stamens twice as many, free; the anthers often tipped with a gland. Ovary raised on a short disk, usually 5 -celled, with 1 pendulous ovule in each cell. Style conical, very short, thick, continuous with the ovary and persistent. Berry 1- or 2-seeded, crowned by the stigma.- Shrubs or trees, without thorns. Leaves pinnate and simple (unifoliolate) on the same stem. Flowers small, in axillary or rarely terminal short panicles.

A small genus, dispersed over tropical Asia and Australia, with perhaps one African species. 
1. G. citrifolia, Lindl, in Trans. Hort. Soc. vi. 72, A tall glabrous shrub. Leaves some simple, on short petioles, oblong-elliptical and obtuse, or oblong-lanceulate and acuminate, 3 to 5 in. long; others pinnate, with 2 or 3 rather smaller leaflets. Panicles dense, shorter or scarcely longer than the petioles of the pinnate leaves. Flowers and ovary almost always 5-merous. Berry globular, depressed and oblique, very pulpy, about $\frac{1}{2}$ in. diameter.Limonia parvifolia, Bot. Mag. t. 2416.

Rather searce in Hongkong, Champion; also Hance and Wright. In the adjacent parts of S. China, in the Philippine Isles, and in Borneo, and probably a variety only of the G. arborea, a species widely diffused over tropical Asia and Australia.

\section{ATALANTIA, Corr.}

(Sclerostylis, Bl. Severinia, Ten.)

Calyx 4- or 5-cleft or lobed. Petals 4 or 5, free. Stamens 8 or 10, or rarely about 15 ; filaments free or united in a tube. Ovary of 2 or 4 cells, with 1 or 2 collaterallỳ pendulous ovules in each. Style short and thick, continuous with the ovary. Berry globular, usually with 1 or 2 seeds.-Shrubs often thorny. Leaves simple. Flowers in axillary clusters or very short racemes.

A genus of several species, dispersed over tropical Asia and Australia.

Stamens 10 .

Stamens about 15 .

1. A. buxifolia, Oliv. MS. A small shrub or dwarf tree, glabrous or with the young branches pubescent, often armed with stout axillary thorns. Leaves obovate-oblong, very obtuse or emarginate, 1 to $1 \frac{1}{2}$ in. long, narrowed into a very short petiole, marked with. numerous fine veins. Flowers sessile or nearly so, solitary or 2 or 3 together in the axils of the leaves. Petals 5 , about 2 lines long. Stamens 10, free. Ovary 2-celled, with 1 ovule in each cell. Berry nearly globular, depressed, black when ripe.-Limonia bilocularis, Roxb. Fl. Ind. ii. 377. Sclerostylis atalantioides, W. and Arn. Prod. Fl. Penins. i. 93. Severinia buxifolia, Ten. Cat. Hort. Nap. 96. Sclerostylis buxifolia, Benth. in Kew Jour. Bot. iii. 326 ; Seem. Bot. Her. t. 81.

Abundant in the island, Champion and others. Also on the adjacent continent and northwards to Formosa, but not known out of S. China, the indications of the Indian Peninsular station having probably originated in a garden mistake.

1. A. Hindsii, Oliv. MS. A glabrous shrub, with stout axillary thorns. Leaves oval-elliptical or oblong, obtuse, $2 \frac{1}{2}$ to $3 \mathrm{in}$. long, obtuse at the base, un a short broad petiole, coriaceous, with fewer veins than the last species. Flowers shortly pedicellate, in axillary clusters, usually 5-merous. Petals about 3 lines long. Stamens about 15, irregularly united, but sometimes becoming quite free after the flower opens. Ovary 2-celled, with 2 ovules in each cell. Style very short and thick. Berry globular, raiher large, of an orange-colour.-Atalantia monophylla, Benth. in Lond. Journ. Bot. i. 483, not of DC. Sclerostylis Hindsii, Champ. in Kew Journ. Bot. iii. 328 ; Seem. Bot. Her. t. 82. S. venosa, Champ. l. c. (a slight variety, with the flowers occasionally 4 -merous).

Common in Hongkong, Champion and others. Not known from elsewhere. The strueture of the flowers as observed by Oliver, shows some approach to that of Citrus. 


\section{ORDER XXV. OLACACEE.}

Calyx small, truncate or toothed. Petals 4 to 6 , hypogynous or slightly perigynous, valvate in the bud, sometimes cohering in pairs or united into a tubular or campanulate corolla. Stamens inserted with the petals, or their filaments united with the tube of the corolla, equal to or twice the number of petals or rarely fewer. Torus small or forming a small disk, adhering to the base of the calyx. Ovary either entirely l-celled, or divided at the base into 3 or 4 cells, or entirely divided into 3 collateral cells. Ovules 2,3 , or 4 , pendulous, one descending into each of the partial cells. Fruit a drupe, either free and superior or enclosed in the enlarged calyx, or more or less adnate and inferior. Seed solitary, usually appearing (by its union with the placenta) erect from the base. Albumen copious. Embryo small, straight, with a small radicle next the hilum.-Trees, shrubs, or rarely woody climbers. Leaves alternate, entire, without stipules.

A tropical Order widely distributed over the New as well as the Old World.

\section{SCHCEPFIA, Wall.}

Calyx small, adhering to the base of the ovary, the free border reduced to an entire ring. Petals united into a tubular or campanulate 4- to 6-lobed corolla. Stamens as many as the lobes of the corolla, and alternate with them, the filaments adnate to its tube. Fruit a semi-inferior drupe, adnate to the enlarged calyx.

A small genus, ranging over tropical Asia and America.

1. S. chinensis, Gardn. and Champ. in Kew Journ. Bot. i. 308. A small much-branched tree or tall straggling shrub, glabrous in all its parts. Leaves from ovate-oblong to oblong-lanceolate, acuminate, $2 \frac{1}{2}$ to $3 \mathrm{in}$. long;, narrowed into a short petiole, rather thick, with a few slender veins diverging from the midrib. Peduncles short, bearing 1 to 3 sessile flowers, placed usually in the axils of young leaves, forming lateral or terminal leafy racemes. Flowers sweet-scented, usually pink, but varying to nearly white (or yellowish ?), nodding, 5 or 6 lines long, the tube rather broad, the lobes very short and spreading. Drupe oblong, very obtuse, 5 to 7 lines long.

Abundant in the Happy Valley woods, Champion and others, but not as yet found out of the island.

\section{Order XXVI. AMPELIDE无.}

Calyx minute. Petals 4 or 5, hypogynous, small, valvate in the bud, distinct or cohering at the base or at the top. Stamens as many as and opposite to the petals, hypogynous, free and distinct or monadelphous. Ovary 2to 6 -celled, with 2 collateral ovules or rarely a single ovule, erect in each cell. Style simple, often very short, or the stigma sessile. Fruit a berry, with 1 or 2 bony seeds. Embryo very small, in the base of a copious albumen, the radicle superior.-Stems usually woody, climbing by means of leaf-opposed tendrils. Leaves alternate or the lower ones opposite, simple or compound. Stipules small, deciduous. Flowers small, greenish, in leaf-opposed cymes or panicles.

An Order of very few genera, but widely distributed over the tropical vegions of the globe, with a few species natives of more temperate climes. 


\section{VITIS, Linn.}

Petals and free stamens inserted on a hypogynous disk. Ovary 2-celled, with 2 collateral erect ovules in each cell.-Vines, with the remaining characters, habit, and distribution of the Order.

Leaves broadly cordate, undivided or lobed.

Petals 5, cohering at the top. Stigma sessile.

Leaves glabrous when full grown . . . . . . 1. V. parvifolia.

Leaves covered underneath with a rusty wool . . . . 2. V. lanata.

Petals 5, spreading. Style short, conical . . . . . . 3. V. heterophylla.

Petals 4, cohering at the top. Style subulate . . . . . 4. V. cordata.

\section{Leaves compound.}

Leaflets 3 , digitate. . . . . . . . . . . . . 5. V. angustifolia

Leaflets 5 , pedate . . . . . . . . . . . 6. V. corniculata.

Leaflets 5 (rarely 3 ), pinnate, or the lower pinnæ again ternately compound

\section{7. $V$. cantoniensis.}

1. V. parvifolia, Roxb. $\mathrm{Fl}$. Ind. i. 662. Young shoots and leaves covered with a short loose tomentum, which very soon disappears. Leaves glabrous when full grown, broadly cordate, acuminate, seldom above 3 in. long and $2 \mathrm{in}$. broad, coarsely toothed, undivided or broadly 3-lobed, and rather thin. Panicle oblong, usually shorter than the leaves. Flowers very small, on short slender pedicels. Petals 5, cohering at the top and falling off all together. Stigma sessile on the top of the ovary.- $V$. succisa, Hance in Walp. Ann. ii. 231. V. Alexuosa, Thunb. in Trans. Soc. Linn. ii. 332 (according to Siebold's specimens).

Hongkong, Wright, Wilford. Common in the Himalaya and Khasia mountains, perhaps also in Java; but the specimens (Zollinger, n. 909) are' somewhat doubtful. Extends northwards to Japan, and the North American $V$. cordifolia is scarcely to be distinguished from it. It is very near the common Grape-Vine, but has always the leaves much smaller.

2. V. lanata, Roxb. Fl. Ind. i. 660. Young branches, under side of the leaves, and panicles clothed with a close, dense, rusty-coloured wool. Leaves broad, cordate at the base, usually obtuse, often 4 or even 5 in. long and broad, coarsely toothed, undivided or rarely broadly and shortly lobed, rather thick, glabrous above but retaining the wool underneath. Flowers very small, in pedunculate narrow panicles like those of the last species, but with 2 to 4 long spreading branches at the base. Petals 5, cohering at the top and falling off all together. Stigma sessile on the top of the ovary. Berry small, purple, globular.

Hongkong, Wright. Common in northern and eastern India.

3. V. heterophylla, Thunb. Fl. Jap. 103. Whole plant glabrous or the young shoots very slightly pubescent. Leaves broadly cordate, acuminate, coarsely toothed, 2 or $3 \mathrm{in}$. long and broad, mostly undivided, but some broadly 3- or 5-lobed, others more deeply divided, with the lobes elongated and sinuate or almost pinnatifid. Flowers larger than in the two last species, in shortly pedunculate, dichotomous, broadly corymbose cymes. Petals 5 , spreading, bent inwards and thickened at the top, near 1 line long. Style short and conical. Berry small, globular.-Ampelopsis heterophylla, Sieb. and Zuce. Fl. Jap. Fam. Nat. fasc. i. 89.

Hongkong, Wright, sent with $V$. parvifolia, which it sometimes resembles in foliage, but the inflorescence and flowers are very different. Also in Formosa, Wilford, and in Japan. 
4. V. cordata, Wall. Catal. $n$. 6008 (partly). Very glabrous and somewhat glaucous in all its parts, the young stems succulent and disarticulating at the joints in the dried specimens. Leaves on rather long petioles, cordate, acuminate, $2 \frac{1}{2}$ to $4 \mathrm{in}$. long and nearly as broad, entire except small, almost bristle-like distant teeth. Flowers, like those of the last species, in corymbose dichotomous cymes. Petals 4, about 1 line long, cohering at the top and falling off all together. Style subulate, with a terminal stigma. - Cissus cordata, Roxb. Fl. Ind. i. 407.

Hongkong, Hance. Extends over northern and eastern India. The leaves in the Chinese plant are not so deeply cordate as in most of the Indian specimens, but are precisely similar to some of those from Assam.

5. V. angustifolia, Wall. Catal. n. 6033. Whole plant glabrous or very slightly pubescent on the young shoots and inflorescences. Leaves digitately compound, the common petiole 1 to $1 \frac{1}{2}$ in. long. Leaflets 3 , petiolulate, ovate-lanceolate or oblong-acuminate, $1 \frac{1}{2}$ to 3 in. long and seldom 1 in. broad, with a few remote serratures. Flowers in loose trichotomous or dichotomous cymes, the common peduncle seldom above $\frac{1}{2}$ in. long. Petals 4 , less than 1 line long, spreading, 2 of them bearing outside at the top a callous protuberance or short point or horn, the other two without it. Style scarcely any, with a 2-lobed stigma.-Cissus angustifolia, Roxb. Fl. Ind. i. 4.08 .

Hougkong, Wright. Also in Silhet and Assam, and, according to Roxburgh, in Sumatra.

6. V.corniculata, Benth., n. sp. Whole plant glabrous. Leaves pedate, that is, the common petiole divided into 3 , the central branch bearing 1 leaflet, the 2 lateral ones 2 each. Leaflets petiolulate, ovate-acuminate or oblong, coarsely toothed, the central one 2 in. long or more, the others rather smaller. Flowers full 1 line long, rather crowded in dichotomous or trichotomous cymes, on a common peduncle of 2 in. or more. Petals 4, oblong, slightly cohering at the top, all bearing on the outside near the top a hoodlike appendage ending in a fine point, which is at first erect, afterwards spreading or recurved. Style shortly subulate.

In a ravine on Mount Victoria, Wilford, also Wright; not received from elsewhere. It is very near the $V$.japonica, Sieb. and Zucc. (Cissus japonica, DC.), a widely distributed plant, extending from the Himalaya to Japan, and gathered in S. China by Millett, and at Amoy by Fortune (A.101), but the shape of the petals is very different. The leaves are also more of the consistence of those of $V$. cantoniensis, and very smooth, although shaped as in $V$. japonica, and the cymes have little or none of the scaly hoariness of the latter species.

7. V. cantoniensis, Seem. Bot. Her. 370. Glabrous in all its parts. Leaves some simply pinnate, with 3 or 5 leaflets, others decompound; the lower pinnæ bearing 3 leaflets each, the upper ones consisting of a single one. Leaflets ovate, whitish underneath, the larger ones 2 to $3 \mathrm{in.} \mathrm{long,} \mathrm{coarsely}$ crenate or toothed and rather broad, but in many leaves they are not 1 in. long, with very few teeth. Flowers scarcely 1 line long, in dichotomous corymbose cymes. Petals 5, spreading, obtuse, without any dorsal protuberance. Style subulate-Cissus cantoniensis, Hook. and Arn. Bot. Beech. 175. Cissus diversifolia, Walp. Pl. Meyen. 314. Hedera hypoglauca, Hance in Walp. Ann. ii. 724 .

Frequent in ravines and on barren hills, Champion and others. Also on the adjacent continent and Khasia. 


\section{ORDER XXVII. BALSAMINE西.}

Flowers very irregular. Sepals and petals usually consisting of 6 or 8 pieces, all more or less coloured, viz. 2 outer opposite (sepals) flat and oblique, usually small and less coloured; the next (upper sepal, although by the twisting of the pedicel it hangs lowest) large, hood-shaped, ending below in a conical protuberance or spur; the fourth (lower petal, but uppermost from the twisting of the pedicel) smaller, but very broad and often bifid or emarginate, the 4 innermost (petals) often combined into 2 bifid ones, very oblique and irregular; and very rarely there are 2 additional small outer sepals. Stamens 5 , hypogynous, with very short thick filaments; the anthers cohering in a mass round the pistil. Ovary 5-celled, with several ovules in each cell. Stigmas $\mathbf{5}$, minute, sessile or nearly so. Fruit a capsule, bursting elastically in $\mathbf{5}$ valves, which roll inwards, scattering the sceds. Seeds pendulous, without albumen. Embryo straight, with a superior radicle.-Herbs mostly glabrous and somewhat succulent, or occasionally undershrubs, or even shrubby. Leaves alternate, opposite or whorled, without stipules, undivided but usually toothed.

An Order almost entirely Asiatic and chiefly tropical, with a few North American and one European species, and comprising besides Impatiens itself but one genus of a single species.

\section{IMPATIENS, Linn.}

Characters those of the Order, except that the 2 additional outer sepals are wanting, and the 4 inner petals are united in pairs.

A large genus, occupying the same area as the Order.

1. I. chinensis, Linn.; Hook. and Thoms. in Journ. Linn. Soc. iv. 119. A glabrous annual, usually creeping or decumbent at the base, then erect, 1 or $2 \mathrm{ft}$. high, often bearing at the nodes 2 or more thick stipule-like bristles. Leaves sessile or nearly so, opposite, linear, acute, 2 to 4 in. long, remotely serrate, glaucous underneath. Flowers pink or white, rather large, on axillary, solitary, or clustered pedicels. Outer sepals linear; spur long, slender, and curved; larger petal orbicular acuminate; inner lateral ones semi-obovate, auriculate at the base on one side.-Impatiens fascicubata, Lam.; Wight, Ic. t. 748 .

Hongkong, Harland, Hance. Common in the mountains of the Indian Peninsula, in Malacea, Burmah, and Khasia.

\section{Order XXVIII. OXALIDEAE.}

Flowers regular. Sepals 5, imbricate in the bud, persistent, often united at the base. Petals 5, hypogvnous, contorted in the bud, free or slightly connate at the base. Stamens 10, hypogynous, free or united at the base, the 5 opposite the petals shorter than the others, or sometimes very small and without anthers. Anthers versatile, the cells opening longitudinally. Ovary usually on a very short stalk, 5-angled or 5-lobed nearly to the axis, 5-celled, with 1 or more, usually several ovules in each cell. Styles 5 , central, free or united at the base; stigmas terminal, entire or divided. Fruit a capsule or a berry. Seeds with a fleshy albumen; embryo straight or slightly curved. Ra- 
dicle superior.-Herbs, shrubs, or trees. Leaves usually pinnate or digitate, with entire leaflets; flowers in axillary umbels or panicles.

An Order limited by most botanists to the two following genera.

Herbs. Fruit capsular . . . . . . . . . . . 1. OxaLrs.

Trees. Fruit succulent, indehiscent .......... 2. Averrhoa.

\section{OXALIS, Linn.}

Stamens all bearing anthers. Capsules opening at the angles in valves which remain adhering to the axis.-Herbs or (in species not Chinese) undershrubs. Flowers in simple or irregularly compound umbels.

A large genus, chiefly American and African, with a very few Asiatic species, one of which is dispersed over all but the colder regions of the globe. The Hongkong species have 3 digitate leaflets. The $O$. sensitiva, with pinnate leaves, common in S. Asia, has not yet been found in S. China.

Rhizome bulbous. Leaves and peduncles radical . . . . . . 1. O. Martiana.

Stem branching, decumbent, leafy. Peduncles axillary . . . 2. O. corniculata.

1. O. Martiana, Zucc. Oxal. Nachtr. 27; Bot. Mag.t. 3938. A stemless herb, with a compound bulbous rhizome, covered with brown 3-ribbed scales. Leaves radical, slightly hairy; the petioles 4 to 6 inches long. Leaflets 3 , digitate, broadly obovate-emarginate, 8 to 10 lines long. Peduncles radical, rather longer than the petioles, bearing a single umbel, or more frequently irregularly divided into 2 or 3 branches, each bearing 1 or 2 umbels of pale-purplish flowers. Sepals obtuse, with 2 small glands at the tip, 2 to $2 \frac{1}{2}$ lines long. Petals glabrous, 3 or even 4 times as long. Stamens and styles pubescent.-O. corymbosa, DC. Prod. i. 696 ?

A native of Southern Brazil, now established as an escape from gardens in Hongkong, as in the Mauritius and some other hot countries.

2. O. corniculata, Linn.; DC. Prod.i. 692; Wight, Ic. t. $18 . \quad$ A decumbent, prostrate or ascending, much-branched delicate perennial, or sometimes annual, more or less pubescent, of a pale green, from a few inches to a foot long. Stipules small, adnate to the petiole. Leaves alternate; the petioles about 1 in. long. Leaflets 3 , digitate, broadly obcordate, usually 3 or 4 lines long. Peduncles axillary, about the length of the petioles, bearing an umbel of 2 to 6 small yellow flowers, on reflexed pedicels of 3 or 4 lines. Capsule column-like, $\frac{1}{2}$ in. long or even more, with several seeds in each cell.

On roadsides and in waste places, Champion and others. A common weed in all but the colder regions of the globe.

\section{AVERRHOA, Linn.}

Stamens either all antheriferous or 5 small and without anthers. Fruit indehiscent and succulent.-Trees. Leaves pinnate. Flowers in small axillary panicles.

A genus of two species, common to both the New and the Old World within the tropies, either indigenous or naturalized.

1. A. Carambola, Linn.; DC. Prod. i. 689. A small tree. Leaves alternate, glabrous or more frequently more or less pubescent. Leaflets 5 to 11, very obliquely ovate, acuminate, $1 \frac{1}{2}$ to $2 \mathrm{in}$. long, of a pale or glaucous colour on the under side, where they are usually more pubescent. Flowers 
small, reddish, in axillary sessile panicles of 1 to $2 \mathrm{in}$., or forming rather large panicles at the ends of short branches. Sepals about 1 line long; petals near twice as long. The five smaller stamens usually very minute and wholly without anthers, or occasionally 1 or 2 of them are longer, with small barren anthers. Berry oblong, angular. Seeds arillate.

Common in the island, both cultivated and wild, Champion and others. Cultivated for its fruit (known by the name of Carambola) in the hotter regions both of the New and the Old World, and almost everywhere it readily establishes itself apparently wild, so that its native country is uncertain.

\section{ORDER XXIX. RUTACE正.}

Flowers usually regular. Sepals 4, 5, or rarely 3, usually small and often united at the base. Petals as many, inserted round a hypogynous or slightly perigynous disk, free or rarely united at the base, imbricate or almost valvate in the bud. Stamens as many or twice as many, inserted with the petals, free. Anthers 2-celled, versatile. Carpels 3 to 5, sessile or on a raised torus or short stalk, usualiy free at the top, but sometimes combined in a 3-to 5-celled ovary. Styles often free at the base, but usually united uprvards, with a capitate or lobed stigma, which is sometimes sessile on the top of the ovary. Ovules 2 or rarely 4 in each cell or carpel. Fruit either entire and indehiscent, or separating into cocci, or consisting of distinct carpels opening in two valves. Seeds usually solitary in each carpel, with a smooth testa, with or without albumen. Cotyledons flat or rarely crumpled.-Trees, shrubs, or rarely herbs. Leaves alternate or opposite, often compound, and almost always marked with glandular dots.

A considerable Order, widely distributed over all but the colder regions of the globe.

Carpels distinct, at least at the top.

Leavēs alternate. Ovules collateral . . . . . . . . 1. XanthoxyLum.

Leaves opposite. Ovules superposed . . . . . . . . 2. Evodia.

Carpels united in a single entire ovary and fruit.

Flowers unisexual. Stamens 5. Leaflets 3 . . . . . 3. Toddalia.

Flowers hermaphrodite. Stamens 8. Leaflets single . . . . 4. Crminosma.

\section{XANTHOXYLUM, Kunth.}

Flowers unisexual or nearly so. Sepals and petals 4,5 , or rarely 3 , much imbricate in the bud. Stamens as many (in the female flowers semiabortive, rudimentary, or wanting). Carpels 5 or fewer, on a globular or raised torus, free or united at the base, with 2 collaterally ascending ovules in each (linear or rudimentary, without ovules, in the males). Styles distinct or united at the top. Fruiting carpels distinct, opening in 2 valves. Seeds ovoid or globular, with a black shining testa. Embryo straight or slightly curved, in a somewhat fleshy albumen.- Trees or shrubs, often prickly. Leaves alternate, pinnately or ternately compound. Flowers small, in axillary or terminal panicles.

A considerable genus, common to the New and the Old World, chiefly tropical, but with a few extratropical species in Asia, N. America, and S. Africa.

Panicles short, nearly sessile. Petals 4 . Carpels 4.

Leaflets 3 to 7 . . . . . . . 1. X nitidum.

Leaflets 15 to $25 \quad \ldots$.

Panicles loose, pedunculate. Petals 5. Carpels 2. . . 3. Avicenne. 
1. X. nitidum, DC. Prod. i. 727; (Bot. Mag. t. 2558?) A woody climber, glabrous in all its parts; the young branches, petioles, and midrib of the leaflets more or less armed with small hooked prickles. Leaves pinnate, with a common petiole of 3 or 4 in. Leaflets 3 to 7 , oval-oblong, usually 2 to $2 \frac{1}{2}$ in. long, obtuse or shortly acuminate, coriaceous and shining, rounded at the base, with very short petiolules. Flowers small, in sessile axillary oblong panicles, seldom above an inch long. Sepals minute. Petals 4, about 1 line long, distinctly imbricate. Stamens longer. Carpels 4, spreading, hard and wrinkled when dry, near 3 lines broad.

Rather abundant in ravines, Champion and others. Found also about Macao, but not known out of S. China. It is possible that the plant figured in the 'Botanical Magazine' may be a form of the following species.

2. X. cuspidatum, Champ. in Kew Journ. Bot. iii. 329. A glabrous woody climber, nearly allied to the last species, of which it may possibly prove to be a variety, but the foliage is different. It is less prickly, the common petioles are usually 6 to 8 in. long, or even more; the leaflets 15 to 25 , with a long obtuse point, and narrowed at the base into a much longer petiolule. Axillary panicles short, branching from the base. Flowers of X. nitidum.

Less common than $X$. nitidum, and rather local, Champion, frequent in ravines, Wilford, also Hance and Wright. Not known from elsewhere.

3. X. Avicennæ, DC. Prod.i. 726. An erect glabrous shrub. Prickles few and small, curved upwards on the branches, few or none on the petioles. Leaves pinnate, with a common petiole of 3 to 5 in. Leaflets 7 to 13, obliquely obovate or oblong, or rarely almost lanceolate, usually obtuse, narrowed at the base into a petiolule, slightly undulate or almost crenate at the edge. Panicles loosely trichotomous, or 2 or 3 times umbellately divided, nearly as long as the leaves, on a peduncle of 2 to $2 \frac{1}{2} \mathrm{in}$. Petals 5 , slightly imbricate, about 1 line long. Carpels 2, when ripe about 2 lines diameter. Seeds black and shining as in the two last species, but smaller.-X. Ientiscifolium, Champ. in Kew Journ. Bot. iii. 329.

On Mount Gough, Champion. Ravines and hillsides, near their tops, Wilford. Also in other parts of S. China, and in the Philippine Islands (Cuming, n. 1622).

\section{FVODIA, Forst.}

(Boymia, Juss. Philagonia, Hook.)

Characters of Xanthoxylum, except that the petals are valvate in the bud, or overlap each other but very slightly; the ovules are usually superposed, and the leaves always opposite. The species are all unarmed.

A small tropical Asiatic genus.

Panicles large, terminal. Leaflets 3 to 7, pinnate . . . . . . 1. E. meliafolia. Panicles small, axillary. Leaflets 3 , digitate . . . . . . . 2. E. triphylla.

1. E. melizefolia, Benth. A tree, glabrous in all its parts, and without prickles. Leaves opposite, pinnate, with a common petiole of 3 to 5 in. Leaflets 3 to 7, on long petiolules, ovate, acuminate, 2 to $3 \mathrm{in}$. long, thin, shining above, pale or glaucous underneath. Flowers very numerous, in a broad terminal corymb or trichotomous panicle. Petals 4 or $\tilde{5}$, about $1 \frac{1}{2}$ lines long, very nearly valvate. Stamens scarcely longer, the filaments hairy inside. 
Carpels 4, when ripe about 2 lines broad.-Boymia glabrifolia, Champ. in Kew Journ. Bot. iii. 330. Megabotrya meliafolia, Hance in Walp. Ann. ii. 259.

Scarce in Hongkong, but abundant on the adjacent coast of China, Champion and others. I have only seen male specimens in flower, and females in fruit. In the former as in the male flowers of the allied $E$. fraxinifolia (Philagonia, Hook.) and $\boldsymbol{E}$. rutacarpa (Boymia, Juss.), the ovaries are abortive, linear, ending in subulate styles. In the females of the two latter species the ovaries terminate in a broad peltate stigma, as is probably the case also in our species. Dr. Hooker has ascertained that all these plants are congeners of Evodia, Forst.

2. E. Lamarckiana, Benth. A tree, glabrous in all its parts and unarmed. Leaves opposite, petiole 1 to $1 \frac{1}{2}$ in. long. Leaflets 3 , digitate, oblong, acuminate, 3 to 4 in. long, very gradually tapering at the base into short petiolules. Panicles axillary, oblong, with opposite spreading branches, scarcely exceeding the petioles. Flowers small, on very short pedicels. Petals 4 or rarely 3 , almost valvate, seldom $\frac{3}{4}$ line long. Stamens glabrous, twice as long. Carpels usually 4, when ripe 2 to $2 \frac{1}{2}$ lines broad.-Fagara triphylla, Lam. Dict. i. 447. Xanthoxylum triphyllum, Wight, Ic. t. 204. X. Lamarckianum, Cham. and Schlecht. in Linnæa, v. 88. X. pteleafolium, Champ. in Kew Journ. Bot. iii. 330. Lepta triphylla, Lour. Fl. Cochinch. 82.

Frequent in the island, Champion and others. Also on the continent of S. China, in Khasia, in the Indian Peninsula, and Ceylon. The E. Roxburghiana, common in the Archipelago, and extending from Ceylon to the Philippines, but not yet found in Hongkong, is very nearly allied, but has much larger and broader panicles, larger flowers, and the ripe carpels are said to be the size of a field bean.

\section{TODDALIA, Juss.}

Flowers of Xanthoxylum, except that the carpels are united in a single 5celled nearly globular ovary, with a broad sessile peltate stigma. Fruit a globular indehiscent berry.-Shrubs with alternate digitately-compound leaves.

A genus of very few species, dispersed over tropical Asia or Africa.

1. T. aculeata, Pers.; W. and Arn.Prod. i. 149 ; Wight, Illustr. t. 66. A shrub, with weak or flexuose branches and quite glabrous, usually bearing rather numerous small recurved prickles on the branches and petioles, but oceasionally unarmed or nearly so. Leaflets 3 , digitate, oblong or oval-oblong, $1 \frac{1}{2}$ to $3 \mathrm{in}$. long, acuminate, with a narrow obtuse point, tapering at the base into a short petiolule, the common petiole about 1 in. long. Flowers small, in axillary or terminal panicles, shorter or but little longer than the petioles. Pedicels solitary in the female specimens, fascicled or umbellate in the males. Petals about 1 line long. Stamens longer. Fruit the size of a large pea.T. floribunda, Wall. : see Thw. Enum. Pl. Ceyl. 69.

Rather scarce in Hongkong, Champion; also Hance and Wright. Very widely spread over India and the Archipelago.

\section{CYMINOSMA, Gærtn.}

Flowers hermaphrodite. Sepals small. Petals 4, narrow, scarcely imbricate. Stamens 8. Ovary raised on a short thick torus, entire, 4-celled, with a single subulate style, and 2 ovules in each cell, one above the other. Fruit 
a 4-celled nearly globular drupe.-Trees or shrubs, with simple opposite leaves (or rather solitary leaflets) articulate on the petiole.

A small genus, limited to tropical Asia and Australia.

1. C. pedunculata, DC. Prod. i. 722; Wight, Illustr.t. 65. A small tree. Leaves oblong, obtuse, 3 to $4 \mathrm{in}$. long, glabrous, articulate on a petiole of $\frac{1}{2}$ to $1 \mathrm{in}$. long. Peduncles axillary, usually shorter than the leaves, bearing a small trichotomous panicle or corymb of yellowish-green flowers. Petals about 3 lines long, recurved when open. Stamens scarcely longer, the filaments pubescent on the edges. Ovary and torus woolly. Style glabrous. Fruit about 4 lines diameter, usually white.-C. resinosa, DC. 1. c.

Common in the island, Champion and others. Frequent in India, from Ceylon and the Peninsula to the Archipelago.

\section{ORDER XXX. SIMARUBACEF.}

Flowers usually regular, unisexual. Sepals 3,4 , or 5 . Petals as many, valvate or imbricate in the bud. Stamens as many or twice as many, inserted on a hypogynous disk, the filaments usually with a small scale at the base (but not so in the Hongkong genera). Carpels 2 to 5, raised on the disk or on a distinct stalk, free or united, with distinct or united styles. Ovules 1 or 2 (very rarely 4 or 5 ) in each cell or carpel. Fruit various. Seeds usually solitary in each cell or carpel. Embryo slender, without or rarely with albumen.-Trees or shrubs, always more or less bitter. Leaves alternate, without stipules, usually compound, without the transparent dots of Rutacea.

An ()rder dispersed over the New and the Old World, but, with very few exceptions, confined to the tropics.

Styles distinct. Flowers clustered in long simple racemes . . . . . 1. Brucea.

Styles united at the top. Flowers in spreading dichotomous cymes . . 2. Picrasma.

\section{BRUCEA, Mill.}

Sepals 4. Petals 4, valvate. Stamens 4 , without any scale, inserted on a 4-lobed disk, semiabortive in the female flowers. Carpels 4, distinct, with distinct linear recurved styles, and 1 ovule in each, abortive or rudimentary in the male flowers. Drupes small. Seed suspended. Embryo straight, in a thin albumen.-Trees, with pinnate leaves. Flowers very small, in little clusters or cymes, along otherwise simple axillary peduncles.

A small genus, dispersed over tropical Asia and Africa.

1. B. sumatrana, Roxb.; Planch. in Lond. Journ. Bot. v. 575. A shrub or tree. Leaves pinnate, 1 to $1 \frac{1}{2}$ feet long; the common petiole as well as the branches and peduncles covered with a soft close yellowish tomentum. Leaflets 5 to 11, ovate-lanceolate, acuminate, about 3 in. long, coarsely toothed, often oblique at the base, softly pubescent or villous, especially underneath, or rarely nearly glabrous. Flowers very small, purple, in little cymes or clusters along the common peduncle, forming slender interrupted axillary racemes 6 to $10 \mathrm{in.}$ long in the males, not half so long in the females. Petals minute, linear. Drupes ovoid, about 3 lines long. 
On low grounds and roadsides, Champion and others. Common in southern Asia, in Ceylon, Tavoy, and the Indian Archipelago, extending to North Australia, and northwards to the Philippines and South China.

\section{PICRASMA, Blume.}

Sepals 4 or 5 , minute in the males, often becoming large in the females. Petals as many, ovate. Stamens as many, inserted round the thick disk; the filaments hairy below, but without any scale. Carpels 3 to 5 , raised on the disk, distinct, with as many styles united upwards, and 1 ovule in each. Drupes 5, or usually fewer, small, globular or ovoid. Embryo straight, in fleshy albumen.-Trees or shrubs. Leaves pinnate. Flowers rather small, in axillary pedunculate dichotomous cymes.

A small genus, dispersed over tropical and subtropical Asia and S. America.

1. P. quassioides, Benn.; Planch. in Lond. Journ. Bot. v. 573. A shrub of about 3 or $4 \mathrm{ft}$. Leaves pinnate, with a common petiole of 6 to 8 in., often pubescent. Leaflets 9 to 15 , oblong or ovate-oblong, acuminate, $1 \frac{1}{2}$ to $3 \mathrm{in}$. long, or rarely more, serrately toothed, glabrous or pubescent on the principal veins underneath. Flowers greenish, expanding to about 3 lines in diameter, in pedunculate dichotomous pubescent cymes, much shorter than the leaves. Petals and stamens 5. Drupes obovoid, or nearly globular, about 3 lines long.

In a ravine of Mount Parker, Wilford. On mountain sides, Wright, also Hance. In the Himalaya, and probably also in N. China, for the specimens we have of $P$. ailanthoides from thence seem scarcely distinct.

The Ailanthus glandulosus, Desf., a common tree, planted or wild in S. China as well as other parts of Asia, has not been received from Hongkong.

\section{Order XXXI. CELASTRACE无.}

Sepals 4 or 5, small, united at the base, imbricate in the bud. Petals as many, inserted on the margin of a thick, more or less perigynous disk. Stamens as many, alternate with the petals, or 3 only, inserted on the margin of or upon the disk. Ovary more or less immersed in the disk, 2- to 5-celled, with 2 , or rarely 1 or more ovules in each cell, at first erect but becoming sometimes at length suspended. Styles as many as cells, free or combined into one fruit, free from the calyx, 2- to 5-celled, or rarely 1-celled, indehiscent or opening loculicidally. Seeds usually with albumen. Embryo straight. Radicle next the hilum.-Shrubs, trees, or woody climbers. Leaves alternate or opposite, simple and undivided. Flowers small, usually greenish.

A large Order, widely distributed over the warmer and temperate regions of the globe.

Stamens 3, inserted on the disk . . . . . . . . . . 1. Hippocr 4teA

Stamens as many as petals and alternate with them. Petals, stamens, and ovary cells, 4 or rarely 5 . Leaves opposite . ..... 2. Evonymus.

Petals and stamens 5. Ovary-cells 2 or 3 . Leaves alternate . . 3. Celastrus.

\section{HIPPOCRATEA, Linn.}

Sepals and petals 5. Stamens. 3, inserted on the disk. Anthers 1-celled, opening transversely. Ovary-cells 3 , with 2 to 6 ovules in each. Style 
single, with 3 stigmas. Fruit of 1, $\%$, or 3 large obovate flat carpels opening longitudinally along the centre of the flat sides in two boat-shaped valves. Seeds few, erect, flattened, expanded in the lower part into a broad membranous wing. Albumen none.-Woody climbers or rarely trees. Leaves opposite. Flowers in axillary, dichotomous or trichotomous cymes or panicles.

A genus dispersed over the New World as well as the Old, within the tropics.

1. H. obtusifolia, Roxb.; W. and Arn. Prod. Fl. Penins. i. 104; Wight, Ic. $t .963$. A woody climber, glabrous in all its parts. Leaves ovaloblong, elliptical, obtuse or shortly and obtusely acuminate, 2 to $3 \mathrm{in}$. long, entire or slightly serrate, coriaceous, of a pale green. Flowers rather large for the genus, spreading to about 4 lines diameter, of a yellowish green, in loose cymes, seldom exceeding the leaves. Petals lanceolate. Ovary-cells with 6 ovules in each. Ripe carpels near 2 in. long, either broadly oblong and entire, or broader and emarginate at the top.

Frequent in ravines on Victoria Peak, Champion. Widely spread in India, from Ceylon and the Peninsula to Silhet: Also in the Philippines.

\section{EVONYMUS, Linn.}

Sepals, petals, and stamens usually 4, rarely 5. Ovary with as many cells; with 2 ovules in each. Style single, short and thick, with an entire or lobed stigma. Fruit a capsule, with as many angles or lobes as cells, and openjing loculicidally in as many valves. Seeds nearly enclosed in a coloured, usually scarlet, arillus.--Shrubs or trees, with opposite leaves. Flowers greenish or purple, in axillary dichotomous or trichotomous cymes.

A genus dispersed over the temperate regions of Europe, Asia, and N. America, with a few more tropical Asiatic species.

Petals, stamens, and ovary-cells 4.

Erect shrub. Flowers 3 to $3 \frac{1}{2}$ lines diameter. Ovules erect . . . 1. E. nitidus.

Stem prostrate or climbing. Flowers 5 lines diameter. Ovules pendulous 4. E. hederaceus. Petals, stamens, and ovary-cells 5.

Leaves narrow, 4 to $6 \mathrm{in.} \mathrm{loug.} \mathrm{Flowers} 3$ lines diameter . . . . 2. E. longifolius.

Leaves oval-elliptical, $1 \frac{1}{2}$ to 3 in. long. Flowers 5 lines diameter . 3. E. laxiftorus.

1. E. nitidus, Benth. in Lond. Journ. Bot. i. 483 ; Seem. Bot. Her. $t$. 83. An erect shrub, quite glabrous in all its parts; the young branches angular. Leaves ovate, obovate, or oblong, about 2 in. long, quite entire, stiff, smooth and shining. Flowers greenish, spreading to 3 or $3 \frac{1}{2}$ lines in diameter, few together in axillary cymes, only once or twice branched, and shorter than the leaves. Petals and stamens 4. Capsule reddish-coloured, 4-celled; the lobes scarcely prominent, and rounded at the top. Seeds with a small thin arillus.

Common in ravines, Champion and others. Also on the adjacent continent, but not known out of S. China.

2. E. longifolius, Champ. in Kew Journ. Bot. iii. 332. An erect shrub, glabrous or nearly so. Leaves stalked, narrow-oblong, 4 to $6 \mathrm{in}$. long, and 1 to $1 \frac{1}{2}$ broad, either quite entire or with a few distant serratures, smooth, and shining, with few veins. Flowers light green, about 3 lines diameter, few together in paniculate cymes, but little longer than the petioles. Petals 5 , slightly crenate or waved on the edge. Stamens 5. Capsule reddishcoloured, flat at the top, with spreading rounded lobes. 
Rare in the Happy Valley woods, Champion; only seen in a wood-cutter's bundle, Wilford; also Wright. Not found as yet out of the island.

3. E. laxiflorus, Champ. in Kew Journ. Bot. iii. 333 (not of Blume's distributed Japan plants). A perfectly glabrous erect shrub, with terete branches. Leaves stalked, oval-elliptical, obtusely acuminate, $1 \frac{1}{2}$ to 3 in. long, quite entire or with a few crenatures, tapering at the base, smooth and shining, with few veins. Flowers purplish, larger than in the other species, spreading to about 5 lines diameter, about 7 together in loose cymes rather shorter than the leaves. Petals 5, crenate, wavy at the edges. Stamens 5. Ovules erect. Capsule flat at the top, with spreading lobes.

In the Happy Valley woods, but rare, Champion; on Mounts Parker and Gough, but not common, Wilford; also Hance and Harland. Not received from elsewhere.

4. E. hederaceus, Champ. in Kew Journ. Bot. iii. 333. A prostrate or trailing glabrous shrub, rooting readily, and perhaps sometimes sending up erect branches; the young branches angular. Leaves stalked, usually ovate, acuminate, 2 to 3 in. long, and narrowed at the base, but varying to narrow oval-elliptical or nearly lanceolate, or occasionally very broad and obtuse, all of a laurel-like consistency, with few veins. Flowers greenish-white, about $\mathbf{5}$ lines diameter; few together, in cymes much shorter than the leaves. Petals 4, quite entire. Stamens 4. Ovules pendulous. Capsule about 5 lines diameter, nearly globular, slightly 4-furrowed, but otherwise entire, 4-celled. Seeds enveloped in a scarlet arillus.

Abundant in a ravine of Victoria Peak, spreading over the rocks, Champion; one (tree?) in the Happy Valley woods, Wilford. Not found as yet out of the island.

\section{CELASTRUS, Linn.}

Sepals 5. Petals 5. Stamens 5, inserted on the margin of a fleshy disk. Anthers 2-celled, opening longitudinally. Ovary 2- or 3-celled, usually with 2 ovules in each cell. Style thick and entire. Capsule opening in 2 or 3 valves, 2- or 3-celled, or reduced to a single cell and seed.-Erect or climbing shrubs. Flowers small, greenish, in small axillary cymes, or the upper ones forming a terminal panicle.

A genus chiefly Asiatic and African, and there tropical or subtropical, with a few North American species.

Cymes on very short peduncles. Capsules globular, scarcely 4 lines long 1. C. monosperma. Peduncles longer than the petioles. Capsules ovoid, about 6 lines long $\quad$ 2. C. Championi.

1. C. monosperma, Roxb. Fl. Ind. i. 625. A trailing or climbing glabrous shrub. Leaves alternate, oblong, obtusely acuminate, 3 to 5 in. long, with callous serratures round the edge, narrowed into a very short petiole, coriaceous and much veined, but usually shining. Flowers small, few together, in little axillary cymes, on a petuncle seldom attaining 3 lines; the upper ones often forming a long narrow terminal panicle. Capsule ovoid-globose, scarcely 4 lines long, marked with 3 furrows and opening in 3 valves, but containing only 1 seed enclosed in an orange-coloured pulpy arillus.-Celastrus Hindsii, Benth. in Kew Journ. Bot. iii. 334. Catha monosperma, Benth. in Lond. Journ. Bot, i. 483 .

Trailing over shrubs and trees in different parts of the island, Champion and others. Extends from $\mathbf{S}$. China to Khasia and Sikkim. 
2. C. Championi, Benth. in Kew Journ. Bot. iii. 334. A glabrous climber. Leaves usually broader than in the last species, oval or oblong, obtuse or acuminate, the longer ones 4 to $5 \mathrm{in}$. long, obtusely serrate, coriaceous and shining. Cymes on axillary peduncles longer than in C. monosperma, usually from $\frac{1}{2}$ to 1 in. Capsule larger and differently shaped, being obovoid, with 3 prominent angles, and narrowed at the base, full 6 lines long, opening like the last in 3 valves, and containing a single large oblong seed.-Catha Benthami, Gardn. and Champ. in Kew Journ. Bot. i. 310.

On Victoria Peak, trailing over bare rocks, Champion, common in ravines, Wilford. Extends to Khasia and Sikkim.

\section{ORDER XXXII. AQUIFOLIACE庄.}

Flowers regular. Sepals 4 to 6 , small, often united at the base. Petals as many, hypogynous, often united into a 4 - to 6 -lobed corolla, imbricate in the bud. Stamens as many, inserted on the base of the petals and alternate with them, or rarely free and hypogynous, usually short. Anthers 2-celled, opening longitudinally. Ovary fleshy, depressed or globular, 2- or severalcelled. Ovules usually solitary in each cell and suspended. Stigma sessile, or nearly so, entire or divided. Fruit a berry or drupe, enclosing 2 or more 1-seeded kernels. Embryo small, near the top of a fleshy albumen.- Shrubs or trees. Leaves alternate or rarely opposite, without stipules. Flowers usually small, white; axillary, and often wholly or partly diœcious.

An Order of few genera, but widely distributed over the temperate as well as the warmer regions of the globe.

\section{ILEX, Linn.}

Petals and stamens usually 4 , rarely 5 or 6 . Ovary 4 -celled, with 4 sessile distinct or united stigmas, and one pendulous ovule in each cell. Drupe enclosing 4 bony kernels or nuts.

A considerable genus, occupying the geographical area of the Order.

Whole plant glabrous.

Flowers almost sessile, clustered. Petals almost free .

Flowers in nearly sessile umbels or fascicles. Petals united at the base.

Pedicels slender, 3 to 4 lines long. Corolla deeply divided .

Pedicels thick, 1 to $1 \frac{1}{2}$ lines long. Berry tipped by a thick obtuse protuberance

Pedicels 2 to 4 lines long. Corolla divided to the middle . .

Pedicels filiform, 6 lines long. Corolla divided nearly to the base Branches and veins of the leaves pubescent or hairy .

1. I. cinerea.

2. I. graciliflora.

3. I. memecylifolia.

4. I. viridis.

5. I. asprella.

6. I. pubescens.

1. I. cinerea, Champ. in Kew Journ. Bot. iv. 327. An erect glabrous shrub, with rather thick branches, angular when young, the bark ashy-grey. Leaves on very short stalks, oblong, obtuse or shortly and obtusely acuminate, attaining $4 \mathrm{in}$. in length and $1 \frac{1}{2}$ or 2 in. in breadth, slightly toothed, very obtuse or almost cordate at the base, rather thick, but not shining. Flowers 8 to 15 together, collected in globular sessile clusters in the axils of the leaves. Petals 4, almost free. Stamens about the same length. Drupe 4-celled, about 3 lines diameter, obtuse at the top.

In a ravine of Mount Victoria, Champion. Not seen in any other collection. The very short petiole and broad base of the leaves distinguish this species from all others known to me. 
2. I. graciliflora, Champ. in Kew Journ. Bot. iv. 328. A glabrous tree, with terete branches. Leaves elliptical or obovate-oblong, obtuse, the larger ones 3 to $3 \frac{1}{2}$ in. long, edged with a few somewhat callous teeth, narrowed into a petiole of full $\frac{1}{2}$ in., coriaceous and shining. Flowers in axillary fascicles or almost sessile umbels. Pedicels slender; those of the males 15 to 20 together and 3 or 4 lines long, those of the hermaphrodite flowers rather fewer and shorter. Petals 4, spreading, orbicular, about $1 \frac{1}{2}$ lines long, very shortly united at the base. Berry purple, globular, the size of a pea, without any projection at the top.

Common in the Happy Valley woods, Champion and others. Not found as yet out of the island.

3. I. memecylifolia, Champ. in Kew Journ. Bot. iv. 328. A glabrous much-branched shrub, with terete branches. Leaves ovate, obovate or rarely oblong, obtuse or shortly acuminate, 1 to $1 \frac{1}{2}$ in. long or in a narrow-leaved variety near twice that length, quite entire, acute at the base, on a petiole of 1 or 2 lines, coriaceous, rather shining and scarcely veined. Flowers 3 to 6 together, in axillary fascicles or sessile umbels, on stiff pedicels of 1 to 2 lines. Petals 4, spreading, white, very shortly united at the base. Berry scarlet, the size of a pea, tipped with the short thick obtuse persistent style.

Very common on the hills, Champion and others, but not yet gathered out of the island.

4. I. viridis, Champ. in Kew Journ. Bot. iv. 329. A glabrous muchbranched shrub of 2 to 3 feet, of a bright green; the young branches angular or striate. Leaves stalked, ovate, obtuse or shortly acuminate, 1 to $1 \frac{1}{2}$ in. long, edged with small crenatures, acute at the base, of a thinner consistence than the preceding species, but smooth and shining. Pedicels axillary, stiff, the females solitary, 3 to 4 lines long, the males shorter and several together. Corolla spreading to about 3 lines diameter; the petals united to the middle. Berry purple, globular, 4 to 5 lines diameter, without any protuberance at the top.

On the hills, Champion; also Wright. Not seen in any other collection. This and the following species appear to be more decidedly diøcious than any of the others.

5. I. asprella, Champ. in Kew Journ. Bot. iv. 329. A glabrous shrub, nearly allied to the last species, but much more slender. Branches terete. Leaves stalked, ovate, acuminate, the point often long, edged with small serratures, acute at the base, thin but shining. Pedicels 1 to 3 together, about $\frac{1}{2}$ in. long, and very slender. Petals 4 (or rarely 5 or 6 ), united at the base only. Berry small, tipped with the short thick persistent style.-Prinos asprella, Hook. and Arn. Bot. Beech. 176, t. 36 .

Frequent in the island, Champion and others. Received also from other parts of S. China.

6. I. pubescens, Hook and Arn. Bot. Feech. 177, t.35. A tall shrub or small tree, the smaller branches, petioles, and principal veins of the leaves pubescent or shortly hairy. Leaves oval-oblong, obtuse or acuminate, 1 to 2 in. long, entire or slightly toothed. Pedicels 3 or 4 or sometimes more together, scarcely above 1 line long, in sessile axillary umbels or fascicles. Flowers light lilac or white. Petals 5 or 6 , united at the base only. Berry scarlet.

Frequent in the island, Champion and others. Received also from other parts of S. China. 


\section{ORDER XXXIII. RHAMNACE无.}

Calyx 4- or 5-cleft, valvate in the bud, lined at the base with the more or less thickened disk. Petals usually as many, small, unguiculate, hood-shaped at the top or rarely flat, inserted at the base of the lobes of the calyx and alternating with them, or rarely wanting. Stamens as many as the petals and opposite to them. Ovary either free upon the disk, or more or less immersed in it, 2- to 4-celled, with a single erect ovule in each cell; the styles free or combined into one. Fruit free or adherent to the enlarged persistent base of the calyx, indehiscent and entire or separating into two or more indehiscent l-seeded carpels. Albumen fleshy, usually thin, or sometimes none. Radicle inferior. Cotyledons flat.- Trees, shrubs, or climbers, often thorny. Leaves simple, alternate, or rarely opposite. Stipules minute. Flowers small, usually clustered or paniculate.

A considerable Order, widely spread over most parts of the globe.

Fruit dry, indehiscent.

Fruit hemispherical at the base, expanded into a broad flat top. Leaves 3-nerved . . . . . . . . . . .

Fruit globular at the base, ending in a flat oblong wing. Leaves pinnately nerved.

Fruit a berry or drupe.

Ovary half-immersed in the disk, 2-celled. Flowers usually pedicellate,

the clusters axillary or racemose .
Ovary surrounded by the disk, 3-celled. Flowers minute sessile, the clusters paniculate . . . . . . . . . . . . . . .

Ovary free, but shorter than the calyx-tube. Flowers pedicellate, the clusters or umbels all axillary.

\section{Paliurus.}

2. Ventilago.

3. Berchemia.

4. Sageretia.

5. Rhamnus.

\section{PALIURUS, Tourn.}

Petals and stamens 5. Ovary half-immersed in the disk, 3-celled, with 3 oblong stigmas. Fruit dry, indehiscent, hemispherical and 3-celled at the base, expanded at the top into a broad flat orbicular or slightly 3 -lobed disk, very thin at the edge. Seeds one in each cell, with a fleshy albumen.--Shrubs or trees. Leaves alternate, 3-nerved ; the stipules usually persistent and converted into prickles.

A small genus, confined to southern Europe and some parts of central and eastern Asia.

1. P. Aubletii, Schult.; Hook. and Arn. Bot.Beech. 177. A moderatesized tree, the young branches and leaves more or less tomentose, but soon becoming glabrous. Stipulary prickles rarely wanting, usually both straight (not one straight and the other recurved, as in the European species). Leaves stalked, ovate, acute, 1 to 2 in. long, crenately serrate, with 3 principal veins very prominent underneath. Flowers in small axillary cymes, on very short peduncles. Calyx tomentose; the lobes triangular, about 1 line long. Petals shorter. Fruit slightly tomentose, the flat top obscurely 3-lobed, from 6 to 9 lines diameter.

Cultivated in the island, if not indigenous to it, Champion; also Hance. A native of South China and Formosa.

\section{VENTILAGO, Gærtn.}

Petals and stamens 5. Ovary immersed in the disk, 2-celled, ending in 2 short conical styles or stigmas. Fruit a 1 -seeded nut, terminating in a long 
oblong flat wing, and seated upon or surrounded by the persistent base of the calyx, its edge usually indicated by a more or less prominent ring. Seed without albumen.-Tall woody climbers. Leaves alternate, elegantly marked with transverse veinlets between the principal pinnate veins. Flowers in small axillary cymes or terminal panicles.

A small genus, confined to the tropical regions of the Old World.

1. V. leiocarpa, Benth. in Journ. Soc. Linn. Lond. v. 77. A glabrous woody climber. Leaves shortly stalked, from ovate to oblong, acuminate, entire or slightly waved at the margin, 2 to 3 in. long. Flowers small, in small axillary clusters or cymes, the upper ones rarely forming a short leafless simple panicle, the pedicels seldom above a line long. Nut 2 or 3 lines diameter, marked round the middle by a prominent ring indicating the remains of the calyx ; the terminal wing smooth and shining, $1 \frac{1}{2}$ to $2 \mathrm{in}$. long, about 4 lines broad. - V.maderaspatana, Benth. in Kew Journ. Bot. iii. 42; not of Gærtner.

In ravines, Champion and others; also Malacea and western tropical Africa.

\section{BERCHEMIA, Neck.}

Petals and stamens 5. Ovary half-immersed in the disk, 2-celled, with 1 ovule in each cell borne on a long erect funiculus. Fruit a small, ovoid or oblong, 2-celled berry or drupe, inserted on the persistent but not enlarged base of the calyx. Seeds with little or no albumen.--Shrubs or woody climbers. Leaves alternate, elegantly marked underneath with parallel veins diverging from the midrib, and small, transverse, often indistinct veinlets. Flowers in small fascicles or cymes, usually forming terminal racemes or panicles.

A small genus, dispersed over tropical and subtropical Asia and the warmer parts of North America.

Flowers pedicellate. Veins of the leaves numerous.

Leaves 1 to $1 \frac{1}{2}$ in. long or more. Flower-clusters in racemes,

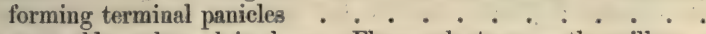

Leaves seldom above $\frac{1}{2}$ in. long. Flower-clusters mostly axillary . Flowers sessile, axillary. Veins of the leaves few

1. B. racemosa.

2. B. lineata.

3. B.? sessiliflora.

1. B. racemosa, Sieb. and Zucc. Fl. Jap. Fam. Nat. part 1. p. 39. A woody climber. Leaves on rather long petioles, ovate, somewhat acute, or rarely obtuse, 1 to $1 \frac{1}{2}$ or rarely $2 \mathrm{in}$. long, white or hoary underneath between the veins. Flowers 2 or 3 together, in clusters, arranged in racemes of 2 or $3 \mathrm{in}$., which again form large terminal panicles. Pedicels 1 line, or in fruit $1 \frac{1}{2}$ lines long. Calyx-lobes about 1 line. Fruit oblong, but little succulent, about 4 lines long. - B. lineata, Benth. in Kew Journ. Bot. iv. 4.2 ; not of Dr.

Hongkong, Champion and others; also on the adjacent continent and in Japan. It is nearly allied to the Himalayan $B$. multiflora, but that has larger leaves, smaller flowers in closer clusters, etc.

2. B. lineata, DC. Prod. ii. 25 ; Hook. and Arn. Bot. Beech. t. 37. A half-climbing shrub. Leaves on very short petioles, ovate or orbicular, and obtuse, much smaller than in the last speeies, seldom attaining $\frac{1}{2}$ in. in length, pale or whitish underneath. Flowers nearly twice as large as in B. racemosa, 2 to 4 together on pedicels of 2 or 3 lines, either in the axils of the leaves or 
a few clusters at the ends of the branches above the leaves. Calyx-lobes about $1 \frac{1}{2}$ lines long, narrow-lanceolate or linear. Berry ovoid, succulent, about 3 lines long.

Hongkong, Wright. Common in S. China, extending northwards to Amoy and Loochoo, and apparently the same species in Sikkim.

3. B.? sessiliflora, Benth., $n . s p$. Leaves shortly stalked, oblong, ob)tuse, about 2 in. long, with fewer and less prominent veins than in most Berchemias, whitish underneath. Flowers (of which I have only seen the remains round the base of the fruit) in axillary clusters, but closely sessile as in Sageretia. Berries nearly globular, 3 to 4 lines long, 2-celled as in other Berchemias.

Hongkong, Wright. I have only seen a single small specimen in fruit, and until the flowers shall have been verified, the genus cannot be determined with certainty.

\section{SAGERETIA, Brongn.}

Petals and stamens 5. Ovary surrounded by the disk, 3-celled, with 1 erect ovule in each cell. Style short, with a slightly 3-lobed stigma. Fruit a berry or drupe, with 3 cells.-Shrubs sometimes half-climbing and often thorny. Leaves alternate or nearly opposite, coriaceous, usually serrulate, with pinnate veins prominent underneath. Flowers minute, sessile in clusters along the branches of small axillary or terminal panicles.

A small genus, distributed over tropical and subtropical Asia and America.

1. S. theesans, Brongn. in Ann. Sc. Nat. Par. ser. i. x. 360. A shrub?, the side-shoots occasionally converted into or ending in a thorn; the branches slender, angular, and slightly tomentose. Lower leaves opposite, the upper ones alternate, ovate, serrulate, seldom 1 in. long, shining above and green and glabrous on both sides, with fine and distant pinnate veins. Lower racemes simple, 1 to $] \frac{1}{2}$ in. long, the upper ones branching into panicles twice that length.

Hongkong, Champion, Wright, Wilford. Also on the adjoining continent, in Penang, and in the Philippines.

\section{RHAMNUS, Linn.}

Petals and stamens 4 or 5 (the former sometimes wanting), inserted at the top of the cup-shaped or hemispherical tube of the calyx. Ovary free, usually shorter than the calyx-tube, 2 - to 4 -celled, with 1 erect ovule in each cell, the style 2- to 4-cleft. Fruit a drupe, with 2 to 4 1-seeded kernels. Albumen fleshy.-Trees or shrubs. Leaves usually alternate, with pinnate veins. Flowers small, greenish, pedicellate, in axillary clusters or umbels.

A considerable genus, spread over the temperate regions of the northern hemisphere, with a very fow tropical species from hilly districts.

1. R. virgatus, Roxb. Fl. Ind. i. 604. An erect shrub, more or less thorny, glabrous, or the young shoots and leaves pubescent. Leaves alternate or nearly opposite, ovate or oblong, acuminate, 1 to $1 \frac{1}{2} \mathrm{in}$. long, serrulate, contracted into a petiole at the base, of a thin consistence. Flowers on pedicels of 1 to 2 lines, clustered at the base of leafy buds. Petals 4, minute. Stamens as many. Ovary 2- or 3-celled, the style divided about halfway. 
On Victoria Peak, Champion; also Wright. Widely spread over the mountainous districts of India, in the Nilgherries, as well as the Himalaya.

\section{ORdER XXXIV. TEREBINTHACE}

Flowers partially or wholly unisexual, or more rarely hermaphrodite. Sepals 5 , or rarely 3,4 , or 7 , more or less united and usualiy very small. Petals as many, inserted on the outside or margin of a perigynous or hypogynous disk, rarely wanting. Stamens as many, or twice as many. Ovary superior, 1- to 5-celled, with 1 or 2 ovules in each cell. Styles 3 to 5, usually distinct. Fruit usually a drupe, 1-celled, with 1 seed, either ascending or pendulous. Albumen none. Radicle usually next the hilum. Cotyledons thick and fleshy. - Trees or shrubs, sometimes climbers, usually with a resinous, gummy, caustic, or milky juice. Leaves alternate, usually pinnate, sometimes simple, not dotted, without stipules. Flowers small, paniculate.

A large Order, widely distributed over the warmer and temperate regions of the globe.

Stamens alternate with the petals. Ovules solitary (Anacardiea) . 1. RHus. Stamens opposite the petals. Ovules 2 in each cell (Meliosmea) . . 2. SABIA.

\section{RHUS, Linn.}

Sepals, petals, and stamens 5. Ovary 1-celled, with 3 short styles or stigmas. Ovule 1, suspended from an erect filiform funiculus. Drupe small, oblique, with very little juice or nearly dry. Radicle short, curved against the edge of the flat cotyledons. - Trees or shrubs. Leaves pinnate in the Chinese species.

A considerable genus, with nearly the geographical range of the Order, but less abundant within the tropics than in subtropical and temperate regions.

Leaves, panicles, aud drupes quite glabrous . . . . . . . 1. R. succedaneum. Leaves white-cottony underneath. Panicles and drupes downy . . 2. R. hypoleuca.

1. R. succedaneum, Linn.; DC. Prod. ii. 68 ; Wight, Ic. t. 560. A tree or tall shrub, quite glabrous in all its parts. Leaves pinnate, the common petiole slender, not winged, 6 to 8 in. long. Leaflets 11 to 15 , oblong or ovate-lanceolate, acuminate, 2 to $3 \mathrm{in}$. long, the point long and acute, very oblique at the base, green on both sides and shining above. Panicles 2 to 4 in. long, clustered in the axils of the leaves, the males more branched than the females, the branches spreading. Petals small and soon falling off. Drupes about 4 lines broad, very oblique, and quite glabrous.-Connarus juglandifolius, Hook. and Arn. Bot. Beech. 179.

In the Happy Valley, Champion and others. In S. China, north-east India, and northward to Japan. In one specimen gathered by Wright the leaflets are narrow as in our Japanese ones; in the others they are broader, with long points and more transverse veins, approaching the north Indian $R$. acuminata, DC., which seems to be a mere variety, with usually, but not always, fewer leaflets. The venation is somewhat variable, even on the same specimens.

2. R. hypoleuca, Champ. in Kew Journ. Bat. iv. 43. A tree. Leaves pinnate, the common petiole cylindrical, 8 to $10 \mathrm{in}$. long. Leaflets 11 to 17 , ovate-lanceolate, somewhat acute, 2 to $2 \frac{1}{2} \mathrm{in}$. long, oblique at the base, with 
very short petiolules or almost sessile, glabrous above or scarcely tomentose on the principal veins, very white underneath, with a short close cotton. Panicle terminal, pyramidal, about 4 in. long, sessile above the last leaves, very much branched and downy. Petals white, more conspicuous than in the last species. Drupes covered with a reddish down.

In woods of the Happy Valley and Mount Gough, but sparingly, Champion, Hance, Seemann, Fortune, Wilford. Not known out of the island.

There are in Wright's collection two specimens, the one with male buds, the other with an unripe fruit, of a diœcious shrub or tree, apparently allied to Spondias, but quite insufficient for determination.

The Mango, Mangifera indica, Linn., has been sent in some of the Hongkong collections, but from cultivated trees, without any indication whether it has established itself in a halfwild state.

\section{SABIA, Colebr.}

Flowers hermaphrodite. Sepals 5 (rarely 4 ), united at the base. Petals 5 (rarely 4), opposite the sepals. Stamens of the same number as and opposite to the petals. Hypogynous disk 5-lobed. Ovary 1-or 2-celled, with 2 superposed ovules in each cell. Styles 1 or 2 , cylindrical. Drupes containing a single reniform seed. Radicle inferior. Cotyledons ovate, incurved.Climbers. Flowers axillary, solitary, cymose or paniculate.

A small Asiatic genus, forming, with Meliosma and Phoxanthus, a small tribe, differing from other Terebinthacere chiefly in the opposition of the sepals, petals, and stamens.

1. S. limoniacea, Wall.; Hook., and Thoms. Fl. Ind. i. 210. A glabrous climber. Leaves from oblong to lanceolate, 3 to 6 in. long, entire, coriaceous. Panicles loosely racemiform or shortly branched, longer or shorter than the leaves, either leafless or bearing a few small leaves. Petals broadly oval, obtuse. Stamens not longer than the petals. Drupes rounded, flattened.Androglossum reticulatum, Benth. in Kew Journ. Bot. iv. 41.

In ravines of Victoria Peak, Champion, Wilford. In eastern India, from Chittagong to Khasia and Sikkim. By some mistake this plant has been referred by Seemann to the S. paniculata, Edg., a very different species both in inflorescence and flowers.

\section{ORDER XXXV. CONNARACEAE.}

Flowers regular. Sepals 5, persistent, free or united at the base, imbricate or rarely valvate. Petals 5 , free, hypogynous, imbricate in the bud. Stamens 10, hypogynous, usually united in a ring at the base. Ovary of 5 distinct carpels, either all perfect, or 1 perfect and 4 slender abortive ones, or rarely reduced to 2 or 1 carpel. Styles entire, continuous from the inner edge of the carpels, with single terminal stigmas. Ovules 2 in each carpel, collateral and erect. Ripe carpels opening along the inner edge. Seed erect, solitary, often enclosed in an arillus. Albumen either none or fleshy. Radicle superior. Cotyledons fleshy where there is no albumen, thin in the albuminous seeds.-Trees or shrubs, without resinous juices. Leaves alternate, pinnate, without stipules. Flowers rather small, in panicles or racemes, usually clustered in the axils of the leaves.

A small Order, almost entirely tropical, common to the New and the Old World. 


\section{ROUREA, Aubl.}

Sepals imbricate. Ovary of 1 perfect carpel and 4 filiform abortive ones, as long as the perfect one. Capsule sessile, usually curved outwards. Seed with a coloured arillus, without albumen.

A considerable genus, with the habit and geographical range of the Order.

Leaflets 3,5 , or rarely 7 , each 2 to 3 in. long . . . . . . 1. R. santaloides.

Leaflets usually 11 to 17 , each seldom above 1 in. long . . . . 2. R. microphylla.

1. R. santaloides, $W$. and Arn. Prod. Fl. Penins. i. 144. A glabrous tree. Leaflets 3,5 , or rarely 7 , or occasionally reduced to a single one, ovate or oval-elliptical, acuminate, 2 to $3 \mathrm{in}$. long, on a petiolule of 1 or 2 lines, veined and shining on both sides. Panicles or racemes usually shorter than the leaves, and clustered in their axils. Flowers rather small, white, pedicellate. Capsule sessile, ovoid, rather oblique, 6 to 8 lines long, with numerous curved longitudinal veins. Seed enveloped in an orange-coloured arillus.-Connarus Roxburghii, Hook. and Arn. Bot. Beech. 179.

Abundant in ravines, Champion, Hance, and others. Apparently dispersed all over eastern India, the Archipelago, the Philippines, and S. China, for I cannot find any characters to distinguish the specimens published by Planchon as species under the names of R. Milletti, $R$. commutata, R. caudata, R. heterophylla, and $R$. n. 18 , or those distributed by Blume as $R$. javanica and $R$. humilis.

2. R. microphylla, Planch. in Linnae, xxiii. 421. A glabrous tree or shrub. Leaflets 11 to 17 (or reduced to 9 or 7 on some of the smaller side branches), ovate or oblong, obtusely acuminate, seldom exceeding an inch in length, usually very oblique at the base but sometimes nearly straight; on very short petiolules, coriaceous, shining above, rather glaucous underneath when young. Racemes clustered in the axils of the leaves, 1 to $1 \frac{1}{2} \mathrm{in}$. long. Flowers white, on slender pedicels. Capsules 6 to 8 lines long, narrower than in $R$. santaloides, much curved. Seed enveloped in a thin arillus.Connarus microphylla, Hook. and Arn. Bot. Beech. 179. Averrhoa sinica, Hance in Walp. Ann. ii. 241.

Abundant in ravines, Champion and others. Also on the adjacent continent, but not known out of S. China.

\section{ORDER XXXVI. LEGUMINOS正.}

Sepals combined into a single calyx, more or less divided into 5 or fewer teeth or lobes, rarely entirely distinct. Corolla of 5 or rarely fewer petals, perigynous or rarely hypogynous, very irregular in the first suborder, less so in the second, small and regular in the third. Stamens twice the number of petals, rarely fewer, or sometimes indefinite, inserted with the petals. Ovary single (consisting of a single carpel), with 1,2 , or more ovules arranged along the inner or upper angle of the cavity. Style simple. Fruit a pod, usually flattish and opening round the margin in 2 valves, but sometimes indehiscent or variously shaped. Seeds with 2 large cotyledons, a short radicle, and (with few exceptions) without albumen.-Herbs, shrubs, trees, or climbers. Leaves alternate, or in a few genera (not Asiatic) opposite, usually furnished with stipules, compound or simple (reduced to a single leaflet or to 
an expanded petiole), the leaflets or simple leaves entire or very rarely toothed. Flowers in axillary or terminal racemes or spikes, when terminal often becoming leaf-opposed by the growth of a lateral shoot, rarely solitary.

The largest natural Order next to Composite, and widely distributed over the whole surface of the globe.

Suborder I. Papilionacea.-Corolla very irregular, the upper petal (or standard) outside in the bud.

Stamens all united or the upper one alone free.

Leaves simple or of 2 or 3 leaflets.

Pod continuous (not articulate).

Leaflets digitate or solitary.

Stamens completely united in a tube. Pod iuflated . 1. Crotalaria.

Upper stamen free, at least at the base. Pod flat . . 21. Eriosema.

Leaflets pinnately arranged, the two lateral inserted below the terminal one.

Ovary and pod 1-seeded.

Pod very small, reniform; the veins much curved . 2. Medicago.

Pod flat, reticulate . . . . . . . . 12. Lespedeza.

Ovary and pod 2-seeded . . . . . . . . . . : 20. Rнуnсноsia.

Ovary and pod with more than 2 seeds.

Two bracteoles under the calyx.

Standard shorter than the other petals (flower large) . 14. Mucuna.

Keel spirally twisted . . . . . . . . 16. Phaseolus.

Petals regularly papilionaceous.

Upper calyx-lobes large, 3 lower ones very small . 15. Canavalia,

Lobes of the calyx nearly equal.

Stems twining. Pod long and linear . . . . . 13. Neustanthus.

Stems decumbent or ascending, Pods short, oblong, turgid . . . . . . . . . 2\%. Pycnospora.

Calyx without bracteoles at the base.

Pod marked with depressed transverse lines between the seeds.

Erect undershrub. Standard with two callosities . 17. Cajanus.

Stem prostrate or twining. Standard without callosities

19. Atrlosia.

Pod without depressed transverse lines. Twiner . . 18. Dunbaria.

Pod articulate.

Leaflets 2

Leaflet 1. Pod scarcely flattened . . . . . . . . 8. Aursicarpus.

Leaflets 3 or rarely 1. Pod very flat.

Pod turned back in the calyx.

Calyx small, with subulate teeth . . . . . 9. Urania.

Calyx enlarged after flowering, with broad teeth . 10. LoukEA.

Pod straight . . . . . . . . . . . . 11. Desmodium.

Leaves pinnate, of 5 or more leaflets.

Herbs or undershrubs.

Pod not articulate.

Upper stamen free. Anthers tipped by a gland or point .

Stamens monadelphous, at least in the middle. Anthers obtuse . . . . . . . . . . . .

Pod articulate

Pod articulate

Herbaceous climbers. Stamens 9. Pod 2-valved . . . 23. ABrus.

Trees or tall woody climbers.

Pods 2-valved. Stamens 10 . : : . . . . . : : 5. Mullettia.

Pod indehiscent.

Anthers small, erect, opening at the top. Flowers small, cymose 
Anthers versatile, opening lengthwise. Flowers racemose.

Tree. Pods thick, not winged . . . . . . 26. Pongamia.

Woody elimbers. Pods thin, with a narrow wing - 25. Derris.

Stamens all free (Sophorece).

Calyx loose, truncate. Leaves simple : . . . . . . 27. Bowringia.

Calyx 5-toothed. Leaves pinnate.

Fruit indehiscent, much contracted between the seeds . . . 28. Sophora.

Pod 2-valved . . . . . . . . . . . . 29. Ormosia.

Stborder II. Cæesalpiniea.-Corolla irregular or nearly regular, imbricate in the bud, the upper petal inside.

Leaves twice pinnate.

Pod very prickly . . . . . . . . . . . . . . . 30. Guilandina.

Pod not prickly . . . . . . . . . . . 31. Casalpinia.

Leaves once pinnate.

Petals conspicuous, yellow, spreading . . . . . . 32. Cassia.

Petals very small, almost like the sepals . . . . . 34. GLeditschia.

Leaves 2-lobed or with 2 leaflets . . . . . . . . . . 33. Bavininia.

Suborden III. Mimoser.-Corolla regular. Petals small, valvate in the bud. Leaves twice pinnate.

Stamens 10 . . . . . . . . . . . 35. Leucena.

Stamens indefinite.

Stamens free, usually short $. . .^{\circ} . .^{\circ}$. 36. Acacia.

Stamens monadelphous, usually long.

Pod straight, thin . . . . . . . . . . 37. A crizzia.

Pod curved or spiral, often thick and pulpy inside . . . 38. Piтhecolobium.

\section{SUBORDER I. PAPILIONACEAE.}

Calyx 5-toothed or -cleft, or 4-toothed by the union of the 2 upper ones, rarely splitting irregularly. Corolla very irregular, papilionaceous, that is, of 5 petals, the upper one, or standard (vexillum), outside in the bud; the 2 lateral ones, called vings (alœ), intermediate; the 2 lowest more or less united along one edge into a single boat-shaped one called the keel (carina). Stamens usually 10, either all united or diadelphous, when one is usually free, and the 9 others united, or all free.

\section{TRIBE I. GENISTEA.}

Leaves simple, or of 3 (rarely 5 ) digitate leaflets, all inserted at the end of the petiole. Racemes terminal or leaf-opposed. Stamens all united in a tube.

\section{CRototararia, Linn.}

Calyx 5-cleft. Standard broad. Wings free, transversely wrinkled above the claw. Keel with a straight or curved point or beak. Stamens all united in a sheath, open on the upper side. Anthers alternately ovoid and oblong. Style suddenly bent in above the ovary. Pod inflated.-Herbs or shrubs. Leaves simple and sessile, or with 3 or 5 digitate leaflets at the end of the petiole. Stipules scarcely conspicuous in the Hongkong species. Racemes terminal or leaf-opposed. Pedicels solitary to each bract, with 2 bracteoles close under or even upon the calyx. Flowers yellow, or rarely bluish or purplish. 
A large genus, chiefly tropical, with a few extratropical species in North America, South Africa, or Australia.

Leaves simple, sessile.

Erect perennial of $3 \mathrm{ft}$. Petals longer than the calyx . . . . . . 1. C. retusa.

Annuals or decumbent perennials. Petals shorter or not longer than the calyx.

Calyx covered with long spreading hairs.

Fruiting calyx near 1 inch. Flowers pale yellow. Seed in a loose raceme . . . . . . . . . 2. C.calycina. Fruiting ealyx 8-9 lines. Flowers blue, in a short dense raceme . 3. C. brevipes.

Calyx slightly hoary or silky with short appressed hairs . . . 4. C. albida.

leaves with 3 leaflets. Pod nearly globular....+ .5 .5$. . . elliptica.

1. C. retusa, Linn.; Benth. in Hook. Lond. Journ. Bot. ii. 480 ; Bot. Reg.t. 253 ; Bot. Mag.t. 2561. An erect undershrub of about $3 \mathrm{ft}$., with few stiff erect branches, hoary with a short pubescence. Leaves simple, cuneateoblong, $1 \frac{1}{2}$ to $3 \mathrm{in}$. long, very obtuse or retuse, glabrous above, more or less hoary or silky underneath with short appressed pubescence. Flowers rather large, yellow, pendulous, in terminal racemes about 6 in. long. Calyx 4 to 6 lines long, slightly pubescent; the lobes lanceolate, the 3 lower united higher up than the others. Standard broadly orbicular, 8 or 9 lines diameter. Pod sessile, glabrous, 1 to $1 \frac{1}{2}$ in. long.

In sandy or grassy places near the sea, Wright. Common in similar localities, as well as near the great rivers in tropical Asia, and in the maritime provinces of tropical America.

2. C. calycina, Schranck; Benth. l.c. 564. A decumbent or nearly erect annual, 1 to $1 \frac{1}{2} \mathrm{ft}$. high, with appressed hairs on the branches and under side of the leaves. Leaves simple, sessile, from oblong or lanceolate to linear, 2 to $4 \mathrm{in}$. long, glabrous or nearly so on the upper side. Racemes terminal, of a few distant pendulous pedicellate flowers, remarkable for their large calyx, thickly covered with long spreading rusty hairs, and attaining, after flowering, near $1 \mathrm{in}$. in length. Petals pale yellow, shorter than the calyx. Pod sessile, glabrous, nearly as long as the calyx, with numerous small seeds.

Hongkong, Eyre, Hance. Common in hot, grassy, and waste places throughout tropical Asia, extending westward into tropical Africa, and eastward to North Australia.

3. C. brevipes, Champ. in Kew Journ. Bot. iv. 44. A decumbent or nearly erect annual, like the last, but with leaves usually narrower, and the flowers blue, rather smaller, in short dense terminal racemes, the calyx seldom attaining 9 lines in length. In these respects it resembles the $C$. sessiliflora, a common species in eastern tropical Asia, and which has been gathered near Canton, but not yet in Hongkong. This species has, however, still smaller flowers, the calyx not attaining above 6 lines in length.

On the border of an estuary at East Point, in a sandy soil, Champion. As this plant has not appeared in any other collection, there is some reason to conjecture that it may be some accidental variety of the $C$. sessiliflora.

4. C. albida, Heyne; Benth. in Hook. Lond. Journ. Bot. ii. 567. Stock perennial, often woody, with numerous decumbent or ascending brancies, from a few inches to above a foot high ; the whole plant'more or less hoary with closely appressed hairs. Leaves from obovate or cuneate-oblong to linear, obtuse or with a small point, 6 to 9 lines long or rarely above 1 in. Flowers rather small, pendulous, in terminal usually one-sided racemes. Upper lobes 
of the calyx falcate-oblong, much larger than the others, 4 to 5 lines long. Petals yellow, not exceeding the calyx. Pod sessile, oblong, glabrous, about half as long again as the calyx.-C. leiocarpa, Vog. in Pl. Meyen. 8.

Common on the slopes of the hills, Champion and others. Widely distributed over the hilly districts of tropical Asia, from the Nilgherries and Cashmere to Burmah and South China.

o. C. elliptica, Roxb.; Benth. l. c. ii. 580. Stem woody at the base, with stiff but slender straggling branches, 1 to 2 feet high, and usually pubescent. Leaflets 3, oval-elliptical, obovate or rarely oblong, the terminal one often $1 \mathrm{in}$. long, or even more, the lateral ones usually shorter, glabrous above, slightly silky-pubescent underneath, the common petiole 6 to 9 lines long. Racemes at first terminal, but very soon becoming leaf-opposed, about $1 \mathrm{in}$. long when in flower, 2 to 3 when in fruit. Flowers small, yellow, the petals longer, however, than the calyx. Calyx obliquely ovoid-globular, about 3 lines long, closely pubescent.

Hongkong, Hinds and others. Apparently common in South China, extending to Cochin China, but not known from elsewhere.

\section{TrIBE II. TRIFOLIE A.}

Stem herbaceous, not twining. Leaves 3 -foliolate, without stipellæ, the numerous veins of the leaflets extending to the edge, and often projecting into minute teeth. Racemes usually axillary. Stamens diadelphous. Ovary with 2 or more ovules, rarely with a single ovule.

\section{MEDICAGO, Linn.}

Pod very much curved, usually spirally twisted, or sometimes 1-seeded and reniform, and then with very much curved veins.

A considerable genus, the species almost all indigenous to the Mediterranean region.

1. M. lupulina, Linn.; DC. Prod. ii. 172. Stock perennial, with several decumbent or ascending pubescent stems, 1 to 2 feet long. Stipules entire. Leaves pubescent, with 3 obovate or obcordate slightly denticulate leaflets. Flowers very small, yellow, in short dense pedunculate axillary racemes. Pod very small (scarcely $1 \frac{1}{2}$ lines long), ovoid-reniform, rather thick, glabrous or pubescent, marked with much-curved veins, black when ripe, with a single seed.

Hongkong, probably introduced with Gram (Cicer), Hance. Common in pastures and meadows over the greater part of Europe and Asia, but so frequently cultivated that in many countries it can only be considered as a naturalized plant.

Some other Trifoliea of the genera Medicago, Trifolium, and Melilotus, are common as indigenous or naturalized pasture plants or weeds in Asia as well as Europe, and may very probably appear also in Hongkong.

\section{TRIBE III. INDIGOFEREA.}

A small tribe, almost limited to the genus Indigofera, distinguished chiefly by the anthers, tipped with a gland or point, from Galegea, with which they would be united, but that the leaflets are in a few species digitate, as in Genistea. 


\section{INDIGOFERA, Linn.}

Calyx small, broadly and obliquely campanulate, with 5 teeth or lobes, the lowest the longest. Standard ovate or orbicular. Keel erect, with long claws, and a small protuberance or spur on each side, above the claw. Stamens diadelphous, the sheath slender, and usually persistent after the fall of the petals. Anthers tipped with a small gland or point. Ovary sessile or nearly so, with several ovules. Pod usually slender, cylindrical or 4-angled, with transverse cellular partitions between the seeds, rarely flattened, or when reduced to a single seed nearly globular.-Herbs, undershrubs, or slender shrubs, more or less hoary or sprinkled with appressed hairs, fixed by their centre. Leaves usually pinnate, with opposite or alternate leaflets and a terminal odd one, sometimes reduced to 3 or 1 , and in a few African species with 3 or 5 digitate leaflets. Stipules small ; stipellæ occur occasionally. Flowers usually red or purple, in axillary spikes or racemes.

A large genus, widely spread over tropical Asia and America, but still more abundant in tropical and southern Africa, with a few Australian species.

Prostrate, decumbent, or ascending herbs. Pods straight, closely reflexed on the peduncle.

Stem hirsute with spreading hairs . . . . . . . . . . 1. I. hirsuta.

Stem glabrous, much flattened . . . . . . . . . . 2. I. endecaphylla.

Erect shrubs or undershrubs.

Pods reflected, much curved and crowded. Flowers small . . . 3. I. Anil.

Pods straight, spreading. Flowers rather large, in loose racemes.

Leaflets much veined, most of them very obtuse . . . . : 4. I. venulosa.

Leaflets slightly veined, most of them acute . . . . . 5. I. decora.

1. I. hirsuta, Linn.; W. and Arn. Prod. Fl. Penins. i. 204. A decumbent or ascending branching annual, 1 to 2 feet high, remarkable in the genus for the spreading hairs which clothe the branches, petioles, and inflorescence. Leaves pinnate, with 3 to 5 pair of opposite leaflets and a terminal one, all obovate or oblong, with stiff appressed hairs, the common petiole 2 to $3 \mathrm{in}$., the leaflets from $\frac{1}{2}$ to $1 \mathrm{in}$. long. Racemes dense, shortly stalked, from 1 to $4 \mathrm{in}$. long. Pods about $\frac{1}{2}$ in. long, straight, quadrangular, reflexed on the peduncle, very hirsute, with 5 to 7 seeds.-I. astragalina, DC. Prod. ii. 228.

On the racecourse, Champion; abundant near the sea, Wilford; also Wright and Hance. Widely dispersed over tropical Africa, Asia, and Australia.

2. I. endecaphylla, Jacq.; DC. Prod. ii. 228 ; Bot. Mag. t. 789. Stock perennial, sometimes almost woody ; the branches prostrate or ascending, somewhat hoary, and always more or less flattened, especially in the upper part. Leaflets from 5 to 11 , alternate, from obovate to oblong, or even linear, from 4 to 6 , or even 8 lines long, obtuse, glabrous above, with appressed hairs underneath, the common petiole about 1 in. long. Flowers small, almost sessile, in axillary racemes about the length of the leaves. Calyx deeply 5cleft, with subulate teeth (or lobes). Pods about $\frac{3}{4}$ in. long, straight, obtusely quadrangular, reflexed on the peduncle, nearly glabrous, usually with 8 to 10 seeds.-I. anceps, Vahl; DC. Prod. ii. 228. I. Kleinii, W. and Arn. Prod. i. 204. I. Schimperiana, Hochst. Pl. Schimp. Abyss.

Hongkong, Wright. Occurs in various parts of tropical and southern Africa, and in the Indian Peninsula, probably therefore introduced into Hongkong. 
3. I. Anil, Linn. ; DC. Prod. ii. 225. A shrub or erect undershrub, 3 to 5 feet high, more or less hoary with appressed hairs. Leaflets in the more luxuriant specimens often 8 or 9 pair, besides the terminal one, and full an inch long, in drier situations often only 2 to 4 pair, and not above 6 lines long, all opposite, from obovate to oblong, glabrous or nearly so on the upper side, hoary with appressed hairs underneath. Flowers scarcely above 2 lines long, in short dense almost sessile racemes, on very short recurved pedicels. Calyx campanulate, with short broad teeth. Pods about $\frac{1}{2} \mathrm{in}$. long, usually densely packed and much incurved, slightly tetragonous, with 6 to 10 seeds.

On roadsides and in other waste places, Hance and others. The species is supposed to be of American origin, but is now so generally cultivated for indigo in America, Africa, and Asia, and spreads so readily as a weed, that it is impossible to fix its native country with any certainty. The $I$. tinctoria, which is rather more generally cultivated in Asia, differs chiefly in the looser racemes, with longer and more slender pods, always straight.

4. I. venulosa, Champ. in Kew Journ. Bot. iv. 44. An erect glabrous undershrub, 1 to $1 \frac{1}{2}$ feet high, the stems usually but little branched. Leaflets opposite, 2 to 6 pair, besides the terminal one, ovate or orbicular, the terminal one often $1 \mathrm{in}$. long, the others shorter, all very obtuse, or sometimes slightly mucronate, green on both sides, the network of smaller veins very prominent, quite glabrous, or with a few appressed hairs underneath. Racemes somewhat shorter than the leaves; the peduncle slender, bearing flowers only in the upper half. Pedicels $1 \frac{1}{2}$ lines long. Flowers showy, of a reddish-lilac, about 7 lines long, the petals slightly pubescent. Calyx-teeth short. Pod straight, glabrous, with several seeds.

Victoria Peak, Champion, also Wright; found also on Silver Island by Fortune, n. 43, but not out of S. China. It is, however, nearly allied to the North Chinese $I$. macrostachya, as well as to the following, I. decora, but may be distinguished from the former by its glabrous surface, from the latter by the smaller leaflets and flowers, from both by the prominent veins of the leaflets.

5. I. decora, Lindl. in Journ. Hort. Soc. Lond. i. 68; and Bot.Reg. 1846, t. 22. An erect shrub or undershrub, 1 to 2 or even 3 feet high, and nearly glabrous. Leaflets opposite, 3 to 6 pair besides the terminal one, from oval to oblong-elliptical, the largest from $1 \frac{1}{2}$ to $2 \mathrm{in}$. long, usually acute or scarcely obtuse, glaucous, and slightly hairy underneath, the smaller veins scarcely conspicuous. Racemes shorter than the leaves, like those of $I$. venulosa, but the flowers themselves are larger and more showy.

East Point, Hongkong, from Col. Eyre's drawings. 'I have not, however, seen Hongkong specimens, but describe it from those gathered near Amoy by Fortune, and from garden specimens. It was also gathered in Japan by Wright.

\section{Tribe IV. GALEGEAE.}

Herbs, not twining, or shrubs, trees, or woody climbers. Leaves pinnate, often stipellate. Racemes axillary or terminal. Stamens monadelphous or diadelphous, the anthers obtuse. Ovary with 2 or more ovules. Pod opening in 2 valves.

\section{TEPHROSIA, Pers.}

Calyx ว-toothed. Standard broad, as long as or longer than the obtuse keel. Upper stamen free at the very base, but adhering to the sheath of the 
others in the middle. Style curved, glabrous, excepting sometimes a tuft of hairs on the terminal stigma. Pod linear, compressed, 2-valved, without partitions between the seeds.-Herbs, undershrubs, or rarely shrubs. I,eaves pinnate, with several pairs of opposite leaflets, and a terminal odd one, very rarely reduced to a single leaflet; the veins of the leaflets numerous, parallel, and oblique. Racemes terminal, leaf-opposed or in the upper axils, often leafy at the base. Flowers 2 to 6 together at each bract.

A considerable genus, widely spread over the tropical regions of the globe.

1. T. purpurea, Pers.; W. and Arn. Prod. Fl. Penins. i. 213. Stock perennial or sometimes woody, with slender but stiff decumbent ascending or even erect stems, 1 to 2 feet high, with spreading branches; the younger shoots often silky-hoary, becoming at length nearly glabrous. Leaflets in several rather distant pairs, cuneate-oblong or linear, about $\frac{1}{2}$ in. long. Racemes terminal or leaf-opposed, the lower ones often very short, the upper ones 6 in. or more, with distant fascicles of 3 or 4 pinkish flowers, each about 4 lines long; the broad standard scarcely exceeding the fine subulate calyx-teeth. Pod rather more than 1 in. long, glabrous or nearly so, with 6 to 8 seeds.

East Point, Champion. Common all over tropical Asia.

\section{MrLLeTtia, W. and Arn.}

Calyx campanulate, truncate, or with very short teeth. Standard broad, without the inflected appendages above the claw of Wisteria and allied genera. Stamens diadelphous. Ovary surrounded by a small cup-shaped disk, shortly stalked; style glabrous, with a termiual stigma. Pod thick, coriaceous, or almost woody, usually flattened, opening when quite ripe in two valves.-Trees or more frequently tall woody climbers. Leaves pinnate, with opposite leaflets and a terminal odd one, usually stipellate. Racemes usually simple, in the upper axils, forming a terminal panicle. Flowers 2 or more together, in fascicles or on short common peduncles.

A considerable genus, dispersed over tropical Asia and Africa.

Leaflets about 5. Standard purple, 1 in. long, silky-tomentose outside. Leaflets 9 to 13 . Standard white or yellowish, near 1 in.long, glabrous Leaflets 5 or 7 . Standard, not $\frac{1}{2}$ in. long, glabrous

1. M. nitida.

2. M. speciosa.

3. M. Championi.

1. M. nitida, Benth. in Hook. Lond. Journ. Bot. i. 484. A tall woody climber, the younger shoots covered with a close rusty tomentum, becoming at length glabrous. Leaflets usually 5, shortly petiolulate, ovate or ovaloblong, shortly and obtusely acuminate, 2 to 3 in. long, coriaceous, glabrous, and shining, the common petiole 2 to $4 \mathrm{in}$. long. Flowers large, purple, in dense terminal panicles. Calyx rusty-tomentose. Standard an inch long, elegantly veined and silky-tomentose outside. Keel long and incurved. Pod villous, 3 to 4 in. long, and 6 to 8 lines broad at the seeds, narrowed between them.-Marquartia tomentosa, Vog. in Pl. Meyen. 35, t. 1, 2 ?

Very common from the level of the sea to the summit of Victoria Peak, Champion and others; also on the adjacent continent, but not known out of China.

2. M. speciosa, Champ. in Kew Journ. Bot. iv. 73. A tall woody climber, the younger branches, petioles, and panicles covered with a dense white tomentum, the older branches glabrous. Leaflets 9 to 13, usually 11, oblong, 
obtuse, or scarcely acuminate, 2 to 3 in. long, smooth and shining above, slightly veined and sprinkled with a few hairs underneath. Flowers rather large, white, intermixed with a primrose-yellow, in racemes of 3 to 6 in. long in the upper axils, flowering from near the base. Pedicels 3 to 4 lines long. Calyx silky-tomentose, with short broad obtuse teeth. Standard near an inch in diameter, rather thick, glabrous or slightly mealy outside. Keel curved, but obtuse, scarcely so long. Pod tomentose, with thick coriaceous valves. Seeds orbicular, flattened.

Common on Vietoria Peak with M. nitida, but not elsewhere, Champion; also Hance and Wright. Not known out of S. China.

3. M. Championi, Benth. in Kew Journ. Bot. iv. 74. A tall woody climber, like the two last, but more slender and entirely glabrous, except a very slight pubescence on the panicles and young shoots. Leaflets 5 or 7 , ovate or oblong, obtusely acuminate, usually about $2 \mathrm{in}$., but varying from 1 to $3 \mathrm{in}$. long, thinner than in the two last, and the veins much more conspicuous. Racemes in the upper axils 1 to 2 in. long, flowering from the base; the upper ones forming a terminal panicle. Flowers white, about half the size of the two last species; the standard marked with a green spot at the base, and all the petals quite glabrous. Disk round the ovary very short, sometimes scarcely perceptible. Ovary and young fruit stalked, quite glabrous, with about 6 ovules: the ripe pod has not yet been observed.

Trailing over rocks on Mount Gough and in the Happy Valley woods, Champion; also Wright. Not received from elsewhere.

\section{TRIBE V. HEDYSAREAE.}

Herbs, or very rarely shrubs or trees. Leaves various. Pod separating transversely into one-seeded articles, usually indehiscent, or sometimes reduced to a single one-seeded indehiscent reticulate article. An artificially distinguished group, having the foliage and other characters sometimes of the Lotea, sometimes of the Galegere, or of the Phaseolea.

\section{6. 画CHYNOMENE, Linn.}

Calyx 5-cleft or 2-lipped. Petals nearly equal, the standard broad, the keel often beaked or pointed. Stamens all united in a sheath open on the upper side, or divided into 2 equal parcels. Pod stalked, linear, flattened, consisting of several articles and tipped by the short style.-Herbs or slender shrubs. Leaves pinnate, with several pair of leaflets usually alternate, and a terminal odd one. Racemes axillary, simple or branched, rarely terminal.

A considerable genus, chiefly American, with a very few species from tropical Asia and Africa.

1. FE. indica, Linn.; W. and Arn. Prod. Fl. Penins. i. 219; Wight, Ic. $t .405$. A slender decumbent or ascending annual, branching at the base, glabrous or slightly rough with a short pubescence. Stipules small, brown, produced at the base below their insertion. Leaflets numerous, usually 20 to 30 pair and an odd one, small, linear-oblong. Racemes few-flowered, often with a small leaf at their base. Flowers yellow, about 4 lines long. Calyx 2-lipped, the upper lip entire or slightly 2-cleft, the lower 3-lobed. Staminal sheath cleft above and below, dividing the stamens into two equal parcels. Pod narrow, with several articles. 
East Point, Champion. Common in tropical Asia, extending also into tropical Africa. The Hongkong specimens are rather stouter than usual, but the flowers are precisely those of $\bar{E}$. indica, not half so large as those of $\bar{E}$. aspera, the other common Indian species.

\section{ZORNIA, Gmel.}

Calyx 2-lipped, usually small and membranous. Petals nearly equal, the standard broad, the keel almost beaked. Stamens monadelphous in a closed tube. Ovary sessile or nearly so. Pod linear, flattened, consisting of several articles, often muricate.-Herbs, usually glandular-dotted. Leaves with 2 or 4 digitate leaflets, without stipellæ. Stipules usually half-sagittate. Racemes or loose spikes terminal; the flowers yellow, usually sessile and solitary between 2 bracts, which are like the stipules, but much larger and concealing the calyx.

A genus of several American and two or three African species, with one widely spread over the whole world within the tropics.

1. Z. diphylla, Pers. Syn. Pl. ii. 318. A low herb, sometimes annual, sometimes forming a thick root-stock of several years' duration; the branches decumbent, ascending or nearly erect, from 6 inches to 1 or 2 feet long. Leaflets 2 only at the end of the petiole, varying from ovate and only 2 or 3 lines long in the lower leaves, to lanceolate or linear, from $\frac{1}{2}$ to 1 in. long in the upper ones. Flowers in the common Asiatic varieties 3 to $3 \frac{1}{2}$ lines long, almost enclosed in the narrow-ovate bracts, which like the stipules are produced into a short auricle below their insertion, and are often, as well as the leaflets, marked with a few pellucid glandular dots. Pod longer or shorter than the bracts, of 3 to 6 articles, usually muricate with hooked or pubescent prickles.

East Point, Champion; also Hance and Wright. A very common species in S. America, where it is exceedingly variable; abundant also but less variable in many parts of tropical Africa, Asia, and Australia. Some of the Chinese specimens are almost without pellucid dots, as in the generality of the W. Indian specimens; but others have several on the bracts and occasionally a few on the leaves also; they correspond to the varieties $\epsilon$ vulgaris impunctata and $\zeta$ vulyaris punctata of my enumeration of varieties in Mart. Fl. Bras. Leg. p. 80 to 83 .

\section{ALYSICARPUS, Neck.}

Calyx narrow, acute at the base, deeply 4- or 5-cleft; the segments dry and stiff. Petals narrow, scarcely exceeding the calyx. Stamens diadelphous, the upper ones free from the base. Pods sessile, scarcely compressed, consisting of several indehiscent 1-seeded articles.-Herbs. Stipules and bracts paleaceous or scarious. Leaves simple (reduced to 1 leaflet). Racemes terminal or leaf-opposed. Flowers 2 together.

A rather small genus, chiefly S. Asiatic, a few species extending into tropical Afriea, or occasionally naturalized in tropical America.

Calyx-lobes narrow-subulate. Pod slightly wrinkled and not coutracted between the seeds . . . . . . . . . . .

Calyx-lobes lanceolate, glumaceous. Pod smooth, slightly contracted between the seeds

\section{A. vaginalis.}

2. A. buplevrifolius.

1. A. vaginalis, $D C$. Prod. ii. 353. A perennial, tufted or much branched at the base; the stems decumbent or ascending, from a few inches to a foot long, glabrous or slightly pubescent. Leaves on short slender petioles, 
the lower ones cordate, orbicular, or oval, not 6 lines long; the upper ones from oval-oblong to lanceolate-linear, and often 9 lines long or more, all obtuse. Racemes slender, terminal, or at length leaf-opposed, from $\frac{1}{2}$ to $1 \mathrm{in}$. long. Calyx about 2 lines long, 5 -cleft; the lobes very narrow, with a subulate or almost hair-like point. Petals scarcely longer. Pod 6 to 9 lines long, slightly compressed, obscurely wrinkled, the separation of the articles marked by transverse raised lines, but without any contraction.- $A$. «ummulariafolius, DC. 1. c.

Hongkong, Hance, Wright. Common in grassy and waste places in India and the Archipelago.

2. A. buplevrifolius, $D C$. Prod. ii. 352. A glabrous perennial, resembling the last, but usually more erect and taller, although sometimes short and decumbent. Leaves mostly oblong-linear, and nearly sessile, the longest often 1 or 2 in. or even more in length ; the lower ones broader and shorter, sometimes ovate. Racemes slender, often $6 \mathrm{in}$. long; the flowers in distant pairs, larger than in $A$. vaginalis. Calyx 3 to $3 \frac{1}{2}$ lines long; the lobes lanceolate, glumaceous, and overlapping each other. Petals scarcely so long. Pod sometimes scarcely exceeding the calyx, sometimes twice as long, the articles quite smooth and separated by distinct although often very slight contractions.

Hongkong, Wright. Common in the plains of India and in the Archipelago.

\section{URARIA, Desv.}

Calyx shortly and broadly campanulate, with 5 subulate lobes or teeth; the 2 upper ones often more or less united. Petals narrow, the standard obovate. Stamens diadelphous, the upper one free from the base. Ovules several. Pod stipitate, often bent back upon the calyx, consisting of 2 to 6 flattened joints, separated by very narrow contractions, and folded on each other.-Perennials or undershrubs. Leaflets 1,3 , or more, opposite in pairs, with a terminal odd one, with stipellæ. Stipules lanceolate, dry, striate. Racemes terminal, usually dense. Pedicels in pairs.

A genus of several S. Asiatic species, a few of which extend into tropical Africa or into Australia.

1. U. crinita, Desv.; DC. Prod. ii. 324. Perennial woody stem or stock usually very short. Flowering stems decumbent or ascending, from 6 in. to 2 or 3 feet high, the whole plant pubescent, with minute hooked hairs. Leaflets usually 3 or 5 , oblong, and often 4 to 6 in. long, or sometimes reduced to one, which is then shorter and more ovate. Stipules broadly lanceolate, striate, with long points. Racemes nearly sessile, cylindrical, and very dense, short at first, but attaining at length in some Chinese specimens 1 to $1 \frac{1}{2}$ feet, and very hairy. Lower bracts ovate, lanceolate, and persistent ; upper ones lanceolate, projecting beyond the flowers in a terminal tuft, but falling off after the flowers expand. Standard about $4 \frac{1}{2}$ lines long. Pod usually pubescent, of 3 or 4 small articles.-U. comosa, DC. I. c. U. macrostachya, Wall. Pl. As. Rar. ii. t. 110.

Common near the Albany barracks, Champion; also Hance. Frequent in the Indian Archipelago ; extends to eastern India and to Ceylon. 


\section{LOUREA, Neck.}

Calyx broadly campanulate, enlarged and membranous after flowering, with 5 ovate-lanceolate shortly pointed lobes. Petals narrow. Stamens diadelphous. Pod straight, consisting of two or more distinct articles folded upon each other as in Uraria.-Herbs or undershrubs, with the habit of some Desmodiums. Leaves with 1 or 3 leaflets. Flowers small, in terminal racemes or panicles.

A small genus, limited to tropical Asia, and chiefly found in the Malayan Peninsula and Archipelago.

1. L. obcordata, Desv.; DC. Prod. ii. 324. Stems slender, prostrate, usually shortly hairy, 1 to $2 \mathrm{ft}$. long. Leaflets usually 3 , the terminal one broadly obovate, orbicular, or reniform, 6 to 9 lines broad, truncate or emarginate at the top, with 3 to 5 lateral veins branching from each side of the midrib, the lateral ones ovate or obovate and smaller, sprinkled with a few small hairs. Racemes mostly terminal, slender, 2 to 6 in. long, or shorter and paniculate. Flowers small, shortly pedicellate. Calyx at first not above 1 line long and hairy, but after flowering attaining 3 lines, and completely enclosing the pod.

Hongkong, Champion, Wright. Frequent in the Indian Archipelago, extending to Burmah, the Philippines, and northwards to Amoy.

\section{DESMODIUM, DC.}

Calyx campanulate, with 4 acuminate teeth or lobes; the upper one 2 toothed or 2-cleft, or rarely equally 5-cleft. Petals narrow, the standard obovate, the wings usually adhering laterally to the keel, which has often on each side at the point of adhesion a small oblique membranous appendage. Stamens either monadelphous, with the sheath open on the upper side, or the upper stamen more or less free. Ovary sessile or stipitate, with 2 or more ovules (except in one Indian species). Style glabrous, with a minute terminal stigma. Pod consisting of 2 or more flat articles, usually reticulate.-Herbs, shrubs, or trees. Leaves with 1 or 3 leaflets. Flowers usually small, in terminal or leaf-opposed racemes or panicles, or rarely in axillary clusters.

A very large genus, widely dispersed over the tropical regions of the New and the Old World, with a few species in extratropical N. America, S. Africa, or Australia. It may be readily divided into 14 or 15 well-marked sections, which have been proposed by myself or others as distinct genera, but on a general review it appears more convenient to retain them all under one common generic name.

Calyx narrow and acute at the base. Keel usually withont lateral appendages.

Leaflet 1, the petiole winged. Keel beaked. Ovules several. Flowers

racemose, with small bracts. Keel obtuse. Ovules 3 . Flowers
Leaflets 3 , the petiole not winged. in dense clusters, sessile on the branches of a large panicle, with a large bifoliolate leafy bract to each cluster.

Leaves very softly hairy, whitish underneath. Pod of 3 silky-hairy articles

Leaves slightly hairy above, softly hairy underneath. Pod of 2 glabrous articles; ciliate on the edge

1. D. triquetrum.

2. D. elegans.

3. D. pulchellum. 
Calyx obtnse at the base. Keel obtuse, usually with a small oblique appendage on each side.

Pedicels or racemes filiform and leaf-opposed.

Pedicels 2 or 3 together, filiform and 1-flowered . . . . 4. D. triflomum.

Raceme slender, with 3 to 6 distant filiform pedicels . . . . . 5. D.parvifolium.

Racemes terminal.

Leaflets 3.

Racemes dense. Pods erect . . . . . . . . . . 6. D. polycarpon.

Racemes long and slender . . . . . . . . . 7. D.reticulatum.

Leaflet 1, broad. Racemes long and slender . . . . . 8. D.gangeticum.

1. D. triquetrum, $D C$. Prod. ii. 326. An erect perennial or undershrub, about $2 \mathrm{ft}$. high, nearly glabrous. Leaves consisting of a single leaflet, varying from ovate-lanceolate to lanceolate-linear, 2 to 4 in. long; the petiole flattened or winged, obovate or cuneate, with 2 stipellæ under the leaflet. Stipules lanceolate, striate. Racemes terminal, simple or branched, with numerous small shortly pedicellate flowers in fascicles of 2 or 3 . Bracts nearly subulate. Keel beaked. Pod sessile, flat, of several almost square articles, both edges of the pod continuous, or the lower edge very slightly indented between the seeds. - Pteroloma triquetrum, Desv.; Benth. in Pl. Jungh. i. 220. Desm. acrocarpum, Hance in Lond. Journ. Bot. vii. 473.

Victoria Peak, Champion; also Hance and Wright. Frequent in India and the Archipelago. It varies much in the size and shape of the leaflet and petiole, as well as in the pod either glabrous or nearly so, or sprinkled or edged with long hairs or thickly silky-hairy all over.

2. D. elegans, Benth. A branching perennial or undershrub. Stems villous. Leaflets 3 , ovate obtuse; the terminal one about 3 or 4 in. long, the lateral ones smaller, all villous above and very softly silky-villous and whitish underneath, the common petiole not dilated. Flowers small, in dense umbels or heads, sessile along the branches of a terminal leafy panicle, and almost enclosed in a 2 -foliolate leaf-like bract at the base of each umbel, each leaflet broadly ovate or orbicular, $\frac{1}{2}$ to $\frac{3}{4}$ in. long and very oblique at the base. Pod usually of 3 flat, nearly orbicular, small articles, very silky-villous, both edges of the pod, especially the lower one, indented between the articles._Dicerma elegans, DC. Prod. ii. 339. Phyllodium elegans, Desv.; Benth. in Pl. Jungh. 217.

Common in low grounds, Champion; also Wright. Only known hitherto from Java and from S. China, and perhaps from Cochin China.

3. D. pulchellum, Benth. A branching perennial or undershrub, like the last in foliage, inflorescence, and flowers, except that the leaves are only slightly pubescent on the upper surface, and softly pubescent not villous underneath, and the pod has almost universally only 2 articles, glabrous or nearly so on the faces, and slightly ciliate at the edges only.-Dicerma pulchel. lum, DC. Prod. ii. 339 ; Wight, Ic. t. 418. Phyllodium pulchellum, Desv.; Benth. in Pl. Jungh. 217.

East Point, Champion, also collected in the island by Hance, Seemann, and Wright. Widely spread over India from Ceylon and the Peninsula to the Archipelago, and northwards to the Himalayas, S. China, and the Philippines.

4. D. triflorum, $D C$. Prod. ii. 334; Wight, Ic. t. 2.91, 292. Stems slender, much-branched, prostrate or creeping, often not above a few inches 
long and sometimes spreading to 1 or $2 \mathrm{ft}$. in length. Leaflets 3 , broadly obcordate or obovate, 3 to 4 or rarely 6 lines long and broad, glabrous or sprinkled with silky hairs. Flowers pink, scarcely 2 lines long, on slender pedicels of 2 to 6 or 8 lines, usually 2 together opposite the leaves. Pod sessile, 4 to 7 lines long, slightly curved, pubescent or glabrous, the upper edge continuous, the lower slightly indented, consisting of 3 to 6 nearly square articles which sometimes separate, but more frequently remain attached and open along the outer edge to shed their seed.

Hongkong, Wright. Common in waste and grassy places in tropical Asia and Africa, and naturalized in several parts of tropical America.

5. D. parvifolium, $D C$. Prod. ii. 334. A very much-branched, slender, procumbent perennial, slightly hairy or pubescent, and often forming spreading tufts of more than $2 \mathrm{ft}$. diameter. Leaflets 3 , obovate or elliptical, usually smaller and more crowded than in $D$. triflorum, but sometimes near $\frac{1}{2}$ in. long. Racemes leaf-opposed or terminal, filiform, bearing 3 to 6 small pink flower's on long filiform pedicels, distant from each other along the common peduncle. Pod like that of $D$. triflorum, or usually more deeply indented.

Hongkong, Harland. Common in the hilly districts of India, from Ceylon and the Peninsula to the Archipelago, and northward to the Himalaya, the Philippines, and S. China to Amoy.

6. D. polycarpum, DC.; W. and Arn. Prod. i. 227; Wight, Ic. $t$. 406. An erect, decumbent or ascending perennial or undershrub, 1 to 2 , 3 , or more feet high, more or less pubescent with appressed hairs. Leaflets 3 , the terminal one obovate or elliptical, $1 \frac{1}{2}$ to $2 \mathrm{in}$. long, the lateral ones usually smaller. Racemes terminal, dense, 1 to near 3 in. long, often several together, forming a short terminal panicle. Bracts lanceolate, imbricate before the flowers expand, but soon falling off. Flowers purple, crowded, 3 or 4 lines long. Pods crowded, erect, hairy, or glabrous, about $\frac{1}{2}$ to $\frac{3}{4}$ in. long, consisting of about 4 to 6 articles, which often open at their maturity; the upper edge continuous, the lower one indented between the articles. $-D$. nervosum, Vog. Pl. Meyen. 28.

Common throughout the island, Champion and others. Extends over the whole of India, the Archipelago, and the Pacific islands.

7. D. reticulatum, Champ. in Kew Journ. Bot. iv. 46. Apparently an erect perennial or undershrub, glabrous or with a few appressed hairs sprinkled on the branches and under side of the leaves. Leaflets 3, oval-elliptical or oblong, obtuse at both ends, the terminal one about an inch long, the lateral ones sinaller, all very glabrous above, pale or glaucous underneath; the veins very conspicuous on both sides, especially underneath. Raceme slender, terminal, about $6 \mathrm{in}$. long, the flowers small, in distant pairs. Bracts lanceolate, longer than the buds, but not imbricate. Standard about 3 lines long, rather broad. Keel obtuse. Pod (seen only imperfect) composed of several narrow articles, one edge straight, the other indented between the articles.

Hongkong, Champion, Wright; S. China, Parkes. A Japanese specimen in the late Dr. Zuccarini's herbarium may also be the same, and if so it may prove to be one of Thunberg's old species. It is allied to, but quite distinct from, the Indian $D$. concinnum.

8. D. gangeticum, DC. Prod. ii. 327; Wight, Ic. t. 271. An erect herb or undershrub, 1 to 3 or even $4 \mathrm{ft}$. high, nsually with a few appressed 
hairs on the stems and under side of the leaflets. Leaflets always single at the end of the petiole, broadly ovate, or the lower ones orbicular, and the upper sometimes ovate-lanceolate, from 2 to $5 \mathrm{in}$. long. Stipules lanceolate-subulate. Racemes long, terminal, slender, simple or slightly branched. Bracts subulate. Flowers small, in distant fascicles of 2 to 6 . Standard scarcely 2 lines long. Pod narrow, about $\frac{1}{2}$ in. long, slightly pubeseent with minute hooked adhesive hairs, and consisting usually of 4 to 6 small indehiscent articles; the upper edge continuous or nearly so, the lower one deeply indented between the articles.

Hongkong, Hance. Common in India from the Peninsula and the Himalayas to the Archipelago, extending northward to the Philippines and S. China.

\section{LESPEDEZA, Rich.}

Calyx campanulate, 5 -toothed or -lobed or the 2 upper teeth united into 1. Standard obovate or oblong. Keel obtuse or beaked, without lateral appendages. Stamens diadelphous, the upper ones free from the base. Ovary sessile or stipitate, with a single ovule. Style usually pubescent, with a small terminal stigma. Pod flat, ovate or orbicular, reticulate, indehiscent, containing a single seed.-Herbs or undershrubs. Leaflets usually 3. Flowers in axillary racemes, often contracted into dense fascicles; the lower fascicles in many species often mixed with numerous minute apetalous flowers, producing nevertheless perfect pods.

A considerable genus, distributed over central and eastern Asia and North America, only fonnd within the tropies in mountainons distriets.

Flowers in axillary faseicles. Calyx-lobes subulate. Keel obtuse . . . 1. L. cuneata. Flowers solitary. Calyx-lobes obtuse. Keel obtuse . . . . . . 2. L. striata. Flowers in loose axillary racemes. Calyx-lobes lanceolate. Keel acute . 3. L. viatorum.

1. L. cuneata, G. Don; Benth. in Kew Journ. Bot. iv. 47. Root-stock thick and woody; stems several, decumbent, ascending or nearly erect, stiff, and but little branched, 1 to 2 or 4 ft. long, hoary when young, at length glabrous. Leaves usually crowded, the leaflets linear-cuneate, 2 to 6 lines long, glabrous above, more or less hoary or silky underneath, the common petiole seldom above a line long. Flowers pink-purple, in dense axillary clusters; those in the upper axils nearly all complete, about 3 lines long, the keel curved but obtuse; those of the lower clusters mostly apetalous, with imperfect stamens. Pod sessile, nearly orbicular, slightly acute, scarcely 1 line diameter.

On the side of a hill on the estuary, East Point, but rare in the island, Champion. Common in the Himalaya, extending eastward to S. China, Amoy, Loochoo, and Japan.

2. L. striata, Hook. and Arn. Bot. Beech. 262. A small diffuse branching herb, often not above a few inches long, and rarely attaining a foot, with an apparently perennial root-stock and wiry branches. Leaflets cuneateoblong, very obtuse, seldom above 3 or 4 lines long, glabrous or with a few appressed hairs on the ribs. Stipules ovate, longer than the very short petiole. Flowers small, solitary or 2 or 3 together, on short pedicels, in the axils of the leaves. Calyx-lobes ovate, obtuse, the length of the tube. Pod nearly orbicular, about 1 line diameter.

Hongkong, Harland, Hance. Found also on the adjacent continent, in Bonin, and Japan. 
3. L. viatorum, Champ. in Kew Journ. Bot. iv. 47. An erect perennial or undershrub, apparently 1 or $2 \mathrm{ft}$. high, glabrous, or hoary with appressed hairs on the branches and under side of the leaves. Leaflets obovate, very obtuse, 1 to $1 \frac{1}{2}$ in. long, or even more, with numerous parallel veins diverging from the midrib. Racemes axillary, either 1 to $2 \mathrm{in}$. long and rather dense, or longer and looser. Flowers 4 to $4 \frac{1}{2}$ lines long, on short pedicels. Calyxlobes lanceolate and acute. Standard obovate. Keel fully as long, shortly acuminate. Pod stalked, ovate, acute, 4 lines long, minutely pubescent.

Common about Little Hongkong, Champion. On the slope at the back of Victoria Peak, Wilford. Also on the adjacent continent, as far north as Amoy.

\section{Tribe VI. PHASEOLEA.}

Stems usually herbaceous, twining or prostrate; the leaves with 3 leaflets, 2 opposite ones inserted below the terminal one, or with 1 terminal one, and almost always stipellate, very rarely trees with pinnately trifoliolate leaves, or herbaceous twiners with pinnate leaves. Inflorescence usually axillary. Stamens diadelphous, with the upper stamen quite free at the very base, although sometimes united with the others in the middle. Pod 2-valved.

\section{NEUSTANTHUS, Benth.}

Calyx campanulate, 4 -toothed, the upper tooth notched or bific. Standard obovate-orbicular, with inflexed auricles above the short claw. Keel incurved or beaked. Upper stamen free at the very base, united with the others in the middle. Ovary sessile, with several ovules. Style filiform, glabrous, with a terminal stigma. Pod linear, nearly cylindrical when ripe.-Twining herbs. Leaflets 3, with stipellæ. Racemes axillary, elongated. Flowers shortly pedicellate, nodding, arising 2 or more together from gland-like nodes. Bracts very deciduous. Bracteoles persistent.

A small genus, confined to tropieal Asia.

Plant hairy. Stipules sessile. Flowers scarcely 4 lines long, the flowering nodes distant .................. Plant glabrous or slightly pubescent. Stipules peltate. Flowers 6 lines long, in dense l-sided racemes . . . . . . . . . 2. N. chinensis.

1. N. phaseoloides, Benth. in Pl. Jungh. i. 235, and in Keno Journ. Bot. iv. 48. A herbaceous twiner, more or less clothed in every part with rusty hairs, often whitish on the under side of the leaflets. Stipules ovatelanceolate, striate, not peltate. Leaflets broad, the terminal one 2 to $3 \mathrm{in}$. long, and usually rhomboid, the lateral ones oblique and rather smaller, all varying from obtuse to acuminate, entire or broadly 3-lobed. Flowers about 4 lines long, on rather distant nodes, on the upper half of peduncles of 4 to $6 \mathrm{in}$. Calyx hairy, the upper teeth scarcely so long as the tube, the lowest one long and subulate. Keel shórtly beaked. Pod at least 2 in. long, about $1 \frac{1}{2}$ lines broad, hairy, with 8 to 10 small transversely oblong seeds.-Dolichos phaseoloides, Roxb. Fl. Ind. iii. 316.

Hongkong, Champion. Extends from the Malayan Peninsula to Silhet, Sikkim, and S. China.

2. N. chinensis, Benth., n. sp. A tall twiner, glabrous or slightly pubescent on the stem, inflorescence, and under side of the leaves. Leaflets 3 , 
broad, 3 to $4 \mathrm{in}$. long, the terminal one rhomboid, the lateral ones oblique, all entire. Stipules ovate-lanceolate, produced below their insertion. Stipellæ subulate. Peduncle $6 \mathrm{in}$. long or more, bearing above the middle a dense one-sided raceme. Flowers 2 or 3 together at each node, full 6 lines long. Calyx-teeth or -lobes all rather longer than the tube, the lowest the longest and acute. Standard orbicular, wings narrow, keel broader, scarcely beaked. Ripe pod unknown.

Hongkong, Harland. Not received from elsewhere. It is a handsome species, coming nearest to the $N$. peduncularis, Benth., from Nepaul, but has larger flowers and differently shaped petals, besides other minor characters.

\section{MUCUNA, Adans.}

Calyx campanulate, 4-toothed. Standard shorter than the other petals. Keel as long or longer than the wings, curved, and usually tipped with a cartilaginous beak. Upper stamen free from the base. Style filiform, with a small terminal beak. Pod thick, ovate-oblong or elongated, usually covered with stinging hairs. Seeds with an oblong or a long linear hilun.-Twiners or tall climbers. Leaflets 3 , the stipellæ subulate or sometimes wanting. Racemes on long axillary peduncles. Flowers large, pedicellate, arising from gland-like nodes.

A cousiderable genus, spread over the tropical regions of Asia, Africa, and America.

Leaves silky underneath. Racemes short. Flowers $1 \frac{1}{2}$ in. long . . 1. M. Championi. Leaves glabrous or nearly so. Racemes long. Flowers 3 in. long . 2. M. macrobotrys.

1. M. Championi, Benth. in Kew Journ. Bot. iv. 49. A tall climber, woody at the base; the young shoots and under side of the full-grown leaves clothed with rust-coloured silky hairs. Leaflets about $3 \mathrm{in}$. long, the terminal one broadly ovate, the lateral ones very oblique, all shortly and obtusely acuminate. Racemes seldom above 4 in. long, including the peduncle, simple, or with 1 or 2 branches. Pedicels solitary, or 2 or 3 together on each node, 6 to 10 lines long. Flowers purple. Calyx 3 lines long, hairy inside and out. Standard about $1 \mathrm{in}$. long, wings $1 \frac{1}{2} \mathrm{in}$.; keel rather long, with a hard incurved point. Pod about 4-seeded, 6 to $7 \mathrm{in}$. long, 2 in. broad, glabrous when ripe, but reticulate, with numerous oblique raised wings, besides a longitudinal wing on each side of each suture.

On rocks and trees above the Buddhist Temple, at East Point, Champion. Not known from elsewhere.

2. M. macrobotrya, Hance in Walp. Ann. ii. 422. A tall climber, like the last, but quite glabrous, except a few small hairs sprinkled on the under side of the leaves. Leaflets oval-oblong, near $5 \mathrm{in}$. long, the lateral ones very oblique. Racemes long, loose, and pendulous, on very long peduncles. Flowers usually 2 together, pedicellate, dark purple, about 3 in. long. Calyxtube near 6 lines, and the lowest tooth but little shorter, sprinkled with a few hairs. Standard $1 \frac{1}{2}$ in., wings $2 \frac{1}{2}$ in., keel 3 in. long, with a hard beak. Pod (which I have not myself seen), 5 in. long, $1 \frac{3}{4}$ in. broad, 2- or 3 -seeded, hispid, and obliquely winged or plaited, as in the last species.

Near the Buddhist Temple, and perhaps introduced, Hance. Not seen from elsewhere. The flowering specimens are like those of $M$. macrocarpa, Wall., from Himalaya, but the pod as described by Hance is quite different. 


\section{Canavalia, DC.}

Calyx tubular-campanulate, the 2 upper lobes united in a large entire or 2-lobed upper lip, the 3 lower teeth very small, free or united into one. Standard large and broad. Wings and keel rather shorter, curved or sometimes slightly twisted. Upper stamen free at the very base, united with the othere in the middle. Style filiform or slightly thickened in the upper part with a terminal stigma. Pod oblong or linear, usually large, flattened or rarely turgid, with a prominent wing or rib on each side of the upper suture. Seeds with a long linear hilum.-Trailing or twining herbs. Leaflets 3 , with small stipellæ. Stipules usually very small. Peduncles axillary, bearing in the upper part a few 1- to 3-flowered nodes. Flowers rather large, purple, pink, or white.

A genus not numerous in species, but widely dispersed over tropical and subtropical Asia, Africa, and America.

1. C. gladiata, DC. Prod. ii. 404; Wight, Ic. t. 753. A large herbaceous twiner, glabrous or slightly pubescent. Leaflets usually broadly ovate, 3 to $5 \mathrm{in}$. long, the lateral ones very oblique. Peduncles about 6 in. long or more, flowering only above the middle. Flowers shortly pedicellate, purplish-red, pendulous, about an inch long. Calyx-tube 4 to 5 lines, the upper lip scarcely shorter, with 2 broadly orbicular lobes, lower lip scarcely ]$_{\frac{1}{2}}$ lines long, with 2 short lateral lobes. Standard broad, turned back on the calyx. Keel curved, but obtuse. Pod generally $1 \frac{1}{2}$ to 2 in. broad, but varying in length from $4 \mathrm{in}$. to near a foot, according to the variety.

Hongkong, climbing over trees and shrubs, Hance, Seemann, Wright. Widely dispersed over tropical Asia, Africa, and America, but some varieties are frequently cultivated, and the specimens received as wild may often have been naturalized only. There may be some confusion also between the wild variety known as $C$. virosa, or Dolichos virosus, Roxb., said to have very poisonous seeds, and those cultivated under the names of $C$. gladiata, DC., and $C$. ensiformis, DC. The materials and notes we possess do not as yet enable us fully to clear up their history and synonymy.

\section{PHASEOLUS, Linn.}

Calyx campanulate or nearly tubular, 5 -toothed or -lobed, rarely 4 -toothed by the union of the 2 upper ones. Standard orbicular, recurved or sometimes slightly twisted. Keel produced at the top into a long spirally twisted beak. Upper stamen free from the base. Style thickened and cartilaginous in the upper part, usually bearded longitudinally under the stigma, which is more or less oblique or lateral. Pod linear, and nearly cylindrical, or more or less flattened and falcate, with several seeds.-Herbs, either dwarf or prostrate, or more frequently twining. Leaflets 3 , rarely reduced to one, stipellate. Peduncles axillary, bearing in their upper part several 2- or 3-flowered nodes. Corollas glabrous, white, yellowish, red, or purple.

A large genus, widely dispersed over the tropical regions of Asia, Africa, and more especially America. Several species from very long cultivation have established races, the wild origin of which it is now difficult to trace.

1. P. minimus, Roxb. Fl. Ind. iii. 291. A rather slender twiner, glabrous or sparingly hairy. Leaflets 3 , ovate-lanceolate or lanceolate, 2 to 3 in. 
long. Stipules lanceolate, striate, produced below their insertion. Peduncles longer than the petioles, with very few flowering nodes at the summit. Flowers nearly sessile, 4 to 5 lines long. Calyx campanulate, the 4 upper teeth very short and broad, the lower one lanceolate, but not so long as the tube. Standard orbicular. Keel with a long lateral spur on one side only. Pod slender, nearly cylindrical, scarcely $2 \mathrm{in}$. long, with 5 to 8 transversely oblong seeds. Hilum linear.

Hongkong, Champion, Hance, Harland. Originally described by Roxburgh, from speeimens raised from Chinese seeds, and not known from elsewhere. It differs from the common Indian $P$. calcaratus, chiefly in its narrow leaflets and glabrous surface.

\section{CAJANUS, Linn.}

Calyx campanulate, 4-toothed or lobed, the upper lobe 2-toothed. Standard orbicular, with inflexed auricles at the base, and 2 callosities inside, above the claw. Wings and keel nearly of the same length. Upper stamen free from the base. Ovary with several (more than 2) ovules. Style thickened above the middle. Pod flattened, marked with oblique indented lines between the seeds. Strophiola of the seeds very small or none.-Racemes axillary. Bracteoles none.

The genus, as thus limited, consists but of one species, but with the two following, which may be considered almost as sections of it, it forms a group resembling Rhynchosia and its allies in habit, in the absence of bracteoles and stipellæ, and other minor points, but readily distinguished by the ovules always more than 2.

1. C. indicus, Spreng.; W. and Arn. Prod. Fl. Penins. i. 256. An erect undershrub of 2 or 3 feet, more or less covered with a short soft tomentum. Leaflets 3 , broadly lanceolate or oblong, acute, $1 \frac{1}{2}$ to 3 in. long. Stipules lanceolate, deciduous. Peduncles axillary, bearing at the summit a short raceme of flowers, either entirely yellow, or with the standard veined outside with purple. Pedicels about 6 lines long. Pod 2 or 3 in. long, with an incurved point, more or less glandular and hairy.-C. bicolor, DC. ; Bot. Reg. 1845, t. 31.

Hongkong, Hance and others, but probably introduced. The species appears to be of African origin, but is generally cultivated for its seed, the dhal of East Indians, in tropical Asia, Africa, and some parts of America, and appears readily to establish itself in cultivated and waste plaees.

\section{DUNBARIA, W. and Arn.}

Flowers and other characters of Cajanus, except that the pod is either not indented between the seeds, or slightly marked with transverse depressions. Herbs, usually twining. Leaflets 3 , without stipellæ. Racemes axillary, often reduced to axillary fascicles.

A genus of several species, all from tropical Asia.

1. D. conspersa, Benth. in Pl. Jungh. i. 241. A slender twining herb, hoary all over, with a minute tomentum, scarcely becoming glabrous when old, and more or less sprinkled with resinous dots. Leaflets broadly rhomboidal, seldom $1 \mathrm{in}$. long, entire, or the terminal one sinuate, or broadly and shortly 3 -lobed. Flowers 2 together, or sometimes solitary in the axils of the leaves, on short pedicels. Calyx-lobes lanceolate-falcate, the upper and lower ones 
longer than the tube. Pod nearly straight, pointed, glabrous or slightly tomentose, 6 - to 8 -seeded.

Ilongkong, Harland, Hance. Received also from Java, from Burmah, and from Silhet.

\section{ATYLOSIA, W. and Arn.}

Flowers and other characters of Cajanus and Dunbaria, except that there are no callosities on the inside of the standard, the pod is marked with transverse depressed lines between the seeds, and the strophiola of the latter is very conspicuous.-Twining or rarely erect herbs or undershrubs, with the habit of Dunbaria or Cajanus.

A genus of about a dozen tropical Asiatic species.

1. A. scarabroides, Benth. in Pl. Jungh. i. 242. A prostrate or twining herb, much branched, and often extending to several feet, softly tomentose in all its parts. Leaflets 3, obovate or elliptical, obtuse, about l in. long, 3 -nerved, wrinkled and soft. Peduncles short, axillary, bearing 1 to 5 flowers about 5 lines long. Lobes of the calyx narrow, falcate; rather longer than the tube, and nearly as long as the petals. Ovules in the ovary 6 to 8 . Pod oblong, about $\frac{3}{4}$ to $1 \mathrm{in}$. long, softly tomentose and hairy, containing usually 3 to 5 seeds, and marked between them by deep transverse lines and furrows.

Abundant near the seacoast, Wilford; also Wright. Common in India, from Ceylon and the Peninsula to the Archipelago, and uorthward to the Himalaya, S. China, and the Philippines.

\section{RHYNCHOSIA, Lour.}

Calyx campanulate, 5 -lobed, or by the union of the 2 upper ones 4-lobed. Standard orbicular, usually with inflexed auricles at the base, but without callosities. Wings and keel nearly of the same length. Upper stamen free from the base. Ovary sessile or nearly so, with 2 or very rarely 1 ovule. Style glabrous, usually thickened above the middle. Pod flattened, oblique or falcate. Seeds 2 (rarely 1), round or slightly reniform, with a short or oblong hilum parallel to the upper edge of the pod.-Herbs or undershrubs, usually twining or prostrate, and more or less sprinkled with resinous dots. Leaflets 3 , or rarely reduced to 1 , usually without stipellæ. Peduncles axillary, racemose or rarely 1 -flowered. Flowers usually yellow, or with a purple standard, pedicellate, without bracteoles.

A large genus, chiefly S. Asiatic and African, with a few American and Australian species.

1. R. volubilis, Lour.; DC. Prod. ii. 385. A slender herbaceous twiner, more or less softly villous or pubescent. Leaflets 3 , oval-rhomboid, the terminal one broad, $1 \frac{1}{2}-2 \mathrm{in}$. long, the lateral ones oblique and usually smaller, all obtuse and 3-nerved. Racemes usually shorter than the leaves, and sometimes shorter than the petiole. Pedicels solitary or 2 together, 1 to 2 lines long. Flowers yellow, small. Calyx-lobes with subulate points. Petals glabrous, the keel narrow, ending in a narrow erect beak. Pod 6 or 7 lines long, 4 lines broad, slightly contracted between the two seeds.

Common in the island, climbing over shrubs and trees, Champion; also Wright. Received also from the adjacent continent, from Chusan and from Java. 


\section{ERIOSEMA, DC.}

Calyx campanulate, 5-lobed. Standard from broadly obovate to oblong, usually with inflexed auricles at the base, and without callosities, or rarely with 2 obliquely transverse callosities inside. Upper stamen free from the base. Ovary sessile, with 2 ovules. Style glabrous, usually slightly thickened above the middle. Pod flattened, obliquely orbicular or broadly oblong. Seeds 2 (or 1), oblong, obliquely transverse ; the funiculus attached at one end of the long linear hilum.-Herbs or undershrubs, erect, prostrate, or sometimes twining, the resinous dots less conspicuous than in Rhynchosia. Leaflets 3 or 1, without stipellæ. Inflorescence and flowers nearly of Rhynchosia, but the standard more frequently villous outside.

A considerable genus, most of the species dispersed over tropical America and tropical and southern Africa, with a single Asiatic one.

1. E. chinense, Vog. in Pl. Meyen. 31. Rhizome a perennial oblong tuber. Stems erect, $\frac{1}{2}$ to 1 foot high, branching at the base only, more or less hirsute with long rufous hairs, intermixed with a short pubescence. Leaves simple (leaflets solitary), nearly sessile, from oblong-lanceolate to linear, 1 to $2 \mathrm{in}$. long, with a few long hairs sprinkled on the upper surface and the veins of the lower one, otherwise glabrous above, hoary or glaucous underneath. Peduncles axillary, 2 to 3 lines long, 1- or 2-rarely 3 -flowered. Petals yellow?, about 4. lines long, the standard obovate, with transverse callosities inside. Pod 4t to 6 lines long, 3 to 4 lines broad, covered with long rusty hairs.-Pyrrhotrichia tuberosa, W. and Arn. Prod. Fl. Penins. i. 238.

Victoria Peak, Champion and others. Frequent in the hilly districts of northern India, also in Ceylon, Burmah, S. China, the Philippines, and tropical Australia.

\section{PYCNOSPORA, Br.}

Calyx small, campanulate, 4-cleft, the upper lobe bifid. Petals nearly equal in length, the standard broad, the wings cohering to the keel. Upper stamen free from the base. Ovary with several ovules. Pod turgid, tranversely veined, with several seeds.

A genus of a single species, with the habit, foliage, and nearly the flowers of a Desmodium, and the pod nearly of a Crotalaria.

1. P. hedysaroides, $R$. Br.; W. and Arn. Prod. Fl. Penins. i. 197.Stock perennial, with several decumbent or ascending branched stems, 1 to 2 ft. long, and pubescent or hairy. Leaves nearly those of Desmodium concinnum. Leaflets 3, obovate or obovate-oblong, the terminal one in some specimens scarcely $\frac{1}{2}$ in., in others above $1 \mathrm{in}$. long, the lateral ones usually smaller. Flowers very small, in short terminal slender racemens. Pod 3 to 4 lines long, oblong, turgid, slightly pubescent, marked with very fine transverse veins. Seeds 6 or 8, small, reniform.-P. nervosa, W. and Arn. Prod. Fl. Penins. i. 197.

Hongkong, Champion, Wright. Also in Ceylon, the Peninsula of India, Burmah, Silhet, S. China, the Philippines, and tropical Australia.

\section{ABRUS, Linn.}

Calyx campanulate, truncate or shortly and broadly 4- or 5-toothed. Standard ovate, adhering at the base to the staminal tube. Keel-petals united from 
the base. Stamens 9 , united in a sheath open above (the 10 th upper one quite deficient). Ovary with several ovules. Style short, curved. Pod oblong or linear, flat, opening in 2 valves. Seeds several, with cellular partitions between them. Stems usually climbing or twining, woody at the base. Leaves pinnate, of several pairs of leaflets, without any terminal one, the petiole ending in a short point. Racemes terminal or apparently axillary, the flowers in fascicles arising from thickened nodes.

A small genus, dispersed over the tropical regions of both the New and the Old World. It is in some measure intermediate between the tribes Viciea, Phaseolea, and Dalbergiece.

1. A. precatorius, Linn.; W. and Arn. Prod. Fl. Penins. i. 236.-A perennial climber or twiner, often woody at the base, glabrous or slightly pubescent. Leaflets in 7 to 10 pair, oblong-elliptical or rarely obovate, usually about $\frac{1}{2}$ in. long. Racemes with 1 or 2 leaves, or at least a leafless pair of stipules below the flowers, the flowering part $1 \mathrm{in}$. or rather more in length, the nodes rather crowded. Flowers pink or rarely white or purple, 5 to 6 lines long. Pod sessile, 1 to $1 \frac{1}{2}$ in. long, 6 to 7 lines broad, alnost squared at the top and at the base, and attached by the inner angle, glabrous or scaly outside. Seeds usually black with a large scarlet spot, sometimes brown with a darker spot, or white and unspotted.

Hongkong, Hance. Very common in India and the Archipelago, extending into tropical and southern Africa, and frequent also, but perhaps naturalized in several parts of South America.

\section{Tribe VII. DALBERGIEA.}

Trees, shrubs, or woody climbers. Leaves pinnate, of 5 or more, or very rarely 3 or 1 leaflets. Stamens all or most of them united. Pod indehiscent.

\section{DALBERGIA, Linn.}

Calyx campanulate, 5-toothed. Wings free, the keel-petals united in the upper pair only. Stamens 10 or 9 , all united in a sheath open on the upper side, or into two equal parcels. Anthers small, erect, the cells opening at the top. Ovary stalked, with 1 or few ovules. Pod oblong or linear, thin, flat, and indehiscent, often wrinkled or thickened about the seed. Seeds 1 or rarely 2 to 4, large, thin, and flat in the centre of the pod.-Trees or woody climbers. Leaves pinnate, the leaflets alternate, with a terminal odd one. Flowers small, in dichotomous cymes or irregular panicles.

A considerable genus, dispersed over the tropical regions of Asia, Africa, and America.

Leaflets 25 or more. Claws of the petals very short . . . . . 1. D. Milletti.

Leaflets under 12. Claws of the petals almost as long as the calyx.

Leaflets 5 or 7, ovate, obtuse, about 1 in. long.

Calyx tomentose. Pod straight . . . . . . . . 2. D. rubiginosa.

Calyx nearly glabrous. Pod falcate, thick, 1 in. long . . . . 4. D. monosperma.

Leaflets 9 or 1l, oblong, 6 to 9 lines long. Calyx pubescent . . . 3. D. Hancei.

1. D. Milletti, Benth. in Journ. Linn. Soc. iv. Suppl. 34. A woody climber, glabrous, except a minute pubescence on the inflorescence and petioles. Leaflets 25 to 35 , linear-oblong, obtuse, 4 to 6 lines long. Flowers scarcely 2 lines long, sessile, in axillary cymes much shorter than the leaves. Calyxteeth all obtuse. Petals on very short claws, the standard almost sessile. 
Stamens 10 or sometimes 9. Ovules 3. Pod usually 1 -seeded, $1 \frac{1}{2}$ to 2 in. long, 7 to 8 lines broad, hardened and wrinkled in the centre about the seed. -D. polyphylla, Benth. Pl. Jungh. i. 256 (in part); Seem. Bot. Her. 375.

Frequent in Hongkong, Champion, Hance, Wright, Wilford. Also S. China, Millett.

2. D. rubiginosa, Roxb. Pl. Corom. ii. 9, t. 115. A woody climber. Leaflets 5 to 7 , ovate or oblong-elliptical, obtuse, 1 to $2 \mathrm{in}$. long, coriaceous, glabrous or minutely pubescent underneath. Flowers about 3 lines long, in short axillary panicles, the pedicels about 1 line long. Calyx covered with a rusty down, the teeth obtuse and nearly equal. Claws of the petals about as long as the calyx. Stamens 9 . Ovary glabrous with 2 or 3 ovules. Style subulate. Ripe pod unknown to me.

Hongkong, Harland, Hance, Wright, Wilford. Also in the Indian Peninsula, but not known as yet from any intermediate station.

3. D. Hancei, Benth. in Journ. Linn. Soc. iv. Suppl. 44. A woody climber. Leaflets 9 or 11, narrow-oblong, obtuse, 6 to 9 lines long, the young ones hairy underneath, at length glabrous. Flowers about 3 lines long, in short dense axillary panicles, the racemes composing it enclosed, when young, in concave imbricate scales, and more or less pubescent. Pedicels searcely $\frac{1}{2}$ line long. Calyx broad, with very short broad obtuse teeth. Petals on long claws. Ovary glabrous. Pod usually 1 -seeded, $1 \frac{1}{2}$ in. long, 4 lines broad, narrowed below into a long stalk, scarcely hardened round the seed.

Hongkong, Hunce, Wilford. Not known from elsewhere.

4. D. monosperma, Dalz.; Benth. in Journ. Linn. Soc. iv. Suppl. 48. A woody climber. Leaflets 5, obovate or obovate-oblong, very obtuse, rather firm, l in. long or rather less, glabrous or minutely pubescent underneath. Flowers 3 to 4 lines long, in short axillary racemes, or few-branched cymes, the pedicels scarcely $\frac{1}{2}$ line long. Calyx broad, with very short broad obtuse teeth. Petals on long claws. Stamens 10, monadelphous. Ovary glabrous, with 2 ovules. Pod shortly stalked, falcate or semicircular, $I$ in. long by 6 in. broad in the middle, rather thick, smooth, l-seeded.

Hongkong, Hance. In the Indian and Malayan Peninsulas, in Silhet, S. China, and the Philippines.

\section{DERRIS, Lour.}

Calyx campanulate, truncate, or very shortly 4 - or 5 -toothed. Wings slightly adhering to the keel-petals, which scarcely cohere to each other at the top. Upper stamen free at the base, but usually cohering with the others in the middle. Anthers versatile. Ovary with 2 or more ovules. Pod flat, varying from nearly orbicular to linear, thin or thick, the upper or both edges marked with a narrow wing. Seeds 1 or more, flat.-Woody climbers, or very rarely trees. Leaves pinnate, the leaflets opposite, with a terminal odd one, without stipellæ. Racemes simple, with the pedicels clustered 2 or more together, or irregularly branched into panicles. Flowers violet-purple or white, never yellow.

A considerable genus, chiefly dispersed over tropical Asia, with a very few tropical American speeies. 
Ieaflets 13 to 19. Ovules 2. (Pod oblong, acute at both ends.) . . 1. D. chinensis. Leaflets 3,5 , or 7 . Ovules 6 to 8 . Pod obliquely oval or orbicular . 2. D. uliginosa.

1. D. chinensis, Benth. in Journ. Linn. Soc. iv. Suppl. 104. Probably a tree. Leaflets 13 to 19 , oblorig or elliptical, obtuse or scarcely acute, about $1 \mathrm{in}$. long, silky-pubescent when young, at length glabrous and thin. Flowers 4 or 5 lines long, clustered 2 to 4 together at the nodes of axillary simple racemes rather shorter than the leaves. Pedicels about 1 line long. Ovules 2.

S. China, Hance. These specimens are in flower only, but fruiting specimens gathered by Wright in Oosima Island appear to belong to the same species. In them the pod is rather more than $1 \mathrm{in}$. long, about 6 lines broad in the middle, narrowed to a point at both ends, 1-seeded, with a very narrow wing along the upper edge.

2. D. uliginosa, var. $\beta$ Loureiri, Benth. in Journ. Linn. Soc. iv. Suppl. 107. A woody climber, glabrous in all its parts. Leaflets in the Hongkong variety usually 3 , in others 5 or 7 , oval-oblong, shortly and obtusely acuminate, $1 \frac{1}{2}$ to 2 in. long. Racemes axillary or lateral, simple, from 2 or 3 to about 6 in. long, the pedicels in rather distant clusters about 1 line long. Flowers about 4 lines long. Ovules about 4, or in some varieties 6 to 8 , all in the lower part of the cavity of the ovarium. Pod very flat and thin, 1 to $1 \frac{1}{2}$ in. long, very obtuse at both ends so as to become nearer square than round, but very oblique, and sometimes as broad as long, but in some varieties considerably narrower. Seeds 1 or 2.-Derris trifoliata, Lour. Fl. Cochinch. 433.

Hongkong, Wright. I have the same variety from Cochin China and from Malacea. It passes however gradually into the common form, with 5 or 7 leaflets and 6 to 8 ovules, which is spread all over India, extending westward to eastern Africa, eastward over the Indian Archipelago to N. Australia, and northward to S. China and Loochoo.

The D. scandens, Benth. (Dalberyia scandens, Roxb.), another common Indian species has been received from the neighbourhood of Canton, but not from Hongkong.

\section{PONGAMIA, Vent.}

Flowers of Derris. Pod oblong, flattened, but thick and hard, indehiscent, 1-seeded, with obtuse edges, not winged. Seed thick, reniform, with a small hilum.

A genus of a single species, scarcely distinct from Lonchocarpus.

1. P. glabra, Vent.; Benth. in Journ. Linn. Soc. iv. Suppl. 115. A tree, either glabrous in all its parts or with a slight pubescence on the smaller branches. Leaves pinnate. Leaflets 5 or 7 , opposite with a terminal odd one, ovate, broadly elliptical or oblong, shortly and obtusely acuminate, about $3 \mathrm{in}$. long, on petiolules 3 to 4 lines long, or sometimes considerably longer. Flowers 6 or 7 lines long, in loose axillary racemes of 3 to 5 inches. Pedicels usually 2 together, from 2 to 4 lines long. Calyx truncate. Ovary hairy, with 2 ovules. Pod usually $1 \frac{1}{2}$ to 2 in. long, 1 in. broad, sessile or nearly so.

Hongkong, Wright. Throughout southern India, on the coast, and in the plains to the foot of the hills, extending over the Indian Archipelago to N. Australia, and northward to S. China and Loochoo.

\section{TrIbE VIII. SOPHOREA.}

Trees, shrubs, or very rarely herbs or undershrubs. Leaves pinnate, of 5 
or more, very rarely 3 or 1 , leaflets. Stamens all free. Pod continuous (not articulate), indehiscent or 2 -valved.

\section{BOWRINGIA, Champ.}

Calyx membranaceous, loosely cup-shaped, truncate and minutely 5 -toothed. Standard broad. Keel-petals rather larger than the wings and scarcely cohering at the outer edge. Stamens 10, free. Ovary stalked, with several ovules. Pod turgid, ovoid or nearly globular, pointed. Seeds strophiolate. Radical straight.

The genus consists but of a single species.

1. B. callicarpa, Champ. in Kew Journ. Bot. iv. 75. A woody climber, glabrous in all its parts. Leares simple, or rather reduced to a single leaflet, ovate or oval-oblong, acuminate, 2. to $3 \mathrm{in}$. long, on a petiole of $\frac{1}{2}$ to $1 \mathrm{in}$., without stipellæ. Stipules minute and deciduous. Racemes very short and axillary, of 2 to 5 white flowers, on pedicels of about 3 lines. Calyx about $1 \frac{1}{2}$ lines long, usually turned back on the pedicel as the flowering advances. Keel-petals nearly $\frac{1}{2}$ in. long, the others rather shorter. Pod about $l$ in. long, of a coriaceous consistence. Seed scarlet.

Abundant in ravines of Victoria Peak, Champion and others. Not known as yet out of the island.

\section{SOPHORA, Linn.}

Calyx campanulate, shortly 5 -toothed. Standard rather broad. Keel-petals equal to, or rather longer than the others, scarcely cohering on the outer edge. Stamens free. Ovary shortly stalked, with several ovules. Style glabrous, with a minute terminal stigma. Pod cylindrical or slightly compressed, fleshy or hard and woody, contracted between the seeds, and usually indehiscent. Radicle curved.- Trees, shrubs, or very rarely herbs. Leaves pinnate, the leaflets usually opposite, with a terminal odd one. Racemes simple, terminal, or several forming a terminal panicle.

A genus not very numerous in species, but widely scattered over tropical and temperate Asia, and tropical and subtropical America.

l. S. japonica, Linn.; DC. Prod. ii. 95. A handsome tree, glabrous in all its parts. Leaflets 11 to 15 , ovate, oblong or almost lanceolate, 1 to 2 in. long, membranaceous, glaucous underneath. Flowers white and pale yellow, full $\frac{1}{2}$ in. long, in large terminal panicles. Calyx narrowed at the base, the teeth obtuse. Pod succulent, contracted between the seeds so as to appear to be composed of 4 to 6 oblong articles, each about $\frac{1}{2}$ in. long.

Hongkong, Hance. Believed to be a native of Japan or China, or both, but so freqnently planted that we have no authentic records of its truly indigenous state.

\section{ORMOSIA, Jacks.}

Calyx campanulate, 5-cleft, or the two upper lobes often united into one. Standard broad. Keel-petals not longer, free. Stamens free, often very unequal, and one sometimes without any anther. Ovary sessile or nearly so, with 2 or few ovules. Style rolled inwards at the top, with a lateral stigma. Pod flattened, 2- to 4-seeded, opening in 2 thickly coriaceous or almost woody 
valves. Seeds shining, scarlet, or scarlet and black, rarely brown-red, the radicle very short.- Trees. Leaves pinnate, the leaflets usually opposite, with a terminal odd one. Flowers in terminal panicles, or rarely in simple racemes, in the upper axils.

A genus of several species, distributed over the hilly districts of tropical Asia and tropical America.

Whole plant glabrous . . . . . . . . . . . . 1. O. emarginato. Under side of leaves, panicles, and pods woolly or cottony . . . . 2. O. pachycarpa.

1. O. emarginata, Benth. in Kew Journ. Bot. iv. 77. A tree, glabrous in all its parts. Leaflets 3 or 5, obovate-oblong, very obtuse or emarginate, $1 \frac{1}{2}$ to $2 \mathrm{in}$. long or sometimes near $3 \mathrm{in}$., rather coriaceous, shining, pinnately and reticulately veined. Flowers 4 to 5 lines long, in small panicles in the upper axils. Pod flattened, thickly coriaceous, about 9 lines broad, from 1 in. long when 1 -seeded to $1 \frac{1}{2}$ or 2 in. when 2 or 3 seeds ripen. Seeds scarlet.Layia emarginata, Hook. and Arn. Bot. Beech. 183, t. 38.

Common in the Happy Valley woods and other parts of the island, Champion and others.

2. O. pachycarpa, Champ. in Kew Journ. Bot. iv. 76. A tree, the young branches, petioles, under side of the leaflets, panicles, calyxes, and pods thickly covered with a whitish cottony wool. Leaflets usually 7, obovate-oblong, the larger ones near 6 in. long. Panicles terminal, 6 in. long, the flowers sessile in pairs along their branches. Calyx 4 to $4 \frac{1}{2}$ lines long, the petals scarcely longer. Ovary very villous, with three ovules, and the peculiar style of the genus. Pod hard, turgid, 1 in. long when 1 -seeded, 2 in. when 2seeded, and near $1 \mathrm{in}$. broad. Seed rather larger than a tamarind, shining, of a brownish-red.

In woods, Champion, whose specimens were in fruit only, but flowering specimens were gathered by Reeves, near Canton. It has not been received from elsewhere.

\section{SUBORDER II. CAESALPINIEF.}

Petals imbricate in æstivation, the upper one innermost, and the two lower outside, either nearly equal or unequal, and occasionally all wanting, except the upper one. Stamens usually 10, and all free, but sometimes, in genera not Chinese, fewer, or monadelphous, or indefinite. Radicle usually straight. Leaves pinnate or bipinnate, rarely reduced to 2 or 1 leaflet.

\section{GUILANDINA, Linn.}

Sepals 5, shortly united at the base, nearly equal or the lowest rather larger and more concave. Petals 5, nearly equal, sessile. Stamens 10, free, all fertile. Ovary sessile, with 2 ovules. Pod ovate, compressed, covered with straight prickles, opening in 2 thickly coriaceous valves. Seeds hard, ovoid or globular. -Leaves twice pinnate.

A genus of 2 species, dispersed over the tropical regions of the New and the Old World.

1. G. Bonducella, Linn. Spec. Pl. 545. A shrub, with loose spreading or climbing branches, pubescent or villous in all its parts, and with numerous hooked prickles, especially on the petioles. Leaves abruptly bipinnate, the common petiole 1 to $1 \frac{1}{2} \mathrm{ft}$. long, the pinnæ in 4 to 6 pairs, each 4 to 6 in. long. Leaflets in 8 to 12 pairs, oblong, $\frac{3}{4}$ to 1 in. long or rarely nearly 
twice that size. Stipules leafy and lobed, deciduous. Racemes 4 to 6 in. long, simple or slightly branched, in the upper axils. Flowers crowded in the upper part, shortly pedicellate. Bracts with a long recurved point, falling off as the flowers expand. Calyx about 4 lines long. Petals scarcely longer. Pod 2 to 3 in. long, about $1 \frac{1}{2}$ in. broad, very prickly. Seeds of a bluishgrey.

On the seashore, Hance. Widely spread, and often very common, especially near the sea in tropical Asia, Africa, and America. It is usually confounded with the G. Bonduc, Linn., which is a much rarer plant, although equally found (but, perhaps, not always indigenous) in East India, in the Archipelago, and in the West Indies. It is nearly glabrous, has usually larger leaflets, no stipules, the bracts are erect, not recurved, and the seeds are said to be always yellow, not grey.

\section{CABSALPINIA, Linn.}

Sepals 5, shortly united at the base, the lower one rather larger and concave. Petals 5, rather unequal, the upper inner one the smallest, the 2 lowest outer ones the largest. Stamens 10, free, all fertile; the filaments hairy. Anthers ovate. Ovary with 2 or more ovules. Pod flattened, obliquely ovate, oblong or falcate, without prickles, opening in 2 valves. Seeds thick or flattened, the radicle short and straight.-Leaves twice pinnate.

A considerable genus, distributed over the tropical regions of the New as well as the Old World.

Pinnæ 2-4 pair. Leaflets 2-3 pair. Racemes glabrous . . . . . . 1. C. Nuga.

Pinnæ 9-12 pair. Leaflets 4-6 pair. Racemes tomentose or villous . . 2. C. vernalis.

1. C. Nuga, Ait.; DC. Prod. ii. 481. A woody climber, glabrous in all its parts, armed with a few recurved prickles, especially on the petioles. Leaves twice pinnate, with 2,3 , or 4 pair of opposite pinnæ. Leaflets 2 or 3 pair to each pinna, opposite, ovate, $1 \frac{1}{2}$ to 2 in. long, coriaceous and shining, usually very obtuse in the Chinese variety, but occasionally almost acute, as is more common in the southern varieties. Racemes 4 to $8 \mathrm{in}$. long, forming large terminal panicles. Pedicels slender. Lowest sepal about 5 lines long. Petals scarcely longer. Ovary with 2 ovules. Pod obliquely oval, acuminate, flat. Seed flattened.-C. chinensis, Roxb. Fl. Ind. ii. 361. C. paniculata, Desf. ; DC. Prod. ii. 481.

Common in ravines, Champion and others. Generally distributed over India, from Ceylon and the Peninsula to the Archipelago, extending also to tropical Australia, aud northward to the Philippines and S. China.

2. C. vernalis, Champ. in Kew Journ. Bot. iv. 77. A shrub, with trailing or climbing branches, with numerous recurved prickles on the petioles. Leaves twice pinnate, the common petiole above a foot long, with 9 to 12 pair of opposite rather short pinnæ. Leaflets 4 to 6 pair on each pinna, ovate-acute, $\frac{1}{2}$ to $\frac{3}{4}$ or rarely nearly 1 in. long, coriaceous, glabrous and shining above; pale, glaucous or rusty underneath. Racemes rusty-tomentose or villous, the upper ones forming a terminal panicle. Pedicels spreading. Flowers nearly of $C$. Nuga, but the calyx is tomentose at the base, the sepals thin and coloured at the top. Pod very oblique, broadly ovate, about 2 in. long, with one large flat seed.

On the banks of a stream running towards Little Hongkong, Champion; also Hance, Wright, and Wilford. Not known from elsewhere. 


\section{CASSIA, Linn.}

Sepals 5, somewhat unequal, scarcely connected at the base. Petals 5, usuilly unequal, spreading. Stamens usually 10 , either all equal and fertile or the upper ones small and sterile, with 2 or more of the lower fertile ones much larger. Anthers, when fertile, opening at the end only, in pores or short slits. Ovary with several ovules. Pod cylindrical or flattened, usually long, but variously shaped. Seeds usually oblong and transverse, with a small quantity of albumen. Radicle short and straight.-Herbs, shrubs, or trees. Leaves abruptly pinnate, the leaflets opposite.

A large genus, widely distributed within the tropics, but particularly numerous in South Lmerica.

Sepals obtuse. Upper stamens small and sterile.

Leaflets 4 to 6 pair, acute. A gland near the base of the petiole
Leaflets 2 to 3 pair, very obtuse. A gland between the leaflets of the

Leaflets 2 to 3 pair, very obtuse. A gland between the leaflets of the

Sepals acute. Stamens all fertile. Leaflets numerous

1. C. occidentalis, Linn.; Vog. Syn. Cass. 2] ; Bot. Reg. t. 83. An erect glabrous annual, 3 to $5 \mathrm{ft}$. high, sometimes hard at the base, so as to appear woody. Leaflets 4 to 6 pair, ovate-lanceolate or lanceolate, 1 or 2 in. or in luxuriant specimens $3 \mathrm{in}$. long, with an ovate gland on the petiole near the base. Racemes terminal, short and few-flowered, with occasionally a few flowers on short pedicels in the upper axils. Flowers yellow. Two of the anthers large, oblong, 4 or 5 others like them, but sinaller, the 3 uppermost small and sterile. Pod linear, slightly curved, 3 to 5 in. long, about 3 lines broad, at first flat, with the edges thickened, but becoming at length nearly as thick as broad.

Common in waste places, Hance and others. Widely dispersed, as a weed, over the warmer regions of the globe, especially in America and Africa.

2. C. tora, Linn.; Vog. Syn. Cass. 23. An annual, of 1 to about $3 \mathrm{ft}$, spreading or erect, the stem nearly glabrous. Leaflets 2 or 3 pair, ovatecuneate, obtuse, mucronate, 1 in. long or rather more, usually pubescent underneath, with a cylindrical gland between the leaves of the 1 or 2 lower pair. Flowers yellow, usually 2 together in the upper axils. Anthers 7 fertile, 3 very small and abortive. Pod very narrow, nearly quadrangular, 4 to $\delta$ in. long, straight or slightly curved.-C. obtusifolia, Linn.; Vog. Syn. Cass. 24.

Hongkong, Hance. A common weed in tropical Asia and some parts of America.

3. C. mimosoides, Linn.; Vog. Syn. Cass. 68. An annual or perennial of short duration, with a hard often almost woody base, and numerous diffuse or ascending wiry stems, 1 to $1 \frac{1}{2} \mathrm{ft}$. long, more or less pubescent. Leaves $1 \frac{1}{2}$ to 2 in. long. Leaflets numerous (20 to 50 pair), linear-falcate, and mucronate, seldom above 2 lines long. Pedicels axillary, solitary or several together, unequal, but seldom above $\frac{1}{2}$ in. long. Sepals about 3 lines long and very acute. Petals yellow, scarcely longer. Pod linear, flat, $1 \frac{1}{2}$ to 2 in. long, scarcely 2 lines broad, slightly curved or oblique.-C. angustissima, Lam.

Victoria Peak and other localities, Champion and others. Widely spread over tropical Asia and Africa, and diffieult to distinguish from some of the common species of the Chamacrista section from tropical America.

Several shrubby Cassias, and especially the $C$. tomentosa, are said to be much planted in the gardens and about the houses of the Chinese. 


\section{BAUHINIA, Linn.}

Sepals 5, united at the base in a short and campanulate or long and cylindrical tube, the upper portion separating into 5 or fewer valvate or induplicate deciduous lobes. Petals 5, inserted at the summit of the tube, usually unguiculate $_{2}$ more or less unequal. Stamens 10 , either all fertile or some smaller and sterile. Ovary stipitate, the stalk connate to one side of the calyx-tube, with several ovules. Pod linear or oblong, compressed, 2-valved. Seeds compressed, albuminous. Radicle short and straight. - Trees or woody climbers. Leaflets either 2, distinct from the base, or more frequently united into 1 entire or 2-lobed leaf, with 5 to 11 digitate nerves. Racemes terminal.

A large genus, distributed over the tropical regions of both the New and the Old World. It has been divided into several genera, which I have in other works been disposed to adopt, but it may be more convenient to follow De Candolle and others in considering them as subgenera. The following Chinese species belong to Phanera, and are distinguished chiefly by the stamens, of which 3 only are long and fertile, the other 7 small, sometimes very minute and sterile. It forms a numerous group, all Asiatic or east tropical African.

Racemes long. Calyx-tube very short, lobes lanceolate

1. B. Championi. Racemes corymbose. Calyx-tube long, slender, lobes considerably shorter 2. B. glauca.

1. B. (Phanera) Championi, Benth. A woody climber, the young branches, under side of the leaves, and inflorescences hoary with a minute tomentum, but otherwise glabrous. Leaves broadly cordate, 5- or 7-nerved, $2 \frac{1}{2}$ to 4 in. long, 2 to $2 \frac{1}{2}$ in. broad, divided to about one-third into 2 broad obtuse lobes. Tendrils simple, leaf-opposed. Racemes leaf-opposed, simple or several together at the ends of the branches, 4 to $8 \mathrm{in}$. long, flowering nearly from the base. Flowers pedicellate, white. Calyx-tube very short, lobes lanceolate, about 2 lines long. Petals scarcely longer, nearly equal, with a few hairs outside. Stamens 3 , about twice as long as the calyx, the other 7 very minute or wanting. Pod about 3 in. long, 1 in. broad, 3- to 5seeded.-Phanera Championi, Benth. in Kew Journ. Bot. iv. 78.

Common in ravines, Victoria Peak, Champion; also Hance and Wright. Not known from elsewhere:

2. B. (Phanera) glauca, Wall. Cat. Herb. Ind. n. 5785. A woorly climber, glabrous except a slight rusty pubescence on the inflorescence. Leaves broad, 9 - or 11-nerved, $1 \frac{1}{2}$ to $2 \frac{1}{2}$ in. long, divided to about the middle into 2 ovate obtuse parallel lobes. Peduncles lateral or terminal, bearing a short corymbose raceme, with a simple or trifid tendril under the flowers. Calyxtube 6 or 7 lines long; the lobes not 3 lines, rusty-tomentose outside. Petals white, 5 to 6 lines long, unguiculate, obovate, spreading. Stamens 3 fertile, rather longer than the petals, 5 to 7 small and sterile. Pod flat, glabrous, about 8 in. long and $2 \mathrm{in}$. wide, with several seeds along the centre attached by funicles very unequal in length.-Phanera corymbosa, Benth. in Kew Journ. Bot. iv. 77, but not the synonyms quoted.

About East Poiut, Champion; also Wright. Extends from Khasia and Burmah to Sumatra and Java. The Chinese specimens have rather large flowers, like those of $B$. corymbosa, Roxb., likewise a S. Chinese plant, for which I had mistaken the Hongkong specimens before I saw the pod. In the true B. corymbosa the pod is not above $\frac{1}{2}$ in. broad, and usually curved. 


\section{GLEDITSCHIA, Linn.}

Flowers polygamous. Sepals 3 to 5 , united in a tube or cup at the base, nearly equal, imbricate in the bud. Petals as many, inserted at the summit of the tube, nearly equal, slightly imbricate. Stamens as many or twice as many, free, nearly equal. Ovary sessile, with 2 or more ovules. Pod long, flat, linear, more or less pulpy. Seeds flattened. Radicle short, straight.Trees, usually armed with stout, entire, or branched thorns. Leaves once or twice pinnate. Flowers small, in axillary or lateral racemes or raceme-like panicles.

A small genus, limited to N. America and temperate or subtropical Asia.

1. G. sinensis, Linn.; DC. Prod. ii. 479. A tree, glabrous or nearly so in all its parts. Thorns on the stem often 2 or $3 \mathrm{in}$. long and branched. Leaves mostly simply pinnate. Leaflets 8 to 10 pair, very obliquely ovatelanceolate or between rhomboidal and falcate, 1 to $1 \frac{1}{2}$ in. long, rather thin, prominently veined and often slightly crenulate. Panicle narrow and racemelike, 4 to $8 \mathrm{in}$. long, the main peduncle stiff and erect, the lateral branches slender, very short, bearing 3 to 5 small, greenish, pedicellate flowers. Petals usually 5 . Stamens 10 .

Rare in Hongkong, more abundant on the adjacent continental coast, Champion. The Hongkoug specimens were mere fragments : I have described it from Canton specimens gathered by Reeves. The species is probably limited to China.

\section{SUBORDER III. MIMOSEAE.}

Sepals 5 , rarely 4 or 3 , free or united. Petals as many, equal, valvate in the bud, free or united. Stamens as many or twice as many, or indefinite, free or united, usually hypogynous. Radicle of the embryo straight. Leaves twice pinnate, or, in one American genus, once pinnate. Flowers usually small, in dense globular heads or cylindrical spikes.

\section{LEUC AENA, Benth.}

Calyx 5 -toothed. Petals 5, free. Stamens 10, free, all fertile. Anthers not tipped by a gland. Pod broadly linear, flat, 2 -valved. Seeds numerous, transverse.-Trees or shrubs. Leaves twice pinnate. Flowers white, in globular heads; usually hermaphrodite.

A genus of few species, all American, one of which is now naturalized in many parts of the Old World.

1. L. glauca, Benth. in Hook. Journ. Bot. iv. 416. A small tree, the young parts slightly tomentose, otherwise glabrous and without prickles. Leaves with 4 to 6 pair of pinnæ. Leaflets 10 to 20 pair on each pinna, oblong-linear, very oblique and slightly falcate, 4 to 6 lines long, pale or glaucous underneath. Peduncles solitary, or 2 or 3 together in the upper axils, 1 to $1 \frac{1}{2} \mathrm{in}$. long, the upper ones forming a terminal raceme, each bearing a globular head of 6 to 8 lines, or, with the stamens, near an inch diameter. Pod shortly stalked, 4 to 6 in. long, 4 to 6 lines broad.

In a ravine at the foot of Victoria Peak, Wilford; also Wright. Probably of American origin, but frequently cultivated in that continent as well as in Africa and Asia, and so often sent as apparently wild, that its jeal native country cannot be given with certainty. 


\section{ACACIA, Willd.}

Sepals 5, 4, or 3, free or united. Petals as many, free or united. Stamens indefinite, usually very numerous, free or slightly connected at the very base. Pod linear or oblong, flat or nearly cylindrical, opening in 2 valves or indehiscent. - Leaves twice pinnate, or in some Australian species reduced to a simple phyllodium or dilated petiole. Flowers usually yellow or white, in globular heads or cylindrical spikes, often polygamous.

A very large genus, one-half Australian, the remainder dispersed over the warmer regions of the globe.

Thorns straight, in stipular pairs. Pod thick, cylindrical or fusiform, dry 1. A. farnesiana. Prickles recurved, seattered. Pod thick, but slightly flattened, snceulent 2 2. A. concinna.

1. A. farnesiana, Willd.; DC. Prod.ii. 461. A much-branched shrub, quite glabrous or slightly pubescent on the petioles and peduncles. Leaves of 4 to 6 or rarely to 8 pair of pinnæ. Leaflets 10 to 20 pair on each pinna, linear, about 2 lines long. Stipules converted into slender straight thorns very variable in length, the plant otherwise unarmed. Peduncles usually 2 or 3 together in the older axils, each bearing a single globular head of yellow or whitish sweet-scented flowers. Pod thick, irregularly cylindrical or fusiform, indehiscent, filled with a pithy substance, in the midst of which lie the seeds. - Vachellia farnesiana, W. and Arn.; Wight, Ic. t. 300.

Common about the houses, Hance. Supposed to be of American origin, but much planted in almost all warm countries, and, spreading readily, has become apparently wild, or is, according to some, really indigenous in many parts of Asia, Africa, and North Australia.

2. A. concinna, DC. Prod. ii. 464. A woody climber, the young parts pubescent, but often glabrous when full grown, with numerous recurved prickles scattered on the branches and petioles. Leaves of 4 to 6 spair of pinnæ, with a gland immediately below the lower 1,2 , or 3 pair. Leaflets 12 to 18 pair, obliquely oblong, obtuse, of a pale green, about $\frac{1}{2} \mathrm{in}$. long. Stipules large, cordate, thin, very deciduous. Flower-heads globular, on slender peduncles of about $1 \mathrm{in}$. long, in branching racemes or panicles. Pod 3 to 5 in. long, near $1 \mathrm{in}$. broad, thick and fleshy, with cross partitions between the seeds, and when ripe either separating into articles but otherwise indehiscent, or sometimes opening on the edges opposite the seeds.-Arthrosprion stipulatum, ¿Hasśk. Retzia, i. 212, but not Albizzia stipulata, Benth.

In the Happy Valley, Champion: also Hance and Wright. None of these specimens are however in flower, and I am therefore uncertain of their identity with the plant I describe from continental Asiatic specimens. The species is widely spread over India and the Archipelago.

\section{ALBIZZIA, Durazz.}

Calyx campanulate or tubular, 5-toothed. Corolla 5-lobed, with a cylindrical tube. Stamens indefinite, usually numerous and long, united in a tube at the base. Pod linear or oblong, flat, thin, indehiscent or opening in two valves.-Trees or shrubs, without prickles. Leaves twice pinnate, with a gland on the petiole below the pinnæ, and others between some or all the pinnæ and leaflets. Flowers in globular heads or rarely cylindrical spikes, usually hermaphrodite; the stamens usually white or pink, rarely yellow, much longer than in Acacia. 
A considerable genus; limited to the Old World, and chiefly tropical.

Pinnæ 7 to 20 pair. Leaflets numerous, small, acute. Stipules large

Pinnæ 3 to 6 pair. Leaflets 4 to 10 pair, obtuse. Stipules small, deci-

duous .

1. A. stipulata, Benth. in Lond. Journ. Bot. iii. 92. A tree, with the young shoots pubescent. Leaves of 7 to 10 pair of pinnæ. Leaflets usually 20 to 30 pair on each pinna, oblong-linear, falcate, acute, 3 to 5 lines long; the nidrib close to the inner edge. Stipules membranous, acuminate, sometimes near an inch long, deciduous. Peduncles usually about $\frac{1}{2}$ in. long, clustered along the branches of a terminal panicle. Heads consisting of 10 to 20 flowers, about 3 lines long. Stamens above 1 in. long. Calyx much shorter than the corolla, both pubescent. Pod 3 to 5 in. long, 9 to 10 lines broad.

Hongkong, Hance. Widely distributed over tropical Asia, chiefly in the mountains, from Ceylon and the Peninsula to the Archipelago, and northwards to the Himalaya and S. China.

2. A. Milletti, Benth. in Lond. Journ. Bot. iii. 89. A tree, glabrous in all its parts. Leaves of 3 to 6 pair of pinnæ. Leaflets 4 to 10 pair on each pinna, obovate-oblong, very obtuse, $\frac{1}{2}$ to $\frac{3}{4}$ in. long, oblique at the base. Stipules small and deciduous. Peduncles usually 2 or 3 together, along the branches of a terminal panicle. Heads consisting usually of 6 to 12 flowers about 2 lines long without the stamens. Calyx very much shorter than the corolla, both glabrous. Filaments full $\frac{1}{2}$ in. long. Pod about 6 in. long, $1 \frac{1}{4}$ in. broad.

In the Happy Valley, Champion; also Hance and Wright. Only known from S. China.

\section{PITHECOLOBIUM, Mart.}

Calyx campanulate or tubular, 5-toothed. Corolla 5-lobed, with a cylindrical tube. Stamens indefinite, usually numerous and long, more or less united in a tube. Pod flattened, usually rather thick, and much curved, annular or spirally twisted, opening in 2 valves. Seeds usually surrounded by a thin pulp.-Trees, or rarely shrubs, without prickles. Leaves twice pinnate, usually with a gland on the petiole below the pinnæ, and others between one or more of the pair of pinnæ or leaflets. Flowers in globular or oblong heads, or rarely in cylindrical spikes, usually hermaphrodite and white.

A considerable tropical genus, distributed over the New as well as the Old World.

Pinnæ 1 to 2 pair. Leaflets 2 to 4 pair. Branches nearly terete . . 1. P. lucidum. Pinnæ 4 to 6 pair. Leaflets 4 to 10 pair. Branches very angular . 2. P. clypearia.

1. P. lucidum, Benth. in Lond. Journ. Bot. iii. 207. A tall tree, the. branches scarcely angular, the young ones as well as the petioles and inflorescences covered with a short rusty tomentum, but otherwise glabrous. Leaves of 1 or 2 pair of pinnæ. Leaflets usually 2 or 3 pair to the lower pinnæ, often 4 or even 5 pair to the upper ones, obliquely ovate, or rarely oblong, obtusely acuminate, the terminal pair often 2 in. long, the others small. Racemes in the upper axils, or forming a long terminal panicle. Peduncles seldom $\frac{1}{2}$ in. long, solitary or clustered. Heads globular, consisting of 10 to 20 slightly pubescent flowers. Calyx 1 line, corolla above 2 lines long. Stamens twice as long. Pod about $1 \mathrm{in}$. broad, twisted into a ring, the outer edge indented between the seeds.-Albizzia? Championi, Benth. in Kew Journ. Bot. iv. 79. Inga bigemina, Hook. and Arn. Bot. Beech. 182, but not of others.

In Woods, Champion; also Hance and Wright. Only known from S. China. 
2. P. clypearia, Benth. in Lond. Journ. Bot. iii. 209. A tall tree, the younger branches very acutely angular, and as well as the inflorescences slightly pubescent. Leaves of 4 to 6 pair of pinnæ. Leaflets in the lower pinnæ 3 to 6 pair, in the terminal ones 10 to 12 pair, all obliquely ovate, nearly rhomboid or trapezoid, obtuse or acute, the terminal ones about $1 \frac{1}{2}$ in. long, the others smaller. Panicle large and terminal. Peduncles short, clustered one above another ; the common bract reduced to a short stalk with a large gland. Flowers few together in small heads, the corolla about 2 lines long, the stamens three times as long. Pod forming 2 or 3 coils of $1 \frac{1}{2}$ in. diameter, indented between the seeds on the outer edge.-Inga dimidiata, Hook. and Arn. Bot. Beech. 181. Java.

Hongkong, Hance. We have it also from the adjacent continent, from Sumatra and

\section{Order XXXVII. ROSACEAs.}

Sepals 5, rarely 4, united into a lobed calyx, either enclosing the ovary, or adhering to it, or quite free. Petals as many, inserted on the calyx at the base of its lobes or rarely none. Stamens usually numerous, inserted with the petals, free. Ovary of 1,2 , or more carpels, usually distinct at the time of flowering, but sometimes combined even then into a single 2- to 5-celled ovary, which is then always inferior or combined with the calyx. Ovules 1 or 2 , or rarely more, in each carpel. As the fruit enlarges, the carpels either remain free, or are variously combined with each other or with the calyx; when ripe, they either remain indehiscent or more rarely open on their inner edge. Seeds without albumen. Embryo with large cotyledons, and a short radicle.-Trees, shrubs, or (in genera not included in the present Flora) herbs. Leaves alternate, mostly toothed or divided, the stipules seldom wanting, and often leaf-like. Flowers either solitary at the end of the year's shoots, or in cymes or panicles, or more rarely in lateral branches or racemes.

A numerous Order, widely spread over the globe, but more in the temperate and cooler parts of the northern hemisphere than within the tropics or in the southern hemisphere.

Ovary or carpels superior or free from the calyx.

Tree. Flowers in racemes. Calyx deciduous. Carpel 1. Fruit a drupe : . . . . . . . . . . .

Scrambling prickly shrubs. Calyx persistent. Carpels numerous. Fruit a compound granular berry . . . . . . .

Shrub not prickly. Flowers in corymbs. Carpels 5 or 6 , with 3 or 4 ovules in each, becoming dry capsules . . . . . .

Ovary or carpels inferior or adhering to the tube of the calyx, which is closed over them.

Fruit enclosing several seed-like hairy carpels irregularly placed .

Fruit 1- to 5-celled, with 1 or 2 seeds in each.

Ovary 2-celled.

Calyx-limb very short, persistent

Calyx-limb narrow-campanulate, deciduous. . . . . . 6. RHAPHIOLEPIs.

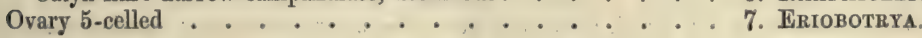

\section{PYGEUM, Colebr.}

Calyx free, deciduous, broadly campanulate or spreading, 5- or 6-toothed. Petals as many, sinall, and usually resembling the calyx-teeth. Ovary superior, 
of a single carpel, with 2 pendulous ovules. Fruit a drupe with little or no juice, usually as broad as or broader than long, with a smooth kernel, containing a single seed.-Trees. Leaves simple, entire, coriaceous. Stipules small, very deciduous. Flowers in axillary or lateral simple racemes.

A small genus, limited to tropical Asia, and scarcely differing from Prunus, except in the small size of the petals, which has oceasioned them frequently to be described as additional calyx-teeth.

1. P. latifolium, Miq. Fl. Ned. Ind. i. 361. A tree, with the young branches slightly pubescent, but soon glabrous. Leaves stalked, ovate or ovaloblong, acuminate or acute, 3 to 5 in. long, glabrous, except sometimes a slight rusty down on the principal veins underneath, the petiole usually more downy. Racemes solitary or clustered, 1 to 2 in. long, more or less pubescent. Flowers white, scarcely 3 lines diameter, on pedicels of 1 to 2 lines long. Petals 5, hairy outside as well as the calyx, and scarcely longer than its teeth. Stamens about 25. Ovary glabrous, with a rather long style.Germaria latifolia, Presl, Epimel. Bot. 221.

Hongkong, Wright. Also in the Philippine Islands and the Indian Archipelago. It is near the North Indian $P$. acuminatum, but readily known by the pubescent racemes, the shorter hairy petals, etc. The $P$. parviflorum from the Indian Archipelago differs in its smaller sessile flowers, in densely clustered racemes, hairy ovary, etc.

\section{RUBUS, Linn.}

Calyx free, deeply 5-lobed, persistent. Petals 5. Stamens numerous. Carpels numerous, with a single pendulous ovule in each. Fruit a kind of granulated berry, formed by the union of the succulent carpels, round the conical or shortly oblong, dry receptacle.-Weak scrambling shrubs (or in some northern species, herbs), usually prickly. Leaves pinnately or palmately divided into distinct segments or leaflets, or rarely simply lobed. Flowers axillary, or in terminal leafy panicles.

A large genus, widely distributed over almost every part of the globe.

Leaves simply lobed, wrinkled above, densely tomentose underneath. . 1. R. reflexus.

Leaves pinnate, with 3 leaflets.

Branches pubescent. Leaflets white, tomentose underneath $\because$. 2. R. parvifolius.

Whole plant quite glabrous. . . . . . . . . . 3. R. leucanthus.

1. R. reflexus, Bot. Reg.t. 461 . Branches and petioles terete, densely clothed with a brown or rust-coloured velvety down, almost concealing the minute prickles. Leaves simple, cordate-ovate or nearly orbicular, usually deeply 3 - or 5-lobed, the middle lobe much longer than the others, wrinkled and nearly glabrous on the upper side, densely tomentose underneath. Flowers 2 or 3 together, almost sessile in the upper axils, or sometimes several crowded in short bunches. Bracts very hairy, deeply divided into narrow lobes, but falling off early. Calyx-lobes about 4 lines long, very hairy outside. Petals white, not much longer. Fruit nearly globular.

Very common in the island, Champion and others. Extends from north-eastern India to the Archipelago, the Philippines, and northward to Loochoo; for surely many of the specimens usually referred to $R$. rugosus, have all the characters of the present species. Whether those which have more numerous and smaller flowers, and entire or nearly entire bracts, are specifically distinct or not, is uncertain. If united, the $R$. rugosus is the older name; unless indeed the whole be considered as varieties of the Linnean $R$. moluccanus. 
2. R. parvifolius, Linn.; DO. Prod.ii. 564; Bot.Reg.t.496. Branches and petioles pubescent, with small hooked prickles. Leaves pinnate, with a common petiole of 1 to 2 in. Leaflets 3 , or very rarely 5 , nearly orbicular, about $1 \mathrm{in}$. long, or in luxuriant shoots, the terminal one $1 \frac{1}{2}$ or near $2 \mathrm{in}$. long, deeply and irregularly toothed, rather thin, glabrous, or nearly so, above, white and cottony underneath. Flowers few, in terminal panicles. Sepals about 2 lines long, softly hoary inside and out. Petals pink, but little longer. Fruit globular, the carpels glabrous or very slightly hairy.

In ravines, Champion and others. Extends from S. China to Loochoo. The Himalayan plant usually referred to this species, appears to me to be much nearer to the $R$. lasiocarpus : the leaflets are almost always 5, much more ovate in shape, usually acute, and the carpels more pubescent or hairy.

3. R. leucanthus, Hance in Walp. Ann. ii. 468. The stems and petioles armed with hooked prickles, and as well as every other part of the plant, perfectly glabrous. Leaves pinnate, with 3 leaflets, or a few of the upper ones reduced to a single one. Leaflets ovate, acuminate, serrately toothed, the larger ones 2 to $3 \mathrm{in}$. long, the lateral ones usually smaller. Flowers 2 to 5 together, on a short axillary common peduncle. Pedicels about 4 lines long. Sepals ovate, smooth, about 4 lines long, closing over the fruit. Petals white.R. glaberrimus, Champ. in Kew Journ. Bot. iv. 80.

In low grounds and ravines of the hills, Champion, Hance, Wright, Wilford. Not yet found out of the island. The two names were both published early in 1852, one at Berlin, the other in London, and the latter, by Champion, on the 1st March, certainly prior to the reception in this country of the part of Walpers' Annales which contained Hance's name and diagnoses. As however Dr. Seemann states that the latter was actually first published, I have here adopted it.

\section{SPIR 开A, Linn.}

Calyx free, persistent, 5-lobed. Petals 5. Stamens numerous. Carpels 3 or more, usually 5 , quite free from the calyx and disk, with 2 or more ovules in each, and becoming, when ripe, small dry capsules, opening along the inner edge, each containing 2 or more small seeds.-Shrubs or herbs, without prickles. Leaves simple or divided. Flowers usually small and numerous, in terminal cymes, corymbs, or panicles.

A considerable genus, spread over the northern hemisphere both in the New and the Old World, but scarcely penetrating into the tropics.

1. S. cantoniensis, Lour. Fl. Cochinch. 322. A shrub of 3 or $4 \mathrm{ft}$. in height, with weak spreading branches, glabrous or very slightly hoary. Leaves lanceolate or oblong, 1 to near 2 in. long, coarsely toothed or slightly lobed above the middle, narrowed at the base into a petiole of about 2 lines. Flowers rather small, white, in terminal racemes, but with the axis so short as to be almost reduced to flat-topped corymbs or umbels, the very slender pedicels, 4 to 6 lines long, starting from nearly the same point. Carpels 5, or very rarely 6.-S. lanceolata, Poir. Dict. vii. 354 , but not the plant figured as such by Cambessèdes in Ann. Sc. Nat. Par. ser. 1, i. t. 25, nor that described by Seringe in DC. Prod. ii. 542. S. corymbosa, Roxb. Fl. Ind. ii. 512, but notof Rafin. S. Reevesiana, Lindl. Bot. Reg. 1844, t. 10.

Hongkong, Wright; and other parts of S. China, but not known from elsewhere. Roxburgh's indication of the north of India is probably founded on some mistake, and the 
Mauritius speeimens seen in herbaria are evidently from the botanic garden of that island, having been introduced from the Calcutta garden. It is very characteristically described both by Loureiro and by Poiret, but Cambessèdes in his monograph gave a figure of a plant quite different in foliage and inflorescence, whence Seringe took his dingnoses for De Candolle's Prodromus. It is this erroneous character that misled Lindley as to the supposed nonidentity of the plant with Poiret's and Loureiro's, and induced him to describe it as new.

\section{ROSA, Linn.}

Calyx-tube globular or ovoid, enclosing the ovary, contracted towards the top; the limb divided into 5 segments, often unequal and sometimes lobed. Petals 5. Stamens numerous. Ovary of several distinct carpels, enclosed in the calyx-tube, with 1 suspended ovule in each; the styles protruding from the tube, and occasionally united. When in fruit the carpels become dry, hairy, 1-seeded achenes, enclosed in the more or less succulent calyx-tube, and sometimes surrounded by pulp, the whole forming a rather dry red or black berry. Erect, scrambling, or climbing shrubs, more or less prickly. Leaves pinnate. Stipules leafy, adhering to the petiole. Flowers showy, terminal, either solitary or in small corymbs or panicles.

A beautiful genus, widely diffused over the temperate regions of the northern hemisphere, but scarcely penetrating into the tropics, except in mountain districts.

Flowers solitary. Leaflets $3 \ldots \ldots$. . . . . . . $R$ sinica.

Flowers several, in corymbs. Leaflets 7 or 5 .

Flowers white, middle sized. Calyx-segments narrow, one or more usually lobed. . . . . . . . . 2. Roschata.

Flowers small, pink. Calyx-segments short, entire . . . . 3. R. multiflora.

1. R. sinica, Ait. Hort. Kew. ed. 2; Lindl. Monogr. and Bot. Reg. $t$. 1922. Stems climbing, glabrous, as well as the leaves, with a few distant hooked prickles. Leaflets always 3 in the wild specimens, ovate, stalked, slightly serrate, the terminal one 1 to $1 \frac{1}{2}$ in. long, cuneate or rounded at the base, the lateral ones rather smaller. Flowers solitary at the ends of the lateral shoots, large, and of a pure white. Peduncles and ovaries thickly covered with straight prickles or bristles. Calyx-lobes downy or cottony, with long points, all or some of them expanding into small oblong leafy tips. Fruit globular. - R. nivea, DC. Prod. ii. 599.

Hongkong, Harland. Appears to be confined to China. Aiton's name would have the priority over De Candolle's, even should it be shown that he was mistaken in identifying it with the $\boldsymbol{R}$. sinica of Linnæus; for if the latter is not this plant, it merges in his $R$. indica. Iinnæus' character applies better to the present species. The specimen in his herbarium is a poor fragment from Jacquin, and much resembling the figure in that author's 'Observationes,' and apparently a garden specimen of $R$. indica in a starved state.

2. R. moschata, Mill.; DC. Prod. ii. 598; Bot.Reg.t.829. An erect or half-climbing tall-growing shrub, glabrous or pubescent on the young shoots and under side of the leaves, with a few stout recurved prickles. Leaflets 5 or 7, nearly sessile, oblong acuminate acute, and often $1 \frac{1}{2}$ to $2 \mathrm{in}$. long in the north Indian specimens; much shorter, ovate, obtuse or almost orbicular in the Hongkong one. Flowers white, not large, in terminal corymbs. Peduncles $\frac{3}{4}$ to 1 in. long, slender, usually pubescent or sometimes glandular, but without bristles or prickles. Ovary small, ovoid. Calyx-lobes narrow, with long points, and occasionally with 1 or 2 lateral lobes on one or both sides.$R$. Brunonis, Lindl.; DC. 1. c. 
Hongkong, Harland. Common in the mountains of northern India. Dr. Harland's specimen is a single one, without any indication of its precise locality. It is a small variety approaching in some measure the following species, but with the calyxes and the white flowers of $\boldsymbol{R}$. moschata.

3. R. multiflora, Thunb.; DC. Prod.ii.598. Stems climbing, slender, pubescent, as well as the petioles; the prickles nearly straight, or slightly recurved. Leaflets usually 7, or on the smaller branches sometimes 5 or 3, sessile, obovate or oblong, shortly pointed, glabrous above, pubescent underneath. Flowers small, pink, in terminal corymbs. Peduncles 6 to 8 lines long, glandular-pubescent. Calyx-lobes scarcely 3 lines long, hoary or cottony inside, with short points, and quite entire.

On the hills, Hinds, Hance. Extends from S. China to Japan.

\section{PHOTIN IA Lindl.}

Calyx-tube adhering to the ovary; the limb short, persistent, 5-toothed. Petals 5. Ovary inferior, completely or partially 2-celled, with 2 erect ovules in each. Styles 2. Fruit succulent, crowned by the remains of the calyxteeth. Endocarps thin, usually 1-celled, with 2 rather small oblong seeds.Erect shrubs, without prickles. Leaves simple, evergreen, usually serrulate. Flowers small, white, in terminal panicles or corymbs. rica.

A genus of few species, dispersed over central and eastern Asia and north-western Ame-

1. P. prunifolia, Lindl. Bot. Reg., under t. 1956. An evergreen shrub. Leaves oblong, 2 to $3 \mathrm{in}$. long, serrulate, narrowed at the base, coriaceous and shining, quite glabrous, but marked underneath with small black dots. Flowers numerous, in dense terminal corymbs, rather shorter than the last leaves, very downy at first, but sometimes becoming glabrous as the fruit ripens. Ovary villous, completely 2-celled. Styles glabrous. Fruit ovoid or nearly globular, red, about 3 lines long.

Common in the Happy Valley woods, Champion and others. Not known out of south China. Another Photinia, apparently P. serrulata, Lindl., from the adjacent continent, is cultivated in Hongkong.

\section{RHAPHIOLEPIS, Lindl.}

Calyx-tube narrow, adherent at the base to the ovary, the upper portion free, deciduous, 5-lobed. Petals 5. Stamens numerous. Ovary inferior, 2-celled, with 2 erect ovules in each cell. Styles 2. Fruit succulent, crowned by a ring or cup indicating the base of the calyx-limb. Seed usually solitary, nearly globular, testa thin ; cotyledons very thick, with scarcely any radicle.Trees or shrubs, without prickles. Leaves simple, evergreen, usually serrate. Flowers in short panicles or corymbs.

A very small genus, extending from $\mathrm{S}$. China to Japan.

1. R. indica, Lindl. Bot. Reg. t. 468. An erect nearly glabrous shrub. Leaves from ovate to oblong or lanceolate, acuminate, $1 \frac{1}{2}$ to 2 in. long, serrate, narrowed into a rather long petiole, coriaceous, smooth and shining above. Flowers white or pink, in short ovate panicles or shorter corymbs. Calyx-lobes usually narrow and acute. Fruit globular, varying in size, the scar of the 
calyx forming a mere rim or line round the top.- $R$. rubra, $R$. phocostemon, and $R$. salicifolia, Lindl. Coll. Bot. and Bot. Reg. t. 652 .

Common in Hongkong, Champion and others, and on the adjacent continent, but probably not extending beyond S. China. It is very variable in the breadth of the leaves, in the panicles more or less corymbose, in the bracts and calyx-lobes subulate or lanceolate, long or shurt, in the ovary tomentose or glabrous, in the flowers larger or smaller, the petals broader or narrow, the stamens longer or shorter, and in the size of the fruit. In one specimen the calyx-lobes are only $\frac{1}{2}$ line long and almost obtuse, in others they are 2,3 or even above 4 lines long, and then very acute. I have never seen the petals quite "lanceolate," nor yet "subrotund," but varying between the two, and most frequently as figured in the Bot. Mag. t. 1726. In some specimens the fruit, apparently, but perhaps not really, full-grown, is from 2 to 3 lines diameter, in others all the fruits are between 4 to 5 lines diameter. $I$ have however in vain attempted to sort the numerous specimens before me into distinct varieties showing any concordance in the characters derived from different organs. The $R$. japonica, Sieb. and Zucc., from Japan and Bonin, and R. integerrima, Hook. and Arn., from Bonin, appear both to be really distinct species.

\section{ERIOBOTRYA, Lindl.}

Calyx-tube adhering to the ovary ; the limb short, persistent, 5-lobed. Petals 5. Ovary inferior, 5-celled, with 2 erect ovules in each cell. Styles 5. Fruit forming with the calyx a fleshy mass, divided in the centre by thin partitions into 5 or fewer cells with one thick round seed in each. Testa rather thick. Cotyledons very thick, with scarcely any radicle.-Tall shrubs, without prickles. Leaves simple, evergreen. Flowers in terminal woolly or villous panicles.

A genus of very few species, from central or eastern Asia, including the common Loquat or $E$. japonica, Lindl., from continental China and Japan, but only known in Hongkong as cultivated for its fruit.

1. E. fragrans, Champ. in Kew Journ. Bot. iv. 80. A shrub, like the E. japonica in many respects, but the branches and leaves are glabrous and the inflorescence alone woolly, but with much closer and shorter hairs than in that species. Leaves oblong-elliptical, obtuse, scarcely toothed, 4 to 6 in. long, on a petiole of an inch ; the lateral veins fewer and less prominent than either in E. japonica or E. elliptica. Panicle sessile. Flowers rather smaller than in the Loquat, very fragrant, either single on pedicels of 2 or 3 lines, or clustered on common peduncles of that length. Calyx-lobes broad and rounded. Fruit about $\frac{3}{4}$ in. diameter.

In a ravine on Mount Victoria, very scarce, Champion. Not yet received in any other collection.

\section{ORDER XXXVIII. ONAGRACEAE.}

Calyx-tube adhering to the ovary, sometimes prolonged above it ; the limb of 4,2 , or rarely 5 lobes, valvate in the bud. Petals as many, inserted on the calyx below its lobes, or rarely wanting. Stamens as many or twice as many as the petals and inserted with them. Style single or divided at the top only into 2 or 4 stigmas. Ovary inferior, 2 - or 4 -celled with several ovules in each. Fruit a capsule or berry. Seeds without albumen. Embryo straight. - Herbs, or, in some American species, shrubs. Leaves in the Hongkong genera alter- 
nate, in some others opposite, undivided unless under water, toothed, without stipules. Flowers solitary in the axils of the leaves or in terminal spikes or racemes.

A considerable Order, ranging over the whole world, but in greatest variety in North America. The Haloragea, sometimes considered as a tribe of Onagracea much reduced in structure, will be found below, next to Cornacea.

Calyx-lobes and petals 4 . Stamens 8 .......... 1. Jussifea.

Calyx-lobes, petals, and stamens 4 each. . . . . . . . . . 2. Ludwigra.

\section{JUSSI卌A, Linn.}

Calyx-tube not produced above the ovary; the limb divided to the base into 4 or rarely 5 segments. Petals as many. Stamens twice as many. Stigma capitate. Capsules 4- or 5-celled, crowned by the calyx-segments and opening longitudinally between the ribs. Seeds numerous, small, without any appendage.-Herbs. Leaves alternate. Flowers axillary, solitary, yellow or rarely white.

A genus of several American species, with a very few spread over Africa and Asia.

1. J. villosa, Lam.;.W. and Arn. Prod. Fl. Penins. i. 336. An erect perennial, pubescent or hairy, attaining 2 to $3 \mathrm{ft}$., and often hard, almost woody, at the base. Leaves from oblong to linear-lanceolate, $1 \frac{1}{2}$ to $3 \mathrm{in}$. long, narrowed into a short petiole. Flowers almost sessile in the axils. Calyx-tube about $\frac{1}{2}$ in. long when in flower; the segments ovate-lanceolate, about 3 lines. Petals broad, rather longer than the calyx. Capsule nearly cylindrical, 1 to $1 \frac{1}{2}$ in. long, 8-ribbed, pubescent, contracted at the base into a short pedicel. Seeds minute.-J. octofila, DC. Prod. iii. 57, and the synonyms adduced by Wight and Arnott as quoted above.

In wet pastures, cultivated and waste places, Champion and others. Widely distributed over the warmer regions of America as well as Asia, and perhaps Africa.

\section{LUDWIGIA, Linn.}

Characters and habit of Jussica, except that the stamens are of the same number as the petals or calyx-segments, not twice the number. Flowers usually smaller.

A small genus, common to N. America, Europe, and Asia.

1. I. parviflora, Roxb.; W. and Arn. Prod. Fl. Penins. i. 336; Wight, Illustr. $t$. 101. An annual, sometimes erect and much branched, scarcely 6 in. high, sometimes spreading to the length of a foot or more. Leaves narrowlanceolate, I to $2 \mathrm{in.} \mathrm{long.} \mathrm{Flowers} \mathrm{on} \mathrm{short} \mathrm{pedicels,} \mathrm{much} \mathrm{smaller} \mathrm{than} \mathrm{in}$ the above Jussiza. Calyx-segments scarcely 1 line long. Petals not longer, oblong. Capsule oblong, tetragonous, 3 to 4 lines long, nearly $1 \frac{1}{2}$ lines broad. L. jussiceoides, Wall. Catal. n. 6335, non Lam.

In wet pastures, but not common, Champion. Widely spread over East India. The other common East Indian species, L. jussicosides, Linn., not Lam., with a still smaller flower and very slender capsule, has not as yet been found in Hongkong.

\section{Order XXXIX. RHIZOPHOREÆ.}

Calyx-tube usually adhering to the ovary, sometimes prolonged above it, or rarely quite free; the limb of 4 to about 12 lobes, valvate in the bud. Petals 
as many as the calyx-lobes, alternate with them, and inserted below them, usually cut or jagged. Stamens as many or twice as many or more, the filaments distinct, anthers erect. Ovary more or less inferior, or rarely quite superior, 2 - or more-celled, with 2 or few pendulous ovules in each cell, or rarely l-celled by the obliteration of the partition. Style simple, with an entire or lobed stigma. Fruit inferior or enclosed in the calyx, with 1 or few seeds, with or without albumen.-Trees or shrubs. J.eaves opposite, simple, entire or slightly toothed, coriaceous. Flowers axillary, solitary, clustered or in cymes.

A small Order, almost entirely tropical, and chiefly Asiatic and African, with a few American species. It is divided into two distinct tribes, by some considered as independent families. 1. Rhizophorea proper : including the following genus Kandelia, consists of the Mangroves, all maritime trees, the seeds without albumen, and almost always germinating before falling off, the thick radicle enlarging rapidly and projecting to a great length from the summit of the capsule. 2. Legnotidece : trees or shrubs, not strictly maritime, with usually smaller flowers, and the seeds albuminous, not germinating before they fall; to this tribe belongs the subjoined genus Carallia.

Calyx-segments and petals linear. Stamens numerous . . . . . 1. Kandelia. Calyx-segments very short. Petals orbicular. Stamens twice as many as the petals :

2. Caralita.

\section{KANDELIA, Arn.}

Calyx-segments 5 or 6 , rarely 4 , linear, shortly united above the ovary, and surrounded at the base by a cup-shaped bract. Petals as many, narrow, divided into several filiform segments, very deciduous. Stamens numerous, or rarely definite; filaments slender, anther's small. Ovary 1-celled (or when very young 3 -celled ?), with 6 ovules ( 2 to each cell) pendilous from a central axis. Style filiform, with a 3 -lobed stigma. Fruit oblong, the reflexed persistent calyx-segments surrounding it in the middle. Seed without albumen, the rapidly enlarged radicle penetrating through the apex of the fruit.

The genus only consists of the following species.

1. K. Rheedii, Arn.; Blume, Mus. Bot. i. 134; Hook. Ic. t. 362; Wight, Illustr. $t .89$. A glabrous evergreen tree, with thick branches. Leaves oblong, obtuse, 3 or 4 in. long, quite entire, coriaceous, on a petiole of $\frac{1}{2}$ to $\frac{3}{4}$ in. long. Peduncles 1,2 , or 3 in each axil, variable in length, but shorter than the leaves, each bearing a compact cyme of 3 to 5 white flowers. Calyxsegments 6 or 7 lines long. Petals rather shorter, and falling off so soon after the flower expands, that they may escape observation in the dried specimens. Stamens from 20 to 25.

In an estnary at Little Hongkong, and the only Mangrove on the island, Champion. It extends generally along the coasts of eastern India and the Archipelago, but is not so common there as other Mangroves.

\section{CARALIiA, Roxb.}

Calyx-tube campanulate above the ovary, with 5 to 8 very short lobes or teeth. Petals as many, clawed, orbicular, jagged or slightly toothed, inserted at the top of the calyx-tube. Stamens twice as many as petals, and inserted with them round the undulated margin of the thin disk. Ovary inferior, or at least admate as high as the insertion of the ovules, 4 -celled or rarely 3 - or 5 -celled, with 2 pendulous ovules in each cell. Fruit succulent, usually con- 
taining a single globular seed. Albumen abundant. Embryo eurved, not growing before the seed falls.-Trees or shrubs. Flowers small, in axillary, pedunculate, usually trichotomous cymes?

A small genus, limited to tropical Asia and Australia.

1. C. integerrima, DC.; Benth. in Journ. Linn. Soc. iii. 65. Usually a tree, glabrous in all its parts. Leaves sessile, obovate, elliptical or oblong, in the Chinese specimens usually acuminate, and about $3 \mathrm{in}$. long, but sometimes very obtuse, coriaceous. Cymes axillary, or from old leafless nodes, on short peduncles, each short branch bearing 3 to 5 sessile flowers. Fruit globular, about 3 lines diameter, crowned by the short connivent teeth of the calyx.-C. zeylanica, Arn.; Wight, Illustr. t. 90. C. sinensis, Arn.; Seem. Bot. Her. 376 .

In a ravine of Mount Victoria, but very rare, Champion; also Wright. Widely spread over East India and the Archipelago, extending eastward to N. Australia, and northward to the Philippines and South China. The Chinese, like the Philippine specimens, have the leaves usually more acuminate and rather narrower than in the generality of Indian ones, but the difference is by no means constant.

\section{ORDER XL. LYTHRARIEA.}

Calyx-tube free, but usually enclosing the ovary, with as many or twice as many teeth as there are petals. Petals 4,5 , or sometimes more, rarely deficient, inserted at the top of the calyx-tube, crumpled in the bud. Stamens as many or twice as many, or rarely indefinite, inserted in the tube of the calyx, often lower down than the petals. Ovary free from the calyx, but generally enclosed within its tube, 2- or more celled, with several ovules in each cell. Style single. Fruit a capsule, sometimes becoming 1-celled by the drying up of the partition. Seeds small, without albumen.-Trees, shrubs, or herbs. Leaves mostly (as least the lower ones) opposite, entire, without stipules. Flowers axillary, or in terminal racemes, or spikes, or panicles.

A considerable Order, some of the herbaceous genera spread over the greater part of the globe, the larger woody-stemmed ones confined to the tropics in the New or the Old World. Small-flowered herbs. Capsule opening transversely or septicidally.

Seeds angular . . . . . . . . . . . . . .

Showy shrub. Capsule opening loculicidally. Seeds winged . . . 2. LAGERSTREMIA,

\section{AMMANNIA, Linn.}

Calyx-tube campanulate; the limb 4- or sometimes 3- or 5-toothed, often with as many external small accessory teeth. Petals as many, or sometimes deficient. Stamens as many, or rarely twice as many. Ovary 2- to 4-celled. Style filiform, with a capitate stigma. Capsule membranous, 2- to 4 -celled, rarely 1-celled by the drying up of the partition, opening either transversely, or in septicidal valves.-Herbs, either annual or with a perennial stock, and usually glabrous. Leaves opposite. Flowers small, single, or clustered in the axils of the leaves, or forming terminal spikes.

A considerable genus, chiefly tropical and Asiatic or African, with a few species from tropieal or northern America, or from more temperate Asia.

1. A. rotundifolia, Roxb. $F l$. Ind. i. 485. A glabrous, low herb, 
diffuse, and often rooting at the base; the flowering stems ascending to the height of 4 to $6 \mathrm{in}$. or seldom more. Leaves almost sessile, orbicular, obovate, or broadly oblong, usually 3 ov 4 lines long. Flowers not above a line long, nearly sessile and single in the axils of bracts or floral leaves about as long as themselves, forming 1 or 3 terminal spikes of $\frac{1}{2}$ to 1 in. long. Calyxteeth 4, without any accessory ones. Petals 4, small, purple. Stamens 4.-Ameletia rotundifolia, Wight, Ic. i. t. 458. Ammannia (Ameletia) subspicata, Benth. in Lond. Journ. Bot. i. 484, and in Kew Journ. Bot. iv. 81.

Common in ditches and marshy places, Champion and others. Extends over India from the Peniusula to Burmah, and northward to the Himalaya and S. China. The first Hongkong specimens I received had remarkably narrow leaves and some apparent differences in inflorescence from the Indian type then known to me, and I was induced to describe it as a distinct species; but I now find that in China as in India the two extremes are so intimately connected as to be inseparable even as marked varieties.

\section{LAGERSTROFMIA, Linn.}

Calyx campanulate; the limb 4- to 9-toothed or -lobed, with the addition occasionally of small intermediate teeth. Petals as many, with distinct claws. Stamens indefinite, inserted near the base of the calyx-tube. Ovary 3-to 6-celled. Style filiform, with a capitate stigma. Capsule surrounded by the persistent calyx, opening loculicidally in 3 to 6 valves, each valve bearing the partition in its centre. Seeds terminating in a wing:- Trees or shrubs. Leaves opposite. Flowers showy, usually in terminal panicles.

A genus of few species, confined to tropical or subtropical Asia.

1. L. indica, Linn.; DC. Prod. iii. 93 ; Bot. Mag. t. 405 ; Wight, Illustr. $t$. 86 (38). A tall shrub, glabrous or nearly so ; the young shoots slightly 4angled. Leaves on very short petioles, orbicular, obovate, or broadly oblong, 1 to 2 in. long; the pinnate veins rather prominent and sometimes slightly pubescent underneath. Flowers of a reddish-purple, in handsome terminal ovate or oblong panicles of about half a foot in length. Calyx about 3 or $3 \frac{1}{2}$ lines long; the tube not furrowed, as in some other species, with ovate lobes. Petals 6, orbicular, crisped at the edge, on slender claws much longer than the calyx-lobes. Stamens indefinite, the 6 outer ones much larger than the others. Capsule nearly globular, 5 or 6 lines diameter, projecting considerably beyond the calyx.

Near the Buddhist Temple, really wild, Champion. Extends from Cochin China to Japan, and is much cultivated for ornament all over the East and occasionally in southern Europe.

\section{ORder XLI. MELASTOMACE巴.}

Calyx-tube enclosing the ovary and usually cohering with its angles, leaving intermediate cavities, or sometimes entirely free or adherent; the limb entire, or with as many teeth or lobes as petals. Petals usually 4 or 5 , sometimes 3 or 6 or more inserted intermediately below the calyx-teeth, twisted in the bud. Stamens usually twice as many, sometimes only as many, and inserted with the petals, the filaments curved down in the bud; the anthers 2-celled, opening at the top in 1 or 2 pores, and before flowering their tips are contained in the cavities between the calyx and ovary. Ovary with 2 to 6 , or 
rarely more cells, and several ovules in each, or sometimes 1-celled by the failure of the partitions. Style simple, with a capitate or minute stigma. Fruit enclosed in the calyx or combined with it, succulent and indehiscent, or opening in as many valves as there were cells to the ovary. Seeds usually numerous and small, straight or cochleate (i.e. curved something like a univalve shell), without albumen. Cotyledons flat or rarely convolute.-Herbs, shrubs, or rarely trees. Leaves opposite, undivided, and (in all but the Memecylon tribe) with 3,5 , or more ribs. Flowers usually in terminal panicles or clusters, rarely solitary or axillary.

A large Order, almost confined to the tropics, and most abundant in S. America, a few species occurring in N. America, in subtropical eastern Asia, southern Africa, or Australia.

Leaves with 3,5 , or more ribs. Ovary several-celled.

Stamens twice as many as petals.

Petals aud calyx-teeth 5 or 6 . Fruit succulent. Seeds cochleate 1. Melastoma.

Petals and calyx-teeth 4, rarely 5 . Fruit capsular.

Anthers without subulate appendages. Seeds cochleate . . 2. OsBeckia.

Anthers with 2 hair-like appendages. Seeds straight . . 3. Dissocheтs.

Stamens and petals 4.

Panicle terminal . . . . . . . . . . . . 4. Oxyspora.

Flowers in axillary clusters . . . . . . . 5. ANPLECTRUM.

Leaves with only the midrib. Ovary 1-celled : . . . 6. MeMrerLon.

\section{MELASTOMA, Linn.}

Calyx-tube campanulate; the limb of 5 or rarely 6 deciduous lobes or teeth, and often as many accessory ones. Petals as many, obcordate or obovate. Stamens twice as many. Anthers long, with a single pore; 5 larger, with the connective produced below into a long curved 2-lobed or 2-pointed appendage; 5 smaller, with the appendage short and 2-lobed or wanting. Ovary 5 - or rarely 6-celled, crowned with a few stiff hairs or bristles. Fruit more or less succulent, opening irregularly. Seeds cochleate.-Shrubs or undershrubs. Leaves usually ovate. Flowers terminal, solitary or few together, usually large and showy; the calyx usually covered with bristles or scales.

A considerable genus, limited to tropical Asia, Australia, and the Pacific islands.

Creeping undershrub

Erect shrub.

Calyx covered with closely pressed, chaffy, scale-like bristles . . 2. M. macrocarpon.

Calyx covered with long, fine, spreading, and incurved bristles . . 3. M. decemfidum.

1. IM. repens, Lam.; Naud. in Ann. Sc. Nat. Par. ser. 3, xiii. 274. A diffuse or creeping undershrub, the branches quite glabrous or with a very few bristles. Leaves broadly elliptical or obovate, $\frac{1}{2}$ to 1 in. long, 3 -nerved, with a few short bristly hairs at the edge, otherwise glabrous. Flowers 1 to 3 together at the ends of the branches, much smaller than in the two following species. Calyx more or less covered with rather short stiff bristles; the lobes lanceolate, about the length of the tube, varying much in breadth, but never subulate from the base in the specimens I have seen. Petals about $\frac{1}{2}$ in. long. Berry purple, rather larger than a Bilberry, and of a pleasant taste.

Common on all the hills, especially near the summits, Champion and others. Also on the adjacent continent, but not known out of S. China.

2. M. macrocarpon, Don; DC. Prod. iii. 145. An erect shrub, the 
branches more or less covered with adpressed scaly bristles. Leaves stalked, varying from broadly heart-shaped and only 2 or $3 \mathrm{in}$. long, to nearly lanceolate and $5 \mathrm{in}$. long. Flowers large, usually 3 together, almost sessile at the ends of the branches, sometimes solitary or 5 together, when expanded often 3 or 4 in. diameter. Calyx thickly covered with closely pressed chaffy bristles or scales; the lobes lanceolate, about the length of the tube, the accessory teeth small and fine or none. Bracts at the base of the calyx varying from ovate to lanceolate, shorter than the tube or as long as the whole calyx. There are two rather marked varieties, viz.-

$a$. Leaves sprinkled on the upper side with short hairs.-M. macrocarpum, Benth. in Kew Journ. Bot. iv. 116, and Naud. in Ann. Sc. Nat. Par. ser. 3, xiii. 281. M. homostegium, Naud. 1. c. p. 286. .

b. Leaves thickly covered on both sides with appressed hairs or bristles, giving them a silky appearance when young.-M. $M$. candidum, Don; Benth. in Kew Journ. Bot. iv. 116. M. calycinum, Benth. in Lond. Journ. Bot. i. 285.

On hills, Champion and others. Also on the adjacent continent and in the Philippine Islands (Cuming, n. 927) the two varieties are found together, and the extreme states appear very different in the clothing of the foliage ; but they are too much connected by intermediate states to be retained as species. The figures usually quoted, Bot. Mag. t. 529, and Bot. Reg. t. 672, are very unsatisfactory representations of this species. They are, however, most probably drawn from plants of East Indian origin, more nearly allied to the M. malabathricum.

3. M. decemfidum, Roxb.; DC. Prod. iii. 146; Naud. in Ann. Sc. Nat. ser. 3, xiii. 282. An erect shrub, the branches with a few scattered scales and spreading bristles. Leaves like those of the last species, but narrower, from ovate-lanceolate to lanceolate, glabrous, or with a few short scattered appressed hairs or bristles. Flowers large, solitary or 3 together, as in the $M$. macrocarpum. Calyx-tube covered with long stiff bristles, spreading at the base, and then turned upwards ; the lobes lanceolate-subulate, much shorter than the tube, with accessory teeth nearly as large.-M. sanguineum, Linn.; Bot. Mag. t. 2241 ; DC. Prod. iii. 145 ; Naud. l. c. 281.

On hills, with the preceding, Champion and others. Extends over the Indian Archipelago from Penang to Borneo.

\section{OSBECKIA, Linn.}

Calyx-tube ovoid; the limb of 4 or 5 lobes or teeth, with appendages between them, which are usually bristle-like, and terminate in a tuft of hairs. Petals as many, obovate. Stamens twice as many. Anthers opening in a single pore, without any or scarcely any appendage to the base of the connective. Ovary 4- or 5-celled, crowned with bristles. Fruit capsular, opening at the top in as many valves as there were cells to the ovary. Seeds cochleate.Herbs, or rarely shrubs. Flowers usually terminal, in clusters or short racemes, smaller than in Melastoma.

A considerable genus, spread over tropical Asia and Africa.

1. O. chinensis, Linn.; Blume, Mus. Bot. i.50. An erect herb, either annual or forming a perennial stock, glabrous, or with a few short stiff hairs; the stem quadrangular, $1 \frac{1}{3}$ to $2 \mathrm{ft}$. high. Leaves very shortly stalked, linear, linear-oblong, or almost lanceolate, 1 to $2 \mathrm{in}$. long, 2 to 4 lines broad. Flowers several together, forming sessile terminal clusters, almost condensed into heads. 
Calyx-tube 3 to 4 lines long; lobes 4 , acute and ciliate, but without any terminal tuft of hairs, with 4 accessory ciliate scales inserted between and a little below them on the outside. Fruiting calyx somewhat contracted near the top, truncate after the lobes have fallen.-O. angustifolia, Don; Wall. Pl. As. Rar. iii. t. 251. O. linearis, Blume, in Flora, 1831, 473. O. decora, Wall. Catal. n. 4070. O. glabrata, Wall. Catal. n. 4071.

In ravines in the island, Champion and others. Common in northern and eastern India, in the Archipelago, the Philippines, and northward to south China and Formosa. This species is well described by Linnæus, although it has been subsequently much confused, owing to his false reference to Plukenet. This has led to the figuring other Indian species, in Bot. Reg. t. 542 and Bot. Mag. t. 4026, under the erroneous name of $O$. chinensis.

\section{DISSOCH 然TA, Blume.}

Calyx-tube ovoid or oblong; the limb 4-lobed, without accessory teeth. Petals 4. Stamens 4 or 8 , of which 4 much smaller. Anthers of the larger ones usually elongated, with a single pore at the top; the connective often produced below at the back into a spur, and usually bearing at the base in front 2 hair-like appendages. Ovary usually adnate to the calyx at the angles only, 4-celled, without bristles at the top. Fruit usually capsular. Seeds nearly straight, with a lateral hilum.-Shrubs, usually glabrous or with a very slight tomentum. Flowers in terminal panicles, usually smaller than in the two last genera, although exceptionally large in the following species.

A considerable genus, limited to tropical Asia, and most numerous in the Archipelago.

1. D. Barthei, Hance, n. sp. A low shrub, with spreading branches, glabrous, or the young shoots slightly mealy-glandular. Leaves oval-elliptical, acuminate, those of each pair unequal, the longer ones 2 to $3 \mathrm{in}$.long, 1 to $1 \frac{1}{2}$ in. broad, on a petiole of half an inch, with 3 ribs besides the marginal nerves. Flowers usually 3 together, at the ends of the branches, white, tinged with pink outside, about 2 in. diameter. Calyx-tube sharply 4 -angled, the lobes about 2 lines long. Petals broad, like those of a Melastoma. Anthers of the 4 larger stamens about 5 lines long, with an oblong dorsal appendage or spur, and the 2 hair-like appendages characteristic of the genus, the 4 others about one-third their size, without the dorsal appendage, but with the two hair-like ones. Ovary crowned by an irregularly lobed ring, with short glandular bristles. Capsule, when ripe, almost free within the calyx, opening in 4. valves.

In ravines on the top of Mount Victoria, Hance and Barthe, and afterwards Wilford. Not as yet seen from elsewhere. The Asiatic Melastomacere of the Miconia tribe have been distributed by Blume, Korthals, Naudin, and others, into so many small genera, founded so frequently upon characters which are only speeific, that it is seldom that any new species discovered will fit precisely into any of them, and thus the genera of this and the two following species must remain uncertain until the whole shall have been reformed into natural groups. For this operation we do not at present possess in this country sufficient materials. In the meantime I have retained the present species in Dissochata, where Dr. Hance proposed to place it, as having the technical character derived from the anthers, although it has the calyx rather of Oxyspora, and differs from both in inflorescence, and perhaps in the fruit, which is not very perfect in the specimens $\mathrm{I}$ have seen.

4. OXYSPORA, DC.

Calyx-tube oblong; the limb of 4 ovate lobes, without accessory teeth. 
Petals 4, acute. Stamens 8 , of which 4 smaller, or 4 only. Anthers of the 4 larger ones linear, opening in a single pore, slightly 2-lobed at the base, but without any appendage. Ovary 4-celled, adhering by the angles only. Capsule almost free, enclosed in the calyx, 4-celled, opening in valves at the top. Seeds nearly straight, with a lateral hilum.-Shrubs usually glabrous, or nearly so. Flowers in terminal panicles.

Besides the following species the genus only comprises one or two from northern India.

1. O.? pauciflora, Benth. Apparently a shrub. Branches slightly rusty-tomentose. Leaves ovate, acuminate, rounded or slightly cordate at the base, 3- or 5-ribbed, glabrous above, more or less covered underneath with glandular dots, and slightly tomentose on the ribs, those of each pair very unequal, the larger one about 3 in. long. Flowers in a loose panicle, much smaller than in the Indian $O$. paniculata. Stamens 4 only, resembling the larger ones of that species.-Allomorphia pauciflora, Benth. in Lond. Jouru. Bot. i. 485 .

Hongkong, Hinds. I described this from a single specimen in Mr. Hinds' collection, and have seen no other one since. Having, however, examined good specimens of the true Allomorphia, I find I was wrong in referring the Hongkong plant to that genus, but it agrees well in habit and characters with Oxyspora, except that the 4 stamens opposite the petals are entirely wanting, instead of being only much smaller than the others.

\section{ANPLECTRUM, A. Gray.}

\section{(Aplectrum, Blime, not Nutt.)}

Calyx-tube campanulate; the limb entire or 4-toothed, but without accessory teeth. Petals 4, lanceolate-acuminate. Stamens 8, of which 4 sterile, or 4 only. Anthers of the fertile ones linear or ovoid, opening in a single pore, slightly 2 -lobed at the base, but without any or only a very small appendage to the connective. Ovary 4-celled, entirely adnate to the calyx. Fruit a globular indehiscent berry. Seeds nearly straight, with a lateral hilum.-Shrubs, either glabrous or slightly tomentose. Flowers very small, in axillary or sometimes terminal clusters or short panicles.

A genus of very few species, alt from tropical Asia.

1. A. parviflorum, Benth. n. sp. A shrub, either glabrous or the branches and under side of the leaves minutely powdery-downy. Leaves on long petioles, oval-oblong, with a long acumen, 3 to $4 \mathrm{in}$. long, and 1 to $2 \mathrm{in.} \mathrm{broad,}$ acute at the base, glabrous above, of a thinner consistence than those of other Anplectra, those of each pair nearly equal. Pedicels 3 to 5 together, in the axils of the leaves, 1 to 2 lines long. Calyx-tube about 1 line long, slightly contracted at the top, with 4 minute teeth. Stamens 4 only, the anthers without appendage. Fruit about $1 \frac{1}{2}$ lines long, ovoid or pear-shaped, not very succulent, and perhaps opening in short valves at the top. Seeds acuminate at both ends.

Hongkong, Wright. Also north-west Formosa, Wilford, and Assam, Masters. The species agrees well with the technical characters of Anplectrum, except in the total absence of the 4 smaller stamens. The habit and foliage come near to those of Driessenia, judging from Korthals' figures, as I have seen no snecimens of that plant. 


\section{MEMECYLON, Linn.}

Calyx-tube hemispherical or campanulate; the limb entire or obtusely 4lobed, or rarely 5-lobed. Petals 4 or rarely 5, ovate or orbicular. Stamens twice as many, all similar. Anthers short, with a thick connective, forming a conical spur at the base. Ovary entirely adnate to the calyx, 1-celled. Ovules attached to a central placenta. Fruit a berry, crowned by the calyxteeth or border. Seeds solitary or rarely 2 or 3, with convolute cotyledons. - Trees or shrubs. Leaves coriaceous, with 1 prominent midrib, and pinnate veins often scarcely perceptible. Flowers usually small, in axillary clusters or cymes.

A considerable genus, spread over the tropical regions of the Old World.

1. M. ligustrifolium, Champ. in Kew Journ. Bot. iv. 117. A perfectly glabrous shrub, with slender branches. Leaves shortly stalked, elliptical, obtuse or obtusely acuminate, 2 to $3 \mathrm{in}$. long and about $1 \mathrm{in}$. broad, acute at the base, of a thick coriaceous consistence, the veins scarcely perceptible. Peduncles axillary, 2 to 3 lines long, bearing a little cyme of 3 to 5 flowers. Buds, when ready to open, globular, obtuse, nearly 2 lines diameter. Calyx-teeth 4 , very broad and short. Ovules 8 or 10 , in a ring round the short central placenta. Berry 4 or 5 lines diameter, with a single seed.-M. scutellatum, Hook. and Arn. Bot. Beech. 186, but not of Naudin.

Hongkong, Champion. Also S. China, Beechey. The species is allied to the common M. ovatum, Sm. (or $\boldsymbol{M}$. edule, Roxb.), but the flowers are fewer and twice the size. It cannot well retain the name of scutellutum, which should be reserved for the Scutula of Loureiro, formerly supposed by Hooker and Arnott to be this species, but which appears to be a different one, from Cochin China and not from Canton. Nandin has given the name of M. ligustrinum to a different species, which I have not seen.

\section{ORder XLII. MYRTACEE.}

Calyx-tube adhering to the ovary and often projecting above it; the limb of 4 or 5 or rarely more lobes or teeth. Petals as many, inserted on the calyx at the top of the tube, imbricate in the bud. Stamens usually indefinite, sometimes twice as many or as many as the petals, curved inwards in the bud, free or variously connected. Anthers small, 2-celled. Ovary inferior, 2- to 5- or more celled, rarely 1-celled by incompleteness or failure of the partitions. Ovules 2 or more in each cell or rarely solitary, the placentas axile. Fruit dry or succulent, indehiscent or dehiscent. Seeds without albumen. Embryo straight or curved.-Trees or shrubs. Leaves opposite or rarely alternate, entire, almost always dotted. Flowers axillary or more rarely terminal.

A large Order, widely spread over South America, tropical and subtropical Africa and Asia, and especially Australia, with a few South African, North American, and one European species.

Stamens 10 or 8 . Leaves subulate, heath-like , . . . . . 1. B שскEA.

Stamens numerous. Leaves flat.

Calyx-tube produced ahove the ovary, and lobed or toothed at the top.

Calyx-tube shortly obovate

2. Srzygium. 
Calyx-tube elongated and tapering at the base.

Calyx-limb obscurely toothed . . . . . . . . 3. ACMENa.

Calyx-limb distinctly 4-lobed . . . . . ..., 4. ЈАмвова.

Calyx entire and closed in the bud, splitting irregularly as the flower opens

Calyx-tube wholly adnate, the lobes reaching to the ovary. Leaves 3- or 5 -ribbed

5. Psidium.

6. Rhodomyrtus.

\section{B疋CKEA, Linn.}

Calyx-tube campanulate, acute at the base, produced above the ovary ; lobes 5, membranous. Petals 5. Stamens 10 or fewer. Ovary 2- or 3-celled, with several ovules in each cell. Capsule opening at the top in 2 or 3 loculicidal valves. Seeds angular. Embryo straight, with short cotyledons. Heath-like shrubs. Leaves opposite, small, and narrow. Flowers solitary in the axils, with 2 minute bracts at their base.

A small genus, chiefly Australian, with one species extending over the Indian Archipelago to China.

1. B. frutescens, Linn.; DC. Prod. iii. 229; Bot. Mag.t. 2802. A glabrous, heath-like shrub, with twiggy branches. Leaves linear-subulate, 3 or 4 lines long, erect or spreading. Flowers small, nearly sessile and solitary in the axils of the leaves, and not attaining half their length. Calyx-lobes orbicular, and almost petal-like. Stamens 10 or rarely 8 . Ovary 3 -celled.-B. Cumingiana, Schau. in Walp. Rep. ii. 920.

Very common in the island, Champion and others. Extends over the Indian Archipelago, the Malayan Peninsula, the Philippines, and South China. The Malacca specimens, as well as the Chinese ones, have the parts of the flowers generally in fives, and only occasionally and accidentally reduced to fours.

\section{SYZYGIUM, Gærtn.}

Calyx-tube shortly obovate, produced above the ovary, bordered with 4 or rarely 5 very short teeth, which disappear as the flower expands. Petals 4 or rarely 5 , more or less cohering and falling off together, or rarely free. Stamens numerous, free. Ovary 2-celled, with several ovules in each cell. Fruit a berry, crowned by the truncate remains or scar of the calyx. Seed rarely more than 1. Embryo straight, the cotyledons thick and usually consolidated into a single mass.-Trees or shrubs. Leaves opposite, coriaceous. Flowers in trichotomous panicles, usually terminal and corymbose, more rarely axillary and few-flowered.

A considerable genus, dispersed over tropical Asia, with a few African or Australian species. It differs in little but the calyx from the very large chiefly American genus Eugenia, and, as well as the two following genera, is united with it by many botanists.

Panicles few-flowered, axillary. Leaves not above 1 in. long. Petals free .

Cymes small, mostly terminal. Leaves narrow, $1 \frac{1}{2}$ to 2 in. long. Petals cohering

Panicles many-flowered, lateral. Leaves 3 to 6 in. long. Petals cohering

1. S. buxifolium.

2. S. odoratum.

3. S. nervosum.

1. S. buxifolium, Hook. and Arn. Bot. Beech. 187. A glabrous, muchbranched shrub, the younger branches quadrangular. Leaves obovate or broadly oblong, obtuse, $\frac{1}{2}$ to $1 \mathrm{in}$. long, narrowed at the base into a very short petiole, rather thick; the lateral veins inconspicuous. Cymes or panicles 
few-flowered, seldom longer than the leaves. Calyx-teeth very short and broad. Petals 4, small, not cohering as in most species of the genus. Ovules about 4 in each cell. Berry 4 to 6 lines in diameter. Seed single, the thick cotyledons not consolidated.

In ravines, Champion and others. On the Chinese continent it extends northward to Amoy.

2. S. odoratum, Hook. and Arn. Bot. Beech. 187, but perhaps not of DC. A glabrous shrub, with slightly compressed branches. Leaves elliptical or oblong-lanceolate, acuminate, $i \frac{1}{2}$ to 2 in. long, narrowed into a petiole, shining above; the veins not very prominent, and uniting into a marginal one about $\frac{1}{2}$ a line from the edge. Cymes few-flowered, compact, mostly terminal and shorter than the leaves. Flowers scarcely pedicellate. Calyx-teeth 4, broadly orbicular. Petals usually cohering and falling off together.

In the Happy Valley woods, Champion and others. Also on the adjacent continent, but not known out of S. China. It is at first sight very similar to the S. cymosum, DC. (S. frondosum, Wall.), but in that species, besides minor differences, the lateral veins are very numerous and parallel, running out almost to the edge.

3. S. nervosum, DC. Prod. iii. 260. A large tree, quite glabrous. Leaves ovate or oval-elliptical, obtuse or shortly acuminate, 3 to 6 in. long, usually of a pale green; the principal lateral veins distant from each other, and very prominent underneath. Panicles usually arising from the leafless nodes of the former year's wood, 3 or 4 in. long, very spreadingly branched from the base; the flowers usually 3 together, sessile at the ends of the ultimate branches. Calyx not distinctly toothed. Berry very juicy and edible. -Engenia operculata, Roxb. Fl. Ind. ii. 486; Wight, Ic. t. 552, and probably E. Paniala, Roxb. l. c. p. 489 , and E. cerasoides, Roxb. l. c. 488; Wight, Ic. t. 615 and 616. Syzygium nodosum, S. costatum, and S. angkolanum, Miq. Fl. Ned. Ind. i. 448. Calyptranthes mangiferifolia, Hance in Walp. Ann. ii. 629.

Near the Albany barracks, Champion. Cultivated in the island, Hance. Spread over northern and eastern India, the Archipelago, and northward to S. China. The berry much eaten, and the tree often planted for its fruit. It is very near the $S$. Jambolana in habit and inflorescence, but may be readily distinguished by the venation of the leaves.

\section{ACMENA, DC.}

Characters of Syzygium, except that the calyx-tube is elongated and tapers to the base.

A genus which, if limited as proposed by Wight (as a section of Eugenia), comprises several Asiatic species, besides one or two Australian ones, to which last others would confine the group. It is probable, however, that most of the species should be united with Syzygium. The following one is as yet doubtful, only being known in fruit.

1. A. Championi, Benth. in Kew Journ. Bot.iv. 118. A glabrous tree. Leaves oval-elliptical or oblong, obtuse or obtusely accuminate, $1 \frac{1}{2}$ to $2 \frac{1}{2}$ in. long, $\frac{1}{2}$ to $1 \mathrm{in}$. broad, tapering at the base into a short petiole, shining above; the lateral veins fine and scarcely prominent. Cymes few-flowered, terminal, or in the upper axils shorter than the leaves. Pedicels very short. The flowers have not been seen. Calyx (evidently just past flower) slender, about 4 lines long, with 4 very short broad teeth. Berry ovoid-oblong, 5 or 6 lines long. Seeds 1 or 2 , the cotyledons consolidated into a thick mass. 
Near the Waterfall in the Happy Valley, Champion. The Memecylon nigrescens, Hook. and Arn., a S. Chinese plant, referred here with doubt by Seemann, is certainly not this species. The specimens lave elose lateral clusters of very young apparently diseased buds, insufficient for their determination. If the plant is a Myrtacea at all, which is not improbable, it most resembles an apparently undescribed S. Chinese Syzygium, allied to S. buxifolium, of which there are specimens from Millett in the Hookerian herbarium, but which has not yet been found in Hongkong.

\section{JAMBOSA, DC.}

Calyx-tube turbinate, usually elongated and tapering at the base, produced above the ovary, with 4 or rarely more distinct lobes or teeth. Petals 4 , or rarely more, distinct and spreading. Stamens numerous, free. Ovary 2celled, with several ovules in each cell. Berry and seeds of Syzygium.-Trees or shrubs. Leaves opposite, coriaceous. Flowers in terminal or rarely axillary short panicles, often rather large.

A considerable genus, limited to the tropical regions of the Old World.

1. J. vulgaris, DC. Prod. iii. 286 ; Wight, Ic. $t$. 435. A glabrous tree. Leaves nearly sessile, lanceolate, acuminate, 4 to $7 \mathrm{in}$. long, 1 to $1 \frac{1}{2}$ in. broad, narrowed at the base, coriaceous and veined. Flowers large and showy, in a short terminal panicle or raceme. Calyx-tube elongated in the adherent part, the free part campanulate, with broad rounded lobes. Petals full $\frac{1}{2}$ in. long, orbicular. Berries globular, crowned by the lobes of the calyx.

A native of tropical Asia, much planted about cottages for ornament, and said to be naturalized in Hongkong.

\section{PSIDIUM, Linn.}

Calyx-tube ovate and adnate at the base; the upper free portion quite entire and closed over the flower in the bud, and coming off entire or splitting irregularly. Petals 4 or 5, free. Stamens numerous. Ovary 2- or more celled, with many ovules in each, inserted on bifid axile placentas. Fruit a berry. Seeds several, kidney-shaped or horseshoe-shaped. Embryo curved, with a long radicle and short cotyledons.-Trees or shrubs. Leaves opposite. Flowers solitary or few together, on axillary peduncles.

The genus is exclusively American, the following species only being introduced into the Old World.

1. P. Guyava, Linn. Sp. Pl.ed. 1, 470. A tree, pubescent on the young branches. Leaves on very short petioles, ovate or oblong, usually acuminate, 3 to 4 in. long, glabrous or nearly so above, softly pubescent underneath, with the principal veins very prominent. Peduncles axillary, $\frac{1}{2}$ to $1 \mathrm{in}$. long, 1- or 3 -flowered. Buds ovoid in the adnate part; the free part also ovoid, but much larger and more or less acuminate or pointed. Petals broad, full $\frac{1}{2}$ in. diameter. Fruit globular or pear-shaped, known under the name of Guava.-P. pomiferum and P. pyriferum, Linn.; DC. Prod. iii. 233 and 234.

Hongkong, Champion, chiefly on roadsides and near habitations, Hance, Seemann. A species of American origin, much cultivated in tropical Asia, and readily becomes naturalized.

\section{RHODOMYRTUS, DC. .}

Calyx-tube campanulate, not produced above the ovary ; limb of 5, or rarely 6 or 4 lobes, broad and reaching to the ovary. Petals as many, free, spreading. 
Stamens numerous. Ovary 3- or 4-celled, with several ovules in each cell, inserted in 2 rows on axile placentas. Ovary globular, crowned by the calyxlobes. Seeds several, horizontal, flattened. Embryo curved, with a long radicle, and semicylindrical cotyledons.

The genus is limited to the following species.

1. R. tomentosa, $D C$. Prod. iii. 240 ; Wight, Ic. $t .522$ (as a section of Myrtus). A shrub of 4 or 5 feet, the branches, the under side of the leaves, the peduncles, and calyx hoary with a very short soft tomentum. Leaves oval-elliptical, obtuse, $1 \frac{1}{2}$ to 3 in. long, with 3 or rarely 5 ribs, starting from near the base as in Melastomacea, on short petioles. Peduncles axillary, shorter than the leaves, bearing 1 or 3 rather large pink flowers. Calyx tomentose, with 2 small bracts at the base. Petals $\frac{1}{2}$ to $\frac{3}{4}$ in. diameter, tomentose outside.

Abundant on the hills, Champion and others. Widely spread over southern India, in Ceylon, Penang, and the Indian Archipelago, and northwards to China and Japan. In some of the stations, however, given by collectors, it is only cultivated or escaped from cultivation.

\section{ORDER XLIII. SAMYDACE正.}

Sepals free or united at the base into a 4- or 5-lobed (rarely 2-, or 3-, or 6-, or more lobed) calyx, free from the ovary, or more or less adherent. Petals either as many as the sepals or calyx-lobes, inserted at their base, persistent with them, and resembling them in consistence, or wanting. Stamens perigynous, indefinite, or not corresponding in number with the petals, or if equal to them, then usually opposite them, with glands or small scales alternating: with them. Ovary superior or more or less inferior, 1-celled, with 2 or more parietal placentas, and several ovules to each placenta. Style entire, or more or less divided into as many branches as placentas. Fruit indehiscent or opening in valves between the placentas. Seeds often arillate. Albumen fleshy. Embryo straight or nearly so, with the radicle next the hilum, and flat cotyledons. - Trees or shrubs. Leaves alternate, undivided, usually toothed. Stipules small or none. Flowers hermaphrodite or rarely diœcious.

A considerable Order, if taken with the limits above given, and widely distributed over the New and the Old World, chiefly within the tropics. The two following genera belong to two of those tribes into which it may be divided, and which are considered by some as distinct Orders, viz. Caseariea, or Samydea proper, without petals, the stamens in a single series; and Homalinea, with sepal-like petals, the stamens inserted singly or in clusters, opposite the petals.

Petals none. Stamens in a single row, alternating with short ciliate

seales. Ovary superior
Petals as many as sepals. Stamens opposite them. Ovary inferior $:$. 2. Homalium.

\section{CASEARIA, Linn., Jacq.}

Calyx-lobes 4 to 5 . Petals none. Stamens 6 to 15 , alternating with as many short ciliate or hairy scales, all in a single series and united in a perigynous ring at the base. Ovary superior, 1-celled, with 3 or rarely 4 parietal placentas. Style entire or shortly 3-lobed. Fruit somewhat succulent, opening in valves, or more fleshy and indehiscent. Seeds often with an arillus. 
Leaves usually dotted with a mixture of round and oblong transparent dots. Stipules lateral. Flowers usually in axillary clusters.

A considerable genus, chiefly American, with a few African and Asiatic species.

1. C. glomerata, Roxb.; DC. Prod.ii. 49. A glabrous shrub. Leaves shortly stalked, oval-oblong, 2 to 4 in. long, entire or slightly serrate, marked with pellucid dots. Flowers clustered in the axils of the leaves on pedicels of about 2 lines. Calyx about 1 line long, 5-cleft. Stamens 8, alternating with as many scales. Style entire, with a capitate stigma. Fruit an oblong indehiscent berry, about $\frac{3}{4}$ in. long.

Hongkong, Wright. I have only seen a single specimen in fruit from the island. It appears, however, to belong to this species, which has a wide range over E. India.

\section{HOMALIUM, Jacq.}

Calyx-tube turbinate or oblong, adherent at the base, lobes 4 to 12 . Petals as many. Stamens 1 or more, opposite each petal, and 1 gland opposite each sepal. Ovary l-celled, adherent in the lower part, conical and free in the upper part, crowned with 3 to 5 styles, either free or united into one. Placentas as many as styles, in the upper free part of the ovary, with 2 to 6 (usually 4) pendulous ovules to each placenta. Fruit slightly enlarged, the calyx-lobes and petals persisting round its centre, and usually opening at the top in short valves between the placentas.-Trees or shrubs. Leaves not dotted. Flowers in axillary racemes or terminal panicles.

- A considerable tropical genus, chiefly Asiatic and African, with a few American species.

1. H. fagifolium, Benth. in Journ. Linn. Soc. iv. 35. A small tree or shrub, the branches pubescent. Leaves shortly stalked, oval or obovate, about 3 in. long, toothed, thin and pubescent, or at length glabrous. Racemes usually shorter, or scarcely longer than the leaves, slender and pubescent. Flowers whitish, pubescent. Calyx-tube narrow-turbinate, with 6 to 8 linearcuneate lobes about $1 \frac{1}{2}$ lines long. Petals nearly similar, and scarcely larger, all ciliate, giving the flower a plumose appearance. Styles usually 4 , glabrous. Free part of the ovary shortly conical._Blackwellia fagifolia, Lindl. Trans. Soc. Hort. Lond. vi. 269. B. padiflora, Lindl. Bot. Reg. t. 1308. B. Loureiri, Benth. in Lond. Journ. Bot. i. 482.

In the Happy Valley woods, Champion and others. Also in the adjacent parts of south China, but not known from elsewhere.

\section{ORDER XLIV. PASSIFLOREE.}

Sepals united at the base into a 5-lobed or rarely 3-or 4-lobed calyx, free from the ovary. Petals as many as the calyx-lobes, inserted at their base, usually persistent with them and nearly resembling them, or rarely wanting. Stamens usually as many as the sepals, rarely twice as many, inserted at the base of the calyx, but often connate with the ovary-stalk to near the top, and appearing to be there inserted. Ovary usually stalked, 1-celled, with 3 or rarely $\mathbf{5}$ parietal placentas, each with several ovules. Style divided into as many branches as placentas, with terminal stigmas. Fruit indehiscent and succulent, or opening in valves between the placentas. Seeds often arillate. 
Albumen fleshy. Embryo straight. Radicle next the hilum. Cotyledons leafy.-Climbers, or rarely erect herbs or shrubs. Leaves alternate, entire or divided, with stipules. Flowers hermaphrodite or unisexual.

Besides Passiffora itself, the Order contains a few small genera dispersed over the tropical regions of the Old as well as the New World.

\section{PASSIFLORA, Linn.}

Calyx-tube short. One or several rings of coloured filaments within the petals. Stamens as many as the sepals, so united with the ovary-stalk as to appear to be inserted at its summit. Styles 3 , with large capitate stigmas. Fruit succulent, indehiscent.-Climbers with axillary tendrils. Flowers usually hermaphrodite. Sepals usually coloured inside as much as the petals.

A large genus, almost entirely American, with a very few somewhat anomalous species from the Old World.

1. P. fœtida, Linn.; DC. Prod. iii. 331 ; Bot. Reg.t. 321 ; But. Mag. $t$. 2619. A herbaceous climber, usually very hairy. Leaves stalked, cordate, and mostly 3 -lobed, 2 to 3 in. long, softly villous on both sides. Stipules fringed with hair-like lobes, tipped with a small gland. Peduncles axillary, 1 to 2 in. long, bearing a single flower, closely surrounded and almost enclosed in a moss-like involucre, consisting of 3 bracts very much divided into hair-like glandular lobes. Petals pale purplish-white, spreading to about 2 in. diameter.

Common about habitations, Wilford. A native of S. America, where it has a very wide range, and introduced from thence it has become a village and roadside weed over a great part of East India.

\section{Order XLV. CUCURBITACE}

Flowers usually unisexual. Calyx superior (or adherent at the base and produced above the ovary), usually campanulate, 5-toothed. Petals 5, or united in a 5-lobed corolla, apparently continuous with the calyx-tube, with the calyx-teeth at the base of the lobes. Male flowers: Stamens usually 5 or 3 . Anthers usually linear and curved, forming a wavy line on the connectivum. Female flowers: Ovary inferior, often 1-celled when very young, with 3 parietal placentas, which soon grow out so as to divide the ovary into 3 or 6 cells. Ovules many, or rarely 1 to each placenta. Fruit succulent, indehiscent, or bursting irregularly. Seeds usually ovate and compressed, in a juicy or membranous arillus. Albumen none. Embryo straight, with the radicle next the hilum, and leafy cotyledons.-Climbers, usually herbaceous, with lateral tendrils. Leaves alternate, palmately veined or lobed.

A considerable Order, dispersed over all but the colder regions of the globe, but most abundant in dry hot countries, especially in Africa.

Stamens inserted at the base of the calyx.

Male flowers (very small) in racemes. Berries small, globular or oblong

Male flowers solitary. Fruits large, globular , . . . . . . . Stamens inserted near the petals.

Connective of the anthers projecting beyond the cells. Fruit oblong, indehiscent . - . - . - . -

Anther-cells sinuous, almost covering the connective. Fruit muricate, opening elastically

1. Karivia.

4. Citruluus.

2. ECHMANDRA.

3. Momordica. 


\section{KARIVIA, Arn.}

Calyx urceolate, with 5 small teeth at the base of as many petals, which appear to form part of the calyx. Male flowers: Stamens 3, with distinct filaments inserted at the base of the calyx. Anthers with a broad connectivum, two with 2 cells each, the third usually 1 -celled, more or less sinuous. Female flowers : Style cylindrical, with 3 large capitate stigmas. Berry globular or ovoid, not beaked.-Leaves very variable, entire or lobed. Flowers small, the males in short racemes or umbels, the females solitary.

A small genus, limited to Africa and tropical Asia, united by Thwaites with Zehneria, Endl., and both scarcely distinct from Bryonia.

1. K. umbellata, Arn. in Hook. Journ. Bot. iii. 275. A glabrous climber, with little or none of the asperities so general in Cucurbitacea. Leaves exceedingly variable in shape, usually 2 or $3 \mathrm{in}$. long, on short petioles, deeply cordate at the base, and more or less angularly 3 - to 5-lobed, the middle lobe the longest, the lower ones very spreading; sometimes heartshaped and toothed only, sometimes divided almost to the base. Male flowers $2 \frac{1}{2}$ lines long, with short broad lobes (petals) and minute spreading teeth between them on the outside; the very short racemes, either sessile in the axils or on a peduncle of near an inch. Female flowers solitary, sometimes in the same axils as the male raceme. Berry small, ovoid-oblong.-Harlandia bryonioides, Hance in Walp. Ann. ii. 648. Bryonia umbellata, Willd.; DC. Prod. iii. 305 .

Hongkong, Hance, Wright. Extends over the greater part of India, and abundant in the Archipelago. Dr. Hance's specimens were by mistake referred by Seemann to the Zehneria mysorensis, which may be at once distinguished by the male flowers, which are shorter, more broadly campanulate, with very spreading lobes (or petals) as long as the tube. The berries are also shorter and more globular. This species has not yet been found in China.

\section{2. 洢CHMANDRA, Am.}

Calyx campanulate, with 5 small teeth at the base of the 5-lobed corolla which appears continuous with it. Stamens 3 , inserted near the petals, in the tube of the calyx ; filaments short, free. Anthers with a broad connectivum projecting beyond the cells, 2 with 2 cells each, the third 1-celled. Ovary oblong, contracted at the top. Stigmas 3, sessile. Berry oblong, indehiscent, obtuse or contracted into a beak at the top.-Flowers small, the males in short racemes or solitary, the females always solitary.

A small genus, spread over Africa and tropical Asia.

1. EE. odorata, Hook. fil. and Thoms. Stems slender, glabrous or slightly pubescent. Leaves broadly triangular or cordate, acuminate, about $1 \frac{1}{2}$ in. long, sinuately toothed or 3- or 5-lobed, thin, but very rough on the upper side, on petioles of $\frac{1}{2}$ to $1 \mathrm{in}$. Pedicels filiform, 1 -flowered, 3 to 6 lines long, usually 1 male and 1 to 3 females in the same axil. Male flowers about 3 lines long, and cleft to about the middle, the small subulate calyx-teeth recurved. Connective of the anthers broad and membranous, the anther-cells reaching to about $\frac{2}{3}$ of its length. Female flowers rather small. Berry oblong, obtuse, not beaked, about $\frac{1}{2}$ in. long, in the Hongkong variety, shorter and globular in the more common Indian form.-Bryonia odorata, Ham. in Wall. Catal. n. 6706. 
Hongkong, Harland and Hance. Apparently common in north-eastern India. I had at first thought that this Chinese form, with more distinctly cordate leaves and a longer berry, might be specifically distinct from the Indian one, but on further comparison it does not appear that the single specimen $I$ have seen is sufficient to justify its separation.

\section{MOMORDICA, Linn.}

Calyx campanulate, 5-lobed. Petals 5, distinct. Male flowers: Stamens 3 , inserted near the petals in the tube of the calyx. Filaments short, free. Anthers sinuous, covering the connective, 2 of them 2-celled, the third 1-celled. Female flowers: Ovary contracted at the top. Stigmas 3, on a short style, 2-lobed. Fruit oblong or ovoid, usually opening elastically in valves.-Peduncles both male and female 1-flowered.

A small tropical or subtropical genus, common to the New and the Old World.

1. M. charantia, Linn.; DC. Prod. ii. 311; Wight, Ic. t. 504. A glabrous or pubescent slender climber. Leaves thin, broadly cordate or orbicular, 2 to 3 in. diameter, more or less deeply divided into 5 or 7 sinuately toothed lobes. Peduncles slender, $1 \frac{1}{2}$ to $2 \mathrm{in}$. long, with a reniform entire bract, 3 to 6 lines broad, at about the middle of the male peduncles and nearer the base of the female ones. Calyx-lobes ovate, acute, about 3 lines long. Petals more than twice as long, obovate-orbicular, yellow. Fruit ovoid or oblong, usually beaked, more or less tuberculate or muricate, often 4 or 5 in. long.

Half spontaneous, climbing over shrubs, Hance. Widely spread over East India and some parts of Africa, but frequently escaped from cultivation.

\section{CitruluUs, Schrad.}

Calyx shortly and broadly campanulate, with 5 short teeth. Corolla deeply 5-lobed. Male flower: Stamens 3, inserted at the base of the calyx. Filaments free, short. Anthers sinuous, 2 of them 2-celled, the third 1-celled. Female flower: Ovary ovoid. Stigmas 3, nearly sessile, 2-lobed. Fruit large, globular, indehiscent, with a hard rind.-Peduncles both male and female 1flowered.

Besides the following, the genus contains one other species, also a native of Africa.

1. C. vulgaris, Schrad.; Naud. in Ann. Sc. Nat. Par. ser. 4, xii. 100. A coarse annual, more or less hairy. Leaves 3 to 5 in. long, sometimes broadly ovate-cordate, with broad short olituse lohes, sometimes deeply pinnatifid, with narrow obtuse sinuate or pinnatifid lobes. Peduncles short, hairy. Male flowers pale yellow, about 1 in. diameter. Fruit usually large, variously coloured, always more or less glaucous.

Knowu as the Water-Melon, and of African origin ; it is said to have become naturalized in many places in Hongkong, as over a great part of tropical Asia.

\section{Order XLVI. BEGONIACEAE.}

Flowers unisexual. Sepals or petals 2 to 8 , all coloured, of which 2 or 3 outer ones (sepals), and 2 to 5 inner and often smaller (petals), the latter occasionally wanting. Male flowers : Stamens indefinite, filaments free or vari- 
ously combined; anthers adnate, 2-celled, opening outwards. Female flowers : Ovary inferior, 3-angled or 3-winged, 3-celled, with simple or branched axile placentas, or rarely 1 -celled, with 3 parietal placentas. Ovules numerous, minute. Style short, 3-cleft; stigmas entire or branched. Fruit inferior, 3 -angled or 3-celled, capsular. Seeds minute, without albumen. Radicle next the hilum. Cotyledons short.-Shrubs or herbs, usually articulate at the nodes. Leaves alternate or very rarely opposite, entire or divided and usually oblique, with stipules. Peduncles axillary, usually dichotomous.

The Order, containing very few species besides the genus Begonia, ranges over the tropical regions of America and Asia, with a very few African species.

\section{BEGONIA, Linn.}

A genus constituting nearly the whole Order, and distinguished from the other two small ones by the placentas always axile, not parietal, and the capsule opening by longitudinal or curved slits on each side of each angle or wing, not by the splitting of the angle itself.

1. B. laciniata, Roxb. Fl. Ind. iii. 649 ; Bot. Mag. t. 5021 . Rhizome thick and perennial. Stems herbaceous, erect or decumbent, $1 \frac{1}{2} \mathrm{ft}$. high, covered more or less, as well as the under side of the leaves, with a rustycoloured wool. Leaves broadly and obliquely cordate, irregularly 5- or 7-lobed, the longer ones 6 to 8 in. long, 4 to 6 in. broad, sprinkled with a few minute hairs on the upper side, the wool of the under side often wearing off at last. Peduncles shorter than the leaves, bearing usually 3 or 4 male flowers and 1 female one, of a pale pink colour. Male flowers with 2 broad nearly orbicular outer petals or sepals about 6 lines long, and 2 inner narrower ones not above half as long. Female flowers with 4 nearly equal obliquely ovate petals, 3 or 4 lines long, with occasionally a fifth smaller one. Stigmas thick and sinuous; capsule 5 to 7 lines long, with 2 narrow wings, the third extending horizontally to the breadth of 7 or 8 lines. Placentas double in each cell, one cell usually empty by the abortion of the ovules. $-B$. Bovoringiana, Champ. in Kew Journ. Bot. iv. 120. Doratometra Bowringiana, Seem. Bot. Her. 379.

Ravines on Mount Parker and other half-shady places, Champion, Hance, Wilford, Wright. Common in Sikkim and Khasia.

\section{Order XLVII. PORTULACE丑.}

Sepals 2 , or rarely 3 , free, and partially united and adherent at the base. Petals 5 or rarely more, sometimes slightly united, perigynous or hypogynous. Stamens either equal in number and opposite to the petals, or more frequently indefinite, perigynous or hypogynous. Ovary free or partially adhering, 1-celled, with several ovules attached to a free central placenta. Style single, with 2 to 8 stigmas or branches. Capsule 1-celled. Seeds several. Embryo curved round a farinaceous albumen, the long radicle next the hilum.- Herbs more or less succulent, with entire leaves, usually opposite, but occasionally alternate.

A small Order, with a wide geographical range over the greater part of the globe, with the greater number of species however from North or South America. 


\section{PORTULACA, Linn.}

Sepals 2. Petals 5, united at the base. Stamens indefinite. Style short, with 4 or 5 stigmas. Capsule opening transversely.-Herbs, with alternate leaves. Flowers terminal, usually surrounded by an involucre of 4 or more leafy bracts.

A considerable tropical or subtropical genus, chiefly American, with a very few species from the Old World, or from more temperate regions.

1. P. oleracea, Linn.; DC. Prod. iii. 353. A low prostrate or spreading annual, seldom attaining above 6 inches, somewhat succulent and quite glabrous, without the long hairs at the nodes of several other species. Leaves small, cuneate-oblong. Flowers small, yellow, sessile above the last leaves or bracts; the petals exceedingly fugacious and scarcely exceeding the calyx.

On roadsides and in waste places, Hance, Wright. Common in similar localities and in sandy wastes in almost all warm countries.

\section{Order XLVIII. CRASSULACE无.}

Sepals 3 or more, usually 5 , but sometimes up to 20 , free from the ovary, but occasionally united in a lobed calyx. Petals as many, sometimes united in a lobed corolla. Stamens as many or twice as many, inserted with the petals at the base of the calyx. Ovary superior, the carpels as many as the petals, distinct, usually with a small flat scale at the base of each, with several ovules in each. Styles simple, distinct. Ripe carpels capsular. Seeds several, with a thin fleshy albumen and straight embryo.-Herbs or shrubs. Leaves succulent, all or only the upper ones alternate or rarely opposite. Stipules none. Flowers in terminal racemes, cymes, or panicles.

A rather numerous Order, extending over the greater part of the globe, but particularly abounding in South Africa and in the rocky districts of Europe and central Asia.

\section{BRYOPHYLLUM, Salisb.}

Sepals united in an inflated 4-lobed calyx. Petals united in a cylindrical 4-lobed corolla. Stamens 8, attached to the base of the corolla. Scales gland-like. Carpels 4. Styles filiform.

The genus is limited to a single species.

1. P. calycinum, Salisb.; DC. Prod. iii. 396 ; Bot. Mag.t. 1409 . A glabrous erect succulent perennial, 2 to $5 \mathrm{ft}$. high. Leaves opposite, flat, but succulent, ovate or oval-oblong, 3 to 5 in. long, either crenate or pinnately divided into 5 or 7 entire or crenate segments. Flowers green, tinged with reddish-yellow, nodding, in loose terminal panicles, the inflated calyx 1 to $1 \frac{1}{2}$ in. long, the corolla rather longer.

In waste places, Champion and others. Widely spread over tropical Asia, Africa, and America, but in many places introduced.

\section{ORDER XLIX. SAXIFRAGACEAE.}

Sepals 4 to 5 , free or united in a calyx, with the tube wholly or partially adherent, and 4 or 5 lobes or teeth. Petals either as many, perigynous, 
epigynous, or hypogynous, or rarely none. Stamens as many or twice as many, or very rarely more, inserted with the petals. Ovary single, either more or less inferior or adherent, or free with a broad base; 2 - to 5 -celled, with axile placentas, or 1-celled, with 2 or more parietal placentas; the carpels often shortly free at the top. Styles as many (or rarely twice as many) as cells or placentas, or styles single, with an entire or lobed stigma. Fruit a capsule, or rarely an indehiscent berry. Seeds several, usually many; the albumen usually copious, rarely wanting.

A considerable family, ranging over nearly the whole world, the shrubby or arborescent genera chiefly tropical, the herbaceous from the more temperate or colder regions of the northern hemisphere, with a few extratropical southern ones.

Shrubs. Leaves opposite. Flowers paniculate. Calyx adherent. Fruit a berry . . . . . . . . . . . . . . . .

Shrubs. Leaves alternate. Flowers racemose. Calyx small, free. Fruit capsular . . . . . . . . . . . . . . . . . . Herbs. Leaves radical, with glandular hairs. Sepals free. Fruit capsular 3. Drosera.

\section{DICHROA, Lour.}

(Adamia, Wall.)

Calyx-tube wholly adherent, with 5 or 6 small distant teeth. Petals 5 or 6, sessile, valvate in the bud. Stamens twice as many. Ovary adherent to above the middle, incompletely 3 - to 5 -celled, the partitions projecting far into the cavity with the placentas on their margins, and numerous ovules. Styles as many as cells, free from the base, diverging and thickened upwards. Fruit a semi-inferior indehiscent berry.-Shrubs. Leaves opposite.

The genus consists of a single species, unless indeed some specimens from the Philippine Islands, with remarkably small flowers, be really distinct.

1. D. febrifuga, Lour. Fl. Cochinch. 301. A shrub, with the habit of a Hydrangea. Leaves opposite, oval-oblong, acuminate, 3 to 6 in. long, serrate, narrowed into a petiole at the base, slightly pubescent as well as the young branches. Panicles terminal, dense, broadly corymbose or pyramidal, pubescent. Flowers numerous, of a dull or rarely bright blue. Berries green at first, but assuming at length a bright blue colour.-Adamia versicolor, Fort. in Journ. Hort. Soc. i. 298; Lindl. and Paxt. Fl. Gard. i. t. 5. A. chinensis, Gardn. and Champ. in Kew Journ. Bot. i. 311. Cyanitis sylvatica, Blume; DC. Prod. iv. 16. Dichroa Cyanitis, Miq. Fl. Ned. Ind. i. pars i. 721; and probably $D$. latifolia, Miq. 1. c. 722. Also a smaller-flowered variety, Adamia cyanea, Wall. Tent. Fl. Nept. 36, and Pl. As. Rar. iii. t. 213. The Bot. Mag. t. 3046, represents a rather larger-flowered variety, with pink flowers.

Ravines of Mount Victoria and Mount Parker, rare, Champion. South China, Cochin China, and the Indian Archipelago, and the smaller-flowered variety in the Himalaya and Khasia mountains.

I have no hesitation in uniting as slight varieties the three supposed species from the Himalaya, from China, and from Java. I have seen but one of the three Javanese varieties mentioned by De Candolle: it has narrow leaves, a somewhat elongated panicle, and the flowers larger even than in the Chinese ones, with longer anthers. The Chinese specimens have mostly broad leaves, and large flowers in a broad rather flat panicle; but in some, the flowers are not larger than in some of the Himalayan ones. The Khasia specimens have broad leaves hut small flowers; the Sikkim and other Himalayan ones have narrower leaves, and, with few cxceptions, small flowers. In all, the number of parts of the flower appears 
to vary from 5 to 6 and very rarely 7 . To each petal are two stamens, one alternating and erect in the bud, the other opposite and inflected in the bud, and I have sometimes seen an additional 1 or 2 stamens in the flower. Loureiro's character, to which attention has recently been called by Planchon, is good, with the exception of the number of stamens, which may be easily explained; and I have therefore, after the example of Miquel, adopted his name as the oldest.

\section{ITEA, Linn.}

Calyx free, short, 5-lobed. Petals 5, perigynous, valvate in the bud. Stamens 5, perigynous. Ovary 2-celled, free. Ovules in 2 series near the axis. Style simple, splitting at length into 2. Stigma capitate or 2-lobed. Fruit a capsule, separating septicidally into 2 carpels, which open inside by a longitudinal fissure. Seeds linear, acuminate at both ends, with albumen.Trees or shrubs. Leaves alternate, without stipules. Flowers in simple racemes.

A genus of few species, from central and eastern Asia and North America.

1. I. chinensis, Hook and Arn. Bot. Beech.t. 39 ; Hook. fil. in Journ. Linn. Soc. ii. 77. A shrub, either wholly glabrous or with a slight tomentum on the young branches and racemes. Leaves obovate or oval-oblong, usually shortly acuminate, about 3 in. long, entire or slightly serrate, elegantly marked with transverse veins between the principal pinnate ones. Flowers white, about $1 \frac{1}{2}$ lines long, on pedicels scarcely as long, in dense axillary racemes, seldom exceeding the leaves. Calyx-teeth or lobes not half so long as the erect petals. Capsules 3 to 4 lines long, surrounded at the base by the persistent calyx-teeth.

In the Happy Valley, Champion and others. Also on the continent of S. China aud in the Khasia hills. The I. macrophylla, Wall., from the Himalaya, is also nearly allied, but has much larger leaves, more slender racemes, the petals reflexed from a little below the middle, the capsules shorter, and the calycine teeth wear off, leaving a prominent ring a little above the base of the capsule.

\section{DROSERA, Linn.}

Sepals 5 , or very rarely 4,6 , or 7 , free from the ovary but shortly united at the base. Petals and stamens as many, hypogynous or slightly perigynous. Ovary 1-celled, with 3 to 5 parietal placentas, and several ovules to each. Styles as many as placentas, but sometimes divided to the base so as to appear twice the number. Capsule 1 -celled, opening in 3 to 5 valves bearing the placentas in their centre. Seeds several, with albumen.-Herbs with a short perennial stock, sometimes lengthening out into leafy stems. Leaves either radical or alternate, more or less covered with long glandular hairs or bristles. Peduncles radical or axillary, terminating in a simple or forked onesided spike.

A considerable genus, found in nearly all parts of the world where there are bogs. It is the type of a group of genera, or Suborder, usually classed as an independent Order among Thalamiflora, but which is really very closely allied to the herbaceous genera of Saxifragacea.

Styles 5, undivided. Leaves broad, with a short petiole . . . . . 1. D. Burmanni.

Styles apparently 6 , really 3 , divided to the base. Leaves narrow-

cuneate, with rather a long petiole . . . . . . . . 2, D. Loureiri.

1. D. Burmanni, Vuhl; Planch. in Ann. Sc. Nat. Par. ser. 3, ix. 190 ; Wight, Ic. t. 944, Illustr. $t$. 20. Leaves radical, rosulate, obovate, spathu- 
late, about 3 or 4 lines broad and long, narrowed into a petiole not so long, thickly fringed with fine red glandular hairs. Stipules scarious. Radical peduncles or scapes solitary, or 2 or 3 from the same tuft, slender, 4 to $6 \mathrm{in}$. high. Spikes usually simple, pedicels glabrous. Sepals divided nearly to the base. Styles 5, undivided, filiform, ereet at the base, slightly dilated at the top, with fringed stigmas. Placentas 5.

Hongkong, Wright, a few specimens mixed with those of the following species. Widely spread over India and the Archipelago, extending northwards to the Philippines and the Chinese continent.

2. D. Loureiri, Hook, and Arn. Bot. Beech. 167, t. 31. Leaves radical and rosulate, with scarious stipules as in D. Burmanni, but narrower, oblong-cuneate, contracted into a petiole as long as the lamina, and with it 6 to 10 lines long, fringed with red hairs, which are however fewer and paler than in the last species. Scapes 3 to $5 \mathrm{in}$. high, slender. Pedicels glabrous and sepals deeply divided, as in D. Burmanni; the flowers are however rather larger, and the styles stiff and curved upwards, connivent at the top, apparently 6 , but really 3 , cleft to the base. Placentas 3 .

Abundant in marshes, Champion and others. Also on the adjacent continent. Not as yet recorded from elsewhere, but probably some of the Droseras from the Indian Archipelago, described as allied to it, may prove not to be really distinct.

\section{ORDER L. HAMAMELIDEEE.}

Calyx-tube more or less adherent or rarely entirely free; the limb 4- or 5lobed or toothed, or rarely entire. Petals either as many, inserted at the base of the calyx-lobes, or fewer or none. Stamens either as many or twice as many, inserted with the petals. Anthers erect; the cells opening laterally in various ways, the connective often produced beyond them. Ovary inferior, semi-inferior, or rarely wholly superior, with 2 , or rarely more cells, and 1 or 2 ovules suspended from the apex of each cell; or rarely more, on axile placentas, the 2 carpels with distinct styles. Fruit coriaceous or woody; the carpels usually diverging at the top, and each one opening in 2 short valves. Seeds usually solitary, with a copious albumen and straight embryo.-Trees or shrubs. Leaves alternate, entire, or slightly toothed, with stipules. Flowers hermaphrodite or unisexual, often in compact heads, or rarely in looser racemes.

A small Order, dispersed over Asia, S. Africa, and N. America, showing great diversity in generic forms, some of which are scarcely separable from Saxifragacea, whilst others are more nearly connected with Cornacea.

Flowers hermaphrodite, united in a head surrounded by imbricate bracts, the petals of all the flowers on the circumference of the head. Ovules several

Flowers monocious, the males in oblong heads of stamens only, without perianth, the females in globular heads. Ovules several

Flowers hermaphrodite, in heads or short racemes, without petals.

Ovules solitary in each cell.

Ovary half-inferior.

Anthers sessile, obtuse, 2-valved. Stigmas very long and flat Anthers on distinct filaments, with a subulate point, 4-valved.

Styles subulate . . . . . . . . . . .

Ovary superior .

\section{Rhodoleta.}

2. Liquidambar.

3. Eustigma.

4. Tetrathyeivm.

5. Distyehum. 


\section{RHODOLEIA, Hook.}

Flowers about 5 together, united in a compact head, having the appearance of a single flower surrounded by many imbricated bracts. Calyx adherent, the limb forming a narrow rim round the middle of the ovary. Petals 2 to 4 to each flower, all turned to the circumference of the head, those of the inner side of each flower deficient. Stamens 7 to 10 , the innermost of each flower deficient ; filaments long. Anthers linear, opening in longitudinal slits, without any prominent connective. Ovary half-inferior, consisting of 2 carpels united at the base into a 1-celled ovary, and more or less free and divergent at the top, with distinct styles and small stigmas. Placentas parietal, with several ovules to each, in 2 rows. Ripe carpels opening at the top in 2 bifid valves.

Besides the following species there is one other one from Java.

1. R. Championi, Hook. Bot. Mag. t. 4509. A small tree, perfectly glabrous except the flower-heads. Leaves alternate, crowded at the extremity of the branches on petioles of $1 \frac{1}{2}$ to 2 in. long, evergreen, ovate or oblong, obtuse or obtusely acuminate, 4 to 5 in. long, quite entire, thickly coriaceous, shining above, glaucous underneath. Flower-heads, including the petals, about $1 \frac{1}{2}$ in. diameter, on very short recurved axillary peduncles. Each head surrounded by several rows of imbricate bracts, the outer ones very small and glabrous, gradually increasing to the innermost, which are near $\frac{1}{2}$ in. diameter, coloured and rusty-hairy outside. Petals about $\frac{3}{4}$ in. long, bright pink, varying in breadth, and from 15 to 20 to each flower-head, giving it the appearance of a semi-double Camellia.

Hongkong, Champion and others. Not found as yet out of the island.

Admitting the general accuracy of the elaborate description of this genus given by Miquel (Versl. en Mededel. der K. Akad. Wetensch. Naturk. vi. 122), I eannot concur with him in his approximation to Diosmece instead of Hamamelidee. The perigynous, almost epigynous, insertion of the petals and stamens is very decided, forming a ring at the base of the short limb of the calyx, round the adherent or semi-inferior ovary, on a level with the top of the ovule-bearing cavity, whilst in the whole Rutaceous group the stamens and petals are essentially hypogynous, and the whole ovary perfectly free, and even gynobasic. If in Rhodoleia Teysmanni, which Miquel seems more especially to have had in view, and which I have not examined, the ovary be only enclosed in, not actually adherent to the calyx-tube, still the petals and stamens are inserted at the summit of that tube, not on the torus, and $I$ cannot conceive that a careful comparison of Rhodoleia with Bucklandia can leave any doubt as to these two genera being closely allied to each other in one and the same family.

\section{LIQUIDAMBAR, Linn.}

Flowers unisexual, in separate compact heads, with 1 to 4 very deciduous bracts at the base of each head. Male heads ovoid or oblong, with numerous almost sessile anthers, without any perianth. Female heads globular. Calyx adherent, with a narrow sinuate or shortly lobed border. Petals none. Ovary half-inferior, 2-celled, with several ovules in each, on axile placentas. Styles 2, linear, spreading. Capsules opening at the top in 2 valves.-Trees. Leaves serrate or palmately lobed. Flower-heads in racemes; the upper ones all male, the lowermost one female.

A genus of very few species, one North American, the others Asiatic. 
1. L. chinensis, Champ. in Kew Journ. Bot.iv. 164; Seem. Bot. Her. $t$. 94. A tall tree, perfectly glabrous except the inflorescence. Leaves ovaloblong, scarcely acuminate, 3 to $4 \mathrm{in}$. long, slightly and obtusely serrated, with minute glands to each serrature, contracted at the base into a petiole of 3 to 4 lines, coriaceous and somewhat shining. Racemes terminal, 2 to 3 in. long, with 8 or 10 male heads; the upper ones almost sessile, consisting of 100 to 200 almost sessile anthers on an oblong-conical receptacle; and one globular female head at the base, on a pedicel 3 or 4 lines long when in flower, above $1 \mathrm{in}$. when in fruit. Calyxes all concrete with the ovaries in a hard almost woody mass, bearing usually a few apparently sterile anthers mixed in with the styles.

Mount Gough and Happy Valley woods, Champion and others. Not known from elsewhere. It is easily distinguished from the Indian and Javanese $L$. Altingia by the coriaceous leaves narrowed into a short petiole.

\section{EUSTIGMA, Gardn. and Champ.}

Calyx-tube adnate, the limb 5-cleft, the lobes imbricate in the bud. Petals replaced by 5 spathulate or cuneate scales, alternating with the calyx-lobes. Stamens 5, opposite the calyx-lobes; anthers sessile, very obtuse, extrorse; the two cells opening each with 1 vertical valve. Ovary half-inferior, 2-celled, with 1 pendulous ovule in each cell; the carpels distinct at the top, each terminating in a long style,-with a broad flat stigma. Capsule hard, the 2 carpels separating upwards and opening in 2 short valves. Flower-heads loose.

The genus consists only of the following species.

1. E. oblongifolium, Gard. and Champ. in Kew Journ. Bot. i. 312 ; Seem. Bot. Her.t.95. A small tree, glabrous, except the inflorescence. Leaves alternate, oblong, acuminate, about 4 in. long, entire, or with a few coarse teeth toward the end, coriaceous and rather shining, on petioles of 4 or 5 lines. Flowers about 2 lines long, on very short pedicels, in small rather loose heads, on short terminal peduncles. Calyx-lobes rounded. Scale-like petals rather shorter than the calyx-lobes, thick, emarginate at the top. Anthers still shorter, as broad as long, the persistent valves opening like doors. Styles 3 to 5 lines long, terminating in broad flat irregularly lobed stigmas, very black when dried.

In the Happy Valley woods, and Mounts Gough and Victoria, Champion and others. Not yet found out of the island.

\section{TETRATHYRIUM, Benth. (n. gen.)}

Calyx-tube adnate, the limb 5-cleft, the lobes valvate in the bud. Petals replaced by 5 short gland-like scales, alternating with the calyx-lobes. Stamens 5, opposite the calyx-lobes; filaments shortly filiform; anthers broad, the 2 cells opening each with 2 vertical valves; the connective produced into a subulate appendage. Ovary half-inferior, 2-celled, with 1 pendulous ovule in each cell; the carpels distinct at the top, each terminating in a subulate style. Capsule hard, the 2 carpels separating upwards, and opening in 2 short valves.-Flower-heads globular.

The genus consists only of one species. 
1. T. subcordatum, Benth., n. sp. A shrub of $3 \mathrm{ft}$., glabrous except the inflorescence. Leaves alternate, ovate, or broadly elliptical, 3 to 4 . in. long, shortly acuminate, entire or with a few minute distant glandular teeth, broadly and slightly cordate at the base, rather thick, with prominent pinnate veins, on petioles of 3 to 6 lines. Peduncles axillary, solitary, 2 or 3 lines long, with a few small fringed scales or bracts at the base. Flower-heads solitary, globular, 4 or 5 lines diameter, slightly hoary, with a few minute linear entire or fringed bracts under the flowers. Flowers about 20, closely sessile, small. Calyx-lobes lanceolate, about 1 line long. Stamens rather shorter; the anthers nearly square, crowned by long points, with 4 persistent door-like valves, as in Hamamelis. Styles glabrous, shorter than the stamens.

A bush, once seen on the Black Mountain, Wilford, from which we have several specimens, but it has not been received from any other collector. It has the habit of Eustigma, but differs in the æstivation of the calyx and in the form of the petal-scales, stamens, and styles.

\section{DISTYLIUIM, Sieb. and Zucc.}

Sepals 3 to 5, free, unequal, imbricate in the bud. Petals none. Stamens 2 to 8 ; anthers oblong, opening longitudinally. Ovary superior, 2-lobed, 2-celled, with 1 pendulous (or laterally attached?) ovule in each cell. Styles 2, subulate. Capsule ovoid or oblong, the carpels separating at the top, and opening in 2 valves.-Trees or shrubs. Flowers polygamous, in short axillary racemes.

A small Asiatic genus, whose affinities have not as yet been satisfactorily established. The superior ovary scarcely admits of its being retained among Hamamelidee, which it resembles in other respects.

1. D. racemosum, Sieb. and Zucc. Fl. Jap. i. 178, t.94? A glabrous shrub. Leaves alternate, narrow-oblong, obtuse or somewhat acute, $1 \frac{1}{2}$ to $2 \frac{1}{2} \mathrm{in}$. long, narrowed at the base into a petiole of 3 to 5 lines, thickly coriaceous. Racemes $\frac{1}{2}$ to 1 in. long, the upper flowers hermaphrodite. Sepals about 1 line long. Anthers exserted, oblong, red, fully 1 line long. Ovary short, the styles at least 3 lines, and both covered with stellate hairs. Male flowers smaller, sessile, with shorter stamens. Young capsules ovoid. Seeds immature in our specimens, but they appear to have very little albumen and a large embryo.

Hongkong, Champion, Wright, Wilford. Also in Japan, if the species be, as I believe identical. I have not, however, seen the Japanese specimens.

\section{ORDER LI. UMBELLIFERA.}

Calyx combined with the ovary, either entirely so or showing a minute border round the summit, with 5 small teeth. Petals 5, inserted round an epigynous disk. Stamens 5, alternating with the petals. Ovary inferior, 2 -celled, with one pendulous ovule in each cell. Styles 2 , with terminal stigmas. Fruit separating into 2 indehiscent dry carpels resembling seeds (called mericarps), usually leaving a filiform axis either entire or split into two. Each carpel marked outside with 10,5, or fewer prominent ribs, and underneath or within the pericarps are often longitudinal oil receptacles called 
vittce. Seed pendulous. Embryo minute, in a horny albumen.-Herbs or shrubs. Leaves alternate, often much divided, the petiole usually dilated at the base, but no real stipules. Flowers usually small, in lateral or terminal umbels, rarely reduced to heads, and often with one or more bracts, forming an involucre at the base of the umbel.

A large Order, widely dispersed over the northern hemisphere, and especially in the temperate regions, with a few tropical species, and rather more in the temperate regions of the southern hemisphere.

Flowers in simple umbels or heads. Carpels orbicular, flat. Creeping or floating herbs

Umbel compound. Fruit globular. Erect annual.

1. Hyorocotyle.

2. Corianurum.

\section{HYDROCOTYLE, Linn.}

Flowers in simple heads, umbels, or whorls. Petals ovate. Fruit laterally compressed, orbicular or broader than long; the carpels flat, placed edge to edge, with 1 or 2 prominent ribs on each side, and without prominent calycine teeth.-Herbs, usually prostrate and creeping, or aquatic. Leaves seldom divided, and usually peltate or cordate.

A considerable genus, dispersed over the greater part of the globe.

Flowers 3 or 4 in a head. Fruit near 2 lines diameter, with 2 scarcely prominent ribs on each side . . . . . . . . .

Flowers 10 or more in a head. Fruit about $\frac{8}{4}$ of a line diameter, with

1 very prominent rib on each side .

1. H. asiatica.

2. $H$, rotundifolia.

1. H. asiatica, Linn.; DC. Prod. iv. 62; Wight, Ic.t.565. A creeping perennial, rooting at the nodes, and sometimes half-floating. Leaves orbicular or kidney-shaped, variable in size, but usually about 1 in. diameter, crenate, and rather thick, glabrous or pubescent, on petioles varying from $\frac{1}{2}$ in. to 2 or 3 in. long. Flowers small, 3 or 4 together, in little heads clustered with the petioles, and either sessile or on peduncles varying much in length. Fruits rather large for the genus, orbicular, near 2 lines diameter, with 2 obtuse and not very prominent ribs on each side of each carpel.H. lurida, Hance in Walp. Ann. ii. 690.

In rice-fields and swamps, Champion and others. Common in tropical Asia and Africa, found also in South America, Australia, and New Zealand, and extending northward to Loochoo and Bonin.

2. H. rotundifolia, Roxb.; DC. Prod. iv. 64; Wight, Ic. t. 564. A much smaller and more slender plant than the last. Leaves from $\frac{1}{4}$ to $\frac{1}{2} \mathrm{in}$. diameter, orbicular or reniform, 5- or 7-lobed, and crenately toothed, glabrous or hispid underneath, on slender petioles. Flowers small, about 10 to 20 together, in globular sessile or shortly pedunculate heads. Fruits about $\frac{3}{4}$ line in diameter, with one acute prominent rib on each side of each carpel.H. perexigua, Hance in Walp. Ann. ii. 691.

Common in rice-fields and damp half-shady places, Champion and others. Extends over the greater part of India and the Archipelago, and northward to the Philippines, Sonth China, and Loochoo.

\section{CORIANDRUM, Linn.}

Flowers in compound umbels, the outer petals of the umbel larger than the others. Fruit globular, crowned by the conspicuous teeth of the calyx, 
the carpels not readily separating, the ribs scarcely prominent, and no vittæ.

The genus consists of a single species.

1. C. sativum, Linn.; DC.Prod.iv. 250; Wight, Ic.t.516. An erect, branching, glabrous annual, 1 to $1 \frac{1}{2} \mathrm{ft}$. high, emitting a very disagreeable smell when rubbed. Lowest leaves once or twice pinnate, with broadly ovate or cuneate deeply cut segments; the others more divided, with linear segments, few and slender in the uppermost. Umbels terminal, rather smatl, of 5 to 8 rays, without general involucre, and only a few slender bracts to the partial ones. Flowers white. Fruits about 2 lines diameter.

In waste places, Hance and others. A native of the Levant, and introduced by cultivation, has now spread as a weed over a great part of Europe and Asia.

\section{ORdER LII. ARALIACEE⿰氵}

Calyx combined with the ovary, either entirely so or showing a minute border round the summit, with as many teeth as petals. Petals usually 4 or $\mathbf{5}$, or rarely more, valvate or rarely imbricate in the bud, inserted round an epigynous disk, or sometimes none. Stamens as many, alternating with the petals. Ovary inferior, 2- to 5- or more celled, with one pendulous ovule in each cell. Styles as many as cells, usually short, and sometimes united into one or reduced to a small cone, stigmatic at the top. Fruit not readily separating into carpels, indehiscent, and usually succulent. Seeds solitary in each cell. Embryo minute, in a fleshy albumen.-Trees, shrubs, or climbers, or very rarely herbs. Leaves simple or compound. Flowers usually small, in heads or simple umbels, which are either solitary or arranged in racemes or panicles.

A considerable Order, chiefly tropical, with a very few species extending into more temperate regions, both in the New World and the Old.

Leaves twice or thrice pinnate. Petals imbricate. Styles free . . 1. Aralia.

Leaves digitate. Petals valvate. Styles united in a cone . . . 2. Paratropia.

Leaves entire or lobed. Petals valvate. Styles united in a cone . - 3. Dendropanax.

\section{ARALIA, Linn.}

Flowers polygamous. Umbels paniculate. Calyx distinctly 5-toothed. Petals 5, imbricate in the bud. Styles 2 to 5, free. Berry 2- to 5-celled.Trees, shrubs, or herbs. Leaves decompound, usually twice or thrice pinnate, very rarely digitate.

A small genus, dispersed over North America and eastern Asia.

1. A. chinensis, Linn.; DC. Prod. iv. 259. A tree, with the branches, leaves, and inflorescences more or less villous, and armed with scattered prickles. Leaves twice or three times pinnate, usually with 7 to 9 pinnæ, and 7 to 11 leaflets on each, or some of these replaced by a secondary pinna of 3 or $\mathbf{5}$ leaflets. Leaflets nearly sessile on the common stalks, ovate-cordate or ovatelanceolate, simply or doubly serrate, about $1 \frac{1}{2} \mathrm{in}$. long, often oblique at the base. Flowers 20 to 30 or more in each umbel; the umbels pedunculate, on 
the branches of a large spreading panicle. Pedicels very short at the time of flowering, near $\frac{1}{2}$ in. loug when in fruit.

Searce in the island, Champion. Only known from South China. There is, however, \& Khasia species very similar in foliage, but with fruits apparently much smaller. The $A$.dysophylla from Java is also near, but the fruits are sessile or nearly so. We have too few specimens of any of these forms to be able to judge how far these differences may be constant.

\section{PARATROPIA, Blume.}

Flowers unisexual. Umbels racemose or paniculate. Calyx-teeth minute or scarcely perceptible. Petals 5 or 6 , free, valvate in the bud. Stamens as many, the filaments elongated, and anthers short. Styles united in a short cone, with minute stigmas. Berry 5- or 6-celled.-Leaves digitately compound.

A considerable genus, dispersed over tropical and eastern temperate Asia.

1. P. cantoniensis, Hook. and Arn. Bot. Beech.189. A glabrous tree. Leaves on long petioles; leaflets 5 to 8 , digitate, oval or elliptical, shortly acuminate, glaucous underneath, the smaller veins between the principal pinnate ones scarcely perceptible, varying much in size; the larger leaflets about 6 in. long, on petiolules of 2 in., the outer smaller ones of the same leaf not above half that size. Racemes or narrow panicles, about $6 \mathrm{in}$. long, tomentose or at length glabrous. Umbels pedunculate, consisting of about 10 to 12 flowers. Pedicels about 2 lines long, or 3 lines when in fruit. Style conical, with 5 or 6 small sessile stigmas. Berry globular, 5- or 6 -celled.

Common in the island, Champion and others. Also on the adjoining continent, but not known out of S. China ; the species is, however, very near the Indian $P$. venulosa, but with the veins of the leaves less conspicuous, the flowers larger, and the berries not furrowed.

\section{DENDROPANAX, Dene.}

Flowers polygamous, not articulated on the pedicel; the umbel resting on the dilated apex of the peduncle. Calyx distinctly 5-toothed. Petals 5, free, valvate in the bud. Stamens 5, the filaments usually short. Styles united at the base or nearly to the top. Fruit globular, succulent, 5-celled. Albumen not ruminate, Leaves entire or lobed. Umbels terminal, solitary, or few in a corymbose panicle.

The genus was established for a few tropical American species, with which the two following agree in every respect, except that the styles are more united in a cone, thus approaching to the true Hedera, but it cannot remain in that genus as now limited by Decaisne and Planchon, for the albumen is not ruminated.

Leaves entire and 1-nerved, or lobed and 2- to 3-nerved. Flowers about $1 \frac{1}{2}$ lines long . . . . . . . . . . 1. Drotea.

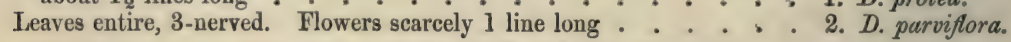

1. D. protea, Benth. A handsome shrub, with the inflorescence and globular berries of the common Hedera Helix, but very different in the venation of the leaves, and in the seeds. Leaves either entire with one midrib, or deeply 2 - or 3 -lobed with as many prominent ribs, varying from broadly elliptical to oblong or lanceolate, coriaceous and shining, the smaller veins scarcely perceptible, from $1 \frac{1}{2}$ to 5 or 6 in. long, on petioles varying from a few lines to 2 in. Peduncles terminal, solitary or 2 or 3 together, $\frac{1}{2}$ to $\frac{3}{4}$ in. long, dilated at the top into a disk-like receptacle, bearing a simple nearly 
globular.umbel of about 30 to 100 flowers. Petals inflexed and mucronate at the top. Styles united in a short cone.-Hedera protea, Champ. in Kew Journ. Bot. iv. 122.

In ravines of Mount Gough and Mount Victoria, Champion, Wright. Not received from elsewhere.

2. D. parviflora, Benth. A shrub resembling some forms of D. protea, of which it may prove to be a variety, although very unlike its more usual states. Leaves entire and 3-ribbed, oval-elliptical or oblong and acuminate, often almost opposite or whorled at the ends of the branches, varying in size and length of petiole, the larger ones about $5 \mathrm{in}$. long and $2 \mathrm{in}$. wide. Inflorescence of $D$. protea, but the flowers are smaller (scarcely 1 line long) and even more numerous in the umbel, the petals with less of the inflected point, the style-cone much longer, the berries smaller--Hedera parviflora, Champ. in Kew Journ. Bot. iv. 122.

Hongkong, Champion. No specimens have been seen from any other collector, and the species is therefore as yet doubtful.

\section{Order LIII. CORNACEAE.}

Calyx adherent to the ovary, with a superior border either entire or with as many teeth as petals. Petals 4, 5, or rarely more, valvate in the bud, inserted round an epigynous disk, or on the border of the calyx, rarely wanting. Stamens as many, or rarely twice as many or more, inserted with the petals. Ovary inferior, 1- or 2-celled, with one pendulous ovule in each. Style simple, with an entire or scarcely lobed stigma. Fruit an indehiscent drupe, with a 1- or 2-celled nucleus. Seeds solitary, pendulous, with a fleshy albumen. Embryo nearly as long as the albumen, straight; the radicle superior and shorter than the flat cotyledons.-Trees, shrubs, or very rarely herbs. Leaves opposite or rarely alternate, entire or slightly lobed, without stipules. Flowers in axillary or terminal heads, cymes, or corymbose panicles.

A small Order, generally scattered over the globe, but most abundant in the temperate regions of the northern hemisphere.

Leaves opposite. Flowers and fruits nnited in a close head. Petals 4.

Ovary 2-celled . . . . . . . . . .

Leaves alternate. Flowers in a loose cyme. Petals 6 to 10. Ovary 2-celled

Leaves opposite. Flowers diocious, in a loose raceme or panicle. Petals

4. Ovary 1-celled

1. Benthamia.

2. Marlea.

3. Aucuba.

\section{BENTHAMIA, Lindl.}

Flowers closely connected in globular heads, with an involucre of 4 petallike bracts. Calyx-border entire, or with 4 small teeth round the summit of the ovary. Petals 4, valvate in the bud. Stamens 4. Style entire. Ovary 2-celled, with 1 pendulous ovule in each cell. Drupes united together in a strawberry-like head, each with a hard, usually 1-seeded stone.-Trees or shrubs. Leaves opposite, entire or toothed. Flower-heads terminal.

Besides the following species the genus contains but one other from the Himalaya. It is nearly allied to the true Corni with capitate flowers, but in those the drupes are always quite distinct. 
1. B. japonica, Sieb. and Zucc. Fl. Jap. i. $38, t$. 16. A tree. Leaves stalked, oval-elliptical or oblong, shortly and obtusely acuminate, $1 \frac{1}{2}$ to $2 \mathrm{in}$. long, $\frac{s}{4}$ to 1 in. broad, of a pale green, glabrous and somewhat shining above, usually minutely pubescent underneath. Peduncles about 2 in. long, flowerheads globular, about 5 lines diameter, surrounded by 4 white bracts about 1 in. long. Calyx-border truncate and quite entire. Petals greenish, ovate, scarcely 1 line long. Fruit globular, about $\frac{3}{4}$ in. diameter, red.

In the Happy Valley woods, rare, Champion. One of the very few species common to Japan and Hongkong, without extending (as far as hitherto known) further to the south or the west. The entire border of the calyx very readily distinguishes it from the $B$. fragifera of our gardens, a native of the Himalaya.

\section{MARLEA, Roxb.}

Flowers distinct. Calyx-border minutely toothed. Petals 6 to 10 , linear, valvate in the bud. Stamens as many ; filaments short, adhering at the base to the petals; anthers long and linear. Ovary adhering to above the middle, 2-celled, with I pendulous ovule in each cell. Style filiform, with a 4-lobed stigma. Drupe often reduced to 1 cell and seed.-Trees or shrubs. Leaves alternate, entire or angularly lobed. Flowers in axillary cymes.

A genus of very few species from tropical or eastern subtropical Asia.

1. M. begoniæfolia, Roxb. Pl. Corom. t. 283; DC. Prod.iv. 267; Bot. $\operatorname{Reg} .1838, t .61$. A tree, either perfectly glabrous or with a slight tomentum on the veins of the leaves, petioles, and young branches. Leaves varying from ovate-acuminate, about $4 \mathrm{in}$. long and 2 broad, to broadly and very obliquely cordate, attaining 6 in. in length and 5 in breadth, and then often broadly and angularly lobed, the petioles from $\frac{1}{2}$ to $1 \mathrm{in}$. long. Cymes but little longer than the petioles, loosely 4 - to 10 -flowered in the Hongkong specimens. Calyx very short, minutely but distinctly toothed. Stamens and style very hairy, nearly as long as the corolla.-Diacacarpium rotundifolium, Hassk. in Bonplandia, vii. 172.

In the Happy Valley, Champion and others. Widely spread over northern and eastern India and the Archipelago. In the Hongkong variety the leaves are perfectly glabrous, the petals usually 6 , rarely 7 or 8 , and about 9 lines long. In Fortune's Amoy specimens the leaves have tufts of hairs in the axils of the principal veins on the under side, and the flowers are scarcely more than 4 lines long, with the calyx-border entire. The more common North Indian and Archipelago forms are more like the Hongkong one, but the leaves are seldom so glabrous, especially on the principal veins underneath, the flowers not quite so large, and the stamens much less hairy, but our specimens do. not warrant our considering any of them as distinct species.

\section{AUCUBA, Linn.}

Flowers diøcious. Calyx-border 4-toothed. Petals 4, valvate in the bud. Stamens 4. Anthers short. Ovary adherent, 1-celled, with 1 pendulous ovule. Style short, with a thick peltate stigma. Berry 1 -seeded.- Shrubs. Leaves opposite, coriaceous. Flowers paniculate, in the upper axils.

The genus comprises only one species from Japan, besides the following.

1. A. chinensis, Benth., n. sp. Probably a shrub, like the A.japonica of our gardens, perfectly glabrous except the bracts, and drying black. Leaves oblong-elliptical, coarsely toothed, attaining 8 in. in length, 1 of each pair 
smaller than the other. Female panicle pyramidal, 5 in. long, loosely manyflowered, with a few bracts at the base, 3 to 6 lines long, and covered with rusty hairs. Ovaries (as yet but little enlarged) oblong, 3 or 4 lines long, on short thick pedicels, otherwise precisely similar in structure to those of the A. japonica. Male flowers and petals of the female unknown.

Hongkong, Harland. The single specimen I have seen is already past flower. It appears very different from the common Japanese species; but it is possible that a better knowledge of the plant may prove it to be a variety only.

\section{ORDER LIV. HALORAGEAE.}

Calyx-tube adnate to the ovary, the limb entire or with as many teeth or lobes as petals. Petals 2 or 4 , inserted round an epigynous disk or on the calyx-border, or none. Stamens as many or sometimes fewer, inserted with the petals. Ovary inferior, 1- or more celled, with 1 pendulous ovule in each cell. Stigmas as many as cells of the ovary, sessile. Fruit dry and indehiscent, 1- or more celled. Seeds solitary, pendulous, with a fleshy albumen. Embryo straight, with a superior radicle and small cotyledons.-Herbs, often aquatic, rarely woody at the base. Leaves opposite or alternate or sometimes whorled. Flowers small, axillary or in terminal racemes or panicles.

A small Order, widely dispersed over the globe, usually associated with Onagracea, but which has recently been shown to have more affinity with Cornacece, from which it differs chiefly in the herbaceous habit and reduced flowers.

\section{HALORAGIS, Forst.}

(Goniocarpus, Koen.)

Calyx-tube (or ovary) terete or angular, the limb of 4 persistent lobes. Petals 4 , concave, deciduous. Stamens 4 to 8 ; anthers long, on very short filaments. Stigmas 4, sessile. Fruit small, hard, indehiscent, 2- to 4-lobed, 2 - to 4-celled. Embryo cylindrical.-Herbs. Leaves opposite or alternate, undivided. Flowers small, solitary or clustered, in the upper axils or in terminal racemes.

Chiefly an Australian genus, with 2 or 3 species, either east Asiatic or ranging widely over the southern hemisphere without the tropics.

1. H. scabra, Benth. A weak, decumbent, branching herb, more or less rough with minute hairs; the slender 4 -angled stems from 6 in. to $1 \mathrm{ft}$. long. Leaves nearly sessile, lanceolate, $\frac{1}{2}$ to $1 \mathrm{in}$. long, with a few serratures. Flowers about $1 \frac{1}{2}$ lines long, almost sessile, and solitary under each bract, forming slender, terminal, one-sided racemes or interrupted spikes, usually branching into narrow panicles. Petals twice the length of the calyxlobes. Anthers 8 , nearly as long as the petals, the 4 inner ones more slender and apparently sterile. Stigmas short, divided at the top into a tuft of hairlike lobes.-Goniocarpus scaber, Kœn.; DC. Prod. iii. 61.

Common on grassy slopes, Champion and others. Also in Khasia. 


\section{ORDER LV. BALANOPHOREAE.}

Succulent herbs, parasites on roots. Flowers in heads or spikes, unisexual. Perianth various, sometimes wanting, usually simple; the parts often in a ternary number and always valvate in æstivation. Stamens various, usually 3 . Ovary adherent, of 1 or rarely 2 or more carpels, more or less coherent, with 1 pendulous ovule in each. Seed either albuminous, with a small embryo, or apparently consisting of a homogeneous mass.- Stems reduced to a simple or branched tuberous rhizome, with 1 or more short thick peduncles or flowering branches. Leaves and bracts reduced to scales, coloured like the stem.

A small Order, belonging chiefly to the tropical and subtropical mountain regions of A sia and S. America, with a few African or Australian species, and one extending into southern Europe.

\section{BALANOPHORA, Forst.}

Male flowers : Perianth of 3 to 6 divisions. Stamens connate with 3 or 6 anthers, opening outwards. Female flowers intermixed with bracts or inserted on their petioles. Perianth none. Carpel and style 1. Seed homogeneous.

A small genus, limited to tropical and subtropical Asia and tropical Australia.

1. B. Harlandi, J. D. Hook., in Trans. Soc. Linn. Lond. xxii. 426, t. 75. A small species, with a lobed rhizome, without the pustules of $B$. dioica. Flower-heads unisexual, globular, on a short thick peduncle, the total height varying from 1 to $3 \mathrm{in}$. Scales or bracts somewhat leafy, forming an involucre at the base of the peduncle. Female flowers sessile in the head, not inserted on bracts. Stamens in the males 3.

Hongkong, Harland; on Mount Gough, Wilford. Not known from elsewhere.

\section{ORdER LVI. LORANTHACEAT.}

Calyx-tube adnate, the limb entire or with as many teeth or lobes as petals. Petals 4 to 8 , free or united in a lobed corolla, inserted round an epigynous disk, valvate in the bud, rarely wanting. Stamens as many, opposite to and usually inserted on the petals. Ovary adherent, with 1 (or 3) pendulous ovules, usually not perceptible till the flower is past. Style or stigma simple. Fruit an indehiscent berry, with a single seed. Albumen fleshy. Embryo straight, with a superior radicle.-Shrubs, usually much branched, parasitical on the branches of trees or shrubs, or sometimes so near their roots as to appear terrestrial. Leaves opposite or rarely alternate, usually thick and leathery. Bracts under each flower usually connate in a little cup, which often has the appearance of a small external calyx.

A considerable Order, chiefly abundant within or near the tropics in both the New and the Old World, with a very few species from more temperate regions in the southern as well as the northern hemisphere.

Flowers hermaphrodite, tubular. Anthers 2-celled . . . . . . 1. Loranthus. Flowers unisexual, minute. Anthers sessile, opening in many pores . . 2. Viscum.

\section{LORANTHUS, Linn.}

Flowers hermaphrodite. Calyx-limb short, truncate or toothed. Petals 4 to 8 (usually 4), more or less united in a tubular corolla. Stamens inserted 
on the base of the petals, with distinct filaments. Anthers 2-celled. Ovule 1 . Style filiform, with a terminal stigma. Berry usually crowned by the limb of the calyx.-Leaves almost always opposite. Flowers sometimes small and green, but usually long and brightly coloured.

A very large genus, almost wholly tropical or subtropical, in America, Africa, Asia, and Australia, with one species however as far north as the south of Europe.

1. L. chinensis, DC. Prod. iv. 301, and Mem. Lor. t. 7. Branches opposite, rather slender; the young shoots and leaves covered with a loose white or reddish tomentum, which soon wears off. Leaves opposite, ovate, obtuse, $1 \frac{1}{2}$ to 2 in. long, cuneate or rounded at the base, on petioles of about 2 lines. Flowers 2 to 5 together, on very short pedicels, usually arising from the nodes of previous years' wood. Calyx-tube or ovary very small, turbinate, pubescent. Corolla red, slightly tomentose, 8 or 9 lines long, very slender and curved in the young bud, swollen in the lower part at the time of flowering; the lobes obliquely spreading, in 4 narrow pointed lobes, about 2 lines long.

Upon trees, Hongkong, Champion. I have seen no other specimens; but, if I am not mistaken as to the identity, it is figured by De Candolle from Chinese specimens gathered by Sir G. Staunton, and is probably the Chinese plant included by Linuæus under his $L$. scurrula, but not the species usually so called and represented by the synonym of Petiver quoted by Linnæus. The young buds in Champion's specimens are as slender as in $L$. graciliflorus, but, just before they open, the tube assumes the oblique swollen form figured by De Candolle, only that it does not appear to slit open on the upper side.

\section{VISCUM, Linn.}

Flowers unisexual, monœcious or diœcious. Petals 3 to 5 , very short. Male flowers : Anthers sessile on the inside of the petals, and opening inwards in several pores. Female flowers: Calyx entirely adnate or with a minute annular border. Ovules 3. Stigma sessile. Seed erect.-Branches dichotomous. Leaves opposite or none. Flowers usually very small, green or yellowish.

The genus, as now reduced to the very few species with porous anthers, appears to be confined to the Old World.

Branches flattened, articulate, witho it leaves . . . . . . 1. V. articulatum. Branches terete. Leaves opposite . . . . . . . . . . 2. V. orientale.

1. V. articulatum, Burm.; DC. Prod. iv. 284. A very much branched parasite, forming tufts from a few inches to 1 or 2 feet diameter. Branches flattened, articulate, often forked at nearly every joint; the articles thick and somewhat fleshy, 3 to 6 lines long and 1 to 2 lines broad in the Hongkong specimens I have seen, in others, from the China coast or elsewhere, of 1 to $1 \frac{1}{2}$ in. long, from 1 to 3 or 4 lines broad, and usually obtuse at the top and narrowed at the base. Leaves quite wanting. Flowers monœcious, minute, sessile and clustered at the nodes; the females scarcely $\frac{1}{2}$ line long, nearly globular, and half-buried in the cup-shaped entire bract; the males still smaller, usually with 3 petals and anthers. $-V$. moniliforme, Blume; DC. Prod. iv. 284; Wight, Ic. t. 1018 and 1019.

On trees in the Happy Valley, Champion and others. Widely spread over India and the Archipelago, extending northward to Bonin and Loochoo.

2. V. orientale, Willd.; DC. Prod. iv. 278. Branches elongated, nearly terete, and always leafy. Leaves opposite, obovate, elliptical or oblong, narrowed at the base, 3 - or 5-nerved, very variable in size, usually about $1 \frac{1}{2}$ 
in. long and $\frac{1}{2}$ to $\frac{3}{4}$ in. wide, but sometimes attaining 3 in. or more, and in other specimens searcely 1 in. long. Flowers minute, in 1 to 3 clusters in each axil, sessile in a small cup-shaped 4-angled or 4-toothed bract, and 3 together in each cluster; the central one female, scarcely 1 line long, the 2 lateral ones males and considerably smaller. Calyx-border distinctly visible as a prominent ring in the female buds. Petals 4 or rarely 3 , triangular, and I have always seen an anther sessile on each petal, but, according to Wight, 2 of the 4 petals are without anthers. Berry globular, about 3 lines diameter.

On trees in the woods, Champion and others. Common in India and the Archipelago, extending westward almost to the Mediterranean and eastward to North Australia.

\section{ORDER LVII. CAPRIFOLIACEXE.}

Calyx-tube adnate; the limb of 4 or 5 lobes or teeth. Corolla gamopetalous, inserted round the epigynous disk, with 4 or 5 lobes, imbricate in the bud and sometimes irregular. Stamens as many as lobes of the corolla, alternating with them and inserted in the tube. Ovary inferior, 2- to 5-celled or rarely 1-celled, with 1 or more pendulous ovules in each cell. Stigmas as many as cells, or united into one, sessile or on a single filiform style. Fruit an indehiscent berry or rarely dry, 1 - to 5 -celled. Seeds 1 or more in each cell. Embryo in the axis of a fleshy albumen. Radicle superior, cotyledons oval or oblong.-Trees, shrubs, or climbers, or very rarely herbs. Leaves opposite, usually without stipules, simple or rarely pinnate.

A rather small Order, chiefly dispersed over the temperate regions of the northern hemisphere, with a very few tropical or southern species, scarcely to be distinguished from $R u b i$ acea except, in some instances by the want of stipules, in others by the irregular corolla.

Erect shrubs. Corolla rotate, regular . . . . . . . . . . 1. Víburnum. Climbers. Corolla tubular, irregular . . . . . . . . . . 2. Lonicera.

\section{VIBURNUM, Linn.}

Calyx with a border of 5 small teeth. Corolla rotate or shortly tubular, regular. Stamens 5. Ovary 1-celled or very rarely 2 - or 3 -celled, with 1 pendulous ovule in each. Stigmas 3 or rarely 2 , sessile. Berry 1-seeded.Erect shrubs or small trees. Leaves entire or palmately lobed. Flowers in terminal cymes or panicles.

A considerable genus, with nearly the range of the Order, including several tropical but no southern species.

Flowers about 2 lines diameter, in flat almost umbellate corymbose cymes . . . . . . Flowers above 3 lines diameter, in ovate or pyramidal panicles $: \quad 2 . V$. odoratissimum.

1. V. venulosum, Benth. A perfectly glabrous shrub. Leaves evergreen, shortly stalked, ovate, elliptical, or oblong, obtuse or very shortly acuminate, 2 to 3 or rarely $4 \mathrm{in}$. long, entire or slightly toothed towards the end, coriaceous and shining above, with a few nerves very prominent underneath diverging from the midrib, and fine transverse veins between them. Flowers white, numerous, in compact broad cymes, sessile above the last leaves and shorter than them, the primary branches 4 or 5 together from the same point. Corolla with a very short tube and spreading limb, about 2 
lines diameter. Stamens rather longer. Berries flattened, shining.- $V$. nervosum, Hook. and Arn. Bot. Beech. 190 (a name preoccupied by a species of Don's).

Common on the hills, Champion and others. Also on the adjacent continent. Not found out of south China, but allied to the Indian $V$. punctatum, which has larger leaves, with a different venation, etc.

2. V. odoratissimum, Lindl.Bot.Reg.t. 456; Hook. and Thoms. in Journ. Linn. Soc. ii. 177. A perfectly glabrous evergreen shrub, like the last, but readily known by the inflorescence. Leaves oval-elliptical, obovate, or oblong, obtuse or scarcely acuminate, 3 to $6 \mathrm{in}$. long, entire or rarely serrate, coriaceous and shining above, with the veins much less prominent underneath than in the last species; the petioles thick, 5 or 6 lines long. Flowers white, rather larger and less spreading than in $V$. venulosum, in loose ovate or pyramidal terminal and sessile panicles, 3 or 4 in. long. Corolla 3 to $3 \frac{1}{2}$ lines diameter. Berries ovoid.

Hongkong, Champion and others. Common in south China, extending to the Khasia mountains and northward to Japan.

\section{IONICFRA, Linn.}

Calyx with a border of 5 small teeth. Corolla with a more or less elongated tube and an oblique limb, either 5-lobed or in 2 lips, the upper one 4-lobed, the lower entire. Stamens 5. Ovary 2- or 3-celled, with several ovules in each cell. Style filiform, with a capitate stigma. Berry small, with one or very few seeds.-Climbers or erect shrubs. Leaves opposite, entire. Flowers 2 or more together, sessile, in axillary or terminal heads.

A considerable genus, dispersed over the temperate and mountainous subtropical regions. of the northern hemisphere. The Hongkong species are all climbers, belonging to De Candolle's division Nintooe, the flowers sessile, in pairs, on short common peduncles, the corolla-tube slender, the limb 2-lipped.

Leaves and branches glabrous. Corolla-tube near 2 in.

Leaves and branches hirsute with spreading hairs. Corolla-tube $i$ to $1 \frac{1}{4}$ in.

Leaves glabrous, shining and wrinkled above, softly tomentose underneath as well as the branches. Corolla-tube $\frac{3}{4}$ in.

Leaves slightly pubescent above and not shining, softly pubescent or tomentose underneath as well as the branches. Corolla-tube $\frac{3}{4}$ in.
1. L. longiflora.

2. L. macrantha.

3. L. reticulata.

4. L. multiflora.

1. L. longiflora, DC. Prod. iv. 333 ; Bot. Reg.t. 1232. A glabrous climber. Leaves stalked, oblong, 2 to $2 \frac{1}{2} \mathrm{in}$. long, $\frac{1}{2}$ to $1 \mathrm{in}$. broad, rather coriaceous, paler underneath, with a few prominent very oblique nerves. Flowerpairs shortly pedicellate, axillary or forming loose terminal heads or short racemes. Bracts small, linear. Bracteoles very short. Corolla-tube slender, about 2 in. long, quite glabrous or slightly glandular; the limb as in the 3 following species, of 2 lips rolled back at the top, the upper one 4-toothed, the lower one narrow, entire.

Largely distributed over the island, but less frequent than the following species, Champion. and others. Only known from S. China.

2. L. macrantha, DC. Prod. iv. 333. A climber, with the young branches thickly hirsute with spreading hairs. Leaves on short stalks, ovate or ovate-lanceolate, more or less cordate at the base, 2 to $3 \mathrm{in}$. long, ciliate 
and hairy, especially on the under side, with reticulate veins. Flower-pairs on very short pedicels, either axillary or in terminal heads. Bracts short, bracteoles very small. Ovary glabrous. Corolla pubescent and hairy, yellowish; the slender tube 1 to $1 \frac{1}{4}$ in. long; the limb $\frac{1}{2}$ in. long, two-lipped.L. japonica, Andr. Bot. Rep. t. 583; Bot Reg. t. 70 ; Hook. fil. in Journ. Linn. Soc. ii. 172 ; not of Thunb. L. hirtiflora, Champ. in Kew Journ. Bot. iv. 166 .

The most common Honeysuckle in the island, Champion and others, and common also in northern India. Although generally passing under the name of $L$. japonica, it is doubtful whether it is a Japanese plant at all. It is not in Zuccarini's enumeration. The original $L$. japonica of Thunberg is the L. flexuosa of our gardens, with shorter reddish flowers.

3. L. reticulata, Champ. in Kew Journ. Bot. iv. 167. A climber, with the branches thickly clothed with a short soft velvety tomentum. Leaves ovate or oblong, obtuse, 1 to $2 \mathrm{in}$. long, on petioles of 4 to 6 lines, rather thick, glabrous and shining above, and wrinkled with a network of impressed veins, covered underneath with a white or yellowish close dense tomentum. Flower-pairs 6 or 8 together in little corymbs on axillary peduncles nearly as long as the leaves, the outer bracts often leafy and 4 to 6 lines long, the others small and linear, the bracteoles about half the length of the ovary, all tomentose. Corolla downy or tomentose, the tube 8 or 9 lines long, the 2lipped limb rather shorter.

On the summits of the hills, in grass or amongst rocks, Champion. Not received from elsewhere.

4. L. multiflora, Champ. in Kew Journ. Bot. iv. 167. A climber, with pubescent branches. Leaves stalked, ovate or oval, obtuse, about $1 \frac{1}{2} \mathrm{in}$. long, slightly pubescent and neither shining nor wrinkled above, softly pubescent underneath. Flower-pairs nearly sessile, 6 or 8 together in heads or short cymes on axillary or terminal peduncles. Outer bracts leafy, 2 to 4 lines long, inner ones and bracteoles very small. Corolla-tube slightly pubescent, 8 or 9 lines long, the 2-lipped limb rather shorter.

From Mr. Cay's garden at Victoria, and according to him indigenous in the island, Champion. I have seen no other specimens. This comes nearest to the $L$. chinensis, DC., or $L$. japonica, Thunb., known in our gardens as L. flexuosa, and of which we have several specimens from the Chinese continent. It is possible indeed that the $L$. multiflora, may prove to be a variety of it, but in that plant, besides some differences in the foliage, the peduncles are in the wild, as well as in cultivated specimens, constantly short and simple, bearing only one pair of flowers.

\section{Order LVIII. RUBIACEAs.}

Calyx-teeth adnate; the limb entire, with as many teeth, lobes, or divisions as lobes of the corolla. Corolla inserted round an epigynous disk, regular, with 4, 5, or more lobes, either imbricate (usually convolute) or valvate in the bud. Stamens as many as lobes of the corolla, alternating with them and inserted in the tube. Ovary inferior, 2- or more celled, with 1 or more ovules in each cell, rarely 1-celled with parietal placentas. Styles simple, with a simple terminal stigma, or with as many stigmatic lobes as cells to the ovary. Fruit varying. Seeds with a horny albumen; embryo usually small, with flat cotyledons.-Trees, shrubs, herbs, or rarely climbers. Leaves opposite, 
entire, with interpetiolar stipules, which are either small and sometimes inside the leaves, or resemble the leaves and form with them a regular whorl. Inflorescence various.

A very large Order, dispersed over every part of the globe; the Cinchonea and Coffeece almost entirely tropical or subtropical; the Stellate chiefly inhabiting the more temperate or cold regions.

TRIBE 1. Cinchoneæ.-L Leaves opposite or rarely whorled, with small stipules between or inside of them. Ovules several (rarely 2 only) in each cell of the ovary.

Corolla valvate in the bud.

Flowers very numerous, closely packed in globular heads on a small receptacle. Fruit capsular. Seeds winged . . .

Flowers in cymes, panicles, or axillary clusters. Fruit capsular. Seed not winged.

Capsule broader than long. Herbs in terminal or rarely axillary cymes . . . . . . . . . . . .

Capsule globular or ovoid. Flowers in axillary clusters or in loose panicles.

Capsule septicidal or indehiscent . . . . . . . . .

Capsule loculicidal . . . . . . . . . . . .

Flowers in terminal corymbs or cymes, 2 outer calyx-lobes very

large and coloured. Fruit a berry . . . . . . 6. Mussswnda.

Corolla imbricate or contorted in the bud.

Fruit capsular. Seeds winged. Prostrate shrubs

1. Adina.

Fruit a berry. Seeds not winged. Ereet shrubs.

Lobes of the corolla and calyx 6 or more. Ovary 1-celled, with parietal placentas. Flowers solitary, terminal . .

Lobes of the corolla and calyx 5. Ovary 2-celled, with axile placentas.

Seeds immersed in a fleshy placenta or thick pulp. Flowers axillary, or 1 to 3 at the ends of short branches . . .

Seeds numerous, angular, with little or no pulp. Flowers numerous, in terminal corymbs ........

Lobes of the corolla and calyx 4. Ovary 2-celled, with 2, or rarely 3 or 4 ovules in each . . . . . 10. Diplospora.

TRIBE 2. Coffeeæ.-Leaves opposite or rarely whorled, with small stipules. Ovules 1 only in each cell of the ovary.

Stipules entire. Fruit a drupe or berry.

Ovules peltately attached to the middle of the cell. Corolla imbricate.

Style bifid at the top, with recurved lobes . . . . . 12. Ixora.

Style entire, or the lobes ereet and connivent. . . . . . 11. PAVETTA.

Orules suspended from near the top of the cells.

Corolla imbricate. Ovary-cells 4 or 5 . . . . . 13. GuettardeltA.

Corolla valvate. Ovary-cells 2 . . . . . . . 14. CanTHiUM,

Ovules erect from near the base of the cells. Corolla valvate.

Ovary-cells usually 4 or more.

Flowers united several together in pedunculate heads . 15. Morinda.

Flowers distinet, clustered in the axils of the leaves . . . 16. LAsianthus.

Ovary-cells 2.

Fruit a drupe, with a hard nucleus. Corolla-tube short . 17. Psychotris.

Fruit a berry. Corolla-tube much longer than the lobes . 18. Pederia.

Stipules fringed with bristles. Fruit dry, small, separating into 2 carpels.

Ovules laterally attached or ascending. Flowers, axillary. . . 19. SPErmacoce.

Ovules pendulous. Carpels opening or separating at the base . 20. Knoxia.

TribE 3. Stellatre.-Stipules similar to the leaves, and with them forming whorls of

4 or more. Ovules 1 in each cell. . . . . . . . . 21. Galium. 


\section{ADINA, Salisb.}

Calyx-limb of 5 persistent linear lobes. Corolla-tube slender; lobes 5 , valvate in the bud. Anthers included in the tube. Style exserted, with a capitate stigma. Ovary 2-celled, with few ovules suspended from near the top of the cells. Fruit capsular, septicidal, the 2 valves and seeds falling off, leaving a persistent axis crowned by the star-like limb of the calyx. Seeds oblong, with a narrow edge or wing.- Shrubs. Stipules united in pairs between the leaves. Flowers densely crowded in globular heads, on axillary or terminal peduncles.

Besides the following species, the genus comprises one other, the A. polycephala, Benth. (Nauclea polycephala, Wall. Catal.n. 6100), with several flower-heads, forming a short terminal raceme or corymb, which extends from Silhet and Chittagong to the vicinity of Hongkong, but has not been found in the island itself. We have also from S. China, but not yet from the island of Hongkong, a species of the closely allied genus Cephalanthus, which can neither be distinguished from some forms of the American $C$. occidentalis, nor from others of the Asiatic $C$. naucleoides; the glabrous and pubescent varieties occur both in America and Asia, and the glands of the corolla are sometimes as large in the American as in the Asiatic specimens.

1. A. globifiora, Salisb.; DC. Prod.iv. 349. An erect glabrous muchbranched shrub. Leaves shortly stalked, oblong or obovate-lanceolate, acuminate, $1 \frac{1}{2}$ to $3 \mathrm{in}$. long. Peduncles axillary or rarely 3 together at the ends of the branches, shorter or longer than the leaves, each with 2 small bracts a little below the middle, and bearing a single globular flower-head, about 5 lines diameter, without the long exserted styles. - Nauclea Adina, Sm., and $N$. adinoides, Lindl. Bot. Reg. xi. t. 895. Adina pedunculata, DC. Prod. iv. 349.

Common in ravines, Champion and others; also on the adjacent continent, but not known out of S. China.

\section{THYSANOSPERMUM, Champ.}

Calyx-limb of 5 , or rarely 4 persistent short lobes. Corolla-tube slender ; lobes 5, rarely 4, spreading, imbricate in the bud. Anthers linear, included in the tube. Style entire, club-shaped at the top, exserted. Ovary 2-celled, with several peltate ovules in each, imbricated upwards, the placenta peltately attached to the middle of the partition. Capsule nearly globular, opening loculicidally in 2 valves which split septicidally. Seeds bordered by a fringed membranous wing.-Flowers axillary, solitary.

The genus comprises only a single species.

1. T. diffusum, Champ. in Kew Journ. Bot. iv. 168. A low prostrate or trailing shrub, the slender branches covered when young with appressed hairs. Leaves shortly stalked, ovate or ovate-lanceolate, acutely acuminate, 1 to $1 \frac{1}{2}$ in. long, glabrous above, with appressed hairs on the midrib and edges underneath. Stipules single on each side, lanceolate, entire. Peduncles axillary, solitary, 1-flowered, 2 to 3 lines long, with 2 minute bracts above the middle. Calyx scarcely 1 line long, the ovate lobes scarcely as long as the globose tube. Corolla white, the tube 5 lines long, pubescent; the lobes near 2 lines long, obtuse, pubescent inside. Capsule like that of a Hedyotis, with about 10 seeds to each cell. *

In ravines, trailing upon rocks, abundant on Mount Victoria and some other places, Champion; also Wright. Not received from elsewhere. 


\section{OPHIORHIZA, Linn.}

Calyx-limb of 5 persistent teeth or lobes. Corolla-tube slender; lobes 5, valvate in the bud. Anthers included in the tube. Style usually included, with 2 stigmatic lobes. Ovary 2-celled, with several ovules in each, attached to a placenta ascending from near the base. Capsule much flattened and very broad, almost 2 -lobed at the top, opening loculicidally in 2 valves. Seeds several, angular.-Herbs, usually of low stature. Stipules very small. Flowers sessile along the branches of terminal or rarely axillary pedunculate cymes.

A rather considerable genus, limited to tropical and eastern subtropical Asia.

Corolla scarcely 3 lines long, with obtuse lobes . . . . . . 1. O. pumila. Corolla about 7 lines long, with acute lobes . . . . . . . . . . 2. O. Eyrei.

1. O. pumila, Champ. in Kew Journ. Bot. iv. 169. A small scarcely branching herb, the stems decumbent and rooting at the base, ascending to 3 or 4 in. or rarely 6 in. in height, and usually pubescent. Leaves ovate, the larger ones $1 \frac{1}{2}$ in. long, acute or acuminate, and narrowed into a long petiole, the smaller ones obtuse, and scarcely $\frac{1}{2}$ in. long, all minutely pubescent or rough. Flowers crowded in small terminal cymes, the common peduncle rarely 2 lines long. Calyx shortly and densely tomentose, the lobes very obtuse. Corolla about 3 lines long, the tube cylindrical and pubescent, the lobes scarcely 1 line long, ovate, obtuse, glabrous. Capsule about 3 lines broad at the top.

Ravines of Mount Victoria, Champion, Wright. Not as yet found out of the island. The form of the corolla rather contracted than dilated below the limb, with very obtuse lobes both to the calyx and corolla, will readily distinguish this species from the smaller Indian ones, which at first sight may much resemble it.

2. O. Eyrei, Champ. in Kew Journ. Bot. iv. 170. An ascending nearly simple glabrous herb, 6 in. or rather more in height, rooting at the base. Leaves ovate, obtuse, or obtusely acuminate, the larger ones 2 to 3 in. long, but often much smaller, assuming, as well as the whole plant, a red tint in drying. Flowers 5 to 10 , or rarely more, in loose terminal cymes, on peduncles varying from $\frac{3}{4}$ in. to twice that length. Calyx-teeth small, triangular, acute. Corolla red when dry, about 7 lines long, glabrous outside; the tube dilated in the upper half; the lobes spreading, acute, rather more than a line long, pubescent inside. Capsules about 3 lines broad.

In moist ravines, Eyre, Wilford; also on the adjoining continent, but not found out of S. China, and a careful comparison shows no immediate affinity with any other known speeies. The flowers are much like those of some Chasalias, but the placentas bear numerous ovules, and the broad capsules are quite those of an Ophiorhiza.

\section{HEDYOTIS, Linn.}

Calyx-limb of 4 (or very rarely 5) persistent teeth or lobes. Corolla-tube usually short; lobes 4 (or very rarely 5 ), spreading, valvate in the bud, and usually hairy inside at the base. Anthers exserted from the tube. Style with 2 stigmatic lobes. Ovary 2-celled or rarely 3-celled, with several ovules in each, attached to placentas arising from near the base. Capsule globular or ovoid, sometimes only half-inferior, separating more or less into 2 (or rarely 3 ) carpels, which either open along the inner edge, or in 2 valves at the top, 
or remain indehiscent. Seeds angular.-Herbs, undershrubs, or rarely climbers. Stipules united with the petioles in a short sheath, entire or fringed with bristle-like subulate lobes. Flowers in axillary clusters or terminal panicles, or rarely in axillary pedunculate cymes.

A large genus, widely spread over tropical and subtropical Asia and Africa, with a few American species.

Stipules truncate, with long bristles. Flowers umbellate, in terminal panicles. Capsule free at the top, opening septicidally and loculicidally (Sect. Macrandria) - * - * - * : * Stipules ovate or triangular. Capsule separating septicidally into the 2 carpels whieh open along their inner edge (Sect. Diplophragma).

Cymes 2- or 3-chotomous, loose, axillary or terminal. Stipules entire.

Stems acutely 4-angled .

Stems terete or obtusely angular.

Cymes terminal Cymes axillary

Clusters sessile, axillary or terminal, nearly globose. Stipules fringed Stipules truncate, with long bristles. Flowers in axillary sessile clusters. Carpels indehiscent (Sect. Metabolos)

1. H. recurva.

2. H. acutangula.

3. H. Vachellii.

4. H. loganioides.

5. H. uncinella.

6. H. auricularia.

1. H. recurva, Benth. in Lond. Journ. Bot. i. 486; and in Kew Journ. Bot. iv. 170 ; Seem. Bot. Her. t. 84. A tall glabrous somewhat climbing herb, the branches terete or nearly so. Stipulary sheaths short, with several bristles on each side, 3 or 4 lines long. Leaves ovate-lanceolate, acuminate, 2 to $2 \frac{1}{2}$ in. long, with 3 or 4 oblique nerves on each side of the midrib, indented above, very prominent underneath. Flowers 10 to 20 together, in little umbels, on short peduncles in the upper axils, the upper ones forming a terminal oblong panicle. Calyx-teeth recurved outwards. Corolla-tube very short; the lobes about 3 lines long, spreading or recurved. Capsule projecting from the calyx, separating septicidally in the upper part into 2 carpels, which open loculicidally in 2 valves. Seeds numerous, very small.

Abundant in ravines, Champion and others. Also on the adjacent continent, but not found out of S. China. The $\boldsymbol{H}$. macrostemon, Hook. and Arn., another species of the same section, apparently common in S. China, but not yet detected in Hongkong, differs chiefly in the dense pubeseence of the stem and foliage, the more compact inflorescence and smaller flowers.

2. H. acutangula, Champ. in Kew Journ. Bot. iv. 171 ; Seem. Bot. Her. $t .85$. A tall glabrous plant, apparently somewhat shrubby at the base. Branches erect, very acutely quadrangular, or even 4 -winged at the base, less so under the inflorescence. Stipules ovate or triangular, entire or slightly toothed. Leaves nearly sessile, ovate-lanceolate, 2 to $3 \mathrm{in}$. long, rather thick, the oblique nerves but little conspicuous. Flowers small, sessile, numerous, in loose dichotomous or trichotomous cymes, forming an oblong or corymbose terminal panicle. Calyx-tube about 1 line long; the lobes shorter, ovate. Corolla-tube about 1 line long; the lobes scarcely so long, ovate-lanceolate. Capsule not prominent above the calyx, separating into the 2 carpels which open along the inner face. Seeds several, small.

Common in ravines, Champion and others. Also on the continent of S. China, but not known from elsewhere.

3. H. Vachellii, Benth., n. sp. A tall glabrous plant, apparently more 
climbing than the last, which it resembles in many respects. Branches terete, or scarcely angular. Stipules triangular and entire. Leaves lanceolate, like those of $H$. acutangula, but narrower, and more evidently stalked. Inflorescence the same, but looser; the flowers more slender, on short pedicels. Corolla. tube full $1 \frac{1}{2}$ lines long, the lobes about 1 line, the throat scarcely hairy. Ovary as in the last species, but I have not seen the ripe capsule.

Hongkong, Harland? S. China, near Macao, Vachell and Beechey. I describe this from the Macao specimens, with which I had identified one from Hongkong in the late Dr. Harland's collection, not now before me to compare. I had named it $\boldsymbol{H}$. scandens, Roxb., under the erroneous impression that Vachell's plant was that species. Roxburgh's plant, a common Khasia one, is, however, quite different, belonging to the section Dimetia, hitherto unrepresented in China.

4. H. loganioides, Benth., n. sp. Apparently an ascending or erect perennial, our specimens above a foot long, and quite glabrous; the branches terete or obtusely angular, or compressed when young. Leaves oblong or lanceolate, acute at both ends, 1 to $2 \mathrm{in}$. long, and $\frac{1}{2}$ to $\frac{3}{4} \mathrm{in}$. broad, or rather longer in some specimens, not unlike those of Logania floribunda, without prominent veins except the midrib, on petioles of one or 2 lines. Stipules ovate, entire. Peduncles axillary, 2 to 6 lines long, bearing a trichotomous cyme of 10 to 20 flowers. Flowers scarcely 2 lines long, glabrous. Calyxlobes linear, rather shorter than the corolla. Corolla-tube short and slender, without any hairs inside. Capsule about 1 line long, crowned by the calyxlobes; the 2 carpels separating to the base, and opening wide by a fissure on the inner face. Ovules numerous, but only a few of them appear to ripen into perfect seeds.

On the top of Mount Gough, Wilford; also Wright. We have apparently the same species from Moulmeyn (Lobb). It comes nearest amongst published ones to the H. obscura, Thw., of Ceylon, but in that one the stipules are pectinate, and the corolla hairy inside at the throat.

5. H. uncinella, Hook. and Arn. Bot. Beech. 192. A glabrous perennial, the stems weak and ascending, or perhaps climbing, and acutely angular. Stipules triangular, fringed with subulate teeth. Leaves oblong or ovatelanceolate, about 1 to $2 \mathrm{in}$. long, with few veins. Flowers about 2 lines long, in dense sessile clusters, forming a globular terminal head of 6 to 8 lines diameter, and two or three distant globular whorls in the upper axils. Calyxlobes oblong-linear, obtuse, about as long as the corolla. Capsules crowned by the calyx, opening inwards in 2 carpels like the last species.- $H$. bor rerioides, Champ. in Kew Journ. Bot. iv. 17]. H. cephalophora, Wall. Catal. n. 842 ?

Common in the neighbourhood of Chukchow, but not on the Victoria side of Hongkong, Champion; Putoy Island, Wright; also S. China, and probably Khasia.

We have three forms of this plant, which have been severally considered as distinct species, but are probably varieties of the same. Our specimens are, however, not as yet sufficient to determine the question satisfactorily. The original ones of $H$. uncinella, Hook. and Arn., from S. China, are far advanced, the leaves are distinctly petiolate, with the limb tapering at the base, the heads are far advanced in fruit and rather lax, the bracts and calycine lobes strongly ciliate. In the $\boldsymbol{H}$. borrerioides, Champ., from Hongkong, the leaves are narrower, longer, and more sessile, but much tapering at the base, the heads very compact and perfectly smooth. In the $H$. cephalophora, Wall., which appears to be frequent in Khasia, the leaves 
are quite sessile and rounded at the hase, with the flower-heads as in $\boldsymbol{H}$. uncinella, but much less ciliate. I see no other difference between the three.

6. F. auricularia, $W$. and Arn. Prod. Fl. Penins. i. 412. A decumbent straggling herb of 1 to $3 \mathrm{ft}$., the branches hairy, somewhat compressed when young. Stipules short, with long bristle-like lobes or teeth. Leaves on short stalks, varying from ovate to oblong-lanceolate, 1 to $2 \mathrm{in}$. long, glabrous or pubescent, with parallel and very oblique raised nerves diverging from the midrib, and very prominent undermeath. Flowers but little more than a line long, in dense axillary sessile clusters. Calyx-tube about $\frac{1}{2}$ line long; the lobes subulate and recurved, about as long, the corolla but little longer. Capsules small, crowned by the calyx-lobes, and quite indehiscent.H. nervosa, Wall. Catal. n. 857.

Hongkong, Wright. The species is widely spread as a weed over tropical Asia, and, besides the following variety, includes probably some others, either enumerated in Wallich's Catalogne, or described by Blume or others as species of Hedyotis or Metabolos.

Var. parviflora.-H. costata, Wall. Catal. n. 849.

Hongkong, Wright, Harland; also Khasia and Assam. Small as are the flowers and fruits in the common form, this variety has them still smaller and more crowded, and the leaves usually, but not always, narrower, the calyx-teeth are also perhaps usually rather shorter, but I can see no essential difference. In both the ovary and capsule have occasionally 3 cells.

\section{OIDENLANDIA, Linn.}

Calyx-limb of 4 persistent teeth or lobes. Corolla-tube usually short, rarely slender; lobes 4, spreading; valvate in the bud. Anthers usually exserted from the tube. Style entire or with 2 stigmatic lobes. Ovary 2-celled, with several ovules in each, attached to placentas arising from near the base. Capsule globular or ovoid, sometimes only half-inferior; the carpels not separating but opening at the top in two loculicidal valves, bearing the partition in their centre.-Diffuse, spreading, or rarely erect herbs. Stipules of Hedyotis. Flowers small, usually axillary, solitary or in clusters or cymes, rarely forming irregular terminal leafy panicles.

A considerable genus if taken, as above characterized, to include Scleromitrion, Kohautia, Anotis, and Houstonia, and widely dispersed over tropical and subtropical Asia, Africa, Australia, and tropical and temperate America.

Flowers sessile, in axillary clusters. Calyx-teeth erect, and connivent when in fruit.

Leaves lanceolate. Stems pubescent or hispid . . . . . 1. O. hispida.

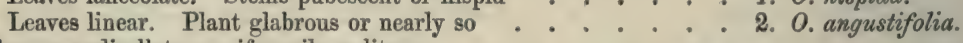

Flowers pedicellate, or, if sessile, solitary.

Flowers axillary, solitary, or 2 or 3 tugether on a slender axillary

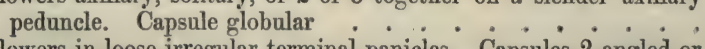

Flowers in loose irregular terminal panicles. Capsules 2-angled or winged at the base

\section{O. herbacea.}

4. O. paniculata.

1. O. hispida, Poir. Stems branched at the base only, diffuse, 1 to $1 \frac{1}{2}$ ft. long, 4-angled and pubescent or hispid. Leaves sessile, lanceolate, $1 \frac{1}{2}$ to 2 in. long, narrowed at the base, 4 or 5 lines broad in the middle. Stipules shortly sheathing with long bristle-like teeth. Flowers scarcely above 2 lines long, sessile, in axillary clusters. Capsules ovoid or nearly globular, hairy and crowned by the narrow-lanceolate calyx-teeth, which are erect and closely 
connivent.-Hedyotis hispida, Retz; DC. Prod. iv. 420. Scleromitrion hispidum, Korth. in Ned. Kruidk. Arch. ii. 155.

Hongkong, Wright. Dispersed as a weed over India and the Archipelago.

2. O. angustifolia, Benth. A diffuse or decumbent herb, with the habit of $O$. hispida, but more slender, and glabrous or seldom very slightly pubescent. Leaves almost sessile, linear, 1 to $1 \frac{1}{2}$ in. long, 1 to $1 \frac{1}{2}$ lines broad. Stipules short, with several bristle-like teeth. Flowers about 2 lines long. Corolla slightly pubescent. Calyx and capsule as in O. hispida, but quite glabrous.-Hedyotis angustifolia, Cham. and Schlecht.; DC. Prod. iv. 419. Scleromitrion angustifolium, Benth. in Kew Journ. Bot. iv. 172. Hedyotis approximata, Wall. Catal. n. 852. Scleromitrion tetraquetrum, Miq. Fl. Ned. Ind. ii. 186.

Hongkong, Champion and others. Also in Khasia, Silhet, and Penang, and apparently a common weed in the Indian Archipelago.

3. O. herbacea, DC. Prod. iv. 425 (but without the Linnacan synonym there quoted*). A much-branched, slender, diffuse annual, 6 in. to 1 foot long, glabrous, or rough with a slight pubescence. Stipules with short bristle-like teeth. Leaves linear or linear-lanceolate, usually $\frac{1}{2}$ to $1 \mathrm{in}$. long, and 1 to 2 lines broad, narrowed at the base. Peduncles axillary, usually solitary, bearing either a single flower or a cyme of 2 or 3 , and almost always shorter than the leaves. Flowers sometimes scarcely above 1 line long and from that to near 2 lines. Calyx-teeth shorter than its tube and about the length of the short broad tube of the corolla, which is glabrous inside or nearly so. Capsule small, usually globular, sometimes almost ovoid, but not so narrow as in $O$. Heyneana, sometimes broader than long, but not didymous as in $O$. brachiata, Wight (O. dichotoma, Kœn.), the minute calyx-teeth distinctly separated from each other in a ring round the apex.-Hedyotis (Oldenlandia) Burmanniana and H. (O.) intermedia, W. and Arn. Prod. i. 414, with the synonyms there adduced; $H$. extensa, Wall. Catal. n. $2869 ; H$. alsinafolia, Wall. Catal. n. 873.

Var. a. uniffora. Peduncles almost always 1-flowered, either very short (O. brachypoda, DC. Prod. iv. 424), or more than half as long as the leaves; the flowers usually from $1 \frac{1}{2}$ to 2 lines long.

Var. b. parviflora. Peduncles slender, mostly 2- to 3 -flowered, sometimes with 1 or with 4 or 5 flowers. Flowers searcely above 1 line long, or even smaller.- - biflora, Limn. Her-

* The Hedyotis herbacea of Linnæus is not in his herbarium, but from his description in the 'Flora Zeylanica,' especially the observation "Corolla infundibuliformis, hine ab $\mathrm{Ol}$ denlandiis diversa," it is evident that he had in view the H. Heyneana, W. et Arn. Olden . landia biflora is represented by a very poor garden specimen of what appears to be the several-flowered variety of the present species; and of $O$. corymbosa there is a satisfactory specimen of the same variety; but neither of these names can well be made to include the single-flowered form, which appears to have been unknown to Linnæus. We have then to choose for the name of the whole species between Oldenlandia herbacea, DC., Hedyotis diffusa, Willd., and Hedyotis (Oldenlandia) Burmanniana, W. et Arn. I have preferred the first, although derived from a mistaken adoption of Linnæus's specifie word, for it is the oldest, in which neither the generic nor the specific term would have to be changed, besides that it is generally adopted for the American specimens. There have been some doubts suggested as to Willdenow's Hedyotis diffusa being really this plant, besides that his name was never transferred to Oldenlandia till after the Prodromus, and Wight and Arnott's name is still more recent. 
barium? (a very bad garden specimen), DC. Prod. iv. 426. O. corymbosa, Linn. Herbarium, DC. 1. c.

Waste places, Hongkong, Champion and others: both varieties mixed. This is a very common weed throughout the warmer parts of Asia and Africa, and in some parts of tropical America. The two forms are often sent together. At first sight they look very distinct; but on carefully measuring the size of the flowers and capsules, I find them pass so gradually one into the other, that I could draw no line of separation. So also in the length of the peduncle; it is not a line long in many specimens of the 0 . brachypoda, DC., from the Archipelago, and in corresponding ones from E. India ; in the Hongkong ones, as in most of the Indian ones, it varies from 1 to 6 lines, and in some very luxuriant specimens from Asia, Africa, and America, 1 have seen it near 1 in. long. The large-flowered specimens are almost universally uniflorous. The small-flowered variety has usually the pedicels longer than the flowers, and 2 or 3 together (rarely 4 or even 5) on an equally slender and scarcely longer peduncle; but very frequently the peduncles are uniflorous, especially in the lower part of the plant. It is probable that besides the synonyms above given, several other described Oldenlandias belong to this species.

4. O. paniculata, Linn. (Herbarium); DC. Prod. iv. 427. A glabrous annual or biennial, usually much branched, diffuse or nearly erect, and only a few inches high, sometimes ascending to the height of a foot more. Leaves ovate or oblong, from $\frac{1}{2}$ to above $1 \frac{1}{2}$ in. long, and almost always much broader than in O. herbacea. Stipulary bristles short. Peduncles 1- to 3-flowered, irregularly arranged in loose terminal panicles, leafy at the base. Flowers little above a line long; the calyx-lobes very short, about the length of the minute corolla-tube. Capsule usually from 1 to $1 \frac{1}{2}$ lines, sometimes 2 lines long, crowned by the minute distant calyx-teeth, and usually with 2 or 4 prominent ribs, sometimes expanded into narrow wings more or less decurrent on the pedicel.-Hedyotis (Oldenlandia) alata, Kœn.; H. (O.) biflora, Br. ; and $H$. (O.) racemosa, Lam., with the synonyms given to each in W. and Arn. Prod. Fl. Penins. i. 413 and 4.14 (except the Linnæan O. biflora, which is O. herbacea), Wight, Ic. t. 312. O. pterita, Miq. Fl. Ned. Ind. ii. 193.

Hongkong, Wright. A common S. Asiatic weed, extending from Ceylon and the Peninsula to Burmah, Siam, the Indian Archipelago, the Philippines, Loochoo, and Japan. The three forms described by Wight and Arnott run very much one into the other. The broadly winged base of the capsule and pedicel of some specimens of $H$. alata passes gradually into the narrower wing of $H$. biflora and the almost entirely wingless state of $H$. racemosa. The Hongkong specimens agree perfeetly with the smaller ones of the latter, such as we have them from Central India, Java, etc.; so also, on a careful examination, does the very poor specimen of Gerontogea racemosa, Cham., from Radack, in the Hookerian Herbarium.

5. O. .... ? A single specimen, in fruit, from Hongkong, in Wright's collection, has the habit of some of the African Oldenlandias of the section Kohautia (characterized by the long tube of the corolla); but as there is neither corolla nor bud, it is impossible to determine it.

\section{MUSS 正NDA, Linn.}

Calyx-limb of 5 deciduous lobes or teeth, one in a few of the outer flowers of each corymb often produced into a large, stalked, bract-like, coloured leaf. Corolla-tube usually elongated; lobes 5, valvate in the bud. Anthers included in the tube or nearly so. Style with 2 stigmatic lobes. Ovary 2 -celled, with many ovules in each, attached to a bifid placenta projecting from the partition. Fruit succulent, indehiscent. Seeds numerous, small.-Shrubs or small trees. Stipules 2 on each side, often united at the base. Flowers in terminal corymbs. 
A small genus, chiefly from the tropical regions of the Old World, with perhaps a single species from tropical America.

Leaves pubescent on the veins underneath. Corolla-lobes narrow, with long points . . . . . . . . . . . . . . 1. M. pubescens. Leaves quite glabrous. Corolla-lobes broad, scarcely pointed . . . 2. M. erosa.

1. M. pubescens, Ait.; DC. Prod. iv. 371. A tall shrub. Leaves on short petioles, oval-oblong or ovate-lanceolate, acuminate, 2 to $3 \mathrm{in}$. long, slightly pubescent on the veins underneath as well as the young branches. Stipules united at the base, subulate above. Corymb terminal, dense, sessile above the last leaves. Calyx-lobes linear, $1 \frac{1}{2}$ to 2 lines long, one of them in a few of the outer flowers broadly ovate or orbicular, acuminate, coloured, 1 to $1 \frac{1}{2}$ in. long, on a long slender petiole. Corolla-tube about 1 in. long, slender, covered with appressed hairs; the lobes 2 lines long, narrow-lanceolate, ending in long points. Berries globular or nearly so, glabrous, 4 or 5 lines diameter.

Common in ravines, Hinds, Champion, and others. Also S. China, but not known from elsewhere. The corolla is much more slender and the lobes much narrower than in $M$. frondosa and its allies or varieties. The leaves are usually narrower, and the corymb even in fruit is more dense. I cannot match it exactly with any $\mathrm{E}$. Indian species. The nearest is one from Rangoon, with still narrower segments and perfectly glabrous. The plant figured in the Botanical Magazine, t. 2099, as M. pubescens, has been correctly referred by Lindley (Bot. Reg. t. 517) to the common $M$. frondosa, although it has since been inadvertently quoted as representing the $M$. pubescens.

2. M. erosa, Champ. in Kew Journ. Bot. iv. 193. A tall shrub or small tree, with the branches and leaves quite glabrous. Stipules united at the base. Leaves shortly stalked, ovate, acuminate, 2 to 3 in. long. Corymbs trichotomous, large and loose, branching out immediately above the last leaves. Calyx-lobes scarcely above 1 line long, the enlarged coloured ones often attaining 2 or 3 in. in length and almost as broad. Corolla-tube about 9 lines long, slender, glabrous at the base, with a few appressed hairs in the upper part; the throat closed with hairs on the inside; the lobes near 2 lines broad and scarcely longer, with very short points.

In ravines, Hongkong, Champion, Wilford, Wright. Also in Sikkim, Assam, Khasia, and Bootan. The name erosa is unfortunately chosen, as the leaves were only accidentally undulate in the specimen from which Col. Champion derived it. It may however be merely a variety of $\boldsymbol{M}$. frondosa, or of $\boldsymbol{M}$. glabra of Vahl, which Miquel unites with $\boldsymbol{M}$. frondosa.

\section{GARDENIA, Linn.}

Calyx-limb tubular, truncate, toothed or lobed, or seldom divided to the base in 5 or more lobes. Corolla-tube cylindrical; lobes 5 or more, imbricate in the bud. Anthers nearly sessile, usually exserted. Style with 2 thick erect stigmatic lobes, or nearly entire. Ovary 1-celled, incompletely divided by 2 to 5 parietal projecting placentas. Fruit succulent, indehiscent, usually crowned by the calyx. Seeds numerous, immersed in the fleshy placentas.Shrubs or trees. Stipules usually solitary on each side, and entire. Flowers usually rather large and solitary, terminal or axillary.

A small genus, confined to tropical and subtropical Asia and Africa, the greater number of species usually referred to Gardenia belonging in fact to Randia or other allied genera.

1. G. florida, Linn.; DC. Prod. iv. 379 ; Bot. Reg. t. 449 ; Bot. Mag. 
t. 3349. An evergreen, glabrous, unarmed shrub. Leaves oblong-elliptical or almost lanceolate, acuminate, 2 to 3 or rarely $4 \mathrm{in}$. long, contracted into a short petiole at the base. Flowers terminal, solitary, sessile or nearly so, rather large, white, and sweet-scented. Corolla-tube about $1 \mathrm{in.} \mathrm{long,} \mathrm{and}$ the narrow-oblong lobes about as much, varying in number from 6 to 8 or rarely 9 . . Berry oblong, above 1 in. long, crowned by the long linear persistent calyx-lobes, and marked outside by as many raised ribs or angles.

In ravines, Champion and others. It appears also to be really wild as well as cultivated in S. China generally. All the specimens received from other parts are evidently from gardens.

\section{RANDIA, Linn.}

Calyx-limb tubular or campanulate, truncate-toothed or lobed, persistent or rarely deciduous. Corolla-tube cylindrical (short or long) or rarely dilated at the top; lobes 5, contorted in the bud. Anthers nearly sessile, included in the tube or shortly exserted. Style with 2 thick stigmatic lobes, or nearly entire. Ovary 2-celled, with several, usually numerous, ovules in each cell attached to a fleshy peltate placenta. Fruit succulent, indehiscent, often crowned by the calyx. Seeds several, immersed in the fleshy or pulpy placenta.-Shrubs or rarely trees, often armed with opposite axillary thorns. Stipules solitary on each side and entire, pointed, with a broad base. Flowers not usually so large as in Gardenia, in axillary cymes or clusters, or solitary at the summit of short branches or tufts of leaves.

A considerable genus, dispersed over the tropical regions both of the New and the Old World.

Thorny. Flowers solitary, on short leafly branches or tufts. Corollatube short, pubescent ..............

Unarmed. Flowers 1 to 5 , terminal or lateral. Corolla-tube short, glabrous . . . . . . . .

Thorny. Cymes terminal. Corolla-tube slender, much longer than the limb ..................

Unarmed. Cymes or pedicels axillary. Corolla-tube rather longer than the limb . . . . . . . . . .

Unarmed. Cymes many-flowered, apparently leaf-opposed. Corollatube short.

1. R. dumetorum.

2. R. leucocarpa.

3. $R$. sinensis.

4. $R$. canthioides.

5. R. densiflora.

1. R. dumetorum, Lam.; W. and Arn. Prod. Fl. Penins. i. 397; Wight, Ic.t.580. A glabrous or slightly pubescent shrub, armed with straight stout axillary thorns, often above 1 in. long. Leaves obovate-oblong, acute or shortly acuminate, or rarely nearly obtuse, 1 to 2 in. long, narrowed at the base, thin, and deciduous. Flowers solitary at the end of very short lateral leafy branches or tufts of small leaves. Calyx-limb 5-lobed, as long as the corolla-tube, usually persistent. Corolla white, pubescent; the tube broad, about 3 lines long; the lobes obovate, obtuse, spreading, about 4 lines long.

At Little Hongkong, Champion, Hance ; also Wright. Common in India and the Archipelago.

2. R. leucocarpa, Champ. in Kew Journ. Bot. iv. 194. A much branched low unarmed shrub, the younger branches densely covered with appressed hairs, the older ones glabrous. Leaves shortly stalked, oblong or obovate, acumi- 
nate, $1 \frac{1}{2}$ to $2 \frac{1}{2} \mathrm{in}$. long, glabrous, except a few appressed hairs on the veins underneath, and deciduous. Flowers 1 to 3 together, on very short pedicels, at the ends of the branches or at the old nodes. Calyx-limb small, campanulate, shortly 5 -toothed, usually persistent. Corolla glabrous, with a short rather slender tube. Berries white, 4 to 6 lines diameter, nearly globular, with a small number of large ovoid seeds immersed in the pulpy placentas.

On the top of Victoria Peak, Champion; also Wright. The very few specimens I have seen are in fruit only, with very young flower-buds. I cannot, therefore, describe exactly the form of the corolla, but it appears to be very near that of the Indian $R$. (Griffithia) fragrans.

3. R. sinensis, Roem. and Schult. Syst. v. 248. An erect shrub, either glabrous or slightly pubescent at the ends of the branches, armed with short straight axillary thorns. Leaves oblong, about $3 \mathrm{in}$. long, and scarcely $1 \mathrm{in}$. broad. Flowers white, in rather dense terminal cymes, on very short common peduncles. Calyx-limb shortly 5-toothed, deciduous. Corolla glabrous or nearly so, with a slender tube about 8 lines long; the lobes lanceolate, 2 to $2 \frac{1}{4}$ lines long. Stigma oblong, scarcely lobed. Berry small, globular. Seeds few, flattened, immersed in the pulpy or almost fleshy placentas.-Oxyceros sinensis, Lour. Fl. Cochin. 151.

Hongkong, Champion; also Lemma Island, Wright, and the neighbourhood of Canton, but not as yet known out of S. China. Hooker and Arnott, it is true, refer here the $R$. longiflora, Lam. (Posoqueria, Roxb., or Griffithia, Korth.), a plant apparently common in the Archipelago, but that has always stout recurved thorns, the flowers are also rather larger, and the shape of the leaves and of the calycine teeth appears different. I do not feel, therefore, sufficiently confident in the specific identity of the two to unite them, without having seen better specimens of the Chinese plant.

This and the following species belong technically to Griffithia, W. and Arn., separated as a genus from Randia chiefly on account of the deciduous limb of the calyx ; but that character is so very uncertain in some species, and so little in accordance with habit in others, that the group can only be maintained, at the best, as an artificial section of Randia.

4. R. canthioides, Champ. in Kew Journ. Bot. iv. 194. A low glabrous unarmed shrub. Leaves oblong, acuminate, 3 to 4 in. long, coriaceous, smooth and shining, like those of Randia corymbosa or of Canthium didymum. Cymes axillary, 3- to 7-flowered, with the common peduncle so short that the pedicels (3 or 4 lines long) appear clustered in the axils of the leaves. Calyxlimb shortly 5-toothed, deciduous. Corolla glabrous; the tube cylindrical, about 4 lines long, the lobes rather shorter. Stigma ovoid. Berry globular, 3 or 4 lines diameter, or sometimes smaller. Seeds angular or flattened, immersed in the pulpy placenta.

Abundant in ravines, Champion and others, but not known out of the island, unless a specimen of Wright's, from Loochoo, in fruit only, belongs to the same species. In the flowering branches of this and some other unarmed Randius, one leaf of each pair will sometimes fall off early, leaving the petiole persistent and hardened, but not really spinescent. The real thorns of Randias, Gardenias, Canthiums, etc., are abortive branches, although they are not always strictly axillary, but appear in some species just above the axillary bud.

5. R. densiflora, Benth. An unarmed shrub, glabrous, excepting the flowers. Leaves oval, oblong or almost lanceolate, coriaceous and shining, 4 to 5 in. long. Flowers rather crowded, in almost sessile cymes, which are really axillary, although they usually appear leaf-opposed by the abortion of the subtending leaf. Calyx-limb usually persistent, very shortly 5 -toothed. Corolla-tube scarcely above 1 line long, the throat very hairy inside; the lobes 
oblong, near 3 lines long, very spreading or reflexed, pubescent outside with minute appressed hairs. Stigma linear, much exserted. Berries small, globular. Seeds several, ovoid, compressed or angular, immersed in the pulpy placenta. - Webera densiflora, Wall., in Roxb. Fl. Ind. ed. Car. ii. 536. Cupia densiflora, DC. Prod. iv. 394. Stylocoryne densiflora, Wall., Catal. n. 8404; Miq. Fl. Ned. Ind. ii. 206. Gynopachys attenuata, Korth. in Kruidk. Arch. ii. 182? Gynopachys oblongata, Miq. Fl. Ned. Ind. ii. 221, and probably the Rubiacee, Wall. Catal. n. 8455 and 8456.

Hongkong, Champion. A single specimen, in very young bud, which on a careful comparison appears to me to belong to this species, although I do not feel certain of its identity. I have described it from Penang and Sumatra specimens, where it appears common, extending northward at least to Tavoy. Although it is difficult to draw a very marked line between Randia and Stylocoryne, this species appears to me to have much more the calyx, and especially the fruit, as well as the habit and inflorescence of the former than of the latter genus. It has probably been referred to Stylocoryne on account of the style, the stigmatic thickened portion of which is longer and thinner than in most Randias. It however is so different in shape in the different species that it cannot be taken even as an artificial generic distinction. The true Stylocorynes have the habit and inflorescence of Pavetta, the seeds numerous, very angular, not immersed in an almost fleshy rather than pulpy placenta, but surrounded by a very thin pulp, scarcely perceptible when dry.

\section{STYLOCORYNE, Cav.}

Calyx-limb short, 5-toothed, deciduous. Corolla-tube cylindrical; lobes 5 , imbricate in the bud. Anthers nearly sessile, more or less exserted. Style long, slightly thickened at the top, undivided. Ovary 2-celled, with numerous ovules in each cell, attached to a peltate placenta. Fruit a globular berry. Seeds angular, without any or with a very thin pulp. - Shrubs or trees, without thorns. Stipules solitary on each side, entire, pointed, with a broad base. Flowers usually numerous, in terminal broad cymes or corymbs.

A genus of several species, dispersed over tropical Africa, Asia, and Australia.

Leaves, stems, and corymbs glabrons . . . . . . . . 1. S. Webera. Leaves, stems, and corymbs softly pubescent . . . . . . . 2. S. mollissima.

1. S. Webera, A.Rich.; W. and Arn.Prod.i. 401 ; Wight, Ic. t. 309 and 584. An evergreen shrub or small tree, quite glabrous, the specimens almost always turning black in drying. Leaves oblong-lanceolate, acuminat $\epsilon$, 3 or $4 \mathrm{in}$. long, contracted at the base into a petiole of 2 to 4 lines. Stipules usually forming at the base a complete sheath within the petioles. Corymb trichotomous, shorter than the leaves. Calyx about 1 line long, with a short 5 -toothed limb. Corolla glabrous, the tube about $1 \frac{1}{2}$ lines long; the lobes oblong, near twice as long. Style linear, scarcely thickened.

In the Happy Valley, scaree, Champion, Hance, Wright. Widely distributed over India and the Arehipelago, and apparently variable in the density of the panicle and size of the flowers; but it would require a further examination of several allied forms to fix the limits of the species. The Hongkong specimens have all rather slender and very glabrous flowers.

2. S. mollissima, Walp. Rep.ii. 517; Benth. in Kew Journ. Bot. iv. 195. A shrub or small tree, resembling in many respects the $S$. Webera, but softly and densely pubescent in every part. Leaves from ovate-lanceolate to oblong or lanceolate, acutely acuminate, 3 or $4 \mathrm{in}$. long. Corymb often pedunculate. Calyx very tomentose, the limb scarcely shorter than the tube. Corolla rather 
smaller than that of $S$. Webera, and pubescent outside, the oblong lobes longer than the tube. Style long and linear, more thickened than in the last species. Berry globular, 3 lines diameter, with about 12 to 14 seeds in each cell.Cupia mollissimu, Hook. and Arn. Bot. Beech. 192.

Searce, in the Happy Valley woods, on Mount Victoria, and near the Buddhist Temple, Champion. Also on the adjoining continent, but not known out of S. China.

\section{DIPLOSPORA, DC.}

Calyx-limb short, 4-toothed or truncate. Corolla-tube short, lobes 4, spreading, imbricate in the bud. Anthers exserted. Style with 2 stigmatic lobes. Ovary 2-celled, with 2 or more ovules attached laterally to a small peltate placenta. Fruit a globular berry. Seeds solitary or few in each cell.Shrubs. Stipules 1 on each side, pointed, with a broad base. Flowers in axillary clusters or close cymes.

A small genus, confined to tropical Asia.

1. D. viridiflora, DC. Prod.iv. 477 ; Benth. in Kew Journ. Bot.iv. 195. An unarmed shrub, with the habit of Canthium, or of some Randias, glabrous in every part. Leaves oval-oblong or nearly lanceolate, usually 2 to $4 \mathrm{in}$. long, coriaceous and shining, on a short peticle. Flowers clustered in short dense axillary cymes of a pale straw-colour, varying from $3 \frac{1}{2}$ to 5 lines diameter. Anthers almost sessile in some specimens, with filaments nearly as long as themselves in others. Ovules usually 2 in each cell. Berries red, the size of a pea.-Gardenia daphnoides, Hance in Walp. Ann. ii. 796.

Common on Victoria Peak, Champion; in the Happy Valley woods and at Little Hongkong, Wilford; also Wright. On the adjacent continent, but not known ont of S. China. Although the number of ovules is variable, I find, in by far the greater number of flowers that I have opened, 2 to each cell as described by Lindley. I have seen, however, as many as 4 , and Col. Champion had counted 6 to each cell, whilst from a memorandum of A. Gray's to one of Wright's specimens, I find he had seen only 1 . In other flowers of the same specimen there were the normal 2 to each cell.

\section{PAVETTA, Linn.}

Calyx-limb small, 4-toothed. Corolla-tube slender, lobes 4, imbricate in the bud. Style exserted, slender, entire or the stigmatic lobes not spreading. Ovary 2-celled, with 1 ovule in each cell peltately attached to the centre of the partition. Berry slightly drupaceous, globular, 2-celled. Seeds attached by their flat face.-Shrubs or small trees. Stipules solitary on each side, pointed, with a broad base. Flowers in terminal corymbs.

A genus of several African, S. Asiatic, or Australian species, scarcely differing from Ixora, with which some botanists unite it.

1. P. indica, Linn.; W. and Arn. Prod.Fl. Penins. i. 431 ; Wight, Ic. $t$. 148. A tall shrub or small tree, glabrous or slightly pubescent, the specimens turning black in drying. Leaves stalked, oval-oblong or almost lanceolate, acute or acuminate, 3 to $4 \mathrm{in}$. long, narrowed at the base. Corymb loosely trichotomous, sessile above the last leaves. Calyx about 1 line long, with minute teeth. Corolla-tube about 6 lines long; the lobes oblong, about $2 \frac{1}{2}$ lines, white or pale-green. Berries globular, 2 or 3 lines diameter. 
In the Happy Valley, at West Point, on Mount Gough, etc., Champion, Wilford, and others. Widely spread over tropical Asia, from Ceylon and the Peninsula to Sikkim, Khasia, Burmah, the Archipelago, and apparently to the north coast of Australia.

\section{IXORA, Linn.}

Calyx-limb small, 4-toothed. Corolla-tube slender, lobes 4, imbricate in the bud. Style exserted, with 2 stigmatic lobes, usually spreading. Ovary 2-celled, with 1 ovule in each cell peltately attached to the centre of the partition. Berry slightly drupaceous, globular, 2-celled. Seeds attached by their flat face.-Shrubs or small trees. Stipules solitary on each side, pointed, with a broad base. Flowers in terminal, dense or large corymbs, or panicles, or sometimes in smaller axillary or lateral cymes.

A considerable genus, dispersed over the tropical regions both of the New and the Old World.

1. I. stricta, Roxb.; W. and Arn. Prod. Fl. Penins. i. 427; Wight, Ic. t. 184. A glabrous shrub. Leaves obovate-oblong, 3 to $5 \mathrm{in}$. long, the lower ones sometimes narrowed at the base into a short petiole, the upper ones, although narrower below the middle, obtuse at the very base and quite sessile, or nearly so. Flowers in dense terminal sessile corymbs. Calyx small. Corolla-tube 1 to $1 \frac{1}{4}$ in. long; the lobes broad, obtuse, about 3 lines long.

In woods at East Point, near the Buddhist Temple, Champion, Wilford; also Hance and Wright. The Hongkong plant is always said to have pale pink flowers, which variety is only known from S. China. A white variety (I. blanda, or I. alba, Roxb.) is deseribed by Roxburgh from cultivated plants introduced from S. China. An orange-coloured variety, which I have not seen, is said to be in the Archipelago.

\section{GUETTARDELLA, Champ.}

Calyx-limb deeply 4-lobed, persistent. Corolla-tube slender; lobes 4, spreading, slightly imbricate in the bud. Anthers included in the tube. Ovary 4or rarely 5-celled, with 1 pendulous oblong ovule in each cell. Style divided at the top into 4 or 5 linear lobes. Fruit a drupe, with 4 or 5 1-seeded stones.Shrubs. Stipules one on each side, pointed, with a broad base. Peduncles axillary, bearing a cyme of few small flowers.

A genus very nearly allied to Guettarda, and of which only one species from the Philippine Islands is known besides the Chinese one.

1. G. chinensis, Champ. in Kew Journ. Bot. iv. 197. A small shrub, the young branches closely pubescent. Leaves oblong-lanceolate, acuminate, 1 to 2 in. long, acute at the base, sprinkled with a few hairs or glabrous above, hoary underneath with close somewhat silky hairs, on a petiole of 1 or 2 lines. Peduncles 6 to 10 lines long, bearing 3 or 5 flowers, the intermediate one sessile, the others terminating the branches. Calyx scarcely 1 line long; with short equal lobes. Corolla 2 lines, with very short obtuse lobes. Drupe ovoid, pubescent, 2 hines long.

On Mount Gough and Mount Victoria, Champion; also Wright. Not as yet found out of the island.

\section{CANTHIUM, Lam.}

Calyx-limb short, 4- or 5-toothed. Corolla-tube short; lobes 4 or 5, spreading, valvate in the bud. Stigma exserted, entire, ovoid or mitre-shaped. 
Ovary 2-celled, with 1 pendulous or descending ovule in each. Berry globular or didymous. Shrubs, either unarmed or with axillary thorns. Stipules 1 on each side, pointed, with a broad base. Flowers in axillary clusters or cymes.

A considerable genus, dispersed over tropical Asia, Africa, and Australia.

Unarmed. Leaves $3 \mathrm{in.}$ long or more, glabrous, shining . . . . . . 1. C. didymum. Thorny. Leaves about 1 in. long, pubescent underneath . . . . 2. C. horridum.

1. C. didymum, Gartn.; Thw. Enum. Pl. Ceyl. 152, with the synonyms there given. An unarmed evergreen shrub, perfectly glabrous. Leaves stalked, ovate or ovate-lanceolate, acuminate, 3 or $4 \mathrm{in}$. long, coriaceous, smooth and shining. Cymes axillary, shortly pedunculate, loose and often many-flowered, but much shorter than the leaves. Corolla 5-lobed, white. Berry distinctly didymous.-C. undulatum, Champ. in Kew Journ. Bot. iv. 198. Vangueria dicocca, Miq. Fl. Ned. Ind. ii. 251, with the synonyms adduced.

In the Happy Valley woods, but rare, Champion; also Wright. Frequent in India, from Ceylon and the Peninsula to Khasia, the Malayan Peninsula, and the Archipelago. Very variable as to the breadth of the leaves, which are always very shining. It is probably the lax inflorescence that may have induced Miquel to remove it to Vanguevia, for I can see no trace in any flowers I have examined of the three empty cells of the ovary which he gives as the character of that section of Vangueria which he has formed out of this and some other Canthiums. In the bud the two carpels are readily separable from each other, and from the surrounding calyx-tube, and if a cross section is not carefully made, there may appear to be an interval between them, but that cannot be called an empty cell of the ovarium.

2. C. horridum, Blume?; Miq. Fl. Ned. Ind. ii. 255? A shrub, more or less pubescent on the young shoots and under side of the leaves, and armed with straight axillary thorns. Leaves ovate, shortly acuminate, scarcely above $\mathrm{I}$ in. long, rounded at the base and almost sessile. Pedicels few, clustered in the axils of the leaves. Berries 1-seeded by the abortion of the other ovule.

Hongkong, Wright. A single specimen, with one fruit, agreeing with the specimens of C. horridum which we have from Java and Penang, but, as there are no flowers, it cannot be determined with certainty.

\section{MORINDA, Linn.}

Flowers usually several together, united at the base in a small head. Calyxlimb short, scarcely toothed. Corolla-tube cylindrical or slightly dilated at the top, usually short; lobes 5, or rarely 4, valvate in the bud. Anthers included in the tube or rarely exserted. Ovary 2- to 4-celled, with 1 erect or ascending ovule in each cell. Style exserted, with 2 stigmatic lobes, or rarely entire. Fruits of each flower-head usually united in one compound berry.Shrubs, small trees, or sometimes climbers. Stipules usually membranous and united at the base in a sheath within the petioles. Flower-heads on axillary or terminal single or clustered peduncles.

A considerable tropical genus, chiefly Asiatic or African, with 2 or 3 American species.

1. M. umbellata, Linn.; W. and Arn. Prod. Fl. Penins. i. 420. A trailing, diffuse or somewhat climbing shrub, glabrous or slightly pubescent on the young branches. Leaves on very short petioles, oblong, or the upper ones obovate, 1 to $2 \mathrm{in}$. long in most of the Chinese specimens, often twice as long in the more southern ones. Peduncles usually 4 to 6 together, form- 
ing a sessile terminal umbel, each peduncle 3 to 6 lines long, and bearing a single small head of 6 to 12 flowers. Ovaries quite united. Corolla scarcely 3 lines long; the tube straight, rather shorter than the lobes. Fruits forming a compound globular berry 4 to 6 lines diameter.

Common in Hongkong, Champion and others. Widely spread over tropical Asia, from Ceylon and the Peninsula to Sikkim, Khasia, Malacea, and the Archipelago, and northwards to the Philippines and Loochoo. The Hongkong specimens have mostly short and rather broad leaves, rarely surpassing 3 in. in length.

\section{LASIANTHUS, Jack.}

\section{(Mephitidia, Reinwo)}

Calyx-limb of 4 to 6 lobes or teeth. Corolla-tube usually dilated at the top, lobes 4 to 6 . Anthers included in the tube, or shortly exserted. Style divided at the top into 4 to 9 stigmatic linear lobes. Ovary 4- to 9-celled, with 1 erect ovule in each cell. Fruit a drupe, crowned by the calyx-lobes or teeth.-Shrubs or undershrubs, often smelling disagreeably. Stipules 1 on each side, pointed, with a broad base. Flowers small, in dense clusters or heads, all axillary in the Chinese species, terminal in some others.

A genus of several species, limited to tropical Asia and chiefly in the Archipelago.

Leaves glabrous above or pubescent. Bracts very small. Calyx-teeth very short. . . . . . * * * * * * . * *

Whole plant very hairy. Outer bracts longer than the flowers. Calyx-

teeth subulate .................. 2. L. cyanocarpa.

1. L. chinensis, Benth. A shrub, with the young branches flattened and shortly tomentose, the older ones terete and nearly glabrous. Stipules broad, the upper ones rather long. Leaves oblong, acuminate, 6 to $10 \mathrm{in}$. long, $1 \frac{1}{2}$ to $2 \frac{1}{2}$ in. broad, narrowed at the base into a petiole of 3 to 5 lines, with parallel veins conspicuous on both sides, diverging from the midrib, glabrous or nearly so above, slightly tomentose underneath. Flowers in dense sessile clusters. Bracts very small. Calyx minutely toothed. Corolla-tube about 2 lines long, hairy in the upper part; lobes 5 or 6 , about the length of the tube, very hairy outside, glabrous within. Drupes globular, pubescent, blue, 5 or 6 lines diameter.-Mephitidia chinensis, Champ. in Kew Journ. Bot. iv. 196.

In the Happy Valley, on Victoria Peak, etc., Champion, Wilford, Wright. Not received from elsewhere. It appears to be nearly allied to $L$. longifolius, Wight, and $L$. constrictus, Wight, from the Malayan Peninsula, but differs from both, as well_in the calyx asi n the pubescence.

2. L. cyanocarpus, Jack.; DC. Prod. iv. 452. An undershrub, with nearly simple, erect or ascending branches of about 2 feet, more or less thickly hirsute, as well as the bracts and under side of the leaves, with rusty spreading hairs. Leaves shortly stalked, oblong, acuminate, 6 to 8 in. long, hirsute or sometimes nearly glabrous on the upper side. Flower-clusters sessile, with several bracts, of which the outer ones are ovate or broadly lanceolate, very hairy, and often 1 in. long or more. Calyx-lobes linear-subulate, hairy, longer than the tube. Corolla scarcely longer than the calyx-lobes.- L. bracteatus, L. Roxburghii, and probably $L$. Jackianus, Wight in Mitchell, Calc. Journ. vi. 501, 502. 
In a ravine of Mount Parker, only one plant seen, Wilford. In Chittagong, Malacea, Penang, Singapore, and Sumatra, and also in the Nilgherries, if $L$. Juckianus be really the same.

\section{PSYCHOTRIA, Linn.}

Calyx-limb short, 5-lobed, 5-toothed or entire. Corolla-tube short; lobes 5, spreading, valvate in the bud. Anthers included in the tube or shortly exserted. Style with 2 short stigmatic lobes. Ovary 2-celled, with 1 erect ovule in each cell. Fruit a drupe, with 2 kernels, flat on the inner face and usually furrowed on the back.-Shrubs or small trees. Stipules 1 or 2 on each side, sometimes all united in a sheath within the petioles. Flowers in terminal cymes or very rarely axillary.

A large genus, ranging over the tropical regions both of the New and the Old World.

Erect shrub. Leaves 3 to 5 in. long . . . . . . . . . 1. P. elliptica. Trailing or spreading shrub. Leaves seldom 2 in. long . . . . . . 2. P. serpens.

1. P. elliptica, Ker; Bot. Reg. viii. 607 ; DC. Prod. iv. 509. An erect glabrous shrub. Stipules broad, membranous, obtuse, more or less connected in a sheath within the petioles, deciduous. Leaves elliptical-oblong, acuminate, 3 to 5 or rarely 6 in. long, narrowed into the petiole. $\mathrm{Pa}$ nicle terminal, sessile; the branches trichotomous and densely cymose at the top, shorter than the last leaves. Flowers about 2 lines long. Calyx very short, truncate; corolla almost campanulate, with a short obconical tube and spreading lobes. Drupes red. Albumen of the seeds much ruminate- $-P$. Reevesii, Wall.; DC. Prod. iv. 519. Grumilia Reevesii, Hook. and Arn. Bot. Beech. 193.

Very common on hillsides, Champion and others. Also on the mainland of S. China and in Malacca.

2. P. serpens, Linn.; DC. Prod. iv. 519. A much-branched, prostrate or trailing shrub, quite glabrous. Stipules broad, obtuse, shortly sheathing, but very deciduous. Leaves ovate or obovate-oblong, 1 to $1 \frac{1}{2}$ or rarely $2 \mathrm{in}$. long, narrowed into the petiole. Panicle terminal, peduncled, trichotomous, not large, and rather dense. Flowers rather smaller than in $P$. elliptica; calyx obtusely and minutely toothed. Corolla slightly mealy outside; the lobes rather longer than the broad tube, hairy in the throat. Berries small, white. Albumen slightly furrowed and pitted, but not really ruminate. $-P$. scandens, Hook. and Arn. Bot. Beech. 193.

Common in Hongkong, Champion and others ; also on the mainland of S. China, in Loochoo, and perhaps also Malacea, Griffith, and the Feejee Islands, American Exploring Expedition, but I do not feel certain of the specific identity of the two latter. Thwaites refers $P$. scandens, Hook, and Arn., to P. sarmentosa, Blume; but that synonym can only relate to the Ceylon plant called $P$. scandens by Gardner and some others, not to the Chinese plaut originally described under that name. The true $P$. sarmentosa, a widely distributed species from Ceylon and the Peninsula to the Archipelago, besides having longer and differently shaped more acuminate leaves, has the stipules (which can only be seen on young shoots) remarkably acuminate, as described by Miquel, and some slight differences in the flower.

\section{P 开DERIA, Linn.}

Calyx-limb small, 5-toothed, persistent. Corolla-tube broad; lobes short, valvate, and folded in the bud. Anthers included in the tebe Style with 2 
short stigmatic lobes. Ovary 2-celled, with 1 erect ovule in each. Fruit a berry, with a thin fragile rind.-Stems twining. Stipules 1 on each side. Cymes loosely dichotomous or trichotomous, either axillary or in terminal panicles.

A small genus, almost limited to tropical Asia.

1. P. fotida, Linn.; DC. Prod. iv. 471. A glabrous perennial twiner, woody at the base. Leaves stalked, ovate or lanceolate, $1 \frac{1}{2}$ to 2 in. long, usually somewhat cordate at the base, but very variable in width. Flowers sessile along the branches of loose dichotomous or trichotomous cymes, forming long loose panicles. Calyx small. Corolla 5 or 6 lines long, white or pale pink, mealy-tomentose outside, the throat hairy, the small spreading limb marked with a star-like pink spot. Berries globular or ovoid.

Mount Victoria, Champion. Common in sonthern Asia, extending from Mauritius, Ceylon, and the Peninsula northward to Khasia, China, and Japan, and eastward all over the Archipelago to Timor. The Chinese specimens have the small globose fruit figured by Gærtner, and I have seen the same in specimeus from Loochoo, from Japan, and from Amboyna. Many of the Indian ones have a much larger, ovoid, and somewhat flattened fruit, but without any perceptible difference in the foliage and flowers; and as the majority of specimens are not in fruit, there are no means of ascertaining how far that character may be constant.

\section{SPERMACOCE, Linn.}

Calyx-limb of 4 or sometimes only 2 small teeth. Corolla-tube usually short; lobes 4, spreading, valvate in the bud. Anthers usually exserted. Style entire, or with 2 short stigmatic lobes. Ovary 2-celled, with 1 ovule in each, laterally attached or ascending. Capsule small, separating into the 2 carpels, either septicidally or leaving more or less of the dissepiment free or attached to one of the carpels. Seeds marked on the inner face by a longitudinal furrow containing the hilum.-Herbs or rarely undershrubs. Stipules shortly sheathing, bordered with bristle-like teeth. Flowers small, clustered in the axils of the leaves or in sessile terminal heads.

A large genus, widely spread over the tropical and subtropical regions of both the New and the Old World, some species being amongst the commonest tropical weeds.

Flowers and fruits about 1 line long, in very dense whorl-like clusters or heads.

Leaves linear, or lanceolate, little veined . . . . . . . . . 1. S: stricta.

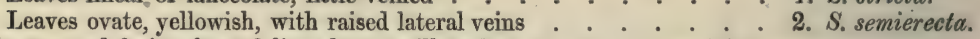
Flowers and fruits about 2 lines long, axillary but not numerous. Plant hispid :

1. S. stricta, Linn. fil.; DC. Prod. iv. 554. An erect or spreading annual, 6 in. to a foot high or rather more, glabrous or slightly and roughly pubescent; the branches 4-angled. Leaves sessile, linear, lanceolate or rarely oblong, 1 to $1 \frac{1}{2}$ in. long, acutely acuminate ; their lateral veins scarcely conspicuous, and having often in their axils 1 or 2 pairs of smaller leaves, which gives them the appearance of being whorled. Bristles of the stipules longer than their sheaths. Flowers not above 1 line long, in very dense axillary whorl-like clusters. Corolla shortly funnel-shaped. Capsule scarcely 1 line long, obovate-globular, slightly compressed, crowned by the 4 teeth of the calyx, more or less pubescent, separating into the 2 carpels, which open on 
the inner face without leaving any free dissepiment.-Bigelowia lasiocarpa, W. and Arn. Prod. Fl. Penins. i. 437, with the synonyms there adduced. Spermacoce pusilla, S. filina, and S. ramosa, Wall. Catal. n. 823, 830, and 831. Bigelowia gracilis, Miq. Pl. Hohen. Terr. Canar. Exs. n. 705 a. B. myriantha, Miq. Fl. Ned. Ind. ii. 334.

Hongkong, Wright. A common weed throughout E. India and the Archipelago, and probably also in eastern tropical Africa, more doubtfully in South America. To the above sy. nonyms should probably be added several others of which I have not seen authentic specimens; also, as more or less marked varieties,-B. lavicaulis, Miq. Fl. Ned. Ind. ii. p. 335, which has an almost perfectly smooth stem, and the corolla very small and cleft almost to the base, but perhaps the few that I have seen are abnormal; B. Roxburghiana, W. and Arn. Prod. i. p. 437 , which has constantly smooth stems, with the corolla very hairy inside at the throat, and Sp. Natalensis, Hochst. in Flora 1844, p. 555 (Diodia elongata, E. Mey. Pl. Drége Exs.), with precisely the characters of the narrow-leaved forms of B. Roxburghiana. B. Kleinii, W. and Arn. Prod. i. p. 437, which occurs in herbaria also under the name of $S p$. ocymoides, a small plant with all the leaves ovate, has a different look, but may be again, as suggested, a variety of the above; and the narrow-leaved B. eryngioides, $\mathrm{Ch}$. and Schl., from S. America, is very nearly allied to the commoner Indian forms of Sp. stricta.

2. S. semierecta, Roxb. Fl. Ind. i. 377, from his draving, $n$. 1333. A rather coarse annual of 1 or $2 \mathrm{ft}$., with long spreading 4 -angled branches, slightly rough on the angles but not hairy. Leaves ovate or ovate-lanceolate, acute, 1 to $1 \frac{1}{2} \mathrm{in}$. long; the lateral veins diverging from the midrib, very prominent and very rough to the touch. Bristles of the stipules longer than their sheaths. Flowers about 1 line long, in very dense, axillary, whorl-like, almost globular clusters. Capsules obovoid-globular, about 1 line long, crowned by the 4 teeth of the calyx ; the 2 carpels separating in 2 valves, leaving however more or less of the thin dissepiment free and persistent between them.-Borreria discolor, Bartl. in DC. Prod. iv. 545 ?; Benth. in Kew Journ. Bot. iv. 199.

Hongkong, Champion; and, if the synonyms are correct, also Sumatra and the Philippines. This is a much stiffer and coarser plant than $S$. stricta, with a yellowish tinge, and all the leaves broad, stiff, and very rough. I can find no corolla remaining on my specimens. The calycine teeth are very short. The dehiscence of the capsule is intermediate, as it were, between those of Borreria (Bigelowia) and Spermacoce proper. In the former the whole dissepiment splits asunder into the two cocci, each opening all the way up in a longitudinal slit; in Spermacoce proper the whole dissepiment is simple, and when the cocci separate, remains free or attached to one of the cocci ; in the present apecies a portion of the dissepiment in the centre, at the base, to about half-way up, is simple and free as in Spermacoce proper, the remainder splits and separates with the cocci as in Borreria; at least, so it is in a great majority of the capsules of my specimens; it may not be constantly so in the species.

3. S. hispida, Linn.; DC. Prod. iv. 555. A coarse, diffuse, littlebranched herb, roughly pubescent or hispid, 1 to $2 \mathrm{ft}$. long. Leaves obovate or the upper ones oblong, $\frac{1}{2}$ to $1 \mathrm{in}$. long or rarely more, obtuse, with few veins, sessile or the lower ones narrowed into a petiole of 1 to 3 lines. Bristles of the stipules rather longer than their sheath. Flowers usually about 3 lines long, sessile, 3 together, or rather more in each axil. Tube of the corolla longer than the calyx-teeth and dilated at the top, but varying considerably in size. Capsule ovoid, hispid, about 2 lines long, crowned by the 4 calyx-teeth, separating into the 2 carpels, 1 of which is always open on the 
inner face, whilst the other is usually closed by the thin dissepiment adhering to it.-S. articularis, Linn. fil.; DC. l.c. S. scabra, Willd., DC. l. c.

In waste places, Champion, Wright. A common weed throughout India, varying much, as observed by Wight and Arnott, in the length and thickness of the tube of the corolla, but as far as can be judged from herbarium specimens, which are so often without good corollas, these differences do not appear to correspond to any other characters.

\section{KNOXIA, Linn.}

Calyx-limb of 4 minute persistent teeth. Corolla-tube slender; lobes 4, valvate in the bud. Anthers scarcely exserted. Style with 2 short stigmatic lobes. Ovary 2-celled, with 1 pendulous ovule in each cell. Fruit small and dry; the 2 carpels either separating from the base upwards or falling off together, leaving a persistent filiform axis.-Herbs or undershrubs. Stipules 1 on each side, usually fringed with bristle-like teeth. Flowers in terminal cymes or corymbs; the branches often lengthened into one-sided spikes.

A small genus, limited to tropical Asia and Africa.

1. K. corymbosa, Willd.; W. and Arn. Prod. i. 439; Wight, Illustr. $t$. 128. A perennial, 1 to $2 \mathrm{ft}$. high, often almost woody at the base, more or less pubescent, and but little branched. Leaves oblong, lanceolate or rarely nearly ovate, 2 to $3 \mathrm{in}$. long. Flowers about $1 \frac{1}{2}$ lines long, numerous, in loose, terminal, dichotomous cymes. Capsule ovoid, about 1 line long, usually falling off entire from the filiform persistent axis.

Hongkong, Champion, Wright. Extends over tropical Asia, from Ceylon and the Peninsula to the Archipelago.

\section{GALIUM, Linn.}

Calyx completely combined with the ovary, without any visible border. Corolla rotate; the tube scarcely perceptible, with 4 spreading lobes, valvate in the bud. Anthers exserted. Style short, deeply 2-cleft. Ovary 2-celled, with 1 ascending or laterally attached ovule in each cell. Fruit small, dry, 2-lobed, indehiscent.-Herbs, with weak quadrangular stems. Leaves sessile, in whorls of 4,6 , or 8 , of which 2 are real leaves and the remainder stipules, although precisely similar in shape and size. Flowers small, in axillary or terminal trichotomous cymes or panicles.

An extensive genus, spread over the whole of the temperate regions of the globe, especially abundant in Europe and northern Asia, with very few tropical species, and those chiefly limited to mountain regions.

1. G. Aparine, Linn.; DC. Prod. iv. 608. A trailing or climbing annual, often several feet long, clinging by the recurved asperities or small prickles on the angles of the stems, and on the edges and midribs of the leaves. Leaves 6 or 8 in a whorl, linear or linear-lanceolate, often above an inch long. Peduncles axillary, rather longer than the leaves, bearing a loose cyme of from 3 to 8 or 10 small greenish-white flowers, with 3 or 4 leaves at the base of the cyme. Pedicels 2 to 4 lines long, straight or but slightly recurved. Fruits usually covered with hooked bristles, forming small very adhesive burrs.-G. sororium, Hance in Walp. Ann. ii. 734 .

In hedges, Hance, probably introduced from Europe, where, as well as in central and northern Asia, it is very abundant, and from whence it has been carried with cultivation to most parts of the globe. 


\section{ORDER LIX. COMPOSIT}

Flowers or florets collected together into a head surrounded by an involucre of several bracts, either in one row or imbricated in several rows, the whole having the appearance of a single flower. Receptacle on which the florets are inserted either naked or bearing chaffy scales or hairs or bristles between the florets. In each floret the calyx is wanting, or converted into a pappus or ring of hairs or scales on the top of the ovary. Corollas either all hermaphrodite tubular and 5- or rarely 4-toothed (heads discuid), or all hermaphrodite and ligulate, or those of the centre or disk tubular and hermaphrodite or male, and those of the circumference ligulate, forming a ray (heads radiate), or filiform and female. Stamens 5, inserted in the tube of the corolla; the anthers linear and united in a sheath round the style (except in Xanthium), often sagittate at the base, the basal lobes sometimes prolonged into fine points called tails. Ovary inferior, with a single erect ovule. Style filiform, usually divided at the top into two short stigmatic branches. Fruit a small dry nut or achene, crowned by the pappus or naked.-Herbs or shrubs, with alternate or opposite leaves, without stipules.

The most extensive family among flowering plauts, and represented in every quarter of the globe, and in every variety of station. In the following table the genera are, for convenience of reference, classed under artificial groups, not always corresponding with the tribes characterized in the text.

\section{$\S 1$. Heads homogamous, the florets all tubular and hermaphrodite.}

Leaves alternate.-

Heads many-flowered. Florets regular.

Involucre imbricate, in 2 or more rows.

Pappus of numerous plumose bristles.

Leaves and usually the outer involucral bracts prickly . 2. Cirsium.

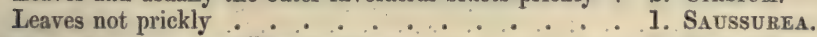

Pappus of numerous capillary bristles . . . . 3. Vernonia.

Involucre of 10 to 15 equal bracts in one row.

Involucre surrounded by smaller bracts at the base.

Style-branches with long points ...... 32. Grnura.

Involucre without outer bracts. Style-branches obtuse 33. SENEcio.

Heads 2- to 5-flowered. Florets slightly irregular.

Flower-heads clustered into compound heads, with a general

involucre. Pappus of stiff awns or scales . . . . . .

Flower-heads solitary, in a long spike. Pappus of plumose bristles.

4. Elephantopus.

Leaves opposite.

Receptacle naked. Achenes short.

Pappus of 3 to 5 short bristles, each tipped by a gland . . 5. Adenostemma.

Pappus of 5 to 10 stiff bristles, chaffy or dilated at the base . 6. Ageratum.

Pappus of numerous eapillary bristles . . . . ..... 7. Eupatorium.

Receptacle bearing scales between the florets. Achenes long,

with 2 to 5 stiff retrorsely hispid awns ........24. Bidens.

$\S$ 2. Flower-heads discoid, but heterogamous. Florets of the circumference slender and female, those of the disk tubular and hermaphrodite or male. Leaves alternate.

Pappus of numerous capillary bristles.

Florets of the circumference few, in 1 or 2 rows. Disk-florets

numerous. Anthers with double tails

17. INULA. 
Florets of the circumference very numerous. Disk-florets few.

Involucral bracts scarious, often coloured

31. Gnaphalium.

Involucral bracts herbaceous or subulate.

Anthers obtuse at the base (without tails).

Florets of the circumference ligulate, though slender, short and ereet . . . 12. ERIGERON.

Florets of the circumference all tubular and filiform . . 13. ConyzA.

Anthers with hair-like points (simple tails) at the base.

Flower-heads clustered or paniculate. Styles of the diskflorets all bifid

Flower-heads corymbose. Styles of the disk-florets often undivided . . . . . . . 15. Pluchea.

Pappus none, or very short.

Florets of the circumference few. Achenes obovate or rounded at the top. Erect herbs or undershrubs . . . . 30. ArTemisia.

Florets of the circumference very numerous. Achenes flat or concave at the top. Prostrate annuals.

Receptacle very convex.

Flower-heads racemose or paniculate. Style-branches in the disk-florets acute ..................

Flower-heads solitary. Style-branches in the disk obtuse 27. Grangea.

Receptacle flat or nearly so.

Florets of the circumference apetalous or nearly so.

Flower-heads terminal . . . . . . . .

Florets of the circumference with a corolla nearly as long as the style. Flower-heads leaf-opposed . , , 29. Mrriogrne.

§. Flower-heads monocious, the males globular, many-flowered, discoid; the females 2-flowered, with a prickly burr-like 2-celled involucre.

\section{\$ 4. Flower-heads heterogamous, radiating.}

Leaves opposite. Receptacle paleaceous.

Pappus none.

External involucral bracts linear-spathulate, spreading, glandular

External involucral bracts ovate or oblong, not glandular.

Disk-florets 4-toothed . . . . . . . . . 20. Eccipta.

Disk-florets 5-toothed . . . . . . . . 23. WoLLAstonia.

Pappus a little fringed cup . . . . . . . . . 22. WEDELIA.

Pappus of 1 to 3 slender deciduous awns . . . . . 23. Wollastonia.

Pappus of 2 to 5 persistent retrorsely hispid stiff awns. Achenes long . . . . . . .

Leaves alternate. Receptacle paleaccons.

Pappus of 2 or 3 stiff persistent awns. Anthers without tails. Achenes long . . . . . . . . . . . .

Pappus of several short pointed scales or awns. Anthers with
tails
18. ANISOPAPPUS.

Leaves alternate, Receptacle naked.

Pappus none or very short.

Achenes ending in a short beak. Flower-heads small. .

24. Bidens.

Achenes not beaked.

Receptacle very convex. Pappus of very short scales or bristles. . . . . . . . . . . . .

Receptacle flat or slightly convex. Pappus none, or a short

ring or cup

Pappus of numerous long hairs or capillary bristles.

No bilabiate florets. Anthers obtuse at the base (stem leafy).

Ray white or purple ............ 11. ASTER.

25. Glossogyne.

8. LAGENOPHORA.

10. Boltonia. 
Ray yellow.

Involuere imbricate in several rows . . . . . . 16. Solidago,

Involucre of a single row of equal bracts, with or without a few small outer ones . . . . . . . . . 33. Senecio.

Florets of the ray mostly with a small upper lip. Some of the others also bilabiate. Anthers with fine points or tails at the base (leaves all radical).

Involucral scales unequal, imbricate. Pappus reddish . . 35. Gerbera.

Involucral scales nearly equal, with a few outer shorter ones. Pappus white.

34. Farfugium.

$\S 5$. Heads homogamous, the florets all ligulate and hermaphrodite. Leaves alternate. Achenes tapering into a filiform beak, bearing the pappus at the top.

Involucre narrow, with few very unequal imbricated bracts . . 37. Lactuca.

Involucre many-flowered, of several nearly equal erect bracts, and smaller imbricated outer ones usually recurved. Achenes

Involucre small, of one row of erect equal bracts, and a few small

outer appressed ones. Achenes ribbed, but not muricate. . 39. Ixeris.

Achenes not beaked. Pappus sessile.

Involucre of a single row of nearly equal bracts, with a few small outer ones

Involucral bracts unequal, imbrieated

38. Taraxacum.

40. CREpis.

41. Sonchus.

\section{TRIBE I. CYNAROCEPHALAE.}

Leaves alternate, often prickly. Flower-heads discoid, the florets all tubular, hermaphrodite, and regular or nearly so, the lobes usually narrow. Anthers usually fringed or tailed at the base. Style usually slightly swollen at the base of the branches, which are narrow and obtuse, or slightly pointed.

\section{SAUSSUREA, DC.}

Florets all tubular and equal. Involucre imbricate, not longer than the florets, the bracts not prickly, the inner ones the longest. Receptacle bristly. Corolla regular, with 5 narrow lobes. Achenes glabrous. Pappus of several plumose bristles united in a ring at the base, with a few outer simple or short scales.-Perennial herbs, not prickly. Leaves alternate.

A considerable genus, spread over the hilly regions of the northern hemisphere, chiefly in the Old World.

Leaves green, upper ones entire. Flower-heads numerons, in a dense corymb. Outer pappus of 2 to 5 deciduous bristles . Leaves white underneath, all lyrate or pinnatifid. Flower-heads few. Outer pappus of several minute scales

\section{S. japonica.}

2. S. earthamoides.

1. S. japonica, DC. Prod. vi. 536. Stock perennial. Stem erect, nearly simple, 1 to $1 \frac{1}{2} \mathrm{ft}$. high, sulcate, and slightly pubescent. Leaves green and scabrous, or pubescent on both sides, linear or lanceolate, the lower ones stalked and more or less pinnatifid, 3 to $4 \mathrm{in}$. long, the upper ones smaller, narrow, and entire. Flower-heads in a dense flat terminal corymb, or, when the stem is branched, dispersed in a number of smaller corymbs. Involucre ovoid, about $\frac{1}{2}$ in. long, the numerous imbricate bracts all terminating in a.little orbicular scarious coloured appendage. Achenes striate, slightly curved. Outer 
pappus of 3 or 4 very deciduous slender awns, about half the length of the inner plumose one.-S. linearis, Champ. in Kew Journ. Bot. iv. 236.

Victoria Peak, Champion, Hance, Wright. Ranges from S. China to Japan. The flowerheads are rather larger, and the leaves usually more entire than in the Amoy specimens, and in De Candolle's figure of the Japanese plant, but they all appear to be forms of one species.

2. S. carthamoides, Benth. Root annual. Stem firm, erect, nearly simple, about $2 \mathrm{ft}$. high, sulcate and slightly cottony. Leaves deeply pinnatifid or lyrate, the lower lobes narrow, the terminal one broad, thin, green above, white and cottony underneath, 3 or 4 in. long; the upper ones few, with narrower lobes. Flower-heads few, on long peduncles. Involucre campanulate, 6 to 8 lines diameter, the numerous bracts linear-lanceolate, acute, slightly scarious at the edge. Achenes striate, slightly curved. Outer pappus of several very short scales, united in a minute oblique ring.-Aplotaxis carthamoides, DC. Prod. vi. 540. Serratula carthamoides, Roxb. Fl. Ind. iii. 407.

Saywan, Harland, Hance, also Wright. Not unfrequent in the hilly districts of northern and eastern India.

\section{CIRSIUM, Tournef.}

Florets all tubular and equal. Involucre imbricate, not longer than the florets ; the bracts, at least the outer ones, prickly-pointed. Receptacle bearing bristles between the florets. Anthers with the basal lobes slightly fringed or toothed. Achenes flattened, glabrous. Pappus of numerous plumose bristles united in a ring at the base, without any outer ones.

A large genus, spread over a great part of the globe, but chiefly in the temperate regions of the northern hemisphere. It is often considered as a section of Carduus, from which it only differs in the plumose hairs of the pappus.

1. C. chinense, Gardn. and Champ. in Kew Journ. Bot. i. 323. Rootstock said to be creeping as in $C$. arvense. Stems erect, 1 to $2 \mathrm{ft}$. high, simple or scarcely branched. Leaves linear or lanceolate, not decurrent, 2 to 4 in. long, bordered with irregular very prickly teeth, glabrous or slightly pubescent above, white-cottony underneath, or at length sometimes glabrous. Flower-heads solitary, on long peduncles, near an inch in diameter. Involucral bracts very numerous, the outer ones slightly prickly, the inner scarious and recurved at the tips. Florets purple, very numerous. Filaments hispid.C. oreithales, Hance in Walp. Ann. ii. 944.

Victoria Peak and other hills, Champion and others. Has been found also in Khasia.

\section{TrIBE II. VERNONIACEA.}

Leaves alternate.* Flower-heads discoid; the florets all tubular, hermaphrodite and regular or nearly so. Anthers obtuse at the base, without tails. Style not swollen or bulb-shaped below the branches, which are subulate and pointed.

\section{VERNONIA.}

Florets all tubular and equal. Involucre imbricate, not longer than the florets, the inner bracts the longest. Receptacle naked. Corolla regular, with

* The opposite-leaved Liaber and Pectidea are much better placed among Senecionidea. 
5 narrow lobes. Achenes mostly striate or angular, rarely cylindrical. Pappus of numerous capillary bristles, usually surrounded by an outer row of very short often scaly bristles, which are rarely entirely wanting.-Herbs, shrubs, or climbers. Leaves alternate. Flower-heads terminal or in the upper axils, in cymes or panicles or sometimes solitary.

A very numerous genus, widely spread over the warmer regions of the globe, but most abundant in America, where it extends beyond the tropics both to the northward and southward.

Annuals. Involucral bracts very pointed.

Panicles cymose, leafless. Achenes cylindrical, hairy, with a very short onter pappus ... . . . . . . . . . .

Panicles divaricate, leafy. Achenes angular, glabrous. Pappus very deciduous, without any outer row

1. V. cinerea.

2. V. chinensis.

Tall perennials. Involucral bracts more or less obtuse.

Erect softly villous plant. Involncral bracts very obtuse and cottony. Achenes glabrous, angular. Outer pappus very short.

Tall climber, slightly pubescent or rough. Involucral bracts rather obtuse. Achenes striate, pubescent. Outer pappus half as long as the inner

\section{V. solanifolia.}

4. V. Cumingiana.

1. V. cinerea, Less.; DC. Prod. v. 24. An erect annual, 1 to $1 \frac{1}{2}$ feet high, usually of an ashy-grey colour, owing to a minute pubescence on the stem, leaves, and involucres. Lower leaves stalked, ovate, oblong, or lanceolate, often irregularly toothed or sinuate, the upper ones few and narrow. Flowerheads small, on slender pedicels, forming a terminal, leafless, cymose panicle. Involucral bracts very pointed. Achenes cylindrical, scarcely striate, hairy. Pappus very white, the outer row very short, and sometimes reduced to very few bristles.

Frequent in waste places near Victoria, Champion and others. A common weed all over S. Asia, from Ceylon and the Peninsula to the Archipelago, extending northwards to Loochoo and Bonin, and eastwards to N. Australia.

2. V. chinensis, Iess.; Miq. Fl. Ned. Ind. ii. 18. An annual, like the last, but very spreading, and the ashy pubescence is often whiter and more cottony, especially on the under side of the leaves. Leaves usually ovate, on rather long stalks. Flower-heads at first ovoid, then globular, or nearly hemispherical, on short pedicels, clustered 2 or 3 together at the ends of the branches, forming a spreading leafy panicle. Florets numerous, purple. Involucral bracts finely pointed. Achenes short, 4- to 5-angled, glabrous. Pappus of white, very deciduous, bristles, without any outer row.-Cyanopis pubescens, Bl.; DC. Prod. v. 69.

In waste places, Champion, Hance, Wright. Common in S. Asia, from Ceylon and the Peninsula to the Archipelago, and extending northwards to Khasia, S. China and the Philippines.

3. V. solanifolia, Benth. in Lond. Journ. Bot. i. 486, and in Kew Journ. Bot. iv. 232. Stem tall and erect, apparently woody at the base, the branches and under side of the leaves thickly clothed with soft velvety or almost woolly hairs, which are shorter and less dense on the upper surface. Leaves stalked, ovate or ovate-lanceolate, 3 to 4 inches long, the lower ones sometimes broad and cordate. Panicle large, terminal, leafy at the base, crowded with numerous heads, containing each about 10 highly perfumed 
purple florets. Involucral bracts short, very obtuse and woolly or cottony. Achenes 4- to 5-angled, glabrous, the basal callus very prominent. Pappus of a dirty white, the outer row very short.

Abundant on the hills, Hinds, Champion, and others (Fortune, n. 175). Not known out of the island. It is however very near to the $V$. javanica, DC., which extends over the Archipelago and Ceylon, but that is generally much less hairy, and its achenes are distinctly striate and hairy, besides other minor differences.

4. V. Cumingiana, Benth. in Kew Journ. Bot.iv. 233. A tall climber' shrubby at the base, sometimes nearly glabrous, but usually rough with a very short rusty down, especially on the branches and under side of the leaves. Leaves shortly stalked, ovate or oval-oblong, scarcely acuminate, obtuse at the base, 3 to $4 \mathrm{in}$. long. Flower-heads rather large, in short panicles, either terminal or in the upper axils, each with about 20 purple florets. Involucral bracts nearly glabrous, rather obtuse, bordered with a thin pale edge. Achenes striate, slightly hairy. Pappus long and very prominent, of a rusty colour, the outer row about half as long as the rest.

On Victoria Peak, Champion, at Little Hongkong, Wilford, also Harland and Wright. Found also in the Philippine Islands, and is nearly allied to the E. Indian V. scandens, but that has the leaves narrowed at the base, the flower-heads smaller, etc.

\section{ELEPHANTOPUS, Linn.}

Flower-heads of 2 to 5 florets, compressed, and collected together in clusters or compound heads, surrounded by a few leafy bracts. Involucral bracts about 8, dry, stiff, alternately plane and conduplicate. Receptacle naked. Corolla with 4 narrow equal lobes, but deeper cleft on one side, so as to be somewhat palmate. Pappus of a few stiff bristles, somewhat dilated at the base.-Stiff herbs, with alternate leaves.

A genus of about a dozen American species, one of which is also spread over tropical Africa and Asia.

1. E. scaber, Linn.; DC. Prod. v. 86 ; Wight, Ic. t. 1086. Stock perennial. Stems stiff, erect, about a foot high, with a few forked spreading branches, more or less covered, as well as the leaves and involucres, with greyish hairs. Radical leaves 2 to 4 inches long, obovate-oblong, more or less crenate, and usually narrowed into a stalk at the base. Stem-leaves few and more sessile. Flower-heads closely clustered into terminal hemispherical compound heads, of near an inch diameter, surrounded by about 4 broadly cordate sessile leafy bracts. Involucral bracts narrow, very pointed, almost prickly.-E. carolinianus, Willd.; E. nudicaulis, Ell.; E. mollis, H. B. K. ; and E. Martii, Grah.; DC. Prod. v. 86.

Waste places, Champion, Hance, Wright. Common in the warmer regions of America, Africa, and Asia, extending in the Old World southward to North Australia, and northward, apparently not beyond South China. It varies everywhere, chiefly in the amount of hairiness, but is scarcely separable into distinct varieties.

\section{TRIBE III. EUPATORIACEA.}

Leaves oppoşite or rarely alternate. Flower-heads discoid; the florets all tubular, hermaphrodite, and regular. Style not swollen or bulbous-shaped 
below the branches, which are elongated, obtuse, and usually thicker or dilated upwards.

\section{ADENOSTEMMA, Forst.}

Flower-heads, florets, and style of Eupatorium. Achenes obovate-oblong, contracted at the base. Pappus of 3,4 , or 5 short stiff spreading bristles, each tipped by a globular or club-shaped gland.

A genus of a very few American species, one of which spreads all round the warmer zone of the globe,

1. A. viscosum, Forst.; DC. Prod. v. 111. Stem annual, erect or ascending, rooting at the base, and possibly renewed a second year by a creeping rootstock or by stolones, glabrous or glandular-pubescent, 1 to 2 feet high. Leaves few, opposite, stalked, from ovate to broadly triangular, usually coarsely toothed, from barely an inch long and rather thick and rough, to 3 or 4 in. long, thin and glabrous. Flower-heads hemispherical, 3 to 4 lines diameter. in a loose, spreading terminal 2 - or 3 -chotomous panicle, with very small leaves under the branches. Involucral bracts oblong, in about 2 rows. Florets numerous, often hairy outside. Achenes more or less muricate or rarely quite smooth.

Little Hongkong, Wilford. A common weed in the warmer regions of the globe, especially in the Old World, where it extends northwards to Japan and southwards to North Australia. The species should include all those published by De Candolle and others from the Old World, and at least the $\mathcal{A}$, brasiliense and $\boldsymbol{A}$. triangulare among the Ameriean ones.

\section{AGERATUM, Linn.}

Flower-heads, florets, and style of Eupatorium. Achenes angular. Pappus of 5 or 10 chaffy scales or bristles dilated at the base.

A genus of a small number of American species, one of which is spread all over the warmer regions of the globe.

1. A. conyzoides, Linn.; DC. Prod. v. 108; Hook. Ex. Flor. t. 15. An erect branching annual, 1 to 2 feet high, more or less hirsute with spreading hairs. Leaves opposite, stalked, ovate, crenate. Flower-heads rather small, in dense terminal cymes. Involucral bracts striate, pointed, in about 2 rows. Florets numerous, pale blue or white. Achenes black, smooth. Pappus of 5 lanceolate aristate chaffy scales, often serrate in the lower part.

Waste places, Hance, Seemann, $W$ right. A common weed, all over the warmer regions of the globe.

\section{EUPATORIUM, Linn.}

Flower-heads cylindrical, campanulate or hemispherical, with several or many florets. Involucral bracts imbricated, in 2 or more series. Receptacle flat or slightly convex, naked. Corolla tubular, with a campanulate 5-toothed limb. Branches of the style elongated, obtuse. Achenes 5-angled, without intermediate striæ. Pappus of a single series of slender, capillary bristles.-Perennial herbs or shrubs, or more rarely annuals. Leaves opposite or very rarely alternate. Heads mostly corymbose. Green parts of the plant often sprinkled with resinous glands. 
A very large American genus, with a few Asiatic species, one of which extends also over Europe.

Leaves mostly ovate. Involneral bracts obtuse.

Stem flexuose. Leaves rounded at the base . . . . . . 1. E. Reevesii

Stem ereet and strict. Leaves narrowed at the base. . . . 2. E. Wallichii.

Leaves mostly linear. Involucral bracts acute . . . . . . 3. E. Lindleyanum.

1. E. Reevesii, Wall.; DC. Prod. v. 179. Branches flexuose, slightly pubescent. Leaves opposite, shortly stalked, ovate, more or less coarsely toothed, rounded or slightly cordate at the base, glabrous or nearly so. Flowerheads in compact terminal cymes, each head containing 5 or 6 florets. Involucral bracts about 10, very unequal, oblong, obtuse, thin and dry at the edges. Achenes slightly hairy.- E. chinense, Thunb. Fl. Jap. 308, and Linn.?

Hongkong, Champion. This is undoubtedly the same us the Loochoo plant gathered by Beechey and afterwards by Wright, and I agree with A. Gray that it answers to Thunberg's description of his $E$. chinense, but De Candolle gives that name to a plant with acute involucral bracts. It is possible that the present species may prove to be a variety of the follow. ing, E. Wallichii.

2. E. Wallichii, DC. Prod. v. 179. Root-stock perennial. Stem erect, strict, and slightly pubescent, usually 2 or 3 feet high. Leaves like those of $E$. Reevesii, except that they are always narrowed or wedge-shaped at the base. Flower-heads of $\boldsymbol{E}$. Reevesii, but the involucral bracts are usually fewer, and there are occasionally only 4 florets. Achenes usually glabrous.-E. Punduanum, Wall., and $E$. nodiflorum, Wall., DC. l. c.

Hongkong, Harland. I saw a single specimen of what appeared to me to be this species in his collection, but have not now an opportunity of comparing it with those from the adjacent continent which I now describe. It is common in the mountain districts of Nepal, Khasia, and Sikkim, and is also Fortune's n. A.30 and A.41 from Amoy. It is very closely allied to the undivided-leaved varieties of the widely spread $E$. cannabinum.

3. E. Lindleyanum, DC. Prod. v. 180. Stem erect, nearly simple, 1 to $1 \frac{1}{2} \mathrm{ft}$. high, more or less pubescent. Leaves nearly sessile, linear or linear-oblong, obtuse, toothed, 1 to $1 \frac{1}{2}$ in. long. Flower-heads with 5 or 6 florets in each, in a compact terminal cyme; the leaves at its base small and few. Involucral bracts about 10 , very unequal, as in $E$. Reevesii, but acute or acuminate, especially the inner ones. Achenes slightly hairy.

Victoria Peak, Champion, Hance, Seemann, Wright. Also in the Philippine Islands, Cuming; in E. Tartary, Harland; and A. Gray refers to it also the E. hyssopifolium, Thunb. (not Linn.), from Japan.

TRIBE IV. ASTEROIDEA. "

Leaves alternate or very rarely opposite. Flower-heads either heterogamous or diœcious; the female florets ligulate or filiform, the hermaphrodite or males tubular and 4-or 5-toothed; or very rarely the heads are discoid, with all the florets hermaphrodite. Style not swollen above; the branches in the hermaphrodite florets flat or flattish; the stigmatic lines conspicuous and not confluent.

\section{LAGENOPHORA, Cass.}

Flower-heads heterogamous. Ray-florets ligulate, in one or few series, spreading, not yellow. Disk-florets numerous, hermaphrodite, tubular. In- 
volucral bracts imbricate, in about 2 series. Receptacle convex or nearly flat, naked. Achenes compressed, obovate-oblong, suddenly narrowed into a short beak at the top. Pappus none.-Small herbs. Leaves radical or on very short stems. Scapes single-headed.

A genus of about ten species, natives of the south temperate zone and chiefly Australia, one only inhabiting also southern and eastern Asia.

1. I. Billardieri, Cass. ; DC. Prod. v. 307. Root-stock emitting several thick, almost tuberous, cylindrical fibres. Leaves radical or on a very short stem, oblong or obovate, sinuately toothed, pubescent, seldom above 1 in. long. Scape slender, 3 to $4 \mathrm{in}$. high, often with 1 or 2 minute scale-like leaves. Flower-head scarcely 2 lines diameter. Involucral bracts linear. Rays very small, in 2 or 3 rows. Achenes obovate-oblong; the beak slightly glandular.-Bellis stipitata, Labill. Pl. Nov. Holl. t. 205. L. sundana, Miq. Fl. Ned. Ind. ii. 32. L. Harveyi, Thw. Enum. Ceyl. Pl. 162.

Hongkong, Champion, Wright. A native of south-east Australia, found also in Ceylon, eastern Bengal, the Archipelago, and China. I have little doubt that this is Labillardière's plant, and it should therefore retain Cassini's name in preference to that of $L$. pachyrhiza, given it by F. Müller. The purely Australian form, with a much larger flower-head and broad achenes, more particularly described by J. D. Hooker (Fl. Tasm. i. 188), may be a distinct species.

\section{DICHROCEPHALA, DC.}

Flower-heads heterogamous. Florets all tubular, those of the circumference in many rows, female, small and slender, those of the disk hermaphrodite, with campanulate corollas. Involucral bracts small, in 1 or 2 series. Receptacle very convex, naked. Style-branches in the disk-florets lanceolate, pointed. Achenes flattened, bordered with a callous margin. Pappus none, or in the disk consisting of a few minute hairs.-Branching herbs. Leaves alternate.

A genus of a very few S. Asiatic, or African, or Australian species.

1. D. latifolia, DC. Prod. v. 372; Wight, Ic. t. 1096. An erect or spreading annual, 1 to $1 \frac{1}{2} \mathrm{ft}$. high, pubescent or nearly glabrous. Leaves stalked, undivided or lyrate; the terminal lobe broadly ovate, coarsely toothed. Flower-heads few, very small, nearly globular, forming short terminal divaricate panicles. Florets very numerous and minute.-D. capensis, DC. 1. c. 371, and D. sonchifolia, DC. l. c. 372 .

Hongkong, Hance. A common weed in the warmer parts of Asia and Africa, extending northward to Loochoo, eastward to the Arehipelago, and southward to Port Natal.

\section{BOLTONIA, L'Hér.}

Flower-heads, involucres, and florets of Aster. Receptacle very convex or conical. Style-branches flat; the appendages lanceolate or trianyular. Achenes of the disk very flat, with a prominent callous or wing-like margin, those of the ray often 3-angled. Pappus of several minute setose or almost chaffy bristles, 2 or 3 (seldom 4) of them elongated into short stiff awns, and all often very deciduous.-Perennial, glabrous or scabrous, paniculately branched herbs. Leaves alternate.

A small genus, chiefly N. American, with two or three E. Asiatic species, including Calimeris incisa, DC. (Heteropappus, Zucc.), but not the other species of Calimeris known to 
me. The latter (including $C$. ciliata, A. Gray) have the setose pappus of Aster, although short, and should all perhaps be reunited with that genus.

1. B. indica, Benth. Root-stock slender and creeping, or perhaps annually renewed by stolones. Stem 1 to $1 \frac{1}{2} \mathrm{ft}$. high, divaricately branched, somewhat scabrous. Leaves oblong-lanceolate, mostly entire and small, the lower ones often broader, with a few coarse or small and glandular teeth. Heads terminating the slender leafy branches. Involucres about 3 lines diameter; the bracts rather broad, in 2 or 3 rows, with slightly herbaceous tips. Pappusscales very minute, slightly connected at the base, all aristate; the 2 or 3 longest sometimes half the breadth of the achenes.-Asteromea indica, Blume ; DC. Prod. v. 303; Miq. Fl. Ned. Ind. ii. 29. Hisutsua cantoniensis, DC. Prod. vi. 44. Hisutsua serrata, Hook. et Arn. Bot. Beech. p. 265.

Hongkong, Hance. Apparently common about Canton, and extending to Loochoo in the north and Java in the south, but in some instances said to be introduced. I do not find, even in the Java specimens, the achenes 4-angled as described by Miquel, nor the scales of the pappus setaceo-multifid as described by DC. and others. That can only be said of the pappus taken as a whole.

\section{ASTER, Linn.}

Flower-heads heterogamous. Florets of the ray ligulate, in a single series, spreading, not yellow. Disk-flowers numerous, hermaphrodite. Involucral bracts imbricated, in 2 or more series. Receptacle flat, usually honeycombed, but not chaffy. Achenes usually compressed. Pappus of numerous, often unequal, scabrous capillary bristles.-Herbs mostly perennial. Leaves alternate or radical. Heads corymbose or paniculate, rarely racemose or solitary. Ray white, purple, or blue.

A considerable genus, widely distributed over the northern hemisphere, especially abundant in North America, and extending also into the hilly or temperate regions of the southern hemisphere.

Flower-heads hemispherical, on peduncles as long or longer than themselves.

Heads simple, on long peduncles. Involucral bracts acute . . . 1. A. striatus.

Heads corymbose. Involucral bracts obtuse . . . . . 2. A. trinervius.

Flower-heads turbinate-campanulate, nearly sessile.

Involucral bracts acute .............. . . 3. A. brevipes.

Involucral bracts obtuse . . . . . . . . . . 4. A. baccharoides.

1. A. striatus, Champ. in Kew Journ. Bot. iv. 233. Stock perennial. Radical leaves obovate or oblong, $1 \frac{1}{2}$ in. long, contracted into a stalk at the base, sprinkled with a few long hairs. Stems divaricately branched, scarcely a foot long, rough with short spreading hairs. Stem-leaves few, narrow, and mostly stem-clasping and erect. Flower-heads hemispherical, few, on long peduncles, forming an irregular spreading panicle. Involucral bracts acute, thin on the edge, in about 2 or 3 series. Style-appendages rather broad. Achenes hairy. Pappus-bristles nearly equal.-Dollingeria trichocarpa, DC. Prod. v. 263.

Hongkong, Champion, Wright; and on the adjacent continent. Not known out of S. China. Its nearest ally is perhaps $\boldsymbol{A}$. altaicus, Willd., which has not been found nearer than Amoy.

2. A. trinervius, Roxb.; Don, Prod. Fl. Nep. p. 177. Stock perennial. Stems erect, 1 to 3 feet. Leaves ovate to obovate or oblong, acute, 
or in the Hongkong specimens mostly obtuse, coarsely toothed, narrowed at the base, the lower ones stalked, all very scabrous, and occasionally pubescent underneath, usually triplinerved. Panicle terminal, corymbose, rather loose, the peduncles mostly about the length of the heads. Involucre hemispherical or subcampanulate, the bracts all obtuse and thin on the edges, in 2 or 3 rows. Style-appendages narrow. Achenes flat, hairy. Pappus rusty-colour, a few of the bristles very much shorter than the others.-Diplopappus asperrimus, DC. Prod. v. 277, with the syn. D. laxus, Benth. in Lond. Journ. Bot. i. 487, and Kew Journ. iv. 233. Aster Benthami, Steetz, in Seem. Bot. Her. 385.

On rather barren hills, Champion; Mount Gough, Wilford; also Hance. Frequent in N. India, from Nepal to Sikhim and Khasia, extending in China to Shanghai and Chusan.

3. A. brevipes, Benth.,n.sp. An erect branching perennial or undershrub. Leaves oblong or obovate, more or less toothed, obscurely triplinerved and scabrous, more like those of $A$. trinervius than of $A$. baccharoides. Flowerheads as in the latter species, few, on short peduncles or nearly sessile at the ends of the branches, and turbinate-campanulate; but the involucral bracts differ from both species in being all acute. Pappus of $A$. baccharoides.

Hongkong, Wright; and a fragment in Champion's collection. It is possible that better specimens may show it to be a remarkable variety of $A$. baccharoides.

4. A. baccharoides, Steetz in Seem. Bot. Her. 385. Stem shrubby at the base and branching. Leaves rather crowded, oblong-lanceolate to obovate-oblong, entire or slightly toothed, narrowed at the base, triplinerved, very scabrous on the upper side. Flower-heads few, sessile or on very short peduncles, crowded at the summit of the branches. Involucre turbinate-campanulate; the bracts numerous, in several rows, obtuse, thin at the edges. Style-appendages broadly lanceolate. Achenes flattened, hairy. Pappus dirtywhite, the short outer bristles very few or sometimes none--Diplopappus baccharoides, Benth. in Lond. Journ. Bot. i. 487, and in Kew Journ. Bot. iv. 233.

Abundant on barren hills in the island. Also on the adjacent continent, but not known out of S. China.

\section{ERIGERON, Linn.}

Flower-heads heterogamous. Florets of the ray ligulate, in several series, not yellow, very narrow, either longer than the involucre and erect or spreading, or shorter and filiform. Disk-florets numerous or few, hermaphrodite. Involucral bracts numerous, narrow, in 1 or 2 nearly equal series, or rarely imbricate; in several unequal series. Receptacle flat or slightly convex, not chaffy. Style-branches narrow, the appendages lanceolate. Achenes compressed, usually pubescent. Pappus of copious capillary nearly equal bristles. - Herbs. Leaves alternate or radical. Heads corymbose or paniculate, rarely solitary, usually smaller than in Aster.

A large genus, ranging over the greater part of the globe, but chiefly in the temperate regions of the northern hemisphere. The following species belong to a section (Cienotus) in which the very slender female florets are hid in the pappus, either all really ligulate or the inner ones, intermediate between the outer ligulate florets and the disk, are tubular and filiform as in Conyza. This section includes some other weeds of warm countries which may possibly introduce themselves into Hongkong, especially the $E$. canadense and $E$. bonariense. 
Annual. Leaves narrow, sessile : . . . . . . . 1. E. linifolius. Tall perennial, often scandent. Leaves stalked, ovate . . . . . 2. E. pyrifolius.

1. E. linifolius, Willd. Spec. iii. 1955. An erect annual, $1 \frac{1}{2} \mathrm{ft}$. high, more or less clothed with soft spreading hairs. Radical leaves stalked, oblong, often coarsely toothed or almost pinnatifid. Stem-leaves sessile, linear, entire and pointed. Flower-heads small, hemispherical, peduncled, forming a short oblong terminal panicle. Involucral bracts narrow-linear, acute, in about 2 or 3 nearly equal series. Female florets very numerous, not so long as the pappus, filiform, but at least the external ones expanded at the top into a minute narrow ligula. Achenes flat, pubescent. Pappus dirty-white or rustcolour.-Conyza ambigua, DC. Prod. v. 381. Erigeron ambiguus, Sch. Bip. in Phyt. Canar. ii. 208.

Common on roadsides and in the town of Victoria, Champion and others. Most abuudant in S. Europe and the Mediterranean region generally, but now naturalized in various parts of the globe, where it has been probably carried out with Europeans. Less common, however, within the tropics than the $\bar{E}$. bonariense, which is a taller plant with smaller and more numerous heads.

2. E. pyrifolius, Benth. A perennial or undershrub, 3 to $6 \mathrm{ft}$. high, the branches weak and often scandent, covered as well as the under side of the leaves with a minute rusty pubescence or rarely nearly glabrous. Leaves stalked, ovate, acuminate, entire or slightly toothed, 2 to 3 in. long. Flowerheads numerous, in a broad terminal leafless panicle. Female florets as in E. linifolius. Involucral bracts linear, nearly obtuse, in several unequal series. Achenes slightly pubescent. Pappus soft and pale rust-colour.-Conyza pyrifolia, Lam. Dict. ii. 89. Microglossa volubilis, DC. Prod. v. 320.

At the estuary at West Point, Wilford. Found usually near the seacoast at various points from Eastern Africa and Madagascar to Ceylon and the Indian Archipelago.

\section{CONYZA, Linn.}

Flower-heads heterogamous. Florets all tubular, the outer ones very numerous, in several rows, female and filiform, those of the disk usually few, hermaphrodite and broader. Involucres, styles, achenes, and pappus as in Erigeron.-Herbs, with the habit nearly of the section Canotus of Erigeron, or of some Blumeas, differing from the former in the total absence of ligulate florets, from the latter in the want of tails to the anthers.

The genus as above defined, and as understood by De Candolle, comprises a considerable number of species dispersed over the warmer parts of the globe. Among them the C. cogyp. tiaca, L., which extends to the adjacent continent; and perhaps some others may find their way to Hongkong with other tropical weeds.

1. C. veronicæfolia, Wall.; DC. Prod. v. 382. Stems ascending from a hard perhaps perennial base, nearly simple, about $1 \mathrm{ft}$. high, pubescent with short spreading hairs. Lowest leaves stalked, obovate or oblong, coarsely toothed, intermediate ones narrowed but stem-clasping at the base, upper ones distant, lanceolate or ovate, all stem-clasping. Flower-heads not numerous, in dense terminal corymbs or clusters. Involucral bracts narrow and very pointed. Outer filiform florets very numerous, the slender corolla not above half the length of the style, which attains the length of the pappus and involucre. Disk-florets few. 
About.Victoria, Wilford. Extends in northern India from Kamaon and Nepal to Sikkim and Khasia.

\section{BLUMEA, DC.}

Flower-heads heterogamous. Florets all tubular, the outer ones very numerous, in several rows, female and filiform, those of the disk usually few, hermaphrodite and broader. Involucres imbricate, the bracts in several rows, the inner ones linear and pointed. Anthers with short fine simple tails. Style-branches filiform. Receptacle nearly flat, naked. Achenes usually somewhat compressed, striate or ribbed. Pappus of numerous capillary bristles, in a single series.-Annual or perennial herbs, sometimes halfclimbing. Leaves alternate. Flower-heads in terminal pyramidal or oblong panicles, sometimes contracted, spike-like or clustered.

A considerable genus, confined to the warmer regions of the Old World, some of them ubiquitous and variable weeds, upon which a large number of spurious species have been fabricated.

Flower-heads all distinctly pedunculate.

Stems winged. Flower-heads ovoid, nodding. . . . . . . 1. B. alata.

Stems not winged.

Half-trailing perennial. Leaves glabrous. Flower-heads few, 8-9 lines diameter . . . . . . . . . . . . . . . .

Erect annual. Leaves pubescent. Flower-heads numerous, about 4 lines . . . . . . . . . . . . .

Flower-heads, at least the upper ones, sessile and clustered. Annuals.

Leaves oblong or obovate-oblong, the upper ones sessile. Involucre about 4 lines long $: C^{\circ} \cdot 0^{\circ} \cdot$

Almost all the leaves stalked and broadly obovate. Involucre 2-3 lines.

Leaves rather firm. Panicle oblong, deuse ..... . . . 5. B. lacera.

Leaves thin and membranous. Panicle looser. . . . . B. B. Wightiana.

1. B. alata, $D C$. Prod. v. 448 ; Wight, Ic. t. 1101 . A tall stiff erect branching perennial, covered with a short rusty or dingy, often glandular, pubescence. Leaves undivided, elliptical or oblong, toothed, forming wings along the stem by their decurrent margins. Flower-heads on short peduncles, nodding, forming a terminal oblong or pyramidal leafy panicle. Involucre near 5 lines long, ovoid, the scales firmer and broader than in the following species, and more like those of a Pluchea.

Hongkong, Seemann, Hance. Found in easteru Africa down to Port Natal, in Ceylon, the Indian Peninsula, and the hilly districts of northern India.

2. B. chinensis, $D C$. Prod. v. 444. A tall weak or trailing branching perennial, glabrous, except a minute rusty pubescence on the upper part of the stem and on the panicle. Leaves shortly stalked, not decurrent, oblong; acuminate, 3 to 4 in. long, with a few small callous teeth, green on both sides. Flower-heads pedunculate, few, broad, erect, in a terminal leafless panicle. Involucres 4 to 5 lines long, the outer bracts lanceolate, the inner linear. Styles and anthers protruding much beyond the florets and the white pappus. Style-branches filiform, acute, as in Vernonia.

Tolerably common, trailing in ravines, Champion, Hance, Wright, Wilford. Also in Penang and Java.

3. B. glandulosa, DC. Prod. v. 438. An erect annual, often 2 or $3 \mathrm{ft}$. high, and more or less covered with a glandular viscous pubescence. Lsaves 
ovate or obovate, coarsely toothed, rather thin, green on both sides, the lower ones often 3 to $5 \mathrm{in}$. long and almost lobed at the base, with long stalks, the upper ones smaller and narrower, but all stalked. Flower-heads about 4 lines long, all pedunculate in the Hongkong specimens, the upper ones nearly sessile and clustered in some $\mathrm{S}$. Indian ones, forming a large pyramidal panicle often a foot long. Style-branches in this and the three following species linearfiliform, as in the two last, but somewhat obtuse.

Roadsides at Aberdeen, Wilford. A south Indian species, extending from Ceylon and the Peninsula to Chittagong and the Philippines, and probably spread over the Indian Archipelago. The Hongkong specimens agree precisely with those of the var. $\beta$, Thwaites (Enum. Ceyl. Pl. 163), which is taller and less glandular than usual, although evidently viscid when fresh.

4. B. hieracifolia, DC. Prod.v. 442; Wight, Ic.t. 1099 (a dwarfform). An erect stiff almost simple annual, 1 to $2 \mathrm{ft}$. high, more or less tomentose or villous, but not viscid. Leaves oblong, irregularly and rather sharply toothed, the lowest nearly obovate, 2 to $3 \mathrm{in}$. long and stalked, the others sessile, though narrowed at the base, the uppermost almost lanceolate. Flowerheads about 4 lines long, mostly sessile and clustered, the lower clusters distant, the upper ones forming a terminal leafy spike, or seldom branching into an oblong terminal panicle. Involucres always tomentose, the bracts linear and acute, but always broader than in the two following species.

Hongkong, Champion, Hance, Wright. Common all over southern Asia from Ceylon and the Peninsula to the Archipelago, extending northwands to Assam, the Philippines, S. China, and Formosa.

This as well as the two following are very variable species, and it is probable that the 55 species classed by De Candolle under the Paniculata, Senecioniflor $a$, and Fasciculaftora, and among which they are included, might be reduced to about 10 , which, from good specimens, would be fairly distinguishable from each other. Of the B. hieracifolia there are three principal forms among the Hongkong specimens :-

Var. a. glabrescens. Tall, stiff, slightly branched; leaves rather rigid and glabrous on both sides.-B. crinita, Steetz in Seem. Bot. Her. 387; but perhaps not of Arnott, for the Ceylon. plant of that name may be a distinct species.

Var. $b$. tomentoso-villos $a$. The old leaves pubescent or nearly glabrous above, more densely villous underneath. - B. javanica, Zoll. ex parte, Benth. in Kew Journ. Bot. v. 234.

Var. $c$. holosericea. Under side of the leaves and panicles thickly clothed with silky or almost woolly white hairs, $-B$. holosericea, DC. Prod. v. 442.

5. B. lacera, $D C$. Prod. v. 436. An erect annual, 1 to $2 \mathrm{ft}$. high, simple or slightly branched, but not so stiff as $B$. hieracifolia, more or less clothed with soft whitish hairs or pubescence. Leaves all stalked, obovate, ovate, or rarely oblong, coarsely toothed, the lower ones often somewhat lyrate. Flowerheads seldom above 3 lines long, and often smaller, very numerous, in narrow oblong dense panicles, leafy at the base, the upper ones of the short branches sessile and clustered. Involucral bracts usually very narrow.

Common in paddy-fields and waste places, Wilford. One of the commonest weeds all over East India, extending westward into tropical Africa and down to Port Natal, and eastward through the Archipelago to North Australia.

6. B. Wightiana, $D C$. Prod. v. 435. Closely allied to B. lacera, and probably, as suggested by Thwaites, a mere variety. It is more slender and more frequently branched, the leaves are broader and thinner, the inflorescence looser, and the involucres still smaller, often not exceeding 2 lines.

Hongkong, Harland, Hance. Equally common with $B$. lacera, and as widely distributed 
over tropical and subtropical Africa (B. Dregeana, DC., and B. Dregeanoides, Sch. Bip.) and southeru Asia to North Australia.

\section{PLUCHEA, Less.}

All the characters of Blumea, except that the style of the disk-florets is usually (not always) entire or minutely 2-toothed, the involucral bracts are usually broader and more obtuse, and the habit is different, the flower-heads always forming terminal, almost leafless corymbs. Styles of the female florets, and occasionally but rarely in the disk also, with 2 subulate branches, as in Blumea.

The genus comprises several N. and S. American species, a very few from Africa and S. Asia, and some Australian ones.

1. P. indica, Less.; DC. Prod.v. 451; Wight, Illustr.t. 131. A branching shrub of about $3 \mathrm{ft}$., either glabrous or covered with a minute glandular aromatic pubescence. Leaves shortly stalked, ovate or oblong, 1 to $2 \mathrm{in}$. long, with a few distant pointed teeth. Flower-heads in dense sessile terminal corymbs, seldom above 3 in. diameter. Involucre ovoid, about 3 lines long; the outer bracts short and very obtuse, passing into the inner linear ones which are almost acute. Female florets very numerous. Disk-florets seldom above 6 , often sterile.

Hongkong, Hance, Wright. Extends from eastern Bengal and the Malayan Peninsula over the Archipelago to N. Australia, and northward to the Philippines and S. China. In some specimens I find the styles of all the disk-flowers entire, as in the American species, in others I find several of them branched, as described by Lessing. In the $P$. tomentosa and $P$. Wallichiana, they are always branched, but these species have the pappus-bristles of the disk-florets shortly plumose, and should be referred to Berthelotia. The original Berthelotia indica has the anthers as much tailed as Pluchea indica.

\section{SOLIDAGO, Linn.}

Flower-heads heterogamous. Florets of the ray ligulate, spreading, yellow like the disk, usually few. Disk-florets hermaphrodite, tubular, 5-toothed. Involucres ovoid or narrow, the bracts imbricated, very unequal, in several series. Receptacle naked. Style-appendages lanceolate. Achenes terete or slightly compressed, ribbed. Pappus of numerous capillary, nearly equal bristles.-Perennial herbs. Flower-heads in terminal or axillary racemes, clusters, or short panicles, rarely corymbose.

A large North American genus, of which a single species spreads across northern Asia into Europe.

1. S. Virga-aurea, Linn.; DC. Prod.v. 338. Stock perennial. Stems erect, strict, nearly simple, from a few inches to about $2 \mathrm{ft}$. high. Lower leaves stalked, ovate or oblong, slightly toothed; upper ones narrower, smaller, and more entire. Flower-heads solitary or 2 to 4 together on short axillary peduncles, forming a terminal narrow oblong or elongated leafy panicle. Involucral bracts narrow and acute. Ray-florets about 8.-Amphirhapis leiocarpa, Benth. in Lond. Journ. Bot. i. 480, and in Kew Journ. Bot. iv. 234.

Abundant in ravines, Champion and others, but only the variety with glabrous achenes. The species extends from the western or mountainous portions of N. America across the Asiatic continent, all over Europe. In Europe the achenes are almost always pubescent; in 
$\mathrm{N}$. India this variety (Amphirhapis pubescens, DC.) is also common as well as a glabrousfruited one, which sometimes is precisely similar to the Chinese specimens, sometimes acquires the luxuriant northern form described as $S$. thyrsoidea, E. Mey.

\section{INULA, Linn:}

Flower-heads heterogamous. Florets of the circumference female, yellow like the disk, either ligulate and radiating, or shorter than the involucre, and tubular or irregular. Disk-florets hermaphrodite, tubular, 5-toothed. Involucral bracts imbricate, very unequal, in several series. Receptacle naked. Anthers with double tails, often fringed. Style-branches linear, somewhat flattened. Achenes nearly cylindrical or 4-angled. Pappus of copions capillary bristles, in a single series.-Perennial stiff herbs, or rarely annuals. Leaves alternate, often stem-clasping, undivided. Flower-heads terminal, solitary or corymbose.

A considerable genus, spread over the northern hemisphere in the Old World, chiefly in temperate Asia and Europe, with very few tropical species.

1. I. Cappa, DC. Prod. v. 469. A shrub or undershrub 3 to $4 \mathrm{ft}$. high. Branches firm, hairy or woolly. Leaves sessile or very shortly stalked, from narrow oblong to nearly obovate, 3 to $4 \mathrm{in}$. long, slightly toothed, green and glandular-scabrous above, thickly silky hairy or woolly underneath. Flowerheads in dense corymbs, either terminal or in the upper axils. Involucres ovoid, 3 to $3 \frac{1}{2}$ lines long, the outer bracts short, obtuse, and tomentose. Flowers yellow, sweetly perfumed. Florets of the circumference shorter than the involucre, unequally 3 -toothed.-I. oblonga and I. pseudocappa, DC. 1. c. 469. Duhaldea chinensis, DC. 1. c. 366 ; Steetz in Seem. Bot. Her. 388. Vernonia congesta, Benth. in Lond. Journ. Bot. i. 487, and Kew Journ. Bot. iv. 232. Moquinia eriosematoides, Walp. Rep. vi. 317.

Very abundant in Hongkong, Champion and others. Coinmon in northern India, from Deyra-Dhoun to Sikkim, Khasia, and the hills about Ava.

\section{ANISOPAPPUS, Hook. and Arn.}

Flower-heads heterogamous. Florets of the circumference female, yellow like the disk, ligulate, in a single series. Disk-florets tubular, hermaphrodite, 5-toothed. Involucral bracts imbricate, in few series. Receptacle chaffy. Anthers with simple hair-like tails. Style-branches short, almost club-shaped, obtuse. Achenes narrow, ribbed. Pappus of chaffy pointed scales, with 3 to 5 longer unequal stiff awns. Leaves alternate.

The genus consists of a single species.

1. A. chinensis, Hook. and Arn. Bot. Beech. 196. A stiff, erect, pubescent herb, apparently perennial. Leaves shortly stalked, from ovate-lanceolate to narrow-oblong, obtuse, coarsely toothed, $1 \frac{1}{2}$ to 2 in. long. Flowerheads few, on short rigid peduncles, forming a terminal corymb. Involucre hemispherical, about $\frac{1}{2}$ in. diameter; the bracts linear, obtuse, pubescent. Ray rather short, yellow.-Verbesina chinensis, Linn.; DC. Prod. v. 618.

- On Victoria Peak, Champion. Only known from S. China.

Tribe V. AMBROSIEA.

Leaves alternate. Flower-heads unisexual. Anthers not united. 


\section{XANTHIUM, Linn.}

Flower-heads monœcious. Males globular, many-flowered. Involucral bracts small, in a single series. Receptacle cylindrical, chaffy. Florets tubular, 5-toothed. Females ovoid, 2 -flowered. Involucral bracts short, in 2 or 3 rows, the 2 inner ones large, consolidated into a hard ovoid 2-celled mass, very prickly outside and terminating in 2 conical points. Florets 1 in each cell. Corolla 0. Style-branches filiform, protruding. Achene obovoid. Pappus 0 .

A genus of two or perhaps three species, from the Mediterranean region or the Levant, but spread as weeds over a great part of the world.

1. X. strumarium, Linn.; DC. Prod. v. 523. A coarse scabrous or pubescent annual, l to $2 \mathrm{ft}$. high. Lẹaves on long stalks, rather large, broadly cordate, coarsely toothed, angular or broadly 3 -lobed. Flower-heads in axillary or terminal clusters or short racemes, the upper ones male, the lower female, sessile, forming, when in fruit, ovoid burrs 6 to 8 lines long, covered with hooked prickles, the stout short conical beaks erect or turned inwards. $-X$. indicum, Roxb. ; DC. 1. c. ; Wight, Ic. t. 1104. $X$. incequilaterum, DC. 1. c. $X$. discolor, $X$. Roxburghii, and $X$. brevirostris, Wallr.; Steetz in Seem. Bot. Her. 390.

In waste places, Hance, Wright. A common weed, in most temperate and warm regions of the globe.

\section{TrIBE VI. HELIANTHEA.}

Leaves opposite, or very rarely alternate. Flower-heads usually heterogamous, the female florets ligulate, rarely irregular or wanting, the hermaphrodite or males tubular, 4- to 5-toothed. Receptacle chaffy. Anthers obtuse at the base. Style of the Senecionidea or approaching that of Asteroideœ. Pappus of stiff awns, on short scales, or rarely none.

\section{ECLIPTA, Linn.}

Flower-heads heterogamous. Florets of the circumference female, shortly. ligulate, narrow, in few series. Disk-florets hermaphrodite, 4 -toothed. Involucre of about 2 rows of broad almost leafy bracts. Scales of the receptacle narrow-linear. Style-branches in the disk-florets linear, flattened, obtuse. Achenes of the ray triangular, of the disk flattened. Pappus none, or reduced to a border of minute teeth.-Leaves opposite.

Besides the subjoined species, some Brazilian perennials are included in the genus, but perhaps not correctly so.

1. E. alba, Hank.; Miq. Fl. Ned. Ind.ii. 65. A branching annual, usually prostrate or creeping, sometimes ascending or erect, $1 \mathrm{ft}$. long or more, sprinkled with closely appressed short stiff hairs. Leaves shortly stalked, from nearly ovate to oblong-lanceolate or almost linear, 1 to 2 in. long, coarsely toothed or nearly entire. Peduncles in the upper axils single or 2 together, very variable in length, bearing a single flower-head about 3 lines diameter. Ray-florets small, white.-E. erecta and E. prostrata, Linn., and the whole section Eueclipta, DC. Prod. v. 490.

Frequent in rice-fields, Wilford; also Wright and Seemann. A common weed throughout the warmer regions of the globe. 


\section{SIEGESBECKIA, Linn.}

Flower-heads heterogamous. Florets of the circumference female, in a single series, shortly ligulate or irregularly 2 - or 3 -lobed. Disk-florets hermaphrodite, 5-toothed. Involucral bracts in about 2 rows, the exterior linearspathulate, spreading, glandular-hispid, the inner ones, like the scales of the receptacle, half-enclosing the achenes, glandular-hispid on the back. Stylebranches in the disk-florets short, somewhat flattened, very obtuse. Pappus none.-Leaves opposite.

A genus of very few species, widely distributed over the warmer regions of the globe.

1. S. orientalis, Linn.; DC. Prod. v. 495; Wight, Ic. t. 1103 . A pubescent, branching, rather stiff annual, 1 to $2 \mathrm{ft}$. high. Leaves from broadly ovate-triangular to lanceolate, $1 \frac{1}{2}$ to 2 in. long or the lower ones larger; petioles variable in length, usually dilated upwards, but not at the base. Flowerheads 3 to 6 lines broad, in a dichotomous leafy panicle. Outer involucral bracts often 4 or 5 lines long, covered with gland-bearing hairs. Florets small, the ray very short. Achenes somewhat turgid and usually curved.S. iberica, Willd.; DC. 1. c. 496.

Waste places, Champion and others. Very common in S. Asia, extending over the Archipelago to Australia and New Zealand, and northwards to Loochoo, but generally as a weed of cultivation. In America this species is rare, but is represented by an allied one, with a smaller ray and stem-clasping leaves.

\section{WEDELIA, Jacq.}

Flower-heads heterogamous. Florets of the circumference female, ligulate, in a single series. Disk-florets hermaphrodite, 5 -toothed. Involucral bracts in about 2 rows, the outer ones leafy, the inner ones smaller, passing into the scales of the receptacle. Style-branches in the disk-florets rather acute, hairy in the upper part. Achenes narrow, obovoid or flattened. Pappus of very short scales consolidated into a little fringed or toothed cup.-Leaves opposite. Ray yellow.

A considerable American genus, with a very few Asiatic, African, or Australian species.

1. W. calendulacea, Less.; DC. Prod. v. 539; Wight, Ic.t. 1107. A low, decumbent, prostrate or creeping perennial, sprinkled with short appressed hairs. Leaves oblong-lanceolate, 1 to 2 in. long, acute or obtuse, coarsely toothed or nearly entire, narrowed at the base but scarcely stalked. Flower-heads nearly $\frac{3}{4}$ in. diameter, solitary, on long axillary peduncles. Rayflorets about 10 or 12 , rather broad, bright yellow.

On the race-course, Happy Valley, Wilford, also Hance, Wright. Frequent in India, from Ceylon and the Peninsula to Java, and northward to Assam, the Philippines, S. China, and Loochoo.

\section{WOLLASTONIA, DC.}

All the characters of $W$ edelia, except that the pappus is either entirely wanting, or consists but of 1 to 3 slender stiff deciduous awns. The outer involucral:bracts are also usually less leafy.

A small genus, confined to the warmer regions of Africa, Asia, and Australia. 
1. W. biflora, DC. Prod. v. 546; Wight, Ic. t. 1108. A straggling half-scandent branching perennial, sometimes nearly glabrous, but more fiequently slightly hoary with closely appressed rigid hairs, especially on the under side of the leaves.: Leaves stalked, from broadly ovate to ovate-lanceolate, the lowest sometimes 3 to 4 inches long and very broadly cordate, the others usually smaller and often cuneate at the base, all acute or acuminate, slightly toothed, 3-nerved. Flower-heads 2, 3, or more, in loose terminal corymbs. Ray-florets about 10 or 12 , not so broad as in the Wedelia.W. scabriuscula, DC. 1. c. 547; W. strigulosa, DC. 1. c. 548 ; and probably some others among the described Wollastonias. Verbesina scandens, Roxb. Fl. Ind. iii. 441.

About rocks and hedges close to the seaside, Champion; also Wright. Widely spread over India, extending westward to E. tropical Africa, eastward over the Archipelago to N. Australia, and northward to S. China and Loochoo.

\section{BIDENS, Linn.}

Flower-heads usually heterogamous. Florets of the ray neuter, ligulate, or sometimes wanting. Disk-florets hermaphrodite, 5-toothed. Involucral bracts few, in about 2 or 3 rows, the inner usually bordered with a thin whitish margin. Receptacle chaffy. Style-branches in the disk-florets with an acute or subulate point. Acheves slender and 4-angled, or (in some species not in Hongkong) broader and flattened, often shortly beaked. Pappus of 2 to 4 rigid retrorsely hispid persistent awns.-Leaves opposite.

The genus comprises 2 sections. The one, Platycarpoe, with flattened achenes, belongs chiefly to the temperate regions of the northern hemisphere, the other, Psilocarpae, is entirely American, with the exception of the two subjoined species, which are spread over all warm countries.

Leaves mostly pinnate, with 3 or 5 segments. Ray white . . . . . 1. B. pilosa.

Leaves mostly bipinnate. Ray yellow . . . . . . . . . 2. B. bipinnata.

1. B. pilosa, Linn.; DC. Prod. v. 597. An erect glabrous or slightly hairy annual, 1 to $2 \mathrm{ft}$. high. Branches angular. Leaves thin, pinnately divided, or the lower ones sometimes simple : segments 3 or sometimes 5, stalked, ovate or ovate-lanceolate, 1 to $2 \mathrm{in}$. long, serrated or rarely lobed. Flower-heads few, terminal, rather small, on slender peduncles. Involucral bracts 2 to 3 lines long. Ray-flowers white, few and short, or sometimes wholly wanting. Achenes slender, 4 -angled, the central one often 6 or 7 lines long, the outer ones shorter.-B. leucantha, Willd.; B. sundaica, Bl. ; and B. Wallichii, DC. 1. c. 598 .

A common weed of cultivation in the island, as over most warm countries both in the New and the Old World. It varies much in the relative numbers of the bordered and unbordered involucral bracts, in the length of the inner achenes, and in the number and size of the rayflowers when present. The Chinese specimens are generally radiate, with the inner bracts conspicuously bordered, the outer unbordered ones few, small, and narrow.

2. B. bipinnata, Linn.; DC. Prod. v. 603 . A glabrous annual, resembling the last, but the leaf-segments are usually again divided into small deeply toothed or lobed segments, the flower-heads are smaller, the involucral bracts less bordered, and the ray-florets small and yellow.

A weed of cultivation like the last, and more common in some countries, but apparently less so in Hongkong, where it has only been gathered by Champion. 


\section{GLOSSOGYNE, Cass.}

Flower-heads heterogamous. Florets of the circumference female, ligulate, in a single series. Disk-flowers hermaphrodite, 4-toothed. Involucral bracts in about 2 rows, narrow. Receptacle chaffy. Style-branches in the diskflorets ending in long subulate points. Achenes as in Bidens, slender, 4-angled. Pappus of 2 stiff persistent awns.-Leaves radical or alternate.

A small genus, ranging from $\mathrm{N}$. Australia to $\mathrm{E}$. India, to which have also been referred one or two Brazilian species.

1. G. tenuifolia, Cass.; DC. Prod. v. 632. Stock perennial, tufted. Leaves mostly radical, pinnately divided into 5 or 7 stiff linear segments, either all entire or the terminal one 3-lobed and the lower ones 2-lobed. Stems dichotomous, erect, glabrous, 6 in. to $1 \mathrm{ft}$. high, almost leafless. Flowerheads small, on slender terminal peduncles. Involucre campanulate, not 2 lines long. Ray-florets small, yellow, spreading. Achenes about 4 lines long, with 2 erect or slightly diverging awns.-Bidens denudata; Turczan. Bull. Mosq. 1851, 183.

Hongkong, Hance, Wright. The species extends from N. Australia to the Philippines and S. China. The Indian G. pinnatifida is perhaps also a variety of the same, distinguished only by the longer, more rigid, and spreading awns of the pappus. The foliage, habit, and flowers are the same.

\section{Tribe VII. ANTHEMIDEAE.}

Leaves alternate, often much cut. Flower-heads heterogamous or very rarely homogamous. Florets of the circumference usually female, ligulate or tubular. Disk-florets tubular, hermaphrodite or rarely male, 4- or 5-toothed. Anthers obtuse or scarcely pointed at the base. Style of Senecionidece. Pappus none or reduced to a small cup or ring or auricle.

\section{CHRYSANTHEMUM, Linn.}

Flower-heads heterogamous. Florets of the circumference female, ligulate, in a single series. Disk-florets 5 -toothed. Involucre hemispherical; the bracts imbricate, in few rows, scarious on the margin. Receptacle flat or slightly convex, naked. Style-branches of the disk-florets truncate. Achenes angular or 3-winged. Pappus a small ring or none.-Leaves alternate, mostly lobed or divided.

A large genus, widely distributed over the northern hemisphere in the Old World, with a very few of the Arctic species extending into America.

1. C. indicum, Linn.; Lindl. Bot. Reg.t. 1287. A shrub of 2 or 3 ft.; the upper branches and under side of the leaves usually cottony-pubescent. Leaves stalked, ovate, toothed and lobed or sometimes deeply pinnatifid with acute or mucronate teeth. Flower-heads few, in short terminal racemes. Involucre about 6 lines broad; the inner scales completely scarious, the outer ones herbaceous and cottony or pubescent in the centre. Ray spreading, pale yellow.-Pyrethrum indicum, Cass.; and Pyrethrum sinense, Sab.; DC. Prod. vi. 62 .

Ravines of Victoria Peak and other parts of the island, Champion and others. In a wild state it appears to range from S. China to Japan. In this state the flower-heads are searcely 
above an inch in diameter, iacluding the single series of pale-yellow ray-florets. But from long cultivation numerous varieties have arisen, mostly so-called double, in which all the florets become ligulate or very much lengthened, and at the same time scarious paleæ are developed on the receptacle between them. These varieties, independent of colour, may be classed in two groups, considered by some as distinct species, the $C$. indicum, with the ligulæ not much longer than in the wild plant, and the $C$. sinense, in which they are twice or thrice as long. The foliage is the same in both; but from Loochoo (Wright) we have a remarkable variety with broad obtuse lobes to the leaves and a much larger involucre.

\section{GRANGEA, Adans.}

Flower-heads heterogamous. Florets all tubular, those of the circumference female, slender, broadly 3 -toothed, in 2 or several rows. Disk-florets hermaphrodite, 5 -toothed. Involucre imbricate, in 2 or 3 nearly equal series. Receptacle hemispherical, naked. Style-branches with a very short obtuse cone, or sometimes the style entire or scarcely notched. Achenes slightly compressed, contracted towards the top and then expanded into a minute, cupshaped, fringed pappus.-Habit of Cotula.

A small genus, limited to the warmer regions of Asia, Africa, and America. It is usually placed amongst Asteroidece next to Dichrocephala, but it appears to me to have much more the style as well as the habit of Cotula, under which the common species was first described.

1. G. maderaspatana, Poir.; DC. Prod.v. 373 ; Wight, Ic. t. 1097. A hairy prostrate branching annual, spreading from a few inches to a foot or more. Leaves 1 to $2 \mathrm{in}$. long, sinuately pinnatifid and toothed, with obtuse lobes, the dilated petiole clasping the stem. Flower-heads solitary, terminal, at first hemispherical, at length nearly.globular, about 4 lines diameter. Involucre pubescent. Female florets very numerous, the length of the disk, with protruding styles.

In rice-fields in the Happy-Valley, Champion, Wilford, Wright. A common Indian weed, from Ceylon and the Peninsula to the Archipelago, and northwards to the Philippines and S. China.

\section{COTULA, Linn.}

Flower-heads heterogamous. Florets of the circumference female, in one or several rows, either apetalous or with a very minute corolla round the base of the style. Disk-florets hermaphrodite or male, 4-toothed. Involucral bracts nearly equal, in 1 or very few rows. Receptacle flat or slightly convex, naked. Style of the disk-florets entire or with truncate or obtuse branches. Achenes oblong or obovate, flattened. Pappus none.-Leaves alternate, mostly pinnatifid.

A small genus, spread over the Old World, with a very few species from extratropical S. America, Australia, or New Zealand. The Hongkong species belongs to the section Pleiogyne, distinguished by the more numerous female florets and the bordered or winged achenes.

1. C. anthemoides, Linn.; DC. Prod. vi. 78. A prostrate, branching, loosely hairy or nearly glabrous annual, from 2 or 3 in. to near 1 foot long. Leaves deeply pinnatifid, with linear lobes mostly toothed or again pinnatifid; the lobes and teeth mucronate. Flower-heads solitary, terminal, hemispherical, scarcely above 2 lines diameter. Inner involucral bracts scarious on the edges. Female florets very numerous: their styles the length of the disk, either without any corolla or with a very minute irregular one at their base. 
Achenes bordered with a narrow callous wing, especially towards the summit. -Pleiogyne anthemoides, C. Koch, in Bot. Zeit. 1843, col. 40. P. cardiosperma, Edg. in Linn. Trans. xx. 7] ; Benth. in Kew Journ. Bot. iv. 235. Machlis hemispharica, DC. Prod. vi. 140 .

In rice-fields, Champion, Wilford. Common in the plains of N. India, extending westward to Egypt and northward to Sikkim and S. China.

\section{MYRIOGYNE, Less.}

All the characters of Cotula, except that the female florets, though very minute, have a tubular corolla nearly as long as the style, and the achenes are 4-angled and but slightly compressed.

A small genus, chiefly S. Asiatic and Australian, with one species from extratropical S. America.

1. M. minuta, Less.; DC. Prod. vi. 139. A prostrate branching annual; the slender somewhat woolly stems 2 to 3 in. or seldom near 6 in. long. Leaves alternate, oblong, 3 to 5 lines long, narrowed at the base or almost stalked, toothed or almost pinnatifid. Flower-heads about $1 \frac{1}{2}$ lines diameter, at first terminal, but soon becoming leaf-opposed and sessile. Involucral bracts in about 2 rows, scarious at the edges. Florets very minute, the females very numerous; their corolla scarcely above a third the length of the ovary. Áchenes slightly hairy.-Centipeda orbicularis, Lour.; Miq. Fl. Ned. Ind. ii. 89. Spharomorphae centipeda, DC. Prod. vi. 140.

In rice-fields, Wilford, Hance, Wright. Very common throughout India, from Ceylon and the Peninsula to the Archipelago, extending also to Australia and northward to the Philippines, China, and Japan.

\section{ARTEMISIA, Linn.}

Flower-heads heterogamous or rarely homogamous, usually few-flowered. Florets all tubular; those of the circumference female, 3-toothed, in 1 or 2 rows or sometimes wanting. Disk-florets hermaphrodite, 5-toothed. Involucral bracts imbricate, unequal, scarious on the edges. Receptacle without scales. Style-branches in the disk-florets truncate. Achenes obovoid, rounded at the top. Pappus 0.-Erect herbs, undershrubs, or shrubs. Leaves alternate, usually divided, with narrow segments. Flower-heads usually small, numerous, nodding.

A large genus, widely spread over the temperate and cold regions of the northern hemisphere, but scarcely penetrating into the tropics.

Perennials. Involucres ovoid. Leaves few-lobed.

Leaves glabrons, shortly lobed or toothed at the top. Female florets dilated at the base. Hermaphrodite florets sterile.......

Leaves white underneath, with long lobes. Female florets slender. Hermaphrodite florets fertile . ............ 2. vulgaris. Annual. Involucres globular, very small. Leaves bipinnatifid . . . 3. A. annua.

1. A. japonica, Thunb. ; DC. Prod. vi. 100. A glabrous erect perennial, 1 to $2 \mathrm{ft}$. high. Leaves mostly cuneate, 1 to $1 \frac{1}{2} \mathrm{in}$. long, lobed or toothed at the upper end, narrow and entire at the base; the upper ones small, deeply 3-lobed or entire, and linear. Flower-heads ovoid, scarcely more than 1 line long, in numerous short racemes forming a long dense 
terminal leafy paniele. In each head are about 8 hermaphrodite but sterile florets, and about as many females, their corolla dilated at the base.

At Saywan and some other plaees, but not common in the island, Champion. On the adjacent continent and in Japan. It is nearly allied to, but I believe distinct from, the more glabrous forms of A. parviflora, Roxb. (A. glabrata, Wall.), a common N. Indian species.

2. A. vulgaris, Linn.; DC. Prod. vi. 112. An erect herb, $1 \frac{1}{2}$ to near $3 \mathrm{ft}$. high. Stem-leaves 2 or 3 in. long, deeply pinnatifid with 3,5 , or 7 linearlanceolate lobes, green on the upper side, white with a close tomentum underneath; the upper leaves often entire. Flower-heads ovoid, about 2 lines long, in short spikes, forming a long terminal leafy panicle. In each head are about 10 or 12 hermaphrodite and fertile florets and about as many females; their corollas slender from the base.-A. indica, Willd.; DC. 1. c. 114; Wight, Ic. t. 1112 . A. leptostachys, DC. 1.c. 113.

Hougkong, Hance. The species ranges over nearly the whole area of the genus, and is in many places very common, in others, as probably in Hongkong,'only as an introduced plant, along roadsides and near habitations.

3. A. annua, Linn.; DC. Prod. vi. 119. An erect, branching, glabrous annual, 1 to $2 \mathrm{ft}$. high. Leaves small, bipinnately divided into short, narrow, toothed or pinnatifid segments. Flower-heads globular, about a line in diameter, very numerous, forming a pyramidal leafy panicle occupying nearly the whole plant. In each head are about 20 hermaphrodite and fertile florets, and nearly as many slender females.

Hongkong, Hance. Widely spread over temperate Asia, from Asia Minor to eastern Siberia, China, and Chusan. Cultivated by the Chinese to mix with their tea.

\section{TrIbe VIII. GNAPHALIEAE.}

Leaves alternate. Flower-heads homogamous or heterogamous; the florets all tubular. Anthers with simple fine points or tails at the base. Stylebranches in the disk-florets truncate. Pappus of capillary bristles or very seldom wanting. - Most of the species cottony or woolly, at least on the under side of the leaves.

\section{GNAPHALIUM, Linn.}

Flower-heads heterogamous. Florets of the circumference numerous, female, filiform. Disk-florets few, hermaphrodite, 5-toothed. Involucre imbricate; the bracts scarious and coloured. Receptacle flat, without scales. Achenes oblong, nearly cylindrical, often papillose. Pappus of a single series of capillary bristles.-Herbs, more or less white-cottony or woolly. Leaves alternate, mostly soft, narrow and entire. Flower-heads usually clustered, either in the upper axils or in terminal spikes or corymbs.

A large genus, distributed over nearly the whole globe.

Flower-heads in terminal corymbs.

Leaves linear, glabrous above. . . . . . . . . 1. G. hypoleucum.

Leaves linear-spathulate, white on both sides . . . . . . 2. G. multiceps.

Flower-heads in axillary clusters or a terminal spike.

Flower-heads about 2 lines long . . . . . . . . . . 3. G.purpureum.

Flower-heads about 1 line long . ... . . . . . . 4. G. indicum.

1. G. hypoleucum, DC. Frod. vi. 422 ; Wight, Ic. $t$. 1114. An erect 
branching annual (or biennial?), 1 to $2 \mathrm{ft}$. high. Leaves linear, pointed, 1 to $1 \frac{1}{2}$ in. long, embracing the stem by 2 small shortly decurrent auricles, green and scabrous on the upper side, covered underneath as well as the stems with white wool. Flower-heads about $2 \frac{1}{2}$ lines in diameter, closely sessile, in clusters forming terminal corymbs. Involucral bracts scarious, from pale to bright yellow, the outer ones slightly cottony. Female florets very numerous, hermaphrodite ones about 8 or 10 in the centre.-G. confertum, Benth. in Lond. Journ. Bot. i. 488.

Hongkong, Hinds. Ranges over the hilly districts of India from the Nilgherries to Sikkim and Khasia.

- 2. G. multiceps, Wall; DC. Prod. vi. 222. An annual or perhaps sometimes a perennial of short duration. Stems ascending or erect, 6 in. to $1 \mathrm{ft}$. high, usually branching at the base only, lower leaves spathulate, the upper ones varying from spathulate to linear, stem-clasping, and sometimes slightly decurrent at the base, white-cottony on both sides as well as the stem. Flower-heads scarcely above $1 \frac{1}{2}$ lines diameter, in globular clusters, forming a small dense corymb, or 3 or 4 peduncled clusters, with 1 or 2 sessile between them. Involucral bracts scarious, yellow, the outer ones cottony. $-G$. javanum, G. ramigerum, and G. confusum, DC. Prod. vi. 222. G. Reinwarditanum, Miq. Fl. Ned. Ind. ii. 91.

In rice-fields, Champion and others. Common in central and northern India, extending eastward to the Archipelago, and northward to S. China, Loochoo, and Japan.

The G. luteo-album, Linn., a common weed in almost all hot countries, but not yet found in Hongkong, is very likely to make its way there. It differs from the last chiefly in the involucral bracts of a dirty white or brown, not yellow.

3. G. purpureum, Linn.; DC. Prod. vi. 232. An annual or perennial of short duration. Stems simple or branching from the base, ascending or erect, 6 in. to a foot high. Leaves mostly spathulate and stalked, or the upper ones rarely linear, white on both sides as well as the stem. Flower-heads about 2 lines long, in short dense clusters, in the axils of the upper leaves, the lower clusters distant, the upper ones forming a terminal leafy spike. Involucral scales linear, scarious, but woolly, of a dirty white or pale brown. Hermaphrodite florets only 2 or 3 in the centre of the very numerous females.

Hongkoug, Hance, Wright. This appears to be a N. American species, although it has been received from several parts of the Old World, where it is probably an introduced weed. Both this and the following species occur in many herbaria and botanic gardeus under the name of $G$. spathulatum.

4. G. indicum, Linn.; DC. Prod. vi. 231. A decumbent or ascending annual, much branched at the base, about 6 in. high, seldom erect. Leaves stalked, spathulate, or the upper ones linear, the white wool much looser than in the last species, and sometimes almost disappearing from the leaves. Flowerheads scarcely above 1 line long, in short dense clusters, forming ovate or oblong terminal leafy spikes, the lower ones more rarely distant. Flowerheads and florets of G. purpureum, but much smaller.-G. niliacum, Raddi; DC. l. c.

In waste places, Saywan, Wilford; also Wright. Very common in India, extending westward to the Niles and eastward to the Malayan Peninsula, N. E. India, and China. 


\section{TRIBE IX. SENECIONIDEAE:}

Leaves alternate. Flower-heads usually heterogamous with radiating female florets, but sometimes homogamous with the florets all tubular and hermaphrodite. Receptacle without scales. Anthers obtuse or scarcely pointed at the base. Style-branches truncate and penicillate, or ending in pubescent points. Pappus of several capillary bristles.

\section{GYNURA, Cass.}

Florets all tubular. Involucre cylindrical, of a single series of nearly equal bracts, with some smaller ones round their base. Corolla hardened at the base. Style bulbous at the base, the branches ending in long linear hairy* points. Achenes striate.-Herbs, often somewhat succulent. Flower-heads terminal, usually loosely corymbose.

A small tropical genus, confined to the Old World.

1. G. pseudochina, DC. Prod. vi. 299. Root-stock perennial, thick and fleshy. Stems erect or ascending, 1 to $1 \frac{1}{2} \mathrm{ft}$. high, somewhat succulent, leafy in the lower part only, ending in a long almost leafless peduncle, bearing a loose corvmb of 2 to 7 or 8 flower-heads, or sometimes a single head. Leaves stalked, from oblong to oval, coarsely toothed, rather thick, glabrous or pubescent, 2 to 3 or even $4 \mathrm{in}$. long, the petiole often expanded at the base into 2 auricles or lobes. Flower-heads about 7 lines long. Involucre shorter than the florets, of about 12 linear-lanceolate nearly equal bracts, with several short slender ones outside. Florets yellow, drying purplish.-G. ovalis and $G$. auriculata, DC. Prod. vi. 300. G. bulbosa, Hook. and Arn.; DC. Prod. vi. 301. Porophyllum hieracioides, DC. Prod. v. 650.

Ravines of Victoria Peak, and other parts of the island, Champion, Hance, Wright, Wilford. Also on the adjacent continent; but not gathered certainly wild out of S. China. The specimens sent from the Manritius or from India are probably all from botanic or other gardens. It is cultivated for its root even in China.

\section{SENECIO, Linn.}

Florets all tubular, or the outer row female and ligulate. Involucre of a single row of nearly equal bracts, with or rarely without a few small ones round their base. Corollas not hardened at the base. Style-branches in the disk-florets truncate and penicillate, or very rarely with a short obtuse appendage. Achenes striate or angular. Pappus of numerous capillary bristles.Herbs or very rarely shrubs. Leaves alternate. Flowers terminal, solitary, corymbose or paniculate. Florets usually yellow, rarely purple.

The largest genus among Composite, and ranging nearly over the whole world, although the individual species are often very local.

Annual. Flower-heads discoid .

Perennials. Flower-heads radiating.

Leaves stalked, ovate-lanceolate .

Leaves stem-clasping, lanceolate or linear

1. S. sonchifolius.

1. S. sonchifolius, Mcench. An erect or ascending annual, about a foot high, rather glaucous and glabrous, or with a few loose hairs near the base. Lower leaves usually orbicular, scarcely an inch diameter, sinuately toothed, 
on long petioles, the upper ones either lyrate or with a broad petiole expanding into stem-clasping auricles, or entire, sessile, and sagittate. Flower-heads few, on long leafless peduncles. Involucre cylindrical or ovoid, about 6 lines long, of about 8 or 10 equal bracts, without any small outer ones. Florets rather longer, all tubular, purple or orange._Emilia sonchifolia, DC. Prod. vi. 302 .

On roadsides and waste places, Hinds, Wright, Wilford. A common weed in tropical Asia and Africa, and some parts of America.

2. S. chinensis, DC. Prod. vi. 363. An erect or half-scandent perennial, attaining 3 or $4 \mathrm{ft}$. in length, glabrous or slightly pubescent. Leaves on petioles of $\frac{1}{2}$ in. or more, ovate-lanceolate, acuminate, toothed, usually about 2 , but sometimes 3 in. long. Flower-heads radiating, in a loose terminal divaricate panicle. Involucre about 3 lines long, of about 12 nearly equal bracts, with some outer ones very minute, and chiefly along the peduncle. Ray-florets about 8 or 10 , yellow. Disk-florets above 20 , rather longer than the involucre. Achenes scarcely pubescent. $-S$. campylodes, DC.'Prod. vi. 370. S. Hindsii, Benth. in Lond. Journ. Bot. i. 488.

Ravines of Mounts Victoria and Gough, Champion and others. Extends over S. China to Khasia and Sikkim. It is also very near to the S. Wightiana, DC., from the Indian Peninsula.

3. S. Stauntonii, DC. Prod. vi. 363. An erect perennial, the branches angular, flexuose, nearly glabrous. Leaves lanceolate, or the upper ones linear, sinuately toothed, embracing the stem by their auriculate base, pubescent or hairy on both sides, or glabrous above, 2 to $4 \mathrm{in}$. long, or even more. Flowerheads in a loose corymbose panicle, the peduncles more erect than in the last, and the heads rather larger. Involucral bracts about $3 \frac{1}{2}$ lines long, with a very few small outer ones, chiefly on the peduncle. Ray yellow, of 8 or 10 florets.

With the last species, Champion, Wright, Wilford. It is also, as well as the last, among Sir G. Staunton's specimens from China, but has not been received from elsewhere.

\section{Tribe X. MUTISIEAE.}

Leaves alterrnate. Flower-heads either heterogamous with radiating female florets, or homogamous with tubular florets, some or all of the outer florets more or less 2-lipped. Receptacle mostly without scales. Anthers pointed or tailed at the base. Style usually thickened under the branches, which are erect and truncate, often short. Pappus bristly or chaffy.

\section{FARFUGIUM, Lindl.}

Flower-heads heterogamous. Florets of the circumference female, ligulate, in a single row, often with a small upper lip. Disk-florets hermaphrodite, tubular, 5-toothed, the outer ones often 2-lipped. Involucre of several nearly equal bracts in a single row, with a few outer smaller ones. Receptacle naked. Anthers with fine points at the base. Style-branches elongated, obtuse, pubescent. Achenes linear-oblong. Pappus of numerous stiff capillary bristles, slightly dilated, and sometimes shortly connate at the base.

An East Asiatic gerrus, of very few species, which it may be difficnlt to separate very pre- 
cisely from Ligularia, of which it has the involucre, style, and many other characters, for in the latter genus the florets are sometimes slightly bilabiate, and in some species there are minute points at the base of the anthers.

1. F. Krempferi, Benth. Root-stock perennial, thick, horizontal, woolly. Leaves radical, on long stalks orbicular, angular, reniform, or deeply cordate at the base, 3 or 4 in. diameter, or rarely 5 or rather more in the wild plant, glabrous or bearing underneath a loose cotton, which soon wears off. Scapes 1 to $1 \frac{1}{2} \mathrm{ft}$. high, leafless, excepting small bracts under the peduncles, bearing 1 to 5 rather large pedunculate flower-heads. Involucral bracts 12 to 15 , about $\frac{1}{2}$ in. long. Ray-florets about as many. Achenes rather large, hairy. Ligularia Kampferi, Sieb. and Zucc. Fl. Jap. i. 77, t. 35. Senecio Krempferi, DC. Prod. vi. 363.

Hongkong, Hance; in a watercourse among rocks, near the top of Victoria Peak, Wilford. A native also of Loochoo and Japan, where it is much cultivated, and where Dr. Siebold mentions a garden variety with blotched leaves, which may possibly be the $F$. grande, Lindl., introduced to our gardens from N. China.

\section{GERBERA, Gron.}

Flower-heads heterogamous. Florets of the circumference female, ligulate, in a single row, with 1 or 2 short slender inner lobes. Disk-florets hermaphrodite, tubular, 5-toothed, and more or less 2-lipped. Involucre imbricate, in few rows. Receptacle naked. Anthers with long points or tails at the base. Style-branches short and obtuse. Achenes usually ending in a beak. Pappus of numerous capillary bristles.- Herbs more or less woolly or cottony. Leaves radical. Scapes 1-headed.

A small African genus, of which one species ranges across south-central Asia.

1. G. piloselloides, Cass.; DC. Prod. vii. 16. Root-stock thick, perennial and woolly. Leaves more or less stalked, from oblong to oval, 2 to 3 in. long, entire, hairy above when young, but often becoming glabrous when old, very woolly underneath. Scape 6 in. to 1 or even $1 \frac{1}{2} \mathrm{ft}$. high, very woolly, especially towards the top, and thickened under the flower-head. Involucre 8 or 9 lines long, narrowed at the base, the bracts linear-lanceolate, pubescent or woolly, rarely glabrous at the edges. Florets numerous and slender. The beak of the achenes very short at the time of flowering, becomes nearly as long as the achenes themselves when quite ripe. Pappus reddish.-G. ovalifolia, DC. Prod. vii. 17. G. amabilis, Hance, in Walp. Ann. ii. 947. G. Schimperi, Sch. Bip.; Walp. Ann. ii. 947.

Victoria Peak and other hills, Champion and others. In East Africs, from Port Natal and Madagascar to Abyssinia. In Asia, from Nepal, Khasia, and Sikkim to S. China, and as far north as Amoy.

\section{AINSLI开A, DC.}

Flower-heads homogamous, with 3 or 4 hermaphrodite tubular florets; the limb unequally cleft into 5 narrow lobes, turned to the outer side or obscurely 2-lipped. Involucre cylindrical, with stiff very unequal imbricate bracts. Receptacle naked. Anthers with long points or tails at the base. Stylebranches short and obtuse. Achenes striate. Pappus of numerous plumose bristles.-Herbs. Leaves radical, except a few bracts on the stem. Flowerheads in long one-sided spikes or a narrow panicle. 
A small genus, limited to the hilly districts of northern India and China. Its affinities appear to be rather with Elephantopus (Elephantosis), than with the other Mutisiea with which it is artificially classed.

1. A. fragrans, Champ. in Kew Journ. Bot. iv. 236. Koot-stock probably creeping. Leaves 2 or 3 , almost radical, on long stalks, ovate, cordate or broadly oblong, 2 or sometimes 3 in. long, in other specimens much smaller, entire, bearing when young, as well as the stem, a little long loose wool, which soon wears off. Flowering stems erect, stiff, simple, 1 to $1 \frac{1}{2} \mathrm{ft}$. long. Flowerheads sessile or nearly so, along the upper half of the stem, and all turned to one side. Involucre 5 or 6 lines long, the bracts few and very pointed. Florets white, rather longer than the involucre, with a sweet smell of almonds.

Rare on Victoria Peak, Champion; who gathered several specimens, but it has not yet been received from any other quarter.

\section{Tribe XI. (or Suborder) CICHORACEAE.}

Flower-heads homogamous, the florets all ligulate and hermaphrodite. Leaves alternate.

\section{LACTUCA, Linn.}

Involucre narrow; the bracts few, very unequal, imbricated, mostly with a scarious edge. Receptacle naked. Achenes ovate or oblong, flat, abruptly contracted into a slender beak, with a pappus of numerous white and silky soft hairs.-Stems erect and leafy. Panicle terminal.

A considerable genus, widely spread over the temperate regions of the Old World; more scarce within the tropies.

1. L. brevirostris, Champ. in Kew Journ. Bot. iv. 237. A glabrous and erect annual, full $3 \mathrm{ft}$. high, and usually simple. Leaves linear or linearlanceolate, 6 to $8 \mathrm{in}$. long or even more, entire or rarely bordered by a few small teeth, especially at the base, where they are sometimes expanded into short half-stem-clasping auricles. Flower-heads in a long narrow pyramidal panicle. Involucre about 6 lines long, the bracts obtuse. Achenes broad and very flat, black, with a beak not half so long as the achene itself.

Hongkong, Champion. Also in Khasia and Formosa. Resembles, in many respects, the N. Indian L. longifolia, Wall.; but the latter species has the leaves sagittate at the base, the panicle much more spreading, and the beak as long or longer than the achene.

\section{TARAXACUM, Juss.}

Involucre of several nearly equal erect bracts, with some smaller imbricated outer ones, often spreading or reflexed. Receptacle naked. Achenes scarcely compressed, striated, muricate, tapering into a long slender beak, with a pappus of copious simple hairs.-Leaves radical. Scape 1-headed.

A genus probably limited to a single species.

1. T. Dens-leonis, Desf.; DC. Prod. vii. 145. Root-stock perennial, with a thick taproot, black on the outside, and very bitter. Leaves varying from linear-lanceolate and almost entire, to deeply pinnatifid, with broad triangular lobes, usually pointing downwards, the terminal ones larger. Scapes from 2 to about 6 in. high. Flowers yellow, rather large. Involucral bracts linear, often thickened at the top, or with a tooth on the back towards the top. Beak of the achenes two or three times as long as the achene itself. 
Among the ruins of an old house, Champion. Widely spread over the temperate and colder regions of the northern hemisphere; and a troublesome weed in almost all cultivated parts of the world.

\section{IXERIS, Cass.}

Involucre cylindrical, of a single row of nearly equal bracts, with a few small outer ones. Receptacle naked. Achenes oblong, slightly flattened, with prominent ribs, not muricate, tapering into a slender beak, with a pappus of very soft usually white simple hairs.-Flower-heads small, florets seldom above 25, yellow in the Hongkong species.

A small Asiatic genus, scarcely differing from the beaked Crepises (or Barkhausias), in the rather more flattened and more prominently ribbed achenes.

Stem erect, paniculate. Flower-heads numerous, 3 or 4 lines long.

Leaves oblong, toothed, lyrate or pinnatifid

Leaves few, linear, mostly entire .

1. I. ramosissima.

Stem creeping. Flower-heads about 6 lines long.

Leaves oblong or lanceolate, entire or slightly pinnatifid . . . . 3. I. debilis.

Leaves ovate, mostly 3 -lobed or in 3 segments . . . . . . 4. I. repens.

1. I. ramosissima, A. Gray, in Mem. Acad. Amer. vi. 397. A glabrous erect much-branched perennial, 1 to $2 \mathrm{ft}$. (or more ?) high. Leaves from oval to oblong or lanceolate, sinuately toothed, lyrate or pinmatifid, 2 to 4 in. long, the lower ones narrowed into a long petiole scarcely clasping the stem with minute auricles, the upper ones sessile, embracing the stem with broad rounded toothed auricles. Flower-heads in dense terminal corymbs, forming a large leafy panicle. Involucre about 4 lines long, of 6 to 8 inner bracts and a very few minute outer ones. Achenes scarcely compressed; the ribs slightly prominent and minutely tuberculate-Brachyramphus ramosissimus, Benth. in Lond. Journ. Bot. i. 489. Dubyaa ramosissima, Hance in Walp. Ann. ii. 1028 .

Hongkong, Hinds, Champion; near Saywan, Hance; in a ravine on Mount Parker, Wilford; also Wright. Not known from elsewhere.

2. I. versicolor, DC. Prod. vii. 151. A glabrous perennial, 6 in. to $1 \mathrm{ft}$. high, with a slender, horizontal, perhaps creeping root-stock. Leaves chiefly radical, stalked, linear or linear-oblong, 3 to 4 in. long, entire or rarely remotely toothed; stem-leaves few and sessile, or sometimes stem-clasping. Flower-heads small, in a loose slender corymbose leafless panicle. Involucre about 3 lines long, of about 8 equal bracts, with a few minute external ones. Achenes slightly compressed, with prominent nerves, slightly muricate, the beak about their own length.-Barkhausia tenella, Benth. in Lond. Journ. Bot. i. 488 .

Hongkong, Hinds, Hance, Wilford. Also on the Chinese continent, and northwards to Dahuria, where the florets are sometimes pink. In Hongkong they are always yellow. The Lactuca gracilis, DC., which we have from various parts of the mountains of northern India, appears to be a slight variety of the same species, with rather smaller flower-heads and fewer florets.

3. I. debilis, A. Gray in Mem. Amer. Acad. vi. 397. A glabrous and glaucous perennial, with shortly creeping leafy runners. Leaves mostly radical, stalked, oblong-lanceolate when in open sandy places, sometimes almost obovate, and only 1 to 2 in. long; when in grassy banks, 6 in. to $1 \mathrm{ft}$. long, very 
thin, entire or remotely toothed, or almost pinnatifid. Flowering stems ascending, 4 in. to $1 \mathrm{ft}$. high, leafless or with a single narrow stem-clasping leaf, bearing 1 to 5 flower-heads on long peduncles. Involucre about 6 lines long; the bracts broader than in the two last, and slightly scarious on the edge. Achenes very strongly ribbed, almost winged, and quite smooth; the beak usually short, but variable.-Youngia? debilis, DC. Prod. vii. 194.

On the seacoast, Harland, Hance. A maritime plant, ranging from S. China to Japan.

4. I. repens, A. Gray in Mem. Amer. Acad. vi. 397. A slender creeping glabrous perennial. Leaves sometimes cordate-ovate and entire, more frequently divided into 3 ovate obtuse lobes on distant segments, from $\frac{1}{2}$ to near 1 in. long, on a petiole of near twice that length. Flower-heads 1 to 5 , on leafless scapes or at the ascending ends of the leafy creeping shoots. Involucre 6 lines long, like that of $I$. debilis. Achenes rather less prominently ribbed, with a still shorter beak.-Chorisis repens, DC. Prod. vii. 177.

On the seacoast, Harland, Hance, Wright. A maritime plant, ranging from S. China to Japan and Kamtchatka.

\section{CREPIS, Linn.}

Involucre of a single row of nearly equal bracts, with a few small outer ones. Receptacle naked. Achenes oblong, cylindrical or scarcely flattened, striate, tapering at the top, but without a distinct beak, with a pappus of copious soft white hairs.

A large genus, widely distributed over the temperate regions of the northern hemisphere, with a very few subtropical species.

1. C. japonica, Benth. An erect slender annual, 6 in. to near $1 \frac{1}{2} \mathrm{ft}$. high, glabrous or slightly pubescent, or hairy near the base. Leaves mostly radical, stalked, varying from obovate, nearly entire, and 1 to $2 \mathrm{in}$. long, to lyrate or pinnatifid, 2 to 4 in. long, with a large terminal toothed lobe. Stem-leaves few or none. Panicle loosely corymbose, slender. Flower-heads numerous. Involucre about $2 \frac{1}{2}$ lines long, containing 10 to 15 small yellow florets.-Prenanthes japonica, Linn. Youngia japonica, DC. Prod. vii. 194; also $Y$. mauritiana, $Y$. Thunbergiana, $\gamma$. runcinata, and some others of DC. See A. Gray in Mem. Amer. Acad. vi. 396.

Roadsides and waste places, Champion and others. Very common in India, extending to Ceylon and the Mauritius; eastward to the Archipelago and N. Australia; and northward to N. China and Japan. The characters by which A. Gray thinks the genus Youngia might still be kept distinct from Crepis, occur nevertheless in the typical European $C$. virens.

A single specimen, from Champion, has the flowers larger and the whole plant stouter and more luxuriant. It may prove a distinct species, but the achenes are too little advanced to determine the characters with precision.

\section{SONCHUS, Linn.}

Involucre ovoid, with imbricate bracts, and usually becoming conical after flowering. Receptacle naked. Achenes flattened and striate, not beaked, with a sessile pappus of copious simple hairs, usually soft and white.

A considerable genus, ranging like Crepis over the temperate regions of the northern hemisphere.

1. S. oleraceus, Linn.; Spec. 1116. An erect annual, with a hollow stem, 1 to 3 or even $4 \mathrm{ft}$. high. Leaves thin, bordered with irregular pointed 
or prickly teeth, otherwise either undivided or pinnatifid, with a broad heartshaped or triangular terminal lobe; the upper ones narrow and clasping the stem with short auricles. Flower-heads in a short corymbose terminal panicle, sometimes almost umbellate. Florets of a pale yellow. $-S$. ciliatus, Lam.; Wight, Ic. t. 1141.

In waste and cultivated places, Hinds and others. A weed of cultivation, probably indigenous to Europe or central Asia, but now distributed over the greater part of the globe. Two marked varieties are generally found growing together; in the one ( $S$. aspera), the ribs of the achenes are perfectly smooth; in the other, for which the name of $S$. oleraceus is more specially retained, they are marked with transverse asperities. The Hongkong specimens I have seen belong to the latter, the Indian ones chiefly to the former.

\section{Order LX. STYLIDIEAE.}

Calyx-tube adnate to the ovary; the limb of 2 to 6 , usually 5 , persistent divisions. Corolla usually irregular, deeply divided into 5 or 6 lobes. Stamens 2; the filaments connate with the style, the anthers lying over the stigma, which is entire or 2-lobed. Ovary 2-celled, with many ovules, or sometimes 1-celled by the contraction of the dissepiment, often surmounted by 1 or 2 glands. Capsule opening from the top downwards in 2 valves parallel to the dissepiment. Seeds numerous, very small, with a minute embryo in a fleshy albumen.-Herbs, with radical or scattered undivided leaves. Flowers in terminal racemes, spikes, or corymbs.

A small Order, almost entirely Australian.

\section{STYLIDIUM, Swartz.}

Corolla irregular, 5-lobed, one of the lobes smaller than the others and turned downwards ; the other 4 ascending in pairs. Anthers 2-lobed. Stigma undivided. The other characters those of the Order.

A genus comprising nearly the whole Order, and all Australian, except the following and one other E. Indian species. The column into which the stamens and style are united is, in this genus, curiously irritable.

1. S. uliginosum, $S w . ; D C$. Prod. vii. 336 . A slender glabrous annual. Leaves radical, rosulate, ovate or orbicular, 2 to 5 lines long, on petioles varying from $\frac{1}{2}$ to 2 lines. Stems erect, filiform, 3 or $4 \mathrm{in}$. high, simple or slightly branched, with a few minute oblong bracts seldom above $\frac{1}{2}$ line long. Flowers sessile, alternate, distant from each other, forming a broken terminal spike. Ovary slender, about 2 lines long when the flower expands, but lengthening to 3 lines. Calyx-lobes linear, scarcely 1 line long, slightly united in 2 lips or free to the base. Corolla scarcely longer, the staminal column protruding. Capsule linear, 2-celled, opening in 2 valves, leaving the dissepiment free.-S. sinicum, Hance in Walp. Ann. ii. 1030.

In wet marshy places, Champion, Wright, Hance, Wilford. Also Ceylon, and if, as is probable, the $S$. Kunthii is merely a robust variety, it is also in Silhet, Chittagong, and the Malayan Peninsula.

\section{ORder LXI. CAMPANULACE无.}

Calyx-tube adnate to the ovary; the limb of 3 to 10 , usually 5 , persistent lobes. Corolla regular or irregular, with 3 to 10 , usually 5 lobes, valvate in 
the bud. Stamens as many as the lobes of the corolla, alternate with them, hypogynous and free from the corolla-tube, or very rarely united to it at the base. Anthers opening longitudinally, free or united in a ring round the style. Ovary inferior, 2- or more celled, usually 3 - or 5 -celled, with numerous ovules in each cell. Style simple, entire or divided at the top into as many stigmatic lobes as there are cells to the ovary. Fruit usually a capsule, opening either in short valves at the top or in lateral pores or slits, rarely an indehiscent berry. Seeds numerous, small. Embryo straight, in a fleshy albumen.-Herbs or very rarely shrubs, with a juice usually milky. Leaves alternate or very rarely opposite, undivided and usually toothed, without stipules. Flowers axillary, solitary or clustered, or in terminal spikes, racemes, or leafy panicles.

A considerable Order, most abundant in the temperate regions of the northern hemisphere or of southern Africa, with a few tropical or Australian species.

Corolla very irregular. Anthers united round the style.

Fruit an indehiscent berry. (Leaves orbicular, cordate.) . . . . 1. Piddingtonia.

Fruit a capsule. (Leaves ovate, not cordate.).

Corolla regular, campanulate. Anthers free. Capsule 3- to 5-valved 3. Wahlenbergia.

\section{PIDDINGTONIA, A. DC.}

Habit and characters of Lobelia and Pratia, only differing from the former in the succulent indehiscent fruit, and from Pratia in the 2 upper lobes of the corolla ascending and forming an upper lip, as in Lobelia.

A genus confined to a single species, which with Pratia might be better re-united with Lobelia as a section.

1. P. nummularia, A. DC. Prod. vii. 341. A prostrate slender more or less pubescent herb, creeping and rooting at the nodes. Leaves stalked, nearly orbicular, cordate at the base, toothed, about $\frac{1}{2}$ in. diameter. Peduncles axillary, 1-flowered, longer than the leaves. Flowers small, purplish-blue, very much like those of Lobelia trigona. Anthers with one short bristle on each of the two lower ones, instead of the little tuft of hairs in L. trigona. Berry ovoid-globular, 4 or 5 lines long, with a thin skin and not much juice, and innumerable small seeds.

Hongkong, Champion. A single specimen, mixed with the broad-leaved pubescent variety of Lobelia trigona, which I had formerly confounded with it. Frequent in the mountains of the central and eastern Himalaya and Khasia, also in Java and Formosa.

\section{LOBELIA, Linn.}

Calyx-tube short or ovoid, limb 5-lobed. Corolla slit open on the upper side to the base, 5 -lobed, the 2 upper lobes usually shorter and erect, forming an upper lip; the 3 lower spreading in a lower 3-lobed or 3-toothed lip. Anthers united in a ring round the style; the 2 lower ones, or all, bearded at the top by a small tuft of stiff hairs. Ovary 2-celled. Capsule opening at the top in 2 loculicidal valves.-Herbs or rarely undershrubs. Pedicels 1-flowered, axillary, or in terminal racemes or spikes.

A large genus, having the widest range in the Order, and although chiefly abundant in temperate regions, it includes several tropieal species.

1. I. trigona, Roxb.; A. DC. Prod. vii. 359 ; Wight, Ic. t. 1170 . A 
slender, decumbent or prostrate, much-branched annual, glabrous or slightly pubescent, rooting at the lower nodes; the branches angular and sometimes ascending or nearly erect. Lower leaves stalked, ovate, not cordate, more or less toothed, about $\frac{1}{2}$ in. long or rather more; the upper ones, especially when the flowering branches are more or less erect, smaller, narrower, and more entire. Peduncles axillary, longer than the leaves. Calyx-tube obconical, about 1 line long when in flower; the lobes narrow, about as long. Corolla blue, rather longer than the calyx. Anthers all shortly bearded at the top. Capsule obovoid, 2 or 3 lines long.-L. trialata, Ham.; A. DC. Prod. vii. 360.

Common in rice-fields, Champion; in ravines, Wilford; also Hance. 'There are two varieties in the island, a creeping, slightly pubescent one, with broader leaves, which is the more common state in wet cultivated fields, and is the L. affinis, Wall.; A. DC. Prod. vii. 360 ; and a glabrous one, with ascending or erect flower-stems and smaller narrower leaves, often entire, growing apparently in more open, waste places. This appears to be the L. chinensis, Lour.; DC. Prod. vii. 360 . But our very numerous Indian specimens show that they pass so gradually one into the other, that they can by no means be distinguished as species.

\section{WAHLENBERGIA, Schrad.}

Calyx 5-lobed. Corolla regular, campanulate or more or less tubular at the base, 5-lobed. Stamens free. Ovary 3- to 5-celled or rarely 2-celled. Style with as many spreading stigmatic lobes. Capsule opening at the top loculicidally in as many valves as cells.-Herbs. Leaves alternate, or very rarely opposite or whorled. Peduncles terminal or in the upper axils, often forming loose terminal dichotomous leafy panicles.

A considerable genus, dispersed over various parts of the world, most abundant in southern Africa. It has all the habit and characters of Campanula, except the dehiscence of the capsule.

Tall perennial, with large flowers. Capsule usually 5 -valved Slender annual, with small flowers. Capsule 3-valved

1. W. grandiflora.

2. W. agrestis.

1. W. grandiflora, Schrad. A glabrous, somewhat glaucous perennial, with a thick fleshy root-stock; the stems sometimes erect and simple, sometimes decumbent and branched at the base, 1 to 2 , or even $3 \mathrm{ft}$. high. Leaves nearly sessile; the lower ones almost opposite or in whorls of 3 , from ovate to oblong or lanceolate, 1 to 2 in. long, usually acute and more or less toothed, firm, of a deep green above and glaucous underneath; the upper ones often alternate, and in some specimens almost all narrow-lanceolate. Flowers of a deep blue, broadly bell-shaped, full 2 in. diameter, and lobed to about the middle, sometimes solitary and terminal, more frequently 2 or 3 in a loose raceme, and sometimes 8 or 10 in a branching raceme or leafy panicle. Capsule usually 5 -celled, opening in 5 valves opposite to the calyx-lobes and bearing the dissepiment in their centre, but sometimes only 3-celled and 3-valved. - Platycodon grandiflorum, A. DC. Prod. vii. 422 ; Sw. Brit. Fl. Gard. ser. 2, iii. t. 208. P. chinense, Lindl. in Paxt. Fl. Gard. ii. t. 61.

On the Chuckchew side of the island only, Champion. On hillsides at Little Hongkong, Wilford. Common in Mantchuria. The character derived from the relative position of the capsule-cells and calyx-lobes appears of too little consequence to separate this species from other Wahlenbergias, being unaccompanied by any others, and failing when the cells are reduced to three.

2. W. agrestis, A. DC. Prod. vii. 434; Wight, Ic. t. 1175 ; Hook. and 
Thoms. in Journ. Linn. Soc. ii. 21, with all the synonyms there adduced. An erect or decumbent annual, branching from the base, from a few inches to 1 foot high, glabrous or pubescent at the base. Leaves alternate, mostly linear, 1 to near $2 \mathrm{in}$. long and slightly toothed; the lowest often much shorter, oblong or even obovate, and narrowed into a petiole at the base; the uppermost small and distant. Flowers few, small, on slender pedicels of $\frac{1}{2}$ to 1 in., forming a loose terminal dichotomous panicle. Calyx-tube about $1 \frac{1}{2}$ lines long; the lobes not so long. Corolla campanulate, about 5 lines diameter, lobed to the middle. Capsule shortly 3 -valved at the top.

In rice-fields, Champion and others. Very common in tropical and subtropical Asia, extending westward to tropical Africa, eastward to Australia, and northward to Loochoo.

\section{Order LXII. GOODENIACEAE.}

Calyx-tube adnate to the ovary; the limb 3 - to 5-lobed or entire. Corolla irregular, slit open on the upper side, 5-lobed. Stamens 5, alternate with the lobes of the corolla, and inserted at its base ; anthers opening in longitudinal slits, free or rarely united in a ring round the style. Ovary usually 2 celled, with 1 or more ovules in each. Style simple; the stigma surrounded by a cup-shaped or peltate indusium, usually ciliate on the margin. Fruit either a capsule opening in 2 valves, or an indehiscent drupe or nut. Seeds usually with a fleshy albumen and straight embryo.-Herbs or small shrubs, the juice not milky. Leaves usually alternate, without stipules. Flowers axillary, or in terminal spikes or racemes, rarely paniculate.

A small Order, almost entirely Australian, a few maritime species extending into tropical Asia or South America.

\section{SC开VOLA, Linn.}

Corolla open on the upper side to the base, deeply 5-lobed. Anthers free. Ovary 1- to 4-celled, with 1 ovule in each. Fruit dry or succulent, indehiscent, 1- to 4-seeded. The other characters, habit, and geographical range as in the family, of which this is the largest and widest-spread genus.

1. S. Lobelia, Linn.; Vriese in Kruidk. Arch. ii. 20. An erect shrub, with a thick, almost succulent stem; the branches, leaves, and inflorescence either silky-pubescent or nearly glabrous, but always with a tuft of woolly or long silky hairs in the axils. Leaves alternate, obovate-oblong, 3 to 5 in. long, rounded and very obtuse at the top, quite entire, narrowed at the base into a very short broad petiole. Cymes axillary, very much shorter than the leaves. Calyx about 3 lines long, including the 5 oblong-linear lobes, rather longer than the tube. Corolla more or less pubescent and always hairy inside; the tube 5 or 6 lines long; the lobes spreading, bordered on each side with a narrow wing folded inwards in the bud. Drupe ovoid or nearly globular, hard, 2-celled, about 4 lines long.-S. Koenigii, Vahl; Bot. Mag. t. 2732, and the six following species in A. DC. Prod.vii.505. S. lativaga, Hance in Walp. Ann. ii. 1055, and the synonyms adduced by Hook. and Thoms. in Journ. Soc. Linn. ii. 8.

Sands and rocks of the seashore, chiefly near Saywan and on the south shore, Champion, Wilford, Wright, Hance, Seemann. A common seacoast plant in the Old World within 
the tropies, and occasionally in the West Indies; but the commonest species there is the S. Plumieri, differing in the calyx-limb entire or nearly so. Although occurring also on several tropical Asiatic coasts, the latter species has not been found in Hongkong.

\section{ORDER LXIII. ERICACEE.}

Calyx of 4 or 5 divisions, either free or with a tube adnate to the ovary. Corolla inferior or superior, usually ovoid or globular, sometimes elongated or campanulate, with 4 or 5 lobes, or very rarely 4 or 5 distinct petals, regular or slightly irregular. Stamens twice as many, or rarely of the same number as the lobes of the corolla, and inserted within the corolla but distinct from it. Anthers 2-celled, opening at the top in pores or short oblique slits, very rarely extending to the base of the cells. Ovary having usually as many cells (rarely apparently twice as many) as the lobes of the corolla, rarely reduced to 3 or 2, with one or several ovules in each. Fruit a capsule or berry. Seeds very small, with a fleshy albumen.-Shrubs sometimes very low, creeping, and almost herbaceous, or occasionally growing into small trees, very rarely true herbs. Leaves entire or toothed, undivided, usually alternate. Flowers either axillary and solitary, or in short clusters or racemes, or forming terminal racemes, corymbs, clusters, or heads.

A large Order, widely spread over the whole world (if considered as including the Australian Epacrida), especially in the temperate and colder regions, but not uncommon also in hilly districts within the tropics. The four Hongkong genera belong to three distinct Tribes, often considered as independent Orders.

Tribe 1. Vaccinieæ. Ovary inferior. Fruit a berry or drupe

Tribe 2. Andromeder. Ovary superior: Fruit a capsule opening in loculicidal valves. (Corolla campanulate, drooping). .

Tribe 3. Rhodorea. Ovary superior. Fruit a capsule opening in septicidal valves. (Corolla slightly irregular.)

Stamens 5, rarely 8 to 10 . Leaves small, deciduous . . . . 4. Azalea.

Stamens 10. Leaves evergreen . . . . : . 3. RHOdOdENdron.

\section{Vaccinium.}

2. Enkyanthus.

\section{VACCINIUM, Lindl.}

Calyx-tube adnate, the limb of 4 or 5 teeth. Corolla superior, ovate, campanulate or shortly cylindrical; the limb of 4 or 5 short lobes or teeth. Stamens 8 or 10. Anther-cells opening in oblique pores at the top of their tubular points. Ovary inferior, 4- or 5-celled, with several ovules in each cell. Fruit a berry.- Shrubs or rarely small trees. Leaves alternate.

A numerous genus, widely distributed over mountainous or boggy regions, chiefly in the northern hemisphere, but occurring also in sonthern as well as in tropical mountains.

1. V. chinense, Champ. in Kew Journ. Bot. iv. 297. A shrub or small tree, very much branched. Leaves evergreen, ovate or oblong, rather acute, and slightly toothed, 1 to $1 \frac{1}{2}$ in. long, or smaller in some specimens, glabrous as well as the branches, narrowed into a petiole of 1 to 2 lines. Racemes terminal or in the upper axils, usually shorter than the leaves. Bracts sometimes leafy, and 3 or 4 lines long, sometimes small and linear. Flowers white, nodding, scarcely 3 lines long, on very short pedicels. Calyx hairy. Corolla ovoid or nearly eylindrical, pubescent outside, with short spreading tecth. 
Filaments hairy. Anthers nearly as long as the corolla, the tubular points long, and with 2 very short awns on the back, turned upwards. Ovary 5celled. Capsule almost divided into 10 cells by false dissepiments. Seeds few.

Happy Valley woods, Champion and others, but said not to be very common. Also on the adjacent continent. It is doubtful also whether this may not be a variety only of a species widely distributed over the mountainous districts of India, China, and perhaps Japan, including $V$. Nilgherrense, $V$. affine, $V$. Donianum, and $V$. Griffithianum of Wight, and $V$. bracteatum of Thunberg, in which case the latter name should be adopted for the whole; but there are slight differences in the shape and pubescence of the corolla, in the awns of the anthers, etc., which require further investigation.

\section{ENKYANTHUS, Lour.}

Calyx free, 5-lobed. Corolla campanulate, shortly 5-lobed, and marked at the base by 5 nectariferous almost pellucid pits. Stamens 10 . Anther-cells tipped with awn-like points, and opening longitudinally to the base. Ovary 5-celled. Capsule hard, 5-angled, opening loculicidally in 5 valves.

A Chinese genus, of which only one species is known for certain.

1. E. quinqueflorus, Lour.; $D C$. Prod. vii. 732. A glabrous erect shrub. Leaves deciduous, crowded at the ends of the branches, oblong or obovate-oblong, acuminate, 2 to $4 \mathrm{in}$. long, entire, narrowed into a petiole of 3 to 4 lines, coriaceous and shining, strongly reticulate on both sides. Flowers pedicellate, drooping, issuing several together from a bud enclosed in imbricate scales, of which the inner ones are lengthened into petiolate oblong, spathulate or linear, coloured bracts. Calyx-lobes lanceolate, varying much in length and breadth, usually 1 to 2 lines long. Corolla about $\frac{1}{2}$ in. long; the tube broad, usually pink or deep red; the lobes obtuse, more or less recurved or spreading, and often white. Stamens shorter than the corolla.-E. quinqueflorus and $E$. reticulatus, Lindl. Bot. Reg. xi. t. 884 and 885 .

Abundant on the hills, Champion and others. Also on the adjacent continent, but not known out of S. China. The E. uniflorus, Benth. in Lond. Journ. Bot. i. 489, originated in a mistake.

\section{RHODODENDRON, Linn.}

Calyx free, 5 -lobed or 5 -toothed. Corolla obliquely campanulate, rarely contracted into a narrow tube, or rotate with scarcely any tube, 5-lobed or very rarely 10 -lobed. Stamens 10 or rarely more, declinate. Anthers without awns, the cells opening in terminal pores. Ovary 5- to 10-celled. Capsule opening septicidally in 5 to 10 valves.-Trees or shrubs. Leaves evergreen, entire, often with a mealy or scaly pubescence. Flowers in dense terminal corymbs or heads, or rarely solitary, issuing with the young leaves from scaly buds.

A large and beautiful genus, numerous in the mountains of tropical and subtropical Asia, with a few N. Asiatic, European, or N. American species.

1. R. Championæ, Hook. Bot. Mag. t. 4609. A shrub of 6 or $7 \mathrm{ft}$., the young leaves and branches more or less clothed or fringed with stiff spreading hairs or bristles. Leaves chiefly at the ends of the branches, shortly stalked, oblong or lanceolate, acuminate, 3 or 4 in. long, dark green above, rather rusty-coloured underneath, with prominent veins. Flower-buds very 
glutinous. Flowers 4 to 6 together on hispid pedicels of about $\frac{1}{2}$ in. Calyxlobes very hispid, unequal, 2 to 3 lines long. Corolla white or pink, tinged with yellow at the base and dotted with ochre; the tube short; the limb campanulate, about 4 in. across. Stamens 10. Capsule oblong-lanceolate, about 1 in. long.

In ravines of Mount Vietoria, Champion; also Wright. Not known out of the island.

\section{AZALEA, Linn.}

Characters of Rhododendron, except that the stamens are usually 5 only and the leaves deciduous. Two of the following species, however, and one or two other east Asiatic ones, have usually 8 or 10 stamens, and are therefore placed by some botanists in Rhododendron, but, on account of the deciduous leaves and habit, they are more generally retained in Azalea.

The genus as generally limited is chiefly $\mathbf{N}$. American, with a few species from temperate or subtropical Asia.

Stamens 5. Calyx glabrons. Corolla nearly rotate . . . . . . 1. A. ovata.

Stamens 8 to 10 . Calyx hairy. Corolla campanulate.

Leaves oval-oblong, hairy. Flowers about 3 from each bud . . 2. A. indica.

Leaves ovate, glabrous when full-grown. Flowers 1 from each bud . 3. A. squamata.

1. A. ovata, Lindl. in Journ. Hort. Soc. i. 149, and ii. t. 2 ; Hook. Bot. Mag. t. 5064. A much-branched glabrous shrub. Leaves few, at the ends of the branches, ovate or oval-oblong, seldom above an inch long, the veins scarcely conspicuous. Flowers issuing singly from scaly buds of which several are usually clustered at the ends of the branches. Pedicels short, slightly glandular, hispid. Calyx-lobes glabrous, ovate, obtuse, thin, about 3 lines long. Corolla nearly rotate, about $1 \frac{1}{2}$ in. across in the wild specimens, white, with purple specks, cleft to near the base into 5 oblong lobes, the uppermost the broadest. Stamens 5, with hairy filaments. Capsule ovate, 5 -celled, about 3 lines long.-A. myrtifolia, Champ. in Bot. Mag. under n, 4609.

On rocks of the Black Mountain, Champion. Also in Chusan, but not known from elsewhere.

2. A. indica, Linn.; Bot. Mag. t. 1480 and 2667; Bot. Reg.t. 811, 1700, and 1716. A much-branched shrub, the young branches and leaves more or less covered with stiff appressed rusty or almost silky hairs. Leaves oblong or oval-oblong, acute, seldom above $1 \frac{1}{2}$ in. long, and often under 1 in. in the wild specimens, narrowed into a very short petiole, often becoming glabrous above, but always retaining the hairs underneath. Flowers almost sessile, usually 3 together from the same scaly bud; the inner scales very hairy. Calyx also hairy; the lobes lanceolate or oblong, 2 or 3 lines long. Corolla with a short tube, obliquely and broadly campanulate, full 2 in. across, divided to about the middle into 5 broad rather unequal lobes. Stamens usually 9 or 10 , of which 1 much shorter than the others. Capsule ovate, acuminate, very hairy, 4 or 5 lines long.-Rhododendron indicum, Sw.; DC. Prod. vii. 726.

Abundant on the banks of streams and on the tops of hills, Champion and others; also in S. China, and northward to Loochoo.

3. A. squamata, Lindl. in Jorrn. Hort. Soc. i. 152; and in Bot. Reg. $1847, t .3$. A shrub, usually bare of leaves, or nearly so at the time of flower- 
ing. Leaves, when first appearing, covered with long rusty hairs, which soon disappear, except on the petioles; when full-grown, ovate, seldom above 1 in. long, dark green and smooth above, glaucous, with a network of rust-coloured veins underneath. Flowers on very short pedicels, issuing singly from long cylindrical scaly buds, more or less covered with rusty-brown hairs. Calyxteeth very short and hairy. Corolla obliquely campanulate, as in A. indica, but smaller, and usually of a pale colour. Stamens 8 to 10 .

Common on the hill-tops, Champion and others. Not known from elsewhere.

\section{ORder LXIV. PRIMULACE王.}

Calyx usually of 5 , sometimes 4,6 , or 7 divisions or teeth, free or rarely shortly adherent to the ovary. Corolla regular, more or less divided into as many lobes or teeth as divisions of the calyx, or rarely wanting. Stamens as many as lobes of the corolla, inserted in the tube opposite the lobes. Ovary 1-celled, with 1 or more ovules attached to or immersed in a free central placenta, which is often thick and globular. Style single, with a capitate stigma. Fruit a capsule, and usually dehiscent. Seeds albuminous.-Herbs or rarely undershrubs. Leaves alternate, simple, entire or toothed, without stipules. Flowers axillary or terminal.

A widely spread Order, inhabiting chiefly the northern hemisphere, and especially high mountains, often at great elevations. A few species reappear in the Antarctic regions, and but very few within the tropics.

\section{LYSIMACHIA, Linn.}

Calyx deeply 5-cleft, free. Corolla rotate or campanulate, deeply 5 -lobed. Stamens 5. Capsule opening in 5 or 10 valves. Perennials, with erect or trailing stems, and opposite or whorled, rarely alternate or tufted leaves. Flowers usually yellow, solitary, on axillary pedicels, or collected in terminal or rarely axillary racemes or clusters.

A considerable genus, having a wide range in the northern hemisphere.

1. L. alpestris, Champ. in Kew Journ. Bot. iv. 299. Stock perennial, short, but emitting occasionally runners of 1 to $3 \mathrm{in}$. Leaves tufted on the stock or at the ends of the runners, narrow-oblong, spathulate, or sometimes almost obovate, 1 to $2 \mathrm{in}$. long, obtuse, entire, narrowed at the base into a short petiole, stiffly hairy on both sides. Peduncles l-flowered, axillary, and about as long as the leaves. Sepals oblong, acuminate, 2 lines long. Corolla rotate, yellow, 8 or 9 lines diameter, divided almost to the base into 5 obovate-oblong minutely fringed lobes. Filaments united in a cup at the base. Anthers oblong. Capsule globular, shorter than the calyx, 5-valved. Seeds numerous.

In subalpine situations, Champion; always on the banks of streams, Eyre; on the top of Victoria Peak, Wilford; also Wright. Not known from elsewhere.

\section{Order (or Suborder) LXV. MYRSINACEÆE.}

Flowers of Primulacea, usually pentamerous or tetramerous. Fruit an indehiscent berry or drupe, or very rarely splitting lengthwise on one side. Seed ${ }^{\mathrm{s}}$ 
albuminous, except in Agiceras. Trees or shrubs. Leaves alternate, simple, entire or toothed, without stipules. Flowers small, in axillary clusters, racemes, or panicles, or rarely in terminal panicles.

A considerable Order, widely distributed over the tropical and subtropical regions of the New and the Old World, and there replacing the Primulacee, of which it may be considered as a Suborder, only differing in the woody habit and succulent fruit.

Ovary wholly or partially inferior ... . . . . . . . , 1. MESA.

Ovary superior.

Petals free to the base.

Petals and stamens usually 5. Racemes slender, forming a terminal

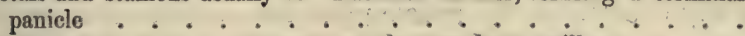

Petals and stamens 4 . Racemes or clusters short, axillory - - " - "

Petals united in a short tube, with a deeply lobed limb.

Flowers in axillary clusters or branching racemes.

Flowers clustered. No scales or appendages to the corolla between

the lobes axillary branching racemes or short panicles. Small appendages or seales alternating with the corolla-lobes between

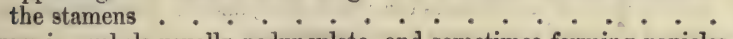

Flowers in umbels usually pedunculate, and sometimes forming panicles. Ovary and fruit obtuse, globular, or ovoid . . . . . . Ovary and fruit acuminate, becoming long and curved. . . . .

\section{Mrrsine.}

7. Reptonis.

5. Ardisia.

6. Egiceras.

\section{M 两SA, Forst.}

Calyx-tube adherent, the limb 5-lobed. Corolla 5-lobed. Stamens 5, filaments slender, anthers short. Ovary inferior or half-superior. Style short. Berry crowned by the calvx-lobes or teeth.-Trees or shrubs. Flowers small, in simple or compound racemes, either axillary or very rarely terminal. Bracts at the base of the pedicels, and 2 bracteoles under the flower, usually very small.

A genus limited to the tropical regions of the Old World.

Corolla-tnbe shorter than the very spreading lobes, and scarcely longer than the calyx

Plant pubescent.

Plant glabrous or the inflorescence scarcely pubescent.

Berry small, nearly dry . . . . . . . . . . . . 2. M. indica.

Berry white, succulent, 3 or 4 lines diameter . . . . . 3. M. montana. Corolla-tube longer than its lobes, and twice as long as the calyx . . . 4. M. coriacea.

1. M. sinensis, DC. Prod. viii. 82. An erect shrub, the branches, the veins, and sometimes the whole surface of the leaves, and the inflorescences pubescent. Leaves oblong or elliptical, 2 to 4 in. long, irregularly toothed, on petioles of 3 to 4 lines, rather thin, or scarcely coriaceous when old. Racemes usually branched, $\frac{1}{2}$ to near $1 \frac{1}{2}$ in. long. Pedicels very short, seldom 1 line long. Calyx-lobes ovate, rather obtuse, longer than the tube. Corolla with a very short tube, the lobes spreading to $2 \frac{1}{2}$ lines in diameter. Berry the size of a grain of pepper, not very succulent.

Common in the island, Champion and others, also on the adjacent coast, but not known out of S. China.

2. M. indica, A.DC. Prod. viii. 80 ; Wight, Ic.t. 1206. A shrub, with the foliage, flowers, and small fruits of $M$. sinensis, but quite glabrous, except occasionally a minute pubescence thinly scattered on the racemes and calyxes. 
Racemes usually more slender than in that species, the pedicels rather longer, and the sepals rather less obtuse.

It is with some doubt that I refer one of Champion's specimens to this species, which has a wide range over the southern districts of India, and over the Indian Archipelago.

3. M. montana, A. DC. Prod. viii. 79. An erect glabrous shrub, usually more or less dicecious. Leaves oblong or elliptical, 3 or $4 \mathrm{in}$. long, shortly acuminate, more or less toothed, on a petiole of 4 to 6 lines long, becoming coriaceous when old. Racemes and flowers in the male plant like those of $M$. indica and $M$. sinensis, but quite glabrous, the ovary small, and the calyx-lobes very obtuse. In the female plant the racemes are more dense, the pedicels shorter, the calyx-tube with the ovary nearly globular, with very short calyx-lobes, the corolla much smaller, with abortive stamens. Berry white, succulent, full 3 lines diameter.

Common in ravines, Champion and others. Widely spread over the hilly districts of India and the Archipelago. It is possible that this and the two preceding species may prove to be varieties of a single one. The toothing of the leaves chiefly relied on by De Candolle is evidently variable, so also is in some instances the pubescence, and the more or less succulence of the ripe fruit cannot be appreciated in our dried specimens.

4. M. coriacea, Champ. in Kew Journ. iv. 300. A perfectly glabrous shrub. Leaves elliptical or oblong, 3 to $5 \mathrm{in}$. long, and very variable in breadth, obtuse or acuminate, on a short stout petiole, more coriaceous than in the preceding species, and either quite entire, or with a few small remote teeth. Racemes either simple and clustered, or branched at the base, and seldom above an inch long. Pedicels short. Calyx-lobes and bracts very obtuse. Corolla different in shape from that of any other Mcesa known to me, full $1 \frac{1}{2}$ lines long, with a broad tube twice as long as the calyx-lobes, and considerably shorter, broad, slightly spreading lobes. Berries globular, about 2 lines diameter.

Common in the island, Champion and others. Not received as yet from elsewhere.

Var. gracilis. Leaves narrower, almost lanceolate, racemes and pedicels more slender and longer, and corolla rather smaller.

Hongkong, Wilford; and some of Champion's early specimens in young bud appear to be referable to this form.

All the above Masas are liable to a peculiar monstrosity, in which the racemes are converted into dense panicles, every flower being also replaced by a dense spikelet of closely imbricate bracts.

\section{FMBELIA, Burm.}

Calyx free, deeply 5- (rarely 4-) lobed. Petals 5, rarely 4, distinct, spreading. Stamens as many, inserted at the base of the petals, not longer than thein, with filiform filaments and short anthers. Ovary superior. Style short. - Shrubs or woody climbers. Flowers small, in simple or branched slender racemes, either axillary, or forming a terminal panicle.

A small genus, limited to tropical Asia or eastern Africa.

1. E. Ribes, Burm.; DC. Prod. viii. 85 ; Wight, Ic. t. 1207 . A pretty bush of 3 or $4 \mathrm{ft}$., with weak slender glabrous branches, sometimes lengthened out and elimbing. Leaves ovate or oblong, shortly and obtusely acuminate, 2 to $3 \mathrm{in}$. long, on petioles of 2 or 3 lines, quite entire, coriaceous, and glabrous, usually glaucous underneath. Flowers very small, white, in elegant 
minutely pubescent branching racemes, forming a terminal panicle. Sepals minute, acute. Petals sprending, about 1 line long, pubescent on the edges. Stamens rather shorter. Berries small, globular.

Common in ravines, Champion and others. Widely spread over southern India, from Ceylon and the Peninsula to the Archipelago. Although the flowers are usually pentamerous, some tetramerous ones may occasionally be met with.

\section{SAMARA, Linn.}

(Choripetalum, A. DC.)

Flowers of Embelia, except that they are constantly tetramerous, and the stamens longer than the petals.- Shrubs often half-trailing. Flowers in short axillary racemes.

A small genus, with the same Asiatic and African range as Embelia.

Leaves obtuse, not 2 in. long. Sepals ovate, obtuse

1. S. obovata.

Leaves 2 to $4 \mathrm{in}$. loug. Sepals lanceolate, acute

2. S. longifolia.

1. S. obovata, Benth. in Kew Journ. Bot. iv. 301. A glabrous shrub, with straggling half-trailing branches. Leaves from obovate to narrow-oblong, always obtuse, 1 to 2 in. long, narrowed into a petiole of 2 or 3 lines. coriaceous, quite entire, smooth above, veined, and somewhat glaucous underneath. Flowers 6 to 10 together, in axillary racemes, so short as to be almost reduced to clusters. Pedicels seldom 1 line long. Calyx-lobes very short and obtuse. Petals yellowish-white, about 1 line long. Stamens rather longer. Fruit globular, 2 or 3 lines diameter.-Choripetalum obovatum, Benth. in Lond. Journ. Bot. i. 490. C. Benthamianum, Hance in Walp. Ann. iii. 10.

Common in raviues in the Happy Valley woods, and at West Point, Champion, Wilford; also Hance and Wright. Not known from elsewhere.

2. S. longifolia, Benth. n. $s p$. Allied to the last species, but the leaves much longer, although not broader, usually about 3 in., sometimes $4 \mathrm{in}$. long, obtusely acuminate and narrowed into a petiole of 3 or 4 lines. Racemes much looser, about $\frac{1}{2}$ in. long. Pedicels 1 to $1 \frac{1}{2}$ lines long. Flowers larger, and the sepals lanceolate, very acute, full $\frac{1}{2}$ line long.

Hongkong, Harland and Hance. Not seen in any other collection.

\section{MYRSINE, Linn.}

Calyx 4- or 5-lobed. Corolla deeply 4- or 5-lobed. Stamens as many, with very short filaments; the anthers much longer, erect and lanceolate. Ovary free. Style short, with a capitate or fringed stigma.-Shrubs or small trees. Leaves coriaceous, entire or rarely toothed. Flowers small, on short pedicels, in dense axillary clusters.

A considerable genus, spread over the tropical and subtropical regions both of the New and the Old World.

1. M. capitellata, Wall.; DC. Prod. viii. 94; Wight, Ic. t. 1211. A glabrous shrub or small tree. Leaves varying from broadly elliptical or oblong or almost obovate, to narrow-oblong, or almost lanceolate in the Hongkong specimens, usually 3 to $4 \mathrm{in}$. long, and $\frac{3}{4}$ to $1 \mathrm{in}$. broad, obtuse or obtusely acuminate, narrowed into a short stout petiole, coriaceous, quite entire, the lateral veins usually inconspicuous. Flowers small, white. Pedicels 1 or 
rarely 2 lines long. Corolla-lobes spreading to about 2 lines diameter.M. phitippinensis, A. DC. Prod. viii. 94, and probably some other supposed species enumerated in that work and in Miq. Fl. Ned. Ind. M. neriifolia, Sieb. and Zucc. Fam. Nat. Fl. Jap. fasc. ii. 13.

Mounts Victoria, Gough, and other hills, Champion and others. Common in India, from Ceylon and the Peninsula to Java, and northward to the Himalaya, the Philippines, Loochoo, and Japan.

\section{ARDISIA, Linn.}

Calyx free, 5- (or 4-?) lobed. Corolla deeply 5- (or 4-?) lobed, the lobes usually very spreading or reflexed and convolute in the bud. Stamens as many, filaments short, anthers lanceolate, erect, the slits of the cells often not reaching the base. Ovary superior. Style subulate, usually long and persistent, the stigma not enlarged. Berry or drupe globular.-Trees, shrubs, or sometimes undershrubs, almost herbaceous. Flowers not so small as in most other genera, usually in umbels or very short umbel-like racemes, axillary or terminal, either solitary or several together in branching panicles. Corolla white or pink, frequently spotted.

A large genus, widely spread over the tropical and subtropical regions of the New and the old World, chiefly in hilly districts.

Erect shrubs. Leaves oblong, usually narrow.

Umbels nearly sessile. Flowers full 4 lines across.

Corolla-lobes acute. . ........... 1. A. crispa.

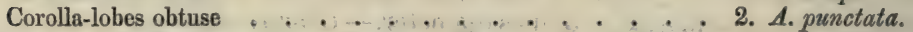

Umbels on slender branching peduncles. Flowers scarcely 3 lines across . . . . . . . . . . . . . 3. A. panciflora.

Stem low, creeping or prostrate at the base. Leaves obovate.

Glabrous. Leaves stalked, about 2 in. long. Peduncles short . . 4. A. chinensis.

Hairy. Leaves sessile, 4 to 6 in. long. Peduncles slender. . . 5. A. primulefolia.

1. A. crispa, A. DC. Prod. viii. 134. An erect, glabrous shrub. Leaves oblong or elliptical, 3 to 5 in. long, usually $\frac{3}{4}$ to 1 in. broad, obtusely acuminate, usually broadly crenate and crisped on the edges with glandular indentures, narrowed into a short petiole, coriaceous, with few lateral veins. Umbels usually nearly sessile, solitary or terminal, but sometimes with 2 or 3 lateral branches, 1 to 4 in. long, each bearing a similar umbel. Flowers white, more or less spotted with purple, from 6 to 10 or 12 in each umbel. Pedicels full $\frac{1}{2}$ in. long. Corolla spreading to full 4 or even 5 lines diameter; the lobes very pointed, often reflexed.-A. crenata, Bot. Mag. t. 1950.

On Victoria Peak and near the Buddhist Temple, Champion; also Hinds and Wright. Known also from the Malayan Peninsula, and the Indian Archipelago, as far as Borneo.

2. A. punctata, Lindl. Bot. Reg. t. 827 ; A. DC. Prod. viii. 135. An erect glabrous shrub, very near the $A$. crispa, but the leaves are usually narrower and more entire, and the corolla less spreading, with the lobes always obtuse.

Abundant on Victoria Peak, Champion, on a ravine on Mount Gough, Wilford; also Wright. Only known from S. China.

3. A. pauciflora, Heyne; A. DC. Prod. viii. 127 ; Wight, Ic. t. 1214. An erect glabrous shrub. Leaves narrow-oblong, obtusely acuminate, 3 to 4 in. long, quite entire, narrowed into a short petiole, coriaceous, the lateral 
veins on the under side numerous and very divergent, but very fine and scarcely prominent. Peduncles axillary or terminal, rather slender, $\frac{1}{2}$ to 1 in. long, bearing sometimes 1 sometimes 3 or 4 umbels, each of 4 to 8 small white flowers. Pedicels slender, 2 to 3 lines long or 4 lines when in fruit. Calyxlobes very small. Corolla-lobes scarcely above 1 line long, and very acute. Drupes 3 or 4 lines in diameter.

In ravines, Champion and others. It has a wide range in southern Asia, as we have it from the mountains of Ceylon and of the Indian Peninsula, from Khasia, from Java, and from Loochoo, and it probably includes some species published in the Prodromus or in Miquel's Flora under other names.

4. A. chinensis, Benth., n. sp. A prostrate glabrous undershrub, the leafy branches ascending to the height of a few inches, seldom above $\frac{1}{2} \mathrm{ft}$. Leaves obovate, obtuse, or obtusely acuminate, $1 \frac{1}{2}$ to $2 \frac{1}{2}$ in. long, entire or with a few irregular obtuse teeth in the upper part, cuneate at the base, on a petiole of 2 or 3 lines; the lateral veins numerous, diverging from the midrib with but little reticulation. Fruiting peduncles slender, about $\frac{1}{2} \mathrm{in}$. long, bearing an umbel of 3 pedicels of 3 or 4 lines. Calyx-lobes small, acute. Berries globular, with the seed and persistent subulate style of Ardisia. I have not seen the corolla or stamens. $-A$. japonica, Benth. in Kew Journ. Bot. iv. 301, not of Blume.

In a ravine of Mount Victoria, Champion. Not received in any other collection. I had at first taken this for the $A$. japonica, which I only knew from Lamarck's figure, but having now seen specimens of that plant from $C$. Wright's collection, I find that it differs in several points, especially in the numerous fine serratures, and much more reticulated veins of the of the leaves, which are also differently shaped.

5. A. primulæfolia, Gardn. and Champ. in Kew Journ. Bot. i. 324. A low hairy half-herbaceous plant. Stem simple, rooting at the base, ascending to the height of a few inches, covered with the knotty scars of old leaves. Leaves in a spreading tuft at the top of the stem, sessile, obovate, 4 to $6 \mathrm{in}$. long, 2 to 3 in. broad, broadly crenate or rarely entire, thin and membranous, covered on the upper side as well as the inflorescences, with long reddish jointed hairs. Peduncles 2 to $3 \mathrm{in}$. long, bearing at the top 1 to 3 or 4 umbels of pink spotted flowers, about the size of those of $A$.crispa. Calyx-divisions narrow-lanceolate, acute, hairy. Corolla-lobes acute. Berry scarlet, 3 or 4 lines diameter.

In grassy places in ravines, Mounts Victoria, Gough, etc., Champion, Wilford; also Wright. Not known out of the island.

\section{6. 开GICERAS, Gærtn.}

Calyx free, 5 -cleft, convolute. Corolla with 5 very spreading lobes, convolute in the bud. Stamens as many, filaments subulate, anthers lanceolate, the cells divided transversely into numerous pits. Ovary superior. Style subulate, acute. Fruit cylindrical, curved, opening as the seed grows in one or two longitudinal slits. Seed without albumen. Cotyledons thick and fleshy.Maritime shrubs or trees, with the habit of Rhizophora, and like them the seed is said to germinate before the fruit falls off, but with the resinous dots and other characters of Myrsinea. Flowers white, in umbels, or very short umbel-like racemes.

A small genus, confined to the seacoast of tropical Asia and Australia. 
1. FE. majus, Gartn.; A. DC. Prod. viii. 142; Wight, Illustr.t. 146. A glabrous shrub or small tree. Leaves obovate, very obtuse, 2 to $3 \mathrm{in}$.long, quite entire, narrowed into a petiole at the base, coriaceous and evergreen. Umbels axillary or terminal, nearly sessile. Pedicels stiff, 3 to 5 lines long. Calyx near 3 lines long, with very obtuse stiff much-imbricated divisions, closely covering the tube of the corolla, which is about their length. Corollalobes about the same length, spreading or reflexed, stiff, and very acute. Stamens shortly exserted. Ovary very pointed, growing out into a curved horn-like fruit, about an in. long.

In salt-water marshes, Champion, Hance. Frequent on the shores of tropical Asia and Australia.

\section{REPTONIA, A. DC.}

(Monotheca, A. DC.)

Calyx 5-lobed. Corolla with 5 spreading lobes, convolute in the bud, and 5 small scales or appendages (or sterile stamens?) alternating with them, inserted in the mouth of the short tube. Stamens 5, inserted in the tube opposite the lobes. Ovary superior, with 1 to 4 ovules erect from the base, without any fleshy placenta. Drupe globular. Seed albuminous.-Shrubs. Leaves evergreen, entire. Flowers small, in axillary clusters or short branching racemes or panicles.

A genus containing, besides the subjoined species, only one other thorny one from Arabia and Western India.

1. R. laurina, Benth., n.sp. A glabrous unarmed shrub. Leaves narrowoblong or lanceolate, acuminate, 3 to 5 in. long, narrowed into a petiole, coriaceous, smooth, with a few raised veins underneath, diverging obliquely from the midrib. Flowers very small, in axillary panicles of near $2 \mathrm{in}$. long, with small scale-like bracts at the base of the branches, and short pedicels. Calyxlobes broad, much imbricated, about $\frac{3}{4}$ line long. Corolla spreading to about 2 lines diameter. Anthers almost sessile. Ovary apparently with only 1 ovule, erect from the base. Berry ovoid-oblong, about $\frac{1}{2}$ in. long, with one seed, not quite ripe in the specimens, but apparently with a thick fleshy albumen.

Hougkong, Harlanid. I regret much that the only specimens I have seen of this very interesting plant are not in a better state, for although the two flowers I examined appear perfect as to the corolla, stamens, and style, the ovule and most of the growing ovaries were more or less diseased. One only fruit appeared to be in a normal state, but that was not ripe enough to see the embryo.

\section{ORDER LXVI. SAPOTACE互.}

Calyx free, of 4 to 8 , usually 5 , divisions or teeth. Corolla regular, more or less divided into as many or rarely twice as many lobes. Fertile stamens, either equal in number to the lobes of the corolla and opposite to them, or twice as many, besides which are often sterile stamens, either alternating with the fertile ones or in the form of small scales, alternating with the lobes of the corolla. Ovary superior, 2- or more celled, with one pendulous or erect ovule 
in each cell. Style simple, with an entire or slightly lobed stigma. Fruit a berry or drupe, usually indehiscent. Seeds either with a fleshy albumen and foliaceous cotyledons, or without albumen and with fleshy cotyledons.-Trees or shrubs, with the juice frequently milky. Leaves alternate, entire, usually coriaceous, without stipules. Flowers axillary, solitary or clustered.

An Order widely distributed over both the New and the Old World, within the tropics or not spreading far beyond them.

\section{SIDEROXYLON, Linn.}

Calyx and corolla 5-lobed. Stamens 5 fertile inserted in the tube of the corolla opposite its lobes, and 5 small sterile scale-like ones alternating with the corolla-lobes. Ovary 5-celled, or rarely 4- or 2-celled. Berry ovoid or globular, with 1 to 3 seeds. Albumen fleshy. Embryo in the centre, almost as long, with broad thin cotyledons.-Flowers small, usually white, in axillary clusters.

A considerable genus, with nearly the range of the whole Order.

1. S. Wightianum, Hook. and Arn. Bot. Beech. t. 41; A. DC. Prod. viii. 178, not of $W$ all. An erect glabrous shrub. Leaves evergreen, from broadly oblong or almost obovate to narrow-oblong, obtusely acuminate, 2 to 4 in. long, quite entire, narrowed into a rather long petiole, pale underneath: the pinnate veins and transverse reticulations conspicuous on both sides. Pedicels about 3 lines long. Flowers small, whitish, the lobes of the corolla and sterile stamens usually rather broader than represented in the above quoted plate. Ovary hairy. Fruit about $\frac{1}{2}$ in. long.

In the Happy Valley woods, Mount Victoria, and Little Hongkong, Champion, Wilford, and others: also on the adjacent continent, but not known beyond S. China.

\section{Order LXVII. EBENACE正.}

Flowers regular, usually diœecious. Calyx free, 3- to 5-lobed, or rarely with 6 or 7 lobes. Corolla-lobes as many, imbricate in the bud. Stamens inserted at the base of the corolla or on the torus within it, indefinite, usually about 15 in the male flowers, much fewer and sterile in the females; anthers erect, linear or lanceolate. Ovary free, 3 - or more celled, with 1 or 2 pendulous ovules in each cell. Styles as many or half as many as cells, distinct or more or less united, simple or 2-cleft, with small terminal stigmas. Fruit a berry, usually indehiscent. Seeds few, with albumen ; radicle superior; cotyledons foliaceous.-Trees or shrubs; the juice not milky. Leaves alternate, entire, without stipules. Flowers axillary, the females often solitary, the males usually clustered or in small cymes.

A rather small Order, spread over tropical and subtropical Asia, Africa, America, and southern Afica, with a very few Australian species,

Ovary 3-celled . . . . . . . . . . . . . . . . . . . 1. Rospidios.

Ovary 4-, 8-, or more celled . . . . . . . . 2. Drosprros.

1. ROSPIDIOS, A. DC.

Characters of Diospyros, except that the ovary is 3-celled with 3 styles.Shrubs with small leaves. 
A genus consisting of the following species only, and perhaps not separated from Diospyros on adequate grounds.

1. R. vaccinioides, A. DC. Prod. viii. 220. A low much-branched evergreen shrub, much resembling the common Box when growing. Branches and young leaves covered with appressed rusty hairs. Leaves ovate, acute, usually about $\frac{1}{2}$ in. long, coriaceous, glabrous when full grown, without any prominent veins except the midrib. Flowers small, axillary, pendulous, nearly sessile. Calyx-lobes 4, lanceolate-subulate, about $1 \frac{1}{2}$ lines long, hairy. Corolla-tube about as long, glabrous except a few hairs on the angles; the 4 lobes short, spreading, and very acute. Berries globular.-Diospyros vaccinioides, Lindl. in Hook. Exot. Fl. t. 139.

- Very abundant all over the island, Champion and others. Also on the hills of the Malayan Peninsula, I have only seen male flowering and female fruiting specimens.

\section{DIOSPYROS, Linn.}

Flowers diœcious. Calyx and corolla-lobes 4, 5, or 6. Stamens usually 15 or 16 in the males, about 8 and sterile in the females. Ovary usually 4or 8-celled, rarely 10 - or 12-celled, with 1 ovule in each cell. Styles 2 or 4 , more or less united at the base and usually 2-cleft at the top. Berry 4- or 8-celled, usually covered at the base by the somewhat enlarged calyx.--Trees or rarely shrubs. Flowers axillary, the females solitary, the males usually several together in little clusters, sometimes lengthening out into cymes or racemes.

A considerable genus, having nearly the same range as the Order, but rare in S. Africa.

Glabrous. Leaves petiolate . . . . . . . . . . 1. D. Morrisiana. Branches, young leaves, and calyxes hairy. Leaves almost sessile . . 2. D. eriantha.

1. D. Morrisiana, Hance in Walp. Ann. iii. 14. A shrub (or tree?), with the young shoots very slightly pubescent, otherwise quite glabrous. Leaves oblong or the lower ones ovate, obtuse or acuminate, 2 to 4 in. long, coriaceous, shining above; the veins underneath few and slight, on petioles of 2 to 4 lines. Flowers white, the males 2 or 3 together, nodding, on pubescent pedicels of about 1 line long. Calyx broadly campanulate, about 1 line long, with 4 short triangular lobes. Corolla-tube nearly twice as long, with 4 short spreading lobes. Stamens 15 to 20, with hairy anthers. Female flowers hitherto undescribed, and I have not seen them. Fruit yellow, oblong or nearly globular, about 8 lines diameter, 4-celled. Seeds 1 in each cell, chestnut-coloured, oblong, compressed.

On Mounts Vietoria, Gough, and Parker, Champion, Hance; also Wright. Not known as yet out of the island.

2. D. eriantha, Champ. in Kew Journ. Bot. iv. 302. A small tree; the young branches and under side of the young leaves covered with stiff appressed rusty hairs, which disappear on the old leaves except on the midrib or principal veins. Leaves nearly sessile, oblong-lanceolate, acuminate, spreading in opposite rows, smooth and shining above, with prominent very oblique veins underneath. Flowers nearly sessile; the females solitary, the males 2 or 3 together, not nodding. Calyx deeply lobed, very hairy, about 2 lines long when in flower, twice as long in fruit, with ovate acute lobes, and surrounded at the base by 2 or 3 imbricate obtuse deciduous scaly bracts. Corolla white, very hairy outside; the tube about 3 lines long; the lobes about 2 lines, 
and very acute. Ovary very hairy, 2-celled according to Champion, with 1 pendulous ovule in each ; I found, however, in the only female flower I could examine, 4 cells with 1 ovule in each. Styles 2 , united to the middle and apparently undivided, but the summits were injured. Berry. oblong, above $\frac{1}{2}$ in. long, glabrous or hairy, with a single seed.

In the Happy Valley woods, Champion; also Wright. Not known ont of the island.

\section{ORDER LXVIII. STYRACACE无.}

Calyx-tube usually more or less adherent; the limb 5- or rarely 4-lobed. Corolla deeply divided into as many lobes or rarely into twice as many, the additional lobes forming an inner smaller series alternating with the outer ones. Stamens usually indefinite, sometimes only twice as many or equal in number to the corolla-lobes, attached in one or more series to the base or within the tube of the corolla. Ovary more or less inferior or very rarely quite superior, 2- to 5-celled, with 2 or more ovules in each cell, either all pendulous or the upper ones erect. Fruit more or less succulent and indehiscent, or rarely opening in valves. Seed usually solitary, the embryo in the axis of a fleshy albumen.- Trees or shrubs. Leaves alternate, entire or toothed, without stipules. Flowers axillary, solitary or in simple or branched racemes.

A small Order, dispersed over the tropical and subtropical regions of Asia and America, with very few African species and oue only extending into southern Europe.

Corolla-lobes much imbricate. Stamens indefinite. Anthers short. Ovules 2 in each cell. Fruit inferior

1. Symplocos.

Corolla-lobes imbricate or valvate. Stamens 10 . Anthers linear. Ovules

several in each cell. Fruit superior .

2. StryaX.

\section{SYMPLOCOS, Linn.}

Calyx 5-lobed, adherent. Corolla 5-lobed or in some American species 6- to 10-lobed, the lobes much imbricate in the bud. Stamens indefinite, usually more than 15 ; filaments filiform ; anthers small, ovoid or globular. Ovary more or less inferior, 2 - to 5 -celled, with 2 or very rarely 3 ovules in each cell. Style filiform, entire or shortly lobed at the top. Berry from globular to oblong, crowned by the persistent calyx-lobes, usually with 1 or 2 seeds only. Embryo with a long radicle and very short cotyledons. Trees or shrubs, the specimens almost always taking a yellow tinge in drying. Flowers small, in axillary racemes or clusters, each nne solitary in the axil of a small bract, with 2 bracteoles under the calyx.

A considerable genus, common to the tropical and subtropical regions of Asia and America.

Flowers in dense clusters, or in racemes not longer than the petioles.

Fruit ovoid or oblong.

Clusters dense, quite sessile. Leaves veined. Ovary glabrous . . 1. S. congesta.

Racemes few-flowered, about as long as the petiole. Leaves very coriaceous, scarcely veined. Ovary hairy at the top
wers in racemes (or loose spikes), longer than the petiole. Fruit

Flowers in racemes
small, globular.

Racemes simple:

2. S. crassifolia.

Racemes branched

3. S. microcarpa.

4. S. spicata.

1 S. congesta, Benth., n. sp. An evergreen shrub, glabrous except a 
slight pubescence on the young buds. Branches short, terete. Leaves ovate, shortly acuminate, 2 or 3 in. long, entire or rarely bordered with small glan. dular teeth, on a thick petiole of about 3 lines, coriaceous and shining above, but less so than in the following species and the veins much more prominent underneath. Flowers closely sessile, in very dense axillary clusters; the bracts broad, short, and slightly hairy. Calyx near $1 \frac{1}{2}$ lines long, divided to bolow the middle into 5 broad obtuse brown lobes. Corolla-lobes obtuse, about 2 lines long. Stamens numerous, inserted in the very short tube, and longer than the lobes. Ovary quite glabrous, 3 -celled, with 2 pendulous ovules in each cell. Fruit oblong, more than $\frac{1}{2}$ in. long.

Rare in the island, Champion. Received also in Fortune's Chinese collection, but in no other one.

2. S. crassifolia, Benth., n. sp. A perfectly glabrous shrub, with angular branches like those of $S$. japonica. Leaves oval-oblong, acuminate, 2 to 3 in. long, quite entire or with a few small teeth towards the top, narrowed into a petiole of 4 to 6 lines, more stiff and coriaceous than in any other species known to me, and not unlike the large entire-leaved varieties of a Holly. Flowers 3 or 4 together in racemes about the length of the petiole; the lowest flower pedicellate, the others sessile. Bracts small, orbicular. Calyx-lobes orbicular, thin, about 1 line long. Corolla divided almost to the base into obtuse lobes about 2 lines long. Ovary hairy at the top. Fruit ovoid, not $\frac{1}{2}$ in. long.

On Victoria Peak, Champion. Not seen in any other collection. I had formerly thought that this and the preceding species might be varieties of the $S$. japonica, but a careful comparison of more numerous specimens discloses too many points of difference to admit of their being united.

3. S. microcarpa, Champ. in Kew Journ. Bot. iv. 303. A shrub or small tree, glabrous except a slight pubescence on the racemes. Leaves nearly sessile, oval or elliptical-oblong, with a long acumen, 2 to 3 in. long, entire or more usually slightly crenated, not very coriaceous although shining above, the reticulated veins more or less conspicuous underneath. Racemes (or rather interrupted spikes) $\frac{1}{2}$ to 1 in. long, simple. Flowers small, quite sessile, each in the axil of a small broad minutely ciliate bract. Calyx not 1 line, with orbicular thin lobes. Corolla scarcely above 1 line long, divided almost to the base. Stamens about 20. Ovary glabrous on the top. Fruit nearly globular, crowned by the inflected lobes of the calyx, about 2 lines diameter.

In the Happy Valley woods, Champion; in a ravine of Mount Gough, Wilford. We have not precisely the same form from the continent, but in Hooker's Sikkim collection is one which may be a variety of the same species, with more pubescent racemes.

4. S. spicata, Roxb.; A. DC. Prod. viii. 254; Wight, Illustr. t. 150. A shrub or small tree, glabrous except the inflorescence. Leaves ellipticaloblong, shortly acuminate, crenate or almost serrate, 3 to $4 \mathrm{in}$. long, narrowed into a petiole of 4 to 5 lines, coriaceous and shining above; the veins prominent undemeath and sometimes on both sides. Racemes 2 to 3 in. long; more or less branched, and usually minutely pubescent or tomentose. Flowers sessile, each in the axil of a broad, short, pubescent bract. Calyx scarcely 1 line long, glabrous, with orbicular lobes. Corolla-lobes 2 lines long, with a 
very short tube. Stamens numerous. Ovary glabrous on the top. Fruit nearly globular, about 2 lines diameter, crowned by the persistent calyxlobes.

Hongkong, Harland. On the adjacent continent, and widely spread over E. India from Ceylon and the Peninsula to Khasia, Silhet, and the Archipelago, varying considerably in foliage. The Chinese specimens agree, however, precisely with the cominon Silhet form.

\section{STYRAX, Linn.}

Calyx campanulate, truncate or obscurely toothed, shortly adherent at the base or free. Corolla deeply 5-lobed (rarely 4 - or 6 -lobed); the lobes imbricate or valvate in the bud. Stamens twice as many as corolla-lobes, apparently in a single series; filaments short; anthers linear, erect. Ovary halfinferior or entirely superior, completely or incompletely 3 -celled or almost 1 celled. Ovules attached to the axis, several in each cell, all erect or the upper ones erect and the lower pendulous. Style filiform, with an entire or 3-lobed stigma. Fruit surrounded at the base by the persistent calyx, globular or ovoid, either indehiscent or the rather thick pericarp opening more or less into 3 valves. Seed solitary, erect, globular or ovoid. Albumen fleshy. Embryo usually oblique.-Shrubs or small trees, usually more or less covered with a close mealy or scaly pubéscence. Flowers much larger than in Symplocos, usually drooping, either 1 or 2 in the upper axils or forming a short loose terminal raceme.

A considerable genus, ranging over the tropical, subtropical, or even temperate regions of the northeru hemisphere, and extending also southward of the tropies in S. America.

Leaves green and glabrous on both sides. Corolla-lobes imbricate in the bud.

Leaves scaly-pubescent, or tomentose underneath. Corolla-lobes val-
vate in the bud :
2. S. suberifolia.

1. S. odoratisima.

1. S. odoratissima, Champ. in Kew Journ. Bot. iv. 304. A beautiful moderate-sized shrub, with very little of the scurfy pubescence of the genus, except on the inflorescence and flowers. Leaves ovate-lanceolate or oblong, acuminate, 2 to $3 \mathrm{in}$. long, on a petiole of 2 to 4 lines, usually entire, thin, green on both sides, and reticulately veined. Flowers white, sweetly scented. Calyx near 3 lines long. Corolla white, near $\frac{1}{2}$ in. long, the lobes thin and much imbricated. Ovary completely 3-celled when young, with the ovules all ascending, and adnate to the calyx to about one-half its length. Fruit tomentose, globular or slightly ovoid, obliquely acuminate by the persistent style, by which it differs from that of most species, either indehiscent, or rarely splitting into 3 valves from the base upwards, or from the apex downwards.

Ravines of Mount Victoria, Champion; also Wright. Not known out of the island.

2. S. suberifolia, Hook. and Arn. Bot. Beech.t. 40; DC. Prod. viii. 261. A shrub or small tree, the branches, under side of the leaves, and inflorescence covered with a dense scaly pubescence or tomentum, which often assumes a reddish colour. Leaves from oval-oblong to oblong-lanceolate, acuminate, 2 to $4 \mathrm{in}$. long, narrowed into a petiole of about $\frac{1}{2}$ in., usually entire, coriaceous, glabrous and reticulate on the upper side. Pedicels very short. Calyx $1 \frac{1}{2}$ lines long. Corolla about 5 lines; the lobes narrow-oblong, valvate 
in the bud. Ovary free, 1-celled from the base at the time of flowering, with near 20 ovules on an axile placenta, the upper ones ascending, the lower ones pendulous. Fruit globular, obtuse, opening in 3 thick valves.-Cyrta suberifolia, Miers in Ann. Nat. Hist. ser. 3, iii, 279.

Rather common in the Happy Valley woods, Champion; and at Little Hongkong, Wilford; also Wright; aud on the adjacent continent, but not known out of S. China. The three groups proposed by Miers, under the names of Styrax, Cyrta, and Strigilia, although they cannot perhaps be so strictly limited as laid down in the work above quoted, form very good sections; but it appears to me that Styrax, as a whole, is far too natural to be thus broken up into distinct genera. The degree of adherence of the ovary, and of the persistence of its dissepiments is variable in species otherwise closely allied.

\section{ORDER LXIX. JASMINACEÆֶ.}

Calyx usually small, 4- or 5-lobed, or rarely 6- to 8-lobed, or toothed, or almost entire. Corolla 4- or 5-lobed, or rarely 6- to 8-lobed, with a long or short tube, or sometimes divided to the base into 4 petals, or rarely 2-petaled or entirely wanting. Stamens 2, adhering to the base of the corolla, on opposite sides of the ovary, or hypogynous in apetalous flowers. Ovary 2-celled, with 2 , or rarely 1 or 3 ovules in each cell, ascending or pendulous, from the inner angle. Fruit succulent or capsular, entire or 2-lobed, 2-celled, or reduced to a single cell and seed. Seeds with or without albumen. Embryo straight.-Trees or shrubs, very rarely herbs. Leaves opposite, or very rarely alternate, entire or pinnate. Flowers in axillary or terminal panicles, sometimes reduced to dense clusters.

A small Order, dispersed over the greater part of the warmer or temperate regions of the globe. The two Suborders are sometimes considered as distinet Orders.

7 Suborder 1. Oleiner.-Corolla 4-lobed or none. Ovules pendulous. Fruit entire. Fruit dry, narrow, ending in a narrow wing. Trees with pinnate leaves . 1. Fraxinus. Fruit succulent. Leaves simple, entire.

Fruit a drupe. Panicles or elusters axillary. Corolla-lobes imbricate . 2. OrEa.

Fruit a berry. Panicles terminal. Corolla-lobes valvate . . . 3. Ligustrum.

SUBORDER 2. Jasmineæ.-Corolla 5- or more lobed. Ovules ascendiny. Fruit (rohen perfect) 2-lobed. (Leaves in the Hongkong species compound with 3 leaflets) 4. JASMr Num.

\section{FRAXINUS, Linn.}

Flowers usually polygamous. Corolla either none, or of 2 or 4 petals, scarcely cohering at the base. Stigma 2-lobed. Fruit dry, indehiscent, narrow, ending in an oblong or linear stiff wing. Seeds 1 or 2 , pendulous, with a thin fleshy albumen.-Trees. Leaves pinnate, the leaflets usually toothed. Flowers in axillary or terminal panicles or racemes.

A rather considerable genus, dispersed over the temperate regions of the northern hemisphere, penetrating into the tropics only in monntain districts.

1. F. retusa, Champ. in Kew Journ. Bot. iv. 330. A glabrous tree. Leaflets usually 5 ; from ovate to ovate-lanceolate or oblong, aeuminate, 2 to $3 \mathrm{in}$. long, on petiolules of 3 to 6 lines, slightly serrate, and much reticulated. Panicles not so long as the leaves. Flowers numerous, white, on slender pedicels 1 to $1 \frac{1}{2}$ lines long. Calyx cup-shaped, truncate, or very shortly and obtusely 4.toothed, about $\frac{1}{2}$ line long. Petals 4, narrow-oblong, $1 \frac{1}{2}$ lines 
long, imbricate in the bud. Stamens longer. Fruit linear, about $\frac{3}{4}$ in. long, including the wing, about $1 \frac{1}{2}$ lines broad in the broadest part, and always emarginate at the top.

In woods in the Happy Valley, near the waterfall, Champion, Hance; also near Amoy, Fortune. I had formerly thought that this might be a variety of the widely spread $F$. floribunda, Wall, but a closer examination shows that it differs in the calyx, which is twice as large, and not deeply lobed as in that species, and in the reticulation of the leaflets, besides the constantly notehed fruit, which appears to be always acute in $F$. floribunda.

\section{OLEA, Linn.}

Flowers often polygamous. Corolla 4-lobed, with a short tube, or rarely none; the lobes usually imbricate in the bud: Ovary 2-celled, with 2 pendulous ovules in each cell. Fruit a drupe. Seed usually 1, pendulous, with a fleshy albumen.-Trees or shrubs. Leaves entire, coriaceous. Flowers small, in axillary racemes, panicles, or clusters, or, in some African species, in terminal panicles.

A genus comprising several African and Asiatic or Mediterranean species, with one from N. America, and another from New Zealand.

1. O. marginata, Champ. in Kero Journ. Bot. iv. 330. A holly-like evergreen shrub, apparently dicecious. Leaves chiefly near the ends of the branches, elliptical-oblong, obtuse or searcely acuminate, $2 \frac{1}{2}$ to near 5 in. long, narrowed into a stout petiole of $\frac{3}{4}$ to $1 \mathrm{in}$., thickly coriaceous, smooth, and shining above, the midrib alone prominent on the under side. Panicles dense, minutely pubescent, not longer than the petiole. Lower bracts linear, the upper ones minute. Calyx obtusely 4 -lobed, about $\frac{1}{2}$ line long. Corollatube about 1 line; the lobes broad, obtuse, quite glabrous, and imbricate in the bud. Stamens rather longer. Ovary, in the flowers examined, all small and abortive. The female specimens are in fruit only. Drupes oblong, about $\frac{1}{2} \mathrm{in}$. long, with a woody putamen.

Near the top of the waterfall in the Happy Valley, Champion; also Hance. Not reeeived from elsewhere, nor yet is it at all like any other Asiatic species known to me. On the other hand, it very closely resembles the N. American $O$. americana, Linn., from which our specimens only show some slight differences in the shape of the bracts, in the glabrous corollalobes, and in the longer fruit.

The $O$. fragrans, Thunb., and $O$. aquifolium, Sieb. and Zuce., are much cultivated in gardens, but are not stated to have established themselves in the island in a wild state.

\section{LIGUSTRUM, Linn.}

Flowers hermaphrodite. Corolla 4-lobed with a long or short tube, the lobes usually valvate in the bud. Ovary 2-celled, with 2 pendulous ovules in each cell. Stigma 2-lobed. Fruit a globular 2-celled berry. Seeds usually solitary in each cell, pendulous, with a fleshy or cartilaginous albumen.Shrubs. Leaves entire, often coriaceous. Flowers rather small, white, in terminal panicles.

A small genus, ranging over the mountains of Asia, from the Himalaya to Japan, with one European species.

1. L. sinense, Lour.; DC. Prod. viii. 294. A shrub, with slender pubescent spreading branches. Leaves ovate or ovate-lanceolate, 1 to 2 in. 
long, glabrous or nearly so, and shining above when full grown, but always more or less pubescent underneath. Flowers in oblong. pubescent panicles of 1 to 2 inches, much like those of the European Privet. Calyx cup-shaped, truncate, entire. Corolla-tube exceedingly short; the lobes spreading, about $1 \frac{1}{2}$ lines long, valvate in the bud. Stamens rather longer. Berry globular or nearly so, small.-Olea Wulpersiana and $O$. consanguinea, Hance in Walp. Ann. iii. 17 and 18.

Much cultivated in the gardens of the island, and found also frequently by roadsides, although not perhaps truly indigenous, Champion; also Hance. It is believed to be of Chinese origin, and probably includes the $L$. Stauntoni, DC., with the characters of which some of our Chinese continental specimens agree well. It is also very closely allied to, if not a variety of $L$. nepalense, Wall., from the Himalaya.

\section{JASMINUM, Linn.}

Flowers heimaphrodite. Corolla-tube usually cylindrical ; the limb spreading, 5 or sometimes 6 - to 8-lobed; the lobes oblique, contorted in the bud. Stamens included in the tube. Ovary 2 -lobed, with usually 2 ascending ovules in each cell. Style 2-lobed at the tip. Berry 2-lobed (or entire by the failure of 1 carpel). Seed usually solitary in each lobe, without albumen, erect.-Shrubs or climbers. Leaves opposite or rarely alternate, pinnate, with 3 or more entire leaflets, or apparently simple, being reduced to 1 leaflet, the petiole being then articulate. Flowers white or yellow, in axillary or terminal panicles, or rarely almost solitary.

A considerable genus, dispersed over the warmer regions of the Old World, with one or two S. American species.

1. J. paniculatum, Roxb.; DC. Prod. viii. 310 ; Bot. Reg.t. 690. An erect (or slightly climbing?) glabrous shrub. Leaves opposite; leaflets 3 or rarely only 1 , oblong, 2 to 3 in. long, coriaceous, smooth and shining, on petiolules of $\frac{1}{2}$ to $\frac{3}{4}$ in., the common petiole about as long. Flowers white, in loose terminal panicles. Calyx about 1 line long, truncate, or very minutely toothed. Corolla-tube near $\frac{1}{2}$ in. long; the lobes lanceolate, mucronate, about 3 lines long. Berries ovoid, about $\frac{1}{2}$ in. long, double and divaricate, or single and erect.

Common on Victoria Peak, and in ravines of other hills, Champion; also Hance. On the adjacent continent, and in Khasia.

\section{ORDER LXX. APOCYNACE西.}

Sepals 5, or very rarely 4, free or slightly united at the base, imbricate in the bud. Corolla with 5 or very rarely 4 lobes, contorted in the bud, and usually oblique. Stamens as many as the lobes of the corolla, alternate with them, inserted in the tube, and seldom protruding from it; the anthers opening inwards, free or cohering to the stigma. Ovary either 2-celled, or rarely 1-celled with 2 parietal placentas, or more frequently the 2 carpels are distinct, but united at the top by a single style, usually thickened or expanded in a ring under the stigma. Ovules usually several in each cell or carpel. Fruit a berry, drupe, or more frequently consisting of 2 follicles opening inwardly. Seeds pendulous, or rarely ascending, usually with albumen.-Trees, shrubs, woody climbers, or very rarely herbs, the sap mostly milky. Leaves 
opposite or whorled, very rarely alternate, entire, usually without stipules, but having frequently glands between the leaves, or in their axils, as also within the calyx at its base. Flowers usually in axillary or terminal cymes or panicles.

A large Order, chiefly tropical, with a few species from more temperate regions, both in the northern and southern hemispheres.

Ovary single, the carpels completely united from the base.

Ovary l-celled, with 2 parietal placentas. Flowers large, yellow. Capsule prickly . .

Ovary 2-celled. Flowers white, in close terminal cymes. Fruit suceulent, smooth

Ovary of 2 distinct carpels, united only by the simple style.

Corolla-lobes ending in a long linear point. Dichotomous shrub, with terminal cymes. . . . . . . .

Corolla-lobes shorter than, or about the length of the tube, obtuse or acute.

Fruit of 1 or 2 drupes or berries.

Straggling or half-climbing shrub, with small, very obtuse, opposite leaves and small flowers. Berries or drupes stalked .

Tall ereet shrub, with long alternate crowded leaves, and rather large flowers. Drupe sessile . . . . .

Fruits follicular. Leaves opposite.

Small erect annual or perennial. Flowers 2 together, sessile in the axils. Follicles small, erect. . . . . . .

Woody climbers or shrubs. Flowers in terminal trichotomous cymes or panicles.

Corolla-lobes narrow, very oblique, about the length of the tube.

Anthers in the middle of the corolla-tube, sagittate .

Anthers small, at the base of the tube, obtuse at the base . . . . . . . . .

1. Atramanda.

2. Mnloninus.

6. Strophanthus.

3. AlyXia.

4. Cerbera.

5. VINCA.

7. RHYNCHOSPERMUM.

8. Aganosma.

Corolla-lobes short, ovate, scarcely oblique. Flowers small and numerous.

Corolla-tube cylindrical or ovoid ; the lobes spreading, about half as long

Corolla shortly campanulate $: \cdots$

\section{ALLAMANDA, Linn.}

Corolla-tube cylindrical at the base, with a large campanulate throat, and broad spreading lobes, with two erect scales at the base of each. Anthers sagittate, within the tube. Disk annular, entire. Ovary 1-celled, with 2 parietal placentas. Style filiform, with a cylindrical 2-lobed stigma. Fruit a prickly ovoid capsule.-Erect shrubs or woody climbers. Leaves whorled, or sometimes opposite. Flowers large, yellow.

A small genus, confined to tropical America, except where introduced.

1. A. cathartica, Linn.; DC. Prod. viii. 318 ; Bot. Mag. t. 338. A tall woody climber. Leaves in whorls of 3 or 4 , or rarely opposite, oblong, acuminate, glabrous or slightly hairy on the midrib underneath, with small glands in their axils. Flowers large, yellow, few together in terminal sessile cymes. Sepals lanceolate, about 5 lines long. Corolla with the narrow part of the tube about $1 \mathrm{in}$. long, the broad campanulate throat about ns long, and the broad oblique lobes also about 1 in. long. 
In the Happy Valley woods, Wilford; also Wright. A tropical American species, escaped from gardens although apparently wild.

\section{MELODINUS, Forst.}

Calyx without glands. Corolla-tube cylindrical ; limb spreading, with oblique or falcate lobes, and 5 or 10 small erect scales at the mouth of the tube, either free or united in a ring or cup. Anthers oblong, included in the tube. Ovary single, 2-celled. Style filiform, with a thickened conical stigma. Fruit ovoid or globular, succulent.-Woody climbers. Leaves opposite. Flowers in terminal sessile trichotomous cymes.

A small genus, confined to tropical Asia and the islands of the South Sea.

Seales of the mouth of the corolla 1 to $1 \frac{1}{2}$ lines long. Sepals very obtuse.

Seales of the corolla united to the middle. Lobes broader than long $\cdot 1$. M. suaveolens.

Scales of the corolla free. Lobes longer than broad . . . . . 2. M. monogynus.

Scales of the corolla exceedingly short. Sepals, at least the outer ones,

acute

\section{M. fusiformis.}

1. M. suaveolens, Champ. in Kew Journ. Bot. iv. 333. A tall woody climber, glabrous, except a slight pubescence on the inflorescence. Leaves ovate, oblong, or almost lanceolate, acuminate, 2 to 3 or rarely near 4 in. long, smooth and shining on the upper side, but not so much so as in the two following species, on petioles of 3 to 6 lines. Flowers white, sweet-scented, in dense terminal trichotomous cymes, sessile above the last leaves, and shorter than them. Pedicels short. Sepals orbicular, very obtuse, about $1 \frac{1}{2}$ lines long. Corolla-tube 4 to 5 lines long; the lobes shorter, narrow at the base, suddenly expanded, chiefly on one side, into a very oblique or falcate lamina, broader than long, with 2 irregular teeth on the inner or expanded edge. Scales of the throat more than a line long, united to about the middle into a 5- or 10-lobed cup. Berry globular.-Lycimma suaveolens, Hance in Walp. Ann. iii. 31.

In the Happy Valley woods, Champion, Hance, Wilford, Wright. Also on the adjacent continent.

2. IM. monogynus, Roxb.; A. DC. Prod. viii. 329 ; Bot. Reg. t. 834; Bot. Mag. $t$. 2527. A tall woody climber resembling the last species in most respects, but the leaves are usually longer and narrower in proportion, often above 4 in. long, more coriaceous, smooth and shining, the sepals scarcely so broad, the flowers larger, the tube full 5 lines long, the lobes obovate or broadly oblong, falcate with 1 or 2 teeth on the inner expanded edge, the scales of the throat free, or scarcely connected at the very base, hairy inside.M. latus, Champ. in Kew Journ. Bot. iv. 332.

Hongkong, Champion, Wright, Wilford. Widely spread over northern and eastern India, and probably also in the Archipelago. The Hongkong specimens have the scales of the corolla longer and broader than most of the Indian ones, and sometimes slightly united at the base, and $\mathrm{I}$ had therefore, in my former enumeration, adopted them as a distinct species, but I now feel convinced, from the examination of more specimens, that whatever may be thought of the two other Hongkong species, the present one is but a variety of the common M. monogynus.

3. M. fusiformis, Chaimp. in Kew Journ. Bot. iv. 332. This species is again very nearly allied to the $M$. monogynus, with the same general habit, foliage and inflorescence, except that the leaves are usually smaller, and the cymes fewer-flowered. Sepals ovate, the outer ones more or less acute. Co- 
rolla of the size of $M$. monogynus, but the lobes less oblique and less distinctly toothed on the inner edge, and the scales of the throat very small and hairy. The berry, according to Champion, is spindle-shaped or pear-shaped, the size of a large apple. In a specimen of Wright's, if not mismatched, it is globular.

Hongkong, Champion, on Vietoria Peak, Wilford; also Wright. Not known from elsewhere.

\section{ALYXIA, R. Br.}

Calyx without glands. Corolla-tube cylindrical or slightly contracted at the top; the limb spreading, the lobes ovate or oblong, without scales at the throat. Anthers enclosed in the tube. Ovary of 2 distinct carpels, united by a single style, with a capitate or oblong stigma. Ovules several in each carpel. Fruit a single-seeded ovoid or oblong drupe or berry, or sometimes consisting of 2 one-seeded joints placed end to end, or rarely 2 from the same flower, as only one of the carpels usually ripens.

A small genus, chiefly Australian or from the islands of the Pacific, with a very few S. Asiatic species.

1. A. sinensis, Champ. in Kew Journ. Bot. iv. 334. A straggling, prostrate, or somewhat climbing glabrous shrub. Leaves opposite or in whorls of three, oval or obovate, obtuse, rarely more than 1 in. long, coriaceous, smooth and shining, with a thick recurved edge, on short petioles. Flowers in small sessile panicles or clusters, either terminal or in the forks of the upper branches. Sepals little more than $\frac{1}{2}$ line long. Corolla-tube rather more than 1 line, cylindrical or slightly contracted at the top; the lobes small, ovate, spreading. Berries ovoid, about $\frac{1}{2}$ in. long.

On rocky hills, in ravines and woods, very common, Champion; not common, Wilford; also Wright. Not known out of the island.

\section{CERBERA, Linn.}

Calyx without glands. Corolla-tube cylindrical. The lobes ovate, spreading, without scales at the throat. Anthers linear-lanceolate, included in the tube. Ovary of 2 distinct carpels, united by a single style, with a conical 2-lobed stigma. Ovules 2 in each carpel. Fruit a nearly globular drupe, flattened on one side, with a woody endocarp, usually one-seeded.-Shrubs or small trees. Leaves alternate, crowded on the young branches. Flowers white, in terminal cymes or panicles.

A genus of very few species, from the Pacific Islands and tropical Asia.

1. C. Odollam, Gartn.; A.DC. Prod. viii. 353 ; Wight, Ic. t. 441. A glabrous erect shrub, with thick herbaceous branches. Leaves oblong or lanceolate, acuminate, 4 to 6 in. long, narrowed into a rather long petiole; the lateral veins transverse. Flowers white, sweet-scented, in a dense terminal pedunculate cyme. Sepals oblong or lanceolate, obtuse or acute, about $\frac{3}{2}$ in. long. Corolla-tube $1 \mathrm{in}$. long; the lobes about half as long, obovate-oblong.

On low grounds, chiefly near the sea, Champion, at Aberdeen and Little Hongkong, Wilford. Widely distributed over the maritime districts of India, the Archipelago, and the Pacific islands.

\section{VINCA, Linn.}

Calyx without, glands inside, but the sepals sometimes glandular-ciliate on the edge. Corolla-tube slender, the lobes ovate or oblong, oblique, spreading, 
without scales at the throat. Anthers included in the tube. Disk of 2 oblong glands, alternating with the carpels. Ovary of 2 distinct carpels united by a single style, with several ovules in each carpel. Stigma conical or cylindrical. Fruit of 2 cylindrical erect or spreading follicles. Seeds oblong-cylindrical, without any coma.-Herbs or undershrubs, erect, or with long creeping branches. Leaves opposite. Flowers axillary, solitary or 2 together.

A. small genus, dispersed over various parts of the world.

1. V. rosea, Linn.; DC. Prod. viii. 382 ; Bot. Mag. t. 248. An erect slightly pubescent perennial, 1 to $2 \mathrm{ft}$. high, branching at the base only, and often flowering the first year. Leaves obovate or oblong, very obtuse, 1 to 2 in. long, narrowed into a very short petiole. Flowers pink or white, 2 together in the axils of the leaves, and almost sessile. Sepals short, subulate, pubescent. Corolla-tube slender, about $\frac{3}{4}$ in. long; the lobes broad, oblique, not much shorter than the tube.

In waste places, apparently wild, Champion, also Wright. A tropical American species, introduced into tropical Asia, where it is now a common weed, besides being much cultivated in gardens for ornament.

\section{STR'OPHANTHUS, DC.}

Calyx with a few glands inside at the base of the sepals. Corolla-tube cylindrical, usually enlarged at the top ; the lobes very long and linear, somewhat broader at the base, with 2 scales at the mouth of the tube opposite each lobe. Anthers sagittate, included in the tube, cohering to the stigma. Disk none. Ovary of 2 distinct carpels, united by a single style, with several ovules in each. Fruit of 2 thick follicles horizontally diverging. Seeds with a terminal coma of long silky hairs.-Erect or climbing shrubs, the branches usually dichotomous. Leaves opposite. Flowers rather large, in short terminal cymes.

A small genus, dispersed over the tropical regions of the Old World.

1. S. divergens, Grah. in Maund. Bot. iii. t. $150 ; A$. DC. Prod. viii. 417. An erect, dichotomous, glabrous shrub. Leaves elliptical-oblong, shortly acuminate and mucronate, 2 to $3 \mathrm{in}$. long, narrowed into a petiole of 2 or 3 lines. Flowers terminal, solitary or few together in sessile trichotomous cymes. Sepals narrow-lanceolate or linear, about 5 lines long. Corollatube about $\frac{1}{2}$ in. long, with a short campanulate throat; the scales about $1 \frac{1}{2}$ lines long; the lobes lanceolate at the base, ending in narrow-linear points, full 2 in. long when full-grown. Follicles hard and woody, very divergent, 4 to 6 in long and very thick. Seerls ending in a long point, with a beautiful coma of very long silky hairs.

Abundant near the level of the sea, Champion. Low ground at Saywan, Wilford, also Wright. Not known out of S. China.

\section{RHYNCHOSPERMUM, A.DC.}

Calyx with a ring of glands inside at its base. Corolla-tube cylindrical; the limb spreading, with oblique oblong or obovate lobes. Anthers sagittate, included in the tube about the middle. Disk 3 -lobed or of 5 distinct glands. Ovary of 2 distinct earpels united by the single style, with several ovules in 
each. Stigma oblong. Fruit of 2 long linear follicles. Seeds ending in a narrow neck, with a coma of long silky hairs.-Woody climbers. Leaves opposite. Flowers in loose terminal trichotomous cymes, sometimes appearing axillary by the growing out of a lateral bud.

A small genus from tropical or eastern Asia, not perhaps sufficiently distinct from Aganosma.

1. R. jasminoides, Lindl. in Journ. Hort. Soc. i. 74, and in Paxt. Fl. Gard. ii. 26, $f$. 147. A slender woody climber, glabrous, or the young branches more or less pubescent. Leaves oblong or oblong-lanceolate, acute or acuminate, 1 to $2 \mathrm{in}$. in the wild specimens, twice as long when cultivated, on a very short petiole. Flowers white, sweet-scented. Sepals about 1 line long, narrow, with a ring of about 20 glands more or less united into 5 at their base inside. Corolla-tube about 3 lines long; the lobes about as long, oblong-cuneate and very oblique or falcate. Disk-glands distinct. Stigma surrounded at its base by a prominent ring. Follicles 3 or 4 in. long. I have not seen the seeds.-Malouetia asiatica, Sieb. and Zucc. Fam. Nat. Fl. Jap. fasc. ii. 39. Echites saligna, Delile, in several herbaria. Parechites Thunbergii, A. Gray in Mem. Amer. Acad. vi. 403. Japan.

Abundant on the top of Mount Gough, Champion. On the Chinese continent and in

\section{AGANOSMA, Don.}

Calyx usually with a ring of glands inside at the base, occasionally with few or none. Corolla-tube cylindrical ; the limb spreading, with oblique narrow lobes about the length of the tube. Anthers sessile near the base of the tube, not sagittate. Disk annular or cup-shaped, shortly 5-lobed or nearly entire. Ovary of 2 distinct carpels united by the single style, with several ovules in each. Stigma spindle-shaped or cylindrical. Fruit of 2 long linear follicles. Seeds with a coma of long silky hairs.-Woody climbers or shrubs. Leaves opposite. Flowers white, in terminal trichotomous cymes, often appearing axillary by the growing out of a lateral bud.

A small tropical Asiatic genus.

1. A. lævis, Champ. in Kew Journ. Bot. iv. 335. An evergreen, glabrous straggling shrub or climber. Leaves narrow-oblong or lanceolate, acuminate, 2 to 4 in. long, smooth and shining, with few distant oblique lateral veins, narrowed into a petiole of 3 to 5 lines. Flowers white, numerous, in trichotomous cymes or dense panicles at the ends of the branches. Sepals small, narrow-ovate, without glands. Corolla-tube 2 lines long, pubescent inside ; the lobes about as long, narrow, oblique, pubescent above. Anthers short, obtuse at the base. Disk annular, minutely toothed. Fruit unknown. - Holarrhena affinis, Hook. and Arn. Bot. Beech. 198 ?

In a ravine, Champion; at Little Hongkong and West Point, Wilford; also Hinds and Wright; and on the adjacent continent. This plant differs from the others of the genus in the absence of the calycine glands. I have not been able positively to verify Hooker and Arnott's synonym, for the original specimen of Holarrhena affinis cannot now be found in the Hookerian Herbarium.

9. POTTSIA, Hook. and Arn.

Calyx with a ring of glands on the inside at the base. Corolla-tube cylin- 
drical; the limb spreading, with short, scarcely oblique lobes. Anthers projecting from the tube, sagittate; the 2 basal lobes ending in long points. Disk annular, deeply 5 -lobed. Ovary of 2 distinct carpels, connected by a single style, with an ovoid stigma. Ovules several in each carpel.-Climbers. Leaves opposite. Flowers small, paniculate.

A genus consisting of only one, or perhaps two, species from tropical Asia.

1. P. cantoniensis, Hook. and Arn. Bot. Beech. 198, t.43. A slender woody climber, glabrous, or the young branches sprinkled with a minute brown pubescence. Leaves from cordate-ovate to oblong, obtusely acuminate, 2 to $3 \mathrm{in}$. long, on a slender petiole of $\frac{1}{2}$ to $1 \mathrm{in}$. long, smooth and shining on the upper side. Flowers small, pink, in a large loose terminal trichotomous panicle, each pedicel about 3 lines long. Calyx scarcely $\frac{3}{4}$ line, and in the Chinese as well as in the Indian specimens I always find about 20 glands. Corolla-tube about 2 lines long; the lobes little more than half as long, ovate and scarcely oblique, although convolute in the bud. Disk-lobes lanceolate, longer than the carpels.-P. ovata, A. DC. Prod. viii. 442. P. Hookeriana, Wight, Ic. t. 1306.

Hongkong, Champion, Wright. Also in Khasia, Silhet, Malacca, and Java.

\section{FCDYSANTHERA, Hook. and Arn.}

Calyx with 1 or 2 glands between each 2 lobes on the inside. Corolla campanulate; the lobes ovate, scarcely obtuse, about as long as the tube. Stamens inserted in the tube; the anthers scarcely protruding, sagittate, the basal lobes short, sterile. Disk annular, entire or slightly crenate. Ovary of 2 distinct carpels, united by a short style with a conical stigma. Fruit of 2 diverging follicles. Seeds with a coma of long silky hairs. - Climbers. Leaves opposite. Flowers small, numerous, in loose terminal or axillary panicles.

A genus of very few species, all from tropical Asia. It scarcely differs from Pottsia, to which at any rate ought probably to be referred the $E$. glandulifera, DC., as well on account of the calycine glands and the disk, as the shape of the corolla.

Leaves glaucous underneath. Corolla 2 lines long . . . . . 1. E. rosea.

Leaves green underneath. Corolla scarcely above 1 line long . . 2. E. micrantha.

1. E. rosea, Hook. and Arn. Bot. Beech. t. $42 ;$ A. DC. Prod. viii. 442. A tall climber, with slender branches, glabrous, except a very slight glaucous pubescence on the inflorescence. Leaves oval-oblong, shortly acuminate, $1 \frac{1}{2}$ to $2 \mathrm{in}$. long or seldom more, narrowed into a petiole of 4 to 6 lines, somewhat shining above, glaucous underneath. Flowers small, pink, very numerous, in an èlegant terminal panicle. Calyx not $\frac{1}{2}$ line long. Corolla about 2 lines long, rather broadly campanulate; the lobes broad, obtuse, rather shorter than the tube, scarcely oblique but contorted in the bud, and from right to left (as seen from the centre of the flower) in all the flowers I have examined of this and the following species, not from left to right, as stated by De Candolle. Disk annular, entire, shorter than the pubescent carpels.

In ravines at West Point, Champion; woods of the Happy Valley, Wilford; also Wright. On the adjacent continent and in Java, and perhaps the Malayan Peninsula.

2. E. micrantha, A. DC. Prod. viii. 442. A tall climber like the last, but not so slender, perfectly glabrous except the inflorescence, which is slightly pubescent, but without the glaucous mealy look of E. rosea. Leaves more 
like those of Pottsia cantoniensis, ovate, obtusely acuminate, 2 to $3 \mathrm{in}$. long, on petioles of $\frac{1}{2}$ in. or more, smooth and shining above and not glaucous underneath. Panicles terminal or in the upper axils, trichotomous, broad and loose. Flowers numerous, much smaller than in $E$. rosea, the corolla scarcely above 1 line long and more broadly campanulate. Disk annular, shorter than the carpels and slightly 5-crenate.

Hongkong, Wright. Also Khasia, Assam, and Sikkim, the broader leaves of the Hongkong specimens, and the flowers perhaps not quite so small, give them a rather different look from the Indian ones; but on a careful comparative examination I can find nothing else to separate them.

\section{ORdER LXXI. ASCLEPIADEZE.}

Sepals 5, free or slightly united at the base, imbricate in the bud. Corolla 5 -lobed, usually rotate or broadly campanulate, with a very short tube, more rarely with a lengthened tube and erect or spreading lobes, valvate or contorted in the bud. Stamens 5, inserted at the very base of the tube; the short filaments connate in a tube (called the gynostegium) enclosing the pistil. Anthers erect, 2-celled or rarely almost 4-celled, opening inwards, each cell containing usually a single globular oblong or linear pollen-mass; those of the adjoining cells (of different anthers) attaching themselves in pairs, or in fours, to 5 processes of the stigma; the anther usually terminating beyond the cells in a small membrane or point. Outside the stamens is often a socalled staminal coronu, consisting either of 5 scales alternating with the lobes of the corolla, or of a ring at its base, or more frequently a 5-lobed wing attached to the staminal tube, each lobe at the back of an anther, and having often an appendage inside it. Ovary of 2 distinet carpels with short styles united at the top. Stigma usually a flat pentagonal disk, sometimes terminating in a cone or long point, bearing at its angles the little processes to which the pollen-masses are attached, and which fall off with them. Ovules numerous. Fruit consisting of 2 follicles (or a single one by the abortion of the other). Seeds several, terminating usually in a coma or tuft of silky hairs. Albumen thin. Embryo straight.-Herbs, twiners, or rarely shrubs or even trees; the juice frequently milky. Leaves opposite, very rarely whorled or alternate, entire. Flowers usually small, in axillary or lateral, "or more frequently interpetiolar (i.e. on one side between the petioles) cymes, racemes or umbels, rarely large and showy.

A large Order, chiefly tropical, with a few extratropical species as well in the New as the Old World, and in both the northern and southern hemispheres.

Corolla with a cylindrical tabe above $\frac{1}{2}$ in. long and spreading lobes . 6. Stephanotis.

Corolla rotate, or campanulate, or urceolate.

Corolla-lobes narrow-linear.

Stem twining. Staminal crown of 5 scales at the back of the anthers with internal appendages. Pollen-masses 4 to each anther

Stem erect. Scales 5, alteruating with the corolla-lobes. Pollenmasses 2 to each anther.

1. Toxocarpus.

8. Pentasacme.

Corolla-lobes ovate.

Leaves thick and fleshy.

Corolla small, with a globular tube of 1 line, and very short lobes .

9. Dischidia. 
Corolla broadly rotate, with scarcely any tube. : . . : 10, Hors.

Leaves membranous or coriaceous.

Stem erect. Corolla rotate

3. Asclepias.

Stem twining.

Corolla withont appendages between the lobes. Staminal corona of 5 lobes or scales on the gynostegium.

Corolla rotate, variegated, $\frac{1}{2}$ in. diameter or more. Pollenmasses pendulous .............

Corolla rotate, $\frac{1}{4}$ in. diameter. Pollen-masses transverse .

Corolla narrow-campanulate, very hairy at the throat. Pollen-masses erect

Corolla very small, nearly rotate, with scales between the lobes. No staminal corona . . . . . . . . .

2. Holosteman.

4. Tylophora.

\section{Marsdenia.}

7. Gymnema.

\section{TOXOCARPUS, Wight and Arn.}

Corolla rotate, with a very short tube; the lobes narrow-linear, slightly contorted in the bud. Staminal corona of 5 lobes or scales attached to the back of the anthers, and each with an appendage inside. Pollen-masses very small, attached in fours to the processes of the stigma. Stigma terminating in a long point or beak.-Twiners. Cymes axillary.

A genus confined to tropical Asia.

1. T. Wightianus, Hook. and Arn.; Done. in DC. Prod. viii. 506. A twiner, with the young branches pubescent. Leaves glabrous, elliptical or oblong, acute or very shortly acuminate, 1 to $2 \mathrm{in}$. long, obtuse at the base, on a petiole of 2 to 3 lines, which is often pubescent. Flowers in small sessile forked cymes, seldom half as long as the leaves. Pedicels very short. Sepals lanceolate, pubescent, about 1 line long. Corolla-tube not half so long; lobes narrow-linear, near 3 lines long, glabrous. Staminal corona longer than the anthers, the lobes ovate, with a flat lanceolate inner appendage fully as long. Stigma ending in a thin linear appendage twice as long as the anthers. Follicles thick, rusty-pubescent, about 2 in. long.-Schistocodon Meyeni, Schau. in Pl. Meyen. 363 ; Walp. Rep. vi. 479.

Hedges near West Point, Champion; also Wright. Not known out of S. China.

\section{HOLOSTEMMA, R. Br.}

Corolla rotate, with a very short tube; the lobes broadly ovate. Staminal corona annular, inserted at the base of the gynostegium, with 5 erect lobes or nearly entire. Pollen-masses pendulous, attached in pairs by their attenuated end. Stigma not beaked. Follicles smooth.-Twiners. Flowers not small, deeply coloured inside, in shortly pedunculate interpetiolar umbels or racemes.

A small tropical Asiatic species.

1. H. pictum, Champ. in Kew Journ. Bot. v. 53. A glabrous twiner. Leaves stalked, oblong, acuininate, 4 to 5 in. long, slightly cordate or rounded at the base, smooth and shining above, pale underneath. Flowers at first in an almost sessile umbel, which lengthens into a simple or forked raceme of 1 in. or more. Pedicels 3 to 5 lines long. Corolla glabrous, the lobes ovate, very obtuse, 4 to 5 lines long, elegantly variegated inside with purple and yellow. Staminal corona shortly annular, with 5 erect lobes, equalling the gynostegium, leaving broad intervals with a minute tooth in each. Follicles 2 to 3 in. long, very spreading, thick towards the base. 
In ravines of Mount Victoria, Champion; in the Happy Valley woods, Wilford; also Hance and Wright. Not known out of the island.

\section{ASCLEPIAS, Linn.}

Corolla rotate; the lobes valvate in the bud, at first spreading, then reflexed. Staminal corona attached to the top of the ginostegium, consisting of 5 erect hood-shaped lobes or scales, each with a horizontal horn-shaped process projecting from the base inside, and curved over the stigma. Pollen masses pendulous, affixed in pairs by their attenuated end. Stigma flattened at the top. Follicles smooth or with soft prickles.-Herbs, usually erect and little branched. Leaves opposite or whorled, rarely alternate. Umbels interpetiolar.

A considerable genus, all North American except where introduced, if the African genus Gomphocarpus be considered as really distinet.

1. A. curassavica, Linn.; Dene. in DC. Prod. viii. 566 ; Bot. Reg. t. 81. An erect perennial, 2 or 3 feet high, sometimes slightly woody at the base. Leaves opposite, lanceolate or oblong-lanceolate, acute, about 4 in. long, narrowed into a short petiole, glabrous on both sides. Umbels many-flowered, on peduncles shorter than the leaves. Corolla orange-red, about $\frac{1}{2}$ in. diameter, the lobes reflexed. Staminal body yellower, on a stalk of about a line. Hood-shaped scales of the staminal corona ovate, shorter than the inner curved horn. Follicles smooth and glabrous, 2 to $3 \mathrm{in}$. long, acuminate and narrowed into a stalk at the base.

Naturalized all over the island, Champion and others. A native of the West Indies, but now spread in great abundance over most inhabited tropical regions.

\section{TYLOPHORA, R. Br.}

Corolla rotate, with ovate or lanceolate lobes. Staminal corona of 5 entire scales, more or less adnate to the gynostegium at the back of the anthers, and usually short, without inner appendages. Pollen-masses transverse or ascending, very sinall, attached in pairs. Stigma not pointed. Follicles smooth.Twiners. Flowers small, in one or in several umbels, alternately sessile along an interpetiolar peduncle.

A considerable genus, spread over the tropical and southern regions of the Old World.

1. T. hispida, Dene. in DC. Prod. viii. 610. A softly hairy herbaceous twiner. Leaves usually ovate, minutely acuminate, rounded or slightly cordate at the base, 1 to $2 \mathrm{in}$. long, on a petiole of 2 to 3 lines; rarely broadly oblong or nearly orbicular. Peduncles 1 to 2 in. long or even more, usually bent in zigzag at each node or sessile umbel. Pedicels slender, 3 to 5 lines long. Flowers $2 \frac{1}{2}$ to 3 lines diameter. Staminal corona of 5 short orbicular gland-like scales, inserted near the base of the gynostegium, and scarcely reaching the base of the anthers.-Diplolepis apiculata, Lindl. in Trans. Hort. Soc. Lond. vi. 68.

Common in Hongkong, Champion and others. Also on the adjacent continent, but not known out of S. China.

\section{MARSDENIA, R. Br.}

Corolla campanulate or almost urceolate, rarely nearly rotate; the lobes short ; the throat frequently closed by a tuft of hairs, but sometimes glabrous. 
Staminal corona of 5 entire scales, inserted on the gynostegium behind the anthers, acute or acuminate, without inner appendages. Pollen-masses erect, ovoid, attached in pairs. Stigma convex or beaked.-Twiners. Flowers usually small, in cymes or dense bunches, on interpetiolar peduncles.

A considerable genus, chiefly found in tropical Asia or in Australia, with a few species scattered over tropical America, one Japanese and one S. European one.

Flowers scarcely $1 \frac{1}{2}$ lines long, turning a blue-black when dried, in dense oblong bunches. Corolla-lobes glabrous, except the hairs closing the throat . . . . . . . . . . .

Flowers 2 lines long, not turning blue, in a rather broad compact eyme. Corolla-lobes tomentose inside.

1. M. tinctoria.

2. M. lachnostoma.

1. M. tinctoria, R. Br.; Dcne. in DC. Prod. viii. 615 ; Wight, Ic. $t$. 589. A twiner, with the young branches softly pubescent, but becoming glabrous with age. Leaves stalked, ovate or oval-oblong, acuminate, cordate at the base, $1 \frac{1}{2}$ to 3 in. long, more or less pubescent when young, but nearly glabrous when full-grown. Peduncles about the length of the petioles, bearing a dense ovoid or oblong bunch of small flowers, drying of a bluish-black colour; in some continental specimens the bunch lengthens out into a clustered raceme of several inches. Sepals about $\frac{1}{2}$ line long, obovate and very obtuse. Corolla nearly $1 \frac{1}{2}$ lines long, narrow-campanulate; the lobes shorter than the tube, and quite glabrous, except the ring of erect hairs which closes the throat. Staminal corona of 5 narrow-lanceolate scales on the backs of the anthers and nearly as long. Stigma not beaked. Follicles hairy, reflexed, about 2 in. long.

In ravines of Mount Victoria, Champion. Common in Eastern Bengal and Assam, extending to Burmah and Java, and northward to Formosa.

2. M. lachnostoma, Benth., n. sp. A twiner, with the young branches and inflorescence slightly pubescent, but otherwise quite glabrous. Leaves oblong, obtuse or obtusely acuminate, 1 to 2 in. long, rounded or slightly cordate at the base, pale or glaucous underneath, on petioles of 3 to 6 lines. Peduncles longer than the petioles, bearing a compact cyme or compound umbel, much shorter than the leaf; the flowers larger than in $\boldsymbol{M}$. tinctoria, without any of the blue tint of that species. Pedicels about 1 line. Sepals about as long, ovate, rather obtuse. Corolla about 2 lines long, narrow-campanulate; the lobes rather shorter than the tube and tomentose inside, with a very dense tuft of woolly hairs closing the orifice, and a few reflexed ones in the upper part of the tube. Staminal corona of 5 thin ovate-lanceolate scales on the backs of the anthers and shorter than them. Stigma not beaked.

Hongkong, Wright. Not in any other collection, except perhaps a specimen in fruit from Canton in the Hookerian Herbarium, which has the same foliage and infloresence. The follicles are narrow, very divaricate or almost reflexed, 3 to 4 in. long, and glabrous.

\section{STEPHANOTIS, Thou.}

Corolla-tube cylindrical or slightly swollen at the base; the lobes oblique, spreading, contorted in the bud. Staminal-corona of 5 entire scales or lobes, attached or adnate to the gynostegium behind the stamens, without imer appendages. Pollen-masses erect, attached in pairs. Stigma conical or ovoid. Follicles spreading.-Twiners. Leaves opposite. Flowers large, usually sweet-scented, white, in pedunculate interpetiolar umbels. 
A genus of several species, from Madagasear or from the Indian Archipelago. The latter belong, with the Hongkong one, to a section with the seales of the staminal corona almost entirely adnate, the tips alone being free, and easily overlooked, constituting the genus Jasminanthes, Blume.

1. S. (Jasminanthes) chinensis, Champ. in Kew Journ. Bot. v. 53. A tall twiner, the young branches softly pubescent. Leaves ovate or oval-oblong, acuminate, cordate at the base, 2 to $4 \mathrm{in}$. long, minutely pubescent, especially on the veins, but becoming nearly glabrous on the upper side, on petioles of $\frac{1}{2}$ in. or more. Flowers white, sweet-scented at night, 2 to 6 together in irregular pedunculate umbels, the pedicels often above 1 in. long. Sepals oblong, 4 to 5 lines long. Corolla-tube about $\frac{1}{2}$ in., rather swollen below, marked inside with oblique hairy lines attaining the height of the gynostegium. Lobes lanceolate-faleate, 9 to 10 lines long. Staminal corona of 5 scales, almost entirely adnate, black when dry, the tips alone shortly free. Anthers terminated by a large oval-oblong concave membrane. Stigma ovoid at the top, as long as the anther-membranes.

Rare in the Happy Valley, Champion; on Mount Gough, Wilford; also Wright. Not known out of the island.

\section{GYMTEMA, R. Br.}

Corolla rotate; the lobes ovate, contorted in the bud, with small thick scales alternating with them, and 2 decurrent hairy lines in the very short tube. No staminal corona. Pollen-masses erect, ovoid, affixed in pairs. Follicles smooth. -Twiners. Leaves opposite. Flowers small, in almost sessile small interpetiolar umbels.

A small genus, confined to the tropical regions of the Old World.

1. G. affine, Dene. in DC. Prod. viii. 622. A twiner, with branches and inflorescence softly pubéscent. Ieaves obovate, oval, or oblong, obtuse or very shortly acuminate, 1 to $2 \mathrm{in}$. long, narrowed or rounded at the base, on a petiole of 3 or 4 lines, glabrous on both sides, the veins regularly pinnate and reticulate. Sepals very obtuse. Corolla about 2 lines diameter, with small broad fleshy scales turned inwards, alternating with the lobes. Stigma broadly and obtusely conical, projecting beyond the stamens. Follicles hard, about 2 in. long, broad and angular near the base.-G. sylvestre, var. chinensis, Benth. in Kew Journ. Bot. v. 54.

Near the Hongkong Magazine Guard, Champion; also Wright, and on the adjacent continent, but not known out of S. China. The Wallichian specimens described by Decaisne were from the Botanic Garden of Calcutta, introduced from China. The common Indian G. sylvestre, to which with Hooker and Arnott I had referred this species, is well distinguished by Decaisue, differing in the pubescence, form, and veuation of the leaves, the more dense inflorescence, the shape of the scales of the corolla, and the slender follicles.

\section{PENTASACME, Wall.}

Corolla nearly rotate, with linear lobes much longer than the tube, and 5 scales alternating with them. No staminal corona. Pollen-masses pellucid at the top, affixed near their base in pairs. Stigma conical or pointed. Follicles slender.-Herbs, with a perennial rhizome, and erect, usually simple stems. Peduncles short, axillary, bearing an umbel of 2 or very few flowers.

A genus containing besides the Chinese species only two from north-eastern India. 
1. P. Championi, Benth. in Kew Journ. Bot. v. 54. Stems simple, 1 to $1 \frac{1}{2} \mathrm{ft}$. high, glabrous, as well as the whole plant. Leaves narrow-lanceolate, acuminate, acute, 2 to $3 \mathrm{in}$. long, 3 to 4 lines broad, without the very long point of $P$. caudata, and not half so broad as in $P$. Wallichii. Flowers much like those of $P$. caudata, but 6 to 8 together, in shortly pedunculate umbels or very short racemes. Pedicels slender, 2 to 4 lines long. Sepals lanceolate, acute, about 1 line. Corolla-lobes about 4 lines long, very narrow, except at the base; the scales short, broad, truncate, and toothed at the top. Follicles linear or oblong-linear, broader near the base.

On rocks in waterfalls, Champion, Wilford; also Hance and Wright. Not known from elsewhere, unless it shonld prove to be a variety of the $P$. caudata from Silhet. Our specimens, however, appear to be constantly distinct in the shape of the leaves and some other points.

\section{DISCHIDIA, R. Br.}

Corolla urceolate, with a globular or ovoid tube, and obtuse spreading lobes, valvate in the bud. Staminal corona consisting of 5 scales inserted at the base of the gynostegium, linear, bifid, and spreading or recurved at the top. Pollen-masses erect, linear-oblong, attached in pairs. Stigma not beaked. Follicles smooth.-Stems usually creeping on rocks or trees, and rooting at the nodes. Leaves opposite, thick and fleshy, here and there in several species converted into pitchers. Flowers small, in axillary clusters or umbels.

A south Asiatic genus, chiefly abundant in the Indian Archipelago.

1. D. chinensis, Champ. in Kew Journ. Bot. v. 55. Stems succulent, but slender. Leaves ovate, $\frac{1}{2}$ to $\frac{3}{4}$ in. long, thick and fleshy, cuneate at the base, with a very short petiole. None of the specimens show any of the pitchers so frequent in the genus. Flowers in sessile axillary clusters. Sepals minute. Corolla with a globular tube rather more than 1 line diameter; the lobes ovate, obtuse, one half shorter with a few hairs in the throat.

In ravines on rocks, Mount Victoria, Champion; also Wright. Not known out of the island.

\section{HOYA, R. Br.}

Corolla rotate; the lobes ovate, valvate in the bud. Staminal corona of 5 scales inserted on the gynostegium, and usually spreading horizontally, the inner angle bearing a small tooth incumbent on the anther. Pollen-masses erect, oblong, attached in pairs. Stigma not beaked. Follicles smooth or with wing-like appendages.--Stems twining or creeping, and rooting at the lower nodes. Leaves opposite, often, but not in all the species, thick and fleshy. Flowers in lateral umbels.

A considerable genus, dispersed over tropical Asia, with one African species.

1. F. carnosa, R. Br.; Dcne. in DC. Prod. viii. 636. Stem succulent. Leaves from broadly ovate-cordate to oval-oblong, shortly acuminate, 2 to 3 in. long, thick and fleshy, on short petioles. Flowers succulent, in rather large umbels, on short common peduncles. Pedicels 1 to $1 \frac{1}{2}$ in. long, pubescent. Corolla expanding to a diameter of 7 or 8 lines, of a dull white, with a pink centre, the lobes broadly ovate, the gynostegium spreading like a star in the centre. Follicles linear, 3 or 4 in. long, smooth. 
On rocks, especially on Mount Victoria, Champion. Also on the adjoining continent. Not known for certain out of South China, but probably extending to Sikkim, as one specimen was found, without any indication of the precise station, among the Hoyas of Dr. Hooker's collection from that country.

\section{Order LXXII. LOGANIACEA.}

Calyx 4- or 5-lobed or -toothed, or the 5 sepals free. Corolla regular; the limb with 4 or 5 or rarely more lobes, valvate, contorted or otherwise imbricate in the bud. Stamens as many as corolla-lobes, alternate with them, inserted in the tube or very rarely reduced to 1 . Ovary free, 2-celled or rarely $3-$ to 5celled, or very rarely incompletely divided, the dissepiments not reaching quite to the centre. Style single, with an entire or lobed stigmatic summit. Ovules 1 or more in each cell of the ovary. Fruit a berry or capsule. Seeds albuminous. Embryo straight, often oblique, with leafy cotyledons.-Trees, shrubs, climbers, or rarely herbs. Leaves opposite, usually connected by interpetiolar stipules, or at any rate by a raised line.

A small Order, somewhat heterogeneous, and not very precisely defined, ranging over the tropical regions of both the New and the Old World, with a few extratropical species, either from the southern hemisphere or from North America.

Ovules several in each cell.

Sepals 5, distinct. Corolla 5-lobed, imbricate. Fruit capsular. Seeds winged. Woody twiner . . . . . . . . . . 1. Gelsemium.

Calyx 4- or 5-lobed.

Corolla valvate.

Slender erect annuals. Capsule 2-lobed at the top. . . . 2. Mrtrasacme.

Shrubs or climbers. Fruit a berry, with a hard rind . . . 4. Struchnos.

Corolla imbricate. Ereet shrub . . . . . . . . . 3. BundLeIA.

Orules solitary in each cell. 'Erect shrub . . . . . . . 5. Gdertnera.

\section{GELSEMIUM, Juss.}

Sepals 5, free, imbricate. Corolla funnel-shaped or narrow-campanulate, with 5 lobes, imbricate in the bud. Stamens 5. Ovary 2-celled, with several ovules in each. Style bifid at the top, with notched or bifid lobes. Capsule opening septicidally in 2 bifid valves, without leaving any central column. Seeds numerous, surrounded by an irregularly toothed membranous wing.Woody twiners. Leaves opposite, entire, without distinct stipules. Flowers in axillary clusters or terminal trichotomous cymes.

Besides the following, the genus comprises one other North American species.

1. G. elegans, Benth. in Journ. Linn. Suc. i. 90. A perfectly glabrous twiner. Leaves ovate or ovate-lanceolate, acuminate, 2 to $4 \mathrm{in}$. long, rounded or narrowed at the base, on a petiole of 3 or 4 lines. Flowers pale yellow, in dense terminal cymes. Bracts small and narrow, and only at the ramifications. Sepals about 1 line long, acute. Corolla 7 to 8 lines long, slightly spotted with red inside; the lobes ovate, acute, shorter than the tube. Stamens exserted from the tube, but shorter than the lobes. Capsule somewhat inflated, ovoid, about $1 \frac{1}{2}$ in. long.-Medicia elegans, Gardn. in Kew Journ. Bot. i. 325. Leptopteris sumatrana, Blume, Mus. Bot. i. 240, t. 34 .

Scarce in Hongkong, Champion; in a ravine ascending from West Point, Wilford; also 
Wright. More abundant on the hills of the opposite China coast, Champion. Also in Sumatra, if I do not err in identifying Blume's Leptopteris with this species.

\section{MITRASACME, Labill.}

Calyx 4-lobed or rarely 2-lobed. Corolla usually campanulate, 4-lobed, valvate in the bud. Stamens 4. Ovary 2-celled, with several ovules in each cell. Style simple, but splitting at the base as the flowering advances. Stigma entire or slightly 2-lobed. Capsule compressed, 2-lobed at the top, surmounted usually by the split style, and opening along the inner edge of the lobes. Seeds ovoid or globular.-Herbs, mostly annual. Leaves opposite, without stipules. Flowers small. Asia.

The genus comprises a considerable number of Australian species, with three from tropical

Leaves collected in distinct pairs along the lower part of the stem . . 1. M. capillaris. I eaves all rosulate at the base of the stem ... . . . . nudicaulis.

1. M. capillaris, Wall.; Benth. in Journ. Linn. Soc. i.92. A slender erect annual, 3 to 6 in. high or rarely drawn up to near a foot, more or less hairy at the base. Leaves collected in the lower part of the stem, but in distinct pairs, oblong or lanceolate, 3 to 6 lines long, more or less hairy, the upper ones at the branching of the inflorescence very few, small and bractlike. Flowers few, in an irregular terminal umbel. Calyx-lobes acute, from half as long to nearly as long as the corolla-tube. Corolla usually about 2 lines long, but varying in size, narrow-campanulate. Style entire at the time of flowering, but splitting at the base as the ovary enlarges.-M. malaccensis, Wight, Ic.t. 1601 .

On roadsides and in stony places, Champion, Wilford. Dispersed over various parts of India from the Peninsula to Nepal and to Malacca.

2. M. nudicaulis, Reinw.; Benth. in Journ. Linn. Soc. i. 92. This may be only a variety of $M$. capillaris, although usually considered as distinct. It is more slender, seldom above 4 in. high. Leaves all collected at the base of the stem and rosulate, from obovate to oblong, 3 or 4 lines long; the bracts at the base of the peduncles very minute. Flowers seldom above $1 \frac{1}{2}$ lines long.-M. chinensis, Griseb. in Pl. Meyen. 51.

Hongkong, Wright. In S. China, Khasia, and Sikkim.

\section{BUDDIEIA, Linn.}

Calyx 4-toothed or 4-lobed. Corolla with a short or long tube, and spreading or rarely erect limb of 4 short broad lobes, imbricate in the bud. Stamens 4, the anthers almost sessile. Ovary 2-celled, with several ovules in each cell. Style entire. Capsule opening septicidally in 2 entire or bifid valves, leaving the placenta free in the centre. Seeds numerous, small, more or less flattened, or obscurely winged. - Shrubs or rarely trees, with more or less of a mealy or woolly tornentum, rarely quite glabrous. Leaves opposite, entire or toothed. Flowers in cymes or clusters, either axillary or in terminal racemes or panicles; in soine species occasionally, but rarely, pentamerous.

A large genus, chiefly tropical and American, with a few Asiatic or African species.

Corolla-tube curved, full $\frac{1}{2}$ in. long . . . . . . . . . . 1. B. Lindleyana. Corolla-tube straight, 1 to 2 lines long. . . . . . . B. asiatica. 
1. B. Lindleyana, Fortune; Bot.Reg. 1846,t.4; Benth. in DC. Prod. x. 446. An erect shrub, with very little of the mealy tomentum of the genus, and chiefly on the young shoots and inflorescence. Branches slender, angular. Leaves from ovate to ovate-lanceolate or oblong, $1 \frac{1}{2}$ to 3 in. long, narrowed into a petiole of $\frac{1}{4}$ to $\frac{1}{2}$ in., thin, glabrous above, pale or slightly tomentose underneath. Flowers of a dull blue, in small clusters, all turned to one side, in a long terminal raceme. Calyx shortly toothed. Corolla tomentose, the tube curved and full $\frac{1}{2}$ in. long, the lobes short and ovate. Capsule reflexed, about $2 \frac{1}{2}$ lines long. Seeds compressed, with a loose testa occasionally expanding into a narrow wing.

Ravines south of Victoria Peak, Eyre; also on the adjacent continent, but only known from S. China. It may, however, prove to be only a variety of the $B$. curviflora, Hook. and Arn., from Loochoo. In the only specimen I have seen of the latter the branches are not angular, the leaves much larger, the tomentum more dense, and the flowers longer and more curved.

2. B. asiatica, Lour., Benth. in DC. Prod.x.446. A small tree or shrub, with the young branches, inflorescence, and under side of the leaves covered with a white or yellowish tomentum, sometimes very thin and close or mealy, sometimes very thick and almost woolly. Leaves lanceolate, acuminate, 3 to 6 in. long, entire or serrulate, on a very short petiole, usually glabrous on the upper side. Flowers in dense clusters, in racemes of 3 to 8 or $10 \mathrm{in.} \mathrm{long,}$ which are sometimes single and terminal, but more frequently 3 or more together at the ends of the branches or in the upper axils, forming a terminal panicle. Calyx usually nearly 1 line long, cottony or woolly. Corolla-tube shortly exceeding the calyx ; the lobes very short, obtuse or spreading. Capsule 2 to 3 lines long, usually spreading or reflexed.

Hongkong, Wright; on the opposite mainland, Champion. Widely spread over the hilly districts of southern Asia from the Peninsula to Nepal, Malacea, and the Archipelago.

There are two, often very marked, varieties which I had formerly, with other botanists, considered as distinct species; but we have now so many intermediate forms that we can no longer separate them, especially as they appear generally to accompany each other over the same geographical range. They are- (I) the original $B$. asiatica, much less tomentose and more slender, with flowers scarcely $1 \frac{1}{2}$ lines long, to which form belong the specimens gathered by Champion on the mainland opposite Hongkong; aud (2) B. Neemda, Ham., Benth. in DC. Prod. x. 446, which is coarser, much more tomentose, with the flowers from 2 to $2 \frac{1}{2}$ lines long. Wright's specimen belongs to this variety, although with characters much less marked than in some Indian ones.

\section{STRYCHNOS, Linn.}

Calyx 4- or 5-lobed. Corolla with a short or long tube, and 4 or 5 spreading lobes, valvate in the bud. Stamens 5, usually exserted. Ovary 2-celled, with several ovules in each cell. Style simple, with a capitate or obscurely 2-lobed stigma. Fruit a globular indehiscent berry, with the rind usually hard. Seeds imbedded in pulp, more or less compressed, and often reduced to one or very few in each fruit.-Shrubs, trees, or woody climbers. Leaves opposite, 3-nerved or 5-nerved at the base, with transverse reticulated veins, usually coriaceous and shining when full-grown. In the climbing species there are usually here and there spirally recurved hooks (abortive branches) in one of the axils; in which case the subtending leaf is usually reduced to a small 
bract, whilst the opposite leaf remains normal. Flowers in axillary or terminal cymes, clusters, or panicles.

A considerable genus, dispersed over the tropical regions of the New and the Old World.

Flowers in axillary penicles, the parts in fours. Corolla divided almost

to the base. Fruit searcely $\frac{1}{2}$ in. diameter

Flowers in small trichotomous terminal cymes, the parts in fives. Co-

rolla-tube as long as the lobes. Fruit full $1 \frac{1}{2}$ in. diameter

1. S. paniculata.

2. S. angustiflora.

1. S. paniculata, Champ. in Kew Journ. Bot. v. 57. A shrub or tree, glabrous except a slight pubescence on the inflorescence. None of the specimens show any thorns or hooks. Leaves ovate, $1 \frac{1}{2}$ to $2 \frac{1}{2}$ in. long, on very short petioles, coriaceous and shining when full-grown, although thin at the time of flowering. Flowers numerous, in axillary panicles, usually longer than the leaves. Calyx minute. Corolla-tube exceedingly short; the lobes usually 4 , rotate, rather more than a line long, with a tuft of woolly hairs at the base. Berry globular, nearly $\frac{1}{2}$ in. diameter, usually 1 -seeded.

In woods in the Happy Valley, Champion. In the Happy Valley and on Victoria Peak, Wilford; also Wright. On the adjacent continent, but not known out of S. China.

2. S. angustiflora, Benth. in Journ. Linn. Soc. i. 102. A woody climber, glabrous except a slight pubescence on the inflorescence, with here and there an axillary recurved hook 1 to $2 \mathrm{in}$. long, and sometimes the old branches become thorny. Leaves from orbicular to ovate-acuminate, $1 \frac{1}{2}$ to 3 in. long, on petioles of 2 or 3 lines, coriaceous and shining when old. Flowers in rather small trichotomous cymes, on short lateral leafy branches. Calyx very small. Corolla-tube $1 \frac{1}{2}$ to near 2 lines long; the limb of 5 narrow lobes, about the length of the tube, hairy at the base. Berry globular, red, full $1 \frac{1}{2}$ in. diameter.-S. colubrina, var.?, Benth. in Kew Journ. Bot. v. 56, not of Linn.

Common in the island, Champion and others. Not as yet received from elsewhere.

\section{GARTNERA, Lam.}

Calyx 5- or rarely 4-lobed or toothed. Corolla-tube cylindrical; the limb of 5 or rarely 4 lobes, valvate in the bud. Stamens as many, included in the tube. Ovary 2-celled, with 1 erect ovule in each cell. Fruit succulent, indehiscent, but readily separating into 2 cocci.-Shrubs or small trees. Leaves opposite, entire, with interpetiolar stipules often forming a short sheath within the leaves. Cymes or panicles terminal, trichotomous.

A considerable genus, ranging over tropical Asia, Africa, and Australia.

1. G.? hongkongensis, Seem. Bot. Her. 384 .

'This species is founded on some specimens of Champion's, evidently in a monstrous state, which I thought might have been those of an Apocyneous plant. The additional specimen, however, described by Seemann, has the lower perfect leaves with stipules like those of a Randia, and the plant may therefore possibly belong to Gartnera, to which Secmann refers it : but the genus must remain very doubtful until the plant is again found. The lower perfict leaves are broadly oblong, 2 or 3 in. loug, narrowed at the base but scarcely stalked; the stipules shortly sheathing, with a long point or bristle on each side. Flowers tetramerous, probably when perfect in a terminal cyme, which in these specimens grows out into leafy branches, some proceeding from the centre of a diseased flower. 


\section{Order LXXIII. GENTIANACE更.}

Sepals 4 or 5 , rarely more, usually more or less united in a lobed or toothed calyx. Corolla usually regular, with as many lobes as sepals, contorted in the bud. Stamens as many as corolla-lobes, and alternate with them, or very rarely fewer, inserted in the tube. Ovary 1 -celled, but with 2 parietal placentas often projecting into the cavity so as partially to divide it into 2 or 4 cells. Ovules numerous. Style single, entire, or with 2 short stigmatic lobes. Fruit a capsule, opening septicidally in two valves or very rarely an indehiscent berry. Seeds small, with a fleshy albumen. Embryo small, straight, with short fleshy cotyledons. - Herbs, or very rarely shrubs, usually glabrous and bitter. Leaves almost always opposite and entire, often 3- or more nerved at the base, without stipules. Flowers usually in cymes.

An Order chiefly abundant in the temperate or mountainous regions of the northern hemisphere, with a few tropical or southern species.

\section{EXACUM, Linn.}

Calyx deeply 4- or 5-lobed; the sepals keeled or winged on the back. Corolla rotate, persistent, with a short tube, becoming globose as the flower fades. Anthers opening in terminal pores. Ovary almost completely 2-celled. Style deciduous, with a capitate stigma. Capsule opening septicidally in 2 valves, usually leaving the placentas free.-Herbs, usually annual and quite glabrous. Flowers blue, purple-pink, or white, in terminal cymes.

A small genus, limited to tropical Asia.

1. E. tetragonum, Roxb.; Wall.Pl. As.Rar.t. 276 ; Bot.Mag.t. 4340; Griseb. in DC. Prod. ix. 44. An erect stout glabrous annual, 1 to 2 feet high, the stem usually simple and acutely 4 -angled or almost winged. Leaves sessile or stem-clasping, from broadly ovate to ovate-lanceolate or oblong, 5 nerved, the larger ones 2 to $4 \mathrm{in}$. long, the upper and lower ones much smaller. Flowers showy, blue or purplish. Calyx more or less winged on the angles; lobes 4 , very pointed. Corolla varying much in size, but the tube usually shorter than the sepals; the lobes ovate, acute, or scarcely obtuse, full $\frac{1}{2}$ in. long. Capsule nearly globular.-E. bellum, Hance in Walp. Ann. iii. 77. E. Horsfieldianum, Miq. Fl. Ned. Ind. ii. 556.

On the top of Mounts Victoria and Gough, Champion, Hance, Wilford, Wright. Common in uorthern and eastern India, and received also from Java, Sumatra, and the Philippines.

\section{ORDER LXXIV. BORAGINE正.}

Sepals 5 or rarely 4 , usually more or less united in a lobed or toothed calyx. Corolla regular or nearly so, 5-lobed, usually imbricate in the bud. Stamens 3, alternating with the lobes of the corolla and inserted in the tube. Ovary 4-celled and often deeply 4-lobed (consisting of two 2-celled carpels), with 1 ovule in each cell. Style inserted between the lobes of the ovary or terminal where the ovary is entire, simple, entire or once or twice bifid at the top. Fruit either a 4-seeded drupe or berry, or divisible into 2 or 4 , or consisting of 4 distinct sinall 1 -seeded nuts, having the appearance of naked 
seeds. Albumen none or very thin. Embryo usually straight, with flat or rarely folded cotyledons.-Herbs or rarely shrubs or small trees, often rough with stiff hairs arising from little tubercles. Leaves alternate, entire or toothed, without stipules. Flowers usually in one-sided simple or bifid spikes or racemes, or on the one-sided branches of a dichotomous cyme, which are often rolled back before the flowers expand.

A considerable Order, dispersed over almost every part of the globe; the arborescent or shrubby genera ehiefly tropical, the herbaceous ones more common in the temperate regions, especially of the northern hemisphere.

Tree: Ovary entire. Style 2-lobed. Fruit a drupe, with four 1-

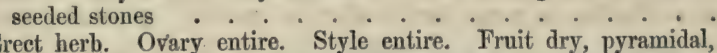
Erect herb. Ovary entire. Style entire. Fruit dry, pyramidal,
and separating into two 2 -seeded nuts (in the Hongkong species) Diffuse slender herb. Ovary 4-lobed. Style entire. Fruit of 4 seed-like nuts

1. Ehretia.

2. Heliotropium.

3. Bothriospermum.

\section{EHRETIA, Linn.}

Calyx 5-lobed. Corolla with a long or short tube and spreading lobes. Ovary entire, 4-celled, with 1 pendulous ovule in each cell. Style terminal, 2 -lobed at the top, with truncate or capitate stigmas. Fruit a berry or drupe, separable into 2 or 4 .- Trees or shrubs, smooth or rough, but not hairy as most Boraginea. Leaves entire or rarely serrate. Flowers usually in cymes or panicles.

A considerable tropical genus, spread over both the New and the Old World.

1. E. longiflora, Champ. in Kew Journ. Bot. v. 58. A glabrous tree. Leaves elliptical or oblong, acuminate, $2 \frac{1}{2}$ to 4 in. long, on a petiole of 3 to 5 lines, entire, quite smooth, with few distant veins. Flowers white or pink, in pedunculate cymes, shorter than the leaves. Calyx not a line long. Corollatube near 5 lines long, enlarged upwards; the lobes ovate, spreading, about 2 lines long. Stamens considerably longer. Style-lobes dilated and truncate at the top. Fruit nearly globular; 3 or 4 lines diameter, sulcate and angular when dry; the bony putamen readily separating into 4 , with 1 pendulous seed in each quarter.

In the Happy Valley woods and on Victoria Peak, and is also the tree which gives its name to One-tree Hill, Champion. In woods at Little Hongkong, Wilford; also Wright. Not known out of the island.

The E. serrata, Roxb., planted for its shade, has not been seen wild in the island.

\section{HELIOTROPIUM, Linn.}

Calyx usually deeply 5-cleft, rarely 5-toothed. Corolla-tube cylindrical; the limb spreading, 5-lobed. Anthers included in the tube. Style short, sometimes scarcely any, with a capitate or conical stigma. Ovary entire, 4celled. Fruit dry, separable either into four 1-seeded nuts or into 2, each one 2-celled and 2-seeded, which in ripening often leave between them cavities, sometimes called empty cells. Seeds without albumen.-Herbs or undershrubs, usually hairy. Leaves entire or rarely toothed. Flowers usually small, in unilateral spikes or dichotomous cymes.

A considerable genus, chiefly tropical or subtropical, both in the New and the Old World, with a few species extending into Europe, temperate Asia, or south Africa. 
1. F. indicum, Linn.; Bot. Mag. $t$. 1837. A coarse erect hairy annual, 1 to $2 \mathrm{ft}$. high, with spreading branches. Leave stalked, ovate or ovatecordate, $1 \frac{1}{2}$ to $3 \mathrm{in}$. long, rough with stiff hairs. Flowers pale-blue or white, in long terminal or leaf-opposed simple unilateral spikes. Calyx cleft to the base. Corolla-tube about 1 line long, Fruit pyramidal or mitre-shaped; the 2 carpels distinct almost from the base when ripe, each one containing 2 cells with 1 seed in each cell.-Heliophytum indicum, DC. Prod. ix. 556.

Waste places near the seashore, Champion. A species of uncertain origin, now a common weed throughout the tropies, both in the New and the Old World.

\section{BOTHRIOSPERMUM, Fisch. and Mey.}

Calyx deeply 5-cleft. Corolla-tube cylindrical; the limb spreading, with imbricate lobes; the mouth of the tube closed by 5 very obtuse scales. Anthers included in the tube. Ovary 4-lobed. Style very short, in the centre of the lobes, with a capitate stigma. Fruit of 4 distinct nuts, erect and attached by the base, convex and muricate or warted on the back, marked with a cavity on the inner side.-Herbs, with the habit of a Myosotis, and very small white or blue flowers.

A genus of very few species, all natives of temperate or tropical Asia.

1. B. tenellum, Fisch. and Mey.; DC. Prod. x. 116. A slender diffuse much-branched annual or biennial, usually 6 to 8 in. long, more or less clothed with appressed or spreading hairs. Leaves ovate or oblong, shortly stalked, usually about $\frac{1}{2}$ in. long, the upper floral leaves smaller. Flowers very small, white or pale blue, on short recurved pedicels, in the axils of the leaves or a little above. Corolla scarcely above 1 line long. Fruiting calyx growing out to $1 \frac{1}{3}$ or even 2 lines long.

A weed in rice-fields, Champion; also Wright. Dispersed over various parts of India, extending southward to the Manritius and northward to China and Mantchuria.

\section{Order LXXV. CONVOLVULACE .}

Sepals 5, persistent, distinct, and much imbricated or very rarely united in a 5-toothed calyx. Corolla usually regular, campanulate or funnel-shaped, or rarely with a cylindrical tube or rotate; the limb 5-folded, 5-angled, or 5lobed. Stamens 5, alternate with the lobes or angles of the corolla and inserted in the tube, often of unequal length. Ovary usually free, entire, 2- to 4-celled, with 1 or 2 erect ovules in each cell, rarely divided into 2 or 4 distinct uniovulate carpels, or 1-celled, with 2 or 4 ovules. Style single or more or less deeply divided into 2. Fruit either a capsule opening in 2 to 4 valves, leaving the dissepiments attached to the axis, or opening transversely, or succulent and indehiscent. Seeds with a small quantity of mucilaginous albumen or without any. Cotyledons usually very much folded, rarely straight or imperceptible.-Herbs, often twining or parasitical, or rarely shrubs, woody climbers or even trees. Inflorescence various, usually axillary and more or less cymose.

A considerable Order, widely spread over almost every part of the globe, but most abun. dant in warm countries. 
Stigma sessile. Tall woody evergreen climbers. Fruit a berry . . 1. EryciBk.

Style filiform, entire or bifid at the top.

Stigma capitate or with 2 short round lobes.

Fruit a berry. Tall woody twiners. . . . . . 2. ARgrria.

Fruit a dry capsule. Herbs prostrate or twining - . 3. IромжA.

Stigmatic lobes flattened, oblong or linear . . . . . . 4. JAcQuemontia.

Styles 2, distinct.

Stems leafy.

Styles bifid. Ovary 2-celled. Stems erect or diffuse ... . . 5. Evolvulus.

Styles entire. Carpels 2, distinct. Stems prostrate or creeping 6. Dichondra.

Leafless parasites, not green. Stems filiform . . . . . 7. Cuscuta.

\section{ERYCIBE, Roxb.}

Corolla broadly campanulate or almost rotate, with a very short tube and 5 deeply bifid lobes. Ovary l-celled, with 4 erect ovules. Stigma sessile, thick, readily divisible into 2 , but marked outside with 5 or 10 angles or furrows (the result of the impression of the folds of the corolla or of the stamens in the bud). Fruit an indehiscent berry, containing usually a single seed. Cotyledons folded.-Tall woody climbers. Leaves entire, coriaceous, usually glabrous. Flowers not large, in cymes or clusters, usually forming axillary or terminal racemes or panicles.

A small genus, confined to tropical Asia.

1. E. obtusifolia, Benth., n.sp. Probably a tall woody climber like the other species, although the specimens show no appearance of twining. Branches glabrous. Leaves oblong, obtuse, 3 to 4 in. long, narrowed at the base, with a petiole of 4 to 6 lines, coriaceous and shining, never acuminate as in $\mathrm{E}$. paniculata and E.glaucescens. Cymes few on short peduncles in the lower axils, more numerous in the upper ones; but the racemes are in all the specimens shorter than the leaves, not forming large terminal panicles as in $\boldsymbol{E}$. paniculata. Sepals orbicular, a little more than a line long, hairy outside. Corolla about 3 lines long; the part exposed in the bud very hairy outside, the rest glabrous. Berry ovoid, above $\frac{1}{2}$ in. long.-E. glaucescens, Hook. and Arn. Bot. Beech. 201 ; not of Wallich.

Hongkong, Champion. Also on the adjacent continent, but not known out of S. China. The $E$. glaucescens, Wall, to which these specimens have been referred, does not appear to be specifically distinct from the common Jndian $E$. paniculata.

\section{ARGYREIA, Lour.}

Corolla either narrow-campanulate or almost funnel-shaped, and entire or angular or else deeply lobed and almost rotate. Ovary 2 -celled, with 2 orules in each cell, or 4-celled by the addition of a spurious partition between the ovules. Style filiform. Stigma capitate, entire or with 2 short round lobes. Fruit succulent and indehiscent. Seeds 4 or fewer; cotyledons folded.Tall, usually woody twiners. Leaves entire or rarely lobed, usually hairy or silvery white underneath. Cymes in the upper axils, or forming terminal leafy panicles. Flowers usually large and showy.

A tropical genus, chiefly Asiatic, but with a few African or American species. It only differs from Ipomae in the succulent fruit, for the habit, although general, is not constant.

1. A. Championi, Benth., n.sp. Young branches, and under side of the 
leaves covered with a close hoary or silky pubescence. Leaves on long stalks, ovate, acute, 3 to $4 \mathrm{in}$. long, rounded at the base, quite entire; the upper surface more or less pubescent with small appressed hairs, sometimes almost silky. Cymes of 4 to 6 flowers, on peduncles seldom above an inch long. Bracts either none or very deciduous. Sepals broad, concave and very obtuse, very tomentose and 3 or 4 lines long at the time of flowering, enlarged and more loosely hairy outside, red and glabrous inside when in fruit. Corolla-tube glabrous, cylindrical, rather longer than the calyx, then enlarged into a campanulate limb above an inch long, hairy on the outer folds, the edge not lobed. Berry globular, crimson.-A. acuta, Benth. in Kew Journ. Bot. v. 57, but probably not of Loureiro.

Ravines of Mount Victoria, Champion. At Little Hongkong, Wilford; also Hance. Not known from elsewhere. It is, however, nearly allied to the north-east Indian A. splendens, Sweet. It differs in the leaves less silky underneath but always pubescent above; in the larger sepals; and in the hairiness of the corolla as well as in its shape, as far as can be judged of in the very few specimens we possess. I had thonght it might have been the $\boldsymbol{A}$. acuta of Loureiro, as it agrees well with his specific description; but it has not the deeply lobed corolla given by that author as one of the generic characters, and is certainly not the A. festiva, Wall., referred by Choisy to Loureiro's plant.

\section{IPON. mA, Linn.}

Corolla campanulate or tubular, with a spreading limb, entire or angular, rarely deeply lobed. Ovary 2 - or 3 -celled, with 2 ovules in each cell, or 4celled by the addition of a spurious partition between the ovules. Style filiform. Stigma capitate, entire, or with 2 short round lobes. Fruit a dry capsule.--Twining, prostrate, creeping, or rarely low and erect herbs, occasionally woody at the base, or very rarely shrubby. Leaves entire, lobed, or divided. Flowers often large and showy, solitary or more frequently in small cymes in the axils of the leaves.

A large genus, dispersed over all warm climates, with a very few species extending into N. America, or into extratropical Africa or Australia.

Leaves digitate, with $\mathbf{5}$ segments

Leaves entire, or slightly 3 -lobed.

Leaves petiolate, thick, broadly emarginate or 2-lobed

Leaves nearly sessile, cordate-lanceolate or linear. Peduncles slender. Seeds glabrous

Leaves petiolate, oblong or cordate-lanceolate. Peduncles short. Seeds very woolly

Leaves cordate-ovate, acnte or acuminate.

Corolla-tube 3 or 4 in. long. Limb flat, 4 or 5 in. diameter . . 5. I. bona-nox. Corolla not $\frac{1}{2}$ in. long.

Plant glabrous. Peduncles several-flowered. Sepals coriaceous, obtuse, narrowed at the base . . . . . . . . .

Plant hairy. Peduncles 1-flowered. Sepals herbaceous, the outer ones cordate at the base .

1. I. quinata.

2. I. pes-capre.

3. I. filicaulis.

4. I. cymosa.

6. I. chryseidis.

7. I. sinensis.

(Dr. Hance writes to me that several other species of Ipomaa grow in Hongkong, and amongst them the $I$. pileata, Roxb., easily known by its flowers capitate within two connate bracts, but as I have seen no specimens, I have been unable to insert them.)

1. I. quinata, Br.; Chois. in DC. Prod. ix. 385. A rather slender twiner, either glabrous or more frequently with a few spreading hairs on the lower part of the stem and on the petioles. Leaves digitate, with 5 distinct 
lanceolate or narrow-oblong obtuse entire segments, 1 to $1 \frac{1}{2} \mathrm{in}$. long, contracted at the base. Peduncles usually l-flowered and shorter than the leaves. Sepals ovate, the outermost about 3 lines long, the innermost twice as long. Corolla near 2 inches long (pale pink ?), the tube dilated upwards into a broadly campanulate shortly 5 -lobed limb. Ovary 2-celled.-I. pentadactylis, Chois. in DC. Prod. ix. 385.

Hongkong, Champion; also in Burmah, and in tropical Australia. Seemann (Bot. Her. p. 401) by some mistake refers this to the $I$. tuberculata, R. and S., of which there are some specimens in Hance's collection from Hongkong gardens. The latter species, probably the same as I. palmata, Forst., is not uncommon in tropical Africa and Asia, but I have seen no wild specimens from Hongkong. It is readily distinguished in the dried state by the iuner sepals being about the length of the outer ones, instead of twice as long, besides minor differences in the shape of the leaf-segments and of the corolla. It has also the seeds bordered at least with long hairs, and they are said to be glabrous in I. quinata. Our specimens of the latter are not in fruit.

2. I. pes-capræ, Swartz; Chois. in DC. Prod. ix. 349. A glabrous perennial, with long prostrate or creeping stems. Leaves on long petioles, oval, obovate, or orbicular, broadly emarginate or very obtusely 2-lobed at the top, 2 to $3 \mathrm{in}$. long, rather thick, with nearly parallel oblique veins, the lower ones converging at the base of the leaf. Peduncles in the upper axils 1- or fewHowered. Sepals oval, obtuse, about 3 lines long, or the inner ones rather longer. Corolla pink, campanulate, obscurely lobed, about $1 \frac{1}{2}$ in. long. Ovary 4-celled, or at least partially so, at the time of flowering. Capsule 2-celled, oblong or ovoid, about $\frac{1}{2}$ in. long. Seeds hairy.

On the seashore near Victoria, Hance. A common seacoast plant in almost all tropical countries, but more especially in the Old World.

3. I. filicaulis, Blume; Chois. in DC. Prod. ix. 353. A glabrous annual, with slender prostrate or twining stems, and usually drying of a brownish-black colour. Leaves on very short petioles, or almost sessile, linear-lanceolate or linear, cordate or hastate, and often toothed at the base, 1 to $1 \frac{1}{2}$ in. long. Peduncles slender, longer than the leaves, 1- or 2-flowered. Sepals ovate-lanceolate or lanceolate-acuminate, about 3 lines long. Corolla yellowishwhite, $\frac{1}{2}$ to $\frac{3}{4}$ in. long.

In sunny places, Hance. Frequent in tropical Asia and Africa, occurring also in tropical Australia, and in some parts of tropical America.

4. I. cymosa, Room. and Schult.; Chois. in DC. Prod. ix. 371; Bot. Reg. $1843, t .24$. A rather coarse twiner, glabrous or with the young shoots more or less pubescent, usually turning dark brown in drying. Leaves stalked, from narrow-ovate to oblong or almost lanceolate, shortly acuminate or obtuse, 2 to $3 \mathrm{in}$. long, the larger ones broadly cordate or almost sagittate at the base, the narrow ones rounded at the base. Flowers pure white, or with a yellow eye, in cymes of 6 to 12 or even more, rarely solitary or nearly so, on a short rather thick common peduncle. Sepals 3 or 4 lines long, glabrous, coriaceous, nearly equal in length. Corolla campanulate, above an inch long, scarcely lobed, often hairy at the top. Ovary 2-celled. Seeds hairy.

On the seashore, Hance. A common species in the greater part of India and the Archipelago.

5. I. bona-nox, Linn. A glabrous twiner often of great size. Leaves on long petioles, broadly cordate-ovate, acuminate with a long point, 3 to 
6 in. long. Peduncles 2 to 4 in. long, bearing 3 to 6 large white flowers, usually forming a simple one-sided raceme. Sepals acuminate, $\frac{1}{2}$ in. long or more. Corolla-tube near $4 \mathrm{in}$. long, slender, scarcely enlarged at the top; the limb opening almost flat, near 5 in. diameter. Stamens and style projecting from the tube.-Calonyction speciosum, var. vulgare, Chois. in DC. Prod. ix. 345 ; Wight, Ic. t. 1361 .

On the outskirts of woods, Hance. Widely spread over the tropical regions of the Old and the New World, but perhaps introduced into the latter, being much cultivated in gardens. The I. muricata referred here by Choisy as a variety, is a totally different species. It has not the "stamina exserta" of the true bona-nox, whilst the latter has not the "corolla infundibuliformis" of I. muricata, although both of these characters are given as essential to the genus Calonyction.

6. I. chryseidis, Ker, Bot. Reg.t. 270 ; Chois. in DC. Prod. ix. 382. A slender glabrous twiner. Leaves on long petioles, broadly ovate-cordate or almost hastate, acuminate, 1 to 2 in. long, entire or with 2 broad rounded and sometimes toothed basal lobes. Peduncles as long as the leaves or nearly so, with 2 spreading branches, each bearing 2 to 4 small flowers, with 1 in the fork. Sepals glabrous, coriaceous, oblong or almost ovate, ol,tuse or truncate, nearly equal, about 2 lines long. Corolla yellow, broadly campanulate, about 5 lines long. Capsule glabrous, usually marked with 4 raised angles.

In open places, Hance. Common in tropical Asia.

7. I. sinensis, Chois.; DC. Prod. ix. 370. A herbaceous twiner, hoary with rather long stiff hairs, reflexed on the stem, more or less spreading on the leaves and calyxes. Leaves stalked, broadly heart-shaped, entire or obscurely 3-lobed. Peduncles axillary, 1 -flowered, rather shorter than the petioles. Flowers about $\frac{1}{2}$ in. long. Sepals herbaceous, the outer ones 3 lines long, broadly cordate-lanceolate, the inner ones narrower, lanceolate, and rather shorter. Corolla narrow-campanulate, not lobed. Stigma, as in the rest of the genus, of 2 rounded lobes. Ovary 2-celled.

Hongkong, Hance. Only known from S. China. This species has all the characters of Aniseia, which however can scarcely be considered otherwise than as a section of Ipomea.

\section{JACQUEMONTIA, Chois.}

Corolla usually broadly campanulate, angular or broadly 5-lobed. Ovary 2 -celled, with 2 ovules in each cell. Style filiform, bifid at the the top, with 2 flattened usually oblong stigmatic lobes. Fruit a dry capsule--Herbs, mostly twining, and sometimes woody at the base. Leaves entire or slightly lobed. Flowers rather small, in axillary pedunculate cymes.

A small tropical genus, chiefly American, with at least one Asiatic species. It is intermediate, as it were, in the shape of the stigma between Ipomaea and Convolvulus.

1. J. violacea, Chois. in DC. Prod. ix. 397. A herbaceous twiner, sometimes nearly glabrous, but usually more or less pubescent. Leaves stalked, heart-shaped, acuminate, entire, 2 to 3 or even 4 in. long, usually more glabrous than the rest of the plant. Peduncles about as long as the leaves, bearing a ciense cyme of blue flowers. Sepals $2 \frac{1}{2}$ to 3 lines long, the outer ones ovate-cordate, acuminate, and always softly pubescent, sometimes enlarging when in fruit to 5 lines. Corolla broadly campanulate, about $\frac{1}{2}$ in. long. Stigmatic lobes broadly linear, obtuse, recurved.-Convolvulus 
ianthinus, Hance in Walp. Ann. iii. 13. C. pentanthus, Jacq. ; Bot. Reg. 439 ; Bot. Mag. t. 2151.

Naturalized in ravines above Victoria, Champion; also Hance. It is a West Indian species, frequently cultivated in tropical gardens. In the dried state it is scarcely to be distinguished from the Convolvulus parviftorus, Vahl, which is common in tropical Asia, and is also a Jacquemontia, but has rather smaller white flowers.

\section{EVOLVULUS, Linn.}

Corolla campanulate or tubular at the base, angular or lobed. Ovary 2celled, with 2 ovules in each cell. Styles 2 , filiform, distinct from the base, and bifid at the top. Fruit a dry capsule.-Herbs, not twining, annual or with a perennial sometimes woody stock. Leaves entire, usually small, and nearly sessile. Flowers small, on axillary peduncles, or in terminal spikes or racemes.

A considerable tropical American genus, of which one or two species are spread also over the warmer regious of the Old World.

1. E. alsinoides, Linn.; Chois. in DC. Prod. ix. 447. A perennial, with a short almost woody stock, but often flowering the first year so as to appear annual, with numerous slender stems 6 in. to $1 \mathrm{ft}$. long; the whole plant more or less silky-hairy. Leaves usually oblong or lanceolate, sessile or nearly so, 3 to 6 lines long, but varying from ovate to almost linear, obtuse or acute. Flowers small, pale blue or white, 1 to 3 together on slender axillary peduncles longer than the leaves, with a small bract at each pedicel. Sepals narrow, acute. Corolla almost rotate, not 3 lines diameter.-E. linifolins, Linn.; Chois. l.c. 449 , and probably some others enumerated by Choisy. $E$. pudicus, Hance in Walp. Ann. iii. 115.

Roadsides and grassy places, Hance; also Wright. Common within the tropics both in the New and the Old World.

\section{DICHONDRA, Forst.}

Corolla campanulate, deeply 5-lobed. Ovary of 2 distinct carpels, with 1 ovule in each. Styles 2, distinct from the base, with thickened stigmas. Fruit of 1 or 2 membranous 1 -seeded capsules.-Prostrate herbs, with small flowers.

A genus containing only one other South American species, closely allied to the following.

1. D. repens, Forst.; Chois. in DC. Prod. ix. 451. A slender creeping perennial, rooting at the nodes, usually hoary with a minute pubescence, often silky. Leaves orbicular or reniform, 4 to 8 lines or rarely 1 in. diameter, on long petioles, and quite entire. Flowers solitary, on axillary pedicels, 2 to 4 lines long. Sepals obovate, scarcely 1 line long. Corolla rather shorter, yellow. Capsules also shorter than the calyx.

Hongkong, Hance. Widely diffused over the tropical and subtropical regions both of the New and the Old World.

\section{CUSCUTA, Linn.}

Corolla campanulate, ovoid or globular, with a short 5-lobed or rarely 4lobed limb. Anthers usually nearly sessile, with a scale below each in the 
base of the tube of the corolla. Ovary completely or partially 2-celled, with 2 ovules in each. Styles 2, distinct, or more or less united. Fruit a dry or searcely succulent capsule, usually opening transversely. Embryo spiral or curved round a fleshy albumen.--Stems leafless, thread-like, parasitical, usually bearing sessile clusters of small white or pink flowers.

A considerable genus, dispersed over every part of the globe, except the extreme north and south.

1. C. japonica, Chois.; Engelm. Spec. Cusc. 67 (Trans. Acad. St. Louis, i. 517). Steins not so slender as in most species. Flowers sessile or on very short thick pedicels, solitary or more frequently clustered, with a broad scalelike bract under each flower or pedicel. Sepals $\frac{1}{2}$ line long, ovate, obtuse. Corolla broadly tubular, 2 to 3 lines long, with 5 short spreading or reflexed lobes. Anthers oval, nearly sessile at the mouth of the tube; staminal scales near the base, ovate or oblong, fringed. Ovary globular, with a central axis, but not completely divided into 2 cells. Style nearly as long as the corollatube, entire or shortly bifid, with thick oblong stigmas. Capsule thick, ovoid, above 3 lines long.

In woods at Little Hongkong, Champion, Wilford; also Wright. In China, Mantehuria, and Japan.

\section{Order LXXVI. SOLANACEXE.}

Flowers regular or nearly so. Calyx usually with 5 , rarely with 4,6 , or 10 teeth, lobes, or segments. Corolla with 5 or rarely with 4 teeth or lobes, folded or rarely imbricate in the bud. Stamens as many as the lobes of the corolla, and alternating with them. Ovary superior, 2-celled, or rarely incompletely 4-celled, with several ovules in each cell. Style simple, with an entire or lobed stigma. Fruit an indehiscent berry, or rarely a capsule, with several seeds. Albumen copious, fleshy. Embryo usually curved or spiral surrounding the albumen, more rarely straight and central.-Herbs, shrubs, or softwooded trees. Leaves alternate, without stipules.

A numerous Order, in the tropical and warmer regions of the globe, with a very few species straying into more temperate climates. A large proportion of the species contain more or less of a narcotic poisonous principle, although several are anong the more important articles of food.

Fruit a prickly capsule. Corolla large, with a long tube . . . . . . 5. Darura.

Fruit a berry. Corolla rotate, campanulate, or with a short tube.

Calyx inflated after flowering. Corolla campanulate.

Calyx deeply 5 -lobed, cordate at the base . . . . . . . 3. Nicandra.

Calyx shortly 5-lobed . . . . . . . . . . . . 2. Physalis.

Calyx not inflated, though often enlarged after flowering.

Corolla rotate. Anthers erect and connivent, much longer than their filaments . . . . . . . . . . .

Corolla contracted into a tube at the base. Anthers shorter than their filaments .

\section{Solanum.}

4. Lycium.

\section{SOIANUIM, Linn.}

Corolla rotate or slightly cup-shaped, 5-angled or 5-lobed, folded in the bud. Anthers on very short filaments, oblong or linear, erect and comivent 
in a cone round the style, opening at the top in 1 or 2 pores, without any prominent connectivum between the cells. Fruit a 2 -celled berry.-Herbs, shrubs, or low soft-wooded trees. Leaves entire or irregularly toothed, lobed, or divided, often in pairs, a smaller one being developed in the axil of the larger one. Flowers solitary, or more frequently in short racemes or cymes, on lateral or terminal peduncles, sometimes paniculate.

A very large genus, with the geueral geographical range of the Order.

No prickles. Plant glabrous or softly pubescent.

Calyx 5-toothed

1. S. nigrum.

Calyx 10 -toothed more or less tomentose, with stellate hairs.

Anthers not above 2 lines long, and not acuminate.

Flowers all fertile, in short loose racemes. Berry 4 or 5 lines diameter

2. S. decemdentatum.

Fertile flowers quite solitary, or single at the base of a 1 -sided raceme of sterile ones. Berry an inch diameter . . . .

Anthers 5 to 7 lines long, narrowed upwards.

Calyx 3 lines long. Corolla-lobes lanceolate. Berry very hairy

Calyx 7 to 8 lines long. Corolla-lobes very broad and short .

\section{S. indicum}

4. S. sanctum.

5. S. ferox.

6. S. Wrightii.

1. S. nigrum, Linn. An erect annual or biennial, with very spreading branches, from 1 to near $2 \mathrm{ft}$. high, glabrous or nearly so in the Hongkong specimens, in some others hairy or rough on the angles. Leaves stalked, ovate, 1 to 2 in. long, with coarse irregular angular teeth or nearly entire. Flowers small and white, in little cymes almost contracted into umbels, on short lateral peduncles. Calyx 5-toothed. Corolla deeply 5-lobed, 3 to near 4 lines diameter. Anthers not acuminate. Berries small, globular, usually black, but sometimes green, yellow, or dingy-red.-Solanum " Morelle vere," Dun. in DC. Prod. xiii. pars i. 45 to 59 , as to the greater number of the supposed species included in the group.

In waste places, Champion and others. A common weed in all the warmer and most of the temperate parts of the globe.

2. S. decemdentatum, Roxb.; Dun. in DC. Prod. xiii. part i. 179. An annual or biennial, like the last, but usually larger and coarser, and always pubescent or hairy. Leaves stalked, ovate, acuminate, entire or slightly sinuate, 2 to 4 in. long. Pedicels 1 -flowered, axillary, sometimes solitary, but usually 2 to 5 or 6 together, 2 to 4 lines long, more or less recurved and hairy. Calyx short, truncate, with 10 linear lobes or teeth, sometimes very short, sometimes $1 \frac{1}{2}$ lines long. Corolla (white?) about 4 lines diameter, 5lobed to about the middle. Anthers not acuminate. Berries red, glabrous, 3 to 4 lines diameter.-S. mollissimum, Blume; S. biflorum, Lour.; S. Calleryanum, Dun.; and S. Osbeckii, Dun. in DC. Prod. xiii. pars i. 178, 179.

Hougkong, Champion. In Khasia, Mergui, the Archipelago, and northward to S. China, Loochoo, and Bonin.

3. S. indicum, Linn. (partly); Dun. in DC. Prod. xiii. part i. 309 ; Wight, Ic. t. 346. Stem shrubby at the base; the branches, leaves, and inflorescence thickly covered with a hoary, close, but soft stellate tomentum. Prickles stout, and mostly recurved on the branches, usually straight on the petioles and nerves of the leaves. Leaves stalked, ovate, irregularly and ob- 
tusely sinuate or lobed; the larger one of each pair 3 to $4 \mathrm{in}$. long. Flowers 3 to 6 , in short loose lateral racemes, all fertile; the common peduncle seldom above $1 \frac{1}{2}$ in. long, the pedicels full $\frac{1}{2}$ in. Calyx more or less prickly on the back; the lobes lanceolate, about 2 lines long when in flower and not much enlarged afterwards. Corolla tomentose outside, 8 or 9 lines diameter, divided to about the middle into 5 ovate lobes. Anthers about 2 lines long, not acuminate. Berry globular, glabrous, 4 or 5 lines diameter.

In waste places, Hance, Wilford. Frequent in India and in the Archipelago.

4. S. sanctum, Linn. Stem shrubby at the base; the branches, leaves, and inflorescence hoary with a soft stellate tomentum, as in S. indicum, and the prickles and foliage are also much the same. Fertile flowers on a stout lateral pedicel of $\frac{1}{2}$ to 1 in. long, either quite solitary or more frequently at the base of a one-sided raceme of sterile although apparently perfect flowers, which soon fall away. Calyx very tomentose, campanulate, with 5 or 6 short spreading teeth or lobes. Corolla about $\frac{3}{4}$ in. diameter, tomentose outside, with short broad lobes. Anthers of S. indicum. Fruit globular, glabrous, at least 1 in. diameter, surrounded at the base by the more or less enlarged calyx, often prickly on the back.-S. Cumingii, S. schoenbrunnense, S. hierochuntinum, and some others of Dun. in DC. Prod. xiii. pars i. 363, 365, 369, etc.

In waste places, Wilford, Wright. A common roadside weed over a great part of India, western Asia, and north-eastern Africa.

5. S. ferox, Linn.; Dun. in DC. Prod. xiii. part i. 255 ; Wight, Ic. $t$. 1399 and 1400. A coarse erect or spreading biennial, or perhaps with a perennial stock; the stems hard and almost woody at the base, and the whole plant thickly covered with a velvety or almost woolly down. Prickles straight, sometimes small and very numerous, sometimes long and stout. Leaves ovate, irregularly and obtusely sinuate, toothed or lobed, the larger one of each pair often 8 to $10 \mathrm{in}$. long by 6 or more in. broad. Peduncles 1-flowered, axillary, solitary or few together, short and very hairy. Calyx at the time of flowering about 3 lines long, with 5 ovate-acute lobes, and very hairy. Corolla hairy outside, near $1 \frac{1}{2}$ in. diameter, deeply divided into 5 lanceolate lobes. Anthers 5 or 6 lines long, narrowed upwards. Berry about 1 in. diameter, thickly covered with long yellowish hairs. - S. stramonifolium, Dun. (but not of Jacq.), S. lasiocarpum, Dun., and S. involucratum, Blume; Dun. in DC. Prod. xiii. pars i. 252 and 255. S. hirsutum, Roxb. Fl. Ind. i. 571. S. immane, Hance in Walp. Ann. iii. 165.

On roadsides, Champion and others. In eastern India and the Archipelago, and northward to the Philippines and S. China.

6. S. Wrightii, Benth., n. sp. Branches and petioles hispid wth stiff stellately branched hairs or bristles, and armed with a few straight stout prickles. Larger leaves near $1 \mathrm{ft}$. long by 6 or 8 in. wide, almost pinnatifid, with irregular ovate or lanceolate lobes, rough on the upper side with bristlelike simple hairs, coarsely stellate-hairy underneath. Flowers very large, in bifid lateral cymes. Pedicels above $\frac{1}{2}$ in. long, very hispid. Calyx 7 or 8 lines long, very hispid, deeply divided into 5 lanceolate lobes with long subulate points. Corolla full $2 \frac{1}{2}$ in. diameter, broadly 5 -lobed, the lanceolate centre of each lobe hairy outside, the intermediate portions broad and glabrous. Anthers about 7 lines long, narrowed upwards and slightly curved. 
Hongkong, Wright. Not seen in any other collection. It is with much hesitation that I publish a new species of so vast and confused a genus as Solanum. But I have endeavoured in vain to match this fine plant either with any specimen in our herbaria, or with any of Dunal's diagnoses. It appears to belong to his group of Melongenas.

\section{PHYSALIS, Linn.}

Calyx 5-toothed or 5-lobed, inflated after flowering. Corolla broadly campanulate or nearly rotate, 5 -angled, folded in the bud. Anthers short, opening longitudinally. Ovary 2-celled. Berry globular, enclosed in the inflated calyx. - Herbs either annual or with a perennial stock. Leaves often in pairs. Flowers solitary, on axillary or lateral pedicels.

$\Lambda$ genus rather numerous in America, one or two species extending over the warmer regions of the Old World as well as the New.

1. P. angulata, Linn.; Dun. in DC. Prod. xiii. part i. 448. A glabrous annual, with very spreading branches, 1 to $2 \mathrm{ft}$. high. Leaves on long petioles, ovate, oblong or almost lanceolate, usually acute, with a few coarse irregular teeth. Flowering calyx about $1 \frac{1}{2}$ lines long, with 5 triangular acute rather short lobes, truncate at the base. Corolla about twice as long, pale yellow, often marked with 5 purple spots. Fruiting calyx above 1 in. long, 5angled, with 5 short connivent teeth, enclosing a small globular berry.- $P$. Linkiana, Nees, $P$. capsicifolia, Dun., and probably several other species enumerated in DC. Prod. xiii. pars i. p. 448, 449, etc.

In waste places, Champion. Frequent in tropical America and Africa, and very common in India. The species should also perhaps include as a pubescent variety the common Indian $P$, minima, Linn.

\section{NICANDRA, Gærtn.}

Calyx of 5 distinct broadly-cordate sepals, becoming much enlarged and inflated in fruit. Corolla campanulate, with 5 broad short lobes, folded (and perhaps also slightly imbricated) in the bud. Anthers short, opening longitudinally. Ovary 3- to ó-celled. Fruit a berry, enclosed in the enlarged calyx.

A genus limited to a single species.

1. N. physalodes, Gcertn. ; Dun. in DC. Prod. xiii. part i. 434; Bot. Mag. t. 2458. An erect glabrous annual or biennial, attaining sometimes 5 or 6 feet. Leaves stalked, ovate, irregularly sinuate or coarsely toothed or lobed, 3 or 4 in. long, or sometimes larger. Flowers pale-blue, solitary, on short pedicels in the upper axils, forming a terminal leafy raceme. Sepals at the time of flowering a little more than $\frac{1}{2}$ in. long, and herbaceous, when in fruit above $1 \mathrm{in}$. long, thin and much veined, and closely connivent, forming a vesicular calyx with very prominent angles. Corolla nearly $1 \mathrm{in.} \mathrm{long.} \mathrm{Berry}$ globular.

In waste places, escaped from gardens, Hance. A S. American species, which has established itself as a weed in several parts of the warmer regions of the Old World.

\section{LYCIUM, Linn.}

Calyx 5-toothed or 5-lobed, persistent, but scarcely enlarged after flowering. Corolla tubular or funnel-shaped, with a small or campanulate 5-lobed 
or rarely 4-lobed limb; the lobes imbricate in the bud. Anthers short, opening longitudinally. Ovary 2-celled. Fruit a globular or ovoid berry.--Shrubs, often thorny. Leaves usually small, entire. Flowers usually pedicellate, solitary or several together in the axils of the leaves or at the old nodes.

A considerable genus, chiefly American, with a few species dispersed over the warmer regions of the Old World

1. L. chinense, Mill.; Dun. in DC. Prod. xiii. part i. 510. A tall glabrous shrub, with long, weak, recurved, or pendulous branches, either unarmed or the lateral shoots here and there converted into short spines. Leaves lanceolate-oblong or obovate, acute or obtuse, $\frac{1}{2}$ to $1 \mathrm{in}$. long, or nearly twice as long on luxuriant shoots, narrowed into a slender petiole. Pedicels usually 2 to 6 together in the axils. Calyx about $1 \frac{1}{2}$ lines long. Corolla-tube rather longer; the limb broadly campanulate, deeply 5 -lobed; the lobes about 3 lines long. Stamens exserted. Berries ovoid or shortly oblong, orange-red. - L. vulgare, $L$. megistocarpum, and perhaps some others of Dun. 1.c.

Naturalized in some parts of Hongkong, Hance. Believed to be a real native of China, from whence specimens have been frequently sent, and now naturalized in various parts of Asia and Europe, where it is much planted in cottage gardens, and spreads readily from suckers.

\section{DATURA, Linn.}

Calyx tubular, breaking off transversely near the base after flowering. Corolla funnel-shaped, with a long tube and a broad 5-angled or 5-toothed limb, folded in the bud. Ovary 2-celled, each cell incompletely divided into two. Fruit an ovoid or globular prickly capsule, opening in 4 short valves.-Tall coarse herbs, shrubs, or small soft-wooded trees. Leaves alternate, often in pairs. Flowers solitary, terminal or lateral, usually very large.

A small genus, chiefly American, with one or two species equally common in, and perhaps indigenous to, the Old World.

1. D. alba, Nees; Dun. in DC. Prod. xiii. part i. 541; Wight, Ic. $t$. 852. A coarse, erect, glabrous aunual, often 3 or $4 \mathrm{ft}$. high, with a hard, almost woody stem. Leaves stalked, ovate, acute or shortly acuminate, entire or irregularly sinuate, usually 3 or $4 \mathrm{in}$. long. Flowers white, large, on very short terminal or lateral pedicels. Calyx near $2 \mathrm{in}$. long. Corolla about 5 in. long; the angles produced into narrow points 2 or 3 lines long. Capsule globular, above 1 in. diameter, resting on the somewhat enlarged, flat, persistent base of the calyx.

In waste places, Hance, Wilford. Very abundant in similar situations all over India, and probably of Asiatic origin.

\section{ORDER LXXVII. SCROPHULARINEÆE.}

Flowers irregular, or seldom nearly regular. Sepals 5, either free or more frequently united in a lobed or toothed calyx, persistent. Corolla usually $2-$ lipped, but sometimes nearly regular, with 4,5 , or rarely more lobes, imbricate in the bud. Stamens usually 2 or 4 , in pairs, inserted in the tube and alternating with the lower lobes of the corolla ; the fifth stamen, between the two upper lobes, usually deficient, or rudimentary, or sterile. Ovary 2-celled, 
with several ovules in each cell. Style simple, with a 2-lobed, or rarely entire stigma. Fruit a 2-celled capsule, or very rarely an indehiscent berry. Seeds with more or less of albumen. Embryo straight or rarely curved.Herbs, or rarely shrubs or small trees. Leaves usually opposite, or verticillate in the lower part of the plant, alternate higher up ; but sometimes all opposite or all alternate, without stipules. Flowers in terminal racemes or cymes, or more rarely axillary.

A large Order, widely dispersed over every part of the globe.

Corolla spurred, 2-lipped . . . . . . . . . . . . 1. Linaria.

Corolla rotate or minutely campanulate, nearly regular, 4 -lobed.

Stamens 4. Much-branched herb of 1 foot or more . . . . 11. Scoparia.

Stamens 2. Herb of about 1 in. Flowers very minute. . . 12. Microcarpea.

Corolla with a distinct tube; the limb 2-lipped or spreading.

Upper lobes of the corolla outside in the bud.

Stamens all inserted within the tube of the corolla.

Calyx 5 -lobed to about the middle . . . . . . . . 2. Mazus.

Sepals free to the base.

Stamens 4.

Lower sepal much larger than the others.

Anther-cells separate, one at least in the lower stamens sterile. Plants hairy . . . . . . .

Anther-cells contiguous, all fertile. Plant glabrous . Sepals nearly equal . . . . . . . . .

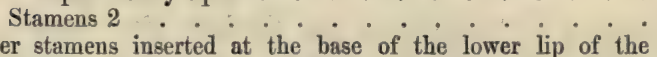
corolla.

Lower stamens arched, bearing anthers under the upper lip. Calyx tubular, with prominent or winged angles . . . . 7. ToRENiA. Calyx short, not angular, or divided to the base . . . 8. VANDELLIA.

Lower stamens club-shaped or 2-lobed, without anthers. Capsule globular or ovoid . . . . . . . . . . 9. Ilysanthes. Capsule linear . . . . . . . . 10. Bonnaya.

Upper lobes of the corolla inside in the bud.

Calyx 5-toothed. Anthers 1-celled, obtuse.

Corolla-tube straight . . . . . . . . 13. Buchnera.

- Corolla-tube bent above the middle ... . . . 14. STrigA.

Calyx oblique, split down the lower edge. Anthers 2-celled, with mucronate cells . . . . . . . . 15. Centranthera.

\section{IINARIA, Juss.}

Calyx deeply 5-cleft. Corolla-tube broad, projecting into a spur at the base; the limb 2 -lipped, with a projecting palate, half-closing or completely closing the mouth of the tube. Capsule ovoid or oblong, 2-celled, opening either in 2 or 3 pores at the top, or by the fall of lateral valve-like lids.Herbs. Lower leaves usually opposite or whorled, the upper ones alternate. Flowers solitary in the axils of the leaves, or forming a terminal raceme or spike.

A considerable genus, spread chiefly over the Old World; the greater number of species about the Mediterranean region; one species only being American.

1. L. elatine, Mill.; Benth. in DC. Prod.x.268. A hairy annual, with slender branching prostrate stems, from a few inches to above a foot long. Leaves shortly stalked, broadly ovate or ovate-lanceolate, angular or hastate at the base, the lower ones scarcely above $\frac{1}{2}$ in. long, the upper ones smaller. 
Peduncles axillary, slender, spreading, longer than the leaves. Flowers small, yellowish. Sepals narrow-lanceolate, about 1 line long. Spur of the corolla straight or slightly curved, full 2 lines long.

In rubbishy ground near the barracks at Stanley (Chuckchew), Hance. Probably introduced with European seeds, for althongh widely spread over Europe and western Asia, especially as a weed of cultivation, it has not been found either in central or eastern Asia.

\section{MAZUS, Lour.}

Calyx broadly campanulate, 5-lobed. Corolla with the upper lip erect, ovate, shortly 2 -lobed, the lower one longer, spreading, 3-lobed, with 2 slight protuberances at the base. Stamens 4. Cells of the anthers contiguous, divaricate. Style with 2 ovate stigmatic lobes. Capsule globular or compressed, opening loculicidally in 2 entire valves.-Low herbs. Lower leaves opposite, the upper ones alternate. Flowers in terminal one-sided racemes.

A small genus limited to tropical and eastern Asia and Australia.

1. M. rugosus, Lour.; Benth. in DC. Prod. x. 375; Sw. Brit. Fl. Gard. t. 36. A low glabrous or slightly hairy annual, rarely if ever continued through another year by means of creeping runners. Leaves mostly radical, or nearly so, obovate or cuneate-oblong, 1 to 2 in. long, coarsely toothed, narrowed into a broad petiole. Branches short, spreading, ending in a leafless raceme of 2 or 3 in. or rarely more. Flowers blue, with a white or yellow palate, on short peduncles. Calyx about 3 lines long, with foliaceous ovate or lanceolate lobes, enlarged after flowering. Corolla scarcely twice as long. Capsule shorter than the calyx. $-M$. vandellioides, Hance in Walp. Ann. iii. 193.

Hongkong, Champion. In rice-fields, at Little Hongkong, Wilford; also Wright. Common in India from Ceylon and Cabul to the Archipelago, extending northward to the Philippines, China, Mantchuria, and Japan.

\section{PTEROSTIGMA, Benth.}

Sepals 5, distinct, the lowest one larger than the others. Corolla with a spreading slightly 2-lipped limb, the upper lobe or lip emarginate, the 3 lower lobes entire. Stamens 4, the 2 cells of each anther separate, one or both cells of the lower anthers and sometimes one cell of the upper anthers empty or sterile. Style flattened at the top, entire or 2-lobed, stigmatic at the extremity, and usually 2-winged below the stigma. Capsule ovoid, almost beaked, opening loculicidally in two valves, which are more or less bifid, leaving a central placentiferous column. Seeds small, striate.-Herbs, usually aromatic and drying black. Leaves opposite. Flowers axillary or in terminal spikes. Pedicels short, usually with 2 bracteoles.

A small genus limited to tropical Asia and Australia.

Flowers axillary or in loose leafy racemes . . . . . . . 1. P. grandiflorum. Flowers in dense terminal globular or oblong spikes . . . . . . 2. P. capitatum.

1. P. grandiflorum, Benth. in DC. Prod.x. 380 ; Hook. and Arn. Bot. Beech. $t$. 45. A rather coarse erect or spreading hairy herb, of 1 or $2 \mathrm{ft}$. Leaves stalked, ovate, crenate-serrate, 1 to $2 \mathrm{in}$. long, or the lower ones larger. Lower flowers solitary in the axils of the upper leaves, upper ones forming loose terminal racemes. Pedicels longer or rather shorter than the calyx. 
Lower sepal lanceolate, 4 lines long when in flower, 6 to 7 lines when in fruit, the 4 upper sepals linear and rather shorter. Corolla 1 in. long. Cells of the upper pair of anthers fertile and equal, those of the lower pair small and glandlike.

Commur on hillsides, Champion and others. Only known from S. China.

2. P. capitatum, Benlh. in DC. Prod. x. 380. An erect stiff simple or branching annual, usually about $1 \mathrm{ft}$. high. Leaves varying from ovate to oblong or lanceolate, obtuse, crenate, the larger ones usually oblong, 1 to 2 in. long, but sometimes all small and ovate. Flowers about $3 \frac{1}{2}$ lines long, of a bluish-purple, with a purple palate, in dense terminal clammy heads, globular or oblong, $\frac{1}{2}$ to $1 \frac{1}{2}$ in. long. Lower sepal lanceolate, the other's linear, nearly as long as the corolla. Anthers of the upper pair with one cell rather smaller than the other, those of the lower pair with only one cell.

Along ditches, Champion; also Hance. Common in India from Ceylon and the Peninsula to the Archipelago, and northwards to the Himalaya and S. China.

\section{LIMNOPHILA, R. Br.}

Calyx deeply 5 -lobed or divided into 5 distinct sepals of equal size, or the lowest rather larger. Corolla with a spreading more or less 2-lipped limb, the upper lip emarginate or 2-lobed, the lower 3-lobed. Stamens 4, shorter than the corolla; the anther-cells all perfect and separate from each other, usually stipitate. Style bent downwards at the top, dilated, entire or 2-lobed, often winged at the bend. Capsule ovoid or globose, opening loculicidally in 2 valves, more or less bifid, leaving a broad free central placenta.-Herbs usually aquatic or growing in marshes, more or less marked with pellucid dots. Leaves opposite or whorled, undivided in the Hongkong species, in some other aquatic species the lower submerged ones divided into filiform segments. Flowers solitary and axillary, or in terminal or axillary racemes, usually with 2 bracteoles under the calyx.

A considerable genus, chiefly tropical and limited to the Old World.

Stem hairy . . . . . . . . . . . . . 1. L. hirsuta.

Whole plant glabrous . . . . . . . . . . . . 2. L. punctata.

1. L. hirsuta, Benth. in DC. Prod. x. 388. Stems decumbent and rooting at the base, ascending to a foot or more in height, and more or less hairy. Leaves sessile or nearly so, opposite, or in whorls of 3 or 4, oblong, and 1 to 2 in. long, or the lower ones obovate, narrowed or stem-clasping at the base, glabrous or hairy, the upper ones small and narrow. Flowers 6 to 8 lines long, in terminal racemes, the pedicels shorter than the floral leaves or bracts. Calyx-segments lanceolate-subulate.

Hougkong, Hance. On the edge of a pond cast of the Happy Valley, Wilford. Spread over India from Ceylon and the Peninisula to the Archipelago, and northward to the Himalaya and S. China.

2. L. punctata, Blume; Benth. in DC. Prod. x. 388. An erect or ascending glabrous annual (or sometimes perennial?) from 6 in. to $\mathrm{l} \mathrm{ft}$. or more in height. Leaves sessile and stem-clasping, oblong-lanceolate, serrate, 1 to $1 \frac{1}{2}$ or even $2 \mathrm{in}$. long, the upper ones smaller. Flowers in the ordinary form 7 to 8 lines long, all axillary, on pedicels scarcely shorter than the floral leaves. Sepals lanceolate, acuminate, not half so long as the corolla. 
Hongkong, Hance, common in the Happy Valley, Wilford; frequent in India, from Ceylon and the Peninsula to the Archipelago, and northward to the Himalaya, S. Chiria, and the Philippines.

Var. subracemosa, Benth. l.c. Flowers smaller, in loose leafy racemes, either terminal or in the upper axils.

Hougkong, Hance. Occurs here and there almost all over the area of the species.

\section{HERPESTIS, Gærtn. fil.}

Sepals 5, distinct, the lower one much broader than the others. Corolla with a spreading more or less 2-lipped limb, the upper lip emarginate or 2-lobed, the lower 3-lobed, or sometimes all 5 lobes nearly equal. Stamens 4 , in pairs, the anthers all with 2 perfect contiguous cells. Style dilated at the top, concave or slightly 2-lobed. Capsule opening in 2 valves, which are sometimes cleft to the base so as to appear 4-valved, leaving a free central column.-Herbs, sometimes aquatic. Leaves opposite, entire, toothed or in some aquatic species divided into filiform segments. Flowers axillary or in terminal racemes, without or rarely with bracteoles under the calyx.

A considerable tropical and subtropical genus, chiefly American, with a few species natives of the Old World.

1. H. Monnieri, H. B. and K.; Benth. in DC. Prod. x. 400 ; Bot. Mag. 1. 2557. A low creeping glabrous leafy annual. Leaves obovate or oblong, seldom above 5 in. long, rather thick, entire or crenate, without prominent veins, or obscurely 1- or 3-nerved. Flowers few, pale blue, rather small, on pedicels usually rather longer than the leaves, with 2 small bracteoles under the ralyx. Outer sepal ovate.-Anisocalyx limnanthiffurus, Hance in Walp. Ann. iii. 195 .

Frequent in marshes, Champion and others. One of the commonest marsh plants throughout the tropical regions of both the New and the Old World.

\section{DOPATRIUM, Ham?}

Calyx deeply 5-cleft. Corolla-tube dilated at the top, the limb 2-lipped, the upper lip short, 2-lobed, the lower large, broadly 3-lobed. Stamens, 2 upper ones fertile, the anthers with 2 distinct parallel cells, 2 lower stamens minute and sterile. Style short, with a 2-lobed flattened stigma. Capsule 4-valved, leaving a free, flat, 2-lobed placentiferous dissepiment. Seeds warted.-Slender glabrous annuals. Leaves opposite, entire, small, the upper ones minute. Pedicels filiform, forming loose terminal racemes.

A small genus, limited to tropical Asia and Africa.

1. D. junceum, Ham. in DC. Prod. x. 407. Stem erect, very slender, simple or slightly branched, usually $6 \mathrm{in}$. to $1 \mathrm{ft}$. high. Lower leaves few, towards the base of the stem, but seldom rosulate as in $D$. nudicaulis, oblong or linear, seldom above $\frac{1}{2} \mathrm{in}$. long, the upper floral ones remote and minute. Pedicels filiform, seldom above 2 lines long. Flowers from 1 to 2 lines long. Ovary in the upper part incompletely 2-celled, the placentas meeting at the base only.

Hongkong, Wright. A marsh plant, widely distributed over India, from Ceylon and the Peninsula to the Archipelago, and northward to the Himalaya, S. China, and the Philippines. 


\section{TORENIA, Linn.}

Calyx tubular, with prominent or winged angles, obliquely 3- or 5-toothed, or 2-lipped. Corolla with the upper lip erect or slightly spreading, emarginate or 2-lobed, the lower lip larger, spreading, 3-lobed. Stamens 4, their anthers cohering or closely contiguous in pairs; upper stamens straight, the lower pair arched under the upper lip, with a tooth-like or filiform appendage near the base. Style filiform, with a dilated slightly 2-lobed stigma. Capsule oblong, not longer than the calyx, opening in 2 entire valves parallel to the thin flat dissepiment.-Herbs. Leaves opposite. Racemes terminal, short, or reduced to clusters, or rarely to 1 or 2 flower's in the upper axils. Flowers often large.

A tropical or subtropical genus, dispersed over the Old World, with one species occurring also as a weed in tropical America.

Glabrous or slightly pubescent, decumbent at the base. Flowers purple . . 1. T. rubens. Hairy and erect. Flowers yellow. . . . . . . . . . . 2. T. fava.

1. T. rubens, Benth. in DC. Prod. x. 410, var. grandiflora. A glabrous or slightly pubescent annual, prostrate and rooting at the lower nodes; the flowering branches ascending to $6 \mathrm{in}$. or a ft., acutely 4 -angled. Leaves on short petioles, ovate, serrate, seldom above 1 in. long, rounded or slightly cordate at the base. Peduncles in the upper axils, 1 to $2 \mathrm{in}$. long, scarcely forming a raceme. Calyx oblong, with 3 narrow wings slightly decurrent on the peduncle, 8 or 9 lines long in the Hongkong variety. Corolla dark purple, scarcely twice as long. Appendage of the longer filaments short.-T. concolor, Lindl. Bot. Reg. 1846, t. 62 .

Common on Victoria Peak and in other parts of the island, Champion and others. Also on the adjacent continent in Assam and in Formosa. The specimens originally deseribed from Assam have much smaller flowers, but their size is variable in the Chinese ones.

2. T. flava, Ham.; Benth. in DC. Prod. x. 411, var. grundiflora. An erect branching hairy annual, $6 \mathrm{in}$. to $1 \mathrm{ft}$. high, the branches acutely angled. Leaves stalked, ovate or oblong, serrate, 1 to near 2 in. long, cuneate at the base. Flowers few, in terminal racemes; the floral leaves small and bract-like, except the lowest pair. Pedicels seldom $\frac{1}{2}$ in. long. Calyx 4 to 5 lines long, 5-angled, acute at the base. Corolla nearly twice as long in the Hongkong specimens, much smaller in the Indian ones, pale yellow, with a purple spot in the throat. Appendage of the longer filaments shortly subulate.

Hongkong, Harland. Also in the Himalaya and in Mergui.

\section{VANDELIIA, Linn.}

Calyx either shortly tubular and 5-toothed, readily splitting after flowering, or divided to the base into 5 segments. Corolla with the upper lip erect, shortly 2 -lobed, the lower larger, spreading, 3-lobed. Stamens 4 , their anther's cohering in pairs under the upper lip; the upper stamens straight; the lower arched, with a tooth-like or filiform appendage near the base. Style filiform, with a dilated often 2-lobed stigma. Capsule globular, oblong or linear, opening in 2 entire valves, parallel to the thin flat dissepiment.-Herbs. Leaves opposite. Flowers usually small, axillary or in terminal racemes often contracted into umbels. 
A considerable genus, dispersed over the tropical regions of the Old World, with 2 or 3 species spreading as weeds into America. It closely connects Torenia with Ilysanthes and Bonnaya, differing from the former in the calyx, from the latter in the stamens.

Calyx 5 -toothed at the time of flowering.

Leaves mostly oblong, rather thick. Calyx 5 -angled .

Leaves broadly ovate, thin. Calyx membranous, scarcely angled, often splitting after flowering . . . . . . . . . .

Calyx 5-cleft to the base from the first

1. V. oblonga.

2. V. crustacea.

1. V. oblonga, Benth. in DC. Prod. x. 413. A glabrous annual, decumbent and rooting at the lower nodes, the flowering branches ascending to 5 or 6 in. or more. Leaves from ovate to oblong or lanceolate, obtuse, rather thick, entire or scarcely crenate, narrowed at the base, but scarcely stalked, 4 to 6 or rarely 7 or 8 lines long. Pedicels few, 1 in. long or more, forming a loose terminal raceme. Calyx about $2 \frac{1}{2}$ lines long, angular, 5-toothed or shortly 5-lobed. Corolla more than twice as long. Appendage of the lower filaments slightly clavate. Capsule ovoid, shorter than the calyx.

Hongkong, Champion, Harland, Wright. Also on the adjacent continent, but not known out of S. China.

2. V.crustacea, Benth. in DC. Prod.x. 413 ; Wight, Ic.t. 863. A diffuse much branched annual, glabrous or with a very few scattered hairs, and usually not exceeding 6 in. Leaves shortly stalked, ovate, broadly crenate, 4 to 9 lines long, broadly rounded or almost cordate at the base, much thinner than in $V$. oblonga. Pedicels usually $\frac{1}{2}$ to near $1 \mathrm{in}$. long, axillary or forming loose leafy racemes. Calyx about 2 lines long, membranous and 5 -toothed, with 5 scarcely prominent nerves at the time of flowering, often splitting into 5 lobes or segments after the flowering is over. Corolla scarcely twice as long. Capsule ovoid or almost oblong, shorter than the calyx.

Frequent in rice-fields, etc., Champion and others. A very common weed throughout tropical Asia, extending also into tropical Africa and Australia, and to some parts of America.

3. V. scabra, Benth. in DC. Prod. x. 414. A diffuse much-branched annual, resembling $V$. crustacea in many respects, but usually slightly hairy, often assuming a blackish tint in drying, and readily known by the calyx, which from the first consists of 5 distinct linear-lanceolate segments. The leaves are also nearly or quite sessile, broadly ovate or orbicular, crenate and scarcely $\frac{1}{2}$ in. long. Calyx about 2 lines long. Flowers rather smaller than in $\bar{V}$. crustacea. Capsule nearly globular.

Hongkong, Wilford. Widely distributed over India, from Ceylon and the Peninsula to the Archipelago and the Philippines, but not nearly so common as the $\nabla$. crustacea.

\section{ILYSANTHES, Rafin.}

Sepals 5, distinct, narrow. Corolla with the upper lip erect, shortly 2lobed, the lower larger, spreading, 3-lobed. Stamens, 2 upper ones fertile with 2-celled anthers, the lower pair rudimentary, usually 2 -lobed, with 1 lobe obtuse and glandular, the other acute, either reduced to a very short tooth, or long and filiform, very rarely bearing a small sterile anther. Capsule ovoid or oblong, shorter than or little longer than the calyx, opening in two entire valves parallel to the thin flat dissepiment.-Glabrous slender annual. Leaves opposite. Flowers usually small, on slender pedicels, axillary or in terminal leafy racemes. 
A small genus, dispersed over America, Asia, and Africa, only differing from Vandellia and Lindenia in the barren lower stamens, from Bonnaya in the short capsule.

1. I. hyssopioides, Benll. in DC. Prod. x. 419. Stem diffuse, ascending or erect, usually about $6 \mathrm{in}$. high. Leaves not numerous, oblong or lanceolate, narrowed at the base, seldom above $\frac{1}{2} \mathrm{in}$. long, and usually half that size. Pedicels filiform, numerous. Calyx 1 to $1 \frac{1}{2}$ lines long. Corolla from 4 to 6 lines long. Lower sterile stamens glandular, with a minute glabrous tooth or lobe below the top. Capsule ovoid, longer than the calyx. -Bonnaya hyssopioides, Benth.; Wight, Ic. t. 857.

Hougkong, Hance, Wright, in a marsh in the Happy Valley, Wilford. Frequent in India, from Ceylon and the Peninsula to the Archipelago.

\section{BONNAYA, Link and Otto.}

Sepals 5, distinct, narrow. Corolla with the upper lip erect, shortly 2lobed, the lower larger, spreading, 3-lobed. Stamens, 2 upper ones fertile, with 2-celled anthers, the lower pair rudimentary, entire, linear, obtuse, and glandular. Style filiform, with the stigma dilated, and usually 2-lobed. Capsule linear, longer than the calyx, opening in 2 entire valves, parallel to the thin flat dissepiment.-Annuals, usually glabrous. Leaves opposite. Flowers axillary or in terminal racemes.

A small genus, limited to tropical or subtropical Asia.

1. B. veronicaefolia, Spreng.; Benth. in DC. Prod. x. 421; Wight, Ic. $t$. 1411. A glabrous annual, much-branched, diffuse, and rooting at the base, the flowering branches often ascending to 6 in. or more. Leaves sessile or narrowed into a short stem-clasping petiole, oblong-lanceolate or almost linear, the lower ones 1 to $1 \frac{1}{2}$ in. long, entire or serrate and rather thick. Flowers in terminal racemes, on spreading stiff pedicels, 3 to 6 lines long, angular and thickened upwards. Calyx narrow, 1 to $1 \frac{1}{2}$ lines long. Corolla about twice as long. Capsule near $\frac{1}{2}$ in. long.-B. verbenafolia, Spreng.; Benth. in DC. 1. c. Gratiola veronicafolia, Roxb. Pl. Corom. t. 154.

Hongkong, Hinds and others. A common weed throughout India, from Ceylon and the Peninsula to the Archipelago, extending northwards to Loochoo.

\section{SCOPARIA, Linn.}

Sepals 4 or 5 . Corolla rotate, 4 -lobed, hairy at the throat; the lobes imbricate in the bud. Stamens 4. Anthers sagittate. Style slightly clubshaped at the top, truncate or emarginate. Capsule opening septicidally in 2 entire valves, leaving the central column free.-Much-branched herbs or low undershrubs. Leaves opposite or whorled. Pedicels axillary, usually 2 together, 1-flowered, without bracteoles.

A small genus, all the species except the following limited to South America.

1. S. dulcis, Linn.; Benth. in DC. Prod. x. 431. A much-branched glabious annual (or sometimes perennial?), erect or decumbent at the base, 1 to $3 \mathrm{ft}$. high. Leaves usually in whorls of 3 , ovate-lanceolate or oblong, $\frac{1}{2}$ to $1 \frac{1}{2}$ in. long, toothed, narrowed at the base, the upper ones small and narrow. Flowers numerous, small, white, on filiform pedicels, 2 to 4 lines long. Sepals 4, ovate-ohlong, about 1 line long. Corolla about 3 lines diameter. Capsule rather longer than the calyx. 
Hongkong, Wright. A species of American origin, now frequently occurring as a weed in tropical Asia, Africa, and Australia.

\section{MICROCARPA巴A, R. Br.}

Calyx tubular-campanulate, 5-toothed. Corolla campanulate, 4-lobed. Stamens 2, short. Style short, with a capitate stigma. Capsule ovoid, opening loculicidally in 2 entire valves.-Annual. Leaves opposite. Flowers minute.

'The genus consists of only one species

1. M. muscosa, R. Br.; Benth. in DC.Prod.x. 433. A glabrous muchbranched annual, scarcely $1 \mathrm{in}$. high. Leaves almost sessile, oblong or lanceolate-linear, 1 to $1 \frac{1}{2}$ lines long, entire. Flowers solitary and sessile in the axils of the leaves. Calyx 1 line long, angular, the teeth spreading and slightly ciliate. Corolla shorter the calyx.

Hongkong, Wright. Also in Ceylon and the Peninsula of India, in East Bengal, in Java, and in tropical Australia.

\section{BUCHNERA, Linn.}

Calyx tubular, obscurely nerved, shortly 5-toothed. Corolla-tube slender, straight or slightly curved, the limb with 5 almost equal obovate or oblong: spreading lobes, the 2 uppermost innermost in the bud. Stamens 4 , in pairs, included in the tube. Anthers 1-celled. Style club-shaped at the top, entire. Capsule straight, opening loculicidally in 2 entire valves.-Stiff, scarcely branched herbs, usually drying black. Lower leaves opposite, the upper alteruate. Flowers in terminal spikes.

A considerable genus, dispersed over the tropical and subtropical regions of America, Asia, Africa, and Australia.

1. B. cruciata, Ham.; Benth. in DC. Prod. x. 495. A simple or scarcely branched, stiff, erect annual, $\frac{3}{4}$ to $1 \frac{1}{2} \mathrm{ft}$. high, pubescent or nearly glabrous. Radical leaves ovate or obovate, spreading, about 1 in. long ; stemleaves linear or the lower ones oblong, distant, the upper ones small. Flowers closely imbricated in a conical or oblong terminal quadrangular spike, seldom above 1 in. long, with bracts about as long as the calyx. Calyx about 2 lines long. Corolla-tube usually twice as long. Capsule about as long as the calyx. - B. stricta, Benth. in DC. 1. c. B. densiflora, Hook. and Arn. Bot. Beech. 203.

West Point and Little Hongkong, Champion. Also in the Himalaya and in Burmah.

\section{STRIGA, Lour.}

Calyx tubular, with prominent nerves, 5 -toothed or 5 -lobed. Corolla-tube slender, abruptly bent at or above the middle ; the limb spreading, somewhat 2-lipped, the upper lip emarginate or 2-lobed, innermost in the bud, the lower 3-lobed. Stamens 4, in pairs, included in the tube. Anthers 1-celled. Style club-shaped at the top, entire. Capsule-straight, opening loculicidally. Stiff erect annuals, parasites on roots, and usually drying black. Lower leaves opposite, the upper entire, sometimes all reduced to small scales. Flowers sessile, usually forming terminal spikes. 
A genus of several species, natives of the tropical or subtropical regions of the Old World. Calyx 10-nerved. Corolla-tube 4 or 5 lines long . . . . . . 1. S. hirsuta. Calyx 15-nerved. Corolla-tube 8 or 9 lines long . . . . . . . 2. S. Masuria.

1. S. hirsuta, Benth. in DC. Prod. x. 502. An erect, scabrous or pubescent, simple or loosely branched annual, usually about 6 in. high, and not always drying so black as the other species. Leaves linear or the lower ones lanceolate. Flowers yellow, red, or white, in terminal interrupted spikes, the lower ones distant. Calyx usually 10 -nerved, one of the nerves very rarely here and there divided. Corolla-tube glabrous, 4 to 5 lines long, bent near the top; upper lip much shorter than the lower one.

Common with grass, on which it is believed to be parasitic, Champion and others. Frequent in tropical Asia, extending westward into Africa, eastward to the Archipelago, and northward to South China and the Philippines.

2. S. Masuria, Benth. in DC. Prod. x. 503. An erect, nearly simple, scabrous annual, often a foot high. Leaves linear, erect. Flowers (blue?) in terminal interrupted spikes. Calyx with 15 prominent nerves. Corolla-tube pubescent, 8 or 9 lines long, bent above the middle; lower lip about $\frac{1}{2}$ in. long, the upper one shorter.

Near Deepwater Bay, very rare, Hance, Harland. Also in the mountains of eastern India in Burmah and the Philippines.

\section{CENTRANTHERA, R. Br.}

Calyx compressed, obliquely acute, split down the lower edge, entire, or 2- to 5-toothed at the top. Corolla with a curved tube dilated upwards; the limb with 5 broad lobes, nearly equal or obscurely 2-lipped. Stamens 4, in pairs, included in the tube. Anther-cells transverse, spurred, or with an awn-like point, one cell usually smaller or empty. Style with a lanceolate flattened end. Capsule obtuse, opening loculicidally in 2 entire valves. Scabrous herbs. Leaves opposite or the upper ones alternate. Flowers almost sessile, axillary, or in interrupted terminal spikes.

A small genus, limited to tropical Asia and Australia.

1. C. hispida, R. Br.; Wall. Pl. As. Rar. t. 45 ; Benth. in DC. Prod. x. 525. A stilf erect annual, simple or with spreading branches, 6 in. to 1 $\mathrm{ft}$. high, or rarely more, very rough with minute hairs or tubercles. Leaves mostly linear, the longer ones 1 to $1 \frac{1}{2}$ in. long, the upper ones much smaller. Flowers nearly sessile in the upper axils, alternate and distant. Calyx 3 to 4 lines long. Corolla purple (or yellow ?) 6 to 8 lines long. One cell of each anther much narrower than the other, with a long point. Capsule ovoidglobose.

Hongkong, Champion. Widely distributed over India from Ceylon and the Peninsula to the Archipelago, extending to tropical Australia, and northward to the Himalaya, S. China and the Philippines.

\section{ORDER LXXVIII. LENTIBULACE无.}

Calyx with 2 to 5 teeth or lobes. Corolla irregular, the tube usually projecting into a spur or pouch at the base, the limb 2-lipped. Stamens 2, in- 
cluded in the tube and inserted at its base. Anthers 1-celled. Ovary free, 1-celled, with several ovules inserted on a short free central placenta. Style short, with a 2-lipped stigma. Fruit a capsule. Seeds minute, without albumen. Embryo with very short cotyledons, or apparently undivided.-Marsh or aquatic plants, with radical or floating leaves (or sometimes none). Flowers solitary or several in a raceme, on leafless radical or terminal peduncles or scapes.

A family of very few genera, dispersed over the greater part of the globe.

\section{UTRICULARIA, Linn.}

Calyx deeply 2-lobed. Corolla spurred; the mouth of the tube closed or nearly so by a convex palate; the upper lip short, broad, and 2-lobed; the lower longer, broadly 3-lobed, all the lobes turned back. Capsule globular, opening in 2 valves.-Marsh plants, either leafless or with entire radical leaves, or floating plants, with leaves divided into capillary segments, and often interspersed with little bladders or vesicles full of air. Peduncles or scapes radical or axillary, often with a few minute alternate scales. Flowers in a terminal raceme, with a similar scale or bract under each pedicel.

A considerable genus, with the wide general range of the Order.

Floating plants. Leaves divided into capillary segments, mostly interspersed with utricles.

Pedicels thickened after flowering. Corolla near $\frac{1}{2}$ in. across. Style elongated . . . . . . . . . . . . . .

Fruiting pedicels slender. Corolla not 3 lines across. Stigma sessile or nearly so

1. U.flexuosa.

2. U. diantha.

Marsh plants. Leaves radical, entire, or none.

Leaves linear or linear-spathulate, usually disappearing before the time of flowering.

Scales and bracts fixed by the base.

Flowers blue or purple. Fruiting pedicels erect or spreading, 3 lines long. Calyx-lobes acute in fruit . . . . . . Flowers yellow. Fruiting pedicels scarcely 2 lines long, recurved. Calyx-lobes obtuse in fruit

Scales and bracts attached by the centre, free and pointed above and below

Leaves orbicular, with slender petioles, present at the time of flowering. Calyx-lobes very unequal.

Spur of the corolla slender, about equalling the lower lip. . . . 6. U. orbiculata.

Spur of the corolla conical, much shorter than the lower lip. . . \%. U. Harlandi.

1. U. flexuosa, Vahl; Oliv. in Journ. Linn. Soc. iii. 175. Stems floating, branched, extending to 1 or more feet. Leaves all submerged and root-like, dichotomously divided into numerous capillary segments, interspersed with little globular bladders or utricles. Peduncles usually 3 to 6 in. long, with few or no scales, bearing a raceme of 3 to 6 yellow flowers. Pedicels erect and slender at the time of flowering, usually turned downwards and thickened upwards when in fruit. Calyx-lobes usually unequal, enlarged and spreading in fruit. Corolla full 5 lines across; the spur obtuse, about 2 lines long. Style above 1 line long. Capsule near 3 lines diameter.- $U$. fasciculata, Roxb. ; Wight, Ic. t. 1568 . U. extensa, Hance in Walp. Ann. iii. 3.

In small streams, Hance. In a small pond at East Point, Wilford. Widely distributed over India, from Ceylon and the Peninsula to the Arehipelago, and northward to the Himalaya and S. China. 
2. U. diantha, Rom. and Schult.; Wight, Ic.t. 1569 ; Oliv. in Journ. Linn. Soc. iii. 176 (not of A.DC.). Nearly allied to the last species, but a smaller and more slender plant. Floating submerged stems seldom above 2 in. long; the filiform leaves short, and little divided, with few small utricles, and in marshy places the leaves are linear-subulate and nearly entire. Scapes or peduncles filiform, 2 to 4 in. long, usually 1 - or 2 -flowered, rarely 3 flowered. Flowers yellow, not above 3 lines across. Calyx-lobes equal, not enlarged after flowering. Spur as long as the under lip, or longer. Stigma small, sessile or nearly so.

In small streams, Champion, Wilford; also Wright. In India, from the Peninsula to the Archipelago, and northward to the Himalaya and S. China.

3. U. ccerulea, Linn.; Oliv. in Journ. Linn. Soc. iii. 179 (not of A. DC.). A slender, simple, or rarely branched annual, usually 6 to $8 \mathrm{in}$. high, without any leaves at the time of flowering. Scales very few, ovate or lanceolate, attached by their base. Flowers blue (or purple?), about 3 lines long, in a loose raceme. Pedicels 2 to 3 lines long when in fruit, ascending or spreading, (not turned down,) equal to or exceeding the length of the calyx. Calyxlobes ovate, near 3 lines long, and acute when in fruit, thin and membraneous, enclosing the capsule. Corolla-spur conical; the upper lip entire, obovate, about the length of the calyx.

In marshes, Champion; in a marsh on Victoria Peak, Wilford; also Hance and Wright. In Ceylon and the peninsula of India. The U. uliginosa, Vahl, for which I had formerly taken these specimens, is referred by Oliver to the more common large-flowered $U$. reticulata, Sin., which, however, does not appear to have been found in Hongkong.

4. U. bifida, Linn.; Oliv. in Journ. Linn. Soc. iii. 152. A little annual, much resembling $U$. coerulea, but usually smaller and the flowers always yellow. Fruiting pedicels recurved, 1 to near 2 lines long, and usually flat and dilated under the calyx. Lobes of the calyx when in fruit about 2 lines long and very obtuse.- $U$. humilis, Wight, lc. 1572 , f. 2 , and probably also of Vahl.

Common in marshes, Champion and others. Frequent also in India from Ceylon and the Peninsula to Malacea, and northwards to the Himalaya, S. China, and the Philippines.

5. U. racemosa, Wall.; Oliv. in Journ. Linn. Soc. iii. 186. A slender but stiff annual, simple or seldom branched, usually 6 to 8 in. high, but soinetimes above a foot, without any leaves at the time of flowering, turning black in drying. Scales few, as well as the bracts under the pedicels, attached by their centre, free and pointed both above and below. Flowers small, purple (or blue?) almost sessile, in little terminal heads or compact racemes, with occasionally a few distant flowers lower down. Corolla 3 to 4 lines long, the spur as long or rather longer than the lower lip. Capsules small, globular.Wight Ic. t. $1573,1575,1578$, f. 2 , and 1579.

Common in marshes, Champion and others. Extends in India from Ceylon and the Peninsula to the Arehipelago, and northwards to Silhet and S. China.

6. U. orbiculata, Wall.; Oliv. in Journ. Linn. Soc. iii. 187. An elegant delicate species, 1 to 2 in. high. Leaves radical, persistent to the time of flowering, orbicular or spathulate, not 1 line diameter, on a slender petiole often 2 or 3 times as long. Scapes filıform. Bracts very minute, attached by the base. Flowers 2 to 4 , (lilac with a yellow palate, very small, on capillary pedicels. Spur very slender, above a line long, and longer than the 
broad sinuate or slightly lobed lower lip of the corolla. Seeds more or less muricate.-U. glochidiata, Wight, Ic. t. 1481 .

Hongkong, Wright. In India from Ceylon and the Peninsula to Burmah, aud northwards to the Himalaya and S. China.

7. U. Harlandi, Oliv. MS. A still more diminutive species than the $U$. orbiculata, with similar orbicular leaves on slender petioles. Scapes $\frac{1}{2}$ to $1 \mathrm{in}$. high, bearing 2 to 4 flowers on capillary pedicels, rather smaller than in $U$. orbiculata, with a spur very much shorter than the rest of the corolla.

Hongkong, Harland; on a roek in a ravine on Mount Gough, Wilford. Not known from elsewhere.

\section{Order LXXIX. OROBANCHACEAT.}

Flowers irregular. Sepals 4 or 5, united in a variously split calyx. Corolla tubular or campanulate, usually curved or oblique; the limb more or less 2-lipped; the upper lip erect or spreading, emarginate or 2-lobed ; the lower lip spreading, 3-lobed. Stamens 4, in pairs, inserted in the tube. Anthers 2-celled; the cells usually pointed or awned. Ovary free, 1-celled, with 2 double or bifid placentas, or 4 distinct placentas, more or less protruding into the cavity, but not united in the axis. Ovules several, usually very numerous. Style simple, with a capitate or 2-lobed stigma. Capsule 2-valved. Seeds small, with a minute embryo and abundant albumen.-Leafless herbs, not green, parasites on roots. Stems usually thick, the leaves replaced by scales or bracts of the colour of the rest of the plant.

An Order not very numerous in species, but widely distributed over nearly the whole globe, except the extreme north and south.

\section{1. 开GINETIA, Linn.}

Calyx spathaceous (flat and split open on one edge). Corolla with a broad incurved tube; the limb of 5 broad nearly equal lobes, obscurely 2 -lipped. Anthers cohering in pairs, 1-celled, those of the lower lip having the connective produced into a spur at the base, which is the rudiment of the other cell. Placentas of the ovaries much branched, covered with ovules, and nearly filling the cavity.-Parasites, with few or no scales on the short stems. Peduncles or scapes long and 1 -flowered.

A genus of 2 or 3 species, all from tropieal Asia.

1. Az. indica, Roxb.; Reut. in DC. Prod. xi. 43 ; Wight, Ic. t. 895. A root-parasite with a very short stock, bearing a very few minute scales. Peduncles or scapes erect, 6 in. to 1 . ft. long, without scales, bearing a single purple terminal flower more or less curved. Calyx ovate or oblong, obliquely acute, varying in length from $\frac{3}{4}$ to near $1 \frac{1}{2}$ in. Corolla also variable in size, but usually about $1 \frac{1}{2}$ in. long, whether the calyx be long or short.

In ravines, on grass-roots abundantly, Chumpion; rare according to Wilford; also Hance and Wright. Dispersed over the greater part of India, and also in the Archipelago.

\section{Order LXXX. GESNERIACE归.}

Flowers usually irregular. Calyx with 5 teeth, lobes, or distinct sepals. Corolla with a long or short tube; the limb 2-lipped or of 5 spreading lobes, 
imbricate in the bud. Stamens 2 or 4, in pairs, inserted in the tube, with the addition sometimes of a fifth barren one. Anthers 2-celled, or 1-celled by the confluence of the two. Ovary superior or more or less inferior, 1-celled, with two parietal entire or lobed placentas protruding more or less into the cavity, but not united in the axis. Ovules numerous. Style simple, with an entire or lobed stigma. Fruit a berry or a capsule. Seeds sinall, numerous, with or without albumen. Embryo straight.-Herbs, or rarely shrubs or climbers. Leaves opposite or whorled.

A considerable Order, chiefly tropical, with a very few species from more temperate climates. The Hongkong species belong to the tribe of Cyrtandree characterized by a superior ovary, and by the seeds containing little or no albumen. This tribe is limited to the Old World, with the exception of a very few American species, whilst the two other tribes, Gesneriece and Besleriea, are exclusively American.

Woody climber. Fertile stamens 4. Anther-cells parallel. Seeds with an appendage at each end. . . . . . . . . .

Herb. Fertile stamens 2. Anther-cells divaricate. Seeds without any appendage.

1. Æischynanthus.

2. Chirita.

\section{1. 冓SCHYNANTHUS, Jack.}

Corolla very oblique or curved, the limb 2-lipped. Fertile stamens 4, exserted. Anther-cells linear, parallel. Stigma undivided. Capsule linear ; the placentas meeting, but not united. Seeds pendulous, with hair-like appendages, 1 only at the lower end, 1 or more at the upper end.-Woody climbers or rarely erect shrubs. Leaves opposite, entire, coriaceous, without prominent veins except the midrib. Flowers usually red.

A considerable genus, limited to tropical Asia, and chiefly found in the Archipelago.

1. AEs. bracteatus, Wall.; DC. Prod. ix. 261. A glabrous woody climber. Leaves ovate, elliptical or oblong, acuminate, 2 to 3 or rarely 4 in. long, narrowed into a short petiole, rather thick; the lateral veins sometimes faintly visible. Peduncles usually 2 or 3 together in each axil of the terminal pair of leaves, about $1 \mathrm{in}$. long, bearing 1 to 3 pedicels, with a pair of broadly cordate bracts at their base. Flowers pendulous, green, yellowish inside and reddish on the edges (Hance), appearing quite red when dry. Calyx very spreading, deeply 5 -lobed; the lobes oblong, obtuse, about 2 lines long. Corolla about $\frac{3}{4} \mathrm{in}$. long; the tube very oblique at the mouth, but not curved, scarcely above 4 lines long under the lower lip; the 2 upper lobes erect, the 3 lower spreading or reflexed. Stamens longer than the corolla, the anthers cohering in pairs by their tips. Capsule 3 to 6 in. long. Seeds very minute, with 1 long hair-like appendage at each end.-AE.acuminata, Wall., DC. Prod. ix. 263 (partly at least). E. chinensis, Gardn. and Champ. in Kew Journ. Bot. i. 320.

Trailing on rocks, in ravines, Champion and others. Also in Khasia and Assam. There has been much confusion in the description of this species, owing partly to some loose calyces of $A$. Peelii, Hook. fil., having been distributed with some of Wallich's specimens of A . bracteata. De Candolle also deseribes the stamens of the latter as being included, owing to his not having scen the flowers fully developed. The specimens I have seen of $\mathcal{A}$. acuminata, Wall., certainly belong also to this species, though some may perhaps be the $A$. Peelii, which had got mixed with it. 


\section{CHIRITA, Ham.}

Calyx 5-lobed. Corolla tubular, the limb more or less 2-lipped. Fertile stamens 2 ; anther-cells divaricate, cohering laterally. Upper stamens small and barren. Stigma flattened and emarginate or 2-lobed; the lobes side by side in the same plane. Capsule linear. Seeds numerous, minute, without appendages.-Herbs, with a short stock or a simple leafy stem. Leaves opposite. Flowers solitary or umbellate, on axillary or radical peduncles.

A small genus, limited to tropical Asia.

1. C. sinensis, Lindl. Bot. Reg. 1844, t. 59. Stock short, thick, and usually horizontal. Leaves radical, those of each pair equal, varying from broadly ovate, almost cordate, and 2 to 3 in. long, to narrow-oblong 5-6 in. long; narrowed at the base into a petiole varying also from 1 to $3 \mathrm{in}$.; all more or less sprinkled or clothed with long hairs. Peduncles or scapes 6 to $10 \mathrm{in}$. high, hairy, bearing either 1 , or more frequently an umbel of 3 to 6 , elegant lilac flowers about $1 \frac{1}{2} \mathrm{in}$. long, on pedicels of $\frac{1}{2}$ to 1 in., with a pair of ovate or lanceolate bracts under the umbel. Calyx deeply 5 -lobed, scarcely 2 lines long. . Anthers glabrous. Pod pubescent, 2 to 3 in. long.

Common in ravines, Champion and others. Not found as yet out of the island.

\section{ORdER LXXXI. ACANTHACEZE.}

Flowers usually irregular. Sepals 5 , free or united, or the upper one rarely wanting. Corolla with a long or short tube; the limb either 2 -lipped or of 5 spreading lobes, imbricate or contorted in the bud, or expanded into a single lower lip. Stamens 2 or 4 in pairs, inserted in the tube. Anthers 2-celled, or 1-celled by the abortion of the other. Ovary superior, 2-celled, with 2 or more ovules or rarely a single ovule in each cell. Style simple, with an entire or 2-lobed stigma. Capsule usually opening elastically in 2 loculicidal valves. Seeds usually flat, attached to placentary processes of the dissepiment either in the shape of hooks called retinacula, or of minute papillæ or cup-shaped dilatations. Albumen none. Embryo usually curved. Herbs, shrubs, or rarely trees. Leaves opposite, entire or toothed, without stipules. Flowers axillary or terminal, in spikes, racemes, or clusters, each usually with 1 subtending bract and 2 bracteoles, which are sometimes large and leafy, completely enclosing the calyx.

A large Order, diffused over both the New and the Old World, chiefly within the tropics, a very few species occurring in more temperate regions either in the northern or the southern hemisphere.

Suborder 1. Thunbergide.e. - Corolla-lobes contorted in the bud. Seeds inserted on cup-shaped dilatations of the placentas.

Climber. Calyx small, concealed within 2 large bracts .

1. Thunbergia.

Suborder 2. Ruelines.-Corolla-lobes contorted in the bud. Seeds inserted on hooked retinacula (or on small papilla).

Corolla 2-lipped, the upper lip notehed, lower 3-lobed. Stamens 4 2. HygrophiLA.

Corolla-lobes 5 , nearly equal, spreading.

Ovules 6 or more in each cell. Style usually 2-lobed. Stamens 4

Ovules 2 in each cell. Style entire or with a minute tooth. Stamens 4 or 2

3. Ruellia.

4. Strobilanthes, S 2 
Suborder 3. Acanthidex.-Corolla-lobes imbricate or 2-lipped in the bud, not contorted Seeds inserted on hooked retinacula.

Corolla-lobes 5, nearly equal.

Corolla with a long tube and spreading lobes. Stamens 4, rarely 2.

Bracts usually leafy ............. . .

Corolla campanulate, with a short tube. Stamens 2. Bracts

Corolla expanded into a single large lower lip. Stamens 4 . Leaves prickly-toothed . . . . . . . .

Corolla 2-lipped, the upper lip notched, the lower 3-lobed or 3-toothed.
6. Lepidatathis.

Stamens 4.

Anthers 2-celled, oblique, the lower cell mucronate or spurred.

Dissepiment remaining attached to the valves of the capsule.

Anther-cells both with pollen . . . . . . .

Lower spurred anther-cell empty. (Flowers small, in cylindrical spikes.) . • • .

Dissepiment separating from the valves and curved upwards.

(Flowers small, in cylindrical or 4-sided spikes) . below the

Anthers 2-celled, the anthers equal, but one much below the
other. Dissepiment separating from the valves . . .

5. Barleria.

13. Codonacanthus.

7. Acanthus.

12. Dictiptera.

Anthers 1-celled. Flowers contained in calyx-like involucres 10. Hypoestes.

\section{THUNBERGIA, Linn. fil.}

Calyx very short, truncate or toothed, concealed between 2 large bracteoles. Corolla-lobes 5 , nearly equal, spreading, contorted in the bud. Stamens 4 , the cells parallel. Ovules 2 in each cell of the ovary. Stigma shortly 2 -lobed. Capsule globose and seed-bearing at the base, terminating in a flattened beak. Seeds globular, hollowed out on the inner face and inserted on a cupular expansion of the placenta.-Stems herbaceous, climbing (in some African species dwarf and prostrate).

A genus limited to tropical Asia and tropical and southern Africa.

1. T. grandiflora, Roxb.; Nees in DC. Prod.xi. 54 ; Bot. Reg.t. 495 ; But. Mag.t. 2366. A tall climber, rough with a short pubescence. Leaves broadly cordate, acuminate, angular or broadly 5- or 7-lobed. Flowers large, blue, on axillary peduncles or in a terminal one-sided raceme. Bracteoles $1 \mathrm{in}$. long, often cohering on one edge, so as to resemble a spathaceous calyx. Real calyx very short and truncate. Anthers ciliate, one cell of each mucronate.

In a ravine at Saywan, Champion. In the hilly districts of India, from the Nilgherries to Assam, Silhet, Chittagong, and perhaps the Malayan Peninsula; and frequently cultivated in other parts of India.

\section{HYGROPHILA, $\mathrm{Br}$.}

Sepals 5 or rarely 4 , free or more or less united. Corolla 2-lipped, the upper lip notched, the lower 3-lobed, convex in the centre. Stamens 4; anther-cells equal and parallel. Style subulate, with a small upper tooth. Ovules several in each cell of the ovary. Capsule oblong or linear, seedbearing along the whole length. Retinacula hooked.-Erect or decumbent herbs. Flowers in sessile axillary clusters.

A small genus, widely distributed over the tropical and subtropical regions of the New and the Old World. 
1. H. selicifolia, Nees in DC. Prod. xi. 92; Wight, Ic. t. 1490. A slightly pubescent annual or biennial, $]$ to $] \frac{1}{2} \mathrm{ft}$. high. Leaves from oblonglanceolate to linear, $1 \frac{1}{2}$ to $3 \mathrm{in}$. long, entire. Flowers light-blue, 2 to 6 or more in each axil, surrounded by oblong leafy bracts of 3 or 4 lines. Calyx oblong, more or less 5-cleft; the segments lanceolate-subulate, pubescent. Corolla about 6 lines. Capsule about 5 lines long. Seeds small, 8 or more in each cell.-H. quadrivalvis, Nees in DC. Prod. xi. 89.

Hongkong, Hance. Very common in wet swampy places throughout India and the Archipelago, and northward to Japan; and probably the common American and Australian $H y$ grophilas are again the same species under other names.

\section{RUELLIA, Linn.}

(Dipteracanthus, Nees.)

Calyx more or less 5-cleft. Corolla-lobes 5, nearly equal, spreading, contorted in the bud. Stamens 4; anther-cells parallel and equal. Stigma 2lobed; the upper lobe sometimes small and tooth-like. Ovules 6 or more in each cell of the ovary. Capsule flattened and seedless at the base, seed-bearing in the middle. Retinacula hooked, usually denticulate at the top.-Herbs or rarely shrubs. Flowers mostly axillary, solitary or clustered.

A considerable genus, distributed over the warmer regions of the New and the Old World.

1. R. repens, Linn. Stems decumbent or with divaricate branches. Leaves shortly stalked, ovate or ovate-lanceolate, entire, 1 in. long or rather more, slightly hairy. Flowers solitary in the upper axils, blue, $\frac{1}{2}$ in. long or rather more. Sepals lanceolate-subulate, about 3 lines long. Capsule near $\frac{1}{2}$ in. long, with 4 to 6 seeds in each cell, clustered together above the middle. -Dipteracanthus lanceolatus, Nees in DC. Prod. xi. 124.

Hongkong, Wright. In the Philippines, in Java, and various parts of India, but less common there than the allied $R$. prostrata, which has the flowers considerably larger, besides other characters.

\section{STROBILANTHES, Blume.}

(Endopogon, Goldfussia, and Phlebophyllum, Nees.)

Sepals 5, free or united. Corolla-lobes 5, nearly equal, spreading, contorted in the bud. Stamens 4 or 2 . Anther-cells parallel and equal. Ovules 2 in each cell of the ovary. Style subulate and entire to the top, or with a very minute upper tooth. Capsule often flattened and seedless at the base, but the seeds distant in each cell. Retinacula hooked, acute--Herbs or shrubs. Flowers in axillary or terminal, sessile or pedunculate, heads or spikes.

A considerable genus, ranging over tropical Asia and Africa.

Prostrate or decumbent herbs. Stamens 4.

Flowers (2 in. long) in interrupted spikes . . . . . . . . . 1. S. Championi.

Flowers ( $\frac{3}{4}$ in. long) in short heads . . . . . . . 2. radicans.

Undershrubs, with stiff leaves, white underneath. Stamens 2 . . . 3. S. apricus.

1. S. Championi, T. Anders. MSS. A glabrous herb. Stems prostrate or decumbent, 1 to $2 \mathrm{ft}$. long, ascending to 6 in. or rather more. Leaves ovate or oblong, usually acuminate and toothed; the larger ones above 4 in. long. Flowers large, in 2 or 3 distant pairs, on axillary peduncles shorter than the leaves. Sepals linear, herbaceous, 9 or 10 lines long when in fruit, 
or the upper one nearly 1 in. Corolla $2 \mathrm{in.} \mathrm{long;} \mathrm{the} \mathrm{tube} \mathrm{curved} \mathrm{and} \mathrm{dilated}$ at the top. Stamens 4 ; the filaments shortly united. Style entire. Capsule about as long as the calyx.-Dipteracanthus? calycinus, Champ. in Kew Journ. Bot. v. 133.

On Mount Parker, Champion; also Harland. Not known out of the island.

2. S. radicans, T. Anders. MSS. Stems prostrate or creeping at the base ( $6 \mathrm{in}$. long in our specimens), nearly glabrous. Leaves ovate, obtuse, crenate, about $1 \mathrm{in}$. long, slightly hairy or pubescent. Flowers in axillary or terminal heads, surrounded by herbaceous bracts. Bracteoles and sepals linear, pubescent, 3 or 4 lines long. Corolla about $\frac{3}{4}$ line long, the lobes ciliate, the throat with 2 hairy lines. Stamens 4 . Style with a small tooth below the subulate summit.-Ruellia tetrasperma, Champ. in Kew Journ. Bot. iv. 132.

Victoria Peak, Champion. Not seen in any other collection.

3. S. apricus, T. Anders. MSS. A hard undershrub about 1 foot high, with diffuse or spreading pubescent branches. Leaves ovate-elliptical, acuminate, $1 \frac{1}{2}$ to $3 \mathrm{in}$. long, stiff and very rough, with short hairs above, white with appressed hairs underneath; the veins very prominent. Flowers lilac, in dense axillary almost sessile heads, with imbricate lanceolate-acuminate bracts, 6 to 9 lines long. Sepals shorter and narrower. Corolla nearly $1 \frac{1}{2}$ in. long. Stamens 2, usually with rudiments of the 2 upper ones. Capsule about $\frac{1}{2}$ in. long.-Gutzlaffia aprica, Hance in Kew Journ. Bot. i. 143. Phlebophyllum apricum, Benth. in Kew Journ. Bot. v. 131.

Hongkong, Hance; towards Tytam and Little Hougkong, Champion; on hills of the south side of the island, Wilford. Not known out of the island, but nearly allied to the S. Kunthianus, T. Auders. (Phlebophyllum, Nees), from the Indian Peninsula.

\section{BARLERIA, Lim.}

Sepals 4 ; the 2 outer larger than the others. Corolla tubular at the base; lobes 5, nearly equal and spreading, imbricate (not contorted) in the bud. Stamens 4 , or the upper pair sometimes abortive. Anther-cells linear, parallel, and equal. Ovules 2 in each cell of the ovary. Style entire, with a truncate stigma. Capsule acuminate. Seeds inserted near the base. Retinacula hooked.-Herbs or shrubs. Flowers axillary, or in terminal spikes or heads; the bracts and bracteoles usually herbaceous or pungent.

A considerable tropical genus, both in the New and the Old World.

1. B. cristata, Linn.; Nees in DC. Prod. xi. 229; Bot. Mag. t. 1615. A large branching shrub, more or less pubescent. Leaves from ovate-lanceolate to oblong-acuminate, 2 to $4 \mathrm{in}$. long, entire, on petioles usually short. Flowers either solitary in the axils of the leaves, or in short heads or spikes of 4 to 6 . Bracts linear, almost pungent. Outer sepals ovate-lanceolate, 6 to 8 lines long. almost pungent and stiffly ciliate. Corolla lilac, purple, or white, $1 \frac{1}{2} \mathrm{in}$. long or more. Capsule about $\frac{1}{2}$ in. $-B$. dichotoma, Roxb. ; Nees, 1. c. 227, and other synonyms adduced by Anderson in Thwaites's Enum. Pl. Ceyl. 230.

Hongkong, Hinds. Indigenous in northern India; but so much cultivated in tropical Asiatic gardens, that its precise native range is not satisfactorily ascertained. 


\section{LEPIDAGATHIS, Willd.}

Sepals 5, the uppermost larger. Corolla 2-lipped; the upper lip entire or 2-lobed, the lower 3-lobed. Stamens 4. Anther-cells parallel and equal. Ovules 1 or 2 in each cell of the ovary. Capsule sessile, 2-celled from the base. Retinacula hooked.-Herbs or undershrubs. Flowers usually in short dense spikes or heads, with imbricate bracts, often mucronate or pungent.

A considerable genus, spread over tropical Asia and eastern Africa.

1. L. hyalina, Nees in DC. Prod. xi. 252. An erect, divaricate or procumbent, coarsely pubescent perennial, 1 to $2 \mathrm{ft}$. high. Leaves ovate to ovate-lanceolate or oblong, usually $1 \frac{1}{2}$ to near $3 \mathrm{in}$. long, and more or less decurrent on the petiole. Flowers in dense terminal oblong cylindrical or somewhat one-sided spikes, which are $\frac{3}{4}$ to 1 in. long or rather more, solitary or 3 together, and softly hairy. Bracts and sepals 3 to 4 in. long, very pointed, stiff though thin, and almost transparent. Corolla 5 or 6 lines long; the upper lip ovate, the lower broader. Anthers ciliate. Ovules 2 in each cell.-Ruellia dependens, Roxb. Fl. Ind. iii. 49.

Near the Buddhist Temple at East Point, Champion. On roadsides at Saywan, Wilford ; also Hance and Seemann. Common in India.

\section{ACANTHUS, Linn.}

Sepals 4. Corolla with a very short tube; the limb expanded into a large entire or 3-lobed lower lip; the upper lip wanting, or scarcely prominent. Stamens 4. Anthers 1-celled, hirsute or ciliate. Ovules 2 in each cell of the ovary. Capsule 2-celled from the base. Seeds large, flat. Retinacula thick. - Herbs or shrubs. Leaves usually prickly. Flowers in bracteate spikes.

A small genus, extending over tropical Asia, northern Africa, and southern Europe.

1. A. ilicifolius, Linn. An erect glabrous shrub. Leaves sessile or nearly so, oblong, 4 to 6 in, long, coriaceous and shining, bordered with undulate prickly teeth or short lobes. Spikes terminal or in the upper axils, 6 in. to $1 \mathrm{ft}$. long. Bracts and bracteoles ovate acute. Sepals oblong, coriaceous; the 2 outer ones $\frac{3}{4}$ in. long; the 2 inner smaller. Corolla-limb broadly ovate, blue, $1 \frac{1}{2} \mathrm{in}$. long. Capsule coriaceous, shining, 1 in. long.Dilivaria ilicifolia, Juss.; Nees in DC. Prod. xi. 268; Wight, Ic. t. 459.

Borders of salt-marshes, Champion and others. A common shrub in maritime or saline swamps in tropical Asia, exteuding from eastern Africa to northern Australia.

\section{JUSTICIA, Linn.}

(Adhatoda and Gendarussa, Nees.)

Sepals 5. Corolla 2-lipped; the upper lip concave, entire or notched; the lower 3-lobed, convex, and veined or rugose in the centre. Stamens 2. Anther-cells oblique, unequally attached; the lower one mucronate or spurred. Style entire, obtuse at the top. Ovules 2 in each cell of the ovary. Capsule laterally compressed below the seed-bearing part. Seeds tuberculate or muricate. Retinacula obtuse.-Herbs or shrubs. Flowers solitary or in spikes.

A large genus, widely distributed over the tropical and subtropical regions of the globe, with a few species in the more temperate parts of $\mathrm{N}$. America or S. Africa. 
Erect shrubs, glabrous or slightly pubescent.

Bracts broad and herbaceous.

Leaves acuminate. Spikes in the upper axils. Corolla above $]$ in. long

Leaves obtuse or nearly so. Spikes terminal, solitary. Corolla 7 or 8 lines long. . . . . . . . . . .

Bracts small, narrow . . . . . . . . . . . . . . .

1. J. Adhatoda.

2. J. ventricosa.

3. J. Gendarussa.

4. J. Championi.

1. J. Adhatoda, Linn.; Bot. Mag.t.861. A large shrub or small tree; the young parts slightly hoary or pubescent, otherwise usually glabrous. Leaves stalked, oblong-lanceolate, acuminate, entire, 5 or 6 in. long: Bracts herbaceous, broadly ovate, $\frac{1}{2}$ to $\frac{3}{4} \mathrm{in}$. long; bracteoles smaller, oblong. Sepals still narrower, 3 to 4 lines long. Corolla white, with coloured pinnate streaks in the centre of the lower lip, above 1 in. long. Anther-cells less unequal than in most species, and the lower one only slightly mucronate. Capsule almost woody, above $1 \mathrm{in}$. long; the flattened base longer than the seedbearing portion.-Adhatoda Vasica, Nees in DC. Prod. xi. 387.

In ravines near Tytam, Eyre; also Wright. Common in most parts of India, but frequently cultivated also, and thus introduced into other tropical countries.

2. J. ventricosa, Wall. Pl. As. Rar. i. $80, t .93$; Bot. Mag. t. 2766. A large evergreen shrub, glabrous except a slight pubescence on the spike. Leaves oval-elliptical, rather obtuse, 3 to 5 in. long, narrowed into a short stalk, entire and rather thick. Spikes terminal, nearly sessile, 3 to 5 in. long. Bracts herbaceous, broadly ovate, obtuse, coneave, 5 to 6 lines long, each enclosing 3 or 4 flowers. Calyx scarcely 2 lines long. Corolla 7 or 8 lines, white spotted with red. Upper anther-cell almost hood-shaped; lower one spurred.-Adhatoda ventricosa, Nees in DC. Prod. xi. 407.

Hongkong, Wright. In S. China, Chittagong, and Martaban.

3. J. Gendarussa, Linn.; Bot. Reg. t. 635. A glabrous shrub, erect, with long straggling branches. Leaves lanceolate, stalked, entire, 3 to 5 in. long. Spikes interrupted, terminal or axillary, forming a terminal, erect, leafy panicle. Bracts srrall, narrow, and deciduous. Flowers in sessile clusters. Calyx small; the segments subulate. Corolla pink, about $\frac{3}{4}$ in. long, with a slender tube. Lower cell of the anthers with a short conical spur.-Gendarussa vulyaris, Nees in DC. Prod. xi. 410 ; Wight, Ic. t. 468.

Hongkong, Wright. In the hilly districts of India, from Ceylon and the Peninsula to Silhet aud Assam, the Malayan Peninsula, the Archipelago, and Philippines, and frequently cultivated in other localities.

4. J. Championi, T. Anders. MSS. A diffuse or prostrate pubescent or nearly glabrous herb of $\frac{1}{2}$ to $1 \frac{1}{2} \mathrm{ft}$. Leaves ovate or oblong, obtuse, shortly stalked; the larger ones about $1 \frac{1}{2}$ in. long, but mostly under 1 in. Flowers small, clustered in the upper axils, with small petiolate obovate or orbicular leafy bracts. Sepals $1 \frac{1}{2}$ to 2 lines. Corolla about 4 lines long, with a short tube. Lower cell of the anthers with a long spur. Capsule 3 lines long; the flattened base very short.-Adhatoda chinensis, Champ. in Kew Journ. Bot. v. 134.

Common in ravines of Mount Vietoria, Champion; in a ravine of Mount Gongh, Wilford; also Hance and Wright. Not known out of the island. This and a few allied species nearly connet Rostellaria with Justicia. 


\section{ROSTELLARIA, Nees.}

(Rostellularia, 'Endl.)

Sepals 4, or with a minute fifth one. Corolla 2-lipped, the upper lip concave, entire or notched, the lower shortly 3-lobed, convex, and veined in the centre. Stamens 2. Anthers 2-celled, the lower cell spurred and sterile. Style entire, obtuse at the top. Ovules 2 in each cell of the ovary. Capsule (very shortly) laterally compressed below the seed-bearing part. Seeds tuberculate. Retinacula obtuse.-Herbs. Flowers small, in spikes, with narrow sepal-like bracts.

A small genus, limited to the tropical or subtropical regions of the Old World, scarcely differing from the smaller flowered Justicias.

1. R. procumbens, Nees in Wall. Pl. As. Rar. iii. 101 ; Wight, Ic. $t$. 1539. A procumbent or prostrate more or less pubescent annual, often above a foot long. Leaves ovate or oblong, obtuse, $\frac{3}{4}$ to $1 \mathrm{in}$. long. Spikes terminal, cylindrical, $\frac{3}{4}$ to 1 in. long. Bracts and sepals linear-lanceolate or linear, acute, 3 to 4 lines long, hirsute with short stiff hairs. Corolla scarcely longer. Capsule 2 or 3 lines, the compressed base very short. $-R$. Royeniana, Nees, with the synonyms adduced by Anderson in Thwaites's Enum. Pl. Ceyl. 234.

On roadsides and in waste places, Champion and others. Common in India, from Ceylon and the Peninsula to the Archipelago, and northward to Loochoo and Japan.

\section{HYPOESTES, Br.}

Involucre calyx-like, of 4 more or less united bracts, enclosing 1 or rarely 2 or 3 flowers. Real calyx small, of 5 lobes or segments. Corolla 2-lipped, the upper lip entire or notched, the lower 3-lobed. Stamens 2 ; anthers 1celled. Ovules 2 in each cell of the ovary. Style bifid at the top. Capsule laterally compressed below the seed-bearing portion. Retinacula subulate.Herbs, shrubs, or small trees. Flower-heads in axillary clusters or short spikes, often numerous, and forming terminal leafy thyrsi.

A considerable genus, dispersed over Africa, tropical Asia, and Australia.

1. H. purpurea, Br.; Nees in DC. Prod. xi. 509. A shrub, the herbaceous branches and foliage slightly pubescent or nearly glabrous. Leaves from ovate-acuminate to ovate-lanceolate, acute, entire, about 2 in. long. Spikes short and rather loose in the upper axils, with leafy bracts under the heads. Involucres narrow, 1-flowered, about 3 lines long. Calyx much shorter. Corolla about 11 lines long, narrow, reddish-purple. Capsule 4 lines long.

Near the Buddhist Temple at East Point, and at Little Hongkong, Champion; also Hance. In S. China and the Philippines. The Assam station given in the Prodromus arose from a mistake in the label: the specimens were from the Calcutta Botanic Garden, introduced from Chiua.

\section{RUNGIA, Nees.}

Calyx 5-cleft. Corolla 2-lipped, the upper lip notched, the lower 3-lobed. Stamens 2. Anthers 2-celled, the lower one spurred. Ovules 2 in each cell of the ovary. Capsule short, the dissepiment separating from the valves and 
turned upwards with the retinacula.- Herbs usually prostrate, or decumbent. Flowers small, in terminal spikes. Bracts often broad and imbricate.

A small tropical Asiatic genus, with the habit and flowers of Rostellaria, and the capsule of Dicliptera.

1. R. chinensis, Benth. n. sp. Stems decumbent, slightly pubescent. Leaves broadly ovate, acuminate, 1 to $1 \frac{1}{2} \mathrm{in}$. long, on a petiole of 4 to 6 lines, sprinkled with a few small hairs. Spikes $1 \mathrm{in}$. or rather longer. Outer bracts ovate, obtuse, or scarcely acute, ciliate, but only slightly scarious at the edges. Bracteoles similar but smaller. Sepals narrow. Capsules about 3 lines long, shortly acuminate. Corolla not seen.

On Mount Parker, Champion. Not in any other collection. Allied to R. repens, but with a very different foliage.

\section{DICLIPTERA, Juss.}

Flowers usually surrounded by 4 bracts, of which 2 larger. Sepals 5 . Corolla 2-lipped, the tube twisted so that the upper entire or 2-toothed lip becomes the lowest, and the lower 3-lobed one is uppermost. Stamens 2 . Anther-cells 2, similar, but one inserted below the other. Ovules 2 in each cell of the ovary. Capsule short, the dissepiment separating from the valves and turned upwards with the retinacula. Seeds disk-shaped.-Herbs. Leaves entire. Flowers in axillary clusters or short cymes.

A considerable genus, dispersed over the tropical and subtropical regions of the New and the Old World.

1. D. chinensis, Nees in DC. Prod. xi. 477. A decumbent or ascending annual or biennial, usually minutely pubescent. Leaves stalked, ovate or ovate-lanceolate, 1 to $2 \mathrm{in}$. long. Flowers in rather loose axillary clusters or shortly pedunculate cymes, the lowest pair of bracts usually (not always) very narrow and pointed. Outer bracts of each flower from obovate to nearly orbicular, 3 or 4 lines long, shortly mucronate or very obtuse, ciliate on the edge. Bracteoles and sepals very narrow. Corolla pale pink, 6 or 7 lines long. Capsule small, orbicular, pubescent.-D. Roxburghiana, and D. Burmanni, Nees, l.c. 483.

On roadsides, Champion, Hance, Wright; at Little Hongkong, Wilford. In Java, on the Chinese continent, and in Loochoo. The Assam locality given in the Prodromus is again a mistake: the specimen was from the Calcutta Botanic Garden, introduced from China. The precise shape of the bracts is very variable even on the same specimen; and the name of Justicia chinensis has been misapplied to several Indian plants, the synonymy of which still remains much confused. There is little doubt however that the Chinese plant originally deseribed by Iinnæus (D. chinensis, Nees), the one figured by Burmann (D. Burmanmi, Nees), notwithstanding its more mucronate bracts, and Roxburgh's Calcutta garden plant, introduced from China (D. Roxburghiana, Nees), all belong to one species.

\section{CODONACANTHUS, Nees.}

Calyx 5-cleft. Corolla obliquely campanulate, with a very short tube, 5lobed, imbricate in the bud, with the lower lobe outermost. Stamens 2. Anther-cells parallel, not spurred. Ovules 2 in each cell of the ovary. Stigma minutely 2-lobed. Capsule laterally compressed below the seed-bearing part. Retinacula hooked.

A genus limited to a single species. 
1. C. pauciflorus, Nees in DC. Prod. xi. 103. Rhizome creeping and perennial. Stems erect, usually simple, and 6 in. to $1 \mathrm{ft}$. high, but twice as much when very luxuriant. Leaves shortly stalked, ovate or elliptical-oblong, obtuse or acuminate, $1 \frac{1}{2}$ to $3 \mathrm{in}$. long, usually glabrous. Flowers in distant pairs, in slender terminal racemes of 3 or 4 in., often branching out into panicles. Bracts and bracteoles very small. Pedicels about 1 line. Calyx $1 \frac{1}{2}$ to 2 lines. Corolla very spreading, about $\frac{1}{2}$ in. diameter. Capsule 6 or 7 lines long, the compressed base about as long as the seed-bearing portion.

In ravines of Victoria Peak, Champion; in a ravine of Mount Gough, Wilford; also Wright. In Silhet and Assam.

\section{ORDER LXXXII. VERBENACEE.}

Flowers irregular or rarely regular. Calyx persistent, truncate, toothed, or lobed. Corolla with 4 or 5 or rarely more lobes, imbricate in the bud, nearly equal, or more or less 2-lipped. Stamens usually 4 , in pairs, inserted in the tube of the corolla, and alternating with its lower lobes. Ovary not lobed, usually 2- or 4-celled, with one ovule in each cell. Style terminal, simple, entire or with 2 short stigmatic lobes. Fruit dry or succulent, indehiscent or separating into 2 or 4 cocci. Seeds erect, without any or with a small quantity of albumen. Embryo straight, with thick cotyledons.-Herbs, shrubs, trees, or climbers. Leaves usually opposite or whorled, without stipules. Inflorescence various.

A large Order, ranging over both the New and the Old World, most abundant in the tropies, but with a few extratropical species, both in the northern and southern hemispheres.

Ткгве I. Verbenere.-Inflorescence indeterminate, in racemes, spikes, or heads. Ooules erect from the base of the cells.

Ovary 4-celled. Fruit dry, separating into small cocci. Flowers in

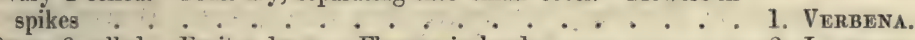

Ovary 2-celled. Fruit a drupe. Flowers in heads . . . . 2. Lantana.

Triве II. Viticee.-Inflorescence determinate, in panicles, cymes, or heads. Ovules pendulous or laterally attached.

Lower lobe of the corolla much longer than the 4 others. Tube short. (Stamens included.)

Fruit dry, separating into 4 cocci, with acute or winged edges.

Lower lobe of the corolla fringed . . . . . . . 3. Caryopteris.

Fruit a drupe. Lower lobe of the corolla entire . . . . . 8. VITEx. Corolla-lobes nearly equal.

Corolla small, usually 4-lobed, with a short tube.

Cymes or panicles terminal. Style acutely 2-lobed . . . . 4. Premna.

Cymes axillary. Style dilated and truncate at the top . . . 5. Callicarpa.

Corolla 5 -lobed.

Corolla-tube slender, much longer than the calyx, except when the latter is inflated. Stamens exserted .

Corolla rather large, obliquely campanulate, with a short tube. Stamens shorter than the corolla ......... 7. GMelina.

\section{VERBENA, Linn.}

Calyx 5-toothed. Corolla with a distinct tube, and a rather unequal spreading 5-lobed limb. Stamens 4 or rarely 2 , included in the tube. Ovary 4 - 
celled. Ovules erect. Fruit dry, enclosed in the calyx, separating into 4 1-seeded nuts.-Herbs, or rarely shrubs. Flowers small, alternate, in terminal spikes.

A genus comprising numerous American species, with only two natives of the warmer or temperate regions of the Old World.

1. V. officinalis, Linn.; Schau. in DC. Prod. xi. 547. An erect perennial, 1 to $2 \mathrm{ft}$. high, with long spreading wiry branches, nearly glabrous, or pubescent, especially on the under side of the leaves. Lower leaves obovate or oblong, stalked, and coarsely toothed or cut, upper ones either deeply pinnatifid and lobed or toothed, or small and lanceolate. Flowers very small, in long slender spikes, the lower ones becoming distant as the spike lengthens, each one sessile in the axil of a small bract.

On roadsides and in waste places, Champion, Hance. Widely spread over Europe and temperate Asia, and (perhaps introduced) in America and South A frica, more rare within the tropics.

\section{LANTANA, Linn.}

Calyx small and thin, truncate or sinuately toothed. Corolla-tube slender; the limb spreading, 4- or 5-lobed, nearly regular or slightly 2-lipped. Stamens 4, included in the tube. Ovary 2-celled. Ovules erect. Fruit a drupe, the kernel 2-celled or dividing into 2-seeded nuts.-Shrubs or rarely herbs. Flowers in pedunculate axillary heads, rarely lengthening into spikes.

A considerable genus, chiefly from tropical or subtropical America, with 2 or 3 Asiatic or African species.

1. L. Camara, Linn.; Schau. in DC. Prod.xi. 598. A tall shrub, with long weak branches, often armed with short recurved prickles, and more or less hairy. Leaves stalked, ovate or slightly cordate, crenate, 2 to 3 in. long, wrinkled and very rough with short stiff hairs. Flowers yellow or orange, turning to a deep red; the heads not lengthening into spikes. Bracts linearlanceolate, shorter than the corolla. Corolla-tube 3 to 4 lines long, lobes of the limb short and broad.- $L$. crenulata, Otto and Dietr., and probably some others enumerated by Schauer in DC. Prod. xi. 597 and 598.

A common species in tropical America, frequently cultivated for ornament, and, escaping from gardens, now naturalized in the Happy Valley, Wilford, Wright.

\section{CARYOPTERIS, Bunge.}

Calyx 5 -toothed or lobed. Corolla-tube short; the limb spreading, 5 -lobed ; the 4 upper lobes nearly equal; the lowest large, concave, and usually fringed. Stamens 4, exserted. Ovary 4-celled, ovules pendulous or laterally attached. Style with 2 subulate stigmatic lobes. Fruit separating into 4 dry nuts, with thin acute or winged edges.-Herbs or undershrubs. Flowers in compact opposite cymes; the upper ones forming a narrow terminal thyrsus.

A small genus, limited to central and eastern Asia.

1. C. mastacanthus, Schau. in DC. Prod. xi. 625. An erect softlypubescent or tomentose perennial or undershrub, $1 \frac{1}{2}$ to $2 \mathrm{ft}$. high. Leaves ovate or oblong, 1 to 2 or rarely $3 \mathrm{in}$. long, soft, coarsely toothed. Flowers blue (or white according to Loureiro). Lower lobe of the corolla deeply 
fringed. Nuts hispid outside.-Barbula sinensis, Lour. Fl. Cochinch. 367. Mastacunthus sinensis, Lindl. Bot. Reg. 1846, t. 2.

In ravines of the Black Mountain, Champion, Hance. Also on the adjacent continent, and northward to Chusan, but not known out of China.

\section{PREMNA, Linn.}

Calyx truncate or sinuately toothed. Corolla-tube short; the limb spreading, of 4 or rarely 5 lobes, nearly equal or slightly 2 -lipped. Stamens 4 , shorter than the corolla or rarely exserted. Ovary 4-celled, ovules pendulous or laterally attached. Style with 2 acute stigmatic lobes. Fruit a drupe, with a 4-celled kernel.- Shrubs or trees: Flowers small, in terminal trichotomous panicles, or in opposite cymes or clusters, forming a spike-like thyrsus.

A genus rather numerous in species, limited to the tropical and subtropical regions of the Old World, but extending to North Australia and the Pacific Islands.

1. P. serratifolia, Linn.; Schau. in DC. Prod. xi.632. A tree, either quite glabrous or with a slight pubescence on the young shoots and inflorescence; the old stems said to be thorny. Leaves ovate or oval-oblong, 2 to 4 in. long, obtuse or acuminate, entire or with a few coarse obtuse teeth, rounded or cordate at the base. Flowers small, greenish-yellow, in dense terminal trichotomous cymes or corymbose panicles. Calyx truncate. Stamens slightly exserted.

Near the seacoast, Champion, Wright. Common on the seacoasts of tropical Asia.

\section{CALLICARPA, Linn.}

Calyx truncate or 4- (rarely 5-) toothed. Corolla with a short tube, the limb 4-lobed (rarely 5-lobed), nearly regular. Stamens 4. (rarely 5), exserted. Ovary 4-celled, ovules pendulous or laterally attached. Style dilated and truncate at the top or rarely shortly and obtusely 2-lobed. Fruit a small juicy berry or drupe, with 4 distinct seed-like nuts or kernels. - Shrubs, rarely undershrubs, more or less cottony or woolly with stellate hairs, or rarely glabrous, and often with numerous resinous glandular dots, especially on the under side of the leaves. Flowers small, in axillary cymes.

A considerable tropical and subtropical genus, chiefly Asiatic, with a few African or American species.

Calyx-teeth long, subulate. Flowers in small dense globular heads, on the short branches of the cymes . . . . . . . . .

Calyx truncate, or the teeth shorter than the tube. Flowers loosely

1. C. tomentosa. cymose to the last.

Leaves very floccose or woolly underneath.

Calyx hairy or tomentose.

Leaves toothed . . . . . . . . . . . . 2. C. macrophylla.

Leaves quite entire . . . . . . . . . . . . 3. C. integerrima.

Calyx glabrous . . . . . . . . . . 4. C. Reevesii.

Leaves green on both sides or slightly floceose underneath.

Leaves glabrous above, narrowed or rarely rounded at the base . 5. C. longifolia:

Leaves sprinkled with hairs on the upper side, cordate at the base 6. C. rubella.

1. C. tomentosa, Willd.; Schau. in DC. Prod. xi. 647. A tall shrub or small tree; the branches, petioles, and inflorescence thickly clothed with a 
tawny wool intermixed with copious spreading hairs. Leaves from oblong to ovate-lanceolate, acuminate, 5 to 8 in. long, wrinkled and minutely hoary above, floccose-cottony underneath. Cymes dichotomous; the short branches terminating in dense globular hirsute heads. Bracts subulate, as long as the calyx. Calyx-teeth subulate, much longer than the tube. Corolla hairy outside. Stamens much longer than the corolla, with small anthers. $-C$. Roxburghii, Schau. in DC. Prod. xi. 640, but not C. incana, Roxb.

Common in ravines, Champion and others. Also about Canton, but not known out of south China.

2. C. macrophylla, Vahl, Symb. iii. 13, t. 53 ; Schau. in DC. Prod. xi. 644. A tall shrub, with the foliage nearly of the last, but very different in inflorescence and calyx. Branches and petioles thickly clothed with a floccose wool, but without long hairs. Leaves oblong, lanceolate or rarely ovate-lanceolate, acuminate, crenately toothed, 6 to $10 \mathrm{in}$. long, wrinkled and nearly glabrous above, floccose-cottony or woolly underneath. Cymes much branched, with very numerous small flowers, all distinet. Bracts small, linear. Calyx hairy, truncate; the nerves protruding into minute or sometimes linear teeth, but always much shorter than the tube. Corolla slightly pubescent. Stamens much exserted. $-P$. incana, Roxb. Fl. Ind. i. 393.*

Hongkong, Seemann, Wright; also on the adjacent contineut, and frequent in northern and eastern India.

3. C. integerrima, Champ. in Kew Journ. Bot. v. 135. A shrub of 8 or $10 \mathrm{ft}$., the branches petioles and inflorescence clothed with a dense floccose yellowish tomentum or wool. Leaves from broadly ovate to nearly oblong, shortly acuminate, 4 to 6 in. long, quite entire, glabrous or nearly so above, densely tomentose or woolly underneath. Cymes loose, with very numerous small flowers. Calyx tomentose, truncate or sinuately toothed. Corolla glabrous. Anthers small, the filaments much exserted.

Common in Hongkong, Champion, Hance, Wright. Also on the adjacent continent, but not known out of S. China. It comes nearest to the $C$. Wallichiana from the Himalaya, but that has much larger flowers, with large oblong anthers on short filanents.

4. C. Reevesii, Wall.; Schan. in DC. Prod. v. 641. A shrub, the branches, petioles, and inflorescence covered with a short close mealy tomentum. Leaves oval-oblong, acute or acuminate, 5 to $8 \mathrm{in}$. long, entire or irregularly toothed, glabrous and nearly smooth above when full-grown, white-cottony underneath. Cymes on rather long peduncles, very much branched. Flowers very numerous, glabrous, and larger than in the foregoing species. Calyx truncate or sinuately toothed. Anthers small, the filaments much exserted. - C. nudiflora, Hook. and Arn. Bot. Beech. 206, t. 46.

Hongkong, Champion, Wright. Plentiful at East Point, Wilford. Also on the adjacent continent, but not known out of S. China.

5. C. longifolia, Lam.; Schau. in DC. Prod. xi. 645, var. brevipes. A shrub, sometimes glabrous, but more frequently more or less sprinkled with

* Specimens were distributed by Roxburgh under the uame of $C$. cana; but the $C$. cana of his Flora is the true $C$. cana, Linn., and was originally named $C$. dentata by Roxburgh. Specimens of the C. macrophylla have been distributed by Wallich as C. Roxburghii, n. 1833, as well as urider the $\mathbf{n} .1832$, which has occasioned much confusion between this species and the preceding one. 
a floccose stellate tomentum. Leaves shortly stalked, lanceolate or linear-lanceolate, 3 to 6 in, long, acuminate, entire or irregularly sinuate, mostly acute at the base, but occasionally rounded or the lower ones almost cordate, green on both sides. Flowers glabrous or nearly so, in small nearly sessile cymes, but each flower distinctly pedicellate. Calyx truncate or sinuately toothed. Anthers oblong, about as long as the exserted part of the filament.

At Saywau, Champion; also Wright and Wilford. This is the variety figured in Hook. F1. Exot. ii. t. 133, and in Bot. Reg. t. 864. The only specimens I have seen are from gardens or from Hongkong. The original form figured by Lamarck, with numerous small flowers in loose cymes, smaller anthers on longer filaments, and long narrow almost entire leaves, has been gathered by Hance near Canton, and by Cuming in the Philippines (n. 1330). A third variety, more common in India and the Archipelago, and found also in S. China by Fortune, has the flowers and inflorescence of Lamarck's plant, but shorter and broader leaves, always tapering at the base. This is the C. lanceolaria, Roxb., and is sometimes scarcely to be distinguished from the American C. americana, Linn. One of Champion's Hongkong specimens is in some measure intermediate between the var. brevipes and Lamarck's form.

6. C. rubella, Lindl. Bot. Reg. t. 883 ; Schau. in DC. Prod. xi. 645. A shrub or undershrub of 2 or $3 \mathrm{ft}$.; the loose floccose tomentum not abundant, and often mixed with a few simple hairs. Leaves shortly stalked, obovate-oblong, acuminate, serrate, 3 to 5 in. long, narrowed below the middle, but rounded-cordate at the base, green on both sides or slightly tomentose underneath, with scattered single hairs on the upper surface. Cymes loose, on slender peduncles. Calyx tomentose, truncate or sinuately toothed. Corolla pink. Anthers oblong, on short filaments.-C. tenuiflora, Champ. in Kew Journ. Bot. v. 135.

At Saywan, Champion; also Wright. On the continent of S. China, in Khasia and Assam.

\section{CLERODENDRON, Linn.}

Calyx campanulate or inflated, 5-toothed or ŏ-lobed. Corolla-tube slender, much longer than the calyx, except when the latter is inflated; the limb spreading, nearly equally 5-lobed. Stamens 4, usually much exserted. Ovary 4-celled; ovules pendulous or laterally attached. "Style with 2 acute stigmatic lobes. Fruit a drupe; the kernel usually large, separating into 2 two-celled or 4 one-celled nuts.-Shrubs, trees, or rarely herbs. Flowers loosely cymose or capitate, in terminal panicles or thyrsi, or rarely axillary

A considerable tropical genus, chiefly Asiatic, with a few African or American species.

Leaves glabrous. Flowers axillary.

Peduncles 3-flowered. Calyx small. Corolla-tube long and slender . Peduncles 5-9-flowered. Calyx 5-angular, inflated, as long as the corolla-tube

Leaves softly pubescent. Flowers in compact heads, forming a terminal corymb

\section{C. inerme.}

2. C. lividum.

3. C. canescens.

1. C. inerme, Br.; Schau. in DC. Prod. xi. 660. A glabrous shrub, or slightly pubescent when young. Leaves stalked, ovate, obtuse or shortly acuminate, entire, 1 to 3 in. long. Peduncles axillary, often nearly as long as the leaves, bearing 3 pedicellate flowers. Calyx truncate, not 2 lines long when in flower, above 3 when in fruit. Corolla-tube slender, about 1 in. long; 
lobes about 4 lines. Stamens much longer. Drupe ovoid, about twice as long as the calyx.

Very common near the sea, Champion and others. Widely spread along the seacoasts of tropical Asia, the Archipelago, and islands of the Pacific.

2. C. lividum, Lindl. Bot. Reg. t. 945. A low glabrous shrub. Leaves varying from broadly oblong and about 3 in. long, to narrow oblong-lanceolate and 5 or 6 in. long, entire or coarsely and irregularly toothed. Cymes axillary, 5- to 9-flowered, much shorter than the leaves. Calyx of a livid purple, inflated, 5-angled, 5-lobed, about 5 lines long. Corolla nearly white ; the tube about as long as the calyx. Stamens shortly exserted.-C'. pentagonum, Hance in Walp. Ann. iii. 238.

Hongkong, Champion, Hance, Wright, Wilford. In the Happy Valley, Seemann. Also on the adjacent contineut, but not known out of S. China.

3. C. canescens, Wall.; Schau. in DC. Prod. xi. 665. A small tree; the branches, young leaves, and inflorescences softly pubescent. Leaves broadly cordate-ovate, acuminate, coarsely toothed, 4 or 5 in. long. Flowers in dense capitate pedunculate cymes, forming a short terminal corymb or flat panicle, each head surrounded by ovate imbricate bracts as long as the calyx. Calyx 5-lobed, about 3 lines long when in flower, becoming much enlarged, spreading and red when in fruit. Corolla-tube slender, above $\frac{1}{2} \mathrm{in}$. long. Stamens much exserted. Drupe globular, shorter than the calyx.-C. homatocalyx, Hance in Walp. Ann. iii. 238.

Common near the level of the sea, Champion and others. Also on the adjoining continent, but not known out of S. China

\section{G̈MELINA, Linn.}

Calyx 4- or 5-toothed. Corolla obliquely campanulate or funnel-shaped, narrowed into a short tube; the limb broadly 4- or 5-lobed. Stamens 4, in pairs, shorter than the corolla. Ovary 2- or 4-celled. Ovules pendulous or laterally attached. Style unequally 2-lobed at the top. Fruit a drupe with a 2- or 4-celled kernel.-Trees or tall shrubs. Flowers large for the Order, yellow or pale pink, in irregular terminal panicles, sometimes almost reduced to simple racemes. Calyx often bearing a few scattered glands.

A small genus, extending over tropical Asia and the Archipelago to North Australia.

1. G. chinensis, Benth., n. sp. Leaves stalked, ovate, acute or acuminate, entire, 3 or 4 in. long, cuneate and 3 -nerved at the base, glabrous above, hoary with a minute meal underneath, with occasionally 2 or 3 glands at the base between the nerves. Panicle short and narrow, slightly tomentose or pubescent. Bracts small, oblong. Calyx campanulate, about 4 lines long when in flower, truncate at the top with 5 minute distant teeth, slightly hoary outside with a few small glands. Corolla above an inch long, not downy, but only whitish with a minute meal, broader, less oblique, and with a shorter tube than the other species known to me, usually 4-lobed, but one flower of the specimen has 5. Ovary 4-celled. Smaller lobe of the style very minute.

Hongkong, Wright. I have seen ouly one specimen, and it is not in any other collection. 


\section{VITFX, Linn.}

Calyx 5-toothed or lobed. Corolla-tube short; the limb spreading, 5 -lobed; the lower lobe larger and longer than the others (as in Teucrium). Stamens 4; in pairs, exserted. Ovary 4-celled, ovules pendulous. Style acutely 2-lobed at the top. Fruit a 4-celled drupe.-Trees or shrubs. Leaves usually digitately compound. Flowers in cymes, sometimes axillary, but usually in terminal panicles, either simple and spike-like or branched.

A considerable tropical or subtropical genus, chiefly Asiatic or African, with a few American or Australian species, and one extending into south Europe.

Stem decumbent. Leaves mostly simple, white underneath. Calyx 2 lines long .

1. V. trifolia, var.

Stem erect. Leaves digitate. Calyx about 1 line long.

Leaflets white underneath. . . . . . . . . . 2. V. Negundo.

Leaflets green on both sides . . . . . . . . . 3. V. Loureiri.

1. V.trifolia, Linn.; Schau. in DC. Prod. xi. 683, var. unifoliolatu. A decumbent shrub; the branches, under side of the leaves, and inflorescence mealy-white, Leaves simple, stalked, obovate or rounded, 1 to $1 \frac{1}{2} \mathrm{in}$. long, glabrous or nearly so above, at least when old. Flowers few, in nearly sessile opposite cymes, forming short simple terminal spike-like or narrow panicles. Calyx about 2 lines long, very shortly 5 -toothed, the corolla twice as long, and both mealy-white outside. Drupe globular.-V. ovata, Thunb.; Hook. and Arn. Bot. Beech. 206, t. 47.

Common in the maritime sands, Champion and others; the Hongkong specimens are all simple-leaved. The species is widely spread along the seacoasts and great rivers of eastern tropical Asia and the Pacific islands, and often has 3 leaflets longer and narrower than in the simple variety, and the cymes more developed, but it has always the flowers nearly twice as large as in $V$. Negundo.

2. V. INegundo, Linn.; Schau. in DC. Prod. xi. 684; Wight, Ic.t. 519. A shrub, usually erect; the branches, under side of the leaves, and inflorescence mealy-white as in $V$. trifolia. Leaves all compound with 3 or 5 leaflets oblong or lanceolate, entire or deeply toothed or pinnatifid, glabrous or nearly so above, the central one 2 to 4 in. long; the lateral ones usually smaller. Flowers small, in close opposite cymes, forming simple or branched spike-like panicles, or very rarely the cymes become loosely dichotomous. Calyx tomentose, not above 1 line long. Corolla much longer, usually tomentose outside, and hairy at the base of the lower lobe.-V. bicolor, Willd. ; Schau. in DC. Prod. xi. $\$ 83$ (when the cymes are looser). $V$. incisa, Lam.; Schau. 1. e. 684 (the cut-leaved forms).

On the seacoast, Hance, both with entire and cut leaflets. Common in tropical Asia, and northwards to Chinese Mongolia. It is readily distinguished from the more western $V$. Agnus-castus, by the flawers not half the size.

3. V. Loureiri, Hook, and Arn. Bot. Beech. 206, t. 48; Schau. in DC. Prod. xi. 686. A shrub or small tree, minutely hoary, pubescent on the branches under side of the leaves and inflorescence, not white as in $V$. Negundo which it otherwise resembles. Leaflets 5 or rarely 3 , oblong or lanceolate, deeply toothed. Flowers small and inflorescence of $V$. Negundo. Calyx tomentose. Corolla glabrous.

Hongkong, Wright; also on the adjoining continent, but not seen from elsewhere. 


\section{Order LXXXIII. LABIAT FE.}

Flowers irregular or rarely nearly regular. Calyx persistent, usually 5 -toothed. Corolla with a distinct tube and 4 or 5 lobes, usually forming 2 lips, rarely nearly equal. Stamens 2 or 4 , in pairs, inserted in the tube of the corolla, and alternating with its lower lobes. Ovary 4-lobed, with one erect ovule in each lobe. Style single, arising from the centre, with 2 short stigmatic lobes at the top. Fruit enclosed in the calyx, separating into 4 small seed-like nuts.-Herbs, or rarely shrubs, frequently aromatic. Leaves opposite or whorled. Flowers in opposite cymes or rarely solitary, either forming axillary clusters, called false-whorls (verticillasters), or in terminal spikes, or racemes, or spike-like panicles or thyrsi, or in loose panicles.

A large Order, distributed over every part of the globe.

Stamens 2; the filaments branched, one branch with a perfect cell, the

other with an imperfect or rudimentary one

6. Salvia.

Stamens 4.

Stamens nearly straight and equal, or bending downwards.

Calyx 2-lipped.

Stamens bending downwards, exserted. Anthers 1-celled . . 1. Mesona.

Stamens not longer than the corolla. Anthers 2-celled . . . 4. Perillia.

Calyx nearly regular, 5-toothed.

Filaments woolly-hairy. Stamens much exserted.

Lower lobe of the corolla longest. Flowers in dense clusters, forming interrupted spikes.

Corolla nearly regular. Flowers in close cylindrical sikes.

Filaments glabrous , . . . . . . . 5. Mentha.

Stamens ascending in pairs.

Stamens shorter than the upper lip of the corolla.

Calyx nearly equally 5 -toothed.

Calyx tubular, 15-nerved. Upper stamens longest. . . 7. NePETa.

Calyx 5-nerved. Lower stamens longest. Leaves deeply cut . 10. LEONURUs.

Calyx nearly equally 10 -toothed.

Calyx with 2 entire lips, and an appendage on the back of the upper one.

11. Leucas.

mens projecting beyond the upper lip or lobes of the corolla.

Short upper lip of the corolla entire behind the stamens. Nuts smooth

8. Scutellaria.

Short upper lip deeply cleft into 2 lobes, between which the stamens protrude. Nuts reticulate ....... 12. Teucrium.

\section{MESONA, Blume.}

Calyx 2-lipped; the upper lip 3-toothed; the lower entire, truncate. Corolla with a short tube; the limb campanulate; the upper lip broad, truncate or 4-toothed; the lower longer, oblong, concave. Stamens 4, declining; upper filaments with a tooth or appendage at the base.-Herbs. Flowers small, the false-whorls in terminal racemes. Calyx-tube transversely wrinkled when in fruit.

\section{A small tropical Asiatic genus.}

1. IM. chinensis, Benth. Stems decumbent, scarcely a foot long, slightly pubescent or hairy. Leaves ovate or oblong, obtuse, 1 to $1 \frac{1}{2}$ in. long, slightly toothed, and narrowed into a rather long petiole. Floral leaves or bracts ovate or lanceolate, scarcely longer than the flowers, mostly coloured at the 
base. Calyx very small at first, about 2 lines long when in fruit. Lower lobe of the corolla hairy outside.

At Saywan, Wilford. Not known from elsewhere, unless it be a variety of $\boldsymbol{M}$. Wallichiana, Benth, from Silhet and Assam. The latter is, however, a coarser and more hairy plant, and the leaves are always acuminate, and have much shorter petioles.

\section{POGOSTEMON, Desf.}

Calyx equally 5 -toothed. Corolla with a short tube; the limb somewhat 2-lipped, the upper lip 3-lobed, the lower lip entire and somewhat longer. Stamens 4, nearly equal, exserted, the filaments often bearded. Anthers terminal, 1-celled.-Herbs. Flowers in dense clusters or false-whorls, arranged in terminal spikes or close panicles.

A rather considerable tropical Asiatic genus.

1. P. parvifiorus, Benth. in DC. Prod. xii, 152. Stems decumbent at the base, ascending to $2 \mathrm{ft}$. or more. Leaves ovate or oval-oblong, more or less toothed, usually 2 to $4 \mathrm{in}$. long, on rather long petioles, thin and glabrous or slightly pubescent. Flowers small, in dense globular clusters, surrounded by ovate or oblong pubescent bracts nearly as long as themselves, and arranged in somewhat broken and one-sided spikes forming terminal panicles. Calyx pubescent, nearly 2 lines long. Hairs of the filaments purplish.

On Mount Parker, Champion. Common in the hilly districts of India, from the Nilgherries to Upper Assam.

\section{DYSOPHYLLA, Blume.}

Characters of Pogostemon, except that the corolla is more regular, the lobes being equal or nearly so, and the false-whorls of small flowers are in a single close cylindrical slender spike.

A small genus from tropical Asia, which ought perhaps to be united with Poyostemon.

1. D. auricularia, Blume; Benth. in DC. Prod. xii. 156 ; Wight, Ic. $t$. 1445. A procumbent perennial, hirsute in every part with spreading hairs, usually of a yellowish-brown. Stems often 2 or 3 feet long. Leaves sessile or very shortly stalked, $1 \frac{1}{2}$ to 2 in. long, ovate-oblong or almost lanceolate. Spike dense, but narrow, 2 to $4 \mathrm{in}$. long, composed of very numerous falsewhorls of small flowers. Calyx less than a line long.

In ditches and moist places, Champion. Abundant in India, from Ceylon and the Peninsula to the Archipelago, and northwards to the Himalaya and south China.

\section{PERILLA, Linn.}

Calyx campanulate, 5-cleft, becoming when in fruit 2-lipped, with an enlarged tube, the upper lip 3-toothed, the lower 2-cleft. Corolla with a short tube, the limb shortly 5-cleft, the lowest lobe rather the longest. Stamens 4 , not exserted, nearly straight. Anthers 2 -celled. Nuts globular, reticulate. -Annuals. Flowers solitary and pedicellate, in the axils of the opposite bract-like floral leaves, forming terminal or axillary racemes.

A small tropical or subtropical Asiatic genus.

Plant hairy. Leaves about 2 in., deeply toothed, purple underneath . . 1. P. arguta.

Plant whitish-hoary or glabrous. Leaves not 1 in., slightly toothed . 2. $P$. lanceolata. 
1. P. arguta, Benth. in DC. Prod. xii. 164. An erect, more or less hairy, rather coarse branching annual, 1 to $1 \frac{1}{2} \mathrm{ft}$. high. Leaves on rather long petioles, broadly ovate, deeply toothed, usually about $2 \mathrm{in}$. long, stained with purple underneath, or sometimes on both sides. Racemes l-sided, 3 to 5 in. long. Flowers small. Calyx-tube hispid.-Mentha reticulosa, Hance in Walp. Ann. iii. 247.

Cultivated for its seed, but also found wild in the island, Hance. Also on the Chinese continent and in Japan. The leaves are nearly those of $P$. ocimoides, var. crispa, or Dentidia nankinensis, Lour.; but the spikes are more slender, the calyx less hairy, and longer when in fruit. We are not however sufficiently acquainted with the native form of the plant to judge how far it may be really specifically distiuct from the common Indian $P$. ocimoides.

2. P. lanceolata, Benth. in DC. Prod. xii. 164. An erect muchbranched annual, seldom $1 \mathrm{ft}$. high, glabrous or more or less hoary with a minute pubescence, but without stiff hairs. Leaves ovate or the upper ones lanceolate, $\frac{1}{2}$ to $\frac{3}{4}$ or rarely 1 in. long, slightly toothed, on petioles of 3 or 4 lines. Racemes slender, 1 -sided. Flowers smaller than in $P$. arguta. Calyx slightly hoary but not hairy. Anthers of the upper stamens smaller than the lower ones, but with 2 perfect cells.-Hedeoma nepalensis, Seem. Bot. Her. 404 ; not Benth.

In waste places, Hance; also Wright. On the adjoining continent to Amoy. The true Hedeoma nepalensis is very like this plant, but is more or less hispid, and has always the 2 upper stamens rudimentary or sterile, a distinction which in this family has always been regarded as generic, although in this instance the $H$. nepalensis might be more naturally removed to Perilla.

\section{MENTHA, Linn.}

Calyx nearly regular, 5-toothed. Corolla with a short tube and a campanulate 4-lobed limb, nearly regular, or the upper lobe rather broader, and sometimes slightly notched. Stamens 4, equal and erect; the anthers 2-celled. Nuts smooth.-Perennial herbs. Flowers rather small, in dense false-whorls, which are either collected in terminal heads or spikes, or axillary and distant.

A genus not numerous in species, widely diffused over the greater part of the globe, without the tropies, one species extending also into the tropical regions of the Old World.

1. IM. arvensis, Linn.; Benth. in DC. Prod. xii. 171, var. javanica. Stem decumbent or ascending, more or less hoary with closely reflexed hairs. Leaves lanceolate or ovate-lanceolate, 1 to $1 \frac{1}{2} \mathrm{in}$. long, narrowed into a short petiole, the upper ones smaller; false-whorls globular, many-flowered, all axillary and distant; the uppermost pair of leaves often without flowers. Calyx usually about 1 line long.-M. javanica, Blume; Benth. in DC. Prod. xii. 173 .

In ditches, Saywan, Hance. Very strongly aromatic. The same variety occurs in Ceylon, the Indian Archipelago, the Philippines, and northward to Chusan. The species itself ranges all over Europe and temperate Asia, where the leaves are generally (but not always) broader and not narrowed at the base, but the North American forms (M. canadensis, Linn.,) connect the Javanese with the European too closely to be any longer regarded as specifically distinct.

\section{SALVIA, Linn.}

Calyx 2-lipped, the upper lip entire or with 3 minute teeth, the lower one 2-cleft. Corolla with the upper lip erect, concave or arched ; the lower spreac ing, 3 lobed, the middl lobe often notched or divided. Stamens 2, but easily 
mistaken for 4 , for the anthers have a long slender connectivum (like branches of the filament), with a perfect cell at the upper end, and at the lower end a small empty cell, usually much deformed or quite rudimentary.

- A very large genus, widely spread over the temperate and warmer regions of the globe, although within the tropics the majority of species are mountain plants.

Leaves mostly with 3 ovate petiolulate segments. Corolla $\frac{1}{2}$ in. long . . 1. S. Fortunei. Leaves undivided. Flowers minute ... . . . . ..... . 2. Slebeia.

1. S. Fortunei, Benth. in DC. Prod. xii. 354. An erect rather slender and nearly glabrous herb, $1 \frac{1}{2}$ to $2 \mathrm{ft}$. high. Leaves stalked, divided into 3 ovate petiolulate segments, the terminal one 1 to $1 \frac{1}{2}$ in. long, the lateral ones smaller, and the uppermost pair of leaves often undivided, Flowers about $\frac{1}{2}$ in. long, in false-whorls of about 6 , forming a long loose terminal raceme. Upper lip of the calyx entire. Lower end of the connectivum of the anther dilated or with a small empty cell.

In ravines, Champion, Hance; also Fortune. Not known out of S. China.

2. S. plebeia, Br. ; Benth. in DC. Prod. xii. 355. An erect branching pubescent or hairy coarse annual, 1 to 2 or even $3 \mathrm{ft}$. high. Leaves stalked, oblong, obtuse or acute, $1 \frac{1}{2}$ to 3 in. long, wrinkled. Flowers very small, in false-whorls of 6 , forming branching paniculate racemes. Calyx pubescent, ovoid and 1 line long when in flower, campanulate and 2 lines long when in fruit; the upper lip entire and obtuse. Corolla scarcely longer than the calyx.

Hongkong, Wright. Common in India, from Ceylon and Affghanistan to the Archipelago, extending into tropical Australia and northward as far as Pekin.

\section{NEPETA, Linn.}

Calyx tubular, 15-ribbed, its mouth oblique and 5-toothed, the upper teeth usually the longest. Corolla with a rather long tube; the throat enlarged; the upper lip erect, slightly concave, notched or 2-lobed; the lower lip spreading and 3-lobed. Stamens 4, in pairs under the upper lip, the upper or inner pair the longest. Anthers 2-celled.-Herbs. Flowers usually blue, in axillary false-whorls or terminal spikes.

An extensive European and Asiatic genus, the great centre of which is western Asia.

1. N. glechoma, Benth. in DC. Prod. xii. 391. A more or less hairy perennial, creeping and rooting at the base, often to a great extent; the flowering stem shortly ascending. Leaves orbicular, crenate, deeply cordate at the base; the lower ones on rather long stalks. Flowers blue, from $\frac{3}{4}$ to near 1 in. long, in axillary false-whorls of about 6 ; the tube of the corolla at least twice as long as the calyx.

At Sheako, but rare in Hongkong, Hance. Common in Europe and temperate Asia, extending eastward to Japan.

\section{SCUTELLARIA, Linn.}

Calyx divided into 2 entire lips; the upper one bearing on its back a hollow scale-like protuberance. Corolla with a rather long tube and small nearly closed lips, the upper one concave, the lower one 3-lobed. Stamens 4, in pairs; the anthers of the lower pair 1-celled. Nuts raised on a short, oblique, 
or curved stalk.-Herbs or rarely shrubs. Flowers solitary, either opposite and axillary, or in terminal spikes or racemes.

A rather large genus, widely distributed over the temperate and some of the warmer regions of the globe.

1. S. indica, Linn.; Benth. in DC. Prod. xii. 417. A procumbent, pubescent, or hairy perennial, with shortly ascending flowering stems. Leaves stalked, orbicular, crenate, cordate at the base, from less than $\frac{1}{2}$ to near $1 \mathrm{in}$. long, seldom varying to broadly ovate. Flowers opposite, in a simple short terminal l-sided raceme. Appendage of the calyx broad and membranous. Corolla blue, 6 or 7 lines long; the tube dilated upwards.

In ravines and to the tops of the hills, Champion and others. Apparently common in S. China ; also in Java, and northwards to Loochoo and Japan; indeed the larger-flowered $S$. japonica, Morr. and Dene., is probably only a variety of the same species. Notwithstanding its name, it is not known from India.

\section{ANISOMELES, Br.}

Calyx 5-nerved, 5-toothed. Corolla-tube the length of the calyx, upper lip erect and entire, lower lip longer, spreading, 3-lobed; the middle lobe 4notched or 2-cleft. Stamens 4, in pairs, projecting from the upper lip of the corolla. Anthers of the upper stamens 1-celled, of the lower 2-celled, all the cells parallel and transverse. Nuts smooth.-Coarse herbs. Flowers in loose cymes or in dense false-whorls, axillary or in terminal racemes.

A small genus, limited to tropical Asia and Australia, or searcely extending into East Africa.

1. A. ovata, Br.; Benth. in DC. Prod. xii. 455 ; Wight, Ic. t. 865. An erect, coarse, softly hairy or pubescent perennial, rarely nearly glabrous, 2 or $3 \mathrm{ft}$. high, with a strong unpleasant smell. Leaves usually ovate, crenate, about 2 in. long. Flowers purplish, numerous, in dense false-whorls; the lower ones axillary; the upper forming a long terminal raceme or spike. Calyx 3 to 5 lines long, with lanceolate teeth.

In the Happy Valley, Champion, at Little Hongkong, Wilford; also Wright. Common in India, from Ceylon and the Peninsula to the Archipelago, and northward to the Himalaya and S. China.

\section{LEONURUS, Linn.}

Calyx 5-nerved, truncate at the top, with 5 subulate or prickly teeth. Corolla-tube rarely exceeding the calyx ; the upper lip erect or oblong or hooded, the lower more or less spreading, 3-lobed, the middle lobe obcordate. Stamens 4 , in pairs, ascending under the upper lip. Anthers 2-celled, with parallel transverse cells. Nuts smooth, truncate at the top.-Herbs. Leaves often deeply cut. Flowers in dense false-whorls.

A small European or Asiatic genus, of which one species is spread as a weed over many other parts of the world.

1. L. sibiricus, Linn.; Benth. in DC. Prod. xii. 501; Sw. Brit. Fl. Gard. t. 204. An erect branching glabrous or slightly pubescent annual or biennial, 2 to 5 or 6 feet high. Leaves stalked, the lowest ovate, with a few broad lobes, the others deeply divided into 3 or more deeply cut oblong-linear lobes, or the uppermost sometimes narrow and entire. Flowers red, nu- 
merous; the lower false-whorls axillary and distant, the upper forming a long terminal spike. Bracts and calyx-teeth subulate, almost prickly. Corolla about 5 lines long, pubescent outside.

On roadsides, Champion and others. Probably of Asiatic origin, now a very common roadside weed over the greater part of tropical and temperate Asia, tropical Africa, and some parts of tropical America.

\section{LEUCAS, Br.}

Calyx usually 10-ribbed, straight or oblique at the top, 10 - or rarely 8 toothed. Corolla-tube not exserted; the upper lip erect, concave, and very hairy, the lower spreading, 3-lobed, with a large often notched middle lobe. Stamens 4, ascending in pairs under the upper lip. Anther-cells divaricate, confluent. Nuts obtuse at the top.-Herbs or undershrubs. Flowers usually white, rarely purple, in axillary false-whorls or terminal spikes.

A considerable genus, confined to the tropical or subtropical regions of the Old World.

1. L. mollissimum, Wall.; Benth. in DC. Prod. xii. 525. A perennial, with decumbent or ascending pubescent or hairy stems, 1 to $2 \mathrm{ft}$. long. Leaves ovate, crenate, $\frac{1}{2}$ to $1 \mathrm{in}$. long, softly hairy, pale or white underneath. False-whorls all axillary and distant, 10- or more flowered. Bracts minute. Calyx 3 lines long, straight, pubescent, with 10 very short erect subulate teeth.

On roadsides, Little Hongkong, Champion; also Hance and Wright. On the adjacent continent, and frequent in the mountains of northern India.

\section{TEUCRIUM, Linn.}

Calyx 5-toothed, either regular or the upper tooth much broader. Corollatube short; 4 upper lobes short, erect, or turned forwards; the lowest lobe much larger, spreading, often concave. Stamens 4 , in pairs, exserted between the 2 uppermost lobes of the corolla. Nuts attached laterally near the base, more or less reticulate.-Herbs or shrubs, varying much in inflorescence.

A large genus, widely distributed over most parts of the globe.

False-whorls 6 - to 10 -flowered, in a simple terminal spike. Calyx in-

flated after flowering . . . . . . . . 1. T. inflatum.

Flowers in pairs, in one-sided terminal racemes or panicles.

Plant slightly hairy. Petioles rather long. Calyx inflated after flowering . - 2. Tstoloniferum.

Plant very hairy. Petioles short. Calyx not inflated . . . 3. T. quadrifarium.

1. T. inflatum, Sw.; Benth. in DC. Prod. xii. 581. A pubescent or hairy perennial, with a creeping rhizome and erect stems 1 to $2 \mathrm{ft}$. high. Leaves shortly stalked, ovate or ovate-lanceolate, 2 to 3 in. long, hoary underneath. Flowers (pale purple?) in whorls of 6 to 10 , collected into a simple terminal leafless spike of 3 or 4 in. Calyx much inflated after flowering, contracted at the mouth; the teeth ovate and obtuse, the uppermost much broader.

In waste places, Hance. A tropical American species, but abundant also in the Feejee and Friendly Islands, in the Pacific, and in some islands of the eastern Archipelago.

2. T. stoloniferum, Ham.; Benth. in DC. Prod. xii. 583. Rhizome perennial, with creeping stolones. Stems erect, 1 to $2 \mathrm{ft}$. high; the whole plant glabrous or pubescent. Leaves on rather long petioles, broadly ovate, 
not so coarse and less wrinkled than in $T$. quadrifarium, deeply crenate, 1 to $2 \mathrm{in.} \mathrm{long..} \mathrm{Flowers} \mathrm{(pale} \mathrm{yellow?)} \mathrm{pedicellate,} \mathrm{in} \mathrm{pairs,} \mathrm{in} \mathrm{loose} \mathrm{branching}$ terminal one-sided racemes. Bract-like floral leaves shorter than the calyx. Calyx more or less inflated after flowering; the upper tooth much broader than the others.

In waste places, Hance. Also on the adjacent continent and eastern India, from Sikkim and Khasia to the Archipelago.

3. T. quadrifarium, Ham.; Benth. in DC. Prod. xii. 583. Rhizome creeping, but perhaps less so than in the last species. Stems erect, 1 to $1 \frac{1}{2} \mathrm{ft}$. high in the Chinese specimens, often double that in India, densely hirsute with spreading hairs, often assuming a golden hue. Leaves on short stalks or nearly sessile, ovate or oblong, 1 to 2 in. long, serrulate, wrinkled and villous. Flowers (purple or whitish?) pedicellate, in pairs, in loose branching terminal one-sided racemes. Bract-like floral leaves ovate, often longer than the calyx, but sometimes much smaller. Upper tooth of the calyx much broader than the others; the tube scarcely inflated after flowering.- T. Fortunei, Benth. in DC. Prod. xii. 583. T. fulvum, Hance in Walp. Ann. iii. 270.

Common in ravines, Champion and others. Frequent in the mountains of northern India.

\section{Order LXXXIV. PLANTAGINE正.}

Flowers regular. Sepals 4. Corolla small, scarious, with an ovate or cylindrical tube and 4 spreading lobes. Stamens 4 , inserted in the tube and alternating with the lobes of the corolla, usually very long. Ovary 1-, 2-, or 4-celled, with 1 or more ovules in each cell. Style terminal, simple. Capsule opening transversely or indehiscent. Seeds peltate, albuminous. Embryo parallel to the hilum.- - Herbs, with radical, tufted, or spreading leaves, rarely branched and leafy. Flower-stalks leafless, bearing a simple spike or a single terminal flower.

A small Order, widely spead over the globe, but most abundant in the temperate regions of the Old World.

\section{PLANTAGO, Linn.}

Flowers hermaphrodite, in heads or spikes on a leafless peduncle. Capsule 2 - or 4-celled, with 2 or more seeds; the other characters and geographical range those of the Order, of which this genus contains all the species but two.

1. P. major, Linn.; Done. in DC. Prod. xiii. part i. 694. A perennial, with a short thick root-stock. Leaves all radical, erect or spreading, broadly ovate, often 4 or 5 in. long, entire or toothed, glabrous or pubescent, marked with 7 (rarely 9 or 5 ) prominent ribs converging into a rather long petiole. Perluncles usually longer than the leaves, bearing a long slender spike of small sessile flowers. 'Sepals about 1 line long, green, with a scarious edge. Capsule 2-celled, with 4 to 8 seeds in each cell.

In waste places, Champion and others. A common weed in Europe and temperate Asia, and spread with cultivation over almost every part of the globe. 


\section{Order LXXXV. PLUMBAGINEAE.}

Flowers regular. Calyx tubular, often enlarged and scarious or petal-like at the top. Petals 5, often united at the base. Stamens 5, inserted at the base of the corolla or between the petals. Ovary single, 1-celled, with 1 suspended ovule. Styles 5, distinct or united at the base. Capsule 1-seeded, indehiscent or opening irregularly. Seed albuminous. Embryo axile, straight; the radicle superior.- Herbs or rarely undershrubs, usually hard and stiff. Leaves mostly radical. Flowers in terminal heads, spikes, or panicles.

A small family, extending over most parts of the world, but chiefly within the influence of the sea air or occasionally on high mountains.

\section{STATICE, Linn.}

Calyx more or less expanded at the top into a dry membranous coloured and slightly 5-lobed limb, each lobe traversed by a green or dark nerve. Petals slightly united at the base. Styles glabrous.-Flowers solitary or 2 or 3 together in little spikelets forming one-sided spikes, arranged in dichotomous or trichotomous panicles or rarely in simple spikes.

The principal genus of the family, ranging chiefly over maritime districts in the northern hemisphere,

1. S. sinensis, Gir.; Boiss. in DC. Prod. xii. 162. Stock short and thick. Leaves all radical, obovate-oblong, $1 \frac{1}{2}$ to $3 \mathrm{in}$. long, quite entire, narrowed into a petiole of variable length. Scape 9 to $18 \mathrm{in}$. high, repeatedly forked so as to form a broad corymbose panicle, with a small green bract under each branch, and in some specimens there are a few entire or forked barren branches, $\frac{1}{2}$ to $1 \frac{1}{2} \mathrm{in}$. long, at the base of the panicle. Flowers numerous, in short dense unilateral spikes, scarcely distributed into spikelets, with an obtuse broadly oblong bract under each flower. Calyx pale pink at the top, with short obtuse teeth. Petals yellow, rather longer than the calyx at first flowering. - S. Fortunei, Lindl. in Bot. Reg. 1845, t. 63.

In estuaries, salt-water pools, and bogs, Champion. On the adjacent continental coasts, and northward to Amoy and Loochoo. It is probably the same species as the S. bicolor, Bunge, from N. China; but not having seen specimens of the latter I have hesitated to adopt the name.

The Boerhaavia diffusa, Liun., belonging to the Order Nyctaginee, is in several of the islands of the Canton river, but has not yet been received from Hongkong.

\section{Order LXXXVI. CHENOPODIACE无.}

Perianth small; segments 5 or in some flowers fewer, herbaceous. Stamens 5 , opposite the perianth-segments. Ovary free, with a single erect ovule. Styles 2 or 3, either free or united at the base. Fruit consisting of a single seed, in a very thin or sometimes succulent pericarp, and enclosed in the persistent calyx, which is sometimes enlarged or altered in form. Seed usually orbicular and flattened. Embryo coiled round a mealy albumen, or spirally twisted, without or with scarcely any albumen.-Herbs or undershrubs, often succulent. Stipules none. Leaves alternate or very rarely opposite, sometimes none. Flowers in sessile clusters, either in axillary or terminal spikes 
or panicles, and often unisexual. Bracts inconspicuous or in a few genera 2 lateral ones (or bracteoles) to each flower, adhering to the perianth, and then often described as an outer 2-lobed calyx.

A considerable Order, spread over the greater part of the world, but most abundant in maritime or saline situations.

Stems erect or procumbent, not twining. Bracteoles free or inconspicuous.

Jeaves flat. Embryo coiled round a mealy albumen

Leaves semi-cylindrical, succulent. Embryo spiral, without albumen Stems twining. Bracteoles adhering to and enclosing the perianth

1. Chenopodium.

2. SUAEDA.

3. Basella.

\section{CHENOPODIUM, Linn.}

Perianth of 5 (rarely fewer in a few flowers) equal segments, which enclose the ripe fruit, without appendages or alteration excepting a slight enlargement or thickening. Stamens 5 (rarely fewer). Styles 2 or 3, often connected at the base. Embryo curved or coiled round a mealy albumen.-Herbs, either glabrous or covered with a mealy dust. Leaves alternate, flat.

The species are rather numerous, widely distributed over the globe, with fewer strictly maritime ones than in most other genera of the Order.

Lower leaves sinuately toothed or angular . . . . . . . 1. C. album.

All the leaves quite entire . . . . . . . . . 2. C. acuminatum.

1. C. album, Linn.; Moq. in DC. Prod. xiii. part ii. 73. A tough annual, usually erect, sometimes under $1 \mathrm{ft}$., sometimes $2 \mathrm{ft}$. high or more, of a pale green or more or less mealy-white, especially the flowers and under side of the leaves. Leaves stalked; the lower ones ovate or rhomboidal, more or less sinuately toothed or angular, the upper ones usually narrow and entire. Clusters of flowers in short axillary spikes, either dense or interrupted, the upper ones forming a long panicle, leafy at the base. Seeds entirely enclosed in the perianth and all horizontal.

In waste places, Hance. A common European and Asiatic weed, carried out with cultivation to most parts of the world.

2. C. acuminatum, Willd.; Moq. in DC. Prod. xiii. part ii. 62. Stems 1 to $2 \mathrm{ft}$. high, usually decumbent at the base; the whole plant pale green or mealy-white like the $C$. album, but the young shoots and spikes often assume a reddish colour. Leaves from ovate to oblong or lanceolate, seldom above $1 \mathrm{in}$. long, all entire; the lower ones obtuse, the upper acute or with a minute point. Clusters of flowers small, globvlar, in interrupted slender spikes, forming the branches of a terminal leafless panicle. Seeds of $C$. album.-C. Vachellii, Hook. and Arn. Bot. Beech. 269.

In waste places, Hance. On the adjacent continent, and northward to Loochoo and eastern Siberia.

\section{SU訛DA, Forsk.}

Flowers and fruit of Chenopodium, except that the embryo is coiled into a flat spire with little or no albumen.-Herbs or undershrubs. Leaves small, linear, semi-cylindrical, and succulent. Clusters of flowers mostly axillary.

A genus of very few species, ranging over the seacoasts of most parts of the globe. 
1. S. australis, Moq. A glabrous annual or biennial, with simple and erect or branched and spreading stems of 6 to 8 in., hard and apparently woody at the base, succulent at the top. Leaves usually about $\frac{1}{2}$ in. long and 1 line broad, thick and fleshy. Flowers very small, in axillary clusters of 3 to 5 or rarely solitary. Seed entirely enclosed in the perianth and always horizontal.-Chenopodium australis, Moq. in DC. Prod. xiii. part ii. 163. Suceda indica, Seem. Bot. Her. 406 ; but not of Moq.

In unaritime marshes, Hance. Extends probably from Australia to eastern tropical Asia, and northward to Loochoo. The Hongkong specimens appear identical with Australian ones which J. D. Hooker refers to the common European S. maritima. It has, however, much thicker leaves, more like those of $S$. indica and $S$, nudiflora; but these are much more shrubby species, with vertical seeds.

\section{BASELLA, Linn.}

Bracteoles adhering to the perianth and united in a 2-lobed external calyx. Perianth ovoid, shortly 5-lobed. Style single, with 3 oblong stigmatic lobes. Fruit enclosed in the globular succulent perianth and bracts. Seed vertical. Embryo spiral, with little or no albumen.-Stems twining. Leaves alternate, flat, but succulent. Flowers sessile, in simple or branched spikes.

A small tropical or subtropical Asiatic genus

1. B. rubra, Linn.; Moq. in DC. Prod. xiii. part ii. 222. A glabrous herbaceous twiner of considerable length. Leaves stalked, broadly ovate, succulent, about 2 in. long. Spikes axillary, pedunculate, simple, 2 or 3 in. long. Flowers about 1 line long, pale red, sessile, at first close together, but becoming distant as the spike lengtheus. Berries (or fruiting perianths) dark purple, about 3 lines diameter.

On the sides of a pond in the Happy Valley, Wilford. A species of uncertain origin, probably Asiatic, commonly cultivated in India, and readily establishing itself on roadsides and in waste places.

\section{Order LXXXVIT. AMARANTACEF.}

Herbs, with the characters of Chenopodium, except that the perianth is usually more scarious, with the segments more distinct ; the bracts and bracteoles more prominent and scarious, and in one tribe there are several ovules in the ovary, attached to a free central placenta as in Caryophyllere. Leaves alternate in a few genera, opposite in the others, without stipules, and not succulent.

A considerable Order, chiefly tropical and American, with a few species spread over the Old World, and some, chiefly weeds, extending into more temperate regions.

Jueaves alternate.

Ovules and seeds several . . . . . . . . . , 1. Cerosia.

Ovules and seeds solitary . . . . . . . . . 2. Amarantus.

Leaves opposite.

Flowers green and reflexed, in long terminal spikes. Anthers 2 celled.

Flowers with 1 pungent bristle on each side

3. Achyranthes.

Flowers with a cluster of hooked bristles on each side . . 4. Cуатнula.

Flowers white, in axillary clusters. Anthers 1-celled... . 5. Anternanthera. 


\section{CELOSIA, Linn.}

Perianth of 5 nearly equal segments. Stamens 5, united at the base. Anthers 2-celled. Ovary with several ovules. Style single, with a eapitate or minutely 2-lobed stigma. Capsule opening transversely. Embryo coiled round the albumen.-Herbs. Leaves alternate. Flowers white or coloured, in terminal spikes.

A tropical genus, dispersed over the New as well the Old World.

1. C. argentea, Linn.; Moq. in DC. Prod. xiii. part ii. 242; Wrght, Ic. $t$. 1767. An erect glabrous annual, 1 to $2 \mathrm{ft}$. high. Leaves stalked, from ovate to lanceolate or linear, acuminate, 1 to 3 or 4 in. long, green on both sides. Spike cylindrical, 1 to 4 or 5 in. long. Perianth-segments white and scarious, lanceolate, about 4 lines long; the bracts similar but smaller.

In waste places, Champion, Hance. Common in tropical Asia and Africa, and introduced into some parts of America.

Var. cristata. Spikes dilated at the top or variously branched, and usually on a shorter peduncle. Flower's often smaller, and many of them barren.-C. cristata, Linn.; Moq. I. c.

In waste places, Hance. A much cultivated variety, which is also frequently sent as wild, but probably of garden origin.

\section{AMARANTUS, Linn.}

Flowers polygamous. Perianth of 5 equal segments. Stamens 5 or rarely 3, free and slightly perigynous. Anthers 2-celled. Ovule solitary. Style divided to the base into 2 or 3 stigmatic lobes. Utricle opening transversely or indehiscent. Embryo coiled round the albumen.-Annuals. Leaves alternate. Flowers small, green or reddish, clustered in axillary or terminal spikes or panicles. Perianth thin, but less scarious than in most genera. Bracts small.

A genus not numerous in species, but widely diffused over the warmer regions of the globe.

Spines axillary. Stigmas usually 2. Utricle opening transversely . . . 1. A. spinosus. Plant unarmed. Stigmas usually 3. Utricle indehiscent or bursting irregularly

2. A. viridis.

1. A. spinosus, Linn.; Moq. in DC. Prod. xiii. part ii. 260 ; Wight, Ic. $t$. 513. A branched, spreading, glabrous, hard-stemmed annual, extending to 1 or $2 \mathrm{ft}$., armed with 1 or 2 straight spines in each axil. Leaves stalked, from ovate to lanceolate, of a dull green, the pinnate veins prominent underneath. Flowers numerous, greenish, in dense axillary clusters, the upper ones forming long dense terminal spikes, either simple or paniculately branched. Stigmas usually 2. Utricle opening transversely.

In waste places all over the island, Hance, Seemann, Wilford. A common weed in tropical and subtropical countries both in the New and the Old World.

2. A. viridis, Linn. A glabrous spreading annual like the last, but without spines, the leaves usually rather broader and more obtuse, the clusters of flowers looser, and the terminal spikes broader and shorter. Stigmas usually 3 , and the utricle has a much thinner and closer pericarp, which either rots away or bursts irregularly.-Euxolus viridis, Moq. in DC. Prod. xiii. part ii. 273. 
Hongkong, Hance (a loose specimen with those of $A$. spinosus). A common tropical and subtropical weed both in the New and the Old World.

\section{ACHYRANTHES, Linn.}

Perianth usually glabrous, of 5 slightly unequal segments, hardened after flowering, with 1 subulate almost spinous bracteole on each side. Stamens 5 , united in a cup at the base, with as many small scales between them. Anthers 2-celled. Ovule solitary. Style simple, with a capitate stigma. Embryo coiled round the albumen.-Herbs. Leaves opposite. Flowers green, or rarely scarious, reflexed, in terminal spikes or rarely heads.

A tropical or subtropical genus, widely spread over the Old World, or as introduced weeds in America.

1. A. aspera, Linn.; Moq. in DC. Prod. xiii. part ii. 314, var. obtusifolia; Wight, Ic. t. 1777. An erect or spreading annual or biennial, with a hard almost woody base, more or less hoary with a soft pubescence. Leaves shortly stalked, ovate or orbicular, 1 to $1 \frac{1}{2}$ in. long, usually in this variety obtuse or very shortly pointed. Flowers of a shining almost silvery green, in long slender terminal spikes. Perianth $1 \frac{1}{2}$ to near 2 lines long, closely reflexed after flowering; the 2 subulate rigid bracteoles nearly as long, and scarious at the base only.

In waste places, Champion, Hance. A very common and troublesome weed in tropical and subtropical Asia and Africa, and some parts of America. The variety with acuminate leaves ( $A$. argentea, Lam.) correctly restored to the $A$. aspera by Grisebach, occurs on the Chinese coast, but I have seen no specimens from Hongkong.

\section{CYathula, Lour.}

Habit, inflorescence, and flowers of Achyranthes, except that on each pedicel, besides 1 or sometimes 2 perfect perianths, there is on each side a cluster of stiff hooked bristles, slightly dilated at the base, consisting of bracts and abortive perianth-segments.

A small tropical genus, common to the New and the Old World.

1. C. prostrata, Blume; Moq. in DC. Prod. xiii. part ii. 326. A slender perennial, more or less hoary or softly pubescent, procumbent and rooting at the lower nodes, ascending to a foot or more. Leaves very shortly stalked, ovate, obtuse or shortly acuminate, 1 to $1 \frac{1}{2}$ in. long. Flowers small, green, pubescent, reflexed, on very short pedicels, in long slender terminal racemes. Perianth about $1 \frac{1}{4}$ lines long, the clusters of hooks rather shorter.-Desmochata prostrata, DC.; Wight, Ic. t. 733.

On roadsides, Hance, Wilford, Wright. Dispersed over tropical America, Africa, Asia, and the Pacific islands.

\section{ALTERNANTHERA, Br.}

Perianth of 5 nearly equal scarious segments, not enveloped in wool. Stamens 5 or sometimes fewer, very shortly united at the base. Anthers 1-celled. Ovule solitary. Style short or scarcely any, with a capitate stigma. Utricle usually flattened, ovate or obcordate, indehiscent.-Herbs. Leaves opposite. Flowers in sessile axillary or terminal clusters or heads.

A considerable genus, widely spread over the tropical and subtropical regions of the globe. 
1. A. sessilis, Br.; Moq. in DC. Prod. xiii. part ii. 357; Wight, Ic. $t$. 727. A prostrate branching glabrous or slightly pubescent annual, extending sometimes to $2 \mathrm{ft}$. or more. Leaves narrow, oblong-lanceolate, or rarely nearly obovate, about $1 \mathrm{in}$. long, tapering at the base. Flowers white, scarious and shining, in axillary clusters, surrounded by a few short woolly hairs. Perianth-segments about 1 line long, rather acute, but not pungent, longer than the otherwise similar bracts. Stamens very short, 3 only, without intervening teeth or appendages.-Telanthera polygonoides, Seem. Bot. Her. 407, not of Moq.

On roadsides and in waste places, Hance; also Wright. Common in tropical and subtropical Asia, Africa, and America. In Hance's specimen the internodes are shorter than usual, and the flower-clusters more abundant and conspicuous. It is not, however, the $A$. polygonoides, which has much longer sepals, the outer ones pungent, and 5 fertile stamens.

\section{Order LXXXVIII. POLYGONACEA..}

Perianth of 6,5 or fewer segments, regular and equal, or the inner ones enlarged. Stamens variable in number, usually 9,8 , or 6 . Ovary free, with a single erect ovule. Styles or stigmas 2,3 , or rarely more. Fruit a small seed-like nut, usually with as many angles as styles, enclosed in or scarcely protruding from the persistent perianth. Embryo straight or curved, in a mealy albumen.-Herbs or rarely shrubs. Leaves alternate. Stipules usually thin and scarious, rarely herbaceous, forming a sheath or ring round the stem within the petiole. Flowers small, herbaceous or sometimes coloured, clustered in the axils of the leaves, or in spikes or racemes forming terminal panicles.

A considerable Order, dispersed over every part of the globe.

Fruiting perianth of 6 segments, the 3 inner ones enlarged . . . . . 1. Rumex. Fruiting perianth of 5 nearly equal segments … . . . 2 PoLYGonur.

\section{RUMEX, Linn.}

Perianth-segments 6 , the 3 inner ones enlarged after flowering, and closing over the triangular nut. Stamens 6 . Styles 3, very short, with fringed stigmas. Herbs or rarely shrubs. Flowers numerons, small, herbaceous, but often turning red, usually pedicellate, in whorl-like clusters, axillary, or in terminal simple or paniculate racemes.

A considerable genus, widely distributed over most parts of the globe, but more especially in temperate regions.

1. R. crispus, Linn.; Meisn. in DC. Prod.xiv. 44. A perennial, with a thick root-stock, and erect furrowed stems 2 to $3 \mathrm{ft}$. high; the branches few and short. Radical leaves narrow, usually 6 to 8 in. long, much waved and crisped at the edges, the upper ones smaller, passing gradually into bracts. Stipules sheathing, ragged at the edges. Whorls of flowers numerous, and when in fruit much crowded in a long narrow panicle. Inner segments of the fruiting perianth broadly ovate, 2 to 3 lines long, with a coloured grain or tubercle on the midrib.

Roadsides at Saywan, Champion; also Hance. Common in Europe and temperate Asia, and now naturalized in many other parts of the globe. The Chinese specimens, like all those grown in warm or dry climates, have tubercles on all the inner perianth-segments. More northern specimens have them frequently on one segment only of each perianth. 


\section{POLYGONUM, Linn.}

Perianth of 5 , rarely fewer, segments, all equal, or the 2 or 3 outer ones enlarged. Stamens 8 or sometimes fewer in the same species. Styles 3 or 2, sometimes united at the base; the stigmas entire. Nut triangular or flattened, enclosed in or surrounded by the persistent perianth.-Herbs varying much in habit. Flowers small, pale green or red, or with white edges, clustered or rarely solitary in the axils of the upper leaves, or in little clusters surrounded by a sheathing bract, and collected in terminal spikes, heads, or panicles.

A large genus, with almost the ubiquitous range of the Order.

Flowers in axillary clusters. Stems prostrate . . . . . . .

Flowers in terminal spikes. Stems erect, ascending, or climbing.

Stipules sheathing, wholly scarious, truncate or ciliate.

Styles 3.

Stems very hispid. Peduncles glandular-hairy .

Stems and peduncles glabrous. Sheathing stipules hairy, Styles 2. with long bristles at the top . . . . . . ...

Spikes slender and interrupted. Perianth glandular-dotted. Stipules shortly ciliate. . . . . . . . . . . .

Spike slender but continuons. Perianth not dotted. Stipules not ciliate

Spike short, oblong or cylindrical. Perianth slightly glandu-

lar-dotted. Stipules scarcely ciliate .
les green and spreading at least at the top.

1. P. plebeium.

Stipules green and spreading at least at the top.

Tall, erect, hairy plant. Stipules sheathing at the base. Leaves ovate-cordate

Glabrous prickly climber. Stipules spreading from the base. Leaves triangular . . Flowers in little heads, in dichotomous panicles. Stems erect or elimbing

1. P. plebeium, Br.; Meisn. in DC. Prod. xiv. 94. A much branched prostrate annual, 6 in. to $1 \mathrm{ft}$. long, glabrous, or the branches shghtly hoary. Sheathing stipules short and scarious, ragged at the edges, but not ciliate. Leaves linear, narrow-oblong, or slightly spathulate, rarely above $\frac{1}{2} \mathrm{in}$. long. Flowers small, in clusters of 2 to 5 in the axils of most of the leaves. Styles 3. Fruiting perianth not a line long; the segments green, with a narrow white edge. Nuts triangular, very smooth and shining. $-P$. herniarioides, DC.; Meisn. in DC. Prod. xiv. 94. P. Miquelianum, P. effusum, P. Roxburghii, P. illecebroides, P. cliffortioides, P. Perrottetii, and P. ciliosum, Meisn. 1.c. 93,94 , and 95 .

In cultivated and waste places, Champion and others. Exceedingly common all over tropical Asia, extending into Africa and Australia. After a careful examination of very numerous specimens, neither Dr. Hooker nor myself have been able to detect any tangible differences between the Egyptian, Indian, and Australian specimens. All come very near to the common European $P$. aviculare, but the nuts are always very smooth and shining, besides that the stems are shorter, more leafy and prostrate, and the flowers considerably smaller.

2. P. viscosum, Ham.; -Meisn. in DC. Prod. xiv. 102. An ereet or ascending annual, 1 to $2 \mathrm{ft}$. high, the stem hispid with long stiff spreading hairs, intermixed with a glandular pubescence. Stipules loosely sheathing, rather short, hispid and ciliate. Leaves lanceolate, glabrous or hairy. Spikes 
on long terminal glandular hairy peduncles, slender but continuous, about 1 line long. Style 3-cleft.

Hongkong, Hance. Also in Nepal, Assam, and Silhet.

3. P. barbatum, Linn.; Meisn. in DC.Prod. xiv. 104; Wight,Ic.t. 1798. Stems ascending or erect, glabrous, 2 to $3 \mathrm{ft}$. high. Stipules sheathing, hairy outside, fringed at the top with long fine bristles. Leaves lanceolate, varying much in breadth and size, usually sprinkled with appressed hairs, especially underneath. Spikes in the slender forms near 3 in. long, with the lower flowers distant, as in P. Hydropiper, shorter and more continuous in the stouter specimens. Style 3-cleft. Nut triangular, smooth.

In swamps and wet places, Hance, Harland. Common in tropical Asia and Africa, extending northwards to Amoy and Shanghae.

4. P. Hydropiper, Linn.; Meisn. in DC. Prod. xiv. 109. A slender erect or decumbent glabrous annual, 1 to $2 \mathrm{ft}$. high. Stipules sheathing, but rather short, ciliate at the top. Spikes slender and interrupted, the lower clusters usually axillary. Perianth; and often the bracts also, dotted with glands, and the whole plant more or less biting or acrid to the taste. Style usually 2-cleft. Nuts flat.

In rice-fields, Wilford. Widely spread, and generally common in Europe, central Asia, and North America.

5. P. glabrum, Willd.; Meisn. in DC. Prod. xiv. 114; Wight, Ic. $t$. 1799. An erect or ascending branching annual or perennial, 1 to $3 \mathrm{ft}$. high, glabrous in every part, and the sheathing stipules truncate, without hairs or bristles. Leaves lanceolate, narrowed at the base. Spikes terminal, rather slender, but nearly continuous, 1 to 2 in. long. Perianth small, not dotted. Style usually 2 -cleft. Nut flattened.

In ditches, Hance. Frequent in the tropical regions both of the New and the Old World.

6. P. lapathifolium, Linn. ; Meisn. in DC. Prod. xiv. 119. An erect or ascending annual, 1 to 2 feet high; the branches glabrous or slightly hoary. Leaves lanceolate, shortly stalked, either glabrous or nearly so on both sides, or more or less hoary or cottony-white underneath. Stipules sheathing, usually slightly hairy, and sometimes fringed with minute fine bristles at the top. Peduncles always with a few glandular hairs. Spikes oblong or cylindrical, thicker than in any of the above species, seldom above an inch long, usually of a pale-green colour. Perianth slightly glandulardotted. Style 2-cleft. Nuts flat, but rather thick, concave on both sides.$P$. orientale, var. discolor, Benth. in Lond. Journ. Bot. i. 494.

Hongkong, Hinds. Widely diffused over the northern hemisphere, but most abundant in N. America. The Hongkong specimens have the leaves cottony-white underneath, as is described of the P.glutinosum, Wall. (Meisn. 1. c. 120), which I have not seen, but which is probably the same species, as the same characters occur in some S. European specimens, distinguished as $P$. incanum. Some specimens from other islands of the Canton river are glabrous, as in the more common varieties of the plant.

7. P. orientale, Linn.; Meisn. in DC. Prod. xiv. 123 ; Bot. Mag.t. 213. An erect, softly pubescent or hairy annual, 2 to $4 \mathrm{ft}$. high. Stipules very hairy, sheathing and scarious at the base, but all, except the uppermost, expanded at the top into a green, spreading limb. Leaves stalked, ovate, or 
cordate, acuminate, 4 to 6 in. long. Spikes continuous, rather slender, $1 \frac{1}{2}$ to 2 in. long, paniculate. Stamens usually 7. Style 2-cleft. Nut flat. Embryo curved, at right angles with the cotyledons, not parallel with them as in all the preceding species:

Hongkong, Champion, Hance. Common in India, from Ceylon and the Peninsula to the Archipelago, extending also into Africa and Australia, and northward to Japan, but in many places cultivated as an ornamental plant.

8. P. chinense, Linn.; Meisn. in DC. Prod. xiv. 130; Wight, Ic.t. 1806. A weak, erect or half-climbing, dichotomously branched perennial, glabrous or nearly so. Stipules sheathing and scarious, but with the addition of short, reniform, green appendages at the base of the petiole. Leaves ovate or oblong, shortly acuminate, 2 to 3 in. long. Flowers in little globular heads, forming dichotomous, corymbose panicles ; the branches and pedicels glandular-pubescent, with broad bracts at their base. Stamens usually 7. Styles 3-cleft. Nut triangular.

In ditches, Hinds and others. Very common in India, from Ceylon and the Peninsula to the Archipelago.

9. P. perfoliatum, Linn.; Meisn. in DC. Prod. xiv. 132. A glabrous, slender climber, armed with small recurved prickles on the young stems and petioles. Stipules leafy, orbicular, and spreading. Leaves on long petioles, nearly triangular or broadly hastate, more or less peltate, $1 \frac{1}{2}$ to $2 \mathrm{in}$. broad. Spikes solitary, on long peduncles, slender but continuous, about 1 in. long, with an orbicular, leafy bract at their base.

Hongkong, Hance, Wright. Dispersed over various parts of India from Nepal to Java and northwards to China, Mantchuria, and Japan.

\section{ORDER IJXXXIX. LAURINEAE.}

Perianth herbaceous, with 6 or rarely fewer divisions, imbricate in the bud, in 2 series or rarely wanting. Stamens usually as many or twice as many, opposite the perianth-segments, either all fertile, or the 3 innermost reduced to barren staminodia, or abortive. Anthers adnate, 2- or 4-celled; the cells opening by persistent valves turned upwards. Ovary free, 1-celled, with 1 or rarely 2 pendulous ovules. Style simple, with an entire, usually disk-shaped, or shortly 2 - or 3 -lobed stigma. Fruit a 1 -seeded berry or drupe; the persistent perianth or part of it often enlarged under or round it. Seed without albumen. Cotyledons large.-Trees or shrubs, with alternate or rarely irregularly opposite leaves, usually entire or evergreen; or in one genus leafless twiners. Stipules none. Flowers usually small, in panicles, umbels, or lateral clusters.

A considerable tropical Order, both in Asia and America, with a few African or Australian species, and a very few penetrating into more temperate regions in the northern hemisphere.

Leafless twiner

9. Cassyta.

Trees or shrubs.

Flowers hermaphrodite. Stamens 9, with 4-celled anthers, of which 3 reversed, with 2 glands at the base. Staminodia 3.

Perianth-segments breaking off in the middle, leaving a persistent 6-lobed cup or disk under the fruit.

1. Cinnamomum. 
Perianth-segments breaking off at the base, leaving a persistent entire cup or disk under the fruit . . . . . . , .

Perianth wholly deciduous

Flowers diœcious. No staminodia.

Flowers in pedicellate involucres. Stamens 9 or more. Anthers 4-celled

Flowers in sessile clusters, with bracts at the base.

Stamens 9.

Anthers 4-celled .

5. Tetranthera.

Anthers 2-celled .

6. ACtinodaphne.

Stamens 6. Anthers 4-celled

7. Daphnidium.

8. Litsea.

\section{CinNamomum, Burm.}

Flowers hermaphrodite or polygamous. Perianth 6-cleft, the upper half of each segment deciduous. Stamens 9, with 4-celled anthers, 6 (opposite the perianth-segments) opening inwards, without glands, 3 (opposite 3 of the above) opening outwards, and bearing a gland on each side at the base. Staminodia 3 (opposite the 3 other outer stamens), with capitate or cordate abortive anthers. Berry resting on the enlarged 6 -lobed base of the perianth. -Trees. Leaves 3-nerved, irregularly opposite.

A genus of several species, all from tropical Asia.

1. C. dulce, Nees, Syst. Laur. 62 ; Wight, Ic. i. 138 . A tall, slender, glabrous tree. Leaves from ovate-acuminate and $2 \frac{1}{2}$ in. long by $1 \frac{1}{2}$ in. broad, to oblong-acuminate and $4 \mathrm{in}$. long by $1 \frac{1}{2} \mathrm{in}$. broad, coriaceous and shining, but not thick. Panicles terminal, usually much shorter than the leaves, and seldom so much developed as represented in the alove figure, slightly hoary. Perianths pale-yellow, about 2 lines long, on pedicels of 2 to 4 lines, fertile stamens not much shorter than the perianth, with oblong anthers as long as the filaments. Staminodia short, with purple heart-shaped heads. Berry small, ovoid.

In the woods, at East Point, near the Buddhist Temple, Champion; behind the Government House, probably not wild, Wilford; cultivated in the island, Hance; also Wright. A native of China, but also frequently cultivated.

The $C$. zeylanica, Nees, or true Cinnamon, with much larger and more coriaceous leaves, larger, loose panicles, etc., is also cultivated in Hongkong.

\section{CAMPHORA, Nees.}

Characters of Cinnamomum, except that the segments of the perianth fall off entirely, the berry resting upon the somewhat enlarged cup-shaped or disk-shaped, entire or slightly sinuate, base or tube.-Trees, with evergreen, alternate leaves, either 3-nerved or penni-nerved. Flowers small, in short pedunculate panicles, at first terminal, but becoming lateral by the elongation of the shoot.

A small tropical Asiatic genus.

1. C. Parthenoxylon, Nees in $W$ all. $P l$. As. Rar. ii. 72. A tall glabrous tree. Leaves scattered, ovate, shortly acuminate, the larger ones 3 to $4 \mathrm{in}$. long by 2 to $2 \frac{1}{2}$ wide, those on the flowering branches much smaller, pinnately nerved. Panicles or cymes 5- to 10 -flowered, on pedicels of about 
$\frac{1}{2}$ in., lengthening to 1 in. when in fruit. Perianth about 1 line long, hairy inside at the base. Staminodia hairy.-Sassafras Parthenoxylon, Nees, Syst. Laur. 491. Parthenoxylon porrectum and P. Pseudosassafras, Blume, Mus. Bot. i. 323. Phoebe latifolia, Champ. in Kew Journ. Bot. v. 197.

In the Happy Valley woods, Champion and others : also in the Indian Archipelago. The 3 inner fertile stamens appear to me always to have their. anthers opening outwards, as in the allied genera, not inwards, as stated by Nees.

\section{MACHILUS, Rumph.}

Characters of Cinnamomum and Camphora, except that the perianth-segments persist entirely around or under the berry without any enlargement or thickening of the pedicel, and that the glands of the inner fertile stamens are decidedly stipitate, one on each side of the base of the filament.-Trees, with alternate pinnately veined leaves. Panicles terminal or becoming lateral by the elongation of the shoot. Outer segments of the perianth usually equal to or longer than the inner ones.

A small tropical Asiatic genus.

Leaves and branches glabrous. Panicles loose, pedunculate at the base of the young shoots

Leaves and branches softly hairy. Panicles dense, sessile, and terminal

1. M. rimosa.

2. M. velutina.

1. M. rimosa, Blume; Mus. Bot. i. 330 ? A tree, glabrous, except the silky-hairy scales of the leaf-buds. Leaves from obovate-oblong to oblonglanceolate, shortly acuminate, 3 to $4 \mathrm{in}$. long, narrowed at the base into a petiole of $\frac{1}{2}$ to 1 in., more or less glaucous underneath. Panicles loosely oblong or pyramidal, longer than the leaves. Pedicels about 3 lines. Perianth-segments 3 lines long when fully open, narrow-oblong, slightly hoary. Stamens about as long, on slender filaments. Stigma scarcely dilated. Berries globular.-M. Thunbergii, Benth. in Kew Journ. Bot. v. 198, but probably not of Sieb. and Zucc.

Hongkong, Champion, Wright, also in Samtong Island, Wright. This is very near the common Indian $\boldsymbol{M}$. odoratissima, but has larger and looser panicles and larger flowers, and agrees very well with Blume's character of the Javanese M. rimosa, but I have no specimens to compare. I had formerly referred it to the Japanese $M$. Thunbergii, but some specimens of Wilford's from that country, which are probably the true plant, differ from ours in the shape of the leaves as well as in the perianth.

2. M. velutina, Champ. in Kew Journ. Bot. v. 198. Branches, under side of the leaves, and inflorescence clothed with a soft yellowish velvety pubescence. Leaves elliptical-oblong, obtusely acuminate, 3 to 5 in. long, narrowed into a petiole of 4 to 9 lines, glabrous and shining above. Leaf-buds softly hairy. Panicles contracted into a dense sessile terminal corymb. Perianth velvety, about 3 lines long, persisting round the globular berry.

At the Buddhist Temple, on Victoria Peak, Mount Parker, etc., Champion, also Wright. Not known out of the island. It is widely removed from Actinodaphree angustifolia, to which Seemann has, by some mistake, referred it.

\section{ALSEODAPHNE, Nees.}

Characters of Cinnamomum and Camphora, except that the perianth falls off entirely; the berry resting on the unchanged or slightly thickened summit 
of the pedicel.-Trees, with alternate pinnately veined leaves. Inflorescence of Cinnamomum. Outer segments of the perianth usually shorter than the inner ones.

A small tropical Asiatic genus.

Leaves 2 or 3 in. long. Perianth-segments oblong-lanceolate, 2 lines

long . . . . . . . . .

Leaves $1 \frac{1}{2}$ to 2 in. long. Perianth-segments ovate, very obtuse, 1 to $1 \frac{1}{2}$

lines long

1. A. chinensis.

1. A. chinensis, Champ. in Kew Journ. Bot. v. 198. A glabrous tree. Leaves from obovate-oblong to oblong-lanceolate, obtuse or shortly acuminate, 2 to 3 , or rarely near 4 in. long, narrowed into a petiole of 3 to 6 lines, coriaceous, slightly glaucous or rust-coloured underneath when dry. Leaf-buds very small, glabrous or pubescent. Peduncles terminal, 2 or 3 together, much shorter than the leaves, each bearing a short panicle of 6 to 10 flowers. Perianth-segments oblong-lanceolate, hairy inside at the base; the inner ones 2 lines long, the outer shorter. Glands of the inner fertile stamens nearly sessile. Staminodia hairy. Berry globular.

In the Happy Valley woods, Champion, Wilford. Not known from elsewhere.

2. A. breviflora, Benth., n. sp. Very near the last, but more glaucous. Leaves narrower, scarcely $2 \mathrm{in}$. long, on very short petioles. Peduncles more numerous, $\frac{1}{2}$ to $I \mathrm{in}$. long; the panicles almost contracted to umbels. Flowers much smaller; the perianth-segments broadly ovate, very obtuse; the inner ones about $1 \frac{1}{2}$ lines, the outer 1 line long.

Hongkong, Wright. I have seen no other specimen.

\section{TETRANTHERA, Jacq.}

Flowers usually diøecious. Perianth either of 6 deciduous segments, or reduced to a few small petal-like scales, or none at all. Stamens 9, all fertile, or sometimes, when the perianth is deficient, 12 to 15 . Anthers 4-celled, all opening inwards; the 3 inner stamens, or sometimes more, with 2 glands at the base of the filaments. Staminodia none. Berry seated on the flat and often somewhat enlarged base of the perianth.- Trees or shrubs. Leaves alternate, evergreen or deciduous, pinnately veined. Flowers in little heads or umbels, in a calyx-like involucre of 4 to 6 broad concave imbricate bracts; the involucres umbellate, or in little racemes or clusters in the axils of the leaves, or at the leafless nodes of the previous year's wood.

A large genus, chiefly Asiatic, tropical or subtropical, with a very few western American species.

Young branches and under side of the leaves pubescent or hoary. Leaves evergreen, obovate or broadly oblong.

Perianth-segments 6 . Involueres in dense sessile clusters . . . . 1. T. monopetala.

Perianth none. Involucres umbellate, on a common peduncle : 2. T. citrifolia. Branches and leaves glabrous. Leaves deciduous, oblong-lanceolate. . 3. T. polyantha.

1. T. monopetala, Roxb.; Pl. Corom. t. 148; Nees, Syst. Laur. 525. A small tree; the young shoots, under side of the leaves, and inflorescence softly pubescent. Leaves evergreen, from broadly-ovate or obovate to ovaloblong, 3 to $5 \mathrm{in}$. long, very obtuse or rarely shortly acuminate. Involucres scarcely above 2 lines diameter before opening, on pedicels of 2 to 4 lines, in 
dense axillary or lateral clusters, with scarcely any common peduncle. Flowers 5 or 6 , sometimes more, in each involucre, on pedicels of scarcely 1 line. Perianth-tube cup-shaped, with 6 small petal-like deciduous segments. Filaments slender, very hairy. Berry ovoid; the disk-shaped base of the perianth enlarged to about 3 lines diameter.

Hongkong, Hance, Harland, Wright. Frequent in India.

2. T. citrifolia, Juss. A small evergreen tree; the young branches, petioles, and inflorescence softly pubescent or hoary. Leaves obovate or oblong, 3 to 4 in. long and very obtuse in the Chinese specimens as in some of the Indian ones, slightly acuminate in others, more or less hoary or pubescent underneath, glabrous above, except the midrib. Involucres full 3 lines diameter before opening, in small umbels on a common axillary or lateral peduncle of $\frac{1}{2}$ in. or more. Flowers numerous in each involucre, on short pubescent pedicels, without any perianth. Stamens usually 9 . Berries globular, on the thickened but scarcely dilated summit of the pedicel.

In the Happy Valley woods, Champion and others. Frequent in India.

3. T. polyantha, Wall.; Nees, Syst. Laur. 545. A handsome tree, quite glabrous except a slight silky-hoariness on the young shoots. Leaves deciduous, oblong-lanceolate, acuminate, 3 or 4 in. long, narrowed into a petiole of $\frac{1}{2}$ in. Involucres on slender pedicels of 2 to 4 lines, in numerous clusters or short racemes along the previous year's branches, usually appearing before the young leaves. Flowers of a pure white, about 6 in each involucre. Perianth-segments 6 , obovate. Stigma very broad.

Common in the Happy Valley woods, Champion and others.' Also on the mainland and in northern India.

\section{ACTINODAPHNE, Nees.}

Characters of Tetranthera, except that the flowers are either in sessile clusters, surrounded by imbricate scales, or in racemes or panicles without involucres.

A small tropical Asiatic genus.

Leaves oval-oblong, 1 to 2 in. long . . . . . . . . 1. A. chinensis.

Leaves oblong-lanceolate, acuminate, 4 or 5 in. long. . . . . 2. A. angustifolia.

1. A. chinensis, Nees, Syst. Laur. 600. A much-branched shrub or small tree, glabrous or nearly so. Leaves oval-oblong, obtuse or very shortly acuminate, 1 to 2 in. long, on very short petioles, usually glaucous underneath. Flowers small, in closely sessile axillary clusters, surrounded by deciduous imbricated scales. Perianth-segments 6 , about 1 line long. Stamens 9, with hairy filaments. Berry globular, on the unenlarged base of the perianth.-Camellia integrifolia, Chois. Mem. Ternstr. et Camell. 60.

Very common on hills and in ravines, Champion and others. Not known out of S. China.

2. A. angustifolia, Nees, Syst. Laur. 594; Wight, Ic.t. 184 l. A tree, glabrous except a slight silky-hoariness on the young shoots. Leaves oblonglanceolate, acuminate, 4 to 5 in. long, very coriaceous, contracted at the base into a petiole of $\frac{1}{2}$ in. or more. Flowers in sessile axillary clusters. Berry ovoid-oblong, 8 or 9 lines long, on a thickened pedicel of 2 or 3 lines, terminated by the enlarged disk-shaped base of the perianth. 
Happy Valley woods, Wilford? The specimens are in fruit only; I am therefore not certain of their identity with the species which is frequent in India and the Archipelago.

\section{DAPHNIDIUM, Nees.}

Flowers diœcious. Perianth-segments 6. Stamens 9, the inner ones with 2 glands at the base. Anthers 2-celled, all turned inwards. Staminodia none. -Inflorescence in dense axillary sessile clusters, surrounded by imbricated scales.

A small tropical Asiatic genus.

1. D. bifarium, Nees, Syst. Laur. 616. A tree. Branches and under side of the leaves softly pubescent or hairy. Leaves from oval-oblong to oblong-lanceolate, acuminate, 3 to $4 \mathrm{in}$. long in the Chinese specimens, 5 to 6 in. in some Indian ones, glabrous and shining above, pinnately veined, on very short petioles. Flowers on very short hairy pedicels, in 2 or 3 clusters in each axil. Anthers in the male flowers all 2-celled, in the female flowers either 1-celled or quite abortive.

In a ravine of Victoria Peak, Eyre, a single female specimen. Also in the Himalaya from Nepal and Kumaon to Assam and Khasia.

\section{IITS泼A, Juss.}

Flowers diœecious. Perianth-segments 4 to 6 . Stamens 6 , of which 2 to 4 with glands at the base. Anthers 4-celled, all opening inwards. Staminodia none. Berry seated on the thickened summit of the pedicel.-Leaves 3-nerved. Inflorescence in axillary sessile clusters, surrounded by imbricated scales.

A small tropical Asiatic genus.

1. I. ceylanica, Nees, Syst. Laur. 626 ; Wight, Ic. t. 1844. A tree, the young branches covered with a minute hoary or rusty tomentum. Leaves oval-oblong, acuminate, usually $1 \frac{1}{2}$ to 3 in. long, but sometimes 4 in., narrowed into a petiole of 3 to near 6 lines, glabrous and shining above, glaucous or white underneath, with the veins silky-pubescent. Flowers rather small, on short hairy pedicels, in a single, or in 2 or 3 clusters in each axil.

On Victoria Peak and in woods at East Point, but rare, Champion; on Mount Gough, Wilford; also Wright. In Ceylon and the Indian Peninsula, and if, as is probable, the $L$. foliosa and L. consimilis are not specifically distinct, it is widely diffused over India and the Archipelago.

\section{CASSYTA, Linn.}

Flowers hermaphrodite. Perianth ovoid or tubular, with 3 outer equal lobes and 3 inner minute ones. Stamens 9 , the 3 inner ones with 2 glands at the base. Anthers 2-celled, those of the inner stamens turned outwards. Staminodia 3, small. Fruit enclosed in the succulent tube of the perianth.Parasitical triners, with the habit of Cuscuta. Leaves reduced to minute scales. Flowers sessile, in axillary spikes.

A small genus, distributed over the tropical regions of the New and the Old World.

1. C. filiformis, Linn.; Nees, Syst. Laur. 642 ; Wight, Ic. t. 1847. Stems filiform or wiry, glabrous or slightly pubescent when young, twining round and attaching themselves to other plants by means of snall protuber- 
ances or suckers. Flowers small, distant, in spikes of 1 to 2 in. Perianth about $1 \frac{1}{2}$ lines long, the lobes about the length of the tube. Filaments of the 3 outer stamens broad and petal-like, of the 6 others filiform. Anthers all fertile. Berry about 3 lines diameter, crowned by the persistent connivent perianth-lobes.

Common all over the island, Champion and others. Widely distributed over tropical Asia, extending into Africa and Australia.

\section{ORDER XC. PROTEACEAT.}

Flowers usually hermaphrodite. Perianth-segments 4, usually valvate in the bud. Stamens as many, opposite to and inserted on the segments. Anthers 2-celled, opening longitudinally. Ovary superior, 1-celled, with 1 or 2 collateral ovules. Style simple, with an entire or rarely 2-lobed stigma. Fruit an indehiscent nut, or a follicular or 2-valved capsule. Seeds 1 or 2 , without albumen. Embryo straight, with an inferior radicle.-Trees, shrubs, or rarely herbs. Leaves usually alternate, entire or divided, without stipules.

A large Order, chiefly abundant in Australia and S. Africa, with a few species dispersed over S. America, or tropical Asia and Africa.

\section{HELICIA, Lour.}

Flowers regular. Perianth-segments linear, more or less dilated at the top. Anthers sessile on the dilated portion. Hypogynous glands 4. Ovules 2, ascending. Style club-shaped at the top. Fruit an indehiscent nut.-Trees or shrubs. Leaves all entire or toothed. Flowers in axillary racemes. Perianth-segments rolled back.

A genus of several species, but confined to tropical Asia.

1. H. cochinchinensis, Lour.; Meisn. in DC. Prod. xiv. 442. A perfectly glabrous tree. Leaves oval-elliptical or oblong, acuminate, entire or coarsely serrate in the upper part, 3 to 5 in. long, narrowed into a petiole of 3 to 6 lines. Racemes 4 to 5 in. long, flowering from the base. Pedicels about 2 lines long, usually in pairs and often united to the middle. Perianth slender, about 6 lines long. Hypogynous scales not half so long as the ovary, very obtuse, free or slightly united at the base.

Hongkong, Wright. S. China, Herb. Hook. I have not seen authentic specimens of Loureiro's plant, which, according to Meisner, has shorter pedicels and the hypogynous scales acute; but the specimens agree so well in other respects, that I have little doubt that they belong to the same species. In that case it extends probably southward to the Archipelago.

\section{ORDER XCI. THYMELEßE.}

Flowers usually hermaphrodite. Perianth tubular or campanulate, 4- or 5-lobed; the lobes imbricate in the bud, with the addition, in many genera, of 1 or 2 small scales alternating with the lobes at their base. Stamens either as many or twice as many as lobes, or rarely 2 only, and if of the same number as the lobes, opposite to them. Anthers opening longitudinally. Ovary free, 1 - or rarely 2 -celled, with 1 or rarely 2 or 3 pendulous ovules. Fruit an 
indehiscent nut or berry, or very rarely a 2-valved capsule. Seed without or rarely with albumen. Embryo straight, with a superior radicle.-Shrubs or trees, with a stringy bark, or rarely herbs. Leaves alternate or opposite, always simple and entire. Flowers in terminal or axillary clusters, heads, umbels, racemes, or spikes.

A large Order, widely distributed over most parts of the globe.

Perianth 4-lobed. Ovary 1-celled.

Stamens 4, with slender filaments, inserted at the base of the tube - 1. CansJERA.

Anthers 8, nearly sessile, in 2 rows near the top of the tube.

Hypogynous seales none. Leaves alternate. . . . . . . 2. DAPHNE.

Hypogynous seales 4. Leaves opposite . . . . . . . . . 3. Wiкstremia. Perianth 5-lobed. Ovary 2-celled . . . . . . . . . 4. Aquiraria.

\section{CANSJERA, Gmel.}

Perianth short, deciduous, with 4 small lobes spreading or recurved, without scales at the throat. Stamens 4, with slender filaments, inserted at the base of the perianth. Hypogynous scales 4, alternating with the stamens. Ovary fleshy, with a minute cavity and 1 (or 2 or 3 when very young) pendulous ovule. Fruit a berry, with a single erect seed. Embryo small, towards the summit of a fleshy albumen. - Shrubby climbers. Leaves alternate. Flowers small, in axillary spikes.

A small tropical Asiatic genus.

1. C. Rheedii, Gmel.; Meisn. in DC. Prod. xiv. 519 ; Wight, Ic. $t$. 1861. Young branches and inflorescence minutely pubescent or glabrous. Leaves almost sessile, ovate-acuminate or broadly lanceolate, $1 \frac{1}{2}$ to 3 in. long, glabrous, evergreen, and rather thick. Spikes about 1 in. long. Flowers yellow, sessile, distant. Perianth about $1 \frac{1}{2}$ lines long, with 2 minute bracteoles at the base.-C. lanceolata, Benth. in Lond. Journ. Bot. i. 491.

At Fast Point, in the Happy Valley and at Little Hongkong, Champion; also Wright. In Ceylon and the Indian Peninsula, and in the Archipelago.

\section{DAPHNE, Linn.}

Perianth tubular, with a spreading 4-lobed limb, without scales at the throat. Anthers 8, almost sessile, in 2 rows, near the top of the tube. Hypogynous scales none. Ovary with 1 pendulous ovule. Fruit a berry. Seed without albumen.-Shrubs or small trees. Leaves alternate. Flowers in terminal or lateral, sessile or rarely pedunculate heads or clusters.

A considerable genus, dispersed over Europe, Asia, and North Africa.

1. D. Championi, Benth., n. sp. A much branched shrub, more or less silky-hairy. Leaves alternate, oval or oblong, rather acute, about 1 in. long, on very short petioles, silky-hairy underneath, less so above. Flowers sessile, usually about 3 together, in axillary or lateral clusters. Perianth densely silky-pubescent, the tube 3 or 4 lines, the lobes ovate and obtuse, not 1 line long. Ovary sessile or nearly so, hairy except at the base.-D. Fortunei, Benth. in Kew Journ. Bot. v. 196; not of Lindley.

Hongkong, Champion, Hance; in a ravine among rocks at the back of Headquarter House, Wilford. Champion's specimens were too young to ascertain the shape of the flower, 
but the fine specimens we have now received from Wilford show that it differs considerably from the north Chinese D. Genkwa, Sieb. and Zucc., or D. Fortunei, Lindl., especially in the lobes of the perianth, which are very small, and apparently of a pure white.

\section{WIKSTRCEMIA, Endl.}

Perianth tubular, with a spreading 4-lobed limb, without scales at the throat. Anthers 8, sessile in 2 rows near the top of the tube. Hypogynous scales 4, or 2. Ovary with 1 pendulous ovule. Fruit a berry. Seed without albumen.-Shrubs or trees. Leaves opposite or rarely alternate. Flowers. in short terminal or axillary racemes or spikes.

A small tropical Asiatic or Australian genus.

Leaves obovate or oblong, mostly obtuse. Spikes sessile or nearly so . 1. W. viridiflora. Leaves ovate or oblong, acuminate. Spikes pedunculate, nodding . . 2. W. nutans.

1. W. viridiflora, Meisn. in DC. Prod. xiv 546. A glabrous much branched shrub. Leaves nearly sessile, from obovate and very obtuse to oblong and almost acute, $\frac{3}{4}$ to $1 \frac{1}{2}$ in. long. Spikes very short, terminal or nearly so, usually quite glabrous, without bracts. Perianth greenish-yellow, the tube about 3 lines, the lobes about half that length. Hypogynous scales 4 , but usually united in pairs so as to appear 2. Stigma large, on a very short style. Berry scarlet, ovoid, about 3 lines long. Seed without albumen.-W. alpina, var., Benth. in Kew Journ. Bot. v. 195.

Common on the hills, Hinds, Champion, and others. Also on the adjoining continent, in Chittagong and Singapore.

2. W. nutans, Champ. in Kew Journ. Bot. v. 195. A glabrous shrub like the last. Leaves ovate or broadly oblong, 1 to $2 \mathrm{in}$. long, and always acuminate. Spikes terminal, rather looser than in $W$. viridiflora, and always nodding on a recurved peduncle of about $\frac{1}{2}$ in. Flowers and fruit of $W$. viridiflora, but larger, the perianth-tube full 4 lines long.

Hills about the Happy Valley, Champion, in the woods of the valley, Wilford; also Wright. Not known from elsewhere.

\section{AQUillaria, Lam.}

Perianth campanulate, 5-lobed, with 10 scales united in a ring at the throat. Stamens 10, inserted at the throat within the ring. No hypogynous disk. Ovary completely or partially 2-celled, with 1 pendulous ovule in each cell. Stigma sessile. Capsule flat, almost woody, opening loculicidally in 2 flat valves, with the narrow dissepiment in their centre. Seed produced at the base into a long horn-like appendage.-Trees. Leaves alternate. Flowers in short terminal racemes.

A small tropical Asiatic genus.

1. A. grandiflora, Benth., n. sp. Young shoots and inflorescence slightly hoary. Leaves ovate or ovate-oblong, acuminate, 2 to $4 \mathrm{in}$. long, glabrous, on very short petioles. Flowers few, on pedicels of $\frac{1}{4}$ to near $\frac{1}{2}$ in. Perianthtube full 2 lines; the lobes rather longer, ovate, spreading. Ovary ovate, very hairy, not so completely 2 -celled as in A. agallochum. Fruit obovate, about $1 \mathrm{in}$. long, hoary or tomentose, 2-celled. Appendage of the seed twice as long as the seed itself, dilated upwards, but suddenly contracted close under the seed.-A. malaccensis, Benth. in Kew Journ. v. 195, but not of Lam. 
Common in the Happy Valley, Champion; also Wright, and in S. China, Reeves. Besides the much larger flowers and usually broader leaves, this appears to differ from the more common $A$. agallochum in the shape of the ovary, in the less woody capsule, and in the form of the appendage to the seed. I had considered that it might be the A. malaccensis, Lam.; but I have since seen Malacea specimens of what is more probably that plant, and which appears to be only a broad-leaved variety of $A$. agallochum.

\section{Order XCII. ELÆEAGNACE无.}

Perianth tubular, free but persistent at the base, and contracted above the ovary, the upper portion deciduous and 2- or 4-lobed. Stamens equal to and alternate with the perianth-lobes or twice as many, inserted in the tube or at its base. Anthers 2-celled, opening longitudinally. Ovary 1-celled, with 1 erect ovule. Fruit indehiscent, usually succulent, enclosed in the persistent base of the perianth. Seed with a very thin or without albumen. Embryo straight, the radicle inferior.-Trees or shrubs, more or less covered with scurfy stellate scales. Flowers in axillary clusters or cymes.

A small Order, chiefly Asiatic or European, with a very few American species.

\section{FL正AGNUS, Linn.}

Flowers hermaphrodite. Perianth 4-lobed, valvate in the bud. Stamens 4 , inserted in the tube. Style subulate, recurved, and stigmatic along one side at the top.

An Asiatic or European genus, with one N. American species.

1. E. Loureiri, Champ. in Kew Journ. Bot. v. 196. A shrub, without any of the thorns so common in the genus, the rusty-brown scurfy scales abundant on the young branches, the under side of the leaves, and especially on the flowers. Leaves ovate or oval-oblong, obtuse or acute, $1 \frac{1}{2}$ to 3 in. long, glabrous above. Flowers usually 2 or 3 together, in lateral clusters or short racemes. Lower portion of the perianth enclosing the ovary, ovoid, $1 \frac{1}{2}$ to 2 lines long when in flower, 7 or 8 lines long and 4 -angled or winged when in fruit, upper deciduous portion campanulate, 8 or 9 lines long, neither angular nor constricted under the lobes, which are lanceolate, about 3 lines long. Fruit slightly succulent; the endocarp very tough and filamentous. Seed oblong, without albumen.

On Mounts Parker and Gough, Champion; in woods at Little Hongkong, Wilford; also Wright. Not known out of the island.

\section{ORdER XCIII. SANTALACE无.}

Perianth-tube wholly or partially adnate; the limb with 3 to 5 lobes or segments, valvate in the bud. Stamens as many as the lobes and opposite to them, inserted at their base or within the free part of the tube. Anthers 2celled, opening longitudinally. Ovary inferior, 1-celled, with 3 to 5 ovules suspended from a free erect placenta. Fruit an indehiscent nut or berry, with a single seed. Albumen fleshy. Embryo straight, with a superior radicle.Herbs or shrubs, rarely trees. Leaves alternate or rarely opposite, entire, 
without stipules. Flowers usually small and green, in terminal or lateral heads, cymes, or spikes.

A considerable Order, widely spread over the temperate regions of the globe, with a few tropical species.

\section{HENSLOWIA, Blume.}

Flowers unisexual. Perianth-lobes 5 or rarely 6 , triangular. Stamens inserted near their base. Style short, stigma 3- to 5-lobed. Fruit a drupe. Albumen deeply lobed.-Shrubs usually parasitical, with the habit of Viscum. Leaves alternate, 3 to 7-nerved. Flowers small, axillary.

A small tropical Asiatic genus.

1. H. frutescens, Champ. in Kew Journ. Bot.v. 194. An erect or trailing glabrous shrub, apparently terrestrial, but probably a parasite on underground stems or roots. Leaves obovate, obtuse, $1 \frac{1}{2}$ to 2 in. long, narrowed into a short petiole. Peduncles axillary, clustered, 1 to 2 lines long. Male flowers globular, not 1 line long, pedicellate, in little umbels or cymes. Female flowers on a separate plant, solitary on each pedicel, and ovoid. Drupe ovoid, about $\frac{1}{2}$ in. long, crowned by the perianth-segments. Endocarp thin, but hard, with numerous projecting plates penetrating between the lobes of the seed. Albumen with numerous obovoid or oblong superposed lobes, radiating from a narrow continuous axis in the centre of which lies the linear embryo.

Common on the hills, Champion; in the Happy Valley woods, Wilford; also Wright. The $H$. heterantha, Hook, fil., from northern India, which I had thought might be the same species, proves distinct in many points. It is easily known by the small flowers, sessile, in little heads at the top of the peduncles.

\section{ORDER XCIV. EUPHORBIACEA巴.}

Flowers always unisexual, either without a perianth in one or both sexes, or more frequently with a simple calyx-like perianth, or sometimes also with 4 or 5 petals alternating with the calyx-lobes. Stamens various. Ovary consisting of 3 or sometimes 2 or more than 3 united 1-celled or rarely 2 celled carpels, each with 1 or 2 pendulous ovules. Styles as many as carpels, free or more or less united, el.tire or divided, the stigmatic surface usually lining their inner face. Fruit either capsular, separating into as many elastically 2 -valved cocci as carpels, leaving a persistent axis, or succulent and indehiscent, the endocarp consisting of as many indehiscent nuts or cocci as carpels. Seed laterally attached at or above the middle, with or without an arillus. Embryo straight, with flat cotyledons and a superior radicle, in a fleshy albumen, or very rarely the cotyledons fleshy, and little or no albumen. -Trees, shrubs, or herbs, often abounding in acrid milky juice. Leaves alternate or opposite, rarely divided or compound, usually with stipules. Inflorescence very varied. Flowers usually small.

A very large Order, most abundant within the tropies both in the New and the Old World, gradually diminishing in numbers in more temperate regions, and very few ascending into alpine or cold climates.

TRIBE 1. Euphorbieæ.--Involucre calyx-like, including several male flowers (single stamens), and 1 central female one (a single pedicellate pistil.), without any perianth, forming a flowerhead resembling a single flower ..... 1. EUрновнц. 
TriBe 2. Crotoner.-Male and female flowers within separate bracts in the same spike, or in different spikes or plants, mostly with a perianth. Ovary-cells 1-ovulate.

Perianth calyx-like. Petals none.

Stamens 2 to 10 , or rarely more.

Stamens 2 or 3 . Anthers didymous. Styles simple. Spikes eatkin-like . . . . . . . . . . .

Stamens about 10. Anthers vermicular. Male spikes eatkin-like. Females in leafy bracts. Styles finely divided.

Stamens 4 to 10. Anthers didymous. Styles plumose. Spikes panicled.

Stamens on a central column. Anthers didymous. Stigma sessile, disk-shaped. Spikes or racemes simple . . .

Stamens 8 , in a ring. Styles long, subulate. Flowers racemose Stamens indefinite.

Anther-cells distinet, erect from the base. Glands alternating with the female perianth-lobes. Leaves alternate. . .

Anther-cells distinct, collaterally attached. No glands within the perianth. Fruit usually echinate.

Filaments simple.

Leaves mostly opposite, or racemes and branches leafopposed . . . . . . . . . . . .

Leaves alternate $: \therefore \div$

2. Stillingia.

3. ACAlypha.

4. MAPPA.

5. Endospermum.

6. Stipellaria.

7. Claoxylon.

Theaves alternate

Petals within the calyx, at least in the male flower. Styles forked or dichotomous

Stamens indefinite. Flowers racemose . . . . . . . 11. Croton.

Stamens 8 or 10. Flowers corymbose . . . . . 12. JatropHA.

Tribe 3. Phyllantheæ.-Male and female flowers separate. Ovary-cells 2-ovulate.

Flowers monœecious (or rarely diœeious), in axillary clusters.

Leaves on short petioles.

Leaves alternate, usually distichous. Styles united or approximate at the base.

Calyx 5-lobed, valvate. Petals 5 ... . . . . 13. Briedelia.

Perianth-segments 4 to 6 , imbricate, in 1 or 2 rows.

Disk entire, or of distinct glands, at least in the males.

Perianth-segments 6 , rarely 5. Stamens 3 or 2 . Capsule

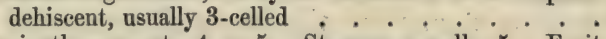

Perianth-segments 4 or 5. Stamens usually 5. Fruit baccate, 2- to 5-celled ...... 15. Cicca.

No prominent disk or gland within the perianth.

Perianth turbinate or campanulate at the base. Lobes 6, inflected in the males, spreading in the females. . 16. Melanthesa.

Perianth-segments 6 . Stamens 3 to 10 . Styles short, thick, and erect . . . . . . . . . . 17. Glochidion.

Leaves opposite. Styles distant at the base . : . . 18. Buxus.

Flowers dioecious, in panicles, racemes, or spikes.

Flowers all in lateral panicles or racemes. Petioles long.

Leaves compound. Ovary 3-celled . . . . . . . . . 19. Bischofria.

Leaves simple. Ovary 2-celled. Berry 1 -seeded : . 20. DaphniphyLuum.

Male flowers in catkins, females in racemes, spikes, or clusters.

Ovary 2-celled. Styles or stigmas 2...... . 21. Aporosa.

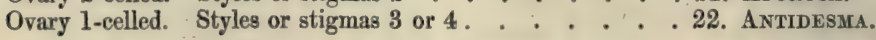

\section{EUPHORBIA, Linn.}

Flower-heads resembling single flowers. Involucre calyx-like, cup-shaped, with 4 or 5 minute teeth, alternating with as many horizontal glands, which 
are sometimes expanded into petal-like appendages. Within are 10 to 15 male flowers, consisting each of a single stamen with an articulated filament, and a single female flower in the centre, reduced to a stipitate 3-celled ovary. protruding from the involucre, with 1 pendulous ovule in each cell. Style 3 -cleft, the branches (or distinct styles) entire or 2-lobed. Capsule separating into 3 2-valved cocci.-Herbs or shrubs, abounding in milky juice. Stemleaves alternate, without stipules, the flowering-branches, umbellate, dichotomous, with usually opposite leaves; or all the leaves opposite and often stipulate; or succulent leafless shrubs.

A very large genus, dispersed over nearly the whole world.

Succulent shrub, leafless, or with small scattered leaves . . . . . 1. E. Tirucalli.

Herbs. Leaves below the umbel alternate . . . . . . . 2. $\mathbb{E}$. helioscopia.

Herbs. Leaves all opposite and minutely stipulate.

Capsules glabrous.

Cymes (small) loosely dichotomous . . . . . . . 3. E. hypericifolia.

Flower-heads 2 or 3 together, almost sessile in the upper axils . 4. E. sanguinea.

Capsules covered with appressed hairs.

Leaves 1 to $1 \frac{1}{2}$ in. Flower-heads very numerous, minute, in very dense pedunculate heads or cymes . : . . . . . 6. E. pilulifera.

Leaves 2 to 3 lines. Flower-heads few, in almost sessile cymes . 5. E. thymifolia.

1. E. Tirucalli, Linn.; Roxb. $F l$. Ind. ii. 470. An erect unarmed succulent shrub or small tree; the branches cylindrical, scattered or clustered, very divergent, of a bright shining green. Leaves none, or very few and small, linear-oblong. Flower-heads clustered on very short pedicels in the forks of some of the smaller branches. Glands of the involucre peltate. Capsule hairy. Styles 2-lobed.

Common in the island, Hance. In hedges, etc., over a great part of India and the Archipelago. It seldom produces flowers, and still more rarely fruits, we possess neither in the Kew herbaria, and I only know them from Roxburgh's description and drawing.

2. E. helioscopia, Linn.; Willd. Spec. ii. 914. An erect or ascending annual, 6 or $8 \mathrm{in}$. to $1 \mathrm{ft}$. high, simple or with a few branches ascending from the base. Stem-leaves alternate, obovate or broadly oblong, narrowed into a short stalk. Umbel of 5 rays, each ray once or twice forked; the branches very short. Floral leaves opposite, broadly obovate or orbicular, minutely toothed. Glands of the involucre entire and rounded. Capsules glabrous and smooth. Seeds pitted, with raised reticulate veins.-E. Peplus, Seem. Bot. Her. 409; not of Linn.

Cultivated and waste places, Hance. A common weed in Europe and temperate Asia, appearing also here and there in northern India.

3. E. hypericifolia, Linn.; Willd. Sp. ii. 895; Hook. Exot. Fl. t. 36. An ascending or erect annual, $6 \mathrm{in}$. to 1 or $2 \mathrm{ft}$. high, glabrous or minutely hoary. Leaves all opposite, from ovate to narrow-oblong, $\frac{1}{2}$ to 1 in. long, obtuse, serrulate, usually very oblique at the base. Cymes small, loosely dichotomous, terminal or in the upper axils. Involucre about $\frac{1}{2}$ line long; the glands small and entire, with small orbicular white petal-like appendages, sometimes scarcely perceptible, sometimes twice as broad as the gland. Capsule about 1 line diameter, quite glabrous. Seeds with 4 prominent angles, and slightly wrinkled between them.

In waste places, Hance and others. A common weed in tropical countries, especially 
America. In tropical Asia it is more commonly replaced by the nearly allied species (or variety P) $E$. cassioides, Presl, with broader leaves and hairy capsules.

4. E. sanguinea, Steud. and Hochst.; Boiss. in Herb. Hook. A dichotomous much-branched prostrate annual, seldom above 6 in. long, glaucous and glabrous, or with a few white hairs. Leaves from ovate to oblong, obtuse, serrate, very oblique, 2 to 4 lines long. Flower-heads smaller than in $E$. hypericifolia, and 2 or 3 together in almost sessile axillary cymes, as in $E$. thymifolia. Involucral glands without petaloid appendages. Capsule glabrous, and seeds of $E$. hypericifolia.

Hongkong, Harland; on the continent of S. China, in the Punjab, and in Affghanistan. Having long since returned the late Dr. Harland's specimens, I describe it from Shanghai and Indian ones. It is perhaps a variety of the widely diffused $E$. Chamasyce.

5. E. thymifolia, Linn.; Willd. Sp. ii. 898. A prostrate slender much branched annual, seldom above 6 in. long, the stems slightly hairy. Leaves all opposite, ovate, obtuse, serrulate, and very obliquely truncate at the base, 2 or 3 , or very rarely 4 lines long. Flower-heads very small, few together in compact almost sessile axillary cymes. Glands of the involucre, hairy capsules, and seeds of E. pilulifera.

Hongkong, Hance, Wright. A common weed in tropical Asia.

6. F. pilulifera, Linn.; Willd. Sp. ii. 897. A decumbent or prostrate annual, more or less hirsute with spreading hairs, 6 in. to a foot long or more. Leaves all opposite, from ovate to ovate-lanceolate or oblong, 1 to $1 \frac{1}{4}$ in. long, very oblique and usually narrow at the base. Flower-heads minute and numerous, crowded in head-like cymes, on short axillary peduncles. Involucre about $\frac{1}{2}$ line long, the glands small and entire, without appendages. Capsule $\frac{3}{4}$ line diameter, more or less hairy with appressed hairs. Seeds ovoid, obtusely 4-angled, slightly wrinkled.

Common in waste places, Hance, Wilford. A very common weed in tropical and subtropical countries, both in the New and the Old World.

\section{STILLINGIA, Gard.}

Flowers monœcious, in catkin-like spikes. Perianth small and calyx-like, irregularly toothed or lobed. Male flowers pedicellate, in distinct sessile clusters, occupying the greater part or the whole of the spike, with a small bract under each cluster. Stamens 2 or 3 , free or united at the base. Anthers globose, didymous. Female flowers few at the base of some of the spikes, and solitary under each bract. Ovary 3-celled, with 1 ovule in each cell. Style 3-cleft, with linear or oblong entire lobes.-Trees or shrubs. Leaves alternate, entire, undivided. Spikes terminal, solitary, or rarely paniculate.

A considerable genus (if made to include Sapium), distributed over the tropical regions of the New and the Old World.

Leaves rhomboidal, sharply acuminate, as broad as long . . . . . . 1. S. sebifera. Leaves oval-oblong, at least twice as long as broad.

Leaves whitish underneath. Primary veins numerous, almost transverse $2 . S$. discolor.

Leaves green on both sides. Primary veins few and obliqne . . . . 3. S. japonica.

1. S. sebifera, A. de Juss.; Miq. Fl. Ned. Ind. iii. 693. A glabrous tree. Leaves rhomboid, sharply acuminate, 1 to $2 \mathrm{in}$. long and broad, green 
on both sides, on slender petioles, with 2 prominent glands at the base of the limb. Spikes solitary, 2 to 4 in. long, the first all male, the subsequent ones with 1 to 4 female flowers at the base. Male flowers 6 or more in each cluster, very small and yellow. Female pedicels 1 to 2 lines long. Style divided to the middle. Capsule glaucous, nearly globular, but rather acute, about $\frac{1}{2}$ in. diameter.

Common as a shrub, though seldom allowed to grow to a tree, Champion and others. A native of China, and perhaps of the Philippines and the Archipelago, and has been introduced into India and tropical America.

2. S. discolor, Champ. in Kew Journ. Bot. vi. 1. A glabrous, more or less glaucous shrub. Leaves oblong or oval-oblong, shortly acuminate, $1 \frac{1}{2}$ to 2 in. long, glaucous or white underneath, the primary veins numerous and almost transverse. Petioles slender, with 1 or 2 small glands at the summit. Spikes about 2 in. long, dense like those of S. sebifera. Perianth usually 3 lobed. Style as in S. sebifera. Capsule rather smaller and very obtuse.

Hongkong, Champion, Wright. Also in Malacca.

3. S. japonica, Sieb. and Zucc. Fam. Nat. Fl. Jap. i. 37. A glabrous shrub, with slender branches. Leaves from ovate to oblong, 2 to 4 in. long, acuminate or the lower ones obtuse, green on both sides, the primary veins oblique and not numerous. Petioles rather shorter than in the two last, with 2 small glands at the base of the limb, sometimes wanting. Spikes slender, about 1 in. long, the clusters rather distant. Male flowers as in the two last species, but few in each cluster and smaller. Style of the females deeply cleft. Capsule rather smaller, obtuse.

Hongkong, Eyre, Wright, Hance, Also in Japan.

\section{ACALYPHA, Linn.}

Flowers monœcious or diœeious. Perianth small and calyx-like. Male flowers clustered in catkin-like spikes, with a small bract under each cluster. Perianth 4-lobed. Stamens 8 to 16, the anthers distinct, linear, and wavy or tortuous. Female flowers 1 to 4 together within a leafy bract. Perianth 3cleft. Styles 3 , finely branched. Ovary 3 -celled, with 1 ovule in each cell.Herbs, shrubs or trees. Leaves alternate. Spikes unisexual or androgynous.

A large genus, widely spread over the warmer regions of the globe.

1. A. indica, Linn.; Roxb. Fl. Ind. iii. 675 ; Wight, Ic. t. 877 . An erect annual of 1 to $2 \mathrm{ft}$, glabrous, or the young leaves and branches slightly hairy. Leaves ovate, toothed, 1 to 2 in. long, on slender stalks. Spikes axillary, interrupted, with 1 to 8 distant orbicular leafy bracts, 3 or 4 lines diameter, each containing 2 to 4 sessile female flowers, and ending in a small slender male catkin, sometimes not longer than the last bract, sometimes twice as long, and occasionally terminated by a single pedunculate 4-lobed flower, often imperfectly female or hermaphrodite. Capsule hairy. Seed smooth.A. chinensis, Roxb. l.c. 677 .

In waste places, Champion, Wilford. A common weed in tropical and subtropical Asia and Africa.

4. MAPPA, Juss.

Flowers monœcious or diœcious, in racemes or panicles. Perianth small 
and calyx-like, usually 2- or 3-lobed. Male flowers clustered. Stamens 3 to 10. Anthers globular, almost 4-lobed. Female flowers solitary, within small or leafy bracts. Ovary 2 -celled (or rarely 3 -celled), with 1 ovule in each cell. Styles distinct, laciniate or plumose along the inner side. Capsule often bearing soft prickles or subulate processes. Cocci 2-valved.-Trees. Leaves alternate, usually peltate. Panicles or racemes axillary or lateral.

A tropical genus, limited to the Old World.

1. M. Tanaria, Spreng.; Miq. Fl. Ned. Ind. i. pars ii. 401. A diœcious tree, more or less glaucous. Leaves rather deeply peltate, broadly ovate, with a long acumen, 6 in. to $1 \mathrm{ft}$. long, entire, angular or irregularly toothed, minutely glandular-dotted and often glaucous, but not softly pubescent, as in $M$. tomentosa. Male panicles much branched, the peduncle minutely tomentose. Bracts ovate, concave, 3 or 4 lines long, acuminate and toothed, embracing the flowers. Female panicles less branched. Capsules about $\frac{1}{2}$ in. broad, with a few long soft processes, sessile in a bract like those of the males but larger.-M. glabra, A. Juss. in Dene. Herb. Tim. Descr. 139.

Hongkong, Hance, Wright. In the Indian Arehipelago, and northward to Loochoo.

\section{FNDOSPERMUM, Benth.}

Flowers diøcious, in spikes or racemes. Perianth small and calyx-like, toothed. Male flowers : Stamens 6 to 10 , inserted along a central elongated column. Anthers globular, 4-valved. Female flowers : Ovary 2-celled, very rarely 3 -celled, with 1 ovule in each cell. Style reduced to a sessile diskshaped stigma (or deciduous, having a disk-shaped persistent base?). Fruit unarmed, with a slightly succulent epicarp, the endocarp of two indehiscent cocci.-Trees or shrubs, more or less scaly-tomentose. Leaves alternate, broad, entire. Spikes axillary.

A small genus, limited to eastern tropical Asia. The characters of the male flower are taken solely from a Borneo species.

1. E. chinense, Benth. in Journ. Soc. Linn. Lond. ined. A tree. Young branches thick, covered as well as the petioles and racemes with a minute scaly tomentum. Stipules 1 line long. Leaves on long stout petioles, broadly ovate, obtuse, 4 to 5 in. long, truncate at the base, nearly glabrous above, hoary or almost silvery underneath, with 2 large convex glands at the base, and here and there a similar one in the axils of the smaller veins. Fruiting racemes not 2 in. long. Pedicels short or scarcely any. Fruits tomentose, near $\frac{1}{2}$ in. diameter. The male plant is as yet unknown.

Hongkong, Champion, Hance. Not known out of the island.

\section{STIPELLARIA, Benth.}

(Bleekeria, Miq.)

Flowers diœcious, in racemes or spikes. Perianth calyx-like, without petals. Male flowers : Calyx of 2 to 4 segments, valvate in the bud. Stamens 8, or rarely fewer, the filaments united in a ring at the base. Anthers versatile, with contiguous cells. Female flowers: Calyx of 5 to 8 narrow sepals. Ovary 3or 4-celled, with 1 ovule in each cell. Styles free almost to the base, linearsubulate, not plumose. Capsule globular, dividing into 2-valved cocci.- 
Trees or shrubs. Leaves alternate, broad. Racemes terminal or from the old nodes.

A small genus, confined to tropical Asia.

1. S. trewioides, Benth. in Kero Journ. Bot. vi. 3. A shrub or tree, the young branches pubescent. Leaves broadly cordate, long-acuminate, irregularly serrate, 4 to $6 \mathrm{in}$. long, glabrous when old, except on the veins, and often turning red. Male racemes about $3 \mathrm{in}$. long, the flowers 4 to 8 together in distant clusters. Sepals about 1 line long, concave. Female racemes longer and stouter. Flowers solitary in the axil of a small bract. Sepals 5 or 6, lanceolate-subulate, $1 \frac{1}{2}$ to 2 lines long. Styles $\frac{1}{2}$ in. long. Capsule hoary.

Common in low grounds, Champion and others. Not known out of the island.

7. CLAOXYLON, A. Juss.

Flowers diœcious or rarely monœcious, in spikes or racemes. Perianth calyx-like, without petals. Male flowers : Calyx of 3 or 4 segments, valvate in the bud. Stamens indefinite. Anther-cells distinct, erect. Female flowers: Calyx 3-lobed, with glands alternating with its lobes. Ovary 2- or 3-celled, with 1 ovule in each cell. Styles free to the base, reflexed, plumose inside. Capsule not muricate, divided into 2-valved cocci--Trees or shrubs, glabrous or tomentose. Leaves alternate, undivided. Spikes or racemes axillary, loose.

A considerable genus, spread over the tropical regions of the Old World.

1. C. parviflorum, A. Juss. in Spreng. Syst. iii. 906 ; Hook. and Arn. Bot. Beech. 212. A shrub, softly tomentose in the young parts. Leaves stalked, from broadly ovate-cordate to oval-oblong, with a cuneate base, 6 to $8 \mathrm{in}$. long, obtuse or acute, usually irregularly toothed, nearly glabrous amd green when full-grown. Spikes tomentose, the males slender, $4 \mathrm{in}$. to $1 \mathrm{ft}$. long, the flowers small, several together in distant clusters. Female spikes 2 to 3 in. Capsules 3 lines diameter, softly tomentose, often reddish.-C. indicum, Endl.; Miq. Fl. Ned. Ind. i. pars ii. 385. C. spiciflorus, A. Juss. in Baill. Euph. 493.

Hongkoug, Hance, Wright; in woods at Iittle Hongkong, Wilford. Widely diffused over eastern India, the Archipelago, and the Pacific isles.

\section{HANCEA, Seem.}

(Axenfeldia, Baill. Echinocroton, F. Muell.)

Flowers monœcious, in spikes or racemes. Perianth calyx-like, without petals or glands. Male flowers: Calyx of 3 or 4 segments, valvate in the bud. Stamens indefinite. Anther-cells distinct, laterally attached above the middle. F: male flowers: Calyx of 4 to 6 narrow segments. Ovary 3-celled, with 1 ovule in each cell. Capsule muricate or echinate, dividing into 2valved cocci.-Shrubs or trees, glabrous or hairy. Leaves alternate, undivided, all or the upper ones opposite, or opposed to the spikes or branches. Spikes terminal or leaf-opposed.

A small tropical genus, limited to A sia and Australia. It is closely allied to Rottlera. 
Stems hispid with long hairs. Upper leaves opposed to a branch, a spike, or a bnd. . . . . . . . . . .

Glabrous or pubescent. Upper leaves opposite, in usually unequal pairs

1. H. Hookeriana.

2. H. muricata.

1. H. Hookeriana, Seem. Bot. Her. 409, t. 96. A shrub. Branches rather slender, very hispid with stiff spreading hairs. Stipules lanceolatesubulate, 4 to 6 lines long. Leaves oblong, acuminate, 3 to $5 \mathrm{in}$. long, obtuse or oblique at the base, entire or remotely toothed, glabrous or nearly so, the upper ones always opposed to a bud, a raceme, or a branch. Male racemes 1 to $2 \mathrm{in}$. long. Flowers about 4 lines diameter, on pedicels of 1 to $1 \frac{1}{2}$ lines, with a subulate bract under each. Female flowers usually solitary, on a peduncle of 1 in. Calyx-segments lanceolate-subulate. Styles 8 or 9 lines long. Capsule $\frac{1}{2} \mathrm{in}$. diameter, glabrous, with numerous prickles.

Hongkong, Champion, Hance, Wright ; in the ravines of the Happy Valley woods, Wilford. Not known from elsewhere.

2. H. muricata, Benth. A shrub, glabrous or slightly pubescent. Leaves mostly opposite, but of unequal size, stalked, oblong, acuminate, 3 to 6 in. long, entire or toothed, narrowed below the middle, but obtuse at the very base. Male racemes 1 to $2 \mathrm{in}$. long, with small clustered flowers, usually sprinkled with resinous dots. Female racemes longer, with few distant flowers. Calyx 6-cleft. Styles much shorter than in the last species. Capsule muricate with soft and usually recurved points.-Claoxylon muricatum, Wight, Ic. t. 1886. Axenfeldia intermedia, Baill. Euph. 419 (from the description).

Hongkong, Hance, Harland. Widely spread over India, from Ceylon and the Peninsula to the Archipelago.

\section{ROTTLERA, Roxb.}

Flowers diœcious or rarely monœcious, in terminal racemes or panicles. Calyx 2- to 5-cleft, valvate in the bud, without petals or glands. Male flowers : Stamens numerous, filaments free or shortly united at the base; anther-cells distinct, laterally attached to a more or less enlarged connectivum. Female flowers : Ovary 3 - or 2-celled, with 1 ovule in each cell. Styles simple, recurved, usually shortly plumose along the inner side. Capsule usually tomentose or muricate, dividing into 2-valved cocci.-Trees. Leaves alternate (or rarely opposite?), entire, toothed, or lobed, 3- or 5-nerved at the base, usually with 2 depressed glands at the base on the upper surface.

A considerable tropical Asiatic and African genus.

Leaves broad, very white underneath.

Capsule thickly covered with subulate plumose processes . . . . 1. R. chinensis.

Capsule bearing long stiff subulate processes . . . . . 2. R. paniculata. Leaves green or pale underneath.

Leaves oblong or ovate-lanceolate. Capsule tomentose, red . . . 3. R. tinctoria.

Leaves cordate-ovate. . . . . . . . . . . 4. R. cordifolia.

1. R. chinensis, A.de Juss.; Hook. and Arn. Bot. Beech. 212. A shrub or tree. Leaves on rather long stalks, very broadly ovate, acuminate, 3 to 4 in. long, entire or irregularly 3-lobed and toothed, truncate at the base, glabrous above, very white with a stellate tomentum undernenth, as well as the branches and inflorescences. Male plant not seen. Female spike terminal, simple, 4 to 8 or even 10 in. long. Stvles short. Capsules very densely 
covered with subulate plumose processes forming woolly masses of $1 \frac{1}{2}$ in. diameter.

Hongkong, Hance, Wright. Also on the adjacent continent, but not known out of S. China.

2. R. paniculata, A. Juss.; Hook and Arn. Bot.Beech. 212. A tree. Leaves on long stalks, broadly ovate rhomboidal, long-acuminate, 3 or 4 or rarely 5 in. long, entire or 3 -lobed, stiffer than in the last, and always cuneate at the base, glabrous above, white-cottony or slightly ferruginous underneath. Racemes usually paniculate or the females rarely simple, 3 to 5 in. long. Styles short, very plumose. Capsule brown-tomentose, with stiff subulate processes, varying in number, but never so densely crowded as in $R$. chinensis.

Common in raviues, Champion and others. In the Malayan Peniusula, the Archipelago, the Philippines and S. China.

3. R. tinctoria, Roxb. Fl. Ind. iii. 827 ; Pl. Corom. t. 168. A tree. Leaves shortly stalked, from oblong to ovate-lanceolate or even ovate, obtuse or acuminate, 3 to 4 in. long, entire, usually rounded at the base, more coriaceous than in the two last, glabrous above, minutely hoary-tomentose underneath. Spikes rather dense, about 2 in. long, in short terminal panicles or the females simple. Flowers small. Anthers usually tipped with a red gland. Styles shortly united, with plumose recurved branches. Capsule 3-celled, not muricate, covered with a red glandular tomentum. $-R$. aurantiaca, Hook. and Arn. Bot. Beech. 270.

Common in ravines, Champion and others. Widely spread over the hilly districts of Iudia, from Ceylon and the Peninsula to the Himalaya, Silhet, and Assam, in S. China and the Philippines, and northward to Ioochoo; but not received from the Malayan Peninsula or the Archipelago.

4. R.? cordifolia, Benth., n. sp. Branches slender, glabrous. Leaves cordiform, shortly and obtusely acuminate, about 2 in. long, entire or slightly sinuate, green and glabrous on both sides, but sprinkled with glandular dots. Male raceme 2 in. long, slightly tomentose. Pedicels about 2 lines long. Calyx globular, 1 $\frac{1}{4}$ line diameter, 5-cleft. Stamens entirely those of the genus.

Hongkong, Wright. I have seen only a single male specimen, which I refer to Rottlera, from its evident affinity to the $R$. dicoce $\alpha$, Roxb. It is, however, much more glabrous, and the leaves are distinctly cordate and not in the least peltate at the base.

\section{RICINUS, Linn.}

Flowers monœcious, in terminal raceme-like panicles; the upper ones female, the lower male. Calyx 3- to 5-cleft, valvate in the bud, without petals or glands. Male flowers : Stamens very numerous; anthers crowded on branched filaments ; the cells distinct, globular. Female flowers : Ovary 3-celled, with 1 ovule in each cell. Styles deeply 2 -cleft and plumose. Capsule mostly echinate, dividing into 2-valved cocci.-Trees or tall herbs. Leaves alternate, peltate, palmately divided.

A tropical genus, of which the 6 or 7 published species may perhaps be varieties of a single one.

1. R. communis, Linn.; Willd. Spec. iv. 564; Bot. Mag.t. 2209. A glaucous, glabrous, erect plant; an annual of 4 to $6 \mathrm{ft}$. in cold countries; a tree of $20 \mathrm{ft}$. or more in hotter climates. Leaves large, with 7 or rarely 
more broadly lanceolate serrate lobes. Racemes or panicles 3 to $6 \mathrm{in}$. long, sometimes becoming leaf-opposed by the development of a terminal shoot. Male sepals about 4 lines long. Capsule $\frac{1}{2}$ in. long or more.

In waste places, Seemann and others. A native probably of western Asia or Africa, but so much cultivated and sowing itself so readily that it has become a common weed in many hot countries. It supplies the castor oil.

\section{CROTON, Linn.}

Flowers monœcious or rarely diceious, in racemes or spikes, or rarely paniculate. Male flowers: Calyx 5-cleft, valvate in the bud. Petals 5, convolute in the bud. Glands 5, alternating with the petals. Stamens usually 10 to 20, free. Anthers 2-celled, adnate. Female flowers : Calyx 5-cleft, persistent. Petals rudimentary or none. Glands 5. Styles 3, 2-cleft or branched. Ovary 3-celled, with 1 ovule in each cell. . Capsule dividing into 2-valved cocci.-Trees, shrubs, or herbs. Leaves alternate, entire or divided. Racemes or spikes terminal, or rarely axillary, usually androgynous.

A large genus, widely distributed over the warmer regions of the globe, both in the New and the Old World.

Leaves and branches glabrous. Petioles very short ..... 1. C. Hancei.

Leaves, at least underneath, and branches tomentose or hairy. Petioles usually 4 to 6 lines.

Bracts entire. Stamens 10 or 12. Styles 2-cleft . . . . . 2. C. lachnocarpum.

Bracts divided. Stamens above 20. Styles 4-cleft . . . . . 3. C. chinense.

1. C. Hancei, Benth., n. $s p$. A shrub or tree, glabrous, except a minute scaliness on the young branches and inflorescence. Leaves oblong-lanceolate, acuminate, 3 to $4 \mathrm{in}$. long or even more, entire or minutely serrate, narrowed below the middle, but obtuse at the base, and there bearing sometimes 2 minute stipitate glands; the petiole very short. Spikes terminal, about 1 in. long. Bracts minute. Pedicels very short. Female flowers single at the base. Sepals green, about 3 lines long. Glands none. Ovary globular, hairy. Style shortly columnar, with 3 short bifid lobes. Male flowers rather crowded, globular, about 2 lines diameter. Petals narrow. Disk small. Stamens about 16, intermixed with a few hairs.-Croton longifolium, Seem. Bot. Her. 410 ; not of Wall.

Hongkong, Hance. Not seen from elsewhere. It is allied to Wallich's n. 8001, from Silhet, but that has longer leaves decurrent on the petiole, looser racemes, larger female flowers, a more deeply divided style, the ovary glabrous. 'It has no connection with $C$. longifolium, Wall., which is a Trigonostemon.

2. C. lachnocarpum, Benth. in Kew Journ. Bot. vi. 5. A shrub, more or less pubescent with stellate hairs. Leaves oblong or ovate-oblong, acute, and mucronate, or rather obtuse, usually 2 to $3 \mathrm{in}$. but sometimes twice as long, serrulate-crenate, with small stipitate glands at the serratures, becoming glabrous above when old, on petioles of 3 to 6 lines. Racemes terminal, 3 to 4 in. long. Bracts minute, subulate. Pedicels about 1 line. Male flowers clustered, about 1 line diameter. Peials oblong. Glands small. Stamens 10 to 12. Female flowers few at the base of the raceme. Sepals 1 to $1 \frac{1}{4}$ lines long. Petals minute, subulate. Glands small. Ovary villous. Styles subulate, bifid.

Common in woods, Champion; also Wright and Hance. Not kuown from elsewhere. 
3. C. chinense, Benth., n. sp. A shrub? Branches, leaves, and inflorescence rather densely stellate-tomentose. Leaves ovate or oblong, obtuse or scarcely acute, serrate or nearly entire, 2 to 3 in. long, on stalks of about $\frac{1}{2}$ in., usually wrinkled and becoming nearly glabrous above. Glands stipitate as in the last, but smaller or fewer. Racemes 1 to 2 in. long. Bracts divided into subulate lobes, often tipped with a gland. Male flowers small, clustered. Petals oblong. Glands very minute or none. Stamens above 20, intermixed with hairs. Female flowers usually several at the base of the raceme. Sepals about 2 lines long. Petals none. Ovary very hairy. Styles deeply 4-cleft. Capsule about 3 lines long, very rusty-hairy.

Hongkong, Hance; on slopes of hills at Aberdeen, Tilford. Putoy Island, Wright, and Amoy, Hance; but not known out of S. China.

\section{JATROPHA, Linn.}

Flowers monœcious in terminal cymose panicles. Calyx 5-cleft, imbricate in the bud. Petals 5, free or united, convolute in the bud, or none. Disk of 5 free or united glands. Male flowers : Stamens 8 or 10, shortly united at the base ; the 3 or 5 inner ones longer. Female flowers : Ovary 3 -celled, with 1 ovule in each cell. Styles 2-lobed or dichotomous. Capsule dividing into 2-valved cocci.-Trees, shrubs, or herbs. Leaves alternate, entire or palmately lobed.

A considerable tropical Ameriean genus, with a very few species either African or generally naturalized in tropical Africa and Asia.

1. J. Curcas, Linn.; Roxb. Fl. Ind. iii. 686. A shrub or small tree, glabrous or nearly so, with a milky juice. Leaves on long stalks, very broadly cordate or peltate, 3 to 5 in. long and broad, angular or obtusely lobed. Cyme terminal, shorter than the leaves, with numerous small yellow flowers. Calyx deeply 5-lobed. Petals united at the base. Stamens 10, the 5 inner united in a column. Capsule ovoid, above 1 in. long.

In hedges and near habitations, Hance, Seemann. An American species, naturalized and now very common in various parts of India.

\section{BRIEDELIA, Willd.}

Flowers monœcious, in axillary clusters. Calyx 5 -lobed, valvate in the bud. Petals 5, small. Male flowers : Stamens 5, inserted on a central column, placed on a flat sinuate disk. Female flowers: Ovary 2-celled (very rarely 3 -celled ?), half-enclosed in a cupular disk, with 2 ovules in each cell. Styles shortly bifid. Fruit globular or ovoid, succulent, enclosing 2 (or rarely 1) indehiscent cocci.-Trees, shrubs, or climbers. Leaves alternate, on very short petioles, more or less distichous; the primary veins usually prominent and parallel.

A genus of few species, all tropical Asiatic or African.

1. B. tomentosa, Blume; Miq. Fl. Ned. Ind. i. pars ii. 364. A shrub, with weak slender more or less tomentose branches. Leaves oblong or oblonglanceolate, 2 to $3 \mathrm{in}$. long, nearly glabrous above, glaucous and more or less pubescent or tomentose underneath. Flowers very small, in globular sessile clusters, 4 or 5 female, and at least as many males in each axil. Drupes nearly 
globułar, about 3 lines long, with 2 hemispherical cocci.-B. Loureiri, Hook. and Arn. Bot. Beech. 211.

In hedges, Champion. On the adjacent continent, in Sikkim, Assam, Silhet, the Malayan Peninsula, and the Archipelago. Hooker and Arnott deseribe it with a 3-merous ovary, but that must have been an exceptional case.

\section{PHYLLANTHUS, Linn.}

Flowers monœcious or rarely diœcious, in axillary clusters or solitary. Perianth-segments 6 , or rarely 5 or 4 in the males, imbricate in the bud, in 1 or 2 rows. Disk prominent and entire or lobed, or consisting of small distinct glands. Male flowers: Stamens 3, rarely 2 or 5, united in a central column or free. Female flowers: Ovary 3-celled, with 2 ovules in each cell. Styles free or united at the base, more or less 2-lobed. Capsule separating into 2-valved cocci or loculicidally dehiscent.-Herbs, shrubs, or trees. Leaves alternate, entire, usually small and distichous, giving the smaller branches the appearance of pinnate leaves, in some American species wholly wanting. Stipules small, usually persistent. Flowers small.

A large genus, copiously diffused over the tropical and subtropical regions of both the New and the Old World.

Herbs, either annual or of short duration.

Disk of male flowers broad, almost petaloid. Capsule ovoidglobose

1. P. bacciformis.

Disk of male flowers of small glands. Capsule depressed-globose.

Flowers nearly sessile.

Perianth-segments ovate-oblong. Capsule muricate . . 2. P. urinaria.

Perianth-segments broadly obovate. Capsule smooth . . ร. P. maderaspatensis.

Pedicels longer than the perianth. Capsules smooth.

Smaller branches almost filiform. Seeds striate. . . 3. P. Niruri.

Smaller branches very flat. Seeds minutely tuberculate - 4. P. anceps.

Trees or shrubs.

Much branched low shrubs, Disk thick, annular, trancate.

Male perianth-segments 6. Anthers 3. Styles united to the middle .............. .

Malc perianth-segments 4. Anthers 2. Styles distinct . . 7. P. leptoclados.

Tree. Disk in the males of distinet glands, in the females cupshaped

1. P. bacciformis, Linn.; Roxb. Fl. Ind. iii. 661. A glabrous glaucous annual, or a perennial of short duration. Branches diffuse, angular, 6 in. to 1 foot or longer. Leaves oblong, 4 to 6 lines long, somewhat fleshy. Flowers nearly sessile; the males few, the females solitary. Perianth-segments broadly ovate, acute. Anthers 3 , sessile on the top of the column. Disk in the males almost petaloid, 6-lobed, lining the base of the calyx, none in the females. Style spreading, 2-lobed. Capsule ovoid, globose, full 2 lines long, smooth.-Agyneia bacciformis, A. de Juss.; Wight, Ic. t. 1893.

Rocks on the seacoast, Hance. Common in pastures near the sea in the greater part of India. The so-called arillus appears to be only a portion of the endocarp which separates readily from the rest and often falls off with the seed.

2. P. urinaria, Linn.; Roxb. Fl. Ind. iii. 660. A glabrous annual, of 6 in. to 1 ft., erect or decumbent at the base, the stems slightly compressed. Leaves distichous, oblong, very obtuse, about $\frac{1}{2}$ in. long. Flowers minute, 
almost sessile; the females solitary, the males 2 or 3 together. Perianthsegments 6 , ovate in the males, narrow in the females. Disk of 6 distinct glands. Anthers 3, on a central column. Capsule depressed-globose, about 1 line diameter, muricate or tuberculate. Seeds angular, transversely wrinkled.-P. cantoniensis, Hornem.; Kl. Pl. Meyen. 420. P. leprocarpus, Wight, Ic. t. 1895 , iv. P. lepidocarpus, Sieb. and Zuce. Fam. Nat. Fl. Jap. i. 35.

In sunny places, Hance. In various parts of India, but much less common than P. Niruri; in Loochoo and Japan.

3. P. Niruri, Linn.; Roxb. Fl. Ind. iii. 659 ; Wight, Ic. t. 1894. Habit and foliage of $P$. urinaria, but usually taller and more branched. Leaves seldom above 4 lines long. Pedicels $\frac{1}{2}$ to 1 line long. Capsules quite smooth. Seeds marked (under the microscope) with longitudinal striæ, without transverse wrinkles.

Hongkong, Harland. A very common weed in tropical and subtropical Asia and Africa and some parts of tropical America. I have not now the Hongkong specimens before me, but describe it from Indian and Philippine Island ones.

4. P. anceps, Willd. Spec. iv. 574. An annual, or perennial of short duration, decumbent and much-branched, $6 \mathrm{in}$. to $1 \mathrm{ft}$. long, glabrous and glaucous; the branches all very flat, though slender, with acute angles. Leaves from oblong and 2 to 4 lines long to linear-oblong or lanceolate and near $1 \mathrm{in}$. long, obtuse or acute. Female pedicels 1 to 3 lines long, the males shorter. Perianth-segments small, oblong. Glands distinct. Stamens 3, distinct or slightly united. Capsule smooth or glandular. Seeds elegantly and regularly marked with microscopical tubercles.-P. simplex, Willd. ?; Roxb. Fl. Ind. iii. 654. P. ussuriensis, Ruppr. ; Maxim. Prim. Fl. Amur. 241.

Near the Happy Valley, Wilford; also Wright. Dispersed over India, from Ceylon and the Peninsula to the Archipelago and Pacific Islands, and northward to China and Mantchuria.

5. P. maderaspatensis, Linn.; Roxb. Fl. Ind. iii. 654; Wight, Ic. $t$. 1895, iii. A glaucous rigid annual, often outliving a second year and then appearing woody, 1 to $4 \mathrm{ft}$. high ; the slender branches more or less flattened. Leaves obovate or cuneate-oblong, 3 or 4 lines to $1 \mathrm{in}$. long. Flowers nearly sessile; the females solitary, the males 2 or 3 together. Perianth-segments broadly obovate. Glands distinct. Anthers 3, nearly sessile on an almost globular column. Capsule quite smooth. Seeds very minutely tuberculate or almost smooth.

Hongkong, Champion. In Ceylon and the Indian Peninsula. Some specimens of this species have got mixed, in Wall. Cat. n. 7906 b., with those of P.obcordatus, Roxb., a very different species.

6. P. cinerascens, Hook. and Arn. Bot. Beech. 211; Seem. Bot. Her. t. 97 (not Wall. Cat, 7915, which is Melanthesa rhamnoides, Blume). A glabrous, much branched, prostrate or divaricate shrub, apparently diœcious. Leaves obovate or oblong, very obtuse, 3 to 5 lines long, almost coriaceous. Stipules ciliate. Flowers 1 to 3 together. Female pedicels 2 to 3 lines long, male ones shorter. Perianth-segments broadly ovate, very obtuse, 1 line in the females, smaller in the males. Anthers 3, oblong, diverging from a thick central column. Disk in the females thick, annulair, truncate. Styles united to the middle, each with 2 recurved lobes. Capsule above 2 lines diameter. Seeds minutely tuberculate. 
Hongkong, Champion, Hance. In ravines of Mount Gough, Wilford; also on the adjacent continent, but not known out of S. China.

7. P. (Reidia) leptoclados, Benth., n. sp. A slender divaricate or prostrate glabrous shrub, the smaller branches almost filiform. Leaves obliquely ovate or oblong, 3 to 6 lines long, mostly mucronate, glaucous underneath. Pedicels filiform; the females solitary, full $\frac{1}{2}$ in. long, the males 2 or 3 together and shorter. Male flowers : Perianth-segments 4, acuminate and denticulate. Glands 4, broad and truncate. Anthers 2, on the top of a short central column. Female flowers: Perianth-segments 6. Disk annular, truncate, entire or lobed. Styles spreading, divided into 2 slender lobes. Capsule depressed-globular, 2 lines diameter. Seeds minutely tuberculate.

Hongkong, Wright. Near Amoy, Hance.

8. P. Emblica, Linn.; Roxb. Fl. Ind. iii. 571. A tree, either wholly glabrous or the smaller branches pubescent. Leaves linear-oblong, obtuse, about $\frac{1}{2}$ in. long, remarkably distichous. Male flowers very numerous, on pedicels of about 1 line. Perianth-segments 6, less than 1 line long. Glands very small. Anthers 3 to 5, oblong, erect on a short column. Female flowers mixed singly with the males in the upper axils. Perianth the same. Ovary half-immersed in an annular disk. Style with 3 thick recurved 2lobed branches.-Emblica officinalis, Gærtn.; Wight, Ic. t. 1896. Dichelactina nodicaulis, Hance in Walp. Ann. iii. 376.

Hongkong, Champion, Hance, and others ; but perhaps only where planted. Frequent in India, but there chiefly in gardens.

\section{CICCA, Linn.}

Flowers monœecious, in axillary clusters or solitary. Perianth-segments 4 or 5 , imbricate in the bud. Disk of small distinct glands. Male flowers : Stamens 4 or 5, distinct. Female flowers: Ovary 2- to 5-celled, with 2 ovules in each cell. Styles bifid and spreading or short and erect. Fruit a drupe or berry.-Trees or shrubs, with the foliage and inflorescence of Phyllanthus. In some species the lateral short flowering branches are leafless and assume the appearance of racemes.

A small tropical genus, common to the New and the Old World.

1. C. microcarpa, Benth., n. $s p$. A glabrous shrub $\rho$ with slender branches. Leaves obliquely ovate, entire, distichous, glaucous underneath, about 2 in. long on the larger branches, scarcely 1 in. on the principal flowering ones, and sometimes wanting on the smaller ones. Flowers usually 1 female and several male in the same axil, on pedicels of 1 to 2 lines, 5 -merous or rarely 4-merous, the males very minute. Stamens 5 or 4 , with short free filaments. Ovary 5-celled, with 2 ovules in each cell. Styles very short and erest, as in some Glochidions. Fruit globular, depressed, $1 \frac{1}{2}$ lines diameter, apparently indehiscent, with a thin succulent epicarp.-Melanthesa, sp., Seem. Bot. Her. 410.

Ilongkong, Seemann. In a ravine on the south side of the island, Wilford. Not known froin eisewhere.

16. MELANTHESA, Blume.

Flowers munøecious, in axillary clusters or solitary. Perianth campanu- 
late or urceolate at the base, with 6 teeth or lobes, connivent over the stamens in the males, spreading and persistent in the females. Disk none. Stamens 3. Anthers sessile at the top of the central column. Ovules 3-celled, with 2 ovules in each. Styles bifid. Fruit succulent, indehiscent.-Shrubs or herbs, with the distichous leaves and habit of Phyllanthus, but almost always turning black in drying.

A small genus, spread over tropical Asia and Australia.

1. M. chinensis, Blume, Bijdr. 592. A glabrous somewhat glaucous shrub. Leaves ovate to ovate-lanceolate, obtuse or almost acute, 1 to $1 \frac{1}{2}$ in. long, coriaceous when old. Flowers 2 to 4 in each axil. Males in the lower clusters, on slender pedicels of 1 to $1 \frac{1}{2}$ lines: Perianth 1 line long. Female flowers in all the other clusters: Perianth turbinate at the base, the border expanding to a diameter of 2 lines when in flower, twice that in fruit. Drupe about 3 lines diameter, enclosing six 1-seeded cocci.-Melanthesa cernua, Benth. in Lond. Journ. Bot. i. 491 ; not of Dene. Phyllanthus lucens, Poir.; Hook. and Arn. Bot. Beech. 210. P. turbinatus; Bot. Mag. t. 1862 ; not of Kœn. $\quad P$. Simsiana, Wall. Cat. n. 7920. Java.

In woods, Champion and others. On the adjacent continent, in Siam, and perhaps in

\section{GLOCHIDION, Forst.}

Flowers monœcious, in axillary clusters. Perianth-segments 6 , free or shortly united, imbricate in the bud. Glands none. Male flowers: Stamens 3 to 5 or rarely more. Anthers oblong, sessile on a central column, tipped by their projecting connectivum. Females: Ovary 3 - to 10 -celled, with 2 ovules in each cell. Styles short, erect and connivent in an oblong or globular mass or in a short ring, or rarely spreading. Capsule globular or depressed, loculicidally dehiscent or separating into 2-valved cocci.-Shrubs. Leaves entire, usually distichous on short petioles, but larger and coarser than in most Phyllanthi.

A considerable genus, extending over tropical Asia and Australia.

Anthers 3. Leaves usually under 3 in. or thin.

Branches and leaves quite glabrous.

Leaves $1 \frac{1}{2}$ in. long. Ovary 3-celled . . . . . . . . 1. G. Wrightii.

Leaves about 3 in. Ovary 5-celled . . . . . . . 2. G. philippinense.

Branches and leaves pubescent or hirsute.

Pubescent. Leaves oblong, glabrous above .. ... . 3. G. sinicum.

Hirsute. Leaves ovate or ovate-lanceolate, pubescent above : 4. G. eriocarpum.

Anthers 5 or more. Leaves coriaceous, mostly above 3 in.

Branches and leaves softly pubescent . ..... . . 5. G. molle.

Branches and leaves quite glabrous.

Capsule 4 lines diameter. Leaves 3 or 4 in. . . . . 6. G. littorale.

Capsule 6 lines diameter. Leaves 5 or 6 in. . . . . . 7. G. macrophyllum.

1. G. Wrightii, Benth., n. sp. A perfectly glabrous glaucous shrub, with slender branches. Leaves oblong, shortly acuminate, about $1 \frac{1}{2}$ in. long, very oblique at the base, on petioles of near 2 lines. Male flowers in small clusters, on pedicels of 1 to $1 \frac{1}{2}$ lines. Perianth-segments less than 1 line. Stamens 3. Female flower's 2 or 3 together, almost sessile. Perianth-segments $\frac{1}{4}$ line long in flower, $\frac{1}{2}$ line in fruit, the 3 inner smaller. Ovary 3 - 
celled. Styles erect, oblong and connivent. Capsules scarcely 3 lines diameter, very depressed in the centre.

Hongkong, Wright. Seen in no other collection. It resembles at first sight Fortune's n. 129, from continental China, but that has broader and more obtuse leaves, 5-merous ovaries, with a much longer style, etc.

2. G. philippinense, Benth. Branches and leaves quite glabrous or. rarely slightly pubescent when young. Leaves ovate-lanceolate or oblong, acuminate, 3 or 4 in. long, oblique at the base, on petioles of 2 or 3 lines. Male flowers nearly of $G$. Wrightii. Female flowers on pedicels of 1 to 2 lines. Ovary pubescent, 5 -celled. Styles thick, connivent in a short almost globular mass. Capsule about 4 lines diameter, pubescent, very much depressed in the centre.-Bradleia philippica, Cav. Ic. iv. 48, t. 371.

Hongkong, Wright. In the Philippine Islands (Cuming. n. 459).

3. G. sinicum, Hook, and Arn. Bot. Beech. 210. An erect muchbranched shrub, densely but shortly pubescent. Leaves oblong, obtuse or acute, $1 \frac{1}{2}$ or rarely $2 \mathrm{in}$. long, glaucous and glabrous above except on the midrib, pubescent underneath. Male flowers usually numerous, on pedicels of 2 to 4 lines. Perianth-segments full 1 line long, narrow, erect at the base and then spreading. Anthers 3. Female flowers clustered, the pedicels $\frac{1}{2}$ line long. Perianth small. Ovary tomentose, usually 5-celled. Styles forming a short thick annular disk. Capsule pubescent, 4 or 5 lines diameter.Bradleia sinica, Willd. Spec. iv. 591.

Hongkong, Hance, Wright. Also in the adjacent continent and neighbouring islands, but not known out of S. China.

4. G. eriocarpum, Champ. in Kew Journ. Bot. vi. 6. A shrub, the branches densely hirsute with short spreading often reddish hairs. Leaves ovate, ovate-lanceolate, or oblong-acuminate, $1 \frac{1}{2}$ to 2 or rarely 3 in. long, wrinkled and hirsute on both sides. Male flowers as in G. sinicum. Female flowers sessile and mostly solitary. Perianth small. Ovary usually 5-celled. Styles shortly oblong, erect and connivent. Capsule very depressed in the centre, hirsute.

In the Happy Valley woods, Champion. Common in ravines, Wilford; also Wright. Not known out of the island.

5. G. molle, Hook. and Arn. Bot. Beech. 210. Branches softly pubescent or hirsute. Leaves ovate, obtuse, or obtusely acuminate, usually above 3 in. long, coriaceous and pubescent on both sides or at length glabrous above. Flower-clusters or cymes often shortly pedunculate. Males manyflowered. Pedicels 3 to 5 lines long. Perianth 2 lines. Anthers 5 to 8 . Female flowers few, on thick pedicels of 1 line. Perianth-segments ovate, hairy, above 1 line long. Ovary usually 5-celled. Style a short thick annular disk. Capsule pubescent, slightly depressed, about 4 lines diameter.

In a ravine at the foot of Mount Gough, Wilford; also Hance and Wright. On the adjacent continent, but not known out of S. China.

6. G. littorale, Blume; Miq. Fl. Ned. Ind. i. part ii. 377. In the size and shape of the leaves, and in the structure of the flower and fruit, this resembles the G. molle so closely that Dr. Hance believes it to be only a variety of that species. It is however perfectly glabrous in every part; the male pe- 
rianth-segments appear to be broader, the female ones much shorter, and the style much more prominent. Capsule 4 lines diameter, usually 5- or 6-celled. Java.

Hongkong, Hance, Wright. In a ravine at the foot of Victoria Peak, Wilford. Also in

7. G. macrophyllum, Benth. in Lond. Journ. Bot. i. 491. Near G. lavigatum, but the capsules are full 6 lines diameter, 7- or 8-celled, with prominent angles, scarcely depressed on the top, and slightly pubescent. Branches stout, glabrous. Leaves oval-oblong, obtuse, 5 or 6 in. long, coriaceous and quite glabrous. Fruiting-clusters quite sessile. Flowers not seen.

Hongkong, Hinds. I have seen no other specimen, and the species must therefore remain at present doubtful. Some specimens from Assam have similar large fruits, but with differently shaped leaves.

\section{BUXUS, Linn.}

Flowers monœcious, in axillary clusters. Perianth calyx-like, of 4 small segments, imbricate in the bud. Male flowers: Stamens 4, opposite the segments, filaments free, anthers adnate. Female flowers: Ovary 3-celled, with 2 ovules in each cell. Styles 3 , distant at the base, undivided, but splitting with the capsule. Capsule coriaceous, loculicidally 3-valved, each valve bearing the dissepiment in the centre, and crowned by 2 horns, being the halves of 2 of the styles.-Evergreen shrubs ur trees, with opposite entire coriaceous leaves.

A small genus, ranging over the temperate or subtropical regions of the northern hemisphere, but confined to the Old World, unless the W. Indian Triceras be admitted as congeners.

1. B. sempervirens, Linn.; Baill. Bux. 59. A glabrous much-branched shrub or small tree. Leaves in the Hongkong variety narrow-oblong, obtuse or emarginate, and nearly 1 in. long, in other Chinese specimens obovate or ovate. Flowers small, sessile, usually several males and 1 female in each axil ; the small bracts and perianth-segments broadly ovate. Stamens much longer. Capsule ovoid, 3 or 4 lines long, 3 -horned till ripe, then 6 -horned by the split. ting of the valves. Seed shining black.-B. chinensis, Link; Baill. 1. c. 66 (from the diagnosis).

Near Taitamtuk, Hance and Harland. In Putoy island, Wright. Ranges over southern Europe and western Asia, and again in China and Japan, and if, as believed by Hooker and Thomson, the $B$. longifolia, Boiss., and $B$. Wallichiana, Baill., are forms of the same species it is also abundant in northern India.

\section{BISCHOFFIA, Blume.}

(Stylodiscus, Benn. Microelus, Arn.)

Flowers diœcious, in axillary panicles. Perianth small, calyx-like; segments 5 , valvate in the bud. Male flowers: Perianth-segments very concave, enclosing the stamens at first, afterwards reflexed. Stamens 5, opposite the segments, inserted round a raised central disk, filaments very short. Female flowers : Perianth-segments lanceolate. Ovary 3 -celled, with 2 ovules in each cell. Styles linear, entire. Fruit a globular drupe, enclosing 3 indehiscent cocci.Leaves alternate, compound.

The genus is limited to a single species. 
1. B. javanica, Blume; Miq. Fl. Ned. Ind. i. part ii. 363 . A large glabrous tree. Leaflets 3 (or rarely 5 ), petiolulate, from broadly ovate to oval oblong, coarsely crenate-serrate, 3 to 5 in. long, coriaceous when old, on a common petiole of 3 or 4 in. Male flowers crowded in broad panicles, muchbranched, but shorter than the leaves. Female panicles looser and less branched, sometimes reduced to simple racemes.-B. trifoliata, Hook. Ic. Pl. t. 844, with the synonyms adduced (Br. and Benn. Pl. Jav. Rar. t. 29; Dene. in Jacqemon. Voy. t. 154).

Hongkong, Harland, Wright; in a wood at Little Hongkong, Wilford. In the hilly districts of India, from the Peninsula to Nepal, Burmah, and the Archipelago, aud northward to the Philippines, S. China, and Loochoo.

\section{DAPHNIPHYLLUM, Blume.}

(Goughia, Wight.)

Flowers diceious, in axillary or lateral racemes. Perianth calyx-like, small, of 3 to 8 segments. Male flowers: Stamens 5 to 12. Anthers ovate, thick, on very short filaments radiating from a central disk. Female flowers: Ovary ovoid, incompletely 2 -celled, with 2 ovules in each cell. Styles united at the base, shortly recurved, undivided. Berry ovoid, indehiscent. Seed solitary. Embryo minute, in a thick fleshy albumen.-Trees or shrubs. Leaves alternate, on long petioles, entire, coriaceous.

A small tropical or subtropical Asiatic, chiefly eastern, genus.

Perianth not $\frac{1}{2}$ line long. Racemes axillary.

Styles spreading . . . . . . . . . . . . . . . 1. D. Roxburghii.

Perianth 1 line long. Racemes mostly lateral.

Styles erect

2. D. calycinum.

1. D. Roxburghii, Baill. Euph.565. A large glabrous tree. Specimens turning black in drying. Leaves oblong, obtuse, acute, or shortly acuminate, 3 or scarcely 4 in. long, very coriaceous, on petioles of 1 in. or rather more. Racemes usually all axillary, scarcely longer than the petioles. Perianth minute, not exceeding the filaments in the males, and not half so long as the ovary in the females. Styles short, spreading. Drupe ovoid-oblong, full $\frac{1}{2}$ in. long.-Goughia Nilgherrensis, Wight, Ic. t. 1879.

Hongkong, Champion, Wright. In Ceylon, the Nilgherries, Loochoo, Corea, and Japan.

2. D. calycinum, Benth., n. sp. A shrub. Leaves longer than in the last, usually 4 to 6 in., not so coriaceous, and seldom turning black. Racemes axillary in the very young state, but before they flower their leaves appear always to have fallen, leaving them below the leafy part of the branch. Bracts 1 to 2 lines long, but very deciduous. Perianth-segments nearly 1 line long in the males, and as long as the ovary in the females. Styles very short, thick, erect, and truncate. Drupe ovoid, 4 or 5 lines long.

Hongkong, Champion, Hance, Seemann; in woods, at Little Hongkong, Wilford. Also near Canton, Reeves.

\section{APOROSA, Blume.}

(Scepa, Lindl. Lepidostachys, Wall.)

Flowers diøcious, the males in catkins, the females in axillary clusters or short spikes. Perianth small, calyx-like, of 4 segments. Male flowers clustered 
under. small bracts. Stamens 2 to 5 ; filaments free; anther-cells distinct, globular. Female flowers: Ovary 2 -celled, with 2 ovules in each cell. Styles very shortly united, short, recurved, retuse, or 2-lobed. Drupes 2-celled, or more frequently 1-celled and 1-seeded by abortion. Cotyledons broad.Shrubs or trees. Leaves alternate, undivided, coriaceous; petioles usually short.

A small tropical Asiatic genus.

Female spikes very short, elustered, without anthers.

Female spikes cylindrical, $\frac{3}{4}$ in. long. Ovary surrounded by sterile anthers .

1. A. frutescens.

1. A. frutescens, Blume, Bijdr. 514. A shrub or tree, either wholly glabrous or the branches and young parts pubescent. Leaves oblong or ovateoblong, shortly acuminate, 3 to 5 in. long, entire or with a few broad teeth. Stipules very deciduous, 2 to 3 lines long. Male catkins solitary, or 2 to 4 together in the axils of the leaves, sessile or shortly pedunculate, $\frac{1}{2}$ to $1 \mathrm{in}$. long. Bracts broad, ciliate. Stamens 2 or 3 . Female spikes very short, usually 2 or 3 together and quite sessile. Ovary quite glabrous or very hairy. Drupe ovoid, 4 or 5 lines long. - Scepa chinensis, Benth. in Kew Journ. Bot. vi. 72 , and probably several other supposed species of Scepa.

Common in the islaud, Champion and others. Widely distributed over a great part of India and the Archipelago.

2. A. leptostachya, Benth., n. $s p$. $\Lambda$ shrub, the young parts rustypubescent. Leaves as in the last species, oblong, scarcely acuminate, entire or with a few callous teeth, 2 in. long (or perhaps more). Stipules obliquely ovate-lanceolate, 2 to 3 lines long. Male catkins 1 in. long; the flowers densely clustered. Stamens 2 to 4 . Female spikes cylindrical, nearly as long as the males. Flowers clustered. Perianth-segments 4 to 6 . Ovary contracted at the base and usually surrounded by 3 or 4 sessile apparently sterile anthers. Styles (or style-branches) short, recurved, retuse, but not 2-lobed.-Alnus, sp. ?, Benth. in Kew Journ. Bot. vi. 115.

Hongkong, Champion. Not seen in any other collection, but a second fragment among Champion's plants, with a female spike, has enabled me to ascertain that it belongs to Aporosa, although still insufficient to say whether it be really distinct or an abnormal state of A. frutescens.

\section{ANTIDESMA, Linn.}

Flowers diocious, the males in catkins; the females in racemes or spikes. Perianth small and calyx-like, of 3 to 5 segments or lobes. Male flowers: Stamens 2 to 5, filaments free. Female flowers: Ovary 1-celled, with 2 pendulous ovules. Styles 3 or 4, very short and divergent, united at the base. Fruit a drupe, usually somewhat flattened and oblique.-Trees or shrubs. Leaves alternate; entire.

A considerable genus, spread over the tropical and subtropical regions of the Old World.

Leaves glabrous, oblong or ovate-lauceolate. Female flowers pedunculate.

Leaves 4 or 5 in. long. Male catkins long and slénder . . . . J. A. Bunius.

Leaves 1 to 3 in. long. Male catkins not 1 in.. . . . . . 2. A.japonicum.

Leaves pubescent, obovate or orbieular. Female flowers sessile . . 3. A.paniculatum . 
1. A. Bunius, Spreng.; Tul. in Ann. Sc. Nat. Par. ser. 3, xv. 186 ; Wight, Ic. t. 819. A tree, usually quite glabrous, Leaves oblong, obtuse, acute, or shortly acuminate, 4 to 5 in. long, or sometimes more, somewhat coriaceous and shining, on petioles of 3 or 4 lines. Male spikes slender, interrupted, 4 to 6 in. long. Stamens usually 3 or 4 . Female raceme much shorter. Flowers nearly sessile. Fruits about 3 lines long, on pedicels of 1 to $1 \frac{1}{2}$ lines.

Hongkong, Champion. In the Philippines and the Indian Archipelago.

2. A. japonicum, Sieb. and Zucc. Fam. Nat. Fl. Jap. ii. 88. A shrub or small tree, glabrous, or the young parts very slightly pubescent. Leaves usually ovate-lanceolate or oblong, acuminate, sinuate, $1 \frac{1}{2}$ to $2 \mathrm{in}$. long, but sometimes short and ovate, or linear or narrow-oblong, and 3 in. long, rather thin, but shining, narrowed into a short petiole. Male spikes seldom 1 in. long, several together in the upper axils, or in a short terminal panicle. Stamens 3. Female racemes slender, solitary, about $1 \mathrm{in}$. long. Drupes small, on pedicels of about 1 line.

In the Happy Valley, Champion; in low grounds, Wilford; also Hance and Wright. In Japan.

2. A. paniculatum, Roxb., Tul. in Ann. Sc. Nat. Par.ser. 3, xv. 288 ; Wight, Ic. t. 820. A shrub or small tree, the young branches, leaves, and inflorescence softly pubescent or tomentose. Leaves obovate, broadly elliptical or nearly orbicular, very obtuse, $1 \frac{1}{2}$ to $2 \frac{1}{2}$ or rarely $3 \mathrm{in}$. long. Male spikes dense, 1 to 2 in long, females seldom 1 in., both in short terminal panicles and very tomentose. Stamens usually 5. Female flowers sessile. Ovaries very villous or glabrous. Drupes small, on short pedicels.

Near West Point, Champion. Widely diffused over the hilly districts of India, from Ceylon and the Peninsula to the Archipelago, and northward to the Philippines and S. China.

\section{ORDER XCV. JUGLANDEAE.}

Flowers unisexual. Male flowers in spikes or catkins. Perianth irregularly 2- to 6-cleft, adnate to entire or divided scale-like bracts. Stamens indefinite, sometimes very few. Female flowers solitary or in clusters or spikes. Perianth with a small superior 3- to 5-lobed border. Ovary inferior, l-celled (or 2- or 4-celled at the base), with 1 orthotropous ovule erect from the base of the cell, or from the summit of the axis of the partial cells. Fruit a 1-seeded drupe, with a hard endocarp. Albumen none.-Trees. Leaves pinnate.

A small Order, dispersed over the northern hemisphere, intermediate between Terebinthaces and Amentacea, and referred by some, as a suborder, to the one or to the other.

\section{ENGELHARDTIA, Lesch.}

Flowers monøcious, in unisexual or androgynous spikes. Male flowers: Perianth unequally 3- or 4-cleft, on a 3-lobed bract. Stamens 5 to $13 . \mathrm{Fe}-$ male flowers adhering to the base of a large 3- or 5-lobed bract. Perianth superior, of 4 or 5 teeth. Styles 2 to 4 , unequal. Drupe small, seated on the enlarged wing-like 3-lobed bract.

A small tropical Asiatic genus.

Of this genus I. have a single specimen from Champion, unfortuuately not in a sufficiently 
perfect state for identification as to species. It may possibly be a variety of $E$. Wallichiana, Lindl., a Silhet species, with glabrous leaves and fruits, but in our specimen the leaflets are more numerous and narrower, and the fruiting bracts smaller and thiner. The drupes have fallen away.

\section{Order XCVI. AMENTACE更.}

Flowers unisexual. Male flowers in catkins. Stamens 2 or more, either within 1 or 3 scales, or surrounded by several scales, sometimes forming a perianth of 5 or 6 segments. Female flowers either solitary, or 2 or 3 together within 1 or 3 scales, in catkins or heads, or surrounded by several empty scales. Perianth none, or closely combined with the ovary, with a minute, free, entire, or toothed border. Ovary 1-celled or several-celled, with 2 or more styles, always resulting in a l-celled fruit, which is either a l-seeded nut, or a several-seeded capsule opening in 2 valves. Seeds without albumen.Trees or shrubs. Leaves alternate, usually with stipules. Flowers small. Catkin-scales usually persistent under or round the fruit.

A considerable Order, widely distributed over the globe, but ehiefly in the temperate regions of both hemispheres, or in mountainous districts within the tropics.

Stamens 6 to 12, surrounded by an almost regular perianth of 5 or 6 scales. Female flowers in an involucre of many imbricate scales.

Nut completely enclosed in a very prickly involucre or opening in valves

Nut either surrounded by a cup-shaped involucre, or enclosed in an involucre not prickly and bursting irregularly . . . . . . . . Stamens 2 to 8 , within 1 or few scales. Female flowers 1 or 2 under each scale. Nut resinous or drupe-like . . . . . . . . 3. Mrrica.

\section{CASTANEA, Tcurn.}

Flowers and habit of Quercus. Fruiting involucre completely enclosing the nut, covered with stout, often branched prickles, and opening in valves when ripe.

A small genus, dispersed over eastern and central Asia, S. Europe, and N. W. America,

1. C. concinna, Champ. in Kew Journ. Bot. vi. 115 ; Seem. Bot. Her. t. 86. A tree, the young branches softly tomentose. Leaves stalked, oblonglanceolate, acuminate, about 3 in. long, quite entire, coriaceous, glabrous above, tomentose underneath, with prominent parallel veins. Male spikes rather lax, erect or spreading, $1 \frac{1}{2}$ to $3 \mathrm{in}$. long, solitary in the axils of the young leaves, but forming with them a terminal panicle. Stamens about 10. Female spikes shorter and solitary. Involucres 1-flowered. Styles 3, subulate, diverging. Fruiting involucre very densely crowded with stout clustered branching prickles. Nut depressed-globular, $\frac{1}{2}$ in. diameter.

In the Happy Valley woods, but rare, Champion; also Hance and Seemann. Not known from elsewhere.

\section{QUERCUS, Linn.}

Flowers monœcious or rarely diœcious. Male flowers: Perianth of 5 or 6 scales. Stamens 6 to 12 or rarely more, inserted round a hairy centre ; filaments slender. Female flowers solitary or 2 or 3 together, within an involucre of numerous small imbricated scales, sometimes united in a solid mass. Ovary 
3- rarely 4-celled, with 2 pendulous ovules in each cell. Styles (or stylebranches) as many as ovary-cells, entire. Nut 1-seeded, either protruding from a cup formed of the enlarged scales, or enclosed in the enlarged involucre, which is then not prickly, and bursts irregularly when ripe. Cotyledons thick and fleshy, entire or sometimes much corrugated, lobed, or crumpled.-Trees or shrubs. Leaves entire, toothed, or lobed. Male catkins slender and interrupted. Female involucres solitary, clustered or in spikes.

A large genus, confined to the northern hemisphere both in the New and the Old World, most abundant in temperate regions or in mountainons districts within the tropics.

SECT. 1. Castaneopsis.-Involucre entirely enclosing the young nut, sometimes splitting open when ripe. Spikes usually erect, paniculate, with a glabrous rachis.

Leaves 6 or $8 \mathrm{in}$. long, lepidote underneath . . . . . . . 1. G. fissa.

Leaves 2 to 4 in. long, green and glabrous on both sides . . . . 2. G. Eyrei.

SECT. 2. Gyrolecana.-Cup surrounding the nut, the scales forming entire concentric rings. Male spikes usually tomentose, slender, pendulous.

Leaves lanceolate, glabrons . . . . . . . . . . . 3. G. salicina.

I heaves obovate or oblong, obtuse, tomentose or lepidote underneath . . 4. G. Championi.

SECr. 3. Lepidobalanus.-Cup surrounding the nut, the scales imbricate, the tips more or less prominent or distinct. Male spikes (in the Hongkong species) tomentose, erect, paniculate.

Leaves glaucous or lepidote underneath. Young branches tomentose . 5. G. thalassica. Leaves green and glabrous on both sides. Branches glabrous.

Nut brown and shining, very prominent above the cup. Leaves entire. or scarcely sinuate.

Leaves usually oblong, 5 in. or more. Minor veins mostly transverse. Flowers (always ?) diœcious. . . . . . . .

Leaves rather broad, $4 \mathrm{in}$. or less. Minor veins much reticulate. Flowers monœeious.

Nut very broad, slightly convex on the top and scarcely prominent above the cup. Leaves slightly ciliate-toothed . . . . . . .

6. G. Harlandi.

7. G. Hancei.

8. G. cornea.

1. Q. fissa, Champ. in Kevo Journ. Bot. vi. 114; Seem. Bot. Her. t. 92. A tree, young branches tomentose. Leaves stalked, elliptical or oblong, shortly acuminate, 6 to 8 in. long, entire or slightly serrate, coriaceous, glabrous and shining above, glaucous, silvery, or yellowish underneath with a minute tomentum. Spikes erect, 4 to $6 \mathrm{in}$. long, in a terminal panicle; the males usually numerous, with 1 terminal female or androgynous one, and 1 or more female spikes solitary in the lower axils. Rachis glabrous. Stamens 10 to 12. Styles 3, very short. Involucre ovoid, 6 to 8 lines long, enclosing the nut when young, afterwards bursting irregularly, slightly tomentose outside, silky inside; the scales scarcely prominent and irregularly zoned. Nut ovoid. Cotyledons intricately crumpled.

In the Happy Valley woods, Champion, and at Little Hongkoug, Wilford; also Wright. Not known out of the island.

2. Q. Eyrei, Benth. in Kew Journ. Bot. vi. 114. A glabrous tree. Leaves stalked, ovate-lanceolate, long-acuminate, entire or with a few coarse serratures, 2 to 3 or rarely 4 in. long, coriaceous, shining, green and glabrous on both sides. Spikes $1 \frac{1}{2}$ to $2 \mathrm{in}$. long, the males numerous in a terminal panicle, the females simple and rather shorter, all quite glabrous except the disk of the male flowers. Stamens 10 to 12 . Styles 2 or 3, prominent, obtuse, spreading. 
Abundant in Wangnachung wood, on the east side of the Happy Valley, Champion, but not seen in any other collection. Although I have not seen the fruit, I have little doubt that this plant belongs to the section Castaneopsis. The inflorescence and flowers are precisely those of Q. cuspidata, Thunb., but in that species the leaves are always more or less glaucous or lepidote underneath. I know not on what grounds Seemann refers the Q. Eyrei to C'astanea chinensis, Spreng., with which it appears to me to have no connection in foliage, inflorescence, or flowers.

3. Q. salicina, Blume; Seem. Bot. Her. 415, t. 91. A tree of $40 \mathrm{ft}$., the very young shoots silky-hairy. Leaves nearly sessile, lanceolate or linearlanceolate, obtuse, entire or rarely slightly toothed, 2 to $3 \mathrm{in}$. long and seldom $\frac{1}{2}$ in. wide, glabrous and green on both sides. Male spikes axillary, very slender and pendulous, 1 to $1 \frac{1}{2}$ in. long, more or less rusty-tomentose. Stamens 6 to 8 . Female spikes short and erect. Styles 3 or 4, very short, divergent, with broad almost peltate stigmas. Fruiting involucre cup-shaped, 7 or 8 lines diameter, tomentose, with 5 or 6 concentric entire zones outside, velvety inside. Nut half-exserted, broadly ovoid, slightly tomentose. Cotyledons entire.

In the Happy Valley woods, Champion, Hance, Seemann, Wright. Not seen from elsewhere.

4. Q. Championi, Benth. in Kew Journ. Bot. vi. 113 ; Seem. Bot. Her. $t .90$. A tree, with more or less of a brown, scurfy tomentum on the young branches, under side of the leaves, and inflorescence. Leaves stalked, obovate or oblong, obtuse, entire, 3 or 4 in. long, glabrous above when full-grown. Male spikes clustered at the base of the young shoots, or solitary in the axils of the nascent leaves, 2 or $3 \mathrm{in}$. long, pendulous when fully out. Stamens 6 to 8. Anthers hirsute. Female spikes short and erect. Styles 3, short, with broad stigmas. Fruiting involucre cup-shaped, tomentose outside, with 3 to 5 concentric zones, silky inside.

In the Happy Valley woods, on Victoria Peak, etc., Champion and others. Not known out of the island.

5. Q. thalassica, Hance in Kew Journ. Bot. i. 176 (1849). A tree of 20 to $30 \mathrm{ft}$. or more, the young branches tomentose. Leaves stalked, from narrow-oblong to ovate-elliptical, acuminate, 3 to $5 \mathrm{in}$. long, entire or irregularly toothed towards the top, glabrous and shining above, glaucous or lepidote underneath, the primary veins alone-prominent. Spikes stiff, erect, tomentose, $1 \frac{1}{2}$ to 4 in. long, simple, and nearly solitary, or the males paniculate. Stamens about 8. Fruiting spikes about 4 in. long, the fruits clustered in the upper half. Cups short, 4 or 5 lines diameter. Nut ovoid, glabrous and shining, about $\frac{1}{2}$ in. long.-Q. reversa, Lindl. ? (1850); Benth. in Kew Journ. Bot. vi. 112 ; Seem. Bot. Her. t. 88. Q. Sieboldiana, Blum. Mus. Bot. 290.

In the Happy Valley woods, Champion, Hance, Seemann. On the Chinese continent and in Japan. Hance's specimens agree perfectly with the Japanese ones distributed as Q. acuta, and referred to by Blume under his $Q$. Sieboldiana. Champion's have the leaves more acuminate and whiter underneath, and the spikes shorter and more dense. Lindley's plant differs slightly in the obovoid acorns which suggested his name, but all these are probably forms of one species. 'The Khasia plant referred here by Seemann differs in several respects, and especially in the much more prominent seales of the acorn-cups, which are almost muricate.

6. Q. Harlandi, Hance in Walp. Ann. iii. 382 ; Seem. Bot. Her. t. 89. 
A tree of about $20 \mathrm{ft}$., glabrous, except the inflorescence. Leaves long-stalked, oblong, or elliptical, obtusely acuminate, 4 or 5 in. long, or in some specimens 6 to 8 in., entire or slightly undulate, green and glabrous on both sides, the primary veins prominent underneath, with very fine transverse reticulations. Flowers apparently diœecious. Male spikes solitary in the upper axils, 1 to $1 \frac{1}{2}$ in. long, erect, tomentose. Stamens about 10. Female spikes terminal, rigid, flexuose, 2 to $3 \mathrm{in}$. long. Styles 3 to 5 , stiffly subulate, divergent. Fruit-cups hemispherical, about 8 lines diameter, the scales very obtuse and not prominent. Nut much exserted, about 1 in. long and 11 lines broad, brown and shining, marked when dry with longitudinal tissures.

In the Happy Valley woods, Hance, Champion, Seemann, Wright. Not known from elsewhere.

7. Q. Hancei, Benth., n. $s p$. A tree?, glabrous like the last; the flowering branches short and stout. Leaves long-stalked, obovate or oblong, acuminate, 3 or 4 in. long, quite entire, green and shining on both sides as in Q. Harlandi, but more coriaceous; the primary veins less prominent, but the minor ones much more reticulate. Spikes tomentose, paniculate, erect, and stiff either all males, and 2 or $3 \mathrm{in}$. long, or the terminal one or nearly all female or androgynous and 3 to 6 in. long. Stamens 10 to 12. Styles usually 3 , stiff and divergent. Fruit not seen.

On Victoria Peak, Champion, in a ravine of Mount Gough, Wilford; also Hance and Wright. Not known from elsewhere.

8. Q. cornea, Lour.; Seem. Bot. Her. 413, t. 87. A tree, the young shoots tomentose. Leaves stalked, oblong, acuminate, usually 2 or 3 in., but sometimes 4 or 5 in. long, slightly ciliate-toothed below the point, green and glabrous on both sides when full-grown, the primary veins very prominent, the minor ones transverse. Spikes mostly androgynous, terminal, erect, stout, 1 to $1 \frac{1}{2}$ in. long, tomentose. Stamens 10 to 12 . Styles 3, diverging, almost acute. Cup broadly turbinate, tomentose, more than 1 in. diameter, muricate with the shortly prominent scales, the upper ones turned inwards round the acorn. Nut hemispherical and glabrous in the enclosed part, the exserted flat top slightly convex and tomentose. Cotyledons lobed and furrowed.Synadrys ossea, Lindl. Introd. Nat. Syst. ed. ii. 441.

Hongkong, Champion, Hance, Wright. Also S. China. This species furnishes the edible acom known in China, according to Seemann; under the names of Shi-Li or King-Li.

\section{MYRICA, Linn.}

Flowers diœcious or rarely monœcious. Male flowers in simple or branched catkins. Perianth none. Stamens 2 to 8 within each primary scale, often with 2 or more secondary scales under them or between the lower ones. $\mathrm{Fe}$ male flowers in short catkins or spikes, 1 or 2 within each scale. Perianth adhering to the base of the ovary, with 2 or more projecting lobes. Ovary 1-celled, with 1 ovule ascending from the base. Styles or stigmas 2, linear. Fruit a resinous nut or drupe. Seed erect, without albumen.-Shrubs or small trees. Leaves alternate, usually resinous-dotted.

A genus of several species, dispersed over the temperate regions of the globe, or the great mountain ranges within the tropics.

1. M. rubra, Sieb. and Zucc. Fam. Nat. Fl. Jap. ii. 106. A shrub or tree. 
Leaves evergreen, obovate-oblong, mostly obtuse, 2 to 3 in. long, entire or very rarely slightly toothed at the top, coriaceous and glabrous. Male catkins about 1 in. long, solitary or clustered, not divided; but within the lower scales are often 2,3 , or more lateral ones, sometimes with 1 or 2 stamens in their axils, showing a tendency in the catkin to ramify. (Drupes globular, densely covered with resinous dots.)

Hongkong, Champion. On the Chinese continent, in Loochoo and Japan. It is very near also to the common Indian $M$. sapida, Wall, ; but has much more obtuse leaves, and the catkins apparently never panienlately branched as in that species.

\section{ORDER XCVII. URTICEAE.}

Flowers unisexual or rarely polygamous, usually in cymes or heads, not in catkins. Perianth calyx-like, of 1 to 5 divisions. Stamens as many as perianth-segments, and opposite to them, rarely reduced to fewer or one. Anthers 2-celled. Ovary free, or rarely adherent, 1 -celled, with 1 ovule, rarely 2 -celled, with 2 ovules, of which 1 only comes to perfection. Style usually short or none, with 1 or 2 long or short stigmas. Fruit a 1-seeded indehiscent drupe, or winged samara, or small seed-like nut. Albumen fleshy or none. Radicle superior.-Trees, shrubs, herbs, or climbers, furnished with stipules. Foliage and inflorescence very various. A scabrous surface and a milky juice or acrid or stinging secretions are very common.

A large Order, distributed over nearly the whole world, abundant within the tropics, less so in temperate regions, and rare in cold climates.

Styles or stigmas 2, equal. Trees or shrubs. Flowers cymose, polyga. mous or dicecions. Filaments nearly erect in the bud.

Flowers polygamous, the fertile ones hermaphrodite.

Stamens not exceeding the perianth. Stigmas linear - . . . 1. CEstis.

Stamens exserted. Stigmas short, plumose . . . . . 2. 2. SponiA.

Flowers diœecious. Stigmas subulate $\ldots \ldots$ 3. GrRonNiera.

Style or stigma simple, unilateral, or rarely with a second shorter branch.

Flowers minute, very closely packed on or inside a succulent receptacle. Trees or shrubs.

Flowers outside a globular or oblong receptacle

Flowers inside a hollow, globular, ovoid or pear-shaped receptacle.

Flowers distinct, in cymes, clusters, heads, or spikes. (Herbs or undershrubs.)

Female perianth 4- or 5-cleft. Stigma short, tufted .

Female perianth tubular, enclosing or adhering to the ovary and fruit. Stigma filiform. Perianth enclosing the fruit.

Clusters of flowers in axillary panicles. Stigma persistent

Clusters of flowers single and sessile. Stigma deeiduous.

Male perianth surrounded by a prominent ring. Leaves 3nerved to the top .

Male perianth without appendages. Leaves 3-nerved at the

base only

Stigma disk-shaped. Perianth adnate

4. Artocarpus.

5. Ficus.

\section{Pellionia.}

7. Behmeria,

9. Memortalis,

\section{CELTIS, Linn.}

Flowers polygamous, in axillary or lateral cymes. Perianth deciduous, of 4 or 5 segments, imbricate in the bud. Stamens as many, incurved, shorter 
than the perianth. Ovary inserted on a hairy disk. Stigmas 2, oblong or linear, recurved, not plumose. Drupe ovoid or globose. Cotyledons folded.Trees or shrubs. Leaves alternate, usually 3-nerved. Cymes usually loose and few-flowered.

A considerable genus, dispersed over the temperate and subtropical regions of the New and the Old World, with a few tropical species limited to mountainous districts.

Leaves serrate in the upper half. Stigmas linear, acute . . . . . 1. C. sinensis.

Leaves quite entire. Stigmas rather thick, obtuse or notched . . 2. C. philippensis.

1. C. sinensis, Pers.; Planch. in Ann. Sc. Nat. Par. ser. 3, x. 256. A large tree, with slender much divided branches. Leaves obliquely ovate, acuminate, $1 \frac{1}{2}$ to $2 \mathrm{in}$. long, serrate in the upper half, glabrous or with a minute rusty pubescence underneath. Flowers in little almost sessile cymes on the nascent branches, those at the base all males, the axillary ones mostly hermaphrodite. Stigmas linear, entire. Fruits usually solitary, on axillary pedicels shorter than the petioles in these and some Japanese specimens, much longer in other Japanese and N. Chinese specimens.-C. Willdenowiana, Roem. and Schult.; Planch. 1. c. 287 ?

About Victoria, but perhaps only where planted for shade, Hance, Wilford, Harland. A. native of China and Japan.

2. C. philippensis, Blanco; Planch. in Ann. Sc. Nat. Par. ser. 3, x. 306. A tree, either quite glabrous or the young shoots and inflorescence slightly pubescent. Leaves ovate or oval-oblong, acuminate, quite entire, 2 to 3 in. long, 3-nerved, smooth and somewhat shining above, pale underneath, on petioles of 2 or 3 lines. Fruits 2 to 5 , in loose irregular racemes of about 1 in., on pedicels of very unequal length, nearly globular, about 3 lines diameter. Styles linear, thick, apparently obtuse.

In the Happy Valley woods, Wilford, Hance. Common in the Philippine Islands. The leaves in the Hongkong specimens are not so large nor so coriaceous as in Cuming's, deseribed by Planchon, but the old ones are already fallen off.

\section{SPONIA, Lam.}

Flowers polygamous, in axillary cymes. Perianth persistent, of 5 segments, nearly valvate in the bud. Stamens longer than the perianth. Stigmas 2, short and plumose, the other characters as in Celtis.- Trees. Leaves alternate. Flowers small, usually numerous.

A considerable genus, dispersed over the tropical regions of the New and the Old World.

1. S. velutina, Planch. in Ann. Sc. Nat. Par. ser. 3, x. 327; Wight, Ic.t. 1990. A tree, the young branches densely and softly pubescent. Leaves ovate-oblong, long-acuminate, serrate, obliquely cordate at the base, 3 to 4 in. long, very rough above, very soft underneath with silky hairs, silvery when young, velvety when full-grown. Cvmes broad, usually rather longer than the petioles, many-flowered. Drupes scarcely $1 \frac{1}{2}$ lines long, either glabrous or very hairy. - S. argentea, Benth. in Kew Journ. Bot. vi. 75 .

On the edges of woods, Hinds, Champion, and others. Common in India, from the Peninsula to the Archipelago, and northward to Sikkim, S. China, and the Philippines.

\section{GIRONNIERA, Gaud.}

(Helminthospermum, Thwaites.)

Flowers small, diœcious, in axillary cymes or branched racemes. Perianth 
of 4 or 5 segments, imbricate in the bud. Stamens 4 or 5 . Filaments slightly incurved. Ovary with 1 pendulous ovule. Styles 2, long and filiform. Drupe slightly compressed.-Trees or shrubs. Leaves alternate.

A small tropical Asiatic genus, extending from E. Africa to N. Australia.

Young branches hairy. Leaves scabrous and prominently reticulate underneath

1. G. chinensis.

Branches and leaves quite glabrous. Leaves not reticulate . . . . . 2. G. nitida.

1. G. chinensis, Benth., n. $s p$. A shrub of 3 to $8 \mathrm{ft}$., with a few long hairs on the young branches, petioles, and midribs of the young leaves. Leaves from ovate to oblong, shortly acuminate, serrate towards the top or nearly entirie, 4 to 6 in. long, narrowed or rounded at the base, glabrous above, scabrous underneath. Male cymes loose, longer than the petioles, with few very divaricate branches. Perianth-segments $\tilde{5}$, broad, glabrous or strigose, and thickened in the middle. Anthers tipped with a short conical connectivum. Female fruiting peduncles $\frac{1}{2}$ to 1 in. long, solitary or 2 together, and very diverging, bearing each 1 to 5 nearly sessile fruits in a perianth of 5 segments.

Hongkong, Champion, Harland, Hance; in a ravine of Mount Gough, Wilford. Not knowu from elsewhere. It is near to G. nervosa, Planch., from Java, and to G. subaqualis, Planch. (Helminthospermum scabridum, Thw.), from Java and Ceylon, but has not the soft hairs of the former, and differs from both in the female periauth as well as the male being constantly 5-merous.

2. G.? nitida, Benth., n. sp. A tree, the whole specimens perfectly glabrous. Leaves on very short petioles, ovate, shortly acuminate, entire, about $3 \mathrm{in}$.long, rounded or cordate at the base, coriaceous, smooth and shining, with the primary veins only prominent underneath. Male flowers in short sessile divaricately branched cymes, quite glabrous. Perianth-segments 5. Filaments short, inflected at the top as in other Gironnieras, inserted round a hairy rudiment. Anthers without any prominent connectivum.

Hongkong, rare, Champion. Not seen in any other collection, and our specimens are all male. The flowers are, however, so exactly those of a Gironniera, that I have little hesitation in placing the species in this genus.

\section{ARTOCARPUS, Linn.}

Flowers monøcious, minute, densely packed on the outside of a globose or oblong succulent receptacle, the males and females in separate heads. Male flowers: Perianth of 2 to 4 segments, imbricate in the bud. Stamens 1 . Female flowers: Perianth tubular, entire. Style usually simple and linear, protruding from the perianth. Ovary usually 1 -celled, with 1 pendulous ovule. Fruit compound, consisting of the somewhat enlarged persistent and consolidated perianths, each enclosing a minute nut. Seeds without albumen.-Trees or shrubs, with milky juice. Leaves alternate, entire or divided. Flower-heads axillary, solitary or 2 together.

A small genus of several species, dispersed over tropical Asia or the Pacific islands.

1. A. hypargyrea, Hance, n. sp. A tree, the young branches and petioles rusty with a minute pubescence. Leaves oblong, narrow-acuminate, 3 to 5 in. long, entire or slightly sinuate-toothed, glabrous and shining above, rough with a minute white tomentum underneath; the primary veins and numerous reticulations raised and pubescent. Flower-heads obovoid, solitary, 
on tomentose peduncles of 6 to 8 lines. Male heads 6 to 8 lines long. Perianthsegments linear-spatliulate, plumose-hairy, so densely crowded with the clavate or subpeltate bracts that it is difficult to distinguish those belonging to each flower. Female flower-heads rather smaller. Perianths densely hairy. Styles shortly protruding.

Hongkong, Hance. Not seen in auy other collection. It is very uear to the A. glaucescens, Tréc., from Java; but that has not the same prominent veins on the uuder side of the leaves, and the flower-heads are much smaller and ncarly sessile.

\section{FICUS, Linn.}

Flowers unisexual, minute, enclosed in a hollow globular ovoid or pearshaped succulent receptacle called a fig or synocium; the minute aperture closed by bracts turned inwards. Male flowers usually near the mouth of the fig: Perianth 3 - to 6 -lobed. Stamens usually 1 or $\dot{2}$, rarely more. Female flowers usually lining the greater part of the cavity. Perianth entire, or of 2 or more lobes or segments. Ovary 1-celled, with ] pendulous or laterally attached ovule. Style usually lateral, with a more or less oblique, variously shaped stigma. Fruiting fig usually enlarged, the enclosed seed-like nuts surrounded each by its membranous or pulpy persistent perianth. Embryo curved, in a fleshy albumen.-Trees or shrubs, with the juice usually milky. Leaves alternate, or very rarely opposite, entire or divided. Figs (receptacles) solitary, or in clusters of 2 or more, axillary or on the old wood below the leaves, usually with 3 small bracts at their base, or at the base of the pedicel.

A very large tropical or subtropical genus, ranging over both the New and the Old World, but most abundant in Asia.

Figs axillary, solitary or 2 or 3 together.

Leaves and figs glabrous.

Figs sessile.

Petioles 1 to 2 in. long . . . . . . . . . . . . 1. F. Wightiana.

Petioles under $\frac{1}{2}$ in. long . . . . . . . . . 2. F. retusa

Figs pedunculate.

Bracts none, or only at the base of the peduncle.

Leaves entire, abruptly acuminate . . . . . . 4. F. nervosa.

Leaves irregularly angular or dentate towards the top . . 3. F. difformis.

Bracts at or near the top of the peduncle.

Erect shrubs.

Leaves (pale-green) coriaceous and very shining; the transverse veins very prominent

Leaves green above, glaucous underneath; the transverse veins not prominent.

Fig pear-shaped, 1 in. long or more . . . . . . 6. F. pyriformis.

Fig glcbular, $\frac{1}{2}$ in. long or less . . . . . . . . . variolosa.

Stems prostrate or creeping.

Leaves rounded at the base. Figs small, globular . 8. F. impressa.

Leaves unequally cordate at the base. "Figs large, pearshaped

Leaves and figs pubescent or hispid.

5. T. Championi.

Leaves glabrous above, very reticulate underneath. Figs almost sessile. (Stem prostrate ?) . . . . . . 10. F. Wrightii.

Leaves pubeseent on both sides, soft. Figs pedunculate . . 11. F. Beecheyana.

Leaves and scssile figs very hispid or bristly . . . . . 12. F. hirta. 
Figs 2 or more, in elusters on the old wood below the leaves.

Figs sessile or nearly so. Stigma subulate. Leaves oblong, longstalked, glabrous

Figs pedunculate. Stigma peltate, concave. (Covellia.)

Figs hispid. Leaves all or mostly opposite . . . . . . . 13. F. hispida.

Figs glabrous. Leaves all or mostly alternate.

Leaves with a short obt ise point, not cordate at the base.

Branches strigose . . . . . . . . . . . 14. F. Harlandi.

Leaves mostly cordate, tapering to a point at the top. Branches glabrous

\section{F. Wightiana.}

15. F. chlorocarpa.

1. F. Wightiana, Wall. Catal. n. 4540. A large tree, quite glabrous. Leaves oblong, shortly acuminate, about $4 \mathrm{in}$. long and $1 \frac{1}{2}$ to $2 \mathrm{in}$. broad, rather stiff; the primary veins arcuate and confluent at some distance from the edge, 3 -nerved at the base, on petioles from $1 \frac{1}{4}$ to 2 in. long. Figs nearly globular, about 4 lines diameter, on peduncles of about 1 line, solitary or in clusters of 2 to 4 on the old wood below the leaves, with very small bracts under the fig.--Urostigma Wightianum, Miq. in Lond. Journ. Bot. vi. 566.

Hongkong, Hance, Wright; at Little Hongkong, Wilford. This agrees well with indifferent specimens we have of $F$. Wightiana from the Indian Peninsula, and it appears to have been found also here and there in other parts of India. It may be a variety only of the common Indian $F$. infectoria, Roxb., which has the same foliage, but the figs are all axillary and closely sessile.

2. F. retusa, Linn. Mant. 129. A large tree, quite glabrous. Leaves from broadly obovate or nearly orbicular to obovate-oblong, obtuse or obtusely acuminate, $1 \frac{1}{2}$ to $2 \frac{1}{2}$ in. long, 3 -nerved at the base; the primary veins rather numerous, oblique, and joining in a continuous vein near the margin. Petioles stout, 2 to 4 lines long. Figs globular, about 4 lines diameter, closely sessile, solitary or in pairs in the axils of the leaves; the subtending bracts rather large.-F. nitida, Thunb.; Wight, Ic. t. 642. Urostigma pisiferum, U. ovoideum, U. nitidum, and U. retusum, Miq. in Lond. Journ. Bot. vi. 580,581 , and 582 .

Hongkong, Champion, Wright; on roadsides and near habitations, perhaps cultivated, Seemann, Hance. Dispersed over India, from Ceylon and the Peninsula to the Archipelago, and northward to the Himalaya, Assam, and Sikkim, and common in China.

3. F. difformis, Lam. Dict. ii. 500? Branches glabrous. Leaves obovate-oblong, more or less oblique, acuminate or obtuse, usually irregularly sinuate or angular, about $4 \mathrm{in}$. long, narrowed and 3 -nerved at the base; the lateral nerves short and almost marginal; the primary veins few, arcuate, glabrous and almost shining, but rough to the touch. Petioles 2 to 3 lines. Figs axillary, globular, 4 or 5 lines diameter, on a pedicel of 2 or 3 lines, with small bracts at its base.

Hongkong, Wright. Also in the Philippine Islands if this be really Lamarck's plant. The specimen is insufficient to deseribe the flowers.

4. F. nervosa, Roth, Nov. Pl. Sp. 388. A large glabrous shrub or tree. Leaves oblong, acuminate, 4 or 5 in. long, smooth and shining above; the primary arcuate veins very prominent underneath, slightly 3-nerved at the base, on petioles of 3 to 6 or 8 lines. Figs axillary, solitary or in pairs, turbinate-globular, 4 or 5 lines diameter, on peduncles of 3 to 5 lines. Bracts none, or very minute at the base of the peduncles. $-F$. angustifolia, Roxb. ; Wight, 1c. t. 660. Urostigma nervosum, Miq. in Lond. Journ. Bot. vi. 585, 
In the Happy Valley woods, Champion; also Hance and Wright. In Silhet and Assam, and perhaps in the Indian Peninsula.

5. F. Championi, Benth. in Kew Journ. Bot. vi. 76. A tree, perfectly glabrous, the foliage of a pale-green. Leaves elliptical or obovate-oblong, obtuse or obtusely acuminate, 2 to 3 in. long, narrowed towards the base, on petioles of 3 or 4 lines, coriaceous, smooth and shining; the primary veins nearly transverse, connected within the margin, prominent on both sides, especially underneath, as well as the smaller ones. Figs globular, 5 or 6 lines diameter, on rather slender pedicels of 4 to 6 lines, with 3 minute bracts about 1 line below the top.

In woods of the Happy Valley, Champion; also Wright. Not known out of the island, but very near to the F. vasculosa, Wall., from Penang and the Malayan Peninsula.

6. F. pyriformis, Hook. and Arn. Bot. Beech. 216 (not of Miq.). A shrub, the young branches pubescent. Leaves from oblong-lanceolate to narrow-lanceolate, 2 to 4 in. long, with an obtuse narrow point, quite glabrous, pale or whitish underneath; the primary veins transverse, connected very near the margin, and, as well as the reticulate veins, darker-coloured but not prominent. Petioles 1 to 2 lines, glabrous. Figs pear-shaped, 1 in. long or even more when full-grown, much contracted at the base. Peduncles 3 to 4 lines long, bracteate near the top.-F . Millettii, Miq. in Lond. Journ. Bot. vii. 438.

Common in watercourses, Champion and others. On the Chinese continent, and a longleaved variety or closely allied species in Assam and Sikkim. Two distinct Chinese species had been laid down in the Ilookerian Herbarium as the F.pyriformis; but Miquel, in separating them, had unfortunately omitted to compare them with the character given in the Botany of Becchey's Voyage, and has given Hooker and Arnott's name to the hairy-leaved instead of to the glabrous one.

7. F. variolosa, Lindl.; Benth. in Lond. Journ. Bot. i. 492. A glabrous shrub (or tree?). Leaves oblong or elliptical, obtuse or shortly and obtusely acuminate, 2 to $3 \mathrm{in}$. long, with the venation of $F$. pyriformis. Petiole 3 to 5 lines long. Fruit nearly globular, 4 or 5 lines diameter (ovoid when young), more or less umbonate at the top. Pedicel about 2 lines, bracteate at the top. Stigma obliquely truncate or notched.

Common in ravines, Hinds, Champion, and others. Not known out of S. China.

8. F. impressa, Champ. in Kew Journ. Bot. vi. 76. A prostrate or creeping much branched shrub, glabrous, except a slight pubescence on the young branches. Leaves distichous, oblong or elliptical, obtuse, entire, 1 to $1 \frac{1}{2}$ or rarely 2 in. long, stiff but not scabrous, 3 -nerved with short lateral nerves, and rounded at the base, the primary veins arcuate and prominent underneath. Figs globular, 3 or 4 lines diameter, on pedicels of 1 or 2 lines, bracteate at the top. Style short, with a dilated unilateral stigma.

In ravines, creeping over rocks, Champion, Wright, Wilford. Not known out of the island.

9. F. stipulata, Thunb.; Miq. in Lond. Journ. Bot. vii. 439? A prostrate or creeping shrub like the last, with similar leaves, except that they are deeply cordate at the base, either very unequally or nearly equally so. Fruits said to be large, pear-shaped or turbinate, bristly when young, then glabrous.

Hougkong, Champion? A single barren specimen, is like the equally barren ones in the Hookerian Herbarium, from S. China, determined by Miquel to be the F. stipulata, 'Thunb. 
Whether they be really that species, or only barren shoots of $F$.impressa, can only be determined when the plant shall have been seen in fruit.

10. F. Wrightii, Benth., n. sp. Branches (climbing or prostrate?) emitting clusters of fibres, and pubescent when young. Leaves oval-oblong, acuminate, entire, 3 to 4 in. long, cuneate and 3 -nerved at the base, the lateral nerves short and nearly marginal, the primary veins arcuate towards the margin, and very prominent underneath, as well as the reticulate smaller ones, glabrous and smooth above, pubescent but scarcely scabrous underneath, on petioles of 3 to 5 lines. Figs small (not yet full-grown?), axillary, globose, slightly pubescent, on petioles of I line, bracteate at the top. Female flowers shortly stipitate. Perianth-segments brown. Stigma long and subulate.

Hongkong, Wright. This much resembles the F. foveolata, Wall. (Pogonotrophe, Miq.), but the characters are those of a Urostigma.

11. F. Beecheyana, Hook. and Arn. Bot. Beech. 271; Miq. in Lond. Journ. Bot. vii. 437. Branches pubescent. Leaves from broadly ovate or obovate to oblong, always acuminate, 3 to $5 \mathrm{in}$. long, more or less cordate, and 3 -nerved at the base, on a petiole of $\frac{1}{2}$ to 1 in., scabrous, hirsute above, or nearly glabrous when old, softly pubescent underneath; the primary veins few and arcuate. Figs pubescent, nearly globular, 7 or 8 lines diameter, on pedicels of 4 or 5 lines, bracteate at the top.

Hongkong, Harland, Hance, Wright. Also Loochoo and Formosa.

i2. F. hirta, Vahl, Enum. ii. 201; Miq. in Lond. Journ. Bot. vii. 456. A tall shrub, the branches, petioles, and figs hirsute with stiff hairs or bristles, often of a rusty or yellowish colour. Leaves very variable in shape, usually 5 to 8 in. long, serrate-crenate, not coriaceous, but green and scabrous on both sides, hirsute on the principal veins, either entire from oblong-lanceolate to broadly oblong-cordate, or shortly 3-lobed, or deeply 3- or 5-lobed, with long lanceolate lobes, on the side branches often small and narrow. Figs globular, from 4 or 5 lines diameter to twice that size, sessile or on very short pedicels, bracteate at the top. - F . hibiscifolia, Champ. in Kew. Journ. Bot. vi. 77.

Common in ravines, Champion and others. In S. China and the Archipelago, and perhaps in Assam and Silhet, but there generally replaced by the closely allied broad-leaved (species or variety ?) F. Roxburghii, Miq.

13. F. hispida, Linn. fil. Suppl. 442. A small tree, the young branches hispid. Leaves mostly opposite, stalked, from ovate or obovate to oblong, shortly acuminate, 5 or 6 in. long, crenate-serrate, very rough on both sides with short stiff hairs. Figs mostly on the old wood, 2 or 3 together on old spurs, which grow out into leafless branches of 1 to 2 in., nearly globose, full $\frac{3}{4}$ in. diameter, shortly but densely hirsute, on short peduncles, bracteate at the top. Female perianth truncate, nearly as long as the ovary, but so thin and transparent that it is easily overlooked. Style short, with a concave peltate stigma.-F. oppositifolia, Roxb. Pl. Corom. t. 124; Wight, Ic. t. $638 . \mathrm{Co}$ vellia oppositifolia, Gasp.; Miq. in Lond. Journ. Bot. vii. 461, and C. hispida, Miq. 1.c. 462.

Hongkong, Harland. Common in northern and eastern India, extending to the Arehipelago and to S. China. I can see no difference in the Javanese specimens named by Miquel C. hispida, and if the two species are identical, the younger Linnecus's name is several years 
older than Roxburgh's, though not so appropriate, the plant being much less hispid than the F. hirta. This and the two following species belong to Covellia, the most marked among the genera proposed by Gasparrini and Miquel for the dismemberment of Ficus, but which it seems much better to consider as sections only, of one most natural and well-characterized genus.

14. F. Farlandi, Benth., n. sp. Branches glabrous or slightly strigose. Stipules $\frac{8}{4}$ in. long, glabrous. Leaves alternate or rarely opposite, oval-oblong or obovate-oblong, shortly acuminate, 4 to 7 in. long, entire or slightly sinuate-toothed, rounded at the base, glabrous or minutely punctate-scabrous, on petioles of $\frac{1}{2}$ to 1 in. Figs on the old wood as in F. hispida, globular, glabrous, about $\frac{1}{2}$ in. diameter, very shortly contracted at the base, on pedicels of 4 to 12 lines, bracteate at the top. Flowers of $F$. hispida, except that the style is rather longer.

Hongkong, Wright, Harland. Not known out of the island. Allied to the N. Indian $P$. congesta, but differs in inflorescence, the shape of the fig, and the longer style.

15. F. chlorocarpa, Benth., n. sp. A large tree, entirely glabrous. Stipules 3 to 4 lines long. Leaves from ovate-cordate or ovate-lanceolate to oval-oblong, acuminate, 5 to 8 in. long, entire, cordate or rarely rounded at the base, smooth and shining above, slightly punctate-scabrous underneath, on petioles of 1 to $2 \mathrm{in}$. Figs in short clusters on the trunk and old branches, globular, at least $\frac{3}{4}$ in. diameter, glabrous and light-green, on pedicels of about $\frac{1}{2}$ in., bracteate a little below the top. Flowers of $F$. hispida.

Hongkong, Champion, Wilford. Not known out of the island.

\section{PELLIONIA, Gaud.}

Flowers diøecious, in axillary cymes or clusters, without any dilated or succulent receptacle. Male flowers : Perianth-segments 5 or sometimes 4, broad, imbricate in the bud. Stamens as many, the filaments inflected in the bud. Female flowers: Perianth-segments 4 or 5, narrow and unequal. Sterile stamens usually as many. Ovary 1-celled, with 1 erect ovule. Stigma sessile, small, tufted. Nut seed-like, surrounded by the persistent perianth. Albumen little or none.-Herbs. Leaves distichous, alternate or unequally opposite, usually very oblique.

A small tropical Asiatic genus.

Leaves obtuse, less than $1 \mathrm{in}$. long. Sterile stamens in the female flowers lanceolate, inflexed. . $\cdot 0^{\circ} \cdot 0^{\circ} \cdot 0^{\circ} \cdot$ Leaves mostly acuminate, $1 \frac{1}{2}$ to $3 \mathrm{in}$. long. Sterile stamens in the female flowers minute or none . . . . . . . . . . . 2. P. scabra.

1. P. brevifolia, Benth., n. sp. A prostrate creeping herb, the leafy branches 6 or 8 in. long, hispid. Leaves very obliquely obovate, obtuse, crenate, $\frac{1}{2}$ to $\frac{3}{4} \mathrm{in}$. long, pubescent, very unequal at the base, on petioles rarely 1 line long. Female cymes almost sessile or on peduncles of 1 to 3 lines, seldom above 3 lines diameter. Perianth-segments very unequal, linearlanceolate. Sterile stamens lanceolate, bent in at about the middle. Nut tuberculate.

In ravines of Mounts Gough and Victoria, Wilford. Not seen in any other collection. The specimens are all female.

2. P. scabra, Benth., n. sp. Stems prostrate, pubescent, $1 \mathrm{ft}$. long or 
more, hard at the base. Leaves alternate, oblique, narrow-elliptical or oblong acuminate, usually $1 \frac{1}{2}$ to $3 \mathrm{in}$. long, serrate above the middle, very unequal at the base, very scabrous above, pubescent underneath. Male eymes loose, on slender pedicels of 2 to 4 lines. Perianth-segments 1 line long, ovate, with a green point below the top, usually 4 only. Female cymes very compact and sessile. Bracts small. Perianth-segments usually 4, narrow, very unequal, the longest about $\frac{1}{2}$ line long. Sterile stamens very minute or none. Nut tuberculate.

Hongkong, Harland, Hance,Wright; in ravines of Mounts Gongh and Victoria, Wilford. Not known out of the island. It is allied to P. heterophylla, Wedd., from Sikkim; but that is glabrous, or nearly so, besides differences in the flowers.

\section{BCEHMERIA, Jacq.}

Flowers monœcious or diœcious, in small dense clusters; the clusters in unisexual spikes or panicles. Male perianth usually of 4 segments, valvate in the bud, with 4 stamens. Female perianth enclosing the ovary, 2- or 4-toothed. Ovary 1-celled, with 1 erect ovule. Stigma subulate, continuous with the ovary and persistent. Fruit a seed-like nut, enclosed in the thin perianth. Seed albuminous.-Under-shrubs, shrubs, or small trees. Leaves alternate or opposite, usually toothed.

A large genus dispersed over the New and the Old World, chiefly within the tropics, with a very few extra-tropical Asiatic or $\mathrm{N}$. American species.

1. B. nivea, Hook. and Arn.; Wedd. Mon. Urt. 380 ; Kew Journ. Bot. iii. t. 8. An erect branching hirsute perennial or undershrub, $4 \mathrm{ft}$. high or more. Leaves alternate, very broadly ovate, acuminate, toothed, 4 or 5 in. long, cordate or cuneate at the base, green and roughly pubescent above, very white underneath. Female clusters small, globular, very numerous, in axillary panicles. Male panicles smaller, usually below the females. Fruiting perianth very small, oblong, compressed.-Urtica tenacissima, Roxb.; Wight, Ic. t 688 .

Common in ravines, Champion. Abundant, either wild or in cultivation, in various parts of China, eastern India, and the Archipelago, furnishing the Chinese Grass-cloth.

\section{POUZOLSIA, Gaud.}

Flowers monoecious, in axillary or spicate clusters. Male perianth of 3 to 5 segments, convex on the back, valvate in the bud. Stamens as many. Female perianth enclosing the ovary, 2- or 4-toothed. Ovary 1-celled, with 1 erect ovule. Stigma subulate, articulate on the ovary, and deciduous. Nut seed-like, enclosed in the persistent and occasionally 2-winged perianth. Seed albuminous.-Herbs or shrubs. Leaves alternate or opposite, usually cutire, 3-nerved, the lateral nerves branching, and never reaching the summit of the leaf.

A tropical genus common to the New and the Old World.

1. P. indica, Gaud.; Wedd. Mon. Urt. 398. A diffusely branched pubescent herb or undershrub, procumbent, ascending or rarely erect. Lower leaves usually opposite, upper ones alternate, all entire, varying much in size and shape, in the Hongkong specimens ovate or almost cordate, about 1 in. 
long. Flowers in small sessile clusters, the males and females mixed. Male perianth 4-merous or rarely 5 -merous. Female fruiting perianth about 1 line long, 2 of the ribs often more raised than the others, but scarcely winged. Nut ovoid, pointed, shining, black at the base or altogether when ripe.

Hongkong, Wright. Widely distributed over India, from Ceylon and the Peninsula to the Archipelago, and northward to the Philippines and S. China. A most variable plant, as will be seen by the numerous figures of Wight, Ic., referred here by Weddell. The Hongkong specimens, belonging to var. vulyaris procumbens, Wedd., very much resemble the European Parietaria officinalis in aspect.

\section{MEMORIALIS, Ham.}

Inflorescence and flowers of Pouzolsia, except that the male perianth-segments have on the back a transverse angle or fold forming a ring round the perianth.-Herbs or undershrubs. Leaves entire, opposite, or the uppermost alternate, 3-nerved, the lateral nerves undivided and continuing to near the summit of the leaf.

A tropical genus limited to the Old World, and might be well considered as a subgenus of Pouzolsia.

1. M. hispida, Ham.; Wedd.Mon. Urt. 426. A decumbent or erect usually pubescent herb, flowering the first year, but forming a perennial rhizome. Stems 1 to $2 \mathrm{ft}$. Leaves all opposite, rarely in threes, nearly sessile, lanceolate, acuminate, 1 to $2 \mathrm{in}$. long. Flower-clusters loose, axillary. Male flowers usually numerous, 5 -merous, nearly 1 line long. Females few, in the same clusters. Fruiting perianth with the ribs all equal, or 2 or 4 expanded into wings. Nut black.-Pouzolsia hispida, Benn.; Benth. in Kew. Journ. Bot. vi. 73. See also the various forms figured in Wight, Ic., referred to this species by Weddell.

In shady places, Champion, Hance, Wright. In the hilly districts of India, from Ceylon and the Peninsula to the Himalaya, Khasia, Silhet, and the Archipelago.

\section{VILLEBRUNEA, Blume.}

\section{(Morocarpus, Sieb. und Zucc.)}

Flowers diœcious, in little axillary or lateral capitate clusters, which are either sessile or on clustered or solitary peduncles. Male perianth of 3 or 4 segments, valvate in the bud. Stamens as many. Female perianth adnate to the ovary, 4- or 5-toothed. Ovary 1-celled, with 1 erect ovule. Stigma disk-shaped, eiliate. Fruit small and seed-like, adhering to the somewhat succulent perianth. Seed albuminous.-Shrubs or undershrubs. Leaves alternate.

A small genus confined to eastern tropical or subtropical Asia.

1. V. frutescens, Blume; Wedd. Mon. Urt. 455. An erect undershrub, pubescent or nearly glabrous. Leaves ovate-oblong or oblong-lanceolate, acuminate, toothed, 2 to 3 or rarely 4 in. long, varying from nearly glabrous to pubescent above, and ashy-white with soft hairs underneath. Male clusters nearly sessile, the flowers always 3 -merous. Female heads very shortly pedicellate, with 8 to 12 minute flowers; the fruiting perianth not attaining $\frac{1}{2}$ line. -Morocarpus microcephalus, Benth. in Kew Journ. Bot. vi. 74. 
In ravines of Victoria Peak, Champion. In the Himalaya, from Kumaon to Sikkim, in Assam, Khasia, S. China, Loochoo, and Japan.

\section{ORDER XCVIII. ARISTOLOCHIACE府.}

Flowers hermaphrodite. Periauth herbaceous, adherent at the base, with a superior variously shaped entire or lobed limb; the lobes valvate in the bud. Stamens epigynous, 5, 6, 8, or more. Anthers 2-celled, opening outwards. Ovary inferior, 3- to 6-celled, with several ovules in each cell. Style simple, with an entire or lobed stigma. Fruit a capsule or rarely succulent. Seeds usually angular. Embryo minute, in the top of a fleshy albumen.-Herbs or rarely shrubs, often climbing. Leaves alternate.

A small Order common to the New and the Old World, chiefly tropical, with a few species dispersed over the temperate regions of the northern hemisphere, and a very few extratropical S. American ones.

\section{ARISTOLOCHIA, Linn.}

Perianth tubular above the ovary ; the limb expanded into an undivided or 3 -lobed unilateral lip. Anthers 6 or rarely 5 , adnate to the style. Stigma 3-, 5-, or 6-lobed. Capsule 6- or rarely 3-celled.-Climbers or rarely erect herbs or undershrubs.

The principal genus of the Order, with nearly the same geographical range.

1. A. longifolia, Champ. in Kew Journ. Bot. vi. 117. An undershrub, with a short woody trunk and decumbent or climbing stems, $1 \mathrm{ft}$. long or more, densely pubescent with rust-coloured velvety hairs. Leaves lanceolate or linear-lanceolate, entire, 6 or 8 in. long, nearly glabrous above, pubescent underneath. Flowers clustered on the trunk on very hairy pedicels. Perianth softly hairy and brown outside; the tube straight and somewhat enlarged for $1 \frac{1}{2}$ in., then bent back to the same length and turning up again, opening into a nearly orbicular shortly 3 -lobed lip, $2 \frac{1}{2}$ in. broad, of a deep purple inside.

In clefts of rocks of Mount Victoria, very rare, Champion. Not seen in any other collection. The flower.I dissected was too much crushed to ascertain the precise structure of the anthers and stigmas; but the species probably belongs to the section (or subgenus) Siphisia of Klotzsch.

\section{Order XCIX. SAURURACE府.}

Flowers hermaphrodite, in dense spikes. Perianth none. Stamens 3 to 6 , usually united with the base of the ovary. Filaments distinct. Anthers adnate. Ovary 3-lobed (rarely 4-lobed, the lobes tapering into short styles stigmatic on the inner face, 3- (rarely 4-) celled, or with 3 parietal placentæ. Ovules 2 or more to each cell or placenta. Fruit a capsule or berry. Seeds few. Embryo small, in the top of a mealy or hard albumen.-Herbs. Leaves alternate, with stipules. Spikes terminal.

A small Order confined to central and eastern Asia and N. America.

1. HOUTTUYNIA, Thunb.

Spikes surrounded by coloured petal-like bracts. Stamens 3. Ovary 1celied, with 3 parietal placentas. 
A genus limited to a single $\Lambda$ siatic species, unless it be extended to include the closely allied Californian Anemonopsis.

1. H. cordata, Thunb. Fl. Jap. 234, t. 26; Bot. Mag. t. 2731. Rhizome creeping. Stems erect, glabrous, 1 to $2 \mathrm{ft}$. high. Leaves stalked, heart-shaped, acuminate, entire, $1 \frac{1}{2}$ to 3 in. long, glandular-dotted, glabrous or slightly pubescent on the nerves. Spikes pedunculate, $\frac{1}{2}$ to $1 \mathrm{in}$. long; the outer bracts usually 4 , obovate, white, 3 or 4 lines long. Stamens longer than the ovary.

Hongkong, Wright. In the mountains of northern India, in Siam, China, Formosa, Loochoo, and Japan.

\section{Order C. ChLORANTHACEAE.}

Flowers hermaphrodite or unisexual. Perianth none. Stamens 1 or more, epigynous in the hermaphrodite flowers. Ovary 1-celled, with 1 pendulous ovule. Stigma sessile, thick, entire or notched. Fruit a small indehiscent drupe. Embryo minute, within the top of a fleshy albumen.-Trees, shrubs, or rarely herbs. Leaves opposite, connected by sheathing stipules. Flowers in simple or branched often articulate spikes, terminal or in the upper axils.

A small tropical or subtropical Order, with one American and one Asiatic genus.

\section{CHLORANTHUS, Sw.}

Flowers hermaphrodite. Stamens consisting of a thick fleshy short filament, inserted on (adnate to) one side of the ovary, with 1 adnate 2 -celled anther, sometimes accompanied by 2 smaller lateral 1-celled ones.

A small genus, comprising all the Asiatic species of the Order.

Anthers single, 2-celled. (Spikes usually 1 or 2.) . . . . . . . 1. C. brachystachys.

A single-celled anther on each side of the 2-celled one. (Spikes slen-

der, paniculate.)

2. C. inconspicuus.

1. C. brachystachys, Blume, $F l$. Jav. Chlor. 13, t. 2. An erect branching glabrous undershrub, of about $3 \mathrm{ft}$. Leaves stalked, from ovate to oblong-elliptical, 2 to $4 \mathrm{in}$. long, serrate, shining above, pale underneath with a few scattered glands. Spikes simple or once (rarely twice) forked, $\frac{1}{2}$ to near 1 in. long. Flowers green. Stamen ovoid, with a single 2-celled anther. Drupe red, the size of a currant.-C. ceylanicus, Miq. Fl. Ner. Ind. i. 802. Sarcandra chloranthoides, Gardn.; Wight, Ic. t. 1946.

In ravines, Champion, Hance. In Ceylon, Penang, the Archipelago, and northward to the Philippines and Loochoo.

2. C. inconspicuus, $S w . ; M i q . F l$. Ned. Ind. i. 802. A glabrous shrub. Leaves usually smaller, less coriaceous, and less toothed than in $C$. brachystachys. Spikes slender, $\frac{1}{2}$ to 1 in. long, in branched panicles. Stamens thick, ovate, 3 -lobed; the central lobe bearing a 2 -celled anther, the 2 lateral smaller ones each with a 1-celled anther.

Hongkong, Hance. A native of China, said to be often cultivated in Chinese and Japarese gardens. 


\section{ORdER CI. PIPERACEAE.}

Flowers hermaphrodite or unisexual, in closely packed spikes or rarely in racemes, each with a subtending bract. Perianth none. Stamens 2 to 10 . Ovary 1-celled, with 1 erect ovule. Stigmas 2 to 6 , sessile or on a short style. Fruit a 1-seeded berry. Embryo minute, in the top of a fleshy albumen.-Herbs, shrubs, or climbers, sometimes succulent, often articulate at the nodes. Leaves alternate or rarely opposite, entire, with or without stipules.

A considerable Order, almost entirely tropical, ranging over the New and the Old World.

\section{CHAviCA, Miq.}

Flowers diœeious. Bracts stipitate, peltate. Stamens 2 to 4 . Ovary sessile, with 3 to 6 sessile stigmas. Berries closely packed, often uniting with or half-immersed in the more or less succulent rhachis.-Shrubs or woody climbers. Leaves alternate. Spikes solitary, pedunculate, leaf-opposed.

A considerable geuus, confined to tropical Asia.

Leaves broadly ovate, glabrous. Female spikes 3 or 4 lines long . . 1. C. sarmentosa. Leaves ovate or oblong, pubescent, at least underneath.

Leaves oblique at the base. Spikes ereet or spreading . . . . 2. C. puberula.

Leaves deeply and equally cordate. Spikes reflexed . . . . . . 3. C. sinensis.

1. C. sarmentosa, Miq. Syst. Pip. 242. A glabrous shrub or undershrub, creeping at the base; the flowering branches ascending or climbing. Leaves broadly ovate or nearly orbicular, shortly acuminate, 2 to 3 in. long, truncate or broadly cordate at the base, 5- to 7-nerved, the upper pair united with the midrib higher up. Male spikes said to be near 1 in. long. Female spikes 3 to 4 lines long or 5 to 6 when in fruit, on pedicels of 4 to 6 lines. Bracts peltate, glabrous, $\frac{1}{4}$ line diameter. Stigmas 3 to 5 , at first scarcely prominent, afterwards recurved.-Piper fragile, Benth. in Lond. Journ. Bot. ii. 234. Chavica Benthamiana, Miq. Syst. Pip. 233. Chavica Betle, Seem. Bot. Her. 415 ; not of Miq.

Hongkong, Hance. In Java, Borneo, and New Gninea. Besides the shape of the leaves, this is at once known from the $C$. Betle by the remarkably short spikes.

2. C. puberula, Benth., n. sp. Branches terete, slender, softly pubescent when young. Leaves shortly stalked, ovate-lanceolate or oblong-acuminate, 2 to $4 \mathrm{in}$. long, very oblique and half-cordate at the base, 5 - to 7-nerved, with the upper nerves united higher up, pubescent on both sides when young, nearly glabrous above when old. Male spikes slender, 1 in. long or rather more, on pedicels of 2 to 3 lines. Bracts stipitate, peltate, glabrous. Stamens usually 3.-Piper arcuatum, Seem. Bot. Her. 415; not of Miq.

Hongkong, Hance. Not seen in any other collection. It has the bracts of a Chavica, not of a Piper, and differs in several essential points from Miquel's character and figure of Piper arcuatum.

3. C. sinensis, Champ. in Kew Journ. Bot. vi. 116. Stems creeping; the young branches softly pubescent. Leaves from ovate to oblong, obtuse or nearly so, 3 to 5 in. long, deeply and almost equally cordate; the rounded auricles almost overlapping, 5- or 7-nerved and reticulate, glabrous above, softly pubescent underneath. Spikes reflexed, on short thick peduncles; the 
males rather more than 1 in., the female shorter. Bracts peltate, glabrous. Stanens 2. Stigmas usually 3. Berries nearly distinct, half-imbedded in the rhachis.

In ravines of Victoria Peak, Champion: creeping over rocks in a ravine of Mount Davis, Wilford; also Harland. Not known out of the island.

\section{ORder CII. GNETACE无.}

Flowers monœcious or diœcious, in spikes or heads. Male flowers 1 or more; stamens protruding from a split or 2-lobed bract (or perianth). Anthers 2-celled. Female flowers a naked ovule (that is, without ovary or style), enclosed in an entire, ovoid, or tubular bract (or perianth) open at the top. Fruit a drupe or berry, consisting of the persistent succulent bract enclosing a single seed. Embryo straight, in the axis of a copious albumen.-Trees, shrubs, or undershrubs, the branches articulate at the nodes. Leaves opposite, entire (in Ephedra small and scale-like).

A small Order, dispersed over the tropical and temperate regions of the New and the Old World.

\section{1, GNETUM.}

Flowers verticillate in articulated spikes, each whorl in a cup-shaped annular bract. Stamen 1.-Leaves stalked, flat. Flowers small, intermixed with articulated hairs.

A small tropical genus common to the New and the Old World.

1. G. scandens, Roxb. $F l$. Ind. iii. 518. A stout climbing glabrous shrub, the specimens usually turning black in drying. Leaves oblong or ovaloblong, shortly acuminate, 4 to 6 in. long, coriaceous. Peduncles terminal or axillary, bearing 1 or 2 pair of opposite spikes, each about 1 or $1 \frac{1}{2} \mathrm{in}$. long when in flower; the annular bracts very close, each containing a large number of clavate male flowers opening on one side, and a single row of minute ovoid female ones. When in fruit the rhachis lengthens to several inches and the bracts are distant. Drupes ovoid-oblong, $\frac{3}{4}$ to near $1 \mathrm{in}$. long. $-G$. funiculare, Sm. P; Wight, Ic. t. 1905.

Hongkong, Champion, Hance, Wright. In the hilly districts of India, from the Peninsula to the Archipelago. Miqnel, after Blume, describes the $G$. funiculare as diœcious. 'The Hongkong specimens I have examined have certainly the female flowers intermixed with the males, as described by Roxburgh.

\section{Order CIII. CONIFER 死.}

Flowers monœcious or diœcious, in cylindrical or short catkins, with closely packed scales, or the females solitary. Stamens inserted either on the axis of the catkin under the scales, or the anther-cells sessile on the inside of the scales themselves, which then form part of the stamens. Ovules and seeds naked, that is, without ovary, style, or pericarp, either inserted under the catkin-scales or solitary and quite exposed. Seeds albuminous. Embryo axile, usually with 3 or more cotyledons.-Trees or shrubs, mostly with resinous 
secretions. Leaves stiff, in the Hongkong genera entire and subulate or linear, in others sometimes short and scale-like or lobed or divided.

An extensive Order, spread over the whole globe, although within the tropics chiefly in mountainous districts.

Anther-cells 2 to each scale in the males. Seeds 2 to each scale in the Anther-cells 3 or 4 to each scale in the males. Seeds 3 to each scale in the female cone :

1. Pinus.

2. Cunninghamia.

\section{PINUS, Linn.}

Male catkins closely imbricated, with 2 adnate anther-cells on the inside of each scale, which is in fact the connectivum of the anther, and the catkin thus really consists of imbricated sessile anthers. Female catkins short, consisting of closely imbricated scales, with 2 ovules on the inside of each, the foramen turned downwards. Fruit a cone, consisting of more or less hardened imbricated scales, each one covering 2 winged seeds.-Trees. Leaves linear or subulate.

A large genus, constituting the great mass of the Conifere of the northern hemisphere, only penetrating into the tropics in some mountain districts, and unknown in the southern hemisphere.

1. P. sinensis, Lamb. Pin. iii. t. 2 ; Endl. Syn. Conif. 153. A tall evergreen tree. Leaves subulate, 6 to 8 in. long, 2 or sometimes 3 together in scarious sheaths of 3 to 4 lines. Male catkins short, in dense spikes of 2 to 3 in., with broadly lanceolate very pointed brown scales under each catkin and protruding beyond them. Cones ovoid, $1 \frac{1}{2}$ to $2 \mathrm{in}$. long; the scales thick, the summit broad, hexagonal or rhomboidal, flat, or with a transverse obtuse protuberance.

The most common tree in the island, Champion and others. Abundant also on the Chinese continent and in Loochoo.

\section{CUNNINGHAMIA, Br.}

Characters of Pinus, except that there are 3 or 4 anther-cells to each scale of the male catkins, and 3 ovules or seeds to each scale of the females.

A genus limited to a single species.

1. C. sinensis, Br.; Endl. Syn. Conif. 193. A lofty evergreen tree. Leaves solitary, alternate, linear or linear-lanceolate, more or less falcate, very pointed and usually pungent, about $2 \mathrm{in}$. long, coriaceous, smooth and shining, glaucous underneath on each side of the prominent midrib. Male catkins erect in a small head, with a number of small imbricated scales or bracts at its base. Cone ovoid-globose, 1 to $1 \frac{1}{2} \mathrm{in}$. long; the scales concave, with a thin edge, and rather spreading.-C. lanceolata, Bot. Mag. t. 2743.

In the Happy Valley, in isolated specimens, Hance, Seemann. In S. China and Loochoo. 


\section{Class II. MONOCOTYLEDONS.}

Stem not distinguishable into pith, wood, and bark, but, when perennial, consisting of bundles of fibres irregularly imbedded in cellular tissue, with a firmly adherent rind outside. Seeds with one cotyledon, the embryo undivided, the young stem being developed from a sheath-like cavity on one side.

Besides the above characters, Monocotyledons may be generally known by their simple entire alternate or radical leaves with simple parallel veins, the base usually encircling or sheathing the stem or the base of the next leaf; and the parts of the flower are most frequently in threes, the calyx and corolla, when present, being generally similar in appearance, forming a perianth of six parts. In several families, however, the perianth is wholly wanting, or the parts reduced in number when irregular, or in the Naiadece in twos or fours; the leaves are exceptionally pinnately or netted-veined in Scitaminea, in most Aroidea, in Dioscoridece and in Smilax. The stem is woody in the Palms, Screw Pines (Pandanus), and Bamboos.

\section{* Stem woody. Flowers 6-merous, in a panicle with a spatha.}

CIV. Palma.

** Perianth 0 or of small scales. Ovaries and stamens crowded in heads or spikes.

CV. Pandanacex. Flowers in heads or branched spikes. Anthers stalked. (Stem woody. Leaves long, prickly at the edge.)

CVI. A RoIDEe. Flowers on a simple spadix, with a spatha. Anthers sessile. Leaves sheathing at the base, often net-veined.

\section{*** Ovaries apocarpous.}

CVII. NaIAdefe. Floating plants. Perianth 0 or of 1 to 4 scales. Carpels 1 , 2, or 4.

CVIII. Alismaces. Perianth 6-merous. Carpels 3, 6, or more. Aquatic or marsh planțs, usually eręct.

\section{**** Ovary inferior. Perianth usually 6-merous in 2 series.}

CIX. Hydrocharides. Aquatic plants. Flowers unisexual. Female perianth with a tube, male without. No albumen.

CX. Scitamines. Flowers irregular, with 1 to 5 perfect stamina, the remainder of the normal 6 being petal-like and barren or wanting. Seeds albuminous. Leaf-veins usually pinnate.

CXI. Orchides. Flowers irregular. Anthers 1 or rarely 2, sessile on a column bearing the stigma. Embryo homogeneous.

CXII. Burmanniacese. Perianth 3-or 6-lobed. Stamens 3 or 6. Ovary 1-celled, with 3 parietal placentas. Embryo homogeneons.

CXIII. IRIDEx. Perianth of $\mathbf{6}$ segments, usually petal-like. Stamens 3. Ovary 3-celled. Seeds albuminous.

CXIV. Amaryluidese. Perianth of 6 segments, usually petal-like. Stamens 6. Ovary 3-celled. Seeds albuminous.

CXV. Drosconidex. Flowers unisexual. Ovary 3-celled. Twiners. Seeds albuminous.

***** Ovary superior, syncarpous. Perianth usually 6-merous, in 2 series.

CXVI. Línuce s. Perianth regular, wholly petal-like.

CXVII. Pontederacese. Perianth usually irregular, wholly petal-like. Aquatic plants.

CXVIII. Commelynaces. Perianth slightly irregular, the inner segments very delicate, the outer more herbaceous. Ovary 3- or 2-celled. Embryo on the edge of the albumen.

CXIX. Xyridaces. Perianth irregular, the outer of 1 broad petal-like segment, with or without 2 lateral ones, inner petal-like. Ovary 1-celled, with 3 parietal placentas.

CXX. Juncaces. Perianth regular, wholly stiff or calyx-like. Flowers hermaphrodite. 
CXXI. Restinces. Perianth wholly stiff and calyx-like or transparent. Flowers unisexual.

******* Perianth rudimentary or 0 . Flowers sessile, within imbricuted glumes.

CXXII. Cyperaces. Leaf-sheaths entire. Each flower usually in the axil of one glume, without a palea.

CXXIII. Gramines. Ieaf-sheaths split open opposite the blade. Flower usually in a secondary bract (palea), within the glume.

\section{Order CIV. PALM}

Flowers unisexual or polygamous. Perianth dry and calyx-like, of 6 lobes or segments, in 2 distinct series, contorted or valvate in the bud. Stamens 6 , or rarely more, or 3 only. Anthers versatile, 2-celled. Pistil usually of 3 carpels, free or united in a 3 -celled ovary. Ovules solitary or rarely 2 in each cell, erect. Stigmas 3, usually sessile, undivided. Fruit either a 3-celled or 1-celled drupe or berry, or of three distinct drupes or berries. Seed erect or laterally attached. Embryo small, in a cavify near the outside of a hard albumen.-Stems woody, usually simple, and often attaining a great height. Leaves large, usually at the summit of the stem, folded in the bud, and pinnately or palmately divided. Flowers usually sessile, in simple or paniculate spikes, enclosed when young in large sheathing bracts, called spathas, and usually with 3 small bracts or bracteoles under each flower.

A large tropical Order, with a very few extratropical species in the warmer parts of the northern or southern hemispheres.

Leaves pinnate. Ovary 3-celled.

Stems climbing. Ovary and fruit covered with imbricate scales . . . 1. Caraurus.

Stem erect. Ovary and fruit without scales. . . . . . . . 2. Phenix.

Leaves palmate. Ovaries 3, distinct. . . . . . 3. RHaprs.

\section{CALAMUS, Linn.}

Flowers diøcious. Outer perianth 3-lobed, inner of 3 segments. Stamens 6. Ovary 3-celled, with erect ovules. Stigmas 3, sessile or on a short style. Fruit closely covered with reflexed imbricated shining scales.-Stems weak, often climbing to an immense height. Leaves pinnate, the rhachis and sheaths usually armed with straight or hooked prickles, and often ending in a long armed simple tendril. Flowers in long drooping panicles below or amongst the leaves.

A considerable genus, chiefly Asiatic, extending also into tropical Africa and Australia. and comprising the greater number of the Rattan Palms or Rotangs.

Wright gathered one specimen of a species of this genus in the island, but I have not seen it; it may be the same species as the one mentioned by Seemann (Bot. Her., 416), doubtfully as a species of Zalacca. The leaf in Hance's collection appears to me to be that of a Calamus rather than of a Zalacca, but it is insufficient to determine the species. Dr. Hance writes to me that he believes there are three Calami in the island.

\section{PHGNIX, Linn.}

Flowers dicecious. Outer perianth cup-shaped, 3-toothed; inner one of 3 valvate segments. Stamens 6 or 3 ; filanents very short; anthers linear. 
Ovary of 3 carpels, uniting in fruit into a 1-seeded drupe. Embryo on the back of the albumen.- Stems erect. Leaves pinnate, with entire linear segments. Spikes paniculate, issuing from coriaceous sheathing spathas amongst the leaves. Flowers yellowish.

A small genus dispersed over $\mathrm{N}$. Africa and tropical Asia.

i. P. acaulis, Roxb.?; Griff. Palm. 137, t. 228? Leaves glaucous; the segments folded, solitary or in clusters of 2 or 3 , about 6 to 8 in. long, by 5 or 6 lines wide. Spathas about 6 to 8 in. long, brown, narrow, usually splitting into two. Peduncle above $1 \mathrm{ft}$. long, with numerous spreading spikes of 3 or 4 in. Flowers small, sessile, on alternate notches of the flexuose rhachis.

In sunny places, Hance; also Wright; and Champion mentions a Phoenix growing near the sea. From the specimens we possess, I cannot with certainty distinguish this from the $P$. paludosa, Roxb., and I have no information as to its size. If it be the true $P$. acaulis, it should have a very short bulb-shaped stem. Both species are natives of the plains of India.

\section{RHAPIS, Linn.}

Flowers diøcious or polygamous. Outer perianth cup-shaped, shortly 3-lobed; inner one longer, tubular or campanulate, also 3-lobed. Stamens 6; filaments filiform; anthers ovate. Carpels 3, distinct. Drupes 3 or fewer by abortion.-Small Palms, with thin stems and fan-shaped leaves.

A genus of 2 or 3 species, limited to E. Asia.

1. R. flabelliformis, Linn.; Kunth, Enum. iii. 251; Bot. Mag.t. 1371. Stems usually 2 or 3 feet high, not much thicker than a finger. Sheaths splitting into brown filaments. Leaves fan-shaped, dividing to near the base into 4 to 10 lanceolate-linear segments, 8 to 10 in. long, minutely denticulate, with twice as many folds at the base, on a petiole of $\frac{1}{2}$ to $1 \frac{1}{2} \mathrm{ft}$. Panicle divaricately branched, about 1 foot broad. Flowers pale-yellow, sessile, scattered. Drupes obovoid-globular, 1, 2, or 3 ripening to each flower.- $R$. Kwanwortsik, Herm. Wendl.; Seem. Bot. Her. 416. Japan.

In the Happy Valley woods, Hance, Wilford. In S. China and Loochoo. Cultivated in

\section{Order CV. PANDANACE正.}

Flowers unisexual, densely sessile, in simple or branched spikes or heads. Perianth none, or rarely 3 or 4 valvate sepals. Male flowers: Stamens several; filaments filiform. Anthers 2 or 4-celled. Female flowers: Ovaries 1-celled, entire, with 1 laterally inserted ovule or with many ovules on parietal placentas. Stigma usually sessile. Fruit a berry or drupe. Embryo small, in the base of a fleshy or horny albumen.--Stems herbaceous, shrubby or arborescent, often branched. Leaves entire or divided.

A small tropical Order, common to the New and the Old World.

1. PANDANUS, Linin.

Flowers dioecious. Males in small dense spikes, sessile in the axils of leafy or coloured bracts, forming a terminal compound spike. Stamens indefinite. 
Anthers 2-celled. Female flowers: Ovaries very numerous, densely packed in a globular or oblong spike or head, with 1 ascending ovule in each. Stigmas sessile on the flat tops. Drupes cohering in clusters in a large cone-like head. -Stem arborescent, branching. Leaves long, linear-lanceolate, coriaceous, prickly on the midrib and edges, spreading, and generally closely inserted round the stem in 3 spiral series.

A considerable genus, limited to the Old World.

Two species of Pandanus, or Screw Pines, are stated to have been observed in the island by Wright, and Champion mentions one, but no specimens were collected. Hance had sent some leaves which Seemann has referred, I know not on what grounds, to $P$. fasicularis, Lam., for they are wholly insufficient for determining the species.

\section{Order CVI. AROIDEES.}

Flowers monœcious, or rarely diœcious or hermaphrodite, closely packed in a dense simple spike, called a spadix, with a convolute or rarely flat, coloured or leaf-like bract, called a spatha, at its base. Stamens and ovaries either in different parts of the spadix, without perianth or bracts; or stamens 6 or fewer round each ovary, with or without a small scale or perianth-segment under each stamen. Anthers usually 2-celled, sessile or on a short filament. Ovaries 1- to 3-celled, with 1 or more ovules in each cell. Stigma sessile or on a simple style. Fruit a berry. Seeds in a pulpy testa, with or without albumen. - Herbs, usually with a perennial rhizome or creeping rarely erect stem. Leaves entire or divided, the veins usually pinnate or reticulate, as in Dicotyledons, rarely parallel as in most Monocotyledons. Spadix often bearing barren organs (abortive stamens or ovaries) above or below the stamens, or ending in a thickened variously shaped barren portion, called the appendix.

A considerable Order, chiefly tropical, but dispersed also over several more temperate regions, especially in the northern hemisphere.

Stamens and ovaries in separate parts of the spadix or in different spadices. (Flowers unisexual.)

Anther-cells terminal.

Ovary 1-celled.

Spadix androgynous. Leaves entire or lobed. . . . . 1. Arum.

Spadix unisexual. Leaves of 3 or more entire segments . 2. ARIS ema.

Ovary 2-celled. Spadix androgynous, Leaves of 3 pinnately divided segments.

Stamens united, 2 or more together, in peltate or truncate masses, with the anther-cells lateral. Leaves entire, large . . .

Stamens 6 or fewer round each ovary. (Flowers hermaphrodite.)

Perianth none. (No scales or bracts under the stamens.) . . 5. Rhaphidophora.

Perianth-segments 6 or fewer. (A scale or bract under each stamen.)

Spatha concave or convolute. Leaf-veins pinnate and reticu-

late

Spatha linear and leaf-like. Leaf-veins parallel . . . .

3. Amorphophallus.

4. Colocasia.

6. Pothos.

7. Acorus.

\section{ARUM, Linn.}

Spatha convolute or tubular at the base. Spadix androgynous, the ovaries at the base, the stamens higher up, with barren organs either between the ovaries and stamens, or above the stamens, or both; the rhachis ending in a 
club-shaped or pointed appendix. Stamens distinct. Anthers 2-celled, sessile or on short filaments. Ovaries 1-celled, with 1 or more ovules.-Rhizome usually tuberous. Leaves entire or 3-lobed, on long radical petioles. Scapes radical, without bracts under the spatha.

A considerable genus, spread over the temperate regions of the northern hemisphere in the Old World, extending in Asia into the mountainous districts within the tropics; that is, if taken in what appears to be the most natural limits of the genus. It has, however, been very much split up by modern authors, and the following as well as most other Asiatic species excluded from it.

1. A. divaricatum, Linn. Leaves cordate-hastate, acuminate, 2 to 4 in. long, the 2 basal lobes or auricles ovate-lanceolate or oblong and divergent. Spatha tubular and green at the base for $\frac{1}{2}$ to $\frac{3}{4}$ in., then expanded into a deep purple ovate lamina, near $2 \mathrm{in}$. broad, and tapering into a point of full $3 \mathrm{in}$. Spadix deep purple. Ovaries at the base in several rows, with 1 or 2 erect ovules in each ; then follow several rows of short subulate erect barren organs, and after an interval of 3 or 4 lines, several rows of sessile anthers, the rhachis terminating in a slightly thickened appendix tapering to a point full $3 \mathrm{in}$. long.-Typhonium divaricatum, Blume, Rumph. t. 36 ; Schott, Prod. Aroid. 106. Arum trilobatum, var., Bot. Mag. t. 2324.

Hongkong, Champion, Hance. Widely spread over India, from Ceylon and the Peninsula to the Arrhipelago.

The A. ternatum, Thunb. (Pinellia tuberifera, Ten.; Schott, Prod. Aroid. 20), a common Chinese and Japanese plant, was gathered by Wright in Putoy Island, and will probably be found in Hongkong. It is readily known by its narrow obtuse spatha, adhering at its base to the spadix, the subulate point of which protrudes several inches beyond it.

\section{ARIS 不MA, Mart.}

Characters of Arum, except that the spadices are unisexual, bearing the flowers at or near the base, and usually barren organs below the point. Anthers usually in distinct scattered clusters of 2 to 4 or 6 cells.-Habit of Arum, except that the leaves are usually divided into 3 or more distinct segments.

A genus of several species, dispersed over tropical and subtropical Asia and N. America.

1. A. laminatum, Blume, Rumph. i. t. 27; Schott, Prod. Aroid. 33. Leaf-segments 3 , ovate-lanceolate or oval-oblong, acuminate and aristate, 3 or 4 in. long; the central one petiolulate, the lateral ones oblique at the base and almost sessile. Spatha convolute at the base, the concave part $1 \frac{1}{2}$ in. long, truncate at the top, with a broadly ovate lamina ending in a fine point of $\frac{1}{2}$ to $1 \mathrm{in}$. Spadix ending in a subulate point, extending to 1 or 2 in. above the flowers, and bearing near the top, or immediately above the flowers, or both, a few scattered subulate barren organs. Stamens in the males loosely scattered, occupying about $\frac{3}{4}$ in. of the base. Ovaries in the females closely packed for 5 or 6 lines. Ovules about 4. Stigma raised on a short style.

Hongkong, Harland, Wright. Also in Java.

\section{AMORPHOPHALLUS, Blume.}

Spatha of Arum. Spadix continuously androgynous, without barren organs, ending in an appendix sometimes acquiring enormous dimensions. Anthers 
sessile, 2-celled. Ovaries distinet, 2-, 3-, or rarely 4-celled, with 1 erect ovule in each cell.-Habit of Arum, except that the leaves are divided into 3 segments, which are again once or twice pinnately divided. Spadix often lividpurple and very fetid.

A small tropical Asiatic and perhaps African genus, lately split up almost to single species, the following one being then excluded from it.

1. A. variabilis, Blume, Rumphia, t. 35, 37; Kunth, Enum. iii. 33. Petiole divided at the top into 3 pinnæ of 8 to $10 \mathrm{in}$., which are again once or twice forked, bearing 8 to 12 or more segments of very unequal size, mostly lanceolate or ovate-lanceolate, acuminate, and sessile, or decurrent on the rhachis, the longest about $3 \mathrm{in}$. Spatha 4 to 5 in. long, obtusely acuminate or obtuse (variously coloured), with longitudinal streaks. Ovaries densely imbricated for about $\frac{3}{4}$ in. at the base of the spadix, then stamens for about $1 \mathrm{in}$; the appendix rather thin, straight, about $3 \mathrm{in.} \mathrm{long} \mathrm{in} \mathrm{the} \mathrm{Hongkong}$ specimens (perhaps not full-grown), twice that as figured by Blume.-Brachyspatha variabilis, Schott, Prod. Aroid. 127.

Hongkong, Harland. A Also Java, and perhaps Ceylon.

\section{COLOCASIA, Ray.}

Spatha of Arum. Spadix androgynous, with ovaries at the base, stamens higher up, and barren organs in the interval and sometimes above the stamens also, the appendix club-shaped. Stamens united several together in short truncate or peltate masses, with the anthers laterally adnate. Ovaries 1-celled or partially 3-celled, with several ovules.-Herbs, with a tuberous and rootlike or caulescent stock. Leaves usually large and glaucous, cordate, and sometimes peltate. Spadix usually sweet-scented.

A small genus limited to tropical Asia, unless where introduced by cultivation.

Appendix of the spadix as long or longer than the flowering part. Auricles of the leaf divided to the petiole

Appendix much shorter than the rest of the spadix. Auricles shortly united below the petiole

1. C. indica.

2. C. odora.

1. C. indica, Kunth, Enum. iii. 39; Wight, Ic. t. 794. Leaves ovatecordate, attaining 2 or $3 \mathrm{ft}$. in length, the broadly ovate basal lobes or auricles distinct to the petiole. Spatha 6 to $8 \mathrm{in}$. long or more when full-grown, of a pale greenish-yellow, convolute at the base, the lamina oblong, obtuse or with a short point. Spadix rather shorter, the flowers densely packed, the ovaries occupying about 1 in. of the base, then about 1 in. of barren organs, and $1 \frac{1}{2}$ or 2 in. of stamens; the appendix marked with reticulate furrows (indicating abortive stamens?), as long or longer than the rest of the spadix.-Alocasia indica, Schott, Prod. Aroid. 144.

Hongkong, Harland. A native of various parts of S. Asia, much cultivated for its succulent stems and small tubers; it may be doubtful whether the specimen may not have been an escape from cultivation.

2. C. odora, Brongn.; Kunth, Enum. iii. 39; Wight, Ic.t.797. Very nearly allied to $C$. indica, but the leaves are usually slightly peltate, the auricles being shortly connate below the insertion of the petiole; the spadix is shorter than the spatha, and the appendix very much shorter than the flower- 
ing part. - Alocasia macrorrhiza, Schott, Prod. Aroid. 146, and A. commutata, Schott, l. c. 148.

Hongkong, Hance. In Khasia and Burmah. Cultivated, like the last, of which it may be a variety.

\section{RHAPHIDOPHORA, Hassk.}

Spatha sessile, deciduous, convolute or concave. Flowers hermaphrodite, in a cylindrical spike, without scales or perianth. Stamens 4 round each ovary. Filaments flat. Anthers terminal, 2-celled. Ovary 1-celled or incompletely 2-celled, with several ovules. Stigma sessile on the truncate top. Berry 1-seeded. Seed albuminous.-Climbers, or creeping herbs or shrubs. Leaves stalked, entire or pinnately divided.

A small genus limited to tropical Asia, unless it be extended to include the whole or the greater part of the American Monsterince of Schott, in which case the genus would take the name of Monstera.

1. R. Peepla, Schott, Prod. Aroid. 380. Stems rooting and attaching themselves to trees or rocks. Leaves on long petioles, oblong, acuminate, more or less falcate, 6 to 8 in. long, entire, coriaceous, with numerous parallel veins diverging from the midrib. Peduncles inserted in long sheathing bracts. Spatha convolute, deciduous, scarcely longer than the spike. Spike about $1 \frac{1}{2}$ in. long.-Pothos Peepla, Roxb.; Wight, Ic. t. 780. Rhaphidophora hongkongensis, Schott, Prod. Aroid. 378. R. lancifolia, Schott, l. c. 380, and (a rather broader-leaved form) R. calophylla, Schott, l. c. 380 .

Hongkong, Champion, a single leaf upon which Schott founded his $R$. hongkongensis, but which appears to me precisely similar to those of the Khasia specimens of $R$. Peepla, which I here describe. The species appears to be common in Sikhim, Khasia, and Silhet.

\section{6. РОтноS, Linn.}

Flowers hermaphrodite, in a globular or cylindrical spike, usually stipitate above the convolute or concave spatha. Perianth of 6 small concave scales or segments. Stamens 6, opposite the perianth-scales. Filaments flat. Anthers 2-celled. Ovary 1-celled, with 1 to 3 erect ovules. Stigma sessile. Berries 1- or 2-seeded. Albumen none.-Stems usually creeping or climbing. Leaves entire, coriaceous, usually articulate on the more or less dilated petioles. Peduncles axillary, often bracteate below the spatha.

A tropical Asiatic genus, extending from E. Africa to N. Australia.

1. P. scandens, Linn. ; Kunth, Enum. i. 65 ; Bot. Reg.t. 1337. Petioles winged, varying from 2 or 3 lines to above 1 in. in length, or sometimes at the base of the branches much longer with an abortive lamina; the lamina usually oblong, acuminate, 2 to $4 \mathrm{in}$. long, coriaceous, but varying much in breadth as well as length. Peduncles recurved (when the flowering branches hang), seldom $\frac{1}{2}$ in. long, with 3 to 5 concave ovate bracts, the uppermost (thê spatha) rather larger and more spreading. Spike globular or slightly ovoid, 3 or 4 lines diameter. Berry red.-P. Seemanni, Schott, Prod. Aroid. 564, and probably the whole of the first 19 species enumerated in that work.

Common in ravines, creeping over rocks, Champion and others. Frequent in India, from Ceylon and the Peninsula to the Archipelago, and northward to the Himalaya and S. China; 
and exceedingly variable both in the absolute and relative size and breadth of the petiole and lamina. The common Hongkong variety is precisely the Chinese one figured in the plate above quoted.

\section{ACORUS, Linn.}

Flowers hermaphrodite, in a cylindrical spike, the spatha linear and continuous with the scape. Perianth of 6 concave scales or segments. Stamens 6 , opposite the segments. Filaments linear, flat. Anthers terminal. Ovary 3celled, with several ovules in each cell. Stigma sessile on the obtuse top. Seeds albuminous.

A genus probably limited to the following species, and to one other closely allied but much smaller one, a native of China and Japan, but not found in Hongkong.

1. A. Calamus, Linn. ; Kunth, Enum. iii. 87. A highly aromatic reedlike perennial, with a thick shortly creeping rhizome. Leaves linear, erect, in some specimens only $1 \mathrm{ft}$., in others 2 to $3 \mathrm{ft}$. long, and from $\frac{1}{4}$ to $\frac{1}{2} \mathrm{in}$. broad. Scape as variable in length, the linear leaf-like spatha sometimes scarcely exceeding the spike, in other specimens a foot long or more. Spike $1 \frac{1}{2}$ to $3 \mathrm{in}$. long, of a yellowish green. - A. Calamus, and probably the 6 following species in Schott, Prod. Aroid. 578.

Common in watercourses at Little Hongkong, Eyre ; in a ravine of Mount Victoria, Wilford; also Wright and Hance, both the large and the small states. Extends over Europe, central and temperate Asia, and N. America. Frequent in gardens in India, and wild in the northern mountainous districts.

\section{Order CVII. NAIADE无.}

Flowers usually proceeding from a small sheathing bract. Perianth none, or of 4 small scale-like segments. Stamens 1, 2, or 4. Ovaries either of 2 or 4 distinct carpels, each with a single ovule and a separate stigma, or single, with 1 ovule and 2 to 4 stigmas. Fruit of 1,2 , or 4 seed-like nuts, each with 1 seed, without albumen.-Aquatic floating or submerged herbs. Leaves either sheathing at the base or accompanied by sheathing stipules, alternate or rarely opposite. Flowers axillary, inconspicuous, solitary or spiked.

An Order not numerous in species, but abundantly diffused over all parts of the world, in shallow seas as well as in fresh-waters.

\section{NAIAS, Willd.}

Flowers unisexual. Perianth none. Male flowers consisting of a single nearly sessile anther, enclosed in a little tubular membranous bract. Female flowers a single ovary, sessile in the sheathing base of the leaf, with 2 to 4 . subulate stigmas or style-branches. Fruit a small seed-like nut. Embryo straight. - Submerged plants. Leaves opposite or ternate, often crowded in clusters, usually serrulate. Flowers axillary.

A genus of few species, widely dispersed over the greater part of the globe.

1. N. minor, All. ; Kunth, Enum. iii. 113. Leaves narrow-linear, usually opposite, $\frac{1}{2}$ to $1 \mathrm{in}$. long, with minute serratures, the sheath short and toothed. Flowers monœcious, solitary, or 2 or 3 together in the same axil, with 1 or 
more leaf-like or small bracts. Ovary sessile, tapering into a bifid style.$N$. indica, Cham., and N. tenuifolia, Br. ; Kunth, Enum. iii. 113.

Hongkong, Wright. Common in tropical Asia, extending on the one hand into Europe, on the other into Australia. I find no difference whatever between the Indian and the S. of France specimens. Some from near Berlin are stiffer, with shorter more recurved and more distinctly toothed leaves, but the Indian ones are also variable in these respects.

\section{ORDER CVIII. ALISMACE五.}

Perianth of 6 segments, either all similar or 3 outer small and sepal-like, and 3 inner ones large and petal-like. Stamens 6,9 , or indefinite. Ovary of 3 , 6 , or many carpels, either distinct from the first or separable when in ripe fruit, each with 1,2 , or many ovules. Seeds consisting, within the testa, of a homogeneous mass, usually considered as an undivided embryo without albumen.-Marsh or water plants, with radical leaves and leafless flowering stems, or rarely with leafy stems. Flowers in terminal umbels, panicles, or racemes.

A small Order dispersed over the greater part of the world.

\section{SAGITTARIA, Linn.}

Flowers unisexual. Perianth of 3 outer herbaceous segments and $\mathbf{S}$ larger inner ones, petal-like and very delicate. Stamens numerous, carpels numerous, 1-seeded, in a dense globular head.-Aquatic herbs. Leaves longstalked, usually cordate or hastate. Flowers in a raceme or narrow panicle, the lower ones female, the upper male.

A small genus dispersed over the northern hemisphere and extending into S. America.

1. S. cordifolia, Roxb.; Kunth, Enum. iii. 161.-An annual, growing in tufts at the bottom of the water. Leaves floating on the surface, broadly ovate or orbicular, and deeply cordate, $1 \frac{1}{2}$ to near $3 \mathrm{in}$. long. Scapes shortly emersed, bearing a raceme of 2 or 3 to 6 or 8 in. long. Flowers in clusters of 2 or 3 , the lower female ones sometimes with a few stamens also, the upper ones male only. Carpels very numerous (3 to 400 ), much flattened, with a deeply-toothed edge.

Hongkong, Harland. Frequent in standing waters in India, extending westward into E. Africa, and eastward over the Archipelago.

\section{ORDER CIX. HYDROCHARIDE丑.}

Flowers mostly unisexual. Perianth of 3 or 6 segments, either all petallike, or the 3 outer ones smaller and herbaceous, with a tube adherent to the ovary in the females, without any tube in the males. Stamens 3 to 12. Ovary inferior, 1-celled, with 3 parietal placentas, or 3-, 6-, or 9-celled. Styles 3, 6, or 9, with entire or 2-cleft stigmas. Fruit small, ripening under water, indehiscent. Seeds several, without albumen.-Aquatic herbs. Leaves undivided. Flowers inclosed when young in an involucre or spatha of 1 to 3 leaves or bracts.

A small Order, widely diffused over the globe. 


\section{BLYXA, Thouars.}

Flowers usually diœcious, in a long tubular spatha, 2-toothed at the top. Male flowers several in the spatha, protruding from it as they expand. Perianth of 3 outer herbaceous and 3 inner petal-like segments. Stamens 8 or 9 . Anthers linear. Female flowers solitary in the sheath, with a long filiform perianth-tube, the segments as in the males. Ovary linear, with 3 parietal placentas. Stigmas 3, entire. Capsule linear, with few seeds.

A genus limited to a single species.

1. B. Roxburghii, Rich.; Miq. Fl. Ned. Ind. iii. 237. Leaves submerged, sessile, in tufts at the bottom of the water, linear, pointed, 3 or $4 \mathrm{in}$. long in shallow still water, but attaining sometimes a foot or more. Flowers small, raised above the surface of the water on a lengthened peduncle. Outer segments about $2 \frac{1}{2}$ lines long, inner ones narrow-linear, twice as long. Diplosiphon oryzetorum, Dene. in Jacquem. Voy. 166, t. 167.

Hongkong, Wright, Hance; in watereourses near Little Hongkong, Wilford. Frequent in India, from Ceylon, the Peninsula, and Cashmere, to the Archipelago and N. Australia. I find the flowers almost always unisexual, even in Jacquemont's specimens, but $I$ have seen a few stamens in some fertile flowers, and it is probably the examination of one of these flowers which induced Decaisne to distinguish a hermaphrodite genus.

\section{ORDER CX. SCITAMINEÆ.}

Flowers usually hermaphrodite and irregular, rarely unisexual. Perianth superior, in 2 series, both petal-like, or the outer one herbaceous or stiff, each 3 -toothed, or 3 -lobed, or of 3 segments. Stamens normally 3 or 6 , but in most genera only one bears an anther; the others are wanting or barren and petal-like, and then often called the inner corolla; one of these, usually larger and opposite the fertile stamen, is then called the labellum. Anthers 2- or 1celled. Ovary inferior, 3 -celled, with 1 or more ovules in each cell, or rarely 1-celled. Style single, with an entire or lobed stigma. Fruit a berry or capsule. Seeds albuminous.-Herbs, usually with a perennial rhizome. Stem usually short or formed of the convolute leaf-sheaths, and then attaining a considerable height. Leaves entire, with long sheathing petioles; the limb often very large, with numerous parallel veins diverging from the midrib. Flowers often very showy, in racemes or panicles, on a radical or terminal scape or peduncle.

A considerable tropical or subtropieal Order, common to the New and the Old World.

Fertile stamens 5. Perianth of 1 outer and 1 inner segment. Leaves

very large, their sheaths forming a tall stem . . . . . . . 1. Muss.

Fertile stamen 1 .

Barren stamens (or inner corolla) of one petal-like labellum, with or without a very small one on each side . . . . . . . . .

Barren stamens 3, all petal-like and as long or longer than the true perianth

2. ALPINIA.

3. CANNA.

\section{MUSA, Linn.}

Flowers usually unisexual. Perianth of 2 concave coloured entire or 3lobed segments; the outer erect, the inner shorter and recurved. Fertile stamens 5. Anthers linear. Ovary 3-celled, with numerous ovules. Stigma 
concave.-Tall often tree-like herbs, the convolute sheaths of their large long leaves forming a stem of considerable height. Scapes protruding from the centre of the leaf-sheath. Flowers clustered in the axils of large coloured bracts, and forming a long drooping terminal spike or raceme.

A tropical or subtropical Asiatic genus, only known in America where introduced.

Of this genus the common M. sapientum, Linn., is often cultivated, and Champion observed a species wild in the ravines of Mount Parker, but did not bring any specimen.

\section{ALPINIA, Linn.}

Outer perianth tubular or campanulate, stiff, 3-toothed, and often splitting to the base. Inner perianth petal-like, united at the base, with the stamens in a tube; the limb of 3 usually unequal lobes. Staminal whorl consisting of one large petal-like labellum, opposite to a single fertile stamen, and in some species a small linear lobe on each side between the labellum and stamen. Filament not dilated. Anther 2-celled. Style filiform, with a concave terminal stigma. Ovary 3 -celled, with many ovules. Fruit globular, scarcely succulent, but not opening in valves. Seeds few, arillate.-Erect herbs, with a tuberous rhizome. Panicles terminal, narrow and raceme-like.

A small tropical genus, limited to the Old World except where introduced from cultivation.

Panicle drooping, the rhachis downy. Labellum full $1 \frac{1}{2}$ in. long, without lateral lobes . $\quad \cdots \quad \ldots$

Panicle erect. Flowers less than $i_{\text {in. long. }} \dot{A}$ small lobe on each side between the labellum and stamens.

Flowers near $1 \mathrm{in.}$ long. Labellum on a long claw . . . . . . 2. A. galangas.

Flowers about 8 lines long. Labellum sessile . . . . . . . 3. A. chinensis.

1. A. nutans, Rosc. in Linn. Trans. viii. 346 ; Bot. Mag.t. 1903 ; Wight, Ic. t. 2027. Stems 4 to $6 \mathrm{ft}$. high. Leaves bifarious, broadly lanceolate, 1 to $3 \mathrm{ft}$. long, glabrous. Panicle raceme-like, drooping; the rhachis and ovaries softly hairy. Bracts under each flower concave, splitting longitudinally, 1 in. long, of a pure white tipped with pink. Outer perianth like the bracts but smaller. Inner perianth lobes pale-pink, the largest $1 \frac{1}{2}$ in. long; the 2 others rather smaller. Labellum full $1 \frac{1}{2}$ in. long, sessile, ovate-cordate, obscurely 3-lobed, of a deep orange-yellow with a crimson ground, without any accessory lobes at the base. Fruit globular, 1 in. diameter.

In ravines of Mount Victoria, Champion, Hance. In Ceylon, eastern India, the Archipelago, and northward to the Philippines. Frequently received in tropical collections from the New as well as the Old World; but in most cases either cultivated or escaped from cultivation.

2. A. galangas, $S w$; Roxb. $F l$. Ind. i. 59. Stems nearly erect, 6 to $7 \mathrm{ft}$. high according to Roxburgh. Leaves oblong or broadly lanceolate, 1 to $2 \mathrm{ft}$. long, with a short round ligula at the base of the blade. Panicle erect, oblong, 8 to 12 in. long, slightly pubescent; the lower branches often bearing 5 or 6 flowers. Outer perianth tubular, 4 or 5 lines long. Inner perianthtube as long; the lobes narrow, nearly equal, about $\frac{3}{4}$ in. long. Labellum broadly ovate, 2-lobed, contracted into a long claw, with a short lanceolate lobe on each side at the base.-Galanga major, Rumph. Amb. v. 143, t. 63. Languas vulgare, Kœn. in Retz. Obs. iii. 64. Alpinia alba, Rosc. in Linn. Trans. viii. 346. 
In ravines of Mount Victoria, Champion, Hance. In Ceylon, the Malayan Peninsula, and the Archipelago, and frequently cultivated for its aromatic rhizomes.

3. A. chinensis, Rosc. in Linn. Trans. viii. 346. Allied to the last but of smaller stature, with smaller narrower leaves. Panicle narrower and quite glabrous; the lower branches usually 3-flowered. Perianth nearly as in A. galangas, but much smaller; the inner lobes scarcely exceeding 4 lines. Labellum sessile, broadly ovate, slightly emarginate, and the small lateral linear lobes at the base turned towards the stamen.-Galanga minor, Rumph. Amb. v. 143. Hellenia chinensis, Willd. Spec. Pl. i. 5.

In ravines of Mount Victoria, Champion; in shady woods of the Happy Valley, Wilford; also Wright. Not known out of S. China. Fortune's plant from N. China, n. 65, and the Bonin plant referred in the Botany of Beechey's Voyage, with doubt, but erroneously to Globba Hura, Roxb., are closely allied to Alpinia chinensis, but in some measure intermediate between that species and $\mathcal{A}$. galangas. Both have a more campanulate outer perianth. In Fortune's specimens the labellum is sessile as in A. chinensis; in the Bonin ones it is stipitate, but much less so than in $A$. galangas. Whether these differences are specific, or whether the labellum is variable, is a point which remains to be determined.

\section{CANNA, Linn.}

Outer perianth of 3 short stiff persistent segments. Inner perianth petallike, united at the base in a tube with the stamens, and deciduous with them; the limb of 3 nearly equal segments. Staminal whorl consisting of 4 petallike segments, 3 barren (often called inner corolla); the fourth bearing a 1celled anther on one side. Ovary 3-celled, with several ovules. Style flattened, with a terminal stigma. Capsule muricate, 3 -valved.-Herbs with erect stems. Flowers in a terminal interrupted simple or branched spike.

A tropical genus, chiefly American, but abundant also in the Old World, especially as escapes from cultivation, producing numerous varieties published as species; $w$ hilst it is probable that the permanent indigenous forms are but few.

1. C. indica, Linn. ?; Roxb. Fl. Ind. i. 1. Stems 3 or 4 feet high. Leaves from ovate to oblong-lanceolate, acuminate, 6 to 8 in. long. Flowers red or yellow. Outer perianth-segments ovate, obtuse, 3 or 4 lines long; inner ones narrow, erect, acute, above 1 in. Petal-like stamens (or inner corolla) longer, more highly coloured, spreading towards the top.

Introduced, on hill-sides near rivulets, Wright and others. A species probably native of eastern India or the Archipelago, but now so abundantly dispersed over tropical Asia as an escape from cultivation, that it is impossible to fix the limits of its really indigenous stations.

\section{ORDER CXI. ORCHIDEÆ.}

Perianth superior, irregular, of 6 usually petal-like segments; the 3 outer ones called sepals, and 2 of the inner ones called petals, usually nearly similar; the third inner one, called the labellum or lip, differing from the others in shape, or direction, or insertion. Opposite to the labellum, in the axis of the flower, is the column, consisting of 1 or rarely 2 stamens combined with the style; the 2-celled anther or anthers being variously situated on the style itself, and each cell of the anther sometimes spuriously or partially divided into 2 or 4 smaller cells. Pollen usually cohering into 1, 2, or 4 pairs of oblong or globular pollen-masses, tapering at one end into a point, and in many genera 
attached in pairs to a stalk or caudicle, or all cohering by their points or caudicles to a gland, detaching itself from the stigma. Ovary inferior, with 3 parietal placentas. Stigmas usually forming a hollow disk on the top of the column, often with an erect projection in front of the anthers, called the rostellum. Capsule 3-valved. Seeds innumerable, minute, resembling fine sawdust. Embryo a solid apparently homogeneous mass.-Herbs (rarely shrubs), always perennial, either by means of a continuous stem or rhizome, or by annually renewed tubers; terrestrial or epiphytes; in the latter case the stems or leaf-branches are often thickened at the base into false-bulbs. Leaves entire, parallel-veined, usually sheathing at the base. Flowers usually in racemes or spikes, sometimes solitary or panicled, with a bract under each flower.

A large Order distributed over all parts of the globe, but most abundant within the tropics.

Tribe I. Operculatæ.-Anther terminal and lid-like, not adnate, and nsually decidaous. Pollen-masses of a waxy consistence. Rhizome or base of the stem usually continuously perennial, often producing false-bulbs, or the stems thickened at the base. Flowers usually pedicellate.

\section{Racemes terminating the more or tess teafy stem.}

Leaves 1 to 3 at or near the base of the flowering stem.

Labellum inserted on a projection from the base of the column and forming with it a pouch or short spur . . . . 4. ERIS.

Labellum sessile at the base of the column.

Sepals and petals very spreading. Flowers small.

Column elongated. Labellum entire . . . . . . 1. LIPARIs.

Column short. Labellum 3-toothed or lobed . . . 2. Dinnia.

Sepals and petals erect.

Anther-cells opening transversely in 2 valves . . . 5. Рноцidota.

Anther-cells opening longitudinally . . . . . 6. CaLogrne.

Leaves numerous, distant, distichous.

Labellum convolute round the column. Flowers large. Leaves

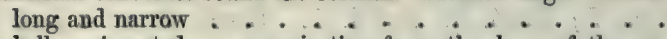

Labellum inserted on a projection from the base of the column, and forming with it a spur or pouch. Flowers scarcely 4 lines. Leaves short ......... 17. Appendicula.

Racemes or flowers on leafless scapes proceeding from the rhizome or creeping stem.

Labellum spurred at the base, convolute round the column . .

Labellum inserted on a projection from the base of the column, and forming with it a short pouch.

Pollen-masses 2, fixed to glands at the base. Flowers large, yellow. Labellum large, concave ... . . . 12. Cyrtopera.

Pollen-masses 8, without glands. Sepals narrow. Labellum flat.

Seapes $1 \mathrm{ft}$. high or more, several-flowered. Sepals and petals scarcely spreading, pubescent. Raceme 1-sided . . . . . . . . . . Sepals and petals very spreading, glabrous. Raceme loose 11. ANIA.

Minute plant, with short filiform peduncles. . . . 4. ERIA.

Labellum sessile at the base of the column, not saccate.

Stems creeping and rooting. Peduncles at the base of 1 -

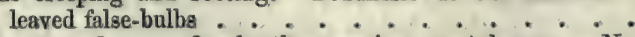

Rhizome underground, shortly creeping or tuberous. No false-bulbs. Leaves long.

Middle lobe of the labellum unguiculate . . . . 9. Spathogromis.

Labellum entire or with a sessile middle-lobe . . . . . 13. Cxмвiniuge. 
Racemes or flowers on peduncles or scapes inserted on the leafy shoots amongst or below the leaves.

Pollen-masses 2 or 4. Leaves usually coriaceous or succulent. Racemes leaf-opposed or axillary.

Leaves terete

Leaves flat.

Labellum constricted in the middle, 2-lobed at the extremity 14. Cortonia.

Labellum undivided at the end. .......... 15. ACAMPE.

Pollen-masses 8. Theaves thin, with prominent veins, Racemes on long scapes from below the leaves . . . . . . . 18. Limatodes.

TRIBE II. INeottiez.-Anther adnate on the back of the column. Pollen-masses granular. Flowering stems usually leafy, without false-bulbs. Flowers usually sessile.

Spikes very short, mostly lateral. Lower sepals connate under the labellum. Stem tall, leafy. . . . . . . . . . . 19. Tropidia.

Spikes elongated, terminal. Stems leafy near the base. Rhizomes shortly creeping or tuberous and annually renewed.

Sepals and petals ereet or slightly spreading at the top, 2 lines long or less.

Flowers in one spiral row. Labellum oblong, denticulate at the end. Leaves linear . . . . . . . . . . . 20. Sprrantres.

Flowers in a dense spike, not evidently spiral.

Labellum concave at the base, shortly recurved at the end. Leaves ovate-lanceolate . . . . . . . 22. Goodrera.

Labellum connate with the column at the base, the lower part narrow, with a transverse folding dilatation at the end. Leaves linear very spreading, 3 lines long or more. Iabellum

Lower sepals very spreading, 3 lines long or more. Labellum
concave at the base, with a transverse dilatation at the end. . 23. Hswaria. 21. ZEUXINE.

Tribe III. Ophryder.-Anther terminal, but adnate on the face of the column. Pollen-masses granular. Flowering stems usually leafy at the base, the rhizomes tuberous or fasciculate, annually renewed. Flowers usually sessile.

Labellum with a spur at the base.

Glands of the pollen-masses enclosed each in a pouch or cavity of the stigma. (Lateral lobes of the labellum long, filiform.). . 24. GLossaspis,

Glands of the pollen-masses naked ....... . 25. HABENARIA. Labellum without a spur. (Leaves small, radical.) : . . 26. AopLA.

Tribe IV. Cypripediex.-Anthers 2, one on each side of the base of a petal-like appendage to the column.

Labellum large and inflated

27. Cypripedium.

\section{IIPARIS, Rich.}

Sepals and petals free, spreading, all alike, or the petals narrower. Lip erect or ascending, shortly united with the column at the base, entire. Column elongated, incurved, winged at the top. Anther terminal, lid-like. Pollenmasses waxy, in 2 pairs, attached by their summit, but spreading laterally into the 2 anther-cells.-Terrestrial or epiphytes. Leaves at or near the base of the stem, which is often thickened at the base. Flowers small, greenishyellow or white, in a terminal raceme.

A considerable genus, chiefly Asiatic and tropical, with a very few species from temperate Asia, Europe, or N. America.

Leaves thin, 2 or 3 times as long as broad. Perianth of 3 or 4 lines. Labellum with 2 tubercles at the base. 
Perianth purple-white and green. Column-wings angular-toothed . . 1. L. nervosa.

Perianth all green. Column-wings not angular . . . . . . 2. L.odorata. Leaves rather thick, 8 or 10 times as long as broad. Perianth scarcely 1

line. Labellum without tubercles . . . . . . 3. L. longipes.

1. L. nervosa, Lindl. Gen. et Sp. Orch. 26. Stems short, slightly thickened at the base. Leaves 2 or 3 , rarely 4 , thin, ovate or oblong, acuminate, 2 to 4 in. long. Raceme 3 to 6 in., loose. Sepals and petals of a pale purple, about 4 lines long, the 2 lower sepals narrow-oblong, the upper one and the petals linear. Labellum greenish-purple, ovate or obovate, obtuse or emarginate, with 2 often stipitate tubercles at the base. Column white, the wings forming an acute angle or tooth on each side.

In clefts of rocks, Victoria Peak, Champion; in a ravine of Mount Parker, Wilford; also Hance. In Japan.

2. I. odorata, Lindl. Gen. et Sp. Orch. 26. Very near the L. nervosa, and perhaps a variety, but the column has an even not an acutely toothed margin; the sepals are oblong and very fleshy; the flowers also appear to be whole-coloured and green.

Hongkong, Champion. Also at Chekiou in China, and in the Indian Peninsula. The species requires further investigation when more satisfactory specimens shall have been obtained.

3. I. longipes, Lindl. Gen. et Sp. Orch. 30 ; Wall. Pl. As. Rar. i. t. 35; Wight, Ic. $t$. 906 . Stems longer and more readily thickening at the base than in the last. Leaves 2 or 3 , rather thick, linear-oblong or lanceolate, 6 to 8 in. long, and $\frac{1}{2}$ to $\frac{3}{4}$ in. broad. Raceme 4 to 6 in. long, with numerous small flowers, white, with a yellow labellum. Perianth not 1 line long. Column narrowly winged at the top. Labellum ovate, fleshy, free from the column, without tubercles at the base.

In clefts of rock, Champion. In India from Ceylon and the Peninsula to Nepal and Khasia.

Champion's collection contains a single specimen of what appears to be a distinct species of Liparis allied to $L$. nervosa, but without the tubercles at the base of the labellum. The specimen is; however, not sufficient for accurate determination.

\section{DIENIA, Lindl.}

Character and habit of Liparis, except that the column is short and straight, and the labellum is very concave, adnate to the column at its base, without tubercles.

A small genus dispersed over tropical and central Asia, and Mexico.

1. D. congesta, Lindl. Gen. et Sp. Orch. 22. Stem very shortly leafy, scarcely thickened at the base, $1 \mathrm{ft}$. high or more, including the raceme and long peduncle. Leaves (of Liparis nervosa) ovate-lanceolate or oblong, acuminate, 4 to 6 in. long. Raceme dense. Flowers small, (white, with a yellow labellum ?). Sepals about $1 \frac{1}{2}$ lines long, linear-oblong. Petals as long, but very narrow. Labellum shorter, very broad, concave or almost saccate, with 3 short thick lobes at the end. Column shorter, with 2 narrow wings at the top.

Hongkong, Hance, Harland. In Nepal, Khasia, and S. China. 


\section{BOLBOPHYLLUM, Thouars.}

Sepals acuminate, nearly equal; the lateral ones oblique and united with the column at their base. Petals shorter, usually very short. Labellum articulate on the base of the column, usually entire. Column very short, with 2 teeth or horns in front. Anther terminal, lid-like. Pollen-masses 4, waxy, one of each pair often much smaller. Rhizome or stem creeping and often epiphyte, with false-bulbs at the nodes, each usually bearing one leaf. Peduncles 1- or several-flowered, arising by the side of the false-bulbs.

A considerable genus, dispersed over tropical Asia and Africa.

1. B. radiatum, Lindl. Gen. et Sp. Orch. 55. False-bulbs narrow-ovoid or oblong. Leaves rather thick, oblong, obtuse or notched, $\frac{3}{4}$ to 1 in. long. Peduncles slender, about 2 in. long, with a small terminal umbel of 4 to 6 white flowers surrounded by a few lanceolate fine-pointed membranous bracts. Sepals near 4 lines long; the short broad base tapering to a long fine point. Petals about half as long. Labellum linear-lanceolate, rather thick, twice as long as the column.

Abundant in a ravine on Victoria Peak, Champion; also Wright. In Tavoy and Khasia.

\section{ERIA, Lindl.}

Sepals unequal; the lateral ones very oblique at the base, and connate with a long projection from the base of the column into a short spur or pouch. Petals equal to or smaller than the upper sepal. Labellum articulate at the end of the projection from the column and folded over it and against the column, 3-lobed or rarely entire. Anther terminal and lid-like. Pollenmasses waxy, usually 8 , free or cohering, 4 of them sometimes much smaller. Stems usually succulent at the base, or forming false-bulbs, often epiphyte. Leaves usually folded. Racemes simple, erect, 1- or many-flowered.

A considerable tropical Asiatic genus.

Minute tufted plant, with small false-bulbs and leaves. Peduncles filiform,

1- or 2 -flowered . . . . . . . . . . . . . . . . . . . .

Stems erect, 6 to 8 in. Leaves nearly as long - . . . . 2osea.

1. E. pusilla, Lindl. in Journ. Linn. Soc. iii. 48. A dwarf plant, forming close patches consisting of an intricate mass of rhizomes and minute falsebulbs. Leaves 2 to 4 lines long, usually 2 on each false-bulb. Peduncles filiform, 3 to 5 lines long, bearing 1 or 2 flowers of a dirty yellowish-green, and slightly fetid. Sepals and petals about 2 lines long, all acuminate. Labellum linear-lanceolate, folded, entire, or minutely serrulate.-Conchidium pusillum, Griff. Notul. t. 310 . Phreatia uniflora, Wight, Ic. t. 1734. Eria sinica, Lindl. in Journ. Linn. Soc. iii. 4.8.

On bare rocks on the top of Vietoria Peak, Champion. Also in Khasia.

2. E. rosea, Lindl. Bot. Reg. t. 978 ; Journ. Linn. Soc. iii. 50. Falsebulbs ovoid, very thick, bearing usually a single leaf; flowering stems 6 to 8 in. high, with 1 or 2 leaves at the base. Leaves oblong-linear or lanceolate, thick, nearly as long as the stem. Flowers 2 to 4 , pink, distant. Bracts linear, 1 to $1 \frac{1}{2}$ in. long. Sepals and petals broadly oblong, obtuse, erect, 6 to 7 lines long. Labellum broadly obovate, 3 -lobed; the 2 lateral lobes erect; 
the middle one large, emarginate, with 1 raised crest along the centre, and 2 short lateral ones at its base.

On rocks on the top of Mount Gough, Champion, Wilford. Not known out of S. China, although certainly nearly allied to the $E$. carinata, Gibs., from Khasia, which Lindley had formerly associated with it.

\section{PHOLIDOTA, Lindl.}

Sepals equal, distinct, erect. Petals smaller. Labellum concave, entire or 3-lobed, inserted at the base of the column, and parallel with it. Anther terminal, lid-like, each cell opening transversely in 2 valves. Pollen-masses 4 , waxy, globular, distinct.-Stems succulent or producing false-bulbs. Flowering branches leafy at the base, with a terminal spike usually distichous.

A small tropical Asiatic genus.

1. P. chinensis, Lindl. in Journ. Hort. Soc. Lond. ii. 308. Rhizome thick, shortly creeping. False-bulbs ovoid, bearing 1 or 2 leaves. Flowering stems 4 to 6 in. long, with 1 or 2 leaves. Leaves oblong or oval-oblong, acuminate, 2 to $4 \mathrm{in}$. long, stiff and folded. Racemes incurved, with 6 to 8 distant greenish-white flowers. Bracts lanceolate, concave. Sepals ovate, about 5 lines long. Petals linear, rather shorter. Labellum broadly obovate, very obtuse, with a small point in the centre, which is ultimately bent down so as to make the labellum appear 2-lobed. Column winged at the top.

Abundant on rocks, Victoria Peak, and other places, Champion; on mountain-sides, Fortune; also Wright, Hance, Seemann. Not known out of S. China.

\section{COELOGYNE, Lindl.}

Sepals equal, distinct. Petals similar or narrower. Labellum concave, inserted at the base of the column, and parallel with it, 3-lobed or entire, with longitudinal crests. Column winged. Anther lid-like, inserted below the top of the column. Pollen-masses 4, waxy, free.-Rhizomes creeping, producing false-bulbs. Flowering stems leafy at the base, 1- or several-flowered.

A considerable tropical Asiatic genus.

1. C. fimbriata, Lindl. Bot. Reg. t. 868. False-bulbs ovoid. Leaves usually 2 , oblong-lanceolate, thick, about $3 \mathrm{in}$. long. Peduncle on the falsebulb between the leaves, and about their length, with several imbricate sheathing scales at the base. Flowers 2 or 3 , of a pale dirty-yellow; the labellum paler, crested with purple. Bracts deciduous. Sepals 10 or 11 lines long, broadly oblong-lanceolate, acute. Petals narrow-linear. Labellum 3-lobed, the middle lobe fringed on the edge, with 2 raised nearly parallel plaits on the disk.

Common in ravines, Champion, Wilford. In S. China and Khasia.

\section{ARUNDINA, Blume.}

Sepals lanceolate, equal. Petals usually broader. Labellum broad, convolute round the column, entire or 3-lobed, not spurred. Column club-shaped at the top. Anther terminal, lid-like. Pollen-masses 4, waxy, equal.- Stems erect, leafy, from a perennial rhizome, without false-bulbs. Leaves distichous. Flowers few, large.

A small tropical and subtropical Asiatic genus. 
1. A. chinensis, Blume; Lindl. Gen. et Sp. Orch. 125. Stems erect, $1 \mathrm{ft}$. high or more, leafy to near the top. Leaves stiff, linear, 4 to $7 \mathrm{in.long,}$ 4 to 5 lines broad. Flowers (pink?) 2 to 5, on short pedicels. Bracts short, concave. Sepals and petals $l$ in. long or more. Labellum rather longer, loosely enveloping the column, spreading and broadly 3-lobed at the top, the middle lobe larger, notched or 2-lobed, with 3 longitudinal veins more or less prominent.-A. Philippi, Reichb. fil. in Linnæa, xxv. $22 \%$.

Common in Hongkong, Champion and others. On the adjoining continent and northward to Amoy.

\section{PHAIUS, Lour.}

Sepals and petals nearly equal, free. Labellum broad, convolute round the column, entire or 3-lobed, spurred at the base. Column semi-cylindrical. Anther terminal, lid-like. Pollen-masses 8, waxy, nearly equal.- Tall erect herbs with large leaves. Scapes radical, leafless except sheathing scales. Flowers large and showy.

A small tropical or subtropical Asiatic genus.

1. P. grandifolius, Lour.; Lindl. Gen. et Sp. Orch. 126. Stems tufted, usually thickened into short tubers or false-bulbs at the base, bearing 2 or 3 ovate-lanceolate or oblong leaves, often above $1 \mathrm{ft}$. long, narrowed into a long petiole. Scape 2 or $3 \mathrm{ft}$. high, bearing a raceme of showy flowers, usually white outside and cinnamon-brown inside; the labellum white, shaded and streaked with crimson. Sepals and petals near 2 in. long.-Bletia Tankervilla, Br. in Bot. Mag. t. 1924.

Common by the sides of streams, Champion and others. Also on the Chinese continent, and frequently cultivated in gardens.

\section{SPATHOGLOTTIS, Blume.}

Sepals and petals nearly equal, free, spreading, the petals rather broader. Labellum articulate at the base of the column, not spurred, but concave or saccate, deeply 3 -lobed, the middle lobe contracted into a claw, and tuberculate or cristate. Column winged or petal-like. Anther terminal, lid-like. Pollen-masses 8, waxy.-Rhizomes underground. Leaves narrow. Scapes radical, leafless.

A small tropical Asiatic genus.

1. S. Fortunei, Lindl. Bot. Reg. 1845, t. 19. Rhizome tuberous. Leaves radical, usually 2 together, linear-lanceolate, 6 to 10 in. long. Scape pubescent, 1 to $2 \mathrm{ft}$. high, leafless except a few sheathing scales. Flowers 3 to 8 , yellow, distant. Bracts short, lanceolate. Perianth-segments $\frac{1}{2}$ in. long or rather more. Lateral lobes of the labellum broadly oblong-falcate, middle lobe obovate, emarginate, the broad claw with 2 lateral angles at its base and 2 much raised longitudinal plaits above the middle.

Common in the island, Fortune, Champion, and others. Not known from elsewhere, unless it be but a slight variety of the S. pubescens, Lindl., from Khasia and Silhet.

\section{PACHYSTOMA, Blume.}

(Apaturia, lindl.)

Sepals and petals ereet or slightly spreading, nearly equal, or the petals 
narrower. Labellum saceate at the base, articulate on a short projection of the base of the column, erect, 3 -lobed, crested in the centre. Anther terminal, lid-like, half-immersed in the dilated summit of the column. Pollen-masses 8, waxy, nearly equal.-Terrestrial leafless herbs, with a tuberous rhizome. Scapes erect, with scarious sheathing scales and bracts. Flowers pubescent, in a 1-sided spike.

A small tropical Asiatic genus.

1. P. chinense, Reichb. fil. in Bonplandia, 1855, 251. Scapes 1 to $1 \frac{1}{2} \mathrm{ft}$. high, with a terminal raceme of about $3 \mathrm{in}$. Bracts lanceolate, scarious with fine points. Ovary densely pubescent. Perianth also pubescent, of a light lilac, about $\frac{1}{2}$ in. long. Sepals lanceolate, pubescent, the upper one rather narrower, the petals linear. Labellum yellow, rather shorter, the 2 lateral lobes broadly oblong, obtuse; the middle one rather longer, broadly oblong, with a short point; and 3 or sometimes 5 longitudinal crests or rows of tubercles on the disk.-Apaturia chinensis, Lindl. Gen, et Sp. Orch. 131.

In marshy spots on the top of Mount Gough, Champion; also Seemann, Hance, Wright. Not known ont of S. China.

\section{ANIA, Lindl.}

Sepals and petals nearly equal, spreading. Labellum connate with the base of the column in a short spur or pouch, 3-lobed, flat, with raised plates on the disk. Column winged. Anther terminal, lid-like. Pollen-masses 8, of which 4 often smaller, waxy.-Rhizome creeping. Leaves radical, proceeding from a false-bulb. Scapes leafless except the sheathing scales. Flowers glabrous, in loose racemes.

A small tropical Asiatic genus.

1. A. angustifolia, Lindl: Gen. et Sp. Orch. 129. Leaves oblong-lanceolate, 6 to $10 \mathrm{in}$. long, $\frac{1}{2}$ to $1 \frac{1}{2} \mathrm{in}$. broad, narrowed into a long petiole, proceeding from an ovoid false-bulb. Scape $1 \frac{1}{2} \mathrm{ft}$. long or more. Flowers distant. Bracts narrow, very pointed. Sepals and petals full 7 lines long, lanceolate, with short fine points. Labellum concave at the base, forming with a projection from the base of the column an obtuse spur of rather more than 1 line; the lamina 6 lines long, obovate-cuneate, entire or slightly 3 -lobed, with 3 slightly raised longitudinal plaits.

In a ravine of Mount Parker, Wilford; also Wright; and probably the same species seen by Champion and gathered past flower by Hance; and supposed to be the N. Indian $A$. latifolia, Lindl. These specimens however agree in every respect with the spurred-flowered A. angustifolia, from Tavoy, except that I find the pollen-masses nearly equal in size, instead of 4 being smaller as described. They had already fallen away in the flower I examined of my Tavoy specimen, but I believe that Dr. Lindley now considers this character as less constant than he at first supposed it to be.

\section{CYRTOPERA, Lindl.}

Sepals and petals nearly equal, spreading, the petals broader. Labellum connate at the base, with a projection from the column into a short broad pouch; the lamina concave, broadly 3-lobed, the lateral lobes erect. Anther terminal, lid-like. Pollen-masses 2, usually 2-lobed, waxy, with a short tri- 
angular caudicle.-Tall herbs. Barren stems leafy, on a succulent or falsebulbous base. Scapes leafless, bearing a raceme of showy flowers.

A small genus, dispersed over S. Asia, Africa, and S. America.

1. C. flava, Lindl. Gen. et Sp. Orch. 189 ; Royle, Illustr.t. 88. Leaves long-lanceolate. Scapes 2 to $3 \mathrm{ft}$. high, with a long raceme of large yellow flowers. Sepals pointed, $1 \frac{1}{2}$ in. long. Petals as long, but broader and less pointed. Concave base of the labellum projecting 4 lines from the pedicel.C. Cullenii, Wight, Ic. t. 1754 .

Hongkong, Wright. On the adjacent continent, and in the mountains of N. India.

\section{CYMBIDIUM, Sw.}

Sepals and petals nearly equal, spreading. Labellum sessile, free or shortly connate with the base of the column, concave, entire or 3-lobed. Column erect. Anther terminal, lid-like. Pollen-masses 2, usually 2-lobed, waxy, almost sessile, on a triangular base.-Rhizome creeping or stems tufted. Leaves radical, or on false-bulbs, or on barren stems. Scapes usually leafless. Flowers in racemes, usually large.

A considerable tropical and subtropical genus, common to the New and the Old World, and extending in Africa to the southern extremity.

4. C. ensifolium, Sw.; Lindl. Gen. et Sp. Orch. 162; Bot. Mag. t. 1751 ; Bot. Reg. t. 1976. Leaves radical, tufted, linear or linear-lanceolate, often above a foot long, rather stiff. Scapes usually shorter, leafless except sheathing scales, with 3 to 6 distant flowers. Bracts.much shorter than the ovary. Sepals about 1 in. long, oblong-lanceolate, of a dirty white, green, or yellowish, with purple streaks. Petals rather smaller and less coloured. Labellum oval-oblong, entire or obscurely 3 -lobed, recurved towards the top, greenish-yellow with spots.

On rocks, Champion; also Hance. Not known ont of S. China.

C. xiphiifolium, Lindl. Bot. Reg. t. 529, is also included in Reichenbach's enumeration of Hance's Hongkong Orchidea. I have not seen the specimens, but believe it to be only a variety of $C$. ensifolium, with the flowers wholly yellowish-green, without streaks or spots.

\section{CotTonia, Lindl.}

Sepals spreading, obovate. Petals rather smaller. Labellum concave, constricted in the middle, the upper half 2 -lobed, the lower half with 2 tubercles at the base. Column erect, with membranous edges. Anther terminal, lidlike. Pollen-masses either 2 and 2-lobed, or 4; caudicles filiform,-Stems leafy, succulent. Flowers in axillary or leaf-opposed racemes,

A small tropical Asiatic genus.

1. C. Championi, Lindl. in Kew Journ. Bot. vii. 35, and Journ. Limn. Soc. iii. 39. A small epiphyte. Leaves distichous, linear-oblong, entire or notched at the summit, $1 \frac{1}{2}$ to $2 \mathrm{in}$. long. Racemes leaf-opposed, few-flowered. Flowers yellow, inconspicuous, with a pale purple column. Sepals and petals nearly equal. Labellum "half-boatshaped, short, with a process at the extremity ending in 2 setiform forks."

On Victoria Peak, Champion. Also in Khasia. Reichenbach (Seem. Bot. Her. 419) mentions a plant without flowers, which he thinks might be the Saroanthus rostratus, Lindl. 
Collect. t. $39 \mathrm{~B}$. In that state, however, he might easily have mistaken the Cottonia for a Sarcanthus.

\section{ACAMPE, Lindl.}

Sepals and petals nearly equal, spreading, fragile. Labellum fleshy, adnate to the unproduced base of the column, hollowed into a spur or pouch in the lower part, the upper part undivided, Column short, thick, usually 2-pointed. Anther ovate, terminal. Pollen-masses 2, waxy, with a subulate caudicle longer than themselves.-Epiphytes, with coriaceous distichous leaves. Flowers densely racemose, on short lateral peduncles.

A small tropical Asiatic genus.

1. A. multiflora, Lindl. Fol. Orchid. i. Leaves linear-oblong, 6 to 8 in. long by about $1 \frac{1}{2}$ in. broad, obliquely obtuse at the top, thickly coriaceous. Peduncles branching, shorter than the leaves. Flowers small, in short racemes or corymbs, yellow dotted with red. Labellum ovate, rather acute; the spur short, with raised lines or folds.

Common in ravines, Champion, Seemann. Not known out of S. China.

\section{LUISIA, Gaudich.}

Sepals herbaceous, the upper one smaller. Petals thinner, usually longer. Labellum undivided, usually auriculate, continuous with the column, not appendiculate, convex or concave. Column very short, fleshy. Anther terminal, lid-like. Pollen-masses 2, with a short broad caudicle.-Stems rush-like, leafy. Leaves stiff, terete. Flowers small, dark green or purple, in lateral racemes.

A small tropical Asiatic genus.

Champion found a species, apparently of this genus, on rocks in the island : but his specimens are not in flower, and cannot be identified. Lindley believes them to be the $L$.teres, Blume, a Javanese plant.

\section{APPENDICULA, Blume.}

Sepals connivent, the lower ones connate with a projection from the base of the column into an obtuse spur. Petals smaller. Labellum connate with or inserted on the projection of the column, sessile, concave, appendiculate at the base or bordered by a raised margin ; the lamina entire or 3-lobed. Column short, tapering into an emarginate beak. Anther terminal. Pollen-masses 8, rarely 6 or 4 , waxy, attached by 2 membranous caudicles.-Epiphytes with short distichous oblique leaves. Flowers small, in lateral or terminal racemes or rarely solitary.

A small tropical Asiatic species.

1. A. bifaria, Lindl. in Kew Journ. Bot. vii. 35. Leaves numerous, oblong, 1 in. long or rather more, obtuse and usually notched, with a minute point in the notch. Spikes terminal, scarcely longer than the last leaves. Flowers nearly 4 lines long, including the broad obtuse pouch or spur. Sepals and petals nearly equal. Labellum "oblong, with a circular membranous appendage and an ovate tooth on the lamina."

In ravines of Mount Gough, Champion. Also in Penang, if the species be really the same. 


\section{IIMATODES, Blume.}

Sepals and petals spreading, free, nearly equal. Labellum inserted at the base of the very short column, concave or convolute, entire or lobed, with folds or tubercles on the disk. Anther terminal. Pollen-masses 8, waxy, attached in fours to a divisible gland. Stems leafy. Scapes or peduncles leafless, erect, inserted at the base of the stem below the leaves.

A small tropical Asiatic genus.

1. I. gracilis, Lindl. in Kew Journ. Bot. vii. 36. Stems 1 to $2 \mathrm{ft}$. high. Leaves oblong, 6 to $8 \mathrm{in}$. long, tapering to a fine point, thin, with prominent veins. Scapes 6 in. to $1 \mathrm{ft}$. long, with several obtuse sheathing scales and a short loose raceme of yellow-green flowers, without bracts at the time of flowering. Sepals and petals nearly $\frac{1}{2}$ in. long, recurved and wavy at the top. Labellum oblong, not spurred, convolute in the lower half, with 2 small lateral lobes; the middle lobe large, very much waved on the edge, with 2 raised lines on the disk.-Calanthe gracilis, Lindl. in Bot. Mag. t. 2714.

On Vietoria Peak, Champion. Also in Khasia and Silhet.

\section{TROPIDIA, Lindl.}

Sepals and petals connivent, the 2 lower connate at the base in a short pouch. Labellum concave or saccate at the base within the lower sepals; the limb erect or spreading, undivided. Column oblique, with an acute or 2-cleft beak. Anther acuminate, adnate on the back of the column. Pollen-masses 2, glandular, affixed by the caudicle to a common gland.-Stems leafy, erect, often branching. Spikes short, terminal or lateral.

A small tropical Asiatic genus.

1. T. curculigoides, Lindl. Gen. et Sp. Orch. 497. Stems tall, erect, flabrous. Leaves distichous, oblong-lanceolate or linear-lanceolate, long-acuninate, 6 to 8 in. long, sessile on a close striate sheath. Spikes very short and few-flowered, terminal or leaf-opposed. Bracts small, herbaceous, striate. Flowers greenish-white, about 5 lines long. Sepals and petals narrow, more or less falcate.-Ptychochilus septemnervis, Schauer in Pl. Meyen. 431, t. 12, f. $B$.

In a ravine of the Wangnachang woods in the Happy Valley, Champion. In Ceylon, the Indian Archipelago, the Malayan Peninsula, Khasia, Sikkim, and the Philippines. The Hongkong speeimens come nearest to the variety described as T. squamata, Blume, with the bracts ovate-lanceolate or linear-lanceolate, but usually without the fine point of the Ceylon and Malacea specimens originally described by Lindley.

\section{SPIRANTHES, Rich,}

Sepals and petals nearly equal, erect or spreading at the tips; the 2 lower sepals oblique, covering the base of the labellum, the upper one cohering with the petals. Labellum adhering to a projection from the base of the column, with 2 tubercles or protuberances below the middle. Anther attached to the back of the short column. Pollen-masses 2, granular, united at the top to a single gland.-Terrestrial herbs. Leaves at the base of the stems or on the annually renewed tuberous rhizome. Flowers small, usually in 1 or 2 spiral rows.

A conside ble genus, dispersed over the greater part of the world. 
1. S. australis, Lindl. Gen. et Sp. Orch. 464, var. pudica. Leaves few, at the base of the stem, linear or linear-lanceolate, the longest about 3 in. long. Stems $\frac{3}{4}$ to $1 \frac{1}{2} \mathrm{ft}$. high, including a spiral spike of 2 to 4 in.; the rhachis glabrous or nearly so in the Chinese variety, pubescent in others. Flowers white, tinged with red, about 1 line long. Labellum oblong, with an ovate base, the upper half crisped on the edge. $-S$. pudica, Lindl. Coll. Bot. t. 30 .

Frequent in marshy places, Champion and others. Common in central Asia and the mountain districts of S. Asia, from Ceylon and the Peninsula to the Archipelago, and in Australia, but usually pubescent and with larger flowers than in China, and perhaps not specifically distinct from the European $S$. astivalis.

\section{ZEUXINE, Lindl.}

Sepals, petals, and anther of Spiranthes. Labellum concave and cohering at the base to the very short column; the lamina thick, transversely dilated at the end into 2 lobes, which fold face to face-Terrestrial herbs, leafy at the base. Flowers sunall, in dense spikes not distinctly spiral.

A small tropical Asiatic genus.

1. Z. sulcata, Lindl. Gen. et Sp. Orch.485, and Journ. Linn. Soc. i. 186. Stems seldom above 3 or 4 in. higit. Leaves linear or linear-lanceolate, $\frac{1}{2}$ to 1 in. long. Spikes short and dense. Flowers about $2 \frac{1}{2}$ lines long. Sepals and petals connivent, white, with a yellow tinge. Labellum narrow, concave, of a bright yellow.

On the race-course in the Happy Valley, Eyre, Wilford. Widely spread over India, from Ceylon and the Peninsula to Nepal, Khasia, and the Archipelago.

\section{GOODYERA, Lindl.}

Sepals, petals, and anther of Spiranthes. Tabellum entire, concave, and without protuberances at the base, but often with callosities on the disk higher up. Column very short.-Terrestrial herbs. Rhizome often creeping. Flowers small, in spikes not distinctly spiral, on stems leafy at least at the base.

A small genus ranging over the northern hemisphere.

1. G. procera, Hook. Exot. Fl. t. 39; Lindl. Gen. et Sp. Orch. 493. Stems 1 to $1 \frac{1}{2} \mathrm{ft}$. high. Leaves towards the base ovate-lanceolate, acuminate, 2 to 4 in. long, tapering into rather long petioles, the upper ones reduced to a few sheaths, Flowers white, mixed with green, in a spike of 3 or $4 \mathrm{in}$. Sepals ovate, concave, about 1 line long. Petals narrower. Labellum almost saccate at the base and glandular inside; the lamina narrow, recurved, rather thick, with 2 ovate protuberances on the disk. Anther half-buried in a pouch at the back of the stigma.-Neottia procera, Bot. Reg. t. 639.

On Mounts Gough and Victoria, Champion; also Hance and Seemann. In the hilly districts of India, from Ceylon and the Peninsula to Assam and Sikkim.

\section{H开MARIA, Lindl.}

Sepals and petals nearly equal; the upper sepal and petals cohering in a helmet over the column, the 2 lower spreading. Labellum free, slightly saccate, with 2 tubercles at the base, flat, with a transverse dilatation at the end. 
Column narrow at the base, dilated at the top into a 2-lobed cup. Anther adnate to the hinder lobe. Pollen-masses 2 , granular, connected by a gland at the top.

A genus limited to a single species.

1. F. discolor, Lindl. Gen. et Sp. Orch. 490. Rhizome at the base of the stem slightly succulent and creeping. Stem pubescent, ascending to 6 or 8 in. Leaves 2 or 3 , near the base, stalked, ovate, 1 to 2 in. long, the upper ones reduced to sheaths. Flowers white, in a loose spike of 2 or 3 in. Ovaries pubescent, near $\frac{1}{2}$ in. long. Sepals ovate-oblong, 4 to 5 lines long. Petals narrow. Labellum full 4 lines long, wavy on the edge, with a terminal transversely oblong dilatation.-Goodyera discolor, Bot. Reg. t. 271.

On rocks in ravines behind the town of Victoria, and in a raviue of the Happy Valley, very rare, Champion; also Wright and Hance. Not known out of S. China.

\section{GLOSSASPIS, Spreng.}

Habit and characters of the small-flowered Habenarias, except that the terminal glands of the caudicles of the pollen-masses are received into distinct cells of the stigma.

A genus limited to a single species.

1. G. tentaculata, Lindl. Gen. et Sp. Orch. 284 ; Bot. Reg. t. 862. Tuber ovoid. Leaves 2 to 4 , at or near the base of the stem, ovate-oblong or lanceolate, 2 to $3 \mathrm{in}$. long. Stem $8 \mathrm{in}$. to $1 \mathrm{ft}$. including the slender spike. Bracts about the length of the ovary. Flowers green. Sepals and petals scarcely 2 lines long, converging over the column. Labellum deeply 3 -lobed, with filiform lobes full $\frac{3}{4}$ in. long. Spur very short, vesicular.-G. antennifera, Reichb. Fil. in Linnæa, xxv. 225.

Very common in moist situations, Champion and others. Also on the adjacent continent, but not known out of S. China.

\section{HABENARIA, Willd.}

(Peristylus, Blume, and Platanthera Rich.).

Sepals and petals nearly alike, or the petals narrow, all converging over the column, or the lower sepals spreading. Labellum spreading, 3-lobed or rarely entire, with a short or long spur at the base. Column short, with a short beak erect under the anther. Anther terminal but adnate on the face of the column ; the cells parallel or diverging, and sometimes free at the tips. Pollenmasses 2, granular; the caudicles terminating in glands, distant from each other, and not immersed in cells of the stigma.-Rhizome tuberous, but annually renewed by the formation of a fresh tuber, when the previous one decays. Stems also annually renewed, erect, usually leafy at the base; the leaves passing into sheathing scales. Flowers sessile in a terminal spike, with a bract under each.

A large genus, dispersed over the greater part of the world.

Spur much shorter than the ovary.

L,abellum narrow, 3-lobed. Flowers small, greenish.

Spur very small, vesicular or ovoid.

Lateral lobes of the labellum short, linear-falcate . . . 1. H. lacertifera.

lobes of the labellum very long and filiform . . . . 24. GLossaspis.

Spur cylindrical, half as long as the ovary . . . . . 2. H. stenostachya. 
Labellum broadly obeordate or rounded. Bracts leafy, mostly longer than the flower. Spur very broad at the base

7. H. galeandra.

Spur longer than the ovary.

Lateral lobes of the labellum entire.

Lateral lobes very short, middle lobe long and linear . . . . 4. H. linguella.

Lobes of the labellum all 3 linear and nearly equal . . . . 3. H. leptoloba.

Lateral lobes broad, deeply fringed, middle lobe linear.

Sepals about 4 lines long. Labellum 6 to 8 lines broad . . . 5. H. Miersiana.

Sepals about 1 in. long. Labellum 2 to 3 in. broad . . . 6. H. Susanna.

1. H. lacertifera, Benth. Tubers small, globular. Leaves few, oblonganceolate, 2 to $3 \mathrm{in}$. long. Stem 6 to $10 \mathrm{in}$., including a somewhat spiral spike of 2 or 3 in. Bracts as long as the ovary. Flowers light green, about $1 \frac{1}{2}$ lines long; the sepals all connivent. Spur very short and vesicular. Labellum rather longer than the sepals, with a raised protuberance on the disk, and divided to the middle into 3 short linear lobes; the 2 lateral ones diverging and somewhat falcate. Anther-cells slightly diverging.-Coeloglossum lacertiferum, Lindl. Gen. et Sp. Orch. 302. Peristylus chlorantha, Lindl. in Kew Journ. Bot. vii. 37.

In marshy spots and slopes on the top of Victoria Peak, Champion. In Khasia and Tavoy.

2. F. stenostachya, Benth. Stems 6 in. to $1 \mathrm{ft}$. (or more?) including a many-flowered spike of 2 to 4 in. Leaves lanceolate, 2 to 3 in. long. Sepals and petals about 2 lines long, linear, obtuse, rather thick, connivent or slightly spreading. Bracts as long as the ovary, ending in a short fine point. Spur slender, shorter than the ovary, usually about 2 lines long. Labellum nearly equally 3 -lobed; the lateral lobes linear-lanceolate and divaricate; the middle one usually (perhaps always) short and obtuse.-Platanthera stenostachya, Lindl. in Kew Journ. Bot. vii. 37. Coeloglossum cernuum, Reichb. fil. in Bonplandia, 1855, 250, corrected to C. peristyloides in Bonplandia, 1856, 321.

Hongkong, Champion. Also in Moulmein (Lobb, в. 363). I have not seen Hance's specimen, but Reichenbach's first description as Caloglossum cernuum agrees very well with Champion's plant. The corrected description appears to have been somewhat modified to include the $C$. peristyloides, Wight, Ic. t. 1702, a species from the Indian Peninsula, certainly very nearly allied, but differing in the long middle lobe of the labellum, and some other points.

3. H. leptoloba, Benth., n. sp. Stem rather slender, 6 in. to $1 \mathrm{ft}$. including a slender and rather long spike. Leaves lanceolate or linear, 1 to 3 in. Flowers distant, with small bracts. Ovary shortly beaked. Sepals and petals ovate-lanceolate, 2 lines long, the upper ones converging over the column; the 2 lower spreading. Labellum rather longer, deeply divided into 3 narrowlinear lobes, adhering at its base to the column with a minute tooth on each side between the labellum and the anther. Spur 5 or 6 lines long, thickened towards the lower end. Anther-cells very diverging, nearly horizontal.

Hongkong, Harland, Hance. Not known from elsewhere.

4. H. linguella, Lindl. Gen. et Sp. Orch. 325. Stem leafy, $\frac{3}{4}$ to $1 \mathrm{ft}$. high. Leaves narrow-lanceolate. Spike dense, 1 to 3 in. long. Bracts subulate-acuminate, nearly as long as the beaked ovary. Flowers at first pure 
yellow, afterwards brown. Sepals and petals broadly ovate, concave, near 3 lines long; the upper ones forming a helmet; the 2 lower more spreading. Labellum 3-lobed, adhering at the base to 2 lateral processes of the column; lateral lobes short, divaricate, close to the base, middle lobe narrow-linear, longer than the sepals. Spur nearly $1 \mathrm{in}$. long, thickened towards the lower end. Anther-cells very divergent.

In marshy spots on Victoria Peak, Champion. On the Chinese coast and in Ceylon.

5. H. Miersiana, Champ. in Kew Journ. Bot. vii. 37. Tuber ovoid. Stem $1 \mathrm{ft}$. high or more. Leaves 2 or 3, oblong, scarcely pointed, the largest 4 in. long. Spike short. Flowers few, pure white. Sepals ovate, acute, about 4 lines long; the uppermost with the rather smaller petals connivent; the 2 lower more spreading. Labellum longer, 6 to 8 lines broad, with 3 lobes of equal length, the 2 lateral broad and deeply fringed, the middle one narrow and entire. Spur $1 \frac{1}{2}$ in. long, slightly thickened towards the end.

In a ravine on Victoria Peak, Champion. Not seen in any other collection, but nearly allied to the $\boldsymbol{H}$. geniculata, Don, from Nepal and Burmah.

6. H. Susannæ, $B r$. Prod. 312. Stems leafy, attaining 3 or even $4 \mathrm{ft}$. Lower leaves from ovate to oblong, 3 to $4 \mathrm{in}$. long; the upper ones passing into lanceolate bracts of $2 \mathrm{in}$. Raceme of 3 or 4 large greenish-white fragrant flowers. Sepals ovate, 1 to $1 \frac{1}{2}$ in. long. Petals linear, about as long. Labellum 2 to 3 in. across, with 2 lateral broad deeply fringed lobes, the middle one oblong-linear and entire. Spur $2 \frac{1}{2}$ to 3 in. long.-Platanthera Susanna, Lindl. Gen. et Sp. Orch. 295. Habenaria gigantea, Hook. Bot. Mag. t. 3374 .

Common on the grassy slopes and summits of the hills, Champion and others. In the hilly districts of India, from the Concan mountains to the Himalaya, Khasia, and the Archipelago.

7. H. galeandra, Benth. Tubers small, globular. Stem 6 to 8 in. high. Leaves oval-oblong; the larger ones 1 to 2 in. long, passing into the bracts, which are all oblong, leafy, and spreading, the lower ones as large as the stem-leaves. Flowers distant, white variegated with lilac, mostly shorter than the bracts. Sepals lanceolate, 3 lines long, the upper one arching over the linear petals, the 2 lower spreading when fully open. Labellum clawed, broadly obcordate or nearly orbicular, 5 lines long, waved on the margin. Spur or pouch very broad at the base, short and obtuse. Anther-cells nearly parallel.-Platanthera galeandra, Reichb. fil. in Linnæa, xxv. 226. P. Championi, Lindl. in Kew Journ. Bot. vii. 38.

Common on Victoria Peak, Champion; also Fortune, Hance, and Wright. Not known out of the island, but nearly allied to the N. Indian Plat. obcordata, Lindl., which is chiefly distinguished by a very much narrower spur.

\section{AOPLA, Lindl.}

Characters of Habenaria, except that the labellum is not spurred, and has the margins connate with the very short column into a sort of cup, with a curved process on each side.

A genus limited to a single species.

1. A. reniformis, Lindl. Gen. et Sp. Orch. 304. Leaves 2 or 3, radical, rosulate, ovate-cordate, about $\frac{1}{2}$ in. long. Stem slender, about 6 in. 
high, with a few sheathing scales. Flowers 3 to 6 , distant. Bracts small. Sepals oval-oblong, $2 \frac{1}{2}$ lines long, the upper one arched over the linear petals, the 2 lower spreading. Labellum linear, entire, 3 lines long, the 2 processes at its base almost hooked. Anther-cells very divergent. Pollen-masses with long caudicles.

Hongkong, Harland and Hance. Also in Nepal.

\section{CYPRIPEDIUM, Linn.}

Sepals and petals spreading, the 2 lowest often united into one under the labellum. Labellum large, inflated. Column very short, terminating in a dilated incurved petal-like lobe, with 2 distinct 2-celled anthers, one on each side. Pollen granular.-Herbs with fibrous rhizomes. Leaves radical or on the stems. Flowers large, solitary or few in a terminal raceme or panicle.

A considerable Asiatic and N. American genus, with one species extending into Europe.

1. C. purpuratum, Lindl. Bot. Reg. t. 1991 ; Gen. et Sp. Orch. 530; Bot. Mag.t. 4901 . Rhizome shortly creeping, with thick succulent fibres. Leaves radical, oblong, 4 to 5 in. long, marked with darker-coloured blotches. Scape 8 in. to $1 \mathrm{ft}$. high, pubescent, bearing a single large flower with a sheathing bract at the base. Upper sepal very broad, acuminate, about $1 \frac{1}{4} \mathrm{in}$. long, white, with purple veins. Lower ones united in a single oblong-lanceolate one. Petals oblong, $1 \frac{1}{2}$ in. long, purple, fringed with a few small hairs, without the tubercles of $C$. barbatum. Labellum also purple, full $1 \frac{1}{2} \mathrm{in}$. long, broadly inflated.

In moist ravines, ou the hills, Champion and others; also in Khasia (and in the Malayan Peninsula ?).

\section{Order CXII. BURMANNIACE无.}

Flowers hermaphrodite, regular. Perianth superior, persistent, tubular or campanulate, usually 6 -lobed, the 3 inner lobes often smaller or sometimes wanting. Stamens 3 or 6 , inserted in the tube and shorter than the perianth. Anthers 2-celled. Ovary inferior, 3-celled, or with 3 parietal placentas and numerous ovules. Style single, with 3 eniire or 2-lobed usually radiating stigmas. Fruit a capsule. Seeds minute. Embryo apparently homogeneous. - Herbs. Leaves usually radical or nearly so, or reduced to scales. Flowers terminal, solitary or several, in spikes, racemes, cymes, or umbels.

A small tropical Order, common to the New and the Old World.

\section{GONYANTHES, Miers.}

Perianth tubular, 3-angled or winged, the 3 inner lobes minute (or wanting?). Anthers 3, nearly sessile below the inner lobes. Ovary 3-celled. Capsule opening by transverse fissures opposite the cells.-Delicate leafless herbs. Flowers terminal, solitary or cymose.

A small tropical Asiatic genus, differing from Burmannia only in the dehiscence of the capsule.

1. G. Wallichii, Miers in Linn. Trans. xviii. 537, t. 38, f. 2. Stem filiform, 1 to $3 \mathrm{in}$. high, either simple with a single terminal blue flower, or 
divided into 2 or 31 -flowered branches. Leaves replaced by minute scales. Perianth narrow-tubular, about 3 lines long, with 3 prominent angles, often dilated into narrow sinuate wings. Outer lobes short, ovate; inner ones very minute.

Among long grass, on the slope of Mount Gough, Wilford. In Burmah and Tavoy.

\section{Order CXIII. IRIDEAE.}

Flowers hermaphrodite, regular or irregular. Perianth superior; with 6 petal-like segments. Stamens 3, inserted at the hase of the segments. Anthers erect, opening outwards. Ovary inferior, 3-celled, with several ovules in each cell. Style single, with 3 stigmas, sometimes dilated and petal-like or fringed. Capsule opening loculicidally in 3 valves. Seeds albuminous, with a small embryo, the radicle next to the hilum.- - Herbs with usually a tuberous, creeping, or bulbous rhizome. Leaves usually either radical or equitant, that is, alternately sheathing on opposite sides of the stem, and vertically, not horizontally, flattened. Flowers usually terminal, solitary or in spikes, racemes, or panicles.

A large Order ${ }_{2}$ consisting chiefly of natives of the temperate regions of the northern hemisphere, or of southern Africa, with a few tropical or Australian species.

\section{PARDANTHUS, Ker.}

Perianth of 6 equal spreading segments. Stamens nearly straight; stigmatic lobes linear, dilated upwards and channelled. Seeds globular, succulent and berry-like.

A genus limited to a single species.

1. P. chinensis, Ker. in Koen. Ann. Bot. i. 217. Rhizome thick and fleshy. Stems erect, 3 to $5 \mathrm{ft}$. high, with equitant leaves, $8 \mathrm{in}$. to $1 \mathrm{ft}$. long or more. Flowers orange-coloured, spotted with crimson, in a terminal panicle, with clustered, stiff, divergent branches, of very unequal length. Bracts sheathing, more or less scarious. Perianth-segments oblong, about 1 in. long. -Ixia chinensis, Bot. Mag. t. 171.

On the sandy sea-beach at Saywan, Champion. In similar situations in Formosa, and said to be also wild in the mountains of northern India ; also much cultivated in gardens both in India and China.

\section{ORDER CXIV. AMARYLLIDEAS.}

Perianth superior, of 6 divisions, lobes, or teeth, all or the 3 inner ones coloured and petal-like. Stamens 6, inserted on the perianth. Anthers opening inwards. Ovary inferior, 3-celled, with several, or rarely 1 or 2 ovules in each cell. Fruit a capsule or berry. Seeds albuminous. Embryo straight or nearly so.- Herbs, usually perennial, either bulbous or with a tufted or tuberous stock. Leaves entire, parallel-veined. Flowers solitary or in umbels, clusters, or spikes, with sheathing membranous bracts.

- A considerable Order, dispersed over the greater part of the world, but most numerous in tropical America and S. Africa. 
Fruit succulent. Hairy plant, with a tufted or tuberous stock.

Flowers small, yellow, in an almost sessile spike. . .

Fruit eapsular. Glabrous bulbous plants. Flowers large, white, umbellate.

Stamens inserted at the base into a cup within the perianth-lobes . .

Stamens separately inserted on the perianth, the filaments not dilated

\section{Curculigo.}

3. Pancratium.

2. Crinum.

\section{CURCULIGO, Gærtn.}

Perianth regular, the tube long, often filiform, the limb of 6 equal deciduous segments. Ovules several in each cell of the ovary. Stigmas 3. Fruil oblong, succulent, crowned by the persistent perianth-tube. Seeds enveloped in a fleshy pulp, with a lateral beak-shaped hilum.-Tufted plants, usually hairy. Leaves long, mostly radical. Flowers sessile, in sheathing bracts, in a sessile or pedunculate head or spike.

A tropical genus, limited to the Old World, with the exception of one S. American species.

1. C. orchioides, Roxb. Pl. Corom. i. 14, t. 13 ; Bot. Mag.t. 1076, var. minor. Leaves radical, grass-like, and seldom above $6 \mathrm{in}$. long and 3 lines wide in the Hongkong specimens, sometimes in India twice as long and broad. Spike nearly sessile, with narrow sheathing bracts. Perianth hairy; the tube filiform, about $\frac{3}{4}$ in. long; the limb yellow, 5 or 6 lines long, with lanceolate pointed segments. Ovary long and narrow, 3-celled. Capsule succulent, usually 1-celled, with very few seeds separated by a spongy substance.-Hypoxis minor, Seem. Bot. Her. 419 ; not of Don.

Common in spring, Champion, Seemann, Hance. Dispersed over India, from the Peninsula to Khasia and the Archipelago. It is also closely allied to the S. American Hypoxis scorzonerafolia, Lam., which is surely a Curculigo, and to the Australian C. ensifolia. It is only at first sight that it resembles the Hypoxis minor, Don, which has no tube to the perianth.

\section{CRINUM, Linn.}

Perianth with a long tube and a regular 6-cleft limb, the segments spreading or recurved. Stamens inserted at the summit of the tube ; filaments free, filiform; anthers linear, versatile. Ovules usually few in each cell. Style filiform, with an entire or 3-lobed stigma. Capsule globular, depressed, bursting irregularly. Seeds few, nearly globular, often converted into fleshy bulbs. - Large bulbous glabrous herbs. Leaves radical. Flowers usually large, white or tinged with purple, in an umbel or head proceeding from a 2- or 3leaved spatha.

A tropical or subtropical genus, dispersed over the New and the Old World.

1. C. asiaticum, Linn.; Kunth, Enum. v. 547; Bot. Mag.t. 1073. Bulb large and long. Leaves 1 to $3 \mathrm{ft}$. long, 1 to $3 \mathrm{in}$. broad. Scape about $1 \mathrm{ft}$. high. Spatha reflexed, membranous. Flowers numerous, sessile or shortly pedunculate. Perianth-tube about 3 in. long; the segments linear, about 2 in. Ovules solitary in each cell of the ovary.

. On the seashore at Saywan, Champion; at Sheko, Hance. Generally on the sandy seacoasts of tropical Asia.

\section{PANCRATIUM, Linn.}

Flowers of Crinum, except that the filaments are united at the base into a petal-like cup, the margin of which is truncate, toothed or lobed between the 
filaments. Ovules several in each cell of the ovary. Capsule opening loculicidally in 3 valves.-Bulbous herbs, with the habit of Crinum, and flowers usually large and white.

A small genus, the species chiefly maritime, and limited to the Old World if the American Hymenocallis be really to be separated from it.

1. P. biflorum, Roxb. Fl. Ind. ii. 125. Leaves several, 1 to $1 \frac{1}{2} \mathrm{ft}$. long, 1 to 2 in. broad. Scape short, 2 - or 3 -flowered, with a spatha of 2 or 3 lanceolate bracts. Perianth-tube slender, 4 to 5 in. long. Segments narrowlinear, nearly as long. Staminal cup about $\frac{1}{3}$ as long, sinuately toothed between the filaments, which are at least as long as the cup.

On the seacoast, Champion, Hance. Scarce in India (Roxburgh). The Hongkong specimens agree very well with Roxburgh's deseription and unpublished drawing of $P$. biflorum, but not with the figure of $P$. verecundum, Bot. Reg. t. 413, to which Herbert refers it.

\section{ORder CXV. DIOSCORIDEÆ.}

Flowers unisexual, usually diœcious. Perianth of 6 lobes or divisions. Stamens 6 or 3 , inserted on the perianth and shorter than its lobes. Anthers 2-celled. Ovary inferior, 3-celled, with 2 pendulous ovules in each cell. Stigmas 3, entire or 2-cleft, on a single or distinct styles or sessile. Fruit a berry or 3-angled capsule. Seeds albuminous, with a minute embryo.--Herbs, usually twining, sometimes woody at the base. Leaves with digitate or parallel nerves and reticulate veins, sometimes compound. Flowers small, in axillary spikes or racemes, simple or paniculate.

An Order of few genera, dispersed over the greater part of the globe.

\section{DIOSCOREA, Linn.}

(Helmia, Kunth.)

Flowers diœcious. Capsule 3-angled or 3-lobed, opening loculicidally at the angles, often leaving the nerve-like edge free. Seeds winged.-Stems twining.

A large tropical or subtropical genus, common to the New and the Old World.

Perianth-segments orbicular. Capsule broader than long. Seeds winged all round. (Leaves mostly opposite.)

Leaves oval-oblong or lanceolate . . . . . . . 1. D. oppositifolia.

Leaves broadly cordate . . . . . . . Datatas.

Perianth-segments narrow. Capsule longer than broad. Seeds winged at the base . . . . . . . . . 3. D. sativa.

1. D. oppositifolia, Linn.; Roxb. Fl. Ind. iii. 804; Wight, Ic. t. 813. A glabrous twiner. Rhizome tuberous. Leaves stalked, mostly opposite, from oval-oblong to lanceolate, 2 to 3 in. long, 3- to 7-nerved. Male spikes when fully out 1 to $1 \frac{1}{2}$ in. long, in axillary clusters or panicles. Flowers distant, sessile. Perianth-segments orbicular, about 1 line long, slightly imbricate in 2 series. Anthers 6, nearly sessile, on a somewhat thickened disk, without any rudiment of the ovary. Female racemes simple, with few distant flowers. Capsule of 3 flat wing-like rounded lobes, each near $\frac{1}{2}$ in. broad, the axis rather longer. Seeds flat, winged all round.

Hongkong, Hance, Wright. In Ceylon, the Indian Peninsula, Khasia, and Silhet. 
2. D. Batatas, Dene. in Rev. Hortic. 1854, 243, and 1855, 69, with a fig. A glabrous twiner like the last, with a similar inflorescence and flowers. Leaves mostly opposite, ovate-triangular or broadly cordate, with rounded basal lobes, shortly pointed but not really acuminate, 2 to $3 \mathrm{in}$. long, and almost as broad. Fruits of $D$. oppositifolia, but usually much larger, the wing-like lobes measuring 9 lines in breadth, and the axis 10 lines inelength.

A native of China, introduced to Europe as the Chinese Yam. Two Hongkong specimens, both in fruit, appear to me to belong to this species; one from Hance, confounded by Seemann with the following, $D$. sativa, under the name of $D$. aculeata, the other from Wright, sent with the $D$. oppositifolia. It is very closely allied to $D$. glabra, Roxb., a common Silhet plant, which is said to have small subfusiform tubers, and may be a wild state of D. Batatas. D. aculeata, Wight, Ic. t. 2060 , but not of Linn., appears to be the same as D. glabra.

3. D. sativa, Linn. Spec. 1463; Hort. Cliff.t. 28, but not of Kunth, Enum. Stems glabrous, often bearing green globular bulbs in the axils of the leaves. Leaves alternate, ovate-cordate, 7- to 11-nerved, more or less acuminate, very variable in size. Male spikes slender, 1 to 2 in. long when fully out, usually numerous in long narrow axillary panicles. Flowers very small. Perianth-segments narrow, almost valvate in each series; the inner ones linear. Stamens 6 ; the anthers almost sessile round a rudimentary style. Female flowers in slender simple spikes. Capsule oblong, full $\frac{3}{4}$ in. long; the lobes scarcely 3 lines broad. Seeds winged at the lower end only. -D. bulbifera, Wight, Ic. t. 878 , but not of Linn. Helmia bulbifera, Kunth, Enum. v. 435.

Hongkong, Hance, and perhaps Wright. The former specimen male, the latter in leaf only. In various parts of India. The Iinnæan names of $D$. sativa and $D$. bulbifera appear to have been transposed by nearly all modern botanists, although all the figures quoted by Linnæus show that in dividing the species he had originally formed upon both, he placed the Helmia under $D$. sativa, and the broad-fruited one under $D$. bulbifera. The figure in the 'Hortus Cliffortianus,' which must be taken as the original of $D$. sativa, is a very good representation of our plant. That in the Hort. Malab. viii. t. 51 , is probably a different species, nearer to $D$. deltoidea, Wall.

\section{Order CXVI. LILIACEAT.}

Flowers usually regular, hermaphrodite or unisexual. Perianth inferior, petal-like, with 6 divisions or teeth. Stamens 6 , inserted at the base of the segments or in the tube (or very rarely 3 of the stamens or of the perianthsegments are wanting): Ovary free, 3 -celled (very rarely incompletely so), with several ovules or one only in each cell. Style single, with an entire or 3-lobed stigma, or rarely 3 sessile stigmas. Fruit a berry or capsule. Embryo immersed in a fleshy albumen.-Perennial herbs, with a creeping bulbous or clustered root-stock, and either radical leaves and peduncles, or annual, biennial, or rarely perennial leafy stems.

A large Order, distributed over nearly every part of the globe.

Flowers dioecious (small). Stems branched. Fruit a berry.

Leaves flat, with digitate nerves and reticulate veins. Stems climbing.

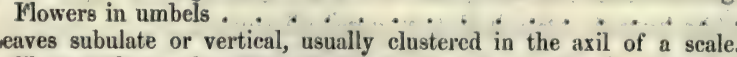
Flowers elustered or racemose ? . . . . . . . . .

1. Smitax.

2. Asparagus. 
Flowers bermaphrodite. Leafy stem simple or none.

Stock not bulbous. Stem leafy at the base only.

Fruit a berry. (Flowers pale-blue or greenish.)

Flowers in a raceme. Filaments slender.

Flowers paniculate. Filaments thickened under the anther

3. Ophiopogon.

Fruit a capsule.

Flowers blue, in a terminal umbel. Inner segments very thin and involute on the edges . . . . . . . . . .

Flowers small, white, distant in a raceme or panicle. Capsule acutely angled or 3 -lobed

Stock bulbons.

Leaves and scape radical. Flowers small, racemose . . . . .

4. Dianella.

Stem leafy. Flowers 1 or few, very large

5. Thysanotus.

6. Anthericum.

7. Scilita.

8. LiliuM.

\section{SMILAX, Linn.}

(Coprosmanthus, Kunth.)

Flowers diøcious. Perianth of 6 spreading segments, all equal, or the 3 outer larger, or the 3 outer united, and the 3 inner wanting. Male flowers : Stamens 6 , inserted at the base of the segments, or rarely 3 , free or monadelphous. Female flowers : Stamens rudimentary. Ovary 3-celled, with 1 or 2 erect ovules in each cell. Stigmas 3, sessile, distinct, or shortly united. Fruit a globular berry. Embryo minute, remote from the hilum.-Climbers. Leaves with digitate nerves and reticulate veins, usually coriaceous and shining; the petioles usually bearing 2 simple tendrils, and often winged below the tendrils. Fiowers small, usually white, in sessile or pedunculate axillary umbels, often forming terminal panicles.

A large genus, dispersed over the tropical and temperate regions of the globe.

Perianth-segments 6 , in 2 series. Stamens 6 , free.

Leaves glaucous or white underneath. Filaments shorter than the anthers.

Outer perianth-segments broadly obcordate. Female umbels many-flowered. Leaves acuminate . . . . . .

Outer perianth-segments ovate. Female umbels few-flowered. Leaves not acuminate. Filaments longer than the anthers.

Leaves green on both sides. Filaments longer than the anthers.

Umbels solitary, in the axils of full-grown leaves
Umbels solitary, in the axil of the lowest leaf of the young shoots.

Umbels in axillary panicles. Leaves large . . . . .

Perianth oblong, 3-toothed. Stamens 3, monadelphous. . . . 6. S. Gaudichaudiana.

1. S. glabra.

2. S. hypoglauca.

3. S. lanceafolia.

4. S. ferox.

S. ovalifor

v. 162 ; Seem.

1. S. glabra, Roxb. Fl. Ind. iii. 792; Kunth, Enum. v. 162 ; Seem. coriaceous, green and shining above, 3 - or 5-nerved, glaucous or white underneath, the old ones rarely green on both sides. Umbels axillary, solitary, sessile or shortly perlunculate, without scales at the base of the peduncle. Flowers numerous both in the males and females. Buds 3-lobed; the outer segments being short, thick, fleshy, very broadly obcordate, concave in the centre; the inner segments very much smaller, orbicular. Anthers short, sessile or nearly so.

Hongkong, Hinds, Champion, Hance. Also in Khasia.

2. S. hypoglauca, Benth., n. sp. Unarmed. Leaves oblong or lan- 
ceolate, rarely almost ovate, green above and white underneath, as in $S$. glabra, but obtuse or with a very short callous point. Male inflorescence as in S. glabra. Flower-buds ovoid, about 1 line long; the outer segments ovate, cononve, rather obtuse; the inner shorter and lanceolate. Anthers shorter than the perianth, on thick filaments almost as long as themselves. Female flowers very few in the umbel, larger than the males; outer segments broadly ovate, obtuse ; inner ones as large, with a minute point. Berry rather larger than in S. glabra.

Abundant in the Happy Valley woods, Hance, Champion, Wright, Wilford. Not known from elsewhere. It is allied to S. glycyphylla, Sm., from Australia, but distinet in inflorescence and some other characters.

3. S. lancezfolia, Roxb. Fl. Ind. iii. 792; Seem. Bot. Her. t. 99. Unarmed (or rarely with a few short recurved prickles). Leaves ovate-lanceolate, lanceolate or oval-oblong, usually shortly acuminate with a callous tip, 3 or 4 in. long, 3- or 5-nerved, green and shining on both sides. Umbels solitary in the axils of full-grown leaves, on short peduncles issuing from 2 or 3 thick concave often united scales. Perianth full 2 lines long, cylindrical when in bud; segments narrow-oblong, all six nearly equal. Filaments as long as the perianth. Anthers small. Ovules 2 in each cell of the ovary.

Hongkong, Seemann, Hance; common in ravines, Wilford. In the east frontier of India (Roxburgh). The S. oxyphylla, Wall, ; Kunth, Enum. v. 238, a common Sikkim and Khasia plant, may be only a variety differing in its usually prickly stem. less coriaceous leaves, and smaller flowers. Both belong to the biovulate group (Coprosmanthus, Kunth).

4. S. ferox, Wall.; Kunth, Enum. v. 251. Stems prickly or rarely unarmed. Leaves when full grown oval, obovate, or almost orbicular, about 2 in. long, coriaceous and shining; when young often much narrower and more acute at both ends. Umbels pedunculate, solitary in the lowest axil of each young shoot, or rarely in the 2 lowest axils, without scales at the base of the peduncle, although there is always one at the base of the shoot. Perianth, stamens, and biovulate cells of the ovary as in S. lanceafolia.-Coprosmanthus japonicus, Kunth, Enum. v. 268 ?

Hongkong, Harland, Hance; in ravines, Wilford. In Nepal, Khasia, Sikkim, near Amoy, and perhaps in Japan.

5. S. ovalifolia, Roxb. Fl. Ind. iii. 794; Wight, Ic. $t$. 809 . Stems stout, prickly, climbing to a great height. ILeaves from nearly orbicular to ovate-lanceolate, 5 to $8 \mathrm{in}$. long, 5- or 7-nerved. Umbels pedunculate, several together in axillary racemes or panicles. Perianth about 2 lines long, with narrow lobes. Filaments rather longer than the linear anthers. Ovary globular, with 1 pendulous ovule in each cell. Styles shortly united at the base.-S. macrophylla, Roxb., Fl. Ind. iii. 793, and S. prolifera, Roxb. I. c. 795 .

Hongkong, Hance, judging from a single specimen without flowers, which is probably correctly ascribed to this species by Seemann. The specimens I describe are from India, where it is widely diffused from Ceylon and the Peninsula to Kumaon, Sikkim, and Burmah.

6. S. Gaudichaudiana, Kunth, Enum. v. 252. Unarmed. Leaves broadly ovate-cordate or almost orbicular, 5-, 7-, or 9-nerved, $1 \frac{1}{2}$ to 3 in. long, green on both sides and rather thin. Umbels solitary, on simple axillary somewhat flattened peduncles of $\frac{1}{2}$ to $\frac{3}{4}$ in., without scales at the base. Perianth about 2 lines long, oblong, minutely 3 -toothed. Stamens shorter, 
the filaments united in a column with 3 sessile anthers, the inner perianthsegments and inner stamens entirely deficient. Female flowers not seen. Berry 1- or 2-seeded.-S. hongkongensis, Seem. Bot. Her. 420.

Hongkong, Hance, Wright, Seemann. S. China (Gaudichaud).

\section{ASPARAGUS, Linn.}

Flowers diœcious. Perianth of 6 distinct nearly equal spreading segments, Stamens 6, free. Ovary 3-celled, with 2 ovules in each cell. Style single. with a 3 -lobed stigma. Fruit a berry. Seeds albuminous, with a transverse embryo. Rhizome creeping. Stems erect or with half-climbing branches. Leaves usually clustered, subulate or laterally flattened (theoretically described as abortive pedicels), surrounded by short scarious scales (theoretically considered to be leaves or bracts). Flowers small, axillary, solitary, clustered or racemose.

A considerable genus extending over the tropical and temperate regions of the Old World.

1. A. lucidus, Lindl.; Kunth, Enum. v. 71. Stems straggling or halfclimbing, much branched, attaining 2 or even $3 \mathrm{ft}$., very smooth and shining, with short frequently reflexed prickles under most of the branches. Leaves usually in threes, flat, linear, much falcate, almost pungent, not $\frac{1}{2}$ in. long in some specimens, above 1 in. in others. Flowers usually 2 or 3 together or sometimes solitary, on pedicels of $\frac{1}{2}$ to $1 \frac{1}{2}$ lines. Perianth scarcelv more than 1 line long.- A. falcatus, Benth. in Lond. Journ. i. 493 ; Seem. Bot. Her. 421 ; not of Linnæus.

Common in the island, Hinds, Champion, and others. In S. China, Loochoo, and Japan. Very near to the true $A$. falcatus, Linn., a Ceylon species, represented by Burmann with leaves twice as long and more numerous in the clnsters, and pedicels 2 or 3 times as long as in A. lucidus. Hance suggests that our plant may be the Melanthium cochinchinense, Lour. Fl. Coch. 216. The description agrees well, except that the fruit is stated to be capsular. Our specimens are indeed not in fruit, but there is every reason to believe it to be a berry, as in all other Asparagi.

\section{OPHIOPOGON, Ker.}

Flowers hermaphrodite. Perianth of 6 equal spreading segments. Stamens 6, free, inserted at their base; filaments short. Ovary attached by a broad base (or half-inferior), 3-celled, with 2 or few ovules in each cell. Fruit a globular berry, 1- or few-seeded.-Rhizome creeping. Leaves radical, linear, parallel-veined. Flowers small, usually blue, clustered, in a simple raceme on a leafless scape.

A small tropical or subtropical Asiatic genus.

1. O. spicatus, Ker in Bot. Reg.t. 593 ; Kunth, Enum.v. 299. Leaves tufted, on a short thick horizontal rhizome, 1 to $2 \mathrm{ft}$. long, grass-like, but stiff. Scapes from 6 in. to $1 \mathrm{ft}$. high. Flowers blue, in clusters of 3 to 6 in the axil of a scarious bract and surrounded by several smaller bracts, forming a rather dense narrow raceme of 2 to 4 in. Pedicels 1 to $1 \frac{1}{2}$ lines. Perianthsegments usually about 2 línes long, but varying in size. Ovary inserted on a broad base, but wholly superior. Style undivided. Berry blue, usually 1sceded.-O. gracilis, Kunth, Enum. v. 298. 
In grassy places, Hance, Champion, Wright. On the adjacent continent, in the Philippine Islands, and in Loochoo. After carefnlly comparing the original garden specimens of $O$. spicatus with the smaller Chinese ones of $O$. gracilis, I can find no definite distinction even in the size of the flowers. I always find the style undivided in both.

\section{DIANELLA, Lam.}

Perianth of 6 equal spreading segments. Stamens 6 , inserted at their base ; filaments short, thickened under the erect anther. Ovary 3-celled, with several ovules in each cell. Style filiform; stigma entire. Fruit a berry. Seeds flat. Embryo small.-Herbs, with a short rhizome, and stems leafy at least at the base. Leaves long and narrow, parallel-veined. Flowers usually blue, pendulous, in terminal panicles.

A small tropical Asiatic or Australian genus, with one species from tropical America.

1. D. ensifolia, Red.; Kunth, Enum.v. 50 ; Bot. Mag.t. 1404. Leaves bifarious almost as in Iridece on the short base of the stem, erect, stiff, above $1 \mathrm{ft}$. long and 6 to 9 lines broad. Peduncle as long as the leaves, with 2 or 3 sheathing scales, and a terminal panicle of 2 to 4 in.; the branches few and short, simply racemose or forked. Perianth greenish-white or pale blue, the segments lanceolate, 5 -nerved, about 5 lines long. Berry purple.-D. odorata, Blume; Kunth, Enum. v. 51.

Common in grassy places on the hillsides, Champion and others. In the Manritius, Snmatra, Java, the Philippines, Khasia, S. China, and Loochoo, and frequently cultivated in India. The Chinese and Khasia specimens are usually almost or quite without the minute serratures which are supposed to distinguish the leaves of the true $D$. ensifolia; but occasionally leaves may be found having them almost as marked as those of the Mauritius specimens.

\section{THYSANOTUS, Br.}

Perianth of 6 spreading segments, 3 -nerved in the centre; the 3 outer with thin flat edges, the 3 inner ones very delicate and rolled inwards in the bud or ciliate on the edge. Stamens 6 ; inserted at their base; filaments flat; anthers erect, the 3 inner longer. Ovary 3 -celled, with 2 ovules attached to the centre of each cell. Capsule 3-valved. Seeds (when both ripen) 1 erect, the other pendulous in each cell; testa black, funiculus thick and fleshy. Embryo curved.-Rhizome perennial, with fibrous or tuberous roots. Leaves almost radical, usually narrow-linear or subulate. Flowers blue, in a raceme or panicle sometimes contracted into an umbel on a leafless scape or peduncle.

A genus entirely Australian, except the following species.

1. T. chinensis, Benth., n. sp. Rhizome short. Leaves radical, linearsubulate, erect and stiff, 6 to 8 in. long. Scape as long, with a terminal umbel of 6 to 10 flowers. Bracts ovate or lanceolate, short and scale-like, with white edges. Pedicels 4 to 6 lines long, recurved after flowering. Perianthsegments near 4 lines long, the inner ones with broad very delicate involute edges, but without the fringe of the Australian species. Capsule ovoid, often with only 1 seed in each cell, but always occupying either the upper or the lower half only.

Hongkong, Hance. I deseribe this from a specimen gathered on the continent of S. China by the Rev. Dr. Krone, and transmitted to me by Dr. Hance as having been also found by himself in Hongkong. It too closely resembles the T. chrysantherus, F. Müll., from 
N. Australia, in foliage, inflorescence, flowers, and fruit, to be generically separated on account of the want of the fringe to the petals.

\section{ANTHERICUM, Linn.}

(Phalangium, Juss., and Chlorophytum, Ker.)

Perianth-segments 6, spreading, nearly equal, persistent. Stamens 6, inserted at their base; filaments filiform, not hairy ; anthers versatile. Ovary 3 -celled, with 2 or more ovules in each cell. Style filiform; stigma entire. Capsule 3 -valved, usually prominently 3 -angled or 3 -lobed. Seeds few, black. - Rhizome short, thick, with fasciculate roots. Leaves radical or nearly so, linear. Flowering stems leafless, erect, often branched. Flowers white or greenish, solitary or clustered.

A small genus widely dispersed over both the New and the Old World.

1. A. parviflorum, Benth. Leaves distichous as in Iridece, crowded in a flat tuft, linear, falcate or curved, 4 to $8 \mathrm{in}$. long. Scapes arising from amongst the leaves, usually shorter than them, slender but stiff, with 1 to 3 branches. Flowers distant, solitary or 2 together under each bract, on slender pedicels of 1 to 2 lines, at first erect, then recurved. Perianth about 1 line long. Ovules 2 in each cell of the ovary. Capsule near 2 lines long and 3 broad, with 3 acute angles or lobes.-Phalangium parviflorum, Wight, Ic. t. 2039. Ph. falcatum, Wall. Catal. n. 5057.

Hongkong, Hance, Wright. In Ceylon and the Indian peniusula, and in Borneo. This species has more the characters of Chlorophyton than of Phalangium, but the two appear to me to run too much into one another to remain separate; and if the old Linnæan name Anthericum be not retained for the group so formed, it becomes entirely suppressed. The few species retained by Kunth under that name are all doubtful, and none of them Iinnæan.

\section{SCILLA, Linn.}

(Barnardia, Lindl., and Ledebouria, Roth.)

Perianth-segments 6 , nearly equal, free or nearly so, spreading or forming a bell-shaped or tubular flower. Stamens 6, inserted below the middle or at the base of the segments. Ovary with 1,2 , or several ovules in each cell. Stigma entire or nearly so. Seeds few, black, oblong or globular.-Bulbous herbs. Leaves radical, parallel-veined. Flowers pink or blue, in a simple raceme on a leafless scape.

A considerable genus, ranging over the northern hemisphere in the Old World, with a few species from western S. America.

1. S. chinensis, Benth. Leaves narrow-linear, 6 to 8 in. long. Scape 1 to $1 \frac{1}{2} \mathrm{ft}$. high. Flowers small, pink, in a raceme of $1 \frac{1}{2}$ to $3 \mathrm{in}$. Bracts small, linear. Pedicels 1 to 3 lines long. Perianth-segments oblong, spreading, 1 to $1 \frac{1}{4}$ lines long. Filaments flattened at the base, tapering to a point. Ovary nearly globular, with 1 ascending ovule in each cell.-Barnardia scilloides, Lindi. Bot. Reg. t. 1029 ; Bot. Mag. t. 3788.

At Chuckchew, Champion. On the adjacent continent, and a somewhat broader-leaved variety in Loochoo. The habit and essential characters are entirely those of the uniovulate $S$ parviflora, Desf., from Algeria, or of the biovulate $S$. autumnalis, L., from the Mediterrauean region; both of them pink-flowered. Other biovulate species (inclnding Ledebouria hyacinthina, Roth; Wight, Ic. t. 2040, which appears to be the same as Barnardia indica 
Wight, Ie. t. 2041) have blue flowers, and pass gradually into the more common severalovulate species. Hooker and Arnott referred Ornithogalum sinense, Lour., to the S. chinensis, hut it is surely different, if correctly deseribed as having the perianth-segments not divided to the base and the bracts spathaceous.

\section{LILIUM, Linn.}

Perianth-segments distinct, narrowed and erect at the base, spreading or recurved at the top. Stamens 6, inserted at their base. Anthers linear. Ovary 3-celled, with numerous horizontal ovules. Style elongated; stigma 3-angled or 3-lobed. Capsule 3-valved. Seeds horizontal, winged.-Tall herbs, with scaly bulbs and simple leafy stems. Flowers few, large, terminal.

A considerable geuus, dispersed over the temperate regions of the northern hemisphere or the mountainous districts of tropical Asia.

1. I. Iongiflorum, Thunb.; Kunth, Enum. iv. 266 ; Bot. Reg. t. 560. Stems $2 \mathrm{ft}$. high or more. Leaves linear-lanceolate, 2 to $3 \mathrm{in}$. long; the upper ones smaller. Flowers white, solitary, or 2 or 3 on short pedicels, nodding; full 5 in. long, narrow-campanulate and much contracted below the middle.

On the sides of hills amongst grass, Champion, Hance, and on the Chinese continent.

\section{ORDER CXVII. PONTEDERACE无.}

Flowers usually irregular, hermaphrodite. Perianth inferior, petal-like, of 6 segments or lobes, in 2 series. Stamens 6 or 3 , often dissimilar. Ovary 3 -celled or with 3 projecting parietal placentas, with 1 or more ovules to each cell or placenta. Style single, with a 3 -lobed or 6 -toothed stigma. Fruit capsular, superior, but sometimes enclosed in the persistent tube of the perianth. Seeds albuminous, with a slender embryo.-Aquatic herbs. Leaves usually petiolate, parallel-veined. Flowers usually blue or white, in spikes or racemes proceeding from the sheath of the last leaf (or sometimes of the only leaf of the scape), usually with 1 or 2 sheathing bracts at the base of the peduncle.

A small Order, dispersed over the tropical and subtropical regions of the globe, or in N. America extending into more temperate districts.

\section{MONOCHORIA, Presl.}

Perianth nearly regular, divided to the base into 6 spreading segments. Stamens 6, unequal, 1 usually larger, with a small tooth or spur on the filament. Ovules numerous in each cell of the ovary. Capsule free, 3-valved, many-seeded.-Leaves radical, on long petioles. Scapes with 1 petiolate leaf, the short raceme in its axil appearing to proceed from the middle of the petiole. Flowers few.

A small tropical Asiatic genus.

Leaves ovate-cordate. Flowers 6 to 12 . . . . . . . . 1. M. vaginalis.

Leaves lanceolate. Flowers 1 to 3 . . . . . . . . . 2. M. plantaginea.

1. IV. vaginalis, Presl; Kunth, Enum. iv. 134. Leaves and scapes forming dense tufts from a creeping rhizome. Petioles long, hollow, sheathing at the base. Leaves cordate, acuminate, 2 to 3 in. long, 1 to near 2 in. broad. 
Racemes appearing to proceed from the side of a petiole, 1 to $2 \mathrm{in.} \mathrm{long,} \mathrm{erect}$ at first, afterwards reflexed, bearing 6 to 12 blue flowers. Perianth-segments about 5 lines long, the outer ones oblong, the inner obovate--Pontederia vaginalis, Roxb. Pl. Corom. t. 110.

In a ditch in the Happy Valley, Wilford. Common in India and the Archipelago.

2. IM. plantaginea, Kunth, Enum. iv. 135. An annual, much smaller than the last. Leaves lanceolate, scarcely cordate, 1 to $1 \frac{1}{2}$ in. long. Racemes loosely 1 - to 3 -flowered or very rarely 4 -flowered. Flowers deep blue, rather smaller than in $M$. vaginalis, the inner segments rather narrower than the outer. Amoy.

Hongkong, Wright. Common in India and the Archipelago, extending northward to

\section{Order CXVIII. COMMELYNACE}

Flowers hermaphrodite or rarely polygamous, .usually slightly irregular. Perianth of 3 outer (sepals) thin but calyx-like segments, rarely united at the base, and 3 inner (petals) very delicate petal-like segments or lobes. Stamens 6 , or fewer by abortion. Anthers 2-celled, or some deformed or barren. Ovary 3 -celled or rarely 2-celled, with 1,2, or more ovules in each cell. Style simple, with an entire or 3-lobed stigma. Fruit a capsule, or rarely indehiscent. Seeds peltate or angular, the testa usually wrinkled. Embryo small, partly sunk in a cavity in the apex or side of the fleshy albumen.-Herbs, often creeping at the base. Leaves parallel-veined, with sheathing petioles. Flowers usually blue, purple, or white, in panicles, umbels, or clusters, either terminal or issuing from the leaf-sheaths.

A considerable Order, chiefly tropical or subtropical, common to the New and the Old World.

Stamens 6 or 4 , of which one half differently shaped and barren. Ovary 3 -celled.

Flowers few, enclosed in a folded cordate or peltate-turbinate oblique bract or spatha. Capsule 2-valved . . . . . . 1. Commelyna.

Flowers paniculate. Bracts small. Capsule 3-valved . . . . 2. Anewema.

Stamens 6. Anthers all with 2 parallel cells.

Perianth-segments free. Bracts small.

Ovary and capsule 2-celled, the cells 1-ovulate . $0^{*} \cdot{ }^{-}$3. Froscopa.

Ovary 3-celled. Ovules numerous. Fruit globular, indehiscent . 4. Pollia.

Perianth-segments united in 2 series. Bracts usually falcate, enclosing the flower .

5. Cyanotis.

\section{COMMELYNA, Linn.}

Perianth irregular, 2 sepals larger than the third, and one petal differently shaped or more sessile than the 2 others. Stamens 6 or rarely fewer, of which 3 fertile, one of them larger than the others, 3 barren, with deformed anthers. Ovary with 1 uniovulate and 2 biovulate cells. Capsule 2-valved.-Flowers few, on 2 peduncles enclosed in a folded cordate or peltate-turbinate oblique bract or spatha, which is usually pedunculate from a split leaf-sheath opposite the blade.

A considerable genus, common to the New and the Old World. 
Spatha cordate, folded, falcate, glabrous.

Spatha acuminate. Sessile petal very broad . . . . . 1. C. salicifolia.

Spatha scarcely acuminate. Sessile petal ovate or lanceolate . . 2. C. communis.

Spatha turbinate, peltate (a flattened inverted oblique or falcate cone, open at the top only), pubescent . . . . . . . . .

1. C. salicifolia, Roxb. Fl. Ind. i. 172 ; Kunth, Enum. iv. 39 . Stems creeping at the base, branching and ascending to $1 \mathrm{ft}$. or more, the whole plant glabrous. Leaves usually lanceolate, 2 to $3 \mathrm{in}$. long, or the lower ones small and ovate, the sheaths ciliate on the edge. Bracts cordate, folded, much falcate, usually acuminate. Lower peduncle usually 1-flowered, the upper one short, abont 3-flowered. Petals nearly orbicular, 2-clawed, the third nearly sessile. Sterile anthers with distinct orange-coloured cells spurred at the base; fertile ones parallel-celled, one much larger.-C. caspitosa, Roxb. Fl. Ind. i. 174? C. ochreata, Schauer in Pl. Meyen. 447.

Hongkong, Wright. Common in India and in the Archipelago. Wilford gathered a variety in which the lower peduncle in each spatha appears to be constantly without flowers, which would remove it to another section of Kunth's, but I can find no other difference in the specimens.

2. C. communis, Linn.; Kunth, Enum. iv. 36. Very near the last, but the leaves are usually shorter and less acuminate, their sheaths shorter and scarcely ciliate, the spathas also shorter and rather acute than acuminate, the flowers rather smaller, 2 of the petals have longer claws, and the sessile one is ovate or lanceolate, not nearly so broad as the others.

- Hongkong, Hance? A common species in India and the Archipelago, to which I believe Hance's specimen has been correctly referred, although I have been unable to examine any flower.

3. C. benghalensis, Linn.; Kunth, Enum. iv. 50 ; Wight, Ic. t. 2065. A creeping pale-green perennial, more or less hairy or pubescent, especially on the bracts. Leaves usually ovate, 1 to $2 \mathrm{in}$. long, more rarely lanceolate and longer, the sheaths and petioles ciliate. Spathas opposite the upper leaves, or 2 to 4 together above them, with the subtending leaves reduced to short sheaths, broadly turbinate and compressed, the margins united, so as to form an inverted cone open at the top, and oblique or somewhat falcate. Lower peduncle longer than the spatha, with 1 male flower, upper one shorter, with 2 or 3 hermaphrodite flowers.-C. canescens, Vahl; C. Blumei, Dietr.; C. mollis, Jacq., and perhaps some others of Kunth, Enum. iv. 49 to 52.

Hongkong, Hance, Wright. Widely spread over tropical Asia, Africa, and America, although apparently not so common in India as the two last species.

\section{ANEILFMA, Br.}

Flowers nearly regular. Perianth-segments free. Stamens 6 or 4 , of which 3 or 2 have differently shaped barren anthers. Ovary 3-celled, with 2 to $\mathbf{5}$ ovules in each cell. Capsule 3 -valved.-Flowers usually small, in terminal panicles. Bracts small.

A considerable genus, dispersed over the tropical and subtropical regions of the New and the Old World.

1. A. nudiflorum, Br.; Kunth, Enum. iv. 66. A slender diffuse or creeping glabrous annual (perhaps occasionally forming biennial tufts) ascending to $6 \mathrm{in}$. or rather more. Leaves lanceolate, 1 to $2 \mathrm{in}$. long, with short 
loose ciliate sheaths. Panicle of few irregular slender branches, each bearing a short raceme of 3 to 10 small flowers. Stamens 2 fertile and 2 small and barren. Filaments hairy. Capsule about $1 \frac{1}{2}$ lines long, with 2 seeds in each cell. - A. debile, Wall. Catal. n. 5215. A. diandrum, Ham. in Wall. Catal. n. 5210. A. compressum, Dalz. in Kew Journ. Bot. iii. 138.

Common in marshy places about Victoria, Wilford. Widely spread over India, from Ceylon and the Peninsula to the Archipelago, extending to Australia, and northward to Loochoo. The 3 ovules in each cell seen by Dalzell must have been in an accidentally abnormal flower. I find 2 only in his own specimens.

Var. ? rigidior. More tufted at the base, taller and stiffer. Leaves longer, sometimes pubescent underneath and on the sheaths. Flowers rather larger.

Hongkong, Wright.

\section{FLOSCOPA, Lour.}

(Dithyrocarpus, Kunth.)

Flowers nearly regular. Perianth-segments free, one petal usually narrower. Stamens 6, all fertile. Ovary contracted at the base or stalked, 2-celled, with 1 ovule in each cell. Capsule flattened, didymous, 2-valved. Seed laterally attached by the broad truncate base.-Erect or ascending herbs, usually creeping at the base. Flowers small, in terminal panicles. Bracts small.

A small tropical genus, common to the New and the Old World.

1. F. paniculata, Hassk.; Miq. Fl. Ned. Ind. iii. 542. Stems ascending to 1 or $2 \mathrm{ft}$., usually glabrous. Leaves lanceolate or ovate-lanceolate, acuminate, 2 to 4 in. long, scabrous on the upper side; the sheath fringed with long hairs, at least at the top. Flowers small, in a dense terminal ovate hirsute panicle $1 \frac{1}{2}$ to $2 \mathrm{in}$. long; sometimes leafy at the base; the branches simple or the lower ones forked. Sepals very hairy, 1 line long or rather more. Petals bright blue, scarcely longer. Stamens exserted.-F. rufa, Hassk., with the synonyms quoted by Miq. Fl. Ned. Ind. iii. 542. Tradescantia paniculata, Roxb. Pl. Corom. t. 109. Dithyrocarpus capensis, D. Meyenianus, D. paniculatus, and D. rufus, Kunth, Enum. iv. 78 and 79. D. petiolutus, $D$. Rothii, and D. undulatus, Wight, Ic. t. 2079 and 2080. Aneilema hispidum, Don.; Kunth, Enum. iv. 70 ; and probably also Floscopa scandens, Lour. Fl. Cochinch. 193 ; and Dithyrocarpus hirsutus, Kunth, Enum. iv. 77.

Hongkong, Harland. Widely diffused over India, from the Peninsula to the Himalaya, the Malayan Peninsula, and the Archipelago, and northward to the Philippines and S. China. Also in S. Africa and Brazil, for I can discover no difference whatever between specimens from thence and the Indian ones.

\section{POLLIA, Thunb.}

\section{(Aclisia, E. Mey.)}

Flowers nearly regular. Perianth-segments free, one petal rather narrower. Stamens 6 ; anthers all with 2 parallel cells, but 3 usually barren. Ovary 3 celled, with numerous ovules in each cell. Fruit globular, slightly succulent, indehiscent, shining and brittle when dry. Seeds angular.-Stems ascending or erect. Leaves large. Flowers in terminal panicles. Bracts small.

A small tropical or subtropical Asiatic genus.

1. P. sorzogonensis, Endl.; Miq.Fl. Ned.Ind. iii. 541. Glabrous or 
slightly pubescent. Leaves broadly ovate-lanceolate or oblong, acuminate, 4 to 6 in. long in the Hongkong specimens, 8 or $9 \mathrm{in}$. in some Javanese ones, narrowed into a rather long petiole above the sheath. Panicle pedunculate, ovate or oblong, 2 or 3 in. long, usually pubescent. Sepals nearly orbicular, about $1 \frac{1}{4}$ lines long. Petals smaller. Fruit 3 or 4 lines diameter.-Aclisia sorzogonensis, E. Mey. in Rel. Hænk. i. 138, t. 24. Anilema didymum, Seem. Bot. Her. 422, not of Hamilt.

Hongkong, Hance, Wright. Also in the Philippines and Java. The true $A$. didymum, Ham., is an allied species of Pollia from Khasia, with the leaves sessile or nearly so, larger more persistent sepals, etc.

\section{CYANOTIS, Don.}

Flowers regular. Sepals united at the base. Petals united more or less by their claws in a 3 -lobed corolla. Stamens 6 ; filaments bearded towards the top; anthers uniform. Ovary with 2 ovules in each cell attached to its centre. Capsule 3-valved. Seeds, one erect, the other pendulous.-Creeping or ascending herbs. Flowers in short dense spikes or clusters, either within the leaf-sheaths, or pedunculate and surrounded by imbricate falcate bracts.

A small Asiatic or African genus, chiefly tropical.

Leaves linear. Flowers few, within the leaf-sheaths ..... . 1. C. axillaris.

Leaves lanceolate, often white-woolly. Flower-spikes bracteate, in terminal or lateral clusters

2. C. fasciculata.

1. C. axillaris, Rom, and Sch.; Kunth, Enum. iv. 105. A glabrous annual with long creeping branches. Leaves linear or linear-lanceolate, 2 to 4 in. long. Flowers 2 or 3 together, nearly sessile within the short loose leafsheaths. Sepals about 2 lines long, divided nearly to the base. Corolla deep blue, the tube longer than the sepals, the lobes ovate. Filaments thickened above a dense tuft of articulate hairs.

Hongkong, Hance. Common in wet fields in India, from Ceylon and the Peninsula to the Archipelago.

2. C. fasciculata, Rom. and Sch.; Kunth, Enum. iv. 104; Wight, Ic. $\boldsymbol{t}$. 2086. A perennial, ascending to about $1 \mathrm{ft}$., more or less clothed with a white loose wool, which readily wears off. Leaves lanceolate, 1 to 2 in. long. Flowers blue, in little heads or short spikes, 2 or 3 together, unequally pedunculate or nearly sessile, terminal or in the upper axils, and each head surrounded by 8 to 10 lanceolate much falcate imbricate bracts, the lower 5 or 6 lines long, the others gradually smaller, filaments white-woolly below the anthers.-C. lanata, Benth. in Hook. Nig. Fl. 542.

Hongkong, Harland. In Nepal, the Indian Peninsula, Ceylon, and tropical Africa.

\section{ORDER CXIX. XYRIDACE丑.}

Flowers hermaphrodite, usually irregular. Perianth of 3 outer segments, one of which much larger, more petal-like, and within the others, or reduced to that one only, and 3 or 2 inner petal-like segments sometimes united into 1. Stamens 3 , either all bearing anthers or 2 barren and petal-like, inserted at the base of the inner perianth. Ovary with 3 parietal placentæ, sometimes meeting or even united in the centre. Ovules numerous. Capsule 3-valved. 
Seeds numerous, very small, albuminous.-Erect stiff herbs. Leaves radical or distichous and equitant, narrow and erect. Flowers yellow, in terminal heads or in interrupted spikes.

A small tropical Order, common to the New and the Old World.

Flowers in short terminal heads. Perianth double, each of 3 segments or lobes

Flowers in a long interrupted spike. Perianth of 2 broad petal-like segments .

1. XYRIS.

2. Philydrum.

\section{XYRIS, Linn.}

Perianth of 2 lateral outer segments (bracts?) keeled and compressed, a third broader and more petal-like, enveloping the 3 inner petal-like segments or lobes. Stamens 3, fertile, opposite the inner segments, and sometimes 3 sterile penicillate filaments between them. Placentas parietal.-Rush-like herbs. Leaves equitant, radical or nearly so, excepting one (sometimes reduced to a sheath) sheathing the base of the otherwise leafless scape. Flowers yellow, in small dense terminal heads, with coriaceous imbricated glume-like bracts or scales.

A genus of several species, distributed over the tropical and subtropical regions of the New aud the Old World.

Scales of the flower-head very broad, with a lighter-coloured margin.

Leaves denticulate (under a lens) . . . . . . . . .

Scales of a uniform brown. Leaves quite entire

1. X. pauciflora.

2. X. schenoides.

1. X. pauciflora, Willd.; Kunth, Enum. iv. 17. Leaves narrow, grasslike, acute, 2 to 4 in. long, minutely denticulate, when seen under a lens. Scape $4 \mathrm{in}$. to $1 \mathrm{ft}$. long. Flower-head broadly ovoid-globular, about 4 lines diameter. Scales very broad, dark and shining in the centre, with a broad thinner and lighter-coloured margin. Perianth-segments 2 outer narrow and acute, the keel winged; the third broad, but with a rather stiff and prominent midrib. Inner perianth 3-lobed, with an anther almost sessile at the base of each. Sterile stamens none or very minute.

In marshes and swamps, Hance, Wright, Wilford. In India, from Ceylon and the Peninsula to Khasia, Sikkim, and the Malayan Peninsula. In Australia and the Philippines, and probably all over the Archipelago.

2. X. schœnoides, Mart.; Kunth, Enum. iv. 16. Leaves narrow and acute, usually 2 or $3 \mathrm{in}$. long, but without the minute denticulation of the last species. Scapes usually above a foot long and slender. Flower-heads usually smaller and more ovoid than in $X$. pauciflora, the seales of a more uniform brown. Lateral outer perianth-segments more obtuse, the third very broad and thin, completely enclosing the inner perianth. Anthers larger, and the penicillate sterile stamens more conspicuous.

Hongkong, Hance, Wright. In varions parts of India.

\section{PHILYDRUM, Banks.}

Perianth of 2 nearly equal petal-like segments (the 2 outer wanting, and the 3 inner united into one). Stamens 3 , inserted at the base of the inner segment; filaments dilated, the middle one bearing an anther, the 2 lateral 
broader and more petal-like, usually without anthers. Placentas parietal, but projecting to the centre of the cavity and 2-lobed.

A genus now limited to a single species.

1. P. lanuginosum, Banks; Kunth, Enum. iii. 380 ; G'uillem. Ic. Pl. Austral. $t$. 5 ; Bot. Mag. $t$. 783 . Stems leafy, about $2 \mathrm{ft}$. high, with more or less of a loose white wool, wearing away with age. Lower leaves nearly 1 ft. long, equitant at the base, upper ones passing into short lanceolate sheathing bracts. Flowers yellow, sessile, and solitary or in pairs in the sheaths of distant bracts. Perianth-segments hairy, about $\frac{1}{2}$ in. long. Capsule about as long.

In marshes at Saywan, Champion, Hance, Wright. Also in Australia.

\section{ORder CXX. JUNCACE无.}

Perianth regular, dry and calyx-like, of 6 free segments. Stamens 6 or rarely 3 only, inserted at their base. Ovary 3 -celled, with 1 or more ovules in each cell, or 1-celled, with 3 or more ovules. Styles usually 3. Capsule 3 -valved. Seeds albuminous, with a very small embryo.-Herbs usually stiff, with narrow sometimes cylindrical and stem-like leaves, and small herbaceous flowers in terminal or apparently lateral clusters or panicles.

A small family, abundantly spread over all parts of the globe.

\section{JUNCUS, Linn.}

Ovary 3-celled, with numerous ovules. Leaves usually cylindrical, at least in the upper portion; the other characters and geographical range those of the Order.

1. J. Leschenaultii, J. Gay; Kunth, Enum. iii. 336. A tufted annual, from 2 or 3 in. to near $1 \mathrm{ft}$. high. Leaves sheathing below, cylindrical upwards, 1 to $3 \mathrm{in}$. long, slightly divided inside by cross partitions of pith, giving them a jointed appearance. Flowers in little clusters of fiom 3 or 4 to 8 or 10 , in a more or less compound terminal panicle with a small leaf-like bract at its base. Perianth-segments $1 \frac{1}{2}$ to 2 lines long, narrow, very acute. Stamens usually 3. Capsule narrow, pointed, full 2 lines long.--J. sinensis, J. Gay ; Kunth, Enum. iii. 336.

Hongkong, Wright; in a ditch in the Happy Valley, Wilford. Common in India. It is chiefly distinguished from the European $J$. articulatus by the much longer perianth-segments and capsules. The smaller specimens have almost the habit of $J$. bufonius, a cosmopolitan species, which I have reason to believe may also be found in Hongkong. It is a small annual, readily known by the leaves not jointed and its flowers mostly solitary or rarely 2 together.

\section{ORDER CXXI. RESTIACEAE.}

Flowers unisexual. Perianth dry and glume-like or very thin and transparent, of 6 or rarely 4 segments in 2 series, the inner ones sometimes united at the base. Male flowers: Stamens 6, 4, 3, or 2, usually inserted on the perianth-segments or at the summit of the tube. Female flowers: Ovary 1 - 
to 3-celled, with 1 pendulous ovule in each cell. Styles or stigmas 3, simple or 2-lobed. Fruit a capsule or a 1-seeded nut. Embryo lenticular on the outside of the albumen, remote from the hilum.-Herbs, usually stiff. Leaves narrow, parallel-veined, the sheaths split lengthwise. Flowering scapes or peduncles usually with 1 or more sheathing scales. Flowers in terminal heads or spikes, rarely paniculate.

A considerable Order, widely distributed over a great part of the globe; most abundant in S. Africa or Australia, and one genus within the tropies, but almost absent from Europe or northern Asia.

\section{ERIOCAULON, Linn.}

Flowers sessile, in androgynous or rarely diœcious heads, with imbricated bracts 1 under each flower, and a few outer ones empty. Male flowers: Perianth of 6 or 4 segments; the outer free or united, inner ones united at the base into a solid stalk. Anthers 2-celled Female flowers : Perianth-segments all distinct or the inner shortly united. Style single, with 3 or 2 stigmas. Capsule 3- or 2-lobed, opening at the angles.-Aquatic or marsh plants. Leaves all radical or crowded on a short stem. Scapes with 1 sheathing scale or short leaf at the base and 1 terminal head. Male and female flowers irregularly mixed in the Chinese species, the inner perianth-segments usually bearing a small black gland.

A large genus chiefly tropical in the New and the Old World, extending also into the cooler regions of N. America, and one species crossing over to N.W. Europe. The greater number of tropical American species have however been recently separated, by purely artificial characters, under the name of Papalanthus.

Bracts coriaceous, more or less mealy-white at the tips. Flowers very flat, the $\mathbf{2}$ outer segments winged (tall species).

Ireaves linear-lanceolate, glabrous. Heads slightly mealy . . . 1. E.Wallichianum.

Leaves linear, hairy. Heads very mealy ....... 2. E. australe.

Bracts thin, the floral ones transparent, glabrous or hairy. Perianthsegments not winged (smaller species).

Heads above 2 lines diameter. Outer male perianth of 2 or 3 distinct segments.

Bracts shining. Outer male perianth of 2 segments; inner lobes minute. . . . . . . . . . . . . . . .

Bracts not conspicuous. Outer male perianth of 3 segments ; inner lobes unequal, very plumose and exserted . . . . . .

Heads not 2 lines diameter. Outer male perianth spathaceous, 3toothed (small slender species).

Outer female perianth of 2 slender segments, inner one wanting. Leaves radical . . . . . . . . . . . . . .

Outer female perianth of 3 obovate segments, inner of 3 spathulate ones. Stem leafy at the base . . . . . 6. E. setaceum.

1. E. Wallichianum, Mart.; Wall. Pl. As. Rar. t. 249; Koern. in Linncea, xxvii. 687. Leaves radical, linear-lanceolate, very pointed, about 4 to 6 in. long and 2 to 3 lines broad. Scapes sometimes scarcely longer, sometimes near $1 \mathrm{ft}$., scarcely angular. Flower-heads ovate-globose; the scales very closely imbricated, coriaceous, broadly obovate, obtuse or with a very short inflected point, and slightly mealy at the tip. Perianth very flat, the 2 outer segments both in males and females boat-shaped with a winged keel. Inner male perianth filiform, with 3 minute lobes and 6 stamens. In- 
ner female perianth of 3 narrow short segments, slightly plumose at the top. Ovary 3-celled. Style long, with 3 short filiform stigmas.-E. cantoniense, Hook. and Arn. Bot. Beech. 219.

Common in moist situations, Champion and others. In Ceylon and the Indian Peninsula, in Tavoy and S. China. The $E$. longifolium, Nees, is probably the same species with the flowers accidentally 3 -androus; at least, in the Chinese specimen from Fortune, n. 120, referred to it by Kornicke, I find the flowers usually 3-merous and 6-androus, even in my specimen from Fortune; although in one instance I found ouly 5 stamens, and occasionally only 2 seeds ripen.

2. E. australe, $B r . ;$ Korn. in Linnce, xxvii. 686. Very near the last, and with flowers of the same structure. Leaves narrower, more or less hairy. Scape 1 to $1 \frac{1}{2} \mathrm{ft}$. high, prominently 7 -angled. Flower-heads rather larger, exceedingly compact, much more mealy-white; the floral scales more turned in and pointed.

Hongkong, Hance, Wright. Also in tropical Australia.

3. E. truncatum, Ham.; Korn. in Linnce, xxvii. 631. Leaves all radical, linear-lanceolate, acute, 1 to $2 \mathrm{in}$. long, 1 to near 2 lines broad. Scape 2 to 6 in. Head hemispherical or at length nearly globular, about $2 \frac{1}{2}$ lines diameter. Outer scales as long as the disk, thin, rather scarious, yellowish and shining; inner ones obovate-oblong, very thin and transparent, minutely ciliate but glabrous. Outer perianths of 2 narrow falcate segments; inner male with 3 minute black glandular lobes; inuer female of 3 linear slightly fringed segments. Style divided to nearly the middle into 3 filiform stigmas.

Hongkong, Hance, Wright, Wilford. Widely dispersed over India from Ceylon and the Peninsula to the Archipelago, and northward to Khasia and Silhet, the Philippines, and S. China.

4. E. cristatum, Mart.; Korn. in Linnaa, xxvii. 609. Leaves all radical, narrow-linear or almost subulate, usually 3 or 4 in. long. Scape usually twice as long, stiff and angular. Heads hemispherical, full 3 lines diameter, dark-coloured at first, then very white as the plumose perianths expand. Outer scales broadly obovate, shorter than the disk; inner ones thin, narrowobovate or cuneate, dark at the top and fringed with short white hairs. Outer perianth-segments 3, nearly equal, dark at the top and fringed like the bracts. Inner segments of the females and lobes of the males very white, plumose, one much longer, and all projecting beyond the scales. Style short, with 3 filiform stigmas.-E. miserum, Koern. 1. c. 607.

Hongkong, Hance. Common in Khasia.

5. E. heteranthum, Benth., n. sp. Leaves all radical, very narrow, 1 to $1 \frac{1}{2}$ in. long, ending in fine points. Stems slender, 3 to $4 \mathrm{in}$. high. Heads at first hemispherical, ovoid-globose when full grown, nearly 2 lines diameter. Outer bracts broad, obtuse, nearly as long as the disk; inner ones obovateoblong, rather acute, very thin and transparent, glabrous. Male outer perianth spathaceous, 3-toothed, inner of 3 short plumose lobes. Stamens 6 . Female outer perianth of 2 linear-subulate acute segments, fringed with a very few long hairs, inner perianth entirely deficient. Style long, with 3 subulate lobes.

Hongkong, Hance, Wright; in paddy-fields at Little Hongkong, Wilford. Not known from elsewhere. Allied to $E$. achiton, Koern., by the absence of any inner perianth to the 
female flowers, but in that species the outer male perianth has 2 narrow segments; the female segments are firmer and less pointed than in ours, and the mature heads are broadly obconical, not ovoid.

6. E. setaceum, Linn.; Korn. in Linnce, xxvii. 603. Stems, when submerged, more or less elongated and leafy. Leaves filiform, $\frac{1}{2}$ to $1 \frac{1}{2}$ in. long, slightly enlarged at the base. Scapes very slender, 2 to $4 \mathrm{in}$. long. Flower-head ovoid-globose, about $1 \frac{1}{2}$ lines diameter. Outer bracts broad, rather shorter than the disk; inner ones obovate-oblong, acute, thin and transparent, with a few white hairs at the tip. Outer male perianth spathaceous, 3-toothed, inner lobes minute. Female outer segments 3, obovate, 3 inner ones spathulate, all narrowed at the base, thin and transparent, slightly fringed at the top. Style deeply 3-cleft.

Hongkong, Wright. In Ceylon and Tavoy.

\section{Order CXXII. CYPERACEAE.}

Flowers in little green or brown spikes called spikelets, consisting of several scale-like bracts called glumes, either distichous as in Graminea, or imbricated all round with one sessile flower in the axil of each, or the lower ones empty. Perianth either none or replaced by a few bristles or minute scales. Stamens 3 , rarely 2 or 1 or more than 3 . Ovary (in the same or in a distinct glume) simple, 1-celled, with 1 erect ovule. Style more or less deeply divided into 2 or 3 branches or linear stigmas. Fruit a small seed-like nut, flattened when the style is 2-cleft, triangular when it is 3-cleft. Seed albuminous, with a small lens-shaped embryo in its base.-Herbs, resembling in aspect the Juncea, or more frequently the Graminea ; but usually stiffer than the latter, with solid stems and the sheaths of the leaves closed all round. Spikelets terminal (or apparently lateral when a leafy bract appear's to continue the stem), solitary or several in a simple or compound cluster, spike, umbel, or panicle. Inflorescence and its branches almost always subtended by bracts, which are usually leaf-like under the general inflorescence, glume-like under the spikelets. When the inflorescence is umbellate it is very irregularly so, one spikelet, cluster, or partial umbel being always sessile, whilst the others are supported on peduncles or rays of very unequal length.

A large Order, abundantly distributed all over the globe, but more especially in moist situations or on the edges of waters.

Flowers, at least the fertile ones, hermaphrodite.

Spikelets several-flowered, with only 1 or 2 empty glumes below the flowering ones.

Glumes distichous, at least in the young spikelet.

Style not thickened at the base. Spikelets in clusters or spikes, on the scape or on the rays of a simple or compound umbel

Style thickened at the base and articulate on the nut. Spikelets single on the scape or the umbel-rays . . . 5. AbildgaAdia.

Glumes imbricate all round.

No hypogynous bristles or scales.

Style thickened at the base and articulate on the nut . .

Style falling off above the thickened base, which remains as a beak or tubercle on the nut.

6. Fimbisistyles.

7. IsOLEPIS. 
Hypogynous bristles 4 or 6 .

Hypogynous seales 3 , flat

Spikelets 1-flowered (or with a second male flower), closely imbricate in small heads or spikes resembling spikelets.

Scales under the spikelets small or none.

Scales under the spikelets as long as them, imbricate and glumelike.

Spikes in a sessile head. Glumes concave (very thiu) Spikes paniculate. Glumes flat, keeled

Spikelets 1-or few-flowered, with several empty glumes below them; in panicles, clusters, or spikes, but not imbricate.

Hypogynous bristles 6 . Nut crowned by the base of the style 10. Rhynchospora. No hypogynous bristles.

Nut thick, tapering at the top. Spikelets paniculate . . . 11. Cuadium.

Style articulate below the bulbous base. Spikelets in a terminal head. No leaves...........

Stamens 4 to 6 , very long and persistent. Spikelets clustered in spikes, forming a narrow panicle .

Nut seated on a thickened toothed disk. Spikelets clustered in compound spikes.

Flowers unisexual, in unisexual or androgynous spikelets.

Nut very hard, seated on a thickened entire or lobed disk . . . 15. Scheria.

Nut enclosed in a 2-toothed utricle . . . ... . . . 16. CAREX.

\section{CYPERUS, Linn.}

Spikelets several-flowered (very rarely 2- or 3-flowered). Glumes distichous, all nearly equal, with 1 flower in each, or 1 or 2 lowest rarely empty. Flowers hermaphrodite, without hypogynous scales or bristles. Stamens 3 or fewer. Style continuous with the ovary, not bulbous at the base.-Spikelets in clusters, heads, or spikes, which are usually several together in a simple or compound irregular umbel.

A very large tropical and subtropical genus, represented by a few species in more temperate regions, and quite disappearing in the extreme north and south.

\section{Style 2-cleft. Nut flattened.}

Spikelets obtuse. Nuts ovate or obovate.

Spikelets pale-coloured, rather narrow, shining. Glumes scarious on the edge. Stamens 2 . . . . . . . . . . . .

Spikelets broad. Glumes edged with red-brown. Stamens 3 . .

Spikelets acute, densely clustered. Nuts narrow-oblong . . . 3. C. polystachya. Style 3-cleft. Nuts more or less 3-angled.

Spikelets obtuse. Nuts as long as the very obtuse glumes.

Spikelets in dense globose heads. Glumes dark-brown, scarcely one-third line long .

Spikelets in loose clusters or spikes. Glumes at least two-thirds of a line long.

Spikelets very flat, yellowish-green . . . . . . . . 5. C. Iria.

Spikelets narrow-linear, more or less brown . . . . . 12. C. distans.

Spikelets acute or tapering to the end.

Spikelets 2 to 3 lines long.

Spikelets clustered at the ends of the rays.

Slender plant. Glumes scarcely pointed, not $\frac{x}{2}$ line long, all flowering . . . . . . . . . . .

Low stiff plant. Glumes above 1 line long, with prominent points, the lower 2 smaller and empty .

6. C. Haspan.

7. C. radians. 
Spikelets spicate along the rays.

Rhachis of the spikes glabrous. Glumes closely imbricate.

Spikelets 2- to 4-flowered, nearly cylindrical, densely imbricate in cylindrical spikes

8. C. umbellatus.

Spikelets 6 - to 10 -flowered, rather flattened, very spreading, in rather dense spikes . . . . . . . . . . .

Rhachis pubescent or hairy. Spikelets loosely 6- to 10-flowered, flat, in loose spikes

Spikelets 5 to 10 lines long.

Spikelets few, in short spikes on each ray. Glumes closely imbri-

cate . . . . . . . . .

9. C. pennatus.

Spikelets very slender, in loose spikes. Glumes alternate, scarcely imbricate

10. C. pilosus.

11. C. rotundus.

12. C. distans.

1. C. vulgaris, Sieb.; Kunth, Enum. ii. 4. Stems tufted, rather slender, $\frac{3}{4}$ to $1 \mathrm{ft}$. high. Leaves narrow, shorter than the stem. Umbel of several rays, the longest 1 to $1 \frac{1}{2}$ in., with 2 or 3 long leafy unequal bracts. Spikelets 3 to 10 or more in each cluster, very spreading, $\frac{1}{4}$ to $\frac{1}{2}$ in. long, flat but narrow. Glumes 20 to 30 or even more, obtuse, pale brown, with a green keel and narrow scarious edges. Stamens usually 2 . Style 2-cleft. Nut obovate, dark brown.

Hongkoug, Hance; a single specimen mixed with other species. Widely spread over tropical and subtropical Asia, extending from eastern Africa and some parts of the Mediterranean region to the Indian Archipelago, and northward to Shanghai.

2. C. Eragrostis, $V a h l ; K u n t h$, Enum. ii. 7. Rhizome slender and shortly creeping. Stems 8 to $10 \mathrm{in}$. or rarely $1 \mathrm{ft}$. high. Leaves much shorter, grass-like. Umbel usually contracted into a single dense head or cluster, or accompanied by 1 or 2 pedunculate ones. Outer bracts leafy, one very long. Spikelets 4 to 10 or more in the cluster, obtuse and very flat, seldom above 4 lines long. Glumes 10 to 20 or rather more, not $\frac{1}{2}$ line long, very obtuse and broad, green on the keel, pale brown, with dark spots on the side, but bordered with a rich red-brown, giving a dark or variegated colour to the spikelet. Stamens 3. Style 2-cleft. Nut ovate, dark-brown.

On the edges of paddy-fields, Wilford. In the Malayan Peninsula and Singapore.

3. C. polystachyus, Rottb. ; Kunth, Enum. ii. 13. Stems tufted from a short horizontal rhizome, $\frac{1}{2}$ to above $2 \mathrm{ft}$. high. Leaves much shorter. Umbel usually contracted into a dense head, surrounded by 3 to 6 unequal leafy bracts. Spikelets numerous, flat but very narrow, acute, about $\frac{1}{2}$ in. long. Glumes about 20, narrow, with short points, of a rather pale brown, with lighter-coloured keel and edges. Stamens 1 or 2. Style 2-cleft. Nut narrow-oblong.

Hongkong, Hance, Wright. Widely spread over the tropical and subtropical regions of the New and the Old World.

C. compressus, Linn.; Kunth, Enum. ii. 23. A widely diffused species, readily known among the 3-gynous Cyperi by its very flat spikelets, with broad acutely keeled and pointed glumes of a pale greenish colour. It appears to be common in S. China, and will probably be found in Hongkong, although I have not as yet seen any specimens from thence.

4. C. difformis, Linn.; Kunth, Enum. ii. 23. A tufted annual, $\frac{1}{2}$ to 1 $\mathrm{ft}$. or rarely higher. Leaves shorter than the stems. Umbel of several unequal rays, rarely contracted into a single head; the outer bracts long and leafy. Clusters small, globular, consisting of very numerous obtuse spikelets 
about 2 lines long. Glumes 10 to 20 , loosely imbricate, shortly obovate and very obtuse, dark brown, with pale edges. Style short, 3-cleft. Nut about as long as the glume.

Hongkong, Hance, Harland, Wright. Common in the tropical and subtropical regions of the Old World, extending northward into S. Europe in the west and to Amoy in the east.

5. C. Iria, Linn.; Kunth, Enum. ii. 38. Stems $\frac{1}{2}$ to $1 \frac{1}{2} \mathrm{ft}$. high or even more. Leaves flaccid, often nearly as long. Umliel of several rays, the longer ones often branched. Spikelets loosely and irregularly clustered or spicate, 2 to 4 lines long, obtuse, very flat. Glumes usually 8 to 12 , but sometimes at least 20 , distant or very loosely imbricate, obovate, very obtuse, of a pale yellow-brown colour. Style short, 3-cleft. Nut as long as the glumes.

Hongkong, Harland, Wright; in wet situations at East Point, Wilford. In India, from Ceylon and the Peninsula to the Archipelago, and northward to the Himalaya, Philippines, and S. China. In some specimens the inflorescence is more contracted and the spikelets longer, so as to give the plant the aspect almost of the diandrous $C$. flavescens.

6. C. Haspan, Linn.; Kunth̆, Enum. ii. 34. Stems slender, tufted, acutely triangular, from a few inches to $1 \frac{1}{2} \mathrm{ft}$. high. Leaves short, sometimes all reduced to sheaths. Umbel-rays often numerous, the longer ones compound, the outer leafy bracts seldom as long as the rays. Spikelets 3 or more together in terminal clusters, lanceolate, acute, 2 to 3 lines long. Glumes 10 to 20 or sometimes more, not $\frac{1}{2}$ line long, scarcely pointed, reddish-brown on the sides, with a broad green keel. Styles long, 3-cleft. Nut not half the length of the glumes.

Hougkong, Hance, Harland, Wright; in marshes in the Happy Valley,Wilford. Common in the tropical and subtropical regions of the Old World, and also not unfrequent in America.

7. C. radians, Nees in Linnaa, ix. 285, and in Pl. Meyen. 63. Stems short, densely tufted. Leaves rigid with broad sheaths. Umbel simple or compound, each ray terminating in a dense cluster or head, with leafy bracts at its base, a long pointed bract usually under each spikelet, and several long leafy bracts under the general umbel. Spikelets lanceolate, 2 to 3 lines long. Flowering glumes 3 to 8 , broad, strongly veined, with a prominent point, green on the back, more or less red-brown on the sides, and there are usually 2 or 3 shorter glumes at the base of the spike, either empty or with a male flower. Style long, 3-cleft. Nut much shorter than the glumes.-C. radicans, Kunth, Enum. ii. 95.

Hongkong, Wright. In Sikkim, Malacea, Singapore, and Borneo.

8. C. umbellatus, Benth. Stems 1 to $2 \mathrm{ft}$. high. Leaves narrow, palegreen, often as long or longer. Umbel of many rays but very dense, often contracted into a head, and seldom above 2 in. diameter. Spikelets 2 or 3 lines long, linear, acute, only slightly compressed, erect or spreading, and very densely crowded in cylindrical spikes, $\frac{1}{2}$ to $\frac{3}{4}$ in. long, occupying often the whole length of the rays. Glumes 4 to 6 , the lowest 1 or 2 usually empty, the others narrow, green, several-nerved, above 1 line long. Style 3cleft. Nut narrow, not much shorter than the glume.-Mariscus umbellatus, Vahl; Kunth, Enum. ii. 118. M. cyperinus, Vahl; Seem. Bot. Her. 422.

Hongkong, Hance, Wright. Widely distributed over the tropical and subtropical regions of the Old World. A. Gray has already adopted, what many botanists had suggested, the re- 
union of Mariscus with Cyperus, no character existing to separate them, and the habit being nearly identical in some species of each.

9. C. pennatus, Lam.; Kunth, Enum. ii. 80. A coarse species, of a glaucous or pale green colour. Stem $2 \mathrm{ft}$. high or more. Leaves often longer, rather stiff, with very rough serrulate edges. Umbel compound, often with numerous rays, but very compact, seldom above 4 in. diameter; the leafy bracts very long. Spikelets lanceolate, not much flattened, about 3 lines long, very spreading, in dense spikes occupying the whole length of the partial umbels. Glumes 6 to 10, closely imbricate, many-nerved, not keeled, of a pale whitybrown colour. Styles 3-cleft. Nuts about half as long as the glume. C. canescens, Vahl; Nees in Pl. Meyen. 61.

Hongkong, Hance, Harland, Wright. In Ceylon and the Indian Peninsula, the Malayan Peninsula, the Archipelago, Pacific islands, and S. China.

10. C. pilosus, $V a h l$; Kunth, Enum. ii. 80. A coarse species, much resembling the last in habit, but greener, the leaves and leafy bracts not quite so long nor so rough at the edges. Umbels similarly compounded but larger and looser, some of the rays often $4 \mathrm{in}$. long. Spikelets 2 to 3 lines long, very spreading, in loose spikes occupying the whole length of the partial rays; the rhachis always hairy on the edges, whilst in all the allied species it is glabrous. Glumes 6 to 10, loosely imbricate and more or less spreading at the tips, pale brown, with scarious edges. Style 3 -cleft. Nut about $\frac{1}{2}$ as long as the glume. -C. obliquus, Nees; Kunth, Enum. ii. 69.

Hongkong, Wright. In northern and eastern India and the Archipelago.

C. marginellus, Nees in Hook. and Arn. Bot. Beech. 222, apparently common in S. China as well as in northern and eastern Iudia, but not yet received from Hongkong, is perhaps a variety only of $C$. pilosus, differing in the longer spikelets (about 4 lines), and more numerous glumes usually of a darker reddish-brown.

11. C. rotundus, Linn.; Kunth, Enum. ii. 58. Stems $\frac{1}{2}$ to $1 \frac{1}{2} \mathrm{ft}$. high, from a short sometimes slightly creeping rhizome, the fibrous roots occasionally forming small tubers. Leaves flaccid, much shorter than the stems. Umbel-rays not numerous, the outer leafy bracts seldom so long as the longest rays. Spikelets linear, acute, usually about 6 lines, but sometimes 10 or 11 lines long, 3 to 8 together, in short spikes at the ends of the rays. Glumes numerous, imbricate, narrow-ovate, scarcely pointed, red-brown, with a green keel and light-coloured edge. Style long, 3-cleft. Nut much shorter than the glume.

Hongkong, Hance and others. Widely diffused over the tropical and temperate regions of the New and the Old World.

12. C. distans, Linn. ; Kunth, Enum. ii. 93. A coarse species, with a horizontal or slightly creeping rhizome. Stems 1 to $2 \mathrm{ft}$. high or even more. Leaves often as long or longer. Umbel more or less compound, with numerous slender rays, and 1 or 2 of the outer leafy bracts much longer than the rays. Spikelets slender, $\frac{1}{2} \mathrm{in}$. long or more, in loose spikes along the rays of the partial umbels. Glumes narrow, rather distant, so as scarcely to overlap each other, red-brown on the sides, more or less green on the keel. Style rather short, 3-cleft. Nut narrow, nearly as long as the glume.

Hongkong, Wright. Diffused over the tropical and subtropical regions of Asia, Africa, and Australia, occurring also in some parts of tropical America. 


\section{KYLLINGIA, Linn.}

Spikelets 1-flowered or with a second male flower, closely imbricate in globular or oblong heads or short spikes resembling spikelets; the bracts under each spikelet very small or altogether wanting in the interior of the spike. Glumes distichous, 1, 2, or 3 empty ones below the flowering one. Flowers hermaphrodite, without hypogynous bristles or scales. Stamens 3 or fewer. Style 2-cleft. Nut flattened. Spikes usually solitary or few together, sessile or shortly pedunculate within 2 or 3 long leafy bracts.

A small genus, chiefly tropical, but extending also into N. America and S. Africa.

1. K. monocephala, Linn.; Kunth, Enum. ii. 129. A small tufted plant with a creeping rhizome; the stem usually 4 to $8 \mathrm{in}$. rarely $1 \mathrm{ft}$. high. Leaves flaccid, shorter than the stem. Spikelets very numerous, in a single sessile head of about 3 lines diameter, between 2 or 3 very long leafy bracts. Glumes usually 3 , the lowest very small, transparent, obtuse and empty; the next also empty, pointed, with a green ciliate keel; the third flowering one similar, but rather longer. Nut obovate, about half as long as the glume, and falling away from it when ripe.

Hongkong, Hance, Wright. Widely diffused over tropical Asia, Africa, and Australia, and probably the tropical American $R$. caspitosa, Nees, may not be distinct. It varies with the head of spikelets quite simple or with 2 short lateral branches.

\section{LIPOCARPHA, Br.}

Spikelets 1-flowered, closely imbricate in globular or oblong heads or short spikes resembling spikelets; the glume-like bracts under each spikelet as long as the spikelets themselves. Glumes 2, very thin and transparent, concave and scarcely keeled, one or both falling off with the nut when ripe. Flowers hermaphrodite, without hypogynous bristles or scales. Stamens 3 or fewer. Style 2-or 3-cleft. Nut slightly compressed or obtusely 3-angled.-Herbs with the habit of Kyllingia. Spikes usually 3 or 5, rarely solitary, sessile between leafy bracts.

A small tropical genus, common to the New and the Old World. The spikes are usually described as spikelets, the subtending bracts as glumes, and the glumes as inner scales, but the view above taken of the nature of the different parts appears to me to be more correct, especially when they are compared to those of the closely allied genus Kyllingia.

Leaves and bracts linear. Glume-like scales with very short erect points

Leaves and bracts subulate. Spikes squarrose with the spreading or recurved points of the glume-like scales . . . . . . .

\section{L. argentea.}

1. I. argentea, $B r$; Kunth,-Enum. ii. 266. A tufted plant, with slender but stiff stems $\frac{1}{2}$ to $1 \mathrm{ft}$. high. Leaves much shorter, narrow-linear, rather stiff. Spikes 3 to 7 , ovoid-globose, about 3 lines diameter, closely sessile within 2 or 3 spreading stiff leafy bracts. Glume-like scales spathulate, closely imbricate, thin and scarious, with short erect points. Spikelets rather shorter. Glumes very thin, the inner one slightly keeled. Style 2-cleft. Nut obovoid-oblong, about half as long as the glumes.

Hongkong, Hance, Wright; in wet places in the Happy Valley, Wilford. Extends over the greater part of tropical Asia, Africa, and America, and northward to Amoy.

2. L. microcephala, Br.; Kunth, Enum. ii. 268. A slender annual, 
with almost filiform stems, 3 to 6 in. high. Leaves short, subulate. Spikes 3 or 1 , ovoid or nearly globular, about 2 lines diameter, with 1 or 2 long subulate leafy bracts. Glume-like scales linear-cuneate, with long spreading or recurved subulate points, giving the spikes a squarrose appearance, Glumes narrow and exceedingly delicate, 3-nerved. Style short (2-cleft?). Nut oblong, nearly as long as the glumes.

Hougkong, Wilford. In Java and Australia, and apparently a larger variety in tropical Africa. This species so closely resembles in aspect the Isolepis squarrosa, Roen. and Sch. (an Indian plant, not found in Hongkong) as scarcely to be distinguished except by the presence of the inner scales or glumes, and by the differently shaped nut.

\section{HYPOELYTRUM, Rich.}

Spikelets 1-flowered, densely crowded in ovoid or cylindrical spikes resembling spikelets, the imbricated glume-like bracts under each spikelet as long as the spikelets themselves. Glumes 2, very flat, acutely keeled. Flowers hermaphrodite without hypogynous scales or bristles. Stamens 3 or fewer. Style 2- or 3-cleft. Nut slightly compressed or obtusely 3-angled, falling away from the glumes when ripe.-Herbs usually coarse. Spikes brown, resembling the spikelets of Scirpus, pedicellate in corymbose panicles like those of Rhynchospora.

A small tropical and subtropical genus, common to the New and the Old World.

1. H. latifolium, Rich.; Kunth, Enum. ii. 271. Stems acutely triangular, 2 to $4 \mathrm{ft}$. high. Leaves usually longer, $\frac{1}{2}$ to $1 \mathrm{in}$. broad, with 3 prominent nerves, and more or less rough on the edges and midrib. Panicles 2 to $4 \mathrm{in}$. diameter, with 2 or 3 long leafy bracts. Spikes oblong-cylindrical when in flower, ovoid when in fruit, 2 to 3 lines long. Glume-like bracts brown, mostly obtuse, or the lower ones acute. Spikelets shorter, very flat. Glumes pointed, ciliate on the keel. Stamens 2. Style 2-cleft. Nut nearly globular, searcely beaked, more or less reticulate with raised veins. $-H$. trinervium, Kunth, Enum. ii. 272. Albikkia scirpoides, Presl, Rel. Hænk. t. 35, and $A$. schoenoides, t. 34.

Hongkoug, Harland, Hance, Wright. Widely diffused over tropical Asia and Africa.

\section{ABILDGAARDIA, Vahl.}

Spikelets several-flowered, flattened, often becoming spiral when old. Glumes distichous; the lower 2 or rarely 3 empty. Flowers hermaphrodite, without hypogynous scales or bristles. Stamens 3 or fewer. Style 3-cleft, often thickened at the base and articulate on the nut, below the bulb.- Habit of Fimbristyles, from which it only differs in the distichous glumes.

A small tropieal and subtropical genus, common to the New and the Old World.

Spikelets solitary

Spikelets several in an irregularly compound umbel.

Leaves glabrous, 1 line broad. Glumes pale brown, scarcely pointed

Leaves pubescent, $\frac{3}{2}$ line broad. Glumes rich-brown narrow-pointed

1. A monostachya.

1. A. monostachya, Vahl; Kunth, Enum. ii. 24.7.

2. A. Eragrostis.

3. A. fusca.

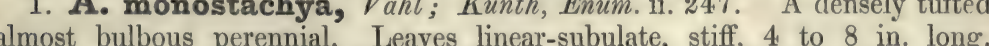
Stems slender, stiff, $8 \mathrm{in}$. to $1 \mathrm{ft}$. long, bearing a single flat ovate-lanceolate 
spikelet about $\frac{1}{2}$ in. long. Glumes pale straw-colour, very pointed, acutely keeled. Style hairy, with a thickly conical base. Nut obovoid-triangular, minutely tuberculate.

Hongkong, Harland, Wright. Widely distributed over tropical Asia, tropical and southern Africa, and tropical America.

2. A. Eragrostis, $V a h l ;$ Kunth, Enum. ii. 249. Densely tufted, stiff, and glaucous. Leaves linear, obtuse, 4 to 8 in. long, about 1 line broad. Stems 1 to $1 \frac{1}{2} \mathrm{ft}$. high, angular. Umbel irregularly compound. Spikelets 3 to 4 lines long, often early becoming spiral, so as to lose the distichous appearance. Glumes pale brown, broad, shortly pointed, or the lower ones obtuse. Nut obovoid, minutely tuberculate.-Fimbristyles quinquangularis, Munro in Seem. Bot. Her. 422 ; not of Kunth.

Hongkong, Hance, Wright. Also in Khasia.

3. A. fusca, Nees; Kunth, Enum. ii. 249. Habit and inflorescence of A. Eragrostis, but a rather smaller and more slender plant, with much narrower leaves more or less pubescent. Spikelets narrower, of a rich uniform brown, 3 to 4 lines long. Glumes lanceolate, very pointed, regularly distichous. Stamens 3. Style glabrous. Nut obovoid, with 3 prominent angles; the sides tuberculate, almost muricate.

Hongkong, Hance, Wright. In Nepal, Java, and Borneo.

\section{FIMBRISTYLES, Vahl.}

Spikelets several-flowered, the glumes imbricate all round, only 1 or 2 of the lowest empty. Flowers hermaphrodite, without hypogynous scales or bristles. Stamens 3 or fewer. Style 2- or 3-cleft, usually thickened at the base and articulate on the nut below the bulb.-Leaves usually radical or sheathing the stem at its base, sometimes all reduced to sheaths. Spikelets solitary on the scape, or more frequently on the rays of a simple or compound umbel, one always sessile, or rarely clustered in a single head or on the rays of the umbel.

A large genus, widely distributed over the tropical and subtropical regions of the globe, extending also sparingly into the warmer temperate zones.

Spikelets 1 or few, rarely 5 or 6,1 sessile, the others pedunculate.

Spikelets solitary (about 4 lines long). Nuts with deep transverse furrows.

Spikelets ovoid-oblong, brown, more or less nodding :.. . . 1. T. mutans.

Spikelet narrow, pale straw-colour, erect . . . . . . 2. F. acuminata.

Spikelets 1 to 3, pale straw-colour, very obtuse. Nuts smooth or nearly so, sessile . . . . . . . . . . 3. F. schonoides.

Spikelets i to 6 . Nuts smooth or nearly so, stipitate.

Spikelets 7 to 10 lines long, usually solitary . . . . . . 4. F. subbispicata.

Spikelets about 5 lines long, usually 3 to 6 . . . . . . 5. F. podocarpa.

Spikelets several, often uumerous, in a more or less compound irregular umbel. Nuts sessile.

Styles 2-cleft (occasionally 3-cleft, with 1 branch smaller).

Stems $\frac{3}{4}$ to $1 \frac{1}{2} \mathrm{ft}$. high. Leaves stiff. Spikelets brown. Nuts more or less conspicuously striate.

Umbel scarcely compound. Leaves very short. Glumes hoary at the top . . . . . . . . . . . . .

Umbel usually compound. Leaves 3 to $6 \mathrm{in}$. long. Glumes perfectly glabrous.

6. F. ferruginea.

7. F. diphylla. 
Stems 2 to 6 in. Nuts minutely tuberculate.

Leaves narrow, flaceid. Spikelets usually green.

Bulb of the style with a few hairs reflexed on the nut - . 8. F. squarrosa.

Bulb of the style quite glabrous . . . . . . . 9. F. astivalis.

Leaves stiff, spreading. Umbel very compact. Spikelets brown 10. F. Wightiana. Styles 3-cleft.

Spikelets numerous, distinct, in loose compound umbels.

Stem much flattened. Spikelets oblong, 3 to 4 lines long . . 11. F. complanata. Stem slender, 4-angled. Spikelets ovoid or globular, 1 line long 12. F. miliacea.

Spikelets (very small) in 2 or more dense clusters, 1 sessile, the others pedunculate . . . . . . . . . . 13. F. leptoclada.

1. F. nutans, Vahl; Kunth, Enum. ii. 221. Stems tufted, slender, 6 in. to $1 \mathrm{ft}$. high, with a short sheath at their base. No other leaves. Spikelet solitary, terminal, usually oblique or nodding, with a short glume-like bract at the base, ovoid-oblong, rather acute, about 4 lines long. Glumes broad, pale brown, striate, obtuse or with a minute point. Style 2-cleft, flattened, ciliate on the edges. Nut white or pale brown, transversely marked with deep ridges and furrows.

Hongkong, Harland. In Ceylon, Bengal, Silhet, and Borneo.

2. F. acuminata, Vahl; Kunth, Enum. ii. 221. Very near the last, but the spikelet is erect, narrower and more acute, of the pale straw-colour of F. schoenoides. The nuts when fully ripe, as well as the style, appear to me to be quite the same.-F. setacea, Benth. in Hook. Journ. Bot. ii. 139.

Hongkong, Hance, Wright. In Nepal, Java, and Bomeo.

3. F. schœenoides, Vahl; Kunth, Enum. ii. 222. Stems and leaves filiform, densely tufted; the stems $6 \mathrm{in.} \mathrm{to} 1 \mathrm{ft}$. high; the leaves shorter. Spikelets 1, 2, or rarely $3 ; 1$ sessile, the others pedunculate, about 3 lines long, ovate and very obtuse, with a subulate leafy bract usually rather longer or sometimes scarcely any. Glumes broad, obtuse or scarcely pointed, pale straw-colour, scarious on the edges. Style 2-cleft, flat, ciliate on the edges. Nut white or brown, obovate, sessile, minutely punctate or tuberculate under a strong lens.

Hongkoug, Wright. Widely distributed over India, from Ceylon and the Peninsula to the Archipelago, and northwards to the Himalaya.

4. F. subbispicata, Nees, $P l$. Meyen. 75 . Stems 1 to $2 \mathrm{ft}$. high, slender and rush-like, with 2 or 3 sheaths at the base bearing short narrow leaves. Spikelet solitary (or sometimes 2 ?), 7 to 10 lines or sometimes near 1 in. long, with a stiff subulate leafy bract at the base often longer than the spikelet. Glumes broad, thin, brown, 1-nerved. Style 2-cleft, flattened, ciliate on the edges. Nut raised on a conspicuous stalk, rounded, minutely punctate under a strong lens.

Hongkoug, Harland, Wright. On the adjoining continent and in the Philippines.

5. F. podocarpa, Nees, Pl. Meyen. 77. Nearly allied to the last, of which it has the stipitate nuts. The leaves are longer, the involucral leafy bract shorter, and there are usually 3 to 6 spikelets, one sessile, the others pedunculate, each one only 4 to 5 lines long.

Hongkong, Hance, Wright. In the Peninsula of India, in the Himalaya and the Indian Archipelago.

6. F. ferruginea, Vahl; Kunth, Enum. ii. 236. Stems $\frac{3}{4}$ to $1 \mathrm{ft}$. high, 
slightly compressed or 3-angled at the top. Leaves very short, narrow-linear and stiff. Spikelets oblong, 4 to 6 lines long, usually 5 to 7 in a simple or slightly compound umbel, with 1 to 3 narrow leafy bracts, seldom exceeding the longest peduncle. Glumes broad, rounded at the top, with a minute point, brown, but more or less hoary in the upper part. Style 2-cleft, flattened, ciliate. Nut sessile, brown, smooth and shining.- $\boldsymbol{H}^{\prime}$. arvensis, Vahl; Kunth, Enum. ii. $23 \%$.

Hongkong, Hance, Harland. Dispersed over the tropical and subtropical regions of the New and the Old World, but evidently not so common as some other species.

7. F. diphylla, Vahl, Enum. ii. 289. Stems slender, $\frac{3}{4}$ to $1 \frac{1}{2} \mathrm{ft}$. high. Leaves tufted, narrow-linear, glaucous, glabrous or pubescent, much shorter than, or sometimes nearly as long as, the stem. Spikelets ovoid-oblong; scarcely acute, 3 to 6 lines long, more or less numerous in a compound umbel. Glumes broad, shortly mucronate, quite glabrous, brown, with a pale or green keel or centre. Style 2-cleft, flat, ciliate on the edges. Nut sessile, obovate, white or pale brown, with minute longitudinal striæ.- $F$. communis, Kunth, Enum. ii. 234.

Hongkong, Wright; at Little Hongkong, Wilford. Common in tropical and subtropical Asia and Africa; also in tropical America, if the F. brizoides, Nees, is not really distinct.

Var. tomentosa. Leaves, especially their sheaths, softly hairy. $-F$. tomentosa, Vahl, Enum. ii. 290.

Hongkong, Wright. Occurs here and there in tropical A sia with the glabrous form.

Var. ? leptophylla. Leaves narrow, almost subulate, like those of $\boldsymbol{F}$. hispidula, Kunth, but perfectly glabrous. Spikelets and nuts entirely as in the common form.

Hongkong, Hance, Harland, Wright. I do not find precisely the same form in any of our Indian collections, although some of the narrower-leaved ones come very near to it.

8. F. squarrosa, $V a h l$; Kunth, Enum. ii. 224. A small densely-tufted pale-green species, seldom attaining 6 in. Leaves narrow-linear or subulate, flaccid, shorter than the stem. Umbel compound, with 3 or 4 narrow leafy bracts seldom exceeding the rays. Spikelets oblong, 2 to 3 lines long, green or pale brown. Glumes ovate, glabrous or pubescent; the green keel projecting into a point, often spreading and sometimes very long. Style 2-cleft, scarcely ciliate, but the bulb of the base fringed with a few long hairs, which are closely reflexed on the ovary and fruit. Nut obovate, sessile, smooth or minutely.punctate.

Hongkong, Harland, Wright; in paddy-fields, Wilford. Very common in tropical and subtropical Asia and Africa.

9. F. astivalis, $V a h l$; Kunth, Enum. ii. 226. A small, densely tufted plant, like $F$. squarrosa, and not always easily distinguished from it except by the constant absence of the reflexed hairs at the base of the style. Leaves usually very few, the leafy bracts longer than the umbel. Spikelets usually rather smaller than in $F$. squarrosa, and the glumes less mucronate. Asia.

Hongkong, Wright, Wilford. Gathered with the last and dispersed with it over tropical

10. F. Wightiana, Nees; Kunth, Enum. ii. 241. Rhizome creeping. Leaves densely tufted, short, stiff, narrow-linear, rather obtuse, falcate or spreading. Stems 3 or $4 \mathrm{in}$. to near $1 \mathrm{ft}$. high. Umbel compound, but very compact; the leafy bracts very short. Spikelets ovate, obtuse, about 2 lines long. Glumes brown, broad, obtuse, with a scarious margin. Style deeply 
2-cleft, glabrous or the branches slightly ciliate. Nut sessile, dark-coloured, smooth or minutely tuberculate.-F. junciformis, Munro in Seem. Bot. Her. 422, not of Nees.

Hongkong, Hance. In the ueighbouring Samtong Island, Wright. In the Indian Peninsula, in Bengal, and some other parts of India. The spikelets although crowded are distinct, not in detached clusters as in the true $F$. juncifolius.

11. F. complanata, Link; Kunth, Enum. ii. 228. Stems 1 to $1 \frac{1}{2} \mathrm{ft}$. high, stiff and distinctly flattened. Leaves glaucous, firm, obtuse, 1 to $1 \frac{1}{2}$ lines broad, usually much shorter than the stem. Umbel compound, like that of $F$. diphylla, with 1 to 3 short stiff erect leafy bracts. Spikelets usually numerous, 3 to 4 lines long. Glumes brown, pointed, usually with narrow scarious edges. Style 3-cleft, glabrous. Nut sessile, minutely tuberculate.

Hongkong, Harland, Wright. Widely spread over tropical Asia, ocenrring also in Africa nd in tropical Brazil.

12. F. miliacea, $V a h l ; K u n t h$, Enum. ii. 230. Stems slender, attaining 1 to $2 \mathrm{ft}$. in height, more or less flattened and acutely 4-angled. Leaves distichous at the base, narrow-linear, shorter than the stem, ending in long fine points. Umbel compound, with 1 to 3 short fine leafy bracts. Spikelets numerous, ovoid-globular, seldom above 1 line long. Style 3-cleft, ciliate towards the top. Nut sessile, slightly striate and tuberculate.

Hongkong, Hance, Wright. Widely spread over tropical Asia and Africa. In Wright's and Wilford's collections are a few dwarf specimens scarcely 3 in. high.

13. F. leptoclada, Benth., n. sp. A densely tufted slender species, apparently annual. Stems filiform, 6 to 8 in. high. Leaves filiform, rather shorter. Spikelets about 1 line long, obtuse, in clusters of 4 to 8, of which there are in our specimens always 2,1 sessile, with a leafy bract of 4 to 6 6 lines, the other pedunculate. Glumes brown, very obtuse and emarginate, strongly keeled, slightly scarious and minutely ciliate on the edge. Stamen 1 . Style 3-cleft, glabrous or nearly so, bulbous at the base. Nut sessile, but only seen in a very young state.

Hongkong, Wright. Not seen in any other collection. From the remarkable glumes it must be very near to the $F$. ciliolata, Steud., from Java; but Steudel's character differs in too many other points for me to venture on referring our species to his without actual comparison.

\section{ISOLEPIS, Br.}

Characters and habits of Scirpus, except that there are no hypogynous scales.

A considerable genus, having the same wide range as Scirpus, and might more naturally be re-amalgamated with some of the sections of that genus.

Spikelets about 2 lines long, in a dense terminal globular head. Stem and

leaves subulate lines long, few together in an apparently lateral cluster.

Leaves very short or none ... . . . . . . . . . 2, I. supina.

1. I. barbata, $B r$.; Kunth, Enum. ii. 208. Stems tufted, very slender, 6 to $10 \mathrm{in}$. high. Leaves shorter, subulate. Spikelets narrow, acute, about 2 lines long, in a dense terminal globular head, with 2 to 4 subulate leafy bracts longer than the head. Glumes acute, with a strong green keel, brown 
on the sides, scarious on the edges. Style 3-cleft. Nut pale-coloured, crowned by the minute persistent bulbous base of the style.

Hongkong, Harland, Wright. Widely spread over tropical Asia, Africa, and Australia.

2. I. supina, Br.; Kunth, Enum. ii. 196. Stems cylindrical, tufted, $3 \mathrm{in}$. to near $1 \mathrm{ft}$. long, erect or decumbent, with a single short leaf often reduced to the sheath. Spikelets oblong, 3 to 4 lines long, 2 to 10 together in an apparently lateral cluster, the leafy bract continuing the stem. Glumes acute or mucronate, with a strong green keel, brown on the sides with scarious edges. Style 3-cleft. Nut dark-coloured, transversely wrinkled and almost muricate, crowned by the very short slightly thickened persistent base of the style.

Hongkong, Wright; common in paddy-fields, Wilford. Frequent in the tropical and subtropical regions of the Old World, extending into S. Europe.

\section{SCIRPUS, Linn.}

(Eleocharis, $\mathrm{Br}$.)

Spikelets several-flowered; the glumes imbricate all round, only 1 or 2 of the lowest empty. Flowers hermaphrodite. Hypogynous bristles usually 6 , sometimes fewer or more. Stamens 3 or fewer. Style 2-or 3-cleft, either not thickened at the base or breaking off above a small bulbous thickening which remains attached to the nut.- Stem leafy or leaves all radical, or reduced to a sheath at the base of the stem. Spikelets solitary or clustered, in terminal or apparently lateral heads, or simple or compound umbels.

A large genus, distributed over every part of the globe.

Stems leafless, except a short sheath at the base.

Spikelets solitary, terminal.

Spikelet very obtuse. Glumes closely imbricate. Style 2-cleft . . 1. S. capitatus. Spikelets rather acute. Glumes looser. Style 3-cleft . . . . . 2. S. afflatus.

Spikelets 1 to 3 , in an apparently lateral cluster . . . . . 3. S, juncoides. Stem tall, leafy. Spikelets numerous, in an irregularly compound umbel 4. S. chinensis.

1. S. capitatus, Willd. Stems tufted, 3 to 6 in. high, leafless except a short sheath at the base. Spikelets terminal, solitary, erect, ovoid or oblong, very obtuse, 2 to 3 lines long; the subtending bract not differing from the glumes. Glumes very closely imbricate, pale straw-coloured, broad, very obtuse, scarious on the edges. Hypogynous bristles 4 to 8 , rather longer than the nut. Style 2-cleft. Nut obovate, smooth, dark-coloured, crowned with the white flattened bulbous base of the style.-Eleocharis capitata, $\mathrm{Br}$.; Kunth, Enum. ii. 150.

Hongkong, Wright. Widely diffused over the tropical and subtropical regions of the New and the Old World.

2. S. afflatus, Benth. Apparently an annual, tufted and slender, 3 to 6 in. high. Leaves none, except a short sheath at the base of the stem. Spikelet solitary, erect, ovoid-oblong, $1 \frac{1}{2}$ to 3 lines long, rather acute, with 1 or 2 broad transparent very obtuse deciduous glume-like bracts at the base. Glumes obtuse or the upper ones rather acute, of a reddish-brown, with a green or brown keel, and often scarious at the edges. Hypogynous bristles about 6 , rather longer than the nut. Style 3 -cleft. Nut crowned by the 
beak-like persistent bulbous base of the style.-Eleocharis afflata, Steud. Syn. Cyper. 76.

Hongkong, Champion, Harland, Wright. In Nepal, Khasia, and the Archipelago. I refer this to E. afflata from Steudel's character. It is very near the European S. multicaulis, Sm., but there is no creeping rhizome, the spikelets are smaller, the glumes more numerous, smaller, and perhaps broader.

3. S. juncoides, Roxb.; Kunth, Enum. ii. 160. Stems tufted, leafless, except a very short sheath at the base, as in the two last species, but much firmer, $\frac{3}{4}$ to $1 \frac{1}{2} \mathrm{ft}$. high. Spikelets ovoid or oblong, 3 to 6 lines long, usually 3 together, sessile in an apparently lateral cluster; the outer leafy bract continuing the stem to the length of 1 or 2 in. Glumes loosely imbricate, very broad and concave, obtuse, or very shortly pointed, of a greenish straw-colour or pale brown. Hypogynous bristles 4 to 6 . Style 2-cleft or with a third smaller branch. Nut crowned by the short slightly thickened persistent base of the style.

Hongkong, Harland; common in paddy-fields, Wilford. Widely diffused over India, from Ceylon and the Peninsula to the Archipelago.

4. S. chinensis, Munro in Seem. Bot. Her. 422. A coarse leafy species, $2 \mathrm{ft}$. high or more. Leaves glaucous, as long as the stem or longer, $\frac{1}{4}$ to $\frac{1}{2} \mathrm{in}$. wide, rough on the midrib and edges. Spikelets numerous, ovoid, about 2 lines long, either closely sessile in clusters of 3 to 8 , or rarely solitary on the unequal rays of a compound umbel. Leafy bracts few, very long. Glumes brown, thin, very broad and concave, and very closely imbricate. Hypogynous bristles 2 or 3 , with the teeth pointed upwards, not downwards as in the 3 preceding species. Style deeply 2 -cleft. Nut flat, shining, crowned by the short slightly thickened persistent base of the style.

Hongkong, Wright. In Assam, Khasia, and Bonin.

\section{FUIRENA, Linn.}

Characiers of Scirpus, except that there are 3 obovate or obcordate hypogynous scales, and, in some species, 3 bristles alternating with them.-Stems usually leafy. Spikelets green, often hairy and squarrose with the spreading tips of the glumes, usually in dense clusters forming an irregular terminal narrow panicle.

A tropical and subtropical genus, common to the New and the Old World, extending also more sparingly into the more temperate regions of N. America and S. Europe.

Stem $1 \frac{1}{2}$ to $3 \mathrm{ft}$. Leaves not ciliate. Hypogynous scales narrowed at

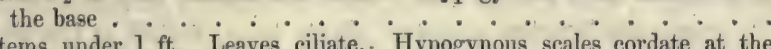

Sterns under $1 \mathrm{ft}$. Leaves ciliate. Hypogynous scales cordate at the

base and stipitate

1. F. umbellata,

2. F. glomerata.

1. F. umbellata, Roth; Kunth, Enum. ii. 185. A perennial $1 \frac{1}{2}$ to $3 \mathrm{ft}$. high. Stem and leaf-sheaths 4- or 5 -angled; glabrous. Leaves also glabrous, the larger ones usually 4 to 6 in. long, 4 to 5 lines broad, the lower ones with long sheaths and very short blades, the uppermost passing into small floral leaves. Spikelets brown-green, usually 3 to 4 lines long, rather acute, in very dense clusters, of which 1 or 2 terminal, the others more or less pedunculate, 1 or 2 together in the axils of the uppermost leaves. Hypogynous scales brown, obovate, near $\frac{1}{2}$ line long, truncate and mucronate at the top, 
narrowed at the base, but nearly sessile. Nut mucronate with the slightly thickened persistent base of the style.-F. pentagona, W. and Arn.; Kunth, Enum. ii. 185.

Hongkong, Hance, Wright, Wilford. Widely diffused over the tropical regions of the New and the Old World.

2. F. glomerata, Lam.; Kunth, Enum. ii. 184. A much smaller plant than the last, and apparently annual, seldom $1 \mathrm{ft}$. high. Leaves more or less pubescent, or at least ciliate on the edges. Spikelets rather longer than in $F$. umbellata, with longer and finer points to the glumes, either in a single terminal head with a leafy bract at the base, or more frequently with the addition of 1 or 2 almost sessile clusters in the axils of the upper leaves. Hypogynous scales distinctly stipitate, broadly cordate at the base.-F. Rottboellii, Nees in Wight, Contrib. Bot. Ind. 94.

Hongkong, Wright, Wilford. Widely distributed over tropical Africa, Asia, and Australia.

\section{RHYNCHOSPORA, Br.}

Spikelets 1- or 2- (rarely 3-) flowered, oblong, more or less pointed. Glumes imbricate all round, several outer ones shorter and empty. Hypogynous bristles 6 or sometimes more. Stamens 3 or fewer. Style 2-cleft. Nut globular or rarely flattened, crowned by the persistent continuous base of the style.-Stems usually leafy. Spikelets usually clustered and of a rich brown, in terminal or axillary heads or corymbs, sometimes forming large terminal leafy panicles.

A considerable genus, nearly as widely distributed as Scirpus over the surface of the globe.

Spikelets in a single dense terminal head Spikelets clustered in a branching panicle.

Spikelets full 4 lines long, in dense clusters. Beak of the nut long and thick, deeply furrowed on each side. . . . . . . . .

Spikelets about 3 lines long, in loose clusters. Beak not longer nor thicker than the nut and not furrowed .

1. R. Wallichiana.

1. R. Wallichiana, Kunth, Enum. ii. 289. A densely tufted perennial, the stems slender, 3 -angled at the top, $\frac{1}{2}$ to $1 \frac{1}{2} \mathrm{ft}$. high. Leaves much shorter, narrow, stiff and pointed. Spikelets 3 to 4 lines long, acute, densely crowded in a terminal head, surrounded by several leafy bracts, dilated and ciliate at the base, the longest much longer than the head. Glumes of a rich brown, the 3 lowest short and empty, the fourth longer, with a hermaphrodite flower, the next still longer, with a male flower, and enclosing a terminal linear empty glume. Hypogynous bristles minute. Style long, 2-cleft at the top. Nut laterally flattened, crowned by the bulbous base of the style.- R. Hankei, Presl; Kunth, Enum. ii. 290. Spharoschoenus Wallichii, Nees, PI. Meyen. 97.

Hongkong, Champion, Harland, Wright. In various parts of India and the Archipelago.

2. R. aurea, $\mathrm{Vahl}$; Kunth, Enum. ii. 293. A coarse glabrous'perennial, 2 to $3 \mathrm{ft}$. high or even more. Leaves long, pointed, very scabrous on the edges. Spikelets very pointed, full 4 lines long, in clusters arranged in compound corymbs, forming an irregular terminal panicle, with smaller corymbs in the axils of the upper leaves. Glumes of a rich brown, the lower ones short, pointed, and empty, one much larger with a hermaphrodite flower, and 1,2 
or rarely 3 narrow ones with male flowers. Hypogynous bristles 6 or 7 , longer than the nut. Nut obovate, thickened at the top, and crowned by a thick conical beak, furrowed on each side and longer than the nut itself.

Hongkong, Harland. Widely distributed over the tropieal regions of the New and the Old World.

3. R. laxa, Br.; Kunth, Enum. ii. 298. Like the last, but much more slender, although $2 \mathrm{ft}$. high or more. Leaves narrow. Spikelets about 3 lines long, in clusters forming small loose corymbs, of which 1 terminal and 2 or 3 axillary and remote. Glumes as in $R$. aurea, but shorter, and there are usually 2 hermaphrodite flowers. Hypogynous bristles 6 or 7 . Style long, 2-cleft at the top. Nut not thickened at the top, marked with minute transverse wrinkles, the conical beak not longer than the nut nor so thick, and not furrowed.

Hongkong, Hance, Wright; at Little Hongkong, Wilford. Widely distributed over the tropical and subtropical regions of the Old World. The R. chinensis, Nees, Pl. Meyen. 108, is a more slender variety, with rather smaller spikelets.

\section{Cladium, Br.}

Characters of Rhynchospora, except that the nut has a thick almost fleshy outer coating, tapering at the top into the style, but without any distinct beak. - Habit of the larger paniculate Rhynchosporas.

A small but widely dispersed genus, common to the New and the Old World, sometimes extended to include several Australian species with a somewhat different habit.

1. C. Mariscus, Br. ; Kunth, Enum. ii. 303. Rhizome creeping. Stems 3 to $6 \mathrm{ft}$. high. Leaves nearly erect, the lowest nearly as long as the stem, with smooth sheaths, the keel and edges very rough and cutting. Spikelets about 2 lines long in the Chinese specimens, from that to 3 lines in others, rather pointed, in small but numerous clusters arranged in corymbose panicles in the upper axils, the whole forming an oblong leafy panicle, often above a foot long. Glumes brown, the 4 or 5 outer ones shorter and empty, one with a hermaphrodite and one with a male flower. Stamens usually 2. Style 2-cleft. -C. chinense, Nees, Pl. Meyen. 116.

Hongkong, Hance. Widely spread over the tropical and temperate regions of the Old World, occurring also, but more sparingly, in America. I can perceive no difference whatever between the Chinese and the European specimens, except that the spikelets are rather smaller than they are usually with us; but this is a variable character in Europe, and in several African and Asiatic specimens they are quite as small as in China.

\section{ARTHROSTYLES, Br.}

Characters of Rhynchospora except that there are no hypogynous bristles, and the style (usually 3-cleft) is articulate upon the ovary and nut below the dilated base, as in Abildgaardia and Fimbristyles.-Stems tufted, leafless, except a sheath at the base. Spikelets in a terminal head.

Besides our species, the genus comprises one from Australia and another from the Mauritius.

1. A. chinensis, Benth., n.sp. Stems slender, almost subulate, 3 -angled, 1 to $1 \frac{1}{2} \mathrm{ft}$. high, with a short sheath at the base. Spikelets narrow, pointed; near 3 lines long, 3 to 6 together in an oblique terminal head, the longest leafy bract about the length of the head and appearing sometimes to continue 
the stem. Glumes finely pointed, 1 or sometimes 2 innermost with a hermaphrodite flower, about 4 others gradually shorter and empty. Stamens 3, with very short filaments. Style 3 -cleft, with a bulbous swelling evidently articulate, although the nut is still very young in our specimens.

Hongkong, Wright. Not known from elsewhere.

\section{GAHNIA, Forst.}

Spikelets 1-flowered or with a second male flower. Glumes imbricate all round, the outer ones empty. Flowers hermaphrodite, without hypogynous bristles or scales. Stamens 4 to 6 , the filaments very long and persistent. Style 3-cleft, the subulate branches often 2-cleft.-Tall rigid rush-like perennials. Spikelets densely clustered in compound spikes, arranged in a narrow terminal leafy panicle.

A small genus spread over Australia, the Pacific islands, and eastern tropical Asia.

1. G. tristis, Nees; Steud. Syn. Cyp. 163. Stems cylindrical, stiff and hard, 2 to $4 \mathrm{ft}$. high. Leaves long, narrow, with subulate points, very rough on the edges. Panicle $8 \mathrm{in}$. to near $1 \mathrm{ft}$. long, consisting of a number of erect dense compound spikes, the lower ones 1 to $1 \frac{1}{2}$ in. long, the upper ones gradually shorter, each in the axil of a leafy bract. Spikelets dark brown, about 4 to 5 lines long, clustered in the axils of short glume-like or sometimes almost leafy bracts, with a small bract under each spikelet. Glumes, 5 or 6 outer empty ones, of which the lowest short, the inner ones longer and very pointed; and within them 3 or 4 more, much shorter, very broad and obtuse, elosely enveloping the flowers. Stamens usually 4 . Style with 3 long hair-like simple black branches. Nut obovoid, near 2 lines long, smooth and shining, pale coloured, with a minute black slightly raised tip.

Hongkong, Harland, Wright; common on the hills, Wilford. Also on the adjacent continent, but not known out of S. China.

\section{LEPIDOSPERMA, Labill.}

Spikelets with 2 or 3 flowers, all apparently hermaphrodite, but only one fertile, with several outer empty glumes. Hypogynous scales 3 to 6 , short and thick or sometimes very minute or wanting, and no bristles. Stamens 3. Style 3 -cleft. Nut obovoid, triangular, surrounded at the base by the hardened scales or seated on a hardened disk as in Scleria.-Stems rigid and rush-like, leafless, but enclosed at the base by the sheaths of the radical leaves.

A small genus, chiefly Australian, extending also over the Pacific islands and tropical Asia.

1. L. chinensis, Nees, $P l$. Meyen. 117. Stems nearly cylindrical, 2 to $3 \mathrm{ft}$. high. Leaves rather shorter, cylindrical, stiff, shortly sheathing the stem at the base. Spikelets 3 to 4 lines long, densely clustered in compound erect spikes of $\frac{1}{2}$ to $1 \mathrm{in}$. long, forming a terminal interrupted spike or oblong panicle of $1 \frac{1}{2}$ to $4 \mathrm{in}$. Subtending bracts oblong, dark brown or glaucous, shorter than the spikes. Glumes dark brown, almost distichous, the inner flowering ones the longest." Flowers usually 3 , of which the lowest fertile. Hypogynous scales reduced to the minute, often scarcely projecting teeth of the thickened disk. Nut dark, spotted with white.

Hongkong, Hinds, Hance ; very common in marshy places, Wilford. Also on the adjacent continent, but not known out of S. China. 


\section{SCLERIA, Linn.}

Flowers unisexual, in unisexual or androgynous spikelets, with several empty glumes below the flowering ones. Male spikelets several-flowered. Stamens 3 or rarely fewer. Females 1-flowered. Style 3-cleft. Androgynous spikelets with the lowest flower female, the others male. Nut bony or brittle, seated on a thickened entire or 3-lobed disk.-Grass-like herbs with leafy stems. Ligula or projection of the leaf-sheath opposite the blade often very conspicuous. Spikelets in clusters or small corymbose or oblong panicles, terminal and in the upper axils, forming either an oblong leafy panicle or an interrupted spike.

A considerable genus, widely spread over the tropical and subtropical regions of the New and the Old World, extending also into the temperate regions of N. America. The species can scarcely be determined unless the nuts are fully formed.

Peduncles scarcely branched, bearing few rather distant small clusters.

Nut smooth and shining. Disk entire . . . . . . .

Nut reticulate and pitted. Disk with 3 lanceolate lobes. $\dot{*}^{-} \cdot{ }^{-}$2. S. tessellata.

Peduncles bearing more or less branched panicles.

Nuts smooth and shining. Panicle spreading . . . . . 5. S. lovis.

Nuts tuberculate or irregularly reticulate.

Leaves pubescent or hairy. Paricle little branched, not spreading. Disk-lobes lanceolate, entire . . . . . . . . .

Leaves glabrous, distant. Panicle rather spreading. Disk-lobes very short and broad . . . . . . . . . . .

Leaves long and numerous, the sheaths often pubescent. Panicles long and spreading (disk-lobes obtuse ?) . . . . . . 6. S. purpurascens.

1. S. lithosperma, Willd.; Kunth, Enum. ii. 349. Stems slender, 3angled, 1 to $1 \frac{1}{2} \mathrm{ft}$. high. Leaves narrow-linear, seldom 1 line broad, in the Hongkong specimens the upper ones passing into subulate bracts. Peduncles axillary and terminal, bearing each 1 to 4 distant clusters of 2 or 3 spikelets each, 1 or rarely 2 female, the other male. Inner glumes very pointed, about 2 lines long. Nut ovoid, white, very smooth and shining, seated on a short broad entire disk.

Hongkong, Harland. Spread over India, from Ceylon and the Peninsula to the Archipelago, and northward to the Philippines and S. China. This is certainly the plant described by Kunth, who had seen Willdenow's specimen. Nees however describes a 3-lobed disk, which I have never found.

A specimen from Wright, in young flower, has much the aspect of the above species, but the spikelets are all androgynous, about 3 lines long, with 1 female flower and 5 or 6 males above it. The disk is entire, but the nut is too young to characterize the species or even to determine with certainty that it belongs to the genus.

2. S. tessellata, Willd.; Kunth, Enum. ii. 343. Stems slender. Leaves narrow-linear, glabrous or nearly so, smooth or rough on the edges. Peduncles short, axillary and terminal, bearing 1 to 4 not very distant clusters of 2 or 3 spikelets as in the last species. Glumes of the female pale-coloured, rather broad, the longest scarcely 2 lines, and 1 or 2 inner ones much smaller. Nut globular, obtuse, white, tipped with the small black persistent base of the style, elegantly and regularly pitted, slightly pubescent on the raised netted lines. Disk with 3 lanceolate lobes.-S. Steudeliana, Miq. Fl. Ned. Ind. iii. 344 . 
Hongkong, Hance. Spread over India, from Ceylon and the Peninsula to the Archipelago. Like the last, it appears to vary in India with much broader leaves than in Hongkong.

3. S. pubescens, Steud. Syn. Cyp. 168. Stems stiff, 3 -angled, 1 to 2 $\mathrm{ft}$. high. Leaves rigid, linear, 3 to 4 lines broad, pubescent, the sheaths acutely 3-angled, but rarely winged. Peduncles usually 1 terminal and 1 axillary, each branching into a small pyramidal panicle. Spikelets not numerous, solitary, or 2 or 3 together. Nut white, ovoid, triangular, slightly tuberculate and pubescent. Disk with 3 lanceolate lobes.

Hongkoug, Hance, Harland, Wright. Also in Java. This plant is certainly very near the S. hebecarpa, Nees, to which Munro (in Seem. Bot. Her. 423) referred it, but in that species the nuts, although pubescent, are smooth and shining as in S. lithosperma, and the leaves are glabrous or nearly so The S. pubescens has the disk of S. tessellata, with the nuts and inflorescence more like those of $S$. chinensis.

4. S. chinensis, Kunth, Enum. ii. 357. Stem acutely 3 -angled, $1 \frac{1}{2}$ to $3 \mathrm{ft}$. high. Leaves linear, rather obtuse, 3 to 4 lines broad, the sheaths 3 winged, the ligula often 4 to 5 lines long. Peduncles several, axillary and terminal, each bearing numerous spikelets in a narrow somewhat pyramidal close panicle, 1 to 2 in. iong. Bracts subulate, with a broad and usually ciliate base. Spikelets usually in pairs, 1 female, the other male. Nut white, nearly glabrous, marked with irregularly reticulate raised transverse tubercles. Disk with 3 short broad obtuse lobes.-S. ciliaris, Nees in Wight, Contrib. 117; not of Mich.

Abundant in ravines, Hinds, Champion, and others. In Bengal, Silhet, and S. China. Munro (in Seem. Bot. Her. 423) refers Hance's specimens to the S. scrobiculata, Nees, but in that species the panicle is more spreading and pyramidal, and the leaf-sheaths are not winged. The limits however of the different species of Scleria are ofteu very difficult to fix.

5. S. Iæevis, Retz; Kunth, Enum. ii. 342. A coarse species, 3 or $4 \mathrm{ft}$. high, the stems acutely 3 -angled. Leaves long, $\frac{1}{4}$ to $\frac{1}{2}$ in. broad, acute, often very rough, the sheaths acutely 3 -angled or with very narrow wings, the ligula very short. Peduncles axillary and terminal, bearing short pyramidal panicles with spreading branches. Bracts subulate. Nuts ovoid or nearly globular, very smooth and shining, of a dark or leaden colour. Disk with 3 short obtuse entire lobes.

Hongkong, Hance. In Ceylon, the Malayan Peninsula, and the Archipelago.

Var. scaberrima. Leaves $\frac{1}{2}$ to $\frac{3}{4}$ in. broad, exceedingly rough, the sheaths more evidently winged. Panicles rather looser. Nut often white.

Hongkong, Harland. This may be the Chinese plant which Nees refers as a variety to the S. American S. communis, Kunth, but my Brazilian specimens of that species have always a small much depressed nut.

6. S. purpurascens, Steud. Syn. Cyp. 169 ? A stout species, several feet high, often acquiring a purple tint, especially the panicle and leaf-sheaths. Leaves numerous, often above $1 \mathrm{ft}$. long, the lower sheaths usually pubescent, angled, but not winged. Ligula rounded, often ciliate. Gereral panicle narrow-pyramidal, 8 in. to $1 \mathrm{ft}$. long, the partial ones much branched with subulate bracts mostly short except a leafy one at the base of each panicle. Spikelets numerous, of a deep reddish-purple. "Disk with 3 entire obtuse lobes."

Hongkong, Harland. The specimens are only in very young flower, and I am therefore 
unable to identify them with certainty. They agree exceedingly well, as far as they go, with the deseriptions given of Steudel's plant. They may possibly however belong to the S. sumatrensis, Retz, a common species in southern India and the Archipelago, but in that species the upper leaves are almost always clustered in twos or threes, whilst in ours they are nearly equidistant, although mostly so near together that the sheaths overlap each other. In the true $S$. sumatrensis the $\mathbf{3}$ disk-lobes are $\mathbf{3}$-toothed at the top.

\section{CAREX, Linn.}

Flowers unisexual, the males and females in distinct spikelets or in different parts of androgynous spikelets. Glumes imbricated all round the axis. Stamens in the males 3 or rarely fewer, without scales or bristles. Ovary in the females enclosed in a bottle-shaped or inflated utricle, contracted at the top, with a small oblique or 2-toothed opening, through which protrudes the style, which is 3-cleft in the Hongkong species, 2-cleft in a few others. Nut enclosed in the persistent utricle.-Leaves grass-like, mostly radical, or on the lower part of the stem. Spikelets either solitary or few, one terminal, the others mostly distant or stalked, or forming a terminal compound spike or panicle. Within the utricle there is occasionally a small bristle, but never hooked nor so strong as in Uncinia.

A very large and well-defined genus, widely spread over Europe, northern and central Asia, and N. America, extending also into mountain ranges within the tropics, and into the extratropical regions of the southern hemisphere.

Spikelets numerous, small, sessile in a compound panicle . . . 1. C. benghalensis. Spikelets few in a simple raceme.

Spikelets 2 or 3 terminal male, 2 to 4 lower female. Dwarf plant

Spikelets 1 terminal male, 2 to 4 lower female (rarely with a few male flowers at their base).

Glumes scarcely pointed.

Glumes obtuse, with a broad scarions margin . . . . Glumes acute, not margined. Utricle glabrous. Nut stipitate Glumes keeled, shortly pointed. Utricle pubescent . . .

Glumes with long subulate points . . . . . . . ...

Spikelets 1 terminal male, 2 or more androgynons, male at the top. Utricles long-beaked.

Stems elongated. Leaves narrow. Androgynous spikes all remote

Stems short. Leaves long and very broad. Upper androgynous spike close to the male

Spikelets several, all short, androgynous and remote. Utricles short

2. C. pumila.

3. C. ligata.

4. C. nexa.

5. C. manca.

6. C. chinensis.

\section{C. tenebrosa.}

8. C. Harlandi.

9. C. cryptostachya.

1. C. benghalensis, Roxb.; Boott, Illustr. Car. 85, tt. 240 to 243. An erect leafy perennial, $1 \frac{1}{2}$ to $3 \mathrm{ft}$. high, resembling at first sight the Scleria scrobiculata and its allies. Leaves 1 to $2 \mathrm{ft}$. long, 3 to 5 lines broad at the base, tapering into long fine points, nearly smooth. Spikelets 3 to 5 lines long, androgynous, female at the base, very numerous, sessile, and spreading in dense compound oval or oblong panicles. Glumes closely imbricate, brown, pointed. Utricles small, ovoid-triangular, with several very prominent veins on each face, and a rather long slender beak.

Hongkong, Champion and others. Common in India, and considered by Munro (in Seem. Bot. Her. 4.23) to be a form of the true $C$. indica, Linn.; Boott, however, retains the latter as a distinct species, with a more simple inflorescence, besides minor differences in the glumes and utricles. 
2. C. pumila, Thunb.; Kunth, Enum. ii. 517. Stems about 6 in. high from a creeping rhizome. Leaves narrow, 8 to $10 \mathrm{in.}$ long, stiff but spreading. Male spikelets 2 or 3 , the terminal one 1 to $1 \frac{1}{2}$ in. long, the lower 1 or 2 sessile immediately under it, and much shorter; female spikelets 2 to 4 , sessile or shortly pedicellate, about $\frac{1}{2}$ in. long. Bracts leafy, scarcely sheathing except the lowest. Glumes lanceolate, with short points. Utricles longer than the glumes, brown, triangular, turgid, with a rather long beak, glabrous, thick and coriaceous, without prominent nerves.-C. littorea, Labill. Pl. Nov. Holl. ii. 69, t. 219.

Hongkong, Wright. In maritime sands, Japan, Loochoo, and N. Australia.

3. C. ligata, Boott, n. sp. Stems slender, tufted with the leaves, 6 to $10 \mathrm{in}$. high. Leaves narrow, rough, I to $1 \frac{1}{2} \mathrm{ft}$. long. Terminal spikelet male, slender, 1 to $1 \frac{1}{2}$ in. long. Females usually 2 , distant, pedunculate, $\frac{1}{2}$ to $\frac{3}{4}$ in. long, rather loose. Bracts with brown sheaths and green subulate leafy points. Glumes very obtuse, broadly scarious on the margin, with 1 to 3 green central nerves about $1 \frac{1}{2}$ lines long. Utricle rather longer than the glume, with a short beak. Nut triangular, obconical at the base but sessile, tapering upwards to a truncate almost concave apex.

Hongkong, Harland, Hance, Wright; in ravines of Mounts Gough and Parker, Wilford. Not known from elsewhere.

4. C. nexa, Boott, n. sp. Leaves long and narrow, and stems slender, with the inflorescence of $C$. ligata, but the stems are often above a foot high, and the spikelets longer and more numerous. Terminal male spikelets usually 2 to $2 \frac{1}{2}$ in. long; the glumes lanceolate, acute or nearly so, pale brown, and almost scarious throughout, or rarely with a green nerve, and often 3 lines long. Female spikelets usually 3 or 4, very loose, and often above 1 in. long. Utricle somewhat curved, acuminate, narrowed at the base, many-nerved, glabrous. Nut narrowed into a distinct stalk at the base.

Hongkong, Hance, Harland, Wright. Not known from elsewhere.

5. C. manca, Boott, n. sp. Very nearly allied to $C$. nexa, but the glumes are distinctly keeled, the keel projecting into a short point, and the utrieles are pubescent.

Hongkong, Harland.' The nuts are not fully formed in the only specimens I have seen, and the plant may not improbably, when better known, prove to be a variety of $C$. nexa.

6. C. chinensis, Retz; Boott, Illustr. Car. 74, t. 36. A rather coarser species than the last 3 ; the radical leaves often $2 \mathrm{ft}$. long and 3 lines broad; the inner ones smaller. Stems 6 in. to $\mathrm{I} \mathrm{ft}$. high. Bracts with loose sheaths and leafy tips. Terminal spikelet male, 1 to $1 \frac{1}{2}$ or rarely 2 in. long, dense. Lower spikes 2 to 5 , distant, either all female or with a very few male flowers at their base, and very rarely male at the top, all usually as long as the male spikelet and rather dense. Glumes scarious on the margin; the keel produced into a long subulate point. Utricle somewhat incurved or oblique, acuminate, tapering at the base, many-nerved, pubescent. Nut obconical at the base but sessile, very obtuse at the top.

Hongkong, Hance, Harland, Wright. Only known from S. China.

7. C. tenebrosa, Boott, Illustr. Car. 88, $t$. 256. Stem stiff though slender, $1 \frac{1}{2}$ to $2 \mathrm{ft}$. high. Leaves rigid, 1 to $1 \frac{1}{2} \mathrm{ft}$. long, 2 or rarely 3 lines 
broad. Spikelets 3 to 5 , each about 2 in. long, the terminal one male, the others distant, androgynous, male in the upper half. Bracts sheathing, with subulate leafy points. Utricles triangular, glabrous, many-nerved, narrowed at the base, and tapering upwards into a long slender beak, the whole utricle above 3 lines long.

In the Happy Valley woods, Champion, Harland, Wilford. Not known out of the island. The specimens appear always to dry almost black.

8. C. Harlandi, Boott, Illustr. Car. $87, t$. 255. Radical leaves $1 \frac{1}{2}$ to 2 $\mathrm{ft}$. long, and mostly $1 \mathrm{in}$. broad. Stems 6 in. to $1 \mathrm{ft}$. high; the central ones with long broad leaves, 1 or 2 lateral ones with only a few short leaves. Spikelets $1 \frac{1}{2}$ to $2 \mathrm{in}$. long, usually 3 close together at the summit; the terminal one male, often rather shorter than the 2 next, which as well as a fourth lower down are usually androgynous, shortly male at the top, the remainder female. Glumes mostly rounded at the top, the keel projecting into a short point. Utricles 4 to 5 lines long, narrowed into a stalk at the base, tapering upwards into a long beak.

Hongkong, Harland; in the woods behind the Buddhist Temple and in a ravine at West Point, Wilford. Not known from elsewhere.

9. C. cryptostachya, Brongn.; Boott, Illustr. Car. 103, t. 310. Leaves $1 \frac{1}{2} \mathrm{ft}$. long or more, very stiff, rough, and glaucous, keeled, and full 3 lines broad at the base, tapering upwards to long subulate points. Stems 6 in. to $1 \mathrm{ft}$. high, flowering almost from the base. Spikelets 6 to 10 or more, rarely $\frac{1}{2}$ in. long and often much shorter, all distant, nearly sessile, androgynous, male at the top. Bracts sheathing, with short leafy points. Glumes ovate, acute or shortly pointed. Utricles about 2 lines long, 3-angled, many-nerved, slightly pubescent, contracted at the base, the beak short.

Hongkong, Harland, Wright, Wilford. In Penang and the Arehipelago.

\section{ORDER CXXIII. GRAMINEEAT.}

Flowers hermaphrodite or unisexual, in spikelets, without any perianth. Each spikelet consists of 3 or more (very rarely 2 or 1 ) chaff-like concave glumes (scales or bracts) arranged alternately on opposite sides of the spikelet, their concave face towards the axis. Two (sometimes 1 or 3 ) lowest glumes empty and often differently shaped from the others, the succeeding or flowering glumes (lower palea of most authors), each enclosing a smaller scale or palea (upper palea of most authors), placed either between the glume and the axis of the spikelet, with its back to the axis, or nearly opposite the glume at the end of the axis. Within the palea, or apparently between the flowering glume and palea, is the real flower, consisting usually of 2 lodicules or minute microscopical scales besides the stamens and pistil. The flowering glume and palea are however generally included in the term flower. Stamens usually 3 , occasionally reduced to 2 or 1 , or in some genera 6 or more; anthers versatile, 2-celled. Ovary 1-celled, with 1 ovule. Style 2 - or 3 -lobed, or more frequently divided to the base into 2 or 3 more or less feathery styles. Fruit 1 -seeded and seed-like, called a grain or caryopsis, free or adhering to the persistent palea, or enclosed in the hardened palea and flowering glume: Pericarp very 
thin, adhering to the seed or rarely loose or opening in 2 valves. Embryo small, at the base of a mealy albumen.-Herbs, with stems usually hollow except at the nodes, sometimes shrubby or arborescent in their stature and hardness of the stem, but very unlike dicotyledonous trees or shrubs. Leaves alternate, entire, parallel-veined (usually long and narrow), sheathing the stem at their base, but the sheaths split open on the side opposite the blade, and often end within the base of the blade in a scarious appendage called a ligula. Spikelets arranged in terminal spikes, racemes, or panicles.

A very large Order, abundantly diffused over the whole world, and supplying many of the most important articles of food and raiment, or applied to a great variety of economical pur. poses. The terminology here used in describing the spikelets is in conformity with the views of Mohl and others, which appear to me to be at once more plausible in theory, and practically more in conformity with appearances than that more generally adopted, in which the flowering glume and palea are both considered as floral envelopes under the name of lower and upper paleas. Under this view all empty glumes except the 2 lowest (or sometimes one of the two lowest, even when these are exactly alike) are called sterile florets, the name glume being reserved exclusively for the one or two lowest.

A. Spikelets 1-flowered, i.e. with one fertile flower, with or without a second male one below it, or 1 or more additional empty glumes besides the outer ones. (See also B, 3.)

1. Spikelets sessile or shortly pedicellate, forming a dense cylindrical spike, raceme, or spike-like panicle.

Flowering glumes awned.

Spikelets flat. Awn very slender and short, on the back of the glume .......... . . . .

Spikelets convex, in pairs, surrounded by long hairs. Awn terminal, twisted at the base .......22. Pogonatherum.

Onter glumes awned.

Racemes simple. Awns much longer than the glumes . 15. PErotis.

Panicle branched but dense and spike-like. Awns very short

Glumes all awnless.

Spikelets surrounded by long awn-like bristles.

Panicle branched though dense and spike-like, the bristles irregularly intermixed ........

Raceme or spike long and simple, the bristles forming an involucre round the spikelets . . . . 5. Grмnotrixix.

Spikelets enveloped in long silky hairs . . . . . . 18. IMPERATA.

Spikelets without bristles or long hairs.

Outer glumes 3 ; flowering glume hard . . . . 4. Panicum (n. 17).

Outer glume 1; flowering glume very thin . . . 16. Zoysia.

2. Spikes singly sessile or in pairs, in 2 or rarely 4 rows, in a simple usually 1-sided spike, or in the sessile spike-like branches of a simple panicle.

Spikelets awnless or with straight awns.

Spikelets hermaphrodite.

Flowering glume enclosing the grain, as stiff as or harder than the outer ones.

Glumes concave, 3-nerved. Fertile flowers terminal. Two outer empty glumes besides the flowering one Three outer glumes all empty or the third with a male flower, the lowest often very minute ...

Glumes strongly keeled. Axis of the spikelet projecting beyond the palea.

Axis ending in a minute point at the back of the palea

\section{Paspalum.}

4. Panicum (n. 1 to 7). 
Axis bearing several empty shortly awned glumes above the fertile flower.

Spikes digitate .......,+ 39 . Chloris.

Spikes distant, in a long panicle . . . . 44. Lophatherum.

Elowering glumes and palea small, very thin and transparent.

Spikelets singly sessile or indented.

Spikelets searcely indented in the axis; 2 stiff outer glumes . . . . . . . . 35. Microchloa.

Spikelets indented in the axis; 1 hard outer glume 13 . Ophiunus.

Spikelets indented in the axis in pairs, 1 sessile, the other pedicellate.

Both spikelets 1-flowered, fertile ...... 14. Heмa zтriria,

Sessile spikelet with a second male flower; pedicellate one reduced to a rudimentary glume . 28. Ischжмuм.

Spikelets mostly nnisexual.

Spikelets in a simple spike, the upper ones male, the

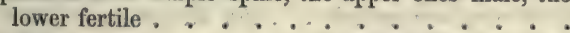

Spikelets diøcious, the males in clustered spikes, the females solitary amidst clustered bracts....

Spikelets with a twisted awn proceeding from the flowering glume.

Spikelets singly sessile or accompanied by a rudimentary pedicel.

Glumes acnte . . . . . . . . . . 17. Dimeria.

Outer glumes broad and truncate $: 23$. A Pocopis.

Spikelets in pairs, 1 sessile, the other pedicellate.

Both spikelets fertile and awned.

Fertile flower solitary in each spikelet . . . . 21. Pollinia.

One fertile and 1 male flower in each spikelet 29 . Spodropogon.

Sessile spikelet fertile and awned; pedicellate one male and awnless or rudimentary.

Fertile flower alone in the sessile spikelet. . 25. Andropogon (n. I and 2).

One fertile and 1 male flower in the sessile spikelet 28. Isсндмum.

Sessile spikelets female, cylindrical, awned; pedicellate ones larger, flat, and awnless. (Pedicel very short) 26. Heteropogon.

3. Spikelets or spikes more or less pedicellate in an irregular or spreading panicle.

Spikelets singly pedicellate, awnless or with a straight or rarely twisted awn.

Two empty glumes besides the flowering one.

Hlowering glume and palea hardened over the grain and not longer than the second outer one.

Spikelets awnless, ovoid-oblong, resting on a callous base . . . . . . .

Spikelets awnless or with a fine awn, narrow, without a callous base $\because \cdot C^{-} \cdot{ }^{-}$

Flowering glume convolute, with 3 awns. Spikelet narrow lowering glume awnless, longer than the outer glumes.

Grain uncovered . . . . . . . . . .

Three glumes besides the flowering one, all empty or the third with a male flower.

Two flowers fertile (or at least with hardened glumes) in most spikelets

3. Eiriochioa.

11. Garnotia.

32. Aristida.

30. Sporobolus.

One flower in each spikelet fertile, with a coriaceous glume and palea.

Palea ciliate, with long spreading hairs. Spikelets minute

7. IsACHNE.

12. Thysanolena. 
Palea scarcely ciliate.

Flowering glume awriless, with a small scale or oblong sear on each side at the base. . . .

Flowering glume without appendages at the base, awnless or with a straight awn .... 4. PANicirm (9 to 16).

Flowering glume with a twisted awn . . . 10. Arundinelin.

Spikelets either in pairs, 1 sessile the other pedicellate, form. ing pedicellate spikes, or $]$ sessile between 2 pedicellate, on a common pedicel. Flowering glumes very thin, transparent, with a twisted awn or rarely awnless.

Panicle with sheathing bracts at its ramifications.

One sessile and 2 pedicellate spikelets in each bract . 24. ApLuda.

Two short spikes in each bract. . . . . . 25. ANDropogon (6).

Panicle without bracts.

Outer glumes thin, enveloped in long silky hairs. $\mathrm{Pa}$ nicle large.

Rhachis articulate. Spikelets awnless. . . . 19. SАсснакUм.

Rhachis continuous. Flowering glume awned : 20. EuLALIA,

Outer glumes stiff, usually longer than the onter hairs.

Spikelets in pedicellate spikes ......25. Andropogon (3 to 5).

Spikelets in threes, 1 sessile between 2 pedicellate . 27. Chrysopogon.

B. Spikelets with 2 or more hermaphrodite or fertile flowers, or the uppermost unisexual.

1. Spikelets all pedicellate and panicled.

Awns long and twisted. (Spikelets large) . . . . 41. Avens.

Awns none or short and straight.

Flowering glumes surrounded by long dense silky hairs.

Tall Reeds with large panicles.

Lowest flowers all fertile . . . . . . . . . . ARUNDo.

Lowest flower male

Hairs few or short or none in the spikelets.

Spikelets small, with 2 flowers.

Glumes of similar consistence, the outer ones shorter and unequal. Panicle narrow ......

Flowering glumes firmer than the 2 outer equal ones.

Panicle short, spreading . . . . 7 . Isachne.

Spikelets flat, with 3 or usually many more flowers . 43. Eragrostis.

2. Spikelets sessile, in 1 or 2 rows along one side of the spike-like branches of a simple panicle.

Spikes digitate.

Spikelets awnless or with short points.

Spikelets very flat, closely imbricate. Glumes shortly

pointed . . . . 37. DACTrLocteniug.

Spikelets narrow. Glumes obtuse $\div$ 38. Eleusine.

Awns louger than the glumes . . . . 39. CHLORIs.

Spikes alternate or clustered in a long panicle, . . . 40. Leprochlos.

3. Spikelets (awnless) sessile, irregularly clustered or solitary, in simple or branched panicles.

Herbs with small flat spikelets $, \ldots, \ldots ., 43$. Eragrostis.

Tall shrubby or tree-like Bamboos, with large spikelets.

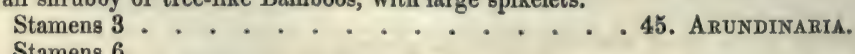

Stamens 6.

Several fertile flowers in each spikelet , , 46. Bambusa.

One fertile flower in each spikelet . . . . . 47. Schizostachyum.

Among the Tribes adopted by Colonel Munro for the distribution of the numerous genera of Graminere, the following 11 are represented in our Flora:- 
* Spikelets with 1 fertile terminal flower, with or without a male or imperfect flower below it (PANICACE A).

1. Phalaridea. Flowering glume and palea becoming hardened and enclosing the grain after flowering. Two outer empty glumes nearly equal, compressed, keeled and longer than the flowering one. Genus:-1. Alopecurus.

2. Panicer. Flowering glume and palea becoming hardened and enclosing the grain after flowering. Outer empty glumes usnally unequal and smaller. Genera:-2. PAsPAlum; 3. Eriochloa; 4. Panicum; 5. Gymnothrix; 6. Ichnanthus; 7. Isachen ; 8. Spinifex; 9. Thouarea.

3. Tristegineæ. Spikelets nearly as in Panicere, but usually with a twisted awn as in Andropogonea. Panicles loose. Genera:-10. Arundinella; 11. Garnotia; 12. ThySANOLANA.

4. Andropogonex. Flowering glume small, exceedingly thin and transparent, with a twisted awn rarely entirely wanting. Genera:-13. OphiURus; 14. Hemarthria; 15. Perotis; 16. Zoysia; 17. Dimeria; 18. Imperata; 19. Saccharum; 20. Eulalia; 21. Pollinia ; 22. Pogonatherum; 23. A pocopis; 24. Apluda; 25. Andropogon; 26. Heteropogon; 27. Chrysopogon; 28. Ischemum; 29. Spodiopogon.

** Spikelets with one or more perfect flowers; the male or rudimentary flowers, if any, above the perfect ones, or the axis ending in a minute point (POAACEA).

5. Agrostider. Spikelets 1-flowered, usually pedicellate and small. Flowering glume thin, awnless or with a simple awn. Grain free--30. Sporobolus; 31. Polypogon.

6. Stipacea. Spikelets 1-flowered, usually pedicellate, and often rather large. Flowering glume firm, with a simple or 3-cleft awn, articulate on the glume or with 3 or more awns, and elosely enveloping the grain. Genus:-32. Aristida.

7. Arundiner. Spikelets 1- or several-flowered, pedicellate, the rhachis with long hairs between the glumes. Flowering glumes like the empty ones or thinner. 'Grain free. Genera: -33. Arundo; 34. Phragmites.

8. Chlorider. Spikelets 1- or several-flowered, sessile along one side of the simple linear branches of a panicle (or of a simple spike). Genera :-35. MicrochloA; 36 . CYnodon; 37. Dactyloctenium; 38. Eleusine, 39. Chloris; 40. Leptochloa.

9. Avenacere. Spikelets 2- or few-flowered, pedicellate. Flowering glumes usually shorter than the outer ones, their awns oflen bent or twisted. Genus :-41. Avena.

10. Festucaceæ. Spikelets several-flowered, pedicellate, glabrous between the glumes or shortly hairy. Genera:-42. Ceelachne; 43. Eragrostis; 44. Lophatherum.

11. Bambusere. Spikelets 1- or several-flowered, usually sessile and clustered. Tall shrubby or tree-like Grasses. Genera:-45. Arundinaria; 46. Bambusa; 47. SchizoSTACHYUM.

\section{ALOPECURUS, Linn.}

Spikelets 1-flowered, flat, and densely crowded into a cylindrical spike or spike-like panicle. Outer glumes boat-shaped, with a prominent keel, but not awned. Flowering glume shorter, with a very slender awn inserted on the back (sometimes concealed under the outer glumes). Palea entirely wanting.

A small genus, widely spread over the temperate and colder regions of both the northern and southern hemispheres, only penetrating into the tropics among occasional weeds.

Onter glumes 3 lines long, united to the middle, glabrous or nearly so 1. A. agrestis.

Outer glumes not $1 \frac{1}{2}$ lines long, free or scarcely united at the base,

hairy on the keel

1. A. agrestis, Linn.; Kunth, Enum. i. 23. An annual, 1 to $2 \mathrm{ft}$. high, erect or slightly decumbent at the base. Leaves rather short, with long, not very loose sheaths. Spike 2 to $3 \mathrm{in}$. long, the spikelets not so closely 
packed, nor so much flattened as in other species, about 3 lines long, usually quite glabrous, the 2 outer glumes united to about the middle, the hair-like awn of the flowering one projecting 2 or 3 lines beyond them.

Hongkong, Harland, probably introduced among European seeds. It is a common weed in Europe and temperate Asia, but almost unkuown in tropical regions.

2. A. geniculatus, Linn.; Kunth, Enum. i. 24. A perennial or sometimes annual only, glabrous except the spike. Stem usually procumbent at the base, bending upwards at the lower nodes, sometimes only 3 or $4 \mathrm{in}$., often a foot high or more. Spike 1 to $2 \mathrm{in}$. long, closely imbricate but slender. Outer glumes hairy on the keel, scarcely pointed, and usually but little more than 1 line long, the hair-like awns of the flowering glumes, not projecting above a line beyond them.

In rice-fields, Seemann, Wright, Wilford. Common in the temperate and colder regions of the northern hemisphere, and naturalized as a weed in many parts within the tropics, or in the southern hemisphere.

\section{PASPALUM, Linn.}

Spikelets 1-flowered, not awned, not callous at the base, solitary or in pairs along one side of slender spikes, either forming the branches of a simple panicle, or rarely solitary. Outer glumes 2, both empty. Flowering glume concave, of a firmer texture. Palea like the flowering glume, but smaller and usually 2-nerved. Grain enclosed in the hardened palea and flowering glume.

A large genus, chiefly tropical or North American.

Spikelets orbicular, obtuse . . . . . . . . . 1. P. scrobiculatum. Spikelets ovoid-oblong, acute .

1. P. scrobiculatum, Linn.; Kunth, Enum. i. 53. An erect or ascending grass, 1 to $2 \mathrm{ft}$. high, usually glabrous, except a few long hairs at the base of the leaf-blade. Spikes usually 2 or 3 , alternate, shortly stalked, 1 to 2 in. long, with a broad flat rhachis. Spikelets sessile or nearly so, in 2 rows, orbicular, obtuse, more or less flattened, 1 to $1 \frac{1}{4}$ lines long. Outer glumes thin, glabrous, 3-nerved.

Common on roadsides, Wright, Seemann, Wilford. Frequent in tropical and subtropical Asia, Africa, and Australia.

2. P. brevifolium, Flügge; Kunth, Enum. i. 48. Stems decumbent or creeping and rooting at the lower nodes, slender, and ascending to a foot or more. Leaves usually short, seldom 2 in. long, glabrous. Spikes 2 to 5, very near together, slender, $1 \frac{1}{2}$ to $2 \mathrm{in}$. long, the rhachis slightly dilated. Spikelets in 2 rows, but not crowded, ovoid-oblong, acute, about $\frac{3}{4}$ line long. Outer glumes thin, but prominently nerved, pubescent or ciliate on the edges. $-P$. chinense, Nees in Steud. Syn. Gram. 41.

Hongkong, Seemann, Wright; on the racecourse in the Happy Valley, Wilford. Widely spread over India.

\section{FRIOCHLOA, Humb. and Kunth.}

Spikelets 1-flowered, often shortly pointed, but not awned, with a small callous base, articulate on short pedicels along the branches of a panicle. Glumes, palea, and grain of Paspalum.

A small genus, chiefly tropical or subtropical, common to both the New and the old World. 
1. E. annulata, Kunth, Enum. i. 73. A perennial grass, 1 to 2 or 3 ft. high, tufted and erect, or decumbent at the lower nodes, usually glabrous. Leaves narrow. Panícle oblong, 3 to 5 in. long; the branches slender, simple or scarcely branched, and somewhat 1-sided; the rhachis glabrous or nearly so. Pedicels $\frac{1}{2}$ to 1 line long, often bearing at the top a few long hairs formerly mistaken for an involucre. Spikelets about $1 \frac{1}{2}$ lines long. Outer glumes hairy, narrowed into a point full $\frac{1}{2}$ line long. Flowering glume glabrous, faintly 3-nerved, obtuse, with a short fine point. Palea rather smaller, 2nerved, without any point.

Hongkong, Wright $;$ salso on the adjoining continent. Frequent in tropical and subtropical Asia and Africa, and elosely allied to the S. American E. punctata.

\section{PANICUM, Linn.}

\section{(Digitaria, Juss.; Oplismenus, Beauv, ; Setaria, Beauv.)}

Spikelets usually small, 1-flowered, or with a second male flower below it, awnless or rarely awned, either along one side of the simple branches of a panicle, or in a loose branching or close and spike-like panicle. Glumes always 4 , the lowest small, sometimes very minute and empty, the next usually larger and always empty, the third empty or with an imperfect or male flower in its axis, the innermost or flowering glume of a firmer texture, smoother, and more faintly 3-nerved. Palea like the flowering glume, but smaller and more or less 2-nerved. Grain enclosed in the hardened flowering glume and palea.

A vast genus, chiefly tropical or $\mathrm{N}$. American, with a very few species spreading into Europe and temperate Asia.

Panicle simple, with sessile one-sided spike-like branches.

Spikelets not arned, in pairs, one or both pedicellate. Spikes digitate or crowded at the summit of the stem. (Digitaria.)

Spikes 2, long and stiff. Pedicellate flower covered with long hairs . . . . . . . . . . . .

Spikes several, clustered. Pedicellate flower glabrous or hairy.

Stem decumbent, ascending. One spikelet of each pair usually sessile; second glume much smaller than the third . . .

Stems tufted at the base, erect. Spikelets all pedicellate; second glume nearly as long as the third . . . . . .

Spikelets not awned, sessile, alternating in 2 rows. Spikes distant

Spikelets often awned, sessile and crowded or clustered.

Spikelets crowded in 4 or more close rows, in dense spikes.

Spikes nearly equal, distant, forming a. long slender panicle. Spikelets 1 line long, not awned . ........ Lower spikes longer than the upper, in a close pyramidal panicle. Spikelets $1 \frac{1}{2}$ lines long, often awned . . . . .

Spikelets awned, in distinct clusters, forming interrupted spikes.

Panicle contracted into a cylindrical spike.

1. P. barbatum.

2. P. sanguinale.

3. P. commutatum.

4. P. distachyum.

Spikelets intermixed with long awn-like bristles . . . .

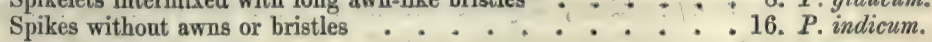

(See also Coelachne.)

Panicle compound, with slender branches, more or less spreading.

Spikelets interspersed with a few long awn-like bristles.

Panicle loose or spreading, the lower branches 4 to $8 \mathrm{in}$. long.

Leaves 1 in. broad or more . . . . . .

Panicle narrow, the lower branches 1 to 2 in. long. Leaves not

$\frac{1}{2}$ in. broad ? 10. P. excurrens.

5. P. colonum.

6. P. Crus-galli.

7. P. compositum.

8. P. glaucum.

\section{P. plicatum.}


Panicle without awns or bristles.

Spikelets clustered or in short spikes along the branches . . . 11. P. nodosum.

Spikelets not clustered, 2 lines long .......... IchNanthus.

Spikelets distinct, all pedicellate, $\frac{1}{2}$ to $1 \frac{1}{2}$ lines long.

Leaves rather narrow, tapering or rounded at the base.

Stem creeping at the base, then simple and ascending.

Panicle little branched. Outer glume short and round . 12. P. repens.

Stem scrambling, branched. Panicle much branched.

Onter glume $\frac{3}{4}$ as long as the others . . . . . 13. P. sarmentosum.

(See also Tsachne australis.)

Leaves broad, cordate at the base.

Leaves lauceolate, 4 to $10 \mathrm{in.} \mathrm{long} \mathrm{.} \mathrm{.} \mathrm{.} \mathrm{.} \mathrm{...} \mathrm{14.} \mathrm{P.} \mathrm{montansm.}$

Leaves ovate-lanceolate, 2 in. long . . . . . . 15. P. ovalifolium.

Leaves ovate, $\frac{1}{2}$ to near 1 in. long. Spikelets minute . . Isachne pulchella.

1. P. barbatum, Kunth, Enum. i. 84. Stems decumbent, habit and foliage of $P$. sanguinale. Spikes 2 only, or very rarely 3 , more rigid than in that species, and often 3 to 5 in. long. Spikelets $1 \frac{1}{2}$ to 2 lines long, in pairs, one sessile, the other on a pedicel as long as the spikelet. Lowest glume very minute and thin, the 2 next nearly equal, both empty and prominently 5-, 7-, or even 9-nerved, thickly covered with long spreading hairs in the pedicellate spikelet, much less hairy in the sessile one.-P. heteranthum, Nees, Pl. Meyen. 174.

In the sands of the Happy Valley, Wright; also on the continent near Amoy, Hance. Only seen besides from the Indian Peninsula.

2. P. sanguinale, Linn.; Kunth, Enum. i. 82. An annual with stems 1 to $2 \mathrm{ft}$. long, more or less spreading or creeping at the base, then ascending or erect. Leaves flat, narrow, more or less hairy. Panicle consisting of 3 to 10 or 12 simple slender branches, 2 to 4 in. long, and all usually spreading from nearly the same point so as to appear digitate. Spikelets in pairs along one side of these branches, one sessile, the other pedicellate, each about 1 line long. Lowest glume very minute, almost microscopic, the seeond concave, about half the length of the third, which is nearly flat and 5-nerved, both glabrous, or more or less ciliate on the edges, and empty.

Rice-fields, very abundant, Hance and others. One of the commonest weeds in all tropical and warm regions.

3. P. commutatum, Nees in Linnaea, vii. 274. Very near the P. sanguinale, of which it may be only a variety. Stems less creeping, usually forming a perennial stock, with a dense tuft of the remains of old leaves, and frequently woolly-hairy. Leaves narrow. Spikes slender and less spreading than in $P$. sanguinale. Spikelets all pedicellate, the second glume but little shorter than the third, the latter prominently s.nerved, and both usually ciliate or hairy.

On hills on the south of the island, Wilford. Occurs in various parts of India, in South Africa, and in Brazil.

4. P. distachyum, Linn.; Kunth, Enum. i. 91. Stems decumbent or creeping and rooting at the lower nodes, ascending to a foot or rather more. Leaves flat, often hairy. Spikes 2 or 3 , sessile, distant and alternate, in a simple panicle, each one 1 to near 2 in. long. Spikelets sessile and alternate, in 2 rows merging into 1 , all on one side, each one $1 \frac{1}{2}$ to 2 lines long. Outer 
glumes glabrous, 3 -nerved, the lowest from $\frac{1}{8}$ to $\frac{1}{2}$ as long as the second and third, which are nearly equal.

Hongkong, Hance. Widely distributed over tropical Asia and Africa.

5. P. colonum, Linn. Stems erect or decumbent at the base, $2 \mathrm{ft}$. high or more. Leaves flat, glabrous. Spikes about 8 or 10 , sessile, onesided, distant and usually erect, in a long narrow simple panicle, each one $\frac{1}{2}$ to $\frac{3}{4} \mathrm{in}$. long, and not diminishing much upwards. Spikelets about 1 line long, sessile, and densely crowded in about 4 rows. Outer glumes coarsely pubescent, the lowest nearly $\frac{1}{2}$ as long as the second and third, which are nearly equal, often ending in short points; the third with a palea in its axil. -Oplismenus colonum, Kunth, Enum. i. 142.

Hongkong, Seemann, Wright. Common in the tropieal and subtropical regions of the Old World, and occurring occasionally also in tropical Ameriea.

6. P. Crus-galli, Linn. A coarse decumbent rather broad-leaved annual. Panicle 4 to 6 in. long, irregularly pyramidal and rather one-sided. Spikelets pubescent, as in $P$. colonum, but rather larger, crowded and clustered along the spike-like branches, the lowest of which are 1 to $2 \mathrm{in}$. long, diminishing gradually to the top. Lowest glume very short and broad, the second and third about equal; the one empty and awnless, the other ending in either a short point or a long coarse awn, and has often a thin palea in its axil. Flowering-glume awnless, smooth and shining.-Oplismenus Crus-galli, Kunth, Enum, i. 143.

Hongkong, Wright. A common weed in most hot and some temperate countries.

7. P. compositum, Linn. Stems decumbent at the base, 1 or rarely $2 \mathrm{ft}$. high, rather slender but stiff. Leaves broadly lanceolate, sprinkled with a few long hairs. Spikes few, slender, one-sided, and distant, the lower ones 1 to 2 in. long, the upper shorter. Spikelets above a line long, glabrous or slightly pubescent, in distant clusters of 2 or 3 , usually surrounded by a few bristly hairs. Lowest glume shorter than the flower, with a rather long awn, the second scarcely longer, with a small point or short awn, the third longer, awnless, with a rudimentary flower in its axil.-Oplismenus compositus, Rom. and Schult.; Kunth, Enum. i. 141.

Hongkong, Hance, Harland. Frequent in most tropical and subtropical countries, especially in the Old World, and extending northwards to Amoy, Loochoo, and Bonin.

8. P. glaucum, Linn. An erect annual, of a pale green, 1 to $2 \mathrm{ft}$. high, with flat leaves, rough on the edges. Spikelets small, crowded into a compact cylindrical spike (or spike-like panicle) 1 to $1 \frac{1}{2}$ in. long, interspersed with very numerous awn-like bristles, inserted under the spikelets, but projecting beyond them; these are rough with minute erect teeth, felt only when the spike is pushed upwards through the fingers. Lowest glume very small, the -second not quite so long as the third, the flowering glume marked with numerous minute transverse wrinkles, visible especially as the seed ripens.Setaria glauca, Beauv.; Kunth, Enum. i. 149.

Common on the lower hills, Seemann, Hance, Wilford. Very frequent in tropieal and subtropical countries, extending more sparingly into temperate Asia and Europe.

9. P. plicatum, Lam.; Kunth, Enum. i. 94. A stout erect grass, 3 to 4 or $5 \mathrm{ft}$. high, glabrous or with hairy sheaths. Leaves long, the larger ones 
1 to $1 \frac{1}{2}$ or even $2 \mathrm{in}$. broad, with numerous longitudinal folds. Panicle oblong, loose, above a foot long, composed of long slender branches at first erect but afterwards. often drooping. Spikelets mostly sessile or nearly so, but scattered, interspersed with a few fine awn-like bristles much longer than themselves. Outer glumes 5 -nerved, the lowest about $\frac{1}{3}$, the next $\frac{2}{3}$ as long as the third, which has often a short point and contains a small palea. Flowering glume rather shorter, with a minute point. $-P$. nervosum and $P$. plicatum, Roxb. Fl. Ind. i. 311. P. nepalense, Spreng.; Kunth, Enum. i. 94.

Hongkong, Harland (a single specimen seen in his herbarium, but not now before me to compare with the following species). Widely spread over tropical Asia and Africa, extending northwards to the Himalaya, S. China, and the Philippines.

10. P. excurrens, Trin.; Kunth, Enum. i. 94. Very near the P. plicatum, but more slender, the leaves much narrower, and not so much folded, the paniele narrow, 8 to $10 \mathrm{in}$. long, with short erect branches, the spikelets rather larger, the second and third glumes have often 7 nerves, and the latter has in its axil a more developed palea and often a male flower.-P. Forbesianum, Nees in Steud. Syn. Gram. 98.

Hongkong, Hance; also Shanghai and in the Himalaya.

11. P. nodosum, Kunth, Enum. i. 97. A rather slender branching grass, decumbent and rooting at the lower nodes, ascending to 1 or $2 \mathrm{ft}$. Leaves rather narrow, rounded at the base, glabrous or hairy. Panicle 6 to 10 in. long, the spikelets in clusters or short spikes along its long slender branches. Each spikelet narrow-elliptical, but scarcely acute, about 1.line long. Glumes faintly nerved, the 2 outer scarcely unequal, and not half so long as the third, which is usually empty.-P. Arnottianum, Nees in Steud. Syn. Gram. 59.

In the Happy Valley woods, Wilford. Dispersed over India, from Ceylon and the Penillsula to the Archipelago, and northwards to the Himalaya and S. China.

12. P. repens, Linn.; Kunth, Enum. i. 103. Stems creeping and rooting at the base, the flowering branches ascending to 1 or rarely 2 feet, simple and rather stiff. Leaves narrow, more or less pubescent or hairy at the base. Panicle slender, not much branched, erect or at length spreading. Spikelets all pedicellate and distant, about $1 \frac{1}{4}$ lines long. Outer glume very short and rounded, the second and third nearly equal, pointed, the latter often with a male flower in its axil.-P. ischcomoides, Retz; Steud. Syn. Gram. 98.

Hongkoug, Hance. Common in the maritime regions of S. Asia, N. Africa, and S. Europe; also on the consts of Brazil.

13. P. sarmentosum, Roxb.; Kunth, Enum.i.126. A tall scrambling branching grass, more or less covered with a minute soft pubescence. Leaves rather broad, rounded at the base. Panicle very much branched, sometimes 4 or 5 in., sometimes near a foot long, with filiform spreading branches. -Spikelets all pedicellate, ovoid, obtuse, less than a line long, pubescent, the lowest glume full $\frac{3}{4}$ as long as the second and third. $-P$. incomptum, Trin.; Kunth, Enum. i. 112. P. concinnum, Nees in Kew Journ. Bot. ii. 97.

In the wood behind the Buddhist Temple, Wilford; also Harland. Extends over eastern tropical Asia, from Assam and Khasia to the Archipelago, the Philippines, and S. China.

14. P. montanum, Roxb.; Kunth, Enum. i. 126. Stems firm, erect, 3 to $4 \mathrm{ft}$. high. Leaves broad, cordate at the base, somewhat hairy and ciliate 
at the edges. Panicle mnch branched and very slender, often a foot long or more, the branches almost capillary, erect or spreading. Spikelets all pedicellate and distant, about 1 line long, acute. Lowest glumie more than half the length of the second and third, which are both empty.

Hongkong, Wright. Dispersed over the hilly districts of India, from the Peninsula to Burmah, the Archipelago, the Philippines, and S. China.

15. P. ovalifolium, Poir.; Kunth, Enum.i. 113. Stems creeping and rooting at the lower nodes, weak and ascending to about a foot. Leaves ovate-lanceolate, seldom above $2 \mathrm{in}$. long and $\frac{3}{4}$ to near $1 \mathrm{in}$. broad, cordate at the base, and ciliate with a few long hairs. Panicle about $4 \mathrm{in}$. long, with numerous capillary spreading branches. Spikelets all pedicellate, not 1 line long, scarcely acute, the 3 outer glumes nearly equal in length, the second very concave, the third often with a male flower in its axil.

In ravines, Wright, Wilford, Hance. Dispersed over tropical Asia and Africa, and oceurs also in eastern Brazil. The habit is very near that of several Isachnes.

16. P. indicum, Linn.; Kunth, Enum. i. 113. A small grass with the habit almost of an Alopecurus. Stems decumbent at the base, ascending to 6 in. or a foot. Leaves narrow. Panicle contracted into a dense cylindrical spike, $\frac{1}{2}$ to $1 \mathrm{in}$. long in the Hongkong specimens, often $2 \mathrm{in}$. or more in Indian ones, without awns or bristles. Spikelets acute, 1 to $1 \frac{1}{4}$ line long, crowded but somewhat spreading, glabrous or pubescent. Lowest glume about $\frac{1}{2}$ as long as the second and third. Flowering glume considerably shorter. -P. angustum, Trin., and P. contractum, Nees in Steud. Syn. Gram. 84.

Common about Victoria, Wilford, Harland, Wright. Dispersed over India from the Peninsula to the Archipelago, and northward to Silhet, Assam, S. China and the Philippines.

\section{GYMNOTHRIX, Beauv.}

Spikelets and flowers of Panicum, but each spikelet surrounded by an involucre of long simple awn-like bristles, and all arranged in a long cylindrical simple and dense spike or raceme.

A small tropical or subtropical genus, common to the New and the Old World.

1. G. japonica, Kunth, Enum. i. 159. A tall erect stiff grass. Leaves narrow-linear, very long, the edges rolled inward when dry. Stem usually hairy under the spike. Spike 4 to 8 in. long, conspicuous from the numerous purplish awn-like bristles that almost conceal the flower, those of each involucre unequal, the longest near 1 in. long. Spikelets solitary within each involucre, narrow, pointed, 3-4 lines long, on very short pedicels. Lowest glume a minute almost microscopical scale, the second full half as long as the spikelet, the third about as long as the flowering one, but empty, all glabrous.

Hongkong, Hance. Common in S. China, and northward to Japan.

\section{ICHNANTHUS, Beauv.}

Spikelets and inflorescence of the large-flowered awnless paniculate Panicums, except that the flowering glume has on each side at the base a small scalelike oblong appendage, either free or in some species so closely adnate as to appear as a depressed scar.

A small tropical American genus, of which one specics also extends into the Old World. 
1. I. pallens, Munro. A weak decumbent branching grass, creeping and rooting at the lower nodes, 1 to $2 \mathrm{ft}$. long, and usually more or less pubescent. Leaves rather broadly lanceolate, 2 to $3 \mathrm{in}$. long, rounded or cordate at the base. Panicle 3 or 4 in. long, the branches slender, but not very spreading. Spikelets scattered, pedicellate or nearly sessile, full 2 lines long. Outer glumes lanceolate, the lowest about $\frac{1}{3}$ shorter than the second, and both empty, the third rather shorter, usually with a male flower. Terminal flowering glume about half as long, shortly stipitate, obtuse and coriaceous, with a small scar or depression on each side at the base, indicating the scales of the other species.-Panicum pallens, Sw.; Kunth, Enum. i. 89.

Hongkong, Wright. A common weed in tropical America, occurring also in many parts of tropical Africa and Asia.

\section{ISACHNE, Br.}

Spikelets 2-flowered, the upper flower female or rarely hermaphrodite, the lower male or sometimes hermaphrodite, and both articulate on the rhachis. Outer empty glumes 2, nearly equal, and often very deciduous. Both the flowering glumes, as well as the paleæ, of a firmer consistence than the outer ones, all awnless. Grain enclosed in the glumes and palea as in Panicum, but very frequently those of both flowers attain maturity. Inflorescence of the small-flowered paniculate Panicums, except that the articulation of the spikelet is usually above, not below the insertion of the outer glumes.

A small tropical genus, common to both the New and the Old World.

Panicle with very numerous short capillary branches. Spikelets about

$\frac{1}{4}$ line long . . . . . . . . . . . 1. I. putchella.

Panicle loose. Spikelets $\frac{3}{4}$ to 1 in. long.

Leaves narrow-lanceolate, very rough. Outer glumes glabrous . . . 2. I. australis.

Leaves ovate, not 1 in. long. Outer glumes pubescent . . . . 3. I. myosotis.

1. I. pulchella, Roth, Nov. Pl. Spec. 58. Stems slender, ereeping, branching, ascending sometimes to near $1 \mathrm{ft}$. Leaves ovate, seldom 1 inch long, deeply cordate, rough, elegantly marked with numerous parallel veins, the edges bordered by long hairs or bristles, the sheaths very hairy. Panicles ovate, 1 to $1 \frac{1}{2}$ in. long, with numerous capillary but stiff spreading branches. Spikelets about $\frac{1}{4}$ line long, the 2 outer glumes falling off very early. Flowering glumes pubescent, the lower flower usually male, but sometimes both flowers are fertile.-Panicum miliaceum, Trin.; Kunth, Enum. i. 113. Grayia elegans, Nees in Steud. Syn. Gram. 119.

Hongkong, Wright, Harland. In Ceylon, the Indian Peninsula, Malacea, and Silhet.

2. I. australis, $\mathrm{Br}$. Prod. 196. Stems rather slender, decumbent, creeping and rooting at the lower nodes, ascending to $1 \mathrm{ft}$. or more. Leaves lanceolate, very rough with a minute pubescence. Panicle ovoid, spreading, 1 to $2 \mathrm{in}$. long, rather loose. Spikelets all pedicellate, obtuse, nearly 1 line long. Outer glumes glabrous. Lower flower usually male, with a glabrous glume, the upper one stipitate, female, and pubescent. Pedicels mostly marked with a pellucid discoloration or gland.-1sachne miliacea of most modern authors, but probably not of Roth. Panicum atrovirens, Trin.; Kunth, Enum. i. 127. P. batavicum, and P. Benjamini, Steud. Syn. Gram. 9.6 . 
Hongkong, Hance, Wright. Widely spread over India, from Ceylon and the Peninsula to the Archipelago, and northward to Amoy.

3. I. myosotis, Nees in Kew Journ. Bot. ii. 98. Stems slender, decumbent, often branched, from a few inches to $1 \frac{1}{2} \mathrm{ft}$. long. Leaves ovatelanceolate, $\frac{1}{2}$ to near 1 in. long, with hairy sheaths and ciliate edges, and rough on the surface. Panicle ovate, very spreading, few-flowered, about $1 \frac{1}{2} \mathrm{in}$. long. Spikelets pedicellate, very obtuse, about 1 line long. Outer glumes strongly nerved and shortly hirsute. Flowering glumes rather longer, glabrous or nearly so, the upper one female, the lower usually hermaphrodite. Panicum myosotis, Steud. Syn. Gram. 96.

In damp situations, about Victoria, Wilford; also Wright. And in the Philippine Islands.

\section{SPINIFEX, Linn.}

Spikelets diøcious, sessile, awnless. Barren ones in spikes, each one with 2 male flowers, and 2 outer empty glumes. Fertile spikelets solitary, with 2 outer empty glumes, the third empty or with a male flower, the terminal one with a hermaphrodite flower. Spikes in the male plants, and single flowers in the fertile ones, collected in dense globular clusters intermixed with long stiff often prickly bracts.

A genus of very few species, confined to the seacoasts of tropical Asia and Australia.

1. S. squarrosus, Linn.; Kunth, Enum. i. 175. A glabrous glaucous hard perennial, creeping and much branched. Leaves clustered, narrow, and very rigid, often pungent, 4 to 6 in. long, the broad short sheaths often imbricate. Male spikes 2 or 3 in. long, the bracts mostly shorter, the rhachis often pungent. Spikelets alternate and distant, each 4 or 5 lines long, the outer empty glumes unequal and both shorter than the flowering ones. Fertile spikelets almost concealed by the long rigid bracts, the glumes rather longer than in the males, and the outer ones usually the longest.

On the sands of the seabeach, Hance. Frequent in the maritime sands of tropical Asia.

\section{THOUAREA, Pers.}

Spikelets in short one-sided androgynous spikes, in the axil of a sheathing bract. Upper spikelets with 2 male flowers, lower ones with a terminal hermaphrodite and lower male flower, and all with only one outer empty glume.

The genus is apparently limited to a single species.

1. T. sarmentosa, Pers:; Kunth. Enum. i. 174. A glabrous or pubescent perennial; creeping to a great extent with short leafy flowering branches. Leaves short and flat, with broad sheaths often almost covering the stems. Spikes $\frac{1}{2}$ to $\frac{3}{4}$ in. long; the sheathing bract about as long, and as the seed ripens turning down over it like a hood. Spikelets about 2 lines long, the outer empty glume rather shorter than the flowering ones.

On the sands of the seabeach, Hance. In similar situations in Ceylon, the Archipelago, North Australia, and the Pacific islands.

\section{ARUNDINELLA, Raddi.}

Spikelets 1-flowered or with a second male flower below it in a loose terminal panicle. Glumes 4 ; the 2 lowest empty, pointed but not awned; the 
third similar but often with a male flower in its axil ; the terminal flowering one smaller, thinner, with an awn twisted at the base, and bent back at or below the middle. Palea smaller, awnless. Grain enclosed in the slightly stiffened glume and palea.

A tropical or subtropical genus, chiefly Asiatic, with a few African or S. American species. Flowering glume ending in 2 fine bristles between which arises the awn. 1. A. setosa. Flowering glume slightly pointed on each side of the awn . . . . 2. A. nepalensis.

1. A. setosa, Trin.; Steud. Syn. Gram. 114. A rather slender erect perennial, $2 \mathrm{ft}$. high or more. Leaves narrow. Panicle slender, 6 to 8 in. long; the branches erect or slightly spreading. Spikelets numerous, solitary, or 2 together on pedicels of unequal length. Lowest glume usually about 2 lines long, shortly pointed; the second tapering into a longer point; the third thinner, smaller, and scarcely pointed, with a male flower; flowering glume ending in 2 very fine bristles nearly as long as itself, between which arises the awn.-A. stricta, Nees in Kew Journ. Bot. ii. 102.

Hongkong, Wright. On the mainland and northward to Amoy, in the Philippines, and more rarely in the mountains of northern India and the Peninsula.

2. A. nepalensis, Trin. Ic. t. 268; Steud. Syn. Gram. 115. An erect perennial, with narrow leaves, like the last but often taller. Panicle narrow, a foot long or more. Spikelets nearly as in $A$. setosa, but the flowering glume is only slightly notched at the top; the minute points on each side of the awn not produced into bristles.-Acratherum miliaceum, Link, Enum. Hort. Berol. i. 230. Arundinella miliacea, Nees in Kew Journ. Bot. ii. 102. A. Eckloni, Nees, Fl. Afr. Austr. Gram. 80.

Hongkong, Hance. Widely distributed over the hilly districts of tropical Asia, extending also to S. Africa and N. Australia.

\section{GARITOTIA, Brongn. \\ (Miquelia, Nees; Berghausia, Endl.)}

Spikelets 1-flowered, in a loose terminal panicle. Outer empty glumes 2 , pointed but not awned. Flowering glume smaller, thinner, usually with an awn twisted at the base, and bent back in the middle, but sometimes straight or reduced to a minute point. Palea awnless, usually with 2 auricles at the base. Grain enclosed in the slightly stiffened glume and palea.

A small tropical Asiatic genus.

Awn of the flowering glume longer than itself, straight . . . . . . 1. G. patula. Awn reduced to a minute point .......... . . . G. stricta.

1. G. patula, Munro. An erect somewhat glaucous perennial, 2 to $4 \mathrm{ft}$. high, with a short creeping rootstock. Leaves rather narrow, the lowest with loose distichous sheaths. Panicle 8 in. to $1 \mathrm{ft}$. long; the slender branches not above 2 in. long, but very spreading. Spikelets about 2 lines long, narrow, minutely hairy. Outer glumes ending in fine points sometimes lengthened into a bristle or short awn in the second. Flowering glume smaller, notched, with a fine straight awn of 4 or 5 lines.-Berghausia patula, Munro in Proc. Amer. Acad. iv. 362.

Hongkong, Wright, Hance. Not known from elsewhere.

2. G. stricta, Brongn, in Duperr. Voy. 133, t. 21. An erect grass, $1 \frac{1}{2}$ 
to $3 \mathrm{ft}$. high, usually not so stiff as the last. Leaves narrow, scarcely distichous. Panicle narrow, often a foot long; the branches short, erect or slightly spreading. Spikelets like those of $G$. patula, but nearly glabrous; the points of the empty glumes much shorter, and the awn of the flowering glume reduced to a minute often microscopical point.-Berghausia mutica, Munro in Proceed. Amer. Acad. iv. 362. Miquelia barbulata, Nees in Pl. Meyen. 178 ?

On rocky cliffs, Hongkong, Wright. Also in Ceylon. As far as Nees's description goes; of the plant gathered by Meyen on the Syngmoon channel (probably in Lantao), it agrees perfectly with this species.

\section{THYSANOL开NA, Nees.}

Spikelets 1-flowered, minute, awnless, crowded along the slender branches of a large panicle. Glumes 4 ; the 2 outer empty and very short; the third also empty but much longer and more pointed; the flowering glume rather smaller and thinner, with a very small point, and edged with long spreading hairs.

The genus is limited to a single species, placed by Nees among Tristeginea, but scarcely distinct from Panicee proper.

1. T. acarifera, Nees, $P l$. Meyen. 181. Stems stout, erect, 4 to $12 \mathrm{ft}$. high. Leaves 1 to $2 \mathrm{ft}$. long, and 1 to 2 in. broad at the base. Panicle 1 to $2 \mathrm{ft}$. long, the numerous slender branches drooping or spreading. Spikelets when fully expanded about $\frac{3}{4}$ line long, the long spreading hairs of the flowering glume very conspicuous.-Melica latifolia, Roxb. Fl. Ind. i. 328. Panicum acariferum, Trin. Ic. t. 87. Agrostis maxima, Roxb. 1. c. 317. Thysañolena Agrostis, Nees, Pl. Meyen. 182.

Frequent in ravines, Hance, Wright, Wilford. Widely distributed over the hilly districts of northern and eastern India, but apparently not in the Peninsula as stated by Nees, through a mistaken quotation from Roxburgh.

\section{OPHIURUS, Br.}

Spikelets 1-flowered, awnless, singly sessile in notches on alternate sides of a simple spike; the axis articulate at each notch. Lowest empty glume hard; the 2 next empty ones, the flowering glume, and the palea all very thin and transparent, and completely enclosed under the outer one.

A small genus, limited to tropical Asia and Australia.

1. O. monostachyus, Presl; Kunth, Enum.i. 464. Stems ascending, rather slender, $\frac{1}{2}$ to $1 \mathrm{ft}$. high, simple or slightly branched. Leaves narrow. Spike terminal, pedunculate, slender, cylindrical, $1 \frac{1}{2}$ to $2 \mathrm{in}$. long, straight or slightly curved. Outer glume about $1 \frac{1}{4}$ lines long, ovate, thick and hard, slightly convex, the veins scarcely conspicuous.-O. undatus, Nees in Kew Journ. Bot. ii. 102.

Hongkong, Hance, Harland. Also in the Philippine Islands.

\section{HEMARTHRIA, Br.}

Spikelets 1-flowered, usually awnless, inserted in pairs, one sessile, the other pedicellate in notches on alternate sides of a simple spike, the axis not arti- 
culate. Lowest empty glume keeled, rigid, several-nerved; the second similar but more pointed in the pedicellate flower, thinner and half-transparent in the sessile one, and more or less cohering to the concave pedicel of the other; the third empty glume, flowering glume, and palea, all very thin and transparent.

A small genus, widely spread over the warmer regions of the globe.

1. H. fasciculata, Kunth, Enum. i. 465. Stems creeping and rooting at the base, ascending to 1 or $1 \frac{1}{2} \mathrm{ft}$., more or less compressed and sometimes branched. Leaves narrow. Spikes 2 to $2 \frac{1}{2}$ in. long, slightly compressed, all axillary; the peduncles not longer than the sheaths, and bearing 2 or 3 sheathing bracts. Outer glumes about 2 lines long, acute or with short points, green and striate.

Hongkong, Hance. Widely distributed over Asia and the Mediterranean region.

\section{PEROTIS, Ait.}

Spikelets 1-flowered in a simple spike-like raceme. Outer empty glumes 2, linear, stiff, with terminal awns. Flowering glume and palea very small, thin, and transparent. Grain longer than the flowering glume, enclosed in the two outer ones.

Besides the following, the genus eomprises one other Australian species.

1. P. latifolia, Ait.; Kunth, Enum. i. 470. Stems decumbent and branched at the base, ascending to $1 \mathrm{ft}$. or more. Leaves flat, rather broad, from $\frac{1}{2}$ in. to near 1 in. long. Racemes pedunculate, usually 2 to $4 \mathrm{in}$. long. Spikelets rather crowded, spreading, on very short pedicels, each spikelet near 2 lines long, with awns of $\frac{1}{2}$ in. in most of the Chinese specimens, much shorter with shorter awns in other varieties. $-P$. patula, Nees, and $P$. longiflora, Nees in Steud. Syn. Gram. 186 (the long-flowered variety). P. hordeiformis, Nees, and P. glabrata, Steud. l. c. (the shorter-flowered variety).

Hongkong, Wright. Widely diffused over tropical and subtropical Asia and Africa, extending northward to Japan, and southward to S.E. Africa.

\section{ZOYSIA, Willd.}

Spikelets 1-flowered, awnless, nearly sessile in a simple spike, the axis not articulate. Outer empty glume 1, keeled, stiff, shortly pointed, the edges often united below round the flower. Flowering glume much shorter, thin and transparent. Palea very small or none. Grain free but enclosed in the outer glume.

A genus limited to a single species.

1. Z. pungens, Willd.; Kunth, Enum. i. 471. Stems creeping or diffuse, and shortly ascending. Leaves narrow and very pointed, sometimes pungent, varying from $\frac{1}{2}$ to $2 \mathrm{in}$. long in different specimens. Spikes pedunculate, about 1 in. long. Spikelets erect, full 2 lines long in the Chinese specimens, scarcely more than 1 line in many others. Outer glume smooth, except the keel, and almost cartilaginous, usually ending in a short point.-Z. tenuifolia, Willd., and Z. japonica, Steud. Syn. Gram. 414. Z. aristata, Z. Brownei, Z. Griffithiana, and Z. sedoides, C. Müll. in Bot. Zeit. 1855, 272 to 274.

Hongkong, Hance. Common in maritime sands in tropical and subtropical eastern Asia and Australia, extending northward to Japan. 


\section{DIMERIA, Br.}

Spikelets 1-flowered, almost sessile, inserted singly on the alternate notches of slender unilateral spikes, which are either solitary or more frequently 2 or 3 together on a terminal peduncle; the rhachis not articulate, and a tuft of short hairs under each spikelet. Outer empty glumes 2, linear, stiff, keeled, not awned; third empty glume smaller, thin and transparent, not awned; flowering glume thin and transparent, notched or 2-lobed with an intermediate awn, twisted at the base, and bent back at or below the middle. Palea minute or none. Seed free, but enclosed in the outer glumes.

A small tropical Asiatic or Australian genus.

1. D. fuscescens, Trin.; Steud. Syn. Gram. 413. Stems erect, rather slender, 1 to $1 \frac{1}{2} \mathrm{ft}$. high. Leaves narrow, erect, very pointed, fringed with long hairs, the sheaths somewhat flattened and distichous. Spikes 2 or rarely 3 together, digitate at the summit of a slender peduncle, each $1 \frac{1}{2}$ to $2 \mathrm{in}$. long. Pedicels short and flat. Outer glumes fringed with hairs on the keel and edges. Inner glumes also ciliate. Awn about 4 lines long. Palea usually deficient.

Hongkong, Hance. On the Chinese continent to Amoy, in Nepal and in Ceylon.

\section{IMPERATA, Cyr.}

Spikelets 1-flowered, awnless, mostly pedicellate, in a dense cylindrical spike-like panicle, the rhachis not articulate. Glumes all thin and transparent, 2 outer empty ones keeled, covered with very long silky hairs, third also empty, smaller; without hairs, flowering glume and palea still shorter, often jagged at the top. Grain free, enclosed in the outer glumes.

A very small genus, widely diffused over the warmer regions of the globe.

1. I. arundinacea, Cyr.; Kunth, Enum. i. 477, var. Koenigii. A stiff erect perennial, 1 to $2 \mathrm{ft}$. high, glabrous except a tuft of hairs at the nodes. Leaves erect, narrow, often longer than the stem. Spike-like panicle 3 to 5 in. long, silvery-white with the long silky hairs of the glumes, concealing the spikelets. Spikelets in this variety usually all pedicellate, the outer glumes about $1 \frac{1}{2}$ lines long, and often slightly coloured.-I. Koenigii, Beauv.

Common in Hongkong, Champion and others. Frequent in tropical Asia and Africa. The form originally described with glabrous nodes and rather larger spikelets, many of them sessile, is equally abundant in the Mediterranean region and in some parts of tropical and northern America. The two varieties run too much into each other to be separable as species.

\section{SACCHARUM, Linn.}

Spikelets 1-flowered, awnless, surrounded by long silky hairs, in pairs, both sessile or 1 pedicellate along the branches of a large panicle, the rhachis articulate at each pair. Two outer empty glumes keeled, thin but rather stiff, third empty glume, flowering-glume, and palea, all smaller and very thin and transparent.

A small Asiatic or African tropical or subtropical genus.

1. S. officinarum, Linn.; Kunth, Enum. i. 474. Stems firm, erect, 6 to $12 \mathrm{ft}$. high. Leaves long, flat, $1 \mathrm{in}$. broad or more, very rough at the 
edges. Panicle terminal, compound, spreading, 1 to $3 \mathrm{ft}$. long, of a grey silvery colour from the long hairs surrounding the spikelets. Spikelets all sessile or one of each pair slightly pedicellate, the outer glumes about 2 lines long, pointed.

Hongkong, Harland, probably cultivated here as in India and other hot countries. We have no authentic record of any really wild station of this the common Sugar-cane.

\section{FULALIA, Trin. (not of Kunth).}

Spikelets 1-flowered, in pairs, along the slender inarticulate branches of a compound panicle, each spikelet surrounded by long silky hairs. Outer empty glumes 2, rather stiff, awnless, the lowest 3- or 5-nerved, the second keeled; third empty glume smaller, very thin and transparent or deficient; floweringglume very thin and transparent, notched, with a fine awn twisted at the base. Palea small or none.

A small tropical or subtropical Asiatic genus, differing from Erianthus in the inarticulate branches of the panicle, from Pollinia in the branched inflorescence.

1. E. japonica, Trin.; Steud. Syn. Gram. 412. An erect perennial, 3 to $6 \mathrm{ft}$. high. Leaves narrow. Panicle $\frac{1}{2}$ to $1 \frac{1}{2} \mathrm{ft}$. long, spreading and much branched, the silky hairs usually assuming a brown or purplish hue. Spikelets both shortly but unequally pedicellate. Outer glumes about $1 \frac{1}{2}$ lines long, with short points. Awn of the flowering glume very fine, 3 to 4 lines long. - Erianthus japonicus, Beauv.; Kunth, Enum. i. 479. Saccharum densum, Nees in Kew Journ. Bot. ii. 100. Eulalia densa, Munro in Seem. Bot. Her. 424. Saccharum progrande, Steud. Syn. Gram. 408.

Hongkong, Hinds, Champion, and others. Extends to the Philippines and Borneo, and northward to Japan.

\section{POLLINIA, Trin.}

(Eulalia, Kunth.)

Spikelets 1-flowered, in pairs, one sessile, the other pedicellate along the spike-like branches of a simple panicle, the rhachis articulate at each pair, each spikelet surrounded by silky hairs. Outer empty glumes 2, stiff, awnless or with a hair-like point, the lowest with 2 of the lateral nerves prominent, the central one faint or wanting; second glume keeled, third smaller, very thin and transparent; flowering glume small and thin, with a fine awn, twisted at the base.

A small tropical and subtropical genus, chiefly Asiatic and African, with a few American or Australian species.

Spikes (3 or 4 ) dense, 3 to $4 \mathrm{in}$. long, very hairy. Outer glumes 2 lines long, the second pointed .. . . . . . . . . . . Spikes (3 to 5 ) slender, $1 \frac{1}{2}$ to 3 in. long, shortly hairy. Outer glumes $1 \frac{1}{4}$

lines long, the second with a long hair-like point ... . . . 2. P. tenuis.

1. P. villosa, Munro, MSS. An erect glabrous perennial, about $2 \mathrm{ft}$. high. Leaves narrow, usually pubescent. Spikes cylindrical, dense, 3 to 4 in. long, 3 or 4 together at the summit of the peduncle. Spikelets closely erect along the rhachis, with silky hairs shorter than the glumes at their base, on the pedicels, and on the back of the outer glumes. Lowest glume about 2 lines long, usually 4-nerved, with 2 of the lateral nerves very prominent; 
second glume keeled, scarcely pointed. Awn of the flowering glume $\frac{1}{2}$ to $\frac{3}{4}$ in. long.-Erianthus tristachyus, Nees, Pl. Meyen. 184 (but not Andropogon tristachyus, Roxb.). Eulalia villosa, Nees, Fl. Afr. Austr. Gram. 91.

Hongkong, Hance. Also on the adjacent continent, and northward to Amoy, and in S. Africa.

2. P. tenuis, Trin.; Steud. Syn. Gram. 409. Stems slender, creeping and branched at the base, ascending to 1 or $2 \mathrm{ft}$. Leaves flat, spreading, narrowed at the base. Spikes slender, $1 \frac{1}{2}$ to $3 \mathrm{in}$. long, usually 3 to 5 at the summit of the peduncle, the hairs of the pedicels much shorter than the glumes. Spikelets about $1 \frac{1}{4}$ lines long. Lowest glume 4-nerved, strongly ciliate; second glume keeled, slightly ciliate, with a hair-like point full half as long as the glume in the sessile spikelet, usually very short in the pedicellate one. Awn of the minute flowering glume very fine, about $\frac{1}{2} \mathrm{in}$. long.

Hongkong, Hance; common about Victoria, Wilford. Also in northern India and in the Philippines.

\section{POGONATHFRUM, Beauv.}

Spikelets in pairs, 1 sessile, the other pedicellate in a simple spike, the rhachis articulate, each spikelet surrounded by long silky hairs. Pedicellate spikelet with 1 female flower; sessile one with 1 hermaphrodite and 1 male flower below it. Glumes all thin and transparent, the lowest 3-nerved, awnless, the second keeled, with a long awn, the third smaller and awnless, empty or with the male flower, the terminal flowering one very small with a long awn, the awns twisted.

A genus limited to a single species.

1. P. saccharoideum, Beauv. A slender, branching, often tufted grass, 6 in. to $1 \mathrm{ft}$. high. Leaves narrow, spreading, 1 to $1 \frac{1}{2}$ in. long. Spike $\frac{1}{2}$ to 1 in., on a slender terminal peduncle, the silky hairs and awns often assuming a golden hue. Spikelets less than 1 line long, the 5 spreading hair-like awns $\frac{1}{2}$ to $\frac{3}{4}$ in. long.--P. crinitum, Trin.; Kunth, Enum. i. 478. P. refractum, Nees, Pl. Meyen. 152.

Common in the island, Hance and others. Widely diffused in India, from Ceylon and the Peninsula to the Archipelago, and northward to the Philippines, S. China, and Loochoo.

\section{APOCOPIS, Nees.}

(Amblyachyrum, Hochst:)

Spikelets 1-flowered or with a second male flower, solitary or accompanied by a rudimentary pedicel of a second spikelet, in a dense simple or double spike, the rhachis articulate. Outer empty glume stiff, broad and truncate, second similar but smaller, third smaller, very thin and transparent, awnless, terminal flowering glume narrow, emarginate, with a twisted awn, or awnless in the lower spikelets.

A small tropical Asiatic genus.

1. A. Wrightii, Munro in Proceed. Amer. Acad. iv. 363. Stems slender, slightly branched, ascending to 1 or $2 \mathrm{ft}$. Leaves rather short, narrow, usually hairy. Spikes $1 \mathrm{in}$. or rather longer, erect, simple or divided into 2 closely erect branches. Outer glumes full 2 lines long, broad and very obtuse at 
the top, with a narrow reddish ciliate margin, closely imbricate and usually concealing the remainder of the spikelet as well as the hairs at its base, and the rudimentary hairy pedicel. Awns protruding to 5 or 6 lines in the upper spikelets, but very deciduous, and often deficient in the lower part of the spike.

Hongkong, on the Syngmoon channel, Wright; also in Borneo.

\section{APLUDA, Linn.}

Spikelets with 1 fertile and 1 male flower, sessile between 2 flattened pedicels, bearing each a rudimentary glume or one of them a perfect spikelet, the whole embraced by a sheathing bract, the bracts clustered on the branches of a leafy panicle. Lowest glume of the sessile spikelet concave and striate, the second keeled, transparent, but stiff ; flowering glumes very thin and transparent, the terminal one often awned. In the pedicellate flower both the glumes concave and striate.

A genus of 2 or 3 species from tropical Asia or Africa.

1. A. mutica, Linn. ; Kunth, Enum. i. 516. Stem creeping or climbing, several feet long, with erect branching flowering shoots. Leaves long, somewhat distichous. Panicles loose and leafy, 1 to $2 \mathrm{ft}$. long. Flowering bracts 3 or 4 lines long, very concave, with short sometimes awn-like points, in clusters of 5 or 6 . Sessile spikelet shorter than the bract; pedicellate spikelets, when present, protruding beyond it. Awns of the flowering glume very minute or entirely deficient.

Hongkong, Hance, Wright. Common in the Indian Archipelago, extending northward to Amoy, and to the eastern districts of India, but less common there than the A. aristata.

\section{ANDROPOGON, Linn.}

Spikelets 1-flowered, in pairs, 1 sessile, the other pedicellate, in a simple spike or along the spike-like branches of a simple or compound panicle, the rhachis articulate at each pair, and at the terminal article 2 pedicellate spikelets, one on each side of the sessile one. Sessile spikelet hermaphrodite, the lowest glume stiff, with 2 of the lateral nerves most prominent, the second keeled, third empty glume very thin and transparent; flowering glume small and transparent, with a long twisted awn. Palea very small and thin or none. Pedicellate spikelet smaller, male only, or reduced to a single glume. Grain free, enclosed in the outer glumes.

A large genus, widely distributed over the globe within the tropics, with a few species extending into more temperate regions, both in the northern and the southern hemispheres.

Spikes single and solitary (Schizachyrium).

Spike full 2 in. long. Rudimentary spikelet on a flat pedicel, with a point shorter than itself.

Spike not 1 in. long. Rudimentary spikelet on a narrow pedicel, with an awn longer than itself . . . . . . . . Spikes pedunculate, in a loose or compound panicle.

Panicle without bracts (Amphilophis).

Outer glumes narrow-oblong, rather thin. Hairs of the pedicels short and pale.

Spikes not $\frac{1}{2}$ in. long, with 2 or 3 articulations . . . . . . 3. A. montanus,

Spikes 1 to near 2 in. long, with numerous articulations . . . 4. A. Vachellii.

Outer glumes ovate-oblong, hard. Hairs of the pedicels very conspicuous, of a rich brown

1. A. zeylanicus.

2. A. brevifolins.

5. A. tropicus.

Panicle with a leafy bract at most of the ramifications (Cymbopogon) 6. A. Martini. 
1. A. zeylanicus, Arn.; not of Nees. Stems rather slender, ascending or erect, slightly branched, 1 to $2 \mathrm{ft}$. high. Leaves narrow, obtuse or searcely pointed. Spikes simple and solitary on short terminal peduncles or in the upper axils, 2 to $2 \frac{1}{2}$ in. long, slender. Sessile spikelets about 3 lines long, narrow, the outer glumes very pointed, the awn of the flowering glume protruding to about $\frac{1}{2}$ in. Pedicel of the barren spikelet flat, ciliate on both edges, the spikelet usually reduced to a single very pointed almost awned glume.-A. pseudograya, Steud. Syn. Gram. 365 .

Hongkong, Wright; at Amoy, and a var. with very hairy spikes at Whampoa, Hance; also in Ceylon.

2. A. brevifolius, $S w . ;$ Kunth, Enum. i. 488. Stems slender, decumbent, much branched, $\frac{1}{2}$ to $1 \frac{1}{2} \mathrm{ft}$. long. Leaves narrow, 1 to $2 \mathrm{in}$. long, obtuse or with a very short oblique point. Spikes solitary, very slender and seldom above 1 in. long. Sessile spikelet not 2 lines long, the outer glume not pointed, the awn of the flowering glume protruding about 4 lines. Barren pedicel slender, not ciliate except at the base, bearing a small rudimentary glume with a long awn-like point.

Hongkong, Hance, Wright. On the adjacent continent, in Silhet, the Indian Archipelago, and tropical America.

3. A. montanus, Roxb. Fl. Ind. i. 267. Stems decumbent at the base, branching and ascending to 3 or $4 \mathrm{ft}$. Leaves narrow, rather long. Panicles terminal, very loose, about $4 \mathrm{in}$. long, with slender almost filiform clustered branches of unequal length and little branched. Spikes not $\frac{1}{2}$ in. long, all pedicellate, consisting usually of 2 or 3 articulations, with a tuft of hairs at each articulation and at the branches of the panicle. Sessile spikelet $1 \frac{1}{2}$ in. long. Outer glumes shortly ciliate. Flowering glume reduced to a fine twisted awn 8 or 9 lines long. Pedicellate spikelet male and awnless, with a few long hairs on the pedicel.-A. (Rhaphis) villosulus, Nees in Steud. Syn. Gram. 397. A. parvispica (Rhaphis microstachya, Nees), Steud. l.c. Rhaphis stricta, Nees in Kew Journ. Bot. ii. 99.

Hongkong, Hance. Common in the hilly districts of northern India; also in S. China and in the Philippines.

4. A. Vachellii, Nees, $P l$. Meyen. 188. Stems and foliage of $A$. montanus, but the panicle is longer, closer, and less branched, and the spikes, on pedicels of $\frac{1}{2}$ to $1 \mathrm{in}$., are from $\mathrm{l}$ to $2 \mathrm{in}$. long, with numerous articulations. Spikelets as in $A$. montanus, except that the pedicellate barren ones appear to be always without stamens.-Chrysopogon strictus, Nees in Kew Journ. Bot. ii. 95 .

Hongkong, Hance, Harland; on roadsides at Aberdeen, Wilford. On the adjacent con. tinent, and very nearly allied to the north Indian $A$. punctatus, Roxb.

5. A. tropicus, Spreng.; Kunth, Enum. i. 503. Stems rather slender, $2 \mathrm{ft}$. or more, with a dense tuft of short hairs at the nodes. Leaves narrow, rough at the edges. Panicle loose, 4 to $6 \mathrm{in}$. long, conspicuous for the rich brown colour of the hairs of the glumes and pedicels; the capillary branches of unequal length, clustered and each bearing a single spike or the lower ones slightly branched. Spikes usually about $\frac{1}{2} \mathrm{in}$. long, consisting of from 2 to 5 articulations, not so readily separable as in most species. Spikelets $1 \frac{1}{2}$ to 2 
lines long, the sessile ones nearly ovoid, the twisted awn usually protruding to $\frac{1}{2}$ or $\frac{3}{4}$ in., but sometimes wanting, the pedicellate one narrower, male or neuter and awnless.

Hongkong, Hance. In Ceylon and the plains of India, in the Archipelago, extending to N. Australia, and northward to the Philippines and S. China. Allied to A. halepensis, Linu., but readily known by the much smaller spikelets and the brown hairs.

6. A. Martini, Roxb.; Nees, Pl. Meyen. 189. Stems erect, often branching, 3 to $6 \mathrm{ft}$. high. Leaves long and narrow. Panicle narrow, 4 to $6 \mathrm{in.} \mathrm{long,} \mathrm{with} \mathrm{a} \mathrm{leafy} \mathrm{or} \mathrm{sheathirg} \mathrm{bract} \mathrm{at} \mathrm{each} \mathrm{ramification,} \mathrm{the} \mathrm{last} \mathrm{sheaths}$ about $\frac{1}{2} \mathrm{in}$. long, each containing usually 2 spikes of about $\frac{1}{2}$ in., on a short common pedicel. Rhachis and pedicels silky-hairy. Sessile spikelets about 2 lines, 2 nerves of the lowest glume and keel of the second bordered by a narrow wing. Flowering glume with 2 almost filiform points between which arises a very slender twisted awn of about $\frac{1}{2}$ in.

Hongkong, Hance. On the adjacent continent and in the hilly districts of N. India, the Peninsula, and Ceylon.

\section{HETEROPOGON, Pers.}

Spikelets monœcious, 1-flowered, in pairs, in a simple 1-sided spike, the rhachis articulate, at least towards the top. Female spikelets sessile, cylindrical, turned to one side of the spike, the outer glume hard and convolute, the second keeled, the third very thin and transparent, the flowering glume reduced to a long stiff twisted awn; palea small or none. Male spikclets lanceolate, herbaceous, awnless, imbricate on the other side of the spike on short pedicels. At the base of the spike the spikelets are often all male or neuter.

A genus of several species, chiefly tropical, both in the New and the Old World.

1. H. hirtus, Pers. Syn. ii. 353. Stems ascending, slightly branched, 1 to $2 \mathrm{ft}$. high. Leaves narrow, ciliate with a few long hairs, the sheaths flattened. Spikes pedunculate, 1 to 2 in. long without the awns. Male or barren spikelets about 4 lines long, green, ciliate, closely imbricate in 2 rows along the back of the spike, almost concealing the females, which are brown, narrow, very stiff, rough with short hairs, and surrounded by brown silky hairs at the base, the stout twisted brown awns protruding to above 2 in.-Andropogon contortus, Linn.; Kunth, Enum. i. 486.

On roadsides, Hance and others. Common in tropical Asia and Africa, and in some parts of tropical America. .

\section{CHRYSOPOGON, Trin.}

Spikelets 1-flowered, narrow-lanceolate, 3 together, terminating the branches of an erect panicle, the central one sessile and hermaphrodite, the 2 lateral ones pedicellate and male. Glumes and flowers of Andropogon, sect. Amphilophis from which this genus differs in all the spikes being reduced to the terminal article.

A small genus, dispersed over tropical and subtropical Asia, Africa, and Australia, with one species extending into southern Europe.

1. C. aciculatus, Trin. Stems tufted or creeping and rooting at the base, then erect and stiff, about a foot high. Leaves short, the lower ones 
crowded, the upper ones few, with long sheaths. Panicle narrow, 2 to 3 in. long, glabrous except a short tuft of hairs under the spikelets. Outer glumes of the sessile spikelet about $1 \frac{1}{2}$ lines long, with short points, the awn of the flowering glume protruding to $\mathbf{3}$ or $\mathbf{4}$ lines. Male spikelets full 2 lines long, with longer points to the glumes, and no awns.-Rhaphis trivialis, Lour. Fl. Coch. 553. Andropogon acicularis, Retz; Kunth, Enum. i. 505. A. (Rhaphis) javanicus, Nees in Steud. Syn. Gram. 396.

On roadsides, Wilford, Wright. Dispersed over India, from Ceylon and the Peninsula to the Archipelago, extending to Australia and the Pacific islands, and northward to the Philippines and China.

\section{ISCH两MUM, Linn.}

Spikelets in pairs, one sessile, 2-flowered, the lowest flower male, the other pedicellate, usually male or rudimentary, in a simple spike or in the spike-like sessile branches of a simple panicle, the rhachis articulate, at least towards the top. Outer glumes 2, stiff and awnless, the lowest with 2 prominent lateral nerves, the second keeled. Flowering glumes and paleas smaller, thin and transparent, all awnless or the glume of the terminal flower with a twisted awn.

A tropical or subtropical Asiatic and Australian genus.

Spikes simple, slender, unilateral, unawned.

Outer glumes not winged, fringed with long bristles . . . . . 1. I. leersioides.

Outer glumes entire or minutely toothed, winged at the top . . 2. I. ophiuroides. Spikes rather thick, divided into 2 erect branches, with twisted awns . 3. I. barbatum.

1. I. leersioides, Munro in Proc. Amer. Acad. iv. 363. Stems tufted and leafy at the base, ascending to 6 in. or $\mathbf{l} \mathrm{ft}$., rarely branched. Leaves narrow, rather pointed. Spike solitary on a long peduncle, simple, slender, 1 to $1 \frac{1}{2}$ in. long and often curved. Outer glumes of the sessile spikelets ovate and loosely imbricate on one side of the rhachis, $1 \frac{1}{2}$ to 2 lines long, slightly pubescent, scarcely obtuse, not winged but elegantly bordered by long spreading bristles. Awns none. Pedicellate spikelet reduced to a short point on a somewhat dilated pedicel.

Hongkoug, Hance ; in open places on the hills, Wilford. Also on the adjacent continent, but not known out of S. China, unless it prove to be a variety of the Indian $I$. pectinatum, which has the outer glume winged as well as fringed.

2. I. ophiuroides, Munro in Proc. Amer. Acad. iv. 363. A small tufted grass like the last, but the leaves usually shorter and more obtuse. Spikes $1 \frac{1}{2}$ to $2 \mathrm{in}$. long, rather firmer than in $I$. leersioides, the outer glumes of the sessile spikelets more closely imbricated, broader and more obtuse, bordered at the top by a scarious wing, with a few minute tooth-like cilia towards the base. Pedicellate spikelet reduced to an abortive glume on a flat stiff green striated pedicel, as long as the fertile spikelet.

Hongkong, Hance; and in some other islands of the Canton river, but not known out of S. China.

3. I. barbatum, Retz; Kunth, Enum. i. 513. Stems ascending or erect, branched, 1 to $2 \mathrm{ft}$. high, usually with tufts of short hairs at the nodes. Leaves very pointed, the lower ones long. Spikes divided to the base into 2 erect branches $1 \frac{1}{2}$ to $2 \mathrm{in}$. long, the outer glumes, pedicels, and rhachis very 
hairy. Sessile spikelets 3 lines long, the outer glume pointed and marked at the base with a few transverse wrinkles, the twisted awn of the upper flowering-glume protruding to about $\frac{1}{2}$ in. Pedicellate spikelet not much smaller, male, on a very short flat pedicel.-Meoschium lodiculare, Nees, Pl. Meyen. 195, and M. Meyenianum, Nees, 1.c. 197.

Common in the island, Hinds, Champion, and others. Also in the Indian Archipelago.

\section{SPODIOPOGON, Trin.}

Spikelets in pairs, 1 sessile, the other pedicellate, in simple, branched, or paniculate spikes, both 2 -flowered, the lower flower male; the rhachis angular and articulate, at least at the top. Outer glumes stiff, the lowest convex, the second keeled. Flowering glumes and palea very thin and transparent, the glume of the fertile flower with a twisted awn.

A small genus dispersed over the tropical and subtropical regions both of the New and the old World.

1. S. obliquivalvis, Nees, $P l$. Meyen. 185. Stems tufted or creeping and rooting at the base, ascending or erect, 1 to $2 \mathrm{ft}$. high, with tufts of hairs at the nodes. Leaves acute, more or less hairy. Spikes 1 to $1 \frac{1}{2} \mathrm{in}$. long, divided into 2 erect branches, the rhachis and pedicels more or less ciliate. Spikelets about 2 lines long, the outer glume wrinkled on the back, the awn of the fertile flower slender, 4 to 6 lines long. Pedicel of the upper spikelet and rhachis, both angular, separated by an obtuse sinus giving the appearance of a little circular perforation.-Andropogon malacophyllus, Steud. Syn. Gram. 372.

Hongkong, Hance. Common in India, from Ceylon and the Peninsula to the Archipelago, and northward to Amoy.

Var. villosus. Sheaths of the leaves with long spreading hairs.-Andropogon patentivillosus, Steud. Syn. Gram. 373.

Hongkong, Wright. Also on the continent of S. China.

30. SPOROBOLUS, Br.

Spikelets small, 1-flowered, awnless, in a loose spreading or rarely spikelike panicle. Outer glumes 2 , keeled, one or both usually shorter and never longer than the acute flowering glume. Palea nearly as long, usually 2-nerved. Grain free, short, deciduous, the seed separating from the thin pericarp.

A considerable tropical and subtropical genus, both in the New and the Old World, differing but little from Vilfa and Agrostis.

1. S. indicus, Br.; Kunth, Enum. i. 211. Stems tufted at the base, erect, simple, 1 to $2 \mathrm{ft}$. high. Leaves narrow, pointed, convolute when dry. Panicle contracted, linear, 6 to $8 \mathrm{in}$. long, interrupted at the base, the short more or less compound branches all erect. Spikelets nearly 1 line long, pointed, shining. Outer glumes usually unequal, obtuse or the second acute, about half as long as the flowering glume. Seed brown, obovate-truncate.

Common on roadsides, Hance and others. Widely diffused over the warmer regions of the globe.

\section{POLYPOGON, Desf.}

Spikelets small, 1-flowered, in a dense spike-like or slightly spreading panicle. Outer glumes 2, narrow, keeled, ending in a fine straight awn, some- 
times very short. Flowering glume shorter, with or without an awn. Palea smaller and thin. Grain oblong or linear.

A small genus very widely distributed over the globe.

1. P. littoralis, Sm.; Kunth, Enum. i. 233. Stems procumbent at the base, ascending to a foot or more. Leaves flat, rather flaccid. Panicle contracted into a dense cylindrical or branched spike, 1 to $2 \mathrm{in.} \mathrm{long,} \mathrm{of} \mathrm{a} \mathrm{pale} \mathrm{or}$ purplish green. Spikelets about 1 line long. Outer glumes notched at the top, with an awn usually reduced to a very short point, and seldom as long as the glume. Flowering glume awnless.

Hongkong, Harland. Usually a seacoast plant, scattered here and there on the shores of the Atlantic and Mediterranean, but also found in Affghanistan, in various parts of N. India, and in Japan.

\section{ARISTIDA, Linn.}

Spikelets 1-flowered, cylindrical, pedicellate in a raceme or panicle. Outer empty glumes 2, pointed or shortly awned. Flowering glume convolute with 3 terminal awns. Palea minute. Grain cylindrical, enclosed in the flowering glume.

A large genus, widely distributed over the warmer regions of the New and the Old World, chiefly in dry or sterile localities.

1. A. chinensis, Munro in Proc. Amer. Acad. iv. 363. Stems slender, erect, 1 to $2 \mathrm{ft}$. high, with fine convolute leaves. Panicle loose, $8 \mathrm{in}$. to $1 \mathrm{ft}$. long; the long slender branches solitary or in pairs, with a tuft of hairs in their axils. Spikelets not numerous, slender, 4 or 5 lines long without the awns, which are $\frac{1}{2}$ in. more. Outer glumes very pointed, the lowest longer than the second. Flowering glume neither twisted nor articulate at the top, the awns not plumose.

Hongkong, Hance, Harland, Wright; and in other islands of the Canton river, but not known out of S. China.

\section{ARUINDO, Linn.}

Spikelets 2- or more-flowered, with long silky hairs on the axis and flowering glumes, all pedicellate in a large much branched panicle. Glumes thin, keeled, distichous and distant, 2 outer ones empty, the flowering ones as long or rather longer, pointed or shortly awned, the terminal one small, empty or rudimental. Palea small.-Tall reeds.

A small genus, widely distributed over the warmer regions of the Old World.

1. A. madagascariensis, Kunth, Enum. i. 247. A stout handsome perennial, $6 \mathrm{ft}$. high or more. Leaves rather narrow. Panicle $1 \frac{1}{2} \mathrm{ft}$. long, with very numerous spikelets about 3 lines long. Flowering glumes usually 4 or 5 , about $1 \frac{1}{2}$ lines long, ciliate with long white hairs on the inner edges, the fine awns seldom so long as themselves.-A. Reynaudiana, Kunth; Steud. Syn. Gram. 194.

Common in the island, Champion and others. In northern and eastern India, in the Archipelago, the Philippines and China, and in tropical Africa.

\section{PHRAGMITES, Trin.}

Characters and habit of Arundo, except that the lowest flower is usually male, and that the silky hairs are all on the axis not on the glumes, which are often more herbaceous than in Arundo. 
A small genus (or subgenus of Arundo), with a still wider geographical range, extending into the temperate regions both of the New and the Old World.

1. P. Roxburghii, Kunth; Nees, Pl. Meyen. 173. Stem stout and erect, 8 to $12 \mathrm{ft}$. high, covered with the leaf-sheaths. Leaves flat, 1 to $1 \frac{1}{2}$ in. broad. Panicle erect or slightly drooping, often $1 \frac{1}{2} \mathrm{ft}$. long or more. Spikelets numerous and crowded, with 3 to 5 distant flowers. Lowest glume about 2 lines long, the next 3 or 4 lines, the third or lowest flowering glume 6 lines long, tapering into a long point but not awned, and usually male, the others rather smaller and more pointed, the terminal pedicel small, with a minute rudimentary glume.

Hongkong, Hance. Widely dispersed over India, from Ceylon and the Peninsula to the Archipelago, and northward to the Himalaya, China, the Philippines, and Japan.

\section{MICROCHLOA; Br.}

Spikelets 1-flowered, awnless, singly sessile on one side of a slender simple spike. Outer glumes 2, nearly equal; the lowest with a double nerve, the second keeled. Flowering glume and palea small, very thin and transparent.

A genus of very few tropical or subtropical species, dispersed over the New and the Old World. Although placed by most botanists next to Cynodon among Chloridece, it appears to me to have unore affinity with the Andropogonea.

1. M. setacea, Br.; Kunth, Enum. i. 258. Stems slender, tufted, from 3 or 4 to 8 or 9 in. high. Leaves fine, convolute when dry, acute. Spike 1 to $3 \mathrm{in}$. long, very slender and curved. Spikelets rather more than 1 line long, the outer glumes very pointed. Flowering glume hairy outside, but very transparent.

Hongkong, Wright. Scattered over the tropical and subtropical regions of both the New and the Old World.

\section{CYNODON, Pers.}

Spikelets 1-flowered, awnless, singly sessile in 2 rows on one side of the slender spike-like almost digitate branches of a simple panicle. Outer empty glumes 2, keeled. Flowering glume thinner and broader. Palea narrower, folded, with a small bristle at its base, being the prolongation of the axis, and sometimes bearing a rudimentary glume.

A genus of very few species, all perhaps varieties of a single one.

1. C. dactylon, Pers.; Kunth, Enum. i. 259. Stems prostrate, often creeping and rooting to a great extent, the flowering branches shortly ascending. Leaves short, of a glaucous green. Spikes 3 to 5 , each 1 to $1 \frac{1}{2}$ in. long. Spikelets less than 1 line long; the outer glumes nearly equal, open, narrow, pointed. Flowering glume rather longer and much broader, becoming hardened when in fruit.

Hongkong, Hance. A common and troublesome weed in all hot countries, extending also into some of the more temperate regions of the northern hemisphere.

\section{DACTYLOCTENIUIM, Willd.}

Spikelets 2- or more-flowered, very flat and closely imbricated along one side of the spike-like digitate branches of a simple panicle. Glumes spreading, keeled and compressed, transparent but stiff, the lowest smaller, the 
second shortly awned, the flowering ones gradually smaller and less pointed, the terminal one usually barren or rudimentary. Palea smaller, folded.

A single species, perhaps not sufficiently distinct as a genus from Eleusine.

1. D. agyptiacum, Willd.; Kunth, Enum. i. 261. Stems tufted or creeping and rooting or shortly ascending, or rarely $1 \mathrm{ft}$. high or more. Leaves flat, ciliate, flaccid, with long points. Spikes usually 3 to 5,1 to $1 \frac{1}{2}^{\circ}$ in. long; the angular rhachis very prominent on the upper or inner side, and the spikelets regularly and very closely packed at right angles to it on the opposite side; the largest glumes about $1 \frac{1}{2}$ lines long, their short fine stiff points very prominent.

Hongkong, Hance. A very common weed in all warm countries.

\section{FLEUSINE, Gærtn.}

Spikelets 2- or more-flowered, awnless, sessile in 2 rows along one side of the spike-like almost digitate branches of a simple panicle. Glumes keeled, usually obtuse, the 2 outer empty ones unequal and shorter than the flowering ones. Paleas rather smaller, folded, the axis usually slightly continued beyond the last one. Seed transversely wrinkled.

A small, widely spread, tropical genus.

1. E. indica, Gartn.; Kunth, Enum. i. 272. A coarse erect tufted grass, 1 to $2 \mathrm{ft}$. high. Leaves narrow, the sheaths flattened and distichous, ciliate with a few long hairs. Spikes 5 to 7, 2 to 3 in. long, digitate, with usually one inserted rather lower down. Rhachis prominent on the upper or inner side; the spikelets loosely imbricate on the opposite side. Each spikelet $1 \frac{1}{2}$ to 2 lines long, containing 3 to 5 flowers. Glumes obtuse, the lowest small and 1-nerved, the second empty one and the lower flowering ones usually 3-nerved.

Hongkong, Hance. A common weed in tropical countries.

\section{CHLORIS, Linn.}

Spikelets with 1 or rarely 2 fertile flowers, and 1 or more empty or rudimentary glumes above it, singly sessile on one side of the spike-like digitate branches of a simple panicle. Glumes keeled, 2 outer empty ones pointed or shortly awned, the others usually awned or the upper empty ones awnless. Grain free.
A tropical or subtropical genus, common to the New and the Old World.

1. C. barbata, Sw. ; Kunth, Enum. i. 264. Stems creeping at the base and branched, in large tufts, ascending to 1 or $2 \mathrm{ft}$. Leaves narrow, very pointed, glaucous, the lower sheaths much flattened and distichous. Spikes 5 to 10 , closely digitate, $1 \frac{1}{2}$ to $2 \mathrm{in}$. long. Outer glumes very unequal, persistent, pointed, the longest about 1 line. Flowering glume about as long, ciliate with long hairs on the inner edges, notched at the top with a fine straight awn of about 2 lines. Upper empty glumes usually 2 , truncate, with short awns.

On the seabeach at Saywan, Wilford. Very common in pastures in India as in most hot countries. 


\section{LEPTOCHLOA, Beauv.}

Spikelets 2- or more-flowered, awnless, sessile or very shortly pedicellate along one side of the slender or spike-like branches of a long paricle. Glumes keeled, pointed or obtuse; the 2 outer ones empty; the axis ending in a short pedicel above the last flower, bearing sometimes a rudimentary glume.

A small genus, chiefly tropical or subtropical, both in the New and the Old World.

1. L. chinensis, Nees; Steud. Syn. Gram. 209. Stems branched, creeping and rooting at the base, ascending to 2 or $3 \mathrm{ft}$., glabrous and slender. Leaves narrow, pointed, flaccid. Panicle slender and elegant, $6 \mathrm{in}$. to $1 \mathrm{ft}$. long, the branches almost filiform, 2 to $4 \mathrm{in}$. long, alternate or clustered, and turned all to one side. Spikelets not quite sessile, usually distant, narrow, 1 to 2 lines long, 4- to 6 -flowered. Outer empty glumes rather unequal, pointed, flowering ones broader and obtuse.-I. tenerrima, Rœm. and Schult.; Kunth, Enum. i. 270.

Hongkong, Hance. Frequent in wet places in India, from the Peninsula to Burmah, and northward to Silhet, S. China, and Amoy.

\section{AVENA, Linn.}

Spikelets several-flowered (usually 3 - to 5 -flowered), in a loose panicle. Giumes scarious, at least at the top, 2 outer empty ones lanceolate, tapering to a point ; the flowering ones smaller, 2-cleft at the top, with a long twisted awn on the back of the glume; the terminal glume often small and empty or rudimentary. Axis of the spikelet hairy under the flowering glumes.

A considerable genus, widely spread over the temperate and colder regions of both hemispheres, but in the tropics only in the higher mountains, or as introduced weeds.

1. A. fatua, Linn.; Kunth, Enum. i. 302. An erect, glabrous annual, 2 to $3 \mathrm{ft}$. high, with a loose panicle of large spikelets hanging from filiform unequal pedicels, arranged in alternate branches along the main axis. Outer glumes near $\frac{3}{4}$ in. long. Flowering glumes 2 or 3 , scarcely so long, of a firm texture at the base, and covered outside with long brown hairs. Awn full twice as long as the spikelet, twisted at the base, abruptly bent about the middle.

In waste, rubbishy places, Hance. A common weed of cultivation in all corn countries, of doubtful origin, but probably a native of the east Mediterranean region.

\section{COELACHNE, Br.}

Spikelets 2-flowered, awnless, small and numerous, in a contracted panicle; the upper flower unisexual, usually female, the lower hermaphrodite. Glumes very concave and obtuse, the 2 outer empty ones smaller than the flowering ones. Paleas rather smaller, 2-nerved. Axis of the panicle not hairy.

A genus limited to a single species.

1. C. pulchella, Br. Prod. 187 ; Endl. Iconogr. t. 2. An annual, usually about 2 in. high, but sometimes drawn up to 3 or 4 times that height. Leaves light-green, narrow, seldom above 1 in. long. Panicle contracted into a linear interrupted spike of 2 to 3 in., or the lower branches slightly spreading. Spikelets about 1 line long.-Panicum (Isachne) simpliciusculum, W. and Arn, in Steud. Syn. Gram. 96. 
In a ditch at Little Hongkong, Wilford. Also in Ceylon, the Indian Peninsula, Nepal, Tavoy, and Australia.

\section{ERAGROSTIS, Beauv.}

Spikelets several-flowered, flattened, awnless, numerous in a spreading or compact panicle. Glumes keeled, very regularly distichous, obtuse or pointed, but not awned, the 2 outer empty ones not longer, and often one or both smaller than the others. Paleas prominently 2-ribbed, often persistent after the glumes have fallen. Axis of the spikelet not hairy, and very rarely articulate.

A considerable genus, or subgenus of $P o a$, widely diffused over the tropical and subtropical regions of the globe, a few species spreading into more temperate climates, but neither so far north or south, nor to so great elevations as Poa proper. The latter genus differs chiefly in the less flattened spikelets, with fewer flowers, the axis always articulate, and often (but not always) bearing a tuft of hairs under each flower. One species extends to the adjoining Chinese continent, but has not yet been found in Hongkong.

Spikelets not 1 line long, very numerous in a narrow but spreading panicle. Axis of the spikelet articulate.

Paleas glabrous .... . . . . . . . . . 1. E. tenella.

Paleas ciliate with long spreading hairs . . . . . . . 2. E. plumosa.

Spikelets 2 to 4 lines long, the axis not articulate.

Spikelets all pedicellate.

Spikelets linear, very loose, not $\frac{1}{2}$ line broad

Spikelets ovate or ovate-oblong, 1t lines broad, very closely imbricate

Spikelets linear-oblong, imbricate, $\frac{3}{4}$ to 1 line broad.

Leaves very hairy.

Leaves glabrous.

Spikelets loosely pedicellate, $\frac{s}{4}$ line broad. Flowering glumes obtuse

Spikelets shortly pedicellate, 1 line broad. Flowering glumes tapering almost to a point

spikelets sessile or nearly so.

Spikelets solitary or in distinct clusters along the branches of a narrow or spreading panicle

Spikelets crowded in a short spike-like panicle . . . . . .

8. E. pilosa.

4. E. unioloides.

5. E. pilosissima.

6. E. orientalis.

7. E. Brownei.

8. E. zeylanica.

9. E. geniculata.

1. E. tenella, Beauv. An erect annual, 1 to $2 \mathrm{ft}$. high. Leaves long and narrow. Panicle narrow and slender, occupying the greater part of the plant, with very numerous short capillary branches. Spikelets shortly pedicellate, ovate, about $\frac{1}{2}$ line long, usually 3 - or 4 -flowered; the axis articulate as in Poa. Flowering glumes obtuse, spreading. Palea not ciliate.-Poa tenella, Linn. Spec. Pl. 101 (except the reference to Plukenet). E. tenuissima, Schrad.; Nees, Fl. Afr. Aust. 410, with the synonyms there given. E. aurea, Steud. Syn. Gram. 267. Sporobolus verticillatus, Nees in Kew Journ. Bot. ii. 101.

Hongkong, Hance; also on the adjacent continent, in northern and eastern India, in the Philippines, and northward to Amoy. Nees appears to have mistaken Cuming's Philippine Island specimen, n. 545, for a Sporobolus. Our specimens of that n. are certainly the $E$. tenella, but the upper flowers of each spikelet fall readily off, leaving very often only a single one with the outer glumes, so as to appear 1-flowered.

2. E. plumosa, Link; Steud. Syn. Gram. 266. Stems slender, tufted or decumbent at the base, ascending to 6 in. or $1 \mathrm{ft}$. Leaves very pointed, 
narrow, but flat. Panicle oblong, usually 2 or $3 \mathrm{in}$., but sometimes twice as long, with numerous short slender branches. Spikelets all pedicellate, usually drooping, ovate, about 1 line long, 4- to 6-flowered, the axis more or less articulate. Glumes rather pointed, especially the lower ones. Paleas ciliate on the ribs, with ratherr long spreading hairs, often persistent in the lower part of the spikelet.-Poa plumosa, Retz; Kunth, Enum. i. 338. Poa umabilis, Linn. Spec. 100 (and Herbarium).

Hongkong, Hance, Harland, Wright. Common in tropical Asia.

3. E. pilosa, Beauv.; Steud. Syn. Gram. 263. A tufted erect or ascending annual, 1 to near $2 \mathrm{ft}$. high. Leaves narrow. Panicles $6 \mathrm{in}$. to $1 \mathrm{ft}$. long, narrow at first, spreading when in fruit, compound, with numerous filiform branches alternate or clustered, and generally with a few long hairs in their axils. Spikelets linear, about 2 lines long, with 6 to 10 flowers loosely alternate on a zigzag inarticulate axis. Glumes thin, keeled, rather pointed, the 2 outer empty ones unequal, but both smaller than the flowering ones. Paleas often persistent, slightly ciliate on the ribs.-Poa pilosa, Linn.; Kunth, Enum. i. 329. P. verticillata, Cav.; Kunth, 1. c.

Hongkong, Hance. A common weed in southern Europe, northern Africa, central Asia, and some parts of north and south America.

4. F. unioloides, Nees; Steud. Syn. Gram. 264. Stems tufted and erect, 6 in. to $1 \mathrm{ft}$. high or more. Leaves rather narrow. Panicle 3 to 6 in. long, more or less spreading; the branches slender, but short and little divided. Spikelets ovate or ovate-lanceolate, very flat, with 16 to 20 or even more flowering glumes very regularly and closely distichous. Outer empty glumes narrower, but fully as long and more pointed.-E. amabilis, W. and Arn.; Nees, Pl. Meyen. 205. Poa unioloides, Retz; Kunth, Enum. i. 335.

Hongkong, Hance, Harland. Common in dry situations in India, from Ceylon and the Peninsula to the Archipelago, and northward to the Philippines and S. China.

5. E. pilosissima, Link; Steud. Syn. Gram. 280. Very near the $E$. orientalis, but the panicle is more spreading, the pedicels longer and more slender, and the leaves flatter, and covered as well as their sheaths with long soft hairs.-Poa pilosissima, Kunth, Enum. i. 330. Eragr. Millettii, Nees, Pl. Meyen. 206.

Hongkong, Harland. Also on the adjacent continent, but not known for certain ont of S. China.

6. E. orientalis, Trin.; Nees, $P l$. Meyen. 205. Stems rather slender, erect, $\frac{1}{2}$ to $1 \frac{1}{2} \mathrm{ft}$. high. Leaves very narrow, glabrous, convolute when dry, rather short. Panicle spreading, 3 or 4 in. long, but little branched. Spikelets pedicellate, oblong-linear, 2 to 3 lines long, about $\frac{3}{4}$ line broad, with 8 to 20 or even more flowers, not very closely imbricated, on a zigzag continuous axis. Glumes firm, the flowering ones very obtuse, the outer empty ones rather shorter and scarcely more pointed.

Hongkong, Wright, Hance. Also on the adjacent continent and in northern India. It is very nearly allied to the $E$. poceoides, Beauv, a common species in southern Europe and central Asia.

7. E. Brownei, Nees; Steud. Syn. Gram. 279. Closely allied to the $E$. orientalis, and perhaps a variety. The panicle is not so loose, the pedicels shorter, the spikelets flatter and broader, usually about 3 lines long and 1 line 
broad, the flowering glumes taper almost to a point, and the seeds are much narrower.-Poa polymorpha, Br.; Kunth, Enum. i. 333.

Very common throughout the island, Wilford, Hance, and others. Widely spread over tropical Asia and Australia.

8. E. zeylanica, Nees in Pl. Meyen. 204. This species is again very nearly allied to the two last, and has the same narrow leaves, but it appears to be more rigid and probably perennial. The panicle is stiff and less spreading, with few branches, and sometimes reduced to an interrupted spike. Spikelets as in $E$. Brownei, about 1 line broad, with almost pointed flowering glumes, but sessile or nearly so, in clusters of 2 or 3 , or sometimes solitary along the branches of the panicle.

Hongkong, with the last, Hance; at Little Hongkong and Aberdeen, Wilford. Widely spread over India and the Archipelago, probably in drier and hotter localities than the $\boldsymbol{E}$. Brownei.

9. ‥ geniculata, Nees in Pl. Meyen. 203. Stems rather stiff, branching or decumbent at the base, ascending to 6 or 8 in. or rarely $1 \mathrm{ft}$. Leaves narrow and very pointed. Spikelets mostly sessile, in a dense spike-like panicle of 1 to $1 \frac{1}{2}$ in., the short branches usually hairy in the axils. Each spikelet oblong, very flat, 6 - to 10 -flowered, about 3 lines long and near 1 line broad, much like those of $E$. zeylanica. Glumes all pointed.

Hongkong, Wright; Cum Syng Moon, Meyen; Amoy, Hance. Not known out of S. China.

\section{LOPHATHERUM, Brongn.}

Spikelets 1-flowered, sessile on alternate sides of the simple branches of a panicle. Glumes keeled, green, with scarious edges, 2 outer empty ones obtuse or slightly pointed, the third or flowering one similar, but with a short stiff awn, and several smaller empty ones with short awns terminating the axis. Palea transparent, folded, with 2 prominent green ribs. Grain free.

A genus limited probably to a single species.

1. I. gracile, Brongn.; Kunth, Enum. i. 391. Stems ascending to 2 or $3 \mathrm{ft}$. Leaves $\frac{1}{2}$ to 1 in. broad, very pointed, and often stalked above the sheath as in Bambusa. Panicle consisting of a few distant stiff branches 3 or 4 in. long. Spikelets distant, lanceolate, 4 to 6 lines long, the short awns of the terminal empty glumes forming a little tuft. Glumes often ciliate on the edges. Awns of the flowering one always shorter than the glume itself.L. Lehmanni, Nees in Steud. Syn. Gram. 300.

Hongkong, Wright, Hance. Dispersed over India, from Ceylon and the Peninsula to the Archipelago, and northward to the Himalaya, Philippines, and S. China.

\section{ARUNDINARIA, Rich.}

Habit of a Bambusa. Spikelets several-flowered, awnless, compressed, not clustered, in simple racemes or branched panicles. Glumes stiff, distichous, often distant, concave, smooth or ribbed, pointed, the 2 outer empty ones smaller and unequal, 1 or 2 upper ones empty or rudimentary. Stamens and styles 3 .

A small tropical genus, common to the New and the Old World. 
1. A. Wightii, Nees; Rupr. Bamb. 26. Flowering stems not above 3 lines diameter, sometimes shortly spinous at the nodes. Upper leaves broadly lanceolate, about $\frac{1}{2}$ in. broad, the midrib and principal veins prominent underneath. Panicles short, loose, and more slender than in most Bamboos. Spikelets about $\frac{1}{2}$ in. long, all pedictllate, 3 - or 4-flowered, the rhachis shortly silky-hairy. Glumes ribbed, the flowering ones 3 or 4 lines long, the outer empty ones rather shorter.

Hongkong, Wright. In the Indian Peninsula and Silhet. Inserted on the authority of Col. Munro. I have not seen Chinese specimens, and can only describe it from imperfect Indiau ones.

\section{BAMBUSA, Linn.}

Spikelets several-flowered, awnless, sessile, and clustered along the branches of a panicle which is also usually clustered. Lower flowers of each spikelet usually male, and sometimes the uppermost also. Glumes concave, stiff, the 2 or 3 outer empty ones smaller. Paleas narrow, about as long as the glumes, enclosing the flower. Stamens 6. Stems shrubby or arborescent. Leaves broad, often stalked above their sheath.

A tropical genus, common to the New and the Old World. Although called shrubby or arborescent from their great height and hard branching stems, the Bamboos bear little resemblance to ordinary trees, and in many species the stems attain their full height of 60 or 70 feet in the course of a few weeks.

Spikelets dense, ovate or ovate-oblong. Glumes very broad . . . . 1. B. verticillata. Spikelets loose, lanceulate or linear. Glumes narrow.

Glumes rather obtuse, $\frac{1}{2}$ in. long. . . . . . . . . 2. B. Tulda.

Glumes very pointed, 4 or 5 lines long. . . . . . . . 3. B. Arundo.

1. B. verticillata, Willd.; Kunth, Enum. i. 432. Stems 6 or $7 \mathrm{ft}$. high or more. Leaves 2 or 3 in. broad, the midrib prominent. Inflorescence simple or slightly branched, often $2 \mathrm{ft}$. long or more, the rhachis pubescent, the spikelets in clusters of 3 to 6 , at regular intervals of 1 to $1 \frac{1}{2} \mathrm{in}$. Each spikelet ovate or ovate-oblong, slightly compressed, $\frac{3}{4}$ in. long. Glumes very broad, stiff and shining, shortly ciliate and often pubescent on the edges, the lowest flower usually male, the others all fertile. Palea hairy. Style very long, with short stigmatic lobes.

Hongkong, Hance. Possibly planted by the Chinese, as it is in other parts of China, in eastern India, and the Archipelago.

2. B. Tulda, Roxb. Fl. Ind. ii. 193. A very tall species; the stems according to Roxburgh attaining 20 to $70 \mathrm{ft}$., and 6 to $12 \mathrm{in}$. in diameter, in the course of about thirty days. Leaves $\frac{1}{2}$ to 1 in. broad; the midrib pubescent and prominent underneath. Flowering shoots leafless, forming one long waving compound panicle, with deciduous sheathing bracts at the ramifications. Spikelets solitary or 2 or 3 together along the last ramifications, 1 in. long or more, with 4 to 8 alternate distant flowers, often all hermaphrodite. Outer empty glumes very short, flowering ones about $\frac{1}{2}$ in. long, lanceolate, mostly obtuse. Ovary obovate, hairy. Style very short, with 3 plumose stigmas.

Hongkong, Hance. Also near Canton, common in Bengal and other parts of India.

3. B. Arundo, Klein; Rupr. Bamb. 53. Stems tall. Leaves broad. 
Panicle large, with numerous clustered branches, and usually spinous at the nodes. Spikelets solitary or 2 or 3 together, about 1 in. long, sessile, or on short pedicels covered with alternate glume-like bracts. Flowers 4 to 8 , almost all male in the spikelets examined. Flowering glumes 4 or 5 lines long, narrow, very pointed. Style semi-bifid.

Hongkong, Hance. Also near Canton and dispersed over various parts of India. The Chinese specimens I have seen are very imperfect.

\section{SCHIZOSTACHYUM, Nees.}

Habit of Bambusa. Spikelets 1-flowered, in distant irregular clusters, arranged in interrupted spikes which are often clustered, with imbricate glumelike bracts at the base of each cluster. Glumes 2, 3, or more; the outer ones short; the inner ones longer, more pointed, and convolute; the uppermost one alone flowering. Palea none. Stamens 6. Style 3-lobed.

A small tropical Asiatic genus with perhaps one Brazilian species.

1. S. dumetorum, Munro in Seem. Bot. Her. 424. Stems 4 to $6 \mathrm{ft}$. high or more. Leaves lanceolate, scabrous, very pointed, $\frac{1}{2}$ to $1 \mathrm{in}$. broad, on very short petioles. Flowering spikes simple and terminal or clustered, 3 to 6 in. long. Spikelets $\frac{1}{2}$ to $\frac{3}{4}$ in. long, slender, terete, and very pointed, either sessile or on short branching pedicels enveloped in glume-like bracts. Flowering glume usually full $\frac{1}{2} \mathrm{in}$. long and very pointed, closely rolled round the stamens and ovary. Outer glumes several, gradually shorter and less pointed. Style nearly as long as the glume, triangular, with 3 short stigmatic lobes.-Bambusa dumetorum, Hance in Walp. Ann. iii. 781.

In hedges and woods, Hance; in a ravine of Mount Davis, Wilford. Not known from elsewhere.

\section{CLass III. CRYPTOGAMS.}

No real flowers, that is, neither stamens, nor pistils, nor true seeds; the fructification consisting of minute, often highly microscopic granules called spores, variously enclosed in small, often minute or microscopic capsules or spore-cases, which are either sessile or stalked, solitary or crowded in masses, superficial or imbedded in the substance of the plant.

The few Hongkong Cryptogams included in the present volume have all of them roots and stems or rootstocks very similar in structure to some of the Monocotyledons, and some have leaves nearly the same or reduced to small scales, but in others they are replaced by foliaceous expansions of the fruiting branches, bearing the fructification on their surface or edges. These foliaceous branches are distinguished by the name of fronds. In the remaining Orders of Cryptogams, called Cellular, there is no distinct stem, or the stem does not contain any fibres or vascular tissue. They are comprised in the five Orders: Musci, Hepatica, Lichenes, Fungi, and Alga. They have as yet been little attended to by the explorers of the island of Hongkong, and are altogether beyond the scope of the present Flora.

CXXIV. Lycopodiaces. Capsules in the axils of leaves or of small scale-like bracts.

CXXV. Frlices. Spore-cases clustered on the backs or margins of fronds, either similar to the barren ones or contracted and spike-like. 


\section{ORDER CXXIV. LYCOPODIACEAE.}

Leaves distinct, radical or alternate, usually small or reduced to minute scales. Spores enclosed in capsules, sessile or nearly so, either at the base or in the axils of the leaves or bracts, or forming a terminal spike interspersed with bracts.

An Order which, besides the two following, comprises but very few genera and species, dispersed over various parts of the globe.

Capsules in the axils of crowded leaves or in terminal spikes . . . . 1. Lycopodium. Capsules distant, on minute bifid scale-like bracts . . . . . . 2. Psilotum.

\section{IXCOPODIUM, Linn.}

Capsules sessile in the axils of the upper stem-leaves or of bracts usually thinner and broader than the stem-leaves and forming a terminal spike; the capsules either all opening transversely in 2 valves and filled with minute powdery granules or spores, or some of them 3- or 4-valved, and containing a very few much larger granules.-Perennial herbs, usually much branched and creeping, crowded with small moss-like entire or minutely serrated leaves.

A large genus widely spread over every part of the globe, and readily divisible into two sections, the true Lycopodia, to which belongs the first of the following species, with all the capsules filled with minute powdery granules, and the Selaginellas, comprising the four remaining Hongkong species, which have capsules of both kinds.

Ieaves subulate, scattered all round the elongated much branched stem.

Spikes terminal, nodding

Leaves distichous, in two rows, with two inner longitudinal rows of smaller leaves on one side.

Stems very short, thick and erect, with short crowded dichotomous branches erect or curved inwards when dry

1. L. cernunum.

Rhizomes or stems decumbent or creeping.

Leafy branches dichotomous throughout. Inner leaves parallel and closely appressed to the rhachis.

Leafy branches mostly pinnate. Inner leaves curved over the rhachis.

Leafy stems proenmbent or trailing and rooting . . . . .

Leafy stems erect from a ereeping rhizome, simple at the base, (the branching part about 6 in. long) . . . . . . 5. L. flabellatum.

1. I. cernuum, Linn.; Spring, Monogr. Lycop. i. 79, and ii. 37. Stems hard, rising to $2 \mathrm{ft}$., or when very luxuriant to 5 or $6 \mathrm{ft}$. in height, with numerous spreading flexuose repeatedly forked branches. Leaves fine, subulate, spreading all round the stem, incurved, 1 to 2 lines long. Spikes terminal, nodding, sessile above the last leaves, 2 to 3 lines long. Bracts ovatelanceolate, ciliate, imbricate in 8 rows, longer than the capsules. $-L$. amentigerum, Goldm. in Pl. Meyen. 468.

In woods, Champion and others. Common throughout the tropies, in the New as well as the Old World.

2. I. involvens, $S w$. Stems very short and thick, when old erect and simple, attaining 2 in. or rather more in height, with numerous dichotomous leafy branches 1 to $3 \mathrm{in}$. long, erect or turned inwards when dry, spreading with moisture. Leaves in 4 rows; the outer distichous ones about 1 line long, obliquely ovate-falcate, acute with a short fine point; the midrib ex- 
centric and indented on the back; the inner leaves rather smaller, with more prominent points. Spikes very short; the bracts nearly similar to the inner stem-leaves.-Selaginella involvens, Spring, Monogr. Lycop. ii. 63.

Hongkong, Champion, Wright. In the Indian Peninsula, the Archipelago, the Philippines, China, and Japan.

3. L. atroviride, Wall.; Hook. Gen. Fil. t. 117 B. Stems trailing and rooting among the leafy branches, dichotomous from the first or the primary branches irregularly pinnate. Leaves usually dark-green and shining, in four rows; the outer distichous ones very regularly spreading, $1 \frac{1}{2}$ to 3 lines long, obliquely oblong-falcate, scarcely pointed, often minutely punctate on the upper side, pale underneath, often but not always with a lateral nerve on each side of the midrib. Inner leaves from $\frac{1}{5}$ to $\frac{1}{3}$ as long, fine-pointed, semicordate at the base, closely appressed to the rhachis and parallel or slightly diverging: Spikes $\frac{1}{3}$ to 1 in. long; the bracts ovate-lanceolate, fine-pointed, imbricate in 4 rows. - Selaginella atroviridis, Spring, Monogr. Lycop. ii. 124, and S. monospora, Spring. 1. c. 135.

In ravines, Harland, Urquhart, Wright, Wilford. In India from Ceylon and the Peninsula to the Archipelago, and northward to the Himalaya, Foochowfoo, and Chusan. The specimen of Hance's, referred by J. Sm. (in Seem. Bot. Her. 431) to Selaginella concinna, Spring, appears to me rather to belong to the present species.

4. I. caudatum, Desv. Stems trailing to a considerable length and rooting among the leafy branches which are loosely pinnate from the base. Leaves in 4 rows, the outer distichous ones obliquely ovate or oval-oblong, 1 to 2 lines long; inner ones $\frac{1}{4}$ to $\frac{2}{3}$ as long, semicordate at the base, falcate, fine-pointed and converging over the rhachis. Spikes 3 to 9 lines long; the bracts keeled, fine-pointed, imbricate in 4 rows.-Selaginella caudata, Spring, Monogr. Lycop. ii. 139. S. argentea, Spring?; Sm. in Seem. Bot. Her. 431.

Abundant in ravines, Urquhart, Wilford, Wright, frequent in India and the Archipelago. This species appears to me to include a considerable number of forms described by Spring as distinct species.

5. L. flabellatum, Linn. Rhizome creeping and rooting to a great extent, emitting erect leafy branches, simple for 2 to 4 in., then expanding into an ovate-triangular form about 6 in. long; the branches about twice pinnate. Foliage nearly of $L$. caudatum, or the outer leaves more distinctly falcate. Spikes precisely as in L. caudatum.-Selaginella flabellifera, Spring, Monogr. Lycop. ii. 174? S. argentea, Spring, 1.c. 154?

Hongkong, Marland, Wright. In the Philippines, the Indian Archipelago, and in tropical America. Sir W. Hooker considers this to be the true L. fabellatum, the specimens agree well with Spring's character of $L$. argentea, and probably S. caulescens, Wall., and several others are mere forms of it. The species of the Selaginella section have been immensely multiplied upon characters extremely difficult to appreciate, especially in dried specimens, and apparently very variable in nature.

\section{PSILOTUM, Sw.}

Stems dichotomous, with few very minute distant scale-like leaves. Capsules distant, sessile upon minute bifid bracts, 3-lobed, 3-celled, opening loculicidally in 3 valves, containing numerous minute spores.

A small tropical and subtropical genus, common to the New and the Old World.

1. P. triquetrum, Siv.; Hook. Gen. Fil. i. t. 87; Fil. Exot. t. 63. 
Rhizome short, thick, and intricately branched. Stems erect (or pendulous when the plant is epiphytal), from 3 or $4 \mathrm{in}$. to a ft. high, repeatedly dichotomous, the fertile branches 3 -angled, the barren ones flattened. Leaves few, distant, very minute, scale-like, subulate, and entire, those which subtend the fruits also small and distant, but forked, bearing each at the base of their fork a single globular capsule of about 1 line diameter.

Hongkong, Dill; on a rock in a ravine of Mount Gough, Wilford. In most tropical or subtropical moist regions, both in the New and the Old World, although apparently rare in Africa.

\section{ORDER CXXV. FILICES.}

No true leaves, but the fruiting branches expanded into leaf-like fronds. Spores enclosed in minute capsules or spore-cases, sessile or pedicellate, and collected together in clusters or patches called sori, on the under surface or on the margin of fronds, which are either similar to the barren ones or more contracted, sometimes resembling simple or branched spikes; the sori either naked or accompanied by an involucre or indusium, either cup-shaped or covering the sorus when young, and opening on the side or at the top, or in 2 valves.-Main stem usually perennial, either erect and woody, or more frequently reduced to a short stock, or to a creeping rhizome, very rarely annual. Fronds radical or alternate, simple or variously lobed or compound; the stalk, called a stipes, and the rhachis frequently bearing narrow brown glossy scales, always more numerous at the base of the stipes and on the rhizome. In the majority of genera, including all those found in Hongkong, the frond is when young rolled inwards at the top.

A very large Order, abundantly diffused over the whole surface of the globe, especially in moist climates; more rare, but seldom entirely absent, in the driest countries. The genera have of late years been multiplied to an extraordinary degree, founded chicfly upon characters derived from the venation, which however useful, in Ferns as in Phanerogams, for the distribution of species into sectional groups, and however constant they may prove occa. sionally in both classes in large genera or groups of genera, are often far too vague and uncertain to be relied on implicitly for the formation even of purely artificial gencra. To me it appears that by maintaining the large genera Acrostichum, Adiantum, Pteris, Asplenium, Aspidium, Polypodium, etc., nearly as proposed by Swartz and his immediate followers, they are at once better defined, more easily understood by the general botanist, and therefore more practically useful, and not more artificial than the innumerable small genera upon which modern Pteridologists have expended so much ingenuity. And in these views I believe I am doing no more than following the example of Sir W. J. Hooker, than whom no one has had more experience nor more ample materials to work upon in this beautiful Order, nor shown more ability and tact in the use he has made of them.

Spore-cases globular or ovoid, opening by a longitudinal slit or in

2 valves (as readily seen with an ordinary lens).

Spore-cases (not numerous), arranged in 2 rows in oblong or shortly linear sori.

Sori without indusia, raised and placed side by side in a continuous row on the under surface of the frond-segments. Large erect Ferns

Sori, with scale-like indusia projecting from the margin of the segments. Climbing Ferns . . . . . . . .

1. ANGiopteris.

3. Lygodium.

Spore-cases numerous, covering the contracted fertile segments of the fronda 
No indusium. Spore-cases very erowded.

Indusium of the recurved margius of the segment. Sporecases loosely scattered.

Spore-cases very small, dotted, few together over the under surface of the pinnate-segments of dichotomously-branched fronds . .

Spore-cases (helmet-shaped, with a vertical or oblique ring, and usually pedicellate) very small and numerous, in sori with or without an indusium or involucre.

Sori longitudinal (elongated and parallel to the midrib), or covering the vohole under surface of the fertile segments.

Sori continuous along the whole, or nearly the whole, length of the segment.

Sori occupying the whole under surface.

No indusium. Spore-cases densely crowded ... . . .

Indusium of the recurved margins of the frond. Sporecases loosely scattered ...................

Sori in two distinct lines, at least when young.

Sori between the midrib and margin (covering the surface when old). No indusium

Sori next the midrib, with an indusium .

Sori interrupted (at least when young) along the midrib.

Indusium longitplinal

No indusium . . 20. Brainea.

Sori marginal, more or less continuous along the margin or ends of the segments or their lobes.

Indusium longitudinal, parallel to the margin or formed by the margin.

Indusium opening along the outer edge

Indusium opening along the inner edge.

Spore-cases fixed to the inside of the indusium. Frondsegments usually reniform or fan-shaped ... . .

Spore-cases fixed to the frond under the indusium. Segments lanceolate-oblong or obovate.

Sori continuous along the margin. . . . . . 12. Pteris.

Sori short, terminating the lobes . . . . . . 13. Cheilanthes.

Indusium cup-shaped.

Small creeping Ferns, with half-pellucid fronds . . . . 24. Trichomanes.

Fronds erect, firm, pinnate or decumbent . . . . . . 23. Davallia.

Indusium coriaceous, 2-valved

No indusium (see below, Polypodiea).

Sori globular or oblong, variously arranged over the surface or, if linear, not parallel to the margin or midrib.

Sori indusiate.

Indusium straight or slightly curved. Sori linear or ob-

long, oblique . . . . . . . . . 15. Asplenium.

Indusium peltate or reniform. Sori circular . . . . . 16. Aspidium.

Indusium cup-shaped or 2-valved. (See above, Sori marginal.)

No indusium (Polypodiea).

Sori along the margin. . . . . . . . . . 14. NotholdenA.

Sori linear, oblique . . . . . . . . . 17. Grammitrs.

Sori short, parallel to the midrib.

Sori in several rows . . . . . . . 18. Meniscium.

Sori in a single row near the midrib . . . . 20. Brainea.

Sori round, or rarely slightly oval.

Herbaceous Ferns. Sori circular or slightly oval, on a

flat or slightly convex receptacle . . . . . . 19. PoLvponium.

Tree-ferns. Sori globular on a raised receptacle . . . 21. Alsophina. 


\section{SERIES I. SPURIOUS FrRIS.}

Spore-cases sessile or shortly pedicellate, opening at the top or obliquely by a longitudinal fissure in 2 valves, without any or with an incomplete or transverse ring.

\section{ANGIOPTERIS, Hoffm.}

Sori oblong, raised, placed side by side in a continuous row near the margin on the under surface of the frond-segments; each sorus consisting of a small number of spore-cases arranged in two rows, at first connate, at length distinct, and all opening inwards in 2 short valves. Indusium none. Fronds large and decompound.

A genus consisting of a single species.

1. A. evecta, Hoffm.; Hook. Fil. Exot. t. 75. Stem forming an erect thick trunk, sometimes attaining 2 or $3 \mathrm{ft}$. in height, and even more in diameter. Fronds twice pinnate, spreading very broad, and sometimes 12 to $15 \mathrm{ft}$. long, on a more or less downy stipes, but otherwise quite glabrous, dark-green, and shining. Segments linear-oblong, 3 to 8 in. long, abruptly acuminate, crenate-serrate or rarely entire. Veins simple, forked, nearly parallel. Sori usually consisting of 8 to 12 spore-cases.

Hongkong, Bowman, Wilford. In S. Asia, from Ceylon and the Peninsula to the Archipelago, in the Pacific islands, Bonin and Japan, and in Madagasear. It varies in the form and venation of the frond-segments, but not nearly to the extent one might suppose from its having been proposed to subdivide it into 60 species, very judiciously re-united with the original one by Hooker in the above-quoted work.

\section{OSMUNDA, Linn.}

Spore-cases stipitate, globular, without any ring, opening in 2 valves, densely clustered and covering the contracted segments of a portion of the frond or rarely of separate fronds. Indusium none--Herbaceous Ferns, with a thick rhizome. Fronds erect, once or twice pinnate.

A small genus, spread over the greater portion of the globe.

Fronds twice pinuate, the fertile branches forming a terminal panicle or a separate frond

Fronds twice pinnate, the fertile branches lateral . . . . . . 2. 0. bipinnata.

Fronds once pinnate, the fertile branches lateral . . . ... 3. O. javanica.

1. O. regalis, Linn.; Hook. in Kew Journ. Bot. ix. 360, var. biformis. Fronds twice pinnate, $1 \frac{1}{2}$ to $2 \mathrm{ft}$. high in our Hongkong specimens, but often very much taller in other countries, quite glabrous. Barren segments oblonglanceolate, 1 to $2 \mathrm{in}$. long, serrulate or nearly entire, very oblique at the base. Fertile segments linear, $\frac{1}{2}$ to 1 in. long, on separate fronds from the barren ones in our Hongkong specimens as in many Indian ones, forming in the more common variety a terminal panicle above the barren branches.O. japonica, Thunb. Fl. Jap. 330 .

In ravines, Harland, Urquhart, Wilford. Widely distributed over Asia, Europe, North America and South Africa; the variety biformis, chiefly in India, China, and Japan.

2. O. bipinnata, Hook. Fil. Exot. t. 9. Fronds $1 \frac{1}{2}$ to $2 \mathrm{ft}$. high or more, glabrous, bipinnate. Larger barren primary pinnæ attaining 4 in. in length, with about 10 pair of oblong-ovate segments, each about $\frac{1}{2}$ in. long, with a terminal oblong or lanceolate one full twice as long, the upper pinnæ 
passing into the segments of the simply pinnate summit of the frond. Fertile pinnæ below the barren ones with linear segments seldom above 4 or 5 lines long.

Hongkong, Harland; Tank Ravine, Urquhart. Not known out of the island.

3. O. javanica, Blume; Hook. in Kew Journ. Bot. ix. 360. Fronds 1 to $2 \mathrm{ft}$. high or more, glabrous, simply pinnate. Barren segments linear or linear-lanceolate, 3 to $6 \mathrm{in}$. long, entire or more or less deeply serrate. Fertile pinnæ occupying the centre, or rarely the base or summit of the frond, each pinna pinnatifid or almost pinnate, with numerous globular or oblong segments (or clusters of spore-cases).-O. Vachellii, Hook. Ic. Pl. t. 15.

In ravines, Hinds, Champion, and others. Widely spread over India and the Archipelago, extending northwards to Mantchuria and Japan.

\section{LYGODIUM, Sw.}

Sori oblong or linear, covering the under side of small lobes which either protrude from the margin of the frond-segments or form distinct parts of the frond, each sorus divided into 2 rows of compartments containing each a single spore-case and covered by a bract-like indusium. Spore-cases transversely oblong, opening by a longitudinal slit, the upper end turned downwards and marked with longitudinal striæ.-Climbing Ferns. Fronds pinnately or dichotomously divided, inserted on the main stem or branches, in divaricate pairs, usually on a very short common petiole.

A small tropical and subtropical genus, common to the New and the Old World, one species extending into temperate $\mathrm{N}$. America.

Fronds in each pair dichotomously divided . . . . . . . . . 1. L. circinatum.

Frouds in each pair pinnately divided.

Segments articulate on the thickened end of the petiolule . . . 2. L. scandens.

Segments continuous with and decurrent on the petiolule . . . 3. L. japonicum.

1. I. circinatum, Sw.; Presl, Tent. Pterid. Suppl. 100. Stems climbing to a great height, and as well as the fronds perfectly glabrous. Fronds of each pair stipitate, either deeply pedately lobed, or divided into 2 deeply 2 - or 3 -lobed segments; lobes linear-oblong, from a few inches to above a foot long, $\frac{1}{2}$ to $1 \mathrm{in}$. broad when barren, narrower in the fruiting part, continuous with and slightly decurrent on the petiolule. Sori 1 to 2 lines long, projecting from the margin, usually in the lower half of the lobes.- $L$. dichotomum, Sw.; Presl, l. c. ; Hook. and Grev. Ic. Fl. t. 55.

Hongkong, Dill, Wright; in the Happy Valley, Urquhart; in a ravine of Mount Gough, and plentiful behind the Buddhist Temple, Wilford. In the Malayan Peninsula, the Archipelago, and the Philippines.

2. I. scandens, Sw.; Presl, Tent. Pterid. Suppl. 102. Stems rather slender but climbing to a considerable extent, glabrous or slightly pubescent. Pairs of fronds usually petiolate. Each frond pinnate. Segments 5 to 10 or more, from cordate-ovate to oblong-lanceolate or hastate, varying in the Hongkong specimens from $\frac{1}{2}$ to $1 \frac{1}{2}$ in. long, but much longer in some Indian ones, often shortly lobed at the base, and always articulate on a slight thickening of the apex of the petiolule, which persists on the common rhachis after the segments have fallen off. Sori short, protruding from the margin of segments 
usually shorter and broader than the barren ones.-L. salicifolium, Presl, 1. c. L. microphyllum, Br. Prod. i. 162.

Hongkong, Hinds, Champion, Wright. In India, from Ceylon and the Peninsula to the Archipelago, extending eastward to N. Australia, and northward to the Himalaya and S. China. Very closely allied also to the tropical American $L$. volubile, Sw.

3. I. japonicum, Sw.; Presl, Tent. Pterid. Suppl. 109. A rather slender tall climber like the last, but usually pubescent, at least on the petioles and rhachis. Fronds once or twice pinnate, the segments always continuous with and more or less decurrent on the petiolule, but otherwise exceedingly variable in shape, the barren ones usually palmately lobed, with one long lanceolate lobe and 1 or 2 small ones on each side, the fertile ones usually at least twice pinnate, with small ovate or lanceolate lobes. Sori either protruding from the margin or occupying the whole under surface, the segment being thus divided to the base into small narrow lobes.

In ravines, Champion and others. In India, from Ceylon and the Peninsula to the Archipelago, and northward to the Himalaya, China, and Japan.

\section{GLEICHENIA, Sm.}

(Mertensia, Willd.)

Sori small, globular or dot-like, scattered on the under surface of the frondsegments without any indusium, each sorus consisting of 2 to 5 small sessile globular spore-cases with a transverse ring and opening at the top in 2 valves. - Procumbent or straggling Ferns, with a dichotomous stipes, the ultimate branches bearing 2 pinnæ, either deeply pinnatifid, or pinnate with deeply pinnatifid pinnules.

A considerable tropical genus, common to the New and the Old World, extending also into extratropical Australia and S. Africa.

Pinnæ deeply pinnatifid (almost pinnate) . . . . . . . . 1. G. dichotoma. Pinnæ pinuate, with deeply pinnatifid pinnules (almost bipinnate) . . 2. G. excelsa.

1. G. dichotoma, Willd.; Hook. Spec. Fil. i. 12. Stipes terete, dichotomous, bearing a pair of sessile pinnæ at the end of each ultimate branch and an opposite pair also under the last or under each of the two last forks. Pinnæ lanceolate, more or less falcate, often 8 or 10 in. long, pinnatifid almost to the midrib. Segments or lobes numerous, linear, obtuse or emarginate, often 1 in. long, rigid, glabrous or nearly so, but glaucous underneath, the lowest pair often longer and pimnatifid.-Polypodium dichotomum, Thunb. Fl. Jap. t. 37 .

Hongkong, Hinds, Champion, and others. Abundant in most tropical countries in the New and the Old World.

2. G. excelsa, J. Sm.; Hook. Spec. Fil. i. 5, t. 4, B. Rhizome long and creeping. Fronds several feet high, the stipes forked, the ultimate branches bearing 2 pinnate pinnæ, the pinnules numerous, distinct, deeply pinnatifid or almost pinnate, very similar to the pinnæ of $G$. dichotoma. Segments linearoblong, obtuse, glaucous underneath. Rhachis of the pinnæ very smooth and brown, with an acute elevated line on the upper side.-Mertensia glauca, J. Sm. in Seem. Bot. Her. 430 ; but not of Swartz.

Hongkong, Seemann. At Foochowfoo and in the Philippines. Very closely allied to the G. glauca, Sw., from Japan and the Pacific islands. 


\section{CERATOPTERIS, Brongn.}

Spore-cases globular, opening in 2 valves with an incomplete or rudimentary ring, arranged along the longitudinal veins of the narrow segments of the fertile fronds, and loosely covering their under surface. Indusium continuous and membranous, formed of the revolute margins of the segments. Spores marked with 3 series of concentric rings.-An aquatic annual, the barren and fertile fronds distinct.

A genus limited to a single species.

1. C. thalictroides, Brongn.; Hook. Spec. Fil. ii. 235; Gen. Fil. $t$. 12. Fronds bipinnate, the fertile ones erect, $6 \mathrm{in}$. to $1 \mathrm{ft}$. high, with linear acute segments $\frac{3}{4}$ to $1 \mathrm{in}$. long; the margins revolute and covering the fructification their whole length. Barren fronds shorter and more spreading, the segments cuneate, with 2 or 3 oblong or lanceolate lobes, of a soft halfsucculent texture. Veins reticulate-_Parkeria pteridioides, Hook. Exot. Fl. t. 147 and 231 ; Hook. and Grev. Ic. Fil. t. 97.

Hongkoug, Seemann ; in the Happy Valley, at the water's edge, Wilford. Widely distributed over tropical Asia, Africa, America, and Australia.

\section{SERIFS II. TRUE FERNS.}

Spore-cases erect, helmet-shaped, with a vertical ring opening by a transverse fissure, usually stipitate, very small and crowded in the sori.

\section{ACROSTICHUM, Linn.}

Spore-cases not distributed in distinct sori, but densely crowded and covering the whole under surface of the fertile segments, which are either on the same or on distinct fronds from the barren ones, and usually narrower. Indusium none--Herbaceous Ferns. Fronds in the Hongkong species all simply pinnate, simple or variously divided in others.

A large genus, chiefly tropical, common to the New and the Old World.

Barren segments coriaceous, the veins all equally reticulate, the fertile on

the same frond

1. A. aureum.

Barren fronds membranous, the primary veins pinnate, fertile fronds distinct.

Segments 3 to 5 (rarely 1), broadly oblong, 6 to $10 \mathrm{in.} \mathrm{long,} \mathrm{decurrent}$

at the base . . . . . . . . . . 2. A. decurrens.

Segments numerous, lanceolate, usually petiolulate, 3 to 5 in. long . 3. A. repandum.

1. A. aureum, Iinn.; Moore, Ind. Fil. 5. Fronds firm, 1 to 3 or $4 \mathrm{ft}$. high, pinnate. Barren segments linear-oblong, about 4 to 8 in. long, very obtuse, oblique at the base and petiolulate, the midrib prominent, the very numerous equally reticulate veinlets covering the under surface. Fertile segments usually occupying the upper part of the frond and rather smaller than the barren ones, the fructification of a rich golden colour when fresh.

Hongkong, Wright; at Tytamtook, Urquhart. Common in most tropical and subtropical countries.

2. A. (Gymnopteris) decurrens, Hook. Fil. Exot. t. 94. Fronds $1 \frac{1}{3}$ to $2 \mathrm{ft}$. high, pinnate or the outer barren ones rarely simple; the stipes rich brown, with subulate scales at the base. Segments of the barren fronds usually 3 or 5 , oblong, acuminate, the lateral ones 5 to 9 in. long, the terminal 
often much longer, and all more or less decurrent on the rhachis. Primary veins pinnate, the secondary reticulate, with free branches in the areoles. Fertile fronds like the barren ones, but the segments narrower and smaller.

Hongkong, Harland; among rocks near the top of Mount Gough, Wilford. Also in Formosa.

3. A. repandum, Blume, Enum. Pl. Jav. 104. Rhizome thick, shortly creeping. Fronds 1 to $1 \frac{1}{2} \mathrm{ft}$. high, pinnate. Segments of the barren ones 11 to 21 , lanceolate, more or less sinuate; the terminal one longer, almost pinnatifid, ending in a point, often viviparous ; lateral ones mostly petiolulate. Primary veins pinnate, sparingly branched, and anastomosing, with here and there a free branch. Fertile fronds distinet, with the pinnæ rather smaller.Heteroneuron proliferum, Fée; Hook. in Kew Journ. Bot. ix. 359. A. heteroclitum, Presl, Rel. Hænk. i. 15, t. 2, f. 2. Poecilopteris heteroclita, Presl; and $P$. repanda, J. Sm. in Seem. Bot. Her. 426.

Hongkong, Hance; Tank Ravine and Water Ravine, Urquhart. 'In India, the Archipelago, S. China, and Formosa.

\section{DRYMOGLOSSUM, Presl.}

Sori forming two continuous lines between the midrib and the margin, at length covering nearly the whole under surface of the narrow fertile fronds. Indusium none.-Rhizome creeping. Fronds small, undivided, the barren ones broader than the fertile. Veins reticulate.

A small tropical Asiatic genus.

1. D. carnosum, Hook. Gen. Fil.t. 78 A, and in Kew Journ. Bot. ix. 358. A small Fern, with slender creeping rhizomes. Barren fronds varying from nearly orbicular, 4 , or 5 lines diameter and almost sessile, to ovate or oblongelliptical, $1 \frac{1}{2}$ to $2 \mathrm{in}$. long, and narrowed into a petiole of 3 to 4 lines, all rather thick and succulent. Fertile fronds linear-oblong, obtuse, petiolate, the lines of fructification when young about midway between the midrib and the margin.

Hongkong, Wright. In the mountains of N. India, in S. China, and Loochoo.

\section{BLECHNUM, Linn.}

Sori forming two continuous lines parallel to and either close to the midrib or between the midrib and the margin, with a longitudinal indusium distinct from the margin.-Fronds pinnate, rarely simple or bipinnate; the fertile and barren nearly similar. Veins simple or forked, rarely anastomosing.

A genus of several species, chiefly tropical or subtropical, common to the New and the Old World, one species extending into N. W. America.

1. B. orientale, Linn.; Hook. Spec. Fil. iii. 52 ; Fil. Exot.t. 77. Stem short, thick, erect or ascending. Fronds pinnate, 1 to $3 \mathrm{ft}$. long, with narrow glossy scales at the base of the stipes. Segments numerous, sessile, linearlanceolate, entire, mostly 6 to $8 \mathrm{in}$. long, or sometimes near $1 \mathrm{ft}$.; the lower pairs suddenly abbreviated or reduced to small scales. Veins closely parallel and usually simple. Sori close to the midrib, almost concealing it when old.

Abundant in the island, Champion and others. In India, from Ceylon and the Peninsula to the Archipelago, and in the Pacific islands, extending nortbward to the Himalaya and S. China. 


\section{WOODWARDIA.}

Sori oblong or shortly linear, more or less immersed in the substance of the frond, near and parallel to the midrib of the pinna or of its segments, and sometimes confluent when old, with a stiff longitudinal indusium.-Stem or rhizome decumbent or creeping. Fronds pinnate or bipinnate; the stipes scaly at the base.

A small genus, dispersed over the temperate regions of the northern hemisphere, more rarely penetrating within the tropics.

Pinnæ of the fertile fronds 3 to 7 , entire ... . . . , . . 1. W. Harlandi. Pinnæ more than 7, pinnatifid . . . . . . . . . 2. W. japonica.

1. W. Harlandi, Hook. Spec. Fil. iii. 70 ; Fil. Exot. t. 7. Rhizome creeping, with small subulate scales. Fronds $\frac{1}{2}$ to $1 \frac{1}{2} \mathrm{ft}$. high, including the long stipes. Fertile pinnæ 3 to 5 , lanceolate, 4 to 8 in. long, more or less decurrent or confluent at the base, rather rigid, entire or serrulate. Veins reticulate. Sori at first distinct, at length confluent along both sides of the midrib, and sometimes with short lateral sori diverging from it. Barren fronds usually cordate at the base, simple or deeply 3-lobed, the segments shorter and broader than in the fertile ones.

Hongkong, Harland, Lorrain; among long grass and low bushes on the first hill going to Victoria Peak, Wilford. Not known from elsewhere.

2. W. japonica, Sw.; Hook. Spec. Fil. iii. 69. Rhizome creeping, with copious linear-lanceolate acuminate scales. Fronds 1 to $1 \frac{1}{2} \mathrm{ft}$. high, pinnate. Pinnæ about 6 to 8 pair, all distinct, or the upper pair confluent with the terminal one, pinnatifid with short obtuse lobes, all ending in a lanceolate entire point. Veins reticulate, with a principal vein corresponding to each lobe. Sori linear, distinct or confluent along the midrib of each lobe, more rare along the midrib of the pinna, and only in its upper portion. Barren fronds smaller, with fewer and broader pinnæ than the fertile ones.-Blechnum japonicum, Linn.; Thunb. Fl. Jap. t. 35.

On hills and in the Happy Valley, Urquhart, Harland. On the Chinese coutinent and in Japan.

\section{IINDS刷A, Dryand.}

Sori linear, continuous or interrupted along the margin of the frond-segments, with a longitudinal indusium opening along the outer edge (next the margin).-Rhizome usually creeping. Fronds pinnate or bipinnate very rarely (in species not Chinese) simple. Veins forked or reticulate.

A considerable tropical and subtropical genus, common to the New and the Old World.

Segments short, obliquely fan-shaped, the dichotomous veins proceeding from the base of the segment . . . . . . . . . . Segments mostly lanceolate, the veins anastomosing, proceeding from a midrib.

Primary pinnæ undivided, 4 to 8 in. long . . . . . . . 2. L. ensifolia.

Primary pinnæ pinnate, pinnatifid or under 2 in. long . . . . . 3. L. heterophylla.

1. L. flabellulata, Dryand.; Hook. Spec. Fil. i. 211. Fronds usually simply pinnate, tufted, the outer barren ones spreading, 2 to $3 \mathrm{in}$. long; the inner fertile and erect, $\frac{7}{2}$ to $1 \frac{1}{2} \mathrm{ft}$. high, occasionally bipinnate in the lower 
portion; the stipes slender, without scales. Segments numerous, nearly sessile, obliquely fan-shaped, seldom above $\frac{1}{2}$ in. broad; the dichotomous veins starting from the base without a midrib. Sori continuous all round the outer margin. Barren segments acutely denticulate.-L. polymorpha, Hook. and Grev. Ic. Fil. t. 75.

In ravines and in the Happy Valley woods, Urquhart, Lorrain, Wilford, Wright. In tropical Asia from Assam and Khasia to the Archipelago, in N. Australia, and northwards to S. China.

2. I. ensifolia, Sw.; Hook. Spec. Fil. i. 220; Hook. and Grev. Ic. Fil. $t$. 111. Rhizome rather thick, shortly creeping. Fronds erect, firm, 1 to $1 \frac{1}{2} \mathrm{ft}$. high, simply pinnate. Segments usually 5 to 9 , rarely 12 or 13 , or in the outer fronds 3 only, oblong-linear or lanceolate, acute, acuminate, or obtuse, 4 to $8 \mathrm{in}$. long, very shortly petiolulate, or the upper ones confluent, all undivided. Veins starting from a midrib, forked and mostly anastomosing. Sori usually continuous a great part of the length of the segment.

In ravines and in the Happy Valley woods, Champion and others. Dispersed over the tropical regions of the Oid World.

3. I. heterophylla, Dryand.; Hook. Spec. Fil. i. 223. Rhizome short, thick, horizontal. Fronds erect, slender but stiff, $\frac{3}{4}$ to $1 \frac{1}{2} \mathrm{ft}$. high, usually bipinnate in the lower portion. Primary pinnæ numerous; the lower ones when pinnate often 3 to 4 in. long, with the lower segments short and rhomboidal, and ending in a lanceolate one; the upper pinnæ passing into shorter lanceolate undivided ones, or sometimes all the pinnæ lanceolate and undivided, but then never more than $2 \mathrm{in}$. long, and usually much less. Veins proceeding from a midrib, forking and anastomosing almost as in $L$. ensifolia, excepting in the shortened lower segments of the pinnæ where they are often dichotomous from the base as in L. fabellulata. - L. variabilis, Hook. and Arn. Bot. Beech. 257, t. 52.

In woods and shady places, Champion and others. In S. China, the Philippine Islands, and the Malayan Peninsula, and northward to Loochoo.

\section{ADIANTUM, Linn.}

Sori continuous or interrupted along the margin of the frond-segments, with an indusium proceeding from the margin and opening along the inner edge. Spore-cases inserted on the inside of the indusium. Fronds usually tufted or sometimes with a creeping rhizome, simple, pinnate, or decompound; the stipes usually slender, black, and shining, with subulate scales or hairs at their base; the segments oblique, and often fan-shaped or reniform. Veins forked or anastomosing.

A considerable genus, common to the New and the Old World, chiefly tropical or subtropical, with a few species extending into more temperate regions, both in the northern and southern hemispheres.

Fronds simply pinnate.

Segments articulate on a slender petiolule . . . . . . 1. A. lunulatum.

Segments nearly sessile, lobed, hairy . . . . . . 2. A. caudatum. Stipes forked or pedate. Pinnæ pinnate . . . . . . . . . 3. A. fabellulatum.

1. A. lunulatum, Burm.; Hook. Spec. Fil. ii. 11; Hook. and Grev. Ic. Fil. $t$. 104. Fronds tufted, 6 to $10 \mathrm{in.} \mathrm{long,} \mathrm{simply} \mathrm{pinnate.} \mathrm{Segments}$ 
articulate on a petiole of 1 to 4 lines, obliquely oblong-falcate, usually near 1 in. long and 3 to 4 lines broad, rounded on the outer edge, and nearly entire, with almost continuous sori, thin and glabrous. Veins dichotomous, proceeding from the base or lower edge. Rhachis in the Chinese specimens usually terminating in a segment rather longer than the lateral ones, in others it is often leafless and rooting at the extremity.

Ilongkong, Harland. Extends over the tropical regions both of the New and the Old World.

2. A. caudatum, Hook. Spec. Fil. ii. 13; Exot. Fl. t. 104. Fronds tufted, 1 to $1 \frac{1}{2} \mathrm{ft}$. long; simply pinnate, usually leafless and rooting at the extremity. Segments numerous, small, sessile or nearly so, obliquely oblongfalcate, cuneate at the base; the upper side more or less deeply divided into narrow-cuneate lobes, each bearing at its extremity a short sorus. Veins forked, primary ones prominent and fan-like. Both surfaces as well as the rhachis more or less hairy; the larger segments 5 to 8 lines long, gradually decreasing towards the top of the frond.

In moist sitnations about Little Hongkong, Wilford, Urquhart; also Wright. Throughout India, from Ceylon and the Peninsula to the Archipelago, and northward to the Himalaya, S. China, and Japan.

3. A. flabellulatum, Linn.; Hook. Spec. Fil. ii. 30. Fronds tufted $\frac{3}{4}$ to $1 \frac{1}{2} \mathrm{ft}$. high ; the stipes forked and pedate or dichotomous, or rarely with 3 or 4 pinnate branches, each pinna 3 to 6 in. long and pinnate. Segments numerous, obliquely fan-shaped or almost trapezoid, 4 to 8 lines long, articulate on a short petiolule, thin and glabrous. Veins dichotomous, starting: from the base. Sori interrupted, oblong or linear, either occupying the whole outer edge, or a portion of it barren and denticulate.

Common in the island, Lorrain, Urquhart, Wilford. In Ceylon, northeru India, the Malayan Peniusula, and the Archipelago, and common in S. China, extending northward to Foochowfoo and Chusan.

\section{PTERIS, Linn.}

Sori linear, continuous along the margin of the frond-segments, with a continuous indusium proceeding from the margin and opening along the inner edge. Spore-cases inserted on the frond itself, under the indusium.-Fronds usually large and compound, from a tufted stock or creeping rhizome, rarely small or nearly simple. Veins simple, forked or reticulate, with or without a midrib.

A large genus distributed over the greater part of the globe.

Fronds simply pinnate with entire pinnæ, not decurrent . . . . 1. P. longifolia.

Fronds very unequally bipiunate or pinnate with the lower pinnæ divided, the uppermost confluent or decurrent.

Lower primary pinnæ divided on one side only . . . . . 2. P. semipinnata.

Lower primary pinnæ divided on both sides or 2-lobed.

Primary pime all distinct except the terminal one . . . . . 3. P. crenata.

Primary pinne mostly decurrent and confluent . . . . . 4. P. serrulata.

Fronds pinnate, or with the lower pinnæ divided. Pinnæ numerous, regnlarly pinnatifid, with numerous segments. . . . . . . 5. P. nemoraitis.

Fronds thrice pinnate, with numerous pinne and segments . . . . 6. P. aquilina.

1. P. longifolia, Linn.; Hook. Spec.Fil.157. Rhizome short, knotty. 
Fronds 1 to $2 \mathrm{ft}$. long, simply pinnate. Pinnæ numerous, linear-lanceolate, entire, sessile and cordate at the base, but not decurrent or adnate, mostly about 4 in. long, the lowest shorter. Sori along the greater part of the margin, the barren portion minutely serrulate. $-R$. costata, Bory ; Hook. and Arn. Bot. Beech. t. 51.

Hongkong, Lorrain, Wright; on dry banks about Vietoria, Wilford. Widely dispersed over the tropical and subtropical regions of the Old World, extending northward to south Europe ; more rare in America, and chiefly in the West Indies.

2. P. semipinnata, Linn.; Hook. Spec. Fil. 169. Rhizome thick, shortly creeping. Fronds 1 to $3 \mathrm{ft}$. high, pinnate, the upper pinnæ undivided and more or less confluent, passing into the pinnatifid apex, the lower 3 to 6 pairs all distinct, quite entire on the upper side, deeply cut on the lower side into 2 or more very unequal oblong or lanceolate lobes, and all ending in a long lanceolate lobe; occasionally the lowest pinna of all is again semipinnate. Sori usually occupying nearly the whole margin of the fertile segments, the barren ones serrulate.

Common in ravines and ditches, Hinds and others. In the hilly regions of India, from Ceylon and the Peninsula to Silhet and Khasia ; in the Archipelago, and northward to China and Japan.

3. P. crenata, Sw.; Hook. Spec. Fil. ii. 163. Rhizome creeping. Fronds 1 to $2 \mathrm{ft}$. high, pinnate, witb few distant pinnæ, the lower ones or nearly all again pinnate, with few usually confluent or decurrent segments, the fertile ones linear or linear-lanceolate, entire, 2 to $3 \mathrm{in}$. long, or the terminal one much longer; the sterile pinnæ or segments much shorter and usually broader and more or less serrulate. Occasionally the whole frond reduced to 5 or 3 segments.

Frequent in ravines, Champion and others. Widely dispersed over tropical Asia, Australia, and the Pacific islands, extending northward to Loochoo and Chusan.

4. P. serrulata, Linn. fil.; Hook. Spec. Fil. ii. 167. Fronds rather slender, $1 \frac{1}{2}$ to $2 \mathrm{ft}$. high, pinnate. Pinnæ few, distant, linear or linear-lanceolate, 3 to 6 in. long, the upper ones entire and decurrent along the rhachis nearly or quite to the next pair, the lower ones more or quite distinct, and either the lowest pair or the greater number deeply pinnatifid, with few long segments or at least deeply 2-lobed. Sori along the greater part of the margin of the fertile segments; the barren segments usually serrulate.

Hongkong, Champion. On the adjacent continent, and perhaps in Japan. Not known from elsewhere, but very closely allied to the widely diffused $P$. cretica, Linn., of which it may possibly prove to be a variety.

5. P. nemoralis, Willd.; Hook. Spec. Fil. ii. 203. Trunk short, erect. Fronds large (usually above $2 \mathrm{ft}$. long), pinnate, with numerous pinnæ, the lowest often divided or again pinnate; all distinct, regularly and deeply pinnatifid; the segments numerous, oblong or lanceolate, more or less falcate and obtuse, the lowest often above 1 inch long, the upper ones tapering to the end. Sori occupying the whole or the greater portion of the margin. Barren segments scarcely broader.-P. quadriaurita, Retz; Hook. Spec. Fil. ii. 179, t. $134 B$.

Common in the island, Champion, Wright, Wilford. Widely distributed over the tropical regions of the New and the Old World. The only character by which the P. quadri- 
aurita and $P$.nemoralis are distinguished by modern Pteridologists is, that in the former the lowest lateral veins of 2 adjoining segments never meet before they reach the sinus, and that they do so occasionally in $P$. nemoralis. In the Chinese specimens by far the greater number reach the sinus without meeting each other, but there is scarcely a specimen in which the junction will never oceur. In the original P. biaurita, Linn., the complete junction of the two lower veins and the emission of several branches towards the sinus, appears more constant; but yet it is not improbable that all the above forms may be mere varieties of the old Linnæan species.

6. P. aquilina, Linn.; Hook. Spec. Fil. ii. 196. Rhizome thick and creeping. Fronds from 1 or 2 to 8 or $10 \mathrm{ft}$. high, usually thrice pinnate. Primary pinnæe distant, the lowest pair much larger and more compound, the upper gradually decreasing, giving the whole frond a broad triangular outline. Secondary pinnæ numerous, linear-lanceolate, deeply pinnatifid or pinnate, always ending in an undivided more or less elongated obtuse segment; the lateral segments ovate or oblong, obtuse, entire, all of a firm consistence, glabrous above, often pubescent underneath. Sori continuous along the margins of the fertile segments, the barren ones seldom broader.

On the hills and in ravines about Victoria, Urquhart, Wilford; also Wright. In almost all tropical and temperate regions of the globe.

\section{CHEILANTHES, SW.}

Sori globular and distinct, or oblong by the confluence of 2 or more, all marginal, with an indusium proceeding from the margin and turned over them. Spore-cases, as in Pteris, inserted on the frond under the indusium. -Small usually slender Ferns, either tufted or with a creeping rhizome. Fronds usually twice or thrice pinnate, with small lobed segments, the stipes black and slender.

A considerable genus, widely distributed over a' great portion of the globe. It differs from Pteris chiefly in habit, and in the sori, or at least the receptacles, short and distinct.

1. C. tenuifolia, Sw.; Hook. Spec. Fil. ii. 82. Rhizome rather slender, creeping. Fronds glabrous, oblong, lanceolate or ovate-triangular in outline, 3 to 6 in. long, on a slender stipes as long or longer, twice or thrice pinnate, with small oblong crenate or lobed segments. Sori along the margin often confluent, with a more or less continuous indusium which, as the fructification advances, opens out flat, and can scarcely be distinguished from the margin of the frond.

In ravines, Champion, Urquhart, Wright, Wilford. In India, chiefly in hilly districts, from Ceylon to the Himalaya and the Archipelago; also in Australia.

\section{NOTHOL正NA, $\mathrm{Br}$.}

Sori small, contiguous and becoming confluent in a line usually marginal, without any indusium. Small tufted Ferns. Fronds pinnate or decompound, with small-lobed segments, usually covered underneath with hairs, scales, or a waxy meal.

A small genus, chiefly tropical, with the habit of Cheilanthes, from which it only differs in the absence of any indusium.

1. N. sulcata, Link, Enum. Hort.Berol. ii. 367, and Fil. Cult. 146. Fronds tufted, 6 to $8 \mathrm{in}$. high, twice pinnate, ovate or triangular in outline, more or 
less densely covered underneath with rust-coloured hairs, more loosely scattered on the upper side. Larger pinnæ about $I$ in. long; segments 1 to 3 lines, lobed or pinnatifid, ovate-oblong or obovate. Sori marginal when young, with the edge of the segment slightly turned down over them; when old often occupying the greater portion of the under surface. $-N$. pilosa, Hook. and Arn. Bot. Beech. 74 and 255.

Hongkong, Dill, Wright, Wilford. Also on the adjacent continent and in the Pacific islands.

\section{ASPIENIUM, Linn.}

\section{(Diplasium, Sw.)}

Sori linear or oblong, scattered on the under surface of the frond-segments, more or less oblique (with reference to the midrib), along one or both sides of a vein, with a longitudinal indusium, straight or slightly curved, proceeding from the vein and opening along the opposite edge.-Rhizome short, with tufted fronds, or creeping. Fronds very various.

A large genus, distributed over nearly the whole globe.

Fronds simple.

Fronds $2 \mathrm{ft}$. long or more, sessile or nearly so . . . . . 1. A. nidus.

Fronds less than $1 \mathrm{ft}$., on a long stipes. . . . . . . . 2. A. lanceum.

Fronds divided.

Fronds simply pinnate. Segments lanceolate, cuneate or acute at the base (rarely obtuse). Veins forked.

Segments rigid, lanceolate-falcate, serrate. Sori much raised, very oblique, all single . . . . . . . . ?

Segments few, oblong-lanceolate, entire or scarcely crenate. Sori rather oblique, often double . . . . . . . . .

Fronds twice or thrice pinnate. Segments small, cuneate. Veins forked.

Segments or lobes 3 to 6 lines long, with 2 or more sori in each

Segments or lobes 1 to $1 \frac{1}{2}$ lines long, with a single sorus on each

Fronds once to thrice pinnate, with long crenate or pinnatifid segments, truncate or cordate at the base. Veins pinnate.

Vein-branches of each set free from those of the adjoining set. Fronds once, rarely twice pinnate, with crenate or searcely lobed pinnæ. Fronds ouce pinnate, with deeply pinnatifid pinnæ Fronds twice or thrice pinnate . . . . . . . . .

Onter vein-branches of each set anastomosing with those of the adjoining set. Fronds mostly thrice pinnate . . . . 10.

5. A. macrophyllum.

6. A. fraxinifolium.

4. A. cuneatum.

3. A. davallioides.

(The insertion of $\boldsymbol{A}$. fontanum, Bernh., in the Enumeration of Hongkong Ferns in Seem. Bot. Her. 428, appears to have originated in a mistake:)

1. A. nidus, Linn.; Hook. Spec. Fil. iii. 77; Bot. Mag.t. 3101 . Fronds simple, entire, lanceolate, sessile or nearly so, in large regular tufts, hollowed in the centre, the larger ones 2 to $6 \mathrm{ft}$. long, and 3 to $5 \mathrm{in}$. broad. Veins numerous, nearly transverse, parallel, simple or forked. Sori along the upper or inner side of nearly all the veins, mostly reaching from the midrib to $\frac{1}{2}$ or nearly $\frac{2}{3}$ of their length.-Neottopteris nidus, J. Sm. in Seem. Bot. Her. 427.

In the Happy Valley, Urquhart; behind the Buddhist Temple, Wilford; also Hance and Seemann. Common in tropical Asia, extending to Australia, and northward to Bonin and Chusan. 
2. A. Ianceum, Thunb.; Hook. Spec. Fil. iii. 235. Rhizome slender, creeping, with subulate scales. Fronds simple, entire or slightly crenate, lanceolate, 4 to $9 \mathrm{in}$. long, and $\frac{1}{2}$ to $1 \mathrm{in}$. broad, narrowed into a stipes of 2 to $4 \mathrm{in}$. Veins nearly transverse, mostly twice forked, and not very close. Sori along their upper or both sides, linear, but usually commencing at some distance from the midrib, and not reaching the margin. $-A$. subsinuatum, Hook. and Grev. Ic. Fil. t. 27. Japan.

Hongkong, Harland, Lorrain, Hance, Seemann. In Ceylon, the Himalaya, China, and

3. A. davallioides, Hook. Spec. Fil. iii. 212 ; Cent. Ferns, ii. t.40.Fronds tufted, 6 to $8 \mathrm{in}$. high, including a stipes of 2 to $3 \mathrm{in}$., twice or thrice pinnate at the base, passing upwards into simply pinnate ends, the rhachis flat and almost winged; the segments cuneate at the base, entire or divided into entire oblong divaricate almost recurved lobes, 1 to $1 \frac{1}{2}$ lines long. Each lobe bears a single sorus occupying almost the whole of its under surface.

Hongkong, Dill. On the adjoining continent, in Loochoo and Japan.

4. A. cuneatum, Lam.; Hook. Spec. Fil. iii. 168. Rhizome thick, shortly creeping, with subulate scales. Fronds 1 to near $2 \mathrm{ft}$. high, including a rather long stipes, twice or thrice pinnate. Segments rigid, cuneate, obovate, or the end ones lanceolate, 3 to 6 lines long, more or less toothed or lobed at the top, narrowed at the base, and mostly petiolulate. Sori 2 to 5 on each lobe or segment, linear, very oblique, along the upper or inner side of the vein (that next the centre of the lobe or segment). $-A$. laserpitiifolium, Lam.; Hook. Spec. Fil. iii. 171, t. 203.

In the Happy Valley, Urquhart; also Hance and Wright. Spread over the tropical and subtropical regions of the New and the Old World; extends northward to Bonin and Chusan.

5. A. macrophyllum, Sw.; Hook. Spec. Fil. iii. 158. Rhizome thick, shortly creeping. Fronds tufted, $8 \mathrm{in}$. to $1 \frac{1}{2} \mathrm{ft}$. high, simply pinnate. Pinuæ usually 11 to 21 , obliquely falcate-lanceolate, acuminate, irregularly sinuate, cumeate at the base, and shortly petiolulate, 2 to $3 \mathrm{in}$. long in the Hongkong specimens, but much longer in some others; the terminal larger pinna often shortly lobed at the base. Sori linear, very oblique, extending from near the midrib almost to the margin, along the upper or inner side of the veins, or here and there in the lower part of the pinna, on the outer or lower side.A. oxyphyllum, J. Sm.; Hook. in Kew Journ. Bot. ix. 342.

Hongkong, Bowring, Wright. In the Mauritius, Ceylon, the Malayan Peninsula, the Arehipelago, and Pacific islands, extending northward to Assam, S. China, and Bonin.

6. A. fraxinifolium, Wall.; Hook. Spec. Fil. iii. t. 40 ; Cent. Ferns, ii. $t$. 19. Rhizome short and thick. Fronds 1 to $2 \mathrm{ft}$. high, simply pinnate. Pinnæ 3 to 11, oblong-lanceolate, acuminate, 4 to 6 in. long, or the terminal one longer, entire or very slightly serrulate, cuneate or very rarely almost rounded at the base, on a short petiolule. Veins slender, once or twice forked, almost always free (not anastomosing). Sori linear, along one or both sides of every second or third vein, sometimes extending almost from the midrib to the margin, but often much shorter.-Diplasium elegans, Hook. in Kew Journ. Bot. ix. 343. 
In ravines, Urquhart, Wilford; also Hance and Wright. In Khasia, Assam, Penang, and Singapore.

7. A. sylvaticum, Hook. Spec. Fil. iii. 249. Rhizome ascending, with a short stem. Fronds from $1 \mathrm{ft}$. high, simply pinnate, with about 9 pinnæ, to twice that height, with numerous pinnæ, the lower ones sometimes again pinnate, passing into a pinnatifid apex. Pinnæ usually 3 or 4 in. long, lanceolate, slightly crenate or with very short broad lobes, obliquely truncate or slightly cordate at the base. Veins pinnate, in transverse sets, proceeding from the midrib, the branches few, those of each set distinct, not anastomosing with the adjoining ones. Sori usually few and simple, and often along the outer or lower side of the lowest branch of the set of veins, so as to be slightly curved, occasionally on the upper or inner side, rarely on both.-Diplasium sylvaticum, Sw.

In ravines, Urquhart, Wilford; also Hance. In the Mauritius, Ceylon, the Malayan Peninsula, and the Archipelago. Some of the Hongkong specimens are of a firmer texture than the southeru ones, and the pinnæ broader, but others are precisely similar, and all appear to me to agree much better with the character and specimens of $A$. sylvaticum than of A. dilatatum, of which Hooker thinks they may be a simply-pinnate variety.

8. A. Schkuhrii, Metten.; Hook. Spec. Fil. iii. 251. Rhizome (at least in the smaller varieties) slender and creeping, fronds $\frac{3}{4}$ to $2 \mathrm{ft}$. high, always simply pinnate, the young stipes and rhachis bearing a few pale brown scales. Pinnæ in the larger specimens attaining $6 \mathrm{in}$., diminishing gradually to the pinnatifid apex, and the lower rather shorter, all lanceolate, deeply pinnatifid, with a broad usually truncate base; the lobes numerous, oblong or ovate, obtuse or almost acute, serrulate or entire. Veins pinnate in each lobe, with 4 to 8 branches on each side, not anastomosing with the adjoining ones. Sori usually on all the veins, and thus regularly pinnate as in $A$. esculentum, simple or the lower ones double.

Hongkong, Hance. In northern India, the Malayan Peninsula, the Feejee Islands, China, Loochoo, Corea, and perhaps Japan.

9. A. dilatatum, Hook. Spec. Fil. iii. 258. Fronds $2 \mathrm{ft}$. high or more, twice (or thrice ?) pinnate, passing into a pinnatifid apex. Stipes with black subulate scales at the base. Pinnules about $2 \mathrm{in}$. long and pinnatifid at the base, but passing on the one hand into longer ones pinnate at the base, on the other into shorter more entire ones. Veins pinnate, with few branches, not anastomosing with adjoining sets. Sori usually short, not on all the veinbranches in the Hongkong specimens, more numerous on others, simple or double.-Diplasium dilatatum, Blume.

In ravines, Urquhart, Wilford. In Ceylon, northern and eastern India, the Archipelago, and Pacific islands.

10. A. esculentum, Presl; Hook. Spec. Fil. iii. 268. Stem stout, erect. Fronds large, twice or thrice pinnate, passing into a pinnatifid apex. Ultimate pinnules lanceolate, acuminate, usually broadly truncate at the base and shortly petiolulate, the longer ones 6 in. long and deeply pinnatifid, passing into shorter broadly crenate ones. Veins pinnate, each set with 5 to 10 branches on each side; the outer ones more or less anastomosing with those of the adjoining ones, thus at once distinguishing this species from $A$. dilatatum, which the specimens sometimes resemble. Sori usually on almost all the vein- 
branches so as to appear regularly pinnate; the lower ones of each set usually double, the upper ones simple on the inner side of the vein-branches._Diplasium esculentum, Sw.; Willd. Spec. v. 354.

In ravines, Urquhart; also Hance and Lorrain. In India, from Ceylon and the Peninsula to the Himalaya, in Moulmein, Java, the Feejee Islands, and S. China.

\section{ASPIDIUM, Sw.}

Sori circular, variously dispersed over the under surface of the frond-segments, covered when young by an indusium attached by the centre or by a point near one side, so that when raised all round by the growth of the sporecases it becomes peltate or more or less reniform.-Rhizome short and thick or creeping. Fronds once, twice, or thrice pinnate, rarely simple.

A large genus, distributed over almost every part of the globe. It is now usually divided at least into two genera (Aspidium and Nephrodium), according to whether the indusium is peltate or reniform; but in several of the Hongkong species both forms occur in the same fronds, and generally the adoption of that character does not appear to me to constitute better defined nor more natural genera than Aspidium retained as a whole, and the very numerous smaller genera into which many pteridologists break it up are perhaps still more vague unless when reduced to single species.

Fronds once pinnate.

Pinnæ 3 or 5 , the lower pair and often the terminal one deeply and

irregularly lobed

Pinnæ entire or crenate.

Pinnæ large or few. Sori dispersed over the surface.

Pinnæ oblong, 9 to 13 . . . . . . . . . 4. A. podophyllum.

Pinnæ ovate-falcate, numerous . . . . . . 5. A. falcatum.

Pinnæ very numerous, articulate on the petiolule. Sori in a single row near the margin.

Pinnæ 1 to 3 in. long, mostly obtuse . . . . . . . . 1. A. exaltatum.

Pinnæ 6 in. long, acuminate . . . . . . . . . 2. A. biserratum.

Pinnæ regularly pinnatifid, with numerous lobes.

Veins of adjoining lobes free from each other.

Pinnæ deeply pinnatifid.

Lobes oblong, straight or nearly so . . . . . . . . 7. 4. Thelypteris,

Lobes lanceolate, very falcate . . . . . . . . 8. A. falcilobum.

Pinnæ semi-pinnatifid . . . . . . . . . 6. A. ciliatum.

Lower veins of adjoining lobes anastomosing.

Sori distinct, either near the midrib or seattered. . . . . 9. A. molle.

Sori in a close row near the margin of the lobes . . . . . 10. A. unitum.

Fronds bipinnate.

Lowest primary pinnæ largest and most compound. Segments

truncate or adnate at the base . . . . . . . 11. A. opacum.

Lowest primary pinnæ not larger than the next. Segments obtuse

or recurved at the base ............ 12. A. Championi,

Lowest primary pinnæ largest and most compound. Segments

obliquely cuneate or narrowed at the base. . . . . . 13. A. aristatum.

1. A. exaltatum, Sw.; Willd. Spec. v. 229. Rhizome short and thick, the fibrous roots forming here and there globular tubers. Fronds 1 to $3 \mathrm{ft}$. long, weak, simply pinnate. Pinnæ numerous, regularly approximate and distichous, oblong-linear or lanceolate, 1 to 2 or rarely 3 in. long, serrate, sessile, truncate at the base, with a protruding angle on the inner side. Stipes with subulate scales, which pass into short woolly hairs on the rhachis or under side of the segments. Veins forked, proceeding from the midrib. Sori 
in a single row very near the margin. Indusium reniform, fixed at the deep sinus or sometimes becoming regularly peltate.-A. hirsutulum, Sw.; Willd. Spec. v. 232. Nephrolepis tuberosa, Presl; Hook. in Kew Journ. Bot. ix. 339 ; J. Sm. in Seem. Bot. Her. 429, but not Asp. tuberosum, Willd. Nephrolepis hirsutula, J. Sm. 1. c.

In ravines, Hinds, Champion, Urquhart. Common in the tropical regions of the New and the Old World; the American specimens usually more glabrous than the Asiatic ones. The tubers, which are said always to be present in the Indian variety at least, are often eaten.

2. A. biserratum, Sw.; Willd. Spec. v. 231. Nearly allied to the last, but glabrous or nearly so ; the pinnæ lanceolate, acuminate, about 6 in. long, the auricle on the inner side of the base more obtuse than in $A$. exaltatum, the sori not so near the margin, and the indusium more frequently peltate.

Among rocks on the hillside near the Happy Valley, Wilford. In the Mauritius, in tropical Africa, and in tropical America.

3. A. trifoliatum, Sw.; Willd. Spec. v. 213. Rhizome thick, horizontal; fronds erect, from a few inches to $1 \frac{1}{2} \mathrm{ft}$. high including the slender stipes, the smaller ones cordate, oblong, and 3-lobed, more commonly with a broader outline, pinnate with 3 or 5 pinnæ, the lower pair and the terminal one 3-lobed, the middle lobe and intermediate pinnæ (when present) broadly lanceolate and irregularly pinnatifid, 4 to 6 in. long, pubescent or glabrous. Veins pinnate, the smaller ones anastomosing. Sori rather large, dispersed over the frond, but usually at some distance from the midrib. Indusium usually peltate.-A. variolosum, Wall. Catal. n. 379. A. intermedium, J. Sm. in Seem. Bot. Her. 428 (a very luxuriant specimen).

Hongkong, Champion; in ravines, Urquhart; on rocks in the Happy Valley, Wilford. In southern India, Ceylon, Chittagong, Silhet, the Malayan Peninsula, the Archipelago, and $\mathrm{S}$. China; also in tropical America. The American specimens have most frequently 3 pinnæ, the Asiatic 5, but both forms are met with in both districts. Many of the Hongkong specimens pass from the one to the other.

4. A. podophyllum, Hook. in Kew Journ. Bot.v. 236, t. 1. Rhizome thick, horizontal, with dark brown or black subulate scales. Fronds 1 to $2 \mathrm{ft}$. high, including a rather long stipes, glabrous, simply pinnate. Pinnæ usually 9 to 13 , lanceolate, often slightly falcate, obtuse or acuminate, 3 to 5 in. long, entire or crenate, lobed, rounded or truncate at the base, and very shortly petiolulate, of a firm consistence; the pinnate veins rarely conspicuous. Sori 2 to 5 to each set of veins, rather large, distant both from the margin and the midrib. Indusium peltate, with a central or slightly eccentric attachment.

Common in ravines, Champion and others. Also Foochowfoo and Chusan. It is referred by J. Smith to the Japanese $A$. Sieboldi, Mett.; but I cannot but agree with Hooker (Fil. Exot. t. 31) in considering that species as quite distinct.

5. A. falcatum, Sw.; Hook. Fil. Exot. t. 92. Fronds tufted, stout, 1 to $3 \mathrm{ft}$. long, simply pinnate, with large brown scales at the base of the stipes. Pinnæ numerous, ovate, falcate-acuminate, 2 to $4 \mathrm{in}$. long, entire or slightly crenate, firm and rather thick, with a prominent midrib and irregularly forked and anastomosing veins. Sori rather large and numerous, scattered over the surface. Indusium peltate.-Polypodium falcatum, Linn.; Thunb. Fl. Jap. t. 36. Cyrtomium falcatum, Presl; Hook. in Kew Journ. Bot. ix. 340.

Near Tytam Bay, Hinds. On the Chinese continent and in Japan. 
6. A. ciliatum, Wall. Catal.n. 351 . Stems short, ascending. Fronds simply pinnate, $\frac{1}{2}$ to $1 \mathrm{ft}$. high, with a few short brown scales on the stipes, and more or less hispid or downy especially on the rhachis and principal veins. Pinnæ numerous, sessile, linear-lanceolate, acuminate or obtuse, regularly pinnatifid, the longer ones 1 to 2 in. long, passing into a pinnatifid apex, and the lowest 1 or 2 pair much shorter; the lobes ovate-falcate, reaching about halfway to the midrib. Veins pinnate, those of adjoining lobes free, Sori few to each lobe, usually near the midrib. Indusium reniform or sometimes peltate, ciliate.-Lastrea ciliata, Hook. in Kew Journ. Bot. ix. 338.

Common in ravines, Boroman; in a ravine near the top of Mount Gough, Wilford. In the Indian Peninsula and in Khasia. Nearly allied to and perhaps a variety of the Javanese A. calcaratum, Blume, but that appears always to have much longer, narrower, and more acute lobes to the pinnæ.

7. A. Thelypteris, Sw.; Willd.Spec.v.249. Rhizome creeping. Fronds $\frac{1}{2}$ to $2 \mathrm{ft}$. high, slender, glabrous or slightly pubescent, simply pinnate, without scales to the stipes. Pinnæ numerous, sessile, lanceolate or linear-oblong, deeply pinnatifid, the longest $1 \frac{1}{2}$ in. to $2 \frac{1}{2}$ long, passing into the pinnatifid apex, the lowest pair smaller. Lobes numerous, usually oblong and obtuse. Veins pinnate, those of adjoining lobes free. Sori in 2 rows not far from the margin of the lobes, often covering the whole surface when old. Indusium usually reniform but soon disappearing.-Lastrea gracilescens, Hook. in Kew Journ. Bot. ix. 338.

Hongkong, Harland; on the banks of a ditch at Pockfoolan, Wilford. Widely distributed over Europe, temperate Asia, and N. America; also in northern India and in Java and New Zealand, if the A. gracilescens, Blume, and A. squamulosum, Kaulf., be really specifically identieal, as they appear to be.

8. A. falcilobum, Hook. Very near the last, but taller and firmer, the rhachis much more pubescent and often the pinnæ also; the pinnæ falcate, more acuminate, attaining 4 in. in length, and their lobes lanceolate-falcate and acute.-Lastrea falciloba, Hook. in Kew Journ. Bot. ix. 338.

Hongkong, Harland: Also in Eastern Bengal.

9. A. molle, Sw.; Willd. Spec. v. 246. Rhizome horizontal or shortly creeping. Fronds 1 to 2 or sometimes 3 feet high, simply pinnate, more or less pubescent, and rather slender, usually of a light green. Pinnæ lanceolate, acuminate, the longest 2 to $4 \mathrm{in}$. long, pinnatifid, truncate at the base; lobes ovate or oblong, obtuse, sometimes very short, sometimes reaching halfway to the midrib, the lowest inner one often longer. Veins pinnate, the lowest of adjoining lobes anastomosing. Sori distinct, only near the midrib or in 2 rows, but not close to the margin. Indusium reniform, usually ciliate and soon disappearing.-Nephrodium molle, Schott; Hook. in Kew Journ. Bot. ix. 340.

Common in ravines, Hinds and others. Abundant in most tropical countries in the New and the Old World, and everywhere variable in size, pubescence, and arrangement of the sori.

Var. latipinna. Seldom above $1 \mathrm{ft}$. high and often much smaller, the pubescence usually minute. Pinnæ few, thin, of a light green, 1 to 2 in. long, broader and less decply lobed than in the common varieties, the apex of the frond long-lanceolate, broad and deeply pinnatifid.

Hongkong, Champion, Harland, Hance; anong rocks, in damp situations, at Little Hongkong, Wilford. 
10. A. unitum, Sw.; Willd. Spec. v. 241. Fronds 1 to $3 \mathrm{ft}$. high, pubescent and simply pinnate, with semipinnatifid pinnæ as in the last, but the pubescence, although more rigid, is much less conspicuous, and the whole frond is firmer and usually larger. Pinnæ often 5 in. long or more; the lobes very regularly ovate, the lowest of each pinna usually smaller, giving its base a rounded appearance. Pinnate veins very conspicuous, the lowest of adjoining lobes anastomosing as in $A$. molle. Sori usually in a close row along the margin of the lobes.

Hongkong, Dill, Urquhart, Wright. Widely spread over tropical Asia, and closely allied to (if really distinct from) the common tropical American $A$. serra, Sw.

11. A. opacum, Hook. Fronds broad, twice pinnate or the lower pinnules again pinnate at the base, often 6 to $8 \mathrm{in}$. long, all tapering rapidly to the pinnatifid apex; the stipes and rhachis with subulate black seales. Segments somewhat coriaceous but not glossy, lanceolate-falcate, with a broad truncate or adnate base, often 1 to $2 \mathrm{in}$. long, pinnatifid or crenate. Veins scarcely conspicuous. Sori large, in 2 rows. Indusium peltate, but often excentrically so, with a more or less indented sinus.-Lastrea opaca, Hook. in Kew Journ. Bot. ix. 339.

Hongkong, Bovring; in the Tank Ravine, Urquhart. On the China coast and in Japan.

12. A. (Lastrea) Championi, Benth., n. sp. Fronds broadly lanceolate, twice pinnate, the stipes and rhachis covered with brown lanceolate scales. Lowest pinnæ 4 or 5 in. long, not longer nor more compound than the 2 or 3 next pairs, which afterwards pass gradually into the short pinnatifid apex. Segments lanceolate-falcate, distinct, sessile and broadly rounded at the base, but not adnate, seldom $1 \mathrm{in}$. long, serrate-crenate or the lowest pinnatifid, the inner lowest lobe rather larger. Veins scarcely conspicuous, pinnate with forked veinlets. Sori rather large, in 2 rows in each segment. Indusium peltate, or rarely reniform.-Polystichum vestitum?, Hook. in Kew Journ. Bot. ix. 339.

Hongkong, Champion, Urquhart. Not known out of the island. Col. Urquhart's specimens are old and Col. Champion's too young, but on carefully examining them with Sir W. Hooker, we have been unable to match them with any known species. They evidently belong to Lastrea and are allied to the $A$. opacum, but differ in the scales and in the general shape of the frond as well as in that of the segments.

13. A. aristatum, Sw.; Willd. Spec. v. 264. Fronds 1 to $2 \mathrm{ft}$. high, broadly ovate-triangular in outline, twice pinnate or the lower pinnæ again pinnate at the base, firm but thin, light-green and glossy ; the stipes slender,

- with a few black scales. Segments very obliquely oblong or lanceolate, $\frac{1}{2}$ to $1 \mathrm{in}$. long, narrowed or cuneate and acute at the base, bordered at the end with a few teeth often ending in short stiff bristle-like points. Sori small, not numerous, loosely arranged in 2 rows. Indusium small, reniform.-Polystichum aristatum, Presl; Hook. in Kew Journ. Bot. ix. 340.

Among rocks, in ravines, Urquhart, Bowring, Lorrain, Wilford. In New Zealand, the Pacific islands, China, and Japan, and closely allied to some Indian forms as well as to A. drepanum from Madeira.

\section{GRAMIMITIS, Sw.}

Sori oblong or linear, straight, more or less oblique with reference to the midrib, proceeding from a branch of the forked or anastomosing veins. Indusium none.-Rhizome usually creeping. Fronds simple or pinnate. 
A considerable genus, chiefly tropical, common to the New and the Old World, differing from Asplenium in the absence of any indusium, and from the closely allied Gymnogramme, chiefly in habit, and in the sori always simple and straight, not forked.

1. G. decurrens, Wall.; Hook. and Grev. Ic. Fil. t. 6. Rhizome rather thick, creeping, with black or brown scales. Fronds erect, 1 to $2 \mathrm{ft}$. high, quite glabrous, deeply pinnatifid or pinnate. Segments 3 to 17, lanceolate, 3 to 5 in. long, acuminate, narrowed at the base, rather distant, but usually connected by a decurrent wing, or the lower ones quite free, all rather thick. Veins proceeding from the midrib and immediately forked, in the fertile segments one branch bears a straight linear sorus, the other, like both branches in the barren segments, is flexuose and anastomosing, and from both are emitted a few short free branches.-Selliguea decurrens, Presl; Hook. in Kew Journ. Bot. ix. 358.

In ravines, Champion and others. In the Indian Peninsula, the Himalaya, Khasia, the Philippines, Loochoo, and Corea.

\section{MEENISCIUM, Schreb.}

Sori oblong, transverse, (parallel to the midrib) and arranged in parallel rows between the primary pinnate veins. Indusium none.

A small tropical genus, common to the New and the Old World, only differing from Polypodium in the shape of the sori.

1. M. simplex, Hook. in Lond. Journ. Bot. i. 294, t. 11, and Fil. Exot. t. 83. Rhizome creeping. Frond simple or 3-lobed at the base, lanceolate, acuminate, 3 to $8 \mathrm{in}$. long on a stipes of 3 to $6 \mathrm{in}$., cordate at the base, $\frac{3}{4}$ to $2 \frac{1}{2}$ in. broad, pubescent. Veins numerous and parallel, diverging from the midrib, and connected by numerous transverse veinlets which, in the fertile fronds, bear the sori.

Common on hillsides, Hinds, Champion and others. Also in Chusan.

\section{POLYPODIUM, Linn.}

Sori circular or rarely somewhat oval, variously arranged on the under surface of the frond. Indusium none. Receptacle not raised.-Herbaceous Ferns. Fronds simple or once, twice, or thrice pinnate.

A large genus, as widely dispersed over the surface of the globe as Asplenium and Aspidium.

Fronds all simple, thick, the veins inconspicnous or the primary ones seareely prominent.

Sori in a single row on each side of the midrib.

Sori scattered in several rows

Sori very closely packed in numerous series occupying the whole breadth of the fertile fronds.

Fertile fronds linear, always barren at the base ... . . . .

Fertile fronds oblong-lanceolate or linear-lanceolate, mostly covered with sori from the base

1. P. Wightianum.

2. P. hymenodes.

Fronds 3-lobed, or sometimes simple, thin, with prominent veins . .

Fronds simply pinnate. Veins parallel, prominent. Sori on transverse veinlets between them.

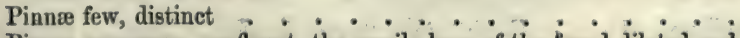

Pinnæ numerous, confluent, the sessile base of the frond dilated and shortly lobed .

3. P. adnascens.

4. P. Lingua.

5. P. tridactylon.

6. P. granulosum.

7. P. coronans.

Fronds thrice pinnate

8. P. tenericaule. 
1. P. Wightianum, Wall. Catal. n. 2222. Rhizome shortly creeping. Fronds linear-lanceolate and acuminate, or rarely linear and obtuse, from 1 to $2 \mathrm{in}$. long in some specimens, near 8 in. in others, narrowed into a short stipes, thick, with immersed inconspicuous reticulate veins. Sori in a single row on each side of the midrib, large and sometimes occupying nearly the whole breadth from the margin to the midrib; in other specimens the frond is thinner and broader in proportion to the sori. When young the spore-cases are concealed under several peltate scales, which soon disappear.-Pleopeltis nuda, Hook. Exot. Fl. t. 63 ; Gen. Fil.t. 18. Drynaria subspathulata, Hook. in Kew Journ. Bot. ix. 356.

Hongkong, Harland. Common on the Chinese coast and extends all over India, and northward to Japan.

2. P. hymenodes, Wall. Catal. n. 283. Rhizome creeping. Fronds simple, lanceolate, 5 to $9 \mathrm{in}$. long in the Hongkong specimens, narrowing into a stipes of 1 to 3 in., obtuse or acuminate, $\frac{3}{4}$ to $1 \frac{1}{4}$ in. broad, glabrous, rather thick; the pinnate and reticulate veins immersed and inconspicuous. Sori rather large, distinct, in 3,4 , or rarely 5 longitudinal rows on each side of the midrib, $(3,4$, or 5 in each obliquely transverse row).

On rocks in a ravine, Wilford. In northern and eastern India, in China, and northward to Corea. It is not unlikely that this and the preceding species may be both referable to some older published Indian or Javanese ones, but the genus Polypodium is at present in too great confusion to aseertain the synonymy without a general revision.

3. P. adnascens, Sw.; Willd. Spec. v. 145. Rhizome slender, creeping, with lanceolate, ciliate, or fringed scales. Fronds simple, entire, thick and coriaceous, more or less covered, especially on the under side, with minute stellate scales or hairs. Barren ones oblong, very obtuse, $\frac{3}{4}$ to $1 \frac{1}{2} \mathrm{in}$. long, on a stipes sometimes very short, rarely $\frac{1}{2}$ in. long. Fertile fronds linear, obtuse, 3 to 5 in. long, covered from about the middle or from rather lower down to the apex with numerous closely packed small sori, arranged in oblique rows, occupying the whole interval from the midrib to the margin, and separated from each other by dense stellate hairs or scales.-Niphobolus adnascens, Kaulf.; Sm. in Seem. Bot. Her. 425. Polypodium pertusum, Roxb.; Hook. Exot. Fl. t. 162. Niphobolus carnosus, Blume; and N. pertusus, Spreng.; Hook. in Kew Journ. Bot. ix. 355.

Common in ravines, Hinds, Champion, and others. In Ceylon, the Indian Perinsula, and Bengal.

4. P. Lingua, Sw.; Willd. Spec. v. 162. Very near the last, with the same habit and indumentum, but the fronds are usually larger, oblong or oblong-lanceolate, more or less narrowed towards the apex, the fertile ones fully as broad as the barren and usually longer, covered from the base with closely serried sori, except in a few imperfectly fruiting fronds, where they generally fail at the top as well as the base. The fronds vary from 1 to 5 in. in length. -Acrostichum Lingua, Thunb. Fl. Jap. t. 33.

Appears to be equally common with the last, being sent with it in most collections from the island. Also on the Chinese continent and in Japan.

5. P. tridactylon, Wall.; Hook. and Grev. Ic. Fil. t. 209. Rhizome creeping. Fronds 3 to $8 \mathrm{in}$. long, narrowed into a stipes of 1 to $3 \mathrm{in}$., sometimes lanceolate and entire, but more frequently divided into 3 lanceolate lobes, 
the lateral ones diverging and half as long as the central one, all acuminate, entire, thin and glabrous. Veins reticulate, the primary branches diverging from the midrib halfway to the margin. Sori rather small, on the anastomosing veinlets, 1 to 3 between each 2 primary veins.

Hongkong, Champion, Harland; in a wet shady situation at Little Hongkong, Wilford. In Ceylon, Khasia, Assam, and the Philippines.

6. P. granulosum, Presl, Rel. Hank. 24, t. 4, f. 2. Fronds $1 \mathrm{ft}$. high or more, pubescent at least on the rhachis and principal veins, simply pinnate. Pinnæ 5 to 7 or sometimes more, oblong-lanceolate, acuminate, slightly falcate, 4 to 5 in. long, entire, rounded at the base and shortly petiolulate. Veins very prominent, the primary ones numerous, parallel, with regularly pinnate transverse veinlets meeting in an intermediate line as in Meniscium. Sori at the junction of the veinlets, in a single row between each 2 primary veins in the Hongkong specimens, more frequently (but not always) in a double row in the Indian ones.-P. urophyllum, Wall. Catal. n. 299. Nephrodium glandulosum, J. Sm. in Seem. Bot. Her. 428.

Hongkong, Hance; in Water Ravine, Urquhart. In Ceylon, Khasia, Sikkim, the Malayan Peninsula, the Archipelago, and northward to Chusan. One or two of the peltate scales intermixed with the sori occasionally persist a long time, so as to have been mistaken for the indusium of an Aspidium.

7. P. coronans, Wall.; Hook. Fil. Exot. t. 91. Rhizome stout, elongated. Fronds densely tufted, sessile, 2 to $3 \mathrm{ft}$. high or more, stiffly coriaceous, glabrous and shining, deeply pinnatifid or almost pinnate. Lobes numerous, the longer ones lanceolate, acuminate, from 3 or $4 \mathrm{in}$. to twice that length, divided almost to the rhachis in the centre of the frond, becoming gradually shorter and more obtuse below the middle, until the frond again expands into a cordate base often 6 to $8 \mathrm{in}$. broad, with short rounded lobes. Veins prominent and parallel, starting from the midrib, and connected by transverse reticulations. Sori in 1 row between each 2 primary veins.

Near Victoria Peak, Wilford. In the mountaius of northern and eastern India.

8. P. tenericaule, Wall.; Hook. in Ken Journ. Bot. ix. 353. Fronds $1 \frac{1}{2}$ to $2 \mathrm{ft}$. high, twice pinnate, with deeply pinnatifid pinnules; the stipes glabrous, not muricate, with a few brown scales at the base. Lower primary pinnæ 6 to 8 in. long, the upper ones passing into the pinnatifid apex. Pinnæ lanceolate, the longer ones $2 \mathrm{in}$. long, the principal veins bearing a few stiff hairs. Segments oblong-linear; the lower ones deeply serrate, the upper short and entire. Sori 1 to 4 on each side of the midrib of the segment.

Near the church of Victoria, W'ilford; in Tank Ravine and Washerman's Ravine, Urquhart. In India, from Concan to Assam, in Singapore and the Archipelago, and northward to the Philippines and S. China.

\section{BRAINEA, Hook.}

(Bowringia, Hook; not Champ.)

Sori at first short and distinct, parallel to and near the midrib, at length usually confluent along the midrib and covering nearly the whole surface of the fertile segments. Indusium none.

A genus limited to a single species. 
1. B. insignis, Hook. in Kevo Journ. Bot. ix. 354; Fil. Exot. t. 38. Trunk erect, attaining 3 to $4 \mathrm{ft}$., with dark-brown scales. Fronds 2 to $3 \mathrm{ft}$. or more, including the short stipes, simply pinnate. Pinnæ numerous, linearlanceolate, acuminate, minutely serrate, cordate at the base, the larger barren ones 4 to $6 \mathrm{in}$. long, the upper ones tapering into the pinnatifid apex, the lowest also diminishing in size; the fertile ones rather smaller and narrower. Veinlets numerous and parallel, diverging from a series of arched veins along the midrib. Sori either on these arched veins only or continued along the veinlets.-Bovringia insignis, Hook. in Kew Journ. Bot. v. 237, t. 2.

Hongkong, Bowring, Champion, and others. Also in Khasia.

\section{ALSOPHILA, Br.}

Sori globular, dispersed over the under surface of the frond-segments, with an elevated receptacle frequently villous. Indusium none, except, in a few species, a minute indistinct membrane or scale at the base of the sorus.Tree-ferns. Fronds usually large, twice or several times pinnate. Veins pinnate, the branches free, simple or forked.

A considerable tropical genus both in the New and the Old World, but the spurious species have probably been much multiplied in books : for herbarium specimens are usually very insufficient for exhibiting the several forms observable in the different parts of the large fronds of these Tree-ferns.

1. A. podophylla, Hook. in Kew Journ. ix. 334. Trunk 4 to $8 \mathrm{ft}$. high. Fronds attaining 8 or $9 \mathrm{ft}$. in length, twice to 4 times pinnate. Stipes glossy, often rough with minute raised points, the base thick, sometimes muricate and bearing long black scales. Ultimate pinnules or segments lanceolate, acuminate, the large ones 4 to 5 in. long, sinuately toothed, truncate at the base and shortly petiolulate, all diminishing upwards and passing into the pinnatifid apex. Sori rather small, globose, seattered, the spore-cases very closely packed.

Hongkong, Bowring, Harland, Lorrain ; in ravines, Urquhart, Wilford. Also in Chusan. Some fronds called by Wilford " young fronds," but probably the first ones of a fresh growth, are simply pinnate with deeply pinnatifid pinnæ.

\section{2. сівотIUм, Kaulf.}

Sori contained in a prominent coriaceous deeply 2-valved indusium, of which the outer valve proceeds from the margin of the segment.-Tall Ferns with twice pinnate fronds.

A small genus, limited to eastern Asia, the Pacific islands, and west-central America.

1. C. glaucum, Hook. and Arn.; Hook. Spec. Fil. i. 82. Fronds bipinnate, glabrous and shining on the upper side, glaucous underneath, with occasionally a few hairs on the rhachis. Pinnules deeply pinnatifid, lanceolate, acuminate, 4 to 5 in. long, the upper ones diminishing and tapering into the pinnatifid apex. Lobes or segments numerous, more or less falcate. Veins simple or forked in different parts of the frond, or both mixed. Indusia very prominent and coriaceous, usually 2 to 4 on each margin of each lobe, or sometimes only 1 on each side at the base. Valves concave, very nearly equal, or the inner one rather narrower.-C. glaucescens, Kunze; Hook. Spec. Fil. i. 82. C. Assamicum, Hook. l. c. i. 83 , t. 29 B. 
Common in ravines, Champion and others. In Assam, S. China, and the Sandwich Islands. The number of sori to each segment, and the proportion of simple and forked veins, is very variable on the same specimen.

\section{DAVALLIA, Sm.}

Sori inserted at the end of a vein at or very near the margin, globular, contained in a more or less cup-shaped indusium, more or less adnate to the frond, and open at the free truncate top, next to the margin of the frond.-Rhizome usually creeping. Fronds simple, pinnate, or decompound. Veins forked and diverging from a more or less prominent midrib.

A large genus, chiefly tropical or subtropical, common to the New and the Old World, but more abundant in the latter.

Fronds triangular, pinnate or pinnatifid, coriaceous, 2 to 3 in. long. 1. D.pedata.

Fronds simply pinnate, pubescent, with long lanceolate segments . 2. D. Hookeriana.

Fronds decompound, $1 \mathrm{ft}$. long or more.

Fronds glabrons, smooth and shining.

Sori terminating the lobes . . . . . 6. D. temuifolia.

Sori on the under surface within the margin.

Sori cylindrical or oblong . . . . . . . . . 4. D. elegans.

Sori as broad as or broader than long . . . . 5. D. Griffithiana.

Fronds pubescent, thin and pale green. Sori in the sinus of the lobes. . . . . . . . . . . D. polypodioides.

1. D. pedata, Sw.; Hook. Spec. Fil. i. 154, t. $45 \mathrm{~A}$. Rhizome creeping to a considerable length, covered with brown scales. Fronds erect, ovatetriangular, 2 to 3 in. long, on a stipes about as long, cordate at the base, coriaceous, deeply pinnatifid or pinnate at the base. Segments oblong-lanceolate, obtuse, sinuate or the lower pair pinnatifid. Veins forked, coalescing into a central one not more prominent than the branches. Sori close to the margin, towards the ends of the segments. Indusium nearly orbicular.

Hongkong, Hinds, Dill, Wright; on a rock at the top of Victoria Peak, Wilford. In the Mauritius, Ceylon, Silhet, and the Indian Archipelago.

2. D. Hookeriana, Wall.; Hook. Spec. Fil. i. 172, t. 47 B. Fronds 1 to $2 \mathrm{ft}$. high, simply pinnate, pubescent. Pinnæ lanceolate, serrate, 2 to 4 in. long, truncate at the base, with a prominent angle or lobe on the inner side, diminishing from the lowest pair to the pinnatifid apex. Veins forked, numerous, parallel, from a prominent midrib. Sori in a row just within the margin of the segment. Indusium broad and short.

In the path to Poke-Fallum, Urquhart. In Kumaon, Silhet, and Khasia.

3. D. polypodioides, Don; Hook. Spec. Fil. i. 181. Rhizome creeping. Fronds 2 to $3 \mathrm{ft}$. high, twice or thrice pinnate, light green, flaccid, and more or less pubescent. Primary pinnæ distant, the 1 or 2 lowest pair smaller than the following, which are often 6 in. to $1 \mathrm{ft}$. long, gradually diminishing to the apex. Segments from lanceolate to oblong or obovate, the larger ones deeply lobed, with obovate obtuse lobes. Sori solitary under each sinus of the lobed segments or near the margin of the entire ones. Indusium short and broad.

Common in ravines, Urquhart, Wilford. Widely spread over the tropical and subtropical regions of the Old World, appearing also in tropical America.

4. D. elegans, Sw.; Hook. Spec. Fil. i. 164. Rhizome creeping, thick, 
scaly and woolly. Fronds $2 \mathrm{ft}$. high or more, very broad, glabrous, firm, smooth and shining, 3 or 4 times pinnate. Pinnæ and pinnules all acuminate, passing into a pinnatifid apex. Segments lanceolate or oblong, acute at the base, but only slightly decurrent on the rhachis, the larger ones serrate. Veins few, diverging from a raised midrib. Sori usually oblong, partially sunk in the under surface of the lobes or smaller segments, with a narrow cup-shaped indusium.

Hongkong, Champion. In Madagasear, Ceylon, the Indian Peninsula, the Archipelago, Australia, and the Pacific islands. The Hongkong specimens belong to Hooker's var. $\delta$ coniifolia.

5. D. Griffithiana, Hook. Spec. Fil. i. 168. Habit of D. elegans, but not so large. Fronds usually twice or thrice pinnate, $1 \frac{1}{2}$ to $2 \mathrm{ft}$. high, the segments shorter and broader than in D. elegans, and more confluent at the base. Sori shorter, and inserted on the under side at a considerable distance from the margin or apex of the lobes.

Hongkong, Wright. In Khasia, Assam, S. China, and northward to Chusan.

6. D. tenuifolia, Sw.; Hook. Spec. Fil.i. 186. Rhizome thick, shortly creeping, covered with thick brown scales. Fronds 1 to $2 \mathrm{ft}$. high, glabrous, firm, smooth, and often shining, twice to four times pinnate, the primary pinnæ more or less acuminate. Ultimate segments or lobes small, linearcuneate in the typical form, but in other varieties passing to broadly cuneate or obovate, the fertile ones terminating in 1 or 2 short broad sori, the edge of the indusium usually on a level with the margin of the lobe. In the barren fronds the segments are usually broader and denticulate.-D. chinensis, Sw.; Hook. 1. c. 187.

Abundant in the island, Hinds, Champion, and others. Generally distributed over India, the Archipelago, and Pacific isles, and northward to S. China and Bonin. The majority of the Hongkong specimens are intermediate between the narrow-lobed Indian varieties, and the broad-lobed small forms considered as representing $D$. chinensis, of which a very wellmarked specimen is among Hinds's, from Hongkoug.

\section{TRICHOMANES, Sm.}

Sori inserted at the end of a vein, and contained in a tubular indusium at or near the margin of the frond, and usually projecting beyond it. Receptacle filiform, often bristle-like, protruding from the indusium, with the sporecases at its base within the indusium.-Herbaceous Ferns, often very small, the half-pellucid fronds variously divided, and inserted on a creeping often densely matted rhizome.

A large genus, chiefly tropical, common to the New and the Old World, with 1 species extending northward into western Europe.

Fronds fan-shaped, 3 to 6 lines diameter . . . . . . . . 1. T. parvulum.

Fronds pinnatifid, $\frac{1}{2}$ to $1 \mathrm{in}$. long . . . . . . . . 2. T. intramarginale.

1. T. parvulum, Poir.; Hook. Spec. Fil. i. 118, t. 39 A. Rhizome slender, tomentose, and densely matted. Fronds orbicular-fan-shaped, 3 to 6 lines diameter, on a filiform stipes about as long, deeply and unequally divided into linear-obtuse or obtusely toothed lobes or segments. Sori rare, sunk as it were into the ends of teeth or lobes, which are usually shorter than the barren ones. 
Hongkong, Wright. In the Mauritius and Madagascar, the Indian Archipelago, and northward to the Philippines and S. China.

2. T. intramarginale, Hook. and Grev. Ic. Fil. t. 211 ; Hook. Spec. Fil. i. 120. A small slender densely matted half-pellucid Fern like the last. Fronds ovate or oblong in their outline, $\frac{1}{2}$ to 1 in. long, deeply pinnatifid, with few broadly linear entire or 2-cleft obtuse lobes, the base of the frond narrowed into a short stipes. Sori immersed in the ends of lobes similar to the barren ones, with a rather long projecting bristle.

Hongkong, Wright. Also in Ceylon.

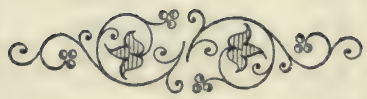





\section{INDEX OF GENERA AND SPECIES.}

The synonyms are printed in italics.

Abelmoschus
moschatus, Møench . 34

Abildgaardia . . . 389

Eragrostis, $V a h l$. 390

fusca, Nees . . 390

monostachya, $V a h l$. 389

Abrus . . . . 91 precatorius, Linn. . 92

Abutilon . . . . 33 indicum, Don . . 33

Acacia . . . . 101 concinna, $D C . \quad . \quad 101$ farnesiana, Willd. . 101

Acalypha . . . . 303 chinensis, Roxb. . . . 303 indica, Linn. . . . 303

Acampe . . . 358 multiflora, Lindl. . . 358

Acanthaceæ . . . . 259

Acanthus . . . . 263 ilicifolins, Linn. . . 263

Acer . . . . . . 47 oblongum, Wall. . . 47 reticulatum, Champ. 47

Achyranthes . . . 285 aspera, Lins. . . . 285

Aclisia sorzogonensis, E.Mey. 378

Acmena .. 119 Championi, Benth。 119

Acorus . . . . 345 Calamus, Linn。 . . 345

Acratherum miliaceum, Link . . 416

Acrostichum . . . 4443 aureum, Linn. . . . 443 decurrens, Hook. $\quad 443$ heteroclitum, Presl . 444 lingua, Thunb. . . 458 repandum, Blume . 444

Actinidia . . . . 26 Championi, Benth. . 26

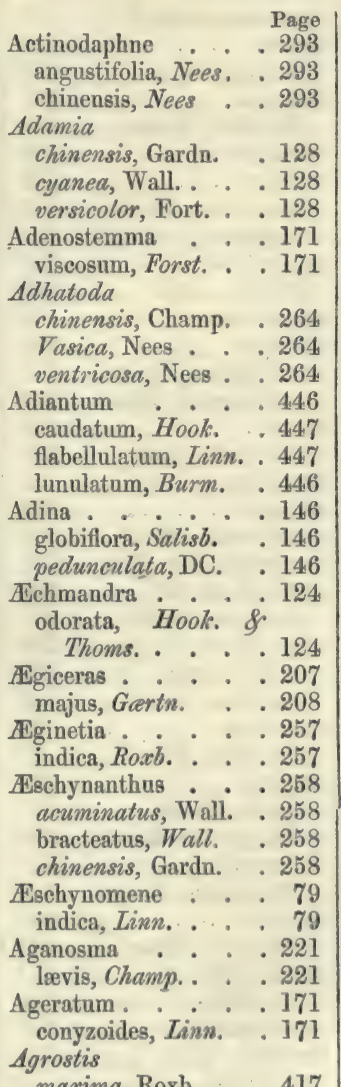
maxima, Roxb. . . 417 Agyneia

bacciformis, Juss. . 310

Ainsliea ?. . 191
Page

fragrans, Champ. . . 192

Albikkia

schonoides, Presl . 389

scirpoides, Presl . . 389

Albizzia . . . . 101

Championi, Benth. . 102

Milletti, Benth. . . 102

stipulata, Benth. . . 102

Alismaceæ . . . 346

Allamanda . . . . 217

cathartica, Linn. . . 217

Allomorphia

panciflora, Benth. . 116

Alocasia

commutata, Schott . 344

indica, Schott . . 343

macrorrhiza, Schott . 344

Alopecurns . . . 407

agrestis, Linn. . . . 407

geniculatos, Linn. . 408

Alpinia . . . . 348

alba, Rose. . 348

chinensis, Rose. . 349

galangas, Swo. . . 348

nutans, Rosc. . . . 348

Alseodaphne .... . 291

breviflora, Benth. . 292

chinensis, Champ. . 292

Alsophila . . . . 460

podophylla, Hook. . 460

Alternanthera . . . 285

sessilis, $\mathrm{Br}$. . . . 286

Alysicarpus . . . 80

buplevrifolius, $D C$. 81

nummulariefolius, $D C .81$

vaginalis, $D C$. . . 80

Alyxia . . . . . . 219

sinensis, Champ. . . 219

Amarantacere . . . 283

Amarantus . . . . 284

spinosus, Linn. : 284

viridis, Linn. . . 284

2 H 


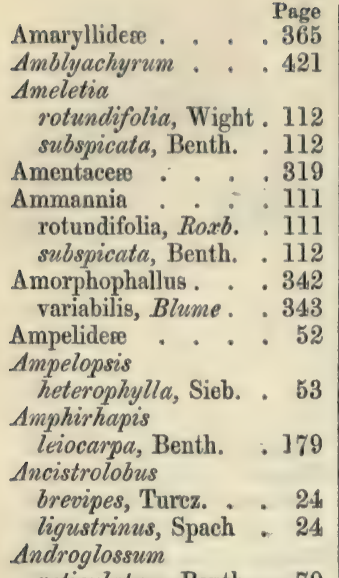

reticulatum, Benth. . 70

Andropogon . . . . 422

acicularis, Retz . . 425

brevifolius, $S w . \quad .423$

contortus, Linn. . . 424

javanicus, Nees . . 425

malacophyllus, Steud. 426

Martini, Roxb. . . 424

montanus, Roxb. . . 423

parvispica, Steud. . 423

patentivillosus, Steud. 426

pseudograya, Steud. . 423

tropicus, Spreng. . . 423

Vachellii, Nees . . 423

villosulus, Nees . . .423

zeylanicus, Arn. . . 423

Angiopteris . . . 440 evecta, Hoffm . . . 440

Ania . . . . 356 angustifolia, Lindl. . 356

Anilema . . . . 376 compressum, Dalz. . 377 debile, Wall. . . . 377 diandrum, Hance . 377 didymum, Seem. . . . 378 hispidum, Don . . .377 nudiflorum . . . 376

Anisocalyx limnanthiflorus,

Hance .. . . . . 249

Anisomeles . . . . 278 ovata, Br. . . . . 278

Anisopappus . $\quad 180$ chinensis, Hook. \& Arn.

Anonacere.

Anplectrum parviflorum, Benth. Page

Anthericum . . . 373 parviflorum, Benth. . 373

Antidesma . . . . 317

Bunius, Spreng. . 318 japonicum, Sieb. \&

Zuce. . . . 218 paniculatum, Roxb. . 318

Aopla . . . . 363 reniformis, Lindl. : 363 Apaturia

chinensis, Lindl. . . 356

Aplectrum . . . 116

Aplotaxis

carthamoides, DC. . 168

Apluda ... . 422

mutica, Linn. . . 422

Apocopis . . . . 421

Wrightii, Munr. . .421

Apocynaceæ . . . . 216

Aporosa . . . . . 316

frutescens, Blume . 317

leptostachya, Benth. 317

Appendicula . . . 358

bifaria, Lindl. . . 358

Aquifoliaceæ . . . 64

Aquilaria . . . 297 grandiflora, Benth. . 297 malaccensis, Benth. . 297

Aralia . . . . . 135 chinensis, Linn. . . 135

Araliaceæ . . . . 135

Ardisia . . . . 206 chinensis, Benth. $\quad 207$ crenata, Bot. Mag. . 206 crispa, A. DC. . . 206 japonica, Benth. . . 207 pauciflora, Heyne . $\quad 206$ primulæfolia, Gardn. 207 punctata, Lindl. . . 206

Argemone ..... 15 mexicana, Linn. . . 15

Argyreia . . . . 236 acuta, Benth. . . 237

Championi, Benth. . 236

Arisæma .. . . . 342 laminatum, Blume . 342

Aristida . . . . . .427 chinensis, Munr. . . 427

Aristolochia . . . 333 longifolia, Champ. . 333 Aristolochiaceæ . . . 333

Aroideæ . . . . . 341

Artabotrys $\quad . \quad 10$ Blumei, Hook. \& Thoms. . . . . 10 odoratissima, $\ddot{B r}$... 10
Artemisia . . Page

annua, Linn. . . . 187

indica, Willd. . . 187

japonica, Thunb. . 186

leptostachys, DC. $\quad 187$

vulgaris, Linn. . . 187

Arthrosprion

stipulatum, Hassk. . 101

Arthrostyles . . . 397

chinensis, Benth. $\quad 397$

Artocarpus . . . 325

hypargyrea, Hunce . 325

Arum . . . . 341

divaricatum, Linn. $\quad 342$

ternatum, Thunb. $\quad$. 342

trilobatum, Bot. Mag. 342

Arundina . . . $\quad 355$

chinensis, Blume. . 355

Philippi, Reichb. fil. 355

Arundinaria . . . 433

Wightii, Nees . . 434

Arundinella ... . 415

Eckloni, Nees : .416

miliacea, Nees . . 416

nepalensis, Trin. . . 416

setosa, Trin. . . . 416

stricta, Nees . . 416

Arundo . . . . 427

madagascariensis,

Kunth . . . 427

Reynaudiana, Kunth 427

Asclepiader .... . 223

Asclepias : . . . . 225

curassavica, Linn. . 225

Asparagus . .... . 371

falcatus, Benth. . . 371

lucidus, Lindl. . . . 371

Aspidium … . . 453

aristatum, $S w . \quad .456$

biserratum, Siv. . . 454

Championi, Benth. . 456

ciliatum, Wall. . 455

exaltatum, Swo. . . 453

falcatum, $S v_{2} \ldots . .454$

falcilobum, Hook. . 455

gracilescens, Blume . 455

hirsutulum, Sw. . . 454

intermedium, J. Sm. 454

molle, $S_{w}$. . . . 455

opreum, Hook. ․ 456

podophyllum, Hook. 454

Sieboldi, Mett. . . 454

squamulosum, Kaulf. 455

Thelypteris, Sw. . . 455

trifoliatum, Swo. . .454

tuberosum, Willd. . 454

unitum, Sw. . . . 456 
variolosum, Wall. : Page

Asplenium . . . 450 cuneatum, Lam. . . $45 \mathrm{I}$ davallioides, Hook. . 451 dilatatum, Hook. . 452 esculentum, Presl . 452 fraxinifolium, Wall.. 451 lanceum, Thunb. . 451 laserpitiifolium, Lam. 451 macrophyllum, $S w$. . 451 nidus, Iinn. . . . 450 oxyphyllum, J. Sm. . 451 Schkuhrii, Mett. . . 452 subsinuatum, Hook. \&

Grev. . . . 451 sylvaticum, Hook. . 452

Aster . . . . . 174 baccharoides, Steetz . 175 Benthami, Steetz . 175 brevipes, Benth. . . 175 striatus, Champ. . . 174 trinervius, Roxb. . . 174 Asteromaa. indica, Blume . . 174

Atalantia ...... . 51 buxifolia, Oliv. . . 51 Hindsii, Oliv. . . 51 monophylla, Benth. . 51

Atylosia . . . . 90 scarabroides, Benth. 90

Aucuba . . . . 138 chinensis, Benth. . 138

Aurantiacer ... . 49

Avena .. . . . 430 fatua, Linn. . . . 430

Averrhoa . . . . 56 Carambola, Linn. . $\quad 56$ sinica, Hance. . . 71

Axenfeldia

intermedia, Baill. . 306

Azalea . . . . . 201 indica, Linn. . . . 201 myrtifolia, Champ. . 201 ovata, Lindl. . . . 201 squamata, Lindl. . . 201

Brekea . . . . 118 Cumingiana, Schau. 118 frutescens, Linn. . 118

Balanophora .. . 140 Harlandi, Hook. . 140

Balanophoreæ . . 140

Balsamineæ . . . 55

Bambusa .. . . . 434 Arundo, Klein . .434 dumetorum, Hance . 435 Tulda, Roxb. . . \$434

\begin{tabular}{|c|c|}
\hline verticillata, Willd. & $\begin{array}{r}\text { Page } \\
.434\end{array}$ \\
\hline Barbula & \\
\hline $\begin{array}{l}\text { sinensis, Lour. } \\
\text { Barkhausia }\end{array}$ & . 269 \\
\hline tenella, Benth. . · & $\begin{array}{r}\cdot 193 \\
262\end{array}$ \\
\hline $\begin{array}{l}\text { Barleria } \\
\text { cristata, Linn. } \\
\text { dichotoma, Roxb. }\end{array}$ & $\begin{array}{l}262 \\
262 \\
262\end{array}$ \\
\hline $\begin{array}{l}\text { Barnardia } \\
\text { scilloides, Lindl. . }\end{array}$ & .373 \\
\hline $\begin{array}{l}\text { Basella } \\
\quad \text { rubra, inn. : . }\end{array}$ & \\
\hline Bauhinia . . & . 99 \\
\hline $\begin{array}{l}\text { Championi, Benth. } \\
\text { glauca, Wall. . . . }\end{array}$ & \\
\hline $\begin{array}{l}\text { Begouia } \\
\text { Bowringiana, Champ } \\
\text { laciniata, Roxb. }\end{array}$ & $\begin{array}{l}126 \\
126 \\
126\end{array}$ \\
\hline $\begin{array}{l}\text { Begoniacer · · · } \\
\text { Bellis }\end{array}$ & 125 \\
\hline
\end{tabular}

stipitata, Labill. . . 173

Benthamia . . . 137 japonica, Sieb.\& Zuce. 138

Berberideæ . . . 14

Berchemia . . . 67 lineata, $D C$. . . 67 lineata, Benth. . $\quad 67$ racemosa, Sieb.\& Zucc. 67 sessiliflora, Benth. . 68

\section{Berghausia}

mutica, Munr. . . 417 patula, Munr. . . 416

Bidens . . . . . 183

bipinnata, Linn. . 183 denudata, Turez. . . 184 leucantha, Willd. . 183 pilosa, Linn. . . . 183 sundaica, Bl. . . . 183 Wallichii, DC. . . 183

\section{Bigelovia} gracilis, Miq. . . 163 Kleinii, W. \& Arn. . 163 lovicaulis, Miq. . . 163 lasiocarpa, W. \& Arn. 163 myriantha, W. \& Arn. 163 Roxburghiana, W. \&

Arn. .. . . . . 163

Bischoffia . . . . 315 javanica, Blume . . 316 trifoliata, Hook. . . 316 Bixacere . . . . 19 Blackwellia fagifolia, Lindl. . . 122 Loureiri, Benth. . . 122 padiflora, Lindl. . . 122 Blechnum . . . . 444 japonicum, Thunb. . 445
Page

orientale, Linn. * $\quad 444$ Bleekeria, Miq. . . . 304 Bletia

Tankervilla, $\mathrm{Br} . .355$

Blumea,..... 177

elata, $D C$. . . . 177

chinensis, $D C$. . . 177

crinita, Steetz . . 178

Dregeana, DC. . . 179

glandulusa, $D C$. : $\quad 177$

hieracifolia, $D C$. . . 178

holosericea, DC. . . 178

javanica, Zoll. . 178

lacera, $D C$. . . . . 178

Wightiana, DC. . . 178

Blyxs.... . 347

Roxburghii, Rich. . 347

Bohmeria ... . : 331 nivea, Hook. \& Arn. 331

Bolbophyllum ... . . 353 radiatum, Lindl. . . 353

Boltonia . . . 173 indica, Benth. . . . 174

Bonnaya .. . . . 252 hyssopioides, Benth. 252 verbenafolia, Spreng. 252 veroniczefolia, Spreng. 252

Boragineæ . . . 233

Borreria

discolor, Bartl. . . 163 eryngioides,Ch.\&Schl. 163

Bothriospermum . 235 tenellum, Fisch. \&

Mey. . . . . 235

Bowringia ... . . . 95

callicarpa, Champ. . 95

insignis, Hook. . . 460

Boymia

glabrifolia, Champ. . 59

Brachyramphus

ramosissimus, Benth. 193

Brachyspatha

variabilis, Schott . 343

Bradleia

philippica, Cav. . . 314

sinica, Willd. . . . 314

Brainea . . . . 459

insignis, Hook. . . 460

Briedelia . . . 309

Loureiri, Hook.\& Arn. 310

tomentosa, Blume . 309

Brucea . . . . 60

sumatrana, Roxb. . 60

Bryonia

odorata, Ham. . . 124

umbellata, Ham. . 124

Bryophyllum . . . 127 


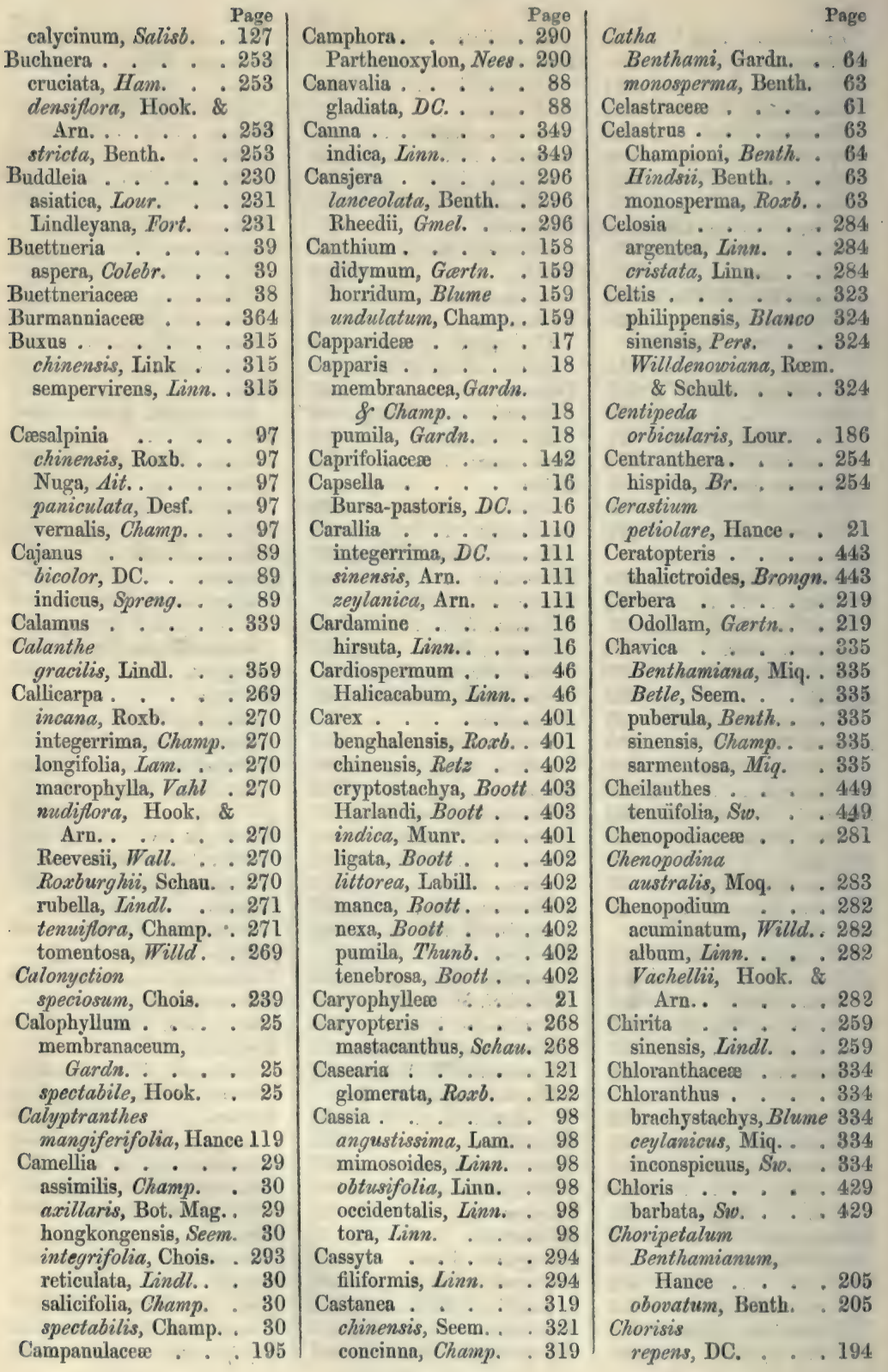


Page

Chrysanthemum . . . 184 indicum, Linn. . . 184

Chrysopogon . . . .424 aciculatus, Trin. . . 424 strictus, Nees. . . 423

Cibotium . . . . 460 Assamicum, Hook. . 460 glaucescens, Kunze . 4,60 glaucum, Hook. \& Arn.. . . . . 460

Cicea . . . . 312 microcarpa, Benth. . 312

Cinnamomum . . . 290 dulce, Nees . . . 290

Cirsium . . . . 168 chinense, Gardn. . 168 oreithales, Hance . 168

Cissus

angustifolia, Roxb. . 54 cantoniensis, Hook.

\& Arn. . . . . 54 cordata, Roxb. . . 54 diversifolia, Walp. . 54

Citrullus . . 125 vulgaris, Schrad. . . 125

Cladium . . . . 397 chinense, Nees . . 397 Mariscus, Br. . . 397

Claoxylon. . . 305 indicum, Endl. . . 305 muricatum, Wight . 306 parviflorum, Juss. 305 spiciflorum, Juss. 305

Clausena . . . . 50 Wampi, Oliv.. . . 50

Clematis . . . . 6 crassifolia, Benth. . 7 hedysarifolia, Bot. Reg. . . . . 6 Meyeniana, Walp. . 6 oreophila, Hance . 6 parviloba, Gardn. \&

Champ. . . : 6 uncinata, Champ. . 6

Clerodendron . . . 271 canescens, Wall. . . 272 hematocaly $x$, Hance 272 inerme, $B r . \quad$. . . 271 lividum, Lindl. . . 272 pentagonum, Hance. 272

\section{Cleyera} dubia, Champ. . . 27 fragrans, Champ. . 27

Cocculus : $: 12$ macrocarpus, $\dot{W} . \dot{8}$ Arn. 12 ovalifolius, $D \dot{C}: 13$
Page

Codonacanthus . . . 266

pauciflorus, Nees . . 267

Coelachne . . . . 430 pulchella, Br.. . . 430

Caeloglossum . . . . 362 cernuum, Reichb. fil. 362 lacertiferum, Lindl. . 36\% peristyloides, Wight 362 Coelogyne . . . . 354 fimbriata, Lindl. . 354

Colocasia . . . . 343 indica, Kunth . : 343 odora, Brongn. . ' 343

Commelyna . . . 375 benghalensis, Linn. . 376 Blumei, Dietr. . .376 caspitosa, Roxb. . . 376 canescens, Vahl . . 376 communis, Linn. . 376 mollis, Jacq. . . . 376 ochreata, Schau. . . 376 salicifolia, Roxb. . 376

Commelynaceæ . . . 375

Compositr . . . . 165

Conchidium pusillum, Griff. . . 353 Coniferæ . . . . 336 Connarus

juglandifolius, Hook.

\& Arn. . microphyllus, Hook. \& Arn. . . . Roxburghii, Hook. \& Am.

Connaraceæ . . . 70

Convolvulaceæ . . . 235

Convolvulus ianthinus, Hance . 239 pentanthus, Jacq. . 240 Conysa . . . . 176 ambigua, DC. . . 176 pyrifolia, Lam. . . 176 veronicæfolia, Wall. 176 Coolia punctata, Retz . . 50 Wampi, Blanco .. 50 Coprosmanthus japonicus, Kunth . 370

Corchorus . . . 40 acutangulus, Lam. . 40 capsularis, Linn. . . 40

Coriandrum ..... . 134 sativum, Linn. . . 135

Cornaceæ . . . . . 137

Cottonia . . . 357 Championi, Lindl. . 357 Cotula 185
Page anthemoides, Linn. . 185 Covellia

hispida, Miq.. . . 329

oppositifolia, Miq. . 329

Crassulaceæ .. . 127

Cratoxylon . . . 24 polyanthum, Korth. . 24

Crepis

japonica, Benth. . 194

Crinum . . . . 366 asiaticum, Linn. . . 366

Crotalaria . . . 73 albida, Heyne. . . 74 brevipes, Champ. . 74 calycina, Schranck . 74 elliptica, Roxb. . . 75 leiocarpa, Vog. . . 75 retusa, Linn. . . . 74

Croton . . . . 308 chinense, Benth. . 309 Hancei, Benth. . 308 lachnocarpon, Benth. 308 longifolium, Seem. . 308

Cruciferæ . . . , 15

Cucurbitaceæ. . . 123

Cunninghamia . . 337 lanceolata, Bot. Mag. 337 sinensis, $\mathrm{Br}$. . . 337

Cupia

densiflora, DC. . . 156 mollissima, Hook. \&

Arn. . .. . . 157

Curculigo . . . . . 366 orchioides, Roxb. . 366

Cuscuta . . . . 240 japonica, Chois. . . 241 Cyanitis sylvatica, Bl. . . . 128 Cyanopis pubescens, Bl. . 169 Cyanotis . . . . 378 axillaris, Roem. \& Sch. 378 fasciculata, Roem. \& Sch. . . . . 378 lanata, Benth. . . 378

Cyathula .... . .285 prostrata, Blume . 285

Cyclea, Arn..... . 13 deltoidea, Miers . . 14

Cymbidium ... . 357 ensifolium, Lindl. . 357 xiphiifolium, Lindl. . 357

Cyminosma . . $\quad 59$ pedunculata, $D C$. $\quad 60$ resinosa, DC. . . 60 Cynodon...... 428 dactylon, Pers. . $\mathbf{4 2 8}$ 


\begin{tabular}{|c|c|c|c|}
\hline & & & Page \\
\hline Сурегасею & .383 & Dendropanax. . . & oppositifolia, Linn. , 367 \\
\hline erus . & .384 & parviflora, Benth. & sativa, Linn. . . \\
\hline canescens, Vahl . & .387 & protea, Benth. , & Dioscorideæ. . \\
\hline compressus, Linn. & .385 & Derris . . . & Diospyros . . . \\
\hline is, Linn. . & . 385 & chinensis, Benth. & eriantha, Champ. . \\
\hline Linn.. , & & trifoliata, Lour. . & Morrisiana, Hance \\
\hline tis, Vahl. & & uliginosa, Benth. & vaccinioides, Lindl. \\
\hline n, Linn. . & .386 & Desmochata & Diplasium \\
\hline Iria, Linn.. . . & .386 & prostrata, DC. & dilatatum, Blume \\
\hline & & Desmodium : . . & elegans, Hook. . . \\
\hline ees. & & acrocarpum, Hance . & tum, Sw. . \\
\hline Lam. & & ans, Benth. . . & cum, Sw. . \\
\hline Vahl. . & & cum, $D C$. . & Diplolepis. . . . \\
\hline & & $n$, Vog. . & apiculata, Lindl. . \\
\hline & & $\mathrm{n}, D C$. & Diplopappus \\
\hline & & $\mathrm{n}, D C$ & nus, DC. . • \\
\hline & & pulchellum, Benth. . & jides, Benth. \\
\hline & & & laxu \\
\hline eb. & .3 & $\mathrm{~m}, D C$. & Diplo \\
\hline Cypr & .364 & $\mathrm{~m}, D C$. & um, Dene. \\
\hline & & & Dipl \\
\hline Cyrtc & & ffolium, Hassk. 138 & viridiflora, $D C$. \\
\hline ia, Miers & .214 & ... . 372 & Dipteracanthus \\
\hline yrto & & ensifolia, Red. & calycinus, Champ. \\
\hline$f a$ & .454 & Plum & us, Nees \\
\hline Cýrto & .356 & Dicer & Dischidia . . \\
\hline Cullenii, & . 357 & eleg & ensis, Champ. \\
\hline & .357 & $\mathrm{DC}$ & Dissochæta .. . . \\
\hline ium & . 428 & $s$, Hance & $\begin{array}{l}\text { Dartinel, Hance. } \\
\text { Distylium. . }\end{array}$ \\
\hline & & Dicho & racemosum, Sieb. \& \\
\hline Dalb & . 92 & repens, Forst. . & Zuec. . . . \\
\hline enth. . & . 93 & .128 & Dithyrocarpus \\
\hline enth. . & . 92 & .128 & Dolichos \\
\hline Dalz. & 93 & Lour. . & phaseoloides, Roxb. . \\
\hline & 93 & a, Miq. . & Dollin \\
\hline & & Dichrocephala . & rpa, DC. . \\
\hline Daphn & . 296 & DC. . & Dopatriun \\
\hline Benth. & . 296 & $D C$. & junceum, Ham. . \\
\hline Benth. & . 296 & $a$, DC. . & Dorato \\
\hline Daph & . 294 & Dicli & Bowringiana, Seem. \\
\hline Nees & & Burmanni, Nees. & Drosera . . . \\
\hline $\operatorname{lum}$. & .3 & chinensis, Nees . & Burmanni, Vahl \\
\hline & & ana, Nees & i, Hook. \& Ar \\
\hline ghii, Baill. & .31 & Dicotyledons . . . & Drymaria. . \\
\hline. .1. & .24 & Dienia. . & cordata, Willd. \\
\hline & & congesta, Lindl. . & glossum . \\
\hline Davallia ...... & . 461 & Digitaria. . . . & carnosum, Hook. . \\
\hline ensis, Sw. & .462 & & Drynaria \\
\hline & & ilicifolia, Juss. & \\
\hline ana, Hook. & & Dilleniaceæ . . & Dubyaa \\
\hline Hookeriana, Wall. & . 461 & Dimeria . & ramosissima, Hance. 193 \\
\hline & & & \\
\hline ides, Don & 4 & Dios & chinensis, DC. \\
\hline $11 a, \Delta w$. & . 462 & aculeata, Wight. & Dunbaria . . . \\
\hline Delima & & Batatas, Done. & conspersa, Benth. \\
\hline & & & Dysophylla . . \\
\hline
\end{tabular}


aturicularia, Blume $\begin{array}{r}\text { Page } \\ 275\end{array}$

Ebenaceæ . . . . 209

Eedysanthera . . . 222 micrantha, $A . D C$. . 222 rosea, Hook. \& Arn. 222

Echinocroton, F. Muell. 305

\section{Echites}

saligna, Delile . 221

Eclipta . . . . 181 alba, Honke . . . 181

erecta, Linn. . . . 181 prostrata, Linn. . . 181

Ehretia . . . . 234 longiflora, Champ. . 234

Elæagnaceæ . . . . 298

Elæagnus . . . . 298 Loureiri, Champ.. . 298

Elæocarpus . . . 42 chinensis, Hook. fil. . 43 lancexfolius, Roxb. . 42 serratus, Benth. . . 43

Eleocharis affata, Steud. . 395 capitata, Br. . . . 394

Elephantopus . . 170 scaber, Linn. . . . . 170

Eleusine . . . . . 429 indica, Gertn. . 429

Elodea chinensis, Hance. . 24

Embelia . . . .204 Ribes, Burm. . . . 204

Emblica officinalis, Gærtn. . 312

Endospermum . . 304 chinense, Benth. . . 304

Engelhardtia . . . 318

Enkyanthus . . . 200 quinqueflorus, Lour. . 200 reticulatus, Lindl. . 200 uniflorus, Benth. . 200

Eragrostis. . . . 431 amabilis, W. \& Arn. 432 aurea, Steud. . . . 431 Brownei, Nees . . 432 geniculata, Nees . . 433 Millettii, Nees . . 432 orientalis, Trin. . . 432 pilosa, Beauv. . 432 pilosissima, Link. . 432 plumosa, Link . 431 tenella, Beauv. . . 431 tenuissima, Schrad. . 431 unioloides, Nees . . 432 zeylanicr, Nees . . 433 Eria
C... Page pusilla, Lindl. . . 353 rosea, Lindl. . . . 353 sinica, Lindl. . . . 353 Erianthus

japonicus, Beauv. . 420 tristachyus, Nees. . 421

Ericaceæ . . . . . 199

Erigeron . . . 175 ambiguus, Sch. Bip. . 176 linifolius, Willd. . . 176 pyrifolius, Benth. . 176

Eriobotrya . . . 108 fragrans, Champ.. . 108

Eriocaulon . . . 381 australe, $\mathrm{Br}$. . 382 cantoniense, Hook. \&

Arn. . . . . 382 cristatum, Mart. . $\quad 382$ heteranthum, Benth. 382 miserum, Korn. . . 382 setaceum, Linn. . . 383 truncatum, Ham. $\quad 382$ Wallichianum, Mart. 381

Eriochloa . . . .408 annulata, Kunth . . 409

Eriosema . . . . . 91 chinense, $\operatorname{Vog} . \quad$. $\quad 91$

Erycibe . . . . 236 glaucescens, Hook. \& Arn. . . . 236 obtusifolia, Benth. . 236

Eugenia

cerasoides, Roxb. . 119 operculata, Roxb. . 119 Paniala, Roxb. . . 119

Eulalia . . . . 420 densa, Munr. . . 420 japonica, Trin. . . 420 villosa, Nees . . . 421

Eupatorium . . . 171 chinense, Thunb. $\quad .172$ Lindleyanum, $D C$. 172 nodiflorum, Wall. .172 Punduanum, Wall. . 172 Reevesii, Wall. . . 172 Wallichii, $D C$. . . 172

Euphorbiaceæ . . . 299

Euphorbia . . . 300 helioseopia, Linn. 301 hypericifolia, Linn. . 301 Peplus, Seem. . . 301 pilulifera, Linn. . 302 sanguinea, Steud. \& Hochst. . . . . 302 thymifolia, Linn. . . 302 Tirucalli, Linn. . . 301 Eurya . chinensis, Champ Page japonica, Thunb. . 28 Macartneyi, Champ. . 28 Eustigma . . . . 132 oblongifolium, Gard. 132

\section{Euxolus}

viridis, Moq. . . . 284

Evodia . . . . 58

Lamarckiana, Benth. 59 meliæfolia, Benth. . 58

Evolvulus . . . 240 alsinoides, Linn. . . 240 linifolius, Linn. . . 240 pudicus, Hance . . 240

Evonymus . . . 62 hederaceus, Champ. . 63 laxiflorus, Champ. - 63 longifolius, Champ. . 62 nitidus, Benth. . . 62

Exacum . . . . 233 bellum, Hance . . 233 Horsfieldianum, Miq. 233 tetragonum, Roxb. . 233 Eyrea vernalis, Champ.. . 48

\section{Fagara}

triphylla, Lam. . . 59

Farfugium . . . 191 Kæmpferi, Benth. . 191

Ficus . . . 326 angustifolia, Roxb. . 327 Beecheyana, Hook.\&

Arn. . . 329

Championi, Benth. . 328 chlorocarpa, Benth. . 330 difformis, Lam. . . 327 Harlandi, Benth. $\quad .330$ hibiscifolia, Champ.. 329 hirta, Vahl . . . 329 hispida, Linn. fl. $\quad$. 329 impressa, Champ. $\quad .328$ Millettii, Miq. . . 328 nervosa, Roth . . . 327 nitida, Thunb. . . 327 oppositifolia, Roxb. . 329 pyriformis, Hook. \& Arn. . . . . 328 retusa, Linn. . . . . 327 stipulata, Thunb. . . 328 variolosa, Lindl. . . 328 Wightiana, Wall. . 327 Wrightii, Benth. . . 329

Filices . . . . 438

Fimbristyles . . 390

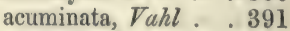
æstivalis, $\nabla a h l \quad .392$ 


\begin{tabular}{|c|c|}
\hline & \\
\hline arvensis, Vahl & Gentianaceæ \\
\hline . . & Gerbera . . . \\
\hline Cunth & amabilis, Hance. \\
\hline & ovalifolia, DC. \\
\hline & ides, Cass. \\
\hline & ri, Sch. Bip. \\
\hline & Germaria \\
\hline & latifolia, Presl \\
\hline & Gesneriacers. \\
\hline & Gironniera . . \\
\hline Nees. & $\begin{array}{l}\text { chinensis, Benth.. } \\
\text { nitida, Benth. }\end{array}$ \\
\hline & 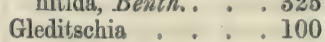 \\
\hline Vahl & sinensis, Linn. \\
\hline Vahl. & Gleichenia . . \\
\hline & dichotoma, Willd. \\
\hline & J. Sm. . \\
\hline Nees. & Glochi \\
\hline irm & pum, Champ.. \\
\hline 36 & Blume. . \\
\hline 7 & llum, \\
\hline & \\
\hline 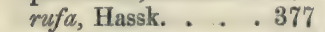 & Iool. \& Arn. \\
\hline tour & e, Benth. \\
\hline Fraxinus .... . 214 & Hook.\&.Arn. \\
\hline a, Champ. . .214 & \\
\hline & Glos \\
\hline chinensis, Gardn.. . 43 & ra, Hance. \\
\hline Guirena $. . . \quad . \quad .395$ & ita, Lindl. \\
\hline & Glo \\
\hline & Cass. \\
\hline Nees. & Glyc \\
\hline Reth & , Lindl. . \\
\hline & is Benth \\
\hline ensis, Seem. & 1... \\
\hline.$\cdot .3$ & $n$, Benth. \\
\hline 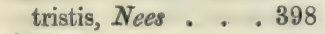 & DC. \\
\hline Gala & um, $D C$. \\
\hline h. . & DC. \\
\hline h. & Linn. \\
\hline Galiu & ps, Wall. . \\
\hline n... & Raddi . \\
\hline - & n, $\operatorname{Linn}$. \\
\hline Garcinia . . . . & um, DC. . \\
\hline multiflora, Champ. & Reinwardtianum, \\
\hline 1, Champ.. 25 & \\
\hline. .153 & Gnetaceæ . . \\
\hline oides, Hance . & Gnetum : : . \\
\hline & culare, Sm. \\
\hline . . . . s & seandens, Roxb. \\
\hline MUEsto & \\
\hline & Kœn. \\
\hline$n \ldots .$. & Gonyant \\
\hline elegans, Benth. & Wallichii, Miers. . \\
\hline condarusen & Goodeniaceæ . . \\
\hline & \\
\hline
\end{tabular}

Page discolor, Bot. Reg. . 361 procera, Hook. . . 360

Gordonia * . . . 29 anomala, Spreng. . . 29 javanica, Hook. . . 29 Goughia

Nilgherrensis, Wight 316

Graminese . . . 403

Grammitis . . 456 decurrens, Wall. . 457

Grangea . . . . 185 maderaspatana, Poir. 185

Gratiola veronicafolia, Roxb. 252

Grayia elegans, Nees. . . 414

Grewia . . . . 41 glabrescens, Benth. . 42 microcos, Linn. . 42 Grumilia

Reevesii, Hook.\& Arn. 161

Guettardella . . . . 158 chinensis, Champ. : 158

Guilandina . . . 96 Bonducella, Linn. . 96

Guttiferæ . . : . . 24 Gutzlaffia aprica, Hance . . 262

Gymnema . . . .227 affine, Dene. . . . 227 sylvestre, Benth.. . 227 Gymnopteris decurrens, Hook. . 443 Gymnothrix . . . 413 japonica, Kunth . . 413 Gynopachys attenuata, Korth. . 156 oblongata, Miq. . . 156 Gynura . . . 189 auriculata, DC. . 189 bulbose, Hook.\& Arn. 189 ovalis, DC. . . . 189 pseudochina, $D C . \quad$. 189

Habenåria . . . 361 galeandra, Benth. . 363 gigantea, Hook. . . 363 lacertifera, Benth. . 362 leptoloba, Benth. . 362 linguella, Lindl. . 362 Miersiana, Champ. . 363 stenostachya, Benth. 362 Susannæ, Br. . . . 363

Hæmaria . . . 360 discolor, Lindl. . . 361

Halorages . . . 139 Haloragis . . . 139 


\begin{tabular}{|c|c|c|}
\hline & & \\
\hline scabra, Benth. & latifolia, Gardn. . & Jasminaceæ : \\
\hline amamelideæ . & Heritiera . . . & Jasminum $\cdot \dot{p} \cdot$ \\
\hline ncea.. & littoralis, Ait. & paniculatum, Roxb. . 216 \\
\hline kerians, Seem. & Herpestis . . . 249 & Jatropha ... . \\
\hline ta, Benth. . & Monnieri, H. B. \& K. 249 & Curcas, Linn. . \\
\hline vides, Hance . & $\begin{array}{l}\text { neuron } \\
\text { iferum, Fée. . } 4\end{array}$ & $\begin{array}{l}\text { Ichnanthus } \\
\text { pallens, Munro }\end{array}$ \\
\hline & $\begin{array}{c}\text { Heteropogon. }: \\
\text { hirtus, Pers. }\end{array}$ & Ilex asprella, Champ. \\
\hline ede & Hibiseus . . & cinerea, Champ. . \\
\hline glauca, Hance & moschus, Linn. . 34 & graciliflora, Champ. . \\
\hline & tiliaceus, Linn. & cylifolia, Champ. \\
\hline & Hippocratea . . & pubescens, Hook. \& \\
\hline $0^{\circ} \cdot 3$ & obtusifolia, Roxb. & Arno... . \\
\hline , Champ. . & Hiptage . . . & s, Champ. \\
\hline & ta, Gartn. & Ilysa \\
\hline Wall. 1 & Hisut & ioides, Benth. 25 \\
\hline$i a$, Ch. \& & $\begin{array}{l}\text { iensis, 1C. . } 174 \\
\text { Hook. \& Arn. } 174\end{array}$ & sis, Linn. \\
\hline$a$, Wail. . ] & Holar & culata, Lam. \\
\hline V. $\& \cdot A r n$ & [ook. \& Arn. 221 & a... \\
\hline & 1. . . . 2 & eea, Cyr. \\
\hline & amp. & Beauv. . \\
\hline$\& \mathrm{~A}$ & Hom & Iudigofera $:$. \\
\hline & a, Benth. & s, Vahl. \\
\hline & Iou & Linn. \\
\hline & Thunb. & ina, DC. \\
\hline & Ioy & Findl. . . \\
\hline & . & Ha, Jacq. . \\
\hline & еæ : & \\
\hline$\& A$ & Hyc & \& Arn. . \\
\hline nth. . & $n n$. & $a$, Hochst. \\
\hline & & amp. . \\
\hline & Hance & Inga \\
\hline & Roxb. & $b i$ \\
\hline & Iy & $x$, Hook. \\
\hline & & Arn. \\
\hline & & Inula \\
\hline Benth. & .. & $D C$ \\
\hline & & DC. . \\
\hline & Man. & осарpa, DC. \\
\hline & , Thunb. & nox $\dot{\text { Linn }}$ \\
\hline & & nox, Linn. . \\
\hline & Нур & $\begin{array}{l}\text { eidis, } \text { Ker: . } \\
\text { sa, Rcem. }\end{array}$ \\
\hline & & , Rcom. \& \\
\hline & Kunth & \\
\hline & & \\
\hline & ea, $B r$. & ctylis, Chois. \\
\hline & & x, Sw. . \\
\hline & & $\rho^{\circ}$ \\
\hline th. & Hypse & usis, Chois. \\
\hline & - 12 & Iivide \\
\hline & & Isacl \\
\hline A & Jacq & australis, $\mathrm{Br}$. \\
\hline Heus & , Chois. & ea, Auct. \\
\hline $1=$ & $\therefore$ & Nees \\
\hline & & 21 \\
\hline
\end{tabular}




\begin{tabular}{|c|c|c|}
\hline \multirow{2}{*}{ simpliciuscula, W. \& ${ }^{\text {Page }}$} & & \\
\hline & Lantana . . & Limatodes. . \\
\hline \multirow{2}{*}{$\begin{array}{c}\text { Arn. } \\
\text { Ischæmum }\end{array}$} & Camara, Linn. & gracilis, Lindl. \\
\hline & crenulata, Otto \& & Limnophila . \\
\hline \multirow{4}{*}{$\begin{array}{l}\text { barbatum, Retz } \\
\text { leersioides, Munr. } \\
\text { ophiuroides, Munr. } \\
\text { Isolepis }\end{array}$} & .268 & hirsuta, Benth. \\
\hline & Lasianthus $\cdot \therefore$. & punctata, Blume. 248 \\
\hline & bracteatus, Wight & Limonia \\
\hline & chinensis, Benth. & bilocularis, Roxb. \\
\hline \multirow{2}{*}{$\begin{array}{l}\text { barbata, } B r . \\
\text { supina, } B r .\end{array}$} & nocarpus, Jack. & \\
\hline & Jackianus, Wight .160 & Linaria \\
\hline \multirow{2}{*}{ Itea ${ }_{\text {chinensis, Hook. \& }}{ }^{129}$} & Roxburghii, Wight . 160 & elatine, Mill. \\
\hline & Lastr & Lindsæa \\
\hline \multirow{3}{*}{ Ixia Arn.. . . . 129} & .455 & ensifolia, Szo. . \\
\hline & Hook. . . 455 & alata, Dry. . \\
\hline & & hylla, Dry. \\
\hline $\begin{array}{l}\text { Juglander }: .318 \\
\text { Juncaceæ }: 380\end{array}$ & Hook. . & polymorpha, Hook. \& \\
\hline Juncacer . . . . 380 & Laurineæ. . & Grev.. \\
\hline Juncus. $: 380$ & $\begin{array}{l}\text { Layia } \\
\text { emarainata Hook \& }\end{array}$ & $\begin{array}{l}\text { variabilis, Hook. \& } \\
\text { Arn. . } 446\end{array}$ \\
\hline $\begin{array}{l}\text { Leschenaultii, J. Gay } 380 \\
\text { sinensis, J. Gay . . } 380\end{array}$ & $\begin{array}{l}\text { emarginata, Hook. \& } \\
\text { Arn. . . . }\end{array}$ & Liparis . \\
\hline \multirow{3}{*}{$\begin{array}{r}\text { Jussiæa } \\
\text { octofila, DC. : : }: 109 \\
\text { villosa, Linn. . } \\
\end{array}$} & Ledebouria & longipes, lindl. \\
\hline & 71 & nervosa, Lindl. \\
\hline & .254 & ta, Lindl. \\
\hline \multirow{2}{*}{$\begin{array}{r}\text { Justicia } \\
\text { Adhatoda, Linn. . } \quad 263 \\
\end{array}$} & Leontoglossum & Lipoc \\
\hline & scabrum, Hance. & $\mathrm{ea}, \mathrm{Br}$. \\
\hline Championi, T.Anders. 264 & Leonurus . . . . & microcephala, $\mathrm{Br}$. \\
\hline \multirow{2}{*}{$\begin{array}{ll}\text { Gendarussa, Linn. } & \text {. } 264 \\
\text { ventricosa, Wall. } & \text {. } 264\end{array}$} & sibiricus, $\operatorname{Linn}$. & Liquidambar . . \\
\hline & his. . & sis, Champ. \\
\hline \multirow{2}{*}{$\begin{array}{r}\text { Ixeris } \\
\quad \text { debilis, } A . G r .\end{array} 193$} & hyalina, Nees. & . . . \\
\hline & sperma . & ceylanica, Nees \\
\hline ramosissima, A. Gr. 193 & chinensis, Nees & Lobel \\
\hline repens, $A$. Gr. . . 194 & Lepidostachys . & affi? \\
\hline \multirow{2}{*}{$\begin{array}{r}\text { versicolor, } D C . \\
\text { Ixora } .\end{array}$} & Lepta & nsis, Lour. \\
\hline & triphylla, Lour. . & trialata, Ham. \\
\hline \multirow[t]{2}{*}{ stricta, Roxb. . . 158} & . . 430 & trigona, Roxb. \\
\hline & & ceæ $\cdot$ \\
\hline $\begin{array}{l}\text { Kadsura } \\
\text { chinensis, Hance. }\end{array}$ & $\begin{array}{r}\text { ten } \\
\text { Lepto }\end{array}$ & lora, Champ. \\
\hline Kandelia ... . 110 & sumatrana, Blume . 229 & ica, Andr. \\
\hline Rheedii, Arn.. & Lespe & flora, $D C$. \\
\hline . . 12 & ata, Don . . & macrantha, $D C$. \\
\hline & striata, Hook. \& A $A r n$. & \\
\hline. .16 & viatorum, Champ. . & ta, Champ. \\
\hline $8 \mathrm{~s}$, Willa. $\cdot 10$ & Leucas . . . & Lophatherum . \\
\hline Kyllingia . . . . . 388 & mollissima, Wall. & gracile, Brongn. . \\
\hline monocephala, Linn. . 388 & Leucæna . . . & Lehmanni, Nees . \\
\hline & glauca, Benth. & еeæ. . • \\
\hline abiatæ . . . $\cdot 2$ & Ligularia & Loranthus ... \\
\hline$\therefore \cdot \cdot 192$ & Kampferi, Sieb. \& & chinensis, $D C$. \\
\hline brevirostris, Champ. 192 & Zuce. . . & Lou \\
\hline Lagenophora. . . . 172 & Ligustrum . . & obcordata, Desv. . \\
\hline Billardieri, Cass. & sinense, Lour.. & Ludwigia. . \\
\hline Harveyi, Thw. . & Liliaceæ . . . & jussicooides, Wall. \\
\hline sundana, Miq. . & Lilium . . . . . 374 & ra, Roxb. . \\
\hline Lagerstromia . . . 112 & longiflorum, Thunb. . 374 & Luisia . . \\
\hline indica, Linn. . . . 11 & $\begin{array}{l}\text { Limacia } \\
\text { cuspidata, Hook. \& } 12\end{array}$ & $\begin{array}{l}\text { teres, Lindl. } \\
\text { Lycimma }\end{array}$ \\
\hline & & \\
\hline
\end{tabular}




\begin{tabular}{|c|c|}
\hline \multicolumn{2}{|r|}{ Page } \\
\hline $\begin{array}{l}\text { Lycium } \\
\text { chinense, } \dot{M} \text { Mill. }\end{array}$ & $\begin{array}{l}244 \\
245\end{array}$ \\
\hline megistocarpum, Duu. & 245 \\
\hline vulgare, Dun. . & 245 \\
\hline Lycopódiaceæ . & 436 \\
\hline Lycopodium . . & 436 \\
\hline amentigerum, Goldm. & 436 \\
\hline atroviride, Wall. . & \\
\hline $\begin{array}{l}\text { caudatum, Desv. . } \\
\text { cernuum, Linn. . }\end{array}$ & \\
\hline flabellatum, Iinn. & 437 \\
\hline involvens, Swo. . & 436 \\
\hline Lygodium. · • & 441 \\
\hline circinatum, Soo. . & \\
\hline $\begin{array}{l}\text { dichotomum, Sw.. } \\
\text { japonicum, Swo. }\end{array}$ & \\
\hline $\begin{array}{l}\text { japonicum, Sio. } \\
\text { microphyllum, Br. }\end{array}$ & \\
\hline salicifolium, Presl & 442 \\
\hline $\begin{array}{l}\text { scandens, Swo. . } \\
\text { simachia . . . }\end{array}$ & 41 \\
\hline $\begin{array}{l}\text { ysimachia } \\
\text { alpestris, Champ. }\end{array}$ & \\
\hline
\end{tabular}

Lythrariez . . . . 111

Machilus . . . . 291

rimosa, Blume . . 291

Thunbergii, Benth. . 291

velutina, Champ. . . 291

Machlis

hemisphorica, D(;. . 186

Мæза . . . . . 203

coriacea, Champ. . . 204

iudica, A. DC. . 203

montana, A. DC. . . 204

sinensis, A. DC. . . 203

Magnolia . . . 8

Championi, Benth. . 8

pumila, Blume . . 8

Magnoliaceæ . . . 7

Malachium

aquaticum, Fries . . 21

Malouetia.

asiatica, Sieb.\& Zucc. 221

Malpighiaces . . 48

Malvaceæ . . . . 31

Malvastrum . . . 31 ruderale, Hance . . 32 tricuspidatum, A. Gr. 32

Mappa...... . 303 glabra, A. Juss. . . 304 Tamaria, Spreng. . . 304

Mariscus cyperinus, Vahl . . 386 umbellatus, Vahl . 386

Marlea. . . . . 138 begoniæfolia, Roxb. 138

Marquartia tomentosa, Vog.
Marsdenia . . . 225

lachnostoma, Benth.. 226

tinctoria, $\mathrm{Br}$. . . . 226

Mastacanthus

sinensis, Lindl. . 269

Mazus .... . 247

rugosus, Lour. . 247

vandellioides, Hance 247

Medicago . . . . 75

lupulina, Linn. . . 75

Medicia

elegans, Gardn. . . 229

Megabotrya

meliafolia, Hance . 59

Melanthesa . . . 312

cernua, Benth. . . 313

chinensis, Blume . 313

Melastoma . . . . 113 calycinum, Benth. . 114 candidum, Don . . 114 decemfidum, Roxb. . 114 homostegium, Naud. 114 macrocarpon, Don . 113 repens, Lam. . . . 113 sanguineum, Lindl. . 114

Melastomaceæ . . . 112 Melica

latifolia, Roxb. . . 417

Melodinus . . . 218 fusiformis, Champ. . 218 latus, Champ. . . 218 monogynus, Roxb. . 218 suaveolens, Champ. . 218

Memecylon . . . 117 ligustrifolium, Champ. 117 scutellatum, Hook. \&

Arn. . . . . . 117

Memorialis . . . 332

hispida, Ham. . 332

Meniscium . . . 457

simplex, Hook. . . 457

Menispermaceæ . . . 11

Mentha . . . 276 arvensis, Linn. . . 276 javanica, Blume . . 276 reticulata, Benth. . 276

\section{Meoschium}

lodiculare, Nees . . 426

Meyenianum, Nees . 426

\section{Mephitidia}

chinensis, Champ. . 160

Mertensia

glauca, J. Sm. . . 442

Mesona . . . 274

chinensis, Benth. 274

Microcarpæea . . . 253 muscosa, Br. . 253
Mioge

icrochloa . . . . 428

setacea, $\mathrm{Br}$. . . .428

Microelus, Arn. . . . 315

Microglossa

volubilis, DC. . . . 176

Millettia .... 78

Championi, Benth. . 79

nitida, Benth. . . 78

speciosa, Champ. . . 78

Miquelia

barbulata, Nees . . 417

Mitrasacme . . . 230

capillaris, Wall. . 230

chinensis, Griseb. .230

malaccensis, Wight . 230

nudicaulis, Reinw. . 230

Mollugo . . . . . 23

stricta, Linn. . . . 23

Momordica . . . 125

charantia, Linn. . . 125

Monochoria . . . 374

plantaginea, Kunth . 375

vaginalis, Presl . . 374

Monocotyledons . . 338

Moquinia

eriosematoides, Walp. 180

Morinda . . . . 159

umbellata, Linn. . . 159

Morocarpus

microcephalus,Benth. 332

Mucuna . . . 87

Championi, Benth. . 87

macrobotrya, Hance 87

Murraya : . . . 50

exotica, Linn. . . . 50

Musa . . . . 347

Mussænda . . . . 152

erosa, Champ. . . 153

frondosa, Linn. . . 153

pubescens, Ait. . . 153

Myrica . . . . 322

rubra, Sieb. \& Zuce. 322

Myriogyne . . 186

minuta, Less. . . . 186

Myrsinaceæ . . . 202

Myrsine . . . .205

capitellata, Wall. . 205 neriifolia, Sieb. \&

Zucc. . . . 206 philippinensis, A.DC. 206

Myrtaceæ. . . . . 117

Myrtus

tomentosa, DC. . . 121

Naiadex . . . . 345

Naias . . . . . 345

indica, Champ. . . 346 


\begin{tabular}{|c|c|c|}
\hline minor, All. . . . . 34.5 & gracilis, Kunth & barbatum, Kunth \\
\hline tenuifolia, Br. & spicatus, $K e r$. & batavicum, Steud. \\
\hline fasturtium . . . & Ophiorrhiza. . & teud. \\
\hline clea & Eyrei, Champ. & \\
\hline $\begin{array}{l}\text { auclea } \\
\text { adina, Sm. }\end{array}$ & $\begin{array}{l}\text { pumila, Champ. } \\
\text { Ophinrus. . . }\end{array}$ & $\begin{array}{l}\text { mutatum, Nees . } \\
\text { positum, Linn. . }\end{array}$ \\
\hline adinoides, Lindl. . & monostachyus, Presl & \\
\hline Neottia & undatus, Nees . . 417 & \\
\hline $\begin{array}{l}\text { pera, Bot. Reg. · } 360 \\
\text { pteris }\end{array}$ & Oplismenus & $2 x .$. \\
\hline $\begin{array}{l}\text { eottopteris } \\
\text { nidus, J. Sm. . }\end{array}$ & $\begin{array}{l}\text { colonum, Kunth } \\
\text { compositus, R.\& Sch. }\end{array}$ & n. $: 412$ \\
\hline epeta $\quad \therefore$. & -galli, Kunth . & Nees \\
\hline homa, Benth. & Orch & \\
\hline - 46 & Orme & Nees \\
\hline Litschi, Camb. & inata, Benth. . & rin. \\
\hline Nephrodium & pachyearpa, Champ.. & 13 \\
\hline $\begin{array}{l}\text { m. } 4 \\
.4\end{array}$ & chaceæ $\cdot$ & $\begin{array}{l}\text { Retz } \\
\text { in. }\end{array}$ \\
\hline $\begin{array}{l}\text { molle, Schott. } \\
\text { Nephrolepis }\end{array}$ & Osbeckia angustifolia, Don & m, Trin. \\
\hline ctula, J. Sm. · 454 & , Linn. . & $s \cdot \cdot$ \\
\hline Presl . . 454 & Wall. . & eng. . \\
\hline Nephroica & glabrata, Wall. & um, Roxb. . 412 \\
\hline & li & Kunth. \\
\hline 6s, Miers . 13 & Osm & im, Poir. \\
\hline , Miers & ta, Hook. & Sw. . . \\
\hline thus $\cdot{ }^{\cdot}, 86$ & $a$, Thunb. & $a m \cdot \cdot$ \\
\hline $\begin{array}{l}\text { chinensis, Benth. } \\
\text { phaseoloides, Benth. } 86 \\
86\end{array}$ & $\begin{array}{l}\text { ca, Blume } \\
\text {, Linn. . }\end{array}$ & $\begin{array}{l}\text { repens, Linn.... } \\
\text { sanguinale, Linn. }\end{array}$ \\
\hline Ticandra $\cdot \cdot \cdot 244$ & Vachellii, Hook. & tosum, Roxb. 412 \\
\hline & $\begin{array}{l}\text { Oudemansia } \\
\text { integerrima, Miq. }\end{array}$ & $\begin{array}{l}\text { simpliciusculum, } \\
\text { Steud. . . . } 4330\end{array}$ \\
\hline . 458 & Oxalideæ . . . . & Papaveraceæ . ... . 15 \\
\hline $\begin{array}{l}\text { osus, Blume . . } 458 \\
\text { usus, Spreng. } \quad .458\end{array}$ & $\begin{array}{l}\text { Oxalis } \\
\text { corniculata, } \operatorname{Linn.}\end{array}$ & $\begin{array}{l}\text { Paratropia } \\
\text { eantoniensis, Hook. \& } 136\end{array}$ \\
\hline rena $\cdot 449$ & corymbosa, DC. . & $\cdot \ldots \cdot \cdot \cdot$ \\
\hline ok. \& Arm. 450 & Martiana, Zuec. . & Pardanthus $\dot{K}: \cdot$ \\
\hline sulcata, Link & 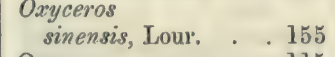 & $\begin{array}{l}\text { chinensis, Ker. * } 365 \\
\text { Parechites }\end{array}$ \\
\hline $\begin{array}{l}\text { Ochranthe } \\
\text { arguta, Lindl. }\end{array}$ & $\begin{array}{r}\text { Oxyspora } \\
\text { pauciflora, Benth. } \quad 115\end{array}$ & $\begin{array}{l}\text { Thunbergii, A. Gr. . } 221 \\
\text { Paritium }\end{array}$ \\
\hline - . 52 & & eum, St. Hil. • 35 \\
\hline Idia ${ }_{\text {titolia, Benth. }} 151$ & nse, Reichb. fil. 356 & ioides, Hook. . 443 \\
\hline $\operatorname{Linn} . .151,15$ & Pæderia . . . . . 161 & Parthenoxylon \\
\hline & , Linn. . & , Blume . 291 \\
\hline & $\begin{array}{l}\text { Paliury } \\
\text { Aub }\end{array}$ & $\begin{array}{l}\text { pseudo-sassafras, } \\
\text { Blume }\end{array}$ \\
\hline & $\begin{array}{l}\text { letii, Schult. } \\
\text {. . . }\end{array}$ & Blume . . \\
\hline Poir. & $\begin{array}{l}\text { Palmæ } \\
\text { Pancratium : }\end{array}$ & brevifolium, Flugge . 408 \\
\hline $\operatorname{Iinn..}$ & um, Roxb. . . . & e, Nees : 408 \\
\hline 1 & aceæ . · · & ulatum, Linn. 408 \\
\hline Olea & Pandanus . . & $+\cdots \cdots$ \\
\hline & Panicum $\cdot \cdot \cdot \cdot$ & Linn. . \\
\hline siana, Hance 21 & ustum, Trin. . . 4 & $\cdots ; \cdots$ \\
\hline 10 & ottianum, Nees . 4 & Linn. \\
\hline Ophiopogon . . . 371 & atrovirens, Trin. . . 4 & Pellionia . . . . . 330 \\
\hline
\end{tabular}


brevifolia, Benth. $\quad \begin{array}{r}\text { Page } \\ 330\end{array}$ scabra, Benth. . 330

Pentaphylax . . . 28 euryoides, Gardn. . 28

Pentasacme . . . 227 Championi, Benth. . 228

Pericampylus . . . 13 incanus, Miers . 13

Perilla . . . . 275 arguta, Benth. . . 276 lanceolata, Benth. . 276

Peristylus chlorantha, Lindl. . 362

Perotis . . . 418 latifolia, Ait. . . 418

Phaius . . . 355 grandifolius, Lour. . 355

Phalangium falcatum, Wall. . 373 parvifiorum, Wight . 373

Phanera.

Championi, Benth. . 99 corymbosa, Benth. . 99

Phaseolus . . . . 88 minimus, Roxb. . 88

Philydrum . . . 379 lannginosum, Banks 380

Phlebophyllum apricum, Benth. . . 262

Phoberos chinensis, Lour. . . 19 savus, Hance . 19

Phoebe latifolia, Champ. . 291

Phœnix . . . 339 acaulis, Roxb. . . 340

Pholidota . . . . 354 chinensis, Lindl. . 354

Photinia . . . 107 prunifolia, Lindl. . 107

Phragmites . . . . 427 Roxburghii, Kunth . 428

Phreatia uniflor $a$, Wight . . 353

Phyllanthus . . . . 310 anceps, Willd. . 311 bacciformis, $\operatorname{Iinn.~} .310$ cantoniensis, Hornem. 311 cinerascens, Hook. \& Am.

Emblica, Linn. . . 312 Tepidocarpus, Sieb. \& Zuce. leprocarpus, Wight . 311 Jeptoclados, Benth. . 312 lucens, Poir. . . . 313
Page maderaspatensis, Linn. 311 Niruri, Linn. . . . 311 simplex, Willd. . . 311 Simsiana, Wall. . . 313 turbinatus, But. Mag. 313 urinaria, Linn. . . 310 ussuriensis, RuJpr. . 311

Phyllodium

elegans, Desv. . 83 pulchellum, Desv. . 83

Physalis . . . . 244 angulata, Linn. . . 244 capsicifolia, Dun. . 244 Linkiana, Nees . . 244

Picrasma . . . . 61 quassioides, Benn. . 61

Piddingtonia . . . . 196 nummularia, A. DC. 196 Pinellia

tuberifera, Ten. . 342

Pinus . . . . . 337

sinensis, Lamb. . . 337

Piper

arcuatum, Seem. .335

fragile, Benth. . . 335

Piperaceæ . . . . 335

Pithecolobium . . 102

clypearia, Benth. $\quad 103$

lucidum, Benth. . . 102

Pittosporaceæ . . 18

Pittosporum ... . . 19 glabratum, Lindl. . 19

Plantagineæ . . . 280

Plantago . . . . 280 major, Iinn. . . . 280

Platanthera

Championi, Lindl. . 363 galeandra, Reichb. fil. 363 stenostachya, Lindl. . 362 Susanna, Lindl. . . 362

Platycodon

chinense, Lindl. . . 197 grandiflorum, A. DC. 197

Pleiogyne

anthemoides, C. Koch 186 cardiosperma, Edg. . 186

\section{Pleopeltis}

nuda, Hook. . . 458

Pluches . . . 179

indica, Less. . . . 179

Plumbagineæ . . . 281

Poa

amabilis, Linn. . . 432

pilosa, Linn. . . . 432 pilosissima, Kunth . 432 plumosa, Retz . . 432
Page

polymorpha, Br. . . 433

tenella, Linn. . . 431

unioloides, Retz . . 432

verticillata, Cav. . 432

Poecilopteris

heteroclita, Presl . 444

repanda, J. Sm. . . 444

Pogonatherum . . . 421

crinitum, Trin. . .421

refractum, Nees . . 421

saccharoideum, Beauv. 421

Pogostemon . . . . 275

parviflorus, Benth. . 275

Polanisia . . . 17

viscosa, $D C$. . . 18

Pollia . . . . 377

sorzogonensis, Endl. 377

Pollinia . . . . 420

tenuis, Trin. . . . 421

villosa, Munro $\quad . \quad 420$

Polycarpæa . . . . 22

corymbosa, Lam. . 22

Polygala . . . . 44 arillata, Ham. . 45 elegans, Wall. . . 44 glomerata, Lour. . $\quad 44$ Loureiri, Gardn. . . 45

Polygalacer ... . . 43

Polygonaceæ . . . 286

Polygonum . . . . 287 barbatum, Iinn. . . 288 chinense, Linn. . . 289 ciliosum, Meisn. . . 287 cliffortioides, Meisn. 287 effusum, Meisn. . . 287 glabrum, Willd. . . 288 herniarioides, DC. . 287 Hydropiper, Linn. . 288 illecebroides, Meisu. 287 lapathifolium, Linn. . 288 Miquelianum, Meisn. 287 orientale, Linn. . . 288 perfoliatum, Linn. . 289 Perrottetii, Meisn. . 287 plebeium, Br. . $\quad 287$ Roxburghii, Meisn. . 287 viscosum, Ham. . . 287

Polypodium . . . 457 adnascens, $S_{w}$. . . 458 coronans, Wall. . . 459 dichotomum, Thunb. 442 falcatum, Iinn. . 454 granulosum, Presl . 459 hymenodes, Wall. . 458 Lingua, Sw. . . . 458 pertusum, Roxb. . . 458 


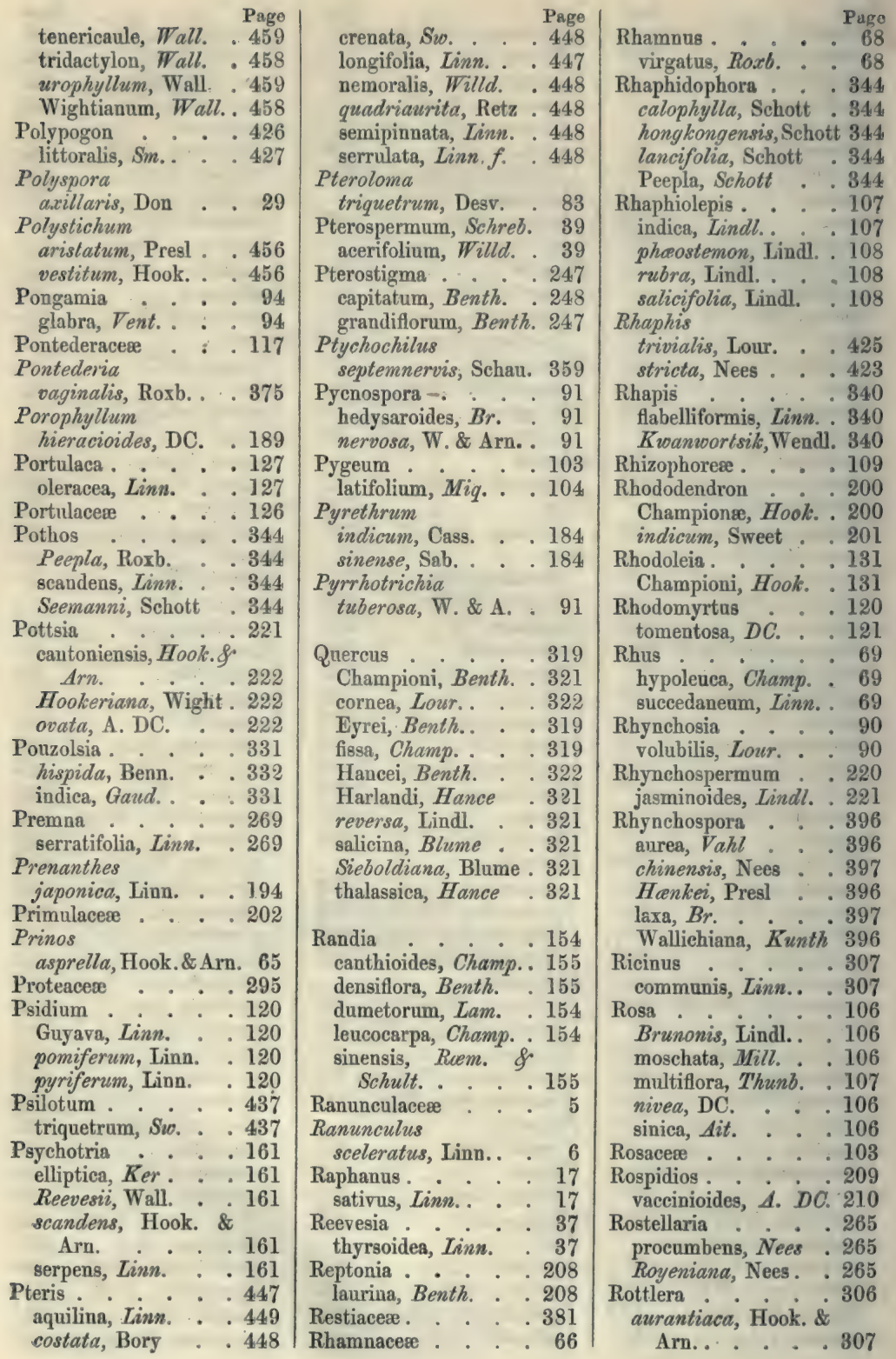


chinensis, Juss. Page cordifolia, Benth. : 307 paniculata, Juss. . . 307 tinctoria, Roxb. . . 307

Rourea . . . 71 microphylla, Planch. 71 santaloides, $W \cdot \& \cdot A r n .71$

Rubiaceæ. . . . 144

Rubus. . . . . . 104 glaberrimus, Champ. 105 leucanthus, Hance . 105 parvifolius, Linn. . 105 reflexus, Bot. Reg. . 104

Ruellia . . . 261 dependens, Roxb. . 263 repens, Linn. . . . 261 tetrasperma, Champ. 262

Rumex .... . 286 crispus, Linn. . 286

Rungia . . . . 265 chinensis, Benth. $\quad .266$

Rutaceæ . . . . 57

Sabia . . . . 70 limoniacea, Wall. 70

Saccharum . . . 419 densum, Nees . . . 420 officinarum, Linn. . 419 pragrande, Steud. . 420

Sageretia . . . . 68 theesans, Brongn. - 68

Sagittaria . . . 346 cordifolia, Roxb. . . 346

Salomonia . . . 43 cantoniensis, Lour. . 44 oblongifolia, $D C$. . 44 obovata, Wight . . 44

Salvia . . . . 276 Fortunei, Benth. . . 277 plebeia, Br. . . . 277

Samara . . . . 205 longifolia, Benth. . 205 obovata, Benth. . . 205

Samydaceæ . . . . 121

Santalaceæ . . . . 298

Sapindacer : . . 45

Sapotacere . . . 208

Sarcandra chloranthoides, Gardn. 334

Sarcanthus

rostratus, Reichb. fil. 357

Sassafras Parthenoxylon, Nees 291

Saurauja. . . . 26 tristyla, $D C$. . . 27

Saururaceæ . . 333
Saussurea . . . P $\begin{array}{r}\text { Page } \\ .167\end{array}$ carthamoides, Benth. 168 japonica, DC. . . . 167 linearis, Champ.. . 168 Saxifragaceæ . . . 127 Scrvola . . . . 198 Koenigii, Vahl . 198 lativaga, Hance . . 198 Lobelia, Linn. . 198 Scepa chinensis, Benth. . 317

Schima . . 28 Noronhæ, Reinvo. $\quad 29$ superba, Gardn. . . 29 Schistocodon Meyeni, Schau. . . 224

Schizostachyum . . 435 dumetorum, Munro . 435

Schœpfia . . . . 52 chinensis, Gardn. - 52

Scilla . . . . 373 chinensis, Benth. . 373

Scirpus . . . . 394 afflatus, Benth. . . 394 capitatus, Willd. $\quad 394$ chinensis, Munr. . . 395 juncoides, Roxb. . . 395

Scitaminers . . . 347

Scleria. . . . . . 399 chinensis, Kunth $\quad 400$ ciliaris, Nees . . . 400 communis, Kunth . 400 hebecarpa, Munr. 400 lævis, Retz . . . 400 lithosperma, Willd. . 399 pubescens, Steud. $\quad .400$ purpurascens, Steud. 400 scrobiculata, Nees . 400 Steudeliana, Miq. 399 tessellata, Willd.. . 399

Scleromitrion

angustifolium, Benth. 151 hispidum, Korth. . 151 tetraquetrum, Miq. . 151 Sclerostyles atalantioides, W. \&

Arn. . . . . 51 buxifolia, Benth. . 51 Hindsii, Champ. . . 51 venosa, Champ. . . 51

Scolopia . . . . . 19 chinensis, Clos . . 19

Seoparia . . . . 252 dulcis, Linn. . . . 252

Scrophularineæ . . . 245 Scutellaria . . . 277
Page indica, Linn. . . . 278

Securidaca . . . 45 seandens, Ham. . . 45 Selaginella

argentea, Spring. . 437 atroviridis, Spring . 437 caudata, Spring . . 437 concinna, Spring . 437 flabellifera, Spring . 437 involvens, Spring . 437 monospora, Spring . 437 Selliguea

decurrens, Presl . .457

Senecio . . . 189

campylodes, DC. . . 190

chineusis, $D C$. $\quad .190$

Hindsii, Benth. . 190 sonchifolius, Mœench 189 Kampferi, DC. . . 191 Stauntonii, $D C . \quad .190$ Serratula

carthamoides, Roxb. 168

Setaria

glauca, Benuv. . . 411

Severinia

buxifolia, Ten. . . 51

Sida . . . . . 32 acuta, Burm. . . . 32 cordifolia, Linn. . . 33 fallax, Walp. . . . 33 humilis, Willd. . 32 rhombifolia, Linn. 32

Sideroxylon . . . 209 Wightianum, Hook. \& Arn. . . . 209

Siegesbeckia . . . 182 iberica, Willd. . 182 orientalis, Iinn. . . 182

Simarubaceæ . . . . 60

Smilax . . . . 369 ferox, $W$ all. . . 370 Gaudichaudiana, $K t h .370$ glabra, Roxb. . . 369 hongkongensis, Seem. 371 hypoglauea, Benth. . 369 lanceæfolia, Roxb. . 370 macrophylla, Roxb. . 370 ovalifolia, Roxb. . 370 prolifera, Roxb. . . 370

Solanacer . . . 241

Solanum . . . . 241 biflorum, Lour. . . 242 Calleryanum, Dun. . 242 Cumingii, Dun. . . 243 decemdentatum, Roxb. 242 ferox, Linn. . . . . 243 


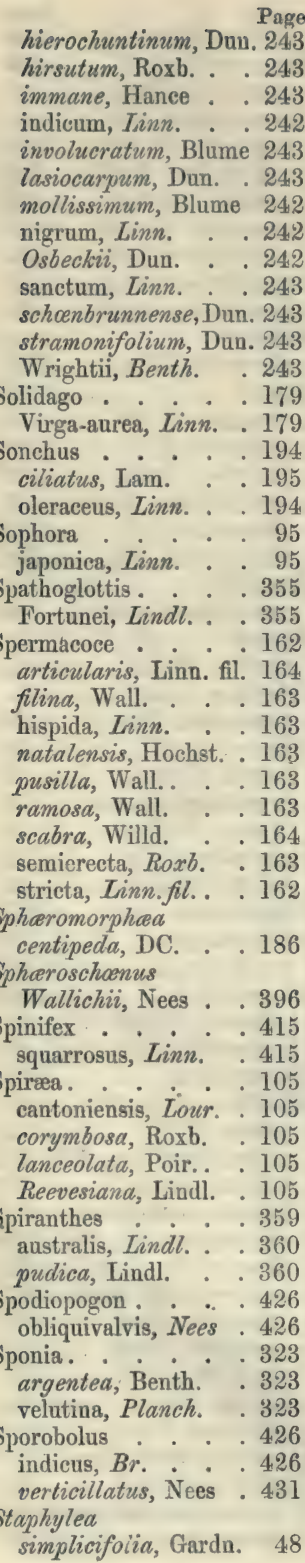

Page

Statice.

Fortunei, Lindl. 281

sinensis, Gir. . . 281

Stauntonia . . . 14

chinensis, $D C$. . . 14

Stellaria . . 21

aquatica, Scop. . . 21

fecunda, Hance . . 21

leptophylla, Hance . 22

media, Vill. . . . 21

uliginosa, Murr. . . 2 I

Stephania . . . 13 hernandifolia, Walp. 13

Stephanotis . . . 226 chinensis, Champ. . 227

Sterculia . . 35

lanceolata, Cav. : . 36

platanifolia, Linn. . $\mathbf{3 6}$

Sterculiaceæ . . . 35

Stillingia . . . . 302

discolor, Champ. . . 303

japonica, Sieb. \& Zucc. . . . 303 sebifera, Juss. . . . 302

Stipellaria. . . . 304 trewioides, Benth. . 305

Striga . . . . . 253 hirsuta, Benth. . .254 Masuria, Benth: . . 254

Strobilanthes . . . 261 apricus, T. Anders. . 262 Championi,T.Anders. 261 radicans, T. Anders. . 262

Strophanthus. . . . 220 divergens, Grah. . . 220

Strychnos . . . . 231 angustiflora, Benth. . 232 colubrina, Benth. . 232 paniculata, Champ. . 232

Stylidieæ . . . . . 195

Stylidium . . . . 195 sinicum, Hance . 195 uliginosum, $S w . \quad .195$

Stylocoryne ... . .156 densiflora, Wall. . 156 mollissima, Walp. . 156 Webera, A. Rich. .156 Stylodiscus, Benn. , 315 Styracacer . . . 211 Styrax . . . . . 213 odoratissima, Champ. 213 suberifolia, Hook. \& Arn. . . . . . 213

Suæda . . . . . 282 australis, Moq. . . 283 indica, Seem. . . . 283

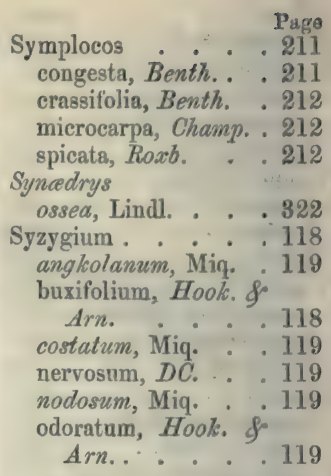

Symplocos . . . .211 congesta, Benth. . . 211 crassifolia, Benth. . 212 microcarpa, Champ. . 212 spicata, Roxb. : . 212 Syncedrys ossea, Lindl. . . . 322

Syzygium . . . . 118 angkolanum, Miq. . 119 buxifolium, Hook. \& Arn.

costatum, Miq. 118 nervosum, DC. . . 119 nodosum, Miq. . . 119 odoratum, Hook. \&o Arn. . . . 119

\section{Talauma}

pumila, Champ. , . 8

Taraxacum 192 Dens-leonis, Degf. $\quad 192$

Telanthera

polygonoides, Seem. . 286

Tephrosia . . . . 77 purpuren, Pers. : . 78

Terebinthaces . . : 69

Ternstrœmia . . . . 27 japonica, Thunb. . . 27

Ternstræmiaceæ . . . 25

Tetranthera . . 292 eitrifolia, Juss. . 293 floribunda, Champ. (*) monopetala, Roxb. . 292 polyantha, Wall. . 293

Tetralhyrium . . 132 subcordatum, Benth. 133

Teucrium . . . . 279 Fortunei, Benth. 280 fulvum, Hance . . 280 inflatum, Sro. . . . 279 quadrifarium, Ham. . 250 stoloniferum, Ham. . 279 Thea assimilis, Seem. . 30 salicifolia, Beem . . 31

Thouarea . . : 415 sarmentosa, Pers. $\quad .415$

Thunbergia . . . 260 grandiflora, Roxb. $\quad 260$ Thymelex .. . . 295

Thysanolæna . . . 417 acarifera, Nees : .417

- This is $T$, polyantha, Wah. the synonym was accidentaliy omitted, p. 293. 


\begin{tabular}{|c|c|}
\hline agrostis, Nees & Page \\
\hline Thysanospermum & $\begin{array}{l}417 \\
146\end{array}$ \\
\hline diffusum, Champ. & $\begin{array}{l}146 \\
146\end{array}$ \\
\hline 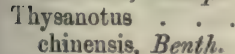 & .372 \\
\hline chinensis, Benth. & 372 \\
\hline Tiliacese. & 40 \\
\hline Toddalia . . : & 59 \\
\hline sculeata, Pers. & 59 \\
\hline floribunda, Wall. . & 59 \\
\hline Torenia • & .250 \\
\hline concolor, Lindl. & .250 \\
\hline flava, Ham. . & 250 \\
\hline rubens, Benth. & 250 \\
\hline Toxocarpus $\cdot \dot{ }$ & 224 \\
\hline Wightianus, $\mathrm{Hooh}$ & \\
\hline
\end{tabular}

Tradescantia paniculata, Roxb. . 377

Trichomanes . . . 462 intramarginale, $H_{o o k}$. \& Grev.. . . . 463 parvulum, Poir. . . 462

Triumfetta . . . 41 angulata, Lam. . . 41 cana, Blume . . . 41 pilosa, Roth . . . 41

Tropidia . . . . . 359 curculigoides, Lindl. 359 squamata, Blume . 359

Turpinia ... . 48 arguta, Seem. . . . 48 nepalensis, Walp. . 48

Tylophora. . . . 225 hispida, Dene. . . 225

Typhonium divaricatum, Blume. 342

Umbelliferæ . . . . 133

Unona

discolor, Vahl . . . 11

Uraria . . . . . 81 comosa, DC. . . . 81 crinita, Desv. . . . 81 macrostachya, DC. . 81

Urena . . . . . 33 lobata, Linn. . . . 34 sinuata, Linn. . 34

Urostigma

nervosum, Miq. . . 327 sitidum, Miq. . . 327 ovoideum, Miq. . . 327 pisiferum, Miq. . . 327 retusum . . . 327 Wightianum . . 327

Urtica tenacissima, Roxb. . 331

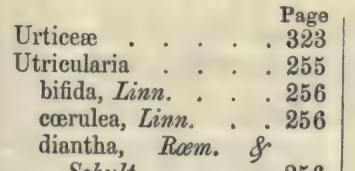

Schult. . . . 256 extensa, Hance . . 255 fasciculata, Roxb. . 255 flexuosa, $\bar{V} a h l$. . 255 glochidiata, Wight . 257 Harlandi, Oliv. . . 257 humilis, Wight . . 256 orbiculata, Wall. . . 256 racemosa, Wall. . . 256 uliginosa, Vahl . . 256

Uvaria . . . . . 9 badiiflora, Hance . 10 microcarpa, Champ. . 10 platypetala, Champ. purpurea, Blume. rhodantha, Hance . 9

Vaccinium . . 199 chinense, Champ. 199

\section{Vachellia}

farnesiana, W.\& Arn. 101

Vandellia . . . . 250 crustacea, Benth. . . 251 oblonga, Benth. . . 251 scabra, Benth. . . 251

Vangueria dicocca, Miq. . . . 159

Ventilago . . . . 66 leiocarpa, Benth.. . 67 maderaspatana, Benth. . . 67

Verbena . . . 267 officinalis, Linn. . . 268

Verbenaceæ . . . 267

Verbesina

chinensis, Linn. . . 180 scandens, Roxb. . . 183

Vernonia . . . 168 chinensis, Less. . . 169 cinerea, Less. . . . 169 congesta, Benth. . . 180 Cumingiana, Benth. . 170 solanifolia . . . 169

Viburnum . . . 142 nervosum, Hook. \&

Arn. . . . . 143 odoratissimum, Lindl. 143 venulosum, Benth. . 142 Villebrunea . . . . 332 frutescens, Blume . 332
Viola Linn. • . . 220

confusa, Champ. . . 20

diffusa, Ging. . . . 20

Patrinii, DC. . : 20

tenuis, Benth. . . 20

Violacer . . . . 20

Viscum : . . . 141

articulatum, Burm. 141

moniliforme, Blume. 141

orientale, Willd. . 141

Vitex . . . 273

bicolor, Willd. . . 273

incisa, Lam. . . . 273

Loureiri, Hook. \& Arn. . . . 273

Negundo, Linn. . 273

ovata, Thunb. . . 273

trifolia, Linn. . . 273

Vitis . . . 53

angustifolia, $W$ all. $\quad 54$

cantoniensis, Seem. . 54

corniculata, Benth. . 54

cordata, Wall. . . 54

flexuosa, Thunb. . . 53

heterophylla, Thunb. 53

lanata, $R o x b$. . . . 53

parvifolia, Roxb. . . 53

succisa, Hance . . 53

Wahlenbergia . . . 197

agrestis, $A . D C$. . 197

grandiflora, Schrad. . 197

Waltheria. . . 38

americana, Linn. . $\quad 38$

indica, Linn. . . 38

Webera

densiftora, Wall. . . 156

Wedelia . 182

calendulacea, Less. 182

Wikstrœmia . . . 297

alpina, Benth. . . 297

nutans, Champ. . . 297

viridiflora, Meisn. . 297

Wollastonia . . . 182

biflora, $D C . \quad . \quad . \quad 183$

scabriuscula, DC. . 183

strigulos $\alpha$, DC. . . 183

Woodwardia . . . 445

Harlandi, Hook. . . 445

japonica, Sw. . . 445

Xanthium. . . . . 181

indicum, Roxb. . . 181

strumarium, Linn. . 181

Xanthoxylon . . . 57 
Avicennæ, $D C . \quad \begin{array}{r}\text { Page } \\ 58\end{array} \quad$ pauciflora, Willd. $\begin{array}{r}\text { Page } \\ .379\end{array}$ cuspidatum, Champ. $58 \quad$ schøenoides, Mart. $\quad 379$ Lamarckianum, Cham. 59 lentiscifolium, Champ. 58 nitidum, $D C$. . . $\quad 58$ pteleafolium, Champ. 59 triphyllum, Wight - 59 Xyridaceæ : . 378 Xyris . . . . 379

\section{Youngia}

debilis, DC. . . . 194

japonica, DC. . 194

mauritiana, DC. . . 194

Thunbergiana, DC. . 194

Zalacca . . . . 339
Zehneria

Page mysorensis, Seem. . 124

Zeuxine . . . . . 360 sulcata, Lindl. . . 360

Zornia . . . . 80

diphylla, Pers. . $\quad 80$

Zoysia. . . . . 418 pungens, Willd. . 418

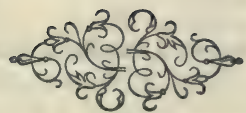


Now ready, in One Vol., 680 pages, price $12 s$.

\title{
HANDBOOK OF THE BRITISH FLORA;
}

\author{
A Description of the Flowering Plants and Ferns Indigenous to, \\ or Naturalized in, the British Isles.
}

\author{
FOR THE USE OF BEGINNERS AND AMATEURS.
}

By GEORGE BENTHAM, F.L.S.

From the 'Athencum.'

"The countrymen of John Ray and Robert Brown can boast of hundreds who, if they have not been creators of the science of Botany as those two can claim to be, have largely contributed to its present position. Amongst these Mr. George Bentham holds no second place. $\mathrm{He}_{e}$ is also well known to thinkers for his work on Logic. It is, therefore, with plessure that we receive from his hands a book intended to assist in the work of teaching botany to the young, and those who have no teachers. On the subject of the plants of Great Britain, we have works from the magniflcent ' English Flora' of Smith and Sowerby, down to the curt and accurate 'Manual' of Babington. But for popular use they may be all objected to, either on the ground of their expense or their technical character. Mr. Bentham's aim has been to produce a cheap, untechnical volume, containing descriptions of all British plants, with an easy method of finding out their names. In this, we think, he has sueceeded."

\section{Professor Asa Gray.}

"One of the best of systematic botanists-of the soundest judgment and the largest experience, both in European and exotic botany-has deemed it no unfit employment of a portion of his valuable time to prepare a volume by which beginners, having no previous acquaintance with the soience, may learn to know, most advantageously and readily, the wild flowers and plants of his native land. The result is a genuine popular Flors, and a clear proof that the plants of a limited country may be described, by one who understands them thoroughly, in comparatively simple language, without any sacrifice of scientific accuracy or of scientific interest. No really good work of this kind was ever made by a compiler; and no one who has not essayed the task, can comprehend how thoroughly faithful writing for beginners brings one's knowledge to the proof.

"The short sections upon classification and the examination and determination of plants, are full of practioal wisdom."

\section{PRESENTATION OF A ROYAL MEDAL TO MR. BENTHAII.}

The following is an Extract from the Address of the President at the last Anniversary of the Royal Society.

"The remarkable accuracy which distinguishes all Mr. Bentham's scientific researches, the logical precision that characterizes his writings, and the sound generalizations which his systematic works exhibit may be in a great measure traced to the influence of his uncle, the late celebrated legal theorist, Jeremy Bentham, who directed much of his early studies, and under whose auspices he published one of his earliest works, 'Outlines of a New System of Logic.' His mind was further imbued in youth with a love of Natural History, and especially Botany, and this taste was eultivated and nourished by a study of the works of the elder De Candolle. Fortunately for the cause of Botany in England, Mr. Bentham has devoted himself almost exclusively to that seience; and to his excellent powers of observation, close reasoning, concise writing, and indefatigable perseverance our country owes the distinction of rauking amongst its naturalists one so pre-eminent for his valuable labours in systematic botany. Amongst Mr. Bentham's numerous writings, those hold the first rank which are devoted to the three great Natural Orders, Leguminosa, Labiata, and Scrophulariacea. These Orders demanded a vast amount of analytic study, for they are amongst the largest and most widely-distributed of the vegetable kingdom, and had been thrown into great confusion by earlier writers. They have been the subject of many treatises by Mr. Bentlam, and especially of two extensive works, the contents of which have lately been embodied in the 'Systema Vegetabilium' of the De Candolles. On their first appearance these works seeured for their author a Euro. pean reputation, and will always rank high as models of skill and elassification. It would occupy too much time to specify the very numerous monograpns and papers which Mr. Bentham has communicated to various scientific societies and periodicals in this country and on the Continent, and especially to the Linnean 'Transactions and Journal. That ' On the Principles of Generic Nomenclature' may be noted as an example of his power of treating an apparently simple, but really abstract and difficult subject in a manner at once philosophical and practical. Mr. Bentham's most recent work, that on British Plants, is the first on the indigenous Flora of our. Islands in which every species has been carefully analyzed and described from specimens procured from all parts of the globe; it is distinguished for its scientific accuracy, advanced general vievs, and extreme simplicity - a combination of qualities which can result only from an extensive series of exact observations, judiciously arranged and logically expressed. The President then addressed Mr. Bentham as follows :-The early rolumes of the 'Philosophical 'Transactions' contain numerous papers relating to botany and the other sciences which are usually comprehended under the general designation of Natural History. As these sciences, but especially botany, became more and more extended, it was thought desi. rable that another Institution should be called into existence, which might share with the Royal Society the privilege of promoting the cultivation of them, and of communicating to the world from time ta time the progress which has been made in this department of knowledge; and such was the origin of the Linnean Society in the year 1788. The Royal Society, however, does not on that account feel the less interested in this class of scientific investigations. It is accordingly with great satisfaction that the Couneil have awarded to you one of the Royal Medals, and that in the name of the Society I now place if in your hands, in testi. mony of their high appreciation of your researches, and of the respect which they have for you as a fellow-labourer in the fleld of science."-Procesdings of the Royal Society. 
In Sixteen Numbers (uniform with 'Curtis' Botanical Magazine'), each containing Four Coloured Plates, price 2s. 6d., of

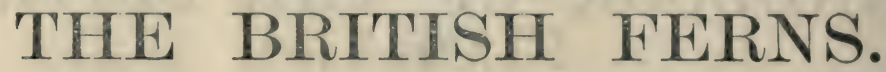

BY

\section{Sir W. J. HOOKER, K.H., D C.L. Oxon., F.R.S.,}

Corresponding Member of the Academy of Sciences of France, and Director of the Royal Gardens of Kow.

\section{THE DRA WINGS BY W. FITCH, F.I.S.}

Notwithstanding the many publications that have appeared of late years upon the Ferns of the British Isles, a new Work, such as we have the pleasure to announce, by Sir W. J. Hook ER, supported by the talents of his unrivalled artist, Mr. FiтCH, will be acceptable both to Cultivators of British Ferns and to Collectors of them for the Herbarium. It is intended to arrange them in Sixty-four Plates of Coloured Figures, with the needful Analyses of Fructification, so as to exhibit the Characters of the Genus as well as of the Species; and the Descriptions will be entirely in English.

The Work will be issued in Monthly Numbers (No. 1 on the 1 st of January), and will be completed in Sixteen Numbers, each of Four Plates, price 2s. $6 d$; making $£ 2$ for the complete Volume.

LONDON : LOVELL REEVE, 5, HENRIETTA STREET, COVENT GARDEN.

\section{NEW WORK on GARDEN FERNS by Sir W. J. HOOKER.}

In Monthly Numbers (uniform with 'Curtis' Botanical Magazine'), each containing Four Coloured Plates, price 2s. 6d., of

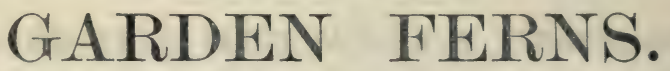

BY

SrR W. J. HOOKER, K.H., D.C.L. Oxon., F.R.S., Corresponding Member of the Academy of Sciences of France, and Director of the Royal Gardens of Kew.

THE DRAWINGS BY W. FITCH, F.I.S.

The attention of horticulturists having been increasingly directed of late years to this lovely tribe of plants, than which few are more easy of eultivation, and, as is now clearly demonstrated, few more easily imported from distant regions of the globe, it is intended to issue a special Work for their Illustration and Descriptinn, uniform in size and style with 'Curtis' Botanical Magazine.' As it may be considered a supplement to that work, the comparatively few Ferns among the 5,200 Species of Plants there Figured and Described, will not be repeated; nor will those so baautifully and faithfully depicted by Mr. FITCH in the recently-completed volume on Exotic Ferns.*

The rich Collections of the Royal Gardens of Kew would alone afford ample materials for such a work; but it is by no means intended to be exclusive. Contributions of good samples of species of great rarity, hitherto undescribed, will be thankfully received and fully acknowledged.

The greatest pains will be taken to give accurate delineations, and such analyses as the Species or Genus requires, accompanied by such descriptions as may render each individual as clear to the mind of the Student or Cultivator as the subject and the size of the page will admit.

The Author, while he willingly acknowledges the great difficulty of defining the exact limits of Genera and Species in plants so notorious for their sportive character as are the Ferns, confesses that he has no sympathy with those who do much to increase that difficulty by the needless mutiplication of both Genera and Species. Synonyms and references to standard authors will be carefully recorded.

A Number, consisting of Four Coloured Plates, will appear on the 1st of January, 1861, and be continued Monthly, price $2 s .6 d$.

* 'Filices Exotice,' being Figures and Descriptions of Exotic Ferns cultivated, chiefly, in the Royal Gardens of Kew: By Sir W. J. Hooker, K.H., ete. Handsome Quarto, 100 Coloured Plates, £6. 11s. Published by Lovell Reeve. 
5, Henrigta Stregt, Covent Gambex, Lom nox, September 1st, 1860.

\title{
MR. REEVE'S
}

\author{
LIST OF
}

\section{PUBLICATIONS IN NATURAL HISTORY, ARCH ÆOLOGY,}

\section{AND STEREOSCOPIC PHOTOGRAPHY.}

\section{The Floral Magazine.}

Comprising Figures and Descriptions of Popular Garden Flowers. By Thomas Moore, F.L.S., F.H.S., Secretary of the Horticultural Society. monthly Numbers, each containing 4 coloured plates by W. Нттсн.

Imperial 8vo. Published Monthly. Price 2s.6d. coloured.

[No. 5 this day.

The 'Floral Magazine' has been projected to supply the long-felt want of some independent periodical, of a popular character, devoted to the Illustration of the many New Varieties of choice Flowers which are being continually produced by the skill of modern cultivators.

The Plates are executed by Mr. WALTER Fitch, who has been so long and so favourably known as the Artist of 'Curtis' Botanical Magazine,' and of other botanical publications emanating from Kew. The selection of subjects, and the descriptions, are by the Secretary of the Floral Committe of the Horticultural Socretr.

'Curtis' Botanical Magazine' will continue to represent the scientific department of Garden Botany, under the superintendence of the Director of the Royal Gardens of Kew. The 'Floral MAGazine' will be devoted to meritorious varieties of such introduced Plants as are of popular character, and likely to become established favourites in the Garden, Hothouse, or Conservatory.

2.

\section{Curtis' Botanical Magazine;}

Comprising the Plants of the Royal Gardens of Kew, and of other Botanical Establishments in Great Britain, with suitable Descriptions. By Sir W. J. Hooker, D.C.L., F.R.S., Director of the Royal Gardens of Kew. In Monthly Numbers, each containing 6 coloured plates by W. Fitch.

Royal 8vo. Published Munthly. Price 3s.6d. coloured.

The attention of Botanists and Horticulturists is especially directed to this old-established and standard record of new and recently cultivated plants. The position of the Author as Director of the largest and most valuable collection in the world, and his habits of friendly communication, not only with Botanists and Botanical Travellers, but with Nurserymen and all the distinguished Horticulturists of the day, ensure the earliest publicity of the more interesting and remarkable species; whilst the acknowledged excellence of Mr. Fitch's drawings, executed at Kew under the superintendence of the Author, is a sure guarantee for the subjects being faithfully delineated. 
3.

\section{Handbook of the British Flora;}

A Description of the Flowering Plants and Ferns Indigenous to, or Naturalized in, the British Isles. For the use of Beginners and Amateurs. By George Bentham, F.L.S.

In One Volume, 680 pages, price $12 s$.

"One of the best of systematic botanists-of the soundest judgment and the largest experience, both in European and exotic botany-has deemed it no unfit employment of a portion of his valuable time to prepare a volume by which beginners, having no previous acquaintance with the science, may learn to know, most advantageously and readily, the wild flowers and plants of his native land. The result is a genuine popular Flora, and a clear proof that the plants of a limited country may be described, by one who understands them thoroughly, in comparatively simple language, without any sacrifice of scientific accuracy or of scientific interest."

Profissor Asa. Gray.

4.

Flora of Tasmania.

By Joseph Dalton Hooker, M.D., F.R.S., L.S., \& G.S.

2 vols., 200 Plates, $£ 1 \%$. 10 s coloured; 212.10 s. plain.

5.

\section{Flora of New Zealand.}

By Joseph Dalton Hooker, M.D., F.R.S. In Two Volumes. With 130 plates by W. Fitch.

2 vols. royal 4to, price $212.12 s$. coloured; $£ 8$. 15s. plain.

"The most important work that has yet appeared in illustration of the vegetation of the British Australian possessions. ... The plates are among the happiest specimens of modern art."

Gardeners' Chrontole.

6.

\section{Flora Antarctica.}

By Joseph Dalton Hooker, M.D., F.R.S. In Two Volumes. With 200 plates by W. Fitch.

2 vols, royal 4to, price $\$ 10$. 15s, coloured; $\$ 7.10$ s. plain.

" The descriptions of the plants in this work are carefully drawn up, and much interesting matter, critical, explanatory, and historical, is added in the form of notes. The drawings of the plants are admirably executed by Mr. Fitch; and we know of no productions from his pencil, or in fact any botanical illustrations at all, that are superior, in faithful representation and botanical correctness."

Athentum. 
7.

\section{Filices Exotica:}

Or, Century of Exotic Ferns, particularly of such as are most deserving of

Cultivation. By Sir W. J. Hooker, K.H., D.C.L. 100 coloured plates.

Royal 4to, price $\mathfrak{L 6 . 1 1 s .}$

A magnificently illustrated work on Greenhouse Ferns.

8.

\section{The Victoria Regia.}

By Sir W. J. НоокеR, F.R.S. With four coloured plates by W. Fiteh.

Elephant folio, price 21s. coloured.

It is now fifty years, as far as our researches enable us to ascertain, since this truly royal plant was first detected. The honour of its original discovery is due to Hanke under circumstances recorded as follows by M. A. D'Orbigny :- "When I was travelling," says this latter gentleman, "in Central America, in the country of the wild Guarayos, who are a tribe of Guaranis or Caribs, I made acquaintance with Father La Cueva, a Spanish missionary. In one of our interviews he happened to mention the famous botanist Hæenke, who had been sent by the Spanish Government in the year 1801 to investigate the vegetable productions of Peru, and the fruit of whose labours has been unfortunately lost to science. Father La Cueva and Hænke were together in a pirogue upon the Rio Mamoré, one of the great tributaries of the Amazon River, when they discovered in the marshes, by the side of the stream, a flower which was so surpassingly beautiful and extraordinary, that Hæenke, in a transport of admiration, fell on his knees and expressed aloud his sense of the power and magnificence of the Creator in His works. 'They halted, and even encamped purposely near the spot, and quitted it with much reluctance."

9.

\section{The Rhododendrons of Sikkim-Himalaya;}

Being an Account of the Rhododendrons receutly discovered in the Mountains of .Eastern Himalaya. By J. D. Hooker, M.D., F.R.S. With 30 plates by W. Fitch.

Imperial folio, price $\& 3.16$ s. coloured.

10.

\section{Illustrations of Sikkim-Himalayan Plants,}

Chiefly selected from Drawings made in Sikkim under the superintendence of the late J. F. Cathcart, Esq., Bengal Civil Service. The Botanical Descriptions and Analyses by J. D. HooKER, M.D., F.R.S. With 24 coloured plates and an illuminated title-page by W. Fitch.

Folio, price 25 . 5s. coloured. 


\section{1.}

\section{Synopsis of British Seaweeds.}

Descriptions of all the known Species, abridged from Professor Harvey's

'Phycologia Britannica.'

A pocket volume, 220 pages, price $5 s$.

"'The Publisher of the 'Phycologia Britannica,' considering that a re-issue of that work in a cheaper and more compendions form would be acceptable to many collectors of British Seaweeds, has prepared in this volume an abstract of the Letterpress, accompanied by an Atlas of Figures copied on a reduced scale from the original Plates; and has requested me to state in this place that he has my sanction for doing so. To this I have readily consented, and have also looked over the sheets as they passed through the press, and suggested some verbal alterations."

From the Author's Preface.

"To purchasers of the 'Atlas,' this 'Synopsis' will of course be indispensable; but we would also recommend it even to those who possess the 'Phycologia." Its small size renders it a convenient pocket volume."

Natural History Review.

\section{2.}

\section{Atlas of British Seaweeds.}

Figures of all the known Species, drawn from Professor Harvey's 'PHycologia Britannica.' In 80 coloured plates.

Demy 4to, price $\mathfrak{e 3}$. 3 s. coloured.

The object of this publication is to supply Seaweed collectors, at the cost of Three Guineas, with a handsome volume, containing a characteristic figure, with dissections, where needful, of every known species of Seaweed inhabiting the shores of the British Isles.

13.

\section{Phycologia Britannica.}

A History of the British Seaweeds; containing coloured Figures and Descriptions of all the Species of Algæ inhabiting the Shores of the British Islands. By William Henry Harvey, M.D., F.R.S., Professor of Botany to the Dublin Society. With 360 coloured plates, drawn on stone by the Author.

In four vols. royal $8 \mathrm{vo}$, arranged systematically, $27.17 s .6 d$.

These magnificent volumes contain a coloured figure, of the natural size, of every species of British Seaweed, accompanied with highly-magnified views of its structure and fructification. An entire plate is devoted to each species, the number of plates in the work amounting to three hundred and sixty. The History and Description of the Plates, with the Synopses and Indexes, occupy 424 pages.

"The 'History of British Seaweeds' we can most faithfully recommend for its scientific, its pictorial, and its popular value ; the professed botanist will find it a work of the highest character, while those who desire merely to know the names and history of the lovely plants which they gather on the sea-shore, will find in it the faithful portraiture of every one of

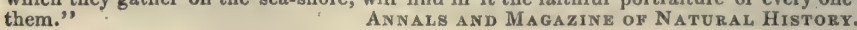

"The drawings are beautifully executed by the author himself on stone, the dissections carefully prepared, and the whole account of the species drawn up in such a way as cannot fail to be instructive, even to those who are well acquainted with the subject.. The greater part of our more common. Algæ have never been illustrated in a manner agreeable to the present state of Algology."

GARDENER' ChRONIOLB. 
14.

\section{Phycologia Australica.}

A History of Australian Seaweeds, containing Coloured Figures and De scriptions uniform with the 'Phycologia Britannica.' By William Henry Harver, M.D., F.R.S. To be completed in Five Volumes, each containing sixty coloured plates, drawn on stone by the Author.

Vols. I. and II. now ready, price $30 s$. each, coloured.

An Illustrated Work on the Marine Botany of Australia, on the plan of the 'Phycologia Britannica,' will, it is thought, be acceptable to Algologists generally, and especially to those who possess a share of the Duplicate Specimens of Australian Algæ distributed by Professor Harvey. Materials amply sufficient for a much more extensive work than that now contemplated have been collected in Dr. Harvey's recent tour; but it is thought that a sufficient illustration of the subject may be given by publishing a selection of Three Hundred of the more characteristic and remarkable species. This number will allow for the full illustration of all the Genera, and of the principal sub-types comprised within each Genus.

At the conclusion of the work a short Introduction and Systematic Synopsis will be given, and such other undescribed Australian Species as are known to the Author, but have not been figured in the work, will be briefly described.

15.

\section{Nereis Australis.}

Figures and Descriptions of Marine Plants collected on the Shores of the Cape of Good Hope, the extra-tropical Australian Colonies, Tasmania, New Zealand, and the Antarctic Regions. By Professor Harvey, M.D., F.R.S. Two Parts, each containing 25 coloured plates, drawn on stone by the Author.

Two Parts, Imperial 8vo, price $\mathscr{E l}$. 1s. each, coloured.

\section{6.}

\section{Ferny Combes.}

A Ramble after Ferns in the Gleus and Valleys of Devonshire. By Charlotte Chanter. Second Edition. With 8 coloured plates, and a Map of the County.

Fep. 8vo, price 5s, coloured.

"To these wild scenes Mrs. Chanter introduces her readers with all the zeal of an enthu. siastic admirer of Nature, and especially of those charming forms in which the vegetable world is so pre-eminent. Her book is not written to wile away a weary hour, but to be used on the spot: it is a field-book of Devonshire botany ; its pages have all the dash and eager verve of a Forbes. In a scramble after plants local difficulties are tossed aside; to rough it is the word; and the discovery of a Fern new to the travellers is ample compensation for fatigue and inconvenience, to say nothing of something like danger."

\section{GARDENFE' ChRoniche.}

"Mrs. Chanter, who, we learn from the dedication, is a sister of the Rev. Charles Kings. ley, has produced a very elegant and charming little book, illustrated with beautiful coloured drawings.",

ATLA:. 
17.

\title{
The Esculent Funguses of England.
}

An Account of their Classical History, Uses, Characters, Development, Nutritious Properties, Modes of Cooking, etc. By the Rev. Dr. Badнам. With 20 coloured plates.

Super-royal 8vo, price 21s. coloured.

"Such a work as the book before us was a desideratum in this country, and it has been well supplied by Dr. Badham. With his beautiful drawings of the various edible Fungi in his hand, the collector can scarcely make a mistake. The majority of those which grow in our meadows and on the decaying wood of our orchards and forests are unfit for food, and the value of Dr. Badham's book consists in the fact that it enables us to distinguish from these such as may be eaten with impunity."

AThenaum.

18.

\section{Illustrations of British Mycology.}

Fignres and Descriptions of the Funguses of interest and novelty indigenous to Britain. By Mrs. Hussey.

Royal 4to; First Series, 90 coloured plates, price E7. 12s. $6 \mathrm{~d}$. coloured; Second

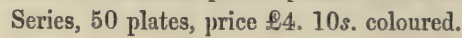

"This talented lady and her sister were in the first instance induced to draw some of the most striking Fungi merely as picturesque objects. Their collection of drawings at length became important from their number and accuracy, and a long-continued study of the nutritive properties of Fungi has induced the former to lay the results of her investigations before the public, under the form of monthly illustrations, of the more useful and interesting species. The figures are so faithful, that there can be no difficulty in at once determining with certainty the objects they are intended to represent; and the observations, especially those of the culinary department, will be found of much interest to the general reader, and we doubt not that our tables will in consequence receive many a welcome addition; while from the accuracy of the figures there will be no danger, with ordinary attention, of mabing any serious blunder."

GARDENER' Chronicle.

\section{9.}

\section{The Tourist's Flora.}

A Descriptive Catalogue of the Flowering Plants and Ferns of the British Islands, France, Germany, Switzerland, and Italy. By JoskPh Woods,

8vo, price 18 s.

\begin{abstract}
"Few books were more required for the use of many English travellers who make the ordinary European tours, in their own country or on the Continent, and who"desire an acquaintance with the many vegetable productions they see around them, than one like the present, and few men are more competent to prepare such a work than Mr. Joseph Woods, a very considerable portion of whose long life has been devoted to travelling at home and abroad, with this special object in view. He is him:elf familiar with most of the plants described $i$ this volume, from having studied them in their native localities, and he has takon great pains to give the essential characters of the genera and species in as few words as possible, so that the whole is compressed into 500 closely-printed pages."

HOOKER'S JOURAL OF BOTANY.
\end{abstract}


20.

\section{Curtis's British Entomology:}

Illustrations and Descriptions of the Genera of Insects found in Great Britain and Ireland, containing coloured figures, from nature, of the most rare and beautiful species, and, in many instances, of the plants upon which they are found.

Commenced in 1824 and completed in 1840, in 193 numbers, with 770 coloured plates, forming 16 volumes, price $\& 43.16 s$.

Now offered at $£ 21$ coloured.

“Vous savez qu'à l'égard d'un grand nombre d'espèces, leur détermination réclame le secours de figures. Il est donc de mon devoir de vous indiquer les livres où vous trouverez les meilleures. Celui de M. Curtis, sur les genres d'insectes indigènes de l'Angleterre, me paraît avoir atteint l'ultimatum de la perfection."

LATREILIE.

"M. John Curtis, naturaliste Anglais, a commencé la publication d"un Generu Iconographique des genres d'insectes et de plantes propres à la Grande-Bretagne. Leurs caractères y sont représentés avec la plus grande fidélité." Cuviez.

21.

\section{Journal of Botany and Kew Miscellany.}

Original Papers by eminent Botanists, the Botanical News of the Month. Communications from Botanical Travellers, Notices of New Books, etc, Edited by Sir W. J. НоокеR, D.C.L., F.R.S. With plates.

Vol. IX., concluding the work, price $£ 1.4 s$.

"We hardly know what the botanical world would do without this useful book. We have found its papers upon economic botany most interesting, and in the Number before us is an article upon the Camphor-tree of Sumatra, a point on which our information has been hitherto deficient. Some further information is also given respecting the plant which furnishes the rice-paper of the Chinese. A very beautiful and curious new Fern, called Deparia Moorii, is figured."

LIVIRPOOL STANDARD.

22.

\section{Icones Plantarum.}

Figures, with brief descriptive Characters and Remarks, of new and rare Plants, selected from the Author's Herbarium. By Sir W. J. Hooker, D.C.I., F.R.S. New series, Vol. V., with 100 plates.

8 vo, price 31 s. $6 d$. 
23.

\section{The Genera of British Beetles.}

A Collection, in one volume, of the Figures of Coleoptera contained in 256 plates of 'Curtis's British Entomology.'

Demy 4to, price 21 . 1s. coloured.

24.

The Genera of British Moths and Butterfies.

A Collection, in one volume, of the Figures of Lepidoptera contained in 193 plates of Curtis's 'British Entomology.'

Demy 4to, price 21 . 1s. coloured.

25.

\section{Insecta Britannica;}

Vols. I., II., and III., Diptera. By Francis Walker, F.L.S. With 30 plates. Vol. III., Lepidoptera: Tineina. By H. T. Stainton. With 10 plates.

8vo, price 25s. each.

26.

A Treatise on the Growth and Future Treatment of Timber Trees; and on other Rural Subjects. With an Appendix. Especially addressed to the Landed Proprietors of North Derbyshire. By G. W. Newton, of Ollersett, J.P. and D.L. of the several Counties of Derby, Chester, and Lancaster.

Half-bound calf, price $10 s .6 d$.

27.

Illustrations of the Nueva Quinologia of Pavon.

With Coloured Plates by W. FiтcH, F.L.S., and Observations on the Barks lescribed, by John Eurot Howard, F.L.S.

Parts I. to IV., Imperial folio, price 10s, each. 
28.

\section{Conchologia Iconica ;}

Or, Figures and Descriptions of the Shells of Molluscous Animals, with Critical Remarks on their Synonyms, Affinities, and Circumstances of Habitation. By Lovel. Refeve, F.L.S. \& G.S. Published Monthly in Parts, demy 4to, each containing eight plates, price 10s, coloured.

Part CXC. just published.

The 'Conchologia IConicA' was commenced in January, 1843, with the view of furnishing Descriptions and Figures of the natural size of all the known Species and wellmarked Varieties of Recent Shells. The existence of so many more Species in England. chiefly in the Cabinets of Mr. Cuming and of the British Museum, than have been collected in any other country, made it desirable that such a Work should be carried out, and the plan was adopted of publishing a Part monthly, each containing Eight Coloured Plates, quarto size, with corresponding Letter-press, at the price of Ten Shillings.

During the seventeen years that have elapsed 190 Parts have been published, containing 1520 Plates of 11,500 Figures, illustrative of 8500 Species, all of which have been drawn by Mr. Sowerby from typical specimens, selected, examined, and described by myself. Each Genus, following the system of Lamarck and Deshayes, is completed as a Monograph as the Work proceeds, and purchasers are presented with the option of buying the Genera in that form. No attempt is made at classification, because if I waited to systematize the material before placing it in the hands of Mr. Sowerby, the delay incident to such a course of proceeding would be fatal tothe success of the undertaking. Ou the completion of the Work it is intended to classify the whole of the Species by a system of Sub-genera, that may serve both as an Index to the volumes and as a General Synopsis of the Nomenclature.

\section{IN V VOLUMFS.}

\section{vol. I.-Conus. Phorus. Cardita. Crprtcardia. Pleqrotoma. Protunoulds, Drlphivela. Habpa.}

Crassatiblua.
[122 Plates, price e\%. 168. 6d.]

\begin{tabular}{|c|c|c|}
\hline VOL. II.-CORBULA. & $\begin{array}{l}\text { Gratconoms. } \\
\text { MYADORA. }\end{array}$ & $\begin{array}{l}\text { RankLLA. } \\
\text { Mitra. }\end{array}$ \\
\hline
\end{tabular}

[114 Plates, price 27. 68. 6d.]

\begin{tabular}{|c|c|c|}
\hline $\begin{array}{l}\text { VOL. III.-MUREX: } \\
\text { CYPR BA. }\end{array}$ & $\begin{array}{l}\text { Majgeli. } \\
\text { Purpura. }\end{array}$ & $\begin{array}{l}\text { Ricinoua. } \\
\text { MoNochios. }\end{array}$ \\
\hline
\end{tabular}

[129 Plates, price \&8. 58.6d.]

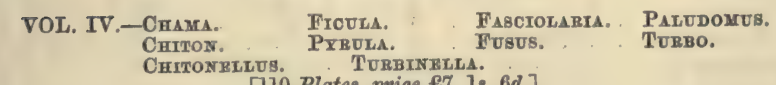

[110 Plates, price \&7. 18.6d.]

\begin{tabular}{|c|c|c|c|}
\hline 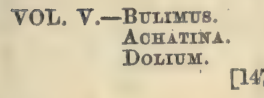 & $\begin{array}{l}\text { Cassts. } \\
\text { TuReItrita. } \\
\text { Mrsalia. } \\
\text { Plates, price } 89 .\end{array}$ & $\begin{array}{l}\text { Egligia: } \\
\text { Cassidaria: } \\
78.6 d .]\end{array}$ & $\begin{array}{l}\text { ONISOIA. } \\
\text { EBURNa. }\end{array}$ \\
\hline $\begin{array}{l}\text { OL. VI.-Voruta. } \\
\text { Fissurietia. } \\
\text { Partula. }\end{array}$ & $\begin{array}{l}\text { ACHATISELLA, } \\
\text { ARTEMIS. } \\
\text { LUOTKA. }\end{array}$ & $\begin{array}{l}\text { HEMTPBOTEN. } \\
\text { OLTVA. } \\
\text { STROMBU. }\end{array}$ & 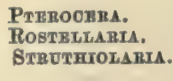 \\
\hline
\end{tabular}

VOT. VII.-HeLTX. [210 Plates, price \&13. 158.]

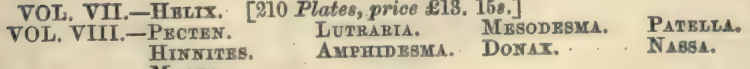

Mactra. [153 Plates, price 29. 18e.] 


\begin{tabular}{|c|c|c|c|}
\hline $\begin{array}{c}\text { VOL. IX.-SPONDYLUg. } \\
\text { NRRITINA. }\end{array}$ & $\begin{array}{l}\text { Natica. } \\
\text { Naviceila. } \\
\text { [119 Plates, price }\end{array}$ & $\begin{array}{l}\text { BipHorARTA. } \\
\text { NERITA. } \\
\text { \&7. 158.] }\end{array}$ & LATIA. \\
\hline $\begin{array}{l}\text { VOL. X. AmpUliaria. } \\
\text { Canceliaria. } \\
\text { LITTORINa. } \\
\text { Solemelina. }\end{array}$ & $\begin{array}{l}\text { CAPSA. } \\
\text { CAPSRLLA, } \\
\text { SANGUINOLARIA. } \\
\text { [126 Plates, price. }\end{array}$ & $\begin{array}{l}\text { Psammobia, } \\
\text { Psammotelia. } \\
\text { Mytilus. } \\
\text { 28. 18. 6d.] }\end{array}$ & $\begin{array}{l}\text { ModroLA. } \\
\text { LiTHODOMUs. } \\
\text { AvicULA. }\end{array}$ \\
\hline $\begin{array}{c}\text { VOL. XI.-Pinna. } \\
\text { PERna. } \\
\text { MaLieus. } \\
\text { VuLSELAa. }\end{array}$ & $\begin{array}{l}\text { Crenatula. } \\
\text { Umbrelis. } \\
\text { Pedum. } \\
\text { Inintina. } \\
\text { [126 Plates, price }\end{array}$ & $\begin{array}{l}\text { Columbelis. } \\
\text { Meta. } \\
\text { Caly ptras. } \\
\text { Cripiduta. } \\
\text { \&8. } 48 .]\end{array}$ & 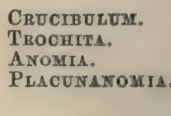 \\
\hline
\end{tabular}

IN MONOGRAPHS.

\begin{tabular}{|c|c|c|c|c|c|c|c|c|c|c|c|c|c|c|c|c|c|c|c|c|}
\hline \multicolumn{8}{|c|}{ Genera. } & \multicolumn{4}{|c|}{ Plates. } & \multicolumn{2}{|c|}{ Figures. } & & \multicolumn{2}{|c|}{ Species. } & & \multicolumn{3}{|c|}{ b. I. $d$} \\
\hline ACRATINA - & & - & - & & & & & & - 23 & & & 160 & & & . 129 & & & 1 & 9 & 0 \\
\hline ACHATINELLA & & & - & & & & & - & 6 & . & & 60 & & & 45 & . & & & & \\
\hline AMPHIDESMA & . & - & - & . & & & & & 7 & & & & & & 53 & & & & & \\
\hline AMPULLARIA & . & & - & & & - & & • & 28 & . & & 174 & & . & 134 & . & & & 15 & \\
\hline ANOMIA . & • & & - & & & & & & 8 & & & 56 & & & 97 & & & & & \\
\hline Arca . & . & - & - & - & - & • & & . & 17 & . & & 129 & & & 122 & & & & 1 & \\
\hline ARtemis. & . & & . & . & - & . & & & 10 & & & 65 & & & 61 & & & & 18 & \\
\hline Avicula. & . & & - & - & - & . & & se & 18 & . & & 80 & & & 75 & & & & 3 & \\
\hline CINUM & . & & - & & - & . & & & 14 & & & 126 & & & 118 & & & & 18 & \\
\hline LIMUs & & & - & . & - & & & & 89 & & & 790 & & & 662 & & & & 12 & \\
\hline BUILIA : & & & - & . & - & & - & & 4 & & & & & & 26 & & & & & \\
\hline CALYPTR $X A$ & . & & - & - & • & & & & 8 & . & & 71 & & & 32 & & & & 10 & \\
\hline CANCELLARIA & . & . & - & - & - & & & & 18 & & & 174 & & & 86 & & & & & \\
\hline SA., & & - & - & . & . & & & & 1 & & & & & & 1 & & & & & \\
\hline CAPSELLA & & - & - & & . & & & & 2 & & & 17 & & & 16 & & & & & \\
\hline Cardita. & & - & - & & - & & & & 9 & & & 7 & & & 50 & & & & 11 & \\
\hline Cardium & & & - & - & - & . & & 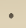 & 22 & . & & 144 & . & & 133 & & & & & \\
\hline CASSIDARia & - & - & - & - & - & . & & & - & & & 4 & & & $\mathbf{3}$ & & & & & \\
\hline Cassis $\cdot$ & . & & - & & - & s & & . & 12 & & & 63 & . & & 33 & & & & 15 & \\
\hline Санама & . & & - & - & . & & & & 9 & & & 64 & & & 55 & & & & 11 & \\
\hline ron. & & & . & . & . & & & . & 33 & & & 430 & s. & & 194 & & & & 2 & \\
\hline CHITONRLLUS & & - & - & - & - & & & & - & & & & & & 7 & & & & 1 & \\
\hline BELLA & & - & • & & . & & & & 37 & & & 370 & & & 240 & & & . & 7 & \\
\hline Conus & & - & - & & - & & & & 47 & & & 380 & & & 268 & & & & 11 & \\
\hline LA & & - & - & - & - & & & & - & & & 5 & s. & & 43 & & & & 6 & \\
\hline Crassatella & a. & - & - & & - & & & & ${ }^{\circ}$ & & & 23 & & & 19 & & & & 4 & \\
\hline TTUA & 。 & - & - & & . & & . & & . & & & 10 & & & & & & & 3 & \\
\hline Crepidula. & & - & - & & - & & & & - & & & 50 & & & 30 & & & & & \\
\hline ULUM & . & - & - & & - & & & & . & & & 67 & & & 25 & & & - & 9 & \\
\hline EA . . & . & - & . & & . & & . & & 27 & & & 218 & & & 15 & & & & 14 & \\
\hline RDIA & . & - & . & & - & & . & & 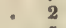 & & & 1 & & & 13 & & & & & \\
\hline INULA & & - & - & & . & & . & & $\bullet$ & & & 4 & & & & & & & & \\
\hline I. . & . & - & - & & - & & - & & - & & & 22 & & & 18 & & & & 10 & \\
\hline & & - & - & - & - & • & . & & - & & & 8 & & & 68 & & & & 12 & \\
\hline EBURNA. . & . & - & . & & - & . & & & 1 & & & & & & s & & & & & 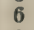 \\
\hline OLARIA & & - & . & - & •. & . & . & & 7 & . & & 30 & & & 16 & & & & & \\
\hline & . & - & - & & - & & & & . & - & & 4 & & & 4 & & & - & & \\
\hline QELLA & & - & • & • & • & - & . & & 16 & - & & 139 & & & 122 & & $\bullet$ & & & \\
\hline & . & - & - & & • & & - & & 21 & & & 133 & & & 91 & & & & & 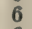 \\
\hline ACONOME & & - & - & . & . & . & • & & - & & & 10 & & & c & & & & & \\
\hline otis. & & - & - & & - & & & & 17 & & & & & & 73 & & & & & \\
\hline CARPA & & . & . & . & - & . & . & & & & - & & & & & & & & & \\
\hline IX & & - & - & & . & & & & .210 & & & . 1883 & & & 195 & & & & & \\
\hline HEMIPECTEN & & - & - & • & . & . & - & & . & & . & 7 & & & . & & & & & \\
\hline ITES . & . & - & . & & . & & & & & & & & & & & & & & & \\
\hline & & - & & & . & - & . & & - & & : & 50 & & & 25 & : & & & 6 & \\
\hline IA . & & - & te & & & & & & & & & & & & & & & & & \\
\hline OMUS & & & & & & & & & - & & & 41 & & & 34 & . & & - 0 & 6 & 6 \\
\hline ORINA. & & - & r & - & - & & - & & - & & & 169 & & & 107 & & & & 3 & \\
\hline & & & & 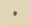 & & & & & 11 & & - & 89 & & & 69 & . & & - & 14 & 0 \\
\hline LUTRARIA & & & & & & & & & & & & & & & & & & & & \\
\hline
\end{tabular}




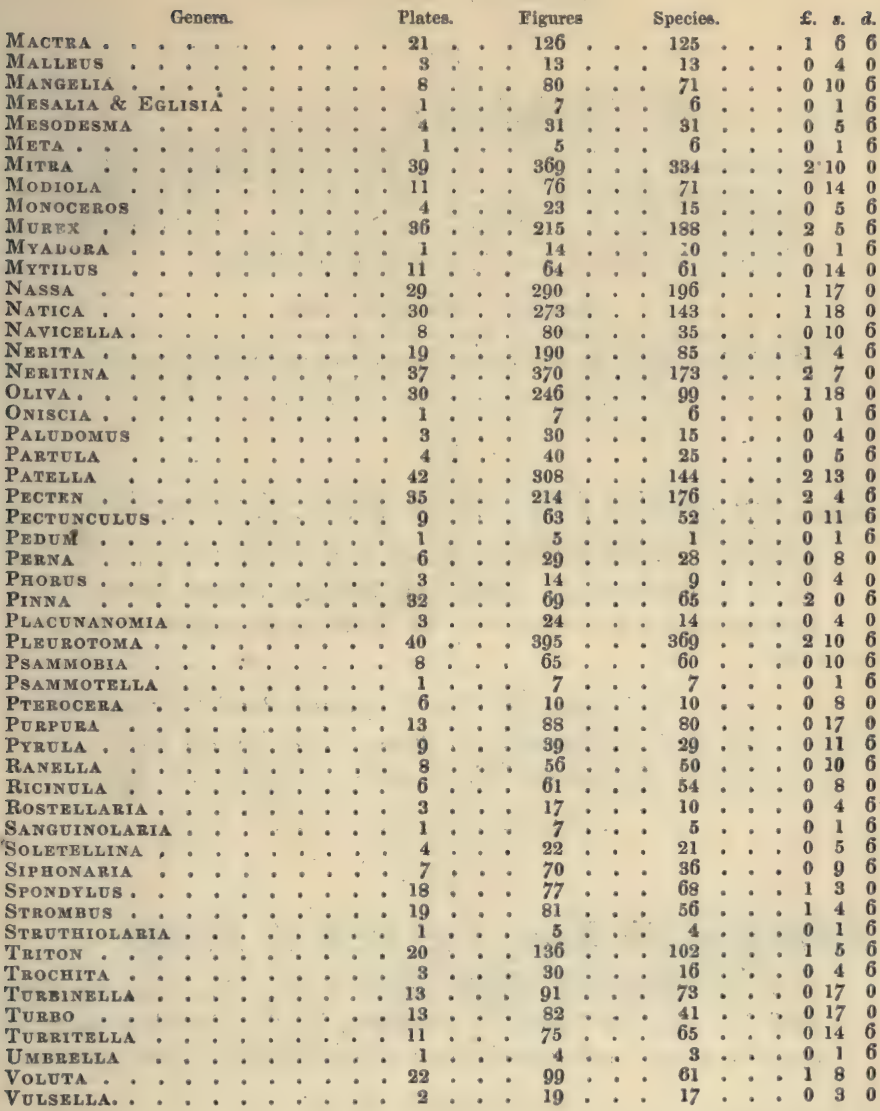

"This great work is intended to embrace a complete deseription and illustration of the Shells of molluscous animals; and so far as we have seen, it is not such as to disappoint the large expectations that have been formed respecting it. The figures of the shells are all of full size; in the descriptions a careful analysis is given of the labours of others: and the author has apparently spared no pains to make the work a standard authority on the subject of which it treats."

ATHEN ARUM,

\section{9.}

\section{Conchologia Systematica.}

A Complete System of Conchology; in which the Lepades and Conchiferous Mollusca are described and classified according to their Natural Organization and Habits. By Lovelu ReEve, F.L.S., F.G.S. With 300 plates of upwards of 1500 figures of Shells.

Two vols. 4to, price $\$ 10$ coloured. 
30.

\section{Elements of Conchology;}

Comprising the Physiological History of Shells and their Molluscous Inhabitants; their Structure, Geographical Distribution, Habits, Characters, Affinities, Arrangement, and Enumeration of Species. By Lovell ReEve, F.L.S., F.G.S. Parts I. to XV., with 60 coloured plates.

Royal 8vo, price $3 s .6 d$. each.

** This Work, which has been for some time in suspension, is just completed.

31.

Zoology of the Voyage of H.M.S. Herald,

Under the command of Captain Kellett, R.N., during the Years 1845-51. By Sir J. Richardson. Edited by Professor Edward Forbes, F.R.S. Published under the authority of the Lords Commissioners of the Admiralty.

Part I. Fossil Mammals, 15 double plates. Royal 4to, $21 s$.

Part II. Fossil Mammals, 10 plates. Royal 4to, 10s. $6 d$.

Part III. Reptiles and Fish, 10 plates. Royal 4to, 10s. $6 d$.

32.

Botany of the Voyage of H.M.S. Herald,

Under the command of Captain Kellett, R.N., C.B., during the Years 1845-51. By Dr. Berthold Seemann, F.T.S. Published under the authority of the Lords Commissioners of the Admiralty. With 100 plates.

Royal 4to, price $\mathbf{L 5}$. 10 s.

33.

\section{Zoology of the Voyage of H.M.S. Samarang,}

Under the command of Captain Sir Edward Belcher, C.B., F.R.A.S., during the Years 1843-46. Edited by ARTHúr AdaMs, F.L.S.

The Vertebrata, with 8 plates, by John Edward Gray, F.R.S.; the Fishes, with 10 plates, by Sir John Richardson, F.R.S.; the Mollusca, with 24: plates, by Arthur Adams, F.L.S., and Lovell Reeve, F.L.S.; the Crustacea, with 13 plates, by Arthur Adams, F.L.S., and Adam White, F.L.S.

Royal 4to, price $£ 3.10$ s. coloured. 
34.

\section{Travels on the Amazon and Rio Negro,}

With an Account of the Native Tribes, and Observations on the Climate, Geology, and Natural History of the Amazon Valley. By ALFred R. Wallace, Esq. With Remarks on the Vocabularies of Amazonian Languages, by R. G. LАтнам, M.D., F.R.S. With 6 plates and maps.

Royal 8vo, 18s.

"Mr. Wallace's explorations on the Amazon and Rio Negro, the northern branch of that mighty river, form an enchanting work. In the novelty of its scenery and manners, in the truthful, albeit somewhat literal, picture of what the traveller saw and felt, in the quiet earnestness by which obstacles were surmounted, by Talleyrand's favourite rule of waiting, and in the patience with which sickness, suffering, and privation were submitted to, 'Travels on the Amazon and Rio Negro' remind us of the simplicity of the old voyagers." SPECTATOR.

"Observant of everything around him, and gifted with all the qualifications essential to the discharge of his task, the author has presented us with a substantial and highly interesting account of the Negro tribes of the Amazon, their habits, institutions, and manners, all of which he does not fail to illustrate by a profusion of anecdotes."

Morning Advertiser.

35.

\section{Travels in the Interior of Brazil,}

Principally through the Northern Provinces and the Gold and Diamond Districts, during the Years 1836-41. By George Gardner, M.D., F.L.S. Second Edition. With Plate and Map.

$8 \mathrm{vo}$, price $12 s$.

"When camping out on the mountain-top or in the wilderness ; roughing it in his long journeys through the interior; observing the very singular mode of life there presented to his notice; describing the curious characters that fell under his observation, the arts or substitutes for arts of the people; and the natural productions of the country; - these travels are full of attraction. The book, like the country it describes, is full of new matter.'

Spkctator.

36.

\section{Western Himalaya and Tibet;}

The Nárrative of a Journey through the Mountains of Northern India, during the Years 1847 and 1848. By Thomas Thomson, M.D., AssistantSurgeon, Bengal Army. With Tinted Lithographs and a Map by Arrowsmith.

8 vo, price $15 s$.

"Few more valuable volumes of travels than this by Dr. Thomson have been for a long time past published. Long after the interest which its novelty will create shall have passed away, it will be a standard book of reference, on account of the valuable facts which it contains, and of the spirit of sound observation in which it is written."

ATHen aum.

"To all those who desire to judge scientifically of what is possible in the cultivation of the Indo-Alpine Flora, which is now so rapidly enriching our gardens, works of this description have great interest." Gardeners' Chronicle.

"We can most cordially recommend Dr. Thomson's work to all those who wish to obtain a clear idea of this magnificent and interesting region, to which our conquest in the Punjaub has brought us into such close contiguity."

Guardia. 
37.

\section{Manual of British Archaology.}

By the Rev. Charles Boutell, M.A. With 20 coloured plates.

Royal $16 \mathrm{mo}$, price $10 s .6 d$.

"Its simple clearness, the result of thorough knowledge in the writer, entices, so to speak, the attentive reader into a pursuit for which it qualifies him by insensible degrees, and the high tone of refined culture which pervades the book communicates an involuntary enthusiasm for a study too often allied with pedantry and curious dullness," LEADER.

"The illustrations, twenty in number, consist of coloured plates of architectural details, heraldic and wall diapers, coloured glass pavement tiles, monumental slabs and brasses, stone coffins and their effigies, heraldic devices, badges and banners, seals, inscriptions, celts, arms and armour, beads, ornaments, pottery and enamels." . OBSERVER.

38.

\section{A Survey of the Early Geography of Western}

Europe, as connected with the First Inhabitants of Britain, their Origin, Language, Religious Rites, and Edifices. By Henry Lawes Long, Esq.

** Printed uniformly with the Collections of the Surrey Archæological Society.

39.

\section{Literary Papers on Scientific Subjects.}

By the late Professor Edward Forbes, F.R.S., selected from his Writings in the 'Literary Gazette.' With a Portrait and Memoir.

Small $8 \mathrm{vo}$, price $6 s$.

"This reprint of reviews forms a charming book of miscellaneous essays. The criticism is genial, sensible, eomprehensive, and compact. It is not common to find eminent scientific men graceful, easy, and piquant littérateurs; but whenever such a union of claims to public farour is manifested, it should meet with honour due. But, besides being a scientific professor, a critic, and littérateur, the late Edward Forbes was before all things a man-genial, sympathetic, brave, and true - a thorough good fellow, as good a fellow as he was a naturalist. The reader cannot do better than possess himself of this amusing and instructive volume, if he have a liking for science without solemnity, criticism without ill-nature, and with knowledge of the subject; pleasant talk with a definite result, and a sense of the comic without the vulgar error of turning all things to a jest."

GLOBB.

40.

\section{Parks and Pleasure Grounds;}

Or, Practical Notes on Country Residences, Villas, Public Parks, and Gardens. By Charles H. J. Simth, Landscape Gardener.

Crown 8 vo, price $6 s$.

"Mr. Smith expresses himself with frankness as well as precision, and with such an evident reliance on the sympathy of his readers as to make him a favourite with those who are familiar with his pages. In short, his book is what was really wanted in these busy times to bring the elegant in country residences abreast of the useful."?

North British Agriculturist. 


\section{STEREOSCOPIC PHOTOGRAPHY.}

41.

\section{The Conway in the Stereoscope.}

Photographed by Roger Fenton, Esq., - M.A., Vice-President of the Photographic Society. Described by James B. Davinson, Esq.

Twenty Stereoscopic Pictures, price $31 s .6 d$., extra bound, gilt edges.

\section{2.}

Stonyhurst College and its Environs.

Photographed by Roger Fenton, Esq., M.A., Vice-President of the Photographic Society.

A Series of Fifteen Stereoscopic Views, mounted on Cards for use in the ordinary Stereoscope, price One Guinea.

43.

The Stereoscopic Magazine.

A Selection for the Stereoscope of Landscape Scenery, Architecture, Rare Antiquities, etc.

In Monthly Numbers, each containing three Stereographs, with Descriptive Letterpress, price $2 s .6 d$.

\section{4.}

\section{The Stereoscopic Cabinet.}

A Monthly Packet of Pictures for the Stereoscope.

In Monthly Packets, each containing three Stereoscopic Pictures, mounted on Cards for use in the ordinary Stereoscope, price $2 s .6 d$.

\section{5.}

\section{Narrative of a Walking Tour in Brittany.}

By John Mounteney Jephson, B.A., F.S.A. Accompanied by Notes of a Photographic Expedition by Loveli REEve, F.L.S.

Royal 8vo, with Map by Arrowsmith, and Stereoscopic Frontispiece, price 12s.

* * Issued separately are Ninety Stereoscopic pictures, mounted on cards for use in the ordinary Stereoscope, in box with lock and key, price 25.58.

\section{Teneriffe.}

46.

An Astronomer's Experiment; or, Specialities of a Residence above the Clouds. By Prof. Piazzi Smytr, Her Majesty's Astronomer for Scotland.

Second Thousand, in One Vol., 450 pages, 20 Stereographs, price $21 s$.

"Nearly all the pictures have been taken at heights of from seven to twelve thousand feet above the level of the sea, and on the lower ground we are shown a dragon-tree walk, a cactus-garden, cochineal-gatherers at work, and other scenes never before realized in this manner to eyes in England. The scientific results of the expedition have been communicated to the Royal Society." EXAMINER. 


\section{New Series of British Natural Histories.}

In broad Octavo Volumes, 400 pages, cloth gilt, each Volume illustrated with 24 Coloured Plates,

\section{LOVELL REEVE'S BRITISH NATURAL HISTORIES.}

\section{An entirely New Series.}

1.

British Fungology.

By the Rev. M. J. Berketier. [Now Ready.

British Mosses.

2.

By the Rev. M. J. Berkeley.

[In preparation.

British Field Plants.

3.

Ву Thомаs Moore.

[In preparation.

British Mollusca.

By Loveit Reeve.

[In preparation.

British Desmidiæ.

By Dr. G. C. WALIICH.

[In preparation.

British Ferns.

By Thomas Moore.

. In preparation.

\section{PERIODICALS IN PROGRESS.}

1.

The Floral Magazine.

By Thomas Moore, F.L.S., F.H.S.

2.

Curtis's Botanical Magazine.

By Sir W. J. Hooker, D.C.L., F.R.S.

3.

Flora of the British West Indian Islands.

By A. H. R. Grisebach, M.D.

Phycologia Australica.

4.

By W. H. HARVEY, M.D., F.R.S.

Conchologia Iconica.

By LOVeit Reeve, F.L.S. \& G.S.

6.

Flements of Conchology.

By LOVELL REEVE, F.L.S. \& G.S.

7.

3 The Stereoscopic Magazine.

By Roger Fenton, M.A.; and Others. 



PLEASE DO NOT REMOVE CARDS OR SLIPS FROM THIS POCKET

\section{UNIVERSITY OF TORONTO LIBRARY}

QK

355

B4

\section{BioMed}

Bentham, George Flora Hongkongensis 
